\title{
MELT INFILTRATED CERAMIC MATRIX COMPOSITES FOR SHROUDS AND COMBUSTOR LINERS OF ADVANCED INDUSTRIAL GAS TURBINES
}

Advanced Materials for Advanced Industrial Gas Turbines (AMAIGT) Program Final Report

for the Period July 1, 2000 - September 30, 2010

By

Gregory S. Corman

GE Global Research

Principle Investigator: Krishan L. Luthra

Project Officers/Managers: Jill Jonkowski, Joseph Mavec, Paul Bakke and Donald Geiling

Project Monitors: Debbie Haught and Merrill Smith

December, 2010

Work Performed Under Cooperative Agreement DE-FC26-00CH11047

(revised from agreement DE-FC02-00CH11047)

For

U.S. Department of Energy

Office of Electricity Delivery and Energy Reliability

Washington, D.C. 20585

Submitted by

GE Global Research

Advanced Ceramics Laboratory

Niskayuna, NY 12309 


\section{DISCLAIMER}

"This report was prepared as an account of work sponsored by an agency of the United States Government. Neither the United States Government nor any agency thereof, nor any of their employees, makes any warranty, express or implied, or assumes any legal liability of responsibility for the accuracy, completeness, or usefulness of any information, apparatus, product, or process disclosed, or represents that its use would not infringe privately owned rights. Reference herein to any specific commercial product, process, or service by trade name, trademark, manufacturer, or otherwise, does not necessarily constitute or imply its endorsement, recommendation, or favoring by the United States Government or any agency thereof. The views and opinions of authors expressed herein do not necessarily state or reflect those of the United States Government or any agency thereof." 


\title{
MELT INFILTRATED CERAMIC MATRIX COMPOSITES FOR SHROUDS AND COMBUSTOR LINERS OF ADV ANCED INDUSTRIAL GAS TURBINES FINAL REPORT
}

Advanced Materials for Advanced Industrial Gas Turbines (AMAIGT) Program

Final Report

for the Period July 2000 - December 2010

\begin{abstract}
By
Gregory S. Corman

GE Global Research

Principle Investigator: Krishan L. Luthra

DOE Project Officers/Managers: Jill Jonkowski, Joseph Mavec, Paul Bakke, and Donald Geiling
\end{abstract}

DOE Project Monitors: Debbie Haught and Merrill Smith

December, 2010

Work Performed Under Cooperative Agreement DE-FC26-00CH11047

(revised from DE-FC02-00CH11047)

\author{
Prepared for \\ U.S. Department of Energy \\ Office of Electricity Delivery and Energy Reliability \\ Washington, D.C. 20585
}

Prepared by

GE Global Research

Advanced Ceramics Laboratory

Niskayuna, NY 12309 


\section{ABSTRACT}

This report covers work performed under the Advanced Materials for Advanced Industrial Gas Turbines (AMAIGT) program by GE Global Research and its collaborators from 2000 through 2010. A first stage shroud for a 7FA-class gas turbine engine utilizing HiPerComp ${ }^{\circledR}$ ceramic matrix composite (CMC) material was developed. The design, fabrication, rig testing and engine testing of this shroud system are described. Through two field engine tests, the latter of which is still in progress at a Jacksonville Electric Authority generating station, the robustness of the CMC material and the shroud system in general were demonstrated, with shrouds having accumulated nearly 7,000 hours of field engine testing at the conclusion of the program. During the latter test the engine performance benefits from utilizing CMC shrouds were verified. Similar development of a CMC combustor liner design for a 7FA-class engine is also described. The feasibility of using the HiPerComp ${ }^{\circledR}$ CMC material for combustor liner applications was demonstrated in a Solar Turbines Ceramic Stationary Gas Turbine (CSGT) engine test where the liner performed without incident for 12,822 hours. The deposition processes for applying environmental barrier coatings to the CMC components were also developed, and the performance of the coatings in the rig and engine tests is described.

\footnotetext{
* Trademark of the General Electric Company
} 


\section{TABLE OF CONTENTS}

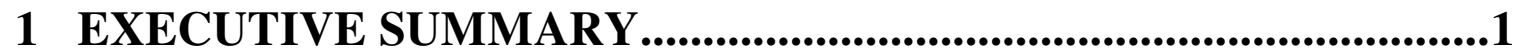

2 INTRODUCTION AND BACKGROUND..................................4

2.1 Program Structure ............................................................................8

3 TECHNICAL APPROACH AND RESULTS ...............................13

3.1 Shroud Activities ...................................................................................13

3.1.1 Task 1.1 - Component Design and Task 2.1 - Detailed Design ...............13

3.1.2 Task 1.2 - Material Data for Design ...............................................................19

3.1.3 Task 1.3 - Benefits Analysis..........................................................................21

3.1.4 Task 2.2 - Shroud Fabrication Trials........................................................21

3.1.5 Task 2.3 - Rig Design and Assembly .............................................................26

3.1.6 Task 2.4 - Shroud Fabrication for Rig Testing..............................................33

3.1.7 Task 2.5 - Thermal Rig Testing................................................................36

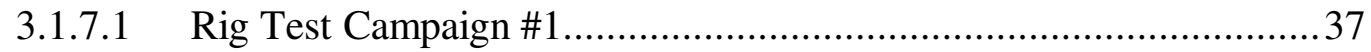

3.1.7.2 Rig Test Campaign \#2.................................................................... 44

3.1.7.3 Rig Test Campaign \#3..................................................................57

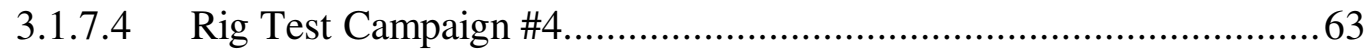

3.1.8 Task 2.6 - Blade Rub and Wear Testing ..............................................70

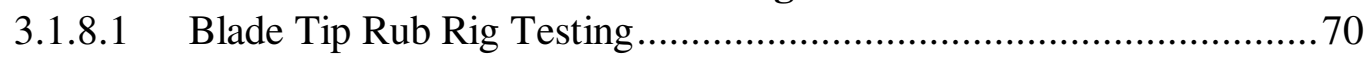

3.1.8.2 CMC Shroud and Damper Mechanism Wear Testing.........................75

3.1.9 Task 2.7 - NDE Technique Validation ............................................................76

3.1.10 Task 2.8 - EBC Development .........................................................................78

3.1.10.1 EBC Deposition Parameter Optimization ……………………..........79

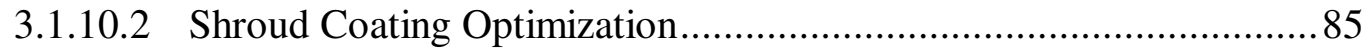

3.1.11 Task 3.1 - Design for Engine Test ................................................................88

3.1.12 Task 3.2 - Material Qualification and Inspection.......................................89

3.1.13 Task 3.3 - Subtask B: Commercialization Plan ..........................................89

3.1.14 Task 4.1 - Outer Shroud Fabrication............................................................89

3.1.15 Task 4.2 - Inner Shroud Fabrication ...........................................................90

3.1.15.1 Engine Shroud Fabrication Campaign \#1 ...........................................90

3.1.15.2 Engine Shroud Fabrication Campaign \#2........................................ 101

3.1.15.3 Engine Shroud Fabrication Campaign \#3 ........................................ 102

3.1.15.4 Engine Shroud Selection Process .................................................... 102

3.1.16 Task 4.3 - Rainbow Engine Testing ..............................................................108

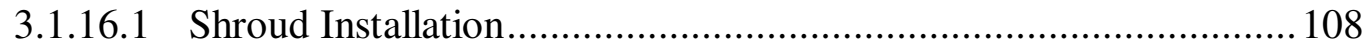

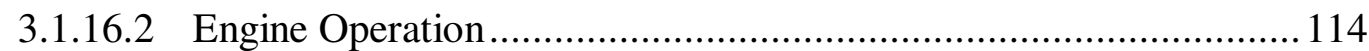

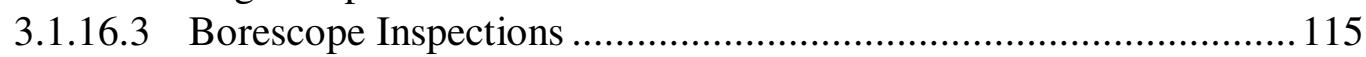

3.1.16.4 Shroud Removal and Disassembly ............................................... 122

3.1.17 Task 4.4 - Post-Test Characterization........................................................125

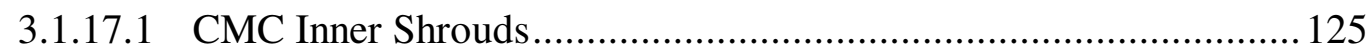

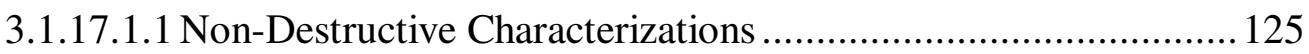

3.1.17.1.2 Destructive Characterization - Microstructure............................ 129

3.1.17.2 Destructive Characterization - Mechanical ....................................... 142 


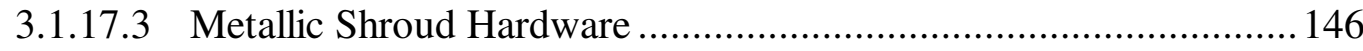

3.1.18 Tasks 6 and S4.4 - Program Management and Reporting ..................... 150

3.1.19 Task S3.1 - Design of New Shroud System .................................................151

3.1.20 Task S3.2 - Rig Testing for Design Validation........................................... 159

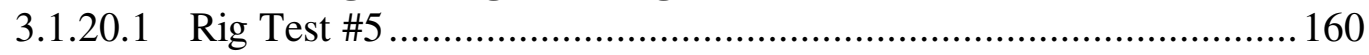

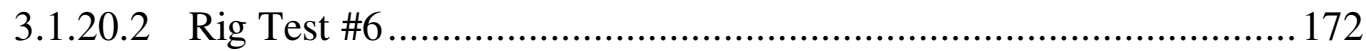

3.1.21 Task S4.1 - CMC Shroud Fabrication for Engine Test \#2 ......................180

3.1.22 Task S4.2 - Metallic Hardware for Engine Test \#2 ..................................200

3.1.23 Task $S$ 4.3 - Field Engine Test \#2 ...............................................................201

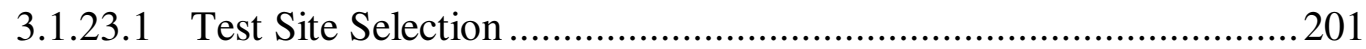

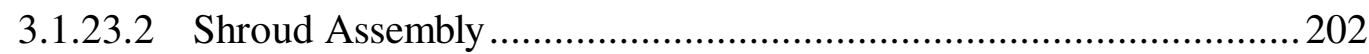

3.1.23.3 Shroud Installation Into the Test Engine ……….............................203

3.1.23.4 Shroud System Performance Measurements .....................................211

3.1.23.5 Shroud System Borescope Inspections .............................................216

3.1.23.5.1 GE Borescope Inspection \#1 ................................................216

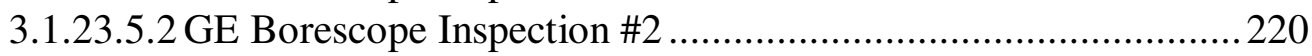

3.1.23.5.3 JEA Hot Gas Path Borescope Inspection....................................224

3.1.23.5.4 GE Borescope Inspection \#3 ...................................................22

3.1.23.5.5 GE Borescope Inspection \#4 ....................................................229

3.1.23.5.6 GE Borescope Inspection \#5 ....................................................233

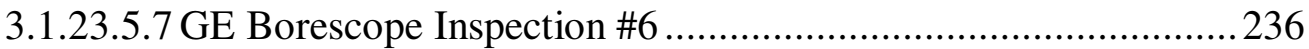

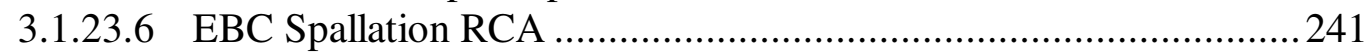

3.1.24 Task S3.3 - Shroud Material and Process Improvements ......................270

3.1.24.1 Investigation of Hybrid CMCs ………….....................................2 271

3.1.24.1.1 Hybrid Structures Using Monolithic Matrix Plies........................2272

3.1.24.1.2 Hybrid Structures Using Uncoated Fiber Plies .............................309

3.1.24.1.3 Shroud Fabrication from Hybrid CMC......................................... 319

3.1.24.2 Evaluation of Tow Coating Process Modifications ............................321

3.1.25 Task S3.4 and S3.5 - Design Support for Engine Test \#3.......................329

3.1.26 Tasks S4.5 and S4.6 - Field Engine Test \#3 ...............................................331

3.1.26.1 Fabrication of CMC Inner Shrouds for Engine Test \#3 .....................331

3.1.26.2 Fabrication of Metallic Hardware for Engine Test \#3 …....................345

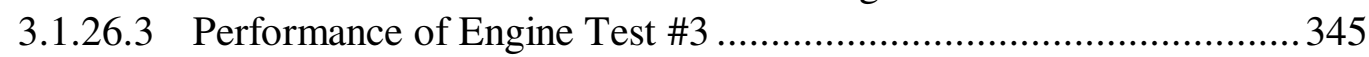

3.2 Combustor Activities................................................................348

3.2.1 7FA Combustor Development.....................................................................348

3.2.1.1 Task C1.1 - Conceptual and Preliminary Design and Task C3 -

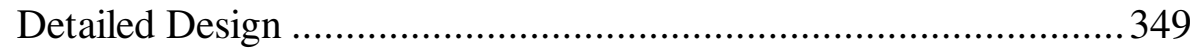

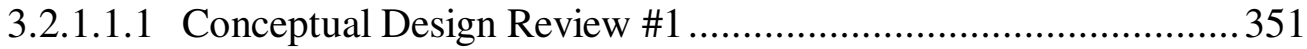

3.2.1.1.2 Conceptual Design Review \#2 ....................................................354

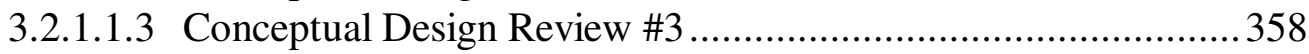

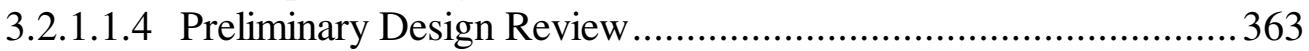

3.2.1.2 Task C2 - 7FA Combustor Rig Testing .........................................368

3.2.1.2.1 Task C2.1 - CMC Liner Fabrication for Rig Test .........................369

3.2.1.2.2 Task C2.2 - Metallic Hardware and Rig Test .............................. 391

3.2.1.2.3 Task C3 - Detailed Design for Engine Testing.............................393 
3.2.1.2.4 Task C4 - Engine Testing …............................................ 395

3.2.2 Task C4.1a - CSGT Inner Liner Engine Test ...................................395

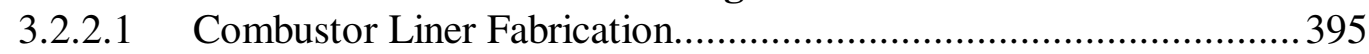

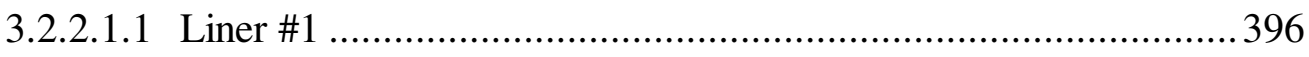

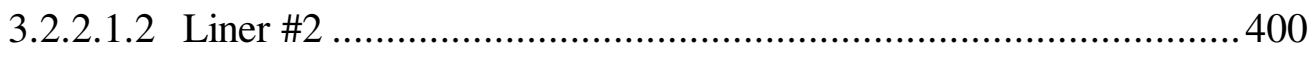

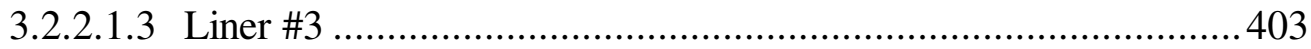

3.2.2.1.4 Liner \#4 ..................................................................... 407

3.2.2.1.5 Pretest Characterization of Liners 3 and 4 ............................ 414

3.2.2.1.6 EBC Coating...................................................................... 416

3.2.2.2 CSGT Engine Test Performance ................................................ 418

3.2.2.3 CSGT Combustor Post-Test Characterization ..............................422

4 SUMMARY AND CONCLUSIONS ................................................463

5 ACKNOWLEDGEMENTS .........................................................4466

6 LIST OF FIGURES ..........................................................................467

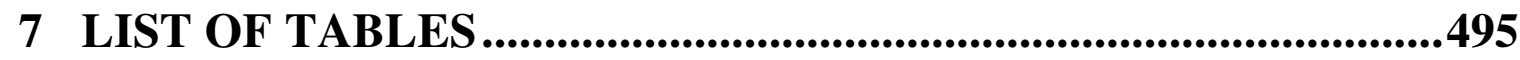

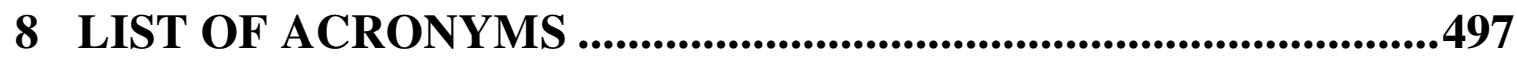

9 REFERENCES ..........................................................................499

10 APPENDIX: PUBLIC DOCUMENTATION...............................501

10.1 Patents Granted or Applied For .....................................................501

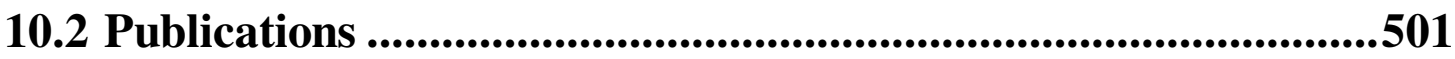

10.3 Technical Presentations .....................................................................502 



\section{EXECUTIVE SUMMARY}

The main goal of this program was to take the ceramic matrix composite (CMC) technology developed under the Department of Energy (DOE) Continuous Fiber Ceramic Composite (CFCC) program (1992-2005) and demonstrate its use in a large frame industrial gas turbine engine. The turbine components targeted for this demonstration were the $1^{\text {st }}$ stage shroud and combustor liner, although the technology could be equally applied to other stationary and rotating turbine components in both industrial and aviation gas turbines.

Continuous fiber $\mathrm{CMCs}$ are a revolutionary class of materials that combine the high refractoriness of ceramics with the defect and damage tolerance of metals. Current gas turbines typically utilize nickel- and cobalt-based superalloys in the hot gas sections of turbines, and these components require quite substantial amounts of cooling to keep them below their maximum allowable operating temperature. Ceramic composites are expected to have much higher allowable material operating temperatures, and thus the amount of cooling needed for the turbine components can be greatly reduced, if not eliminated. Thus the compressor air normally used for cooling of metallic components can be redirected to the benefit of the overall turbine cycle, thereby improving both the power output and efficiency of the engine while reducing NOx and $\mathrm{CO}$ emissions.

The CMC material utilized for this program was a silicon carbide-based system fabricated by a silicon melt infiltration process. Although various process improvements were introduced, and the process was scaled-up to allow fabrication of much larger size and larger numbers of CMC components, the fundamental process was essentially the same as that developed under the DOE CFCC program [1,2]. The process for fabricating this material was transitioned to GE Ceramic Composite Products, in Newark, DE, where it is now available as a commercial product under the name of HiPerComp®.

Development of any new technology for gas turbines involves some risk. In the case of the shroud component, field tests were necessarily performed in utility-owned engines that the utilities relied upon for generation of power for their customers. The liability should a test component fail can be up to $\$ 1 \mathrm{MM}$ per day in lost power generation, and engine disassembly, component replacement, and engine reassembly can take up to several weeks. Consequently, the risk to the engine operator needs to be minimized by following wellestablished procedures for component design, testing and validation. It is for these reasons that development and demonstration of a technology as radically new as CMCs requires a significant amount of time and resources.

The main highlights of this program were two successful field engine tests of CMC shrouds, amounting to nearly 7000 engine hours of exposure, and a successful field test of a CMC combustor liner for over 12,000 hours. In both tests the CMC components performed as expected, with no negative impact on turbine engine availability, and survived the exposure with minimal material degradation. 
During the performance of this program many important milestones were successfully completed. Some of the more important achievements are listed below:

- A CMC shroud system for a 7FA-class engine was designed and analyzed, and the design was validated through a series of high-temperature, high-pressure combustion rig tests.

- A partial engine set of CMC-based shrouds, consisting of the CMC inner shrouds, metallic outer shroud blocks and all intermediate attachment hardware, were successfully field engine tested in a utility 7FA-class gas turbine engine in Florida for 5366 hours. Post-test characterization of the shroud system validated that the prepreg melt infiltrated shrouds survived the engine exposure test with minimal material degradation, even in regions where the environmental barrier coating had spalled.

- The fabrication process for the prepreg melt infiltrated CMC material in general, and for the CMC inner shrouds specifically, was transitioned to GE Ceramic Composite Products, which enabled the fabrication of a full engine set of shrouds (corresponding to $96 \mathrm{CMC}$ inner shrouds) that incorporated an improved shroud-toshroud sealing configuration.

- A methodology for applying abradable environmental barrier coatings was developed for the CMC inner shroud components, and the coating robustness was tested using simulated blade rub testing.

- The full set of CMC engine shrouds incorporating the abradable EBC was installed in unit \#1 at the Brandy Branch generating station of the Jacksonville Electric Authority in April 2006, and continues to operate without incident, having accumulated $>1500$ hours of engine running time with 497 start-stop cycles. The shrouds are anticipated to continue in the engine until the Fall of 2012.

- A second full engine set of CMC shroud components has been fabricated and assembled, and is awaiting an appropriate opportunity for insertion into a third field engine test. The goal of this third shroud test will be to demonstrate the long-term (up to 24,000 hours of engine operation) durability of the CMC shroud system.

- The design of a 7FA-class engine CMC combustor liner was developed, including the conception and analyses of novel liner attachment and sealing schemes. Fabrication trials of this liner, measuring up to $0.46 \mathrm{~m}$ in diameter and $1 \mathrm{~m}$ in length, were performed that demonstrated a path to successful liner fabrication.

- Four CMC combustor liners were fabricated in the development process for production of a liner for testing in Solar Turbines Ceramic Stationary Gas Turbine (CSGT) engine. One of the CMC combustor liners was successfully engine tested in the Solar CSGT engine at Chevron/Texaco in Bakersfield, CA, for a total of 12,822 hours. This test represents the longest gas turbine engine exposure for the GE HiPerComp® CMC material to date.

- The environmental barrier coating (EBC) on the CSGT combustor liner survived the full 12,822 hours of engine testing with $>99 \%$ of the EBC remaining intact. Posttest characterization of the CSGT combustor liner indicated minimal degradation of the CMC material, and elucidated important degradation mechanisms for the EBC. 
Overall GE considers its participation in the AMAIGT program to have been a resounding technical success. The successes of the shroud and combustor field engine tests have effectively laid the groundwork for the eventual commercialization of this technology for industrial gas turbines. The successful component demonstrations on this program have also aided the adoption of the HiPerComp® CMC material for use as both stationary and rotating components in aviation turbines by GE Aviation [3, 4, 5].

Despite the successes described above, technical and business challenges still remain to the full commercial introduction of CMC gas turbine hardware. The long-term durability of the EBC coatings still needs to be demonstrated, and that is precisely the objective of the third shroud field engine test that GE hopes to initiate in early 2011. The high cost of HiPerComp ${ }^{\circledR}$ components is still a major challenge, but at least now that the projected benefits have been quantified a realistic cost-to-performance tradeoff can be done to arrive at justifiable cost targets for the CMC.

This program has also been highly successful in disseminating information about the use and characterization of CMC materials and components. Patents, presentations and publications related to the work performed on the AMAIGT program are listed in the Appendix. 


\section{INTRODUCTION AND BACKGROUND}

Improvements in gas turbine engine performance have historically followed developments in materials and cooling technologies that have allowed engines to operate at higher and higher firing temperatures. It is commonly recognized that current superalloy components are operating at their temperature limits and that new materials and/or cooling technologies will be needed for further improvements in engine performance. Ceramic materials have long been considered the next step in turbine materials technology. Ceramics, in the form of zirconia-based thermal barrier coatings (TBCs), are currently in use in many gas turbine engines; however, utilization of ceramics as structural components has not been commercially adopted.

The historic trend in gas turbine structural material temperature capability is summarized in Figure 2-1. This particular graph shows the trend in creep rupture life, but other timedependent properties, such as fatigue and oxidation, show similar trends. The historic trend for metals development shows a steady, but slow progression in allowable material temperatures. One interesting observation is the lack of new alloy development since the mid-90's, indicating that the typical $\gamma^{\prime}$-hardened Ni-based superalloys have reached their limit of development. While alternate technologies, such as improved thermal barrier coatings and newer component cooling techniques, are expected to allow for modest increases in engine firing temperatures, the prospects for metallic materials with significantly higher temperature capability are bleak. Even newer experimental alloys, such as the oxide dispersion strengthened (ODS) alloys and intermetallics, such as $\mathrm{NbSi}$, typically tend to fall close to the historic trend line. The only materials that have the potential to give a large increase in temperature capability are ceramics, represented in Figure $2-1$ by ceramic matrix composites (CMC).

The use of ceramic composites in gas turbines offers several potential benefits, including higher efficiency, reduced NOx and $\mathrm{CO}$ emissions, higher power output, increased time between inspection/repairs, and reduced maintenance costs. Most of these benefits are derived from the higher temperature capability of the ceramic composite materials allowing for reduced component cooling and/or increased turbine firing temperature. By US Department of Energy (DOE) estimates [3], a new gas turbine completely redesigned to utilize CMCs for the components indicated in Figure 2-2 could reduce overall turbine fuel consumption by $13 \%$ and reduce NOx, $\mathrm{CO}$ and unburned hydrocarbon (UHC) emissions by over $75 \%$. All of these factors would reduce the environmental impact of electricity production, and reduce the cost of electricity to utilities and to customers. 


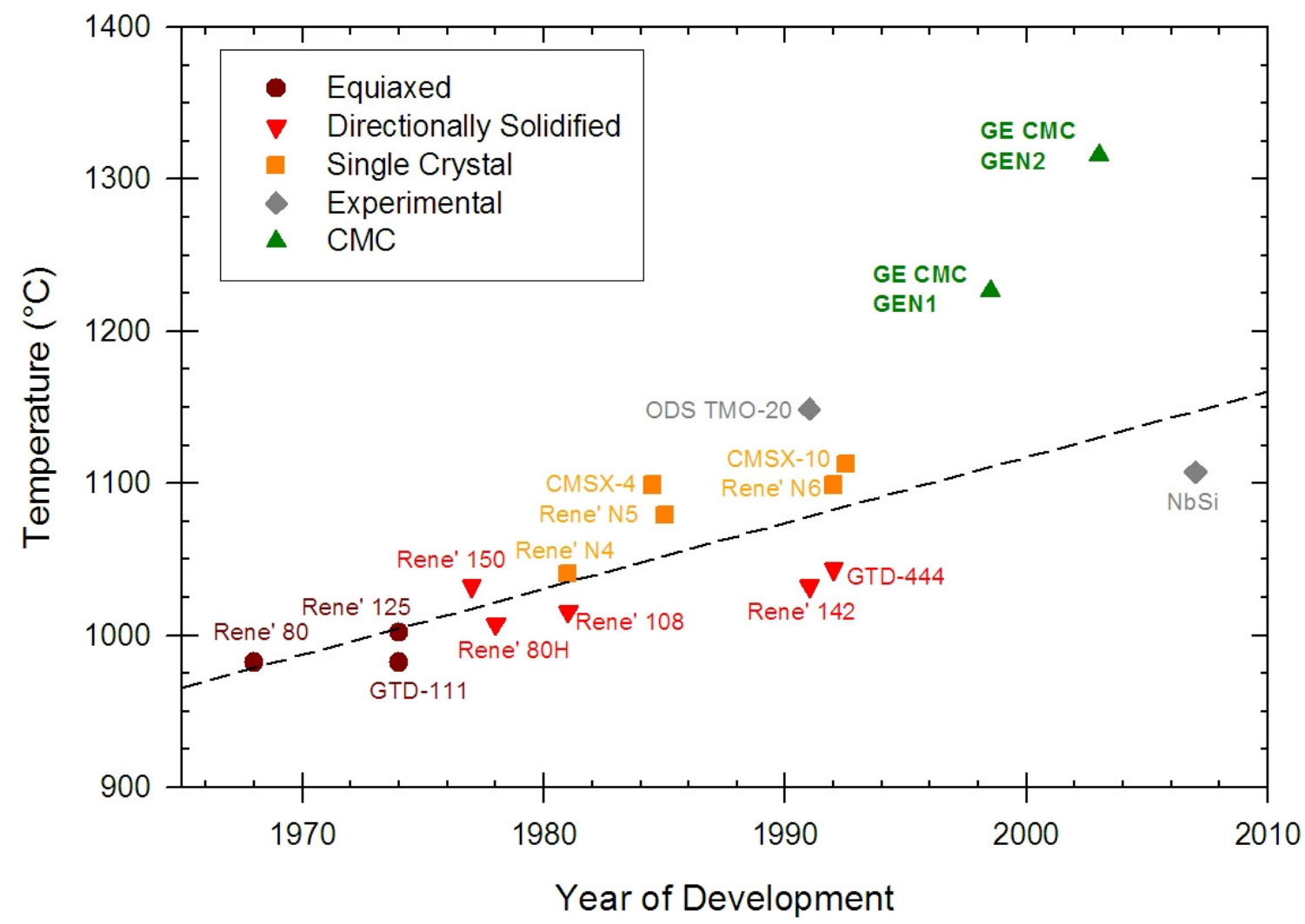

Figure 2-1. Trend in material temperature capability (based on 1000 hour creep rupture at $103 \mathrm{MPa}$ tensile stress) over time for gas turbine engine structural materials.

The General Electric Company (GE) has been working to develop ceramic matrix composite materials for gas turbine applications for over 25 years at its Global Research Center (GRC), Aviation and Energy divisions. During this time GE has researched and/or evaluated numerous types of continuous fiber CMC materials, including $\mathrm{Al}_{2} \mathrm{O}_{3}$-based oxideoxide, SiC-mullite, SiC-cordierite, $\mathrm{SiC}-\mathrm{SiC}$ via chemical vapor infiltration $(\mathrm{CVI}), \mathrm{SiC}-\mathrm{SiC}$ via polymer impregnation and pyrolysis (PIP), and $\mathrm{SiC}-\mathrm{SiC} / \mathrm{Si}$ made by silicon melt infiltration (MI). Multiple engineering studies, done as part of the National Aeronautics and Space Administration (NASA) sponsored High Speed Civil Transport/Enabling Propulsion Materials program [7] and the DOE-sponsored Continuous Fiber Ceramic Composite (CFCC) program [1,2], have shown that MI-CMCs are the best suited CMC materials for use in these applications. The reasons for this assessment involve the unique combination of mechanical and physical properties achievable with MI-CMCs, such as low porosity, high thermal conductivity, low coefficient of thermal expansion, high matrix cracking stress, high ultimate strengths and strains, long-term thermal stability and resistance to internal oxidation.

There are two general approaches to the fabrication of MI-CMCs, generally referred to as the slurry casting and prepreg MI approaches. The focus of material development and evaluation for this program has been on the prepreg MI material, which was invented at GE Global Research and is currently sold commercially by GE Ceramic Composite Products 
division under the name of HiPerComp®. The fabrication and properties of this material have been described previously $[1,2,8,9]$.

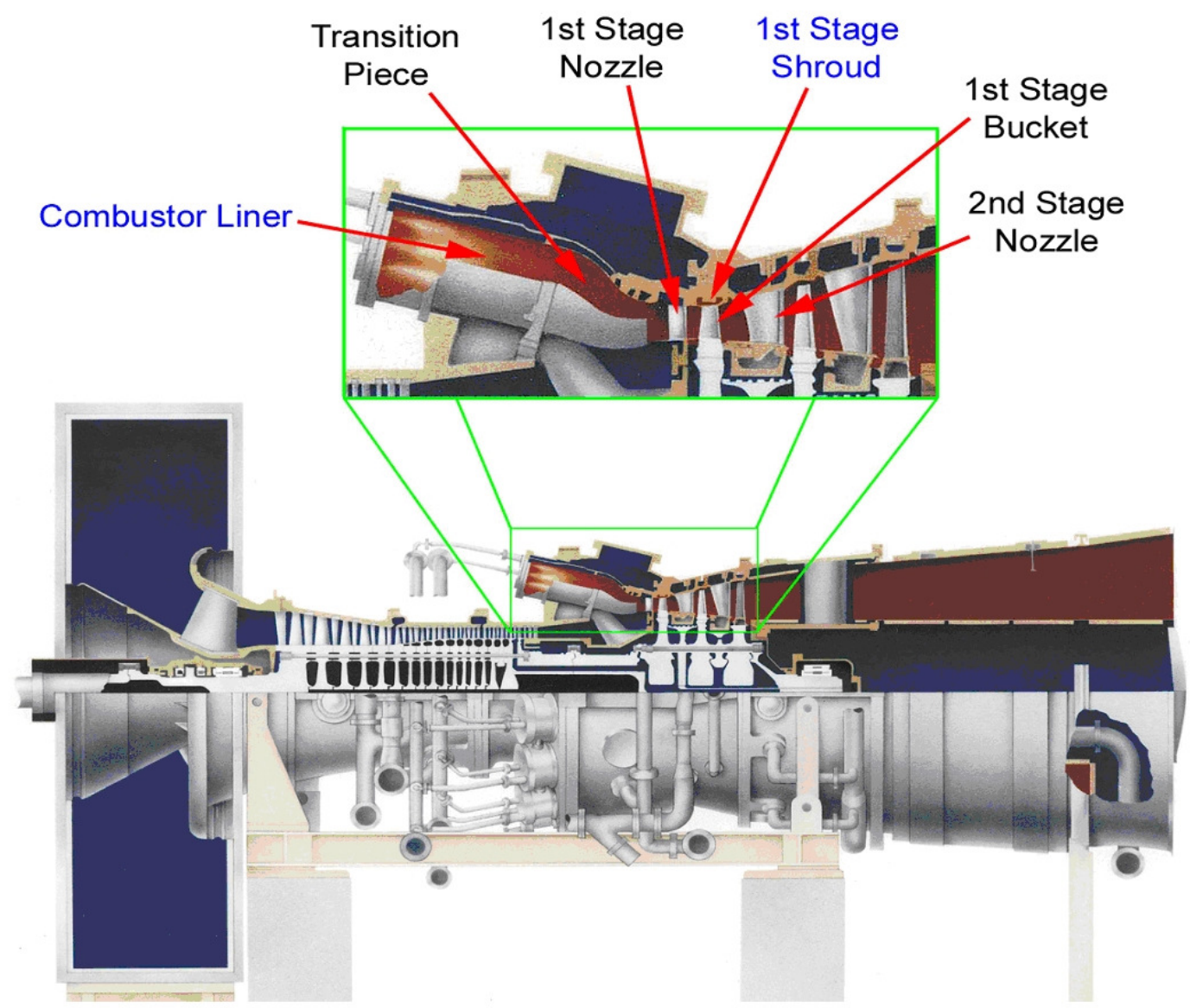

Figure 2-2. Cross sectional view of a GE 7FA class gas turbine engine. The blow-up view shows the positions of several components for which use of ceramic composite materials would be highly desireable. The specific components that were the focus of this program, namely the combustor liner and $1^{\text {st }}$ stage shroud, are labeled in blue.

During the CFCC program, the feasibility of using MI-CMC materials in turbine engines was demonstrated by a series of successful rig and engine tests on both turbine shroud and combustor liner components [2]. For instance, the feasibility of using MI-CMC shroud components in high-pressure, high velocity combustion gas environments, like those experienced in the hot gas path sections of gas turbine engines, was demonstrated with a series of combustion rig tests performed on an early shroud concept design. Use of MICMC for shrouds in real engines was then demonstrated with a 1000 hour engine test of $1^{\text {st }}$ and $2^{\text {nd }}$ stage shroud rings in a small, 2MW gas turbine (GE-2) engine at GE Oil \& Gas (Nuovo Pignone). This engine test showed that the MI-CMC components had sufficient fatigue resistance to withstand the vibrational loading of a real engine, as well as survive unintentional, though quite real, operational events such as blade tip rubs. It also 
demonstrated that adequately robust attachment schemes could be developed that could accommodate the thermal expansion mismatch between the MI-CMC components and the metallic turbine parts.

The CFCC program was largely focused on material and process development, and on feasibility demonstrations of ceramic components using controlled rig testing and small scale engine testing [1,2]. The purpose of the Advanced Materials for Advanced Industrial Gas Turbines (AMAIGT) program was to extend the results of the CFCC program to field testing of components in large-scale utility turbines. The historic development and testing of the GE MI CMC material, and of gas turbine components made from this material, is shown schematically in Figure 2-3.

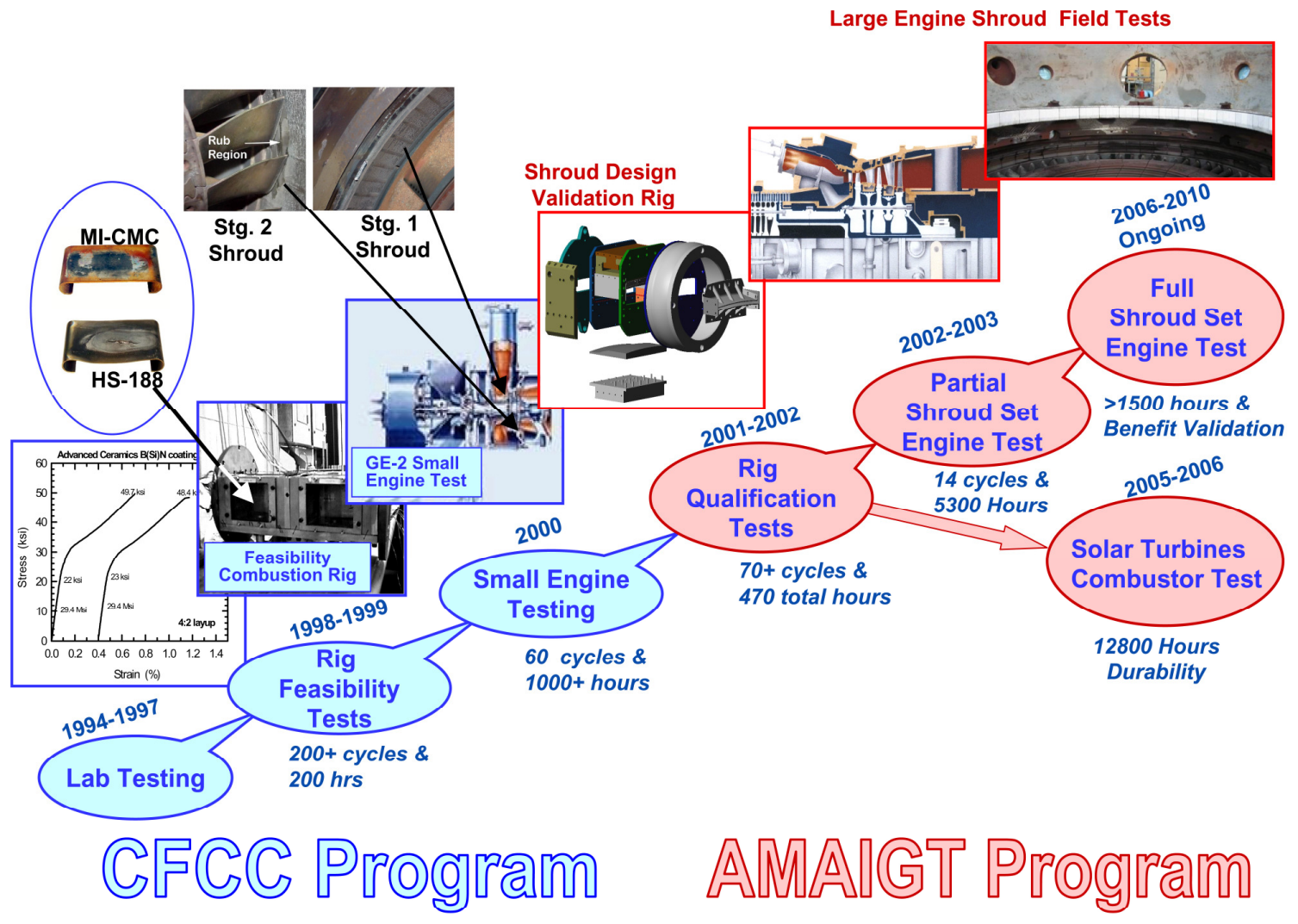

Figure 2-3. Schematic diagram showing the historic progression from CMC material and process development to feasibility rig and small engine testing under the DOE CFCC program, transitioning to more extensive rig and field engine testing under the AMAIGT program.

Although first stage turbine buckets have the greatest potential benefit to the overall engine cycle, they also represent the greatest challenge in that substantial centrifugal and aerodynamic stresses are present in addition to thermal stresses. Consequently the two 
components selected for implementation in this program were the first stage shroud and the combustor liner. The application of ceramic composites to these components was anticipated to entail relatively moderate risk while still producing substantial efficiency and emissions benefits.

The engine platform selected for CMC component introduction was the MS7001FA, or "7FA", which is a 170MW simple cycle industrial gas turbine used primarily for generation of electricity [10]. Two major considerations for selecting the engine platform were the availability of engines for conducting the component tests and the engine having cycle conditions that would benefit from the use of ceramic components. With an installed base of over 670 engines and a firing temperature of over $1200^{\circ} \mathrm{C}$, the $7 \mathrm{FA}$ engine was the logical choice.

\subsection{Program Structure}

As mentioned previously, this program was intended to continue the work started under the GE CFCC program, where the material and process development for GE's prepreg-based, melt infiltrated ceramic composite had been essentially completed. The feasibility of using this material for shroud and combustor liner applications had been demonstrated using laboratory rig testing of shrouds and combustor liners, and with small-scale engine testing of the shroud [2]. Although these feasibility demonstrations were very successful, they used component designs that were either incompatible with existing 7FA engine hardware, or not fully optimized for 7FA engine conditions, and had little or no component life analysis associated with them.

Due to the very high liability of having a component failure in a utility turbine, which could amount to over $\$ 1 \mathrm{MM}$ per day in lost generating capacity for a combined cycle plant, a more rigorous component design and more rigorous component validation rig testing would be required before the $\mathrm{CMC}$ components could be considered for a field engine test. The intent of this program was to provide for this next level in component design and testing, culminating in field engine testing of CMC shroud and combustor liner hardware.

Although both shroud and combustor components were included in the program proposal, only activities related to shroud development to the level of an initial field engine test were included in the initial program award due to funding constraints. The tasks included in the original program are shown by the black lines in Figure 2-4.

The tasks in the original program were established to achieve the following goals: 1) develop and improve a robust CMC shroud component design, 2) measure the CMC material physical and mechanical properties needed to support the design process, 3) demonstrate fabricability of the improved shroud design, 4) demonstrate that the new shroud would survive blade tip rub events, 5) develop environmental barrier coating (EBC) application technology for coating of the shrouds using existing EBC compositions, 6) validate non-destructive evaluation (NDE) techniques for verifying the quality of the CMC components, 7) validate the new design using high pressure, high temperature combustion 
rig testing, and 8) fabricate and field engine test a shroud system incorporating CMC inner shroud components.

This initial engine test was to be a "rainbow" test where only a portion of the 96 metallic inner shrouds would be replaced with CMC inner shrouds. This was done to minimize the expense of fabricating the new shrouds and also to minimize the risk to the engine operators. GE did not, and still does not, own and operate any large-frame gas turbine engines. Consequently engine testing is necessarily done using engines owned by utility or industrial operators. These operators depend on their engines for power and/or process heat production, and thus they are understandably reluctant to host trials of new technologies that may pose a risk to the ongoing operation of the engines. The economic consequences of an engine outage, and thus the liability to GE for causing such an outage, are quite severe. For these reasons the number of CMC shrouds to be tested in the initial engine test was just nine out of 96 inner shrouds in a full shroud set.

Over the course of this 10-year program there have been several changes, or modifications, to the overall program task structure. In 2002 a modification was proposed and approved to include the development of 7FA combustor liner hardware. The tasks for this effort are shown by the red lines in Figure 2-5. (Program tasks related to the combustor liner include the prefix " $C$ " to differentiate them from the shroud tasks.) The task structure of this effort paralleled that set up for the shroud, but took advantage of synergies between the components. For instance, separate tasks for material property characterization, NDE development or EBC process development for the combustor liner were not necessary since the results from the shroud-based tasks could be adapted.

A second program modification was proposed in 2003, and subsequently approved in 2004, to include a $2^{\text {nd }}$ engine test of the shroud component. Results from the $1^{\text {st }} 7 F A$ engine test had shown that CMC shrouds could operate successfully in a utility engine, but problems were seen with EBC durability and the shroud system cooling and leakages had not been fully optimized to derive maximum benefits from the CMC shrouds. A second round of rig and engine tests was therefore desired to validate improvements in the $\mathrm{EBC}$ and the shroud sealing scheme. At this time a task to fabricate and field engine test of a combustor liner in a Solar Turbines Ceramic Stationary Gas Turbine (CSGT) engine was also added to the combustor liner program. The tasks added to the program with this modification are shown by the blue lines in Figure 2-4 and Figure 2-5. (The new shroud tasks include an "S" prefix to distinguish them from the original program tasks.)

A final program modification was proposed in 2006, and subsequently approved in 2007, wherein allowances were made for up to two additional shroud engine tests. This addition was necessary to allow for a full-life demonstration of the CMC shroud hardware. At this time the $2^{\text {nd }}$ engine test had successfully demonstrated the expected engine cycle benefits of the CMC shroud system; however, the particular engine used for this test was being utilized only for peak demand generating capacity, and therefore was accumulating operating hours very slowly, and would not reach the full 24,000 hour desired part life for several years. Additional testing in base-load engines was needed to demonstrate full CMC component 
life. The program tasks added from the 2006 modification are shown as the green lines in Figure 2-4.

Details of the performance and results from all of the program tasks are discussed in the next section. 


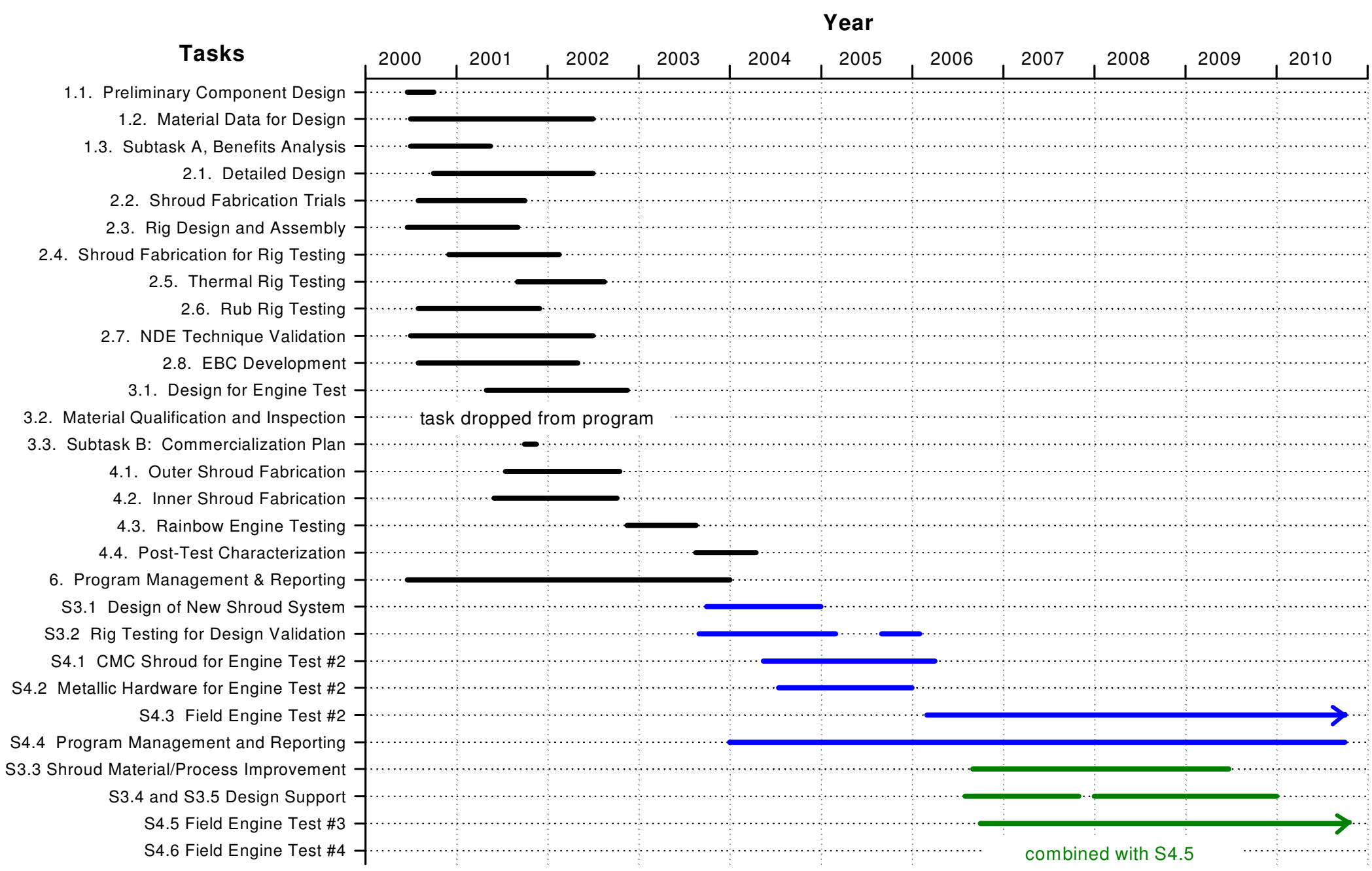

Figure 2-4. Overall program task performance for the shroud-related tasks. Black lines are from the original program started in 2000; blue lines are from the 2003 contract modification; green lines are from the 2006 contract modification. Tasks S4.3 and $\mathrm{S} 4.5$ are continuing past the end of the program. 


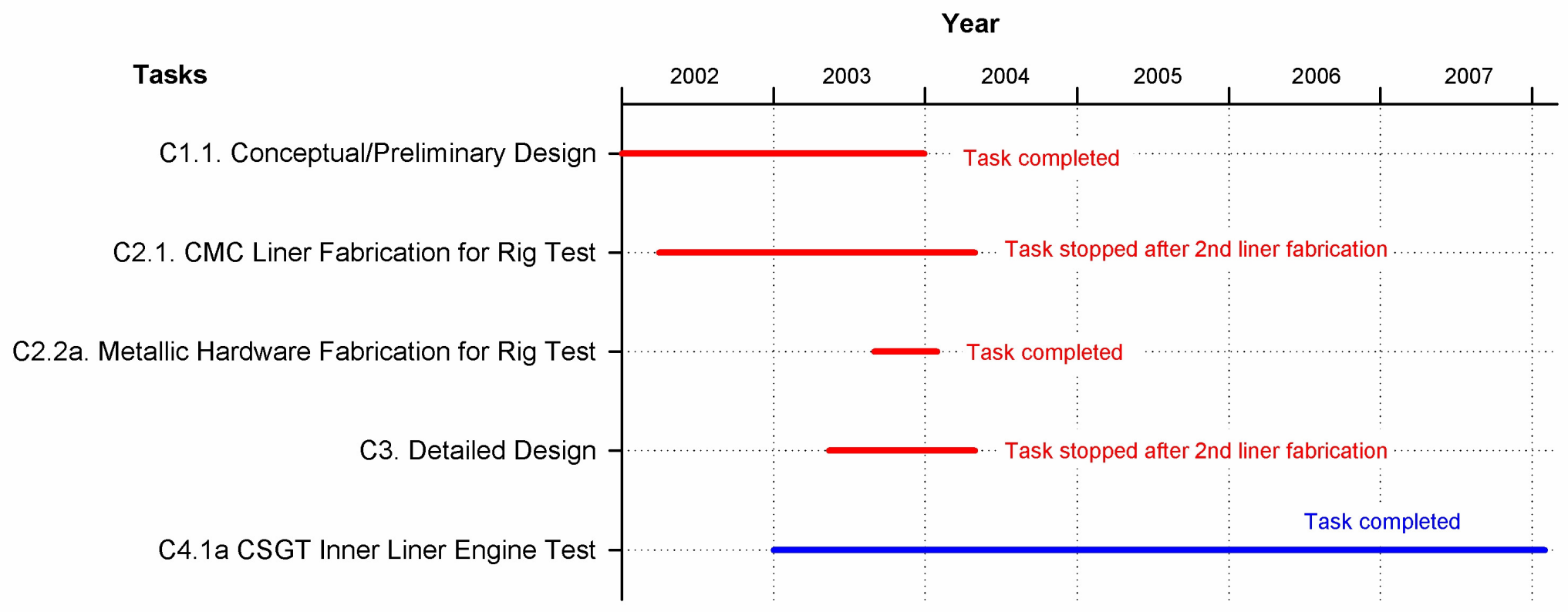

Figure 2-5. Overall program schedule for the combustor-related tasks. Red lines are from the 2002 contract modification and blue lines from the 2003 contract modification. 


\section{TECHNICAL APPROACH AND RESULTS}

Where appropriate, the discussion of the technical results of the program is arranged first by the component of interest (shroud or combustor liner) and then by program task number. The purpose of each task will be reviewed followed by the experimental results of that task.

As noted in the previous section, the fundamental development of GE's prepreg MI CMC material, also known as HiPerComp ${ }^{\circledR}$, and fabrication process had been completed under the CFCC program. This material and process are documented elsewhere [1, 2, 8, 9] and will not be discussed in this report except where specific modifications to the material or process were being studied.

\subsection{Shroud Activities}

\subsubsection{Task 1.1 - Component Design and Task 2.1 - Detailed Design}

The purpose of these two tasks was to build upon the shroud design effort done under the CFCC program and to further refine the design sufficiently to pass formal design reviews with the GE Energy Chief Engineer's Office. After passing the design reviews the shroud system would be ready for combustion rig testing. These tasks would also allow for modifications to the shroud design based on findings in the shroud rub and combustion rig tests. Since the progression of a component design from the "preliminary" to "detailed" design phases is a continuous process with no clear separation point, these two tasks will be discussed together.

The GE 7FA class gas engines incorporate a $1^{\text {st }}$ stage shroud system consistiong of 96 inner shroud segments attached to 32 outer shroud blocks. The outer shroud blocks act as the intermediate attachment between the inner shrouds and the turbine casing, and also provide for attachment of the $1^{\text {st }}$ stage and $2^{\text {nd }}$ stage nozzles to the casing. A diagram of the cross section of part of the turbine hot gas path, showing the positions of the inner and outer shrouds relative to other turbine hardware, is shown in Figure 3-1.

The segmented shroud design that was combustion rig tested under the CFCC program is shown in Figure 3-2, and was commonly referred to as the "toboggan" design in GE program reports. Although this design showed adequate durability for completion of up to 200 hours of rig testing, it was readily recognized that the leaf springs used to maintain the position of the CMC inner shroud against the outer shroud block were inadequate for engine use due to relaxation and limited oxidation life of the leaf springs. Additional design modifications were made to the shroud under the CFCC program, culminating in the design shown in Figure 3-3. 


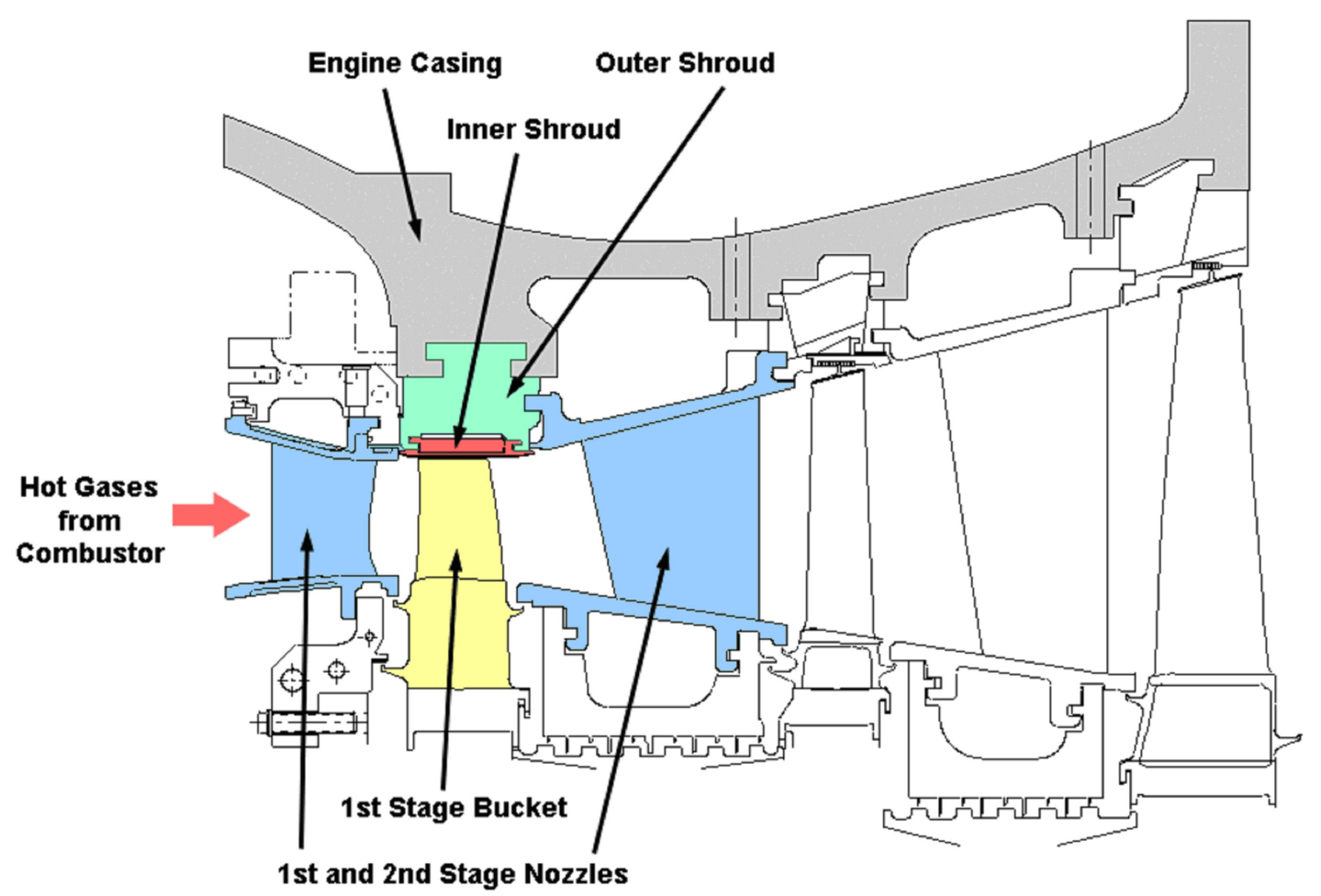

Figure 3-1. Cross section diagram of the turbine section of a 7FA engine showing the position of the $1^{\text {st }}$ stage inner shroud and outer shroud block.

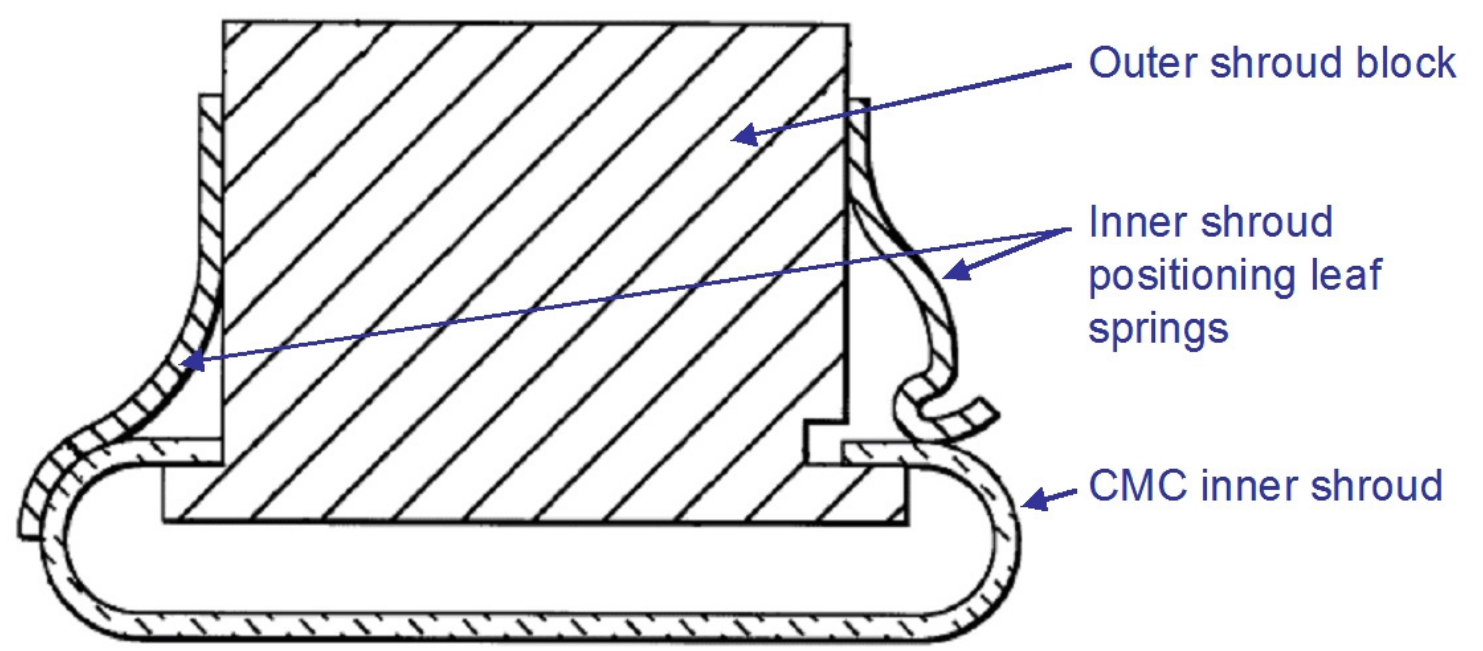

Figure 3-2. Simplified diagram of the CMC shroud system that was combustion rig tested under the CFCC program. 


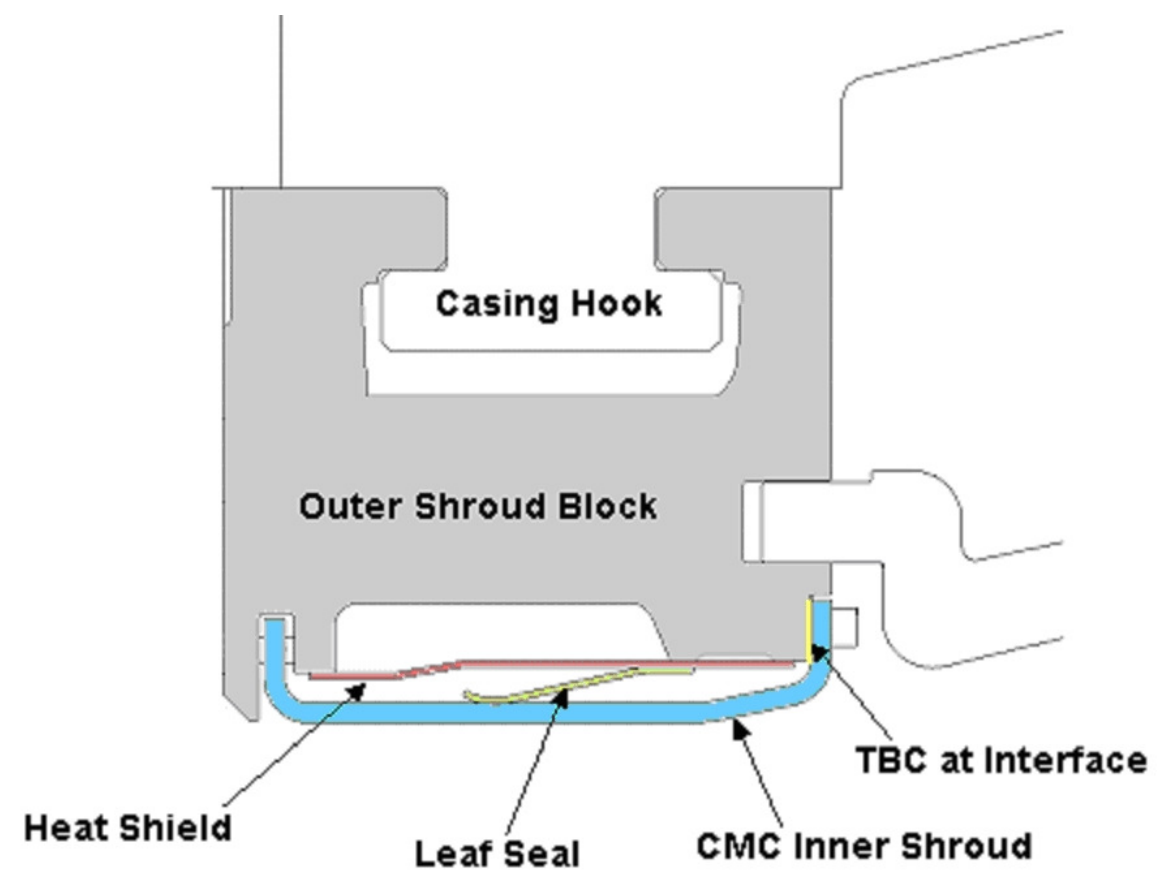

Figure 3-3. Diagram of the final CMC shroud system design generated under the CFCC program. This concept served as the starting point for shroud design for the AMAIGT program.

The essential features of the new design was the elimination of the 180 degree bends at the forward and aft ends of the inner shroud, being replaced with simpler 90 degree bends and vertical flanges. Attachment to the outer shroud block is through pins and/or bolts in the outer shroud that engage holes and/or slots in the flanges of the inner shroud. This arrangement allows for differential thermal growth between the CMC inner shroud and metallic outer shroud block in both the axial and circumferential directions. A heat shield is placed between the inner and outer shroud to reduce the heat load to the outer shroud from convective and radiative heat transfer. A metallic leaf seal attached to the outer shroud block presses against the inside surface of the inner shroud to block combustion gas flow behind the inner shroud and to keep the inner shroud positively seated against the attachment pins and bolts.

Thermal and structural finite element modeling (FEM) analyses of the shroud system in Figure 3-3 indicated that the inner shroud temperatures and stresses would be within the CMC material capability for 7FA engine conditions. Material selection for the heat shield and leaf seal were more problematic. As with the earlier toboggan design there were no alloys identified that had the necessary stiffness, creep resistance and oxidation resistance to be able to function as a leaf spring for the desired shroud lifetime of 24,000 hours under the temperature conditions predicted for the cavity behind the inner shroud. 
Details of the turbine component design process, including the procedures, protocols and analytical tools used, are highly proprietary information. Consequently a detailed description of the shroud design process will not be given in this report. However, a general description of the evolution of the shroud design will be described with the reasoning behind the various design modifications.

Several brainstorming session were held within the design and materials teams to address the problems with the heat shield/leaf spring configuration. Through these sessions the design of the CMC shroud system evolved to the configuration shown in Figure 3-4.

In this new configuration the spring element was moved upward in the outer shroud block to a cooler location where a metallic spring would retain its elasticity. A piston at the base of the spring transmitted the spring force downward to a "damper block", which then in turn transmitted the force onto the CMC inner shroud. In this design the damper block performed four important functions: 1) it transmitted the spring load to the inner shroud in order to maintain proper seating of the shroud on the attachment pins, 2) it acted as a heat shield blocking radiative heat transfer from the inner shroud and convective heat transfer from hot combustion gases that would be ingested around the shroud leading edge, 3) it helped to direct the flow of the spring cavity cooling air that leaked down from the spring cavity, passed the damper piston, and out behind the inner shroud, and 4) it effectively provided additional mass and dampening to the inner shroud to help control its model frequency response (hence the name "damper block").

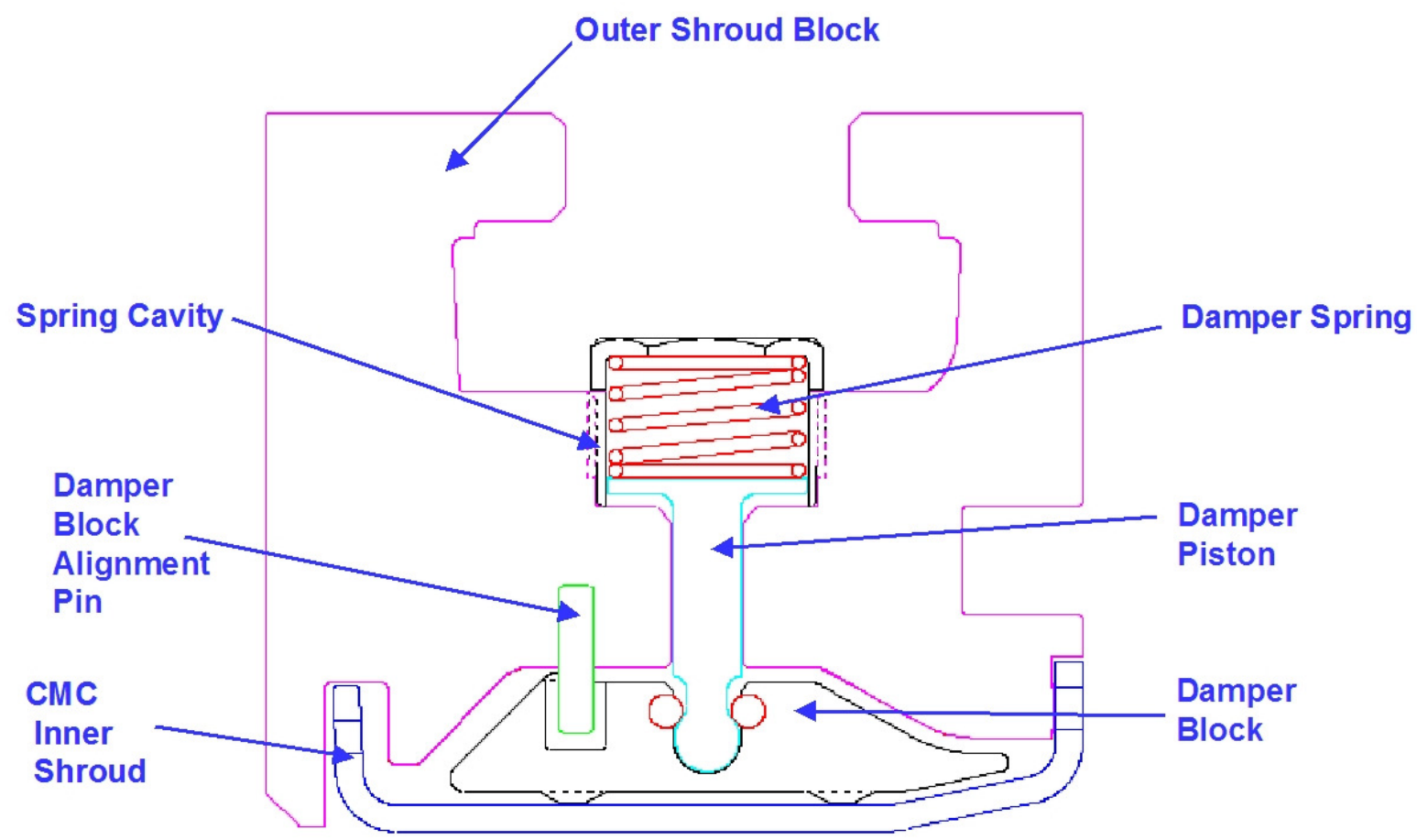

Figure 3-4. Schematic of the new CMC shroud system design incorporating a springloaded damper block. This configuration was used in shroud rig test \#1. 
Coolant and leakage air flow models were generated for the new shroud design, which helped to provide the temperature and heat transfer coefficient boundary conditions for a full finite element analysis (FEA). Results of the FEA temperature predictions are shown in Figure 3-5. The analysis predicted a maximum temperature on the CMC inner shroud of $1196^{\circ} \mathrm{C}$ about $1 / 4$ of the way back on the shroud hot gas path face. Because of the ingestion of hot gases around the shroud leading edge the thru-thickness gradient in the CMC inner shroud was relatively small; however, this hot gas ingestion did cause the metal outer shroud block temperature to get as high as $1000^{\circ} \mathrm{C}$ locally just behind the inner shroud front flange. This relatively high temperature in the outer shroud required a change of alloy from the normal stainless steel to a more oxidation resistant alloy. Except for the local area around the leading edge of the inner shroud, the outer shroud block temperatures were considered acceptable.

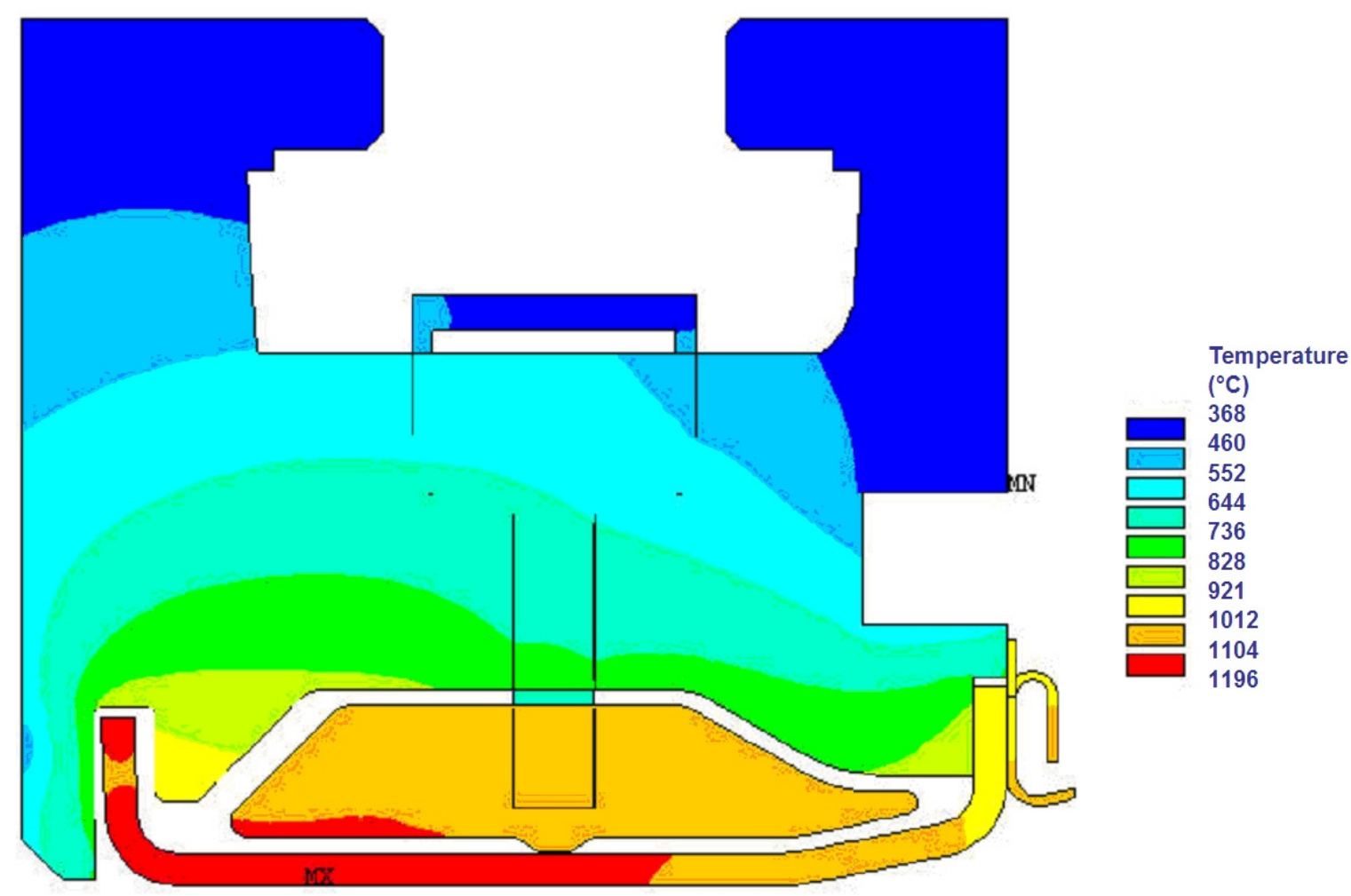

Figure 3-5. Temperature prediction results from the initial FEA of the new shroud design.

The maximum temperature predicted for the damper block was $\sim 1120^{\circ} \mathrm{C}$. The selection of an alloy for this part was thus largely dictated by oxidation rate considerations. Creep of the damper was also considered an issue despite the relatively small load imposed by the spring mechanism. Since the temperatures in question were typically above those of other turbine components there was not a strong experience base with alloys in this temperature 
range to guide the selection. In the end it was decided to perform the shroud rig tests using different damper block candidate alloys and use the rig testing results to select the damper alloy for the engine test.

Rig test \#1, to be described in Section 3.1.7.1, was run using the shroud configuration shown in Figure 3-4. Due to problems with the test rig not related to the shrouds themselves, the test was stopped early after only 34 hours of running time. Although the damper block/piston/spring design used in this test appeared to perform as desired, this was really insufficient testing time to differentiate the performance of the three damper block alloys.

Refinement of the shroud system design continued while the shroud test rig was being designed and manufactured, while the rig test were being carried out, and certainly following the completion of rig test \#1. Most of the design changes were made to address potential problems seen in the analysis results rather than to address any specific result seen in the rig test.

Due to the pressure drop across the $1^{\text {st }}$ stage buckets, the forces on the inner shrouds that would tend to lift them off the attachment pins is larger at the upstream end of the shroud than at the downstream end. In order to locate the spring load force closer to the front of the inner shroud the spring cavity was moved forward in the outer shroud block. The damper block was also shortened in order to increase the distance between the hot gas leakage path behind the damper and the location where the stage 2 nozzle mates with the outer shroud block. Keeping this nozzle attachment region cool is a major factor in being able to support the nozzle loads.

Following rig test \#2 the design focused shifted to optimizing the spring cavity cooling in order to prevent creep relaxation of the springs. Machinable ceramic washers (Corning's Macor) were added to the load train between the springs and damper piston in order to limit the heat conduction to the springs from the damper block and piston. The pins in the damper blocks that were used to retain the damper on the end of the damper piston (in case of a shroud failure so the damper block would not drop down into the flow path) were also switched moved from the sides of the damper block to a cooler location at the rear face of the damper. This was done to try to limit oxidation of the retention pins and possible chemical reaction of the pins with the damper block.

The revised design of the CMC shroud system is shown in Figure 3-6. It was this configuration that was used for both rig tests \#3 and \#4, and for the eventual field engine test. Minor changes were made to the outer shroud blocks between rig test \#3 and \#4, and prior to the engine test, but these mainly involved modifications to the cooling channels supplying spring cooling air, and minor modifications to the seals between adjacent outer shroud blocks. The damper piston tip profile was also adjusted slightly after rig test \#3 in order to minimize contact area creep deformations. 


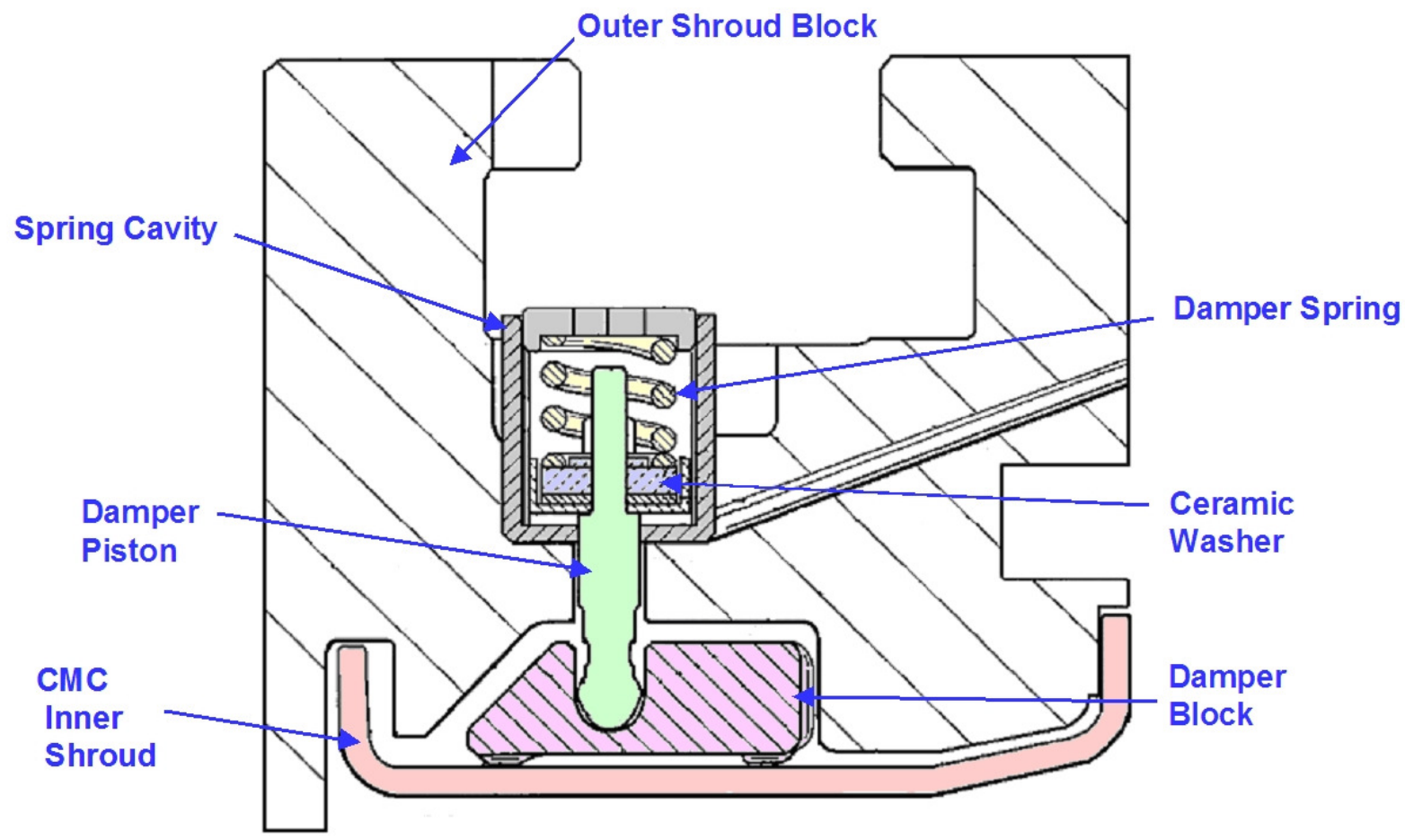

Figure 3-6. Schematic of the revised new CMC shroud system design used for rig tests \#3 and \#4 and for the first field engine test.

\subsubsection{Task 1.2 - Material Data for Design}

Task 1.2 was part of the initial program awarded in 2000, with the experimental work running from mid 2000 to mid 2002. The first primary goal of Subtask 1.2 involved the measurement of crack initiation and propagation behavior of the MI-CMC materials. Lowvelocity impact testing, using a "drop-dart" test facility at GE Plastics in Pittsfield, MA, was chosen as the technique for studying crack initiation and propagation in the CMC materials. This testing simulated the type of damage that one might expect from routine handling mishaps, e.g. dropping a partially assembled shroud block or accidentally hitting a shroud with a tool during engine assembly. Low-velocity impact testing was complementary to the high velocity (ballistic) impact damage testing that was done under the CFCC program [2], which was intended to simulate foreign object damage that may occur during turbine operation.

Initial tests were completed on prepreg MI composites using 8-ply (nominally $2.3 \mathrm{~mm}$ thick) $3.8 \times 3.8 \mathrm{~cm}$ rectangular specimens. The specimens were impacted at different energy levels, velocities and with different impactor diameters in order to gage the amount of damage that occurs under these various conditions. The impactor points were mounted onto a sled mechanism in order to assure proper trajectory. The minimum weight of this impactor/sled mechanism was roughly $4.65 \mathrm{~kg}$, which was used for most of the testing. The results of these initial screening tests are listed in Table 3-1. 
Testing was started at energy levels of roughly 37,13 and 4 Joule using a $6.4 \mathrm{~mm}$ diameter impactor. At 37 and $13 \mathrm{~J}$ the impactor completely penetrated the composite sample. At $4 \mathrm{~J}$ the dart did not penetrate the composite, but it did create a large bulge on the back side of the panel and in-plane cracking. A subsequent test at 2.6J showed similar, though less severe, damage as the $4 \mathrm{~J}$ impact. With a $12.7 \mathrm{~mm}$ diameter impactor the damage was less at the $2.6,3.8$ and $12.5 \mathrm{~J}$ levels than with the $6.4 \mathrm{~mm}$ impactor. At $12.5 \mathrm{~J}$ the $12.7 \mathrm{~mm}$ impactor did not penetrate the composite panel. Further increasing the impactor to $1.9 \mathrm{~cm}$ diam. gave similar results at 3.9 as with the $12.7 \mathrm{~mm}$ impactor at $3.8 \mathrm{~J}$.

Additional testing had been planned using $10 \mathrm{~cm} \times 3.8 \mathrm{~cm}$ panels, which would allow for measurement of residual tensile strength of the composite following impact. Prepreg MI composite samples for these tests were fabricated and drop-dart impact testing performed. However, at this point in the program that the available funding had been exhausted due to the need for multiple shroud rig tests, so that post-impact environmental exposure of the samples was not performed.

Table 3-1. Summary of Drop-Dart Impact Damage Tests on Prepreg MI Composites

\begin{tabular}{|c|cc|c|c|c|l|l|}
\hline Sample & $\begin{array}{c}\text { Drop } \\
\text { Height } \\
(\mathbf{m})\end{array}$ & $\begin{array}{c}\text { Drop } \\
\text { Weight } \\
(\mathbf{k g})\end{array}$ & $\begin{array}{c}\text { Velocity } \\
(\mathbf{m} / \mathbf{s})\end{array}$ & $\begin{array}{c}\text { Energy } \\
(\mathbf{J})\end{array}$ & $\begin{array}{c}\text { Dart } \\
\text { Diam. } \\
(\mathbf{c m})\end{array}$ & Result & \\
\hline $1007-1-1$ & 0.22 & 17.0 & 2.0 & 37.0 & 0.64 & complete penetration & \\
\hline $1007-1-2$ & 0.29 & 4.65 & 2.0 & 13.3 & 0.64 & complete penetration & \\
\hline $1007-1-3$ & 0.085 & 4.65 & 1.0 & 3.90 & 0.64 & $\begin{array}{l}\text { large amount of bulging on back of } \\
\text { specimen }\end{array}$ \\
\hline $1007-1-4$ & 0.057 & 4.65 & 0.80 & 2.60 & 0.64 & $\begin{array}{l}\text { moderate bulging on back of } \\
\text { specimen }\end{array}$ \\
\hline $1007-2-5$ & 0.057 & 4.65 & 0.80 & 2.60 & 1.27 & slight bulging on back of specimen \\
\hline $1007-2-6$ & 0.082 & 4.65 & 1.0 & 3.77 & 1.27 & slight bulging on back of specimen \\
\hline $1007-2-7$ & 0.27 & 4.65 & 2.0 & 12.5 & 1.27 & $\begin{array}{l}\text { large amount of bulging on back of } \\
\text { specimen }\end{array}$ \\
\hline $1007-2-8$ & 0.082 & 4.84 & 1.0 & 3.92 & 1.91 & slight bulging on back of specimen \\
\hline
\end{tabular}

The second main goal of this subtask was the selection and specification of a heat shield (i.e. damper block) material for the CMC shroud system. Based on a screening evaluation of the available manufacturer's literature, three candidate superalloy heat shield materials were selected for evaluation, namely PM2000, Haynes 214 and Haynes 230. Rather than rely on a laboratory tests for oxidation measurements, for which the extrapolation to engine conditions may not have been accurate, it was decided to utilize all three candidate materials in the initial shroud rig tests. Exposure testing in the shroud rig was expected to yield information as to the oxidation, deformation and fatigue behavior of these materials in a much more engine-like environment. Evaluation of the heat shield materials will therefore be discussed as part of the rig testing subtasks. 


\subsubsection{Task 1.3 - Benefits Analysis}

Early in the program in 2001 a benefits analysis of the CMC shroud component in a 7FA+e class engine was conducted; however, the details of the analysis, including engine operating conditions, cooling flows, component temperatures, etc., are highly proprietary information and could not be disclosed publically. A proprietary letter report was submitted to DOE that summarized the findings of the benefits analysis. Overall the findings were very consistent with those projected by Grondahl and Tsuchiya[11].

One of the issues with this early benefits analysis was that the design of the CMC shroud system had not yet been completed so that only estimates of the cooling air reductions were available. A much more detailed benefits analysis was conducted later in 2008 after the CMC shroud system design had been finalized. This analysis will be described later as part of engine test \#2 in Section 3.1.23.4.

\subsubsection{Task 2.2 - Shroud Fabrication Trials}

The purpose of this subtask was to perform fabrication trials on the shroud concepts developed under Tasks 1.1 and 2.1 in order to demonstrate the ability to fabricate the CMC inner shroud components, and to provide feedback to the design effort as to what features could and could not be fabricated from CMC. The focus of this task was on the GEdeveloped prepreg MI composite material and process as the development and evaluation of the slurry cast MI process capability was left to the vendors of those materials (Goodrich and Honeywell Advanced Composites). This task was part of the original program award and ran from mid 200 to late 2001.

One of the main differences between the new CMC inner shroud design and the older conceptual design used for rig testing under the CFCC program was the increase in wall thickness from $2.5 \mathrm{~mm}$ to $5 \mathrm{~mm}$. At the start of the program there had been very limited experience with fabrication of thick wall sections, and it was therefore necessary to evaluate our ability to infiltrate thick sections. A prepreg composite preform panel was prepared which was $7.6 \mathrm{~mm}$ in thickness, and it was then cut into a set of individual small panels. Each of these panels was then infiltrated using four different hold times for the infiltration heat treatment and two types of silicon source material. After infiltration the samples were sectioned and the extent of infiltration evaluated via metallography.

Qualitatively, the samples infiltrated for the standard hold time duration were found to be practically $100 \%$ infiltrated. Because the infiltration temperature is roughly $25^{\circ}$ above the melting point of silicon and there is a finite furnace heating and cooling rate, the actual amount of time spent above the melting point of the silicon infiltrant was roughly 45 minutes. Samples held for shorter times showed progressively smaller extent of infiltration, with the sample held for 0 minutes (still $\sim 15$ minutes above the infiltrant melting point) being only about $50 \%$ infiltrated. The extent of infiltration was equivalent between the two silicon source types for the infiltration times evaluated. The results of these experiments 
indicate that infiltration of a $5 \mathrm{~mm}$ thick shroud component would be within the capabilities of the infiltration process as it was practiced at that time.

Preliminary fabrication trials of actual CMC inner shroud components were initiated to evaluate two types of lay-up tooling. Shrouds were laid-up using either an internal or an external lay-up mold. Both types of mold have advantages and disadvantages regarding ease of lay-up and dimensional control of the hot gas path surface, so both were tried to see which mold type gave the best overall quality of the CMC shroud component. A picture of the two CMC shroud parts is shown in Figure 3-7. Overall the dimensional quality of both shrouds was comparable regardless of the lamination mold used; however, there was better ply compaction, particularly in the corner regions, when using the internal mold. The internal mold was therefore used for all subsequent shroud fabrication efforts.

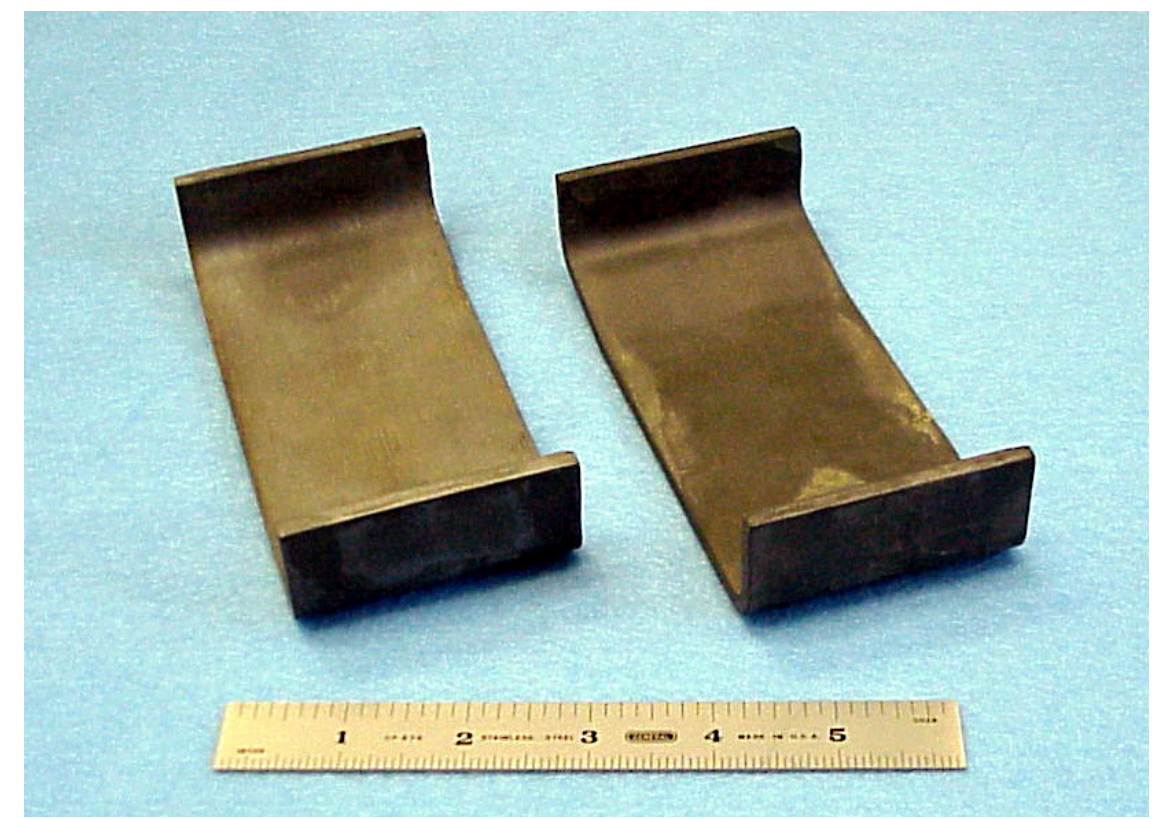

Figure 3-7. Photograph of the initial trial CMC shroud parts made with external (right) and internal (left) lay-up molds. Dimensional fidelity of the shrouds was comparable for either lay-up mold, but the surface finish and flatness was slightly better for the surfaces directly against the molds (outer surface for the external mold and inner surface for the internal mold.)

A second major difference between the newer CMC shroud design and the older "toboggan" design used in the CFCC program was the method of attachment between the CMC inner shroud and the metallic outer shroud block. In the new design this attachment was accomplished using pins or bolt in the outer shroud block that passed through holes machined into the vertical flange sections of the CMC inner shroud. During the early design reviews questions were raised as to the load carrying capacity of such an attachment. Since contact stresses for such a configuration are difficult to predict with FEA analyses it was 
necessary rely on experimental evaluations of the failure load. Due to material availability constraints the testing was performed in three iterations.

At the time of the initial testing CMC material that was the same thickness as the CMC inner shroud $(5.1 \mathrm{~mm})$ was not available, and so initial testing was performed using $2.3 \mathrm{~mm}$ thick test bars. Holes were diamond core drilled near the ends of $10 \mathrm{~cm} \mathrm{x} 1.3 \mathrm{~cm}$ test bars. These samples were then loaded to failure in a tensile testing machine using the pin/clevis arrangement shown in Figure 3-8. The tests were conducted at $1 / 2$ scale, i.e. the sample thickness, hole diameter and distance of the hole from the edge of the bar were each $\sim 1 / 2$ the nominal dimensions as in the CMC shroud components.

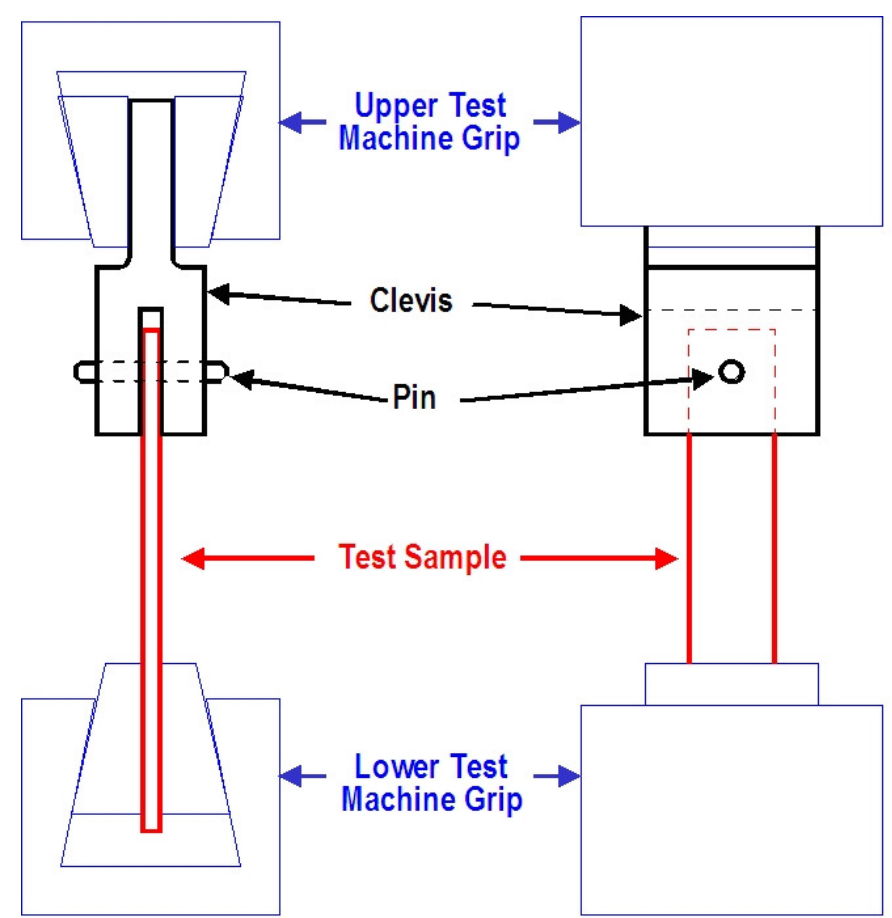

Figure 3-8. Clevis/pin test fixtures used for evaluating the pin-in-hole shroud attachment failure loads.

The result of these tests showed that the failure loads for both prepreg and slurry cast MI samples were comparable, and both well above the contact loads expected at the pin attachments for shroud components. However, there were differences noted in the failure modes of the prepreg and slurry cast MI composite materials. Figure 3-9 shows photographs of the samples after pull testing. The prepreg samples tended to fail by forming tensile cracks laterally outward from the sides of the holes and upward from the center of the hole. As the sample could not be viewed during the test it was not obvious whether the lateral or vertical cracks formed first. The crack openings were wider near the hole on the lateral cracks, and narrower near the hole on the vertical cracks, both of which are consistent with the bending load applied to the ligament of material at the end of the bars once cracking was initiated. The slurry cast samples, on the other hand, showed a 
crushing and shear-type failure where the plug of material directly above the hole appeared to be pulled out from the end of the bars.

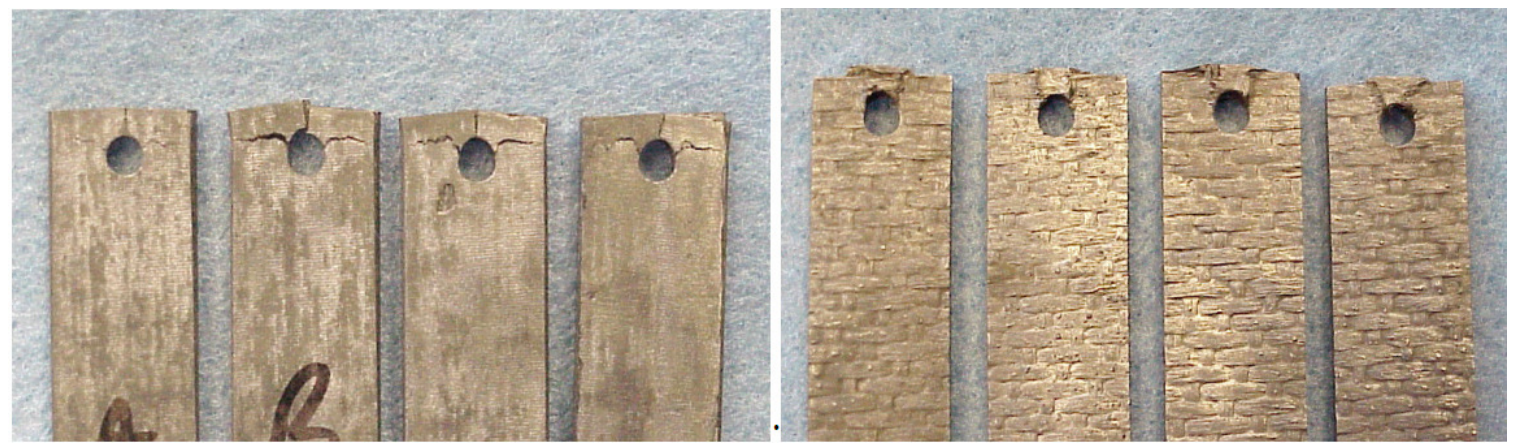

Figure 3-9. Photographs of the pin pull-out test samples after testing to failure: Left prepreg MI samples; Right - slurry cast MI samples.

The second set of pin pull-out testing was performed on slurry cast MI material with the same thickness as the inner shroud $(5 \mathrm{~mm})$ in order to verify that the subscale testing was valid and that the results were scalable. The graph in Figure 3-10 gives the stressdisplacement response from the $1 / 2$ scale tests on prepreg and slurry cast materials, and the newer results on the full-scale test on slurry cast material. The change in scale of the test samples is reflected in the stress calculations, and the agreement between the $1 / 2$ scale and full scale test failure stresses indicates that the failure loads did indeed scale as expected. Moreover, the absolute maximum hole loading anticipated on the shroud, which assumes all of the damper block force is supported on only one pin, corresponds to a net section stress of only about $5 \mathrm{MPa}$, so the load capability of this attachment configuration for both CMC materials far exceeds any anticipated loading. (The differences in displacement between the sets of tests are caused by the compliance of the testing machine and test fixtures. The loads in the full scale test were roughly $4 \mathrm{X}$ those in the $1 / 2$ scale tests so that the displacement needed to generate these loads was substantially larger for the full scale samples because of test fixture compliance.)

The initial pin pull-out tests were all performed on as-fabricated material with round holes in the CMC; however, two of the mounting holes in each shroud are actually elongated slots. Also, the edges of the holes in the CMC would be exposed to oxidation, and the actual shroud mounts would be subject to cyclic, rather than steady state, loads. In order to verify that the load capability of the pin-and-hole arrangement would not be compromised by CMC oxidation, cyclic loading or hole (slot) geometry a third round of pin pull-out testing was performed. In these tests slotted holes were evaluated using the pin pull-out test in the as-fabricated state and following either 100 hours of oxidation in $90 \%$ steam at $1200^{\circ} \mathrm{C}, 105$ cycles of fatigue loading at $355+/-45 \mathrm{~N}$ at room temperature, or combined oxidation treatment followed by fatigue loading. The net section stress versus displacement curves generated from these samples are shown in Figure 3-11. It should be noted that different slot widths were also tested where the ratio of slot width to slot height were 1 
(round hole), 1.2 and 1.65. The distance of the holes from the end of the test samples was the same for all tests.

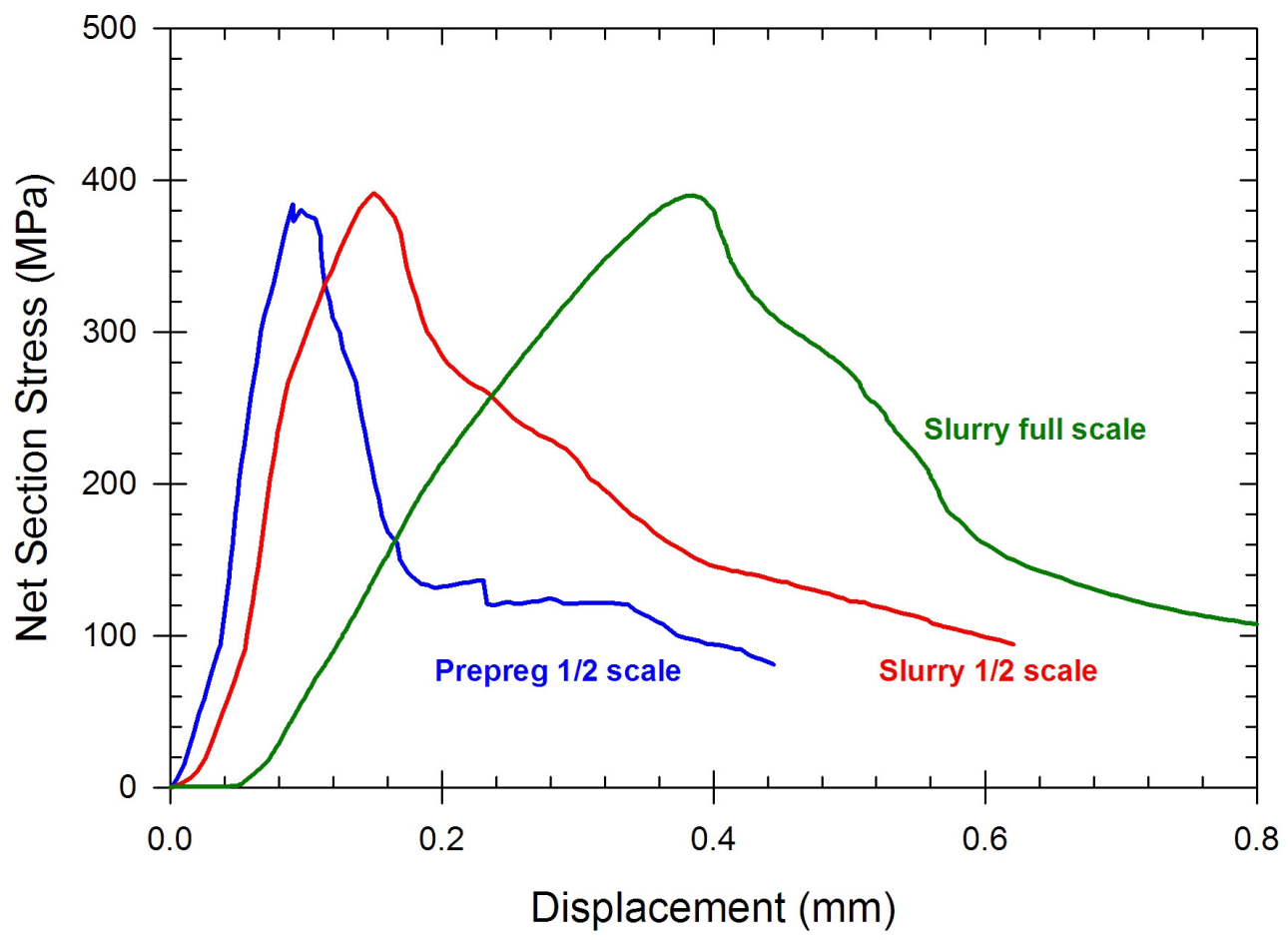

Figure 3-10. Stress-displacement curves for pin pull-out tests on as-fabricated MI composites from the $1^{\text {st }}$ and $2^{\text {nd }}$ rounds of testing.

The maximum net section failure stress for the round hole was about $20 \%$ less than that indicated for the same geometry in Figure 3-10, but this was consistent with the difference in tensile strength properties observed for the different panels used in these two sets of tests. The results from the new tests indicated that neither the oxidation treatment nor the fatigue loading treatment had an appreciable effect on the load bearing capability of the attachment holes. Hole geometry did appear to have a minor effect, as going from a round hole to a slot decreased the maximum stress capability of the attachment, but there was no discernable difference in the response between the low aspect ratio and high aspect ratio slots. In any case, the stress capability of all of the configurations tested, even after oxidation and fatigue exposure, far exceeded the anticipated maximum attachment stress of $5 \mathrm{MPa}$, and so this attachment configuration was deemed to be robust enough to proceed with shroud rig testing. 


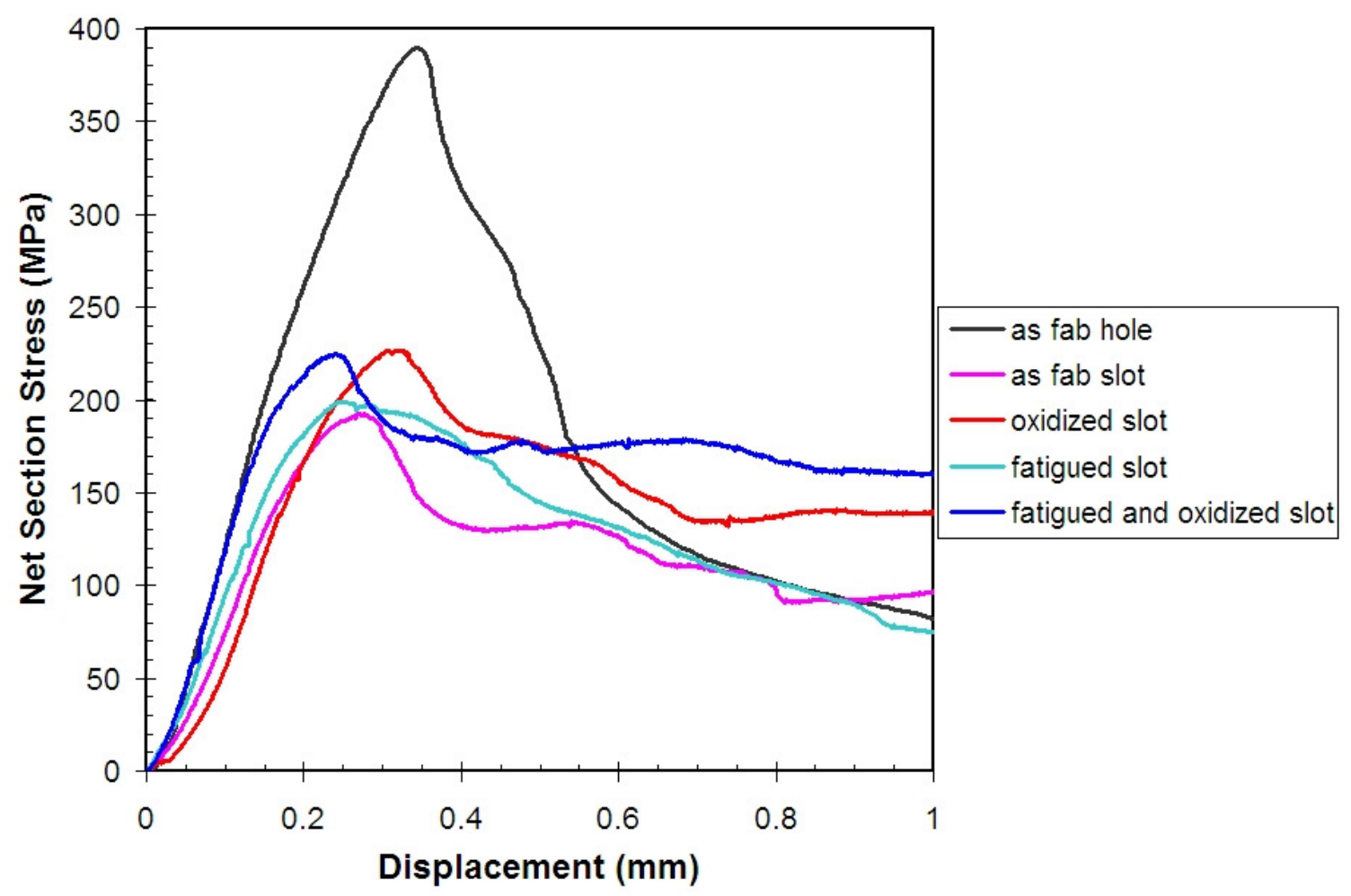

Figure 3-11. Stress-displacement plots for the third round of pin pull-out testing on samples with round holes or elongated slots.

\subsubsection{Task 2.3 - Rig Design and Assembly}

The goal of this subtask was to design and fabricate the high temperature, high pressure combustion test rig for exposure testing of the CMC shroud system under turbine-like environmental conditions. More specifically, the rig was designed to simulate the thermal and aerodynamic environment near the 1st stage turbine shroud in a typical GE 7FA-class engine. The rig was then used to test prototype shroud designs and attachment schemes for their ability to perform in a simulated gas turbine environment.

The first rig design review was held on August 13, 2000, with the GE Energy Chief Engineer's Office, at which time the basic design of the rig was approved. Fabrication of parts for the rig was started in the Fall of 2000, with rig assembly and debugging starting in the Spring of 2001. Details of the rig design are described below.

The design target values for combustion gas temperature, pressure and Mach number in the shroud test section inlet were $1210^{\circ} \mathrm{C}, 7.6$ bar and 0.35 , respectively. The shroud test section was designed to simulate the engine pressure and temperature gradients along the shroud and to provide the secondary flows fore and aft of the shroud that exist in the engine and may exacerbate the thermal gradients present in the CMC shroud. 
Figure 3-12 shows a cross section view of the shroud test rig assembly. Preheated air was supplied at the upstream end of the rig at a flow rate of approximately $4 \mathrm{~kg} / \mathrm{s}$. Natural gas fuel was injected using a premixer assembly that was capable of both premixed and diffusion operation. A ceramic-lined combustor section directed the hot product gases to a transition section whose flow cross section changed from round to an annulus sector. The hot gas then passed through the shroud test section.

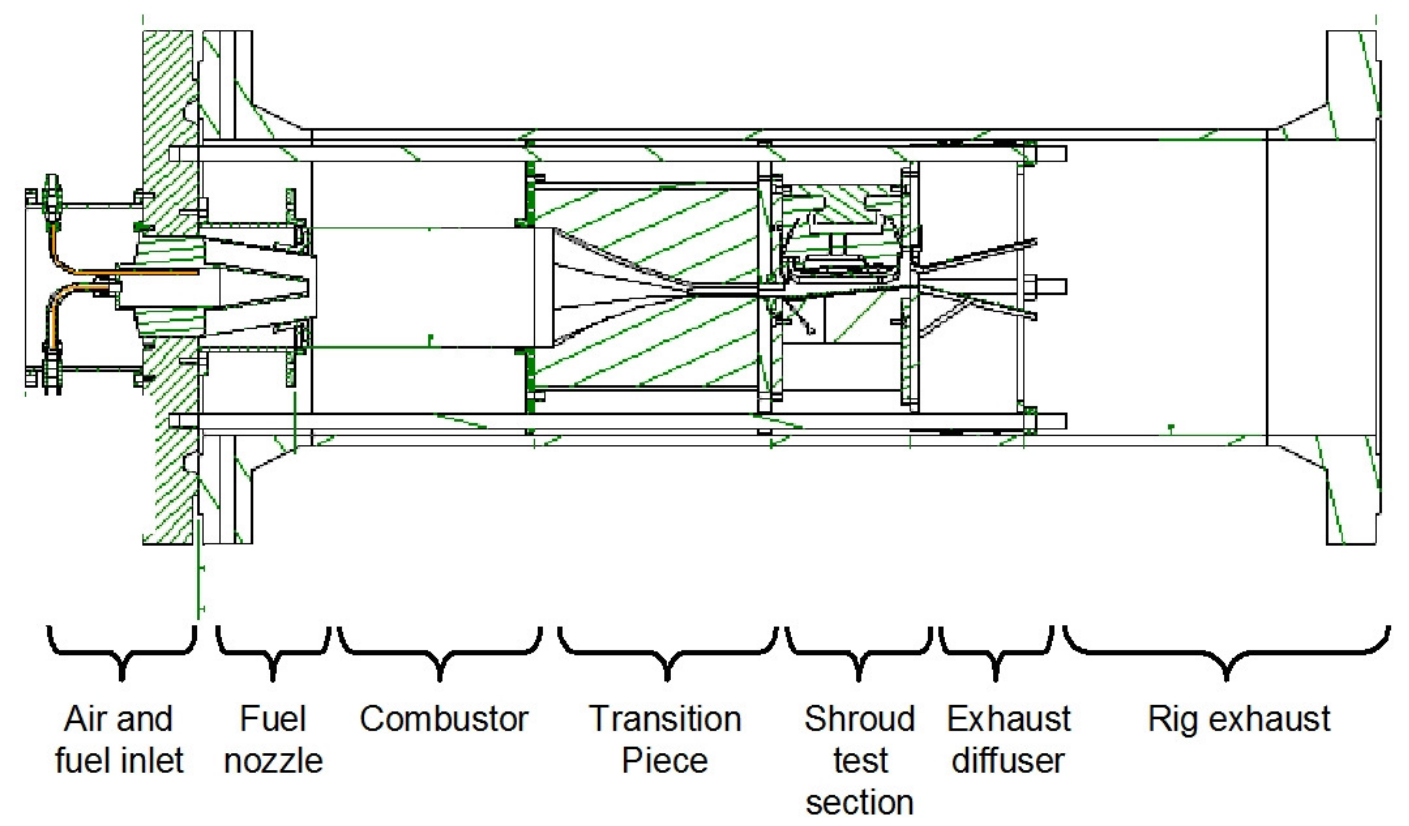

Figure 3-12. Cross sectional schematic of the shroud test rig design including the existing pressure vessel.

The shroud test section, shown in Figure 3-13, was designed to replicate the prototype CMC shroud installation in the GE 7FA engine. Three CMC shrouds were mounted sideby-side and held in place by an outer shroud block. The attachment between the CMC inner shroud and outer shroud block was identical to that proposed for the engine. The outer shroud block was chorded using a radius identical to the engine. The lower wall of the test section was contoured to accelerate the flow as it passed the shrouds. This flow acceleration resulted in axial pressure and temperature gradients similar to those experienced in the engine. Two-dimensional computational fluid dynamics (CFD) modeling was used to predict the test section flow field and aid in the design of the flow path in the shroud test section. Figure 3-14 shows an example of predicted gas temperature contours through the test section flow path, and how it mimics the temperature drop through the $1^{\text {st }}$ stage of an actual 7FA engine. 


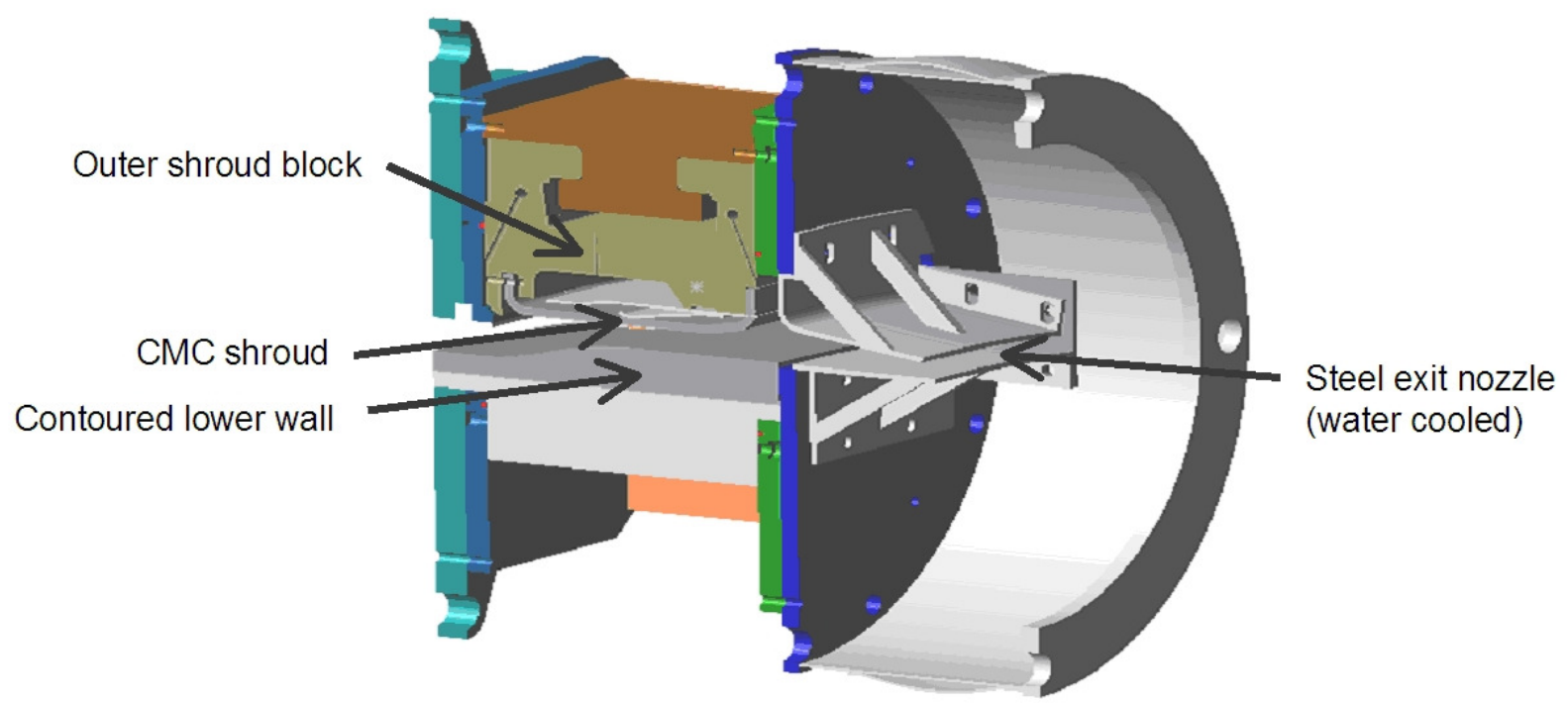

Figure 3-13. Cut-away view of the shroud test section and exhaust diffuser of the shroud test rig.

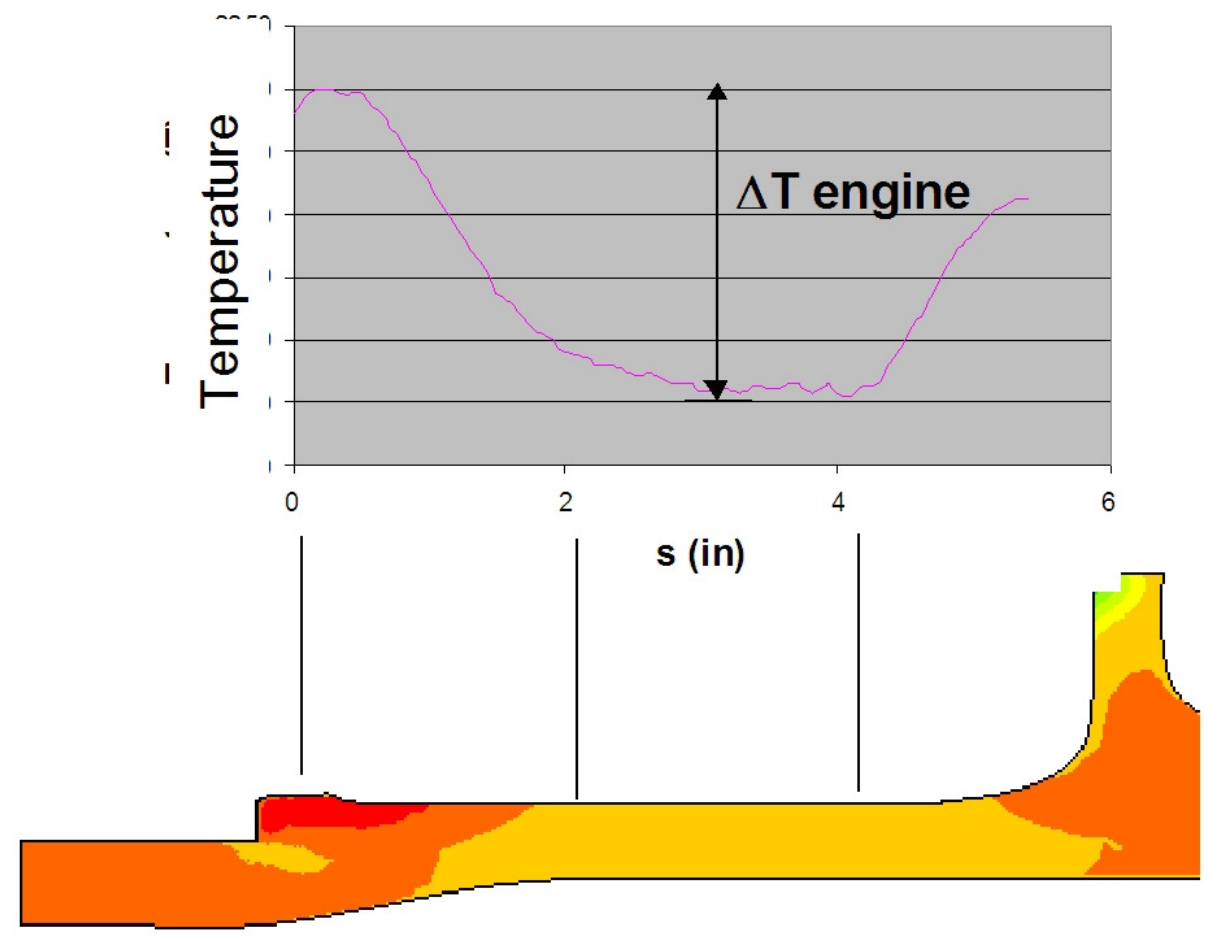

Figure 3-14. Computational fluid dynamics (CFD) prediction of the combustion gas temperature profile in the shroud section of the test rig compared to the nominal temperature drop in the $1^{\text {st }}$ stage shroud section of a 7FA engine. 
The side walls of the shroud test section utilized CMC plates at the gas path surface. This was done in order to improve the durability of the rig since direct exposure of metallic side walls to the $1200^{\circ} \mathrm{C}$ combustion gases would have meant very limited oxidation life of the walls. The CMC plates acted as heat shields, reducing the heat load to the test section side walls and also minimizing heat loss to the side walls, thereby minimizing the lateral thermal gradient in the shroud test section.

Rig assembly started in early 2001 . Figure $3-15$ shows a diagram of the test rig as it would look when inserted into the pre-existing pressure vessel, and indicates the inlet flows that were supplied to various sections. The photograph in Figure 3-16 shows the partially assembled internal parts of the test rig, including the fuel inlet manifold, pressure vessel cover flange, combustor and transition sections (left to right).

The test section was instrumented with thermocouples to monitor critical temperatures of the shroud and other surfaces near the hot gas path. Pressure taps were also included in order to verify the proper pressure drops within the test rig and across the inner shroud from the cooling circuit flows. Figure 3-17 shows a preliminary layout for thermocouple and pressure measurement locations.

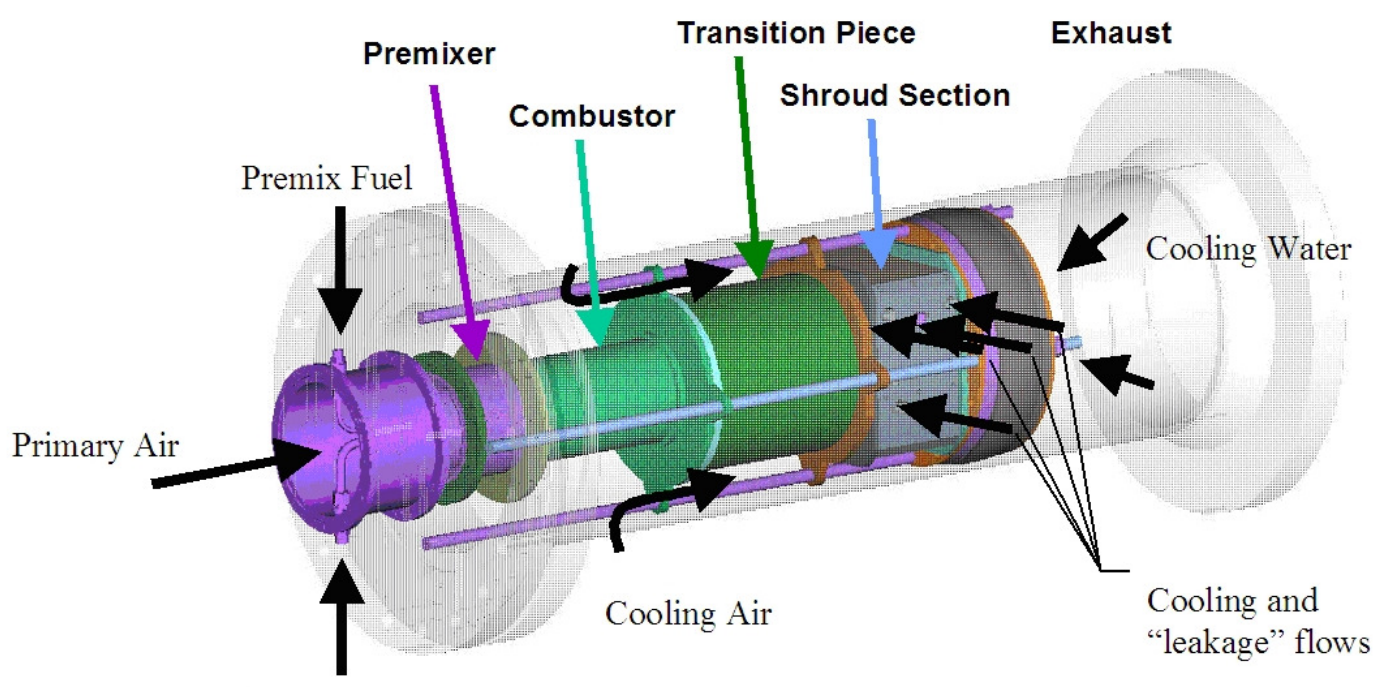

Diffusion Fuel

Figure 3-15. Diagram of the shroud test rig showing the location of various sections within the pressure vessel, and also indicating various inlet flows. 


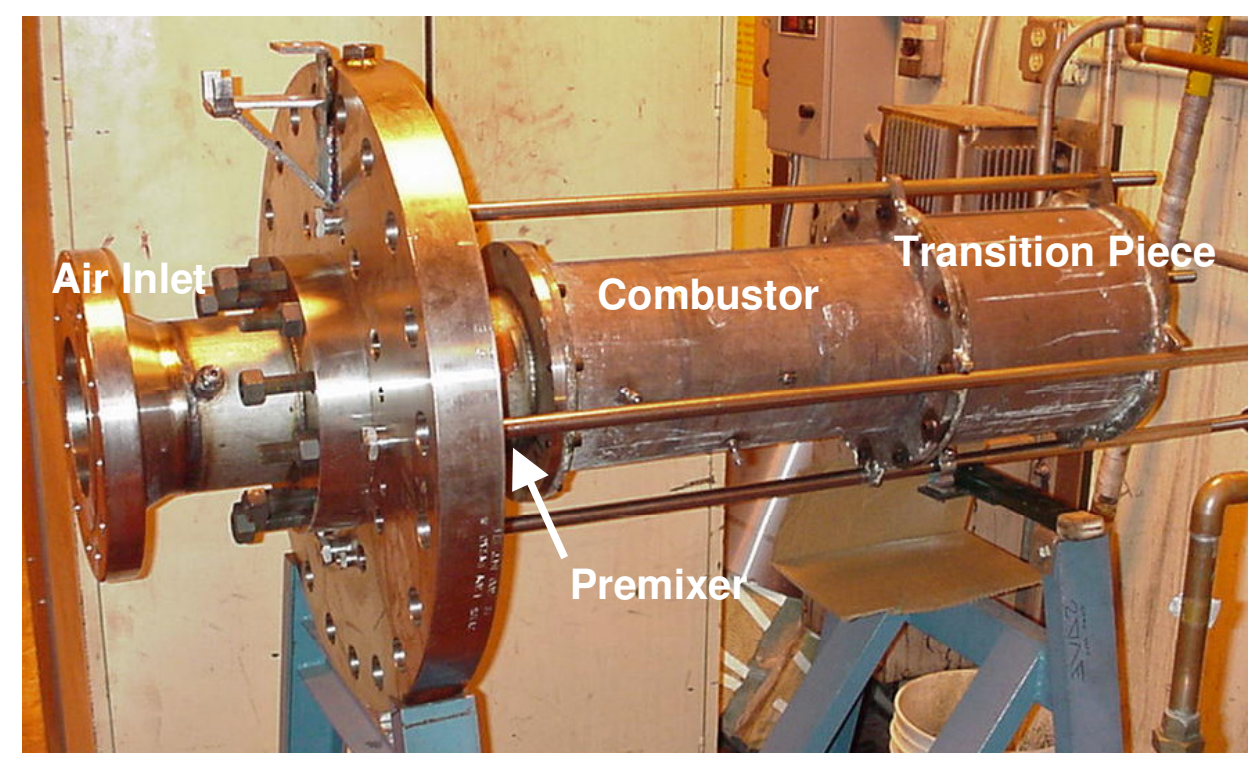

Figure 3-16. Photograph of the shroud test rig internals during initial assembly.
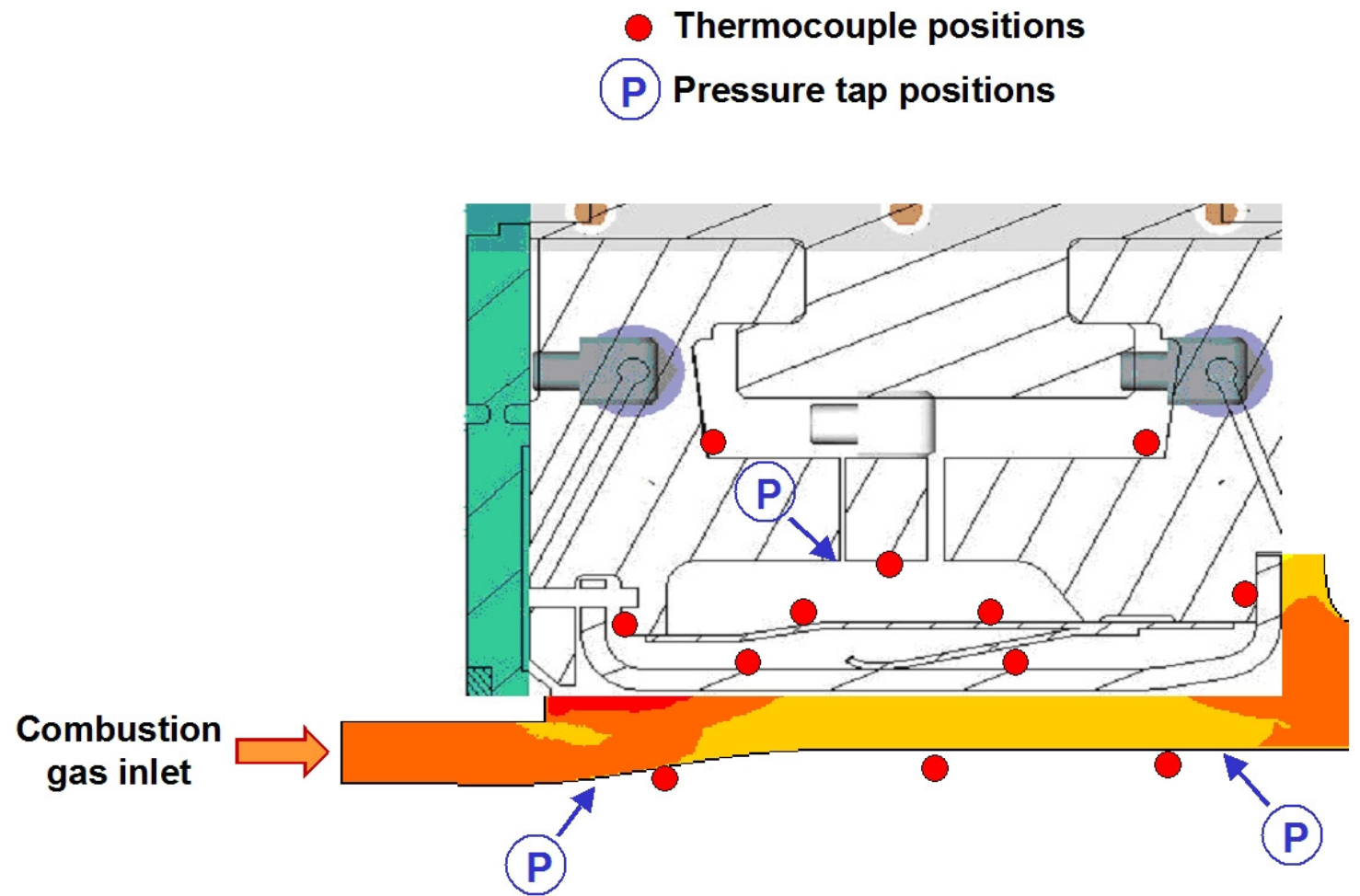

Figure 3-17. Instrumentation plan for the shroud test section of the shroud test rig, showing planned positions of thermocouples and pressure taps.

Rig fabrication and assembly proceeded through the $1^{\text {st }}$ half of 2001 . Initial rig shakedown testing was started in June of 2001, initially using instrumented metallic inner shrouds. Table 3-2 gives a summary of the cold and hot flow rig tests that were run as part of the 
shakedown procedure. Preliminary shroud rig tests were conducted to examine operability and flow characteristics of the gas path. First, two cold flow tests were conducted to evaluate pressure and flow instrumentation performance. Subsequent to this several hot flow (combustion) tests were conducted to examine combustor operability and test section temperature uniformity and pressure characteristics.

During the initial hot flow tests the test section pressure was reduced to approximately 3.4 bar to reduce the heat load on the system during these exploratory runs. The combustor was easily ignited while fueling the diffusion fuel circuit only with an air preheat temperature of $250^{\circ} \mathrm{C}$, giving a bulk flame temperature of approximately $600^{\circ} \mathrm{C}$. The flame temperature was subsequently increased by adding fuel through the premix circuit; however, bulk gas temperatures were not increased beyond $700^{\circ} \mathrm{C}$ in order to prevent overheating of the surrogate metallic inner shrouds.

Table 3-2. Summary of Shroud Rig Shakedown Tests

\begin{tabular}{|c|c|c|c|c|c|}
\hline Date & Mode & $\begin{array}{l}\text { Shroud } \\
\text { Type }\end{array}$ & Duration & Purpose & Result \\
\hline $\begin{array}{c}\text { June } 1 \text {, } \\
2001\end{array}$ & cold & metal & $2 \mathrm{hrs}$ & $\begin{array}{l}\text { Check instrumentation and } \\
\text { calibrate by-pass flows }\end{array}$ & $\begin{array}{l}\text { Identified faulty transducer } \\
\text { connections } \\
\text { Adjusted flow split between main } \\
\text { and bypass hot air feeds } \\
\text { Test section lower wall failure } \\
\text { allowed wall to lift into flow path }\end{array}$ \\
\hline June 6 & cold & metal & $2 \mathrm{hrs}$ & $\begin{array}{l}\text { Recheck instrumentation and } \\
\text { by-pass flows }\end{array}$ & $\begin{array}{l}\text { Ran without shroud test section in } \\
\text { place } \\
\text { Everything OK }\end{array}$ \\
\hline June 8 & hot & metal & $3 \mathrm{hrs}$ & $\begin{array}{l}\text { Check fuel system, light-off } \\
\text { and temperature profile }\end{array}$ & $\begin{array}{l}\text { Emissions profile indicated } 200^{\circ} \mathrm{C} \\
\text { temperature peak from center to } \\
\text { edge }\end{array}$ \\
\hline June 15 & hot & metal & $3 \mathrm{hrs}$ & $\begin{array}{l}\text { Investigate effect of premix / } \\
\text { diffusion fuel flow split on } \\
\text { temperature profile }\end{array}$ & $\begin{array}{l}\text { Flow split had small effect on } \\
\text { temperature profile }\end{array}$ \\
\hline June 21 & hot & metal & $3 \mathrm{hrs}$ & $\begin{array}{l}\text { Validate temperature profile } \\
\text { using thermocouple }\end{array}$ & $\begin{array}{l}\text { Thermocouple and emissions } \\
\text { measurements were in agreement }\end{array}$ \\
\hline June 26 & hot & metal & $3 \mathrm{hrs}$ & $\begin{array}{l}\text { Investigate effect of dome air } \\
\text { cooling holes on temperature } \\
\text { profile }\end{array}$ & $\begin{array}{l}\text { Dome cooling air had little or no } \\
\text { effect on temperature profile } \\
2^{\text {nd }} \text { lower wall failure. }\end{array}$ \\
\hline July 5 & hot & metal & $4 \mathrm{hrs}$ & $\begin{array}{l}\text { Investigate effect of premixer } \\
\text { shroud fuel injection of } \\
\text { temperature profile } \\
\text { Ran without shroud test } \\
\text { section because of failed } \\
\text { lower wall }\end{array}$ & $\begin{array}{l}\text { Significant improvement in } \\
\text { temperature profile. }\end{array}$ \\
\hline Sept. 3 & hot & $\mathrm{CMC}$ & $1 \mathrm{hr}$ & $\begin{array}{l}\text { Check rig operation with } \\
\text { ceramic shrouds in place } \\
\text { Test new lower wall with } \\
\text { CMC brackets }\end{array}$ & $\begin{array}{l}\text { Proper rig operation verified } \\
\text { Lower wall casting cracked after } \\
20 \text { min at } 650-870^{\circ} \mathrm{C} \text { but } \mathrm{CMC} \\
\text { brackets remained intact }\end{array}$ \\
\hline
\end{tabular}


The very first cold flow test revealed a problem with the attachment technique used to secure the test section lower wall made of the castable alumina refractory. The pressure drop across the shroud test section was creating a lifting force on the test section lower wall, which was sufficient to fail the ceramic casting in regions adjacent to the attachments. This in turn allowed the cast ceramic lower wall to lift up and partially block the flowpath in the test section. The ceramic attachment method was then modified and a new lower wall casting was fabricated. The June 8 through June 21 were performed without problem using the new lower wall design; however, eventually the metallic structure holding the wall overheated, melted and again the lower wall lifted up to block the flow path during the June 26 test. Figure 3-18 shows a photograph of the failed lower wall taken from the exit end of the shroud test section.

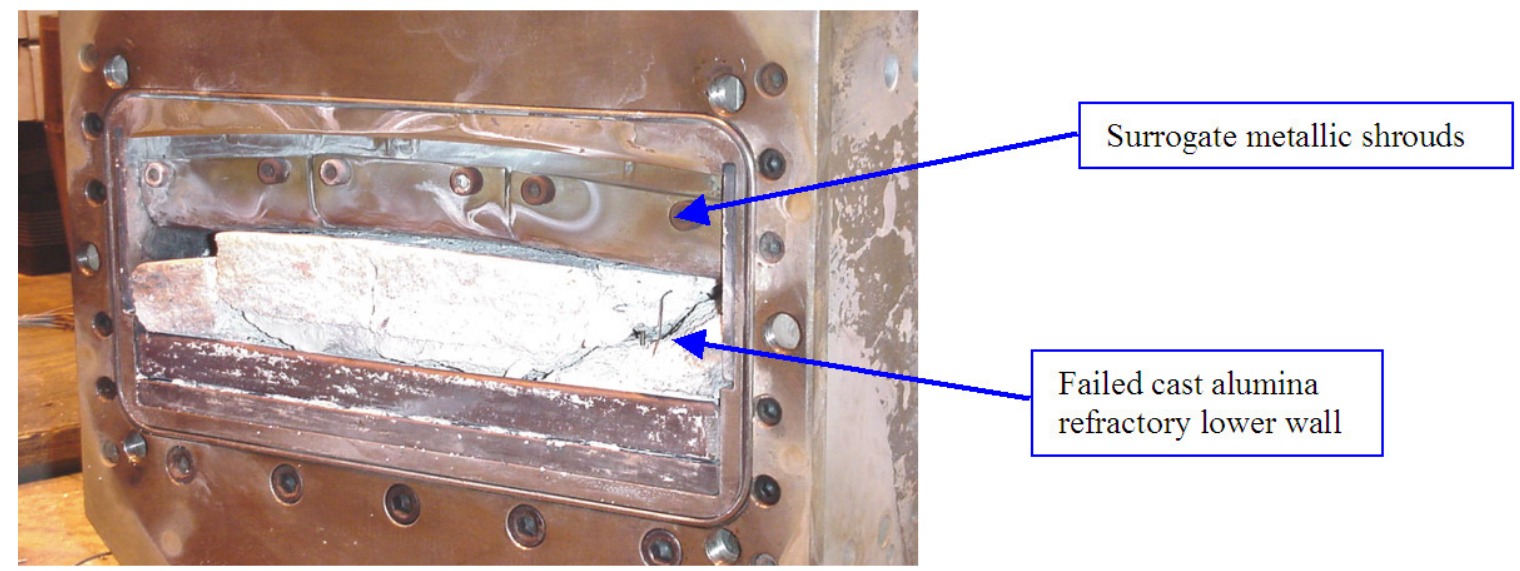

Figure 3-18. Photograph of the second failed cast alumina refractory lower wall from the exit end of the shroud test section of the shroud test rig.

The method of holding onto the castable alumina refractory lower wall was again modified to incorporate brackets of $\mathrm{CMC}$ on both the forward and aft edges of the wall. The prepreg MI CMC brackets were successfully fabricated and a new lower wall was cast to conform to the new brackets. Unfortunately, during the initial rig run with this wall (on September 3rd) it also failed. Although the CMC brackets remained intact, the castable alumina fractured across the middle section not covered by the CMC brackets and again lifted into the flow path. A photograph of the failed castable wall with intact CMC brackets is shown in Figure 3-19.

At this point the shakedown testing of the shroud rig was essentially completed. Apart from the lower wall failures, the rig was showing good operability with minimal combustion dynamics and a relatively flat temperature profile, and the initial test with CMC shrouds showed no immediate issues with the shrouds or attachments. Subsequent runs in the shroud rig were therefore considered part of the shroud exposure tests, and are described under Task 2.5. 


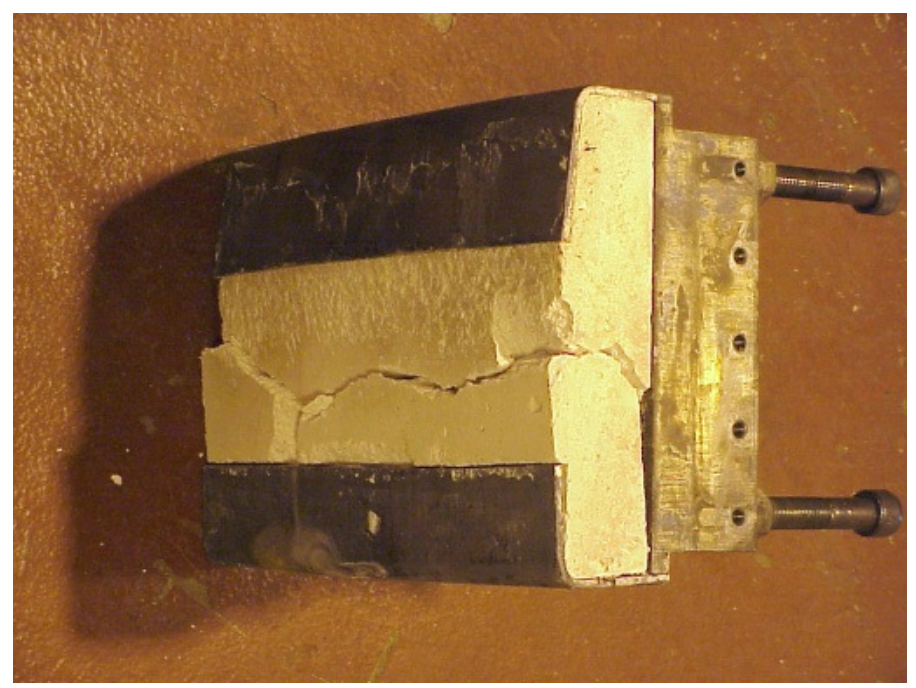

Figure 3-19. Photograph of the shroud rig lower wall made from castable refractory and $\mathrm{CMC}$ forward and aft brackets showing the failure of the castable refractory section.

Two solutions to the lower wall problem were devised; 1) rebuild the lower wall completely out of CMC using the castable only as an insulting backing, and 2) convert the rig to a cooled metallic lower wall. Option 2 was not attractive since having a cold wall across the gas path from the shrouds would allow for radiative cooling from the hot face of the shrouds. This in turn would lower the shroud temperature relative to the combustion gas temperature, necessitating that we fire the rig at still higher temperatures to compensate. The radiative cooling would also modify the heat flux through the shroud, disrupting the desired temperature distribution. It was therefore decided that the preferred solution was to build a lower wall where the complete hot gas path flow surface would be made of CMC. This lower wall could then be run without backside cooling, preserving the desired gas path temperature distribution.

\subsubsection{Task 2.4 - Shroud Fabrication for Rig Testing}

Prepreg MI shrouds for use in the shroud rig tests were fabricated at GE GRC in late 2000 to early 2001. Slurry cast MI shrouds were also procured from Honeywell Advanced Composite, Inc. (CCP) and from Goodrich Aerospace in early 2001. Detailed discussion of the fabrication procedures used for the prepreg MI shrouds would require divulging highly proprietary information, and thus only a description of the finished shrouds and their characterization will be given. Details of the fabrication of the slurry cast shrouds were not available from the vendors for the same proprietary information reasons.

Four prepreg MI shrouds were fabricated at CRD using coated Hi-Nicalon fiber. The first shroud through the process was burned-out and infiltrated free standing, i.e. no support mold was used during either the binder burn-out or silicon infiltration process steps. Through this process the hot gas path face of the shroud was found to curve slightly, which effectively caused the end flanges to cant inward, making the flange-to-flange distance come out below the specification. Consequently a carbon form was used for burn-out and 
infiltration of the other three shroud preforms. The carbon forms maintained the proper flange-to-flange spacing and improved the flatness of the hot gas path surface of the shrouds.

Following infiltration all of the shrouds were examined using transient infrared radiation (IR) imaging and laser ultrasound imaging. Evidence of interlaminar defects was found in all of the prepreg shrouds. These defects were more prevalent and more severe along the corner regions of the shrouds between the gas path surface and the mounting flanges, but less severe defects were also detected within the hot gas path surface itself. NDE indications were less prominent with the slurry cast shrouds, but, as will be shown later, quite substantial microstructural problems were found in these shrouds during destructive analysis.

Witness coupons processed along with the prepreg shrouds typically showed good composite strength properties. Tensile test results for the witness coupons are summarized in Table 3-3. The prepreg shrouds were fabricated two at a time, so the witness coupons represent either shrouds 1 and 2 or shrouds 3 and 4 .

Eight slurry cast MI shrouds were received from CCP, four of which had silcon-doped BN fiber coatings and four had pure BN fiber coatings. All were made with Hi-Nicalon fiber in an 8 harness satin weave. The tensile strength behavior of witness coupons cut from the shrouds with the pure BN coatings were substantially better than those for the CCP shrouds with Si-doped BN interface coatings. NDE images from these shrouds did not tend to show discrete interlaminar defects, but indicated dispersed defects probably related to porosity. The porosity also tended to be most prevalent in the corner regions of the shrouds.

Two slurry cast MI inner shrouds made with Hi-Nicalon fiber were also received from Goodrich Aerospace. The single stress-strain curve supplied with these shrouds also indicated good room temperature mechanical properties, as summarized in Table 3-3.

Two of the CCP slurry cast shrouds, two GE prepreg shrouds and the two Goodrich slurry cast shrouds had final machining performed at Goodrich Turbine Component Services (GTCS), a standard GE Energy machining vendor. Although GTCS had extensive experience with machining of thermal barrier coating (TBC)-coated turbine components, they had little prior experience with ceramic components. GTCS had considerable difficulty machining the mounting holes on the shrouds, resulting in substantial surface chipping around the holes, particularly for the prepreg shrouds. Photographs of some of the asmachined holes are shown in Figure 3-20. There was also some minor damage to the hot gas path surface of the shrouds that was caused by the clamping fixtures used during machining. 
Table 3-3. Tensile Strength Data from CCP and Goodrich Slurry Cast and GE Prepreg MI Shroud Witness Coupons

\begin{tabular}{|c|c|c|c|c|c|c|c|}
\hline Source & $\begin{array}{c}\text { Interface } \\
\text { Coating }\end{array}$ & $\begin{array}{c}\text { Shroud } \\
\text { Number }\end{array}$ & $\begin{array}{c}\text { Test } \\
\text { Temperature } \\
\left({ }^{\circ} \mathbf{C}\right)\end{array}$ & $\begin{array}{c}\text { Prop. } \\
\text { Modulus } \\
(\mathbf{G p a})\end{array}$ & $\begin{array}{c}\text { Ultimate } \\
\text { Limit* } \\
(\mathbf{M P a})\end{array}$ & $\begin{array}{c}\text { Strain to } \\
\text { Strength } \\
(\mathbf{M P a})\end{array}$ & $\begin{array}{c}\text { Failure } \\
(\%)\end{array}$ \\
\hline CCP & Si-BN & 007 & 25 & 199 & 119 & 315 & 0.69 \\
& & & 1200 & 81.4 & 71.0 & 265 & 0.47 \\
CCP & Si-BN & 008 & 25 & 216 & 103 & 288 & 0.72 \\
& & & 1200 & 124 & 174 & 273 & 0.40 \\
CCP & Si-BN & 009 & 25 & 172 & 121 & 190 & 0.25 \\
& & & 1200 & 124 & 174 & 273 & 0.40 \\
CCP & Si-BN & 010 & 25 & 179 & 123 & 190 & 0.48 \\
& & & 1200 & 134 & 115 & 261 & 0.53 \\
CCP & BN & 012 & 25 & 207 & 108 & 419 & 0.76 \\
CCP & BN & 013 & 25 & 234 & 98.5 & 407 & 0.73 \\
CCP & BN & 014 & 25 & 222 & 112 & 408 & 0.73 \\
CCP & BN & 015 & 25 & 241 & 100 & 399 & 0.74 \\
& & & & & & & \\
Goodrich & BN & $2 \& 3$ & 25 & 150 & 103 & 372 & 0.71 \\
& & & & & & & \\
GRC & Si-BN & $919-1 \& 2$ & 25 & 267 & 152 & 318 & 0.83 \\
GRC & Si-BN & $919-1 \& 2$ & 25 & 205 & 126 & 310 & 0.85 \\
GRC & Si-BN & $945-1 \& 2$ & 25 & 225 & 165 & 333 & 1.22 \\
GRC & Si-BN & $945-1 \& 2$ & 25 & 253 & 162 & 352 & 1.29 \\
\hline
\end{tabular}

*Proportional Limit $\sim$ matrix cracking stress
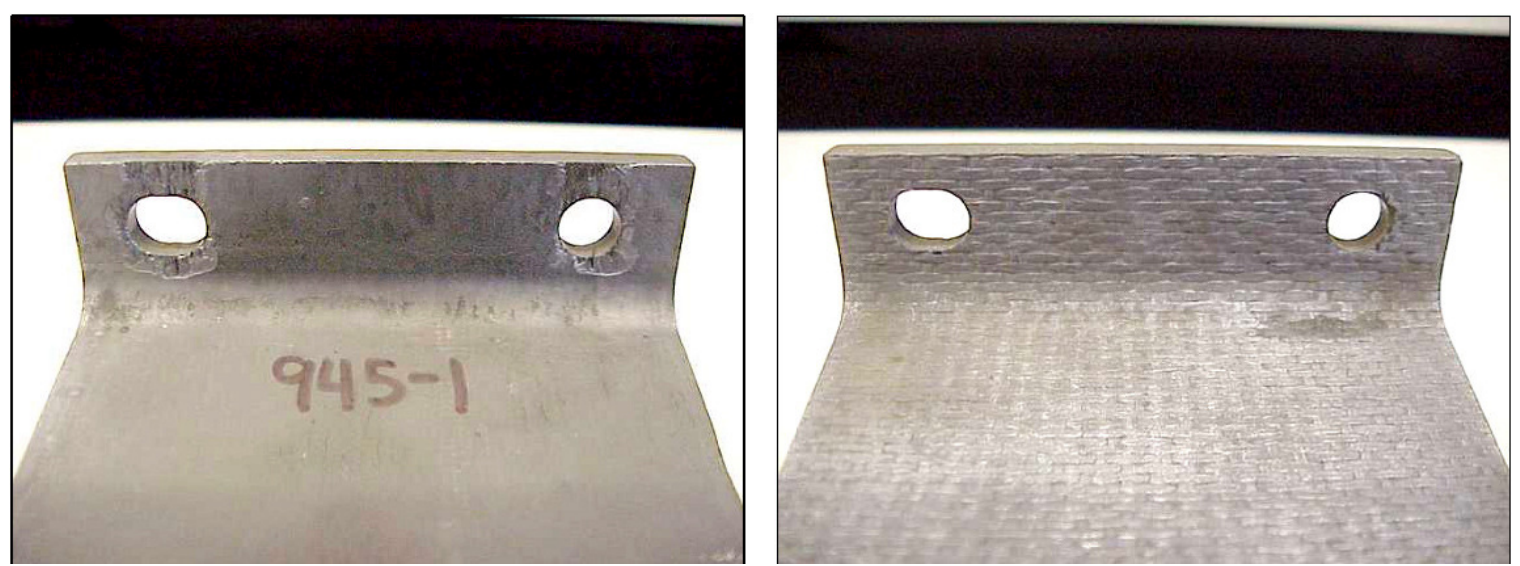

Figure 3-20. Photographs of the inside leading edge of as-machined prepreg (left) and slurry cast (right) CMC inner shroud components. Chipping around the mounting holes can be seen. 

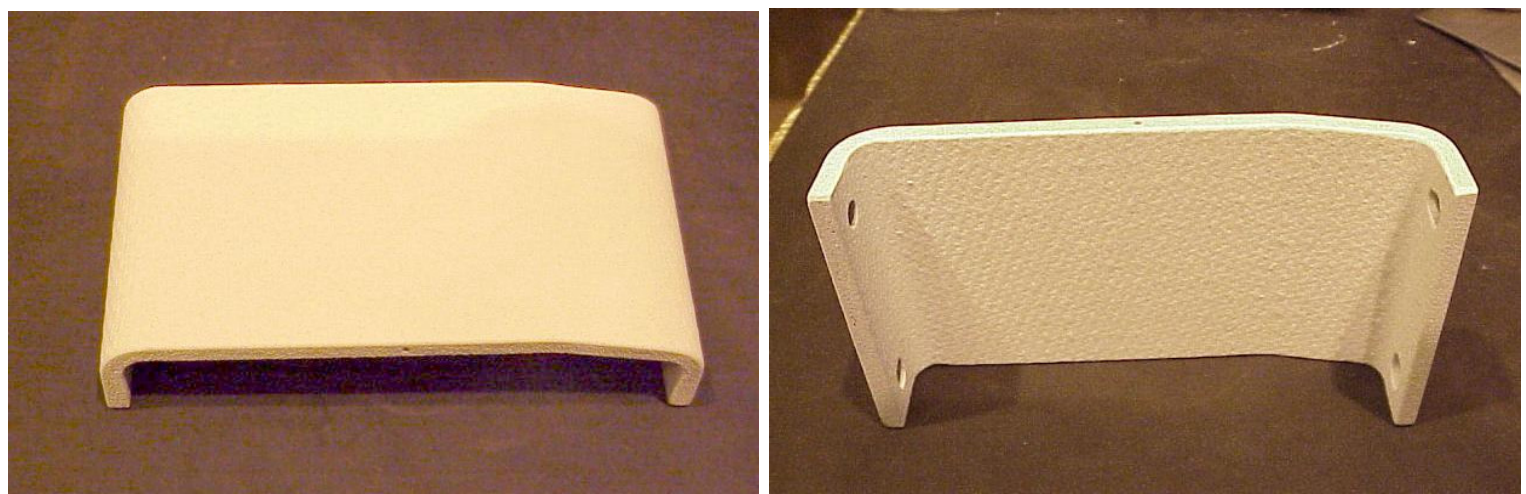

Figure 3-21. Photographs of a Goodrich slurry cast MI CMC shroud after EBC coating: Left - hot gas path face, Right - inside surface.

A total of six MI CMC shrouds were put through the full NDE characterization, final machining and EBC coating deposition steps. Photographs of a representative shroud after EBC coating are shown in Figure 3-21. One of the coated shrouds needed to be destructively characterized during development of the EBC coating process in order to verify proper coating thickness and microstructure. A CCP shroud was chosen for this purpose because of the relatively poor witness coupon data obtained from the Honeywell shrouds with Si-doped BN fiber coatings. Three of the remaining EBC-coated shrouds, one GE prepreg MI, one CCP slurry cast with pure BN fiber coatings, and one of the Goodrich slurry cast, were subsequently selected for use in the initial shroud rig testing.

As noted earlier, it was necessary to perform four sets of rig tests of the shroud components in order to solve the various issues observed with the shrouds and to obtain approvals for proceeding with the first engine shroud test. Unfortunately during the first rig tests all three CMC shrouds were damaged, as will be described in Section 3.1.7.1. Additional shrouds from the rig test set were subsequently used in rig test \#2 and also as test samples for the various attachment tests to be described. Rather than expend additional resources fabricating new shrouds specifically for the subsequent rig tests, it was decided to utilize some of the lower quality shrouds from the set fabricated for the engine test. The procedure used to select the shrouds for rig testing use is described in Section 3.1.15.4.

\subsubsection{Task 2.5 - Thermal Rig Testing}

Although the initial program plan called for only one set of shroud rig tests, unexpected observations during the tests, including both shroud damage and rig hardware failures, required that the rig testing be done over four iterations, or campaigns. The overall rig testing procedure was to initiate a set of planned tests, stop the testing due to observed shroud or rig damage, perform post-test analysis of the hardware and rig operating data to identify the causes of damage, formulate shroud system or rig design changes to alleviate the causes of damage, fabricate new rig and shroud hardware as needed, and then reassemble the test rig and begin another iteration of testing. This whole process involved efforts in shroud system re-design (Task 2.1), rig design and fabrication (Task 2.3), new 
shroud fabrication (Task 2.4) and rig testing (Task 2.5); however, this entire process will be described in this section for the sake of continuity.

\subsubsection{Rig Test Campaign \#1}

As described in Section 3.1.5, the shroud combustion test rig had been assembled and its operation verified, with both metallic and CMC inner shrouds, but only at relatively low operating temperatures. The failures of the cast refractory shroud test section lower wall were being addressed by the fabrication of an all-CMC lower wall. However, fabrication of the new CMC lower wall would require time and their was a strong desire to initiate the shroud rig tests in order to support a possible October 2001 engine test start date. In order to start rig testing of the $\mathrm{CMC}$ shrouds as quickly as possible a Hastelloy $\mathrm{X}$ sheet metal lower wall was fabricated and assembled into the test rig. This metallic lower wall was uncooled, and thus the combustion gas temperature was limited to $1150^{\circ} \mathrm{C}$ for the initial tests. While this meant that the CMC shrouds would run cooler than desired, it would allow for the measurement of pressure drop and rig transient response data to compare to the rig flow models. Further testing at full combustion gas temperature would then proceed once the new all-CMC lower wall was ready. The rig was therefore rebuilt using the final design of outer shroud block, incorporating the shroud pre-load piston/spring assemblies, the heat shields and shroud attachment bolts and pins. Three CMC inner shrouds, one prepreg MI from GE and two slurry cast MI from Goodrich and CCP as described in Section 3.1.6, were utilized for the rig tests.

A summary of the individual rig tests for this first testing campaign is listed in Table 3-4. During the first rig run a fuel line failed 3 hours into the test, necessitating a shutdown and repair. During the second run the rig reached full operating pressure, but the temperature was somewhat below target due to the limitations of the Hastelloy lower wall in the shroud test section, and included five thermal transient cycles. The transient cycles were conducted by igniting the combustor with a fixed air preheat temperature, $\mathrm{T}_{3}$, of approximately $750^{\circ} \mathrm{F}$ and then varying the fuel flowrate to rapidly change the gas temperature in the test section. The air mass flowrate and test section pressure remained approximately constant during the cycle. Figure 3-22 shows a typical temperature history of a single transient cycle. In between thermal cycles, the rig was operated at a constant gas temperature of approximately $2150^{\circ} \mathrm{F}$ at steady state conditions. Six transient thermal cycles were run in the second block of testing.

The third rig run (Sept. 15) continued the exposure testing of the shrouds, along with limited thermal cycles. The run was terminated after 23 hours of testing due to a detected leakage in the metallic seal just forward of the CMC shroud test section. The test section was therefore removed from the pressure vessel and disassembled for inspection at the end of this rig run. 
Table 3-4. Summary of Shroud Rig Tests Run During the $1^{\text {st }}$ Testing Campaign

\begin{tabular}{|c|c|c|c|c|c|}
\hline Date & Mode & $\begin{array}{c}\text { Shroud } \\
\text { Type }\end{array}$ & Duration & Purpose & Result \\
\hline $\begin{array}{l}\text { Sept 13, } \\
2001\end{array}$ & hot & CMC & $3 \mathrm{hrs}$ & $\begin{array}{l}\text { Begin reduced } \\
\text { temperature shroud } \\
\text { testing using } \\
\text { Hastelloy lower wall }\end{array}$ & $\begin{array}{l}\text { Rig operated at } 650^{\circ} \mathrm{C} \text { and } 5.7 \\
\text { bar until a fuel line broke } \\
\text { while increasing flame } \\
\text { temperature }\end{array}$ \\
\hline Sept 14 & hot & $\mathrm{CMC}$ & $8 \mathrm{hrs}$ & $\begin{array}{l}\text { Fuel line replaced and } \\
\text { continued with } \\
\text { shroud exposure } \\
\text { testing }\end{array}$ & $\begin{array}{l}\text { Ran } 5 \text { thermal transient cycles } \\
\text { Reached } 6.9 \text { bar and } 1150^{\circ} \mathrm{C} \\
\text { steady state }\end{array}$ \\
\hline Sept 15 & hot & CMC & $23 \mathrm{hrs}$ & $\begin{array}{l}\text { Continued shroud } \\
\text { exposure testing }\end{array}$ & $\begin{array}{l}3 \text { thermal transient cycles } \\
\text { Remainder of time ran steady } \\
\text { state at } 1150^{\circ} \mathrm{C} \text { and } 7.6 \text { bar } \\
\text { Seal failure between transition } \\
\text { piece and shroud test section } \\
\text { necessitated rig shut- down }\end{array}$ \\
\hline
\end{tabular}

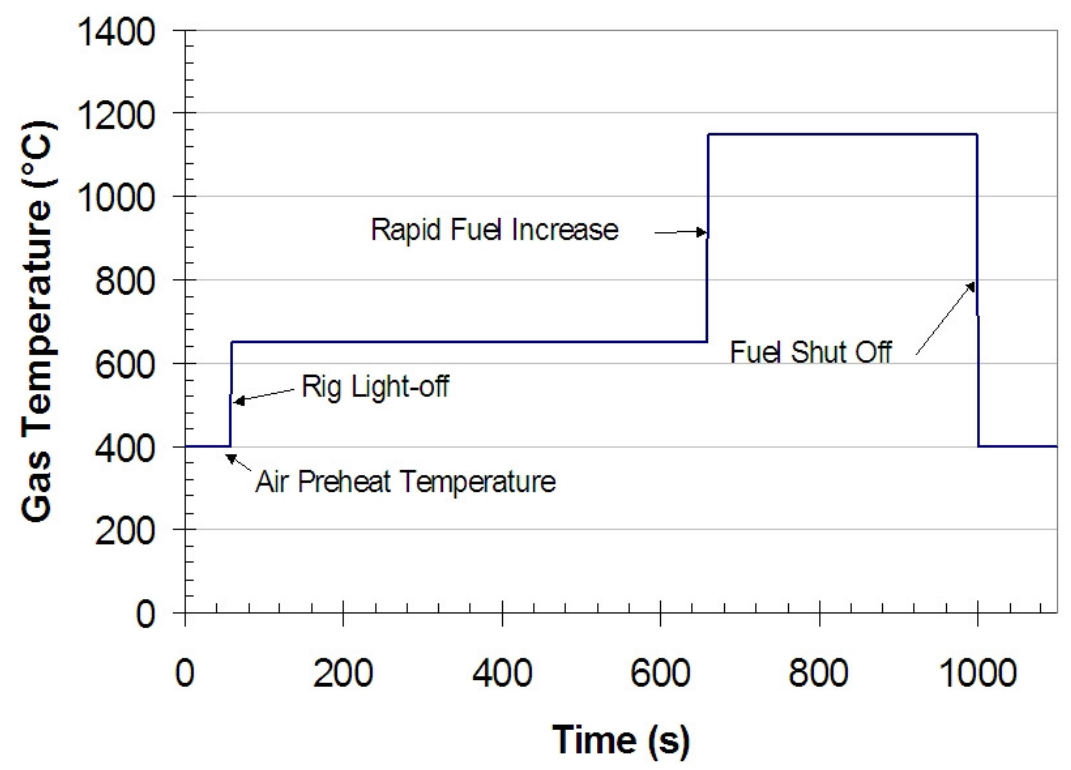

Figure 3-22. Temperature-time history of a typical transient cycle during shroud rig testing.

The rig disassembly revealed that a number of the shroud test section parts were damaged. The flanges mating the transition section and shroud test section were warped, though it was not clear whether the warping of the flanges caused the seal leakage, or was caused by overheating as a result of the seal leakage. A photograph of the distorted flanges is shown in Figure 3-23. In addition, the test section exit nozzle showed distortions, likely as a result of being over-heated, near the center of the test section flow channel (see Figure 3-24). The Hastelloy X lower wall also had indications of similar thermal stress near the centerline region of the test section, as shown in Figure 3-25. 


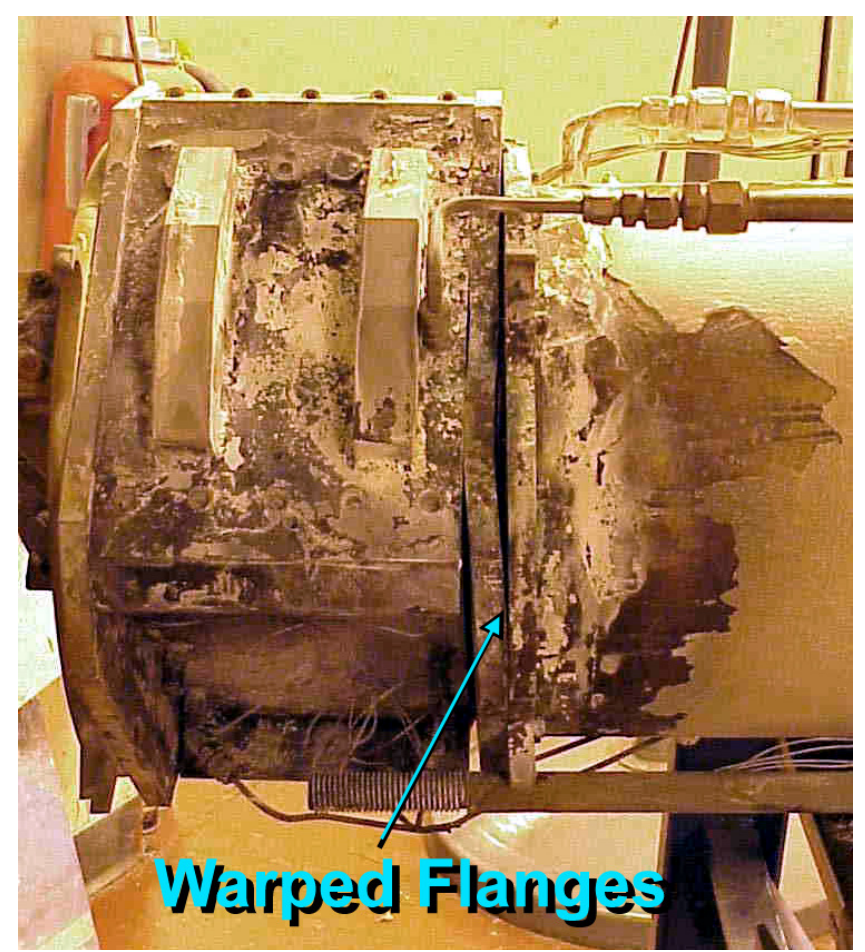

Figure 3-23. Photograph of the shroud rig transition piece (on the right) and shroud test section (on the left) following the initial set of shroud rig tests. The seal between the aft flange of the transition piece and the forward flange of the test section leaked, causing the flanges to overheat and warp.

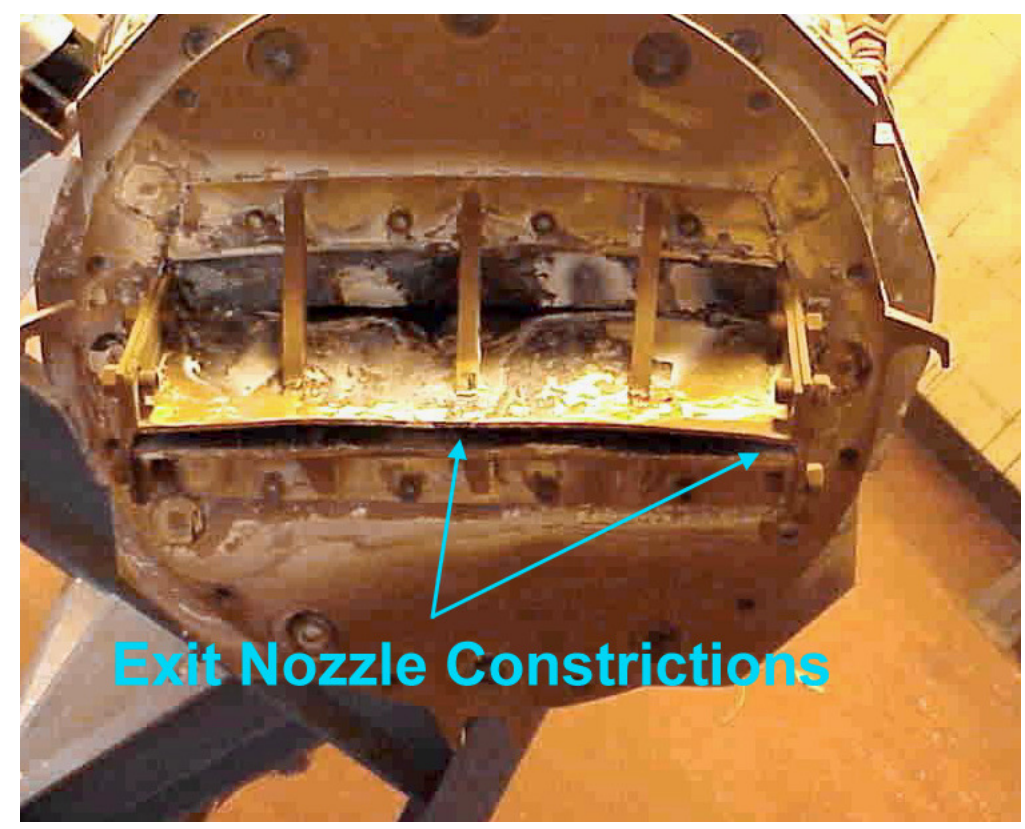

Figure 3-24. Photograph of shroud rig test section exit nozzle showing constriction of the flow path near the center and right edge. 


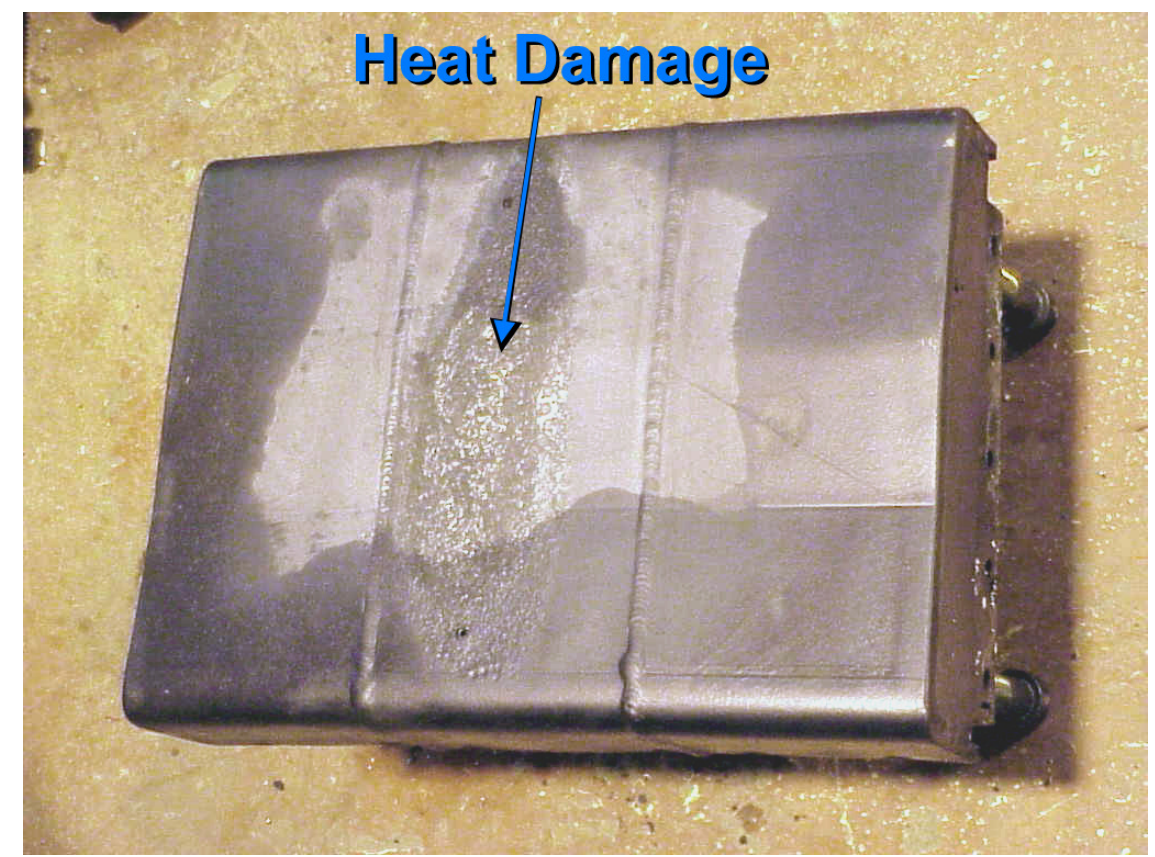

Figure 3-25. Photograph of Hastelloy X lower wall from the shroud rig test section showing heat damage to the center section of the wall. The combustion gas flow direction was from top to bottom.

In addition to the damage to the test rig itself, there were indications of EBC and/or composite chipping of the $\mathrm{CMC}$ shroud pieces at the front attachment points. A photograph of the front attachment holes on the prepreg MI shroud, which was in the hottest center position in the rig, is shown in Figure 3-26. The slurry cast shroud from CCP showed the most extensive mounting hole damage, as indicated in Figure 3-27. The Goodrich shroud also showed chipping damage at the forward attachment holes, as shown in Figure 3-28, though it was less severe than seen in the other two shrouds and limited mostly to the EBC. Upon further inspection, it was apparent that the spring-loaded pistons in the outer shroud block had partially seized to the damper blocks, and therefore did not apply the proper seating load to the inner shrouds.

The degree of damage to the rig, to the CMC inner shrouds and to the pistons were all sufficient to warrant an in-depth root cause analysis (RCA) of this first round of rig testing. The damage also made it necessary that another round of rig testing be performed in order to demonstrate that the design changes and rig fixes identified by the RCA would indeed ameliorate the damage observed in this first round of testing. 


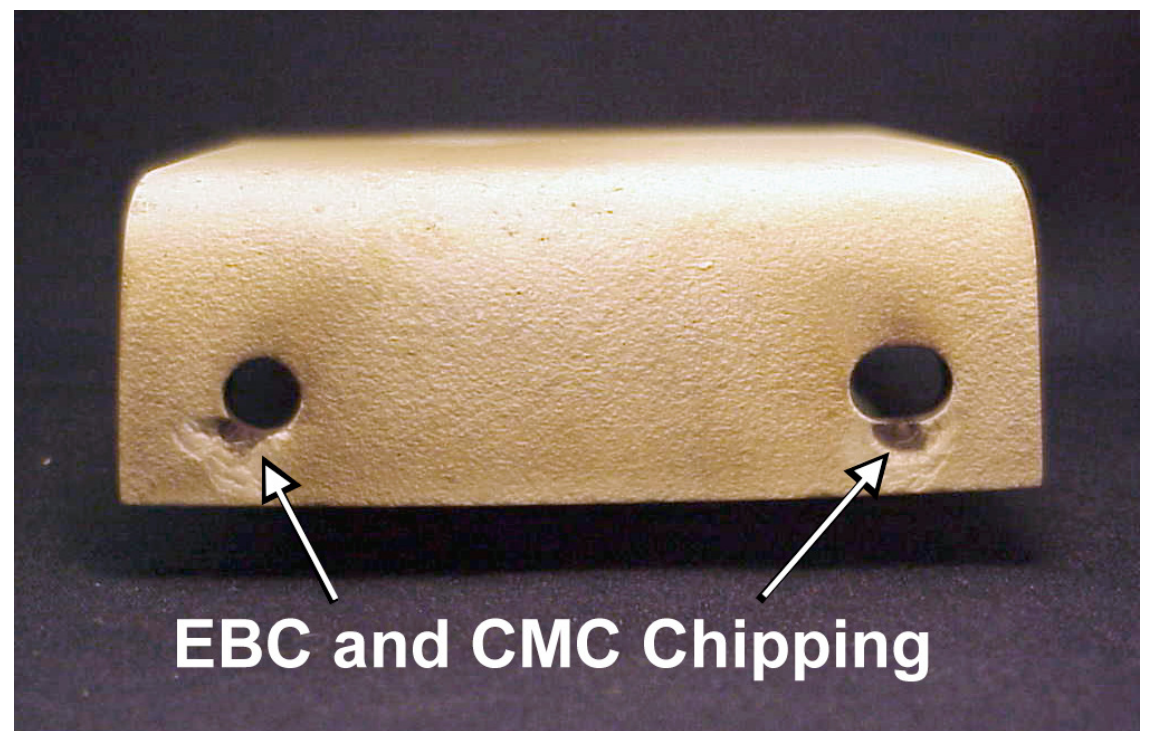

Figure 3-26. Photograph of prepreg MI shroud front attachment holes showing chipping of the EBC coating and composite at the contact point with the mounting pins.

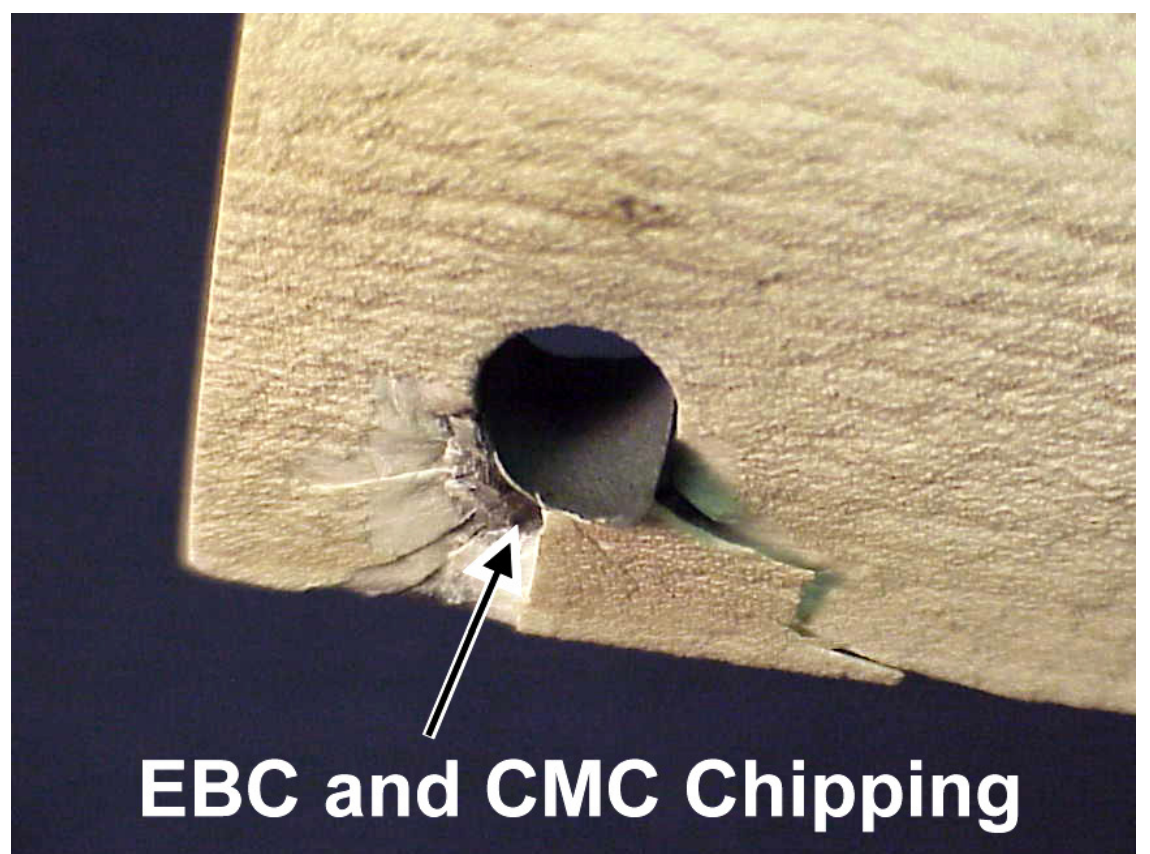

Figure 3-27. Photograph of front mounting hole on the CCP slurry cast MI shroud showing damage to the EBC and underlying CMC. Some of the T800 wear coating from the support pin is adhered to the inside of the mounting hole. 


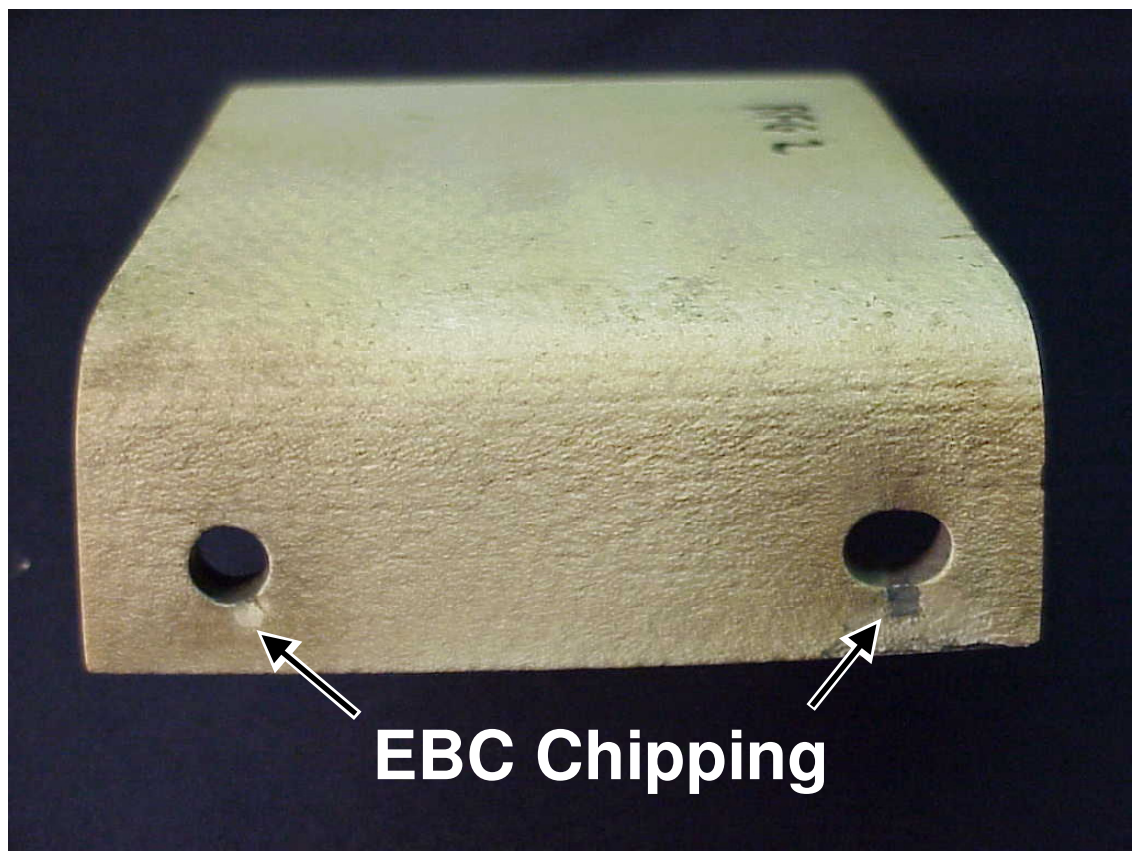

Figure 3-28. Photograph of front mounting holes on the Goodrich slurry cast MI shroud showing chipping damage to the EBC.

Two of the damaged shrouds were sectioned at the attachment region and examined metallographically. Two types of damage behavior were observed. In the slurry cast shroud from CCP the appearance of the damage strongly suggested that the shroud was over-loaded at the edge of the attachment hole, leading to crushing and buckling of the composite plies at the edge of the hole. A micrograph of this section is shown in Figure $3-$ 29. In this case, the damage appears to have originated in the $\mathrm{CMC}$ itself, and was probably aided by a layer of high porosity near the composite mid-plane. The EBC coating was still adhering to the $\mathrm{CMC}$, even in regions where the $\mathrm{CMC}$ had crushed and buckled.

The other shroud sectioned was the prepreg MI shroud prepared by GE GRC. In this case the damage was very localized at the surface of the shroud at the edge of the attachment hole. There was no crushing of the underlying CMC, but only chipping of the top 1 or 2 surface plies adjacent to the attachment hole. The EBC remained intact right up to the edge of the damage in the CMC. A micrograph of inside surface of the attachment hole in the prepreg shroud is shown in Figure 3-30. 


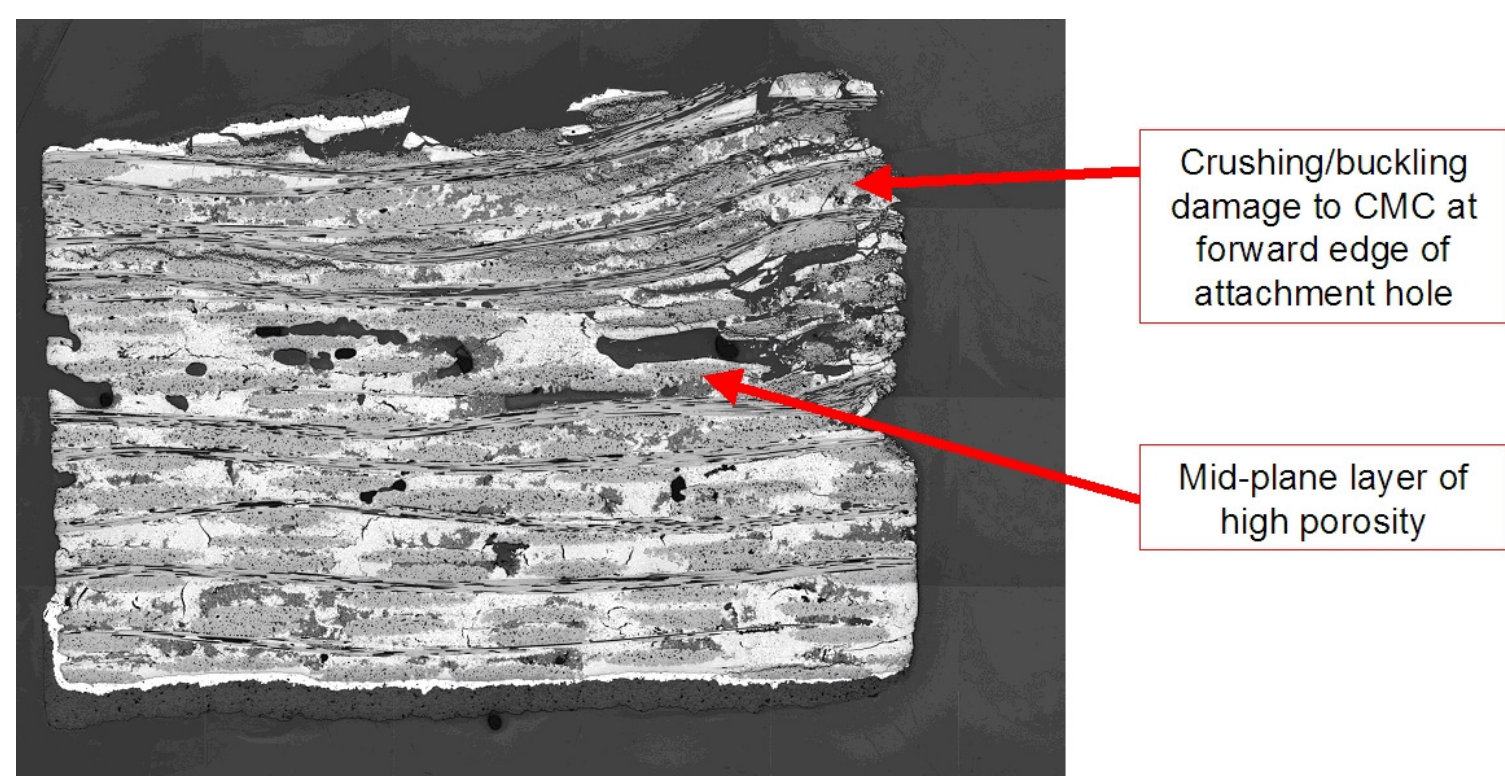

Figure 3-29. Micrograph of attachment hole region of the CCP shroud following 30 hours of combustion rig testing. Crushing of the composite and buckling of the fiber plies is seen at the forward edge of the attachment hole.

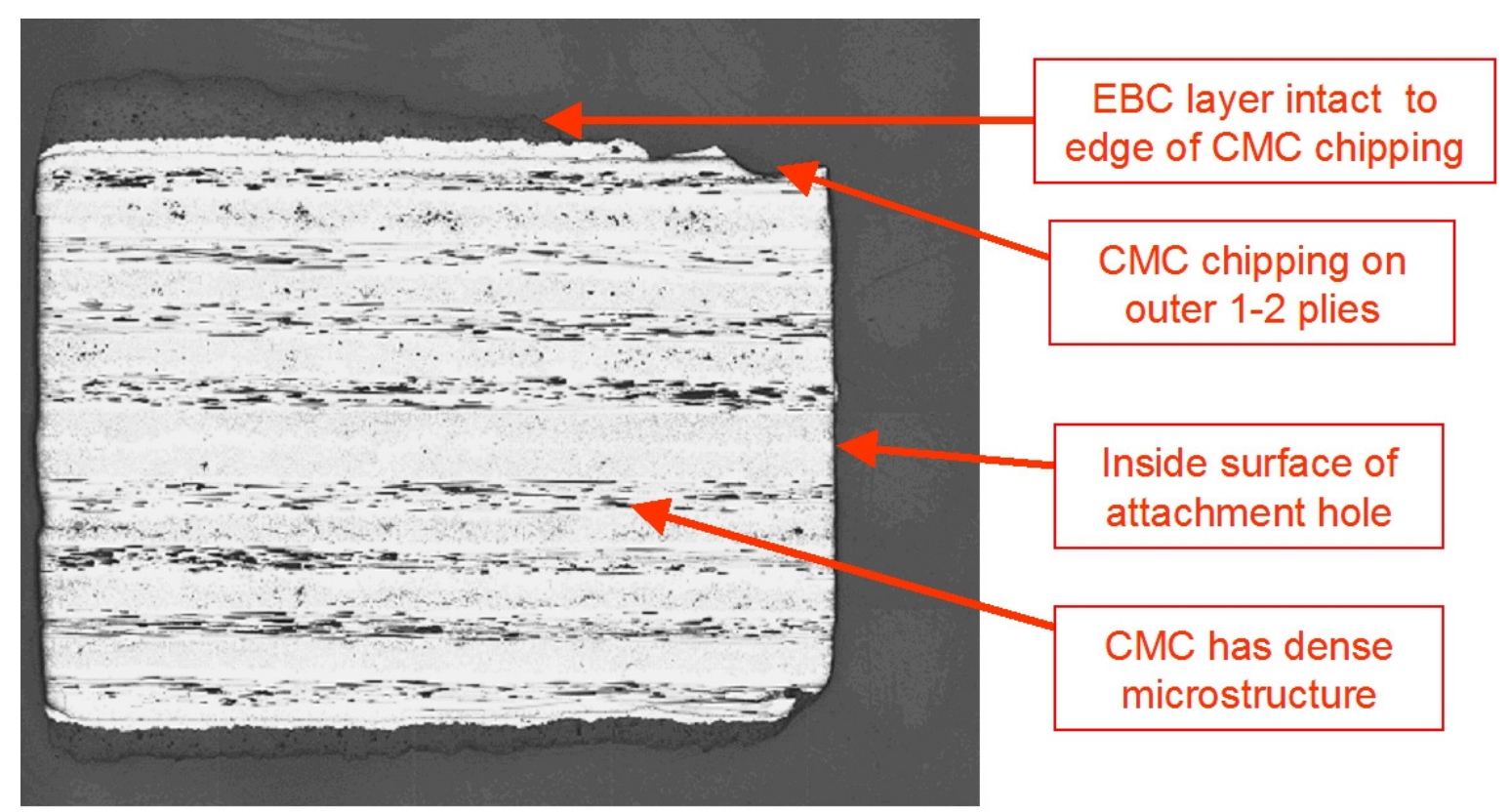

Figure 3-30. Micrograph of attachment hole region of the GE prepreg MI shroud following 30 hours of combustion rig testing. Edge chipping damage to the composite at the forward edge of the attachment hole was limited to one to two plies. 
The overall observations on the chipped attachment holes from the September 2001 rig tests were suggestive of overloading at the attachment holes, though not conclusive. The crushing type damage seen in the CCP slurry cast shroud attachment suggested overloading, rather than chattering, as the likely cause of damage. However, the chipping seen in GE shroud was consistent with either type of damage.

During the RCA it was discovered that at least one of the heat shield/damper components was not machined to print, and that this was probably the major cause of the damper seizing problem. Seizing of the dampers was at the time believed to be the cause of the overloading and subsequent chipping of the $\mathrm{EBC} / \mathrm{CMC}$ at the inner shroud attachments.

A re-design of the shroud system, concentrating on the heat shield / damper mechanism, was initiated. The piston-to-damper joint was re-designed to be more tolerant of machining inaccuracies. Some of the metallic materials being used in the outer shroud block assembly were also changed to make the overall system less susceptible to fretting wear and galling. It was also recognized that the damper pre-load on the shrouds might not have been sufficient to ensure uninterrupted contact of the inner shrouds with the mounting pins. Consequently the shroud damper preload was increased, and the positions of the contacts between the damper and the inner shroud were moved forward, mostly for modal frequency considerations.

\subsubsection{Rig Test Campaign \#2}

Many modifications were made to the shroud combustion test rig as a result of observations made during the first testing campaign. Oxidation and warping of the stainless steel flanges between the transition piece section and the shroud test section of the rig was what eventually caused the rig to be shut down. Due to the space requirements for the attachment of the shroud section lower wall those flanges were partially exposed to the hot combustion gases at their inner diameter (ID) surface. It had been hoped that cooling on the outside of the flanges from the by-passed compressor air would be sufficient to keep these flanges cool, but this cooling was obviously not sufficient. Consequently several of the rig flanges were replaced with a more heat-resistant alloy (HS-230) to prevent this oxidation/warping problem.

Another major change to the rig was the inclusion of an all-CMC lower wall in the shroud test section. The CMC lower wall was a one-piece construction and required compound curvature of the flow surface - cross-stream curvature to replicate the axi-symmetric nature of the gas flowpath and to follow the shroud curvature, and streamwise curvature to produce flow acceleration through the test section. A photograph of the CMC lower wall after following fabrication and machining is shown in Figure 3-31, where the CMC wall is sitting on the lay-up tooling to show the good shape fidelity of the finished part.

In the test rig the CMC lower wall was attached to a stainless steel outer wall block, which served as the structural wall for the test section, using six superalloy pins (three along the front and back edges) along with stainless steel bolts. The bolts were threaded loosely in 
their holes to allow for differential thermal expansion between the CMC and the stainless outer wall block. The space between the CMC wall and the metal block was filled with a cast ceramic material (phosphate-bonded alumina insulating refractory) to reduce the dead volume and inhibit leakage.

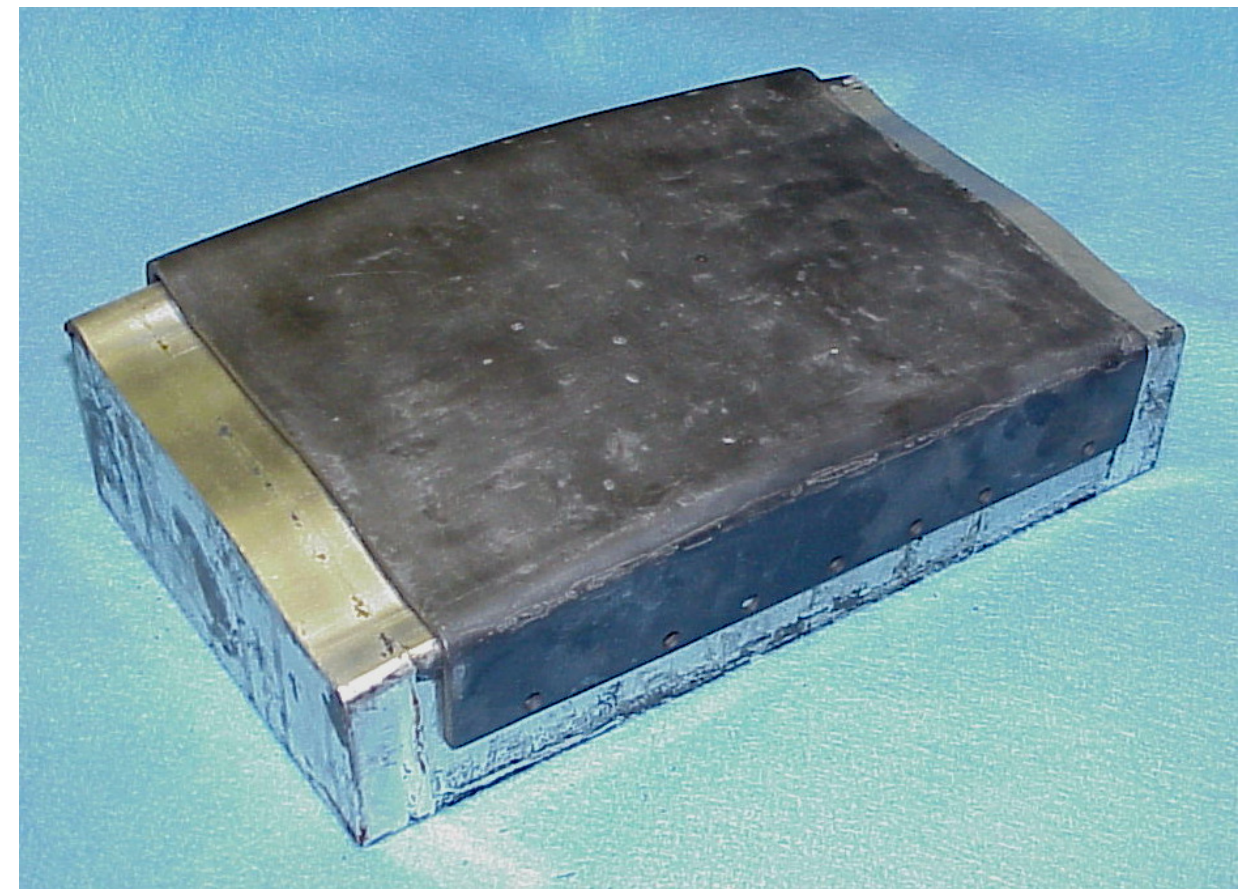

Figure 3-31. Photograph of a finished shroud rig CMC lower wall sitting on the part lay-up tooling.

Given the problems with the previous rig lower walls, the CMC lower wall was tested in the shroud rig to validate its robustness to the high pressure loading prior to installing the CMC shrouds. In this test, stainless steel surrogate inner shroud segments were mounted in the outer shroud block. The center shroud was instrumented with a row of pressure taps to measure the stream-wise pressure profile in the center of the test section. The configuration was tested for approximately 2 hours in the shroud rig facility. The air flow rate and flame temperature were raised continuously during the test until full load conditions were reached (test section pressure of $7.6 \mathrm{bar}$, combustion gas mean temperature of $1200^{\circ} \mathrm{C}$ ).

Figure 3-32 compares the measured and predicted axial pressure gradient through the test section with the CMC lower wall in place. The profiles have been normalized to better compare the shape of the profiles. The maximum pressure drop in the test section for the measured profiles was not as large as predicted. This was due to the contour of the surrogate metal shrouds used in the test, which did not create the proper throat dimension in the test section. Also the prediction did not take into account three-dimensional effects and leakage between shroud elements that were known to exist in the experiment. 


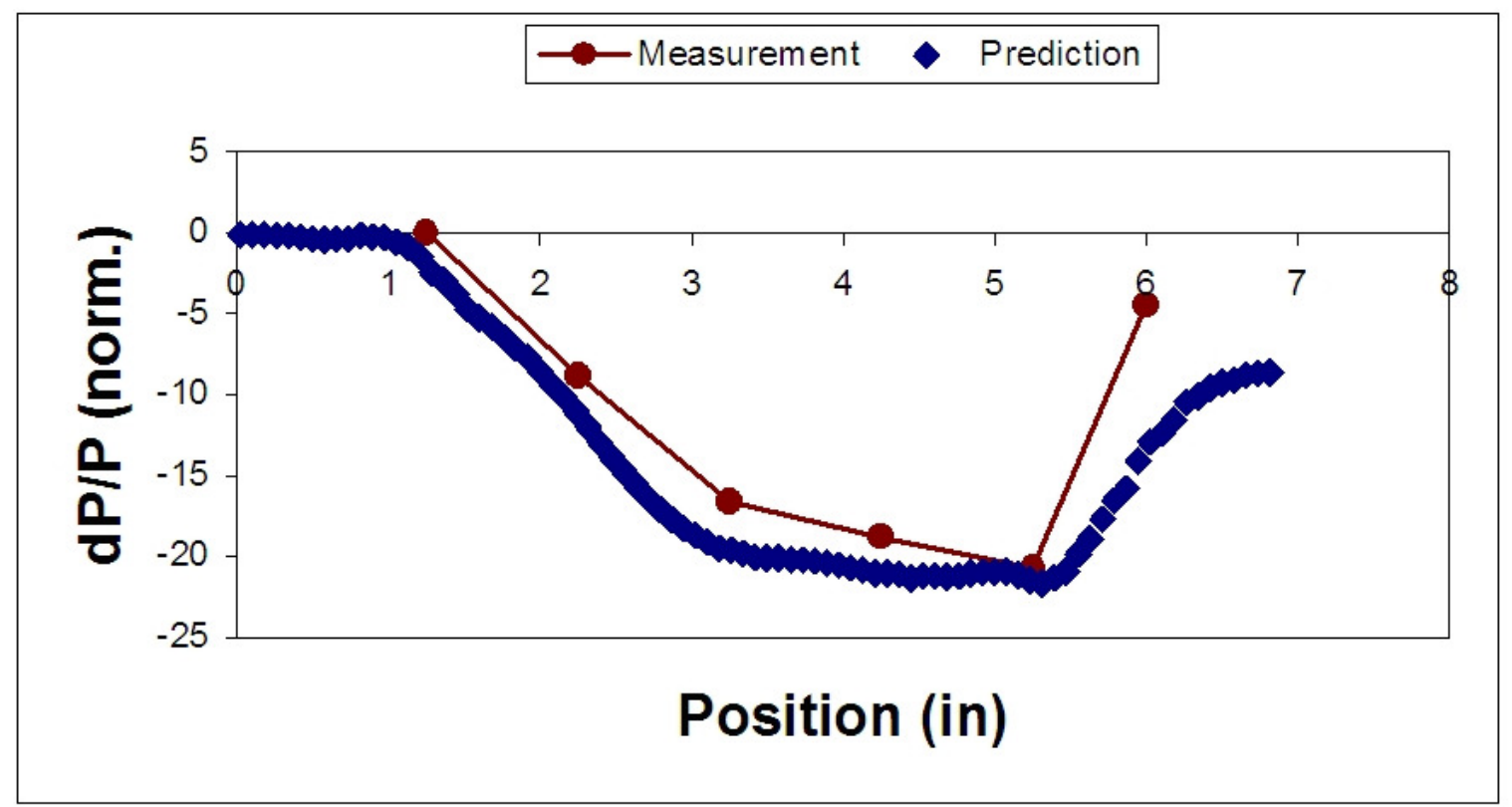

Figure 3-32. Comparison of predicted and measured axial pressure profile shape in shroud rig test section with the CMC lower wall and surrogate metal shrouds installed.

The CMC lower wall showed no signs of wear after the test. The shroud test section of the rig was therefore disassembled and rebuilt with the CMC inner shrouds. As part of the rebuild a new outer shroud block was manufactured, which had been modified to the latest engine shroud design, including a new heat shield/damper configuration. Two of the new heat shields were fabricated from a nickel-based superalloy and the third from an oxide dispersion strengthened (ODS), ferrous powder metallurgy processed alloy. The spring preload tension was increased to exert additional down force on the CMC shroud to alleviate any tendency for chatter, which required that the machined helical springs used in the first test be changed to a stiffer wire-wound configuration. All these changes were incorporated into the rig shroud test section and the rig was reassembled.

Rig test campaign \#2 was completed as a near-continuous 150 -hour test run. The run commenced on February 1, 2002, and ended the morning of February 7. After initial air preheating under reduced pressure conditions, the combustor was ignited and the shroud test section was exposed to a high velocity gas steam with a test section inlet pressure and temperature of 8.3 bar and $1200^{\circ} \mathrm{C}$, respectively. The combustor was tripped off after approximately 24 hours to check a faulty pressure transducer. After relight (approximately 45min later) steady-state operation was resumed. At approximately 35 hours into the test, another combustor trip was experienced due to a frozen vacuum line on the exhaust tunnel safety system. This was fixed and full temperature steady state operation resumed $15 \mathrm{~min}$ after the trip. 
After approximately 80 hours into the test, regular thermal cycling of the test section was initiated. Cycles consisted of manually reducing the fuel flow to the combustor to achieve a test section gas temperature of approximately $600^{\circ} \mathrm{C}$, and after approximately 20 minutes rapidly increasing the fuel flow back to a test section gas temperature of $1200^{\circ} \mathrm{C}$. Thermal cycles were repeated at a rate of one per hour until 30 cycles had been achieved. Steady state operation resumed up to approximately 142 hours of cumulative testing, at which time 5 more thermal cycles were imposed, to bring the total to 35. After a cumulative run time of 150 hours the test was terminated through a 2 hour cool-down phase where the flame was quenched, the air preheater was shut off and the air flow was gradually reduced. Following the test, the test section was disassembled and all components were examined for wear and damage. The CMC lower wall was found to have performed well in the rig test as it was still intact and showed no obvious damage.

The CMC inner shrouds were removed from the outer shroud block for full examination. The Goodrich slurry cast MI inner shroud exhibited delamination of the CMC plies along the flat surface adjacent to the hot gas path. This delamination is shown in Figure 3-33. This defect was known to exist in the shroud prior to the rig testing from visual and NDE inspections. The delamination opened up during rig exposure, making it more noticeable, but it did not appear to have grown in size laterally.

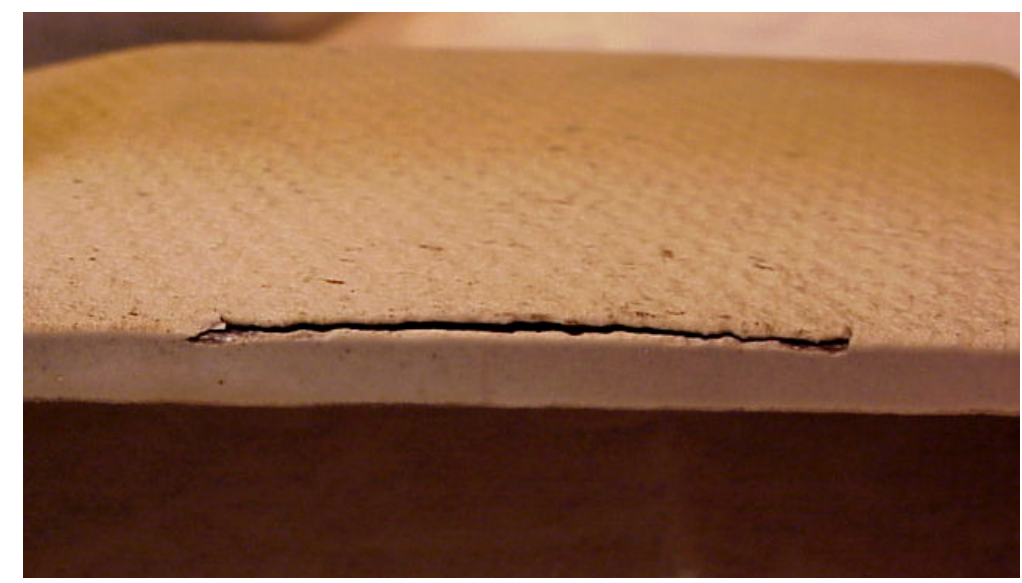

Figure 3-33. Delamination on the side of Goodrich slurry cast CMC shroud following completion of rig test \#2.

During the rig teardown there were three issues noted with the operation of the CMC shroud system. The first issue was that two of the three shrouds had again exhibited chipping near the leading edge mounting hole. There was no damage observed near the leading edge slots or trailing edge mounting holes or slots. Figure 3-34 shows an example of the chipping damage near the front hole of the shroud located in the center position. This chipping phenomenon is similar to that which occurred in the 30 hour rig test $\# 1$. 


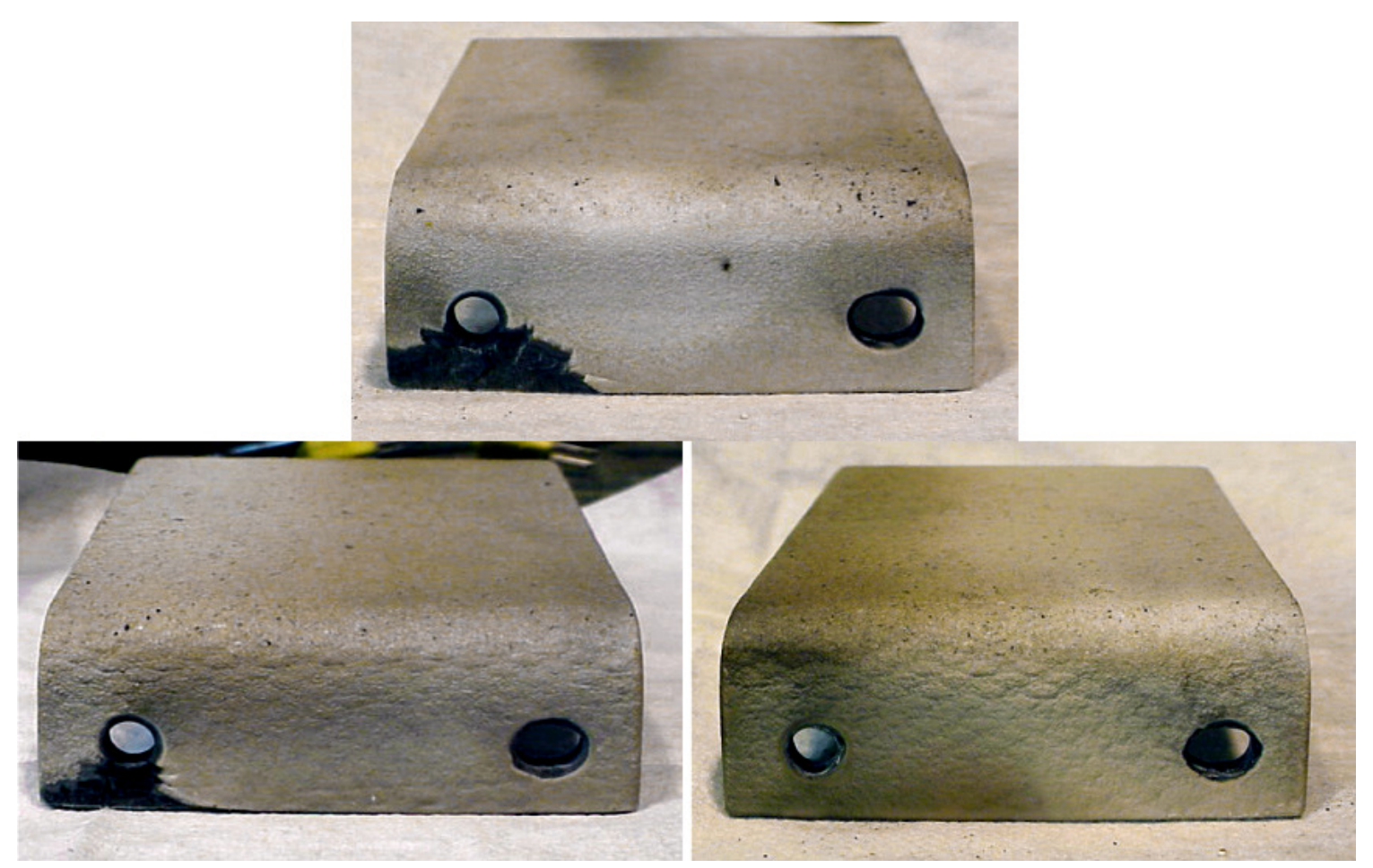

Figure 3-34. Photographs of the front flanges of the CMC shrouds from rig test \#2 showing chipping near leading edge hole on the GE prepreg shroud (top) and Goodrich slurry cast shroud (bottom left), but no chipping on the CCP slurry cast shroud (bottom right).

The CMC inner shroud attachment chipping was examined more rigorously following this test. Detailed evaluation of the shroud FEA model indicated that thermal strains during the thermal cycles caused rotation of the CMC inner shroud attachment holes relative to the mounting pins in the outer shroud block, and that these strains were larger than was originally accounted for in the tolerance stack-up. This situation led to the full shroud load being supported on the edge of the holes, and thus created a situation where overloading of the shrouds would lead to shear delamination at the front surface. The CCP slurry cast shroud did not exhibit this cracking as inspection of the attachment holes via coordinate measuring machine (CMM) indicated that the holes in the CCP shroud were incorrectly machined at an angle to the datum surface. Fortuitously the angled holes compensated for the thermal rotation of the shroud and outer shroud block so that the holes on this shroud were not loaded on the edges.

Based on the pin pull-out testing described in Section 3.1.4, it was not believed that simple loading of the shroud at the edge of the hole from the normal damper block force would be sufficient to cause the chipping failures observed. An additional factor must have contributed to cause an overload situation on the hole edges. Three additional mechanisms were postulated for contributing to the chipping damage, and they are shown schematically in Figure 3-35. 
The first proposed mechanism involved chattering of the shroud on the attachment pins. As will be described later, the springs used to maintain proper seating of the shroud on the attachment pins were found to have creep relaxed during the shroud test. Consequently the force pushing the shrouds onto the attachment pins was reduced to near zero during the test. This could have lead to vibration of the shroud due to combustion dynamic pressure variations, and a chattering of the CMC shrouds on the attachment pins. The repetitive impact loading from the chattering then caused the chipping cracks on the shrouds.

The second proposed mechanism was that the relative thermal rotations of the CMC inner shroud and the outer shroud block could have been large enough to mechanically bind the pin against both the forward and aft edges of the mounting hole. The mechanical interference caused an overloading situation on the hole edges, leading to the surface chipping.

In the third proposed mechanism the relative thermal expansion of the shroud and outer shroud block during thermal cycling would cause the shroud forward flange to slide along the attachment pins, as was the design intent. However, when combined with the normal force being carried mostly at the front edge of the hole, the rubbing on the pin would lead to interlaminar stresses on the surface plies at the hole edge, and consequently lead to the observed chipping.

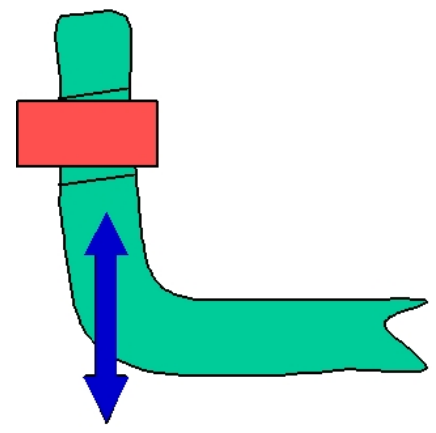

(a)

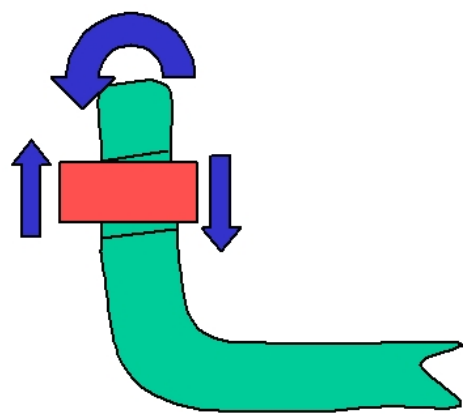

(b)

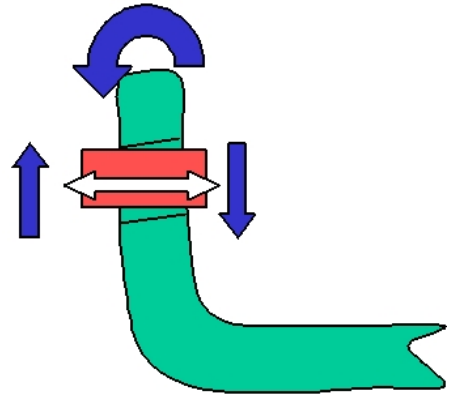

(c)

Figure 3-35. Schematic diagrams of proposed shroud hole chipping mechanisms: (a) attachment hole loading due to dynamic excitation causing cyclic vertical motion (chatter) between pin and flange; (b) hole edge loading due to pin binding caused by relative rotation of pin and $\mathrm{CMC}$ inner shroud; (c) pin binding from relative rotation combined with lateral sliding on the pins during thermal cycling.

In order to verify which of the above mechanisms was responsible for the observed shroud hole chipping two experimental efforts were undertaken. In order to assess the damage that might be caused by the chattering mechanism shown in Figure 3-35(a) an electromagnetically excited test fixture, shown in Figure 3-36, was built that allowed both static and dynamic forces to be applied to a pin-in-hole configuration. The furnace also visible in Figure 3-36 enclosed the test fixture so that temperatures consistent with the 
shroud operation could be imposed. The static load was applied via a spring and the dynamic load was applied with an electromagnetic transducer.

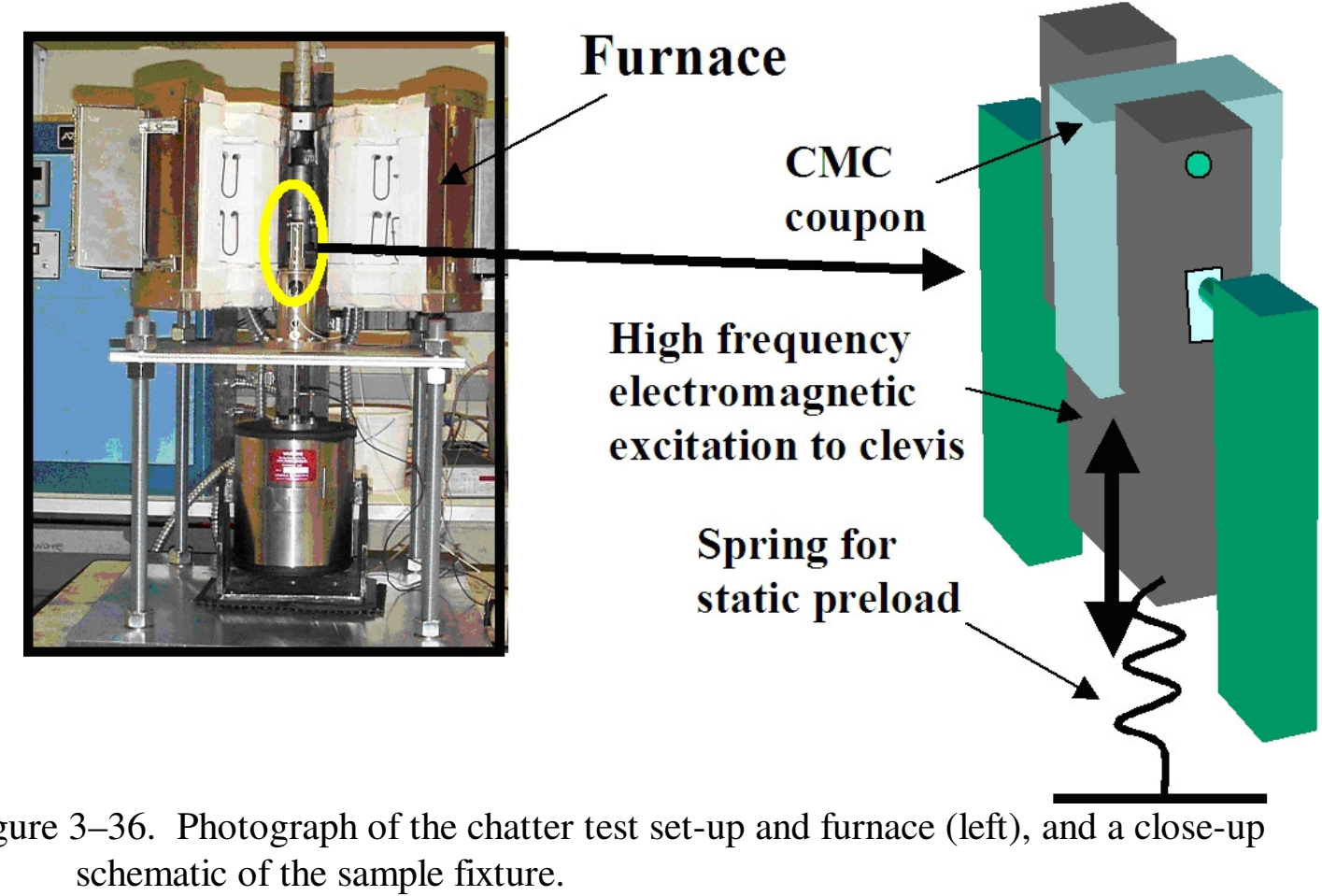

In the shroud test rig the driving force for the dynamic loading of the shroud would come from rig combustion dynamics. However, in an actual engine the dynamic pressures are largely associated with blade passing loads, which could act as a significant driving force to produce damage through chattering or hammering at the pin/hole attachment points. Analyses were conducted to quantify these loads for the turbine application being considered. Using this model, the expected dynamic excitation and the designed static load at the pin/hole attachment were defined and applied to the test configuration in Figure 3-36. A test was run at elevated temperature representative of the shroud application for 150 hours. After completion, the CMC specimen was examined and no damage was observed at the CMC holes. This result provided some initial confidence that the shroud attachment design was not susceptible to damage due to the dynamic excitation loads to be expected in the turbine. Additional testing was performed at higher loads to identify the onset of damage by this mechanism, but the loads that were required to initiate damage were well beyond any expected loading level possible in the shroud rig. Consequently this chattering mechanism was not responsible for the observed rig shroud chipping.

The second proposed hole chipping mechanism was that thermal strains in the inner shroud and outer shroud block lead to actual binding of the edges of the holes on the pin. The test configuration used to investigate this potential mechanism, as illustrated in Figure 3-35(b), is shown in Figure 3-37. This test, which was designed to be run at both room temperature 
and elevated temperature, used an eccentrically applied load to produce concentrated forces at the hole where it intersects the face of the CMC coupon. During the tests a load was applied until damage was observed.

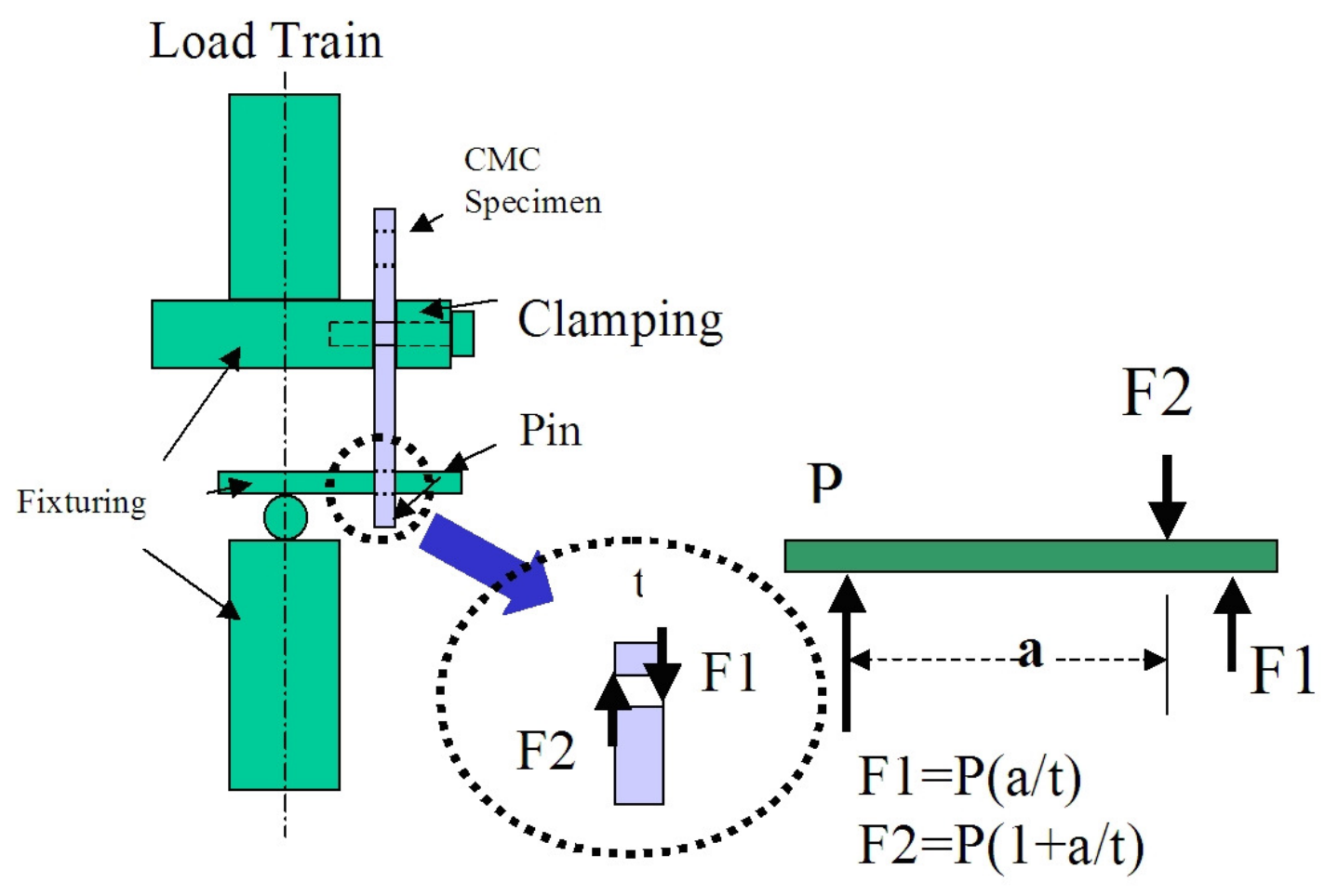

Figure 3-37. Schematic diagram of the pin binding test configuration.

Tests in this configuration were run on both EBC coated and uncoated CMC specimens at room temperature and at elevated temperature. Both slurry cast and prepreg CMC coupons were tested. During room temperature tests of EBC coated specimens, chipping damage was produced at the hole interfaces in both the slurry cast and pre-preg materials. This damage is illustrated in Figure 3-38. Because the tests were stopped at the onset of observable damage, the chipping was strictly limited to the EBC coating and no damage was observed in the underlying $\mathrm{CMC}$ material.

Tests were also run on uncoated samples - both slurry cast and pre-preg. During these tests the CMC samples were broken macroscopically. The macroscopic modes of failure and the local damage around the hole were different for the slurry cast and pre-preg materials. In the case of the slurry cast material, the macroscopic failure was interlaminar in nature as shown in Figure 3-39; however, local crushing damage was also seen in the vicinity of the hole. In contrast, the pre-preg material failed macroscopically in bending at the hole as shown in Figure 3-40. Local damage at the hole was not visible in one of two specimens. In the other, the monolithic ceramic outer layer of the CMC was slightly 
chipped. The metallic pin used in the pre-preg test was bent and significantly gouged at the point of contact with the $\mathrm{CMC}$, as was the pin used in the test on the slurry cast sample.
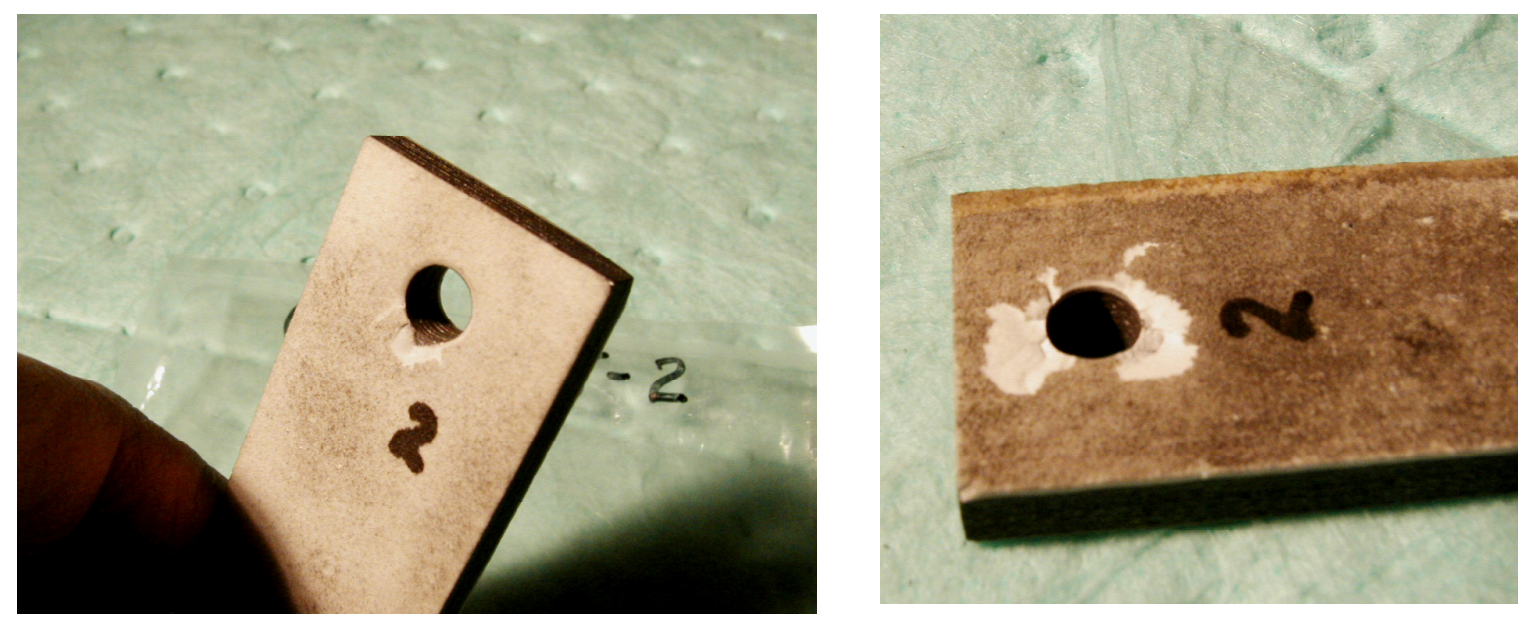

Figure 3-38: Photographs of EBC chipping damage on a coated pre-preg CMC (left) and a coated slurry cast $\mathrm{CMC}$ (right) following room temperature pin binding testing.
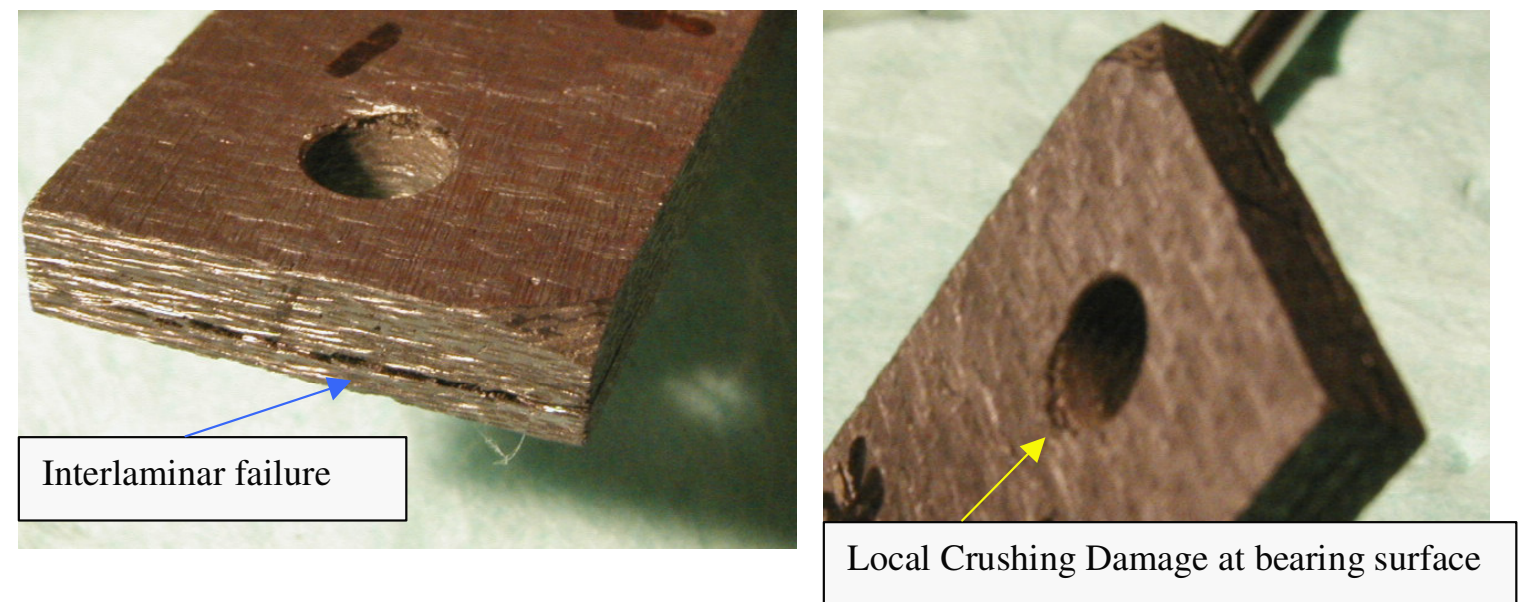

Figure 3-39. Photographs of an uncoated slurry cast composite specimen following testing in the pin binding test showing (Left) macroscopic interlaminar failure, and (Right) local crushing damage in the pin-bearing area of the hole.

Samples were also tested at elevated temperature. During these tests there was no damage observed to any of the CMC's - either local to the hole or macroscopic. In all cases the metallic pins yielded and permanently deformed, thus limiting the load that could be applied to the CMC.

Since the observed damage modes were not entirely consistent with the observations on the rig test shrouds, and because no evidence was found for pin indentation or bending from the 
binding loads, this mechanism was also considered to not be the probable cause of the attachment hole chipping seen in the shroud rig.
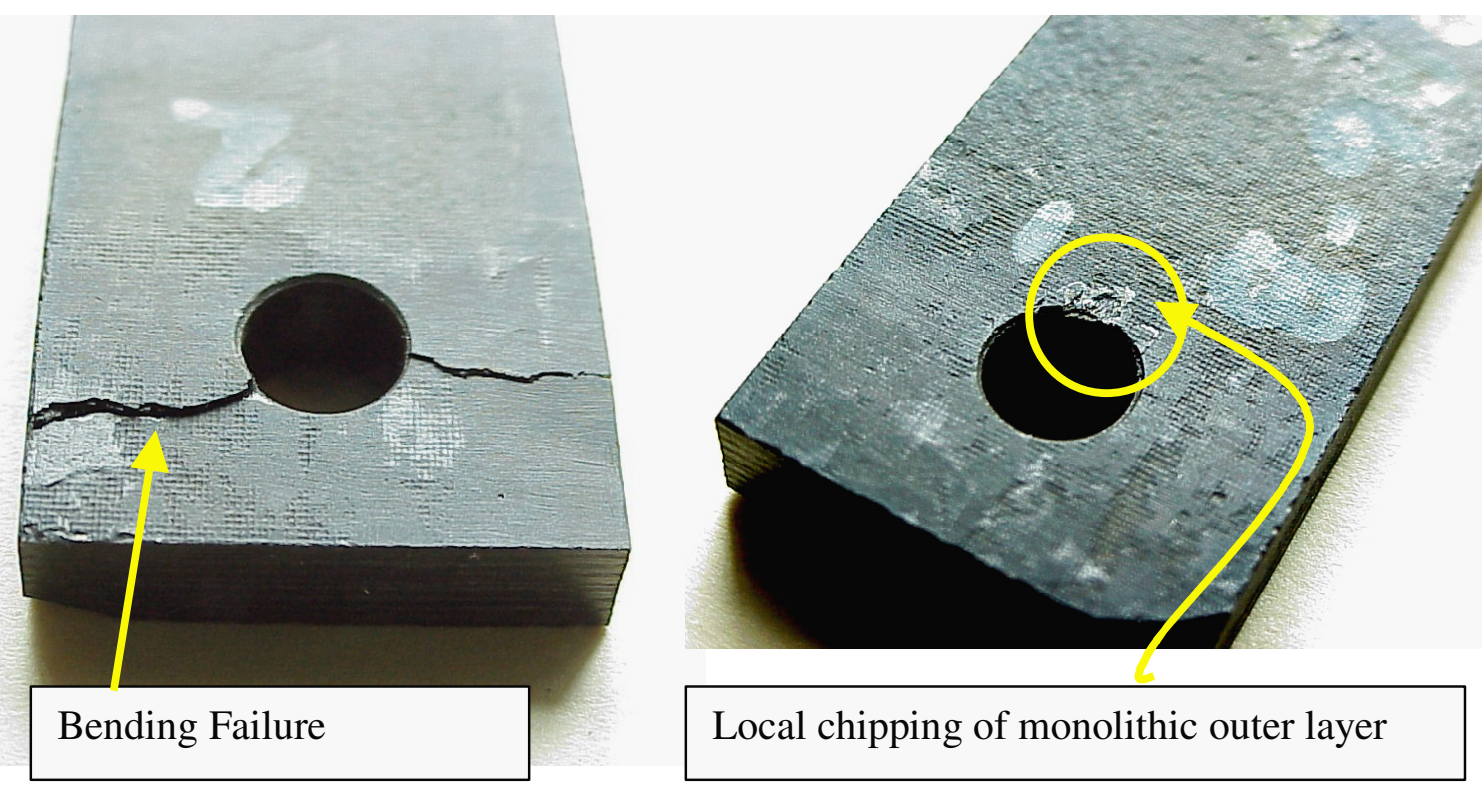

Figure 3-40. Photographs of uncoated prepreg MI composite samples following pin binding testing. Left - macroscopic bending failure of the CMC. Right - limited local chipping of the monolithic outer layer of the composite in the vicinity of the pin-bearing location

Because neither of the above tests could replicate the damage seen in the rig test, the third mechanism of combined loading and lateral scraping at the edge of the attachment hole was considered to be the likely cause of the observed damage. The fix identified to deal with this hole chipping problem was to add relatively deep chamfers to the shroud attachment holes. In this way there would be extra clearance near the shroud surfaces to accommodate minor machining errors and thermal deformations in the shroud. In the event that binding did occur, the binding location would be at the inside edge of the chamfer and not at the shroud surface, thus minimizing the tendency to form surface delamination cracks and surface chipping.

The second major issue noted with the performance of the CMC shroud system during rig test \#2 was cracking that was observed in the damper blocks. The cracking was worst in the center damper block, which was the hottest of the three positions during the rig test. Figure 3-41 shows the center damper block with cracks emanating from the heavily oxidized piston retention bolts. Two materials were used for the damper blocks: a nickelbased alloy for the outer blocks and a ferrous powder metallurgy ODS alloy for the center block. Even in the hottest position, the ODS alloy damper tended to have less oxidation than the nickel-based alloy dampers; however, being a more brittle material, the ODS alloy exhibited more extensive cracking compared to the nickel-based alloy dampers. The cracking was largely driven by heavy oxidation and swelling of the stainless steel retention 
bolts, and better selection of the bolt alloy was considered to be the ultimate fix for the damper block cracking. The bolt location was also moved to a cooler location in the damper block.

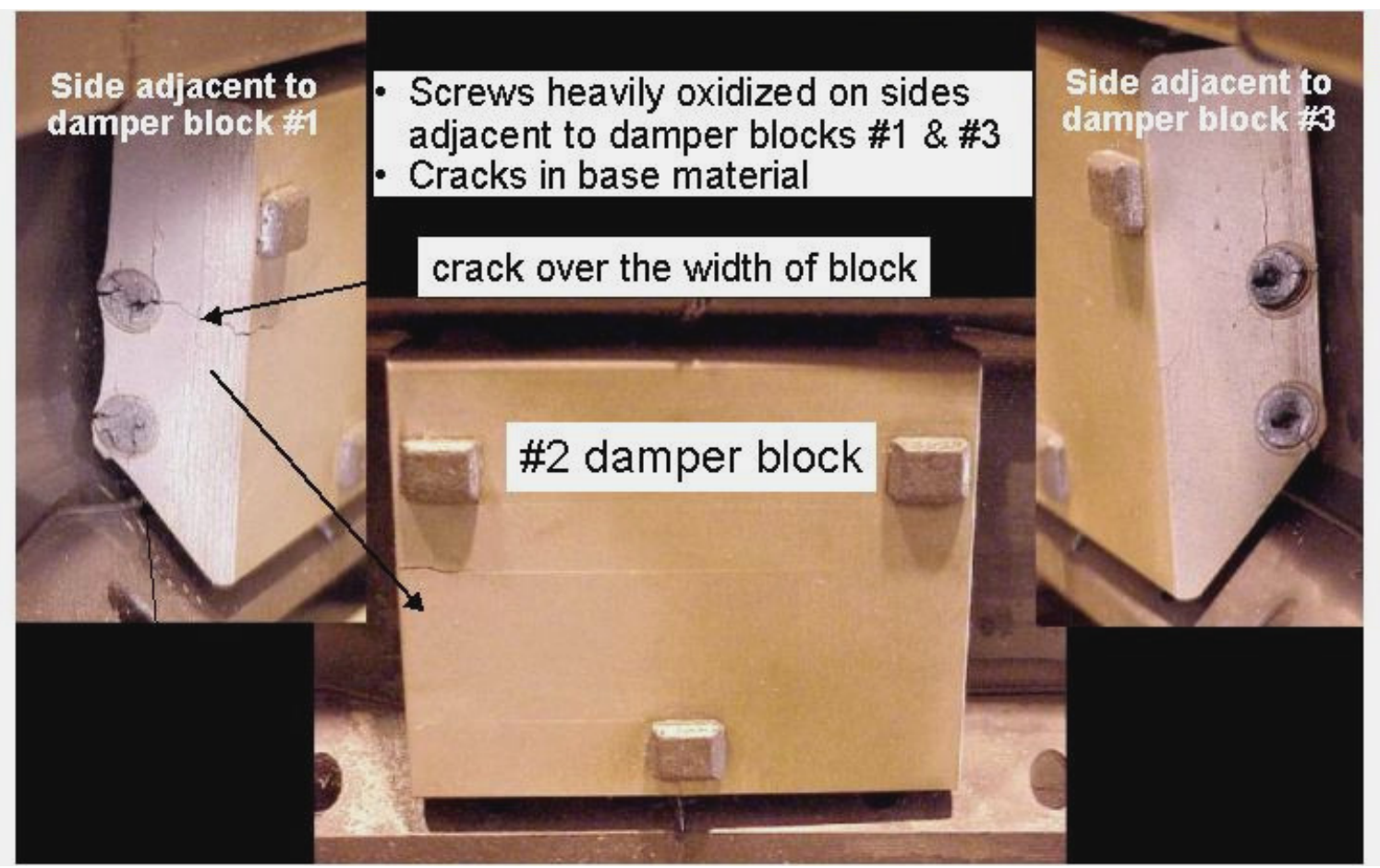

Figure 3-41. Photographs of the center shroud damper block indicating cracks from swelling/oxidation of the piston retaining bolts.

The third issue with the performance of the shroud system was that the damper springs, which are used to press the damper blocks onto the back faces of the shrouds, and in turns keep the shrouds positively seated onto the attachment pins, had relaxed during the rig test. Figure 3-42 shows a comparison of a new spring and a spring removed from the shroud rig after the test. The spring length was reduced by approximately $7.5 \mathrm{~mm}$. This deformation represents the entire preload displacement in the spring, indicating that the damper block was completely unloaded during the test.

The RCA performed on the springs revealed that they had undergone the wrong heat treatment cycle at the manufacturer, which strongly decreased their resistance to creep. With the incorrect heat treatment the spring service temperature would have been limited to approximately $540^{\circ} \mathrm{C}$. This temperature was definitely exceeded during the rig test where the cavity temperature was estimated to be $>650^{\circ} \mathrm{F}$ based on thermocouple data from the outer shroud block. The incorrect heat treatment and high spring cavity temperatures explained the relaxation of the springs. Going forward the springs were changed to a more creep resistant alloy in order to eliminate the spring heat treatment as a possible cause of future failures. 


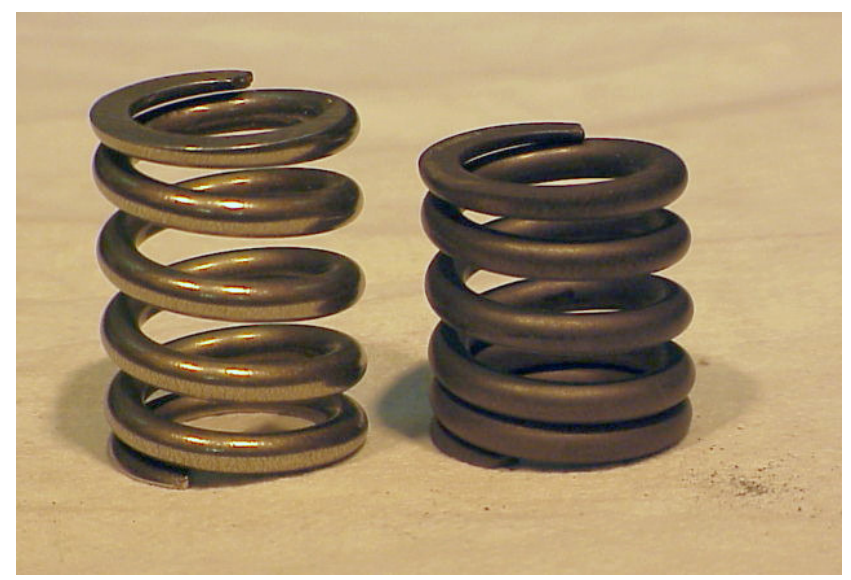

Figure 3-42. Comparison of spring length for new (left) and rig tested (right) springs showing permanent creep relaxation from overheating.

Creep relaxation testing was used as the main criteria for selection of a new spring alloy. Creep testing was performed at CCP, and a photograph of the creep testing setup is shown in Figure 3-43. The spring under test would be loaded between the alumina push-rods and then the furnace heated to the desired test temperature with the spring under a very nominal load. Once at temperature the spring was loaded to the equivalent pre-load of the shroud system. The spring displacement would then be fixed and the load measured as a function of time. The test was mostly isothermal, but the furnace was turned off for 5 minutes every 5 hours to simulate a turbine thermal cycle.

Although testing was limited to spring materials offered by the spring vendors, the most creep relaxation resistant spring tested was made from Rene'-41 alloy. Typical creep relaxation curves for the R-41 springs are shown in Figure 3-44. In these tests the brief load increase above $100 \%$ was due to not leaving sufficient time for the test fixtures to come to thermal equilibrium before starting the test, and thus continued thermal growth of the loading rams caused additional compression of the spring very early in the test. The important information to be obtained from the plots is the rate of load reduction after the initial $\sim 1$ hour period.

The deformations measured in this test were dominated by primary stage creep, which was verified by subsequent tests run for longer times. In order to eliminate primary stage creep as a contributor to the overall spring deformation the new springs were exposed to a "conditioning cycle" where they were held under load at a temperature greater than their use temperature until all of the primary creep relaxation had occurred. Testing showed that springs subjected to such a treatment displayed greatly reduced relaxation rates (essentially un-measurable in the time frame studied) when tested at the expected stress and temperature conditions that would occur in the shroud assembly. 


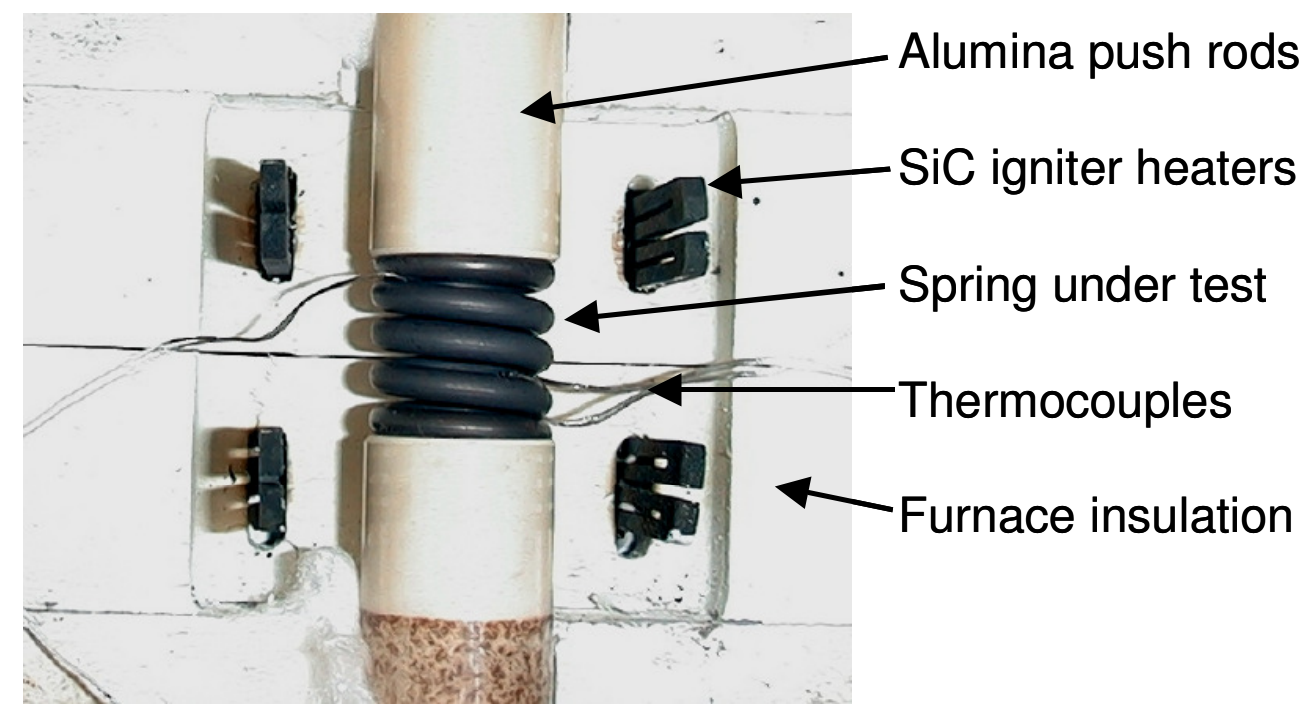

Figure 3-43. Photograph of the shroud damper spring creep relaxation test arrangement.

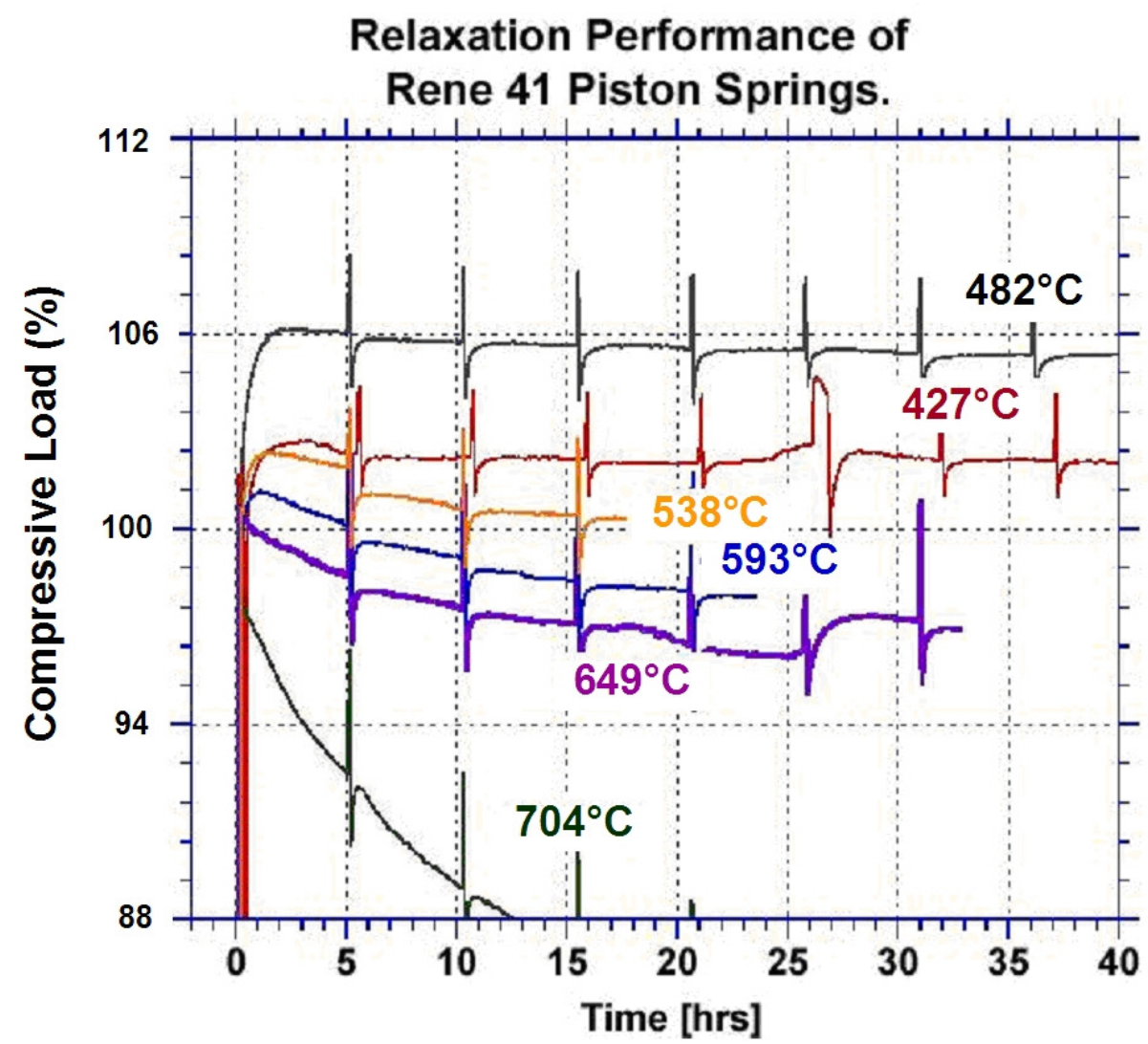

Figure 3-44. Creep relaxation performance of R-41 springs.

In addition to the spring material change, the cavity where the spring is located was also redesigned. A cold flow test of the test section was performed in order to measure the flow through the spring cavity. Based on these measurements and a sub-model flow analysis, an 
additional coolant air passage was added to the spring cavities. An insulating washer was also added to the damper piston assembly to better insulate the spring from heat being conducted outward through the piston. These changes were also incorporated into the overall shroud system design and were subsequently evaluated in the subsequent rig tests.

\subsubsection{Rig Test Campaign \#3}

The shroud test rig was re-assembled with the necessary hardware modifications needed to accommodate the shroud design changes mentioned above. Two new prepreg MI shrouds, one reinforced with Hi-Nicalon fiber and one with Hi-Nicalon type-S fiber, were used for this test along with the existing CCP slurry cast shroud from test \#2. The CCP slurry cast shroud had the original attachment hole configuration whereas the new GRC prepreg shrouds had the new chamfered attachment hole design.

There also had not been a clear winner between the damper block candidate materials from the previous rig test, to that this set of testing included three different damper block configurations: one made of the PM2000 ODS alloy with brazed piston retainting pins, one with the same alloy but with welded piston retaining pins, and one of HS-230 alloy with welded pins.

Rig testing was started on May 16, 2002 and was completed on May 21. The first 10 hours of rig testing were performed at a nominal hot gas temperature of $1120^{\circ} \mathrm{C}$, followed by 132 hours at $1200^{\circ} \mathrm{C}$ firing temperature, including 37 thermal cycles. A pressure anomaly occurred in the rig at the 142 hour mark, causing the tests to be halted for rig inspection. During initial visual inspection it was noted that the outer shroud block of the rig test section and the weld of the rear flange of the transition section had both cracked. The cast alumina refractory lining of the transition piece had also begun to crumble, though it was not clear whether the liner failure had occurred before or after the flange weld failure.

The crumbling of the transition section liner would have released pieces of refractory into the gas path. These refractory pieces then blew through the shroud test section, imparting foreign object impacts on the test shrouds. Boroscope inspection of the shroud test section showed very little damage to the CMC shrouds; however, the cracking in the metallic outer shroud and shroud and transition piece flange necessitated a complete disassembly of the test section.

After disassembly the damage to the transition section liner was seen to be quite severe. A photograph looking downstream through the transition section after rig disassembly is shown in Figure 3-45. Rubble from the failing cast alumina liner is seen stuck in the transition piece exit throat. Much of the forward part of the liner had crumbled and fallen out during rig disassembly. 


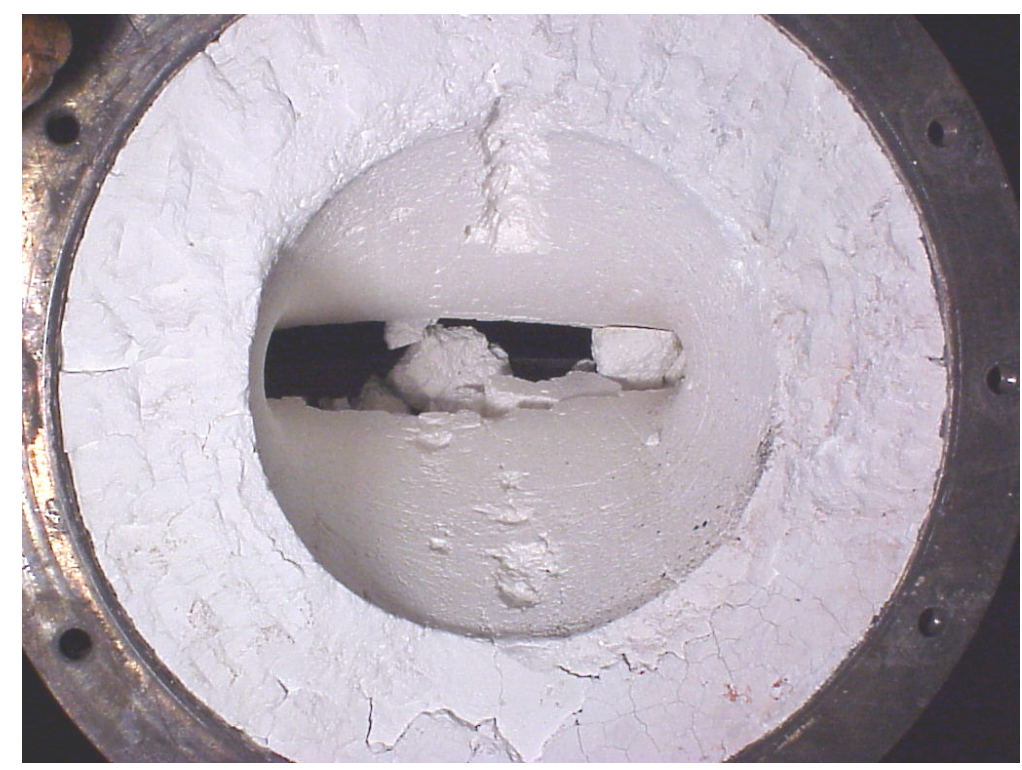

Figure 3-45. Photograph of the transition section of the shroud test rig following test \#3. Several loose pieces of rubble are visible at the exit to the transition section. Pieces of refractory smaller than those seen here would have passed through the shroud test section during the rig test.

Closer inspection of the CMC shrouds indicated some superficial surface damage on the EBC coatings caused by the impacts from the transition piece lining, as shown in Figure 346. The shrouds also had very small chips in the EBC along the edge corners, again caused by foreign object impacts, where EBC was removed down to the substrate (see Figure 347). There was also a region of spalled EBC along the side edge of one of the shrouds that corresponded to the location where a delamination intersected the shroud surface. There was some apparent oxidation inside the delamination, though it is not clear whether the oxidation followed the local spallation of the EBC or if it caused the EBC spall.

Cracking of the EBC was noted at the inside leading edge corners of all of the shrouds, and was associated with increased EBC thickness in this region. An extreme example of this cracking, where EBC was actually lost, is shown in Figure 3-48. The white color of the chipped EBC suggests that EBC loss occurred late in the rig test or possibly during rig disassembly. The greater EBC thickness along these edges was a result of the specific spraying pattern used to apply the EBC to the shroud edges and to minor masking errors.

Of the three problems seen in the earlier rig test two appeared to have been resolved. The two CMC shrouds with the new attachment hole design showed no surface chipping or damage around the attachment holes. The one shroud with the old design, shown in Figure 3-49, had very similar chipping around the attachment hole as had been seen in rig test \#2. These results indicated that the root cause of the shroud chipping was indeed the insufficient clearances in the attachments, and that the new attachment hole design had adequately addressed this problem. 


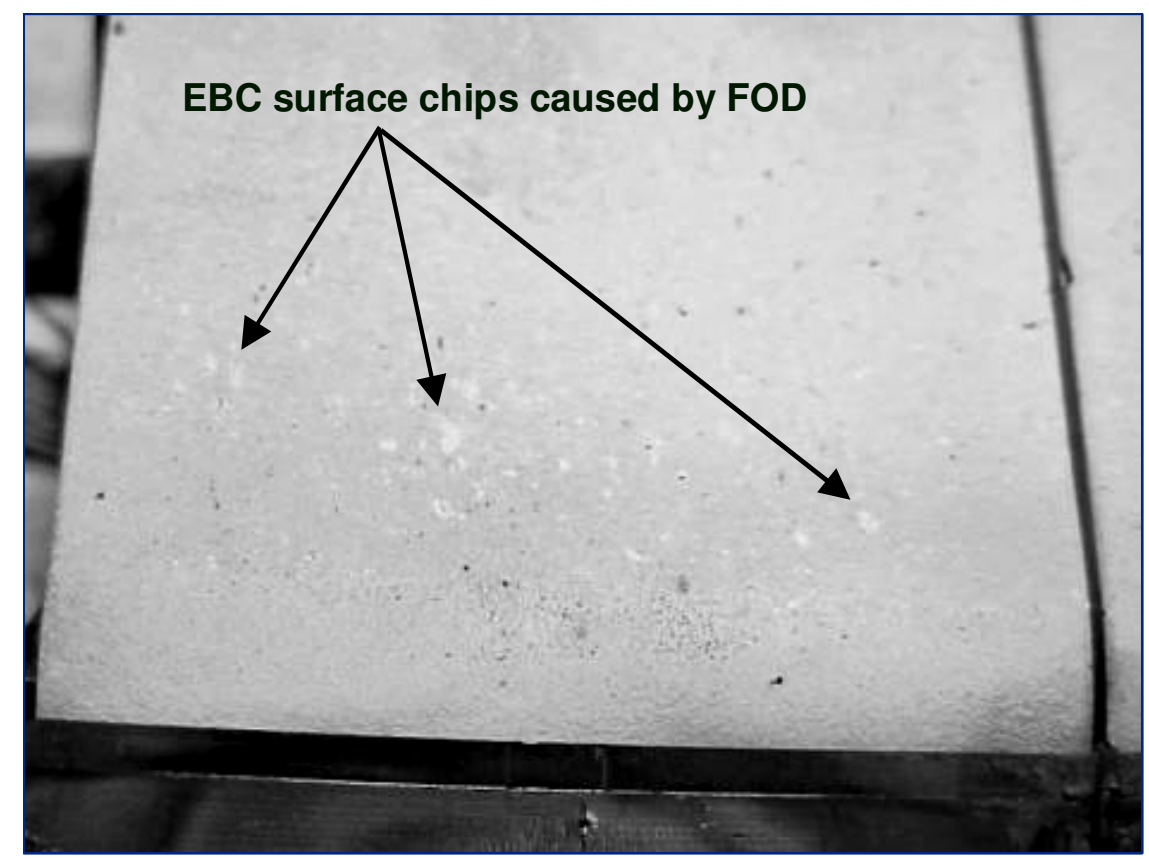

Figure 3-46. Upstream end of the hot gas path surface of one of the prepreg MI shrouds from rig test \#3 showing surface chipping of the EBC coating likely to have been caused by foreign object damage from pieces of the cast refractory transition section of the test rig.

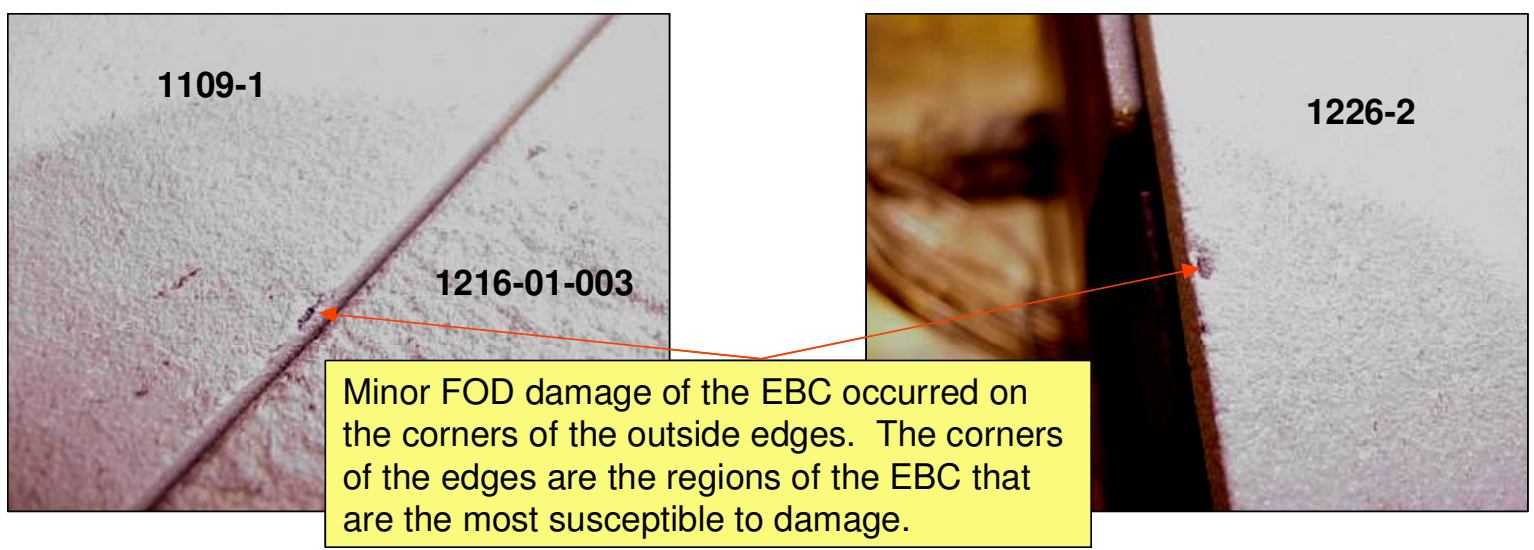

Figure 3-47. Photographs of CMC inner shrouds from the $3^{\text {rd }}$ rig test showing minor edge chipping damage to the EBC coatings caused by foreign object damage. 


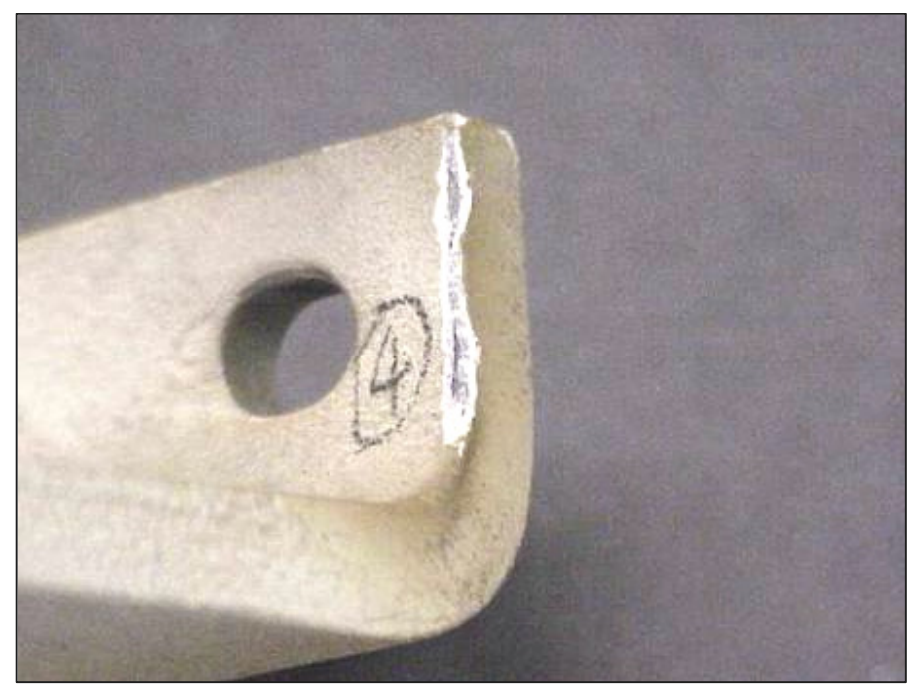

Figure 3-48. Photograph of a CMC inner shroud from the May rig tests showing EBC loss from of the front inside edge where the EBC was thicker than desired.
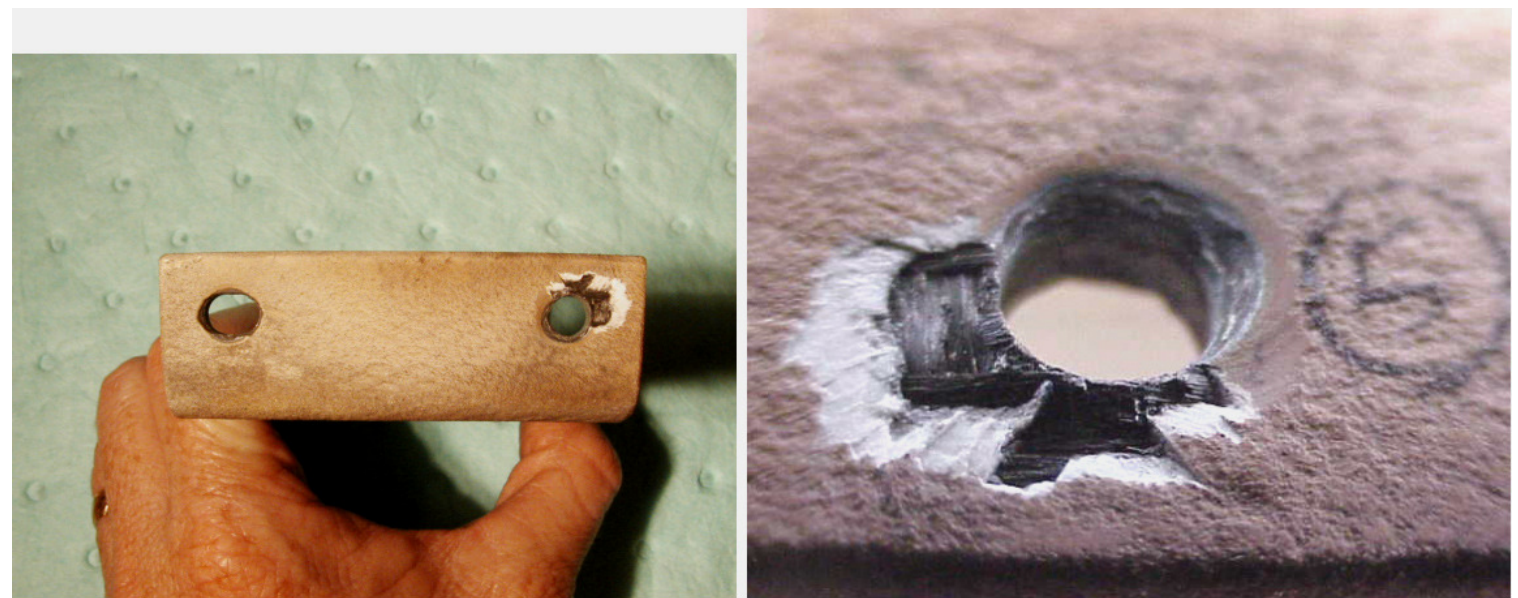

Figure 3-49. Photographs of the CCP slurry cast shroud from rig test \#3, which had the older attachment hole design, showing EBC and CMC chipping around the forward attachment hole.

The second shroud problem from rig test \#2, that of the relaxation of the damper springs, also appeared to have been corrected by the design changes incorporated into test \#3. The springs themselves showed no residual strain after rig testing. The spring force constants were measured at CCP and were found not to have changed appreciably as a result of the rig test, indicating that no relaxation had occurred.

Unfortunately, the third problem from the $2^{\text {nd }}$ rig test, that of cracking of the damper blocks, was not completely resolved. Cracking and evidence of reaction was noted on the ODS alloy damper that had brazed piston retention pins. The interaction of the braze alloy with the ODS alloy apparently caused some swelling and cracking of the damper block. Relatively minor cracking was noted on the ODS alloy damper with the welded pins. An 
RCA was initiated to better understand the cracking mechanism in the welded-pin damper block, which was sectioned and examined metallographically. The damper blocks had been fabricated using electrical discharge machining (EDM). This process leaves a thin "re-cast" layer on the metal surfaces, and in the damper block this layer was found to contain shallow cracks. It was felt that these small surface cracks, in combination with the large grain size of the alloy, led to thermal fatigue cracking along the grain boundaries. In order to alleviate this issue future damper blocks would be machined by milling rather than by EDM, and all edges were given a radius to avoid any stress concentrations caused by the sharp corners.

A new performance issue was noted in the $3^{\text {rd }}$ rig test. The attachment pins and bolts used for this test were made of L-605 alloy with a thermal sprayed T800 wear coating. Both the attachment pins and bolts showed excessive material loss, with the wear coatings having been removed down to the bond coat in several locations. Photomicrographs showing this coating wear are shown in Figure 3-50. Similar wear coating loss had been seen in rig test \#1, but was at that time attributed to a poor deposition process. GE Energy engineers had been working with the coating vendor to improve the wear coating deposition process, but pins with improved coatings were not available in time for rig test \#2. Consequently rig test \#3 was the first test of the "improved" wear coating, which still showed unacceptable wear rates.

It is not clear whether the wear coating loss is a result of excessive oxidation, reaction with the CMC part, mechanical wear, or a combination of these mechanisms. A CMC combustor liner being tested by GE Aircraft Engines under a separate NASA-sponsored program also showed excessive wear of this same coating in a similar attachment scheme. Closer inspection of the bolts/pins from rig test \#2 indicated that uncoated alloy pins used in that test actually showed somewhat less wear than those with wear coatings used in rig test \#3.

The premature stop of the $3^{\text {rd }}$ rig test, caused primarily by the transition piece failure, prevented the completion of an over-temperature test that had been planned. In practice, shroud components can be exposed to a range of operating temperatures because of engineto-engine variations, specific operating conditions of each engine, circumferential temperature "hot-streaks", etc. In order to assure CMC shroud system robustness it would be necessary to do exposure testing at the extreme limit of what a shroud would be expected to see in the field. Also, the continued issues with the damper block cracking, and the new observation of attachment pin wear, made it necessary that an additional rig test be performed. 


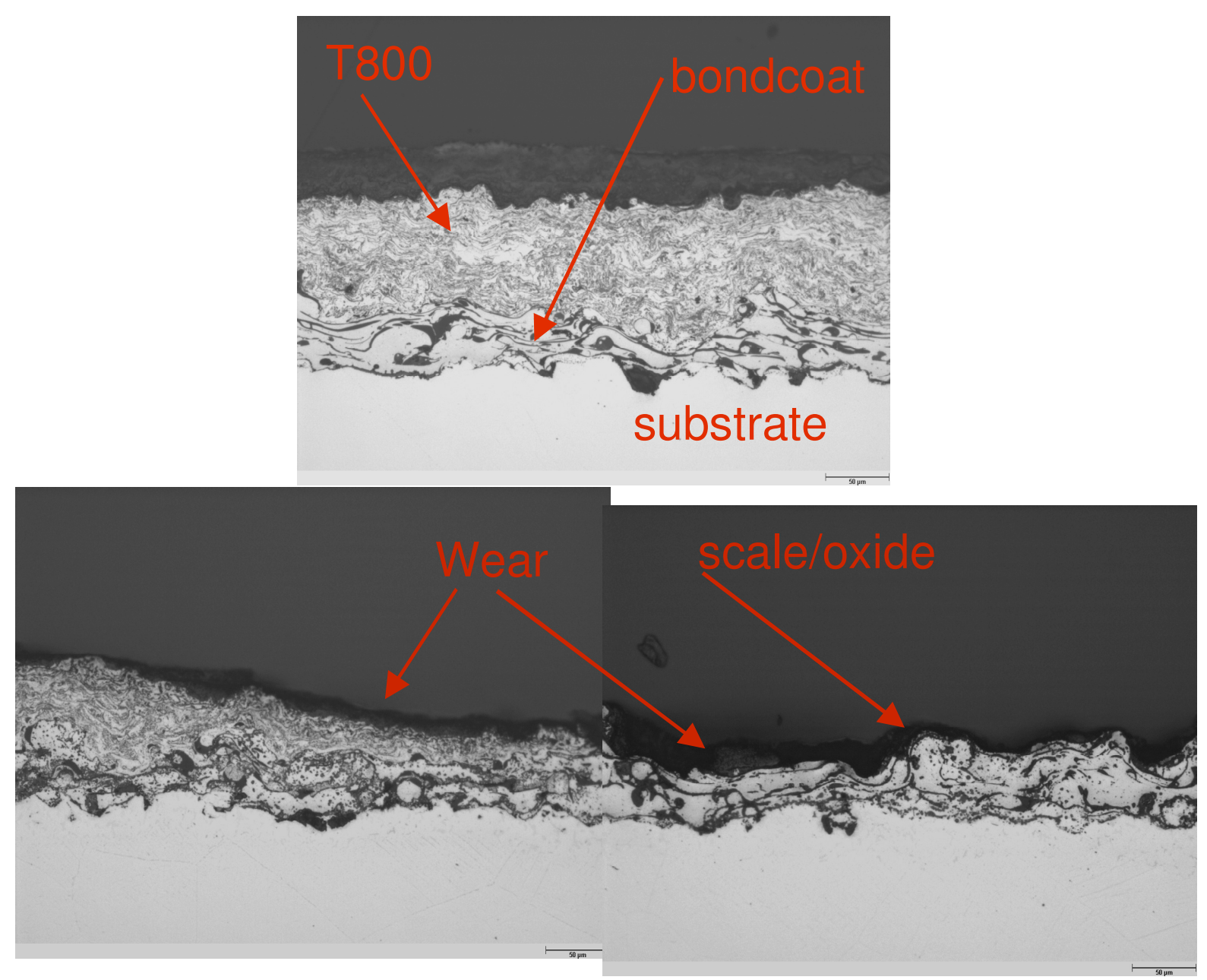

Figure 3-50. Photomicrographs of a T-800 coated shroud attachment pin: Top - Assprayed coating microstructure; Bottom - area of the pin showing coating wear down to the bond coat in localized areas.

Performance of a $4^{\text {th }}$ rig test would require substantial repairs to the test rig. The complete transition section needed to be re-manufactured, and the shroud test section outer shroud block and lower outer wall both needed to be replaced. The CMC inner lower wall was also showing signs of distress. Due to the expansion difference of the CMC wall and the alumina-based filler insulation and the metallic outer wall plate to which it was attached, the flanges of the CMC wall would be forced apart at the rig operating temperature. Tensile cracks on the inside of the leading edge bend, and delamination cracks within the bend, were noted on the CMC lower wall after rig test \#3, as shown in Figure 3-51. This damage was considered severe enough that a new CMC lower wall was required for rig test \#4. 


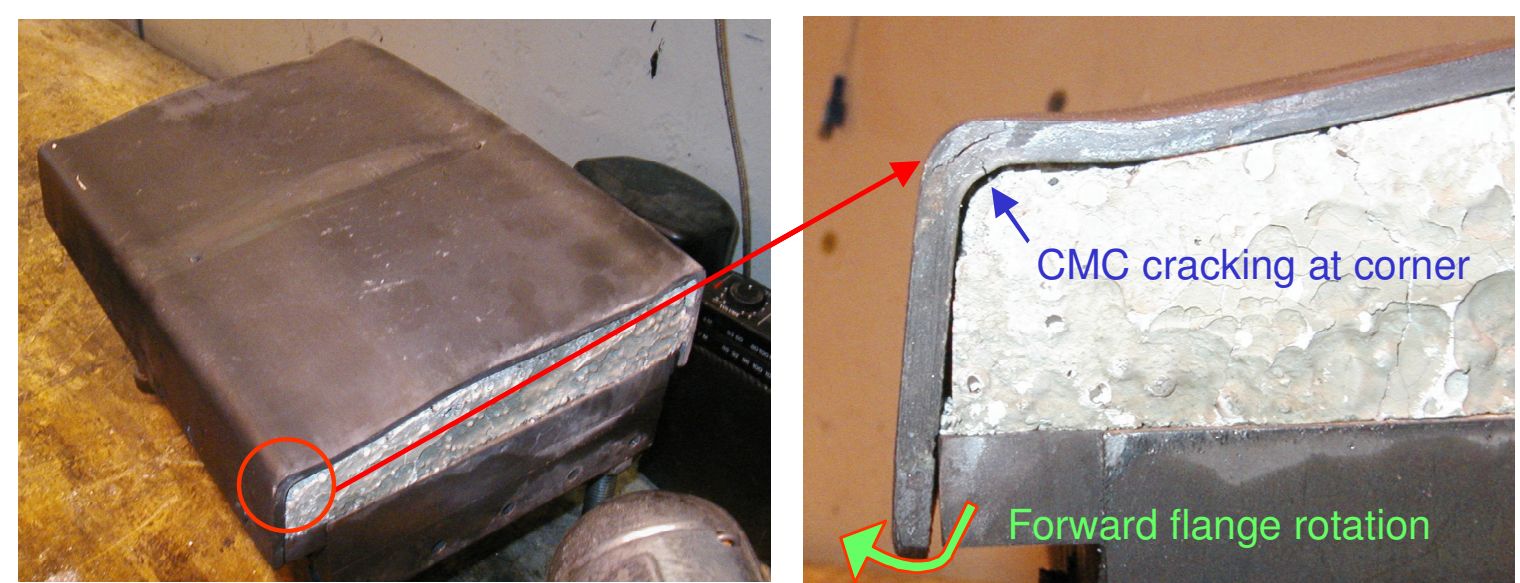

Figure 3-51. Photographs of the rig shroud section lower wall after rig test \#3. Cracks in the forward corner of the CMC wall are indicated.

\subsubsection{Rig Test Campaign \#4}

Rig test \#4 had two main goals. The first was to perform a detailed design of experiments with regard to cooling flow to the spring cavity and its effect on the spring and outer shroud block temperatures. Such information was needed in order to properly size the cooling air passages in the outer shroud block to ensure adequate cooling of the springs during the pending field engine test. In order to accomplish this goal the outer shroud block was more heavily instrumented for this rig test than it had been in the previous tests. The cooling air feed to the shroud test section was also divided into several circuits, each with and independent flow controller, in order to enable adjustments of the outer shroud cooling flows in real time during the rig test. Two photographs of the outer shroud block during assembly for rig test \#4 are shown in Figure 3-52, which show the many thermocouples and pressure taps needed for full shroud system instrumentation.

The second goal of rig test \#4 was to evaluate various attachment pin materials and wear coatings. As noted above, one of the remaining problem areas for the shroud system design was the excessive wear of the metallic pins and bolts used to attach the CMC inner shroud to the metallic outer shroud block during rig test \#3. Numerous options for pin/bolt materials and wear coatings were considered, of which 5 combinations were chosen for evaluation in rig test \#4. These combinations included two base alloys, two types of oxidation coatings, two types of TBC coatings, and the use of a separate monolithic ceramic sleeve between the pin/bolt and CMC. Although the overall shroud design was the same for each of these attachment options, the details of the attachment holes in each CMC inner shroud changed slightly to accommodate the different pin/bolt concepts.

The two prepreg MI shrouds from rig test \#3, which had experienced only very minor EBC coating damage due to foreign object damage (FOD), were also used in rig test \#4. This was done in order to see if the minor EBC chips and cracks observed from rig test \#3 would continue to grow during additional exposure testing. The third for rig test \#4 shroud was newly fabricated by $\mathrm{CCP}$ using a new processing variation on the slurry cast MI process. 
EBC coating pattern modifications were also used to coat the new shroud to eliminate the overly-thick EBC coatings on regions of the shroud edges.
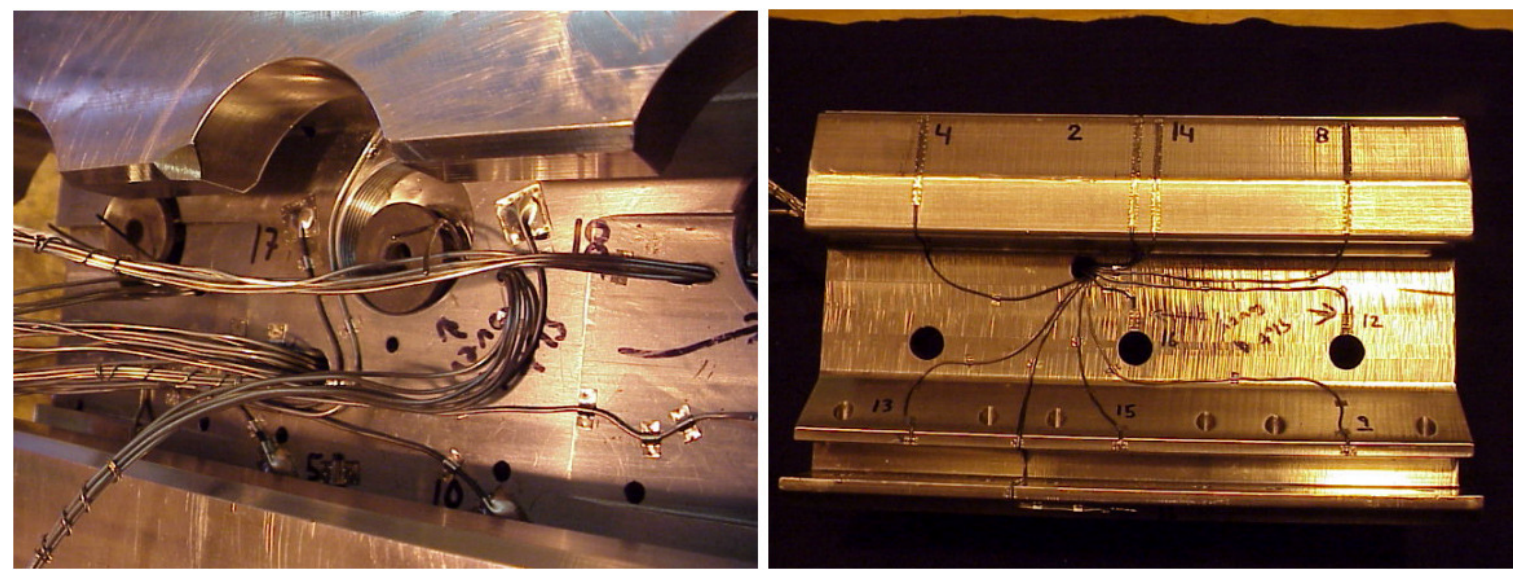

Figure 3-52. Photographs of the outer shroud block for rig test \#4 with instrumentation being installed: Left - view of the top of the outer shroud block inside the casing hook channel; Right - view of the bottom of the outer shroud block.

Rig test \#4 was started August 4, 2002, and was run in two segments. The first segment lasted for 120 hours, most of which was run at $1200^{\circ} \mathrm{C}$ rig gas temperature, and included 4 inadvertent trip cycles. A boroscope inspection was then performed and the rig hardware and shroud test samples all appeared to be in good condition. Only minor chipping of castable refractory from the rig transition piece was noted, which was probably a result of thermal shock from the rig trips. Some very minor surface cracking was noted on the EBC coatings of the shrouds, but no EBC spallation was observed.

The second segment of testing started on August 13, and was to include 30 hours of cyclic testing and over-temperature exposures. This segment was stopped after 28 hours and 13 thermal trip cycles when a pressure build-up was noted in the rig. During rig disassembly it was discovered that the new CMC lower wall of the shroud test section had failed at the bend to the rear flange. Overstressing of the CMC inner wall by the thermal expansion of the cast alumina refractory backing apparently caused the failure.

Visual inspections of the CMC inner shrouds showed little additional damage beyond what was seen after rig test \#3. Cracks in the EBC coating grew somewhat, especially near the shroud edges, but no failure of the EBC or CMC shrouds was evident. Post-test NDE characterization of the shrouds showed no change compared to the pre-test NDE signatures.

All three CMC inner shrouds from rig test \#4 were sectioned after rig testing and used for microstructural and mechanical characterization. Metallographic cross sections taken from the major flat face of each shroud are shown in Figure 3-53. The first prepreg MI shroud, made with Hi-Nicalon fiber, had a large delamination along the $4^{\text {th }}$ ply from the hot gas path 
face in the large flat section of the shroud. This defect was known from pre-test NDE, where it was shown to have grown very slightly during rig test \#3. NDE after rig test \#4 showed no change in the size or severity of the delamination, suggesting that the shroud was mechanically stable even with this defect.

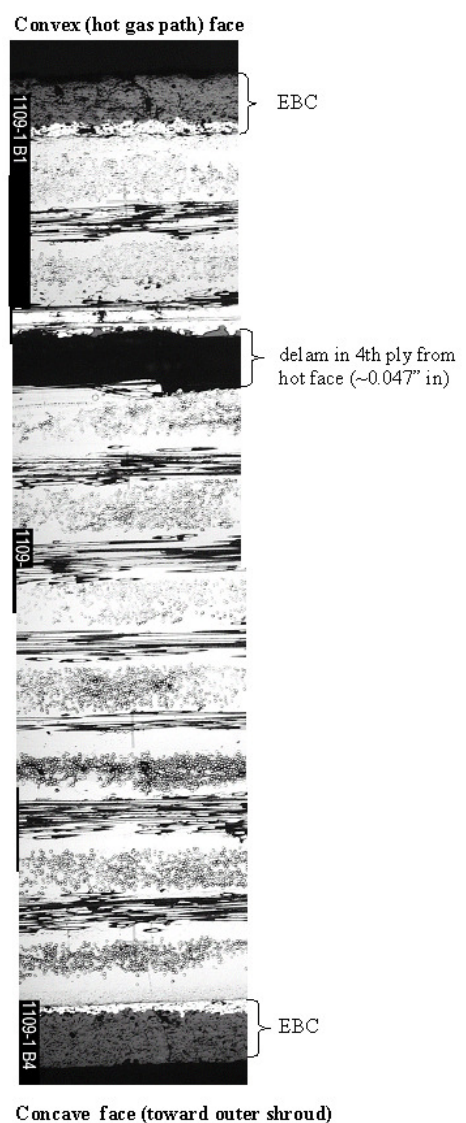

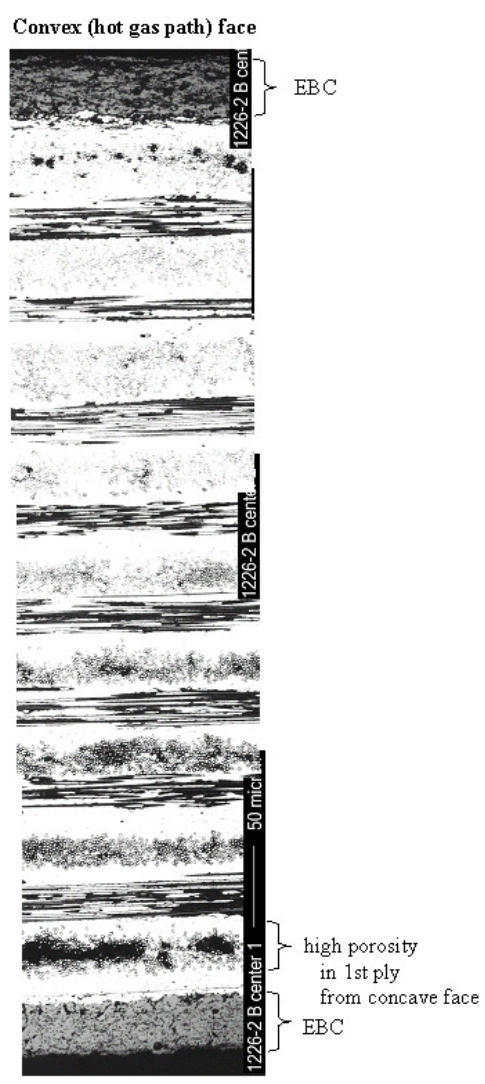

Concave face (tow ard outer shroud)

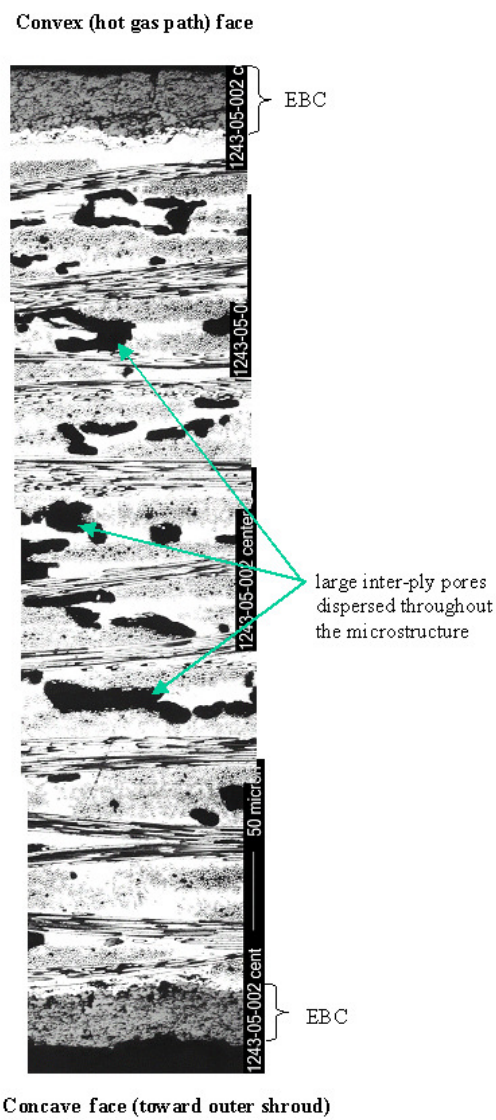

Concave face (tow ard outer shroud)

Figure 3-53. Micrographs of shroud used in rig test \#4 from cross sections taken the center of the hot gas path face: Left - Prepreg MI shroud with Hi-Nicalon fiber showing delamination in the $4^{\text {th }}$ ply from the hot gas path surface; Center - Prepreg MI shroud with Hi-Nicalon Type S fiber showing high porosity in the $17^{\text {th }}$ ply (near the inner surface); Right - Slurry cast shroud showing distributed large pores.

The second prepreg MI shroud, made with Hi-Nicalon Type S fiber, had a near-surface ply with a relatively high level of porosity. The porosity was not concentrated enough to look like a delamination, and thus did not give a strong NDE signal.

The slurry cast shroud, made with Hi-Nicalon fiber and a new processing variation to try to minimize porosity, did show significant microstructural improvement over previous slurry cast shrouds. The cross sections examined showed it to be fully infiltrated in regions where matrix precursor was present. There were still large pores distributed throughout the body where neither matrix nor silicon had penetrated, as shown in the right micrograph in Figure 
3-53. However, the concentration of this large porosity was much less than in the previously characterized slurry cast shrouds and there was no un-infiltrated fine porosity.

Detailed metallographic examinations were also done in the region of the forward attachment holes to look for signs of CMC wear at the attachments. Figure 3-54 contains micrographs of the cross sections of the forward holes for each of the three shrouds. As indicated by the circularity of the front holes in the micrographs, no CMC wear was seen in any of the three shrouds.

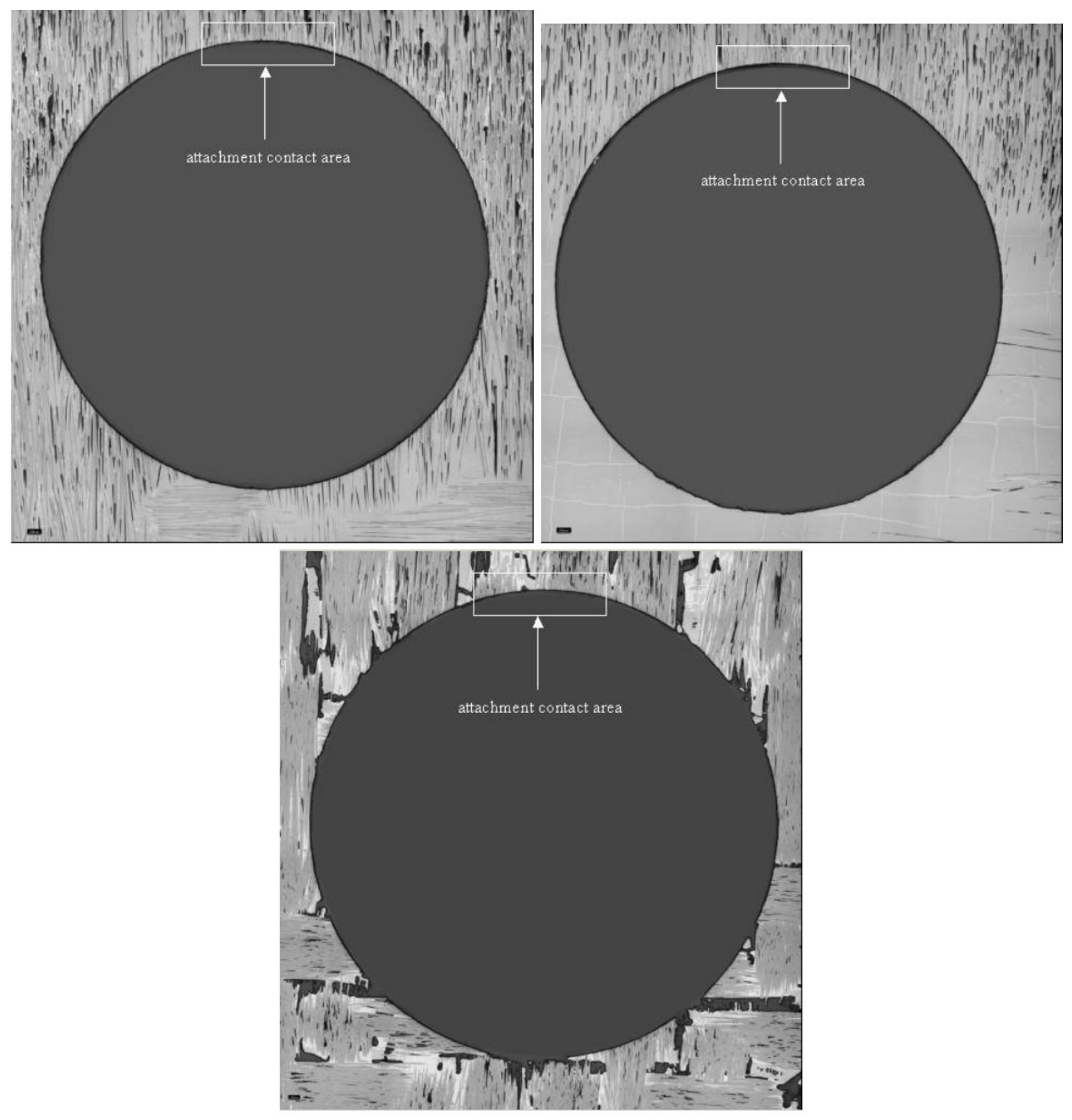

Figure 3-54. Photomicrographs of the forward attachment hole cross-sections for the three shrouds in rig test \#4. No wear was evident in the attachment contact regions.

Top Left - prepreg shroud with Hi-Nicalon fiber

Top Right - prepreg shroud with Hi-Nicalon Type S fiber

Bottom - slurry cast shroud with Hi-Nicalon fiber 
Post-exposure mechanical testing of the CMC inner shrouds included in-plane tensile testing of samples cut from the hot gas path section of each shroud, as well as pin pull-out testing of the forward flange attachment slots. Results of the in-plane tensile tests are shown in Figure 3-55. The tensile stress-strain behavior for both the prepreg shrouds showed similar changes, exhibiting a roughly $15 \%$ decrease in ultimate tensile strength and matrix cracking stress, but constant or even increasing strain to failure values. However, it should be noted that the pre-rig-test bars were tested without the EBC coating present whereas the bars after rig testing did have EBC. Assuming the EBC contributes no strength of its own to the CMC sample, the additional $0.8 \mathrm{~mm}$ of specimen thickness caused by the presence of the $\mathrm{EBC}$ is sufficient to account for nearly all of the observed loss in strength. The slurry cast shroud, which had been exposed only during rig test \#4, showed little change in overall stress-strain behavior.

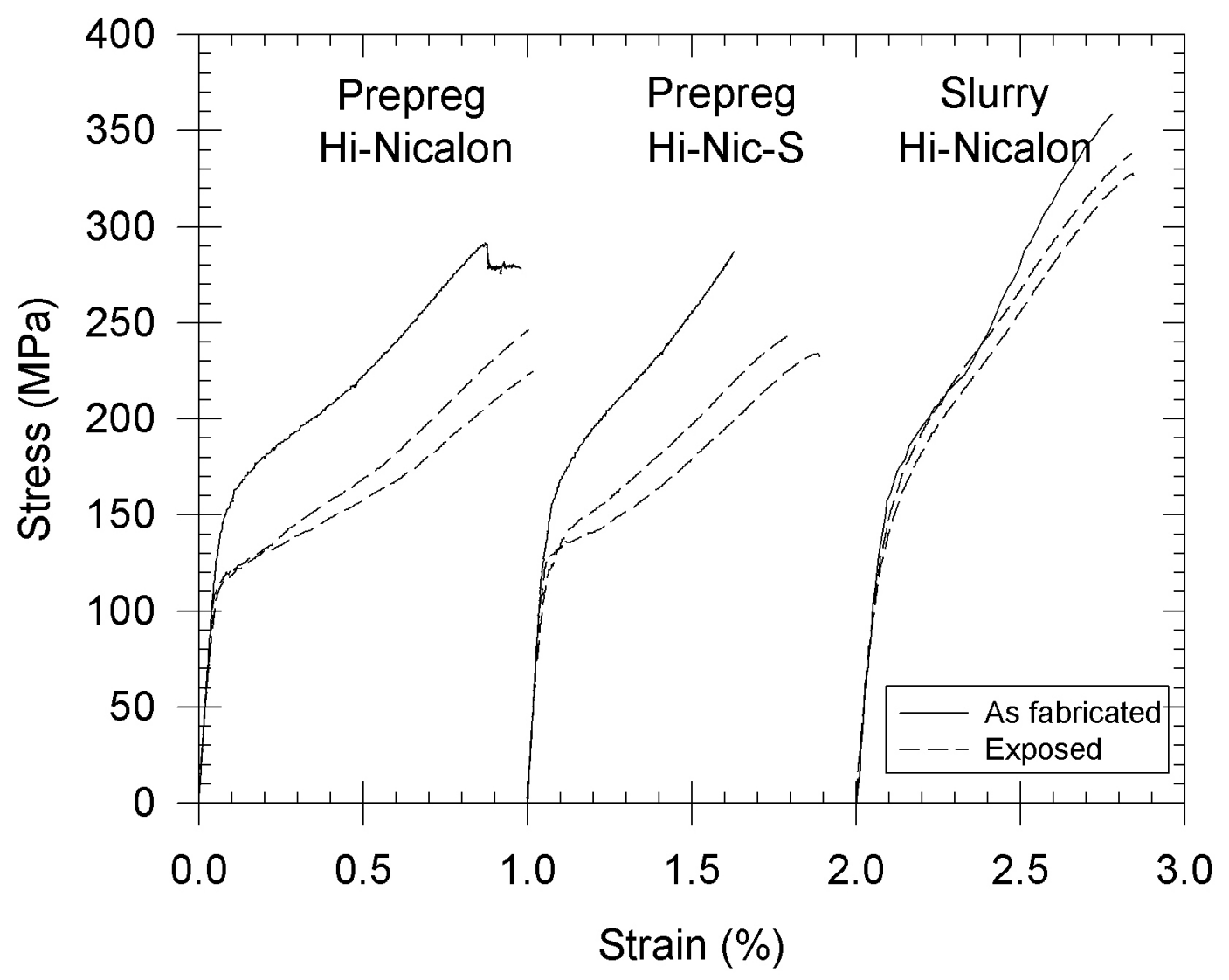

Figure 3-55. Tensile stress-strain behavior of shrouds used in rig test \#4. The prepreg shrouds had been exposed in both rig test \#3 and \#4 for a total accumulated rig exposure of 290 hours. The slurry cast shroud had been exposed only in rig test \#4 for 148 hours. The tensile strength behavior of the shrouds after rig testing (dashed lines) is compared to the behavior before rig testing (solid lines). 
Pin pull-out testing was also performed on the rig-tested shrouds, analogous to that described in previous program reports. Load-displacment curves for the three shroud specimens are shown in Figure 3-56. The curves give maximum loads in the range of 9000 to $12500 \mathrm{~N}$, which is consistent with values measured previously on $0.5 \mathrm{~cm}$ thick panels and shroud samples. All of the samples exhibited "tough" behavior, as acoustic evidence of matrix cracking was noted to start around $4500 \mathrm{~N}$ where the loading curves begin to bend over. Even beyond the large load drops the loads did not fall completely to zero and each of the samples remained intact.

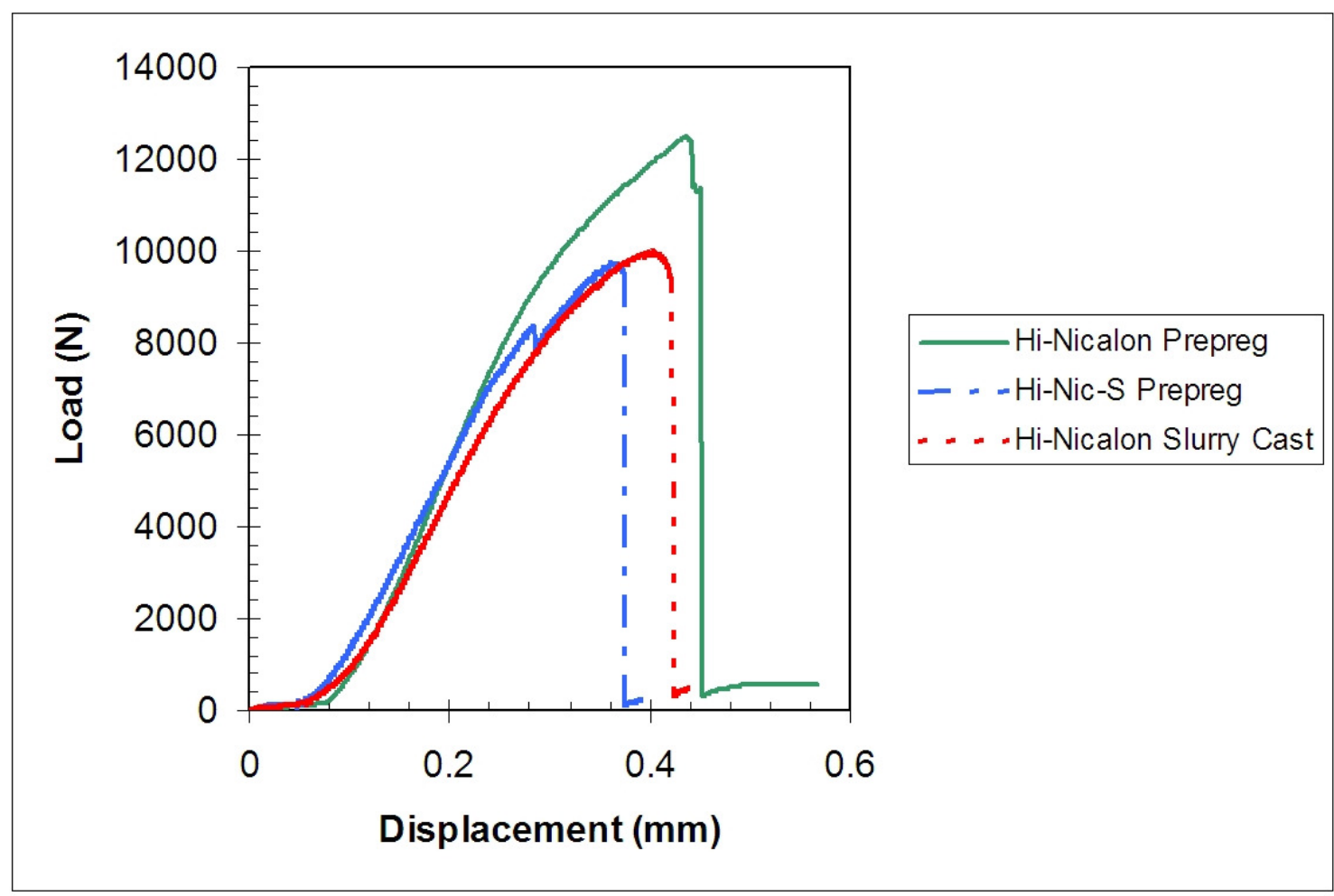

Figure 3-56. Load-displacement behavior for forward slot samples cut from the shrouds exposed in rig test \#4.

The above microstructural and mechanical data indicate that there was no substantial degradation of the CMC shroud components through rig tests \#3 and/or \#4. Unfortunately the same cannot be said of the attachment pins. The monolithic ceramic sleeves were found to have cracked and lost significant material at the 120 hour boroscope inspection. Upon final disassembly none of the sleeves was intact. Evidently the thermal transient and vibrational stresses were sufficient to cause failure of the sleeves.

Results were only marginally better for the pins and bolts with TBC or oxidation/wear coatings. All of the pins showed wear marks from visual inspection. Photographs of the wear marks from the pins in the forward shroud slots, which is the attachment location that experiences the largest axial and radial relative movements between the CMC shroud and 
attachment during thermal cycling, are shown in Figure 3-57. The depths of the wear marks were measured using optical interference profilometry, examples of which are shown in Figure 3-58. Wear track depths were found to range from 50 to $75 \mu \mathrm{m}$ for the TBC coated pins, and averaged around $130 \mu \mathrm{m}$ for the pins with metallic oxidation coatings. Metallographic sectioning and examination of the pins indicated that little of the TBC coating itself was lost, rather the pin below the contact region appeared to have deformed plastically. This deformation of the substrate caused significant sub-surface cracking on the TBC-coated pins, strongly suggesting that spallation failure of the coatings was imminent with further exposure. The pins with the metallic oxidation coatings also showed plastic deformation, but most of the deformation was in the coatings themselves. There was little material loss from these pins, but rather the coatings were plowed up to the edges of the contact areas.
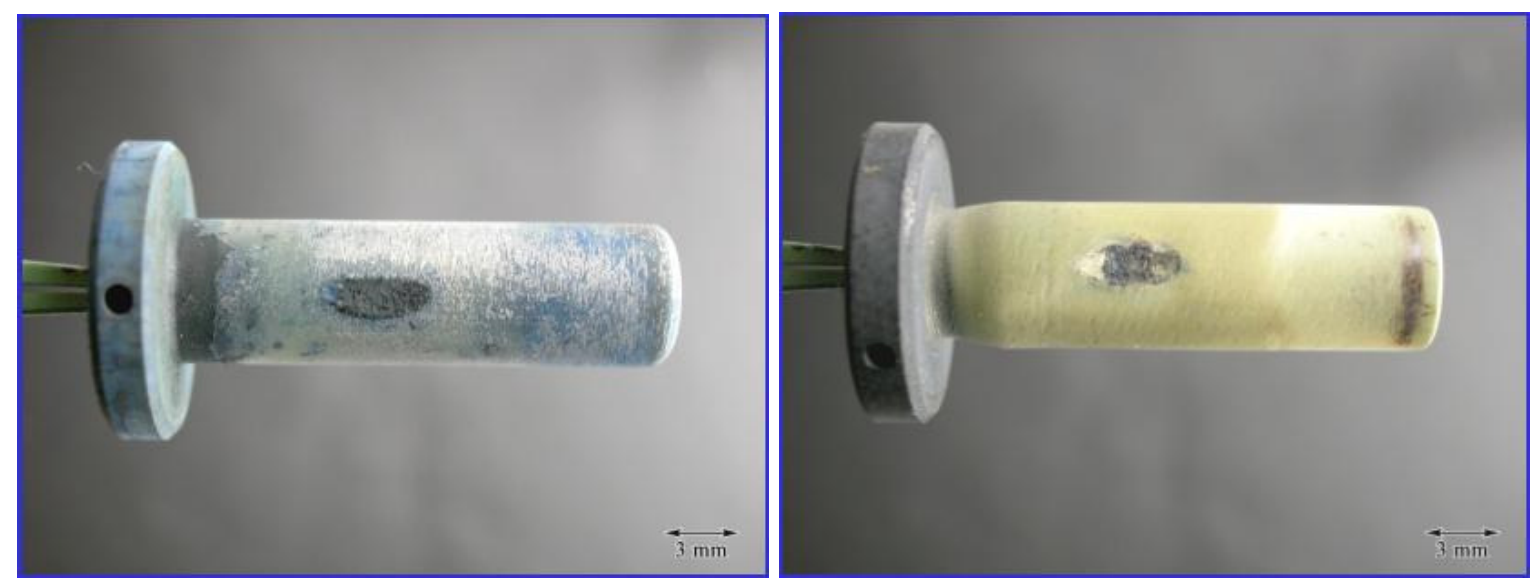

Figure 3-57. Photographs of shroud attachment pins following rig test \#4, showing wear marks at the shroud contact region: Left - pin with metallic oxidation coating; Right - pin with TBC coating.

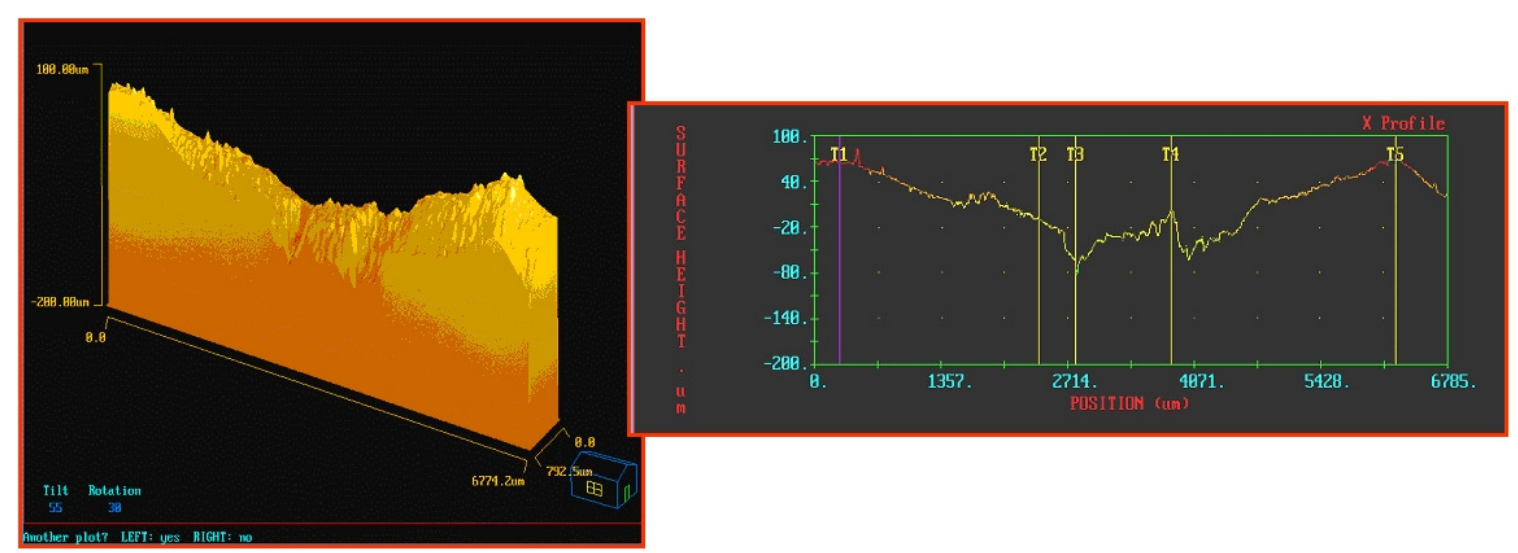

Figure 3-58. Example of optical profilometry results from the shroud attachment pins from rig test \#4. These results are from an Ultimet alloy pin coated with a metallic CoNiCrAlY oxidation coating. 
The above post-test analyses of the attachment pins and bolts indicated that there was no appreciable advantage to using coatings on the attachment pins. Uncoated pins, as were used in rig test \#2, showed no more wear than the pins with metallic coatings, and would not be susceptible to coating spallation and accelerated three-body wear as might be expected with the TBC coatings. Consequently uncoated pins were chosen for use in the upcoming field engine test.

The thermocouple and pressure tap data collected during the rig test was analyzed in detail. Variations in the outer shroud block, damper spring, damper block, and attachment pin temperatures were determined as a function of coolant air flow into the casing mounting slot and to the individual spring cavities, and also as a function of the coolant air temperature and rig firing temperature. Of the 24 planned test conditions in the design of experiments only one condition could not be measured due to an over-temperature alarm on one of the spring cavity thermocouples. This detailed information allowed the cooling flow orifices within the outer shroud blocks of the engine test shrouds to be precisely sized to ensure adequate spring performance over the anticipated 8,000 hour engine test.

\subsubsection{Task 2.6 - Blade Rub and Wear Testing}

The original intent of this task was to measure the effect of blade tip rubbing against a CMC shroud as might be expected in the field engine test. However, various material couple wear issues had been noted during shroud rig testing, as discussed in Section 3.1.7. Consequently the scope of this task was broadened to cover wear testing done at Oak Ridge National Laboratory (ORNL) to look at wear rates between CMC/EBC and candidate damper block alloys, and between the damper piston alloy and the outer shroud block and damper block alloys. The results of these blade tip rub and damper block wear testing are discussed in the following sections.

\subsubsection{Blade Tip Rub Rig Testing}

The use of CMC materials as shrouds in industrial gas turbines provides for the possibility that the tips of rotating buckets may contact the shrouds during operation. Such bucket rubs were seen in the PGT-2 shroud engine tests under the CFCC program [2], and bucket rubs into metallic shrouds was a well know occurrence in the 7FA engine fleet. For this reason, it was essential to understand the interaction between the metallic bucket material with the $\mathrm{CMC}$ and $\mathrm{EBC}$ during blade tip rub events. Blade tip rub experiments were therefore performed in a GE-owned rub test rig.

GRC prepreg and CCP slurry cast MI CMC panels were fabricated for use in rub testing. The panels were nominally $5 \mathrm{~mm}$ thick in order to simulate the proposed thickness of the $\mathrm{CMC}$ shroud. The panels were sliced to yield $5.1 \mathrm{~cm} \times 7.6 \mathrm{~cm}$ rub test specimens. Threelayer EBC, consisting of silicon bond-coat, mullite/BSAS transition layer, and a BSAS topcoat, was spray deposited on the specimens according to the test matrix shown in Table 3 5. Blade tip rub tests of CMC with and without EBC were performed at GE Aircraft 
Engines using a specially designed test rig. The test conditions studied were a blade tip speed of $427 \mathrm{~m} / \mathrm{s}$, a blade material of DS GTD-111, an incursion rate of $2.5 \mu \mathrm{m} / \mathrm{s}$, and a final incursion depth of 0.13 or $0.38 \mathrm{~mm}$. "Ambient temperature" within the rub rig was approximately $65^{\circ} \mathrm{C}$.

Table 3-5. Test Matrix Used for the Blade Tip Rub Tests

\begin{tabular}{|c|c|c|l|c|}
\hline $\begin{array}{c}\text { Sample } \\
\text { ID }\end{array}$ & Temperature & $\begin{array}{c}\text { Incursion } \\
(\mathrm{mm})\end{array}$ & \multicolumn{1}{|c|}{ Sample Type } & $\begin{array}{c}\text { EBC top coat } \\
\text { thickness } \\
(\mathrm{mm})\end{array}$ \\
\hline S-31 & Ambient & 0.38 & Pre-preg CMC without EBC & 0 \\
\hline S-32 & $1200^{\circ} \mathrm{C}$ & 0.38 & Slurry-cast without EBC & 0 \\
\hline S-33 & Ambient & 0.13 & Pre-preg CMC with Porous EBC & 0.25 \\
\hline S-34 & Ambient & 0.38 & Pre-preg CMC with Porous EBC & 0.74 \\
\hline S-35 & $1200^{\circ} \mathrm{C}$ & 0.13 & Pre-preg CMC with Porous EBC & 0.25 \\
\hline S-36 & $1200^{\circ} \mathrm{C}$ & 0.38 & Pre-preg CMC with Porous EBC & 0.74 \\
\hline S-37 & $1200^{\circ} \mathrm{C}$ & 0.13 & Slurry-cast CMC with Porous EBC & 0.25 \\
\hline S-38 & $1200^{\circ} \mathrm{C}$ & 0.38 & Slurry-cast CMC with Porous EBC & 0.74 \\
\hline
\end{tabular}

Figure 3-59 shows the rub test rig with specimen assembly in place. The rub rig consists of a combustor, a rotor with blade tip insert, and the counter-face specimen assembly. An $\mathrm{Al}_{2} \mathrm{O}_{3}-\mathrm{Al}_{2} \mathrm{O}_{3} \mathrm{CMC}$ material was used as an insulating block to maintain rub sample temperature during operation by insulating the $\mathrm{CMC}$ from the metallic specimen holder. A notch was cut into the insulating block to allow for sample back-side temperature measurement via thermocouple. The sample front-side (rub face) surface temperature was calibrated relative to the back-side TC measurement by measuring the front-side surface temperature with an $8.5 \mathrm{~mm}$ wavelength infrared detector during a trial exposure to the combustion flame.

Table 3-6 summarizes the test conditions and weight change data for the rub tests. With one exception, all tests resulted in weight loss from the blade tip and weight gain on the substrate. This indicates that the tip was wearing and tip material was transferring to the EBC, which was not wearing significantly. The one exception was the ambient temperature test of prepreg CMC, where transferred tip material was not observed on the CMC surface, resulting in a lack of weight gain of the substrate. The uncoated CMC tests, specimens S$31 \&$ S-32, exhibited trends different than the EBC coated specimens, and the trends were likely influenced by differences in surface roughness and hardness between coated and uncoated substrates.

Comparing the data at the two incursion distances for the EBC coated samples, the results indicate that rub tips generally lost more weight as incursion distance increased. The CMC samples did not generally gain additional weight as tip weight loss increased, indicating that more rub tip material was lost and not transferred to the substrate as incursion distance increased. The very high mass gain of the uncoated slurry cast sample was likely caused by 
the much rougher surface of this sample compared to the EBC coated or uncoated prepreg composites.
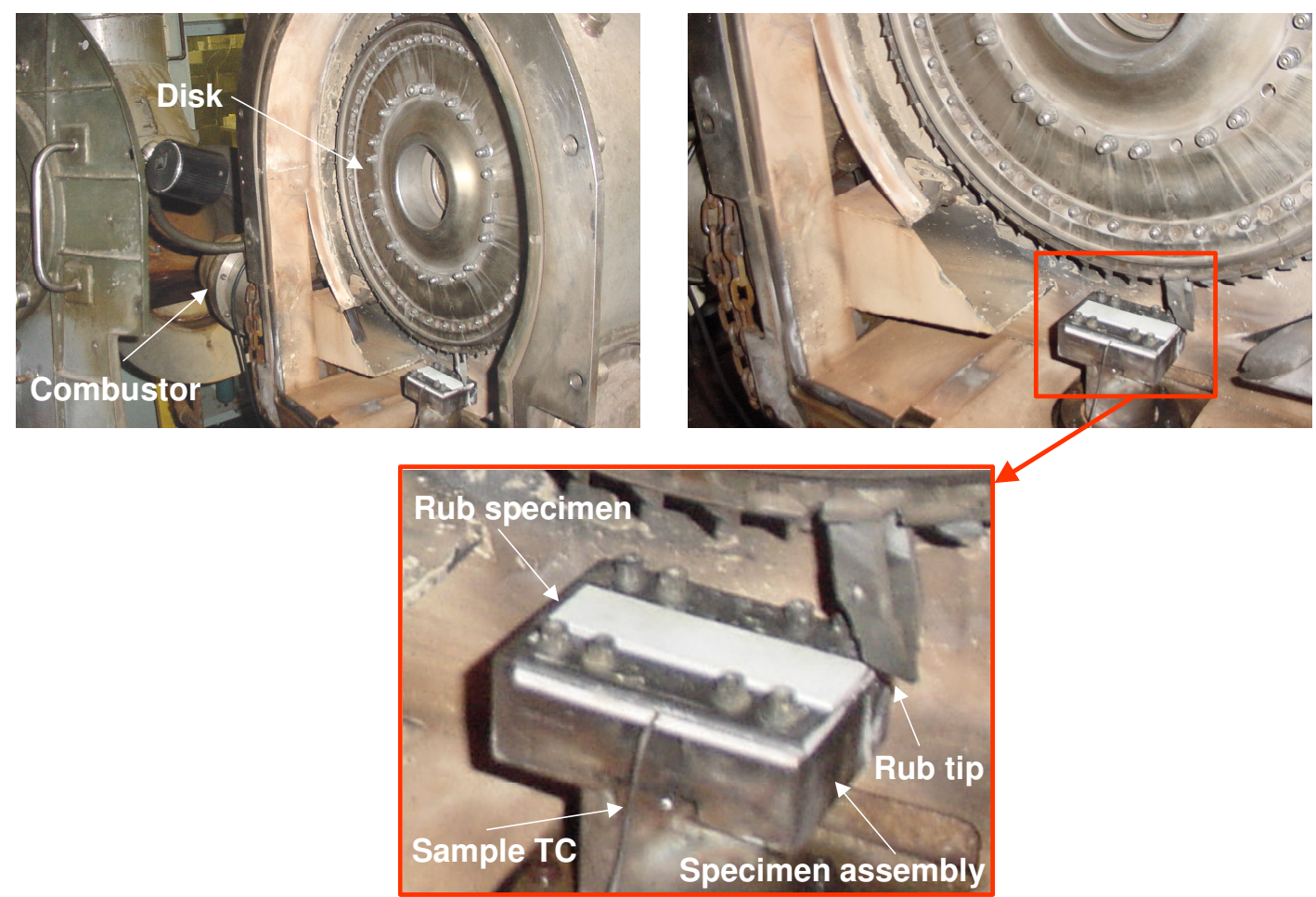

Figure 3-59. Photographs of the blade tip rub test rig showing the test specimen assembly and rub tip (metallic simulated blade) in place.

Table 3-6. Summary of Blade Tip Rub Test Results

\begin{tabular}{|c|c|c|}
\hline Sample ID & $\begin{array}{c}\text { CMC Sample Mass } \\
\text { Change (g) }\end{array}$ & $\begin{array}{c}\text { Blade Tip Mass } \\
\text { Change (g) }\end{array}$ \\
\hline S-31 & -0.013 & -0.116 \\
\hline S-32 & +0.629 & -0.121 \\
\hline S-33 & +0.048 & -0.024 \\
\hline S-34 & +0.006 & -0.093 \\
\hline S-35 & +0.029 & -0.029 \\
\hline S-36 & +0.031 & -0.097 \\
\hline S-37 & +0.163 & -0.025 \\
\hline S-38 & +0.068 & -0.124 \\
\hline
\end{tabular}

The data in Table 3-6 also indicates that tip weight change did not vary significantly with variation in surface temperature. However, the substrate did gain additional weight at higher surface temperature, and this may be an indication of differences between the chemical nature of the material transferred from the tip to the substrate relative to surface 
test temperature. The material transferred from tip to substrate during low-temperature tests was gray-colored and during high-temperature tests was green-colored. The increase in weight gain of the substrate during testing at elevated temperature, the relatively constant weight loss of tip material relative to temperature, and the change in color of the transferred material to green at elevated temperature, together indicate that the metal blade material transferred to the substrate during elevated temperature rub tests was oxidized.

The rub samples and blade tips were examined visually following rub testing. With the exception of the uncoated slurry cast sample all of the blade tips showed very similar wear patterns. In the case of the uncoated slurry cast sample the blade tip had exaggerated wear markings caused by the rougher surface of the slurry cast CMC sample.

Figure 3-60 and Figure 3-61 show the CMC sample surfaces from the rub test of uncoated prepreg and slurry cast CMC, respectively. It is difficult to tell from visual observation if any tip material was transferred to the prepreg MI substrate, and weight change data indicated that it was not. Conversely, substantial tip alloy was noted on the uncoated slurry cast substrate after rub testing, as shown in Figure 3-61. The transferred alloy was oxidized during the rub event, as evidenced by the greenish color.
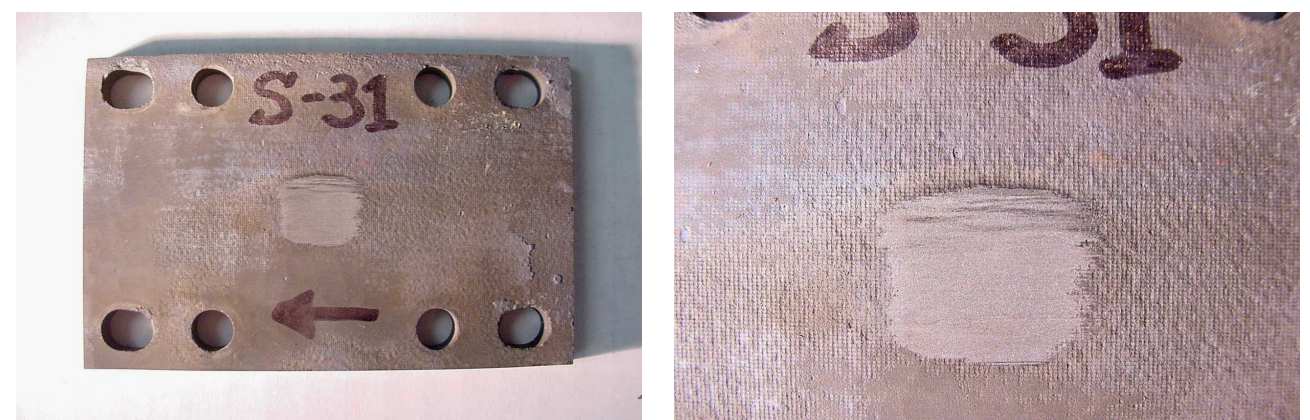

Figure 3-60. Photographs of rub specimen S-31 (prepreg MI CMC substrate with no EBC) following rub testing at $\sim 65^{\circ} \mathrm{C}$ substrate surface temperature with a $0.38 \mathrm{~mm}$ incursion distance. 

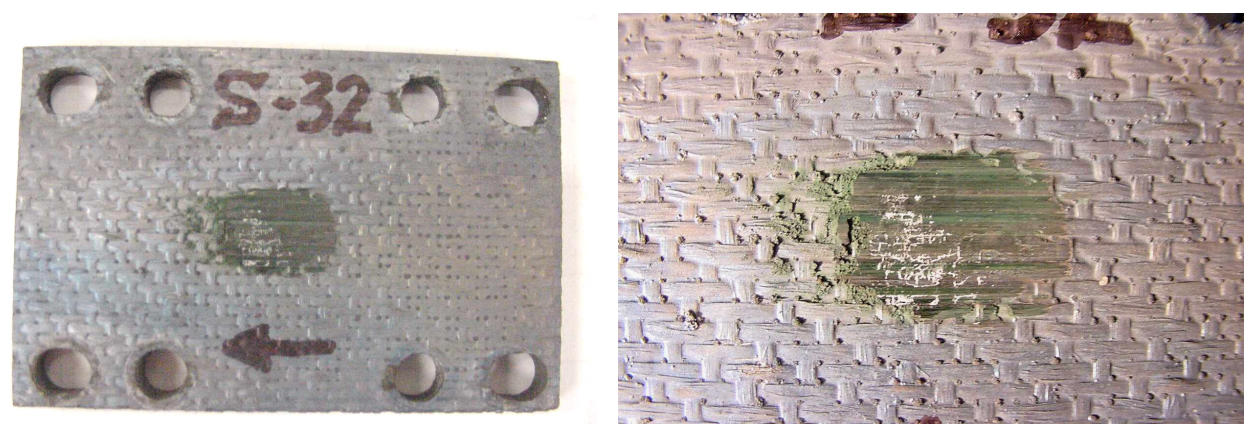

Figure 3-61. Photographs of rub specimen S-32 (slurry cast substrate with no EBC) following rub testing at $1200^{\circ} \mathrm{C}$ substrate surface temperature with a $0.38 \mathrm{~mm}$ incursion distance.

Figure 3-62 shows photographs of sample S36 (prepreg MI with EBC coating) following rub testing at $1200^{\circ} \mathrm{C}$ with an incursion distances of $0.13 \mathrm{~mm}$. Figure 3-63 shows photographs of sample S38 (slurry cast MI with EBC coating) following rub testing under the same conditions. These wear surfaces, along with the wear surfaces from the other EBC-coated specimens, indicated the following similar trends:

- All rub tests of CMC with EBC coatings showed material transfer from the blade tip to the CMC sample, which was consistent with the weight change data.

- The blade tip material transferred to the $\mathrm{CMC}$ at $\sim 65^{\circ} \mathrm{C}$ was gray, and that at $1200^{\circ} \mathrm{C}$ was green. The gray-color is indicative of un-oxidized alloy being transferred and smeared over the EBC surface, and the green-color is indicative of transferred alloy having been oxidized.

- There were no failures of the EBC coatings or CMC substrates during any of the rub tests.
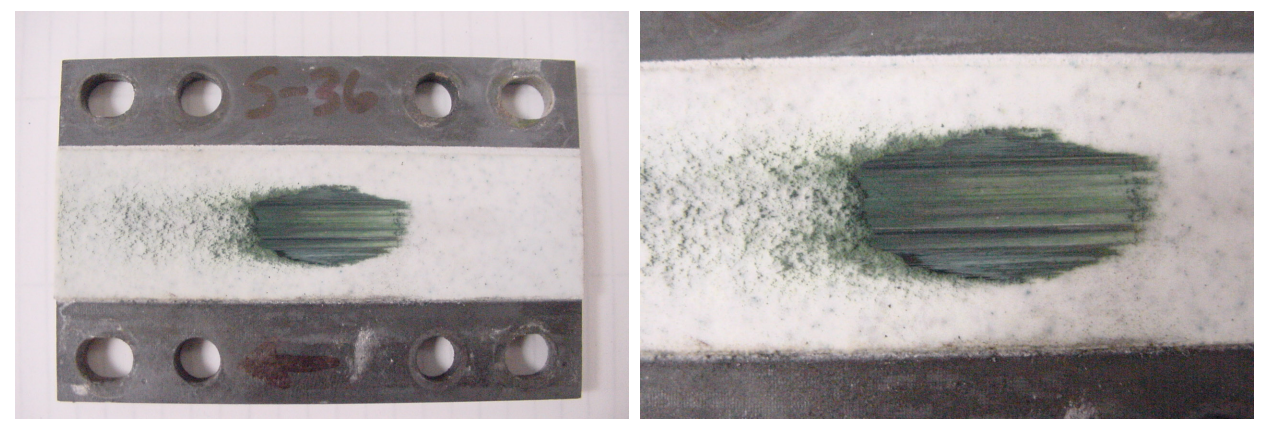

Figure 3-62. Specimen S-36; Prepreg MI composite substrate with EBC following rub testing at $1200^{\circ} \mathrm{C}$ substrate surface temperature with a $0.38 \mathrm{~mm}$ incursion distance. 

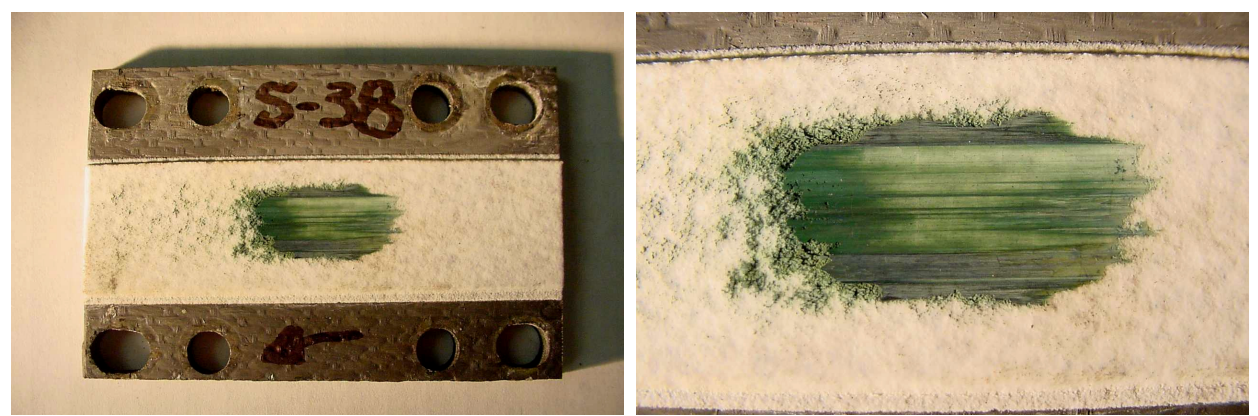

Figure 3-63. Specimen S-38; Slurry cast MI composite substrate with EBC following rub testing at $1200^{\circ} \mathrm{C}$ substrate surface temperature.

In summary, no observable macroscopic damage was done to the $\mathrm{EBC}$ or $\mathrm{CMC}$ substrate during the rub tests with a DS GTD-111 simulated turbine blade. Post-rub microstructural evaluations were done on several of the rubbed CMC samples, but no evidence for vertical cracking of the $\mathrm{EBC}$ or damage to the $\mathrm{CMC}$ was found. One must keep in mind, however, that all tests were performed on rigidly supported, flat CMC test samples. Blade tip rub of an actual CMC shroud assembly would induce additional stresses into the shroud and attachments such that the shroud assembly could be damaged to a greater degree than indicated in these simple material tests. Nevertheless, the risk of a shroud failure due to a bucket tip rub was judged to be acceptable to proceed to the field engine test.

\subsubsection{CMC Shroud and Damper Mechanism Wear Testing}

There are numerous opportunities for material wear in the normal operation of the shroud system. During thermal cycling of the shroud it is necessary that there be relative motion of the different subcomponents, which are made from a variety of materials. Unfortunately little is known of the wear behavior of some of these material couples at elevated temperatures. For this reason a wear testing program was conducted with ORNL to look at the wear properties of candidate materials for the outer shroud, piston, damper blocks and CMC inner shrouds.

The tests were a reciprocal pin-on-disk type test, and all were conducted at $1000^{\circ} \mathrm{C}$ in air with a total load of $1500 \mathrm{~g}$. Four different material couples were tested: two candidate damper block alloys (pins) were tested against EBC-coated CMC (disk) to simulate the damper block-to-inner shroud contact behavior, and the damper piston alloy (pin) was tested against two disk alloys, one of which was the outer shroud block alloy and the other was one of the damper block alloys.

The extent of wear of the disk materials was determined from measurement of the wear track area and depth. Wear of the pins was to be determined by weight change, but this proved to be unreliable because of pin oxidation. Wear tests were run for periods of 2, 5 and 10 hours. The wear data are summarized in Table 3-7, where the wear rates listed were calculated as shown in equation 1 .

$$
\text { Wear Rate }\left(\mathrm{m}^{3} / \mathrm{N}-\mathrm{m}\right)=\frac{\text { Disk wear volume }}{[\text { Load } / \text { Pin contact area }]^{*}[\text { Total sliding distance }]}
$$


Although the data were not as consistent as had been hoped (i.e. the wear rates were much larger at $10 \mathrm{~h}$ than would have been expected based on the $2 \mathrm{~h}$ and $5 \mathrm{~h}$ data), they did show some valuable trends. First, damper block alloy \#2 caused much greater wear of the EBC/CMC material than did damper block alloy \#1. Damper block alloy \#1 also displayed much less oxidation during these tests than the other alloys. These data were valuable for the overall selection of damper block alloy \#1 for the rig and engine tests.

With the exception of the PA-DB1 couple at 10 hours, the other couples showed relatively minor amounts of wear. The PA-DB1 couple at 10 hours was also anomalous in that the coefficient of friction from the start of the test to the end of the test remained relatively high $(>0.6)$ whereas at 2 and 5 hours this same couple showed a reduction in the coefficient of friction to below 0.3. Ignoring the anomalous 10 hour result, the candidate piston alloy (PA) did not cause unacceptable wear with either the damper block alloy \#1 (DB1) or the candidate outer shroud block alloy (OSB). These results helped to confirm the selection of these alloys for the shroud system.

Table 3-7. Summary of Pin-On-Disk Wear Test Data from ORNL

\begin{tabular}{|c|c|c|c|c|c|}
\hline \multicolumn{2}{|l|}{ Pin material $\dagger$} & DB1 & DB2 & PA & PA \\
\hline \multicolumn{2}{|l|}{ Disk material $\ddagger$} & $\mathrm{EBC} / \mathrm{CMC}$ & $\mathrm{EBC} / \mathrm{CMC}$ & DB1 & OSB \\
\hline Disk wear volume & $2 \mathrm{~h}$ & 0.17 & 18.71 & 0.56 & 0.05 \\
\hline$\left(\mathrm{mm}^{3}\right)$ & $5 \mathrm{~h}$ & 0.44 & 27.29 & 1.31 & 0.03 \\
\hline & $10 \mathrm{~h}$ & 13.48 & 215.79 & 52.60 & 2.04 \\
\hline
\end{tabular}

$\dagger$ Pin materials: DB1 - Damper block alloy \#1, DB2 - Damper block alloy \#2, PA - Piston Alloy

† Disk materials: EBC/CMC - EBC-coated prepreg MI CMC, DB1 - Damper block alloy \#1, OSB Outer shroud block alloy

\subsubsection{Task 2.7 - NDE Technique Validation}

The initial primary goal of this task was to generate prepreg and slurry cast MI CMC panels with known seeded defects, which would then be used as tools for evaluating and calibrating various NDE techniques. The most appropriate technique would then be used for inspection of CMC hardware to be used in the rig and engine tests. However, the need for NDE inspection outpaced the progress in validation under this task, such that IR thermography was used quite extensively in the characterization of the shrouds fabricated for engine testing.

Intentional fabrication of defects of known size, shape and location proved to be much more difficult than anticipated. Initial work focused on simulating delamination defects. A method was developed at GRC for impregnating a polymer cloth with BN slurry. Pieces of the cloth were then incorporated between plies of the prepreg CMC during lay-up. The loose $\mathrm{BN}$ powder remaining between the plies following binder burn-out was only 
moderately effective at preventing subsequent infiltration of the "delamination" with silicon during the melt infiltration step.

Figure 3-64 shows the IR NDE image of a panel fabricated with such BN inserts, where the yellow and blue indications correspond to the simulated delaminations. Very small $(3 \mathrm{~mm}$ in diameter) simulated delaminations at the right side of the panel were not detected. Subsequent sectioning of the panel showed that the smaller defects had been partially filled with silicon during melt infiltration, and thus it was not surprising that they did not show up in the IR images. Laser ultrasound images of this panel were much less distinct, leading to the dropping of that technique from consideration fairly early in the program.

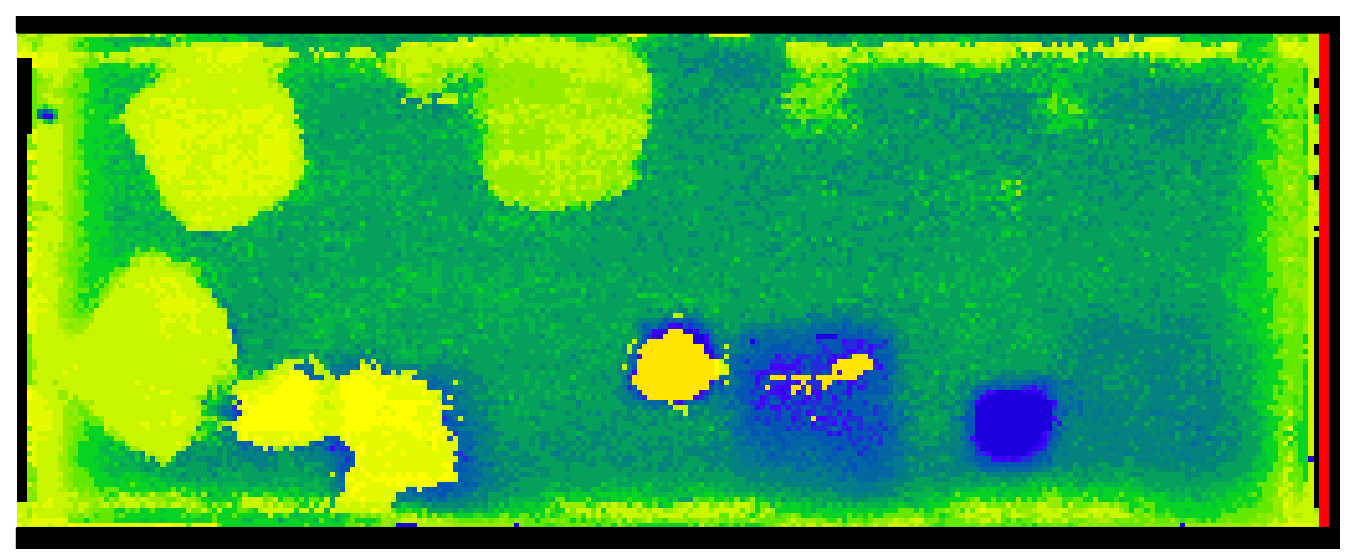

Figure 3-64. Transient IR image of the trial prepreg "delamination standard". The yellow and blue squares indicate the presence of the simulated delaminations.

CCP fabricated a similar delamination standard panel using the slurry cast MI process, but they chose to use a shim of carbon as the defect source. Initial IR NDE inspections of the panel showed no detectable defects in the positions of the carbon shims, as shown in Figure 3-65. Evidently the thermal diffusivity of the carbon shims, which remained intact through the CMC fabrication process, was not sufficiently different enough from the surrounding $\mathrm{CMC}$ to perturb the thermal wave.

CCP subsequently sectioned the panel to expose the carbon shims near the edge, and also drilled a hole to the shim in the panel center, and then subjected the panel to an oxidizing heat treatment. Re-inspection following oxidation of the carbon shims showed that the intentional defects were now detectable, but were still relatively indistinct and partly hidden by normal processing defects. 

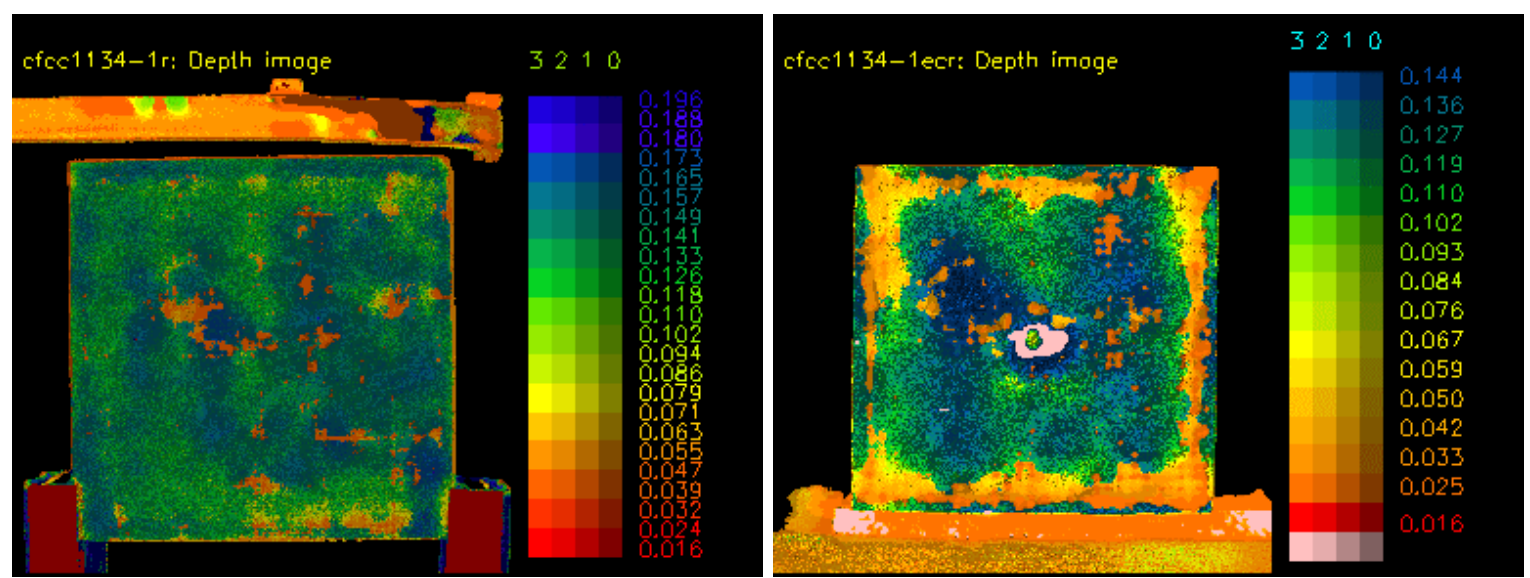

Figure 3-65. IR thermography images of the CCP delamination standard panel both as fabricated (left) and after cutting and oxidation of the internal carbon shims (right).

Shroud for rig and engine testing were now being fabricated and were available for destructive characterization. Consequently the focus of this task shifted away from the fabrication of NDE standards and more to the comparison of NDE images with cut-up shroud components in order to understand the defect detectability limits.

\subsubsection{Task 2.8 - EBC Development}

An $\mathrm{EBC}$ is required for gas turbine applications due to the oxidation/volatilization behavior of silicon-based non-oxide materials, such as $\mathrm{Si}, \mathrm{SiC}, \mathrm{Si}_{3} \mathrm{~N}_{4}$, etc. Such materials rely on the formation of a protective oxide layer of $\mathrm{SiO}_{2}$, which is a very effective oxygen diffusion barrier. Consequently oxidation proceeds with relatively slow parabolic kinetics, with the reaction depth being proportional to the square root of time. The oxidation rate is higher in moist environments than in dry environments, but even in the worst case the amount of SiC that would be consumed in 8,000 hours at $1200^{\circ} \mathrm{C}$ by normal oxidation would be less than $40 \mu \mathrm{m}$ [12], which would be perfectly acceptable for an industrial gas turbine component.

However, it has been well established [13, 14] that silica forms volatile silicon hydroxide species in the presence of water vapor at high temperatures. In typical moist air environments the equilibrium concentration of $\mathrm{Si}(\mathrm{OH})$ x species is sufficiently low that in stagnant or low velocity gas streams the surface boundary layer is a sufficient barrier to limit the amount of hydroxides formed, and thus prevent recession of the $\mathrm{SiC}$ material. However, in gas turbines the pressure of water vapor in the combustion gas is in the range of 0.5 to 1 bar and the gas velocity is near sonic velocity. Under these conditions the volatilization rate of the protective silica layer occurs at a sufficient rate that paralinear oxidation of the base $\mathrm{SiC}$ or $\mathrm{Si}_{3} \mathrm{~N}_{4}$ is observed. In other words, the self-limiting, parabolic oxidation process is replaced by a much faster constant rate oxidation/recession process. The rate of the recession process depends on the specifics of the turbine operating conditions, including gas velocity, water vapor content of the combustion gases and material temperature, but in extreme conditions recession can be as high as $0.5 \mathrm{~mm}$ per 1000 
hours of exposure. The desired life of the CMC components in a large industrial turbine is of the order of 24,000 to 48,000 hours. Since the desired wall thickness of these components is only a few millimeters such a material loss rate would be unacceptable. Consequently it is necessary that the surface of the CMC material be protected from water vapor within the turbine in order to prevent such volatilization/recession, and that is precisely the function of the EBC coating.

The main goal of this task was to optimize the existing environmental barrier coating (EBC) system so that it could be used on the shrouds in the initial 8,000 hour engine test with reasonable assurance of its success. At the start of this program a 3-layer EBC coating and plasma spray deposition process had been developed under the NASA-funded High Speed Civil Transport/Enabling Propulsion Materials (HSCT/EPM) program. Although it had been shown that his coating could be effective at limiting CMC volatilization from water vapor exposure, the repeatability of the deposition process and the robustness of the coating had not yet been demonstrated.

Two specific activities were performed under this task to get the EBC deposition process ready for shroud component coating. These activities were 1) optimizing the feed powder characteristics and plasma gun operating parameters to yield high density, crack-free, adherent coatings, and 2) optimization of the spray patterns and masking techniques used for coating the inner shroud components so that the coatings would have uniform thickness and microstructure over the entire shroud surface. Each of these activities is discussed below.

\subsubsection{EBC Deposition Parameter Optimization}

The EBC of interest for this task was the 3-layer coating shown in Figure 3-66. The $1^{\text {st }}$ layer of the EBC is silicon metal, which acts as a bond coat between the CMC and outer oxide coating layers, and is also an oxygen barrier to prevent oxidation of the $\mathrm{CMC}$ substrate. Direct oxidation of the $\mathrm{SiC}$-based $\mathrm{CMCs}$ gives $\mathrm{CO}_{2}$ as a reaction product, which cannot diffuse out through the upper oxide layers and therefore tends to form bubbles in that disrupt the coating. The silicon layer, which does not form any $\mathrm{CO}_{2}$ during oxidation, prevents such bubble formation.

The top coating layer is made of barium-strontium-alumino-silicate (BSAS) with the chemical formula $\left(\mathrm{Ba}_{0.5}-\mathrm{Sr}_{0.5}\right) \mathrm{Al}_{2} \mathrm{Si}_{2} \mathrm{O}_{8}$, and having the celsian crystal structure. The primary function of this layer is to prevent water vapor from reaching the silicon bond coat or $\mathrm{CMC}$ substrate, and it must therefore be hermetic. This in turn requires that the $\mathrm{EBC}$ have a coefficient of thermal expansion that is a very close match to the CMC substrate in order to prevent cracking of the coating during thermal cycling, which is one of the main reasons that BSAS was chosen for this application. Note that at the intended EBC operating temperature of $1200^{\circ} \mathrm{C}$ the diffusivity of oxygen through BSAS is high enough that it does not prevent oxidation of the silicon bond coat. 


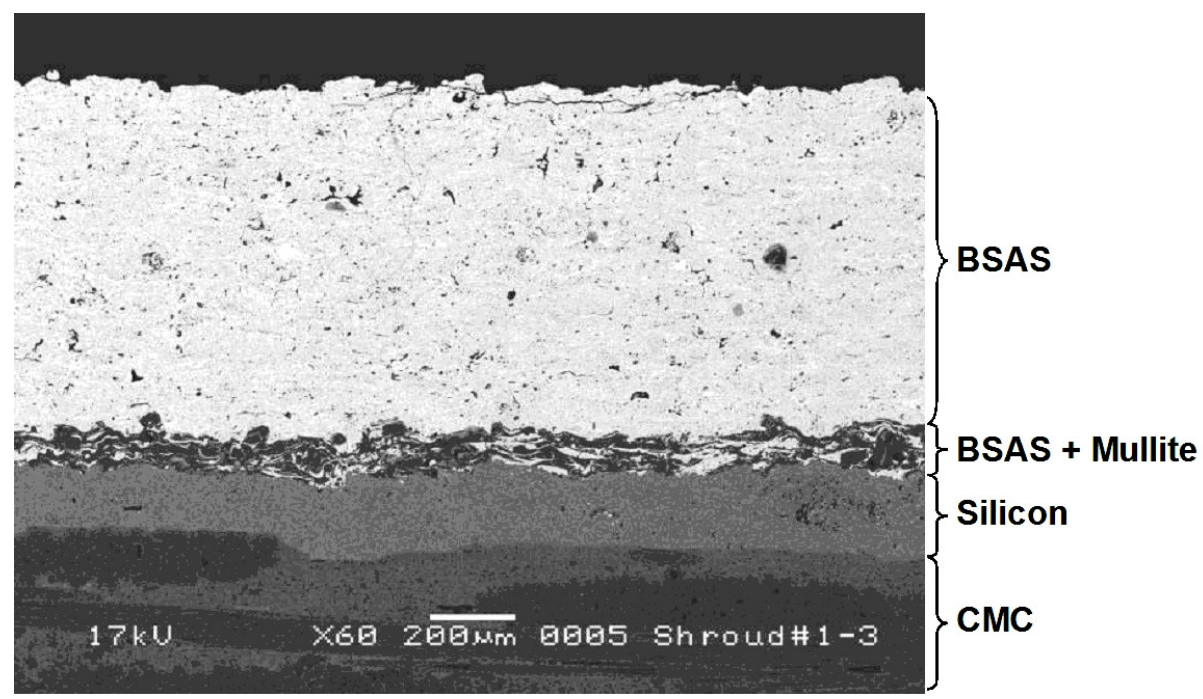

Figure 3-66. Scanning Electron Microscope (SEM) micrograph of the 3-layer EBC coating on a slurry cast CMC substrate.

It may at first seem counterintuitive to use a silicate to prevent volatilization of silica, but by careful control of the stoichiometry of this layer the activity of silica can be kept very low, and thus the tendency to form volatile $\mathrm{Si}(\mathrm{OH})_{x}$ species is greatly reduced. Consequently the BSAS layer is stable in turbine-like environments for many times longer than silica.

The middle EBC layer contains a mixture of mullite $\left(\mathrm{Al}_{6} \mathrm{Si}_{2} \mathrm{O}_{13}\right)$ and $\mathrm{BSAS}$. This layer serves as a transition layer between the substrate/bond coat and the top coating layer.

At the start of this program an EBC plasma spray deposition process had already been developed, however, the coating produced by this process tended to have low density (high porosity). During the development of this process it had been observed that under certain processing conditions that a relatively dense coating could also be deposited, but that this denser coating typically had vertical cracks in the EBC oxide layers. Such cracks would act as paths for both oxygen and water vapor to reach the bond coat and promote rapid oxidation, and thus were a microstructural feature that should be avoided. One of the goals of this subtask was to determine the range of processing conditions that lead to the formation of either porous but crack-free coatings versus the dense but vertically cracked coatings, and to hopefully identify a processing regime where dense uncracked coatings could be formed. The second major goal was to perform oxidative life testing on typical EBC specimens to demonstrate a minimum of 8000 hour EBC life in order to proceed with the field engine test.

As part of the first goal several "Design for Six Sigma" (DFSS) projects were conducted. The focus of the DFSS projects was to reduce the variability in the air plasma spray (APS) deposition of the EBC. There were two projects that addressed the type of plasma gun used and the flow rate of the powder carrier gas on EBC microstructure and thickness and on gun life. A third DFSS project consisted of a large "Design of Experiments" matrix that 
evaluated the effects of 7 additional variables on the microstructure and thickness of the deposited EBC. Methodologies for measuring substrate and particle temperatures were developed. Microstructural features such as porosity, thickness and crack density were then correlated to the processing conditions in order to determine the optimum air plasma spray process conditions.

Throughout the various DFSS projects microstructural evaluations were done on all of the EBC coatings, with particular attention to the microstructure of the BSAS layer. The qualitative inverse relationship between BSAS density and vertical crack density was verified quantitatively through these studies. Figure 3-67 shows the relationship found between vertical crack density and density of the BSAS layer. The individual deposition variables that controlled the BSAS density are highly proprietary and will not be discussed here.

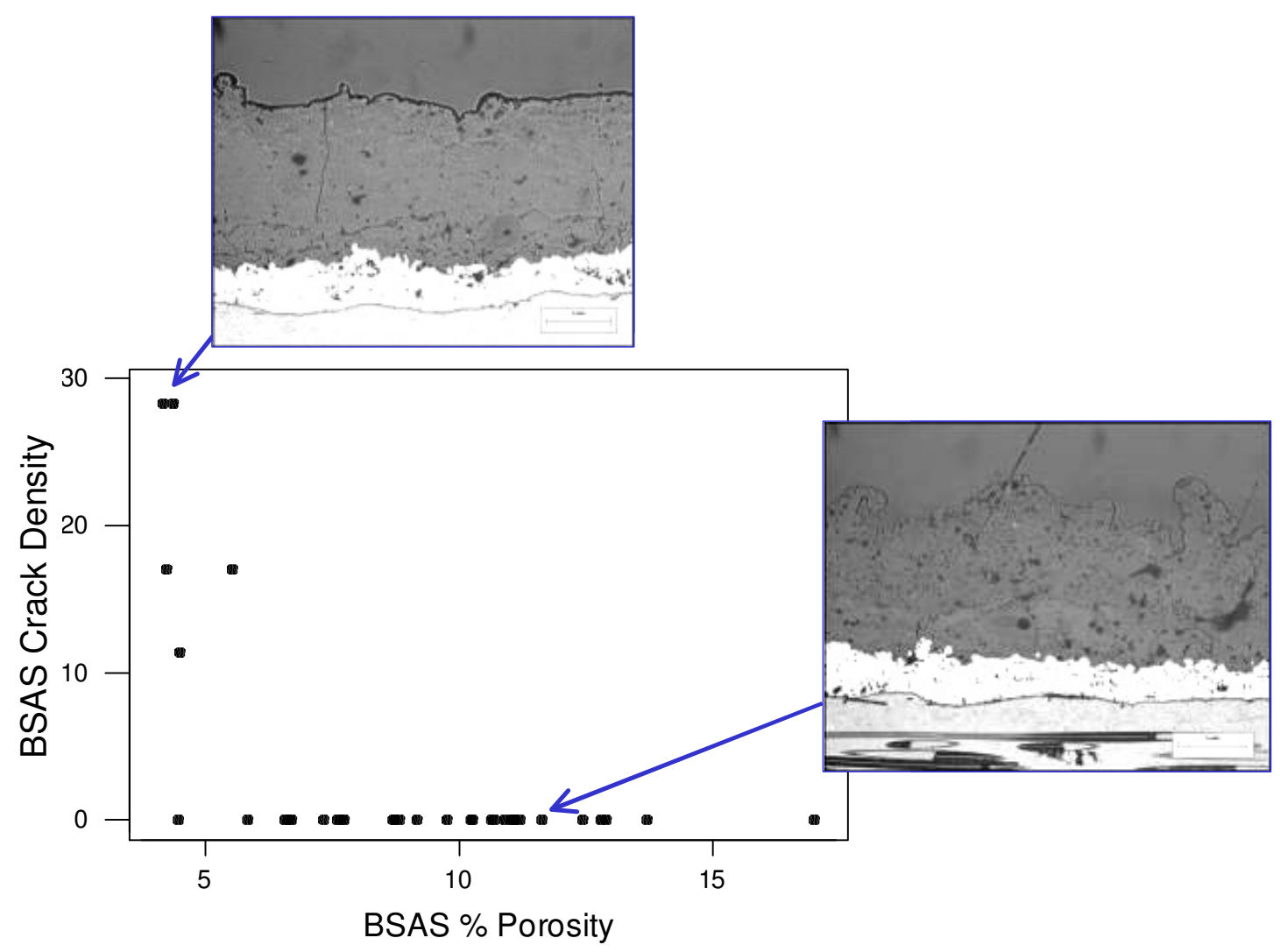

Figure 3-67. Relationship between BSAS layer porosity and vertical crack density. The insert micrographs show typical examples of a high density BSAS layer with vertical cracks, and a low density BSAS layer with no observable vertical cracking.

In parallel with the above studies, both isothermal and cyclic steam oxidation testing was performed on examples of porous and dense vertically cracked EBC coatings on both prepreg and slurry cast substrates. In the isothermal testing the sample is held at the test 
temperature (typically $1204^{\circ} \mathrm{C}$ ) in a $90 \% \mathrm{H}_{2} \mathrm{O} / 10 \% \mathrm{O}_{2}$ atmosphere. In cyclic testing the samples are exposed to similar conditions, but every 2 hours the sample is removed from the furnace for 10 minutes to simulate a turbine on-off cycle. The specimen is then reinserted into the furnace and the cycle repeated. Only the time at temperature is counted as exposure time for the cyclic steam furnace test.

Testing with the cyclic exposure test generally proceeded until a coating spallation was observed. Microstructural examination of the samples after testing was generally compromised by the loss of the EBC coating. However, meaningful microstructural information could be obtained from samples removed from the isothermal steam exposure test. For instance, the oxidation thickness of the silicon bond coat was measured as a function of exposure time for uncracked EBC coatings. Discerning the thickness of the thermally grown oxide was not always straight forward since optical microscopy could not differentiate between the deposited oxide coating and the thermally grown oxide (TGO) at the bond coat interface. Similarly there was insufficient contrast between the TGO and mullite phase in the EBC transition layer under standard back-scattered electron imaging to be able to unambiguously measure the TGO thickness. Only with energy dispersive analysis of X-rays (EDAX) was there sufficient contrast to pick out the TGO layer, as shown in Figure 3-68.

Isothermal oxidation tests were run on both prepreg and slurry cast CMC substrates having BSAS layer thicknesses of $0.13 \mathrm{~mm}$ and $0.25 \mathrm{~mm}$. Samples were removed from furnace exposure and the TGO thickness analyzed after 2500 and 8000 hours of exposure. Results of these measurements are shown in Figure 3-69 along with results from some earlier testing from the CFCC program.

In Figure 3-69 the expected oxidation rates of uncoated silicon in both high oxygen and high water vapor atmospheres [12] are shown compared to the isothermal oxidation data on the EBC-coated CMC samples. The oxidation rates of the EBC bond coats were clearly higher than predicted for dry oxidation of silicon. There are two possible explanations for this behavior: 1) that the EBC is not an effective water vapor barrier and water was still reaching the bond coat and enhancing the oxidation rate, or 2) that the oxidation product formed on the EBC bond coat was not as effective a barrier to oxygen diffusion as the oxide formed on pure silicon.

Further evidence for the second mechanism was found at the longest exposure times. At 8000 hours there was a distinct reaction layer formed between the thermally grown oxide and the BSAS phase in the transition layer. As shown in Figure 3-70, the TGO directly adjacent to the bond coat was a pure $\mathrm{SiO}_{2}$, but that a significant portion of the TGO had a composition that was a mixture of $\mathrm{SiO}_{2}$ and $\mathrm{BSAS}$. It is likely that the constituents of BSAS were slowly dissolving in the $\mathrm{SiO}_{2}$ TGO phase, leading to the formation of a bariumalumino-silicate glass. Since the addition of any element to pure $\mathrm{SiO}_{2}$ glass is known to increase the oxygen diffusivity of the glass, the reaction product would be expected to be less protective than a pure $\mathrm{SiO}_{2} \mathrm{TGO}$. Consequently the oxidation rate of the $\mathrm{EBC}$ bond coat would be expected to be higher than the oxidation rate of pure silicon. 

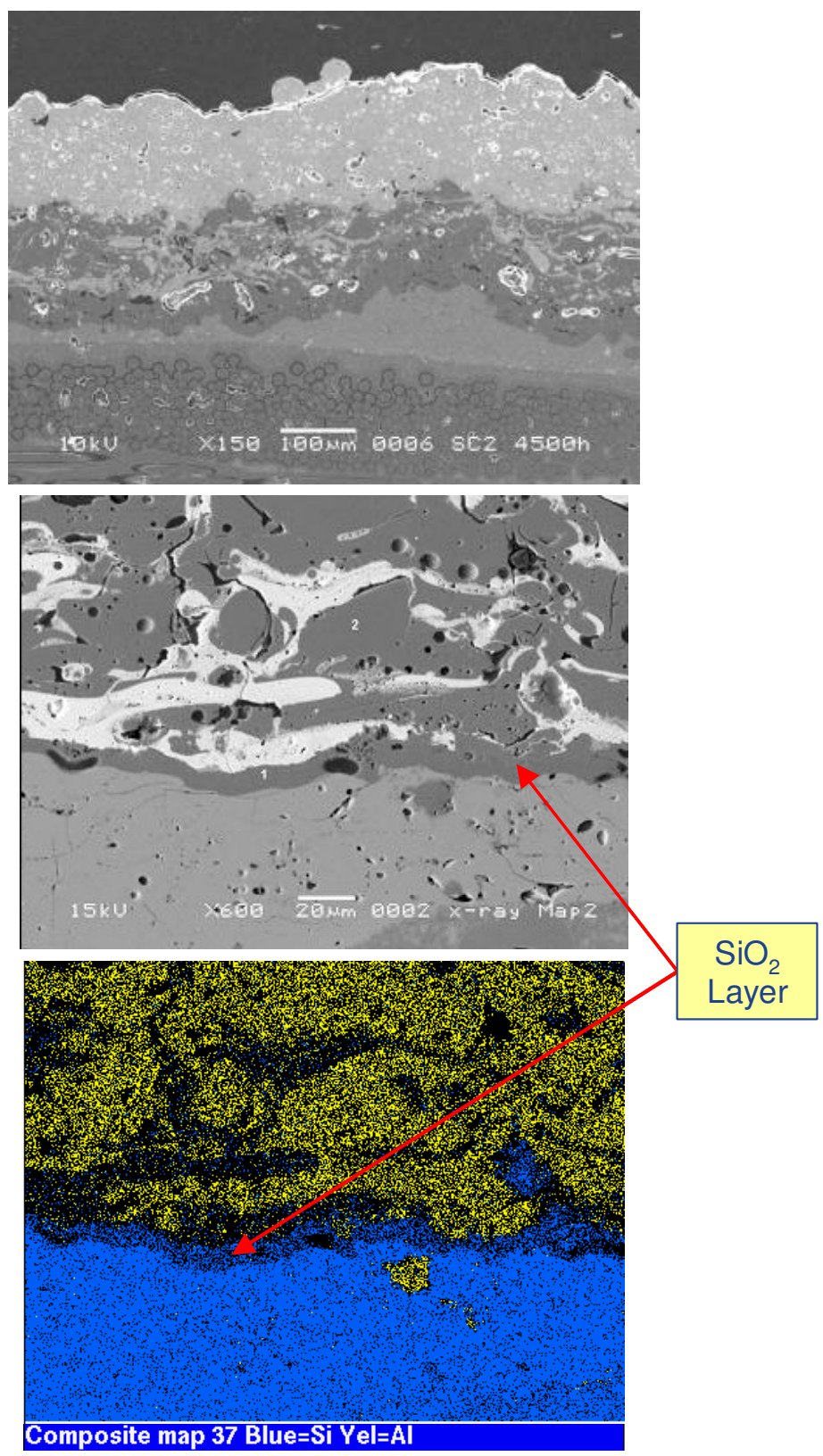

Figure 3-68. Examples of SEM micrographs of samples from the isothermal steam test after 2500 hours oxidation. Top - back-scattered electron micrograph of the full coating and slurry cast CMC substrate; Middle - higher magnification micrograph of the bond coat-to-transition layer interface; Bottom - EDAX elemental map of the interface region region showing the TGO layer (depleted in silicon relative to the bond coat, but without the Al that was present in the BSAS plus muullite transition layer). 


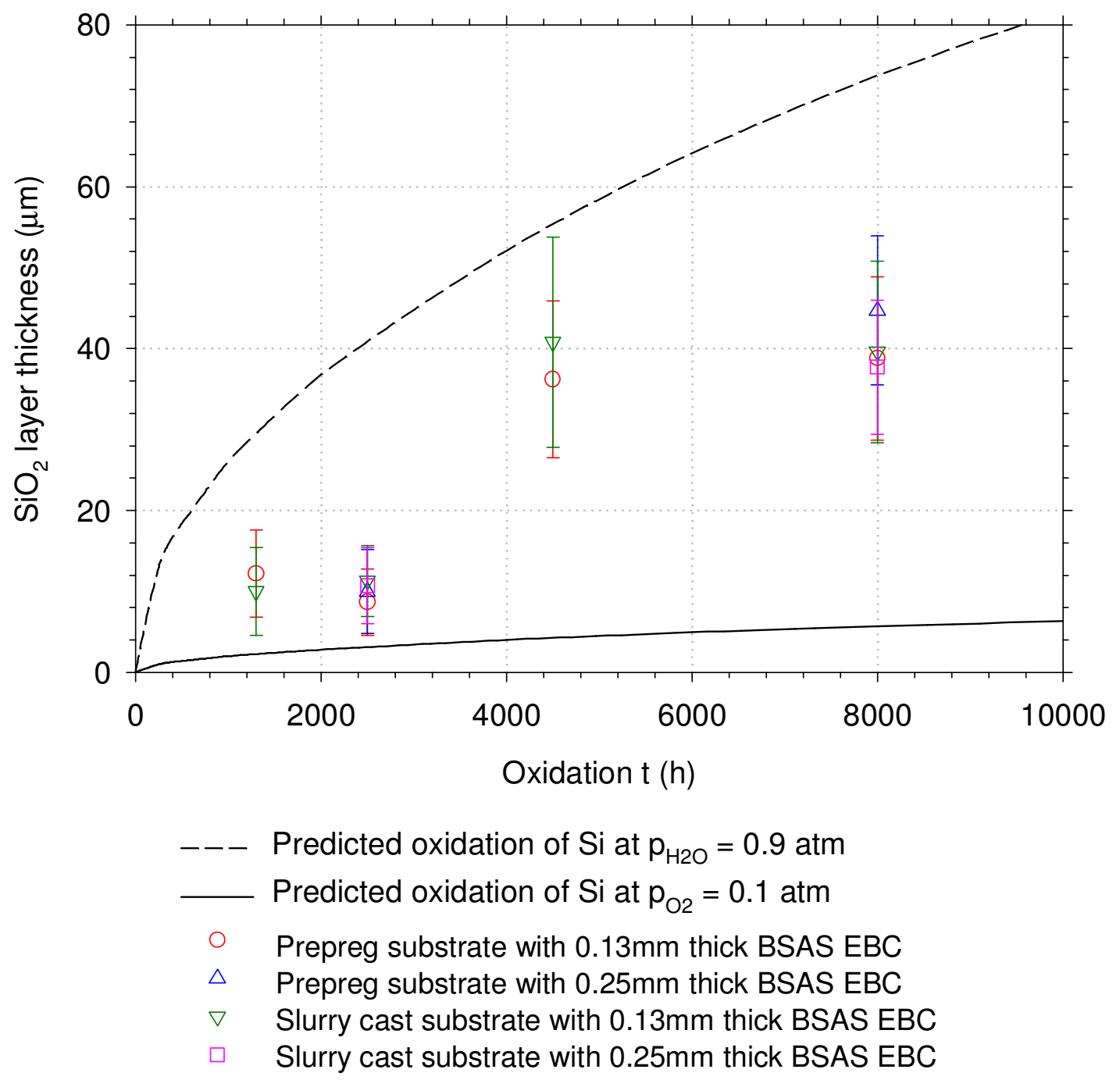

Figure 3-69. Bond coat oxide thickness as a function of exposure time in the isothermal steam test. Data points at 1300 and 4500 hours are from an older version of the EBC coating (data determined under the CFCC program) whereas the data points at 2500 and 8000 hours are for newer coatings deposited under this program. 

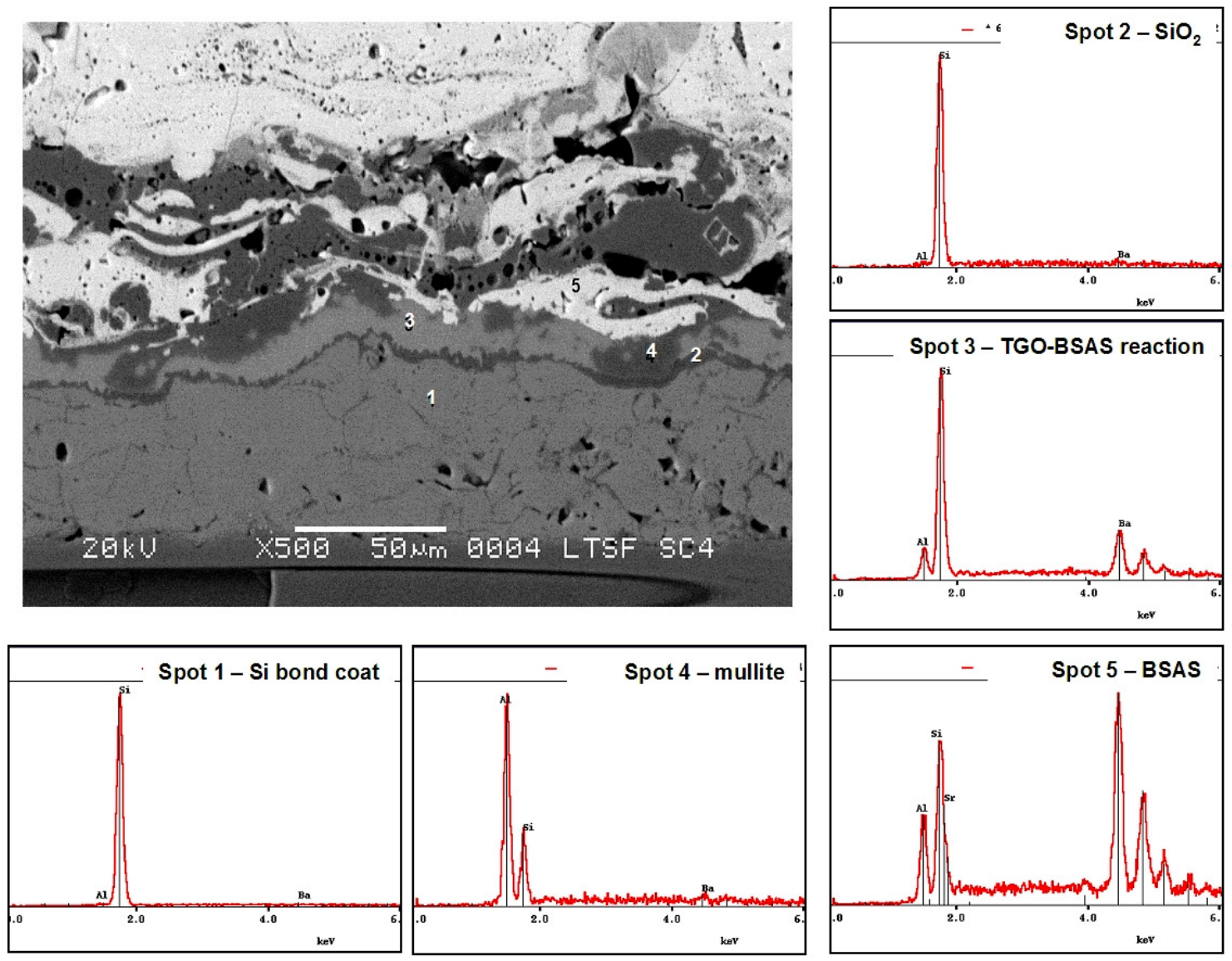

Figure 3-70. Microstructural and EDAX chemical analysis of the TGO layer formed on the EBC bond coat after 8000 hours isothermal steam exposure. The micrograph shows the interface between the EBC bond coat, at the bottom, and the transition layer coating at the top. EDAX spectra show that in addition to the normal EBC phases ( $\mathrm{Si}$ bond coat at spot 1, BSAS at spot 5 and mullite at spot 4) that there are two oxidation reaction products $\left(\mathrm{SiO}_{2}\right.$ at spot 2 and a reaction product of $\mathrm{SiO}_{2}$ and BSAS at spot 3).

\subsubsection{Shroud Coating Optimization}

Most of the investigations discussed above utilized flat panel specimens for EBC deposition and evaluation. The goal of this task was to utilize that learning to optimize the coating process for coating actual CMC inner shroud components. This effort involved the design and fabrication of fixtures for holding the shrouds, optimizing configurations for masking during the spray process, programming of the thermal spray robotic system, and evaluating the results of the thermal spray process on trial shrouds.

The spraying and microstructural analysis of the trial shrouds proved invaluable as feedback for optimizing the spray patterns and gun parameters. Overall nine shrouds were coated with $\mathrm{EBC}$ and then destructively characterized in order to measure the coating thickness and evaluate the EBC microstructure over the entire shroud surface. Figure 3-71 
shows a photograph of one of the trial shrouds after EBC coating and sectioning for coating analysis. In general the microstructure of the EBC on these trial shrouds, as shown in Figure 3-72, was very uniform with low residual porosity and no indications of vertical cracking, which is testament to the effectiveness of the coating deposition optimization studies described above.

Coating thickness was measured via metallographic examination of the coatings of the various shroud sections shown in Figure 3-71. Variation in EBC coating thickness is evident in the micrographs shown in Figure 3-73, which were taken at different locations along section \#6 and are a direct result of the intentional variation of deposition conditions used in this region of the shroud. Quantitative measurements of this EBC layer thickness variation as a function of position on the shroud, as shown in Figure 3-74, were used to derive transfer functions between the local deposition parameters and layer thickness. This information, along with that from the EBC deposition optimization studies described above, were used to define an optimum coating process for coating of the shrouds for the rig tests.

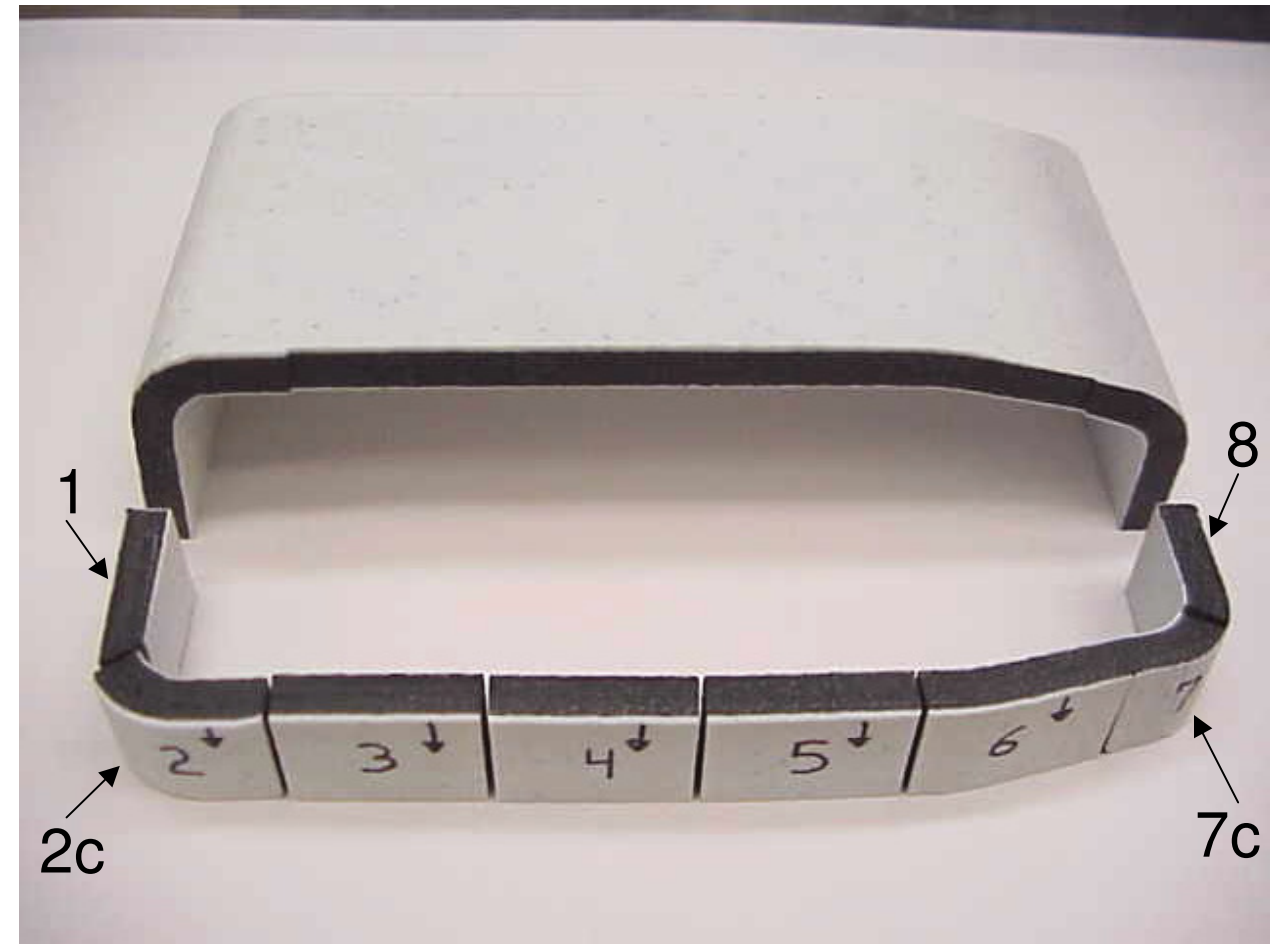

Figure 3-71. Photograph of one of the shrouds used for EBC coating trials showing how it was sectioned for metallographic characterization of the coating thickness and microstructure. 


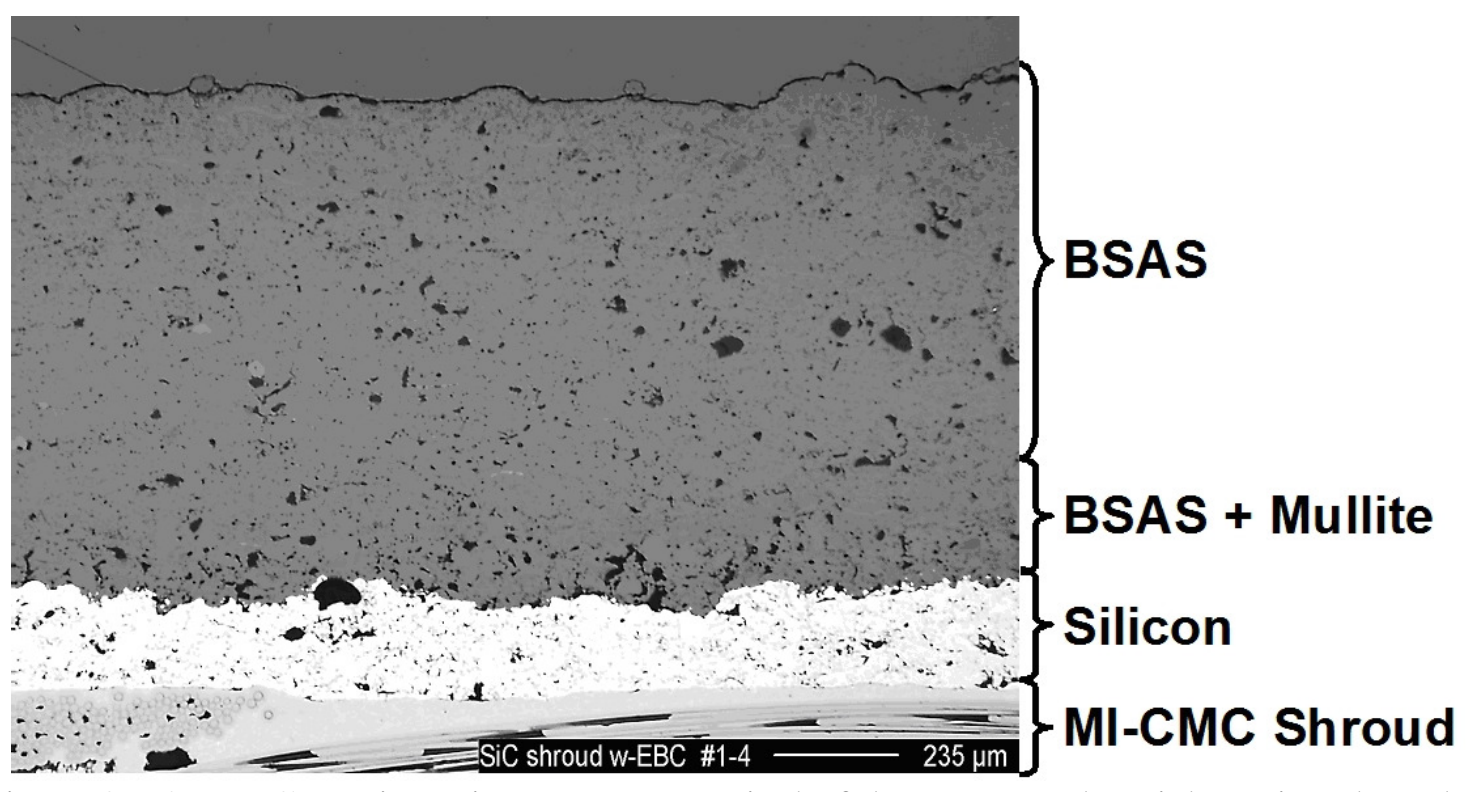

Figure 3-72. EBC coating microstructure typical of that seen on the trial coating shrouds, showing relatively low and uniform porosity and no evidence of vertical cracking.

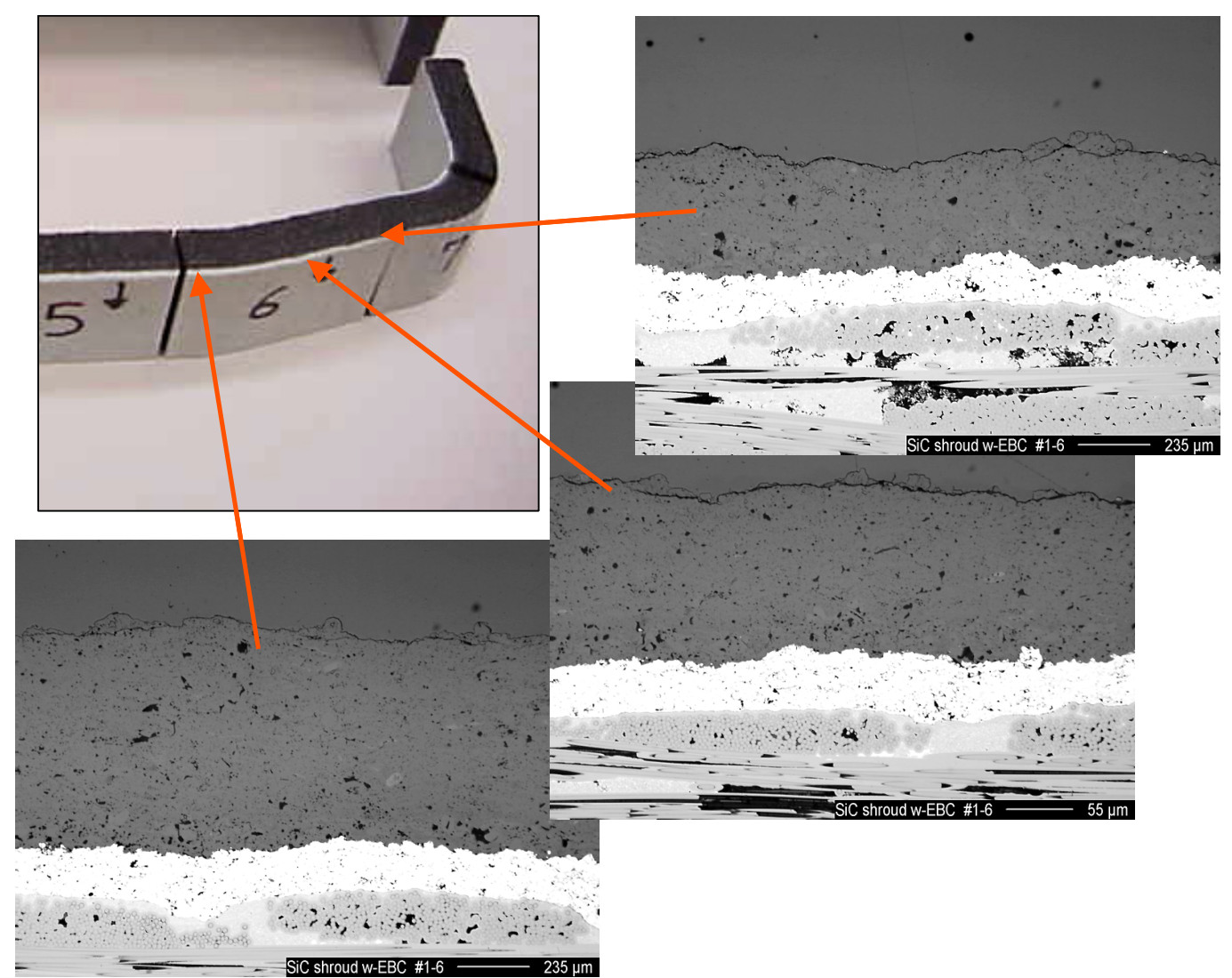

Figure 3-73. Micrographs of EBC coatings taken from trial shroud section \#6 showing variation of EBC thickness that resulted from varying the thermal spray deposition conditions across this region. 


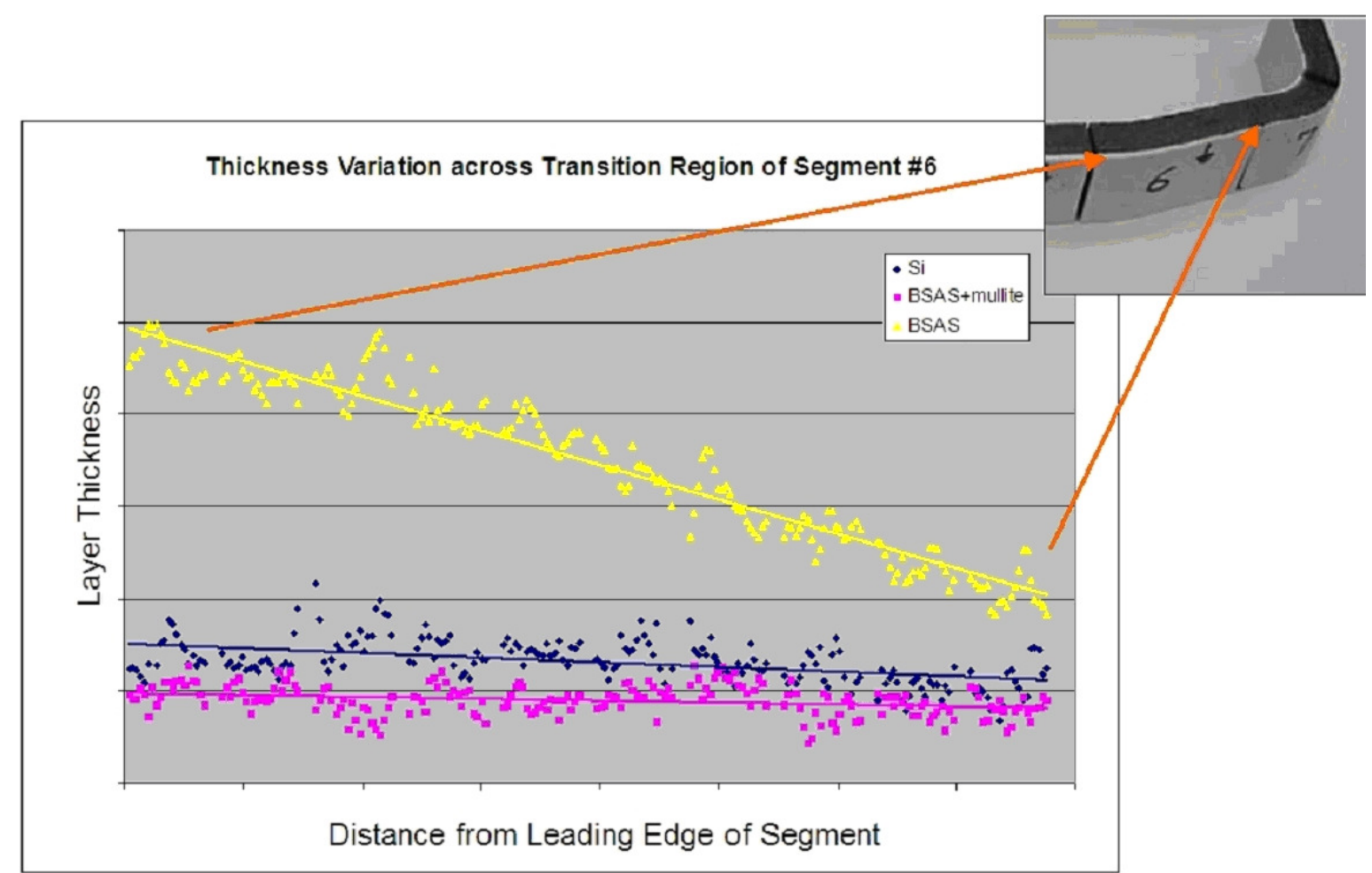

Figure 3-74. Quantitative variation of EBC layer thickness across trial shroud section \#6 as a result of intentional EBC deposition condition changes across this section.

One particularly challenging region on the shrouds for application of the EBC coating was around the attachment holes on the forward and aft flanges. It was desired to have EBC coating up to the edges of the holes, but not within the holes. A hole masking technique was therefore developed to allow for coating right up to the edges of the holes without filling the holes with overspray.

The technique used was to coat the hole surfaces with an epoxy resin prior to thermal spraying the EBC. The epoxy would partially decompose under the plasma plume, and thus deposition of the EBC material on the hole was minimized. The remnants of epoxy would be oxidized away during the normal post-deposition heat treatment of the EBC, so that any coating that did deposit on the epoxy would now be free-standing and could be easily brushed from the shrouds without damaging the shroud coating. A lip of EBC around the hole would occasionally be left behind, but it was easily removed by hand rubbing the hole chamfer with a conical grinding tool.

\subsubsection{Task 3.1 - Design for Engine Test}

As noted earlier, the design processes and evolution of the shroud system design were kept the same between the rig shrouds and engine shroud system so that the rig tests would 
provide an accurate prediction of shroud performance in the engine test. The design process described in Section 3.1.1 therefore equally applies to this task.

The major difference between the shroud design process for the engine test shrouds compared to that for the rig test shrouds is that the full outer shroud block, including the attachment to the turbine casing, could be used in the FEA along with the approved engine boundary conditions. Analysis of this large FEA model gave temperature, stress and modal frequency results very similar to the individual component models as used in the rig shroud design process, and thereby served as a validation of those simpler models.

One part of the design that was unique to the engine test was defining the interface between the $\mathrm{CMC}$ shrouds and the neighboring metallic shrouds. In particular the shroud-to-shroud seals in both the inner shrouds and the outer shroud blocks were different between the metallic and CMC shroud systems. Transition shroud blocks therefore had to be designed and fabricated that could accommodate these changes in sealing.

\subsubsection{Task 3.2 - Material Qualification and Inspection}

This task was dropped from the program due to resource constraints caused by the necessity of running 4 rig tests during preparations for the $1^{\text {st }}$ field engine test. Much of the technical effort planned for this task was effectively performed as part of the shroud selection process for engine test \#1, and will be described under report Section 3.1.15.

\subsubsection{Task 3.3 - Subtask B: Commercialization Plan}

The commercialization plan for CMC components in GE gas turbines is competition sensitive and highly proprietary information. Consequently the plan was not supplied to DOE in written form, but instead the plan was described verbally to the program monitors in early 2002.

\subsubsection{Task 4.1 - Outer Shroud Fabrication}

Fabrication of all the components of the outer shroud blocks was done by, or under the direction of, GE Energy. The components included the actual shroud blocks, the damper blocks, damper retaining pins, pistons, Macor washers, damper springs, spring cups and lids, shroud loss detection washers, inner shroud attachment pins, and outer shroud block seals. GE Energy also procured all the necessary instrumentation, including thermocouples and pressure sensors, to instrument the outer shroud blocks. Aerodyn Engineering was contracted to do the instrumentation installation and to set up an automated system for data logging during the engine test. 


\subsubsection{Task 4.2 - Inner Shroud Fabrication}

The goal of this task was to fabricate shrouds for the $1^{\text {st }}$ field engine test. This test was to be a "rainbow" test of shrouds, meaning that a mixture of standard metallic and newer CMC shrouds would be used in the test. This was done to minimize the expense of fabricating the new shrouds and also to minimize the risk to the engine operators, as described previously in Section 3.1. Minimizing risk to the engine operator would dictate the use of as few CMC shrouds as possible, whereas the technical goal of assessing the feasibility of the CMC shroud system would argue for a high number of CMC shrouds in order to establish statistical significance of the result. Selecting the number of CMC shrouds to include in the engine test was therefore an exercise in balancing the perceived risk of the new shrouds against the technical need.

The final compromise was to utilize nine CMC inner shrouds, corresponding to 3 full outer shroud blocks, for the test. This compromise was based primarily on the fact that the 7FA engines have 14 combustor cans and transition pieces. There is a circumferential thermal and flow gradient around the engine caused by these 14 discrete combustors. Three outer shroud blocks out of the total of 32 in the engine (corresponding to a $34^{\circ}$ arc in the shroud ring) would be needed to fully cover one period of the circumferential gradient caused by the combustors (corresponding to a $26^{\circ}$ arc of the flow path). Therefore nine CMC inner shrouds ( 3 inner shrouds per outer shroud block) would be required for the engine test.

Fabrication of the CMC inner shrouds was a relatively new procedure for both GE GRC and the two slurry cast CMC shroud vendors (Goodrich and CCP, who was at the time still Honeywell Advanced Composites, Inc.). Prior shroud fabrication under Tasks 2.2 and 2.4 had shown that the process yield for the prepreg shrouds was still relatively low, and the same was presumed of the slurry cast shroud vendors. Mechanical and microstructural characterization of sample shrouds, as will be described below, also pointed out that many of the shrouds were not suitable for engine testing. As a consequence of the poor yields significantly more shrouds were fabricated than just the nine needed for the engine test.

Fabrication of the CMC inner shrouds for engine testing was started in 2001 with the expectation that only one shroud rig test would be needed. As described in Section 3.1.7, it became necessary to run four shroud rig tests before the system design was demonstrated to be sufficiently robust to allow for the engine test. The additional year afforded by these extra rig tests made it possible to do additional shroud fabrication for the engine test. In all three distinct shroud fabrication campaigns were performed, which will be described below.

\subsubsection{Engine Shroud Fabrication Campaign \#1}

The general fabrication process for prepreg MI and slurry cast MI materials have been described previously [1, 2, 8, 9]. Detailed descriptions of the shroud fabrication processes used by GRC or the slurry cast shroud vendors would include proprietary and export controlled information, and therefore will not be discussed here. 
This first campaign of shroud fabrication was carried in June to August of 2001. At GRC fabrication was initiated on sixteen inner shrouds, of which three were rejected outright due to processing errors during fabrication. It is not known how many shrouds were initiated in production at Goodrich and CCP (at that time they were still HACI) in order to generate the four and five shrouds, respectively, that were delivered as engine test shrouds during this campaign.

As described in Section 3.1.7, the shrouds utilized for the $1^{\text {st }}$ rig test were damaged during the test. Most of the other shrouds fabricated for rig testing were subsequently used in the attachment tests and microstructural evaluations described in that Section. Rather than fabricate new shrouds for the subsequent rig tests it was decided to utilize shrouds from the engine test set for those rig tests since the designs of the $\mathrm{CMC}$ inner shrouds were identical between the rig test and engine test shroud systems. Essentially the "best" shrouds from this combined set were reserved for the engine test with "marginal" shrouds being utilized for the rig tests. The poorest quality shrouds were used for destructive microstructure and mechanical characterization or as practice shrouds for the machining and EBC coating application processes.

In order to determine which CMC inner shrouds should be preserved for engine testing and which could be used in rig tests and other characterizations a "Quality Function Deployment" (QFD) analysis was utilized. This analysis is part of the GE 6-sigma process rigor, and was used to quantitatively rank the shrouds based on NDE image quality, modal frequency response, dimensional conformance, and witness bar mechanical data. It should be noted that much of the material characterization and establishment of shroud selection criteria that went into this QFD fulfilled the many of the technical objectives of Task 3.2 as well.

All of the 22 available shrouds from the first fabrication campaign (13 GE prepreg, 5 Goodrich slurry cast and 4 CCP slurry cast) were evaluated in the QFD. Witness bars were obtained for each of the shrouds in order to measure their as-fabricated mechanical properties. For the GRC prepreg and CCP slurry cast shrouds the witness bars were cut directly from the shrouds themselves, whereas Goodrich supplied separate coupon specimens that were processed at the same time as their shrouds. Most of the witness bars were tensile tested at room temperature, with some bars being tested at $1200^{\circ} \mathrm{C}$. Tensile strength results from these witness bars are given in Table 3-8.

The relatively low matrix cracking stresses (proportional limits) of the slurry cast witness samples, especially of the CCP samples tested at $1200^{\circ} \mathrm{C}$, were initially alarming. The cracking stresses from the $\mathrm{CCP}$ coupons were all under $97 \mathrm{MPa}$ at $1200^{\circ} \mathrm{C}$, which was the lower limit of material strength assumed for shroud design purposes. The moduli for the CCP slurry cast samples were also anomalously low. These observations alone caused these CCP slurry cast shrouds to be rejected from engine test consideration.

In order to better understand the correlations between microstructure and mechanical properties of the various types of shrouds, and also to hopefully learn the cause of the poor 
mechanical properties of the CCP slurry cast shrouds, one shroud of each type was sectioned for metallographic examination. The selection was based primarily on which shroud of each set had the largest NDE indications so that sectioning of the shrouds would allow for verification of presence of defects corresponding to the indications. A diagram of how the shrouds were sectioned and a photograph of the cut-up GRC prepreg shroud are shown in Figure 3-75.

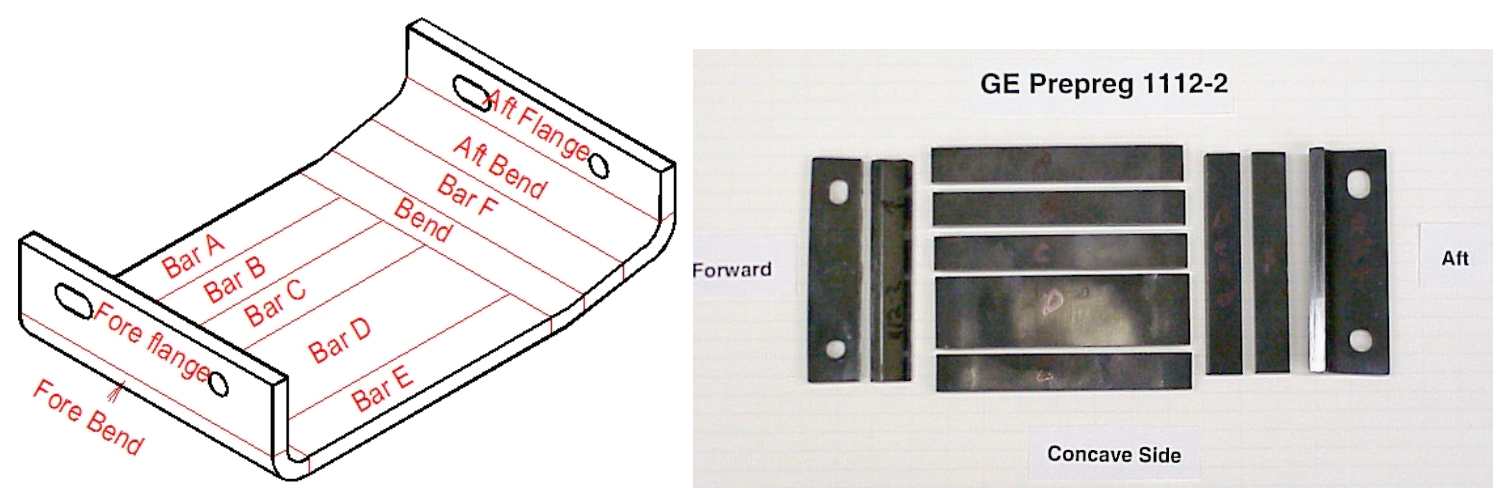

Figure 3-75. Diagram of how shrouds selected for destructive analysis were sectioned (left), and photograph of the GE prepreg shroud following sectioning (right).

Micrographs of sections cut from the hot gas path surface (center area of bar $\mathrm{C}$ in the diagram in Figure 3-75) are shown in Figure 3-76 through Figure 3-78. The prepreg shroud selected for sectioning (1112-2) showed the presence of a large "delamination" in the center flat section of the shroud from the NDE inspection. Figure 3-76 shows a montage photomicrograph taken in the defected area, and it verified the presence of an uninfiltrated ply in the composite that led to the delamination. There were also several smaller delaminations in the fore and aft bend regions of the shroud, but elsewhere the prepreg shroud showed a uniform, dense microstructure. The size and position of the large delamination was consistent with the features on the NDE image, indicating good detectability for this defect in the prepreg MI material.

A similar photomicrograph from the center of bar C of the CCP slurry cast shroud (121601-004) is shown in Figure 3-77. The CCP shrouds uniformly showed lower moduli and proportional limits in the mechanical testing of shroud witness bars, and also had lower than expected resonant frequencies. Both of these observations are consistent with a low composite density. The low density was confirmed with the cut-up, as much of the cross section of the CCP shroud was un-infiltrated. There were substantial amounts of residual porosity in the flat sections of the shroud, as shown in Figure 3-77. Moreover, there was much higher levels of porosity in the fore and aft bend regions, to the extent that the majority of composite cross section was un-infiltrated. Surprisingly, this poor infiltration and extensive porosity did not show up well on the IR NDE images taken from the shroud. 
Table 3-8. Summary of Tensile Strength Data From the CMC Engine Shroud Witness Coupons from the $1^{\text {st }}$ Shroud Fabrication Campaign

\begin{tabular}{|c|c|c|c|c|c|c|}
\hline Source & Shroud ID & Test Temp. & $\begin{array}{c}\text { Proportional } \\
\text { Limit Stress* } \\
\text { (MPa) }\end{array}$ & $\begin{array}{c}\text { Initial } \\
\text { Modulus } \\
(\mathrm{GPa})\end{array}$ & $\begin{array}{l}\text { Ultimate } \\
\text { Strength } \\
\text { (MPa) }\end{array}$ & $\begin{array}{c}\text { Strain to } \\
\text { Failure } \\
(\%)\end{array}$ \\
\hline \multirow{28}{*}{ GRC } & \multirow{2}{*}{$1106-1$} & $\mathrm{RT}^{\dagger} \dagger$ & 169 & 300 & 347 & 1.12 \\
\hline & & $\mathrm{RT}$ & 194 & 266 & 348 & 1.06 \\
\hline & \multirow[t]{2}{*}{$1106-2$} & RT & 126 & 245 & 359 & 1.08 \\
\hline & & RT & 124 & 215 & 294 & 0.96 \\
\hline & \multirow[t]{2}{*}{$1108-1$} & RT & 122 & 254 & 322 & 1.02 \\
\hline & & RT & 159 & 298 & 351 & 0.97 \\
\hline & \multirow[t]{2}{*}{$1108-2$} & RT & 193 & 287 & 283 & 0.82 \\
\hline & & RT & 149 & 256 & 304 & 0.99 \\
\hline & \multirow[t]{2}{*}{$1109-1$} & RT & 124 & 253 & 292 & 0.87 \\
\hline & & $1200^{\circ} \mathrm{C}$ & 154 & 203 & 223 & 0.38 \\
\hline & \multirow[t]{2}{*}{$1109-2$} & RT & 181 & 273 & 302 & 0.99 \\
\hline & & RT & 220 & 272 & 323 & 1.01 \\
\hline & \multirow[t]{2}{*}{$1112-1$} & RT & 176 & 265 & 354 & 1.19 \\
\hline & & RT & 205 & 296 & 295 & 0.76 \\
\hline & \multirow[t]{2}{*}{$1112-2$} & RT & 134 & 265 & 335 & 1.07 \\
\hline & & RT & 120 & 256 & 320 & 1.02 \\
\hline & \multirow[t]{2}{*}{ 1116-1 } & RT & 114 & 230 & 308 & 0.94 \\
\hline & & RT & 112 & 222 & 288 & 0.92 \\
\hline & \multirow[t]{2}{*}{$1116-2$} & RT & 117 & 218 & 274 & 0.88 \\
\hline & & RT & 105 & 194 & 279 & 0.81 \\
\hline & \multirow[t]{2}{*}{$1117-2$} & RT & 143 & 278 & 310 & 1.06 \\
\hline & & $1200^{\circ} \mathrm{C}$ & 157 & 225 & 272 & 0.56 \\
\hline & \multirow[t]{2}{*}{$1118-1$} & RT & 161 & 258 & 234 & 0.84 \\
\hline & & $1200^{\circ} \mathrm{C}$ & 148 & 217 & 254 & 0.46 \\
\hline & \multirow[t]{2}{*}{1119} & RT & 145 & 276 & 329 & 0.98 \\
\hline & & RT & 109 & 212 & 296 & 0.99 \\
\hline & \multirow[t]{2}{*}{ Average } & RT & 148 & 255 & 310 & 0.97 \\
\hline & & $1200^{\circ} \mathrm{C}$ & 153 & 215 & 250 & 0.47 \\
\hline \multirow[t]{10}{*}{$\mathrm{CCP}$} & \multirow[t]{2}{*}{ 1216-01-003 } & RT & 114 & 147 & 278 & 0.52 \\
\hline & & $1200^{\circ} \mathrm{C}$ & 77.2 & 125 & 170 & 0.32 \\
\hline & \multirow[t]{2}{*}{ 1216-01-004 } & RT & 108 & 141 & 256 & 0.59 \\
\hline & & $1200^{\circ} \mathrm{C}$ & 75.8 & 128 & 165 & 0.24 \\
\hline & \multirow[t]{2}{*}{ 1216-01-007 } & RT & 106 & 141 & 253 & 0.54 \\
\hline & & $1200^{\circ} \mathrm{C}$ & 75.8 & 133 & 173 & 0.32 \\
\hline & \multirow[t]{2}{*}{ 1216-01-008 } & RT & 115 & 145 & 286 & 0.57 \\
\hline & & $1200^{\circ} \mathrm{C}$ & 67.6 & 143 & 194 & 0.41 \\
\hline & \multirow[t]{2}{*}{ Average } & RT & 111 & 143 & 268 & 0.56 \\
\hline & & $1200^{\circ} \mathrm{C}$ & 74.1 & 132 & 176 & 0.32 \\
\hline \multirow[t]{6}{*}{ Goodrich } & \multirow[t]{4}{*}{$4104-4 * *$} & RT & 96.5 & 165 & 401 & 0.78 \\
\hline & & RT & 108 & 239 & 381 & 0.65 \\
\hline & & $1200^{\circ} \mathrm{C}$ & 125 & 160 & 308 & 0.48 \\
\hline & & $1200^{\circ} \mathrm{C}$ & 137 & 167 & 276 & 0.35 \\
\hline & Average & RT & 102 & 202 & 391 & 0.72 \\
\hline & & $1200^{\circ} \mathrm{C}$ & 131 & 163 & 292 & 0.42 \\
\hline
\end{tabular}

* Equivalent to matrix cracking stress.

$\dagger$ Room Temperature (RT)

** The witness bars from Goodrich were from a separate panel rather from the shrouds themselves. 
Figure 3-78 shows a photomicrograph from the center of bar $\mathrm{C}$ of the Goodrich slurry cast shroud (4104-1-1). In general the Goodrich shroud was better infiltrated than the CCP shroud, but the infiltration was still far from complete. The amount of porosity seen in the shroud cut-up was much higher than that seen in the witness bars supplied with the shrouds. (The Goodrich witness bars were actually processed as a separate panel at the same time as the shrouds, whereas the GRC and CCP witness bars were actually cut from the shroud components.) This discrepancy in porosity levels means that the mechanical data measured on the Goodrich witness bars was not indicative of the properties of the actual shrouds. As with the CCP shroud, this poor infiltration and extensive porosity did not show up well on the IR NDE images.

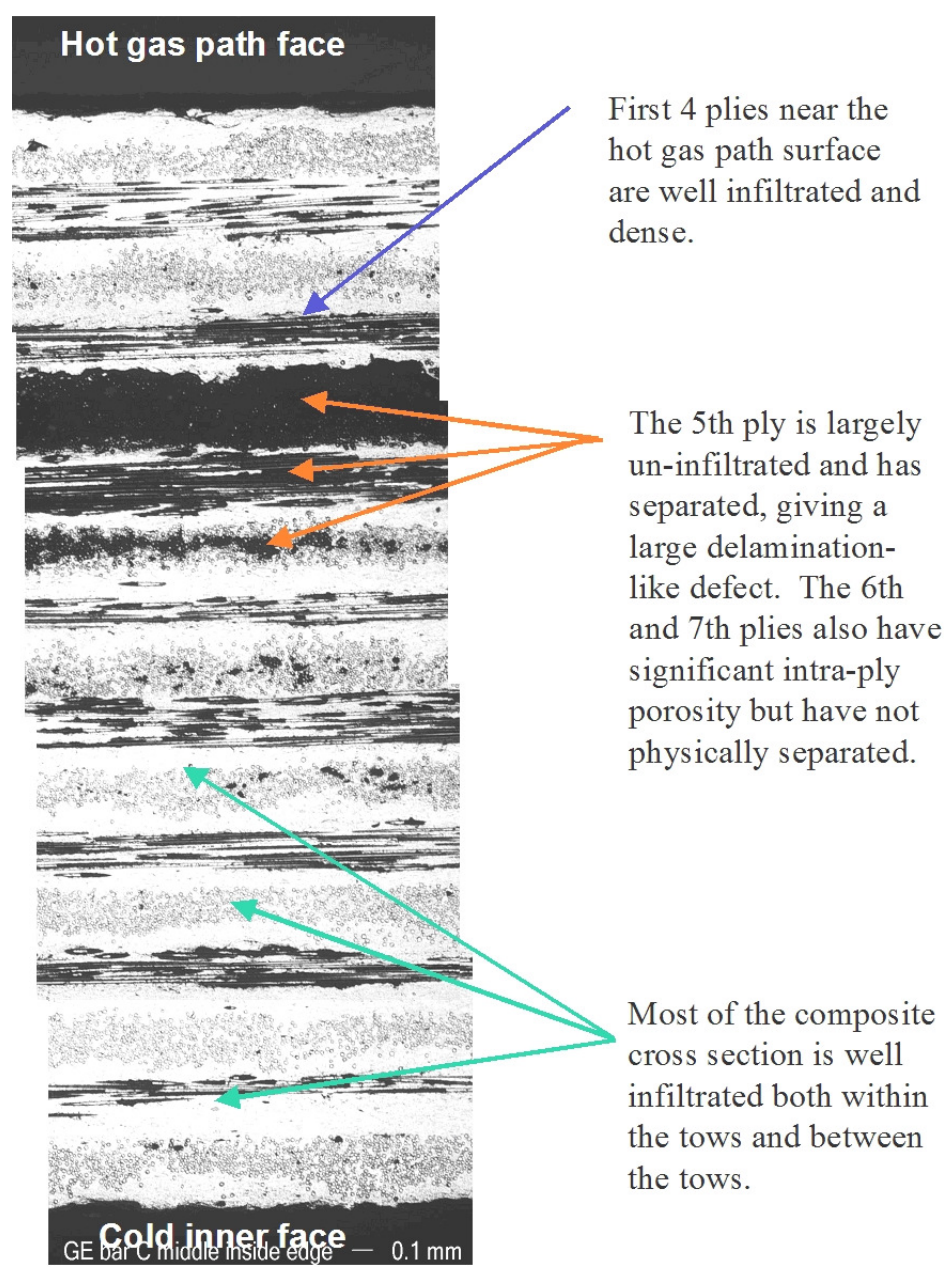

Figure 3-76. Photomicrograph montage of the cross section of the GE prepreg MI CMC shroud 1112-2 near the center of bar $\mathrm{C}$, showing the presence of a delamination resulting from poor infiltration of the $5^{\text {th }}$ ply. 
Overall, the destructive, microstructural analysis of the shrouds resulted in several important observations. First, the types of defects found in the prepreg shroud were all detected well by NDE. This particular shroud was chosen for cut-up because it had, by far, the most severe defects in the NDE images. Since there was good detectability and correlation between NDE and microstructure, it was likely that the remaining shrouds with better NDE images also had better microstructures. On the other hand, the poor infiltration and large amount of residual porosity in the slurry cast shrouds was not detected well in the NDE images. It was therefore likely that the remaining slurry cast shrouds (CCP or Goodrich) had similar microstructures to the ones destructively characterized. 


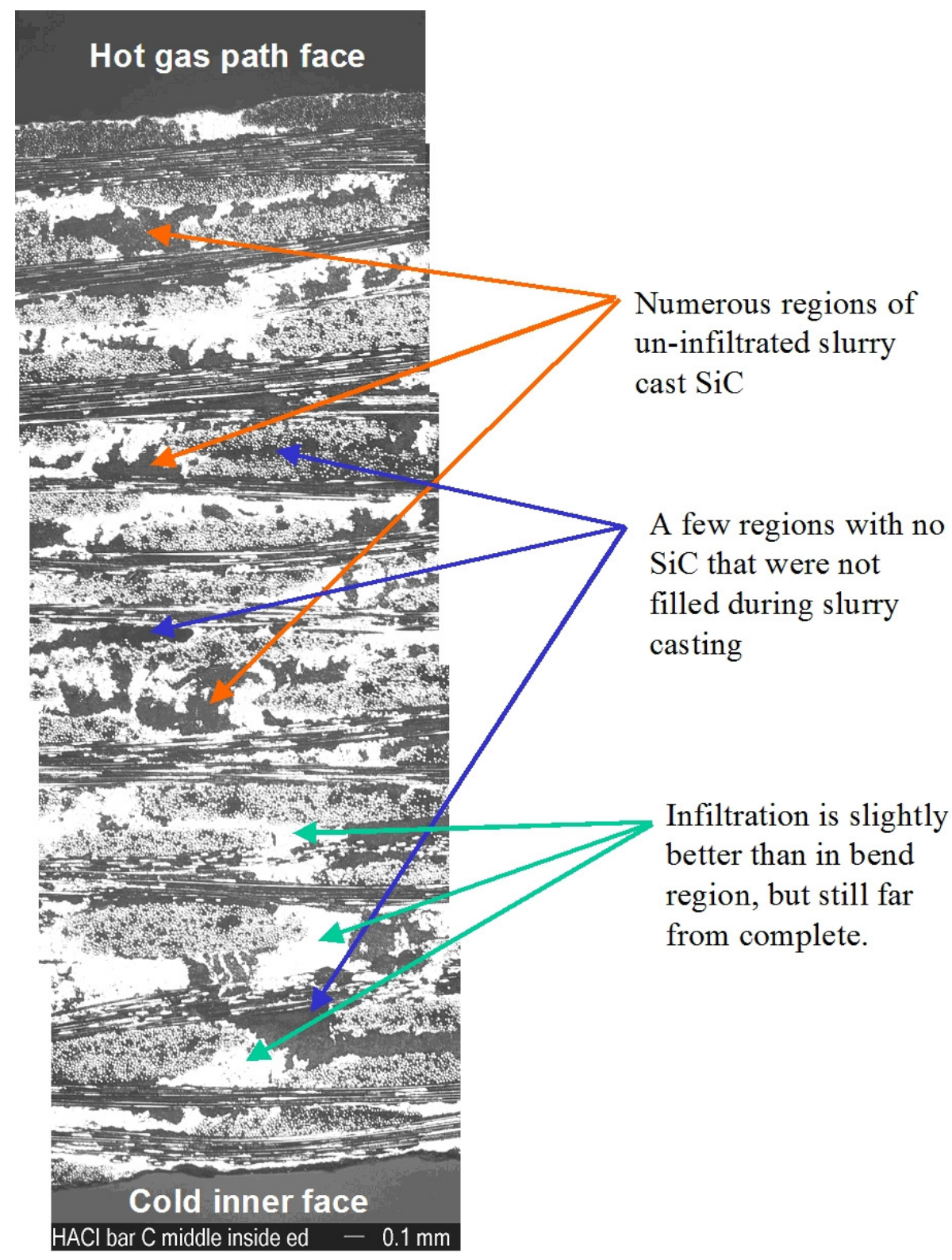

Figure 3-77. Photomicrograph montage of the center section of bar C from the CCP slurry cast shroud 1216-01-004 showing extensive residual porosity and generally poor infiltration of this shroud. 


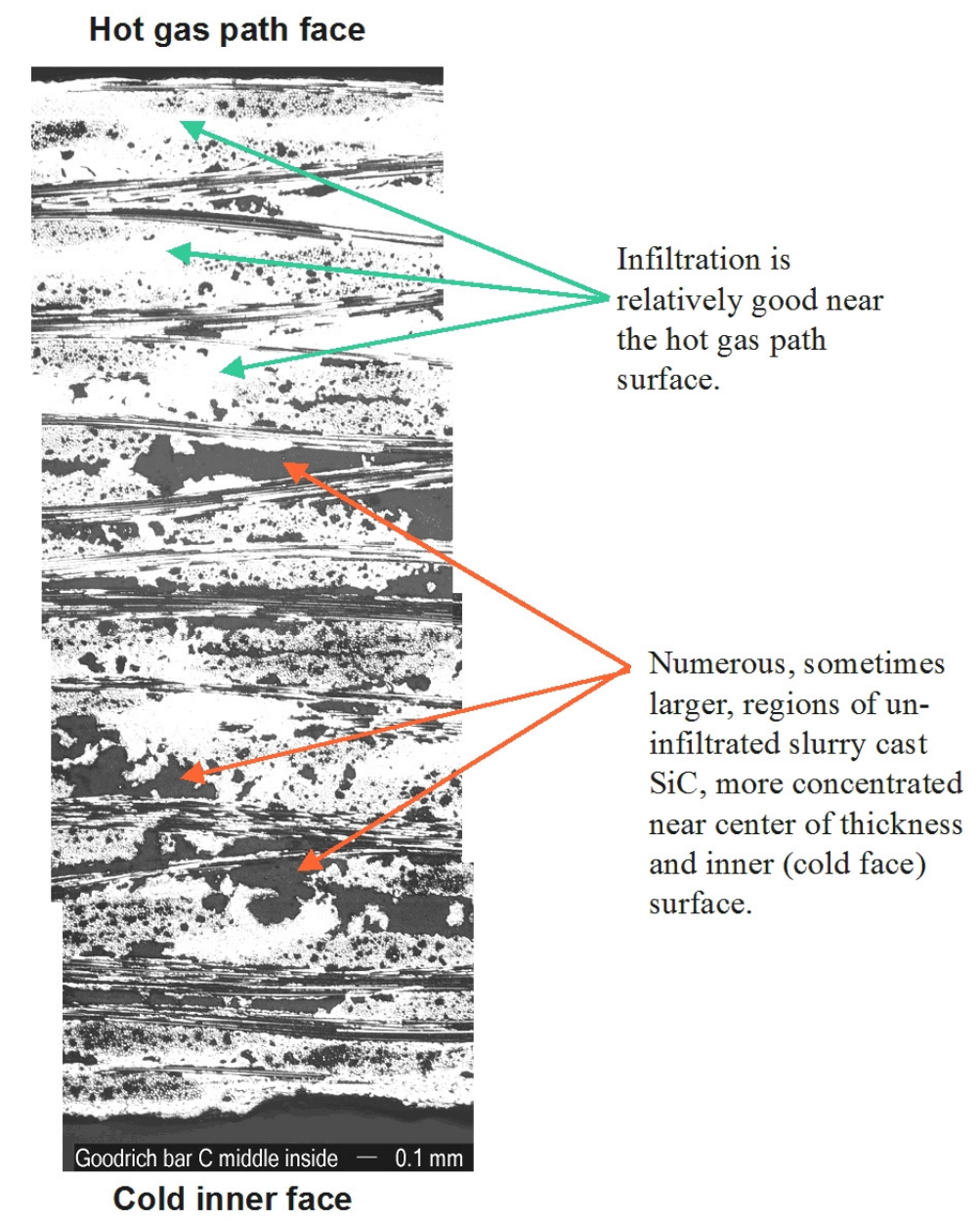

Figure 3-78. Photomicrograph montage of the center section of bar $\mathrm{C}$ from Goodrich slurry cast shroud 4104-1-1 showing extensive residual porosity and generally poor infiltration, particularly near the inner surface of the shroud.

The high level of residual porosity in the slurry cast shrouds was expected to lead to environmental degradation when exposed to high temperature combustion atmospheres. The effect of the delamination (actually an un-infiltrated ply) in the prepreg shroud on the mechanical properties and environmental degradation response was not as clear. For these reasons various bars cut from the shrouds were subjected to steam oxidation exposure to simulate engine use, and then tested mechanically.

Several pieces of each shroud were exposed to $400 \mathrm{~h}$ of steam oxidation $\left(90 \% \mathrm{H}_{2} \mathrm{O}+10 \%\right.$ $\mathrm{O}_{2}$ ) at $1200^{\circ} \mathrm{C}$. Two bars cut from the hot gas path face of each shroud (bars $\mathrm{B}$ and $\mathrm{E}$ in Figure 3-75) were exposed in steam. The tensile strength behavior of these bars was then compared to that for un-oxidized samples.

In order to measure the effects of the delamination in the prepreg shroud on the in-plane strength properties one bar was surface ground through roughly one half of its thickness in order to eliminate the delamination. This ground bar would also give an indication of the 
shroud strength in regions not containing the delamination. Elimination of the porous regions from the CCP or Goodrich shrouds was not possible as it was distributed throughout the entire shroud.

Figure 3-79 is an edge-on photograph of three of the bars cut from the different shrouds following steam exposure testing. The high residual porosity found in the slurry cast shrouds made them susceptible to internal oxidation. Both of the CCP shroud bars and one of the Goodrich bars swelled extensively because of internal oxidation to the point where the bar surfaces had to be machined in order to get end surfaces flat enough for gripping for the tensile tests. The GRC prepreg shroud bar showed only minor swelling in the region of the delamination.

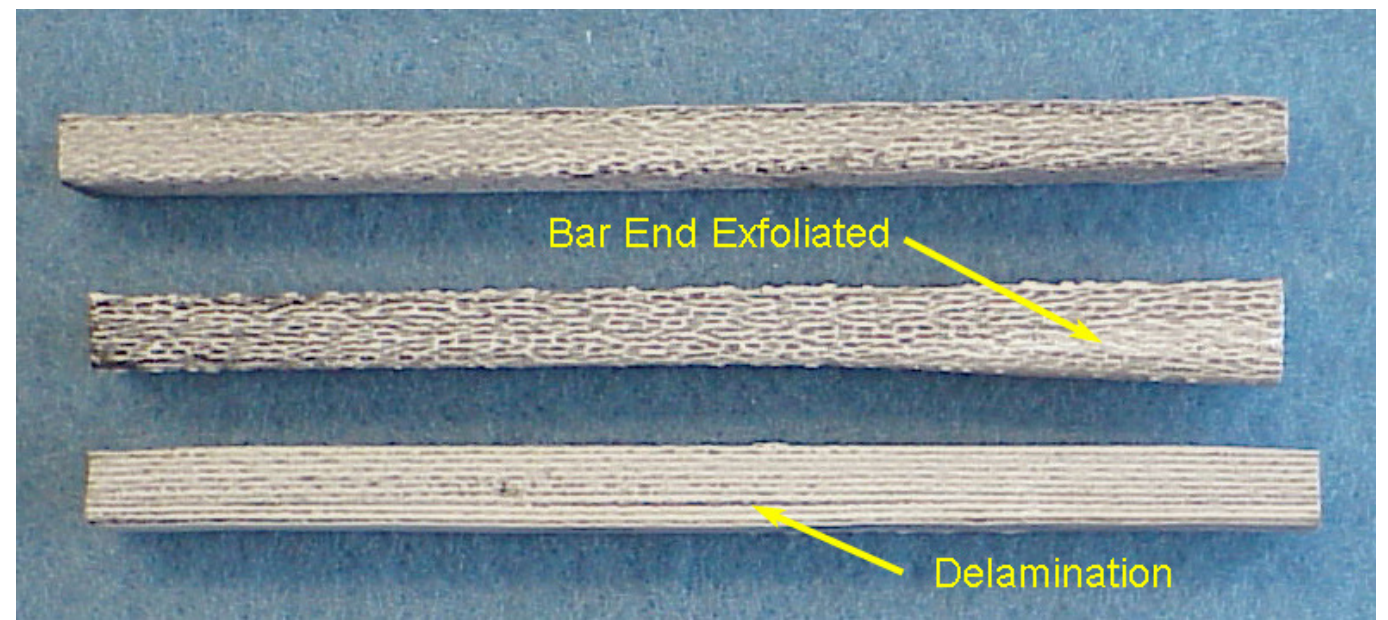

Figure 3-79. Photograph of test bars, shown edge-on, cut from engine shrouds and following $400 \mathrm{~h}$ steam oxidation at $1200^{\circ} \mathrm{C}$. The top bar is from Goodrich shroud 4101-1-1, the middle bar from CCP shroud 1216-01-004, and the bottom bar from GRC shroud 1112-2. Swelling caused by extensive internal oxidation is apparent at the right end of the CCP bar.

Figure 3-80 shows the tensile test data from bars cut from the shrouds and tested either asfabricated or after steam oxidation. The delamination in the GRC shroud caused the initial modulus of the test bar to measure low, but this was probably an effect of the delamination affecting the extensometer tracking rather than a real material property change. The test bar without the delamination showed very typical tensile failure behavior for GE prepreg MI material. Following steam oxidation exposure there was some reduction in the proportional limit, ultimate strength and strain to failure values compared to the as-fabricated bars, but the values by themselves were still quite good and met the shroud design requirements.

The slurry cast shrouds from CCP and Goodrich showed more severe degradation, as would be expected from the large amounts of porosity found in these shrouds. Both ultimate strength and strain to failure values were significantly reduced by the steam 
oxidation exposure, with one of the two oxidized bars from each set having $0.2 \%$ or less strain to failure (strain at the maximum stress).

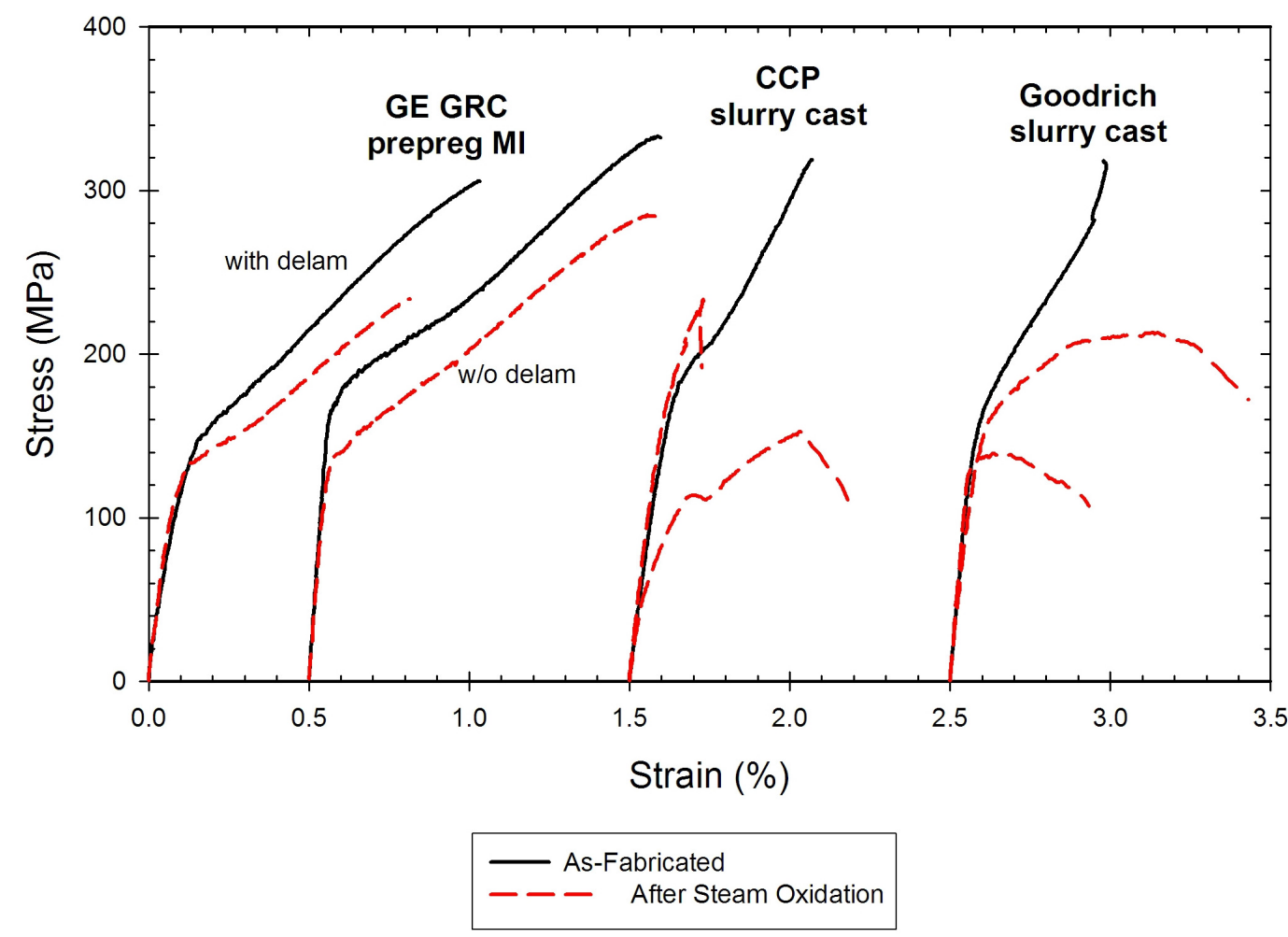

Figure 3-80. Tensile test results for witness bars cut from engine shrouds both asfabricated and after $400 \mathrm{~h}$ steam oxidation exposure at $1200^{\circ} \mathrm{C}$. Curves are offset on the strain axis for clarity.

Pin pull-out tests on the flanges cut from the shrouds were also performed with samples asfabricated and following $400 \mathrm{~h}$ steam oxidation exposure. The load-displacement curves from these tests are shown in Figure 3-81. Both the GRC prepreg and Goodrich slurry cast shrouds showed similar load bearing capacity in the pin pull-out tests. Initially the Goodrich shroud showed a somewhat more graceful failure with strain capability beyond the maximum load; however, after steam oxidation the strain capability beyond the maximum load was less, and very similar to the GRC prepreg shroud. The CCP slurry cast shroud showed much lower ultimate loads for the pin pull-out test, roughly $40 \%$ of those of the other two shrouds. There was actually a small increase in pin pull-out load for the oxidized sample compared to the as-fabricated sample, but this was likely caused by position-toposition variability within the shroud rather than the effect of oxidation. 


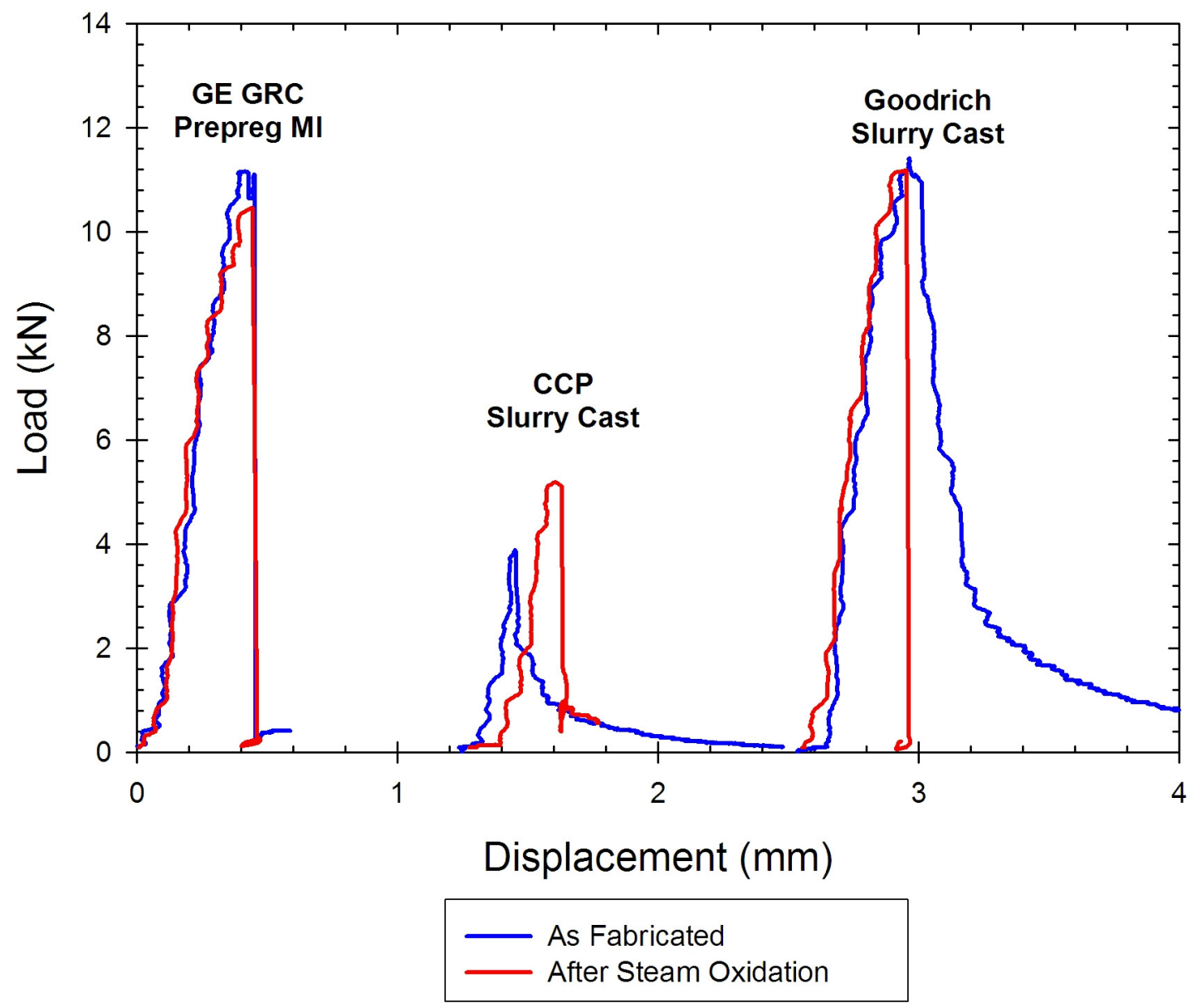

Figure 3-81. Load vs. displacement curves for pin pull-out tests on the cut-up engine shrouds both as fabricated and after $400 \mathrm{~h}$ steam oxidation at $1200^{\circ} \mathrm{C}$. The curves are offset on the strain axis for clarity.

Figure 3-82 shows a photograph of the shroud flanges, shown on-edge, following the postoxidation pin pull-out tests. As with the tensile bars, the CCP flange sample showed very substantial swelling caused by internal oxidation. In this case the swelling was nearly $50 \%$ of the specimen thickness, and necessitated machining of the CCP flange in order for it to fit within the test fixture. Surprisingly this loss of material to oxidation and to machining did not reduce the measured pin pull-out load relative to the sample tested without oxidation. All of the samples tested before oxidation, and both the GRC prepreg and Goodrich slurry cast specimens tested after oxidation, failed by tensile fracture of the ligaments beside and above the holes. The oxidized CCP flange also showed delamination failure during the pin pull-out test, with the path of the delamination crack following a layer of heavy oxidation. 


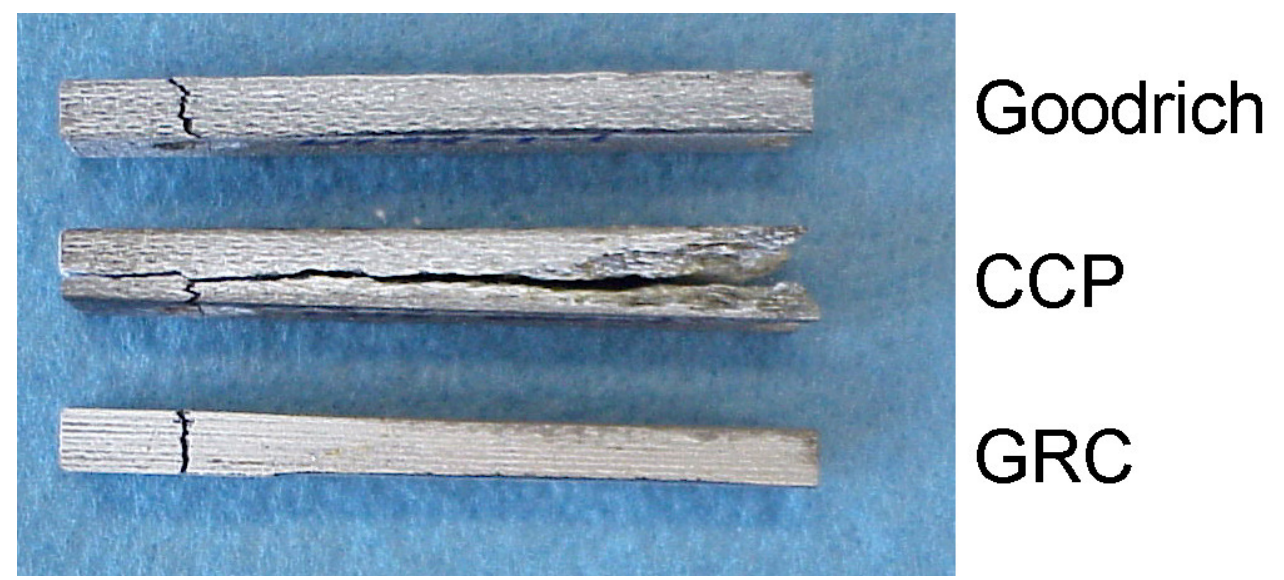

Figure 3-82. Photograph (edge-on) of the steam oxidized pin pull-out test specimens cut from the three engine shrouds. The delamination failure of the CCP shroud test sample is evident.

Based on these mechanical testing results and the microstructural analysis results, all of the slurry cast shrouds originally produced for the shroud engine test were considered to be of insufficient quality to be used for engine testing. GRC prepreg shrouds containing significant interlaminar defects that extend to the shroud edges were similarly judged to be unacceptable for engine testing. However, small isolated interlaminar defects, which did not connect to the shroud surfaces, and should therefore not have a detrimental effect on the shroud mechanical behavior or life, were considered acceptable if they met all other applicable criteria. Fortunately, interlaminar defects in prepreg shrouds were easily identified with the existing IR thermography NDE technique so that acceptable shrouds could be screened from the pool of candidates.

\subsubsection{Engine Shroud Fabrication Campaign \#2}

This second round of CMC inner shroud fabrication for use in the $1^{\text {st }}$ engine test was performed from December 2001 to February 2002.

Given the lack of acceptable slurry cast shrouds for engine testing, CCP was asked to prepare several additional $\mathrm{CMC}$ inner shrouds using internal GE funds. (At this time in the program CCP had become part of GE Energy, operating under the name of "GE Power Systems Composites", and thus GE Energy could absorb fabrication costs for the new shrouds.) Eight new shrouds were fabricated and witness coupon data was measured for each shroud. Five of the shrouds were judged to be promising based on preliminary dimensional and density screenings and on NDE inspection results. One of these five was later used in rig test \#4, but the other four were used up in attachment testing, machining trials, EBC trials or in destructive metallographic analysis.

There was also a desire to have additional prepreg shrouds available that would have either reduced defect content relative to the $1^{\text {st }}$ set or that would incorporate Hi-Nicalon Type-S fiber. Ten new prepreg shrouds were therefore processed at GRC, six with Hi-Nicalon fiber and four with Hi-Nicalon Type-S fiber. Unfortunately the quality of the incoming Hi- 
Nicalon fiber, and therefore the handle-ability of coated fiber in the prepregging operation, was worse in this round of shroud fabrication attempts than it had been during the $1^{\text {st }}$ set. Consequently all of the newer Hi-Nicalon reinforced shrouds contained poor quality prepreg tapes, which resulted in un-infiltrated plies in the shroud components as detected by NDE. Of the two shroud preforms fabricated from Hi-Nicalon Type-S fiber (each preform yields two shrouds) one preform was found to have delaminated after binder burn-out. The other Hi-Nicalon Type S preform yielded two shroud components with relatively good NDE signatures and witness coupon strength values, and thus these two shrouds were added into the pool of potential shrouds for engine testing. Unfortunately both shrouds were later removed from the engine test pool, one because it was used in rig tests \#3 and \#4 and the other due to a machining error during machining of the attachment holes.

\subsubsection{Engine Shroud Fabrication Campaign \#3}

The pool of potential shrouds available for the engine test had been as high as nineteen, including the 12 remaining prepreg shrouds from the $1^{\text {st }}$ fabrication campaign, two new prepreg Hi- shrouds with Hi-Nicalon Type-S fiber and the five CCP slurry cast shrouds from the $2^{\text {nd }}$ campaign. However, continued use of shrouds from this pool for the ongoing shroud rig tests and for mechanical testing, environmental exposure evaluations, machining trials, NDE technique validation and EBC deposition process optimization were depleting the pool of available shrouds. It was therefore decided in the Spring of 2002 to attempt another round of shroud fabrication to repopulate the pool of potential engine test shrouds and hopefully improve the overall quality of the shrouds within the pool. Fabrication of this set of shrouds was done in May to July of 2002.

In this campaign GRC initiated fabrication on a total of 16 additional prepreg MI CMC inner shrouds, 10 reinforced with Hi-Nicalon fiber and 6 with Hi-Nicalon Type-S fiber. $\mathrm{CCP}$ also initiated fabrication of 16 additional shrouds, 8 using their standard slurry cast MI process and 8 using the newer modified process. Of the 16 fabricated by GRC only 8 were of sufficient quality, as judged by NDE inspection and mechanical testing of witness bars, to be considered for the engine test. The 8 shrouds made by CCP using the modified slurry casting approach all yielded relatively high porosity and poor mechanical properties, and were subsequently dropped from consideration. Therefore only the 8 slurry cast shrouds made by the standard process were accepted into the engine test pool.

\subsubsection{Engine Shroud Selection Process}

The 16 good shrouds from the $3^{\text {rd }}$ shroud fabrication campaign, along with 5 prepreg shrouds remaining from the $1^{\text {st }}$ fabrication campaign, were extensively characterized using all non-destructive means available. Witness bar mechanical properties, thermal diffusivities (from the IR thermography NDE process), NDE images, modal frequency measurements, and dimensional tolerance data were all collected and compared to select the best shrouds for the engine test.

An important step remaining in the fabrication process for the CMC inner shrouds was the machining of the attachment holes. GE had been working closely with Goodrich Turbine Component Services (TCS) in Greenwood, SC, to develop them as a machining house for the CMC inner shroud components. Goodrich TCS is a $1^{\text {st }}$ tier commercial machining 
vendor to GE Gas Turbines for a variety of turbine components, and was selected as the CMC machining vendor based on their strong business relationship with GE and general responsiveness. Machining trials were carried out on CMC test pieces where several variables were studied, including type of machining operation, type of cutting tool and/or abrasive, and specific machining procedures. Through these trials, machining practices were established for both slurry-cast $\mathrm{CMC}$ and prepreg CMC materials. CMC shrouds for the engine rainbow test were then successfully machined and delivered to GE at the end of September, 2002. Dimensional accuracy of the size and location of the machined attachment holes were included in the data used for selecting shrouds.

The resonant, or modal, frequencies of the CMC shrouds were a concern since high cycle fatigue is a known failure mode of metallic turbine hardware. Although the available material property data on melt infiltrated CMCs had shown fairly good resistance to cyclic fatigue, general turbine hardware design practice dictates that the resonant frequencies of any component cannot be within $10 \%$ of certain known vibration driving frequencies. For shrouds, the most important driving force for vibration is the pressure pulses produced from the blade tips passing the shroud. Engines of the 7FA class produce electricity at $60 \mathrm{~Hz}$, and therefore rotate at 3600 RPM. There are 92 buckets in the $1^{\text {st }}$ stage of the engine, which would correspond to a bucket tip passing frequency of $5520 \mathrm{~Hz}$. Therefore none of the resonant frequencies of the shrouds, as they would be mounted in the engine, could be between 4970 and $6070 \mathrm{~Hz}$.

A technique for measuring the free resonance frequencies of the CMC shrouds was developed. In this technique the shrouds were suspended on strings, as shown in Figure 383. Excitation of the shroud was provided by a calibrated hammer tap at the locations marked A, B and C in the photograph. An accelerometer mounted at position D measured the vibrational response of the shroud in the time domain, and commercial fast-Fourier transform (FFT) software was then used to convert the response to the frequency domain.

A typical response from one of the prepreg shrouds is shown in Figure 3-84. Although the magnitude of the response varied depending on the excitation location, the actual modal frequencies were very consistent between the three locations, adding confidence that the true resonances of the shroud were being measured. The modal frequencies were compared to those predicted by FEA analysis and the agreement was generally within 5\%. This was considered very good correlation since the predicted frequencies were based on average material modulus, density and thickness values and were not adjusted for variations from location to location on individual shrouds. Some shrouds did show frequency deviations from prediction of up to $10 \%$, but these were always shrouds that showed large defects in the NDE images that no doubt contributed to the discrepancies. 


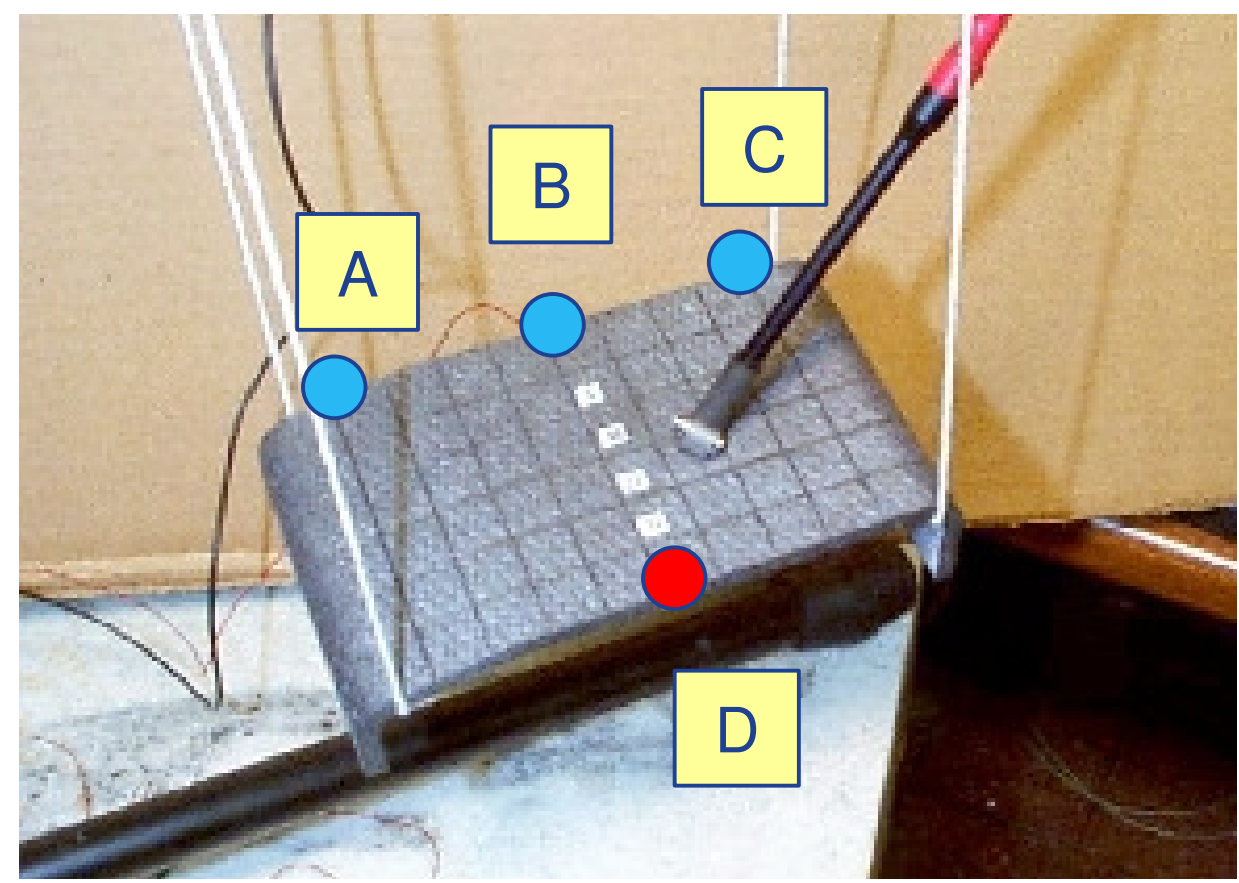

Figure 3-83. Photograph of a CMC shroud suspended from strings as used for measurement of shroud modal frequencies.

Shourd 1108-1

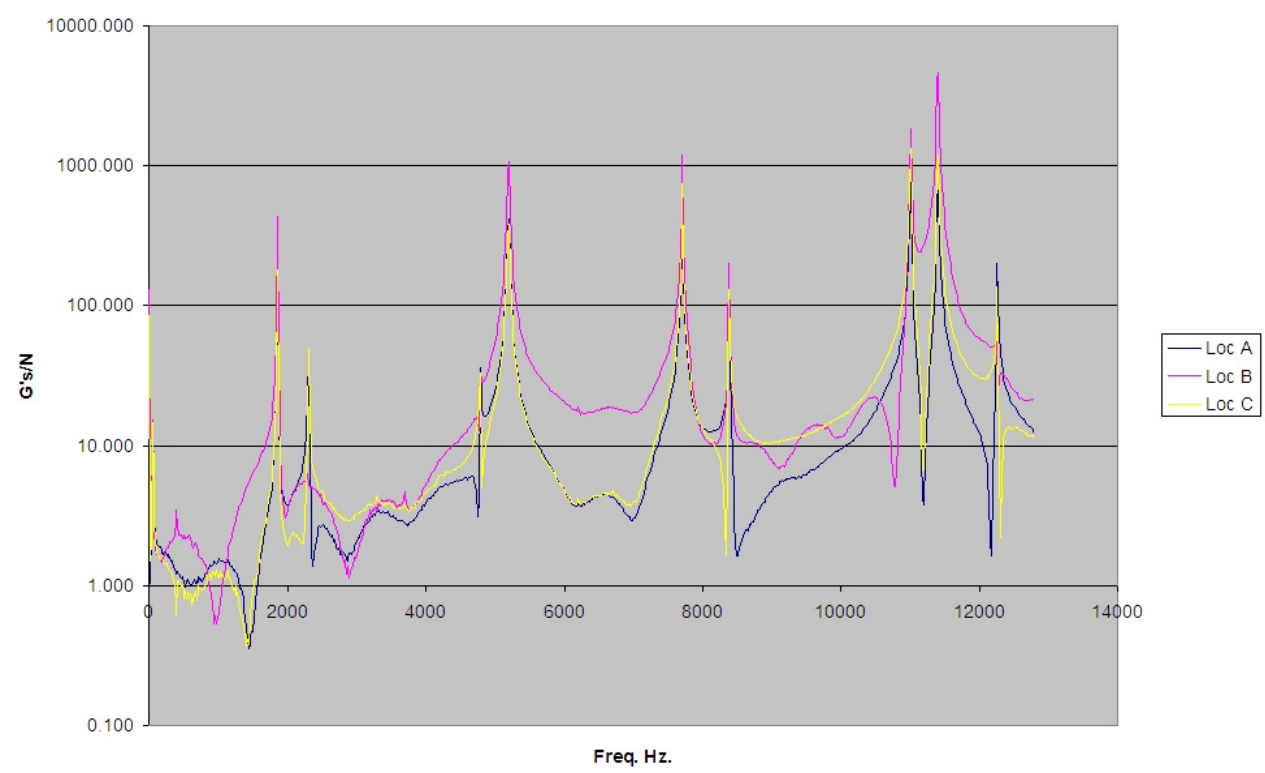

Figure 3-84. Typical modal frequency response of a prepreg shroud in the unconstrained condition. The three curves correspond to excitations in the three locations indicated in Figure 3-83. 
Although the unconstrained room temperature response of the shrouds was easiest to measure, the effects of temperature, EBC coatings and, in particular, the loading of the shroud by the attachments and damper block when assembled in the outer shroud blocks needed to be accounted for. This latter factor was accounted for by taking several of the rejected shrouds, measuring their free modal response, mounting them in an outer shroud block, and then re-measuring the modal response while in the shroud block. The shifts in resonant frequencies were consistent in direction and magnitude for the number if shrouds tested in this way, such that simple offsets of the unconstrained modal frequencies could be used to predict the modal frequencies after assembly.

Similarly the unconstrained shroud modal response was measured on all shrouds both prior to and after EBC coating. In general the added mass of the coating was offset by the additional stiffness provided by the increase in thickness, such that there was almost no effect of the EBC coatings on the shroud resonant frequencies.

Finally the measured free resonant frequencies were adjusted to the projected shroud operating temperature based on the measured variation of modulus with temperature and on the thermal expansion behavior of the CMC. Again, these adjustments for temperature were typically small and overshadowed by the frequency shifts caused by mounting in the outer shroud block.

Shroud dimensional tolerances were another evaluation criterion that required some procedure development. Initial measurements were done with a CMM to verify the overall outer dimensions of the shrouds after fabrication. However this technique proved to be inadequate for gauging the proper alignment and positioning of the attachment holes, which had been demonstrated to be an important factor in preventing hole damage in the rig tests. Consequently a hard tooling fixture was made to test that attachment holes all aligned properly and that the shrouds would have the proper clearances when assembled. A photograph of this tooling is shown in Figure 3-85.

Overall thirty different dimensions and/or clearances between the tool and shrouds were measured for each shroud to ensure proper fit of the shrouds during assembly into the outer shroud blocks. This dimensional check was found to be especially important after the EBC coating step in order to account for varying EBC thickness on the various shroud surfaces. In fact several of the shrouds required the EBC coating on the flange edges to be polished slightly to ensure the proper shroud-to-shroud clearances. 


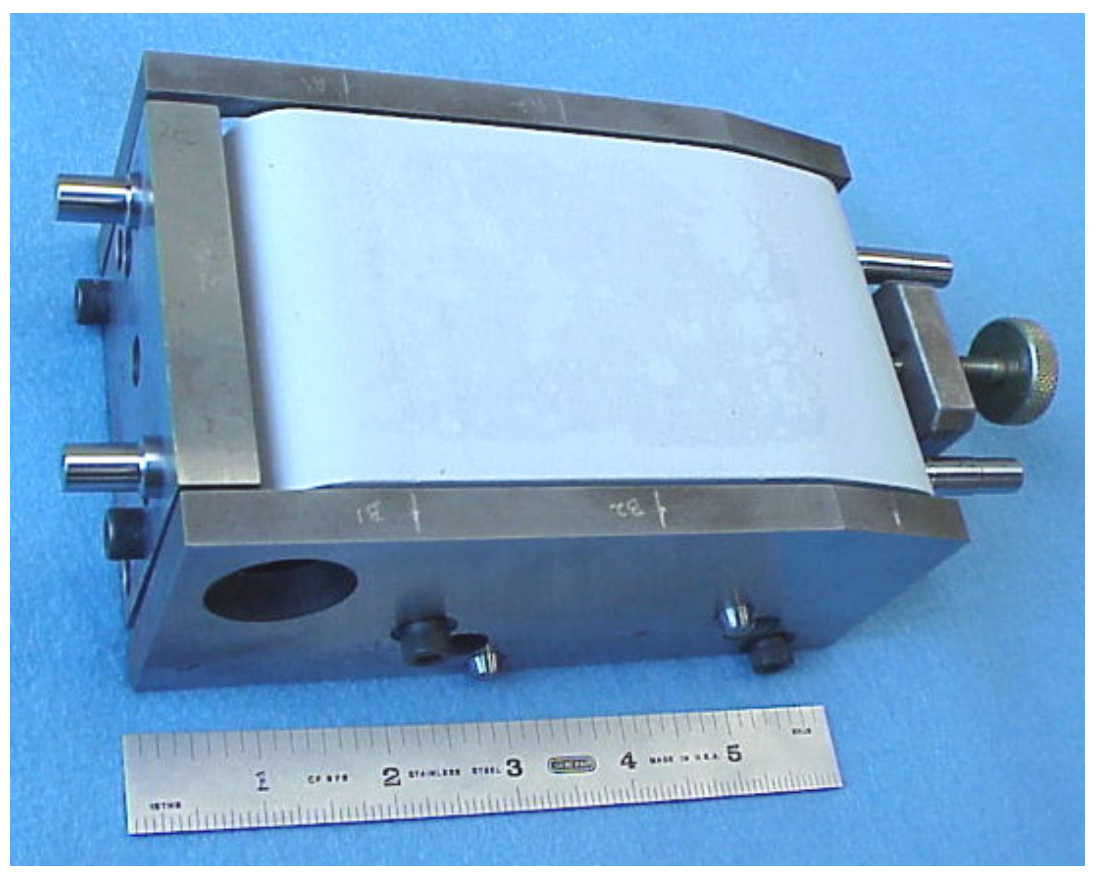

Figure 3-85. Photograph of the shroud dimensional check tool, with an EBC coated CMC shroud installed, used for verifying the attachment hole alignments and overall shroud dimensional accuracy.

The 15 top rated CMC shrouds were coated with EBC at GE GRC. The shrouds were extensively photodocumented prior to coating, after surface grit blasting in preparation for coating deposition, and again after coating. Initially adhesion problems were observed during spraying of the prepreg shrouds, which were eventually solved by optimizing the surface preparation treatment before coating application. The optimization involved selection of the proper abrasive grit composition and size and an optimum gas pressure for the grit blast nozzle. Coating cracking and spallation was also noted on the third of the five slurry cast shrouds to be coated. This cracking was not evident in the as-sprayed coatings, but only became noticeable following a post-spray thermal anneal step. Again, surface preparation optimization was performed before coating the final two slurry cast shrouds and no further coating cracking and/or spallation was observed.

Following EBC coating the pool of shrouds was further narrowed based on the qualitative assessment of the EBC coatings. Nine shrouds were finally selected for engine testing, including 6 prepreg shrouds and 3 slurry cast shrouds, all reinforced with Hi-Nicalon fiber. Two prepreg shrouds with Hi-Nicalon Type-S fiber were also selected as back-ups in case any damage occurred to the nine primary shrouds during outer shroud block assembly or insertion into the engine.

These selected shrouds were shipped to GE Energy in Greenville, SC, in October of 2002 for assembly into the outer shroud blocks. Assembly of the CMC inner shrouds into the outer shroud blocks, including all attachment hardware and instrumentation, was completed on October 23. Figure 3-86 shows a photograph of one of the outer shroud assemblies 
after insertion of the CMC inner shroud components. Two prepreg and one slurry cast inner shroud were assembled into each of the three outer shroud blocks. No problems were encountered during the shroud block assembly.

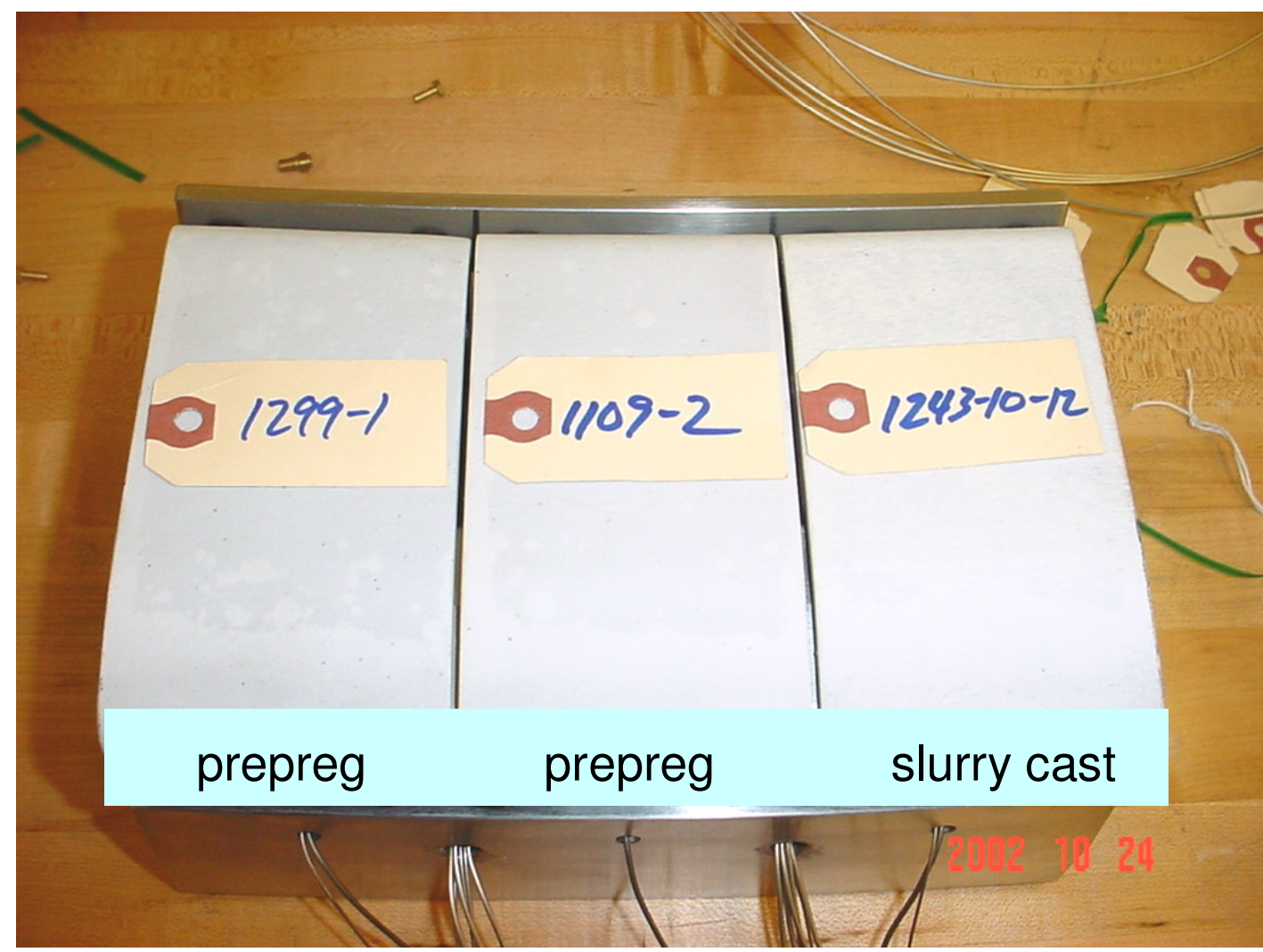

Figure 3-86. Photograph of three CMC inner shrouds assembled into a single outer shroud block assembly in preparation for field engine testing. The tubes coming out the back of the outer shroud block (bottom of the picture) are the thermocouple and pressure tap instrumentation.

An important consideration for this $1^{\text {st }}$ large engine test was what precautions needed to be taken, if any, to prevent blade tip rubs on the CMC shrouds. Clearly rub rig testing, as described in Section 3.1.8.1, had demonstrated that the $\mathrm{CMC}$ and $\mathrm{EBC}$ materials could withstand blade rub events. Also, prior engine experience with single piece ring shrouds in a 5MW PGT-2 test engine had shown that the CMC shrouds could withstand multiple blade tip rubs without failure [2]. Nevertheless, since this test would occur in a utility-owned engine, with the inherently large liability should any of the test hardware fail, it was decided to move the CMC inner shrouds outward radially by $1.5 \mathrm{~mm}$ relative to the normal metallic shroud position in order to minimize the likelihood of a bucket rub event. The outer shroud blocks for the CMC shrouds had therefore been designed and machined accordingly. During shroud system assembly the relative positions of the CMC and metallic inner shrouds were measured to verify that they indeed had the intended offset. The photograph in Figure 3-87 shows the interface between a transition shroud block with metallic shrouds 
and a CMC shroud-containing shroud block and the step in inner shroud radial position is indicated.

The pre-assembled shroud blocks, three with CMC inner shrouds and two transition shroud blocks with metallic shrouds, were then shipped to the engine test site for installation.

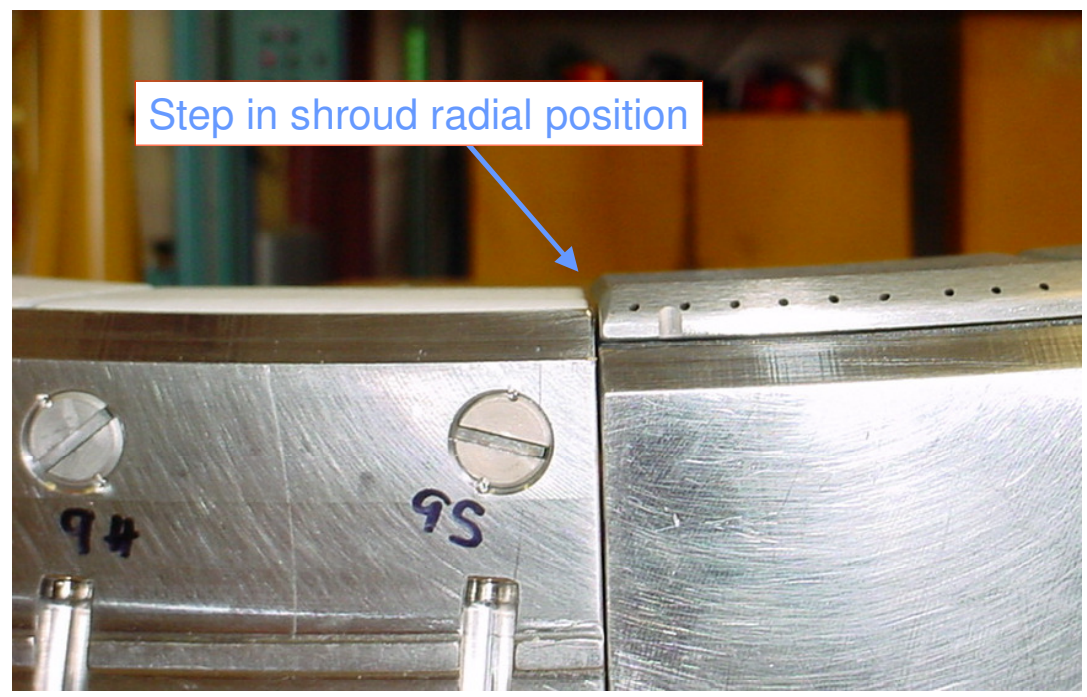

Figure 3-87. Photograph of an outer shroud block with CMC inner shrouds (left) and a transition shroud block with metallic shrouds (right), showing the step in radial shroud position between the CMC and metallic shrouds.

\subsubsection{Task 4.3 - Rainbow Engine Testing}

Considerable preparation work and negotiations with the utility engine operators was needed to get them to host the shroud engine test. This preparation work had started over a full year prior to the shroud installation, and required several presentations to different utility engineering and business teams on the benefits of CMC technology and on what steps GE had taken to minimize the risk of the CMC shrouds causing an engine outage. Eventually a utility engine operator in southern Florida agreed to allow the shroud test in one of their 7FA engines. The utility company and generating station location have not been divulged publicly at the request of the utility.

\subsubsection{Shroud Installation}

The service outage for the shroud test engine started in late October of 2002. The CMC shrouds were shipped to the engine site, unpacked and inspected for any shipping damage. Engine disassembly proceeded at a normal pace for a major overhaul outage, with the turbine shell not being opened until November 16. 
Since only five of the 32 outer shroud blocks were to be replaced for this shroud test it was necessary to select where in the engine the CMC shrouds would be placed. Based on past experience with the 7FA fleet on the whole it was decided to place the CMC shrouds near the top dead center position in the turbine casing. This was done since it was anticipated that this location would be the least likely to have a blade rub event, and also because shrouds in that location would be close to the borescope access holes. The circumferential position of the CMC shrouds in the shroud ring is shown schematically in Figure 3-88. However, upon engine disassembly it was evident that the prior metallic shrouds in outer shroud block locations 6 through 10 had all experienced blade rub events. Despite this observation it was decided to still install the shrouds in OSB locations 6 through 10 as had been planned. Figure 3-89 shows these OSB locations on the turbine top shell after it had been removed from the engine.

After the metallic shrouds were removed the first step in the installation of the CMC shrouds was to drill a hole in the upper shell to accommodate the instrumentation to the outer shroud blocks. The turbine shell was laid on end (exit end down) to accommodate installation of the new shrouds and nozzles. Figure 3-90 shows several photographs in the process of drilling the hole and threading through the instrumentation wires and sealing the penetration using a "chico bowl" seal.

The $2^{\text {nd }}$ stage nozzles are supported by the $1^{\text {st }}$ stage outer shroud blocks so that removal of the nozzles was required for installation of the new shrouds. Figure 3-91 shows a photograph of the five outer shroud blocks (three central blocks with CMC inner shrouds and the two neighboring transition shroud blocks) that were part of this test after insertion into the turbine shell. The wiring hanging downward from the shroud blocks is the instrumentation wiring before it had been threaded through the shell penetration.

In order to ensure survival of the instrumentation wires it was necessary to affix them to the turbine casing in the space outside of the $2^{\text {nd }}$ stage nozzles. This was done by tack welding tabs over the wires and onto the casing to fix the location of the wires, as shown in Figure 3-92.

The remaining installation of the new $1^{\text {st }}$ stage shrouds and $2^{\text {nd }}$ and $3^{\text {rd }}$ stage buckets into the turbine shell was completed without incident. Figure 3-93 shows a photograph of the turbine upper shell after installation of all the new hardware. At this point the upper shell was ready for installation back on the engine.

Installation of other new hardware in the engine and engine reassembly proceeded without incident, such that the reassembly was completed on December 16. At that time a borescope inspection was performed to look for any evidence of damage to the CMC shrouds or EBC coatings that may have occurred during engine assembly. No evidence of $\mathrm{CMC}$ or EBC damage was found. 


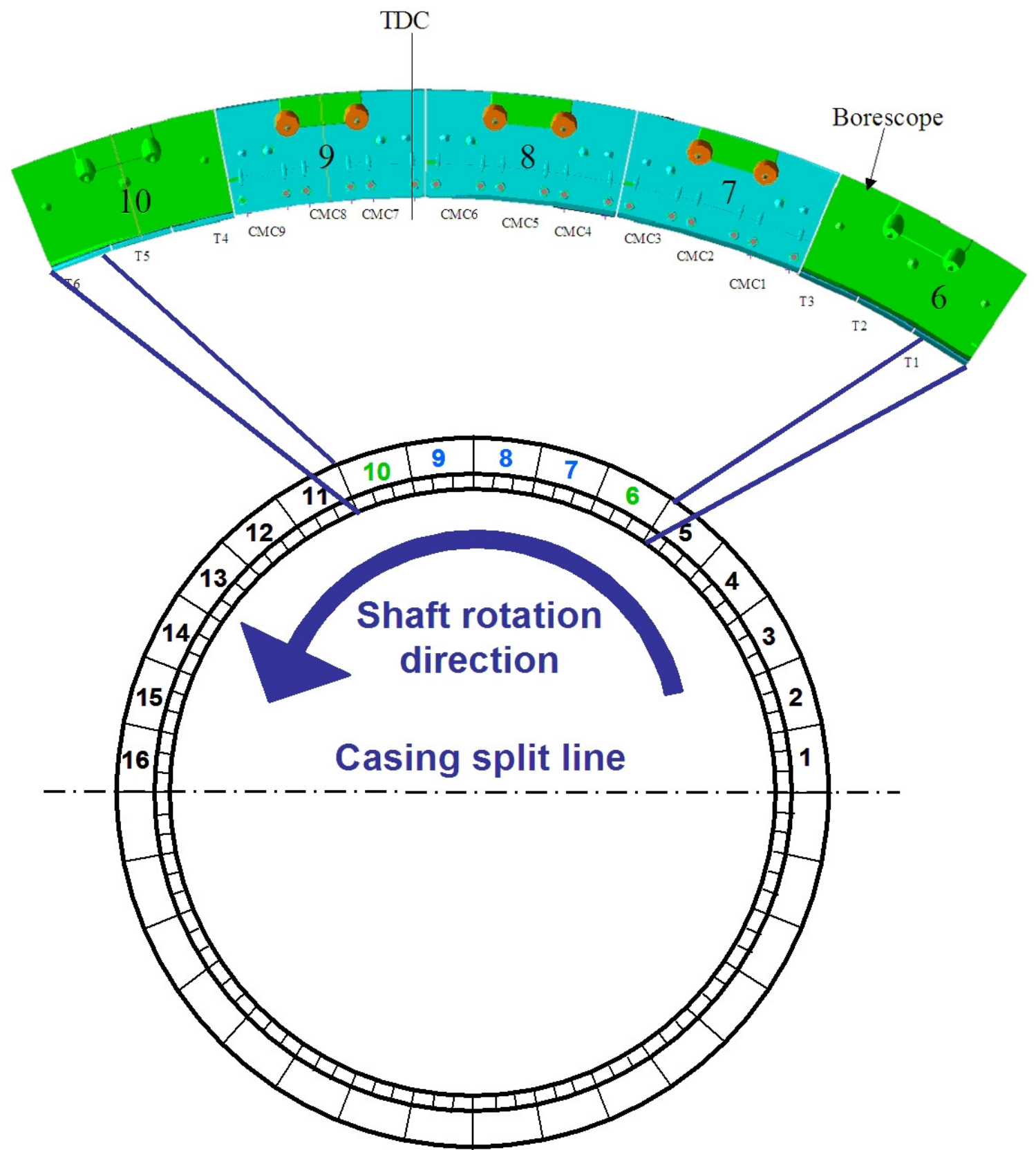

Figure 3-88. Schematic diagram showing the positions of the special shroud blocks within the engine. The lower part shows the circumferential location of the shroud blocks within the engine (forward looking aft perspective). The upper part is a blowup of the CMC shroud section showing the locations of the individual inner shrouds. 


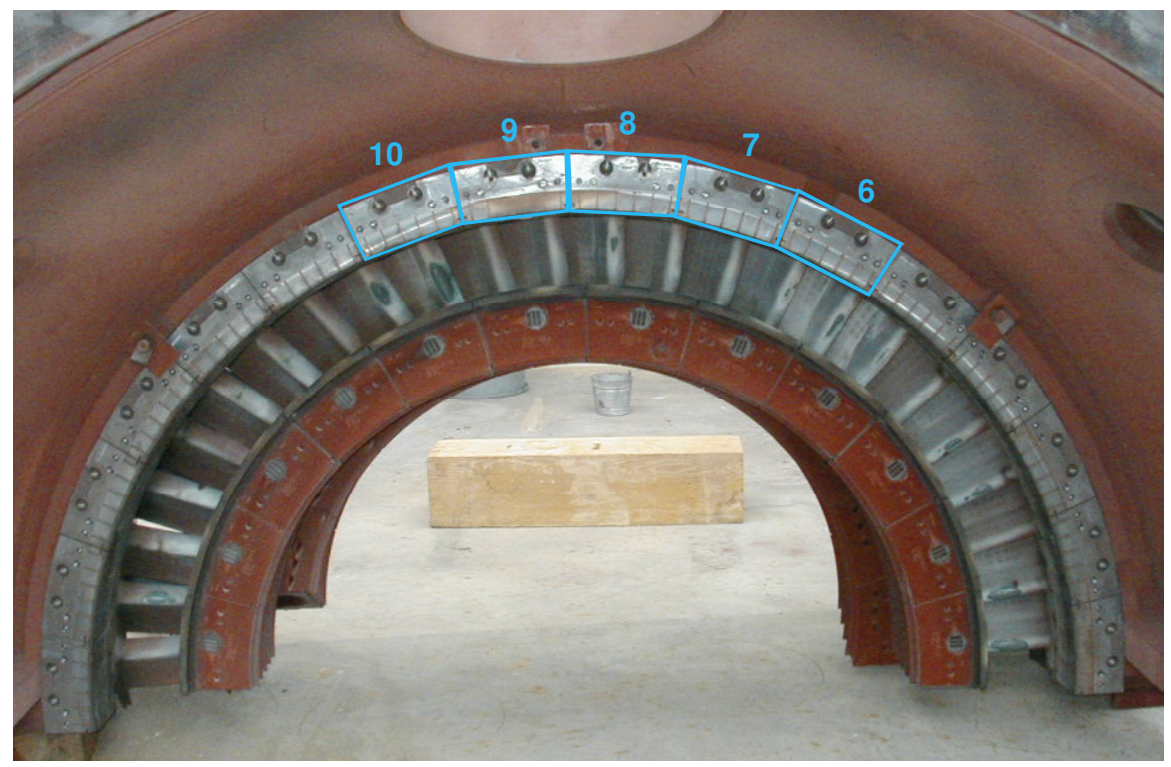

Figure 3-89. Photograph of the top half of the turbine shell after removal from the engine. The view is forward looking aft and the $1^{\text {st }}$ stage shrouds and $2^{\text {nd }}$ and $3^{\text {rd }}$ stage nozzles are still installed on the casing. The positions of the five outer shroud blocks that were replaced for this test are marked by the light blue outlines. The CMC shrouds were in OSB positions 7 through 9. 

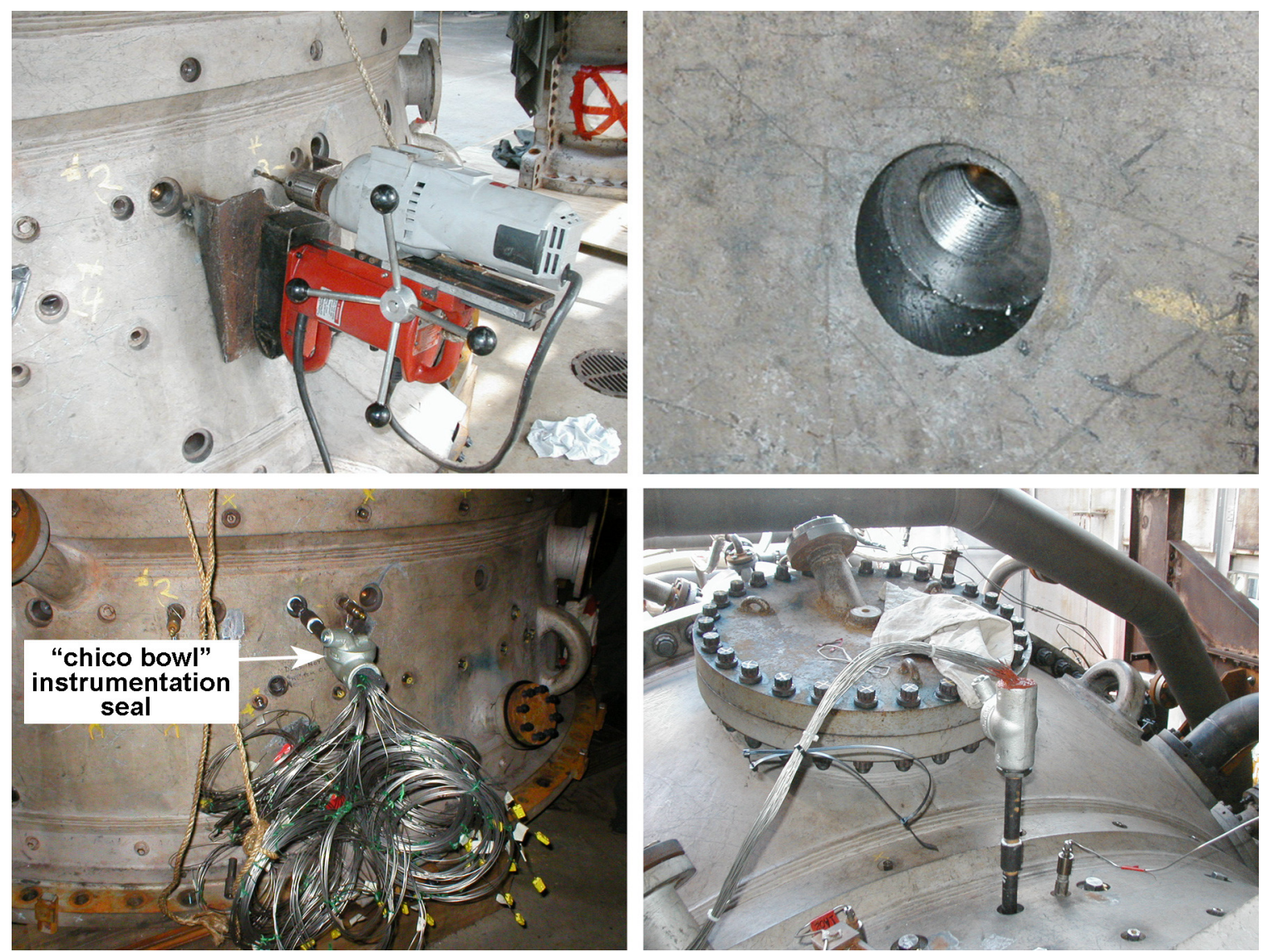

Figure 3-90. Photographs of the turbine casing penetration that was added to accommodate the CMC shroud instrumentation wiring: Top left - at the beginning of drilling; Top right - the finished drilled and tapped instrumentation hole; Bottom left - after installation of the "chico bowl" seal and threading of the instrumentation wiring; Bottom right - the finished and sealed instrumentation bundle after the turbine shell had been re-assembled on the engine. 


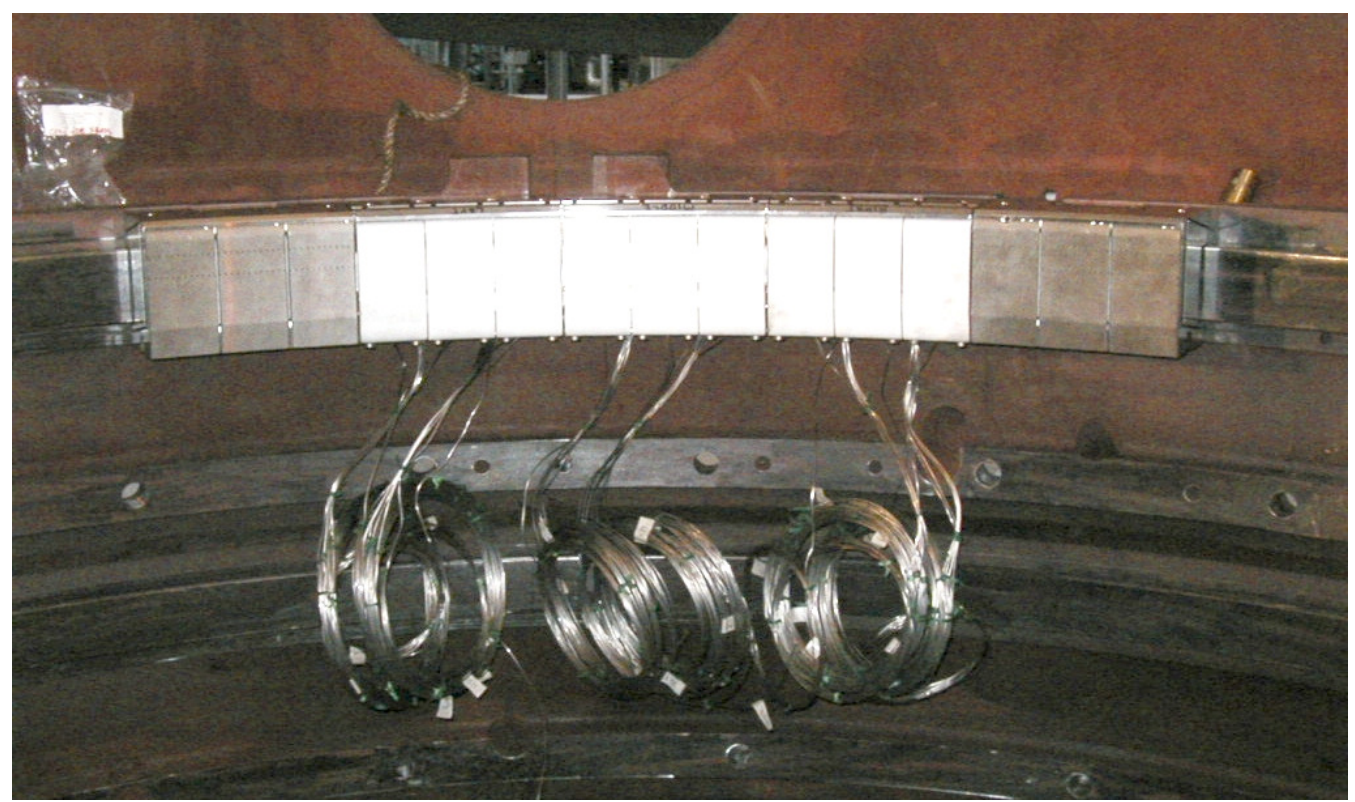

Figure 3-91. Photograph of the test set of shrouds after installation into the upper turbine casing. The nine white EBC-coated CMC shrouds are in the center three shroud blocks, with the transition shroud blocks that interfaced between the CMC and normal metal shroud systems, on either side. The wires hanging from the outer shroud blocks are the thermocouple and pressure tap instrumentation.

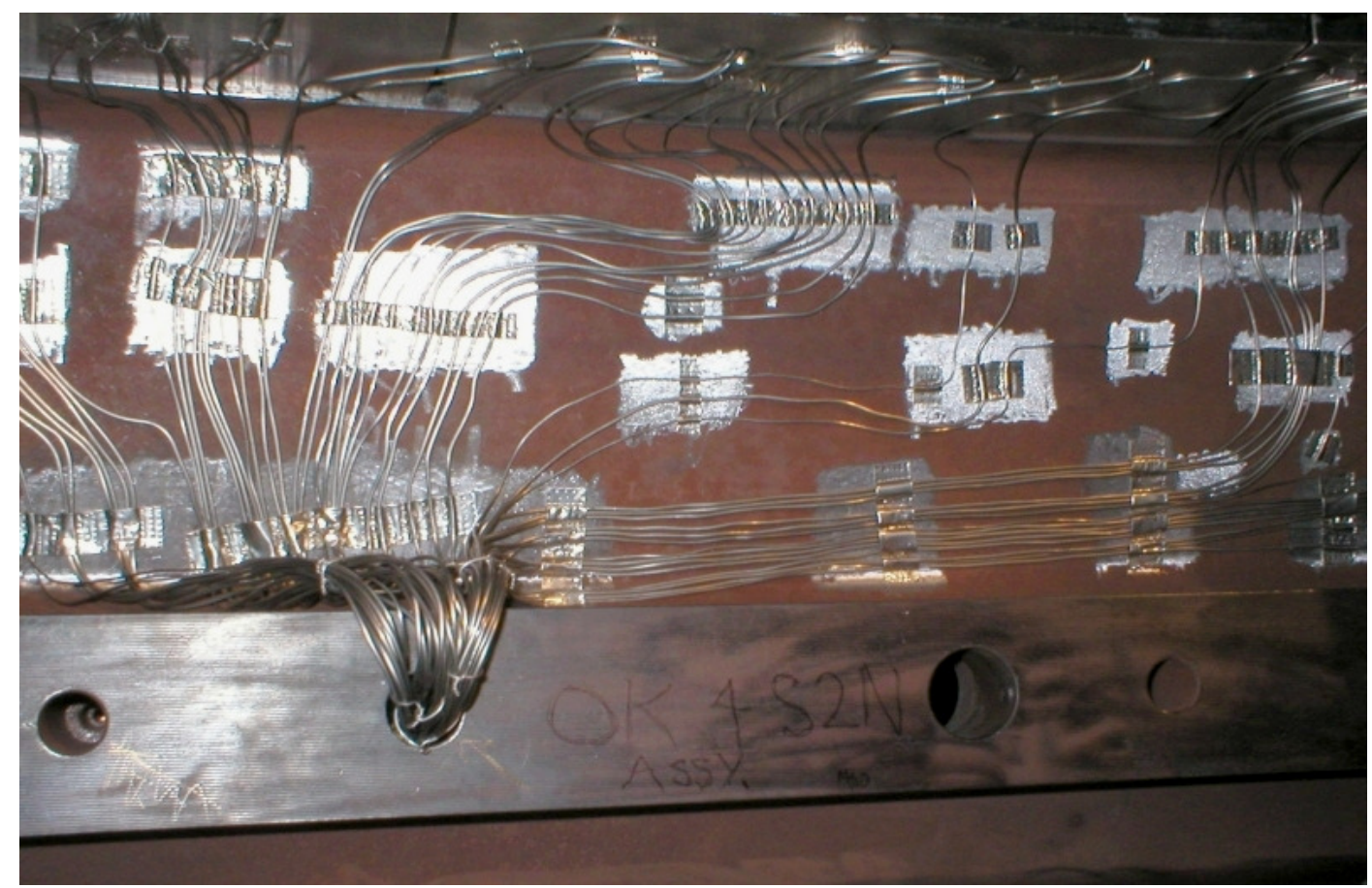

Figure 3-92. Photograph of the shroud instrumentation wiring after being tack welded to the casing and routed through the casing hole. 


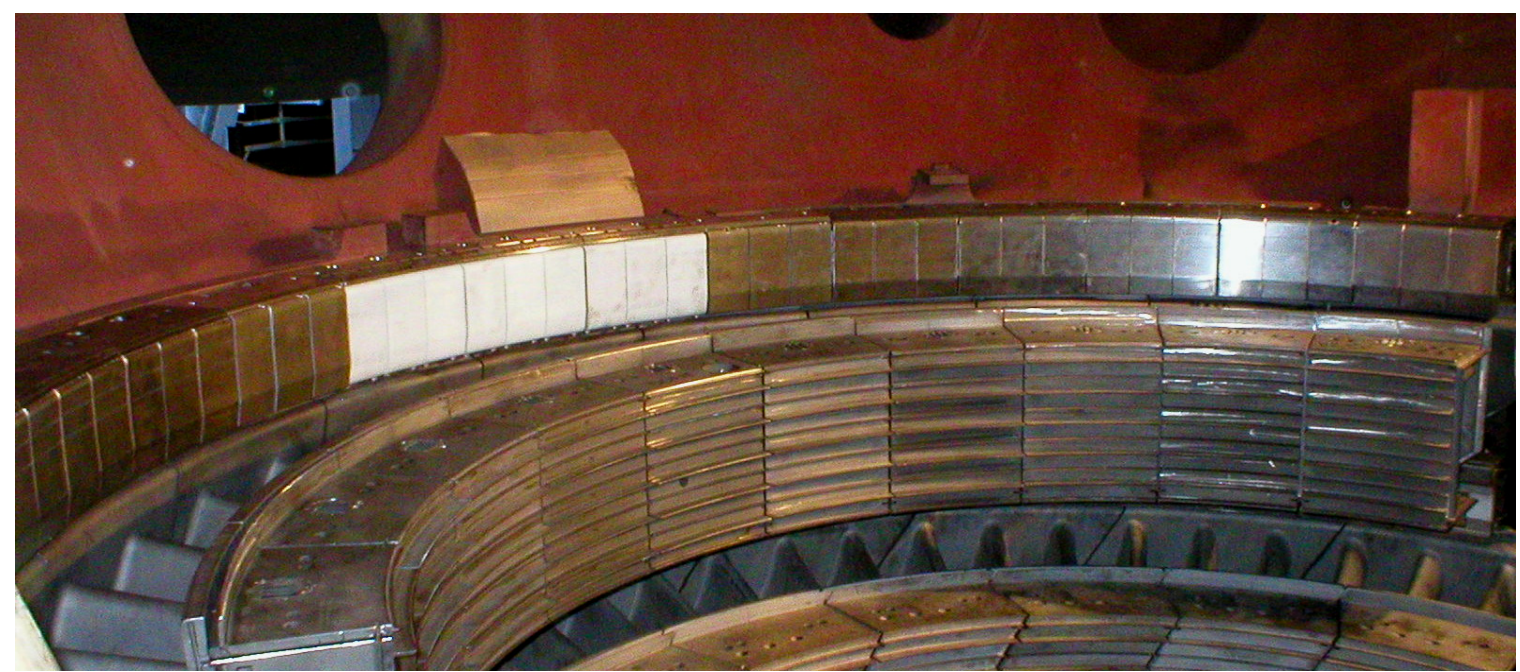

Figure 3-93. Photograph of the turbine top shell after completed installation of the $1^{\text {st }}$ stage shrouds and $2^{\text {nd }}$ and $3^{\text {rd }}$ stage nozzles. Outer shroud block \#1 is to the right and the white EBC-coated CMC shrouds in OSB positions 7 through 9 are obvious.

\subsubsection{Engine Operation}

Initial firing of the engine occurred on December 19. Initial start-up following an outage generally involves a slow ramp to full turbine speed without load to validate operation of the engine and control system, and then a stepped increase in the load on the engine until full speed-full load (FSFL) conditions are reached. This full start-up and check-out procedure ran from December 19th to the $21^{\text {st }}$, at which point the engine was shut down. During this period the engine had run for 42 fired hours with $>24$ hours at FSFL conditions. A borescope inspection was then performed to look for any infant mortality damage to the CMC shrouds. Results of this, and all the subsequent, borescope inspections are discussed in the next section.

During the performance of this shroud engine test the engine was operated in a near baseload generating mode, i.e. the engine operated for extended times with a minimal number of shutdowns (only 14 start-stop cycles occurred during the 8 month test). However, not all of the hours were at FSFL conditions. Due to daily variations in the electrical grid requirements the engine was throttled back to as much as $\sim 60 \%$ load overnight, which corresponds to a decrease in turbine firing temperature of about $60^{\circ} \mathrm{C}$ compared to FSFL conditions. A plot of engine output on a time of day basis for the period of December 23, 2002 until August 14, 2003 is shown in Figure 3-94. 


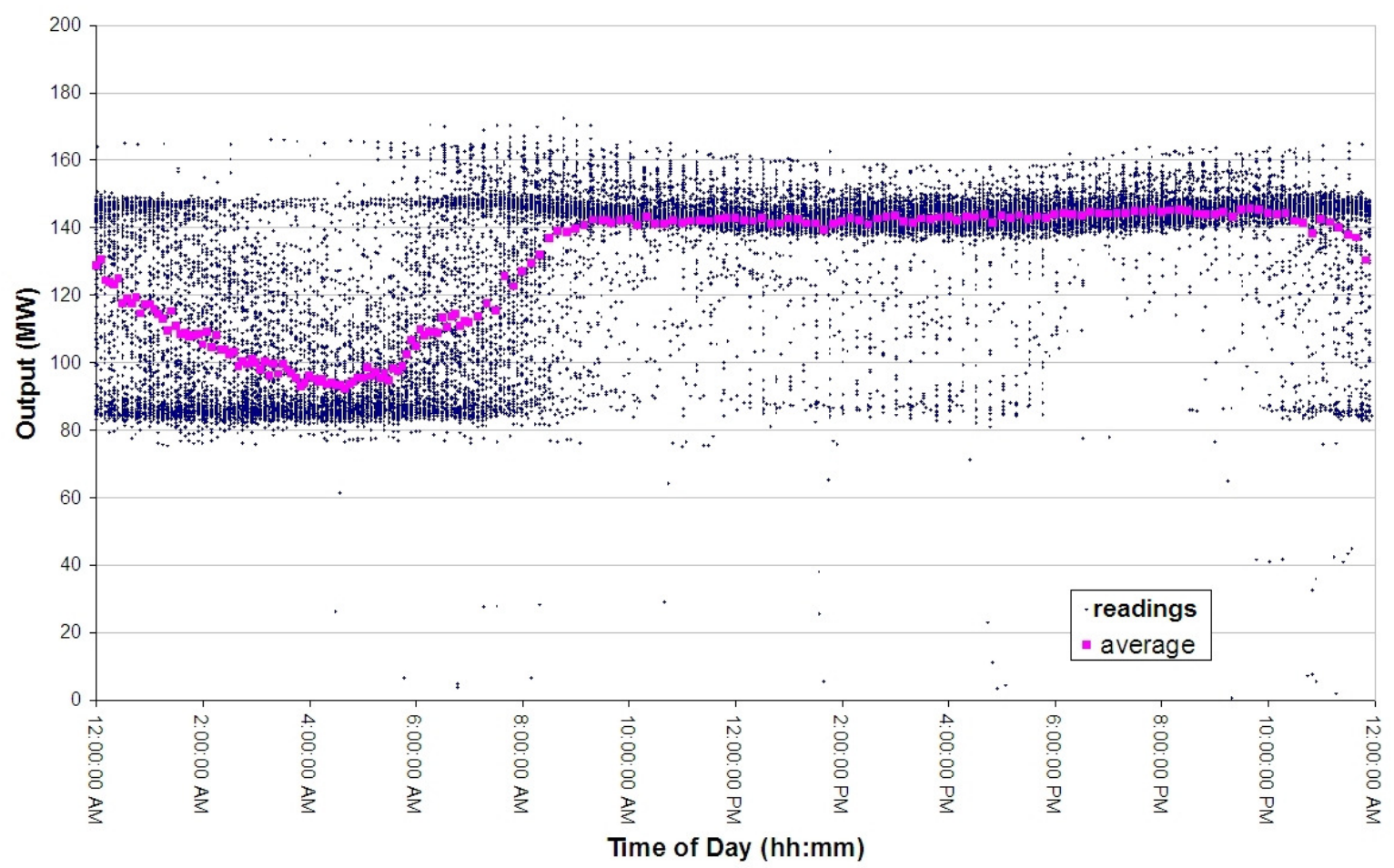

Figure 3-94. Variation of shroud test engine operation based on time of day for the period of December 23, 2002 to August 14, 2003.

\subsubsection{Borescope Inspections}

Periodic borescope inspections were performed on the $\mathrm{CMC}$ shrouds during the engine test as was permitted by the engine operation schedule. Six inspections were performed over the 8-month test in addition to the initial borescope inspection done after engine assembly. The timing of these inspections and the running hours on the shrouds at each inspection are listed in Table 3-9.

Table 3-9. Summary of CMC Shroud Inspections Done During Engine Test \#1

\begin{tabular}{|l|c|c|c|}
\hline Event & Date & $\begin{array}{c}\text { Engine Run } \\
\text { Hours }\end{array}$ & $\begin{array}{c}\text { Full Start- } \\
\text { Stop Cycles }\end{array}$ \\
\hline Borescope \#0 (following engine assembly) & $12 / 16 / 2002$ & 0 & 0 \\
\hline Borescope \#1 & $12 / 21 / 2002$ & 42 & 1 \\
\hline Borescope \#2 & $01 / 13 / 2003$ & 537 & 5 \\
\hline Borescope \#3 & $02 / 15 / 2003$ & 1206 & 8 \\
\hline Borescope \#4 & $03 / 26 / 2003$ & 2110 & 10 \\
\hline Borescope \#5 & $05 / 01 / 2003$ & 2935 & 11 \\
\hline Borescope \#6 & $06 / 28 / 2003$ & 4276 & 13 \\
\hline Engine disassembly & $08 / 17 / 2003$ & 5366 & 14 \\
\hline
\end{tabular}


As noted above, no evidence for shroud damage during the engine assembly process was found during borescope inspection $\# 0$. Similarly, there were no significant observations at borescope inspection \#1 after the first 42 hours of engine operation.

The first evidence of any shroud damage was first noted during borescope inspection \#2 at 537 hours of engine running time, but both occurrences were considered to be relatively minor. The first of the observations was evidence of small indents or pits being formed in the EBC surface on at least two of the shrouds. Such features were found on at least two shrouds, as shown in Figure 3-95, but since they were only noticeable at rather shallow viewing angles they may have been present on other shrouds but not detected. Initially it was believed that these pits were caused by FOD events, but in the case of the slurry cast shrouds it eventually became evident that there was another root cause.
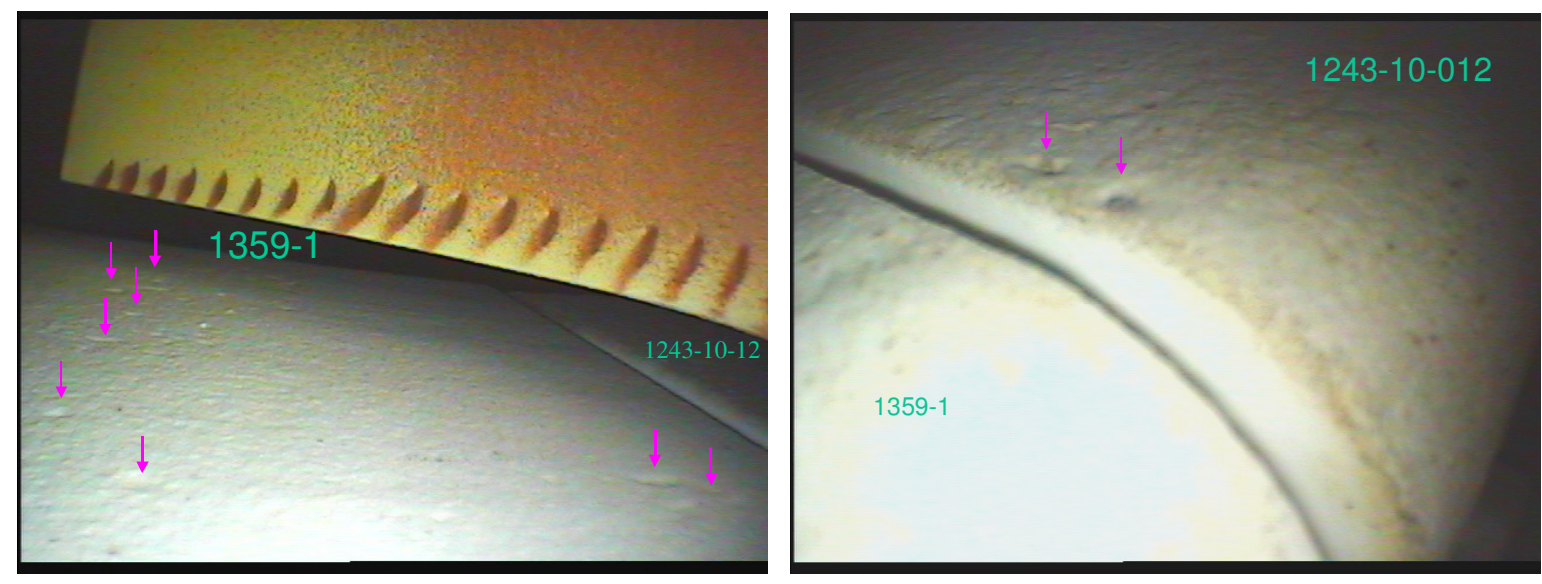

Figure 3-95. Borescope photographs from borescope inspection \#2 showing small indents or pits in the EBC surface of GE prepreg MI shroud 1359-1 (left) and on slurry cast MI shroud 1243-10-012 (right).

The second type of EBC damage observed in borescope inspection \#2 was a small chip in the EBC coating around the rear flange bolt head on shroud 1109-2. This EBC chip is shown in Figure 3-96. This damage did not correspond to any unusual feature seen on the pre-test shroud photographs, and was likely caused by insufficient clearance of the bolt head and the CMC shroud such that during thermal cycling the EBC at the edge of the bolt head became crushed and subsequently flaked off. 


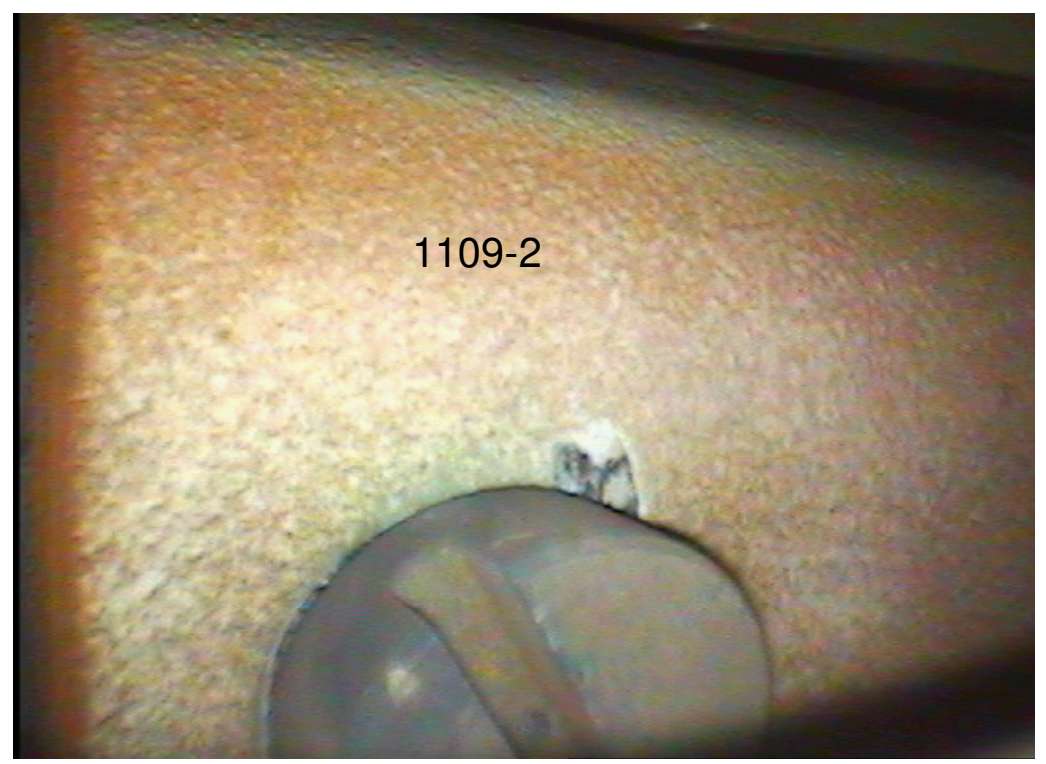

Figure 3-96. Borescope photograph showing the EBC chip at the rear hole bolt attachment of shroud 1109-2.

As the engine test progressed more and more types of damage to the EBC coatings were noted in the later borescope inspections. An attempt was made to classify the types of damage based on their size, shape, location and general appearance during the borescope inspections. The categories used for classification were "pits", which were generally round in shape and occurred away from the shroud edges, "chips", which were more irregular in shape than the pits and generally associated with a shroud edge, "cracks", which were thin cracks in the EBC, "spall/cracks", which were where areas of the EBC adjacent to a crack had been liberated, and "bulges", which were raised areas of the EBC/CMC surface that were only observable at shallow viewing angles and were seldom associated with any EBC damage. As time went by the "spall/crack" category was expanded to include large areas of EBC spallation since these areas seemed to initiate primarily at the crack-like features, although some of the later large spalls appeared more associated with a FOD-like chip in the CMC. The classification of the defects was very subjective and only used as a general guide for keeping track of the various damage features seen in the borescope images.

The schematic diagram in Figure 3-97 represents the progression of EBC damage seen in the borescope inspections through the engine test. In this diagram each row represents the results of a different inspection, from borescope inspection \#3 across the top row down to the post-test inspection across the bottom row. Each of the gray rectangles in each row represents a different shroud, the identity of which is given below the bottom row. The larger green boxes represent the three outer shroud blocks so that the position of each shroud within the shroud blocks is represented. The types of defects are color coded according to when they were first noted according to the legends at the bottom of the figure. 
The first indications of significant EBC damage were during borescope inspection \#3, which was performed on February 15, 2003, after 1206 hot hours on the shrouds. By this time the EBC pits previously noted on slurry cast shroud 1243-10-12 had definitely penetrated down at least as far as the EBC bond coat or possibly even into the CMC, as shown in Figure 398. Three of the prepreg MI shrouds now also had similar pits in the EBC, but the depths of the pits on these shrouds were smaller than shown in Figure 3-98.

The small EBC chip at the aft bolt head on shroud 1109-2, as shown in Figure 3-96, did not grow between borescope \#2 and \#3 at all; however, a new small EBC chip was found on the edge of this same shroud. The more alarming observation was the start of EBC cracks along the edges of many of the shrouds, some of which had already liberated chips of EBC. Figure 3-99 shows two examples of an early stage of this type of damage as seen in borescope \#2.

By the time of borescope inspection \#4, at 2110 engine hours, the number and size of the EBC edge cracks and chips had grown. Also a large number of EBC pits became evident, especially on the three slurry cast shrouds. The first and only bulge was also first noted at this time in shroud 1106-1. A borescope photograph of this feature is shown in Figure 3100. The location of the bulge was consistent with the location of a near-surface delamination in the shroud, as seen in the IR NDE image of the shroud also shown in Figure $3-100$.

At borescope inspection \#5, at 2935 test hours, there was again only a slight growth in the number and size of the edge crack/spall defects. There were also a few additional EBC chips and pits detected during this inspection. At this point the pit defects in the slurry cast shrouds were showing a definite regular pattern, as shown in Figure 3-101. This pattern and spacing of EBC pits replicated the location and spacing of holes in the CVI tooling used for deposition of the fiber coatings during manufacture of these shrouds. During the CVI fiber coating step the sheets of fiber cloth are held compacted inside graphite tooling with periodic holes to allow in the ingress of the reactant gases. There is a tendency for the fiber cloths to bulge outward slightly at these tooling holes, forming small bumps on the surface of the parts. These bumps then persist through the remaining process steps, including $\mathrm{SiC}$ matrix CVI deposition, slurry casting and final melt infiltration densification. These "tooling bumps" are only a few tenths of a millimeter in height, and thus it was not clear why they should influence the EBC coating deposition process or the adhesion of the EBC. Nonetheless similar EBC spalls at tooling bumps had been observed during testing of slurry cast MI combustor liners in the Solar CSGT engine [15]. 


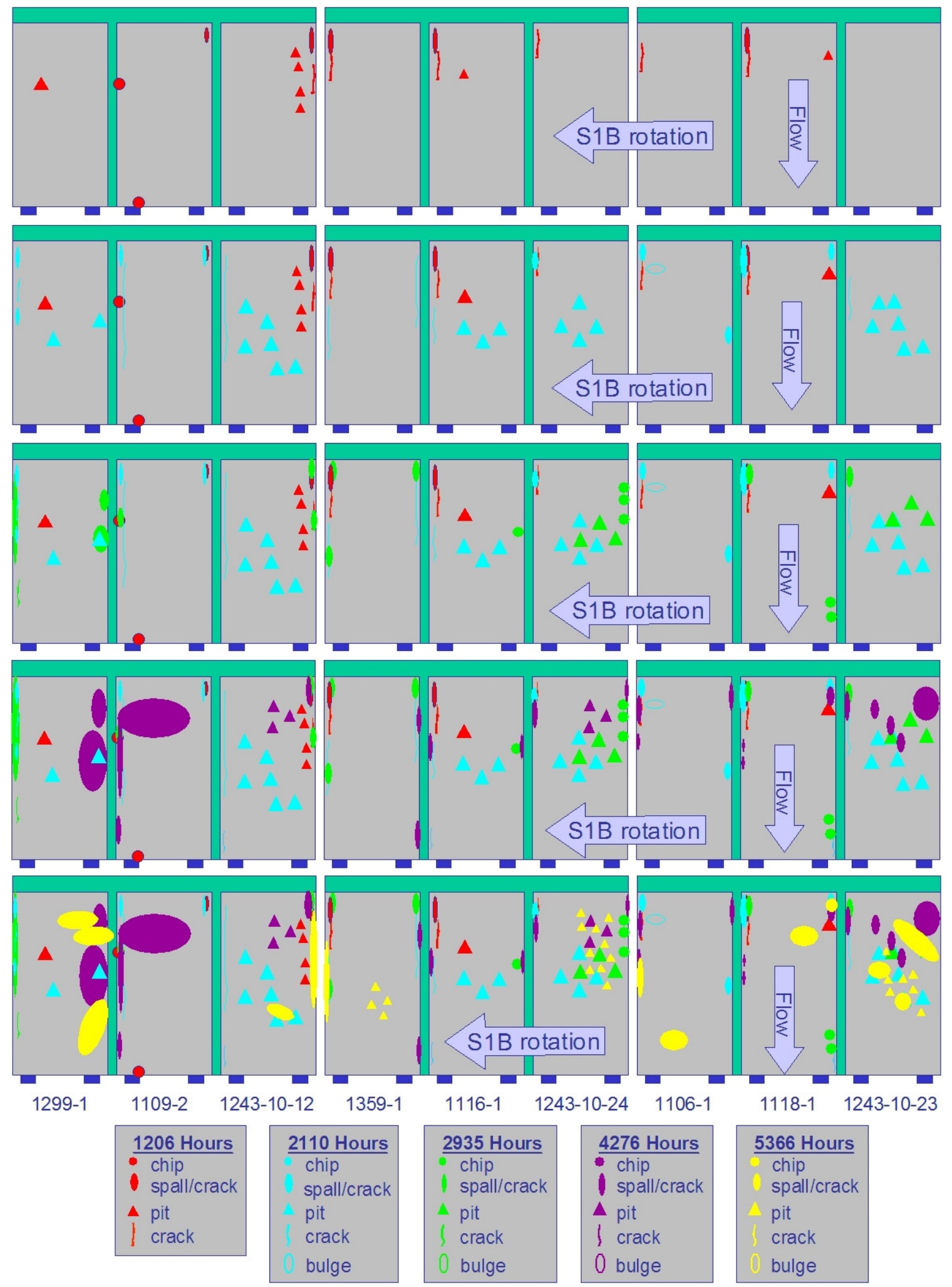

Figure 3-97. Schematic of the progression of EBC damage noted during the shroud engine test. Each row represents a separate inspection, from borescope \#3 at the top to the post-test condition of the shrouds across the bottom. 


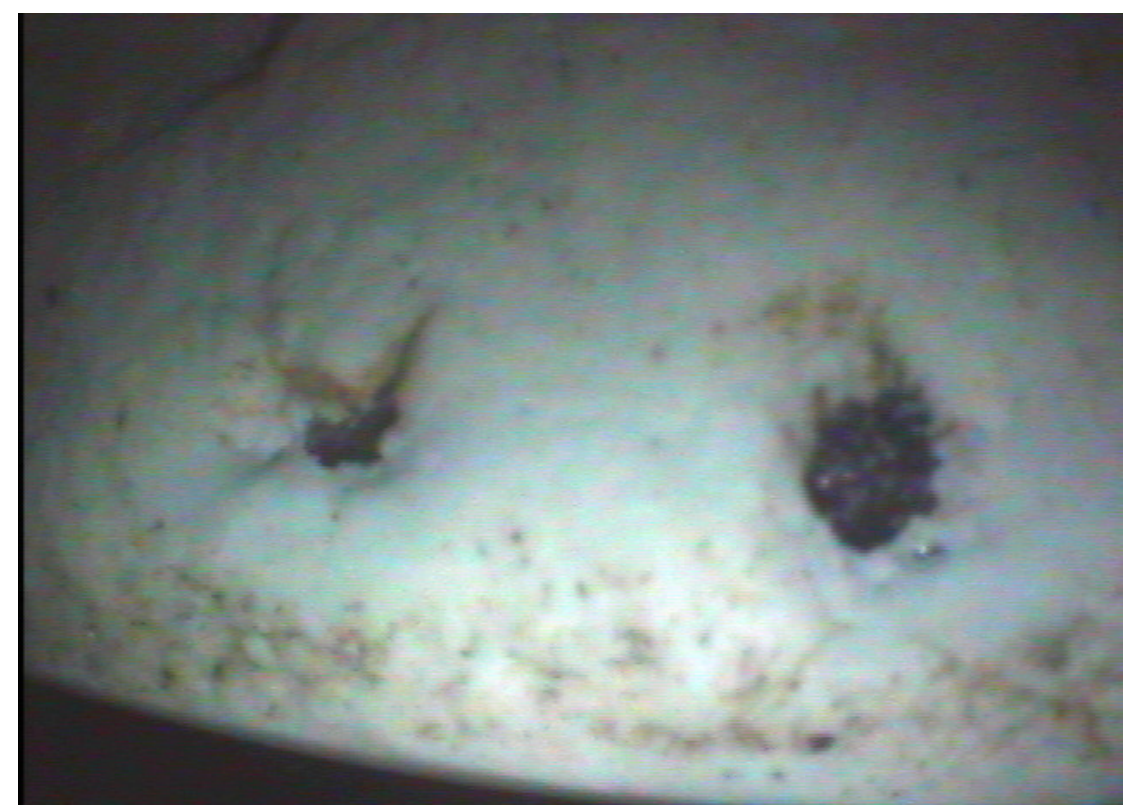

Figure 3-98. Borescope photograph of the surface EBC chips on shroud 1243-10-12 taken during the $3^{\text {rd }}$ borescope inspection on $02 / 15 / 2003$. The dark areas at the bottom of the pits indicate that $\mathrm{EBC}$ bond coat and/or $\mathrm{CMC}$ has been exposed.
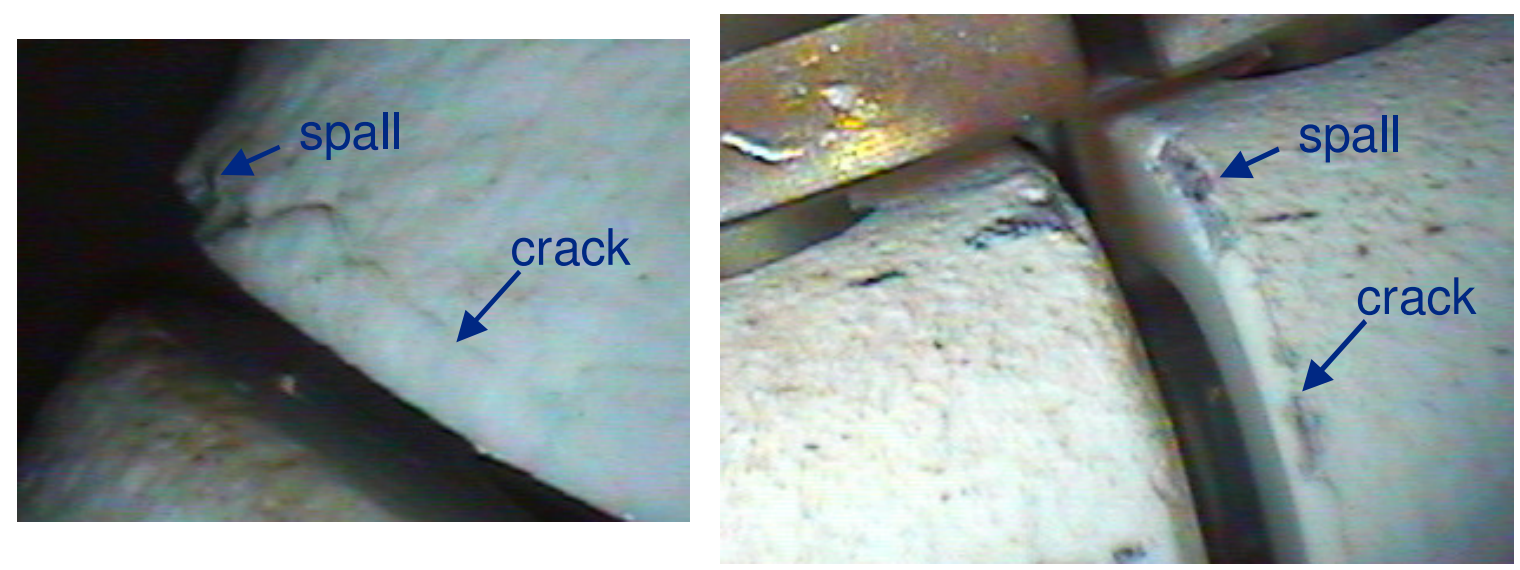

Figure 3-99. Borescope photographs of two of the initial EBC crack/spall defects seen during borescope inspection \#3: Left - shroud 1118-1; Right - shroud 1359-1. 


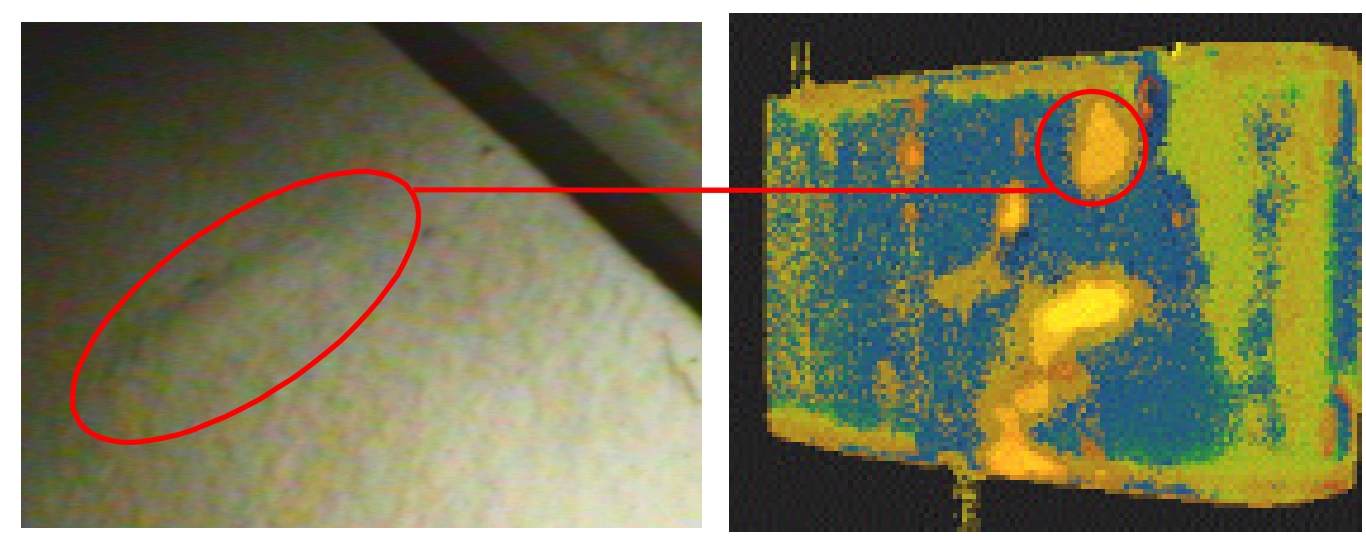

Figure 3-100. Left - borescope photograph of the "bulge" detected in shroud 1106-1 during borescope inspection \#4. Right - corresponding IR NDE image of this shroud indicating that a near-surface delamination was in this same location on the shroud.
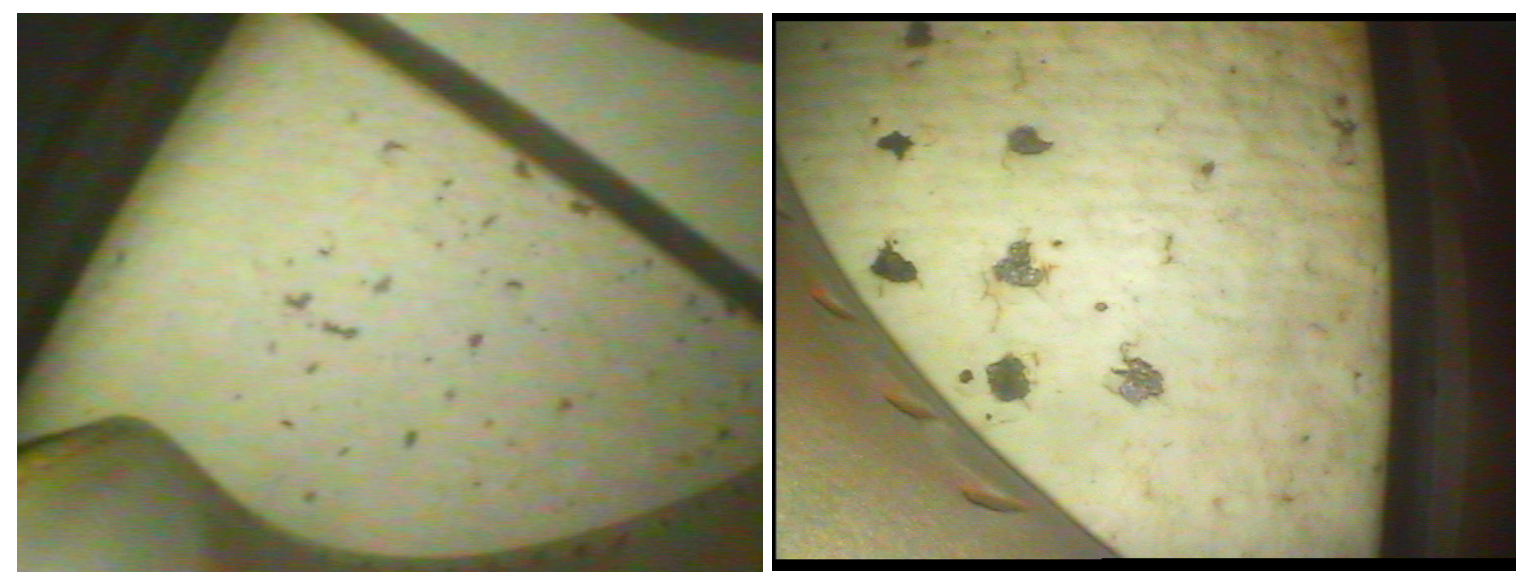

Figure 3-101. Borescope photographs of slurry cast shrouds 1243-10-24 and 1243-10-23 taken during borescope inspection \#5, showing the regular, periodic spacing of the EBC pits on these shrouds.

Large-scale spalls in the EBC coating were not noted until borescope \#5 at 4276 engine test hours. Two of the prepreg MI shrouds (1299-1 and 1109-2) and one of the slurry cast shrouds (1243-10-23) had large EBC spalls (i.e. covering more than $\sim 50 \mathrm{~mm}^{2}$ ) at this inspection. The spalls on the prepreg shrouds were believed to have resulted from the propagation of pre-existing damage from the edges of the shrouds out onto the hot gas path faces of the shrouds; however, there had only been a few small pits previously in the location of the spall on the slurry cast shroud. Borescope photographs of each of these spalls are shown in Figure 3-102. 

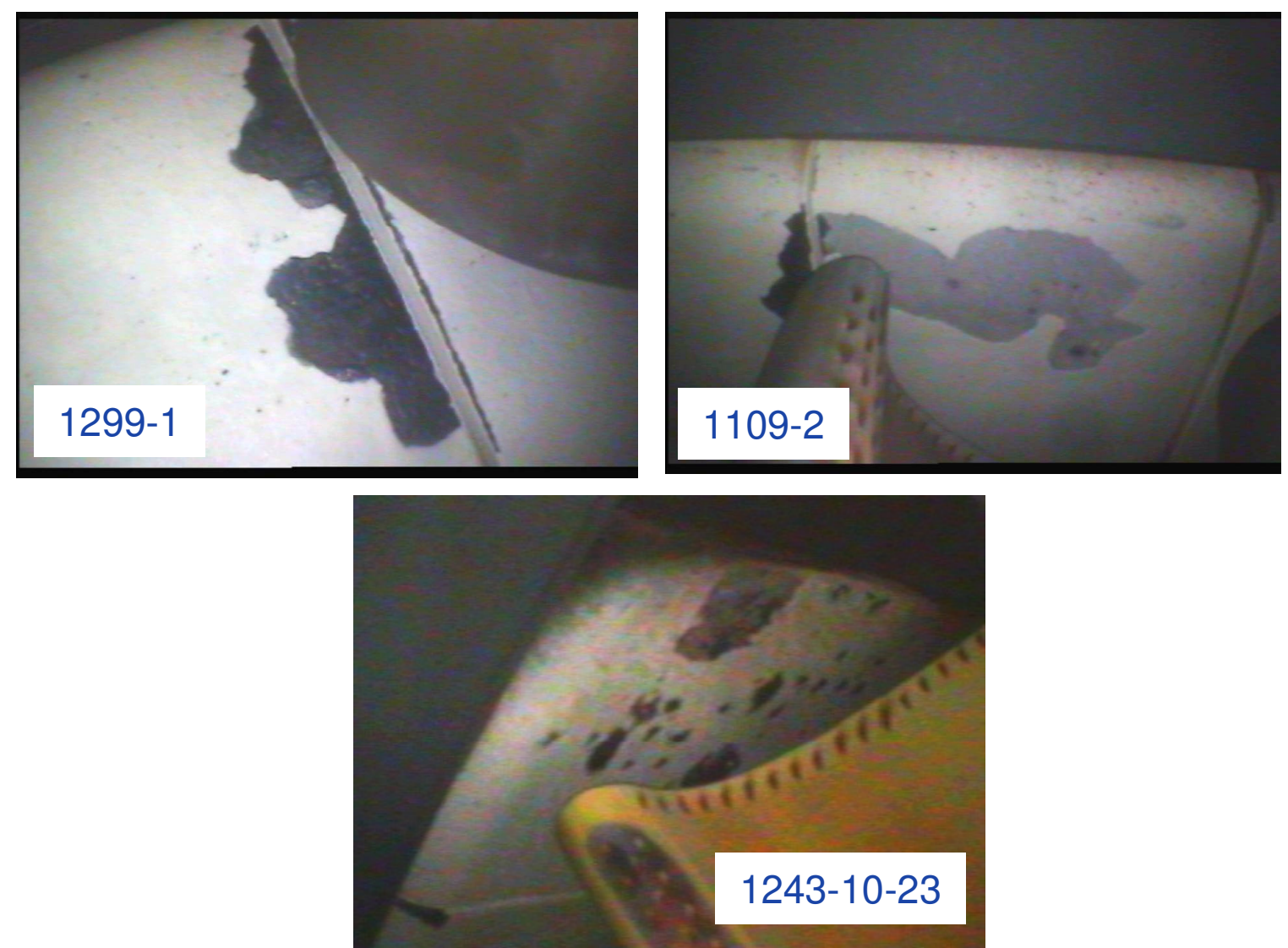

Figure 3-102. Borescope photographs from borescope inspection \#5 showing the large area EBC spalls first noted at this interval.

\subsubsection{Shroud Removal and Disassembly}

The shroud engine test was stopped prematurely on August 14, 2003 after the shrouds had seen a total of 5366 fired hours. The original intent had been to run the shrouds for a full year, or 8,000 hours of engine operation; however, there had been a turbine component failure in one of the sister engines at this generation site and the utility operator decided to disassemble the turbine section of each of the engines on site to do a detailed hardware inspection. At this time the shrouds had reached over $2 / 3$ of their intended exposure time and were showing EBC damage, as summarized in the previous section. If the CMC shrouds were to remain in the engine they would be required to operate for an additional year and up to an additional 8,000 hours until the next engine outage opportunity, and there was a significant perceived risk in doing so owing to the EBC damage and CMC recession that was undoubtedly occurring. It was also feared that important information related to the observed EBC spalls would be lost through continued spallation and CMC volatilization should the shrouds continue in the engine for an extended period. The decision was therefore made to remove the $\mathrm{CMC}$ shrouds from the engine test to allow for detailed characterization of the $\mathrm{CMC}$ and $\mathrm{EBC}$. 
Engine disassembly after the shroud test proceeded normally. Figure 3-103 shows a photograph of the top half of the turbine shell after it had been lifted off the engine and the white EBC-coated CMC shrouds are clearly visible. Figure 3-104 shows photographs of the three outer shroud blocks with CMC inner shrouds after the engine test while they were still mounted in the turbine upper shell. The $2^{\text {nd }}$ stage nozzles were first removed from the turbine shell so that the $1^{\text {st }}$ stage shroud blocks could be removed. The shroud blocks containing the CMC shrouds and the two metal transition shrouds were shipped to GE GRC intact for further disassembly.

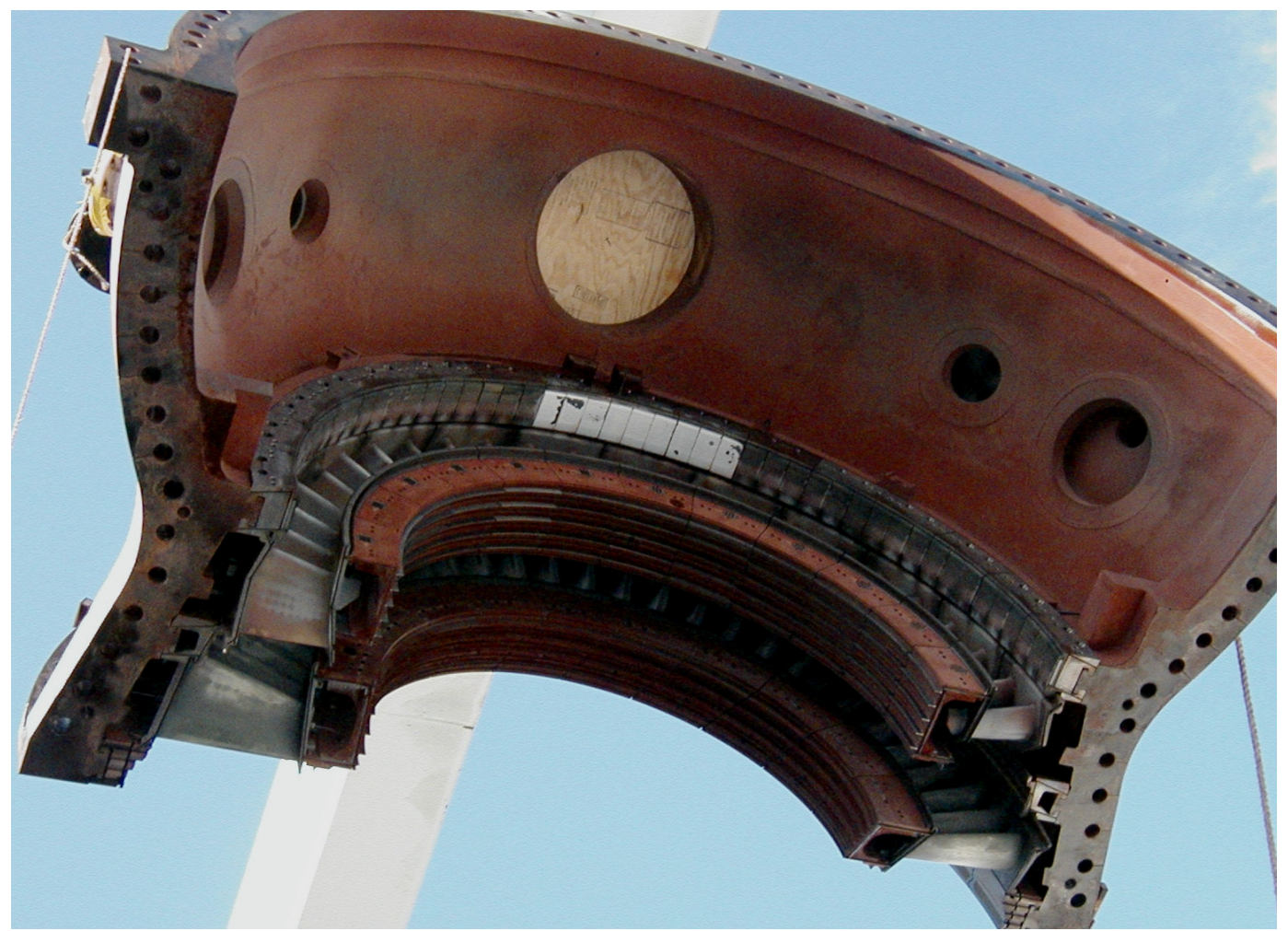

Figure 3-103. Photograph of the shroud test engine upper turbine shell after it had been lifted off the turbine showing the location and condition of the CMC shrouds (white rectangles in the center of the shroud half ring) 


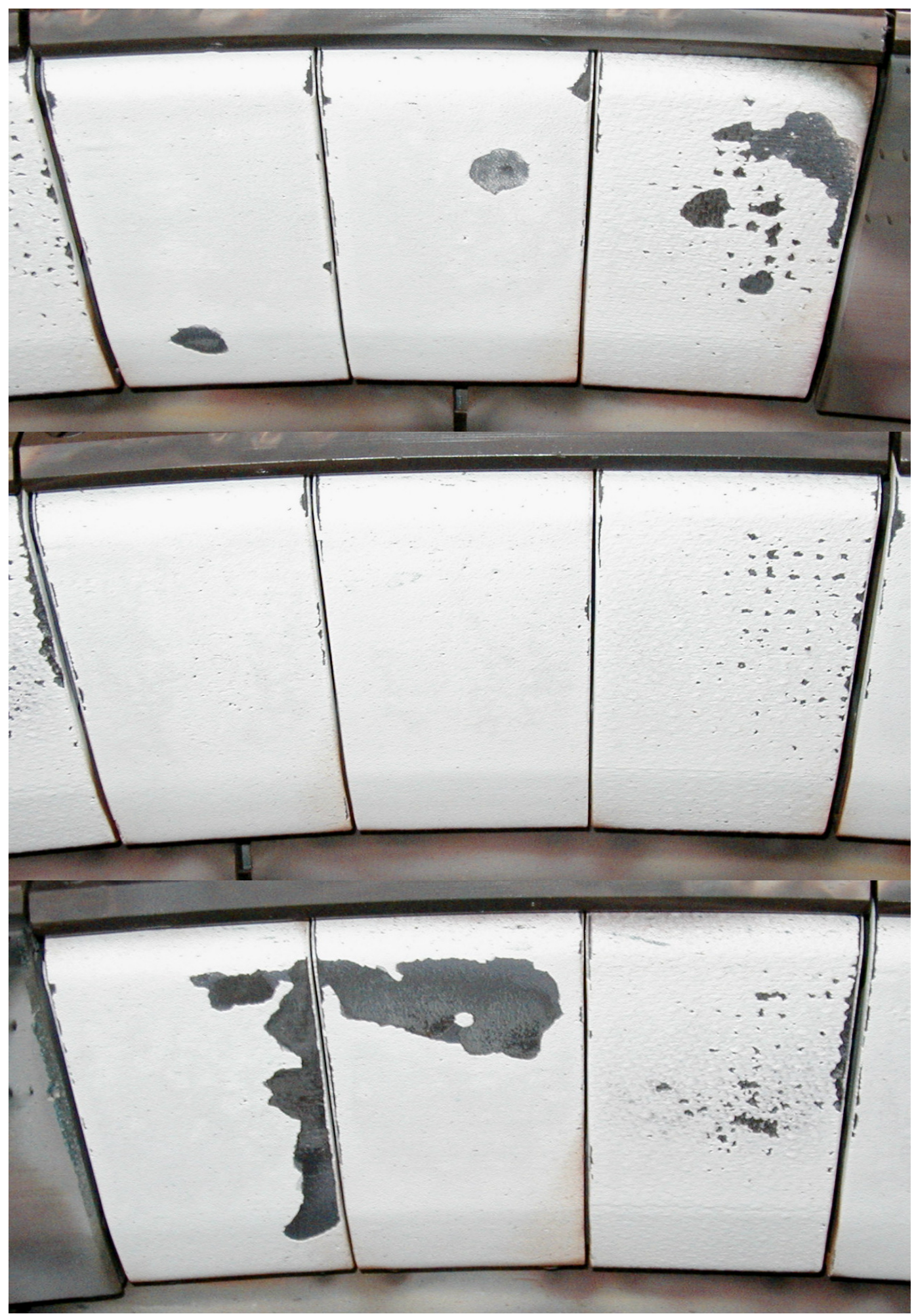

Figure 3-104. Photographs of shroud outer blocks \#6 (top), \#7 (middle) and \#8 (bottom) while still mounted in the turbine upper casing following the shroud engine test \#1. 


\subsubsection{Task 4.4 - Post-Test Characterization}

\subsubsection{CMC Inner Shrouds \\ 3.1.17.1.1 Non-Destructive Characterizations}

Photographic documentation and IR NDE were performed on the CMC shrouds while still in the outer shroud blocks in order to document their condition following the engine test and before any handling damage from shroud disassembly could occur. The photographic documentation agreed exactly with that done at the engine test site before the shrouds were removed from the turbine shell (except for some grease smears on the shroud faces), thereby indicating that there had been no additional damage to the shrouds during removal of the outer shroud blocks. Extensive measurements were taken of the shrouds while still in the outer shroud blocks, which confirmed that the inner shroud-to-inner shroud and inner shroud-to-outer shroud clearances and tolerances were all maintained throughout the test.

The overall shroud attachment hardware was found to be fully functional with all of the shrouds positively seated on the pins/bolts. During disassembly most of the metallic hardware in the outer shroud block could be removed without any problems; however, there were a few parts that required "coaxing" with a few taps of a hammer, and some of the forward attachment pins had to be partly drilled out of the outer shroud block in order to fully free the CMC inner shrouds. Figure 3-105 shows photographs of the hot gas path face and inner surface of the CMC inner shrouds after removal from the outer shroud blocks.

In addition to the EBC damage found on the hot gas path faces of the shrouds, quite extensive damage was also noted on the backs of many of the shrouds, particularly the prepreg shrouds. In many cases the EBC spalls on the back of the shrouds was associated with the contact areas between the inner shroud and damper blocks; however, it could not be determined unambiguously that such contact was the initiating cause of the EBC spallation.

Overall there were five types of EBC damage noted on the shrouds as had been observed and described during the borescope inspections: 1) EBC cracking and chipping along the edges of the shrouds, 2) formation and growth of pin-holes on the slurry cast shrouds related to the tooling bumps, 3) small pits on the prepreg shrouds that did not appear to grow appreciably during exposure, 4) large spall regions on the hot gas path faces, and 5) large spall regions on the back surfaces. Items 1-4 were all noted during the borescope inspections of the shrouds, but number 5 was not seen before because there was no borescope probe access to the backs of the shrouds. Examples of each of these types of damage are shown in Figure 3-106. 
Hot Gas Path Surfaces

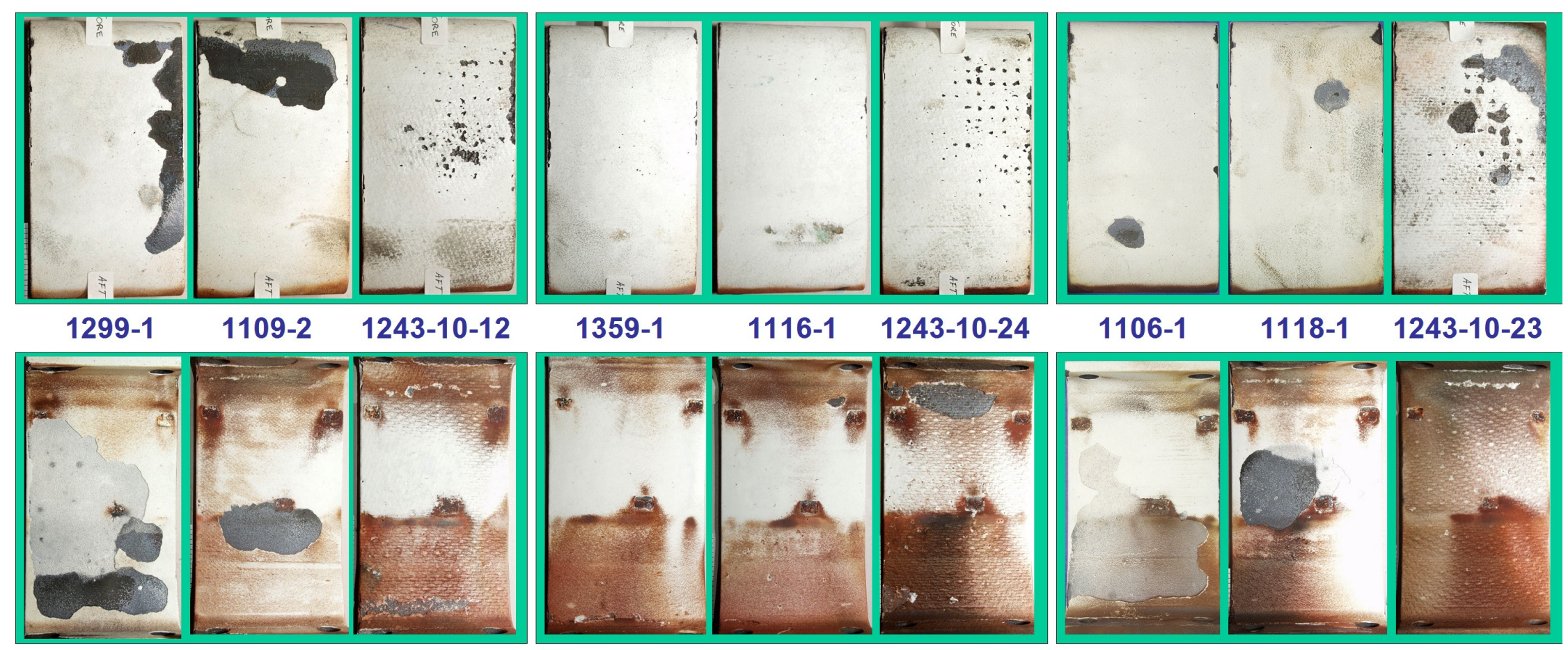

Inside Surfaces Toward Outer Shroud Blocks

Figure 3-105. Photographs of the CMC inner shrouds after the engine test and after removal from the outer shroud blocks. 


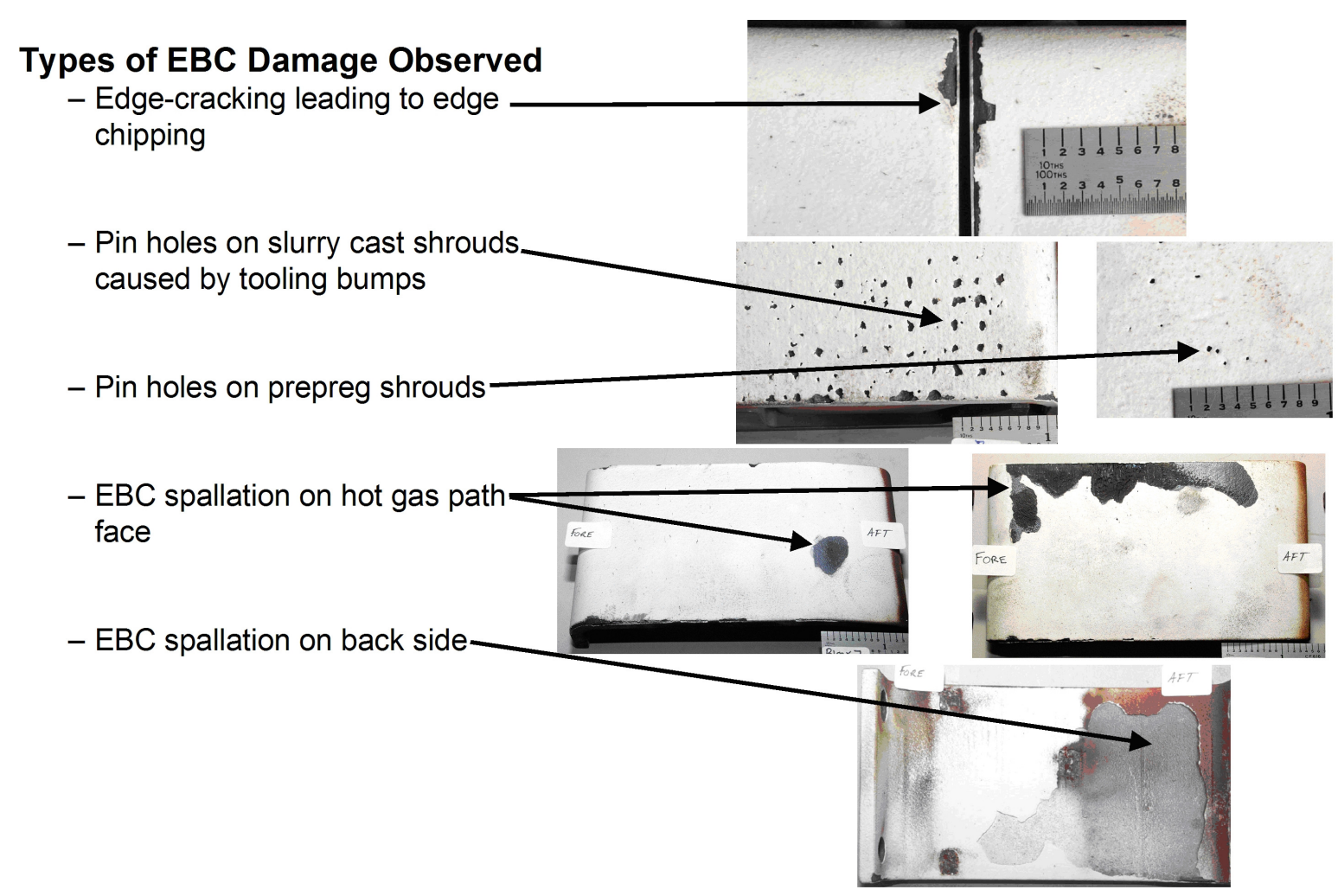

Figure 3-106. Examples of EBC damage noted on the shrouds following the 5366 hour engine test.

Transient IR NDE was performed on all of the shrouds to look for evidence of EBC coating debonding away from the spalled regions. Figure 3-107 shows a photograph and IR image of prepreg shroud 1299-1, the prepreg shroud that showed the earliest and most extensive EBC spallation on the hot gas path face. In the NDE image the blue color represents areas where the thermal wave was not impeded in its conduction into the sample, so that either the EBC was still well-bonded to the substrate or there was no EBC at all. The yellowgreen color indicates areas where the thermal wave was interrupted at a depth corresponding to the EBC bond coat. As can be seen, the edge of the existing spall shows evidence of continuing delamination, or at least continuing bond coat oxidation and cracking. Even the green region near the bottom is extending inward from an edge chip. These results suggest that most of the EBC damage on this shroud was caused by growth of the delamination from edge defects, which is consistent with the borescope observations. However, in other prepreg and slurry cast shrouds there were regions noted where NDE indicated a loss of coherence between the EBC and substrate without an obvious, significant defect in the EBC in the immediate vicinity. 


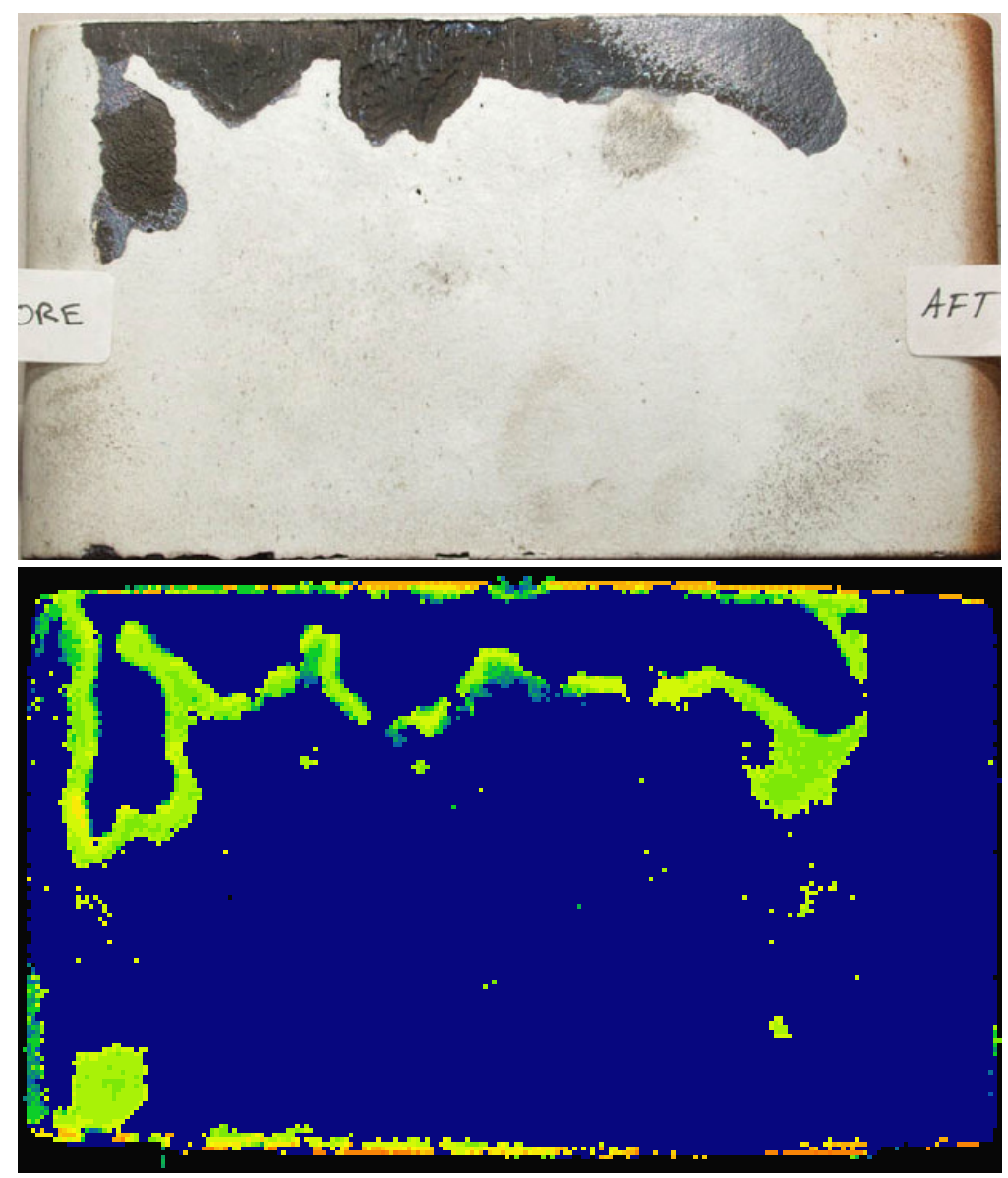

Figure 3-107. Photograph (top) and IR NDE image (bottom) of prepreg shroud 1299-1. The green-yellow areas on the NDE image indicate regions where the EBC has lost intimate contact with the substrate.

The modal response of each of the shrouds was also measured after the engine test and compared to the response measured on the as-machined shrouds. Subtle changes in modal frequencies, on the order of $2 \%$ to $4 \%$, were attributable to the presence of EBC coating, which was not present on the shrouds during the initial testing. The effect of EBC was determined by doing the modal analyses before and after EBC deposition on one of the shrouds not used in the engine test. Very similar 2\%-4\% shifts in the modal frequencies were observed as a result of the EBC coating. The scatter in frequency shift was somewhat higher for the engine-tested shrouds, but this is easily attributable to the varying degree of EBC spallation and recession that occurred in these shrouds.

One important concern going into the engine test was what would happen to pre-existing defects in the CMC shrouds during engine exposure. Pre-test NDE examinations indicated that all of the prepreg shrouds showed evidence of pre-existing defects, mostly delamination-like cracks. For example, the first NDE image in Figure 3-108 shows a delamination in the aft bend region of shroud 1299-1. After sectioning of the shroud (to be discussed in the next section) the EBC coating was removed from the rear bend section of 
this shroud and IR NDE was performed on this piece. The post-test NDE image shows the same defect with no changes in defect shape or severity. This result indicated that the CMC shrouds were relatively resistant to propagation of pre-existing defects. This observation was also consistent with the microstructural examinations of the shrouds, described in the next section, which did not detected any CMC damage other than simple recession in the region of failed EBC.
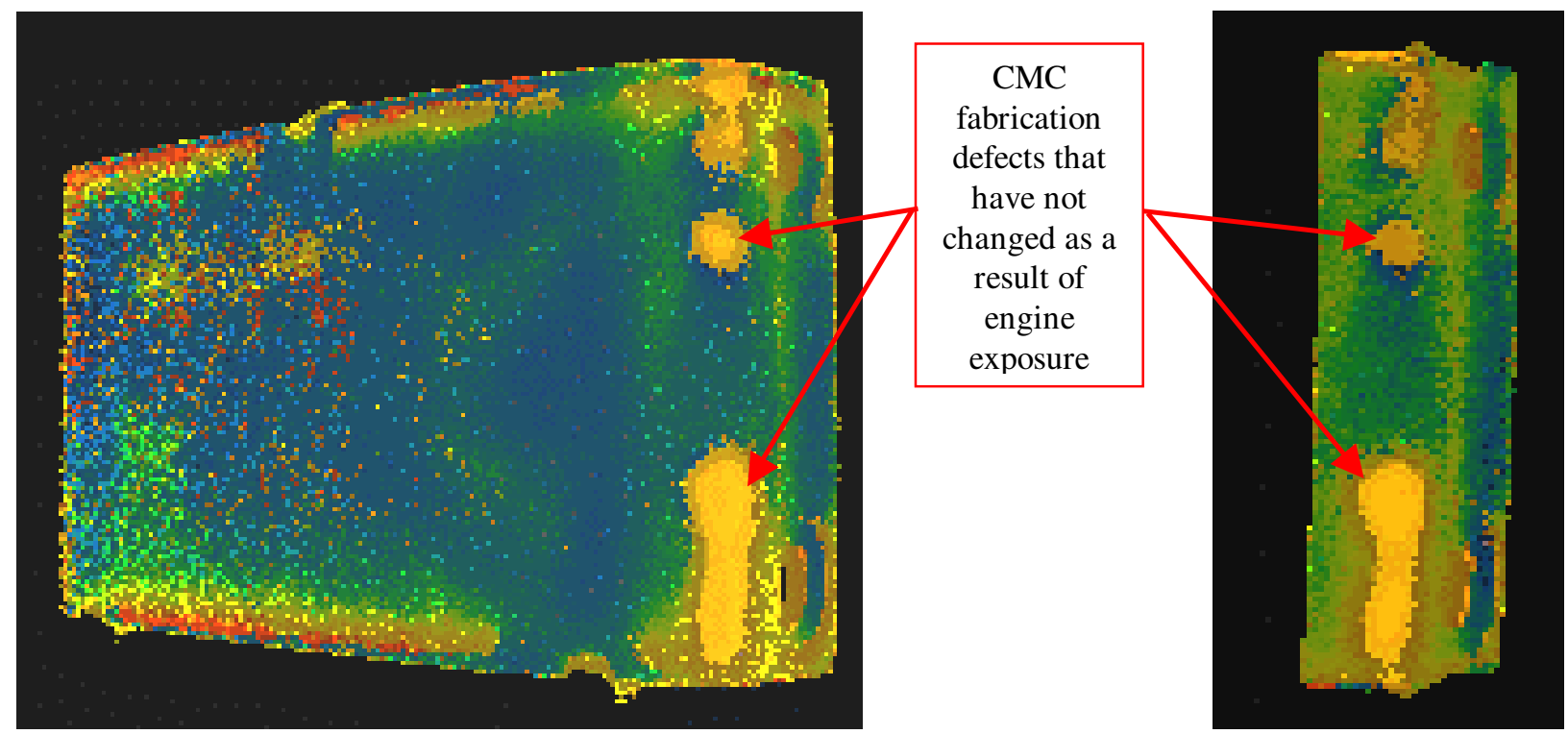

Figure 3-108. NDE images showing the rear bend region of shroud 1299-1 prior to EBC coating (left) and after EBC removal following the field engine test (right).

\subsection{Destructive Characterization - Microstructure}

Following dimensional and NDE examination five of the nine shrouds were selected for destructive examination, including three prepreg and two slurry cast shrouds. The shrouds were generally sectioned in the pattern indicated in Figure 3-109, which allowed for samples for both mechanical and microstructural evaluations. The sectioning pattern was adjusted as needed in order to preserve specific features unique to any particular shroud. In general, the fore bend, aft flat, aft flange and edge bars were reserved for microstructural analysis of both the EBC coating and CMC substrates.

As would be expected, any region on the hot gas path face where the EBC was damaged (edge chips, pits or large spalls) showed evidence of CMC recession. Recession was typically deeper on the slurry cast shrouds, but this was probably due to the relatively early formation of the tooling bump pits and therefore longer exposure time of the CMC to the environment. Micrographs of the more extreme recession features, from a spall on prepreg shroud 1299-1 and a tooling bump pit on a slurry cast shroud, are shown in Figure 3-110. 

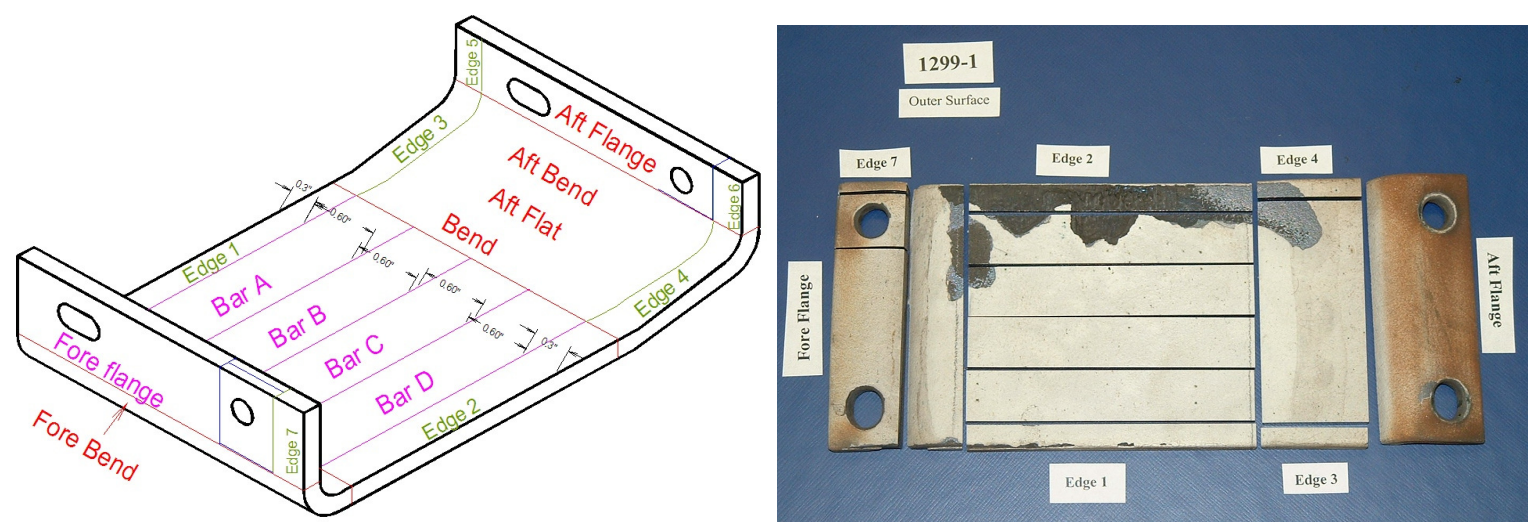

Figure 3-109. Diagram of how the shrouds were sectioned for destructive evaluations (left), and a view of the pieces of shroud 1299-1 after sectioning (right)

It was practically impossible to determine the exact time when a specific tooling bump pit first formed on the slurry cast shrouds; however, the start time of the large spall on shroud 1299-1 was clearly bracketed based on the borescope inspections. This spall is known to have not been present at the 2110 hour inspection, and was only starting to appear along the edge of the shroud at the 2935 hour inspection. However, because this spall started along the edge of the shroud, and the edges had poorly defined chamfers, it was impossible to determine unambiguously the depth of recession immediately at the edge. At the 4276 hour inspection the spall was well developed away from the immediate edge of the shroud. Thus the spall had been present for between 2431 and 1090 hours in the region where we could perform a reasonable measurement on the recession depth.

Based on this range of exposure times, and allowing for variation in other factors such as local surface temperature, gas velocity, and gas moisture content, the predicted amount of recession ranged from 1.1 to $2.5 \mathrm{~mm}$ using the GE recession model, or from 0.5 to $1.1 \mathrm{~mm}$ using the published NASA model [13]. As shown in Figure 3-110, the maximum observed recession depth on prepreg shroud $1299-1$ was $0.798 \mathrm{~mm}$. This result indicates that, within the uncertainty in exact exposure conditions, the prepreg shroud recessed less than was expected from the GE recession model. 

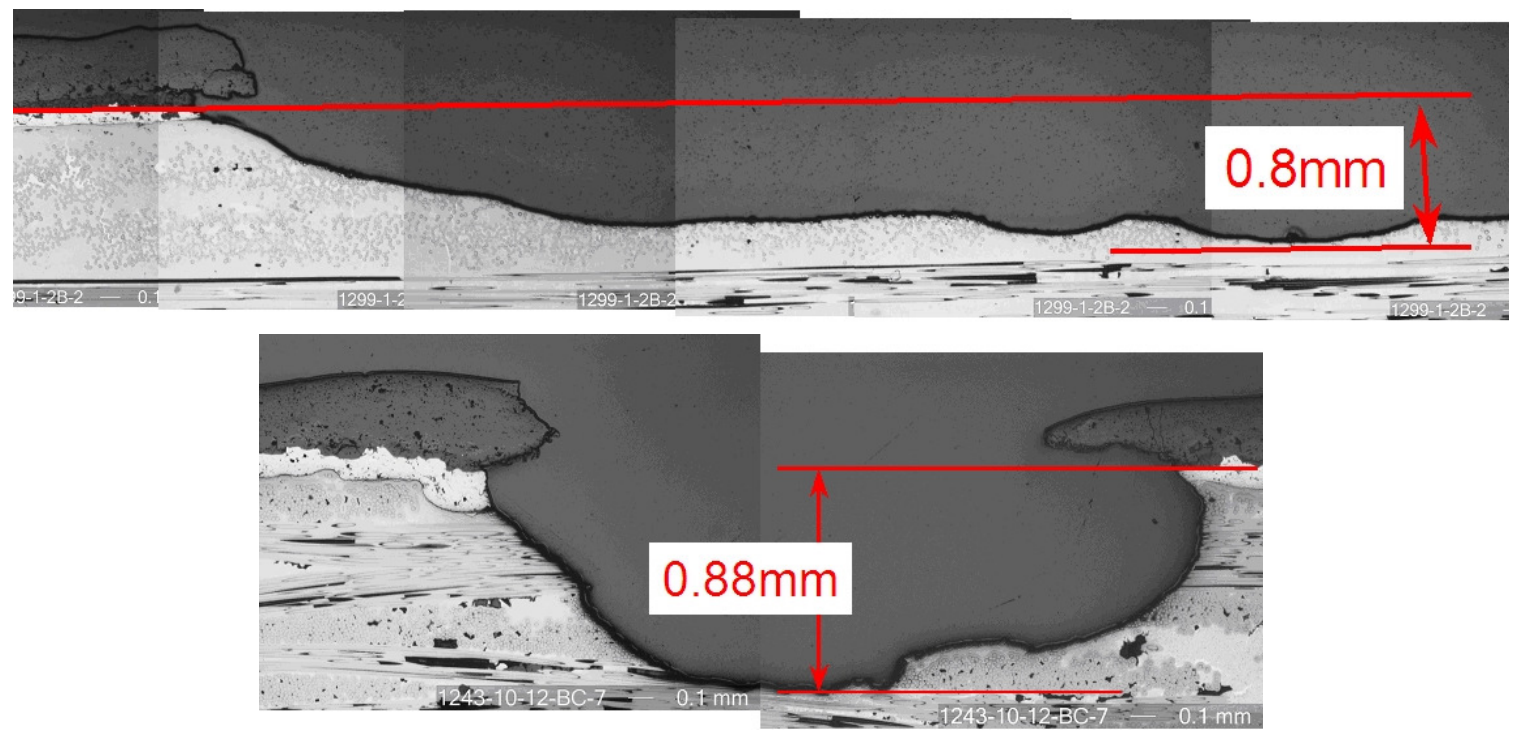

Figure 3-110. Top - Micrograph montage of the CMC recession at the EBC spall location on prepreg shroud 1299-1.

Bottom - Micrograph montage of CMC recession under an EBC tooling bump pit on slurry cast shroud 1243-10-12.

Although holes in the EBC were mostly associated with tooling bumps on the slurry cast shrouds, the prepreg shrouds also had a smaller number of small holes in the EBC. A typical example from shroud 1118-1 is shown in Figure 3-111. Although the size of the hole in the EBC was rather small, the cross section of the pit shows that there was undercutting of the EBC coating due to recession of the CMC. This undercutting of the EBC oxide layers was a common feature to most of the EBC holes or spalls, and is testament to the stability of the EBC oxide coating layers in the combustion gas environment.

One of the earliest EBC damage modes noted in the engine test was the generation of cracks along the shroud edges and subsequent spalling of regions of the EBC from the edges. In parallel with the engine test there had been efforts at GE GRC to investigate the initiation of this type of EBC damage in the laboratory. Several of the "extra" shrouds that had been EBC coated in preparation for the first engine test were sectioned and the edges of the shroud examined metallographically. Several of the shrouds used in the shroud rig tests were also sectioned and these regions of the shrouds characterized in more detail. An important feature found on these shrouds was regions of porous silicon bond coat, preferentially at the corner between the hot gas path surface and the left edge of the shroud. A series of micrographs from these corners at various locations around shroud 1365-1 are shown in Figure 3-112. 

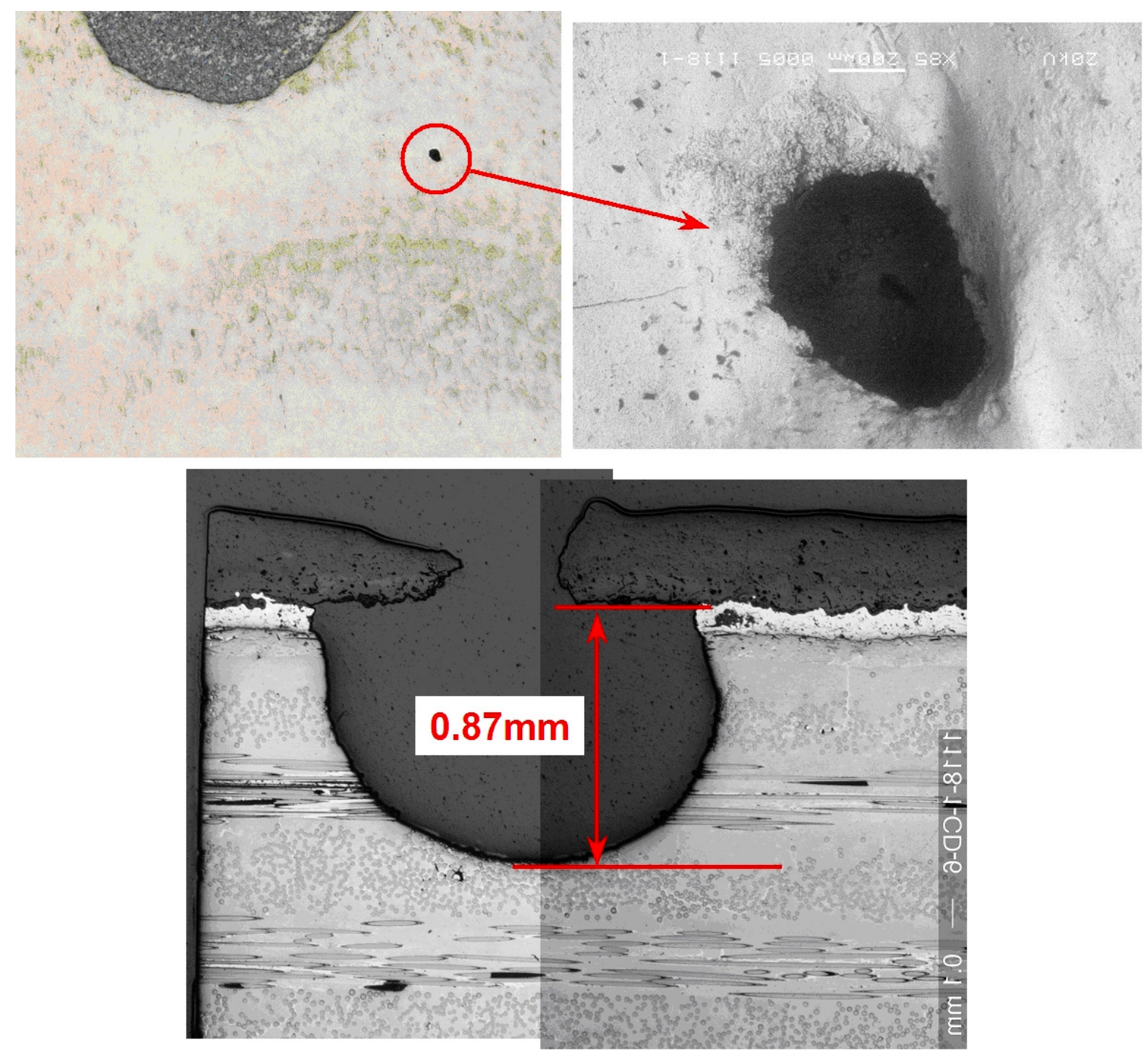

Figure 3-111. Micrographs of a pin-hole defect in the EBC coating of shroud 1118-1. Top left - stereomicroscope image of the surface of the shroud showing the EBC pin hole which was $<0.5 \mathrm{~mm}$ in size; Upper right - SEM micrograph of the same pin hole showing the local appearance of the EBC coating; Bottom - Optical micrograph of the cross section of the recession pit in the $\mathrm{CMC}$ below the $\mathrm{EBC}$ pin hole. 

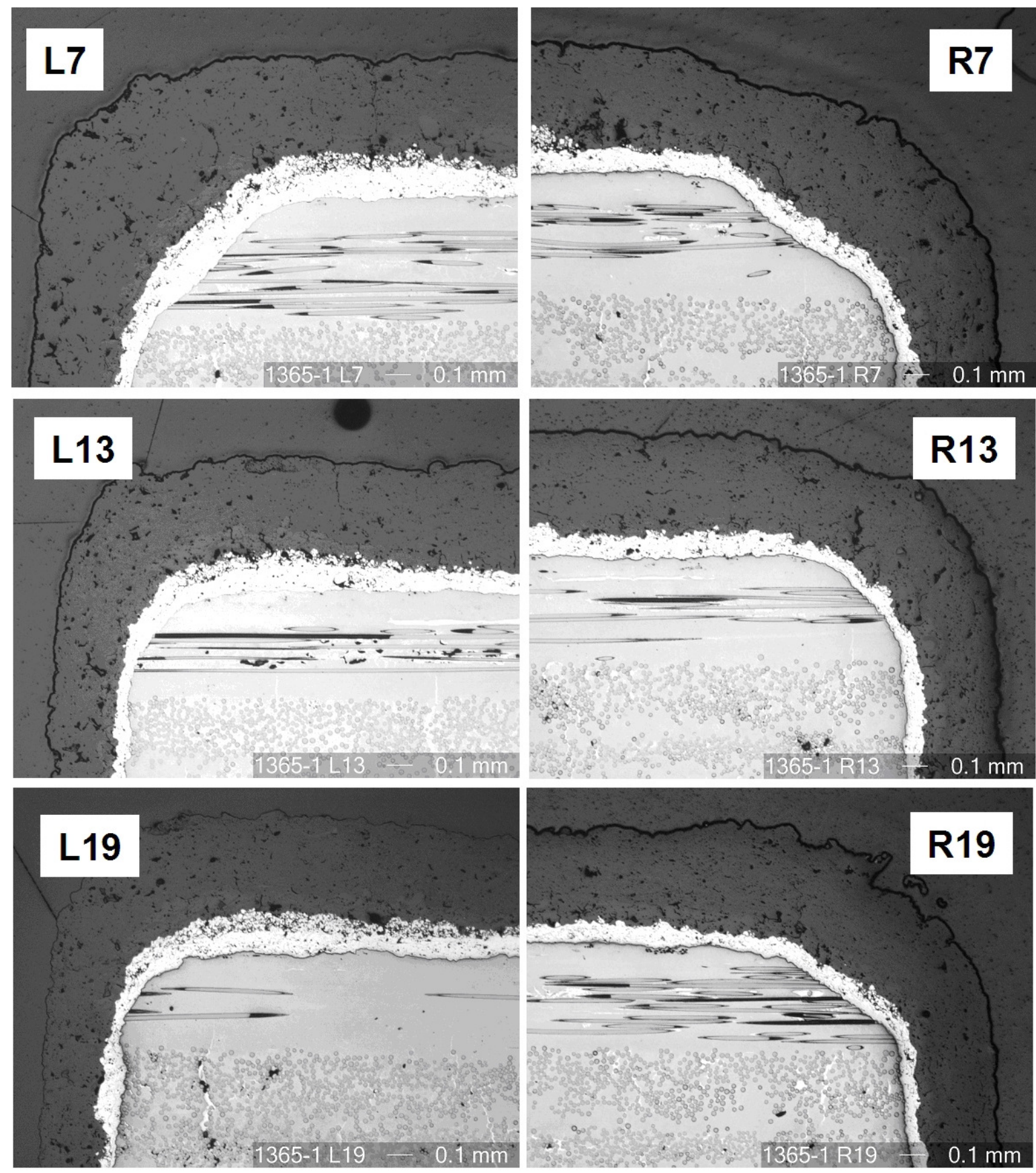

Figure 3-112. Photomicrographs of spare engine test shroud 1365-1 at various locations showing the corner of the hot gas path surface (top surfaces) and the shroud edges (vertical surfaces).

Examination of several of the shrouds used in rig tests 1 through 4 also showed that this porous silicon bond coat could be oxidized at much faster rates than a dense bond coat, and that swelling associated with this oxidation would lead to EBC cracking and further oxidation. Examples of the corner cracking found on the rig tested shrouds are shown in Figure 3-113. Because the number of hours of exposure in the rig tests was rather low this 
bond coat oxidation had not progressed to the point where EBC spallation had occurred, and thus this failure mechanism had not been indentified prior to the engine test.
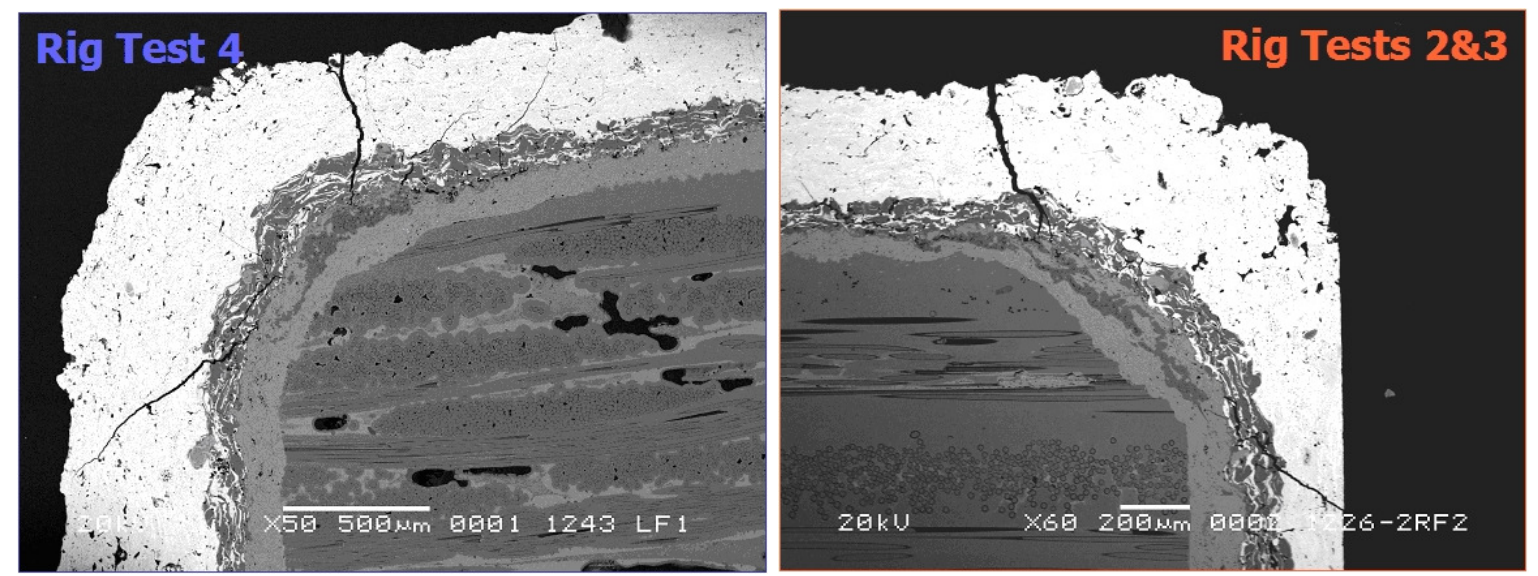

Figure 3-113. Photomicrographs of the hot gas path corner region of a slurry cast shroud from rig test \#4 (left) and a prepreg shroud used in rig tests \#2 and \#3 (right). Enhanced oxidation of the porous silicon bond coat in these regions has caused swelling of the bond coat and cracking of the outer oxide EBC layers.

The post-test characterization of the engine tested shrouds was consistent with this proposed EBC loss mechanism. Figure 3-114 shows several micrographs taken from the edge of prepreg shroud 1299-1 at several axial positions. The borescope inspections indicated that the EBC edge cracks tended to form near the leading edge of the shroud and then propagate rearward with time, so that examining the microstructure of the shroud edge corner in sequence from rear to the front should provide a proper sequence of the progression of damage with time. Initially the formation of thermal oxide on the silicon bond coat led to the formation of cracks in the EBC top layers, as shown in the upper left micrograph. Ingress of water vapor along these cracks leads to enhanced oxidation and volatilization of the bond coat laterally from the crack position, eventually leading to the formation of additional EBC cracks around the corners. Eventually the bond coat oxidation was severe enough that entire pieces of EBC are liberated along the corners.

The ability of thermal oxide to cause cracks in the EBC was validated using a simple FEA model of a corner region, as shown in Figure 3-115. Assuming a zero stress state initially and linear elastic behavior of all materials, stresses at the surface of the EBC coating were found to grow to $>350 \mathrm{MPa}$ with only 13 microns $(0.5$ mil $)$ of oxide growth. Circumferential shear stresses upwards of $700 \mathrm{MPa}$ also occurred around the corner between the bond coat and the top EBC layers, which probably contributed to cracking and the lateral oxidation observed at this interface. The presence of porous silicon bond coat layers along the shroud corners, which most likely came from coating overspray during coating of the shroud edges, would have contributed to this mechanism by providing a bond coat that would be readily oxidized, and would therefore swell. 


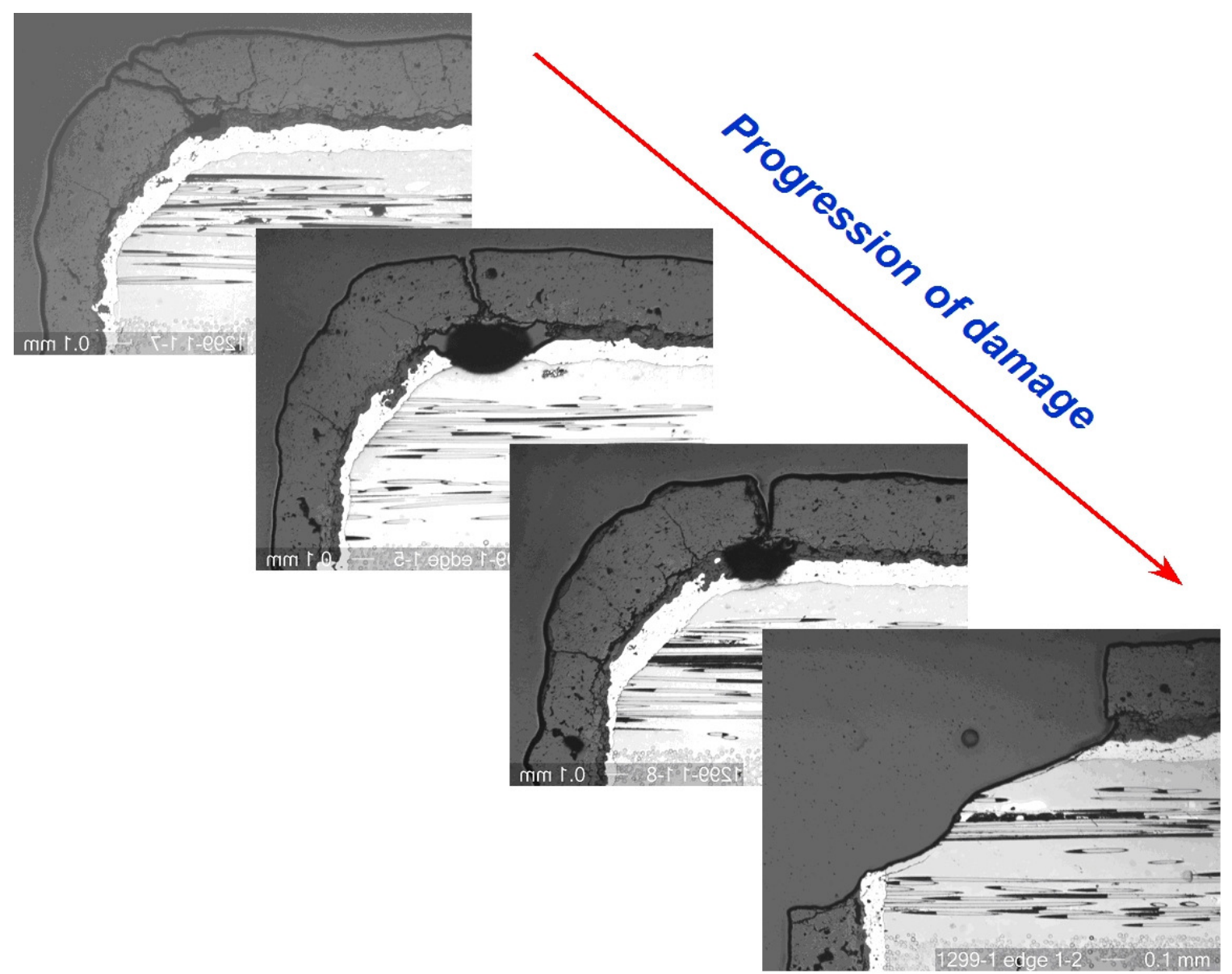

Figure 3-114. Photographs from the edge of prepreg shroud 1299-1 showing the proposed time progression of EBC damage along the shroud hot gas path edges.

Most of the other spalls noted on the hot gas path face of the prepreg shrouds progressed from the edge spalls or from other coating defects, such as pin holes or possible FOD damage. Evidence for this interpretation comes from the microstructural evidence plus the EBC damage pattern observed in NDE, as was shown back in Figure 3-107. The vast majority of the regions where the EBC had lost coherence with the CMC substrate were areas adjacent to a crack or spall edge, which strongly suggested that the spalls were growing as a result of bond coat oxidation initiated at a coating defect, such as the edge cracks mentioned above.

EBC retention on the back side (concave side) of the shrouds was highly variable. As shown in Figure 3-105 the extent of EBC spallation on the back side of the shrouds varied as much, if not more than, the spallation on the front sides. Quite extensive spallation was noted on four of the six prepreg shrouds (1299-1, 1109-2, 1106-1 and 1118-1), while minimal spallation was noted on the other two (1359-1 and 1116-1). In general, EBC spallation on the back side of the slurry cast shrouds was somewhat less than that seen on average for the prepreg shrouds. 


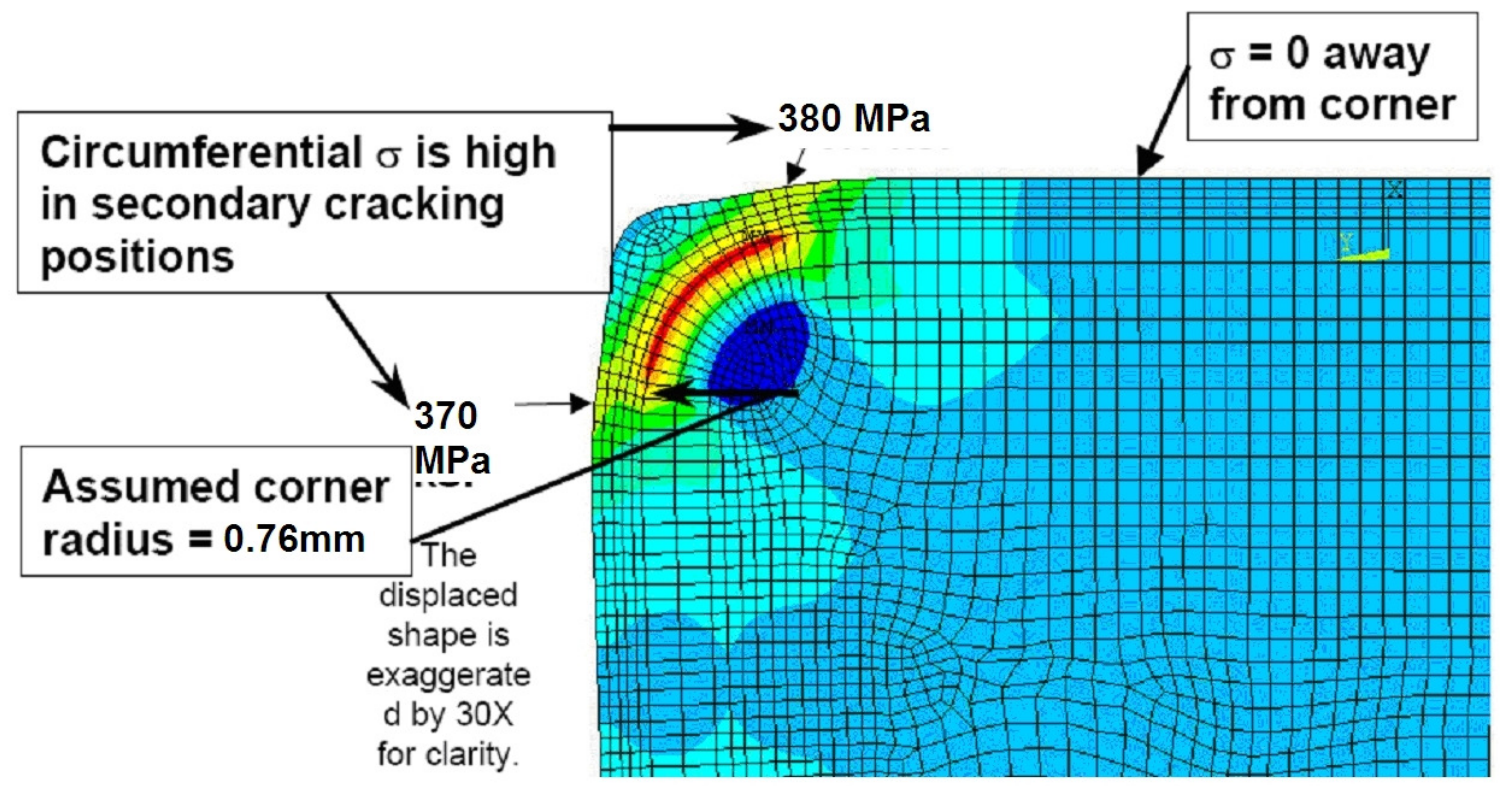

Figure 3-115. FEA results for model of EBC bond coat oxidation and its effects on EBC stresses along the shroud edges.

There were two postulated causes for the back side EBC spalls. The first was that the EBC bond coat on the backside of the shrouds was more likely to have a porous structure due to sticking of "overspray" or rebounded material during spraying. During any plasma spray process there is a temperature gradient across the plasma plume and a distribution of powder within the plume. Powder near the edges of the plume tend to be colder and are less likely to stick to the substrate than are the hotter particles near the center of the plume. When spraying flat or convex surfaces the rebounding powder at the edges of the plume that does not stick to the substrate simply bounces off and does not interfere with the deposition in the center of the plume. However, when spraying concave surfaces, such as the inside of the flange bends on the shrouds, the rebounding cold powder bounces into the path of the plume where it can get partly re-heated and deposit along with the powder from the center of the plume. Since the rebounding powder is cooler, it is generally less fully melted and tends to deposit as particles rather than as fully molten splats. A consequence of this is that the coating tends to be porous when such rebounding powder is not properly handled. A porous bond coat would lead to increased oxidation, swelling and lateral cracking at the bond coat-to-outer layer interface in the EBC.

Evidence for this mechanism was found in the cut-ups of the spare shrouds and in metallography of the engine tested shrouds. As an example, the micrographs in Figure 3116 were taken on one of the spare shrouds prepared for use in the engine test. The micrographs show the EBC coating around the edge of the shroud at a location near the forward flange bend, where it would be most probable to get rebound material entrapped in the coating during plasma spraying. The bottom surface of the figure, which is the inside surface of the shroud, shows both a very large thickness of the bond coat and a very high 
level of porosity within the bond coat. Examination of shrouds from the engine test showed that the porous bond coat in these regions, if it was retained, was highly oxidized.

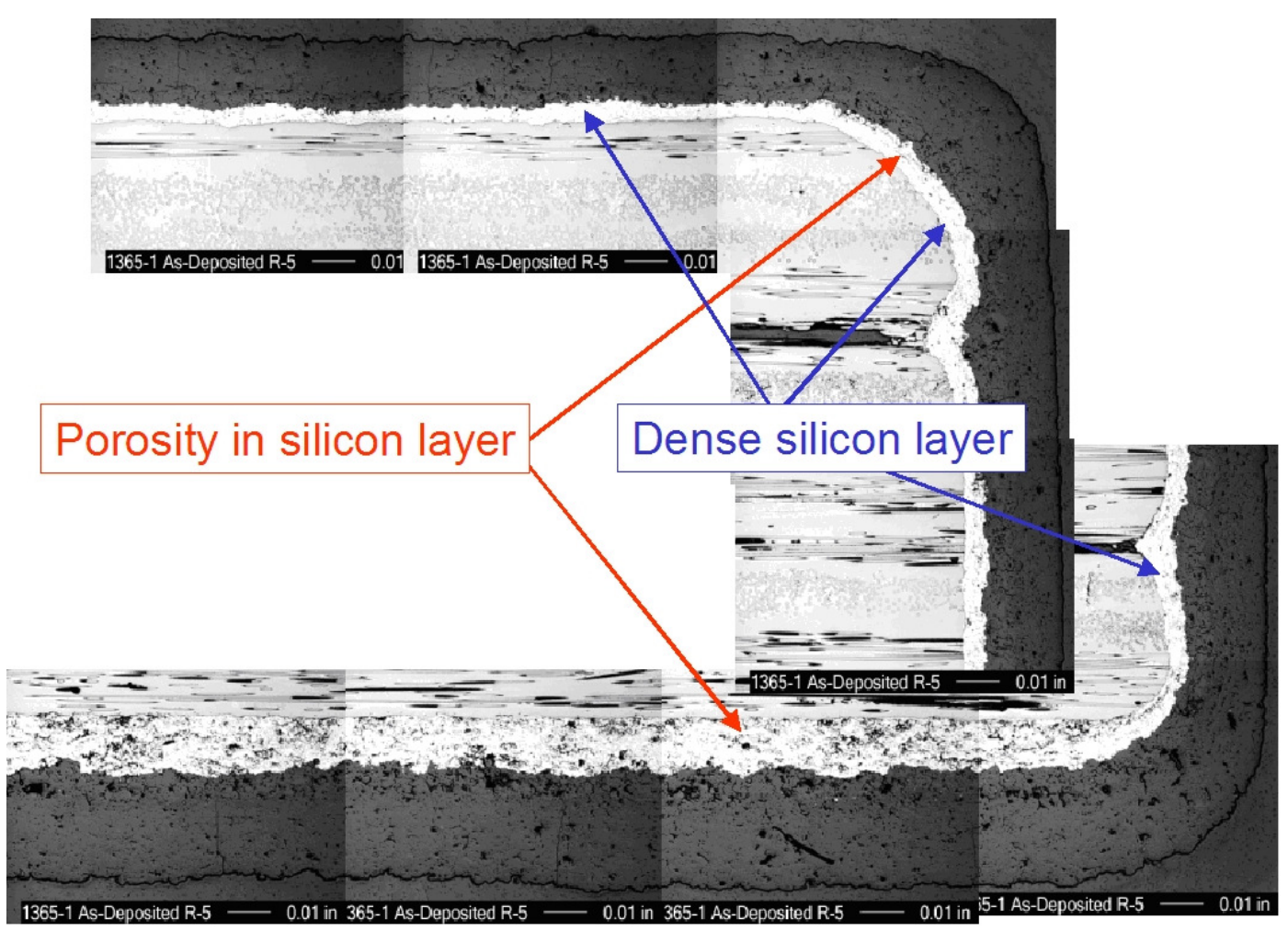

Figure 3-116. Photomicrographs around the edge of shroud 1365-1 (a spare from the field engine test) near the forward flange bend showing exaggerated porous bond coat on the inside of the shroud (bottom surface in micrographs), much thicker and more porous than any porous bond coat layer on the hot gas path to side corner.

Secondary evidence of the porous and laterally cracked bond coat came from NDE images of the back sides of the shrouds. Figure 3-117 shows a comparison of the back side condition of the EBC after the engine test to the IR NDE images obtained from these faces. The NDE images indicate significant regions of poorly adhered EBC coating (yellowishgreen in color) even in areas not adjacent to or affected by the EBC spalls or damper feet locations. 

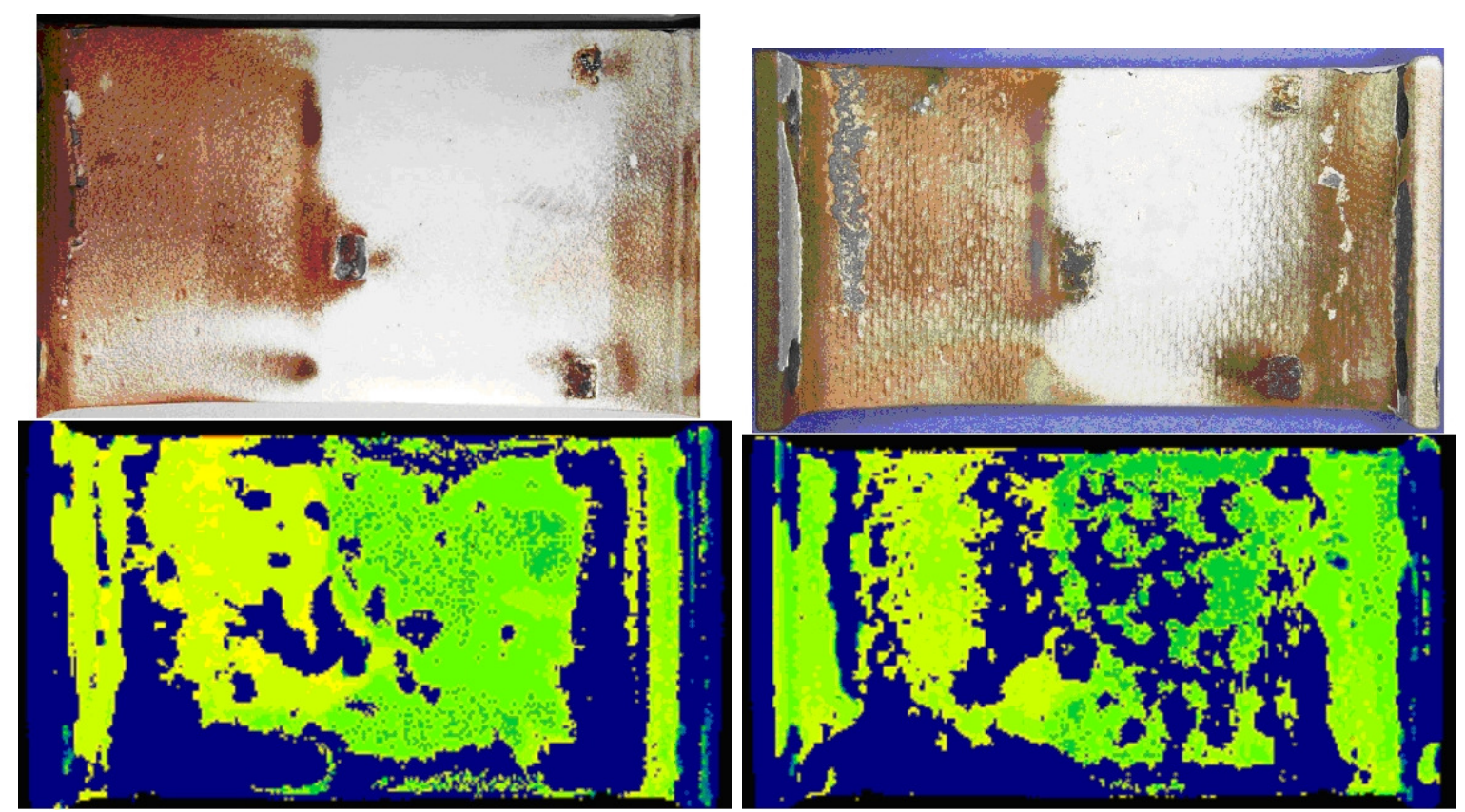

Figure 3-117. Photographs (top) and IR NDE images (bottom) of shroud 1359-1 (left) and 1243-10-12 (right) following the engine test with the EBC coating still intact. The NDE images are scaled so that regions with a thermal break between the EBC and CMC (i.e. heavily oxidized porous silicon bond coat) shows as greenish yellow and intact EBC shows as dark blue.

The second postulated cause for the EBC spalls on the back sides of the shrouds involved the contact of the damper blocks on the shrouds. Simple visual observation of the shrouds strongly indicated that there were physical and/or chemical interactions between the EBC and the damper block feet. Wear of the EBC coating at the contact regions was evident, as was wear of the damper block feet themselves. There were iron oxide deposits within the EBC coating, and at places the EBC had been completely worn through to the CMC substrate. Figure 3-118 shows photographs of the back side of shroud 1106-1 after the engine test and the regions where the damper block feet contacted the shroud are obvious. It was postulated that wear of the EBC at these damper block feet locations could expose bond coat directly to the environment, thereby allowing for accelerated, water-assisted lateral oxidation at the bond coat to oxide coating interface. 


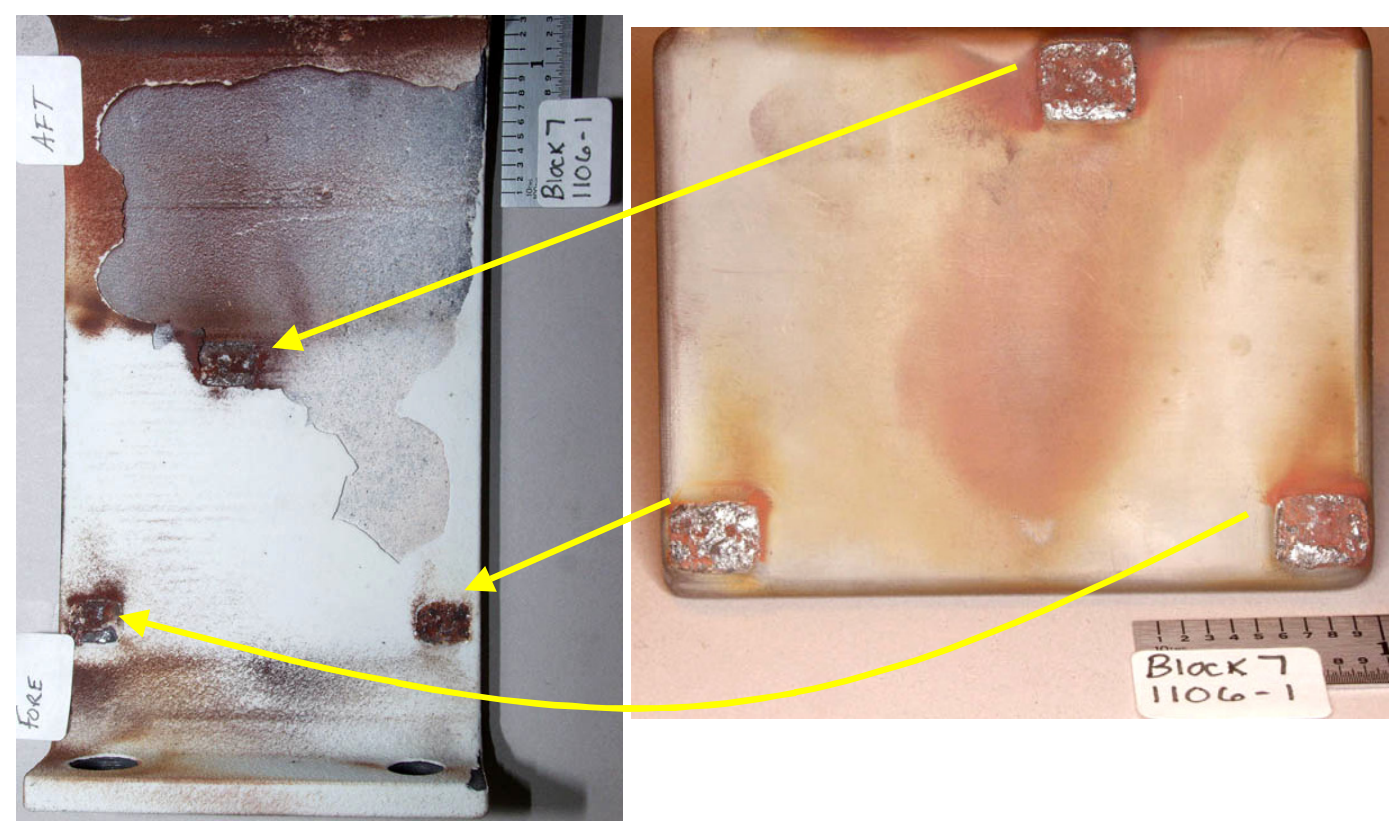

Figure 3-118. Photographs of the back side surface of shroud 1106-1 and its damper block after engine testing. The wear marks in the EBC on the back side of the shroud corresponding to the feet on the damper block are indicated.

Profilometry was performed on both the damper block feet and on the feet imprints onto the shrouds to assess the relative amounts of material removal. Figure 3-119 shows a typical example of such wear characterization where the EBC coating has been completely removed around the edges of the contact area. The wear pattern on the damper foot is a relative mirror image of the EBC wear in that the damper foot has less wear around the edges of the foot and more in the center.

The best evidence for deciding between these mechanisms was the distribution of EBC spalls on the backs of the shrouds. Only in four of the nine shrouds did the spalls intersect with a damper block foot position, and even in those cases not every foot location was involved in the EBC spall. EBC wear at the damper feet locations were just as severe on the shrouds without spalls as on those with spalls, in many cases exposing bond coat or CMC but not inducing any EBC loss away from the immediate contact area. Also, in several cases spalls were seen that did not involve any of the feet locations, and tended to be more prominent in the flange bend regions. All of these observations support the porous bond coat oxidation mechanism and refute the spall initiation at damper feet mechanism. 


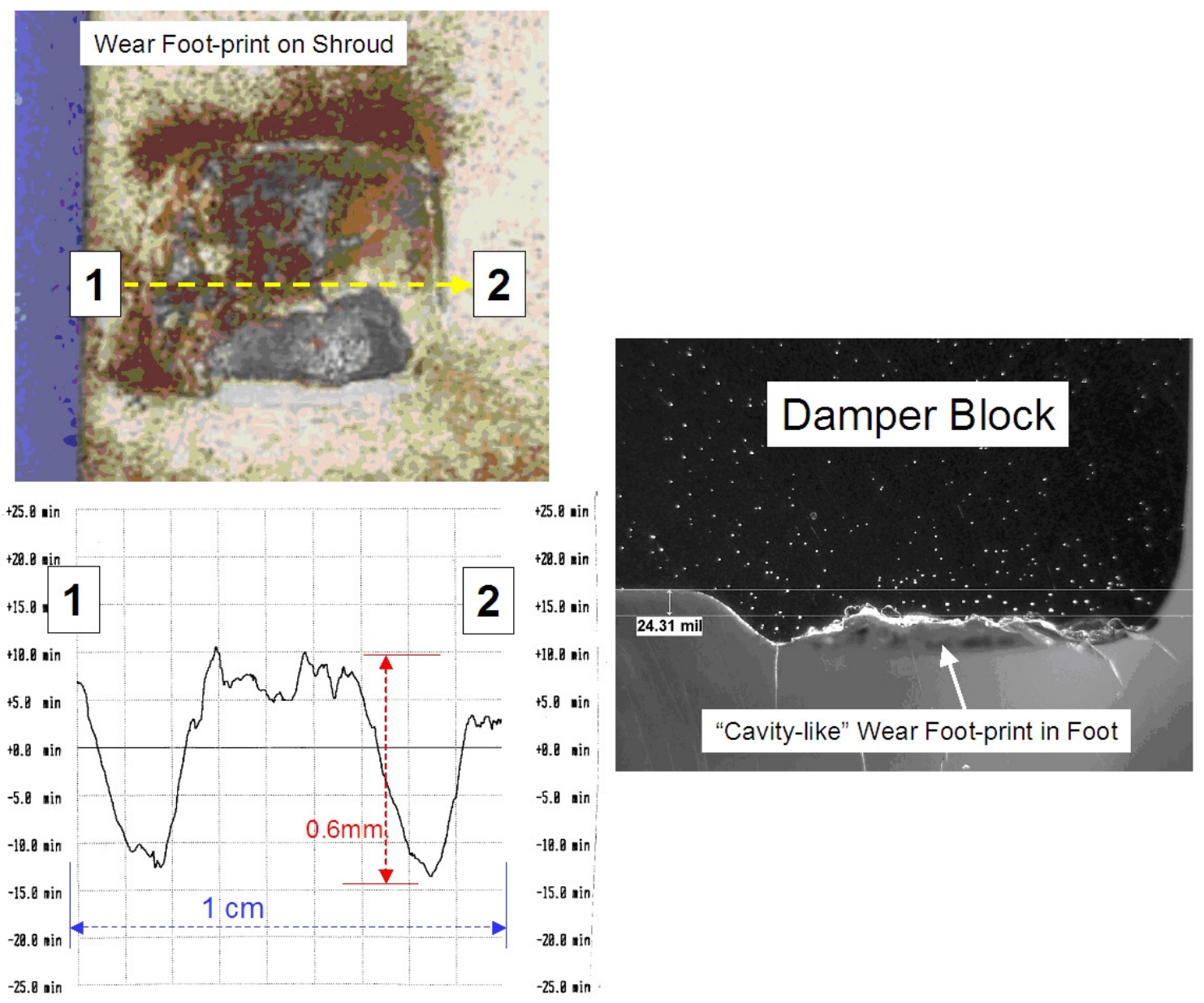

Figure 3-119. Top left - photograph of wear footprint on shroud from damper block foot showing the direction of the profilometer trace

Bottom left - profilometer trace across the wear footprint in the above photo showing wear preferentially at the edges of the damper foot through the complete depth of the EBC coating

Right - micrograph of the cross section of the damper foot in contact with this shroud at this location showing greater material loss at the center of the foot than at the edges

The other location on the shrouds where they contacted metallic hardware, and were thus susceptible to wear or chemical interaction, was at the attachment holes. In general, very little evidence of any wear or chemical interaction was seen at any of the attachment holes of the shrouds. Photographs of the inner surfaces of the attachment holes that would have been in contact with the attachment pins or bolts from the prepreg shrouds (1118-1) are shown in Figure 3-120. Small marks are seen at the locations where there would have been contact, but they appear to be only a smoothing of the hole surface and/or very slight transfer of metal oxides from the pins and bolts to the CMC surface. 


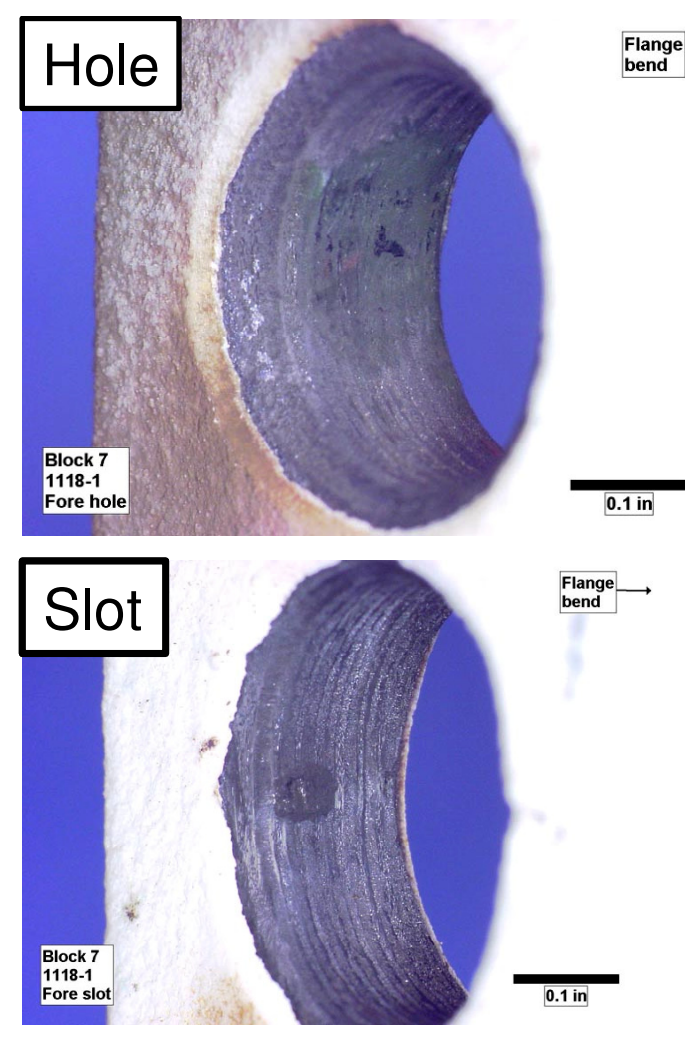

Forward Flange
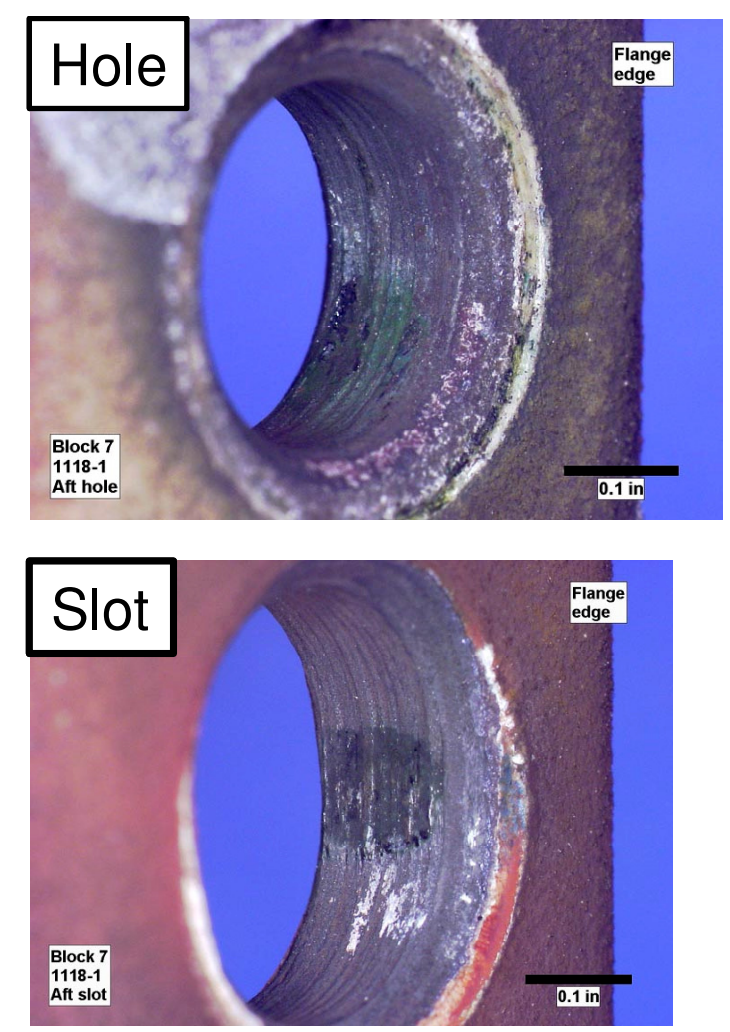

Rear Flange

Figure 3-120. Photographs of the regions of the attachment holes from shroud 1118-1 that would have been in contact with the attachment pins or bolts during the engine test, showing very minimal, if any, indications of wear or chemical interaction between the $\mathrm{CMC}$ and metallic pins.

Several of the holes in the forward flanges of the engine-tested shrouds were examined more closely using metallography. Figure 3-121 shows cross sections of the forward attachment holes from three of the shrouds. Overall the holes remained very circular and there was no evidence of wear of the CMC or internal oxidation of the CMC around the holes. 


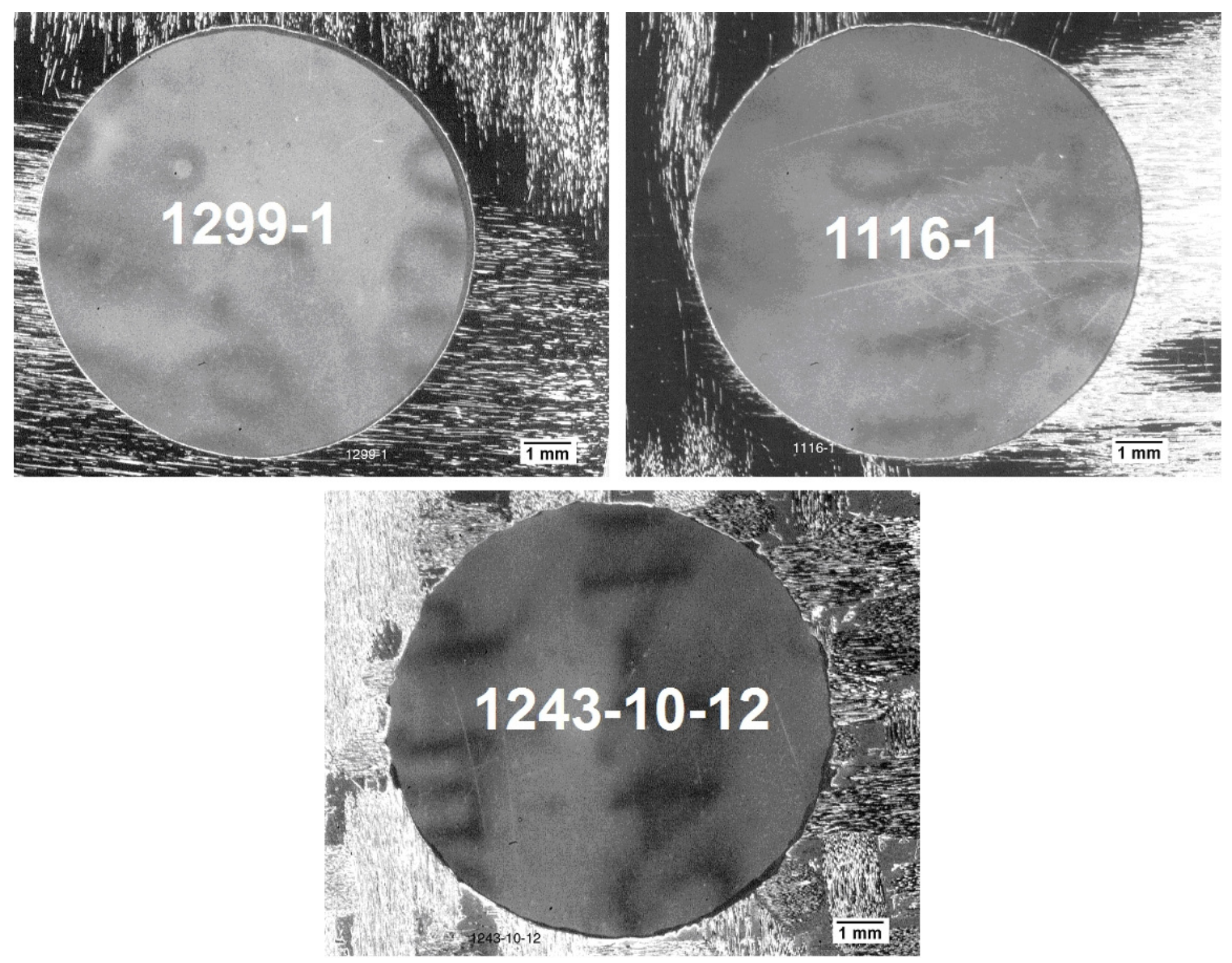

Figure 3-121. Micrographs of the cross sections of the forward attachment holes from three of the engine-tested shrouds. No evidence for $\mathrm{CMC}$ wear or chemical interaction of the CMC with the attachment pins was found. The slightly irregular surface on the hole of the slurry cast shroud (1243-10-12) was a result of the machining operation and fiber architecture.

\subsubsection{Destructive Characterization - Mechanical}

Typically, some of the A-D bars from the main hot gas path face of the shrouds (see Figure 3-109) were used for room temperature in-plane tensile testing, and the forward flange piece was used for pin pull-out tests. Typical in-plane tensile data from the three prepreg MI shrouds is shown in Figure 3-122, and that of the slurry cast MI shrouds in Figure 3123. For each shroud the as-fabricated shroud tensile behavior, as measured from witness coupons cut from the shrouds during initial machining, are included for comparison. In each case the remaining EBC coating was removed by grit blasting before tensile testing to make sure that the EBC, which was not on the witness bars, would not influence the tensile data.

Prepreg shroud 1116-1, which showed only a few EBC pits on the hot gas path face but no large spalls, had tensile properties of the CMC after the engine test that were clearly as good as, if not better than, those of the starting witness bars. It should be noted that one of 
the bars cut from the shroud had two recession pits in the gage section (underneath the EBC pin holes), but that ultimate failure did not occur at the pit location and the strength of the bar was as good as those which had no recession pits. This would indicate that the recession pits in the prepreg shrouds did not cause any degradation to the surrounding material or act as significant stress risers.

Prepreg shroud 1118-1 had a rather unusual stress-strain behavior in the witness bar, showing exceptionally high matrix cracking stress with a near flat loading curve beyond matrix cracking. After the engine test the general shape of the stress-strain curves was more normal, with the proportional limit having dropped modestly and the ultimate strength and strain to failure showing almost no change.

As discussed above, prepreg shroud 1299-1 had substantial CMC recession in the region of the EBC spall. Tensile bars tested from areas away from the spall showed no change in mechanical properties, as expected; however, even the bar cut directly from the region with maximum recession showed no appreciable strength degradation. These results indicated that the prepreg shrouds were very tolerant of EBC defects and surface recession damage.

Two bars each were cut from slurry cast shrouds 1243-10-12 and 1243-10-23; the first from a region that had very little or no EBC pitting and the second from an area with extensive EBC damage in the form of tooling bump pits. The bars cut from the relatively undamaged area showed near full retention of the as-fabricated ultimate strength and strain to failure, although the shape of the stress-strain curve was qualitatively changed. The bars cut from the heavily pitted region, however, showed significant loss of strength and strain capability. This result indicated that the slurry cast CMC material was less tolerant of EBC damage than was the prepreg CMC.

The other mechanical test performed on the post-engine-test shrouds was a pin pull-out test performed on the forward flange attachments. The geometry of the test and the test results are shown in Figure 3-124 in the form of the load-displacement curves. This test could not be performed on the as-fabricated shrouds due to a lack of sufficient excess material, so that the as-fabricated curve in Figure 3-124 is from a different shroud tested at an earlier date. The earlier shroud had a slightly different attachment geometry (smaller pin size and smaller slot size) than was used in the field engine test, so it is not surprising that the load capability is somewhat higher. In this test the higher fiber volume fraction of the slurry cast shrouds tended to give them a slight advantage in breaking load, but all shroud samples showed very high failure loads and strains (displacements), indicating no significant material degradation around the attachment holes. Indeed, the material load capability for all of the shrouds was still well beyond the maximum attachment design load, indicated by the red dashed line. Metallographic examination of the attachment holes, as described earlier, also found no signs of CMC degradation or mechanical wear, with only very minor indication of CMC oxidation and recession. 

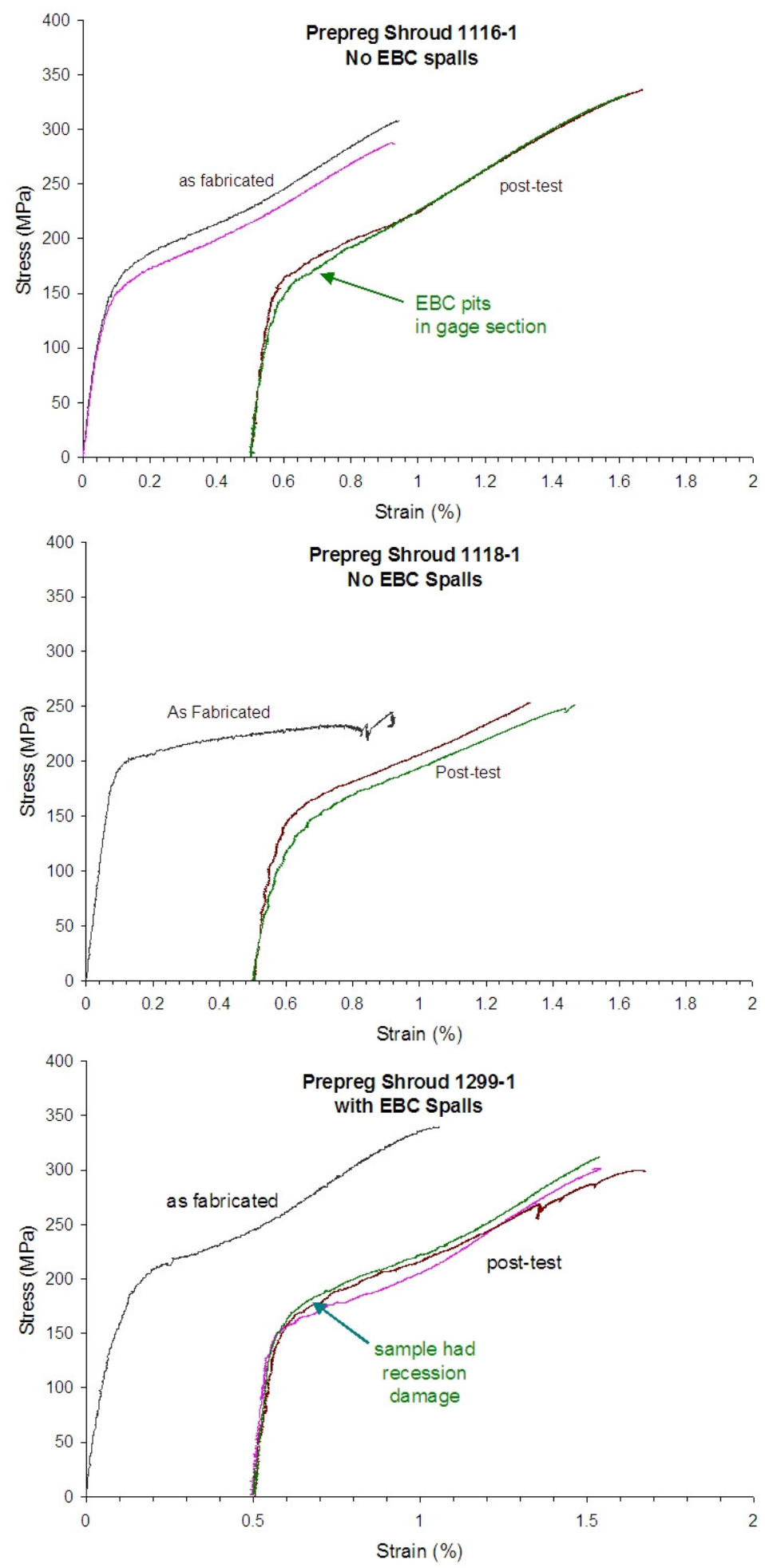

Figure 3-122. In-plane tensile stress-strain response of test bars cut from prepreg shrouds after 5366 hours of engine testing compared to as-fabricated material cut from the same shrouds. 

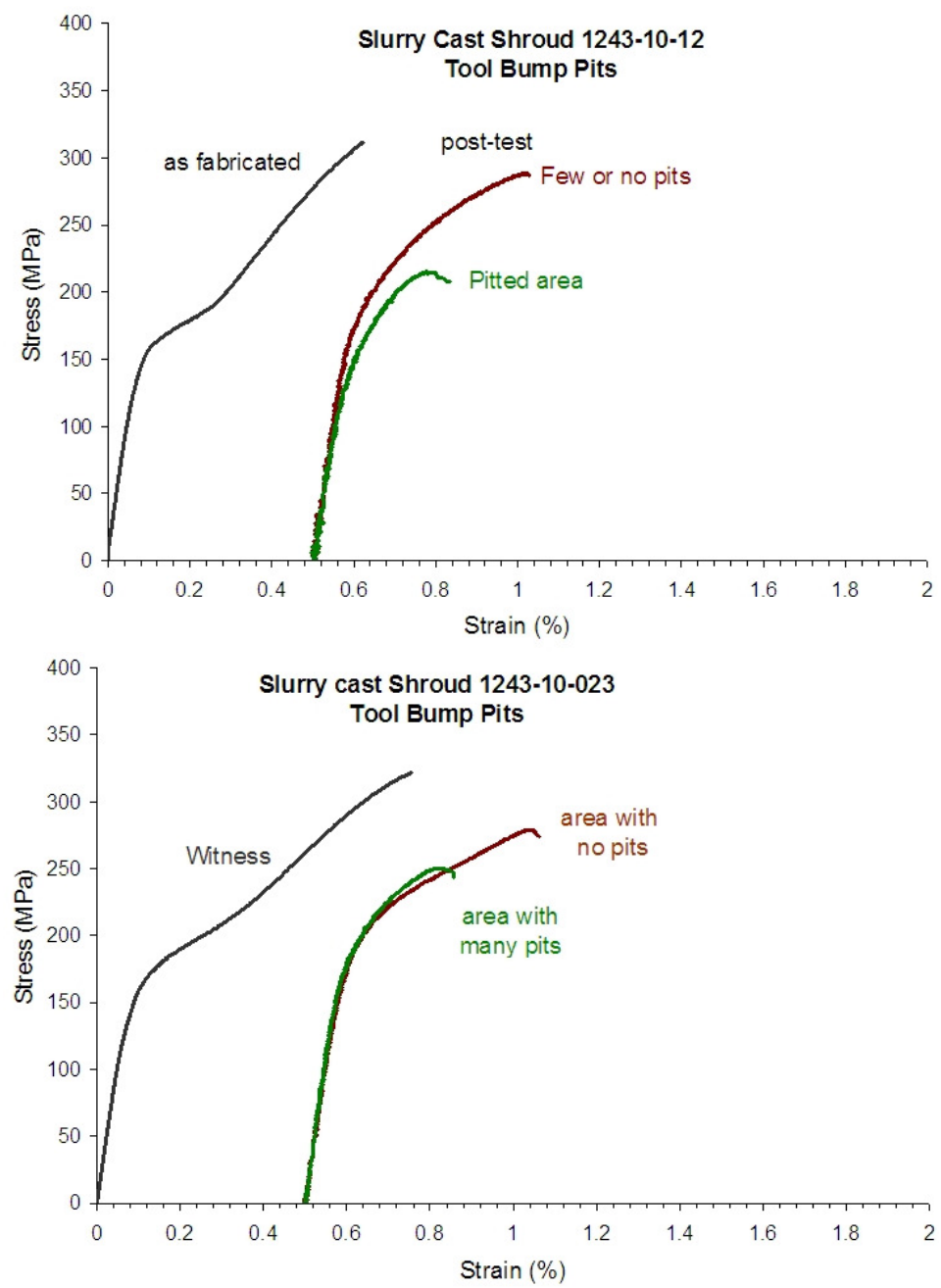

Figure 3-123. In-plane tensile stress-strain response of test bars cut from the slurry cast MI shrouds after 5366 hours of engine testing compared to as-fabricated material cut from the same shrouds. 

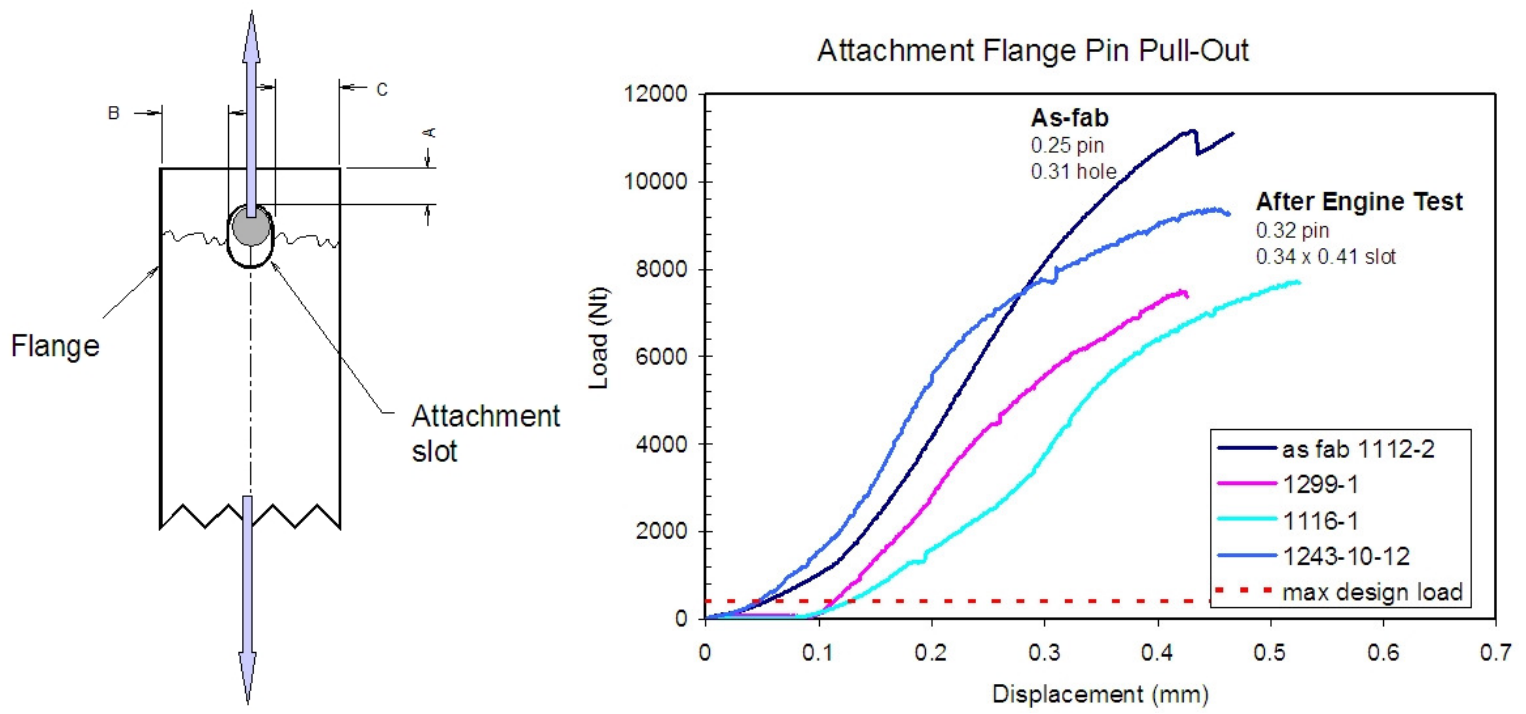

Figure 3-124. Left - Schematic of pin pull-out test performed on the front flange attachment slots of the shrouds from the field engine test.

Right - Load-displacement curves from the pin pull-out tests.

\subsubsection{Metallic Shroud Hardware}

All of the metallic hardware used in the shroud engine test, including the outer shroud blocks and seals, shroud attachment pins and bolts, damper blocks, damper pistons, damper spring cups, and springs, were inspected for any signs of distress during shroud disassembly. In general the outer shroud blocks and seals were found to be in good condition with expected amounts of oxidation based on the predicted thermal gradients.

The only unexpected observation was some wear of the outer shroud blocks from contact with the damper blocks and, particularly, the damper block retaining pins. Each damper block had two piston retaining pins that were inserted into the aft end of the damper and engaged the head of the damper piston. These pins were tack welded to keep them in position within the damper block. During the engine test two of these retention pins were found to have broken the tack welds and moved outward until they contacted the rear lip of the outer shroud block. Over time the pins then wore holes into the shroud block lip. The photograph in Figure 3-125 shows the damper block that was used with shroud 1106-1, which had one of the damper retention pins come loose. The damper retention pin is shown extending from the aft end of the damper block, and the corresponding hole in the lip of the outer shroud block is just below. It is also evident in this photograph that the contacts between the rear-facing damper feet the outer shroud block also experienced some wear. The pattern of wear was similar to what was seen between the damper blocks and CMC inner shrouds, but was generally much less severe. 


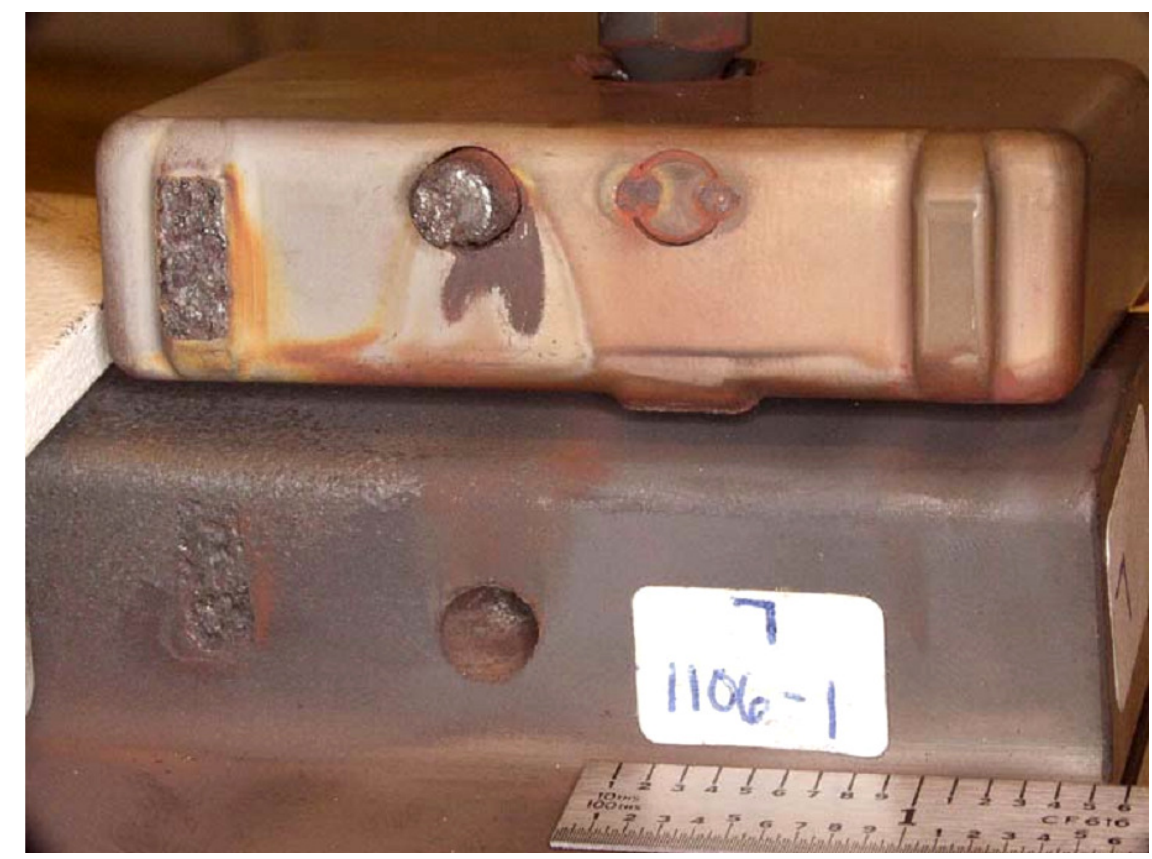

Figure 3-125. Photograph of the damper block from shroud 1106-1 showing how one of the damper retention pins broke the tack welds and came out of the damper block, and the corresponding hole that was worn into the outer shroud block by the pin.

The damper pistons themselves were all in relatively good condition. Some wear was noted between the end of the damper piston and the damper blocks, but it was very minor. More severe wear was observed between the pistons and the damper retention pins that had worked loose during the test. Despite the movement of the retention pins there was no sign of binding or galling of the pistons within the outer shroud blocks, and all indications were that the damper mechanism performed as intended.

The one part of the damper mechanism that was considered the most risky was the damper springs. During the early shroud rig tests the springs were observed to have relaxed after only $\sim 150$ hours of rig testing. Consequently several steps were taken to ensure that the damper springs used in the engine test would be stable. First the springs were redesigned to have a larger gage wire and a more creep resistant alloy. Secondly the springs were all precrept for 120 hours at $540^{\circ} \mathrm{C}$ and $\sim 400 \mathrm{~N}$ compressive load in order to allow for any primary stage creep relaxation to occur prior to using them in the engine test. Thirdly the cooling passages to the spring cups were increased to be sure that the springs would have adequate cooling air and would not be overheated.

Comparison of the spring heights and spring constants measured after the engine test with those measured before the test shows that the measures taken to ensure spring stability were indeed effective. Table 3-10 lists the pre-test and post-test characterization data for the springs. All of the springs compressed slightly during engine exposure, but the average compression was less than $1 \%$. The spring constants were measured in a universal testing machine with calibrated load cell and linearly variable differential transformer (lvdt) for 
displacement measurement, and the exact same instrumentation and operator were used for the before and after tests. Changes in the spring constants were all very low and were both in the positive and negative directions. The repeatability of the measurement was evaluated by re-testing one of the springs that was not used in the engine test, and the change in spring rate measurement from before and after the test was larger than most of the differences measured on the springs used for the engine test. It was therefore determined that the spring constant had not changed within the accuracy of the measurement technique.

Table 3-10. Results of Pre-Test and Post-test Measurements on the Damper Springs Used in the 5366 Hour Shroud Engine Test

\begin{tabular}{|c|c|c|c|c|c|c|}
\hline Spring ID & $\begin{array}{c}\text { Pre-test } \\
\text { length } \\
(\mathrm{cm})\end{array}$ & $\begin{array}{c}\text { Post-test } \\
\text { length } \\
(\mathrm{cm})\end{array}$ & $\begin{array}{c}\text { Length } \\
\text { change } \\
(\%)\end{array}$ & $\begin{array}{c}\text { Pre-test } \\
\text { spring } \\
\text { constant } \\
(\mathrm{kN} / \mathrm{m})\end{array}$ & $\begin{array}{c}\text { Post-test } \\
\text { spring } \\
\text { constant } \\
(\mathrm{kN} / \mathrm{m})\end{array}$ & $\begin{array}{c}\text { Spring } \\
\text { constant } \\
\text { change } \\
(\%)\end{array}$ \\
\hline $\mathrm{R} 41-13$ & 2.642 & 2.626 & -0.6 & 131.7 & 132.1 & +0.3 \\
\hline $\mathrm{R} 41-14$ & 2.611 & 2.583 & -1.0 & 136.1 & 135.7 & -0.3 \\
\hline $\mathrm{R} 41-15$ & 2.642 & 2.619 & -0.9 & 131.4 & 130.5 & -0.7 \\
\hline $\mathrm{R} 41-16$ & 2.619 & 2.591 & -1.1 & 135.1 & 132.6 & -1.8 \\
\hline $\mathrm{R} 41-17$ & 2.644 & 2.609 & -1.3 & 132.4 & 134.5 & +1.6 \\
\hline $\mathrm{R} 41-20$ & 2.626 & 2.601 & -1.0 & 134.8 & 136.0 & +0.9 \\
\hline $\mathrm{R} 41-22$ & 2.624 & 2.596 & -1.1 & 133.1 & 130.7 & -1.8 \\
\hline $\mathrm{R} 41-25$ & 2.634 & 2.604 & -1.2 & 133.2 & 138.4 & +3.9 \\
\hline $\mathrm{R} 41-26$ & 2.619 & 2.606 & -0.5 & 132.5 & 132.8 & +0.2 \\
\hline & & & & & & \\
\hline $\mathrm{R} 41-1 *$ & & & & 122.6 & 120.1 & -2.0 \\
\hline
\end{tabular}

* This was a control sample that was not used in the engine test but was still measured before and after the test using the same procedures.

The second highest risk metallic components going into the engine test were the inner shroud attachment pins and bolts. Small amounts of wear of these attachments had been seen in the shroud rig tests, but it was not known whether the wear rates observed were from a low frequency, large amplitude rubbing (i.e. from rig thermal cycles) or from high frequency, low amplitude fretting type wear. The wear track sizes on the pins and bolts were consistent with the thermal cycling type displacements, but the results were not without uncertainty. Consequently it was not clear as to how to predict the wear in the engine test since the low frequency rubbing wear would be expected to scale with thermal cycles whereas the high frequency fretting type wear would scale with the engine running time.

All of the pin and bolt attachments were extracted from the outer shroud blocks and examined in detail visually. Figure 3-126 shows photographs of the set of pins and bolts used with shroud 1118-1. Each pin in the figure is oriented so that the contact region with the CMC inner shroud is at the top surface. Qualitatively the variance in the amount of 
wear for the different attachment locations was consistent with the low frequency rubbing wear. The most constrained attachment location (the rear hole) would have seen the least amount of relative motion between CMC and the metal. The rear slot location would have seen only differential circumferential motion, the forward hole only differential axial motion, and the forward slot would have seen both circumferential and axial relative motion. The depth of wear on the attachments for each shroud showed the same pattern; it was always least at the rear hole location and always greatest at the forward slot location.
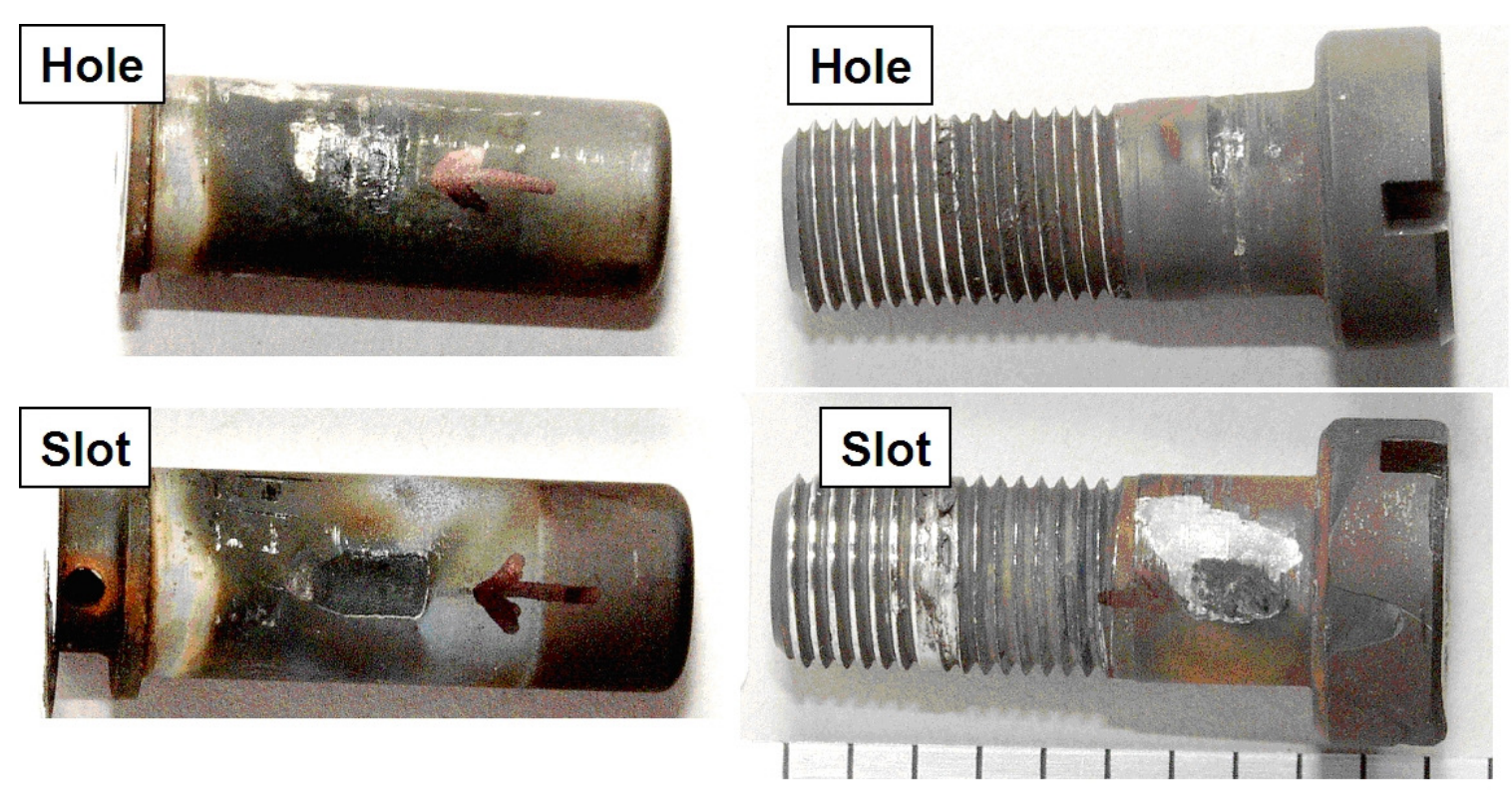

Front Rear

Figure 3-126. Photographs of the forward attachment pins (left) and rear attachment bolts (left) used with shroud 1118-1 in the shroud engine test showing the regions that contacted the shroud.

The depth of wear on each attachment was quantified using 3D optical profilometry. Figure 3-127 shows the profilometry plots from the attachments used with shroud 1116-1. The relative wear depths were consistent with the qualitative visual observations and were consistent shroud-to-shroud. This pattern of wear depth between the attachment locations and the widths of the wear tracks provided strong evidence that the wear was dominated by turbine thermal cycles. 

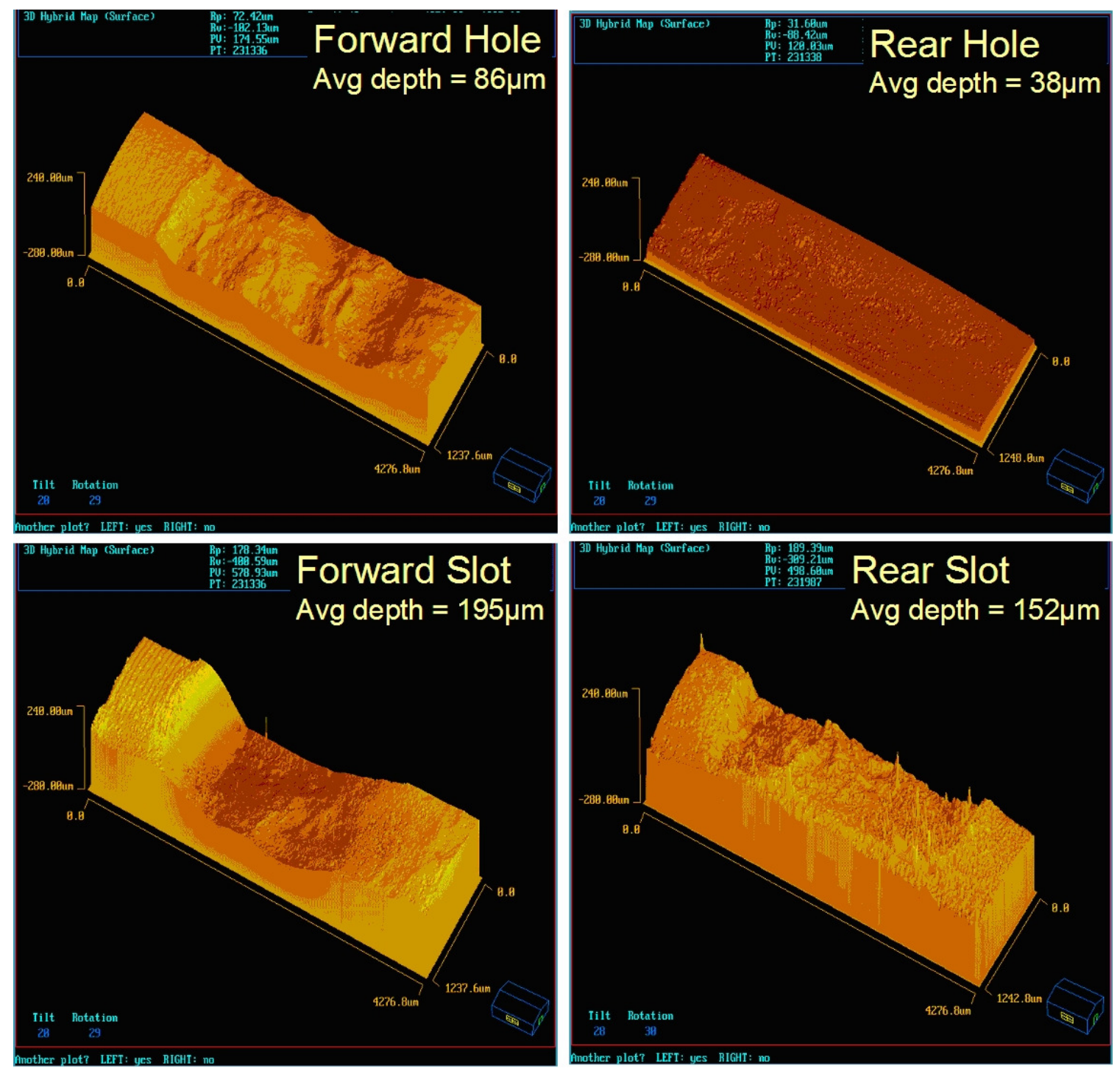

Figure 3-127. 3-D optical profilometry images of the attachment pins (forward) and bolts (rear) used with shroud 1116-1 in the shroud engine test. The areas shown are from the wear tracks caused by contact with the CMC inner shroud.

\subsubsection{Tasks 6 and S4.4 - Program Management and Reporting}

This task was present in the program to capture activities related to writing program reports, technical and programmatic reviews held with DOE, presentations at technical conferences where work from this program was discussed, and general program management activities that were not exclusively applicable to the other tasks. During the course of this program numerous publications, presentations and patent applications were issued that communicated the technology developments to the wider technical community. These patents, publications and presentations are listed separately in the Appendix. 


\subsubsection{Task S3.1 - Design of New Shroud System}

The first rainbow shroud test had very successfully demonstrated the feasibility of using MI CMC materials as hot gas path components in industrial gas turbine engines; however, it had not validated the performance benefit that could be achieved with the use of this technology. As long as metallic shrouds were still present in the turbine the shroud cooling air could not be fully eliminated and the real engine cycle benefit could not be measured. Thus validation of the performance benefit from CMC shrouds would require testing a full $\mathrm{CMC}$ shroud set in a field engine. As described in Section 2, while the $1^{\text {st }}$ rainbow shroud engine test was in progress a contract modification was awarded for the purpose of extending the shroud field testing to a full shroud set.

The purpose of this task was to develop and finalize the design of the shroud system to be used in the full shroud set engine test. This was done in two steps: a preliminary design suitable for rig test validation, and a final detailed design suitable for insertion in a utility gas turbine. Any major design or material change from the previous design required validation in a shroud rig test in order to qualify it for inclusion in the engine shroud design. Preliminary and detailed design reviews were held with the GE Energy Chief Engineer's Office in order to verify that all "Critical to Quality" (CTQ) and "Design Practice" (DP) requirements were met before proceeding to shroud rig and engine tests.

Initially the GE Energy Chief Engineers' were promoting a major re-design of the CMC inner shroud in order to overcome several perceived issues with the shroud attachment scheme. However, due to the success of the $1^{\text {st }}$ field engine test, that attitude changed to one of preserving and optimizing the existing attachment scheme, including optimization of coolant flows and minimization of leakages.

Results from the $1^{\text {st }}$ field engine test in 2002-2003 were analyzed and design changes developed to address the observed problems. Several of the issues were the result of intentional choices made during the shroud system development. For instance, the seals between the inner shrouds were not needed for the rainbow engine test since the number of shrouds was small (9 out of 96) and the extra leakage from not having the seals would not be a huge deficit to the engine performance. Also, a suitable seal concept had not been developed or rig tested, so that waiting for this additional development would have delayed the engine test significantly. Furthermore, since the $1^{\text {st }}$ test was not a test of shroud system performance benefit to the engine, additional cooling leakage from the damper system could be allowed that would minimize the ingestion of combustion gases behind or between the shrouds. For all these reasons it was judged that having seals between the inner shrouds was not critical to the success of the $1^{\text {st }}$ shroud test, and seals were therefore not included.

The major design issues that still needed to be addressed following the $1^{\text {st }}$ engine test are listed below:

- No sealing was provided between the CMC inner shrouds and outer shroud blocks, and between the inner shroud segments.

- Cooling air flows to cool the damper spring and attachment pins and bolts were higher than desired to meet performance benefit targets. 
- There were indications of damper piston wear against the damper retention pins with the potential for damper piston seizing.

- The "feet" on the damper blocks were found to wear into the EBC on the backs of the inner shrouds, possibly contributing to EBC spallation.

Various shroud design changes were made in order to address the above design concerns, some of which are listed below:

- The feet were removed from the damper block. This change created a much larger contact region between the damper and the inner shroud, which helped to limit leakage around the back of the CMC inner shroud and also distributed the damper load over a larger area, thereby lessening any wear between the damper and EBC.

- The design of the damper was changed to eliminate the separate piston assembly, and thus had the damper spring push directly on a boss on the damper itself.

- An alternate damper design, incorporating a layer of oxide-oxide CMC between the damper and the inner shroud, was also developed. The use of the oxide CMC interface was intended to improve sealing between the inner shroud and damper, decrease EBC and damper wear by changing the material couples, and thermally insulate the damper block from the hot CMC inner shroud.

- A chordal seal was also added to the back of the damper blocks to help further minimize hot gas leakage behind the CMC inner shroud. The spring assembly was tilted slightly so that the damper would be pushed slightly backward to help maintain engagement of this seal.

- Metallic dogbone shim seals were added between the damper blocks to minimize hot gas path leakage down the gaps between the shroud segments.

All of these design changes were thoroughly analyzed using thermal and structural FEA. Two important changes were noted in the calculated thermal stress conditions of the CMC inner shrouds as a result of the design changes. First, the thermal gradient stresses in the $\mathrm{CMC}$ were increased due to the effects of the sealing. By allowing less hot gas leakage behind the shroud the temperature of the shroud, and particularly the shroud flanges, decreased. The larger footprint, and therefore greater heat conduction, of the damper blocks also tended to decrease the hot gas path temperature of the CMC shroud, but not to the same extent that the flange temperatures were decreased. Consequently the thermal gradient between the hot gas path and the flanges increased, generating increasing tensile stresses along the edges of the shrouds. For the flat-bottomed metallic dampers the increase was on the order of $35 \mathrm{MPa}$ over the original design. A damper concept incorporating an oxide CMC interface was less effective at cooling the hot gas path surface of the CMC, and therefore had an even higher thermal gradient and higher shroud tensile stresses, being over 55MPa higher than the previous design. These higher CMC shroud stresses were accepted because of the necessity for the lowered leakages in order to meet overall shroud system performance benefit targets.

In addition to the major changes listed above there were a few minor design and material changes were made to the outer shroud block and, in particular, to the inner shroud attachment hardware. These design changes included changing the attachment pin and bolt 
alloy and changing the rear attachment bolt from a threaded configuration to one using a "bolt retaining pin". This later change was made so that the gripping force on the shrouds at the rear bolt locations would not be so sensitive to and dependent on bolt torque, but would rather rely on bending of the retaining pin to keep the bolt head and shroud rear flange snug up against the outer shroud block. This design was also more tolerant of variances in the inner shroud thickness.

It was necessary to begin fabrication of the outer shroud blocks for the engine test prior to completing the full cooling flow design of experiments (DoE) in the rig tests. Consequently the optimum cooling flow to the spring cavity had not been determined, so a method of adjusting the cooling flow without having to do major modifications to the outer shroud blocks was needed. The solution used was to incorporate air metering orifice discs into the cooling channel feeding the spring cavity such that the amount of cooling could be easily adjusted if needed by simply changing the size of the hole in the orifice.

A schematic diagram of the overall, final shroud system design for the engine test is shown in Figure 3-128. A more detailed description of the full shroud design can be found in reference [16].

The above shroud system design changes were incorporated into the shroud design for rig test \#5. The main purposes of rig test \#5 were to validate the robustness of the above design changes, to quantitatively evaluate the effectiveness of the sealing scheme, to identify the optimum/minimum cooling air required to maintain the damper spring temperature within it working range, and to evaluate the spallation resistance of the EBC coatings following several EBC process changes. Running of this rig test is described later in Section 3.1.21. As will be described, an over-temperature condition was experienced during that rig test that compromised the collection of some of the desired test data and also confounded any observations regarding the reliability of the shroud hardware changes. Also, any conclusions as to the robustness of the EBC changes were invalidated due to the observed melting of the bond coat. Consequently a $6^{\text {th }}$ rig test was deemed to be necessary.

Following the shut down of rig test \#5 the shrouds were inspected to determine the effects of the over temperature on the CMC inner shrouds and the EBC coatings. The thermal data from the cooling flow DoE experiments were analyzed to determine the seal effectiveness of the damper chordal seal and the damper-to-damper chordal seals. Based on the thermal data collected during the rig test the chordal seal had performed as desired and blocked the flow of cooling air at the rear section of the dampers. The dampers showed some signs of micro cracking in the seal slot area, which was attributed to the EDM recast layer created in the slot machining process. The spring cooling air DoE data was skewed due to lower than desired temperatures of the cooling air. Transfer functions were derived from the available data and extrapolated back to the desired temperature range. A chief engineer's review of the Rig test \#5 events and performance conclusions was conducted in July of 2004. 


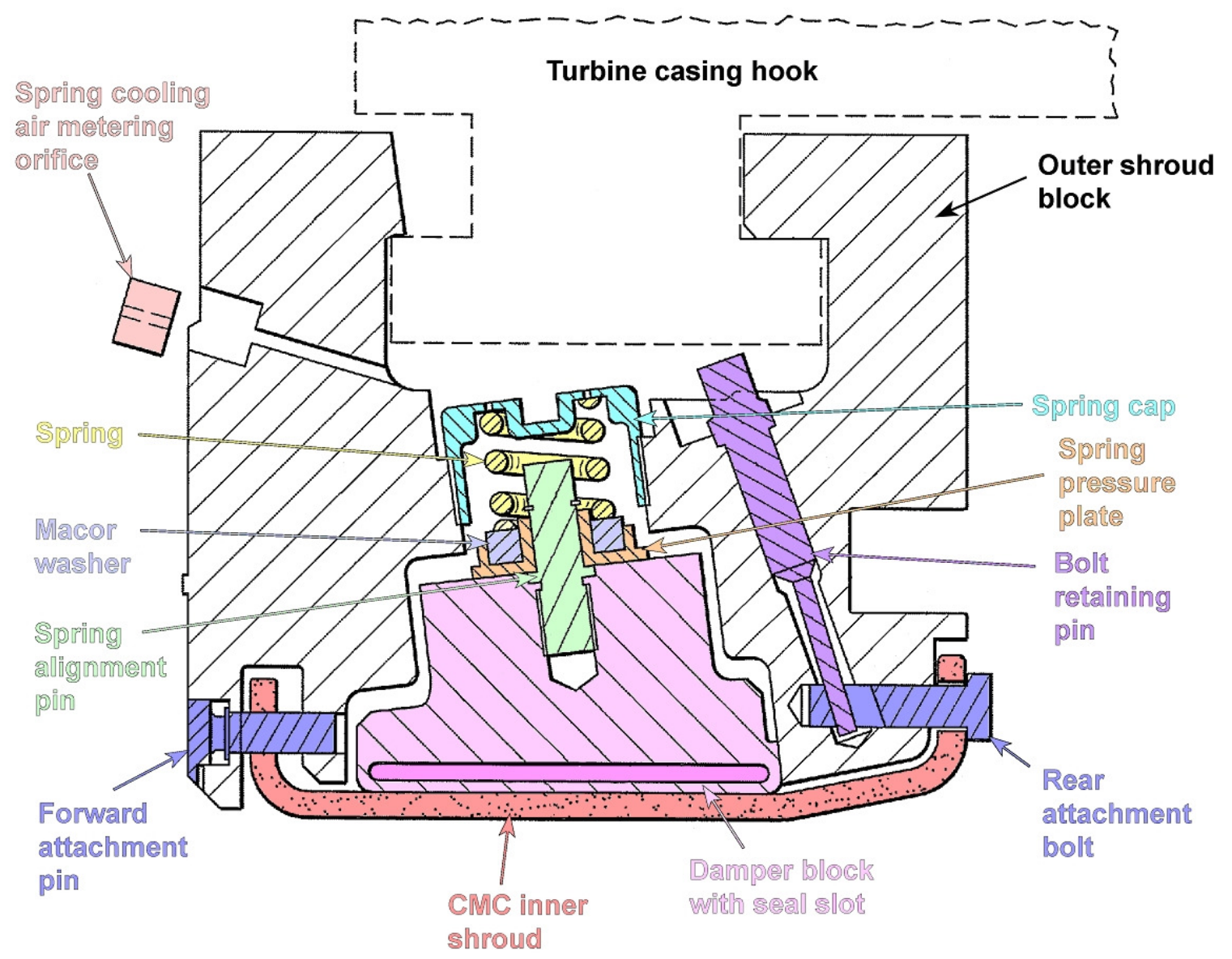

Figure 3-128. Schematic cross section of the overall new shroud system design with the various major components indicated.

In preparation for rig test \#6 two separate Red Flag Reviews were held with the GE Energy Chief Engineers' Office to describe the hardware modifications to be tested, and to solicit approvals for the overall test plan. There were three main goals for this rig test. The severe combustion gas temperature spikes experienced in the last rig test made it impossible to evaluate the durability of any of the EBC modifications being tested. The first goal of rig test \#6 was therefore to gather meaningful exposure data on these same EBC modifications. The rig test facility control system was also upgraded to prevent the occurrence of any temperature excursions such as those seen in rig test \#5.

The second goal was to provide a more accurate simulation of the cooling and leakage air flows that would be expected in a real engine. During rig test \#5 a rather extensive DoE was performed to look at the effects of cooling and leakage flow changes on the temperature distributions within the outer shroud block and other metallic hardware. This DoE was very successful in quantitatively defining the effects of cooling and leakage flows. Unfortunately the temperature of the main auxiliary cooling flow used during the rig test was only $\sim 180-230^{\circ} \mathrm{C}$, whereas the cooling air temperature in a $7 \mathrm{FA}$ engine is in the range 
of $380-430^{\circ} \mathrm{C}$. The effects of this lower temperature air could be, and were, evaluated analytically, but experimental verification was still needed. The results of the initial DoE also indicated that there was probably design margin in the outer shroud block hardware temperatures to allow even lower levels of cooling flow than were examined in rig test \#5. Unfortunately cooling flow can have very nonlinear effects on the hardware temperatures, especially at low flow rates where leakages and pressure fluctuations become more important. It was therefore rather risky to extrapolate the previous DoE results from rig test \#5 to predict outer shroud block temperatures at still lower cooling flows, and thus additional measurements were needed at these lower flow rates. The delivery system for the cooling air on the rig was re-configured so that cooling air of the desired temperature and flow rates could be achieved.

The third major goal of rig test \#6 was to more thoroughly test the shroud sealing system prior to insertion into the field engine test. Several variations of sealing configurations were evaluated in rig test \#5, and a preferred configuration was selected. However, because multiple sealing schemes were used it was difficult to evaluate the effectiveness of the seals across the entire outer shroud block. Rig test \#6 utilized a consistent sealing scheme for all 3 shrouds, and thereby provided valuable data as to the expected behavior of this system in an engine. Additional temperature and pressure measurement instrumentation was also been added to the rig to better define coolant and leakage flows in several critical areas.

Rig test \#6 was very successful in terms of validating the shroud system design changes and allowing for completion of the cooling flow DoE using the proper temperature cooling air. The GE Energy Chief Engineers' Office subsequently approved this shroud design to be used in engine test \#2 with one modification to the CMC inner shroud, as is described below.

The main goal of engine test \#2 was to be able to validate the engine performance benefits for the CMC shroud system that were being predicted based on reduced cooling air flow to the shrouds. Although the benefit projections varied considerably depending on certain assumptions made in the modeling calculations, the performance targets for the shroud, in terms of fraction of compressed cooling air saved, had remained relatively constant. However, for simplicity in hardware manufacture, the CMC inner shroud design had a simple, flat hot gas path surface. If the CMC inner shrouds were placed in the engine with the center of the shrouds at the normal metallic shroud position, the flat surfaces would cause an increased blade tip to shroud gap of about $0.6 \mathrm{~mm}$ at the edges of the inner shrouds. Such a shroud arrangement is shown schematically in Figure 3-129. This increase in effective blade tip gap was sufficient to counteract enough of the projected benefits from the anticipated cooling air reduction that the ability to reliably measure a real performance benefit for the CMC shroud system was questioned.

The design team evaluated several options for closing this bucket tip gap to an average level comparable to the existing metal shroud design. These options included using an extrathick layer of abradable EBC, using a curved shroud profile, or adjusting the inner shroud position relative to the blade tips and running a greater risk of a blade tip rub. 
The approach selected for the second engine test was to include a thick abradable EBC layer that would compensate for the increased gap of the flat shrouds. The abradable EBC would be applied over top of the normal protective EBC and the shrouds would be ideally located so that the bucket tips would cut into the abradable EBC, forming a minimum bucket to shroud gap during engine operation. The abradable would need to be thick enough to allow for the bucket tips to contact out to the edges of the shrouds while not hitting the protective EBC layer at the center of the shrouds. The remaining abradable would serve to fill in the blade tip gap, reducing it to essentially zero, and conform to the circular path of the blade tip, as shown in Figure 3-130.

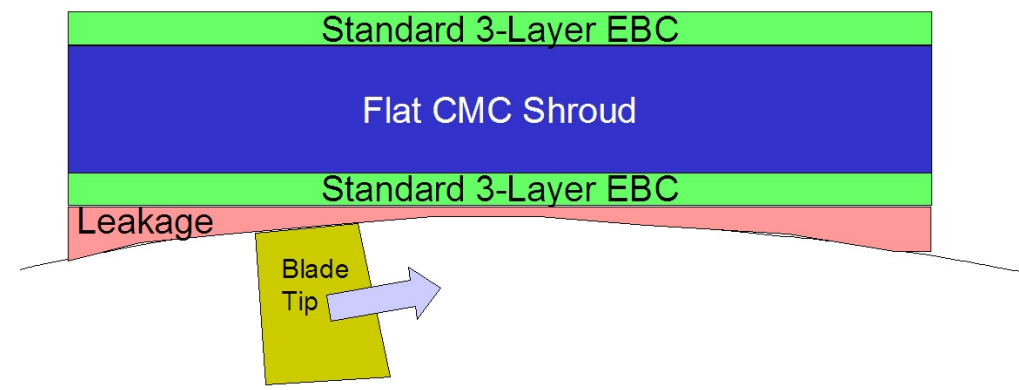

Figure 3-129. Schematic diagram illustrating the additional blade tip leakage area (in pink) caused by the use of the flat CMC shrouds (the curvature of the bucket tip path is exaggerated relative to the size of the shroud).

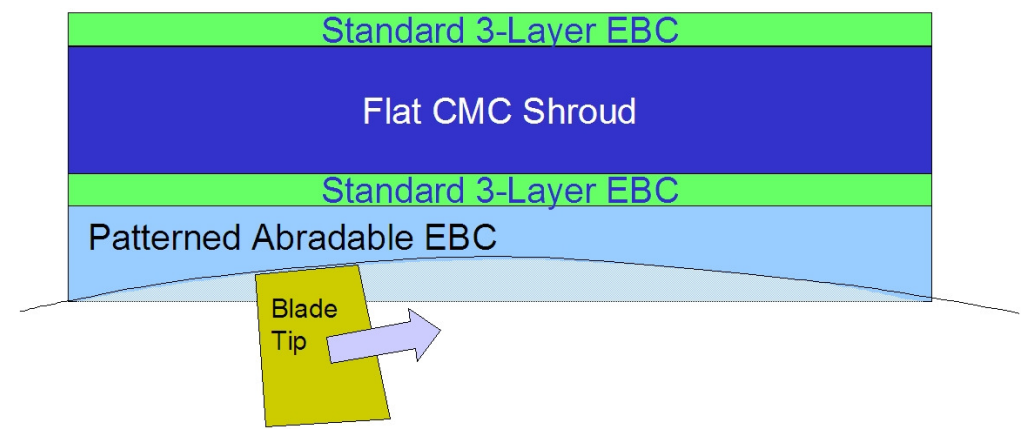

Figure 3-130. Schematic diagram illustrating how bucket rubbing into the abradable EBC layer (light blue) would compensate for the flat shroud surface and minimize the effective bucket to shroud gap. The palest blue represents abradable EBC that would be removed by the bucket tip rub.

The abradable EBC solution was selected primarily because most of the CMC inner shrouds had already been fabricated with a flat hot gas path surface. Also, accommodation of a curved shroud into the outer shroud block would require some modifications of the damper blocks and of the inner shroud machining fixtures. Furthermore, metallic shrouds were being employed in the field with abradable TBC coatings that helped to minimize bucket tip gap leakage in the metallic systems, and thus it was deemed necessary to have a similar 
abradable shroud coating option for the CMC shroud system. Nevertheless, several curved shrouds were included in the engine test plan to evaluate them as a potential further improvement for future engine tests.

As will be discussed later and initial effort was made to initiate the $2^{\text {nd }}$ engine test in the Spring of 2005 immediately following the completion of rig test \#6. However, due to issues that will be discussed the engine test could not be started at that time. Up until this postponement of the full shroud set engine test the primary goals of the rig and engine tests were to test the CMC and EBC material capability and to validate the mechanical design of the shroud system. Once that test opportunity was abandoned due to quality concerns with the CMC shrouds, the priorities of the testing program were reassessed. Demonstration of the engine performance benefits to be provided by the CMC shroud system became the overriding priority for the second engine test. This increased emphasis on shroud system performance required some increased scrutiny and control of the overall shroud system cooling air flow requirements.

A more detailed flow-net analysis was performed that pointed out a potentially problematic leakage path between the outer shroud block and its attachment to the turbine casing, referred to as the "T- hanger". This identified leakage path is shown in the diagram in Figure 3-131. A metallic "V" seal was added to the outer shroud block to minimize air leakage via this path; however, further analysis indicated that if this seal were too tight and completely eliminated any leakage of cooling air around through the T-hanger slot that the outer shroud block could become too hot. An assessment of the performance of the V-seal was therefore needed to ensure that it (1) blocked the leakage flow sufficiently that the overall shroud system cooling air reduction goals could be achieved, (2) that the leakage was not completely blocked and would therefore lead to possible overheating of the outer shroud block, and (3) to ensure that other undiscovered leakage paths were not present that would compromise the performance of the shroud system.

An analytical assessment was attempted first, but it was soon apparent that, quite surprisingly, adequate flow measurements of many of the seal systems then in use in conventional shroud systems had never been made. It thus became necessary to evaluate the full cooling and leakage flows of the shroud system experimentally. A flow test cell was therefore constructed to precisely measure air flows and pressure distributions throughout a single outer shroud block assembly, which included three CMC inner shrouds. The diagram in Figure 3-131 is an end-view of the flow rig with one side wall removed so that the seal channels on the end of the outer shroud block are visible. 


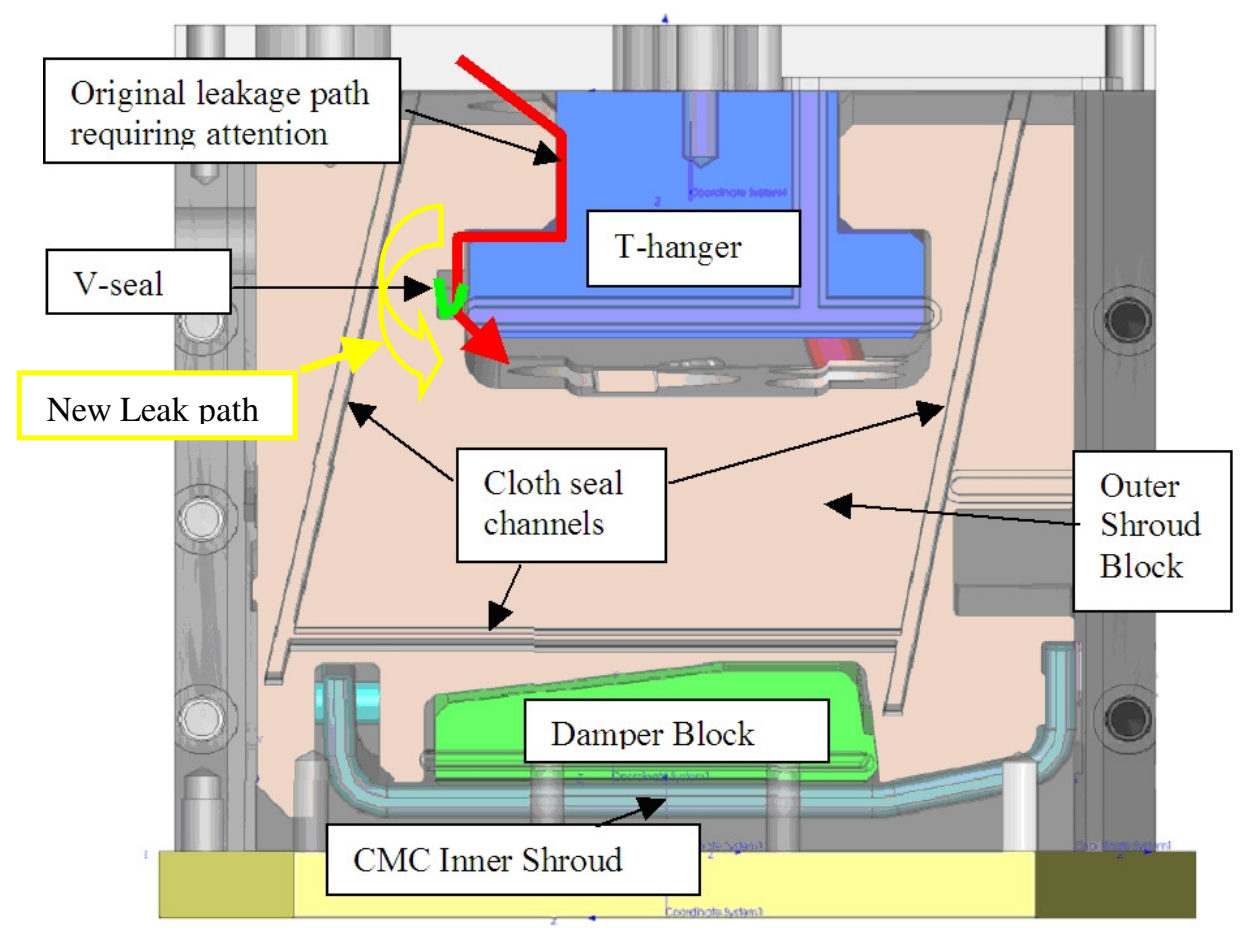

Figure 3-131. Solid model diagram of the shroud system flow test cell with the end cover plate removed. The leakage flow path through the T-hanger slot, shown by the red line, is the one originally identified through flow-net analyses as requiring the addition of the metallic V-seal.

Most of the flow tests were carried out at room temperature and at pressures representative of what the shroud system will see in the field. The pressure drop associated with the first stage blades in the HGP could not be duplicated in the test, but the effects of that pressure drop could be accounted for in the flow net model. After conducting most of the tests under cold air flow conditions, "warm " tests were done at $\sim 260^{\circ} \mathrm{C}$ to simulate the expected temperature in V-seal slot and measure any thermal growth effects on seal performance.

The initial results from the flow tests indicated that there would not be a problem with outer shroud block overheating due to low leakage flow. However, there was still more overall shroud system leakage than the models had predicted. Consequently a new leakage path was identified that had not been included in the flow model. This path allowed air to bypass the new V-seal at the gaps between outer shroud blocks as shown in Figure 3-131.

The long term solution identified for this problem was to move the current cloth seal slot in the outer shroud block toward the new V-seal slot, as shown in the Figure 3-132. This change significantly reduced the area of, and thus the leakage flow through, the newly identified leakage path. Flow net model simulation of the new leakage path verified that changing the seal slot location would eliminate $85 \%$ of the leakage flow through this path. This reduction was also later validated using the flow test rig. The outer shroud blocks for engine test \#2 were all modified to move the cloth seal slots to the new location. 


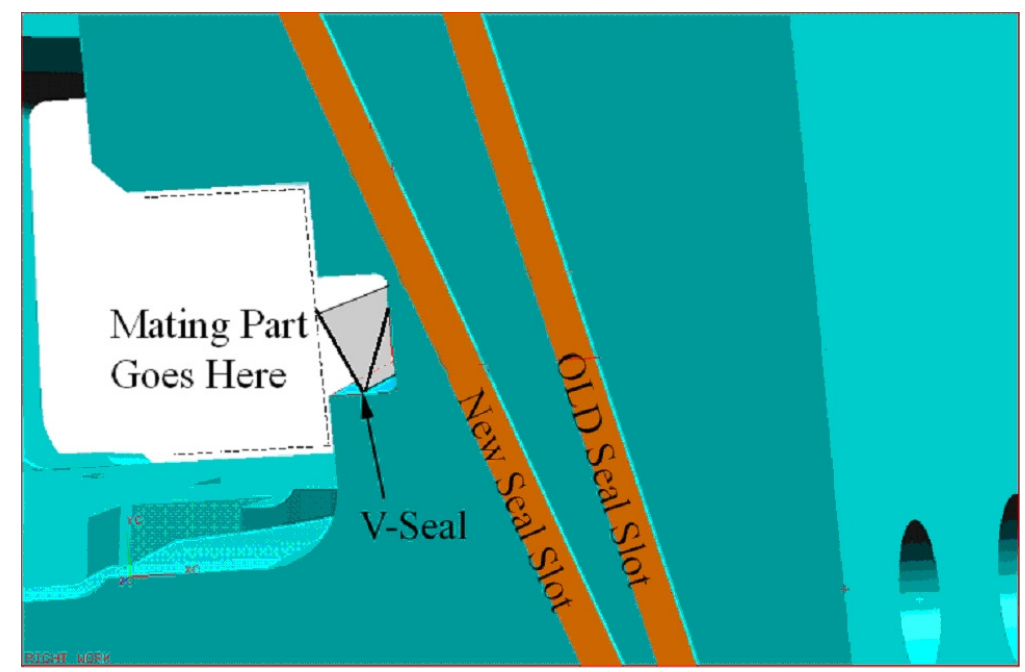

Figure 3-132. Diagram showing re-positioning of the cloth seal slot on the end of the outer shroud block closer to the V-seal between the outer shroud block and the T-hanger. (This diagram shows the opposite end of the outer shroud block as what was shown in Figure 3-131.)

\subsubsection{Task S3.2 - Rig Testing for Design Validation}

The purpose of this task was to perform validation testing on the new shroud system design using the high-pressure/high-velocity gas turbine thermal simulation rig. Specific goals of the tests, as described earlier, were 1) to provide realistic testing conditions for evaluation and selection of various component design options, 2) to verify the proper operation and robustness of any new hardware, particularly the shroud-to-shroud seals, 3) to optimize the cooling flow to the spring cavity in order to maintain spring temperature within the working range with a minimum of cooling air, and 4) to evaluate the resistance to spallation of the EBC coatings applied using the new process modifications. As will be discussed two additional rig tests were necessary due to an over-temperature condition that occurred during rig test \#5 that confounded the post-test observations.

This task included several subtasks. On the design side the test rig design was modified to accommodate the new shroud system. Lessons learned from the performance of the first 4 rig tests was also used to make rig modifications intended to improve the durability and reliability of the test rig. A second subtask was the fabrication/refurbishment of rig hardware that was changed or damaged in the earlier rig tests. A third subtask was the fabrication of new CMC shrouds and application of EBC coatings using a modified deposition process that was expected to alleviate many of the root causes of the EBC spalling seen in the first engine test. The fourth subtask was the performance of the actual rig testing. The final subtask was the post-test analysis of the data and hardware to verify that the entire shroud system and its individual components all operated as intended and were ready for field engine testing. 
Based on the degradation of the slurry cast shrouds seen in the $1^{\text {st }}$ rainbow engine test, and on the recurring issue of EBC durability at the tooling bumps on slurry cast parts, a decision was made to proceed with further rig and engine tests using only prepreg MI CMC inner shrouds. Fortunately at this time (mid 2003) the prepreg MI process had been transitioned to CCP so that both GE GRC and CCP could fabricate shrouds for the tests. Obviously the long-term goal would be that CCP would become the soul producer of CMC turbine hardware for GE, but shroud fabrication at GRC was continued as a backup while the process at CCP was being optimized and qualified.

Despite having selected a single CMC fabrication process, there were still CMC material options that needed to be evaluated in the rigs. These options included the use of the higher-performance Hi-Nicalon Type-S fiber and a change in the fiber architecture from the normal $0-90^{\circ}$ layups that had been used for all previous shrouds to a $+/-45^{\circ}$ fiber architecture. Laboratory testing of these material variations had indicated that they would be acceptable for shrouds, but verification of this conclusion by rig testing was needed before they could be considered for use in the $2^{\text {nd }}$ engine test.

\subsubsection{Rig Test \#5}

As described above, considerable effort was spent in analyzing the performance of the EBC coatings from the $1^{\text {st }}$ field engine test in order to understand the mechanisms leading to coating failure. From this understanding potential solutions to the spalling problems were developed. These potential solutions included the following:

- use of an alternate plasma spray gun in order to improve the microstructure of the silicon bond coat

- use of an alternate thermal spray technique (high-velocity oxy-fuel, or HVOF) to improve the microstructure of the Si bond coat

- modifications to the spray patterns to minimize overspray around shroud edges

- use of more generous radii on the edges of the $\mathrm{CMC}$ to reduce oxidation-induced stresses in the EBC

- use of a multi-layer EBC (i.e. multiple applications of the full 3-layer EBC) in order to provide improved coating robustness

The type of CMC shrouds, EBC coatings, and metallic hardware combinations finally chosen for use in rig test \#5 are summarized in Table 3-11. Localized pads of porous EBC top coat (BSAS) were added to one edge of the center shroud. These pads were used in an attempt to verify whether the shroud-to-shroud gaps were decreasing at temperature due to thermal growth of the CMC inner shrouds relative to the thermal growth of the outer shroud block. If the shroud gaps were closing more than expected from the thermalstructural analyses then the EBC pads would show evidence of contact with the adjacent shroud after the rig test. 
Table 3-11. Type of CMC Inner Shroud, EBC Coating and Metallic Hardware Configurations Used in Rig Test \#5

\begin{tabular}{|l|c|c|c|}
\hline Rig position & $\mathbf{1}$ & $\mathbf{2}$ & $\mathbf{3}$ \\
\hline CMC shroud type & $0-90^{\circ}$, Hi-Nicalon & $0-90^{\circ}$, Hi-Nicalon & $+/-45^{\circ}$, Hi-Nicalon \\
\hline Shroud left edge & radius A & standard chamfer & standard chamfer \\
\hline Shroud right edge & standard chamfer & standard chamfer & radius B \\
\hline Damper Block & oxide-oxide interface & flat metallic & flat metallic \\
\hline $\begin{array}{l}\text { Spring/Piston } \\
\text { new no-piston } \\
\text { design }\end{array}$ & modified piston & new no-piston design \\
\hline $\begin{array}{c}\text { EBC Si bond coat } \\
\text { deposition }\end{array}$ & HVOF & $\begin{array}{c}\text { 11MB APS gun with } \\
1250 \mathrm{C} \text { heat treat }\end{array}$ & 9MB APS gun \\
\hline $\begin{array}{c}\text { Other EBC } \\
\text { modification }\end{array}$ & - & $\begin{array}{c}\text { pads of crushable } \\
\text { BSAS added to one } \\
\text { edge }\end{array}$ & $\begin{array}{c}\text { multilayer EBC on } \\
\text { rear half of hot gas } \\
\text { path face only }\end{array}$ \\
\hline
\end{tabular}

Several reviews regarding the shroud system designs and rig test plans were held with GE Energy Chief Engineer's Office, with the final review being passed on April 5, 2003. Many of the details regarding the CMC shrouds and EBC coatings had been previously approved, such that the final fabrication step on the shrouds, namely deposition of the EBC coatings, was completed on April 7.

Assembly of the test rig took longer than anticipated due to a variety of hardware issues and due to the necessity of passing the April 5 Chief Engineers' review before fabrication of much of the hardware could be initiated. The rig was finally assembled with the CMC shrouds on June 2, at which time cold flow testing was initiated. This was immediately followed by rig light-off on June 3. The rig was run nearly continuously through June 8, at which point a major pressure increase was experienced and the rig was shut down. During this testing period the shrouds were exposed for 108 hours at temperatures between $1090^{\circ} \mathrm{C}$ and $1290^{\circ} \mathrm{C}$, including one complete off-on-off cycle, 18 warm thermal cycles $\left(1290 \rightarrow 840 \rightarrow 1290^{\circ} \mathrm{C}\right)$, and two cycle as part of the spring cooling flow DoE $\left(1090 \rightarrow 1200 \rightarrow 1090^{\circ} \mathrm{C}\right)$.

Unfortunately there were also several unplanned thermal cycles. At two points during the test the fuel compressor tripped off, causing two quench cycles from $1200 \rightarrow 370 \rightarrow 1200^{\circ} \mathrm{C}$. More importantly, the air compressor also tripped twice during the testing. During the second compressor trip the drop in air flow caused the fuel to air ratio to increase in an uncontrolled fashion, which in turn caused a dramatic increase in the combustion gas temperature of over $620^{\circ} \mathrm{C}$, up to $\sim 1920^{\circ} \mathrm{C}$. Figure $3-133$ shows the measured temperature during one of these air compressor trips.

There were two methods for determining the combustion gas temperature in the shroud rig. The first was based on calculation of the adiabatic combustion of the natural gas/air mixture composition derived from the gas mass flow measurements (T_flame_flows in Figure 3133). The other method is by estimating the combustion temperature based on the oxygen 
depletion measured in the exhaust gas stream (Est_Tflame_O2 in Figure 3-133). Generally these two combustion gas temperature estimate methods do give temperature trends that are consistent even though there is an offset in the absolute values, as shown in Figure 3133. Based on these two estimation methods the combustion gas temperature during each of the two excursions peaked at $1900-2000^{\circ} \mathrm{C}$.

The effect of the combustion gas temperature excursion on the shroud hardware varied depending on how exposed the particular part was to the hot gas path. Temperatures near the center of the outer shroud block (Tspring in Figure 3-133) increased only slightly $\left(<100^{\circ} \mathrm{C}\right)$ due to the large heat capacity of the OSB and because the OSB was not directly impinged by the hot gas path flow. The forward attachment (T_pin) showed a greater increase $\left(\sim 230^{\circ} \mathrm{C}\right)$ due to its closer proximity to the hot gas path. Temperatures on the backside of the rig lower wall (T_lower_wall), which was again made of CMC, also showed $\sim 200^{\circ} \mathrm{C}$ spikes, reaching as high as $1300^{\circ} \mathrm{C}$. As this thermocouple was not necessarily on the hottest section of the lower wall, and was measuring only the back-side wall temperature, it is very likely that other regions of the lower wall, and of the CMC shrouds themselves, exceeded $1400^{\circ} \mathrm{C}$ for a short time. The magnitude of the temperature spike was very important since silicon, which is part of the CMC matrix and also used as the EBC bond coat, melts at $1405^{\circ} \mathrm{C}$.

The rig test cell pressure increase that eventually led to the shutdown of the test was found to be a result of failure of the lower wall in the rig. A large section of the lower wall surface had delaminated and come loose, effectively blocking the gas flow in the test section. Despite this loss of a significant thickness of the $\mathrm{CMC}$, the lower wall as a whole remained intact. A photograph of the lower wall following the rig test is shown in Figure $3-134$.

Fairly extensive EBC damage was noted on the shrouds upon removal from the rig. This damage was not as severe as seen in the 5366 hour field engine test, but was definitely worse than seen in any of the previous four rig tests. A photograph of the shrouds following the rig test is shown in Figure 3-135 and Figure 3-136. Moreover there was clear evidence of molten silicon on the surface of two of the three shrouds. The largest accumulation of silicon occurred on the shroud with the oxide CMC damper interface, which was consistent with the analysis predictions and actual measured results that showed that this shroud would run hotter than the other two due to the insulating effect of the oxide CMC. Photographs of silicon found on the EBC surfaces are shown in Figure 3-137. That these metallic deposits were indeed silicon was later verified using SEM/EDAX analysis. These remnants of silicon that had been molten were direct proof that the inner shroud temperatures had exceeded $1405^{\circ} \mathrm{C}$ locally during at least one of the temperature excursions. 

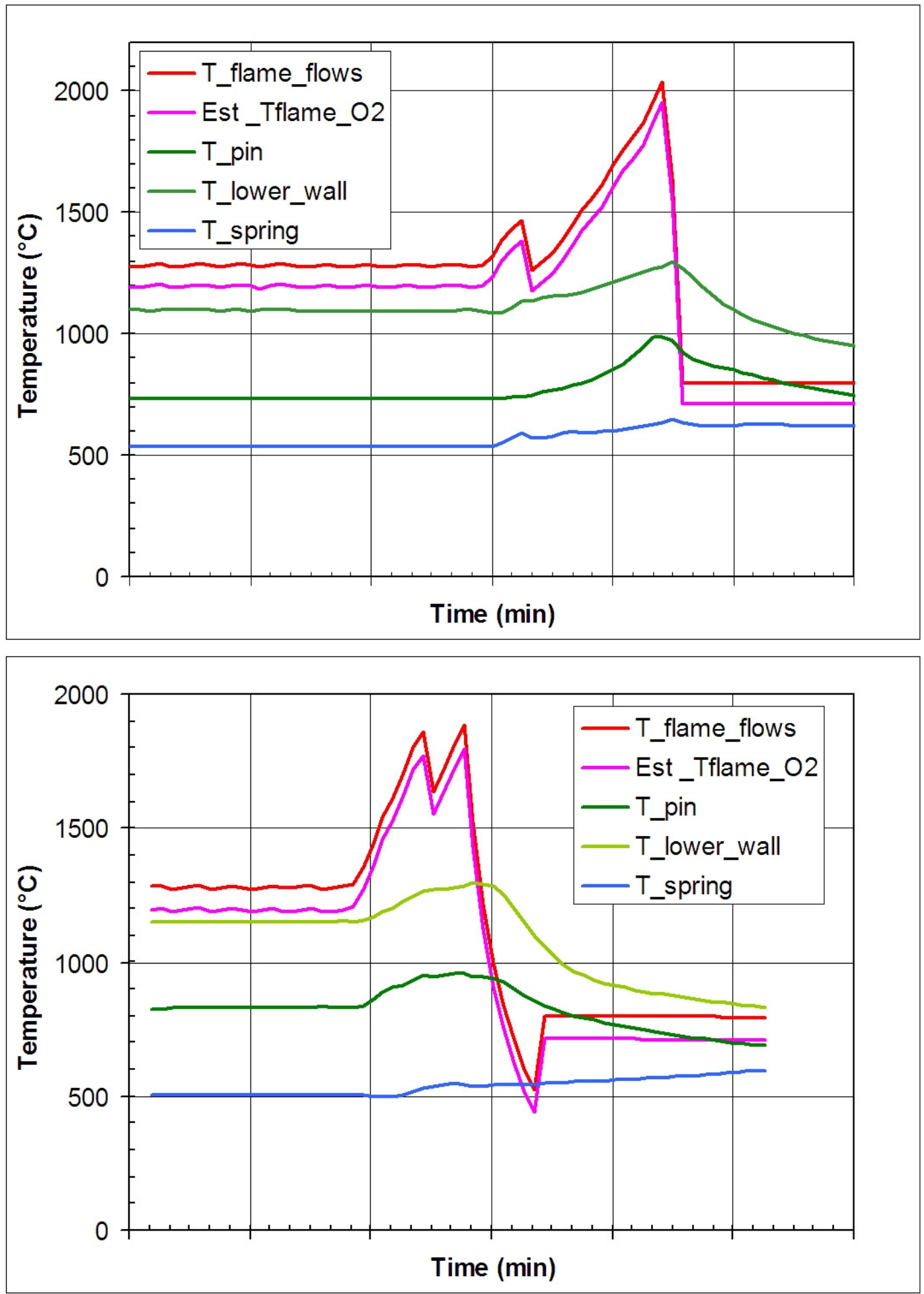

Figure 3-133. Temperatures in the shroud test rig vs. time during the two air compressor trips during rig test \#5. 


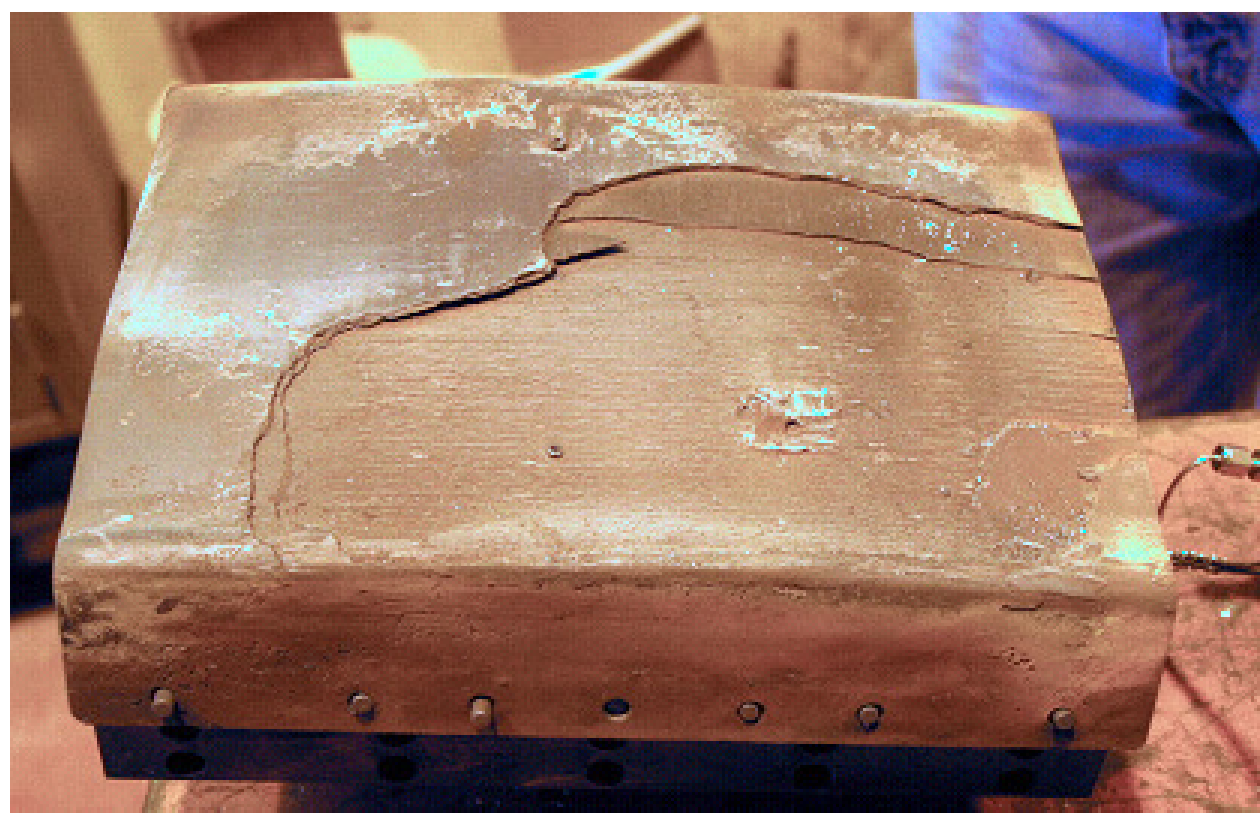

Figure 3-134. Photograph of the shroud test section CMC lower wall following rig test \#5.

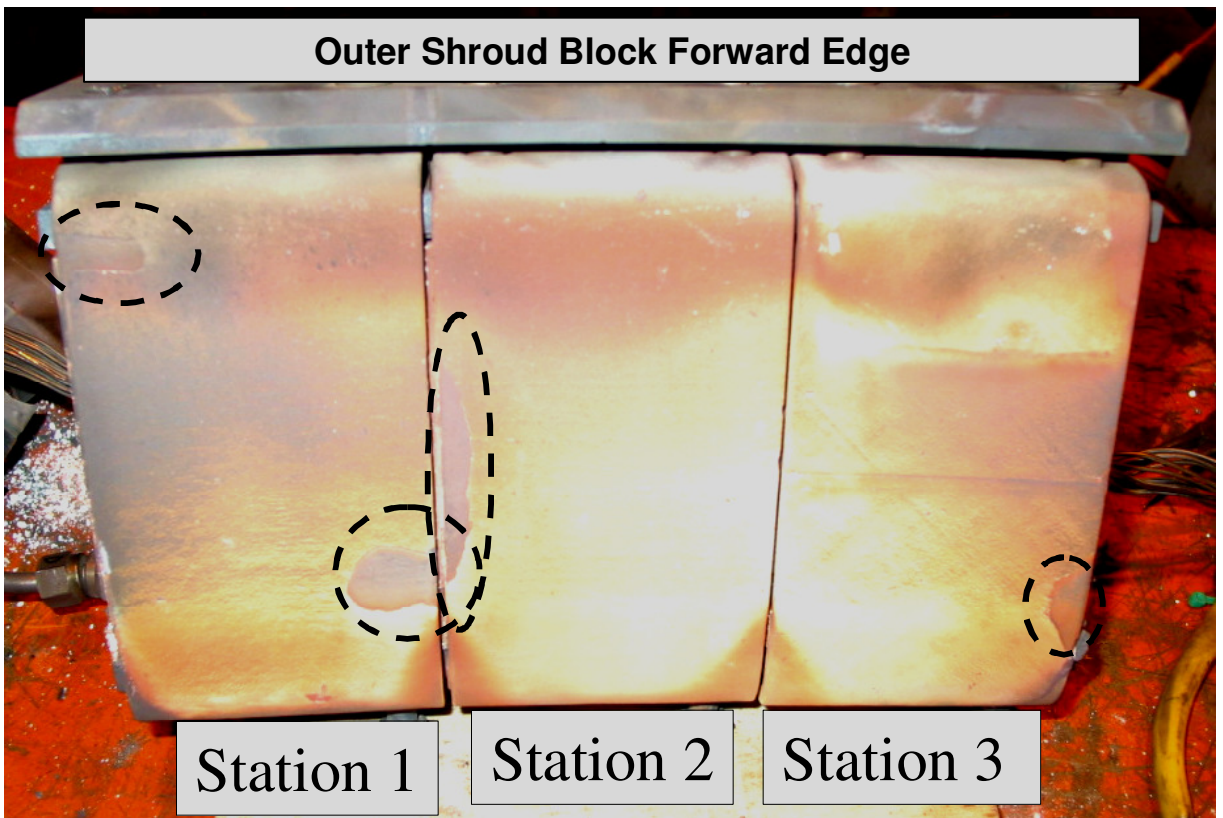

Figure 3-135. Photograph of the CMC shrouds, still mounted in the rig outer shroud block, following rig test \#5. Areas of EBC spallation are circled. 


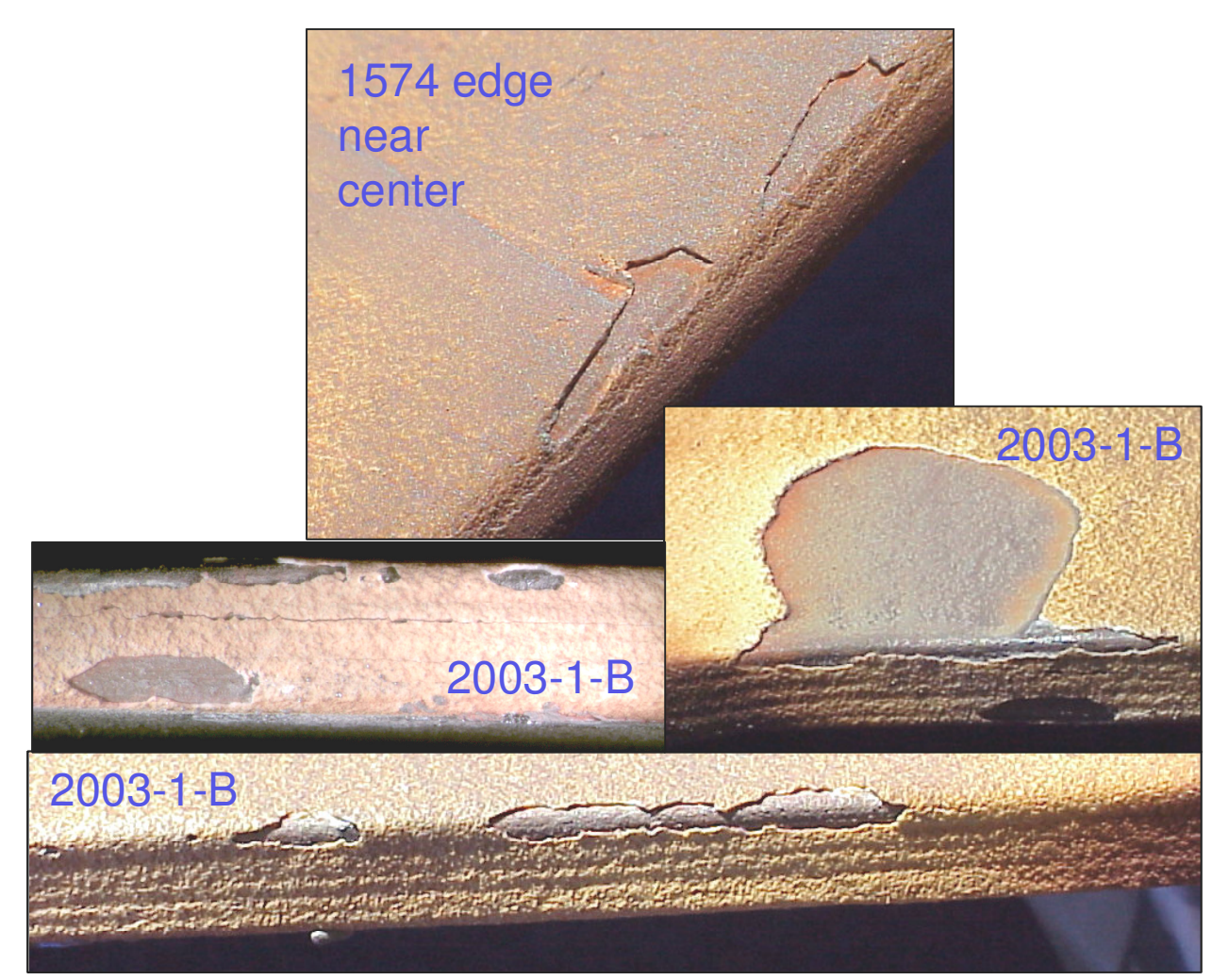

Figure 3-136. Close-up photographs of several of the EBC spalls seen on the shrouds from Rig Test \#5.

Observations made during disassembly of the shroud test section indicated that nearly all of the shroud hardware performed well despite the extreme temperature spikes. All of the seal hardware was intact and functional. The new damper blocks showed little distress either from the heat exposure or due to wear against the CMC inner shrouds. There were some minor cracks noted on the damper blocks emanating from the grooves cut in the sides to hold the metal shim seals. This cracking was a result of improper machining techniques being used on the dampers by the supplier, and was a known issue going into the test. The operation of the metallic dampers was so good that the damper design with the oxide CMC interface was no longer considered for use due to its higher cost, complexity and higher temperatures and stresses it causes in the shrouds. No damper-induced spallation of EBC from the backside of the shrouds was found. The new spring-damper assemblies operated as desired with no indications of seizing or wear. Also, the extensive instrumentation placed into the rig enabled the determination of a very detailed transfer functions for predicting cooling air flows on outer shroud hardware temperatures. However, as noted before, because the cooling air feed line was too cool during the test an extrapolation of the cooling DoE results to actual engine conditions was judged to not be prudent. 


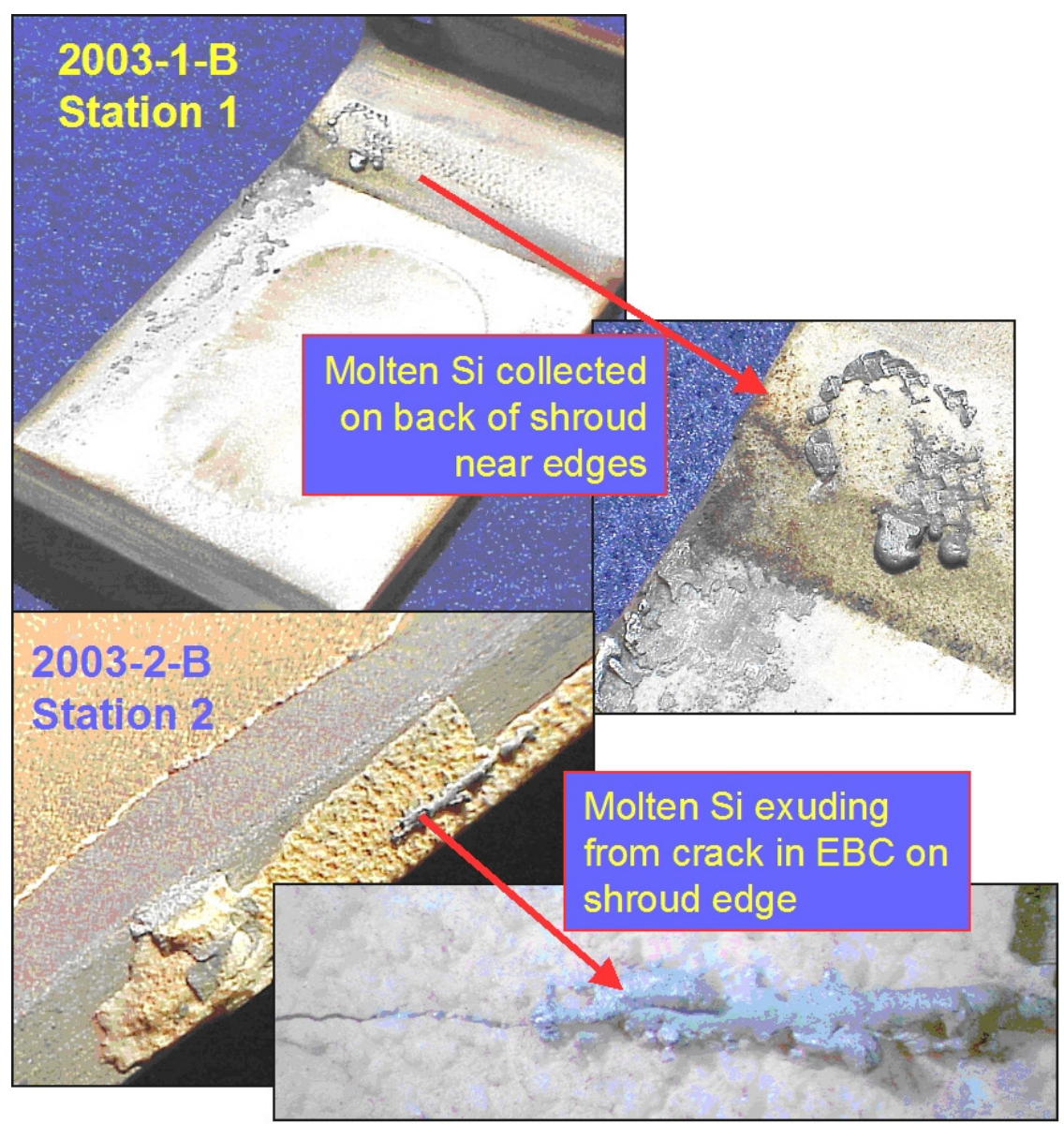

Figure 3-137. Photographs of melted silicon on the surface of shrouds from Rig Test \#5.

Quite extensive post-test characterization of all of the shroud hardware from Rig Test \#5 was performed. In general the final analyses of the metallic hardware were consistent with the early assessments made through visual inspection, namely that the new damper/piston system and the shroud-to-shroud seals all performed very well with little or no distress. Characterization of the CMC shrouds, and the EBC coatings in particular, showed considerably more degradation than seen in any of the previous rig tests. The damage to the EBC and CMC was undoubtedly attributable to the two temperature excursions experienced during the rig test where the combustion gas temperature reached $\sim 1930^{\circ} \mathrm{C}$, and the shroud surface temperatures exceeded $1410^{\circ} \mathrm{C}$.

Microstructural analysis of the shrouds from rig test \#5 concentrated on areas where EBC spallation was evident. The spalls observed were very similar to those seen on the previous engine test shrouds, and were concentrated near the shroud edges, as shown in Figure 3136. In a few of the spall regions there appeared to be cracks in the underlying CMC, as shown in Figure 3-138.

A total of 75 metallographic sections were prepared from various areas of the three rigtested shrouds. The majority of these sections involved edge regions where the majority of 
EBC spallation was observed to occur. Although the three shrouds varied somewhat in edge geometry, EBC configuration and the sealing schemes used, the microstructural results were very consistent between all three. For this reason, detailed results will only be presented for one of the shrouds, namely 2003-2-B, which was the center shroud in the rig test.

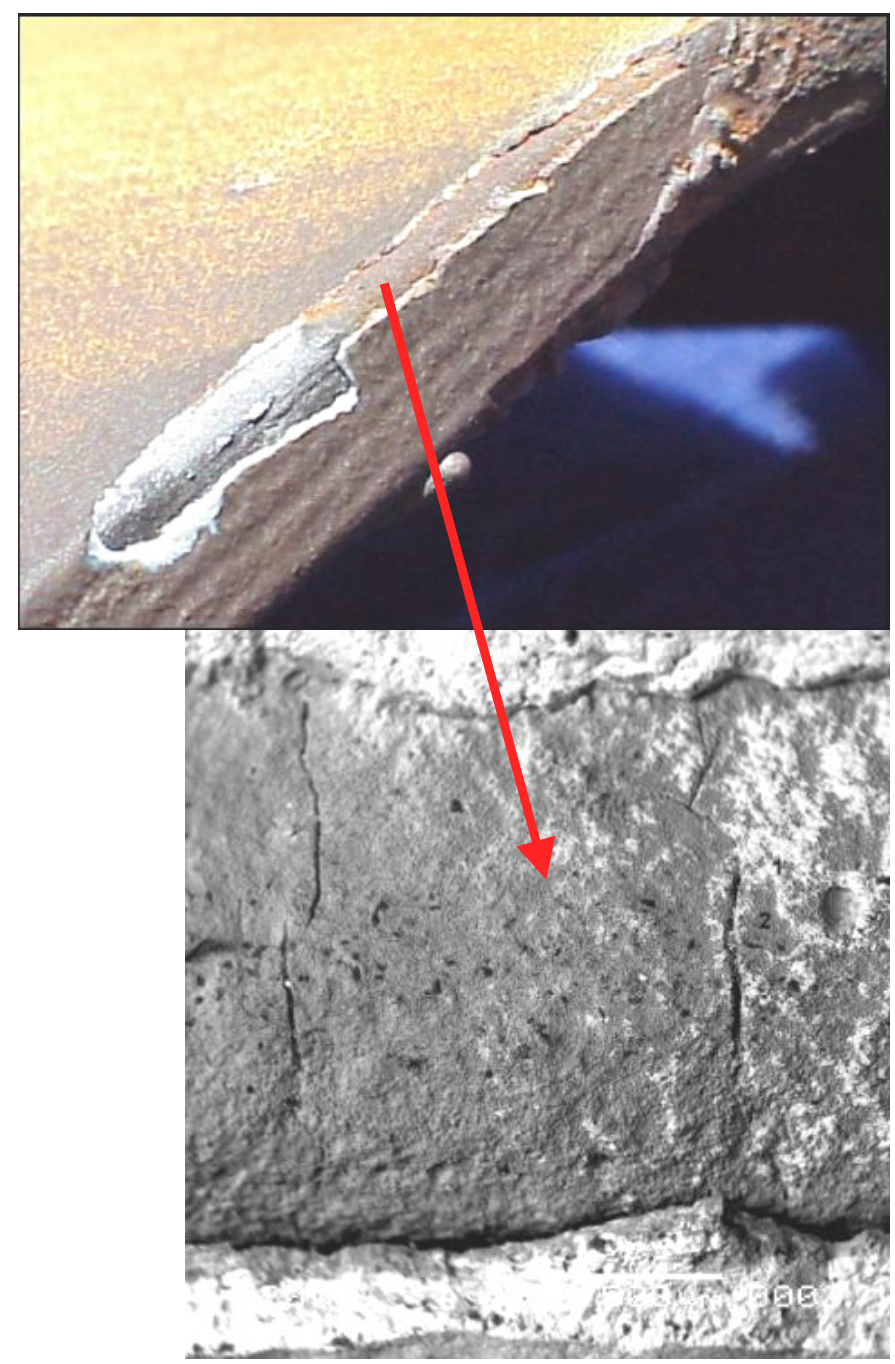

Figure 3-138. Photograph (top) and SEM micrograph (bottom) of an edge spall region of a shroud from rig test \#5 showing what appears to be surface cracking of the CMC shroud.

Figure 3-139 shows a photograph of shroud 2003-1-B following rough sectioning for metallographic sample preparation. Section R6 was of particular interest because it was in the center of the hot gas path face with spalls of the EBC at the shroud corners both upstream and downstream of this location. In general, areas where the EBC top layers had spalled were more difficult to evaluate, but regions such as R6, which were close to spalls 
but not entirely spalled themselves, typically gave the best insight as to the failure mechanisms.

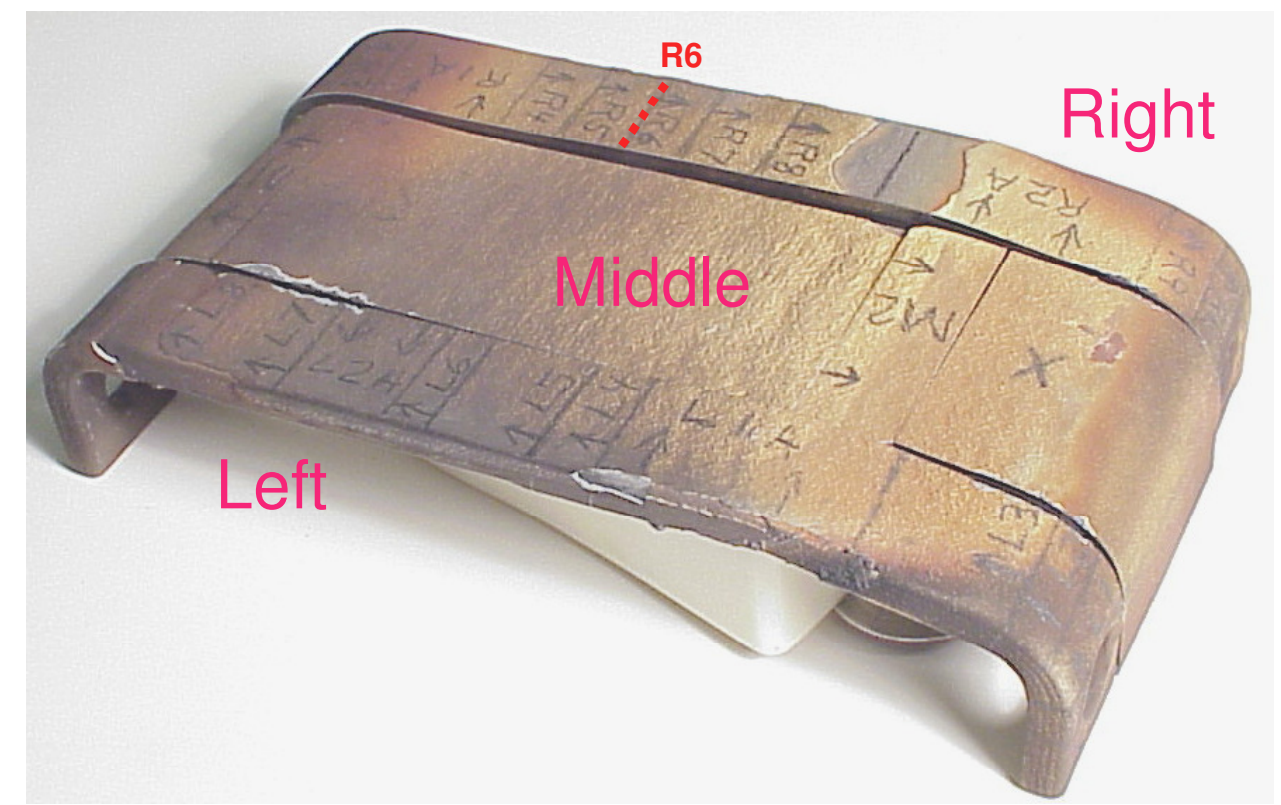

Figure 3-139. Photograph of Shroud 2003-1-B following rough sectioning for metallographic sample preparation. The position of section R6 is marked by the dashed line.

Figure 3-140 is a photomontage of the edge of the shroud from section R6. Although the EBC top coat was present continuously around this edge, the bond coat was obviously missing from much of the area. The close-up micrographs show important features in the EBC around the shroud edge. To a large extent, the Si bond coat was absent from the hot gas path face (top surface), around the edge and even extending somewhat around the backside of the shroud. The island of silicon in the upper corner, which was probably responsible for the corner not spalling in this particular location, shows clear signs of having melted (absence of porosity and redistribution of impurity phases). One had to look nearly $3 \mathrm{~mm}$ in from the corner on the back side of the shroud in order to observe unmodified silicon bond coat. These observations strongly indicated that the shroud surface did indeed exceed the melting point of silicon during the rig test thermal excursions, and that substantial bond coat melting and redistribution took place. In every examined area of EBC spallation similar microstructural evidence of bond coat melting was found. Consequently, all of the observed EBC degradation could be at least partially attributable to bond coat melting during the thermal excursions, and thus little information as to the durability of the EBCs under normal engine conditions could be obtained. 


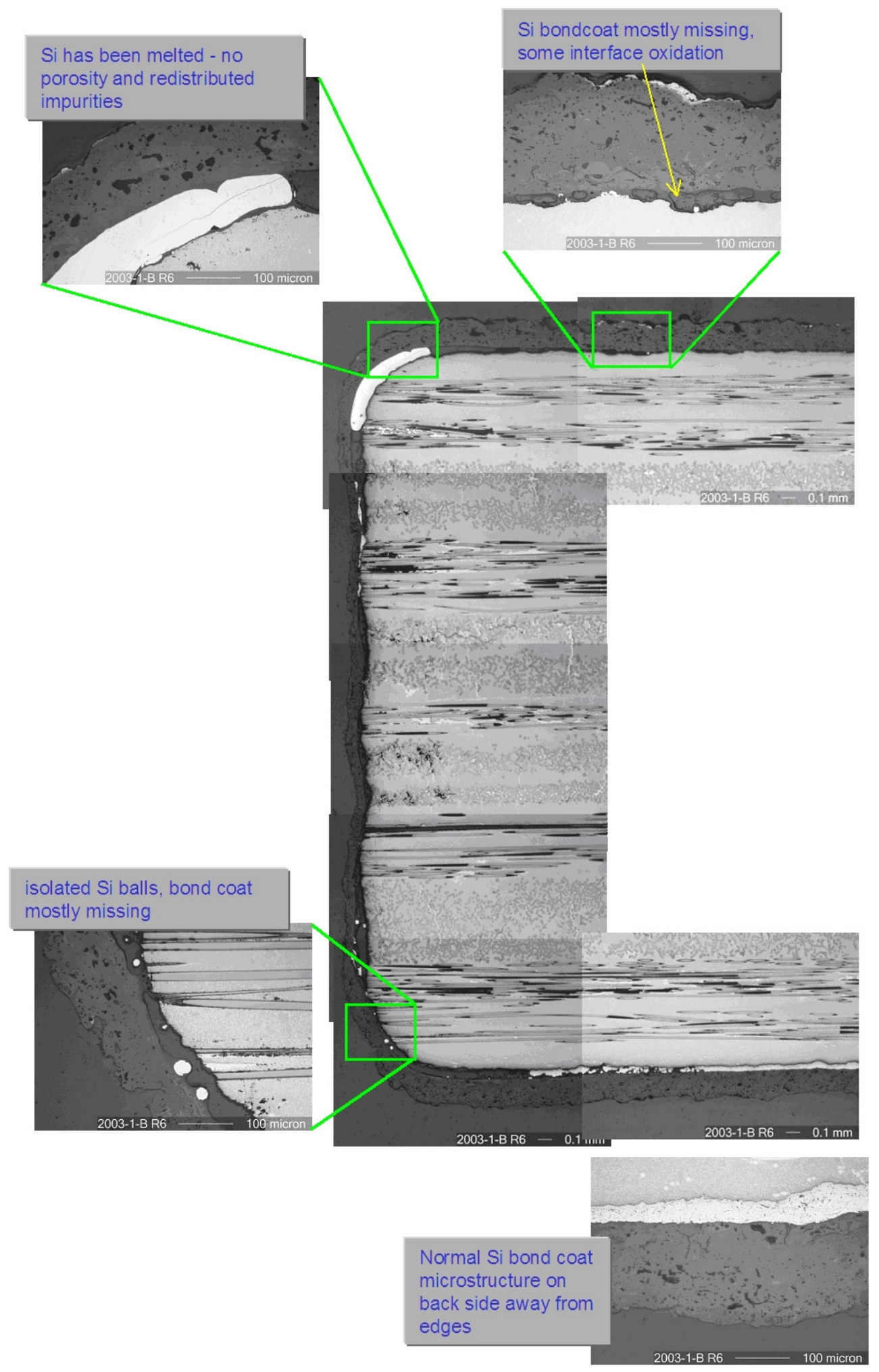

Figure 3-140. Photomontage of the edge of shroud 2003-1-B in region R6. The silicon EBC bond coat was missing over nearly all of the edge and a large portion of the hot gas path face. 
Metallographic examinations also elucidated the nature of the CMC "cracks" seen on the shroud surfaces in some of the EBC spall regions, as shown in Figure 3-138. During fabrication of a Prepreg HiPerComp ${ }^{\mathrm{TM}}$ composite there are steps, such as the binder burnout step, where the matrix of the composite undergoes a small shrinkage. This shrinkage is not accommodated by the reinforcing fibers, and thus small, localized cracks open in the matrix, generally running perpendicular to the fiber direction and limited to individual plies. During final densification via silicon infiltration these cracks fill in with silicon, and have practically no impact on the mechanical properties of the finished composite. Figure 3-141 shows a micrograph of a region of the hot gas path face of shroud 1574 where one of these cracks in the near-surface ply reached the surface. During the thermal excursion the silicon in the crack melted and re-distributed, just as the silicon from the missing bond coat had pooled elsewhere. The depleted silicon veins, when viewed optically from the surface of the shroud, appeared as cracks in the CMC.

Once it was concluded that the central sections of the shrouds would not be needed for additional metallographic analysis, the middle sections of each shroud were cut into two tensile bars for mechanical evaluation. Room temperature tensile tests were performed, and the strengths of the bars compared to the shroud witness bars. The results of these tests are summarized in Figure 3-142. The data listed with the "-W" suffixes in were from the shroud witness bars, measured on shroud material before rig testing, whereas the other two bars for each shroud, with the "-E" and "-C" suffixes, were cut from the shrouds after rig testing. The stress-strain curves for the samples from shroud 1574 show quite different fracture behavior, but this is due to the differences in fiber architecture whereas shroud 1574 had the reinforcement in $+/-45^{\circ}$ orientations relative to the axial length of the shroud and the other two shrouds had the normal $0-90^{\circ}$ fiber architecture. Based on previous fiber architecture studies, the shroud 1574 samples, if measured in a 0-90 orientation, would have ultimate strength values in excess of $345 \mathrm{MPa}$.

Overall there was substantial degradation in proportional limit and initial modulus values, and in most cases in the ultimate strength and strain to failure values. The observed drops in proportional limit and modulus are suggestive of microcracking of the CMC matrix; however, no such microcracking was observed in the metallographic examinations. The degradation of these samples was considerably worse than in all previous rig tests, which indicated that the two thermal excursions had a significant effect on CMC properties. The mechanism of this impact, however, was not clearly understood, but may have been related to the removal of silicon veins from the composite matrix near the surface, as discussed previously. 

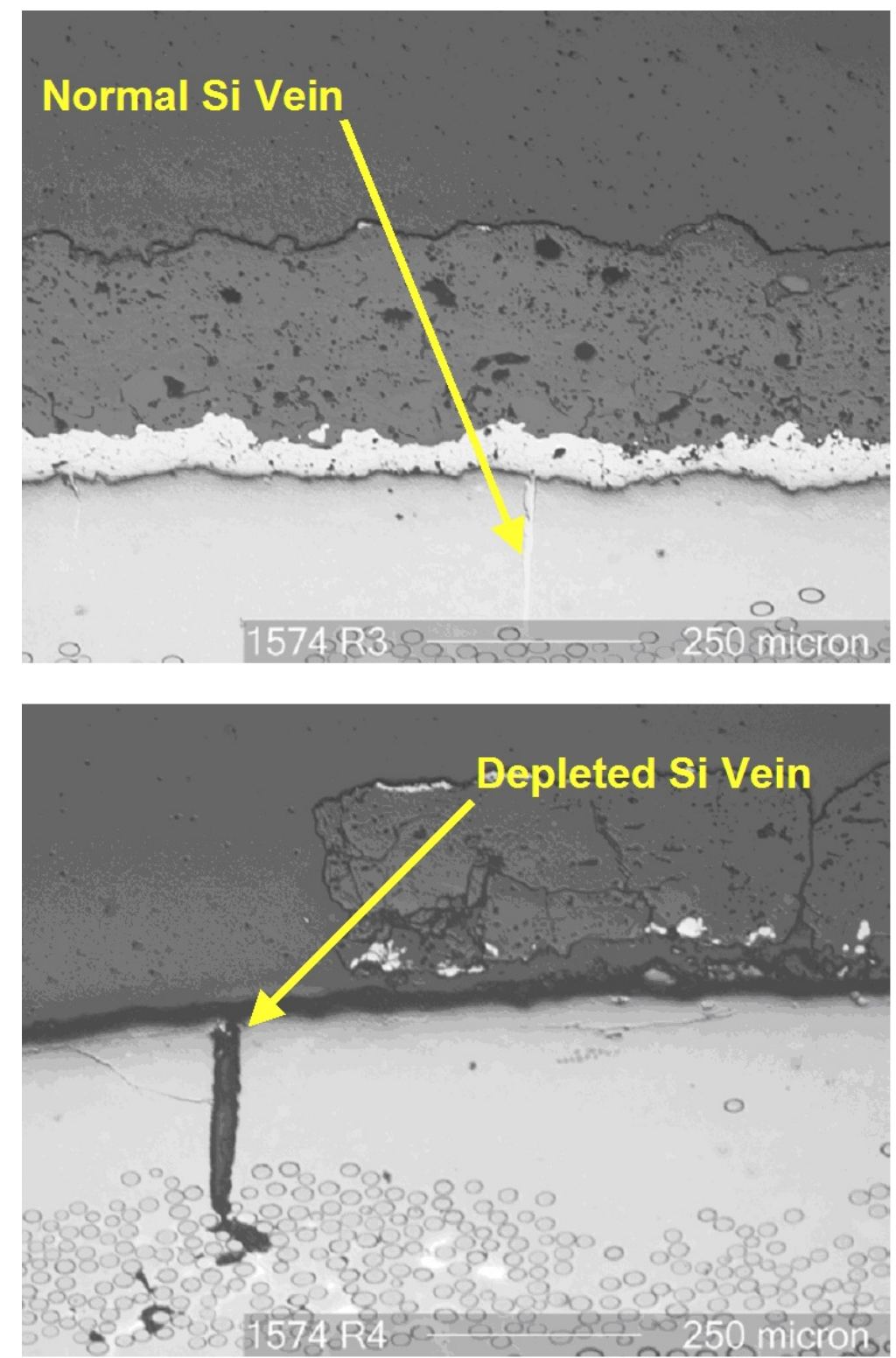

Figure 3-141. Photomicrographs of shroud 1574 showing the appearance of normal and "depleted" silicon veins. The depleted vein appears wider than the filled vein due to damage and rounding of the edges during polishing. 


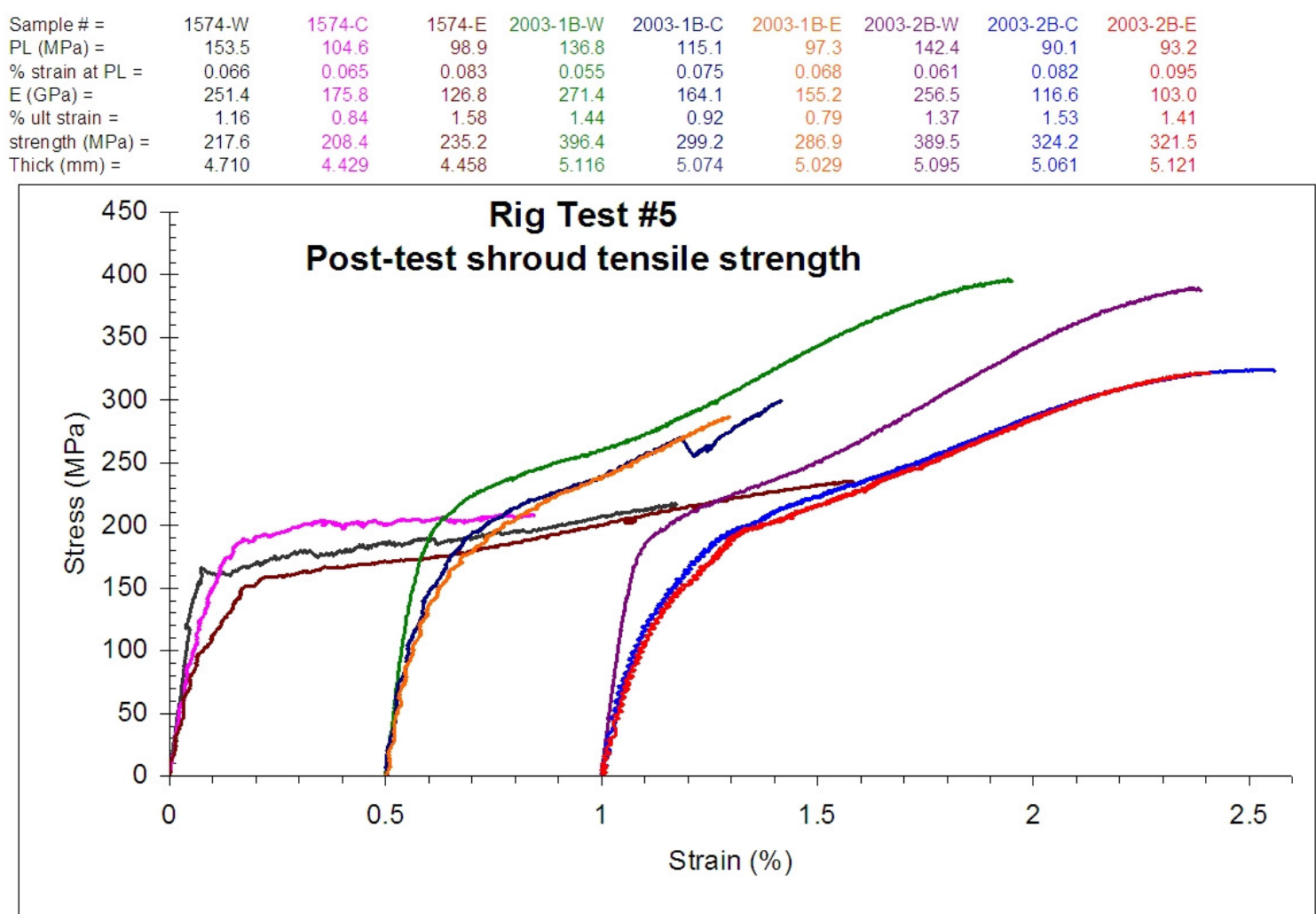

Figure 3-142. Tensile stress-strain results of shrouds from before (-W samples) and after ($\mathrm{C}$ and $-\mathrm{E}$ samples) exposure in Rig Test \#5. The color coding of the fracture data above the graph serves as the legend for identifying the different curves. The curves for each shroud are offset on the strain axis for clarity.

\subsubsection{Rig Test \#6}

The CMC inner shrouds utilized in Rig Test \#6 were selected from the pool of prepreg shrouds made in 2003 that had not been used in Rig Test \#5. No additional CMC shroud fabrication or machining, except for some minor changes in select edge radii, were required. EBC configurations were selected that very much mirrored the variants utilized in Rig Test \#5. Two of the shrouds for the test were EBC coated at GRC, and the third was coated at the Material and Process Engineering (M\&PE) Lab at GE Energy, Schenectady. MP\&E was to have responsibility for EBC coating the majority of shrouds for the full shroud set engine test, and this rig test presented a valuable opportunity to validate the MP\&E coating process. Table 3-12Table 1 lists the EBC variations that were included in rig test \#6. 
Table 3-12. CMC Inner Shroud EBC Configurations Used in Rig Test \#6.

\begin{tabular}{|c|c|c|c|}
\hline & Left Position & Center Position & Right Position \\
\hline Shroud ID No. & $1374-1$ & $1374-2$ & $1106-2$ \\
\hline Matrix Type & Standard & Standard & Standard \\
\hline Fiber Type & Hi-Nic Type S & Hi-Nic Type S & Hi-Nicalon \\
\hline Edge configuration & 4 radiused edges & $\begin{array}{l}2 \text { radiused edges } \\
2 \text { chamfered edges }\end{array}$ & 4 radiused edges \\
\hline $\begin{array}{l}\text { Si bond coat } \\
\text { deposition gun }\end{array}$ & HVOF & SG100 & $7 \mathrm{MB}$ \\
\hline $\begin{array}{l}\text { Overall EBC } \\
\text { configuration }\end{array}$ & $\begin{array}{c}\text { "Low porosity" } \\
\text { BSAS and abradable } \\
\text { pattern on hot gas } \\
\text { path face }\end{array}$ & Six-layer multilayer & $\begin{array}{c}\text { Baseline GEN } 1 \\
\text { EBC coated at } \\
\text { M\&PE }\end{array}$ \\
\hline
\end{tabular}

The first major effort for rig test \#6 was making the desired design changes to the outer shroud block and to the test rig facilities in order to accommodate the increase in coolant flow temperature and reduced flow rates desired. The design changes to the rig outer shroud block were sufficient to require the fabrication of a new block and new damper/piston assembly hardware. Modifications were made to the cooling air metering and valving system to allow for better control of the outer shroud coolant flows, especially at lower flow rates. Insulation was also added to the coolant air piping internal to the rig in order to keep the cooling air temperature close to the engine compressor discharge temperature, thus better simulating the cooling conditions in an engine.

The second major effort required to prepare for rig test \#6 was to refurbish the test rig internals. Other than the shroud block assembly mentioned above, most of the shroud test rig internal structure was re-used from the previous tests. However, some of the shroud test section outer walls and flanges needed to be fabricated anew due to changes in the test section coolant piping and changes in instrumentation. A new shroud test section lower wall and side walls were fabricated from prepreg HiPerComp ${ }^{\mathrm{TM}}$ at GRC since the walls from the previous rig test were damaged during the temperature excursions.

Please recall that several variations of outer shroud block damper design, sealing concepts and seal materials, inner shroud edge geometry, and inner shroud EBC configuration and deposition techniques had been tested in rig test \#5. The over-temperature excursions experienced in that test exposed the inner shrouds to temperatures above the melting point of silicon, thus compromising the EBC bond coat and making any evaluation of EBC performance rather tentative. However, the seals and dampers were relatively unaffected by these over-temperature events, and it was possible to down select to single preferred designs for the dampers and seals. In rig test \#6 all of the outer shroud block hardware, including dampers and seals, was consistent between the three shroud positions, and matched the configuration that was to be used in engine test \#2. 
The only new feature in the seal configurations was that CMC shims were used as seals between the left and right shrouds and the test section walls. Use of such shims in the engine test was not anticipated, but there was a desire to test the viability of using CMC seal shims for possible future applications.

Cold flow testing of the rig was started on December 3, 2004, and the system was fired up on December 4. After confirming that the targeted cooling flow rates and temperatures could be achieved, the shroud system was put through a cooling flow DoE. The results of this initial DoE were used to identify the appropriate cooling flow conditions, at the nominal $1200-1230^{\circ} \mathrm{C}$ firing temperature, to reach the maximum allowable temperature in the region of the outer shroud block springs. The test rig was then run at 10 hours at these "maximum spring temperature" conditions. The shroud system would not intentionally be designed to run under these conditions in a real engine application, but it was necessary to be sure that there was sufficient margin in the design to allow operation even at these extreme conditions in case there were ever a blockage of the coolant air delivery system. After this exposure the rig test conditions were reduced back to nominal engine conditions.

After 75 hours of hot running the cooling flow DoE was repeated to look for any changes in the response of the shroud system. The rig firing temperature was then raised to $1290^{\circ} \mathrm{C}$ in order to assess the shroud response to even more advanced engine cycle conditions, such as $\mathrm{FB}$ or $\mathrm{H}$ class engines.

The test plan was to run under these conditions for roughly 50 hours and then complete 15 thermal cycle exposures before shutting down the test. However, at the 115 hour mark, including 27 hours at the $1290^{\circ} \mathrm{C}$ firing temperature condition, the rig fuel supply was automatically shut off when it tripped a hot gas temperature limit set up for this test. The operators determined that the cause of the firing temperature increase was a blockage of the rig test section, though the cause of this blockage was not obvious. An attempt was made to restart the test, but the blockage did not clear itself, and so the rig test was terminated on December 9.

After allowing the rig to cool down a borescope was used to look for the cause of the test section blockage. Several large pieces of the cast alumina refractory transition piece, which is upstream of the shroud test section, were found wedged into the entrance to the shroud test section. One of the borescope photographs is shown in Figure 3-143.

Despite the early termination the rig test was considered an overall success. Data from the cooling flow DOEs was fairly consistent between the two repeat tests, and also with the results of rig test \#5. Temperatures of the attachment and spring hardware were within $20^{\circ} \mathrm{C}$ between the $1^{\text {st }}$ and $2^{\text {nd }}$ DoE with the exception of one test condition. Unfortunately the two DOEs were not exact repeats as a change in the cooling flow pressures and temperatures was observed during the exposure testing between the DoE experiments. During rig disassembly a crack in one of the cooling air lines was found, which is shown in Figure 3-144. Leakage from this cracked line was believed to be the major cause of outer shroud temperature differences noted between the $1^{\text {st }}$ and $2^{\text {nd }}$ DoE experiments. 
Degradation of the potting material used to seal where the thermocouples entered the outer shroud block also occurred, and caused some additional coolant air leakage into the shroud test section. Some cold flow tests were done on the rig before full disassembly in order to evaluate the effect this cooling line crack would have on the DoE experiments, and these effects were taken into account during the data analysis.

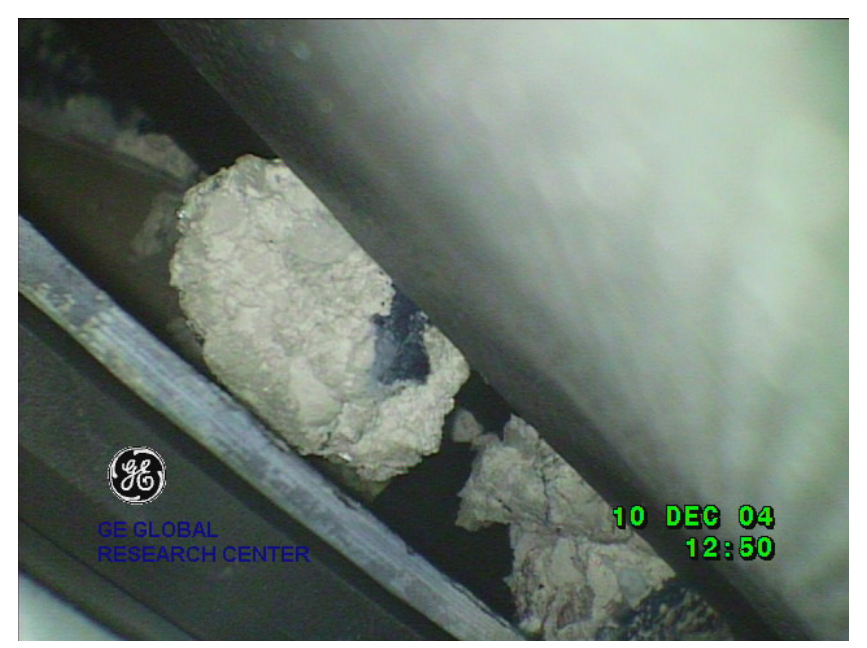

Figure 3-143. Borescope photograph of the shroud test rig showing fragments of the rig transition piece blocking the entrance to the shroud test section.

During the DoE experiments, the temperature of the outer shroud block hardware was measured over a range of firing temperature, cooling air temperature, and cooling flow rate to the attachment pins and to the damper spring cavities. As the spring cavity cooling flow was decreased a rapid rise in the spring cavity temperature was noted, as shown in Figure 3-145. The flow rate where this rapid rise in temperature starts represented the minimum flow required to prevent ingestion of hot gases into the spring cavity.

The other critical cooling flow rate determined in this test was the minimum cooling flow necessary to keep the shroud attachments within their operating temperature limits. This cooling flow was also predicted from the DoE results. Figure 3-146 shows the trend of attachment temperature versus cooling air flow rate for 3 rig firing temperatures. Spring cavity flow also strongly influenced the attachment temperatures, so there are a pair of lines for each firing temperature corresponding to the highest spring cooling flow used in the DoE and the minimum spring cooling flow as determined by the limit in Figure 3-145. The nominal hot gas path temperature of a 7FA engine in the region of the shrouds is roughly $1200^{\circ} \mathrm{C}$. Allowing for over-firing of $60^{\circ} \mathrm{C}$, and assuming the minimal allowable cooling flow for the spring cavity, the minimum attachment cooling flow could be defined as shown in Figure 3-146. It should be noted that this set of conditions represented the worst possible case for attachment cooling. At more normal operating conditions the cooling air could be decreased further, or the lower-than-needed attachment temperatures could be used to extend attachment life and provide design margin. 


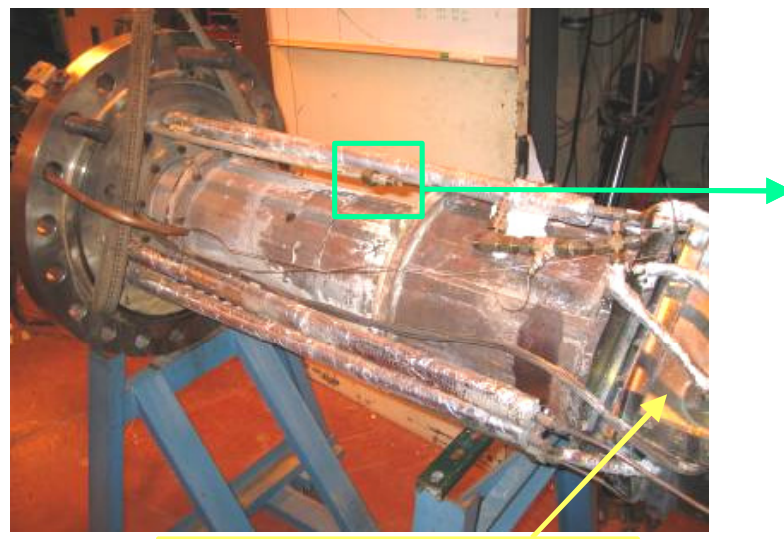

Shroud Test Section

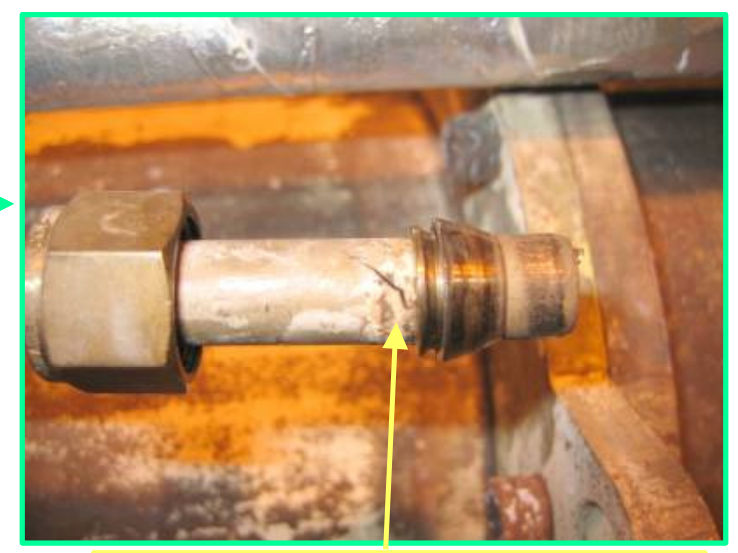

Crack in Cooling Air Line

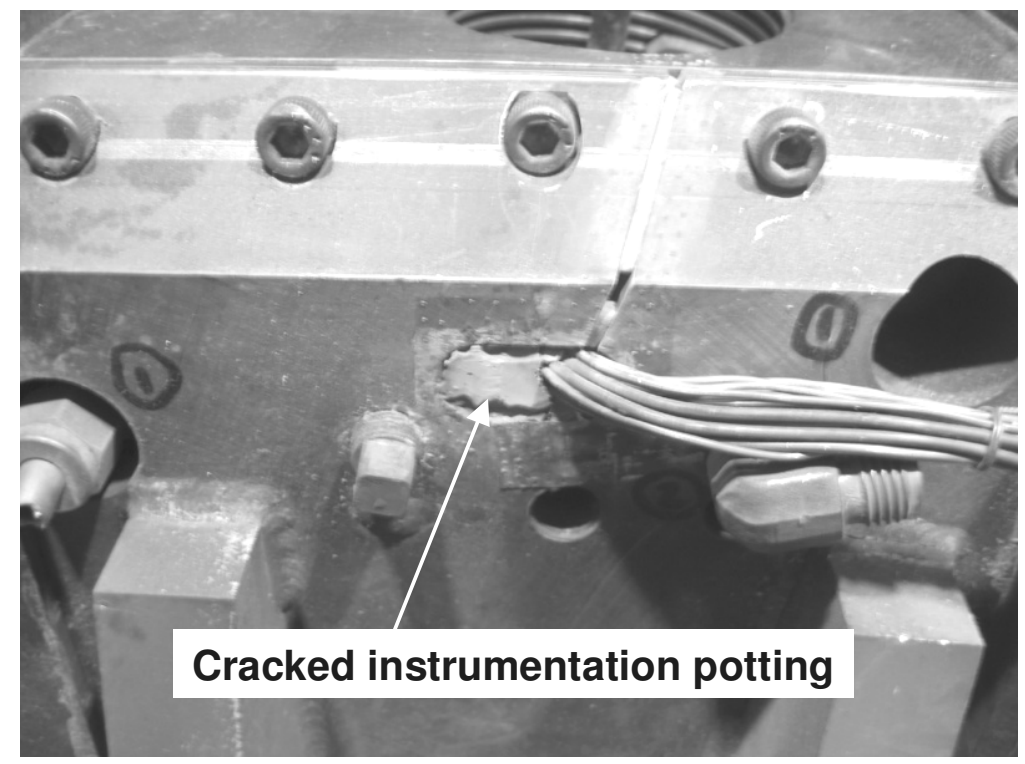

Figure 3-144. Photographs of shroud rig components indicating the location of a crack in one of the cooling air lines found during rig disassembly (top) and cracked potting compound at the thermocouple penetrations into the shroud test section (bottom). 


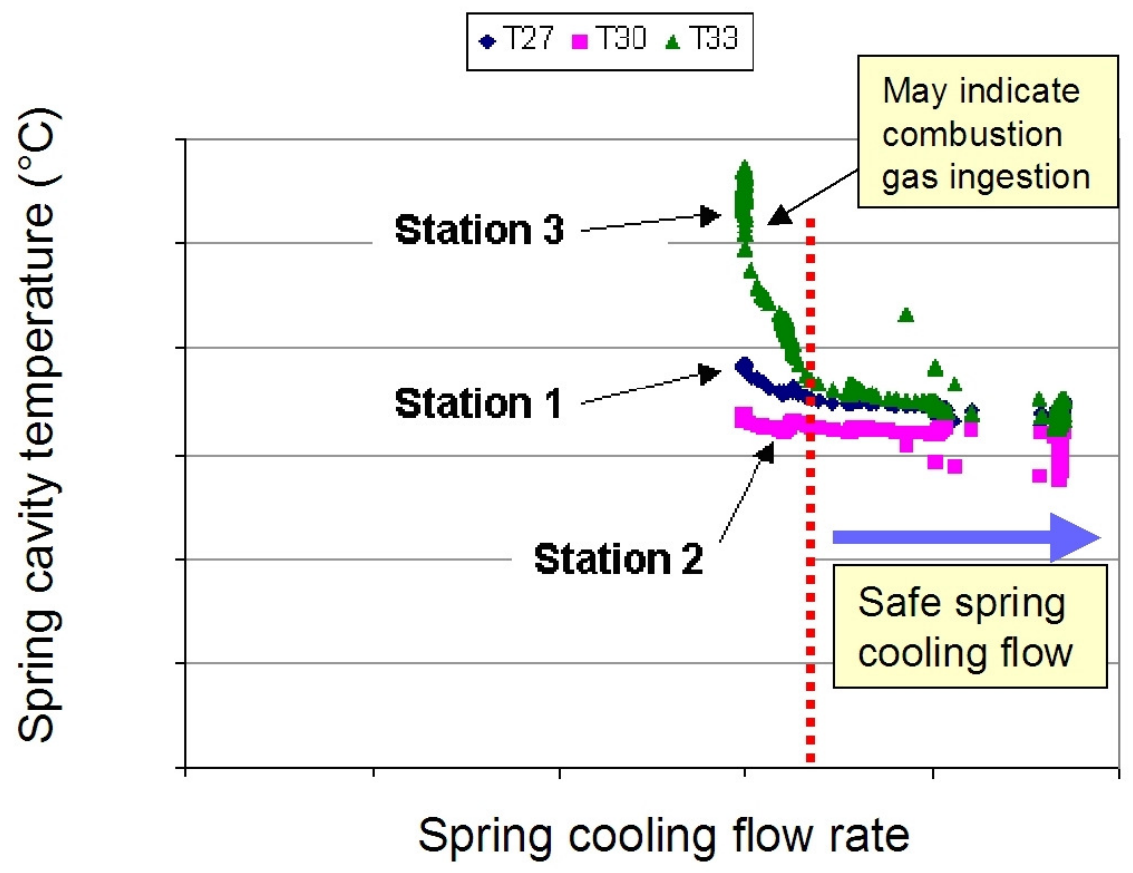

Figure 3-145. Trend of spring cavity temperature versus cooling flow used to determine a minimum cooling flow to prevent hot gas ingestion into the spring cavity.

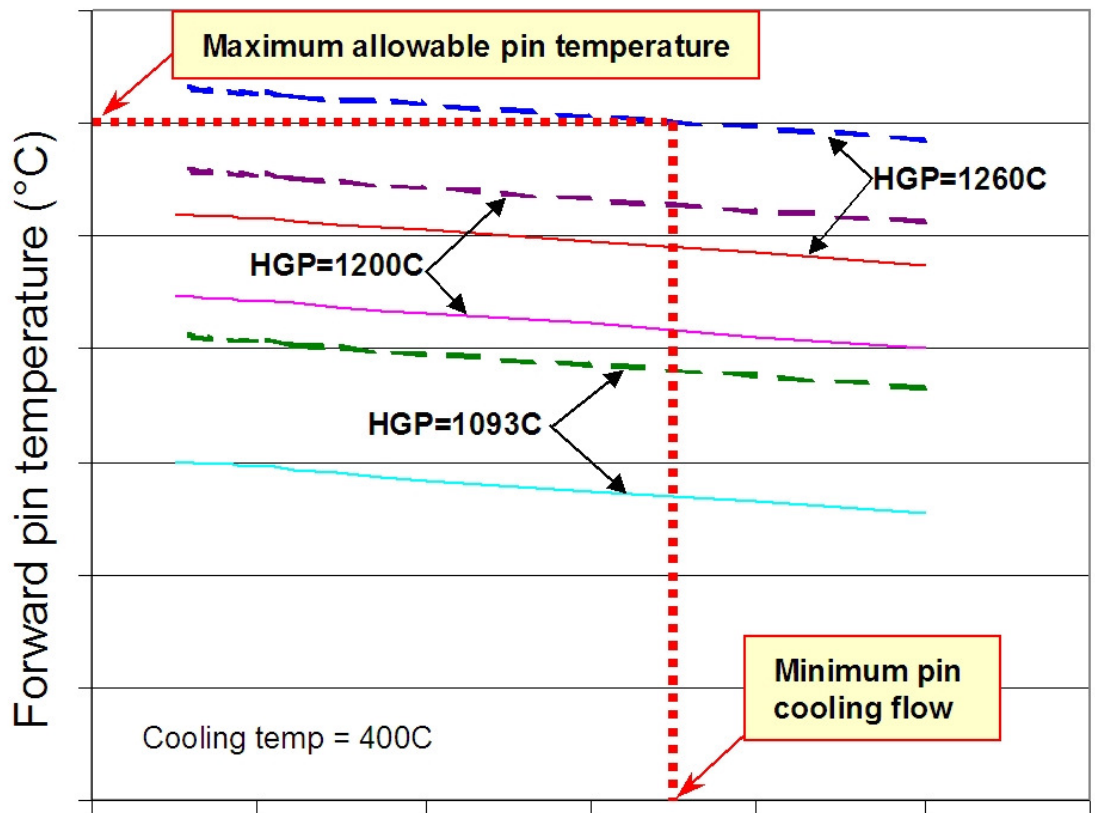

Pin cooling flow rate

Figure 3-146. Attachment temperature as a function of cooling air flow rate for several rig firing temperature conditions and two levels of spring cavity cooling air flow, indicating the worst case minimum cooling flow needed to keep the attachments below their temperature limits. 
Adding together this minimum attachment cooling flow, the required spring cavity flow (with appropriate design margin) and other leakage flows assigned to the shroud gives the total cooling flow allocated to the shrouds. When extrapolated to the exact engine conditions, this minimum required cooling air flow limit was within the targeted cooling flow range for the shroud system where it was at that time considered to be a commercially viable product.

Preliminary evaluation of the hardware from rig test \#6 was very promising. It was a near certainty that the shrouds were impacted by debris from the crumbling lining of the transition piece, yet no discernible damage was done to the shrouds or EBC coatings. EBC integrity was very good over the entire hot gas path faces and even in regions on the back face where they were in contact with the damper blocks. Figure 3-147 shows a photograph of the back of one of the shrouds and the surface of the corresponding damper block. In general the shroud and damper appeared to have contacted preferentially in the center of the front and rear edges of the damper blocks as a result of the thermal distortions that occur in the two parts. Contact marks in the EBC were very minor and matched very closely the relatively minor wear marks in the damper blocks. The dark streaks on the EBC are primarily remnants of metal worn off of the damper block and no appreciable removal of EBC was noted.

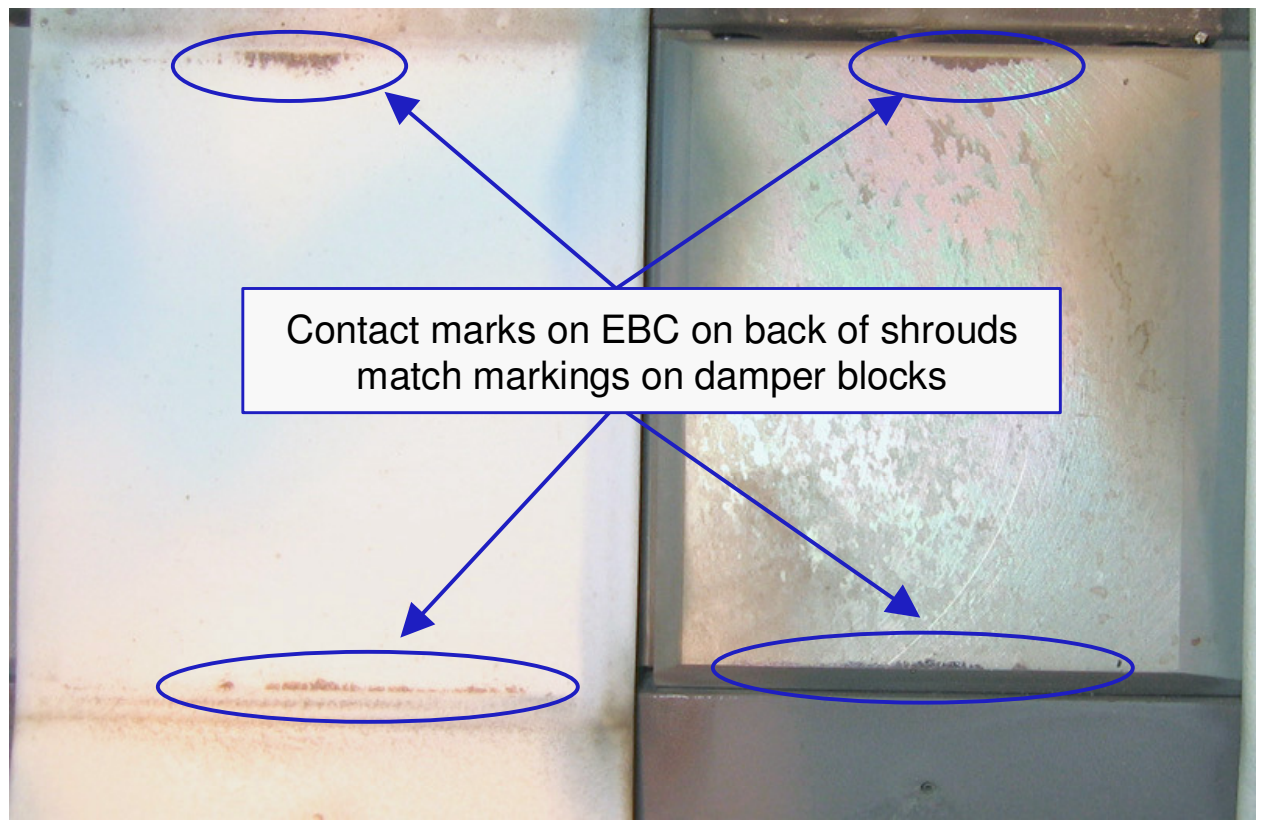

Figure 3-147. Photograph of the back side of one of the shrouds from rig test \#6 (left) compared to the corresponding damper block surface (right) showing that the contact marks on the two components match and are of relatively minor severity.

The only defect in the EBC coatings noted after the rig test was a crack along the edge on the back-side face of shroud 1374-1. Photographs of this crack are shown in Figure 3-148. This particular shroud had the Si bond coat layer put down by a different spray process, 
using a high-velocity oxy-fuel (HVOF) spray gun. Due to our limited experience of using this gun and process with the shroud geometry there were some part masking issues with the Si layer in this region. In effect, the masking in this region was not effective at blocking overspray from the coating of the shroud edges, leading to a thick, porous silicon layer along the edge. This situation was recognized during the spray operation, but due to the rig test schedule there was insufficient time to attempt a coating strip and re-coat to fix the problem. The added thickness of the silicon bond coat also caused a bump along the back edge of the shroud, which was smoothed by hand after all EBC layers were deposited in order to prevent loading of the edge by the damper block. Consequently the EBC top layer was thinner than normal in this region. The porous silicon layer and thin top coat are both conditions which are know to promote bond coat oxidation.

All of the shrouds were sectioned for metallographic evaluation, primarily focused on the EBC. Figure 3-149 shows a cross section through the edge crack region on shroud 13741. The oxidative swelling of the porous bond coat is evident as well as the generation of cracks in the EBC caused by this swelling. The masking problem that caused this porous bond coat was resolved, and shrouds coated for use in the engine test \#2 using this same spray gun did not show any porous bond coat issues.

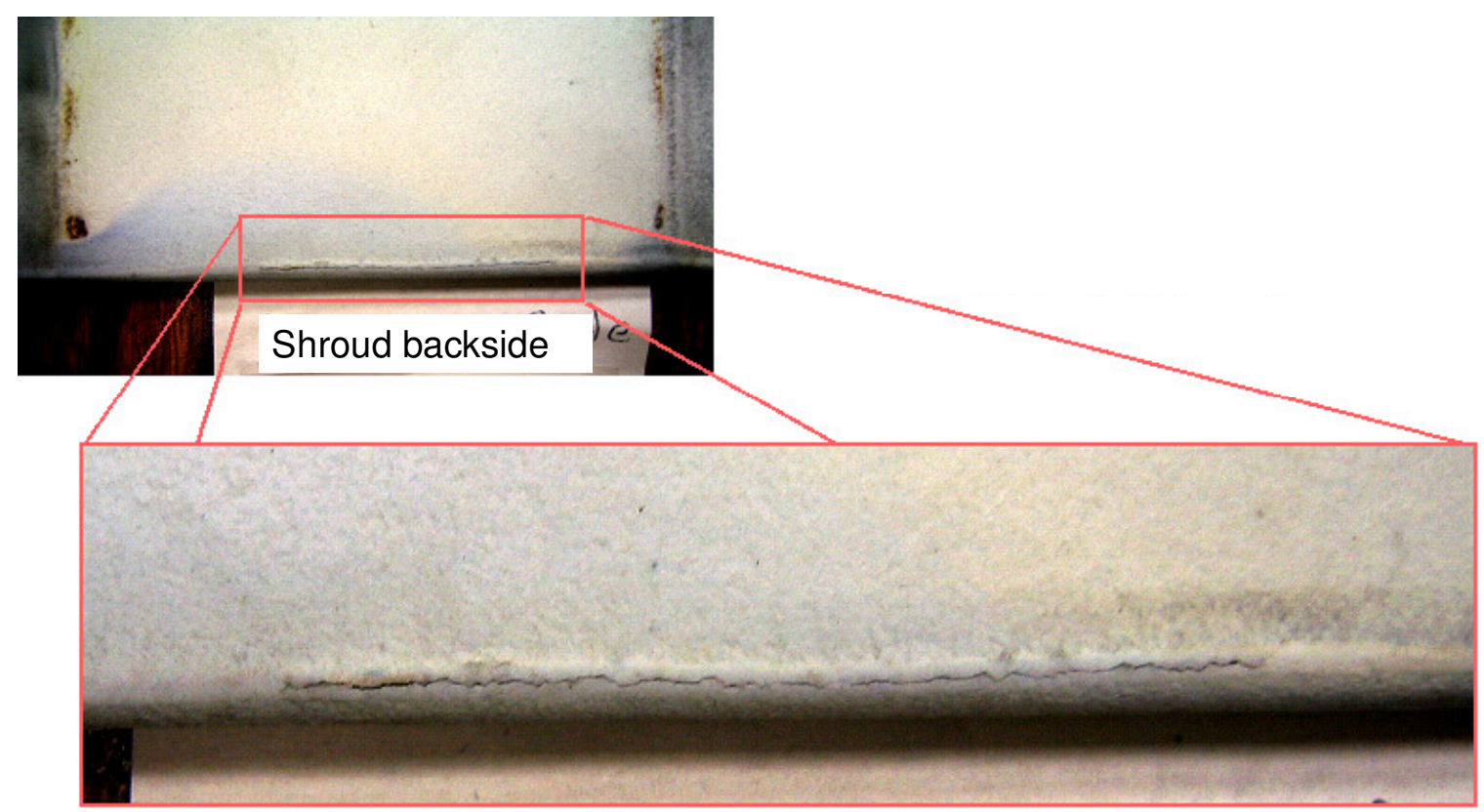

Figure 3-148. EBC crack on the rear face edge of shroud 1374-1 following rig test \#6. 


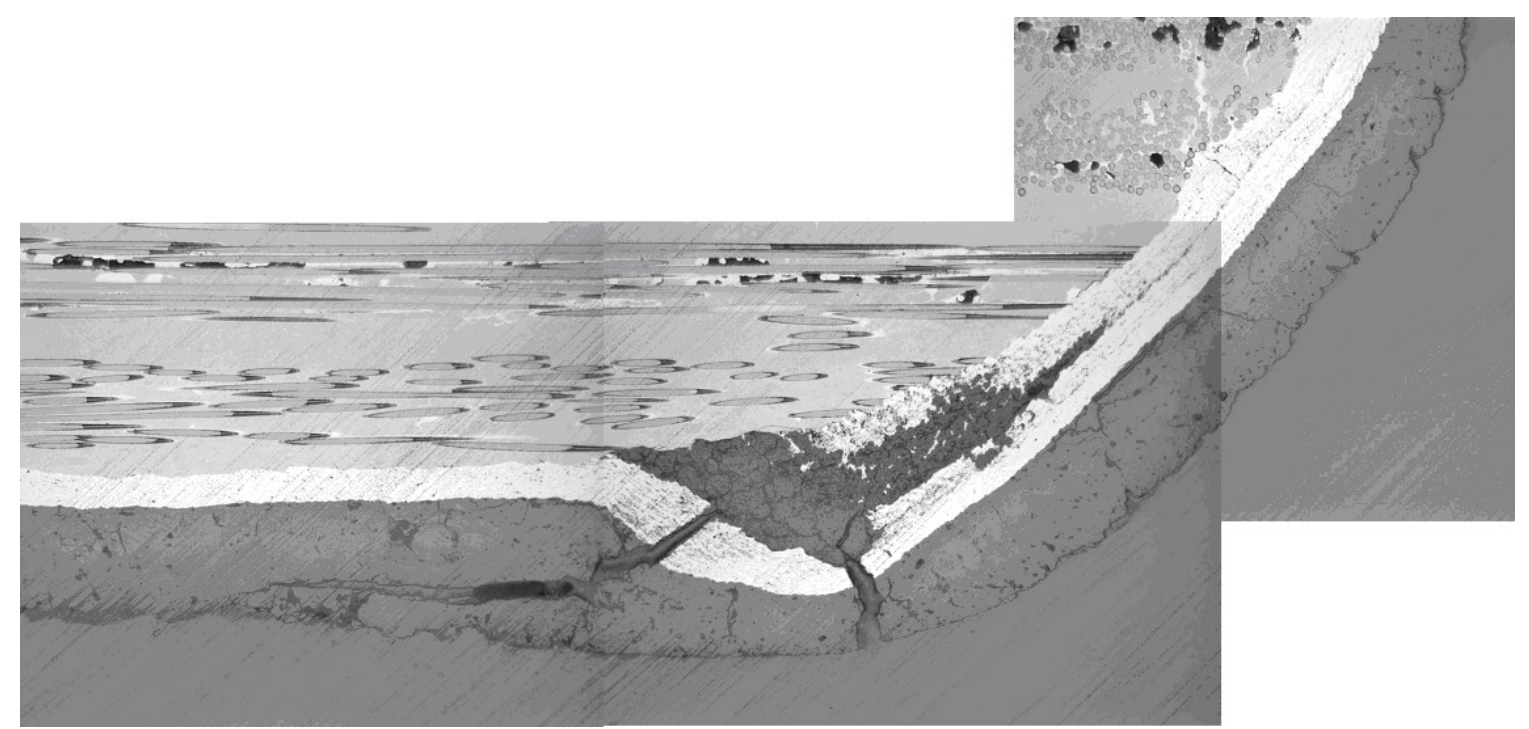

Figure 3-149. Optical micrographs of the EBC-crack region from shroud 1374-1 showing accelerated oxidation of the porous silicon and subsequent swelling of the bond coat and coating cracking.

Overall the results from rig test \#6 were very positive. Results of the cooling flow DOEs were adequate to define the needed attachment and spring cooling flows for the upcoming engine test. No hardware distress was noted to any of the metallic hardware, reinforcing the prior conclusion that hardware damage seen in rig test \#5 was caused by the overtemperature excursions and not to any design flaw of the shroud system. The CMC inner shrouds and EBC coatings all performed well with the exception of the HVOF silicon edge crack noted above. These results were sufficiently positive to convince the GE Energy Chief Engineers' Office to approve proceeding with the full shroud set field engine test.

\subsubsection{Task S4.1 - CMC Shroud Fabrication for Engine Test \#2}

The purpose of this task is to allow for fabrication of prepreg MI-CMC inner shroud components for the second field engine test. As will be discussed, there were several issues with the fabrication of these shrouds that required various activities related to improving the process yields and demonstrating that the shrouds possessed sufficient mechanical properties for use in the engine test. These extra activities pushed back the start of the engine test from the Spring of 2005 to the Spring of 2006.

The original plan in the 2003 contract modification proposal called for the testing a partial shroud set for a prolonged period of up to 24,000 hours. However, in early May of 2004 the shroud team was challenged by GE Energy management to try to accelerate the engine test schedule, even if it meant giving up the second rig test, and to test a full set of CMC shrouds. Very aggressive program plans were developed for starting a new engine test in the Fall of 2004. It was recognized that there were very serious risks involved with this plan related to the fabrication of both the CMC and metallic hardware needed for a full 
engine test. In particular, CCP had never before made a prepreg MI shroud component, and they were now being asked to fabricate the majority of the shrouds for the engine test. Due to the uncertainties in shroud component yields at CCP, the plans called for $\sim 150$ shrouds to be fabricated by CCP and 45 by GRC, with the hope that at least 96 of this set would be of sufficient quality to be used in the engine test.

Fabrication of the prepreg CMC inner shrouds was started in mid-May of 2004. Production was ramped up at CCP using a process modeled after the GRC shroud fabrication process. By the end of August CCP had fabricated over 20 shrouds; however, all of the shrouds had lower than acceptable density. Shrouds being made at GRC were largely meeting preliminary quality criteria, but the combined shroud yield from CCP and GRC was obviously not going to produce enough good shrouds in time for a Fall 2004 engine outage. Consequently the engine test was pushed back to early 2005 (still somewhat earlier than, but closer to, what had originally been on the planned program schedule).

The return to the original engine test schedule allowed time for a reassessment of CCP's implementation of the shroud fabrication process. Two CCP production engineers visited GRC in August of 2004 to observe the shroud fabrication process and identify areas where their process at CCP differed with that practiced at GRC. Several differences regarding the handling of the prepreg tapes and lay-up procedures to form the shroud preforms were noted. The CCP engineers returned to $\mathrm{CCP}$ and re-trained their production technicians to follow more precisely the procedures being used at GRC. Following this re-training process, shroud densities and witness bar strengths at CCP improved markedly. Figure 3150 shows distributions of shroud density and ultimate strengths from before and after the re-training. As indicated, most of the GRC shrouds were meeting the required levels for density and strength whereas most of the early shrouds produced at CCP failed these two criteria. After technician retraining most of the shrouds produced at CCP were now meeting the acceptance criteria.

CMC shroud fabrication for the anticipated Spring 2005 start of the engine test was in full swing at the end of 2004. Shroud production at CCP was ramped up in early October following the demonstration of acceptable shroud properties. As of the end of $2004 \mathrm{CCP}$ had fabricated 106 shrouds through infiltration. All of the shrouds being produced at CCP were of the GEN1 CMC variety, i.e. they contained Hi-Nicalon ${ }^{\mathrm{TM}}$ fiber and the standard CMC matrix composition.

A total of 32 shrouds were processed at GRC in 2004, of which 29 were considered successful and passed on to CCP for inclusion in the engine test pool of shrouds. Out of the 29 shrouds shipped nine were of the GEN1 variety, twelve were of the GEN1.5 variety (HiNicalon Type-S fiber and standard matrix), and eight were of GEN2 CMC (Hi-Nicalon Type-S fiber and a reduced Si matrix composition). Unfortunately, four of the GEN1.5 and two of the GEN2 shrouds were incorrectly machined at CCP and were dropped from engine test consideration. 


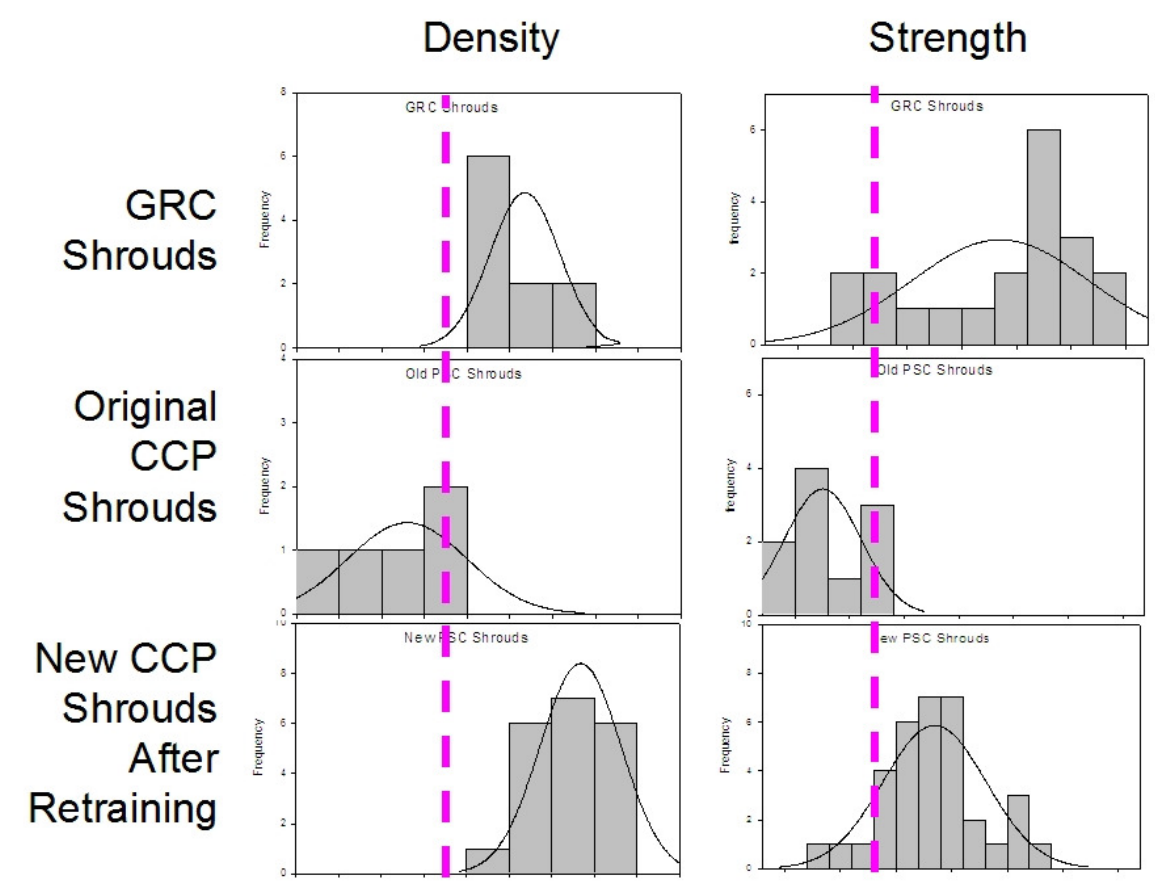

Figure 3-150. Distributions of density and ultimate strength values from prepreg HiPerComp ${ }^{\mathrm{TM}}$ shrouds produced at GRC and at CCP both before and after technician retraining at $\mathrm{CCP}$. The pink lines indicate the property acceptance criteria for the shrouds.

Deposition of EBC coatings onto the shrouds was in progress in late 2004 through January of 2005. However, in early January an anomaly was noted by GE Energy Materials and Process Engineering (M\&PE) personnel on shrouds coming out of heat treatment following coating with EBC. Shiny to black nodules were noted on the surfaces of several shrouds that appeared very similar to silicon nodules. Such nodules are seen on the surface of MI CMC's if the parts are heated above the melting point of silicon. Photographs of the nodules are shown in Figure 3-151. The nodules were preferentially seen in areas of the shroud not covered by EBC, i.e. within the attachment holes. However, several cases of nodules on the surface of the EBC coating were also noted.

Micro X-ray Fluorescence ( $\mu \mathrm{XRF}$ ) was performed on three such nodules and all were found to consist entirely of silicon within the detection limits of the technique. Both the appearance and analysis of the nodules strongly suggested that the shrouds had been heated above the melting point of silicon, which is present in the matrix of the MI composites as well as used for the bond coat layer in the EBC. Subsequent re-calibration of the heat treatment furnaces at M\&PE revealed that the wrong type of thermocouple had been installed, which caused the heat treatment temperature to be roughly $150^{\circ} \mathrm{C}$ higher than desired. Instead of heat treating the shrouds at $1250^{\circ} \mathrm{C}$ the thermocouple error caused the shrouds to be heated to roughly $1400^{\circ} \mathrm{C}$. 
Overheating of the shrouds presented two potential problems. First, melting of EBC silicon bond coat could lead to changes in the coating microstructure, or even complete loss of the bond coat, either of which would greatly impact the durability of the EBC coating. Secondly, if the silicon in the CMC matrix had been molten then there was the potential for increased degradation of fibers or fiber coatings, leading to degradation of composite mechanical properties. Consequently several of the overheated shrouds were cut up and evaluated both metallographically and by tensile testing.

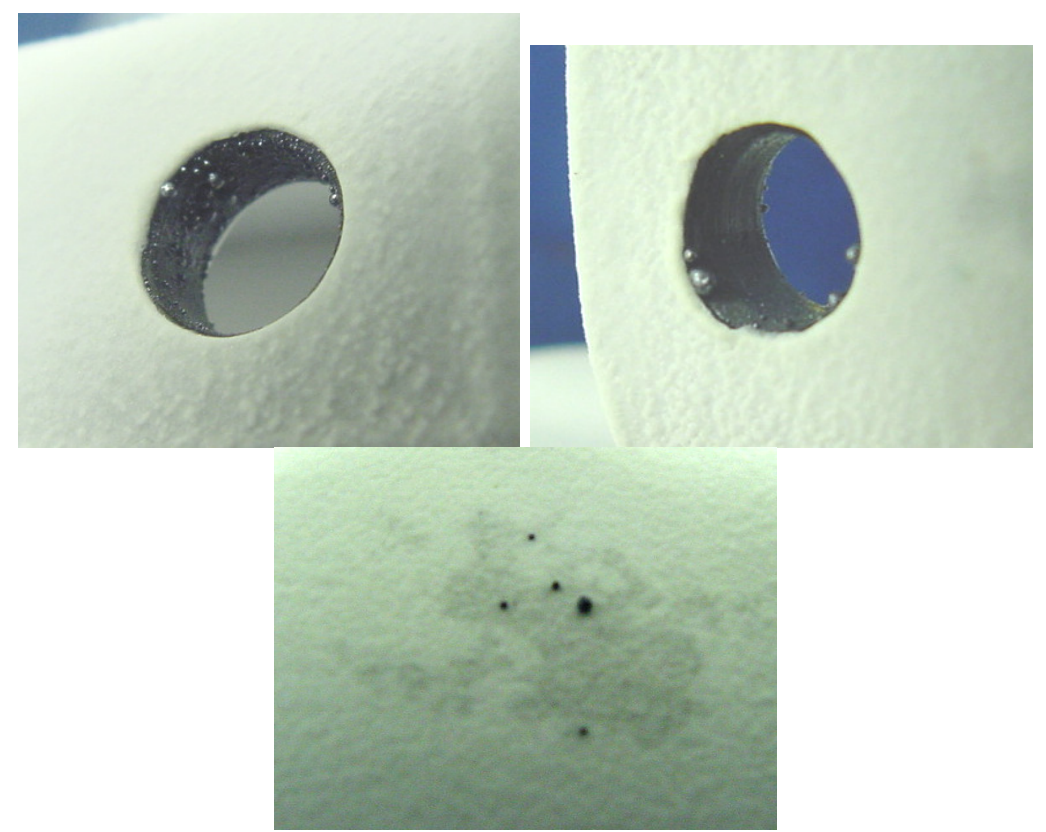

Figure 3-151. Examples of silicon nodules found on the surfaces of shrouds after postEBC heat treatment at M\&PE: Left and Center - nodules seen in shroud mounting holes; Right - nodules seen on the EBC surface with concurrent dark patches in the EBC.

Many of the cross sections that were examined from the overheated shrouds showed normal EBC microstructures, an example of which is shown in Figure 3-152, where the three layers of EBC are delineated. Porosity and decorated splat boundaries are visible in the Si bond coat, which are typical of thermal spray coatings. However, there were substantial sections in all of the examined overheated shrouds where the EBC bond coat had been affected. Figure 3-153 shows two micrographs from different areas of the same shroud as shown in Figure 3-152, but in regions where the $\mathrm{Si}$ bond coat had been compromised. In the top micrograph the porosity and splat lines in the Si layer have been removed, strongly suggesting that the bond coat had been molten. This by itself would not be an issue, except that this densification of the Si layer also leads to the generation of gaps in the bond coat. In the bottom micrograph nearly the entire silicon bond coat has been removed, either by sweating to the surface or by absorption into the composite. 


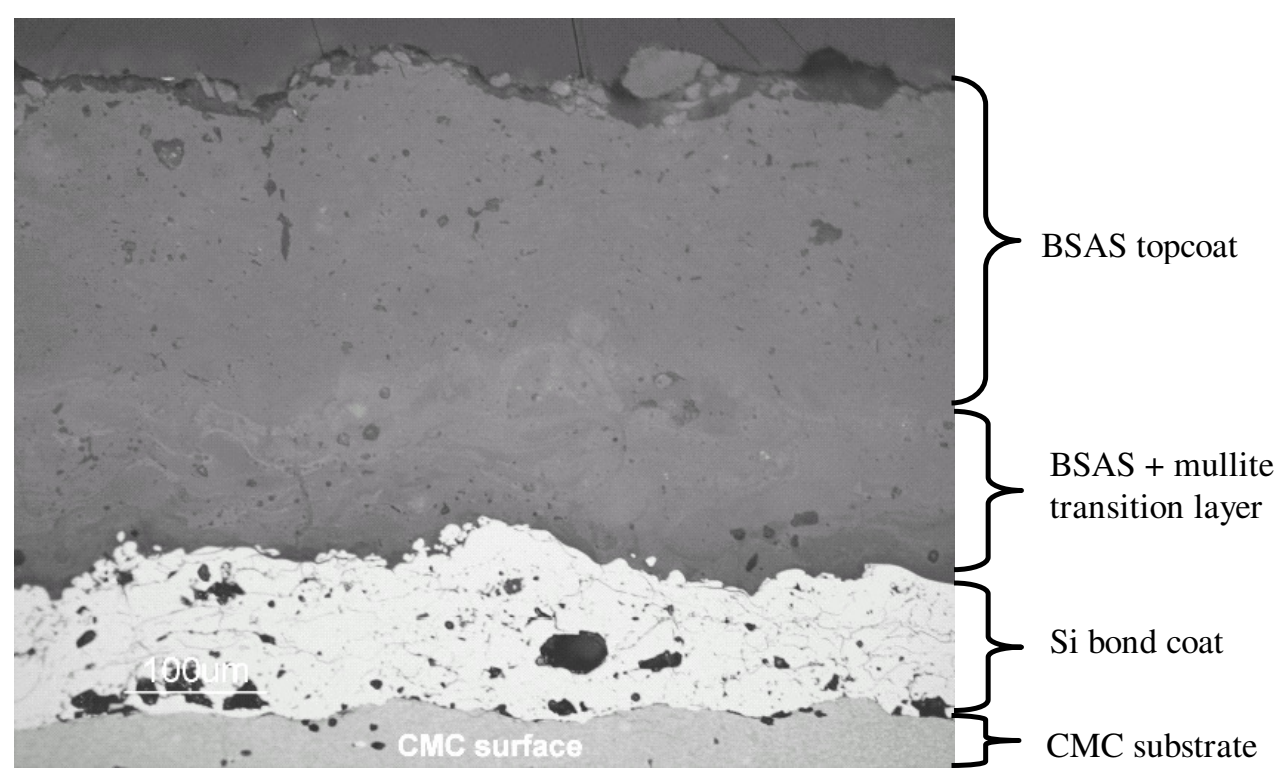

Figure 3-152. Microstructure of a "normal" EBC coating region on shroud 3312-01-041.

It could have been possible to address the EBC bond coat problems by simply stripping and re-coating the shrouds. However substantial degradation of the CMC was also noted. Figure 3-154 shows micrographs of an area of shroud 3312-01-041 where very severe reaction between the matrix $\mathrm{Si}$ and the fibers was noted. The Hi-Nicalon ${ }^{\mathrm{TM}}$ fibers have an excess of carbon and readily react with any molten silicon that penetrates the fiber coating. This reaction is accompanied by a slight increase in reflectivity, resulting in the reacted regions of fibers showing up as somewhat lighter in the reflected light micrographs. The amount of fiber reaction noted in this shroud, and in several others from the group that were overheated, was excessive compared to a normally fabricated prepreg MI CMC.

The increased reaction of the fiber with the silicon alloy was expected to have caused a substantial degradation of the CMC mechanical properties. Ten shrouds were sectioned and tensile tests performed on bars cut from the hot gas path surface of the shrouds. However, due to geometric limitations of the shrouds, the bars were cut in the axial direction as opposed to the transverse direction corresponding to the original shroud witness bars. The majority of shrouds had an unbalanced lay-up, i.e. having more fiber plies in the transverse direction than in the axial direction, so that a nominal reduction of mechanical properties of the bars cut from the shrouds compared to the original shroud witness bars would be expected. The average observed reductions in mechanical properties were about $33 \%$ for ultimate strength, $37 \%$ for strain to failure and $19 \%$ for proportional limit. The expected differences based solely on the fiber architecture differences were $22 \%$, $8 \%$ and $17 \%$ respectively. The measured degradation in ultimate strength and especially strain to failure, both of which are fiber-dominated properties, were clearly in excess of the effect of fiber architecture. These mechanical property measurements, when combined with the microstructural evidence of fiber reaction, as shown in Figure 3-154, were strong evidence that the overheated shrouds had experienced substantial mechanical degradation. 

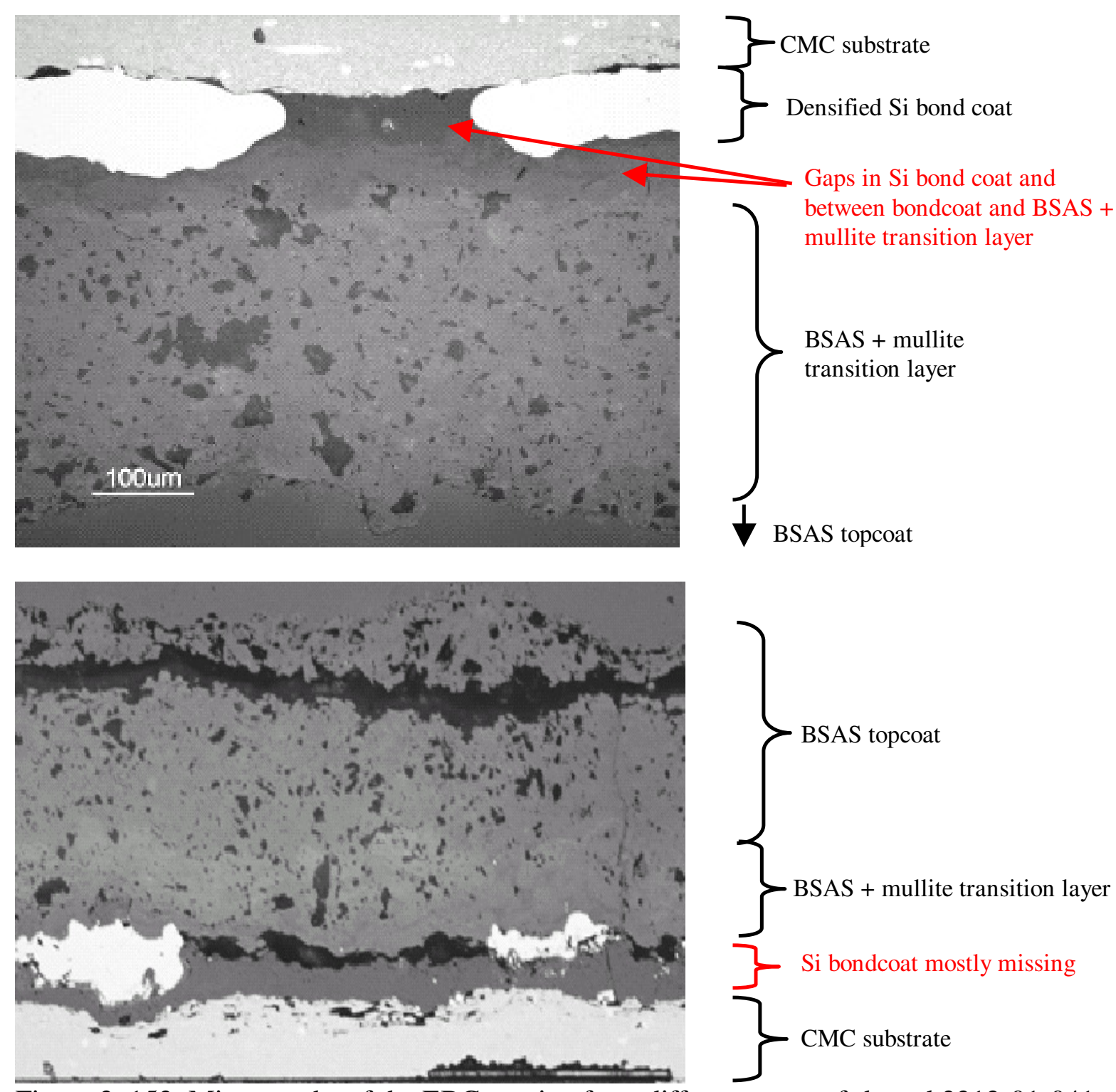

Figure 3-153. Micrographs of the EBC coating from different areas of shroud 3312-01-041 showing a densified bond coat with gaps (top), and a largely missing bond coat (bottom). 


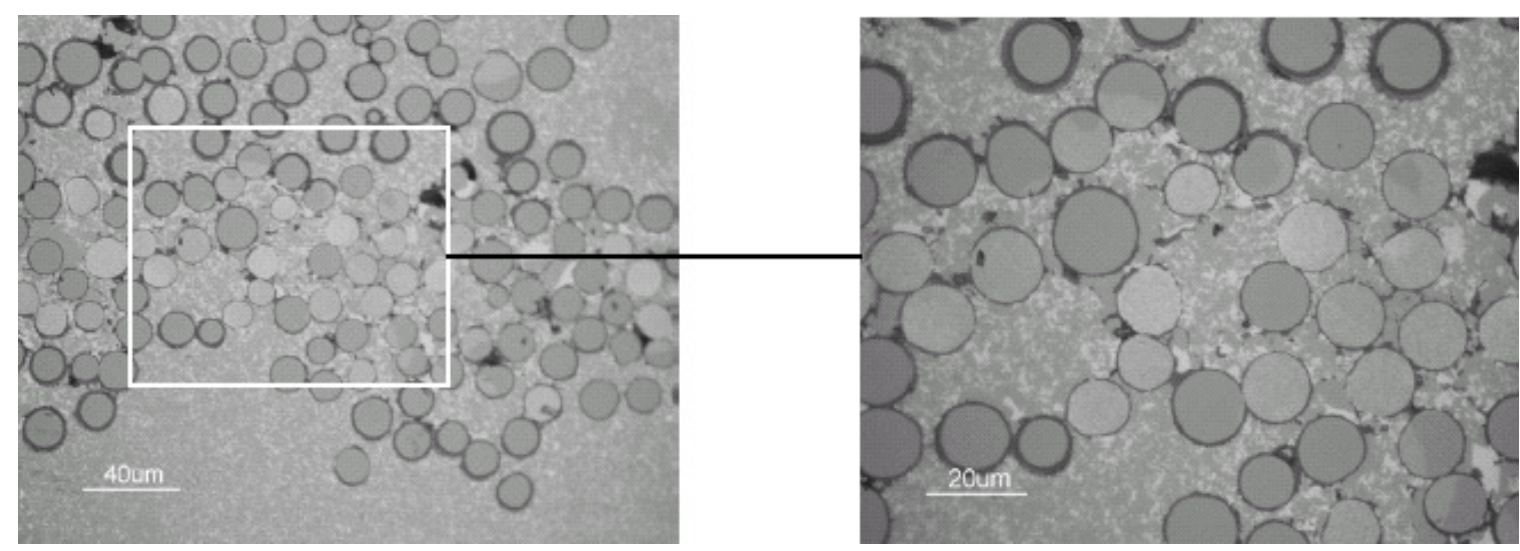

Figure 3-154. Micrographs from shroud 3312-01-041 showing an area of the CMC with excessive fiber coating degradation and reaction of the Hi-Nicalon ${ }^{\mathrm{TM}}$ fiber with the silicon alloy. The lighter colored fibers have been reacted with molten silicon.

These degraded shrouds were judged to represent too large a risk to use in the engine test, and were subsequently rejected from consideration. Unfortunately fully 75 shrouds were subjected to the EBC heat treatments with the improper thermocouples, reducing the total pool of potential engine test shrouds down to only 60. It was also clear from NDE evidence that a significant number of these 60 remaining shrouds would also be rejected from the engine test. It thus became necessary to fabricate a large number of additional shrouds under a very highly accelerated schedule in January-February of 2005 in an attempt to prepare enough CMC inner shrouds for the targeted Spring engine test.

Both GRC and CCP began fabrication of new shrouds in mid-January. By early February GRC had fabricated 15 new shrouds, of which 13 were judged to be successful enough to be considered for engine testing. Production at CCP ran through late February, at which time they had fabricated 70 new shrouds. Fabricating such a large number of shrouds in such a short period of time was unprecedented and a major challenge for both organizations.

Unfortunately, due to this highly accelerated schedule, it was impossible to get adequate feedback on the quality of the shrouds being produced in a timely fashion. Following the majority of fabrication it was noted that all of the shrouds from CCP were showing significant NDE indications in the flange bend regions, more significant than had been seen in earlier shroud batches. The shroud witness test bars were also indicating relatively low strain to failure values. Not having time to adequately address the potential problems such defects could cause in an engine test, GE decided that utilizing these shrouds in a base-load engine test, as had been scheduled, was too large of a risk. Consequently the planned Spring ' 05 engine test was cancelled.

The shrouds made in early 2005 were rejected from use in the Spring '05 engine test not because it was certain that the problems would cause shroud failures, but because of the uncertainty of what could happen. It was considered possible that with some additional characterization of the defects and with a better understanding of the impact the defects 
would have on the performance of the shrouds that these shrouds could eventually be judged acceptable for a future engine test. Considerable effort was therefore directed at characterizing the bend defects and shroud mechanical properties, and tests were devised to try to quantitatively assess the amount of additional risk these problems represented for an engine test.

The problem with the strain to failure of the early 2005 shrouds is demonstrated by the data in Figure 3-155, which shows distributions for strain to failure for three populations of GEN1 shrouds: those made at GRC in 2004 and 2005, those made at CCP in 2004, and those made at CCP in 2005. The minimum specification limit initially set for strain to failure was $0.61 \%$. All of the GRC produced shrouds met this particular specification, as did the majority of shrouds produced at CCP in 2004. However the reject rate of 2005 CCP shrouds from this criterion alone would have been about 50\%, leaving us well short of a complete engine set of shrouds. (Please recall that a large number of the 2004 shrouds were degraded by an over-temperature condition during EBC annealing, the consequences of which are not reflected in Figure 3-155.)

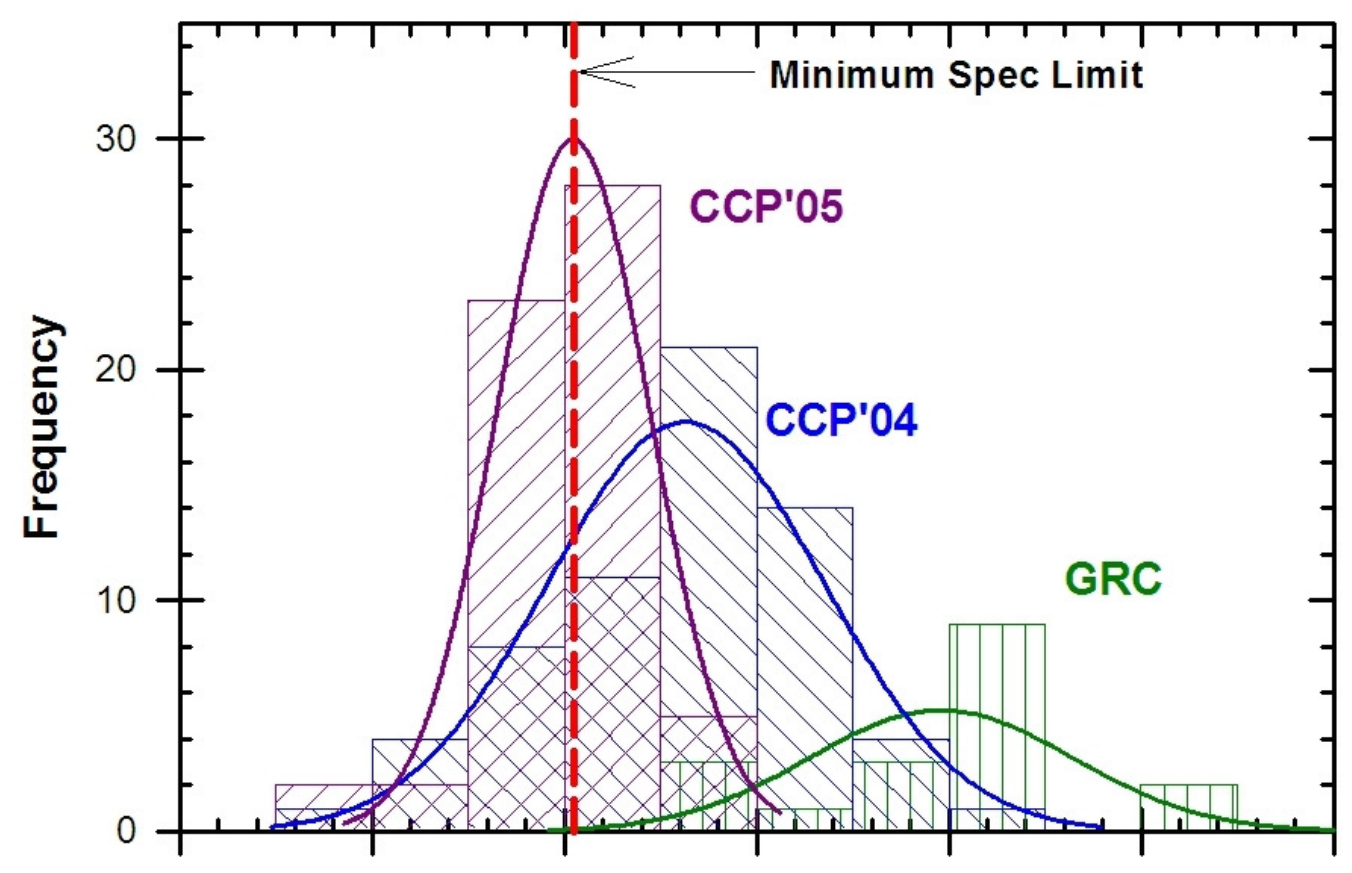

\section{Strain to Failure (\%)}

Figure 3-155. Distributions of strain to failure values from shroud witness bars taken from three populations of GEN1 CMC inner shroud components: GRC - shrouds fabricated at GRC from June 2004-Jan. 2005, CCP'04 - shrouds fabricated at CCP during the Fall and Winter of 2004, and CCP'05 - shrouds fabricated at CCP during Jan.-Feb. 2005. 
In actuality the situation was somewhat worse than reflected in the measurements in Figure $3-155$ in that the GEN1 shrouds were made with a biased $0^{\circ}-90^{\circ}$ lay-up (i.e. more fiber in $90^{\circ}$ direction than in the zero direction) and the witness bars were from the $90^{\circ}$, or stronger, direction. In order to better understand the magnitude of the strain to failure problems several of the shrouds were sectioned and tensile properties measured from bars cut in the $0^{\circ}$, or axial, shroud direction as well as the $90^{\circ}$, or transverse, direction. Normally, one would expect the properties of bars cut in the transverse direction to match exactly those of the shroud witness bars, which are also tested in the transverse direction. Test bars cut in the axial orientation would be expected to have $22 \%$ lower ultimate strengths and $8 \%$ lower strain to failure values than the witness bars based on the different number of plies aligned in the tensile direction. (The expected property drops going from transverse to axial directions were based on the results of previous fiber architecture studies done on panels under the CFCC program.)

The ultimate strength and strain properties were found to be much lower in the hot gas path surface of the shrouds from CCP, both when tested in the axial and transverse directions. The properties in the axial direction were also much lower than could be explained by just the fiber architecture difference. A shroud from GRC tested in the same manner showed no difference in properties between witness bars and test bars cut in the transverse direction. The reductions in properties between transverse and axial directions was also smaller in the GRC shroud, although there were still slightly higher than would be expected based solely on the architecture difference. The results of these shroud tests are given in Table 3-13.

Table 3-13. Effect of Sample Orientation on the Ultimate Strength and Strain to Failure Properties of Test Bars Cut from GEN1 Shroud Components Prepared for the Abandoned Spring 2005 Engine Test

\begin{tabular}{|l|c|c|c|c|c|}
\hline & & \multicolumn{2}{|c|}{ Ultimate Strength } & \multicolumn{2}{c|}{ Strain to Failure } \\
\hline \multirow{4}{*}{ Shroud } & $\begin{array}{c}\text { Sample } \\
\text { Type* }\end{array}$ & $\begin{array}{c}\text { Measured } \\
\text { Value (MPa) }\end{array}$ & $\begin{array}{c}\text { \% decrease } \\
\text { relative to } \\
\text { witness bar }\end{array}$ & $\begin{array}{c}\text { Measured } \\
\text { Value (\%) }\end{array}$ & $\begin{array}{c}\text { \% decrease } \\
\text { relative to } \\
\text { witness bar }\end{array}$ \\
\hline \multirow{2}{*}{$\begin{array}{l}\text { CCP } \\
\text { 1411-06-050-2 }\end{array}$} & Witness & 322 & -- & 0.67 & -- \\
\cline { 2 - 6 } & HGP trans & 274 & 15 & 0.31 & 54 \\
\cline { 2 - 6 } & HGP axial & 190 & 41 & 0.19 & 72 \\
\hline GRC 2023-2 & Witness & 376 & --- & 0.96 & --- \\
\cline { 2 - 6 } & HGP trans & 364 & $\sim 0$ & 1.03 & $\sim 0$ \\
\cline { 2 - 6 } & HGP axial & 250 & 33 & 0.84 & 12 \\
\hline
\end{tabular}

* Sample types are "witness," which is a bar cut from the ends of the flanges with the tensile direction in the transverse direction (across the width) of the shroud, "HGP trans," which is a bar cut from the hot gas path face also in the transverse direction, and "HGP axial," which is a bar cut from the hot gas path face with the tensile direction along the axial direction of the shroud.

Strain to failure was not specifically used in the design of the shroud components, but it was used primarily as a measure of the CMC's resistance to damage initiation and damage propagation. The main perceived risk was that shrouds with lower than normal strain to 
failure would be particularly susceptible to foreign object damage or damage related to blade tip rubs. In order to evaluate whether or not these concerns were well founded ballistic impact tests were performed on sample shrouds showing a range of strain to failure values.

These impact tests were done using $1.27 \mathrm{~cm} \mathrm{K-monel} \mathrm{projectiles.} \mathrm{The} \mathrm{size} \mathrm{and} \mathrm{composition}$ of the projectiles were chosen after a detailed evaluation of the size and properties (strength, hardness, density) of what would represent a worst-case possibility for up-stream hardware fragments coming downstream into the turbine section. Also, due to the size of the shroud parts, the temperature of the target that could achieved during the impact tests was only $980^{\circ} \mathrm{C}$ as compared to the expected in-turbine temperature of $1200^{\circ} \mathrm{C}$.

Impacts were carried out at velocities ranging from 54 to $184 \mathrm{~m} / \mathrm{s}$, corresponding to impact energies of 13.8 to $161 \mathrm{~J}$, respectively. At the higher impact velocities the projectile completely penetrated the CMC shroud, leaving relatively clean entrance holes with a conically shaped damaged area on the exit side. At the lower velocities the projectile caused damage to the impacted face and material ejection from the back side, but the projectile did not completely penetrate. The lowest energy where complete penetration occurred was $42.4 \mathrm{~J}$ in a sample with a strain to failure of $0.59 \%$, and the highest energy without complete penetration was $31.3 \mathrm{~J}$ in a sample with a strain to failure value of $0.43 \%$. Photographs of these two particular impact specimens are shown in Figure 3-156. In previous tests with thinner CMC panels and smaller projectiles the cut-off between complete and incomplete penetration occurred around 5 to $8 \mathrm{~J}$. In none of the impact events was there significant damage away from the impact site, and no shrouds failed due to impact.

These impact tests demonstrated that there was little risk of catastrophic failure of a shroud from FOD or blade rub events, even for shrouds with low strain to failure. However, the tests did not address the susceptibility of damaged shrouds to further damage propagation during use. The GE Energy Chief Engineer for materials made the decision, based on observations of crack arrest in previous rig tests and from prior oxidation testing of impacted panels, that the added risk of damage propagation and shroud failure was low enough to allow a reduction in the strain to failure specification for shrouds.

The second problem with the shrouds from January-February 2005 was the relatively severe indications in the front and rear bend regions seen in IR NDE. Examples of NDE images (thermal diffusivity plots) from the late '04 and early '05 shroud sets at CCP, and from the '05 set from GRC, are shown in Figure 3-157. It is clear that the CCP shroud from '05 showed a much lower thermal diffusivity (red to black shading) in the bend region compared to the early CCP or GRC shrouds. Such low values of diffusivity are generally associated with multiple delaminations and/or very severe porosity. 

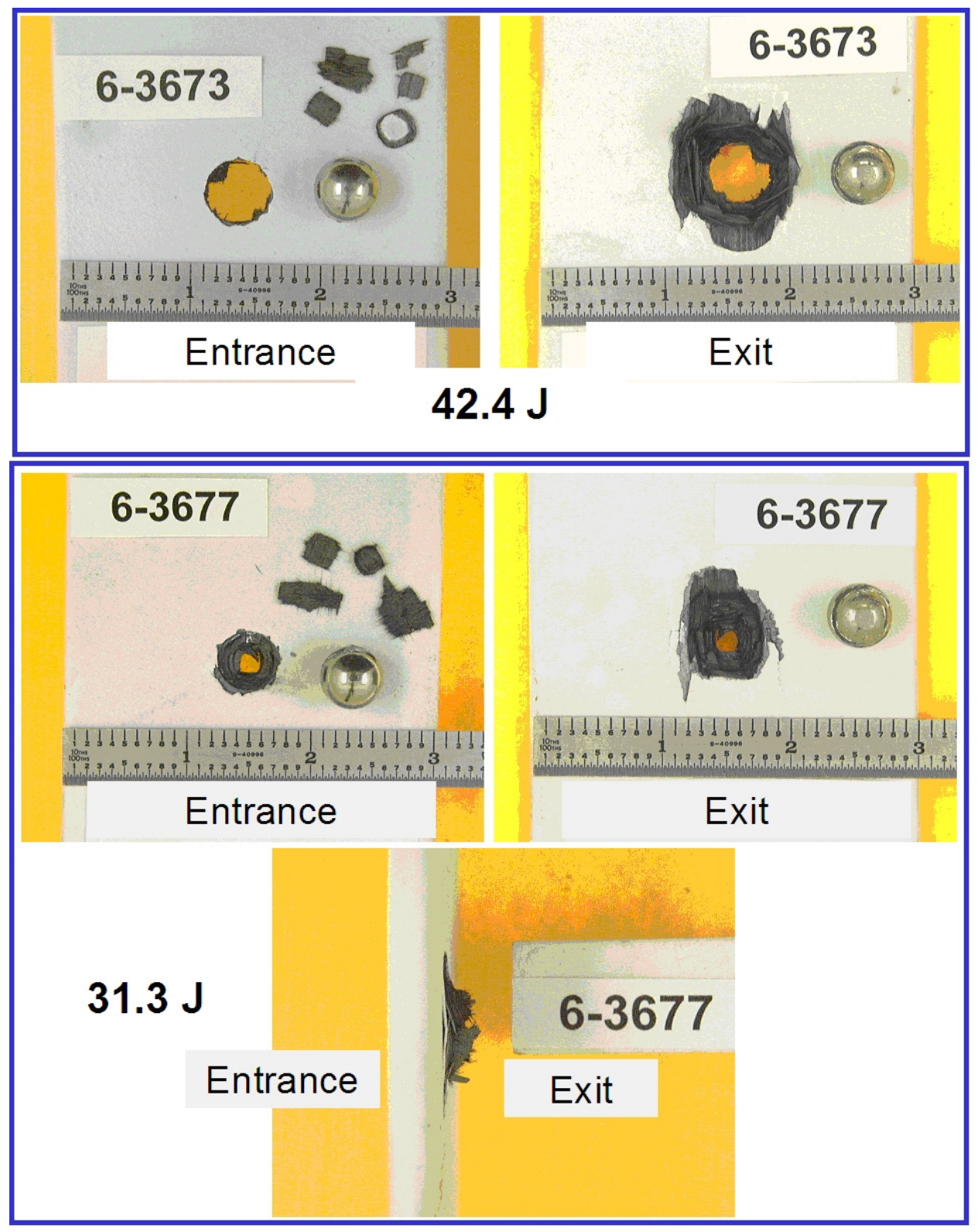

Figure 3-156. Photographs of CMC shroud samples following ballistic impact testing. Top - complete projectile penetration at $42.4 \mathrm{~J}$.

Bottom - partial projectile penetration at $31.3 \mathrm{~J}$. 

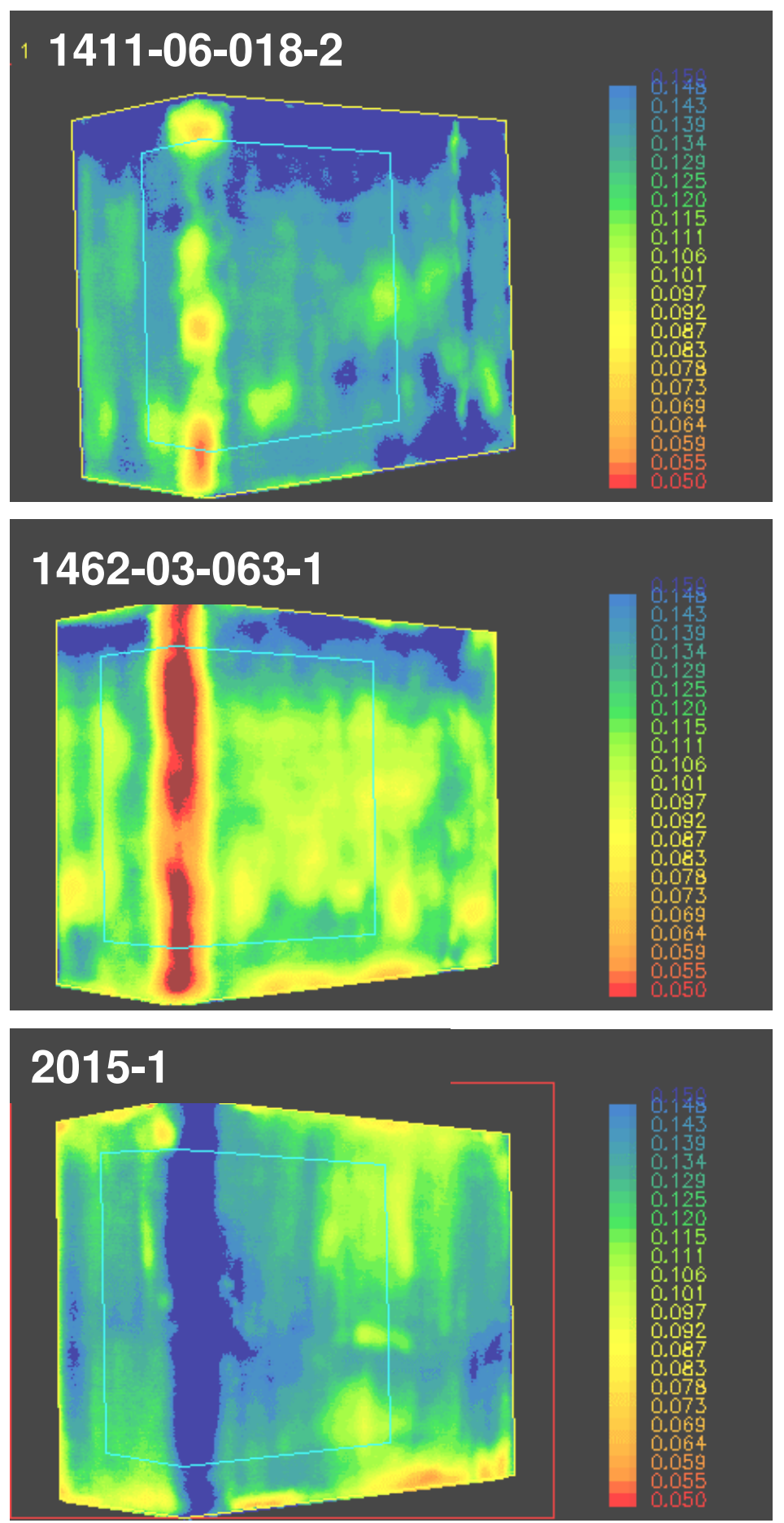

Figure 3-157. IR NDE thermal diffusivity images from the front bend region of GEN1 prepreg CMC shrouds: Top - CCP shroud from Nov.-Dec. '04; Middle - CCP shroud from Jan.-Feb. '05; Bottom - GRC shroud from Jan.-Feb. '05

Closer examination of the different populations of shrouds showed that the situation was not a clear cut as suggested by Figure 3-157. The method of calculating thermal diffusivity 
from the raw IR NDE information involves having a measured specimen thickness. However, several of the GRC shrouds had corner bends that were noticeably thinner than the flat sections of the shrouds. The reason for this thickness variation in the corners is a known result of the pre-compaction and debulking steps used in the shroud lay-up at GRC. The thin cross section in the bends gives an artificially high value for the thermal diffusivity calculated from the IR data in these regions, and thus the GRC shrouds have somewhat lower diffusivity in the bends than would be indicated in Figure 3-157. Corrections for thickness variation would bring the bend regions of the GRC shroud (2015-1) into the green range $\left(0.1\right.$ to $\left.0.12 \mathrm{~cm}^{2} / \mathrm{s}\right)$ on the diffusivity scale instead of the very dark blue shown. Nevertheless, the corrected data still indicates much higher diffusivity for the GRC shroud bends than the red to black $\left(<0.055 \mathrm{~cm}^{2} / \mathrm{s}\right)$ range shown for the '05 CCP shroud.

Microstructural analysis of some shrouds showing particularly bad NDE indications in the bend regions was performed. Figure 3-158 shows several photomicrographs taken from a CCP shroud made in the Jan.-Feb. '05 time period. The particular section shown in Figure 3-158 is for a region that appeared orange-to-yellow in the IR NDE thermal diffusivity image ( 0.06 to $0.07 \mathrm{~cm}^{2} / \mathrm{s}$ diffusivity). There are multiple large delamination cracks visible that typically run through the centers of the transverse plies.

The main concern with the bend defects is that they could represent continuous paths for the ingress of environment during shroud use in the engine, leading to embrittlement of the $\mathrm{CMC}$ in these regions from fiber coating oxidation.

The delaminations had two potential negative effects on the performance of the shrouds. First, the interlaminar mechanical properties and thermal conductivity in these regions would obviously be compromised, potentially leading to unpredicted thermal stresses that would propagate the delaminations out into the rest of the shroud and lead to shroud failure. Fortunately the CMC shroud configuration, by design, uses minimal cooling and therefore the thru-thickness thermal gradients are very small. Consequently the presence of the delaminations was predicted to have a minimal impact on the thermal profile, and therefore on the thermal stress distribution.

Interlaminar stresses in the shrouds were localized and relatively low in magnitude, and thus did not provide a strong driver for propagating the bend delaminations beyond the bend regions. It should also be noted that in previous shroud rig tests shrouds of relatively low quality were utilized while keeping the best quality shrouds in reserve for planned engine tests. Shrouds with substantial defects were thus exposed in the rig tests and no evidence of defect propagation had ever been found. Two of the shrouds in the first engine test also had similar, though less severe, delaminations in the flange bend regions, and they also showed no evidence of growth of the delaminations. 


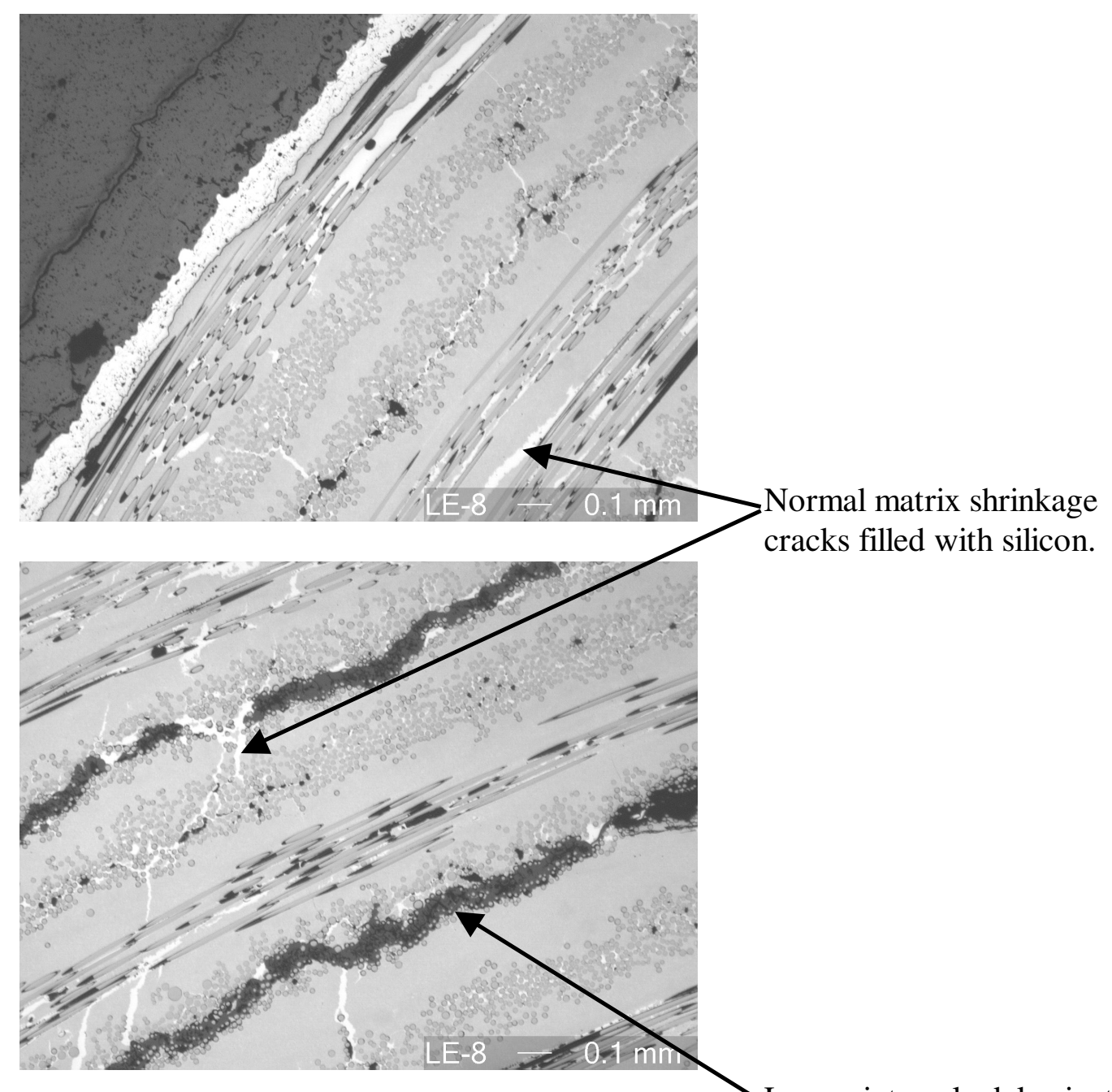

Larger intra-ply delamination

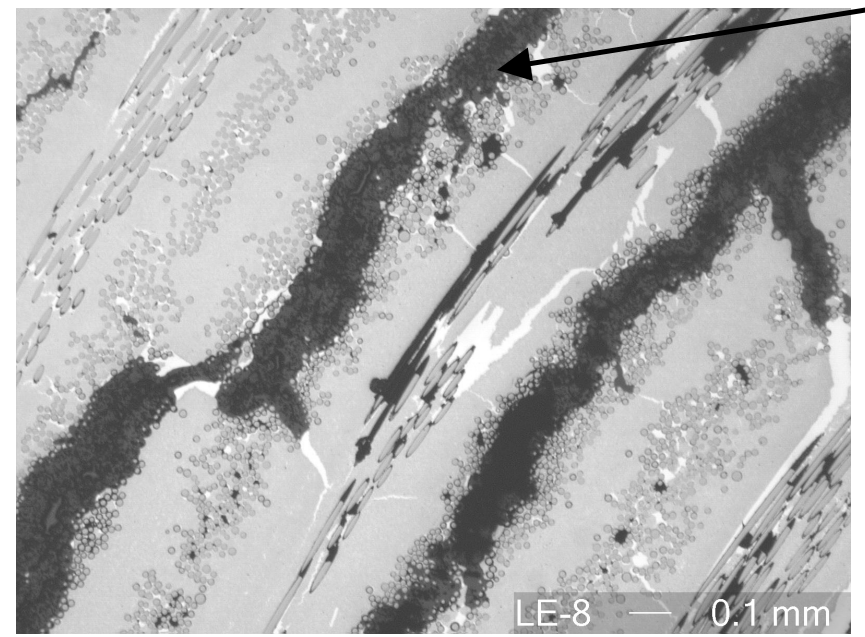
cracks and porosity.

Figure 3-158. Photomicrographs of the CCP shroud 1411-06-043-2 forward bend in a region appearing yellow to orange in the thermal diffusivity image, showing multiple examples of intra-ply delaminations and mid-ply cracks. 
Despite the previous rig and engine experience, the severity of defects of the new shrouds was such that there were still concerns as to the mechanical response of the shrouds, particularly in the bend regions. Interrogating the in-plane tensile strength of the material in the bend regions was not possible due to the part geometry; however, the interlaminar properties could be investigated using a bending test. The test configuration that was developed is shown in Figure 3-159. Slices from the shrouds up to $1.27 \mathrm{~cm}$ wide were clamped in the lower fixture by gripping the front flange. A clevis and pin arrangement then engaged the hot gas path surface of the shroud and pulled it upward, thereby applying a bending stress trying to open the bend in the shroud. This loading caused interlaminar tensile stress in the bend region of the shroud section.

Pieces trimmed from the edges of shrouds during machining, as well as a few slices cut from the centers of shrouds, were tested using this shroud flange bend test. One of the shrouds remaining from the previous field engine test was also sectioned and tested to give a baseline data point for comparison. The "strength" of the bends was then compared to the severity of the defects in the bend, as gauged by the thermal diffusivity value of the bend measured from the NDE inspections (qualitatively the defect severity is inversely proportional to the thermal diffusivity). A plot of the results is shown in Figure 3.

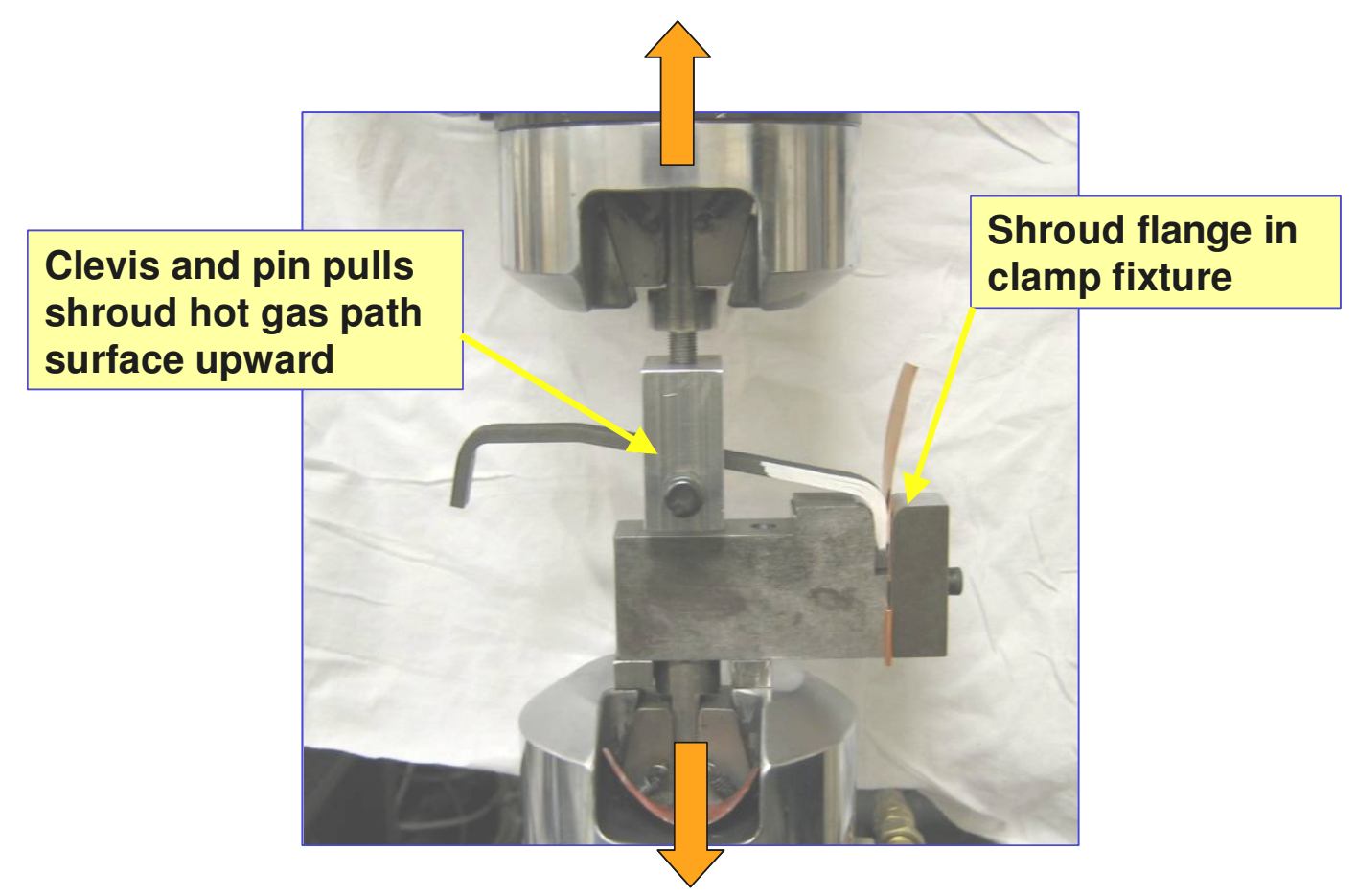

Figure 3-159. Photograph of the shroud flange bend test apparatus.

The data in Figure 3-160 indicates a clear correlation between the thermal diffusivity of the corner region and the interlaminar strength as measured by the flange corner bend test. The plot also shows a dashed horizontal line that signifies the maximum expected interlaminar 
tensile stress in the flange corner region. Despite the presence of the delamination defects, the effective interlaminar strengths (i.e. the stress required to further propagate the delaminations) were still all above the anticipated stress level in the shroud. In addition, the extra compliance of the delaminated material would tend to reduce the expected stress even further. These results indicated that there was not a significant risk that the shroud thermal stresses would alone cause propagation of the delaminations defects. Nevertheless there was still a risk that the delaminations could propagate under the influence of a mechanical stress, such as from a major FOD event, blade tip rub, or seizing of the shroud on the attachment pins. In each of these cases the expected mechanical stress could easily exceed the interlaminar strength of even a near-perfect shroud, and thus the presence of the corner defects does not necessarily increase the risk of a shroud failure under these scenarios.

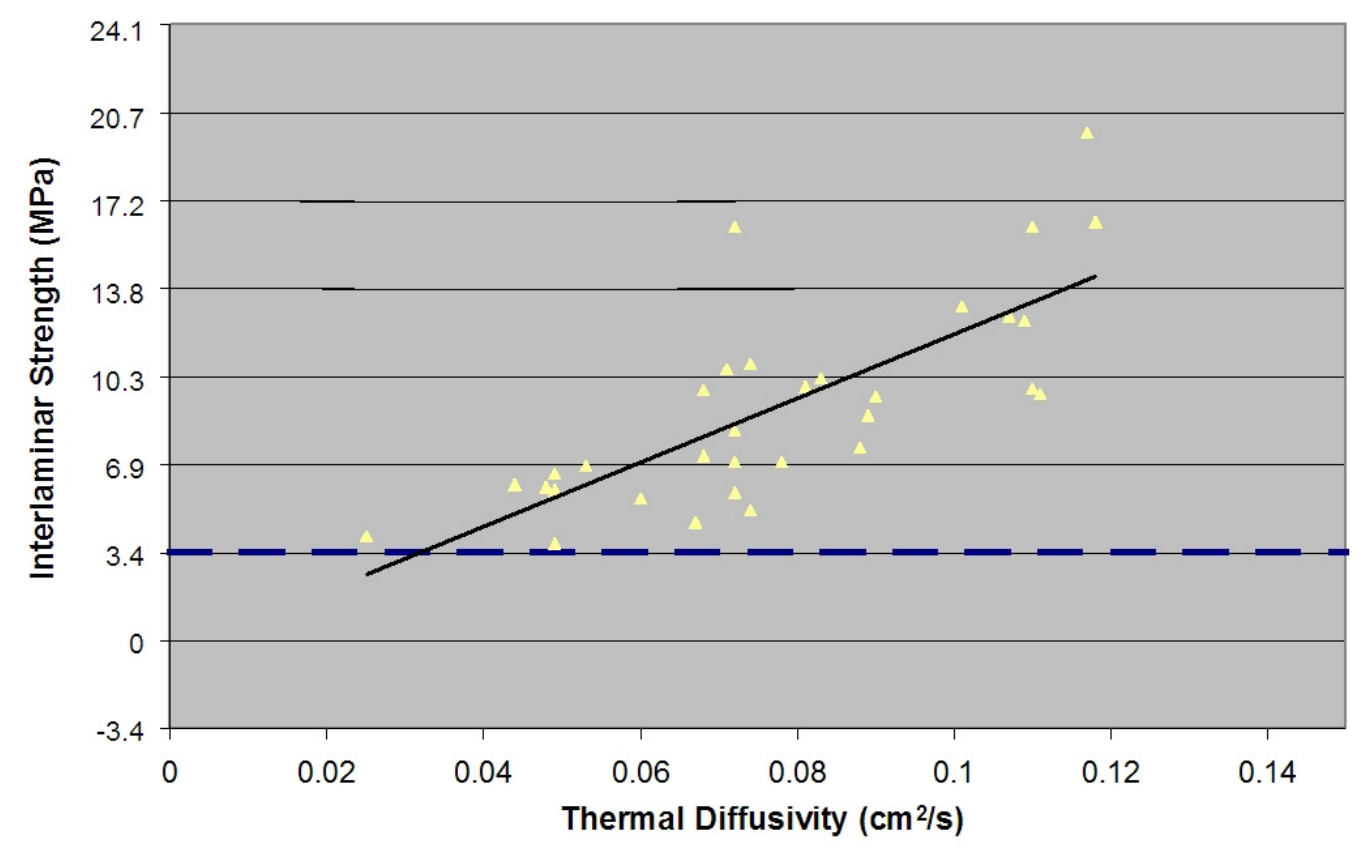

Figure 3-160. Plot of interlaminar strength from the flange bend tests versus the thermal diffusivity of the bend as determined by flash IR NDE.

The second failure mode where the corner delaminations were likely to have an impact was from internal oxidation and embrittlement of the CMC. If the delaminations were to become exposed to the environment during the engine test, as from an EBC spall from the shroud edge or an FOD event, they would serve as conduits for oxygen and water ingression across the full width of the shroud. Embrittlement from such internal oxidation had been previously well documented for slurry cast MI composites, and the concern was that a similar mechanism would now be active in the prepreg MI shrouds.

In order to test for the potential of oxidation-induced embrittlement steam oxidation exposures of corner sections cut from a shroud was performed. The shroud selected (CCP shroud 1411-06-043-2 ) had a range of delamination severity, as determined from the IR 
thermal diffusivity values. The IR thermal diffusivity images for this shroud are shown in Figure 4, and the various slices used for oxidation testing are indicated. Samples from both the "leading edge" (LE) and "trailing edge" (TE) bends were used, and were semiquantitatively classified into one of five defect severity ranges (brown, red, orange, yellow and green from most to least severe). Several of the slices were tested using the corner bend test without oxidation in order to confirm that this shroud matched the overall population. Other slices were then exposed in a flowing $90 \% \mathrm{H}_{2} \mathrm{O}+10 \% \mathrm{O}_{2}$ environment at $1200^{\circ} \mathrm{C}$ for times of 250,500 or 1000 hours. Some of the exposed samples were examined metallographically without bend testing to determine the amount of internal oxidation. The other slices were tested using the shroud corner bend test to look for signs of composite embrittlement, and then also examined metallographically.

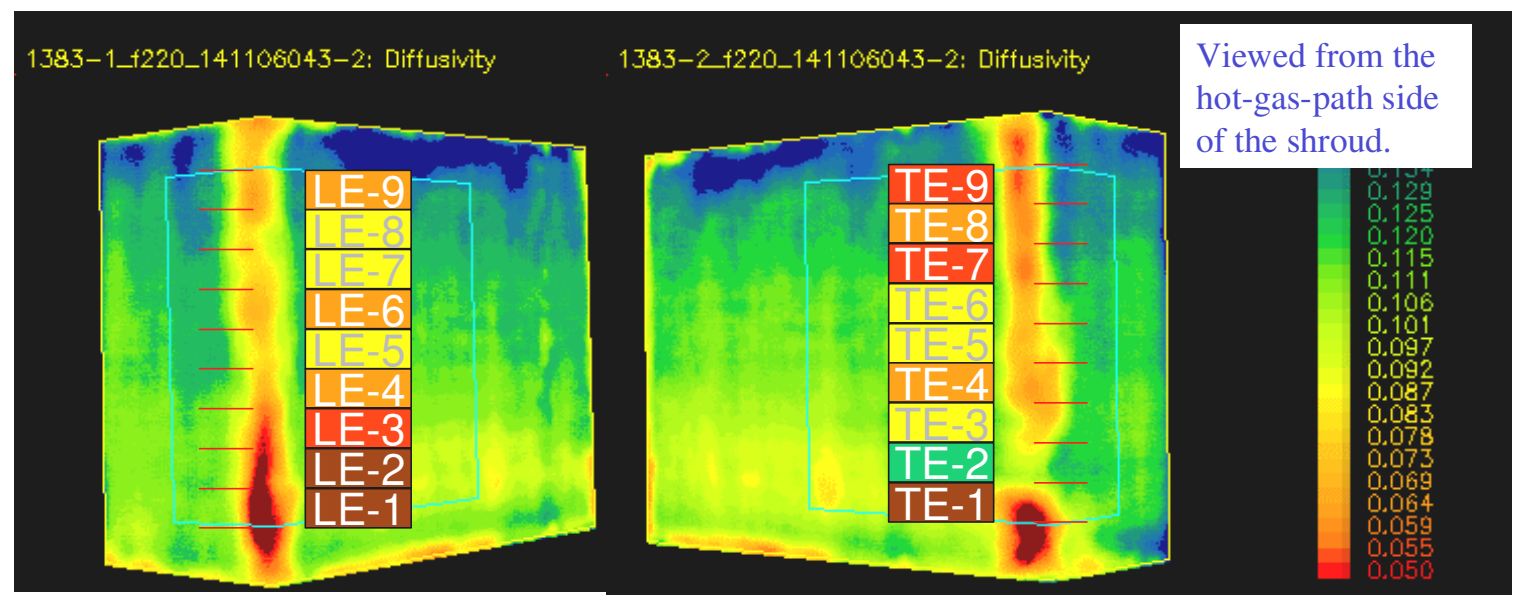

Figure 3-161. IR thermal diffusivity images of the leading edge (left) and trailing edge (right) bend regions from CCP shroud 1411-06-043-2 used for oxidation and bend testing. The short red lines show the positions of the slices and the sample labels are color coded according to the relative defect severity in that slice.

The results from the mechanical bend tests are summarized in Figure 3-162. The data points from the new shroud 1411-06-043-2 have been included in the plot of bend data from the previous shroud tests summarized in Figure 3-160, and also includes tests done on one of the shrouds used in engine test \#1. Results for the shroud from the previous engine test tend to fall above the trend line for the 2005 shrouds. Two of the three data points from the new shroud measured without oxidation (blue squares) fall within the population band for the 2005 shrouds, with the other point being considerably higher. Following oxidation, most of the corner interlaminar strengths were significantly above the trend range for the population of 2005 shrouds, suggesting that the oxidation treatment may have actually improved the interlaminar strength of the corners. It is possible that during oxidation the growth of oxide on the inside surfaces of the delaminations would effectively fill in some of the porosity and act to glue the delaminated surfaces together. Although all of the oxidized samples had interlaminar bend strengths above the trend line, there was no distinct trend of interlaminar strength with oxidation time between 250 and 1000 hours. 
The most important observation from these experiments was that none of the bend samples failed in a brittle fashion. Load drops did occur with the onset of interlaminar crack extension, but all samples remained intact to very high levels of strain. Metallographic examination showed little evidence of brittle fracture of any composite plies. In a number of cases matrix cracks running perpendicular to the axial fibers were found, but fibers bridging the cracks remained intact. Only in one case, in a sample oxidized for only 250 hours, was there a brittle failure of a composite ply, as evidenced by an un-deviated matrix crack and all fibers along the crack path having fractured exactly at the matrix crack, thereby indicating no fiber debonding or pull-out.

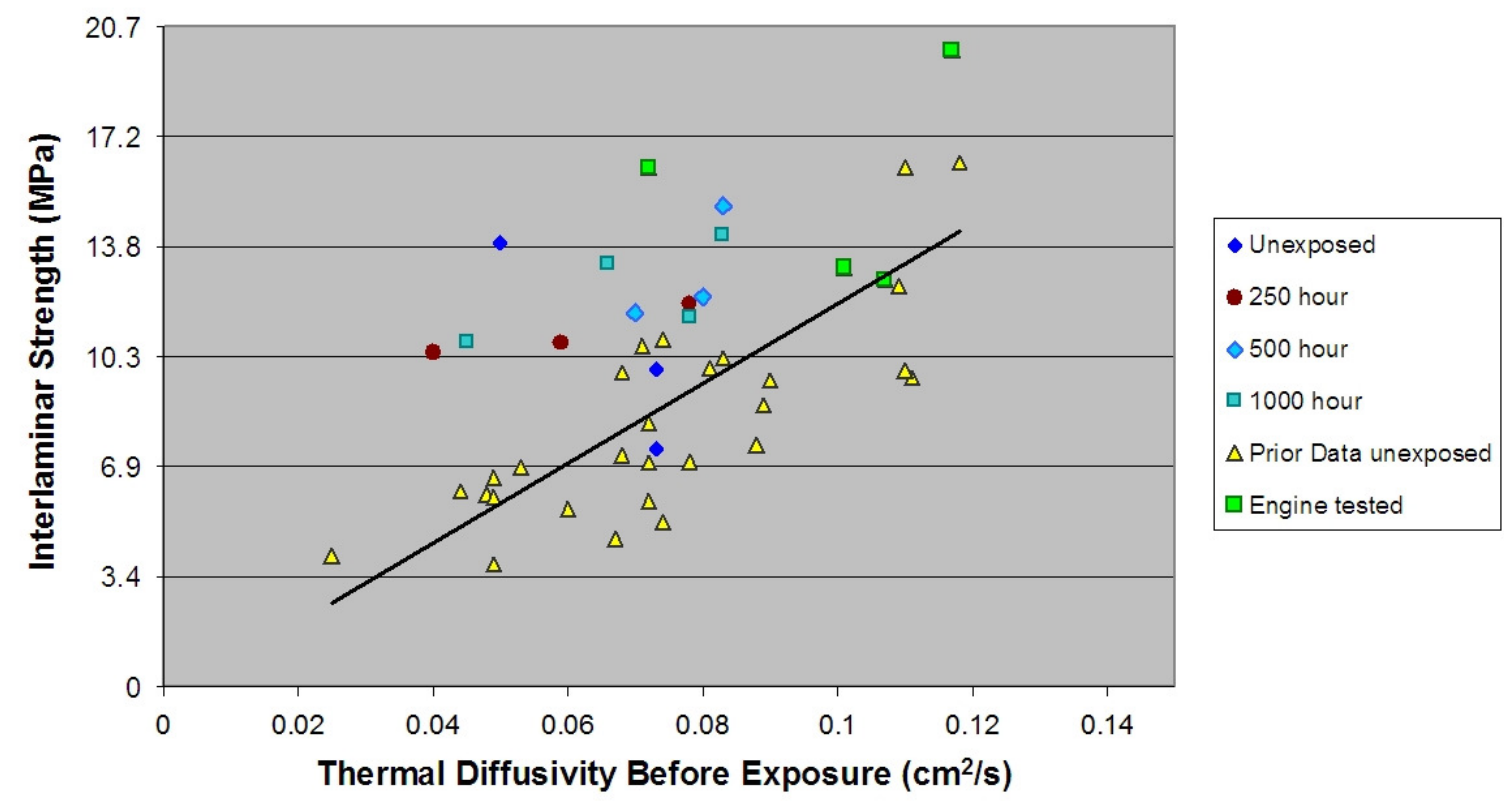

Figure 3-162. Interlaminar strength data from shroud corner bend tests on slices of shrouds. The yellow triangles represent the prior tests done on as-fabricated shrouds made in early 2005. The other data points are for shroud 1411-06-043-2 which was tested both as-fabricated and after steam oxidation exposure for 250 to 1000 hours. Additional data from a shroud used in the 2003 field engine test are also shown.

Extensive metallographic characterization was done on many of the corner samples following oxidation exposure and testing. Although there was substantial sample-to-sample variability in the severity of the delaminations and in the extent of oxidation, it was possible to estimate the exposure time necessary to fully consume an axial ply at a minimum of 3000 hours. This estimate is based on having a severe, fully open delamination in a transverse ply with matrix defects extending into the neighboring axial ply, which represented the worstcase microstructure observed. However, full oxidative consumption of only one axial ply would not be sufficient to cause catastrophic failure of a shroud corner based on the 
observations from the corner bend tests. Rather, it was estimated that nearly three full axial plies would have to be consumed before having a substantial risk of catastrophic shroud corner failure, thus extending the expected life considerably. Assuming that the onset of interlaminar oxidation would be delayed by the presence of the EBC coating, the shroud team concluded that there was a sufficiently low risk of oxidative embrittlement to allow use of the current population of shrouds for up to 5000 hours of engine testing.

The overall conclusion from the impact, corner bend and oxidation testing was that there was a low risk of the delamination defects themselves resulting in a shroud failure. Consequently the current population of shrouds was approved for use in a field engine test for a total exposure time of up to 5000 hours. This restriction matched the operational envelope of a peak-load engine where the expected total hot hours ranges up to 4000 hours per year.

Although the testing described above had indicated that the remaining population of shrouds fabricated in late 2004 and early 2005 would be acceptable for a short-duration engine test, shroud fabrication was continued at a low level throughout 2005. The intent was to use any new shrouds in the engine test in place of the shrouds with the most serious defects. Since the engine test would be for limited hours it also presented the opportunity to test some new variations of CMC material with minimal risk of shroud failure. The CMC shroud variations that were eventually included in the shroud set used in the engine test are listed in Table 3-14. The shroud variations include two fabrication sources (GRC or CCP), three generations of the CMC material (based on fiber type and matrix composition), two types of fiber architecture (0-90 or $+/-45)$ and whether the shrouds had flat or curved hot gas path surfaces.

Table 3-14. List of CMC Shroud Material Variations Included in Field Engine Test \#2.

\begin{tabular}{|cccccc|}
\hline Type & Fiber & Matrix & Fabricator & Architecture & $\begin{array}{c}\text { Straight or } \\
\text { Curved }\end{array}$ \\
\hline GEN1 & Hi-Nicalon & standard & CCP & $0-90$ & straight \\
GEN1 & Hi-Nicalon & standard & GRC & $0-90$ & straight \\
GEN1 & Hi-Nicalon & standard & GRC & $+/-45$ & straight \\
GEN1.5 & Type S & standard & GRC & $0-90$ & straight \\
GEN2 & Type S & low-silicon & GRC & $0-90$ & straight \\
GEN1 & Hi-Nicalon & standard & GRC & $0-90$ & curved \\
GEN1 & Hi-Nicalon & standard & GRC & $+/-45$ & curved \\
\hline
\end{tabular}

As noted at the beginning of this section, the change of the main goal of engine test \#2 away from demonstrating full life durability to measuring the engine system performance benefit of the CMC shrouds made it necessary to include an abradable EBC coating on the CMC inner shrouds. The base EBC coatings were mostly the standard 3-layer coating of a silicon bond coat, mullite plus BSAS transition layer and BSAS top coat, though some shrouds also had coatings that incorporated multiple stacks of layers or rare earth silicate 
compositions in the outer layer. It was therefore necessary to develop an EBC spray deposition process to apply an abradable EBC structure over top of the base EBC coating.

The standard technique for making normal $\mathrm{ZrO}_{2}$-based TBC coatings abradable is to have a pattern of ridges in the TBC. As there was no prior experience with the behavior, or "abradability", of patterned EBC coatings rub rig testing of abradable EBCs was performed. Of particular concern was whether the EBC layers would indeed be abradable, i.e. would the EBC erode from contact with the blade tips rather than eroding the blade tips themselves, and whether the localized blade tip rubs on the $\mathrm{EBC}$ ridges resulted in $\mathrm{EBC}$ cracking or spallation. Over $30 \mathrm{CMC}$ samples with an abradable EBC, made by spraying additional ridges of BSAS on top of the normal 3-layer EBC, were prepared and tested in the same blade tip rub rig described previously in Section 3.1.8.1. Photographs of CMC samples with abradable EBC ridges both before and after rub testing are shown in Figure 3163. Variables studied during the rub testing included the blade-to-shroud incursion distance, the incursion rate, and thermal spray conditions used during deposition of the abradable ridges.

For blade rubs less than the depth of the EBC ridge height there was little material transfer from the blade tips to the EBC samples. The ridges were eroded rather cleanly with practically no EBC chipping beyond the immediate rub area. Wear of the blade tips under these conditions was minimal. Metallographic examination showed that the abraded EBC ridges did show periodic cracking, but that this cracking did not penetrate through the normal EBC topcoat.

When the blade rubs were done at depths greater than the ridge height, i.e. the blade rubbed into the underlying continuous EBC layer, significantly more blade tip abrasion occurred. Substantially more blade material was deposited on the EBC surface, which appear as green in the bottom photograph in Figure 3-163. Nevertheless, no EBC spallation was noted in any of the rub tests even when the rubs were deep into the normal EBC coating. Metallographic examination of the rubbed specimens again showed periodic vertical cracks in the $\mathrm{EBC}$ in the region of the rubs, but the cracks never extended to the silicon bond coat. 


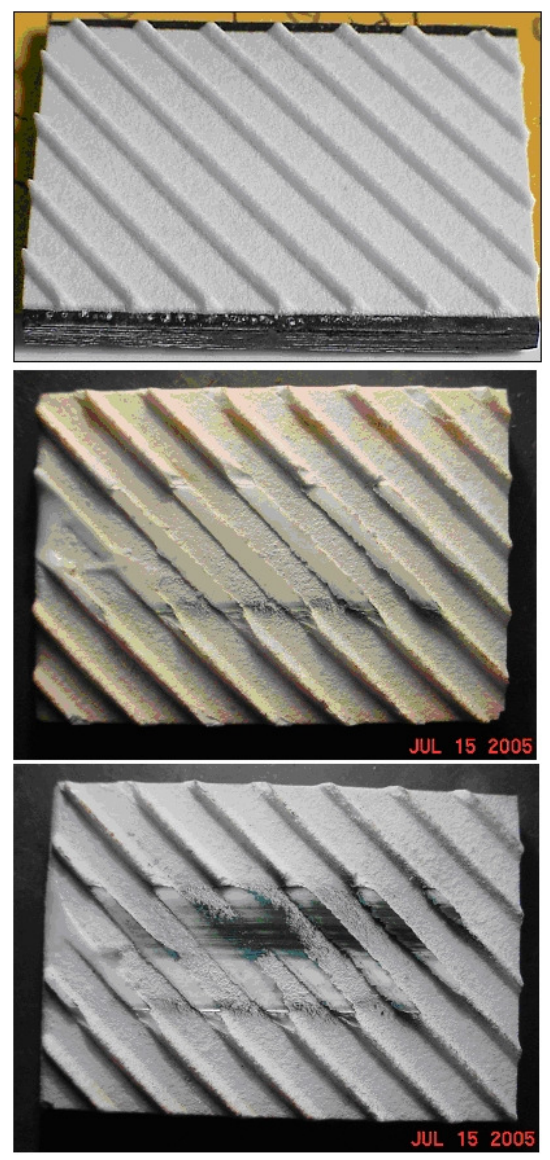

\title{
As-Sprayed
}

\author{
Rubbed into \\ abradable ridges \\ only
}

\section{Rubbed into EBC topcoat}

Figure 3-163. Photographs of CMC samples with abradable EBC layers applied over the normal 3-layer, BSAS-based EBC.

\subsubsection{Task S4.2 - Metallic Hardware for Engine Test \#2}

Thirty-two outer shroud blocks are needed for a full engine set, and forty-seven parts are needed for each outer shroud block assembly, of which only six (3 CMC inner shrouds and 3 ceramic washers) are not metallic. All of the necessary hardware had been fabricated and/or procured in preparation for the planned Spring 2005 engine test. However, when this engine test opportunity was missed and the goal of the test was changed from a durability demonstration to a demonstration of shroud system performance, several changes were needed to the outer shroud blocks. In particular, to meet the aggressive performance targets the attachment cooling flows needed to be further restricted below the levels originally planned for the test. These adjustments did not require fabrication of new outer shroud blocks, but required adjustments to cooling air controlling orifices.

A detailed instrumentation plan was developed for the shrouds. Only four outer shroud blocks were instrumented due to the practical limitations on the number of wiring harnesses that could be accommodated during engine assembly. All of the instrumented shroud blocks were spaced across a single quadrant of the engine. 


\subsubsection{Task S 4.3 - Field Engine Test \#2}

The goal of this task was to perform the actual field engine test of the improved CMC shroud system. This task included the identification of a suitable test site, assembly of the shroud system components into the outer shroud blocks, installation of the CMC shrouds in the test engine, detailed characterization of the engine operating performance before and after installation of the CMC shrouds, and continued monitoring of the condition of the shrouds throughout the engine test.

\subsubsection{Test Site Selection}

GE had been negotiating with a preferred engine test site and had received approval to utilize this engine for the shroud test. The engine was scheduled for shutdown in February 2005 with restart in March. However, as discussed previously, the field engine test planned to start in February was cancelled due to questions about the CMC inner shroud quality and to vendor delays in getting the outer shroud blocks completed. A plan to use the CMC shrouds in a peeking unit test starting in June was initially considered, but eventually rejected as there would not be sufficient time to assess the impacts of the shroud quality problems. The engine test was therefore initially pushed back to the Fall of 2005. Several potential engine test site candidates with maintenance shut-downs scheduled the Fall 2005 season had been identified. Unfortunately contractual and/or timing considerations eliminated all of these sites from contention.

In late January the Jacksonville Electric Authority agreed to allow GE to test the CMC shroud set in their Brandy Branch Station Unit \#1 engine following several weeks of negotiation. This engine is a 7FA+e class engine (GE unit number 297379) that was used in simple cycle mode as a "peeker," meaning that it was typically run only during peek demand hours, which were typically 8-10 hours a day mostly during the summer months. The Brandy Branch Generating Station is approximately ten miles west of Jacksonville Florida. An aerial view of the station is shown in Figure 3-164. This particular gas turbine had been in service since May of 2001 and the outage during which the CMC shrouds were installed was the machine's first overhaul. 


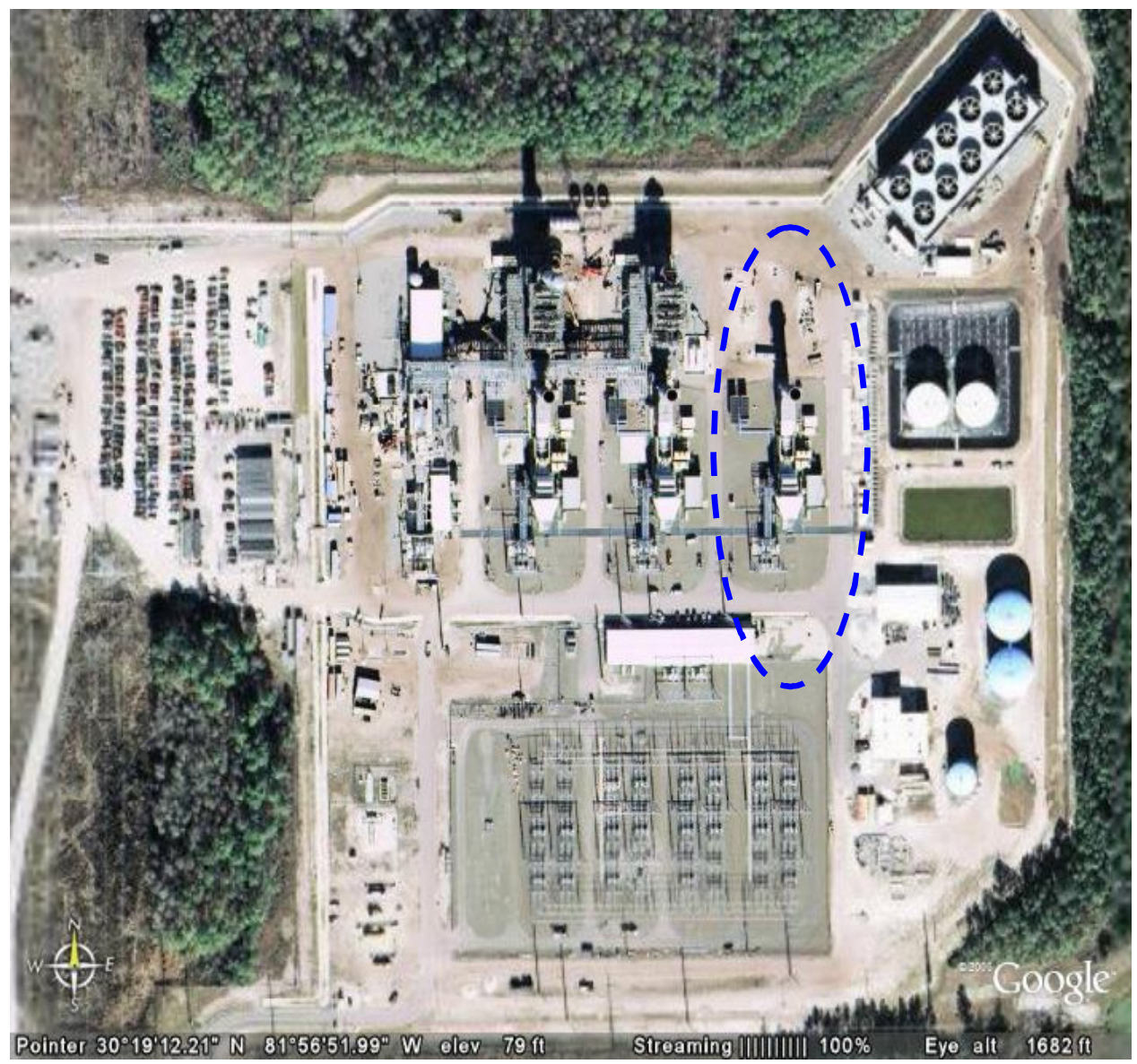

Figure 3-164: JEA Brandy Branch generating station with the dashed blue ellipse highlighting the location of the 7FA+e gas turbine in which the CMC stage 1 shrouds were installed.

\subsubsection{Shroud Assembly}

Assembly of the shrouds, including installation of all of the shroud attachment hardware and then mounting the CMC inner shrouds into the metallic outer shroud blocks, was started in early March 2006 and completed in about 2 weeks.

During shroud block assembly the amount of compression used in the damper springs was a primary concern. As described previously, the function of the springs is to maintain positive seating of the CMC inner shrouds on their attachment pins in the presence of the forced vibration due to blade passing excitation. In the previous rainbow engine test in 2002 the cold pre-compression introduced in the springs was $2.8 \mathrm{~mm}$. Post-test characterization of the CMC shroud assemblies indicated that wear-related phenomena observed during the 5366 hours of operation may have contributed to as much as $0.6 \mathrm{~mm}$ of spring precompression displacement loss. This reduction in spring compression would have resulted in a decrease in the spring load of $\sim 20 \%$. In spite of this potentially reduced spring load, there was no evidence of any ill effects on either the pins or the mounting holes in the CMC inner shrouds. 
A significant contributing mechanism to this loss of operating spring load in engine test \#1 was wear on the pin attachments. The wear mechanism affecting the pins was driven by thermal cycles and the engine used for test \#1 was operated primarily in base load with only 14 start/stop cycles. In comparison, the simple cycle unit at JEA was to be operated in a cyclic mode and as a result was likely to see more wear for an equivalent number of hours. Although it was unclear exactly when the CMC parts in the JEA unit would be extracted, it was considered unlikely to occur before two years. Assuming that the machine runs for 2000 hot hours in 8-hour cycles leads to an expectation of 250 on-off cycles. Estimates of wear based on the engine test \#1 experience lead to a spring compression loss of $0.7 \mathrm{~mm}$. If the same pre-compression of the spring were used in JEA as in engine test \#1 this loss of pre-compression would place the JEA spring loads below the desired minimum limit. As a result, the pre-compression ambient displacement introduced in the JEA springs was set at $3.3 \mathrm{~mm}$. This assembled spring compression should maintain spring loads at levels equal to or above those in engine test \#1. In addition, the stress penalty for this added load on the CMC inner shroud was only about $7 \mathrm{MPa}$. Expected shroud stress levels for the JEA configuration would then be approximately 60-70MPa - still well below the original 97MPa material allowable.

In the assembly sequence, the inner shrouds, damper blocks, Macor washers and springs were installed first with the threaded spring sleeve left off. The spring sleeve was then threaded into the outer shroud block until resistance from contact with the spring was encountered. From the spring sleeve location of first contact, the sleeve was then rotated the required number of revolutions to establish the desired spring precompression based on the thread pitch of the spring sleeve and the initial cold spring constants.

The assembled shroud blocks were then shipped to the engine site the last week of March for installation. The service outage for this engine began on March 30, 2006, with the upper turbine shell being removed on April 1.

\subsubsection{Shroud Installation Into the Test Engine}

Each CMC shroud installed in the JEA unit had a manufacturing identification number and a set of quality data that included witness coupon data, infrared NDE image and natural frequency data. Figure 3-165 (view from forward looking aft) defines the numbering system used to define the individual shroud locations in the engine. Each outer shroud block was identified with a number from 1 to 32. Within each outer shroud block, a number varying from 1 to 3 identified the individual inner shroud location. When viewing the hot gas path surface of the inner shrouds in an individual shroud block with the inner shrouds upward, from forward looking aft orientation, location 1 was at the right, location 2 in the middle and location 3 on the left. Figure 3-165 identifies all 96 of the inner shroud locations with this two-number identification system - shroud block number followed by inner shroud location number. The figure also identifies the circumferential locations of the four instrumented outer shroud blocks, the borescope access locations, and the instrumentation penetrations through the turbine shell. 


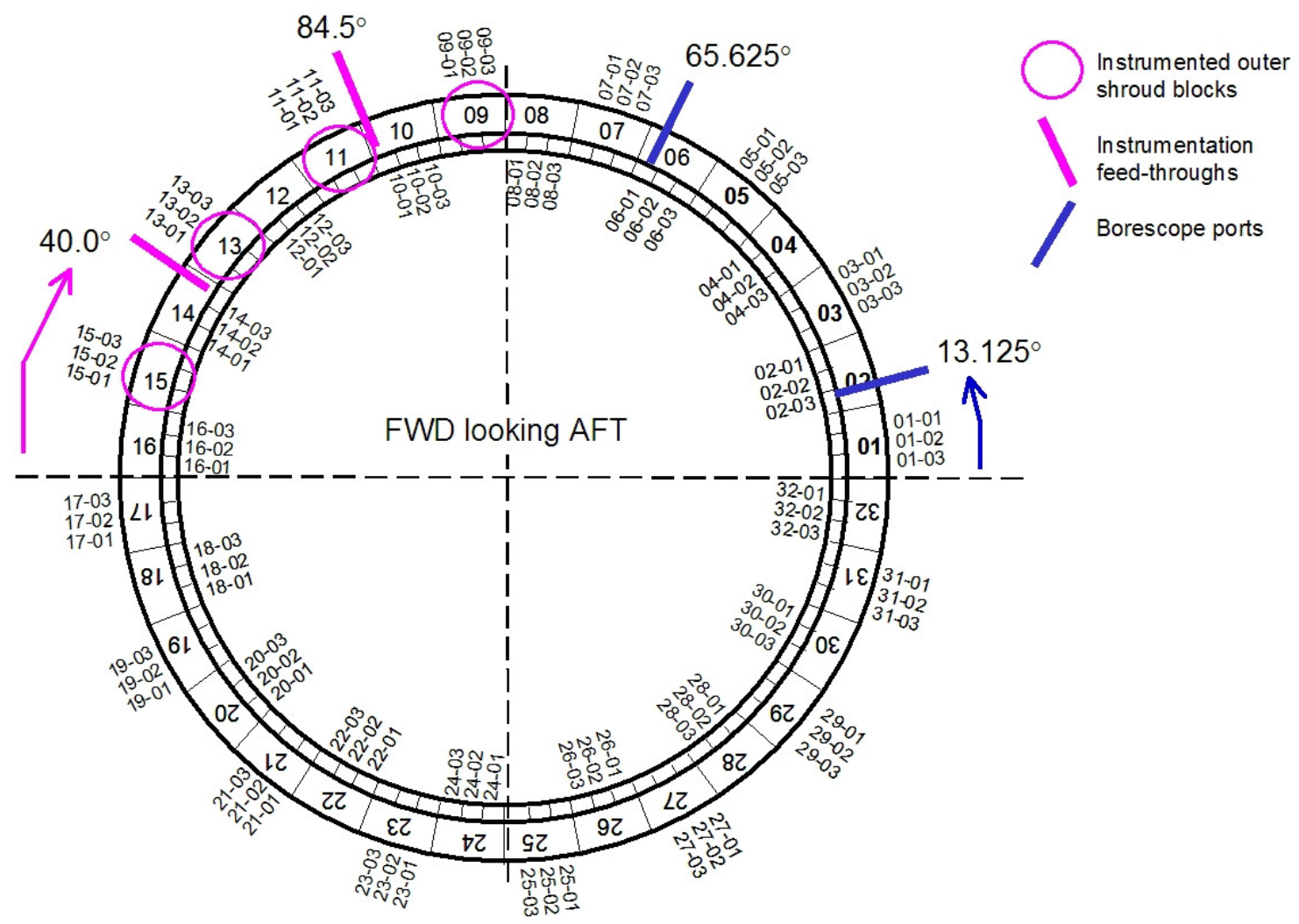

Figure 3-165: Inner shroud location numbering system.

Once the assembled outer shroud blocks were delivered to the engine test site they were unpacked and a detailed visual inspection was performed. No shipping damage to the shrouds was noted.

Preloading of the shrouds and free movement of the damper/spring mechanism was checked prior to installation of the shroud blocks in the engine. This check was done by applying force to the hot gas surface of each inner shroud by hand and feeling for movement of the inner shroud relative to the outer shroud block. This check was carried out on all the inner shrouds before assembly into the turbine. There were three inner shrouds that showed no displacement response to the hand force. There was not adequate time to disassemble the blocks in question to investigate and correct the observed noncompliance of the inner shrouds. Visual inspection of the shrouds indicated that the most likely cause for the lack of give in the inner shrouds was binding of the damper block dog-bone seals. Performance of this shroud motion check was incorporated into the shroud block assembly procedures for any future engine test. If the absence of freedom of motion is detected, the block should be disassembled and examined to determine the cause and perform any corrective action.

Actual installation of the CMC shrouds into the upper shell of the turbine was started on April 4. Representatives of DOE (Donald Geiling, Debbie Haught and Merrill Smith) visited the engine test site during the shroud installation process to witness the installation 
process and to examine the CMC hardware. Throughout the installation process various checks were done to insure the shrouds were intact and that the spring-loaded damper mechanism was operating as intended. A few problems also surfaced during shroud installation process that needed to be addressed on-site.

One of the issues that occurred during shroud installation was an interference between the aft pin retaining pegs in the outer shroud blocks and the T-slot hanger on the turbine casing. The rear flange attachment pins are held in place with retention pegs that are inserted from the T-slot in the outer shroud block, as shown in Figure 3-166. In order for the outer shroud block to slide onto the T-slot hanger on the turbine casing, adequate clearance is required between the top of the retention peg and the bottom of the T-slot hanger. At the desired design clearance the T-slot hanger would prevent the retention peg from disengaging with the aft pin attachment even if the stakes introduced during outer shroud block assembly became ineffective. During initial assembly of the outer shroud blocks onto the T-hanger of the outer casing, interference was observed between the retention pegs and the T-hanger. It is unclear whether the interference was universally present for all retention pegs or whether it was selective. In order to proceed with the assembly, the tops of the retention pegs were ground down using hand-held grinders to alleviate any interference and allow assembly.

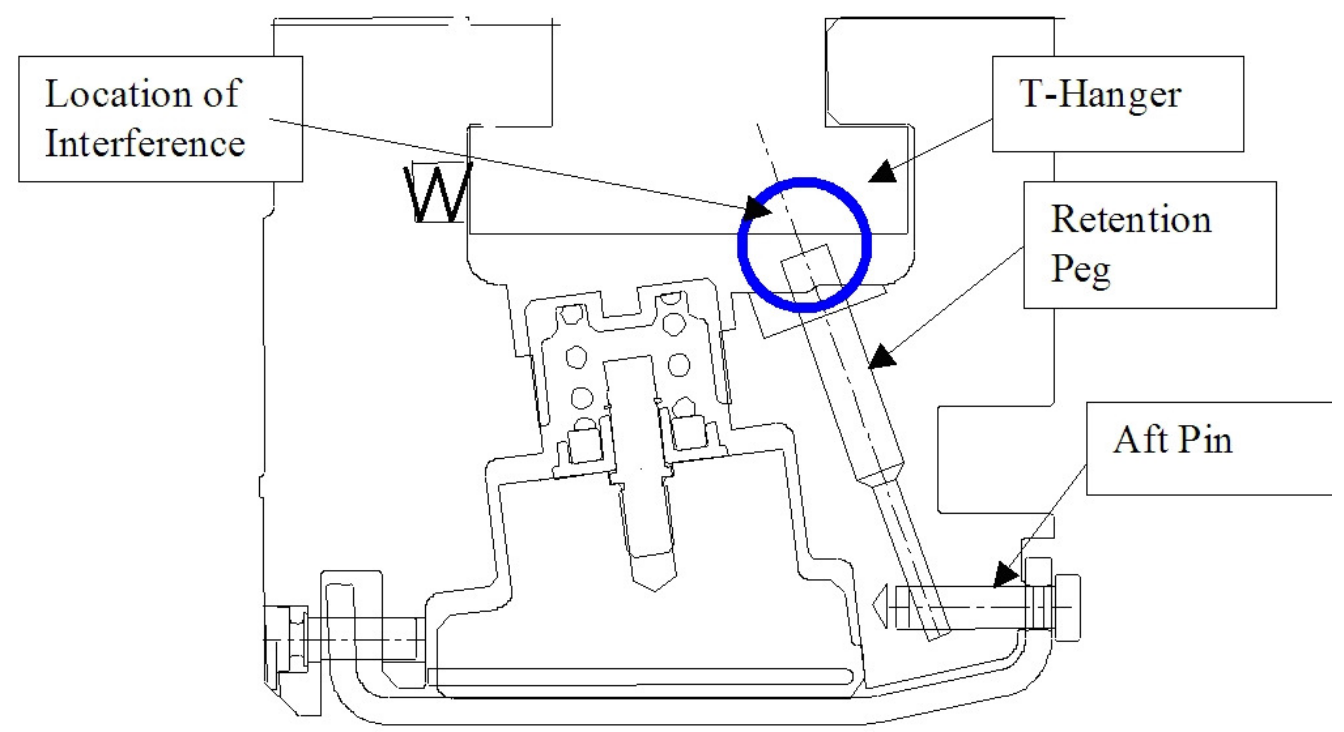

Figure 3-166: Location of interference between retention peg and T-slot hanger.

Once the interference between the retention pegs and T-hanger was eliminated installation of the shrouds was restarted; however, another problem with the outer shroud blocks was immediately noted. The outer shroud blocks slide onto a T-hanger rail that runs circumferentially along the inside of the turbine shell. A photograph of an outer shroud block being installed onto the upper casing T-hanger rail is shown in Figure 3-167. 
The outer shroud blocks must be spaced appropriately to ensure that they do not establish circumferential contact from thermal expansion as the engine heats up during operation. In order to prevent contact, an appropriate circumferential clearance between adjacent blocks is established and then locating-pins are inserted through holes in the turbine shell (Figure 3-168) and into corresponding holes in each outer shroud block (Figure 3-169). At this stage of assembly, it was discovered that due to a drawing error the locating pins would not engage the receiving-holes in the outer shroud blocks. Although correctly located circumferentially on each outer shroud block, the positioning holes were located incorrectly by approximately $2.3 \mathrm{~mm}$ in the axial direction. (This mismatch of locking pin location was not an unheard of occurrence during an engine re-build as the axial position of the locking pins is not constant throughout the entire fleet of 7FA engines.)

The only available solution was to take the assembled outer shroud blocks, with CMC inner shrouds still in place, to a local GE service shop to have the holes re-machined. The circular hole in each outer shroud block was elongated as shown in Figure 3-170 to properly receive the positioning pin inserted through the turbine half-shell. The increased hole length in the axial direction did not affect shroud functionality since the T-slot hangers establish the outer shroud block position in the axial direction.

Re-machining of the outer shroud block positioning holes was completed over a 3-day period, with the final shroud blocks being delivered to the engine site on April 7. Installation of the shrouds onto the upper turbine casing was completed on April 6, and installation in the lower turbine casing was completed on April 8.

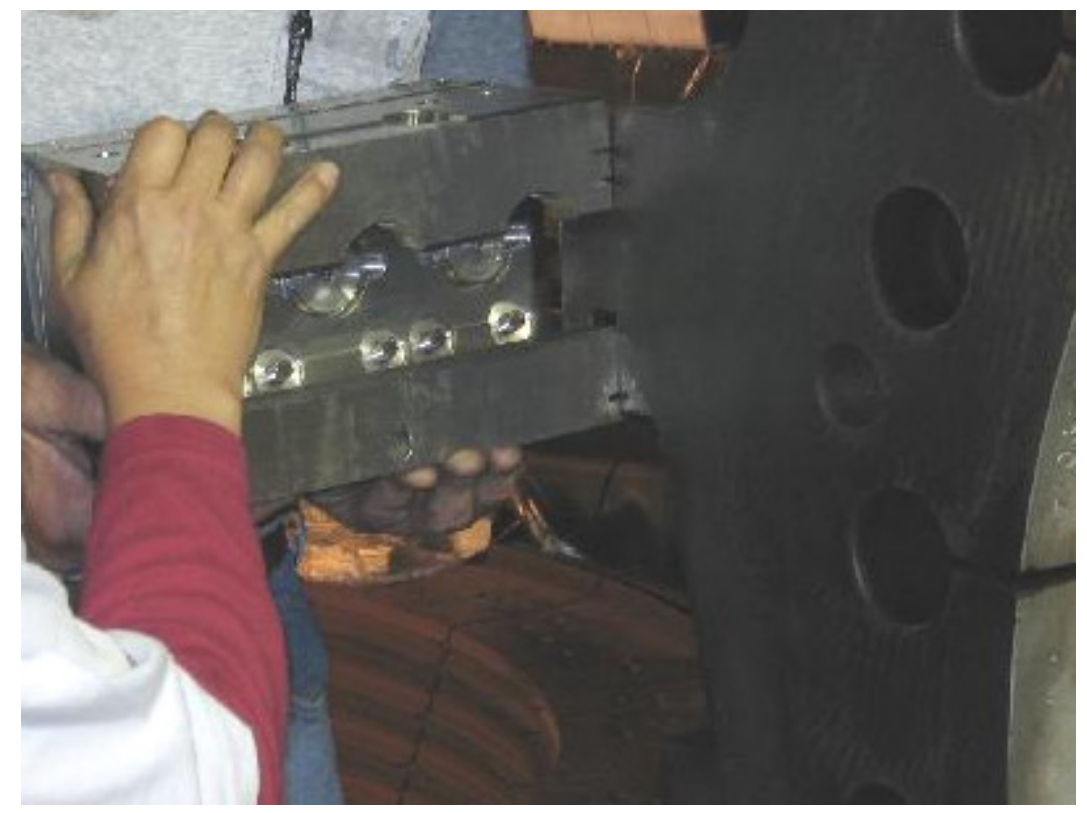

Figure 3-167. Photograph of an outer shroud block being positioned onto the T-hanger rail on the inside of the upper turbine casing. 


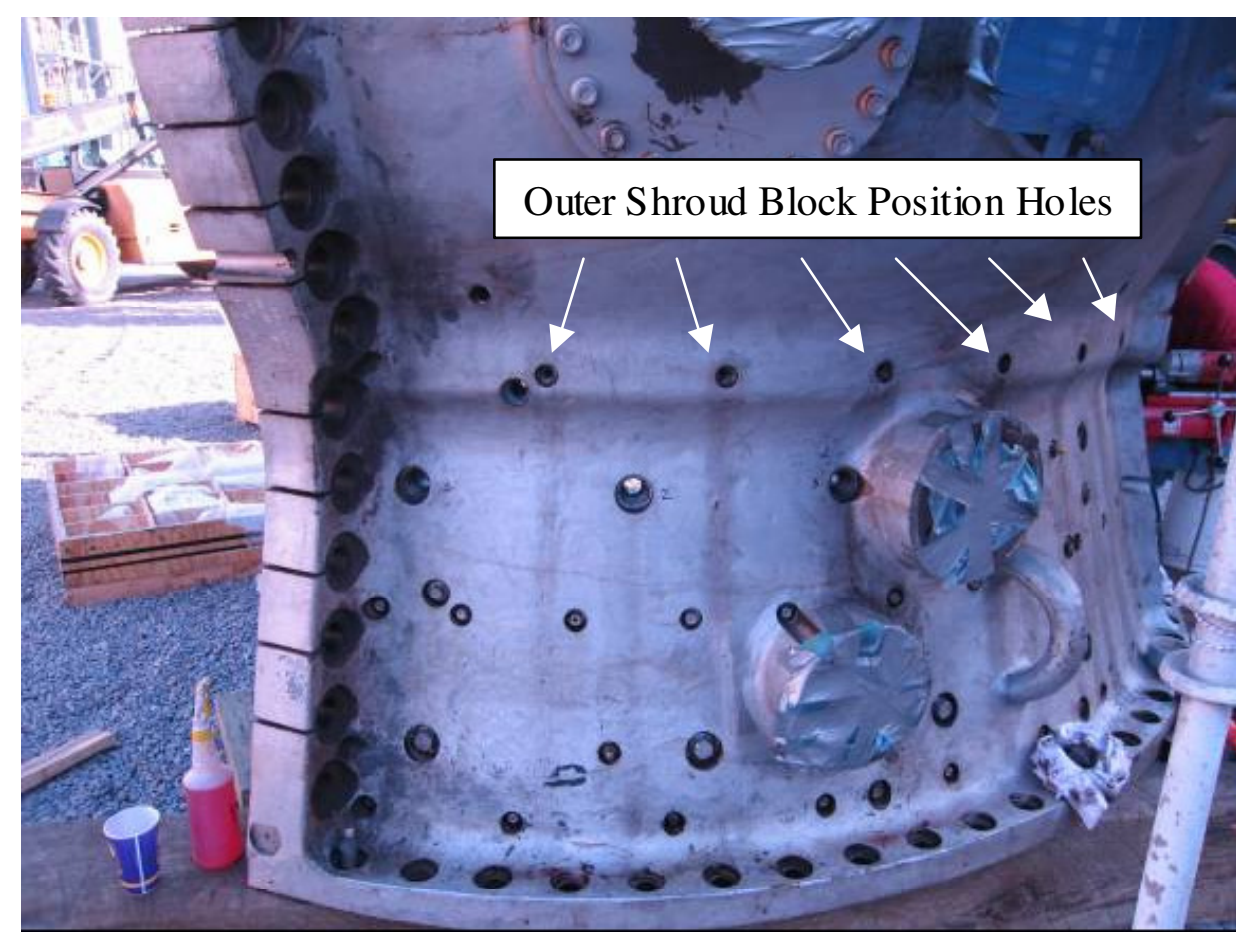

Figure 3-168. Photograph of the outside surface of the upper turbine casing showing the locations of the shroud block circumferential positioning holes.

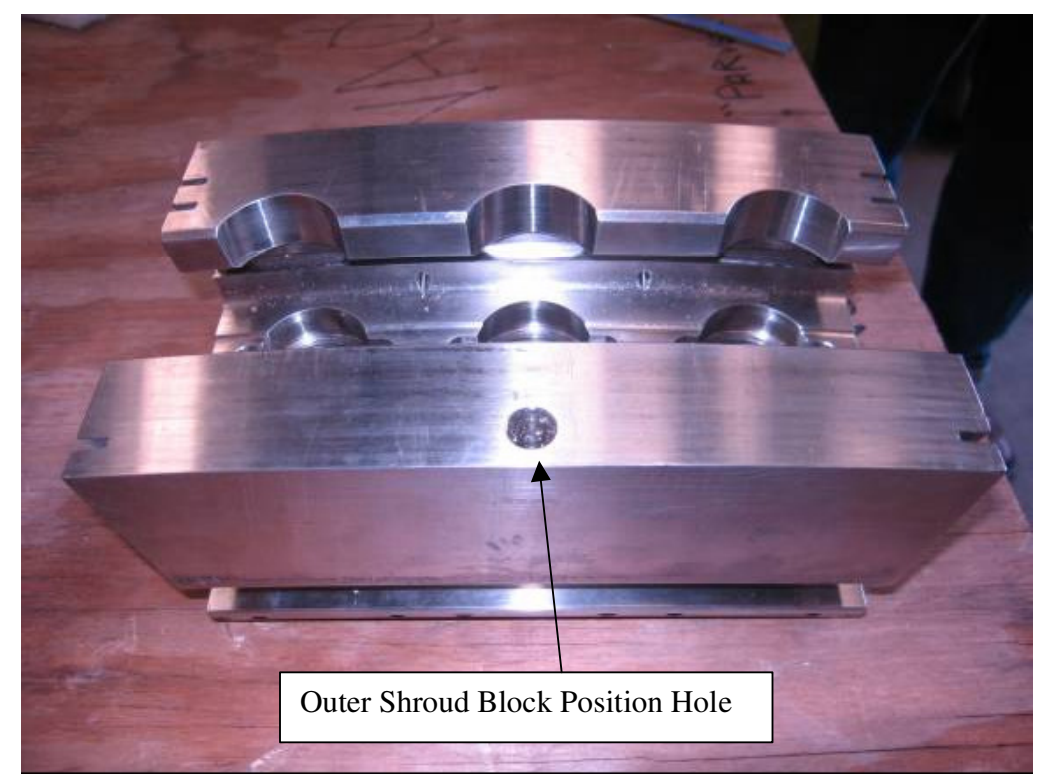

Figure 3-169: Photograph showing the location of circumferential positioning hole on an outer shroud block. 


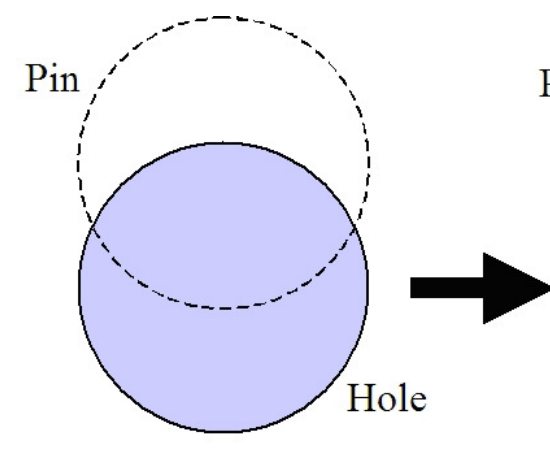

Original pin/hole geometry with fit-issue

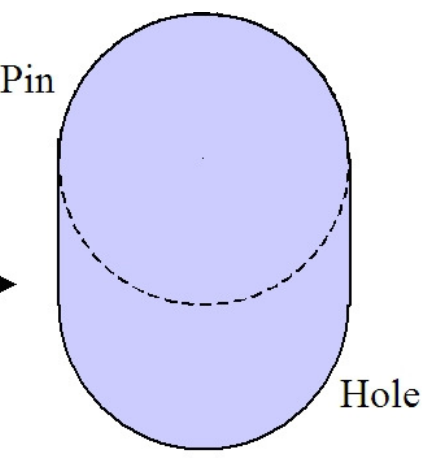

Altered pin/hole geometry allowing fit

Figure 3-170: Diagram showing the alteration of the circumferential positioning hole in the outer shroud blocks to allow fitting with the positioning pins in the axial location.

One of the CMC inner shrouds was damaged during the outer shroud block machining process, and another was damaged during installation of the $2^{\text {nd }}$ stage nozzles into the lower turbine casing, which occurred after shroud installation. The shroud damaged during machining was on shroud block 25-03 (eventually installed near bottom dead center in the lower turbine casing), and had three very small chips in the EBC layer along the outer edge. Photographs of the EBC chips are shown in Figure 3-171. The largest of the chips occurred at the bend in the hot gas path surface at the aft edge of the abradable EBC pattern, and was roughly $6 \mathrm{~mm} \times 3 \mathrm{~mm}$ in size. The other chips were along the same side of the shroud, but more toward the leading edge and in the valleys between the abradable EBC ridges.

The other damaged shroud was at position 17-03, which was at the turbine split-line. The shroud showed no damage following insertion of the shroud blocks into the engine lower casing; however, following insertion of the $2^{\text {nd }}$ stage nozzles a chip in the EBC coating on the rear flange edge of the shroud was noted. A photograph of the EBC damage is shown in Figure 3-172. The location of the EBC chip damage, which was adjacent to the slot in the outer shroud block where the $2^{\text {nd }}$ stage nozzles get inserted, and the large amount of anti-seize grease on the shroud suggest that the damage was caused by contact with a $2^{\text {nd }}$ stage nozzle during nozzle installation. There was no damage immediately visible to either the CMC inner shroud or shroud attachments. 


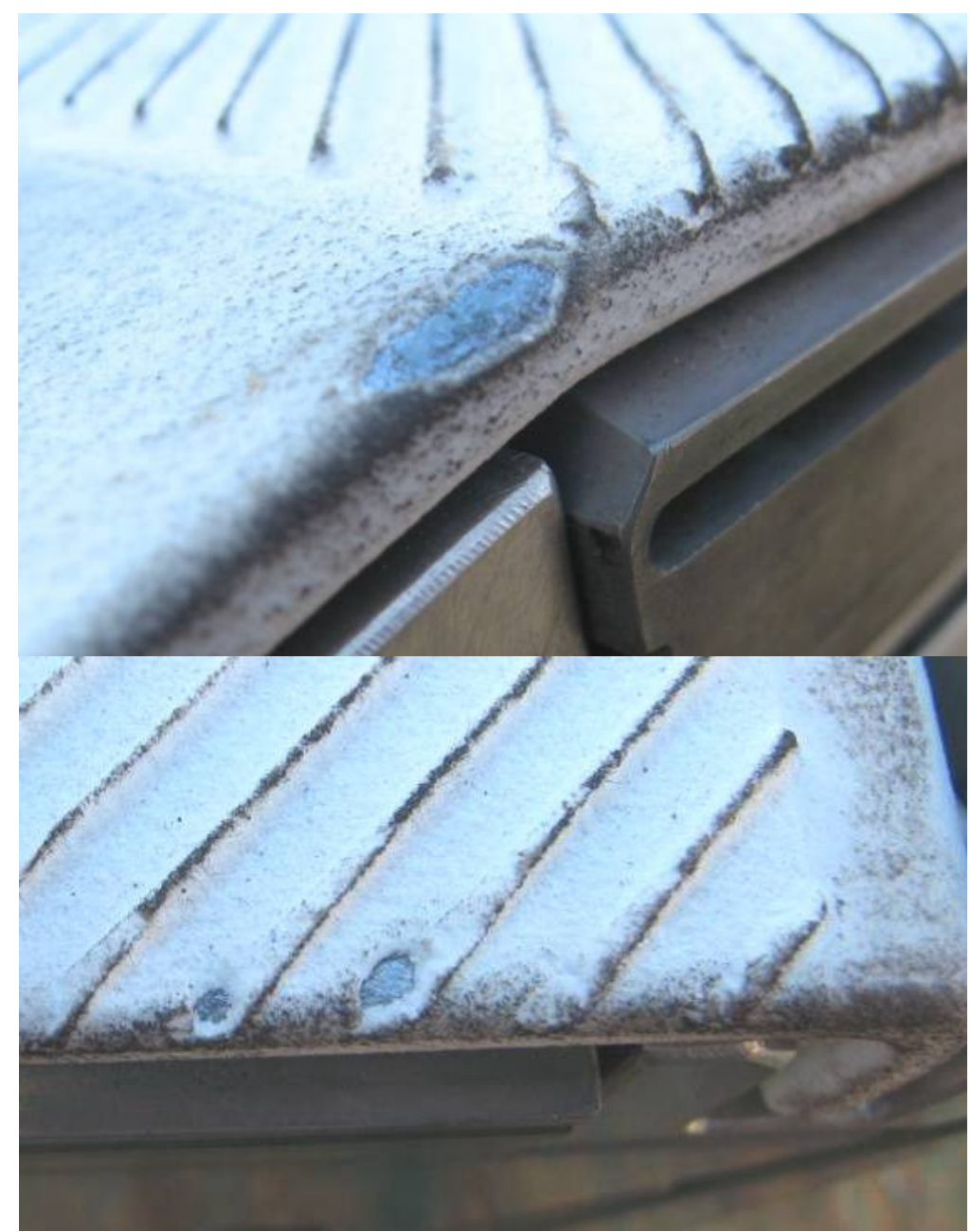

Figure 3-171. Photographs of the largest (top) and smaller (bottom) chips in the EBC of shroud 25-03 following re-machining of the circumferential location pin hole in the outer shroud block.

Neither of the shrouds with observed EBC damage was considered to pose a risk to the engine test. All indications were that the damage was limited to the $\mathrm{EBC}$, and none of the damage was in a critical location. 


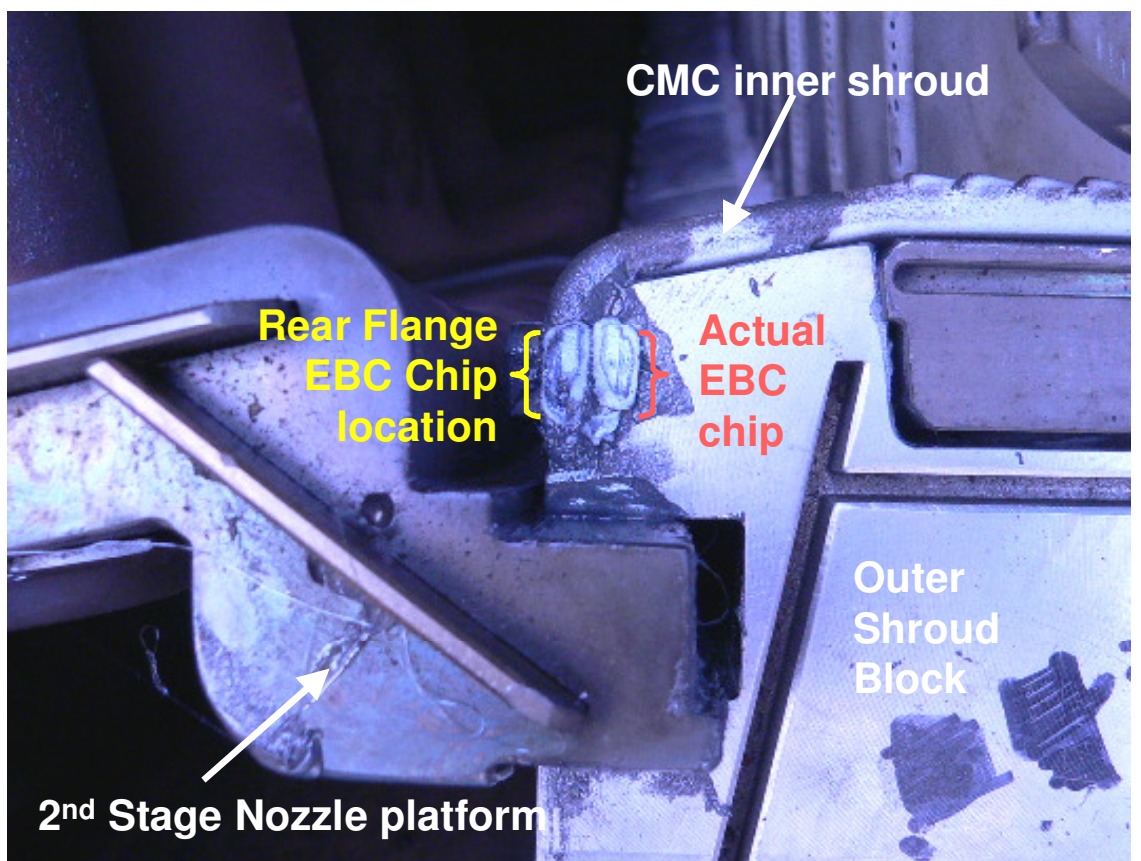

Figure 3-172. Photograph of edge of shroud block 17 showing the damaged EBC coating on the side of the rear flange of the CMC shroud at the split line, and its location relative to the $2^{\text {nd }}$ stage nozzle.

Just prior to closing the turbine casing the clearance between the bucket tips and the inner shrouds was measured at the lower casing split line. Figure 3-173 illustrates the relative positions of blade to shroud in the lower half of the turbine casing at the split line prior to insertion of the first stage nozzle ring.

Although shroud installation was completed by April 8, other servicing issues with the engine prevented successful restart until April 17. Engine tuning (i.e. an adjustment to the operating control conditions to account for the hardware changes) was performed immediately and detailed engine performance measurements were made on the 18 th. 

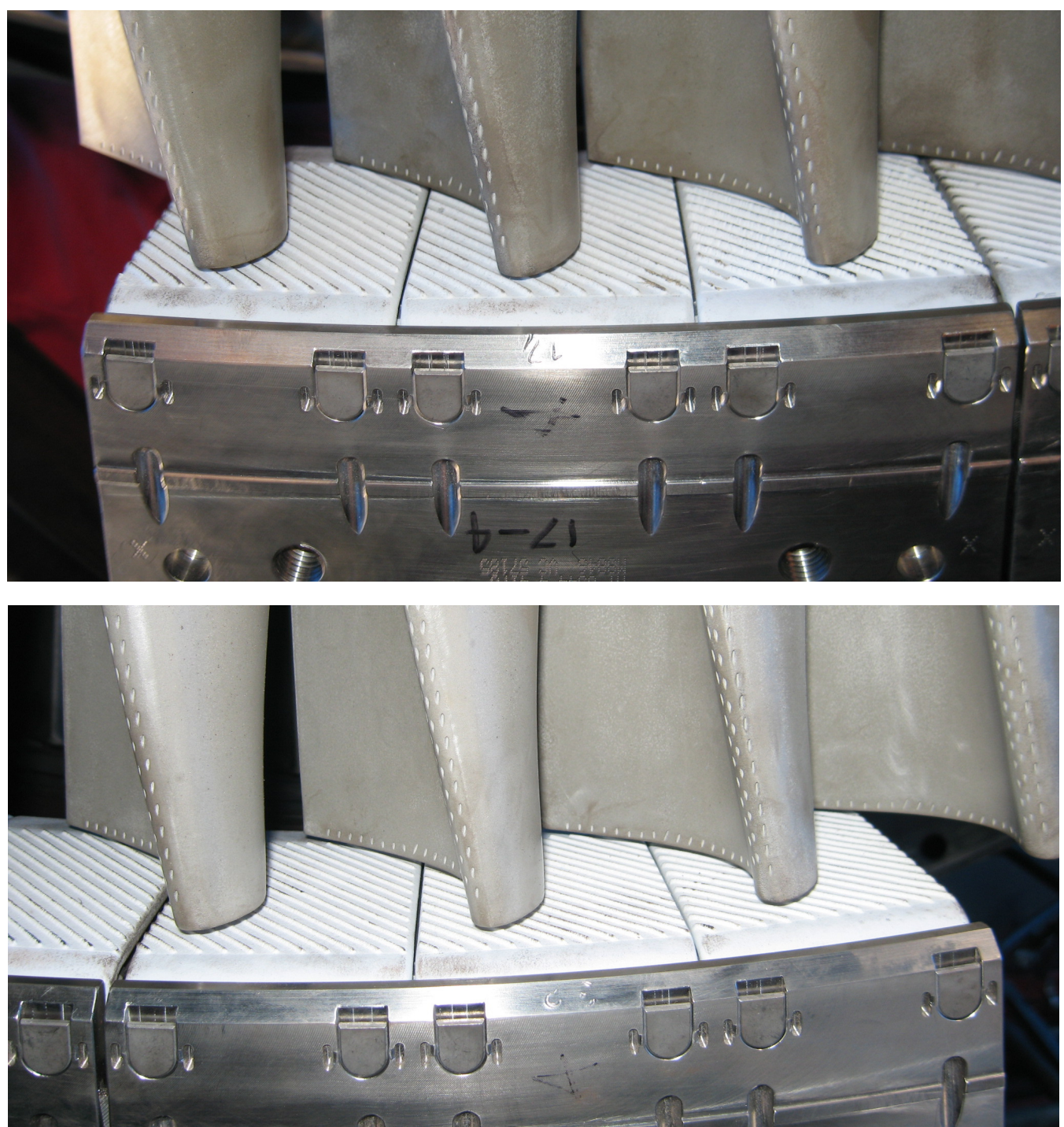

Figure 3-173: Photographs showing the bucket tip to shroud radial clearance at the location of outer shroud block 17 (top) and block 32 (bottom).

\subsubsection{Shroud System Performance Measurements}

Well before the start of the shroud engine test the design team had been developing the methodology for predicting the performance benefit to be expected from the CMC shrouds. The most well-defined performance benefit associated with the CMC stage 1 shroud system was due to the reduction of secondary cooling and leakage air flows. These secondary flows can be reduced because the CMC material can withstand higher temperature environments than the metals typically used for inner shrouds. Reduction of these parasitic flows effectively increases both the power output and the efficiency of the gas turbine.

The first-stage shroud configuration tested at JEA also had a second potential source of performance enhancement in the form of the patterned abradable layer added to the EBC coatings on the CMC shrouds. Such patterned coatings had been under development for 
use on both metal (as a patterned TBC coating) and CMC (as a patterned EBC coating) shrouds. The positive effects of the patterned abradable coatings on engine performance (both power and efficiency) result from reducing the combustion gas flow leakage between the blade tips and the shroud.

Although it would be informative to test the individual effects of each of these two performance improvements separately, such was not possible for this engine test. In finalizing the shroud design for this field test, while the main goal was still for a long-term demonstration of the shroud system durability, the engineering decision was made to minimize the potential of blade/shroud rub events by opening blade-to-shroud tip clearances by $0.5 \mathrm{~mm}$. This increased clearance would have had the effect of reducing engine performance. When the primary goal of the test was changed to validation of the engine performance benefits of the CMC shroud system many of the outer shroud blocks had already been manufactured, so that reducing the bucket tip clearance back to the nominal value was not possible. The performance loss from the increased tip clearance would effectively counteract the expected benefit from the shroud cooling reduction, making measurement of any engine performance benefits very difficult. As a result, the decision was made to apply abradable coating to the CMC shrouds with a thickness that would bring the blade tip clearance back to a level equivalent to the 7FA+e fleet.

Detailed flow net analyses were conducted on the full CMC shroud system for comparison to the standard metallic shroud system. Both intentional cooling air flows and unintended leakage flows were included in the analysis since both represent parasitic losses on the turbine cycle. Overall, the CMC shroud system had a predicted total secondary flow that was $63 \%$ less than for the metallic shroud system. Since practically all intentional cooling flow to the shrouds had been eliminated in the CMC design, the remaining secondary flow was essentially all leakages. Using established performance derivatives for secondary flows the improvements in turbine efficiency and power output for the CMC shroud system were predicted.

Prior to the scheduled hot gas path maintenance outage for the JEA machine, a GE precision performance team installed the necessary equipment and made baseline performance measurements on the engine. Similar measurements were made following the outage in order to compare the performance before and after the outage. After standardizing the pre- and post-outage performance measurements to ISO-conditions, the simple cycle power was found to have increased by $1.76 \%$, the heat rate decreased by $1.13 \%$, giving a simple cycle efficiency increase of 0.42 percentage points. These measured performance improvements significantly exceeded the expectations based on the secondary flow analysis mentioned above.

Although the CMC shrouds were the only new technology parts installed in the engine during the HGP maintenance outage there were other turbine parts replaced. Since the performance improvements were larger than expected, an effort was made to identify other possible sources of performance change that could have been associated with the maintenance changes and then to quantify the effect on power and heat rate. Table 3-15 is 
a list of the identified potential sources of performance change during a HGP maintenance outage and the measurements that were planned to allow an approximation of the effect on power and heat rate.

Table 3-15: List of Potential Sources for Engine Performance Change Following the Hot Gas Path Maintenance and the Actions Taken to Estimate Their Potential Effects

\begin{tabular}{|l|l|}
\hline Potential Source of Performance Change & Action Taken to Estimate Effect of Change \\
\hline $\begin{array}{l}\text { Replacement of stage } 1 \text { and stage } 2 \\
\text { buckets caused changes in bucket cooling } \\
\text { flows }\end{array}$ & $\begin{array}{l}\text { Measured cold flow in new and removed } \\
\text { buckets; used established performance } \\
\text { derivatives to estimate effects }\end{array}$ \\
\hline $\begin{array}{l}\text { Replacement of stage } 1 \text { and stage } 2 \\
\text { buckets resulted in change of bucket } \\
\text { surface roughness }\end{array}$ & $\begin{array}{l}\text { Measured airfoil surface roughness on new and } \\
\text { removed airfoils; used established performance } \\
\text { derivatives to estimate effects }\end{array}$ \\
\hline $\begin{array}{l}\text { Replacement of stage } 1 \text { shroud seals } \\
\text { caused a reduction in outer shroud block } \\
\text { leakages }\end{array}$ & Engineering estimate \\
\hline $\begin{array}{l}\text { Replacement of stage } 1 \text { nozzle caused a } \\
\text { change in nozzle throat area }\end{array}$ & $\begin{array}{l}\text { Measured nozzle throat area on new and } \\
\text { removed stage 1 nozzles; used established } \\
\text { performance derivatives to estimate effects }\end{array}$ \\
\hline $\begin{array}{l}\text { Bucket tip clearance was larger than } \\
\text { normal as the result of bucket rubs in } \\
\text { stages } 1 \text { and } 2 \text { prior to outage }\end{array}$ & $\begin{array}{l}\text { Used bucket tip clearance measurements taken } \\
\text { during engine disassembly and compared to } \\
\text { fleet average clearance specs to estimate } \\
\text { performance change }\end{array}$ \\
\hline
\end{tabular}

Following the procedures listed in Table 3-15 the team was able to determine reasonable estimates for the effects of the metallic hardware changes. Details of those calculations will not be presented here as they involve highly proprietary engine cycle information.

Figure 3-174 summarizes the size of the potential contributors to the measured differences in power and heat rate before and after the HGP maintenance outage at JEA. There was a degree of uncertainty in the measurement of the power and heat rate values and this uncertainty is shown by the error bars in the figure. In each plot the red double-arrow indicates the magnitude of the measured performance change that was attributed to the CMC shroud system. The portion of the power output increase that was assigned to the CMC shrouds still exceeded what had been predicted by just cooling flow reductions. The reduction in heat rate, on the other hand, was consistent with the predictions.

There were at least three potential explanations for the measured power output improvement exceeding expectations. First, although the original design expectation was that the abradable EBC configuration would not contribute to power or heat rate improvements, the analysis of the performance measurements suggested that there might have been a positive performance improvement associated with the abradable coating. A second possible explanation is that the decrease in S1S cooling and leakage air was larger 
than expected. Finally, the third possibility is that the performance improvements attributed to the other hardware changes may have been under-estimated.

During the performance measurement process the shroud systems in test at JEA performed as expected with one exception. As described previously, four of the outer shroud blocks have been heavily instrumented with thermocouples and pressure taps to allow verification that the temperatures and coolant flows in operation matched those of the analytical predictions. All of the measurements did in fact agree with the predictions except for one temperature in the outer shroud block associated with the spring cavities. In three of the four instrumented shroud blocks the temperature in this region was running roughly 80$110^{\circ} \mathrm{C}$ higher than predicted. The temperature of the third instrumented block was running slightly below prediction. It was therefore not immediately clear if the high temperatures were an instrumentation anomaly, especially since other thermocouples in the outer shroud blocks were not indicating higher than predicted temperatures. However, since three of the four instrumented outer shroud blocks were showing this single elevated temperature it was assumed that the instrumentation was correct.

A root-cause analysis was performed to determine the reason for this apparent temperature discrepancy. The final conclusion from this study was that there was limited combustion gas ingestion up into the outer shroud blocks. All intentional inner and outer shroud cooling flows had been eliminated, leakage of cooling air in the shroud had been reduced as much as possible, in order to maximize the engine performance benefit of the shroud system for this engine test. The instrumentation evidence suggested that these reductions were so effective that there was no longer sufficient flow of cooling air to completely purge the spring cavity in the outer shroud block, thereby allowing ingestion of combustion gases.

The main risk to the operation of the shroud system was that these high temperatures were occurring in the vicinity of the damper spring. If the springs were running hotter than intended then there was a chance that they would undergo creep relaxation, thereby relieving the spring preload on the CMC inner shrouds, which would then allow the shrouds to vibrate excessively and potentially wear the shroud attachment features. Evidence for such wear was not seen in any of the borescope examinations (to be discussed in the next section). Nevertheless, accelerated creep relaxation testing of some damper springs was conducted at CCP in order to better quantify the potential effects of these high temperatures on the performance of the damper springs. 

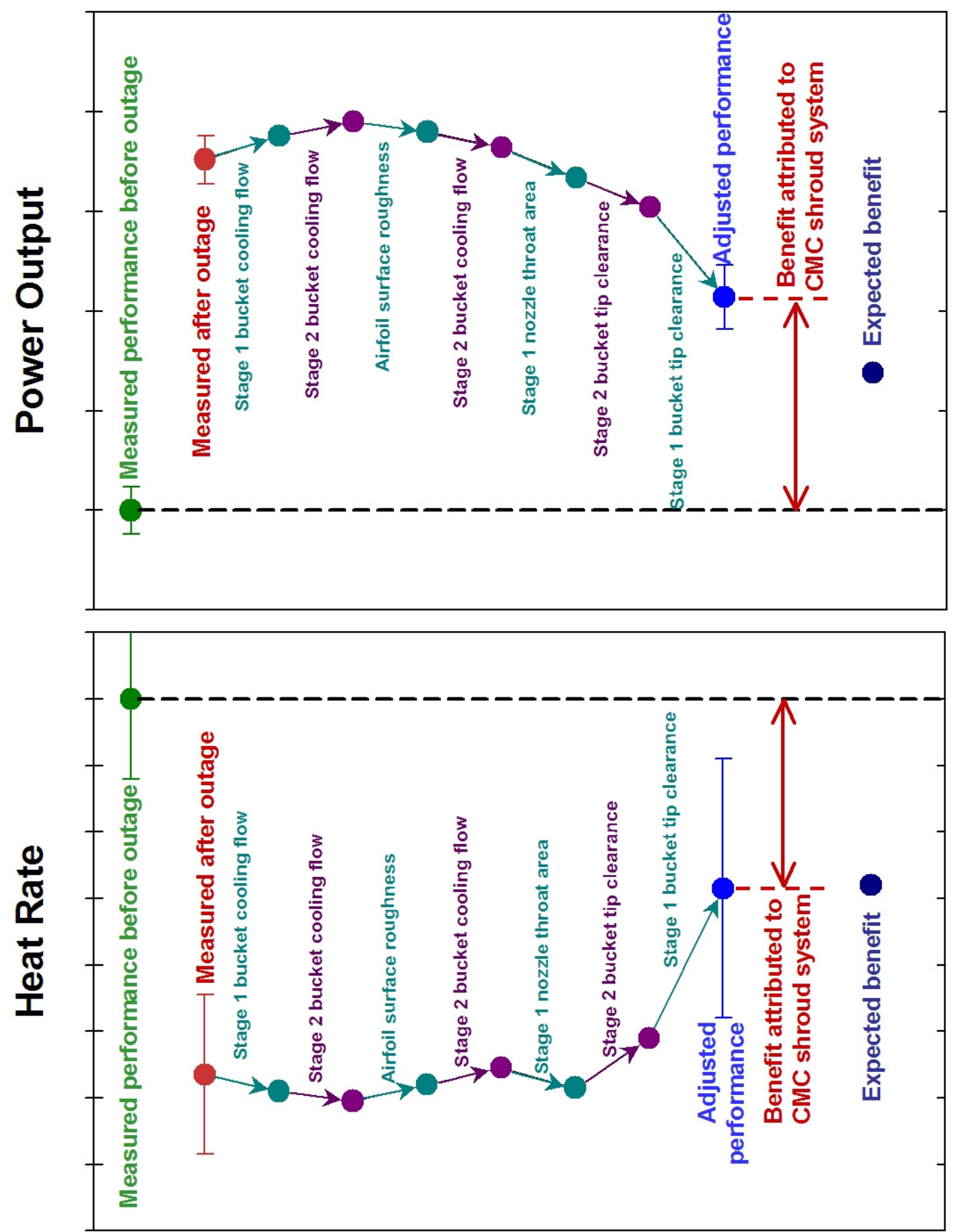

Figure 3-174. Comparison of turbine power output (top) and heat rate (bottom) before and after installation of the CMC shroud system. The progression of points shows the corrections made to the measured performance based on the other hardware changes as listed in Table 3-15, resulting in the actual engine performance change attributable to the CMC shroud system. The expected benefits from the cooling flow reductions are also shown for comparison. 


\subsubsection{Shroud System Borescope Inspections}

Through the end of September, 2010, the ending date for technical work under this cooperative agreement, the shrouds had accumulated 1673 hours of engine operation, including 497 start-stop cycles with no engine operation issues noted. Since the start of the shroud test on April 17, 2006, the condition of the shrouds under test has been monitored using periodic borescope inspections. The inspections were spread out over time due to the slow accumulation of engine operating hours and because of normal scheduling issues with the engine operator. Overall, six borescope inspections focused on the CMC shrouds were performed by GE personnel. The engine operator, JEA, also performed periodic hot gas path inspections, but these were general inspections and detailed data on the conditions of all the shrouds were not collected. However, a description of the observations during one of these JEA inspections are included below where the results were particularly pertinent to the shroud test.

\subsection{GE Borescope Inspection \#1}

The first borescope inspection of the shrouds was performed on May 21, 2006, approximately 1 month after installation. At this point the engine had accumulated only 38 hours of running time. Using 3 different borescope access points all of the $96 \mathrm{CMC}$ inner shrouds were at least partially viewable via borescope.

The main observations made during the borescope inspection were as follows:

- There was no evidence of any structural problems with the CMC inner shrouds or attachments.

- Extensive "spatter" was observed on stage 1 shrouds, nozzles and buckets that caused a spotted appearance. The source of the spatter was not identified, but the spots appeared to be metallic in some instances.

- Nothing unusual was seen on the shrouds, EBC coatings or seals (limited view) in the instrumented outer shroud blocks; meaning the operating conditions measured by the instrumented blocks are expected to be realistic.

- Roughly $40 \%$ of the shrouds showed evidence of bucket tip rubs into the EBC abradable layer:

- The deepest tip rubs occurred in outer shroud blocks 16 and 17 at the turbine splitline. This was consistent with the observations of the metallic shrouds that were removed from the engine in that metal shrouds on outer shroud block 17 showed significant bucket tip rubs.

- The rubs were always deeper on trailing edge region of shrouds.

○ The deep rubs in outer shroud blocks 16 and 17 had $75+\%$ of the abradable peaks removed and had green/black deposits of EBC/bucket debris left in valleys between EBC ridges.

- The debris deposited on the shrouds looks very similar to that in seen rub rig testing of EBC-coated specimens with deep rubs.

- Many other shrouds had clean rubs into $10-50 \%$ of the depth of the abradable layer in the trailing edge region of shrouds, which was the desired effect of having the abradable layer. 
- There was substantial erosion of most BSAS-based EBC abradable ridges in the leading edge region of the shrouds with no evidence of tip contact.

- Some of the Gen1 EBC abradable layers seemed more prone to erosion than others.

- The Gen2 EBC abradable layers were much more resistant to erosion than Gen 1 abradable, at least after 35 hours of engine operation.

- Very little EBC spallation was noted:

- One very small EBC spall was seen on left edge of 1 shroud with a Gen2 EBC, which may be associated with erosion/impact of abradable ridge in that location.

- Small EBC spalls were believed to have been seen on the right edges of the leading edge flange radius on 4 to 5 shrouds with the baseline Gen 1 $\mathrm{EBC}$, apparently always in a similar location.

Figure 3-175 is a borescope photograph showing the "spatter" observed on the shrouds, nozzles and buckets. The dark speckles seen on the surface of all components were not expected; however, borescope inspections are not typically performed after only 38 hours of engine operation.

Figure 3-176 is a photograph of one of the shrouds that had a tip rub slightly into the abradable layer along the bucket trailing edge. This is the condition that was desired from the abradable EBCs. The tip rub into the abradable layer minimized the bucket tip clearance, but the rub was shallow enough that only the ridges of the abradable layer were affected and there was little evidence of bucket tip material loss.

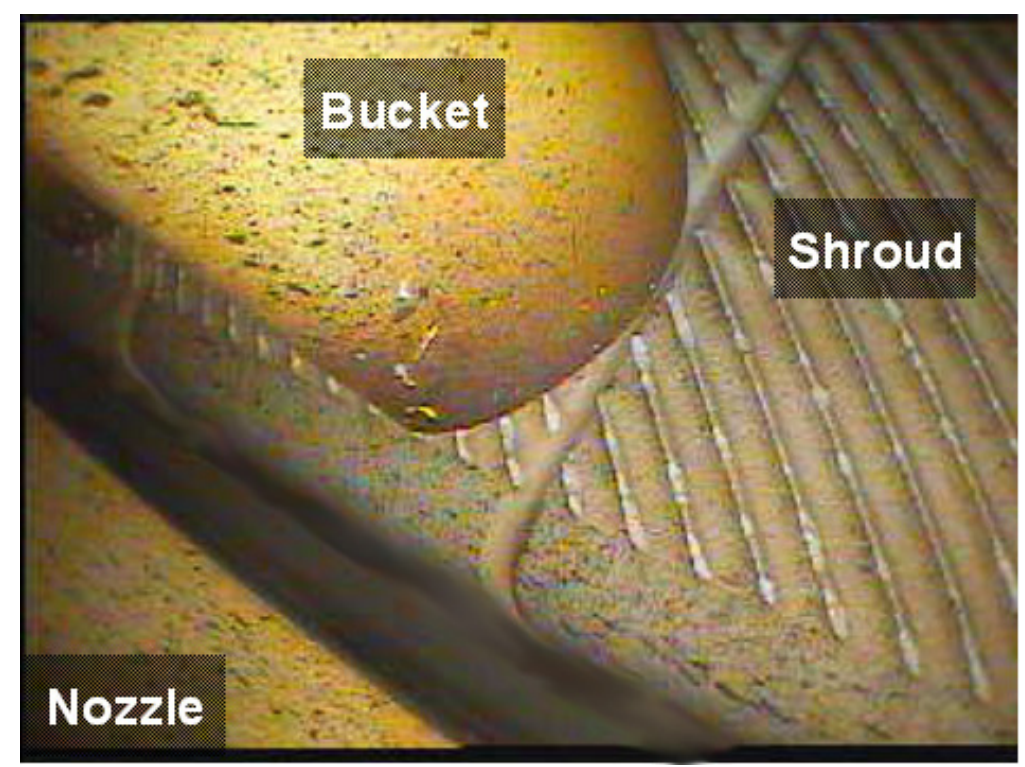

Figure 3-175. Borescope photograph showing the speckled appearance of the $1^{\text {st }}$ stage turbine hardware after 35 hours of engine operation. 


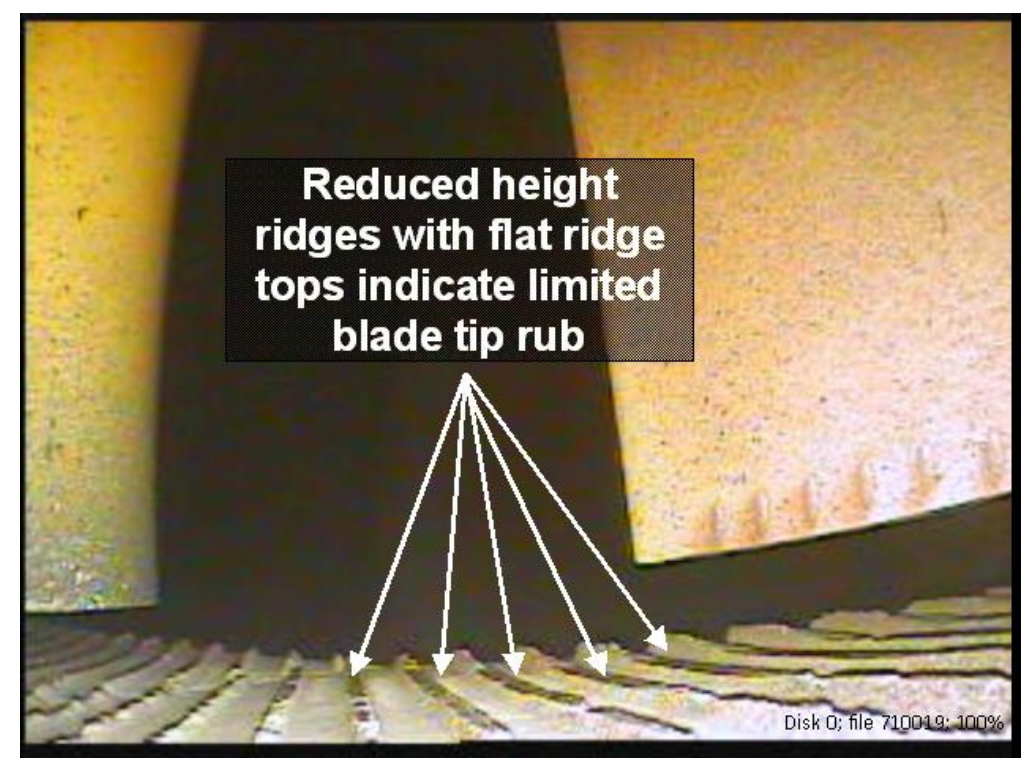

Figure 3-176. Borescope photograph showing a shallow bucket tip rub region where only the peaks of the abradable ridges have been contacted by the bucket tips.

As noted above, shrouds in outer shroud blocks 16 and 17, adjacent to the turbine split line, showed evidence of deeper, more severe bucket rubs. This situation was expected based on the observed bucket rubs into the metallic shroud that were removed from the engine in this region. Photographs of shrouds showing the most severe bucket tip rubs are given in Figure 3-177. In each case there was substantial smearing of EBC and bucket tip material (greenish-gray) on the surface of the EBC, filling in the valleys between the abradable ridges. This appearance was consistent with those seen during relatively deep rub events in the EBC rub rig tests where the bucket tips came into contact with the continuous EBC layer at the base of the abradable ridges. The occurrence of this smearing of the bucket and/or EBC material over the surface of the shrouds was typical only in regions where other evidence suggested that the bucket tips had rubbed completely through the abradable ridges and into the base EBC coating nearby. This smeared material was subsequently referred to at "blade material transfer" and was considered as a potential precursor to more extensive EBC damage. 

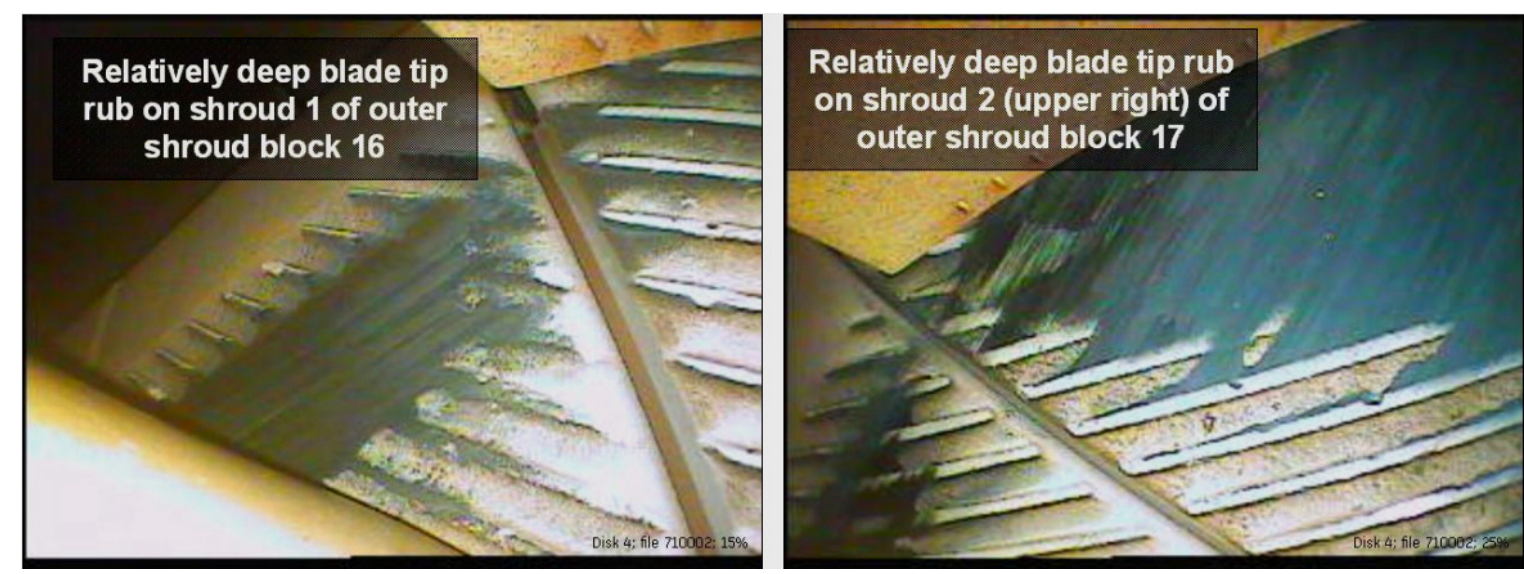

Figure 3-177. Borescope photographs showing relatively deep bucket tip rub events on shrouds from outer shroud blocks 16 and 17. The rub appears to have proceeded down through the abradable ridges to the main EBC coating. There does not appear to be any damage to the main EBC coating, but smearing of the bucket tip debris across the shrouds makes observation of the EBC very difficult.

In addition to the bucket tip rubs, the height of the abradable EBC ridges was also significantly reduced by what appears to be an erosive mechanism. The amount of erosion varied from region to region in the engine, and was typically more severe on the shroud leading edges than on the trailing edges. Another general observation was that shrouds with Gen2 EBC appeared to be more resistant to this erosion than shrouds with Gen1 EBC. The right photograph in Figure 3-178 shows this difference in abradable EBC ridge erosion for shrouds adjacent to each other.

No growth was noted in the EBC chips on shroud 25-03 caused during the re-machining operation on the outer shroud blocks. The EBC chip on shroud 17-03, which was caused during $2^{\text {nd }}$ stage nozzle insertion, was not directly observable during borescope inspection due to its location on the side of the rear flange. New EBC chips or spalls were observed on the leading edge flange bend or hot gas path edge regions of six shrouds, all of which were very minor in size and depth. (Note that the identification of EBC chips is rather subjective, and that based on the viewing angle and distance the quality of the view on many shrouds was not optimal. As such small EBC defects could have been missed, and determining the depth of any given EBC defect was problematic.) The worst of these possible spalls is shown in Figure 3-179. Spalls on the hot gas path faces of the shrouds, though not seen, would have been difficult to detect due to the irregular surface of the abradable layers and to physical interference of the buckets preventing a full view of the shroud surfaces. 

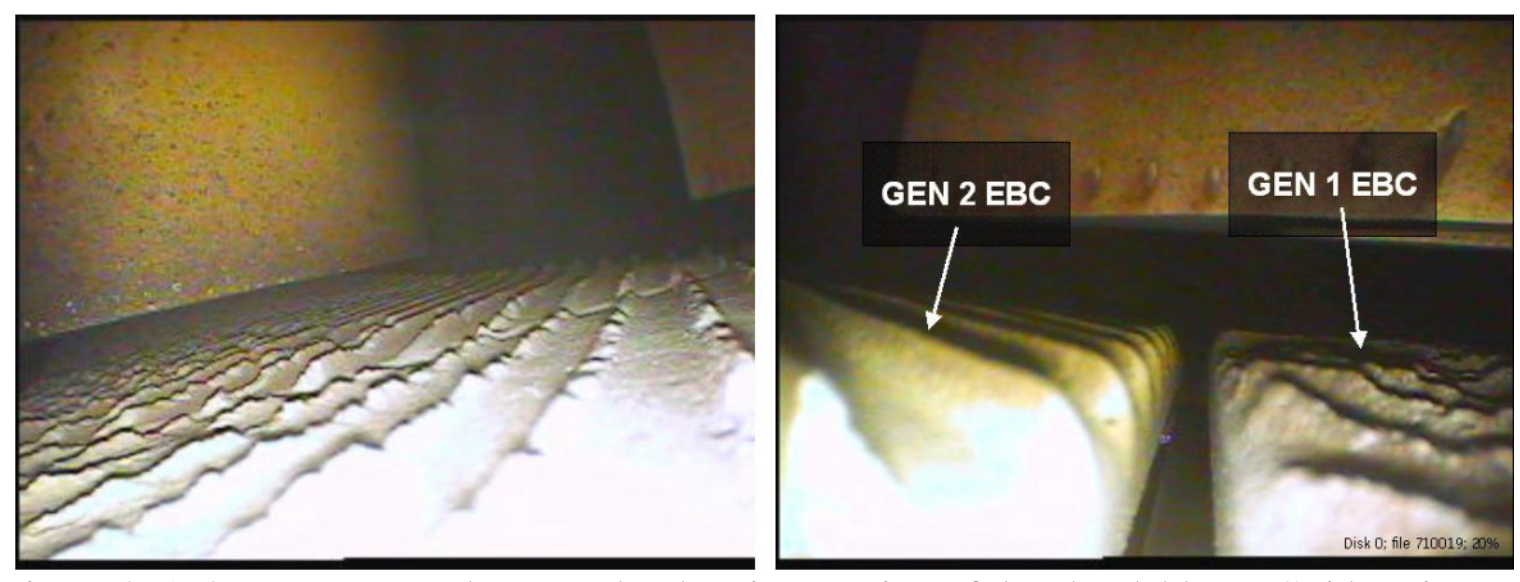

Figure 3-178. Borescope photographs showing erosion of the abradable EBC ridges in regions without bucket tip rubs. Erosion was typically limited to the ridges of the abradable EBC layer as there was no evidence of erosion of the primary EBC. The right photo shows a comparison of adjacent Gen2 and Gen1 EBC coatings, suggesting that the Gen2 EBC was more resistant to erosion.

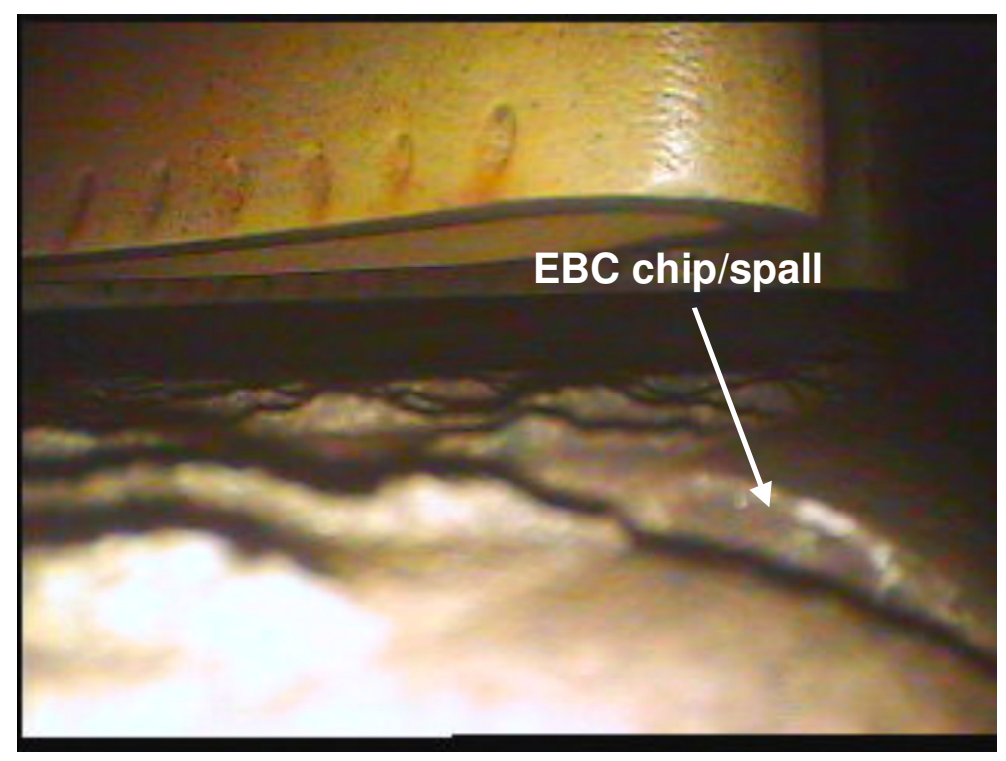

Figure 3-179. Evidence for a chip/spall in the EBC on shroud 20-02 near the forward flange bend on the left (upstream) edge.

\subsection{GE Borescope Inspection \#2}

The second borescope examination of the shrouds was performed on September 10, 2006. At that time the shrouds had seen 165 hours of engine running time. The overall appearance of the CMC shrouds was very similar to that seen during the first borescope inspection after only 38 hours of engine exposure. There was still no evidence of any structural damage to the CMC inner shrouds or of any degradation of the outer shroud 
block hardware and inner shroud attachments. Other specific observations of the CMC inner shrouds and EBC coatings from this inspection are summarized below:

- The occurrences of "clean" shallow rubs into the abradable EBC were more common and more uniform around the circumference of the engine. Whereas the rubs tended to be slightly deeper near the trailing edge of the buckets at the first inspection, the rubs now extend more toward the leading edge of the buckets as well.

- Deep rubs, where there was significant build-up of rub debris between the ridges of the abradable EBC, were still the most severe on outer shroud blocks 16 and 17 near the turbine split line. However, deep rubs were also noted on up to $25 \%$ of the shrouds, primarily toward the trailing edge, during the second inspection (see Figure 3-180).

- The substantial erosion of the EBC ridges seen in the $1^{\text {st }}$ borescope inspection was qualitatively unchanged at the $2^{\text {nd }}$ inspection, as shown in Figure 3-181. This observation suggested that the initial erosion was caused by "dirt" present in the engine after the service outage that then eroded the EBC during the initial engine start-up.

- There was no change in the appearance of the few, very minor EBC spalls noted in the $1^{\text {st }}$ inspection. The size and severity of the EBC spalls that occurred during shroud installation were also unchanged, as shown in Figure 3-182.

- Despite the clear evidence of bucket tip rubs there was no signs of extensive damage, or bulging or cracking of the bucket tip caps.

- There was no change in the appearance of small EBC chips/spalls near the leading edge bend area of a few shrouds. Three new such spalls were observed in locations that were not viewed during the 1 st borescope inspection. The newly observed spalls were likely present at the $1^{\text {st }}$ borescope. 


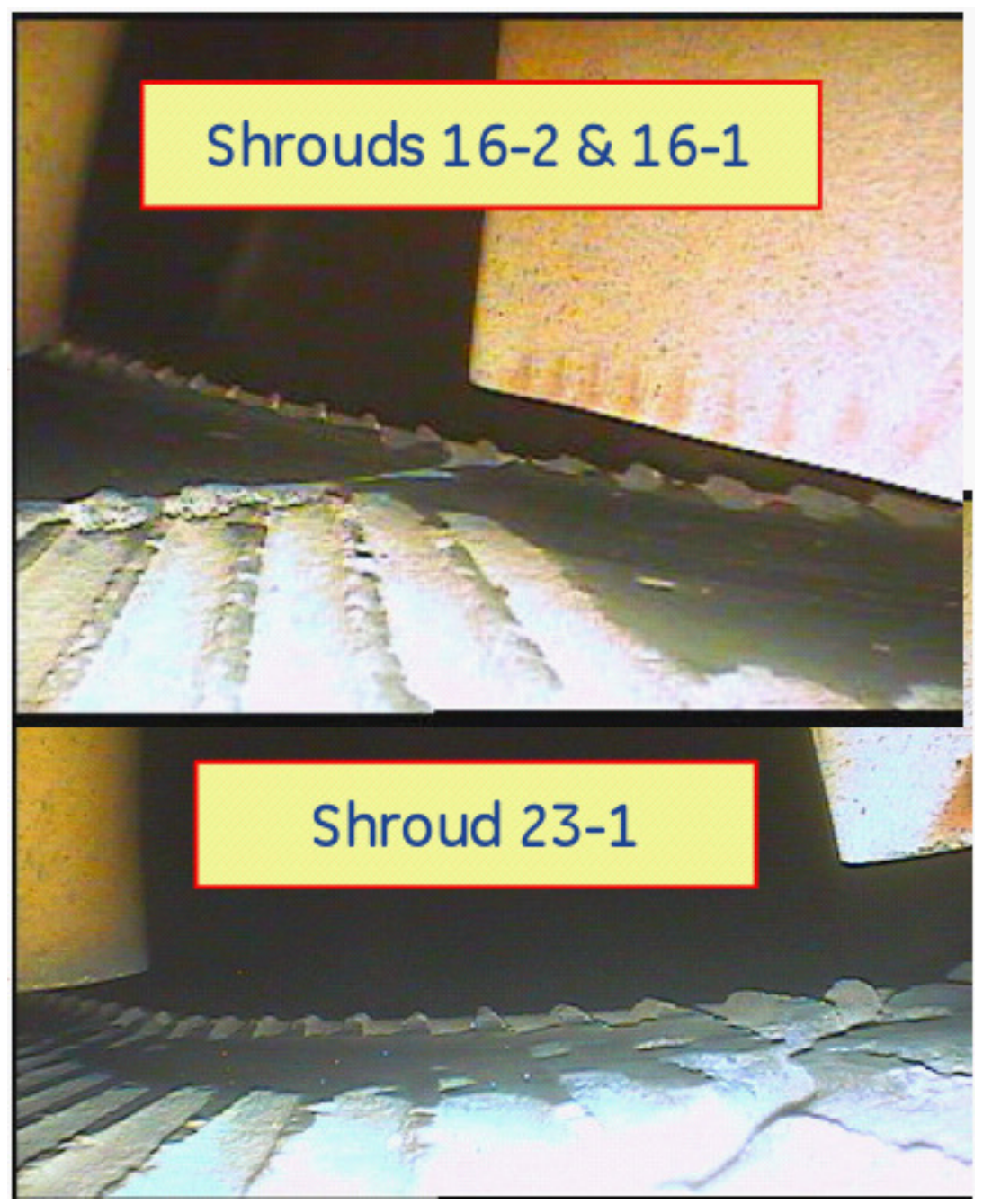

Figure 3-180. Borescope photographs of deep rubs into the abradable EBC taken during the $2^{\text {nd }}$ borescope inspection on September 10, 2006. The rub into the shrouds on outer shroud block 16 (top) was somewhat deeper than observed in the first borescope examination, and additional deep rubs on other shrouds, such as 23-01, were also noted. 


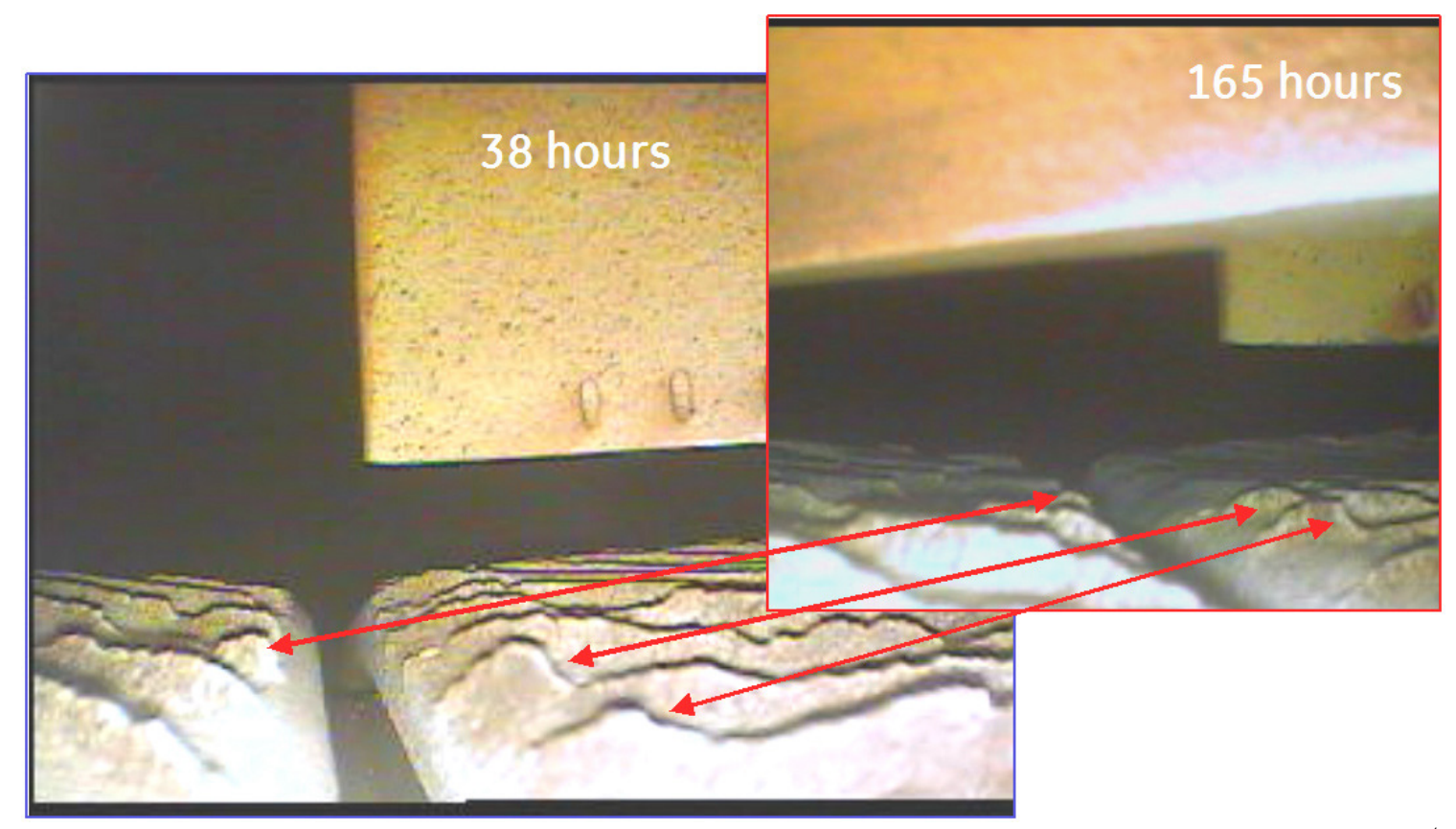

Figure 3-181. Borescope photographs of inner shrouds $24-1$ and $25-3$ taken during the $1^{\text {st }}$ (left) and $2^{\text {nd }}$ (right) borescope inspections. Note the similar features on the abradable EBC ridges at 165 hours exposure vs. that at 38 hours. Very little additional erosion of ridges was noted.

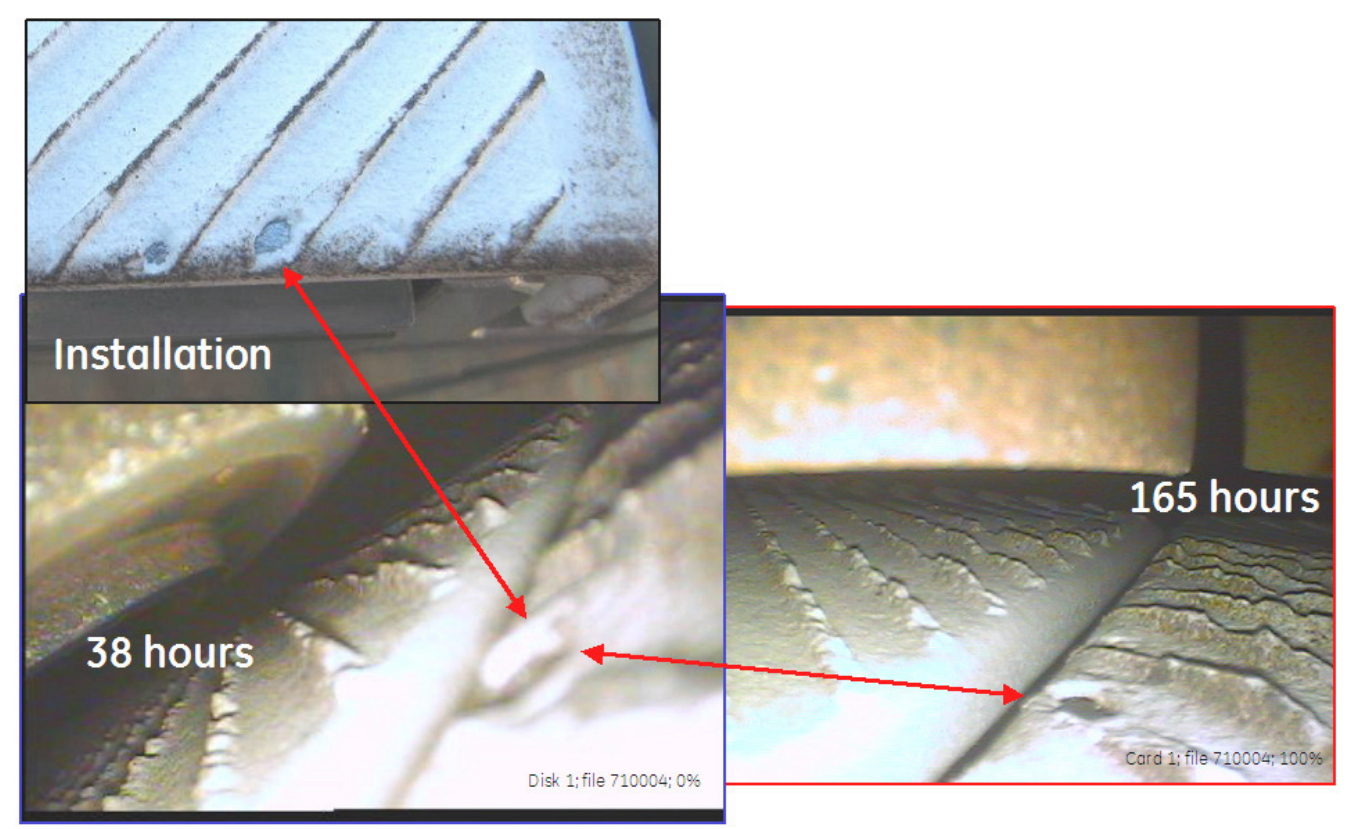

Figure 3-182. Photographs of the EBC chips on the edge of shroud 25-03 that was created during shroud installation (top left photograph). No obvious growth of the chips was noted at either 38 hours (lower left borescope photograph) or 165 hours (right borescope photograph). The similarity of the chips on EBC ridges from erosion suggests little additional erosion between the $1^{\text {st }}$ and $2^{\text {nd }}$ borescope inspections. 


\subsection{JEA Hot Gas Path Borescope Inspection}

Following the $2^{\text {nd }}$ borescope inspection September $2006 \mathrm{GE}$ began negotiating with JEA for the next inspection opportunity. However, since there had been little change in the conditions of the shrouds between the first two borescope inspections, and because the engine operator had not experienced any engine operation issues, there was not a strong emphasis at JEA for scheduling the next inspection.

Unknown to GE at the time, JEA had been performing abbreviated compressor, combustion system and hot gas path inspections on an irregular basis. One such JEA inspection of the engine hot gas path occurred on October 25, 2007. During this inspection several large EBC spalls were noted on the shrouds.

GE was informed about the results of this inspection and given access to the borescopic images in December of 2007. Although the JEA inspection was not intended to be a detailed examination of the shrouds, and thus the number of shroud images was limited and were most often shot from a distance where details were not easily discernible, at least four separate shrouds were seen to have anomalous appearances. Evaluation of the JEA images, and comparisons with images from the prior two borescope inspections, lead us to believe that three shrouds were displaying rather large EBC spalls on the hot gas path faces, and that at least one other shroud was showing evidence of fairly deep bucket tip rubs, having completely rubbed through the abradable ridges and penetrating into the base EBC coating. Several of the pertinent borescope images from this inspection are shown in Figure 3-183. These observations emphasized the need for a detailed shroud examination in order to more clearly understand the nature of the EBC damage, how prevalent the damage was, and if it represented a threat to the continued operation of the CMC shrouds.

\subsection{GE Borescope Inspection \#3}

Using the information gained from the JEA borescope inspection as leverage, the third shroud borescope inspection was scheduled in late 2007 and performed on March 22, 2008. The shrouds had accumulated 1122 hours of engine running time at that point, including $\sim 169$ start-stop cycles. The borescope operator, two turbine engineers from GE Energy, one engineer and two material experts from GRC were all present at the inspection, which lasted 10 hours. During that time they were able to inspect, at least in a cursory manner, 93 of the $96 \mathrm{CMC}$ inner shrouds.

Of the 93 shrouds inspected, 16 were found to have large ( $>1 / 2$ the hot gas path face area) EBC spalls on the hot gas path surface, 4 had smaller spalls on the hot gas path surface, and 5 had small EBC chips/spalls along a shroud edge. 

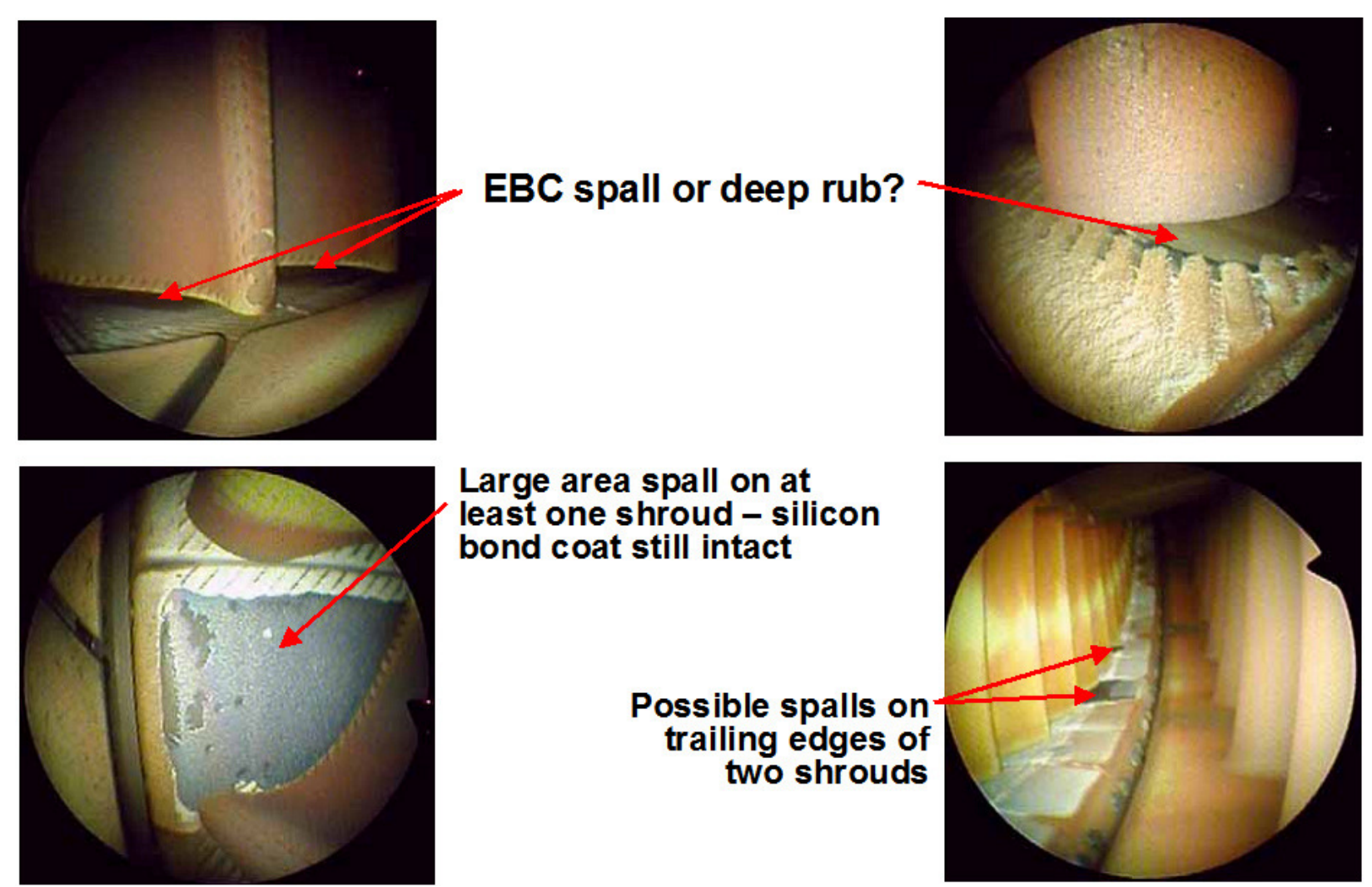

Figure 3-183. Select borescope pictures from the JEA hot gas path inspection performed in November, 2007. The shrouds indicated show evidence of large area EBC spalls and/or deep bucket tip rubs through the EBC abradable layers and into the base EBC.

Borescope photographs of several examples of large and small EBC spalls are shown in Figure 3-184. The large hot gas path spalls tended to occur along the center of the shrouds with the EBC remaining intact along the shroud edges, as shown in the upper left photograph in Figure 3-184.

Three of the shrouds that displayed the large center spalls had an early variant of the Gen2 EBC coating, which represented $100 \%$ of the shrouds with this type of EBC coating in the engine test. Cyclic steam furnace exposure testing of this variant of the Gen2 coating was started at about the same time as the shrouds went into service, and quickly displayed some unexpected behavior. The Gen2 coating system contains layer(s) of rare-earth silicate materials. The particular rare-earth silicate used in these specific Gen2 coatings has four stable or metastable polymorphs depending on temperature. The "C type" polymorph was the desired phase as it shows the best thermomechanical compatibility with the CMC substrates. During the EBC post-deposition heat treatment the desired polymorph, type C, crystallizes from the largely amorphous, as-deposited coating. The post-deposition heat treatment and subsequent steam oxidation testing that lead to the selection of this rare-earth silicate coating were all done above $1300^{\circ} \mathrm{C}$ with the expectation that if the system was stable at this higher temperature it would also be stable at the lower use temperature of the shrouds, around $1200^{\circ} \mathrm{C}$. However, Gen2 EBC samples subjected to cyclic steam furnace 
testing at $1200^{\circ} \mathrm{C}$ soon showed conversion of the $\mathrm{C}$ type polymorph to the $\mathrm{D}$ type. This structure change is accompanied by a large amount of grain growth, and the thermal expansion anisotropy of the large grained D polymorph leads to cracking of the EBC and eventual EBC spallation. It was therefore anticipated that the shrouds with this variant of the Gen2 EBC coating would show similar behavior in the engine, leading to eventual spallation of the coating from the conversion of the rare-earth silicate layer to the coarsegrained type D polymorph. The borescope observations were consistent with this expectation in that all three of the Gen2 EBC coated shrouds showed complete edge-toedge spallation of the EBC, and these were the only shrouds that displayed this complete spallation across the entire hot gas path face. Subsequent to the steam furnace observations the composition of the Gen2 EBC was adjusted so that transition to the type D polymorph was eliminated, and stability of the newer variant of Gen 2 coating was validated with cyclic steam furnace testing at $1200^{\circ} \mathrm{C}$.
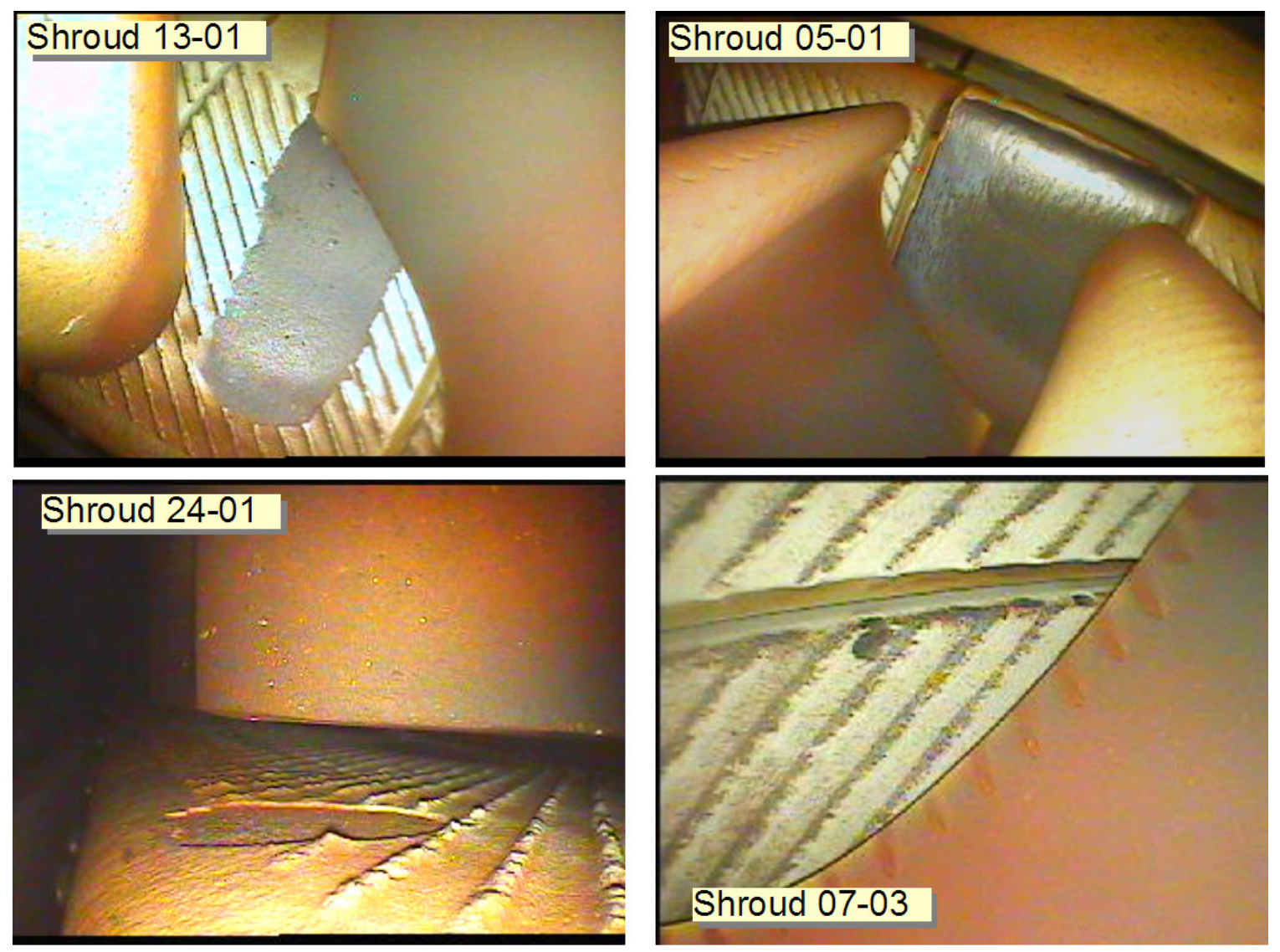

Figure 3-184. Borescope photographs of several examples of EBC spalls:

Upper Left - large hot gas path spall along center of shroud

Upper Right - complete edge-to-edge spall of one of the shrouds with a Gen2 EBC coating variant

Lower Left - smaller hot gas path spall near the center leading edge of a shroud

Lower Right - small edge spalls 
The causes of the other large hot gas path spalls were unclear at the time of inspection. The EBC tended to spall along the center of the hot gas path face and yet remained intact along the two edges. This observation would tend to suggest that the spalls were related to bucket passing, since the bucket tip clearance was smaller at the center of the shrouds than at the edges, by $0.6 \mathrm{~mm}$, due to the shrouds being flat. However, most of the large center spalls tended to occur on the right side of the engine near the split line, which was the section of the $1^{\text {st }}$ stage with the largest clearance between shrouds and buckets (based on rub observations of the metallic shrouds that were removed from the engine and from borescope evidence of limited bucket rubs into the abradable EBC on the right side of the engine).

The smaller spalls seen in the lower photos of Figure 3-184 were more consistent with EBC damage seen in the previous shroud rainbow test. The edge spall shown in Figure 3-184 actually started as EBC chipping that occurred during shroud handling during the engine assembly process. Through the 1122 hours of engine exposure the three EBC chips had been relatively stable. The two smallest chips appear to have connected in the axial direction, but none of the chips appears to have grown laterally across the shroud face.

Other edge spalls were mostly located in the forward bend region of the shroud along the upstream edge. None of the thermomechanical models of the shrouds incorporated tangential variations in the hot gas path thermal boundary conditions applied to the shrouds, so it was unclear whether there could be any unusual thermal conditions in this region of the shroud that could contribute to the spalls. It was possible that these edge spalls originated simply from FOD impacts since they preferentially occurred on the upstream corner of the shroud relative to the combustion gas flow direction. It was also speculated at the time that the small flange edge spalls were somehow related to the flange bend delaminations present in many of the shrouds used for this test, but no correlations could be found between these spalls and the presence of flange delaminations seen in the NDE images of the shrouds before the engine test.

In addition to the EBC spalls, there was a substantial growth in the number of shrouds having deep rubs. The bucket tip rubs were still concentrated at the left side of the engine near the casing split line, around outer shroud blocks 16 and 17; however, now the region showing deep rubs with blade material transfer extended from the middle of shroud block 15 down to as far as shroud block 23. Within this group with deep rubs, there were numerous shrouds where the depth of rub appeared to have penetrated as deep as the EBC bond coat or actual CMC.

A "Root Cause Analysis", or RCA, was initiated to investigate the conditions of occurrence of EBC spallation seen in the borescope inspection, to postulate spallation mechanisms that could explain the observations, and to devise strategies for fixing the EBC spallation problem. The details of the RCA are described in Section 3.1.23.6. 
Despite the presence of the EBC spalls and the deep rubs, the safety and performance of the gas turbine was not at risk. CMC volatilization rate estimates for shrouds were on the order of $0.5 \mathrm{~mm} / 1000$ hours. Given the limited running time and high number of cycles that this engine was accumulating, it was estimated that there would be no more than an additional 2000 hours of operation before the cycle limit for a hot gas path overhaul was reached. Therefore no more than 1 to $1.5 \mathrm{~mm}$ of $\mathrm{CMC}$ surface recession was expected, which was not enough to cause shroud failure.

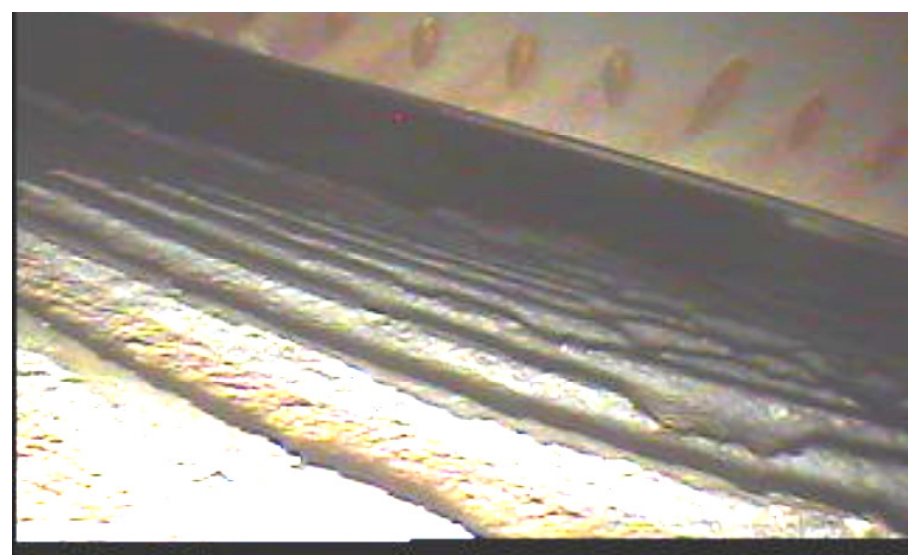

Example of a normal abradable EBC rub where the tops of the ridges have been rubbed smooth but the ridge structure is intact. Gouges in the ridges are thought to have been caused by debris present in the engine during initial start-up.

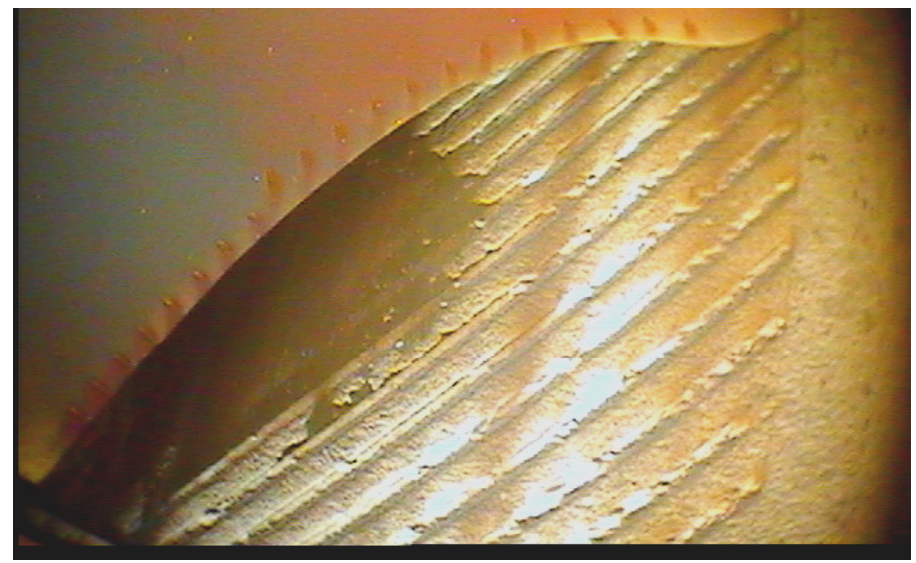

Example of a "deep" rub where the abradable ridges have been worn through or the gaps between them filled with rub debris.

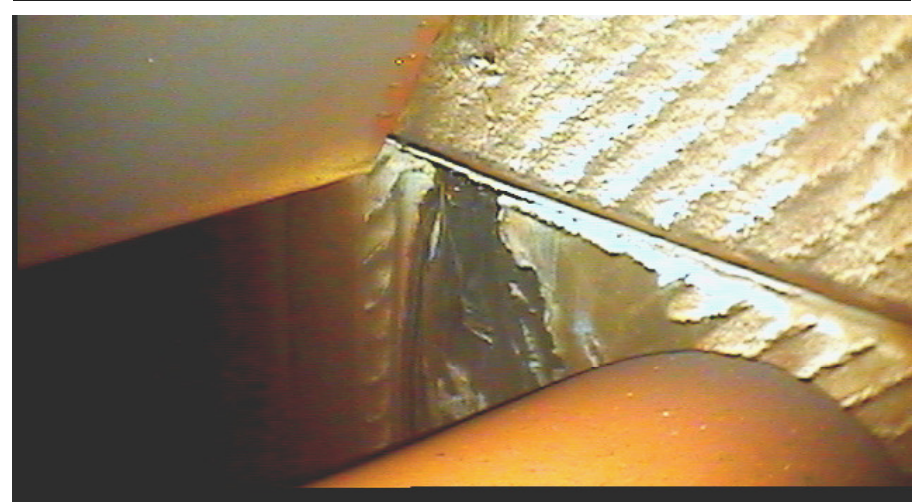

Example of a "very deep" rub where the rub appears to have penetrated the full EBC leading to exposure of the bond coat and/or CMC shroud.

Figure 3-185. Several examples of the variations in bucket tip rubs on the shrouds that were observed during the March 2008 borescope inspection. 


\subsection{GE Borescope Inspection \#4}

A fourth borescope inspection of the JEA engine shrouds was conducted on December 11, 2008, at which point the shrouds had seen 1206 operating hours and 214 cycles. Two persons from GE GRC and two from GE Energy were present for the inspection. The primary goal of this inspection was to further quantify the occurrence of EBC spall events, as had been observed during the third borescope inspection and to look for evidence of new spalls or growth of older spalls. New spalls were of particular interest in that continued occurrence of additional hot gas path spalls would indicate an ongoing coating degradation process that could eventually affect all shrouds. The lack of new spalls would tend to suggest that the ones observed to date may have occurred due to a special cause, such as an unusual operating condition in the engine, and that the unspalled coatings could be expected to remain intact, barring the re-occurrence of the special event. Understanding the time progression of the spall events could also help in identification of the spallation mechanism, and in the eventual development of a solution. However, in the nine months since the previous borescope inspection the engine had been run only an additional 150 hours, which included 45 start-stop cycles.

The main observations from GE borescope inspection \#4 could be summarized as follows:

- A much higher resolution borescope was used than for previous inspections, so additional shroud and EBC details were observable.

- There was much better access to the shroud trailing edge regions and very good access to the leading edges. Consequently some "new" EBC features seen in this inspection may not have really been new but were just missed in previous inspections.

- Massive FOD and spatter of foreign material onto the shrouds, buckets and nozzles had occurred since the previous borescope inspection. Markings on the components were similar to, but more severe than, those seen at the $1^{\text {st }}$ inspection in May 2006.

- There were many new and somewhat larger spalls on the right edges of the leading flanges, which were likely caused by FOD. There were many new spalls in the bucket TBC coatings associated with the spatter, and one bucket with an actual dent, both of which supported the probability of new FOD events.

- There were a few new small spalls that looked like traumatic FOD damage with crushed coating and irregular edges; i.e. they did not have the appearance of conventional coating spalls. An example of such a spall is shown in Figure 3-186.

- There were no new large center spalls. Most of the center spalls were enlarged slightly by nibbling along the spall edges. A few of the prior large center spalls had large extensions, mostly from the trailing edge towards the leading edge. A few of the center spalls had extended laterally to a shroud edge (primarily the left edge). There was one new center spall, on the leading edge region only of a shroud that was not well investigated during the previous borescope inspection, and thus the spall may have been there previously and just not been seen.

- Many new trailing edge flange spalls were seen on the right edge near the bolt attachment, one of which is shown in Figure 3-186. They looked like fresh spalls, but many were in regions not seen well in the previous inspections and thus may have been missed. 
- A crack was seen in the leading edge of one of the metallic Outer Shroud Blocks (OSB). The crack was at a leading edge pin and probably connected the pin hole with the hot gas path edge of the OSB.

- The size and location of the region that showed distinct bucket tip rubbing onto the shrouds, with concurrent transfer of bucket material onto the EBC and shroud surfaces, was virtually identical to that observed in the previous inspection, suggesting that no deeper rub events had occurred since then.

- The higher resolution of the new borescope instrument clearly showed some very deep rubs that expose multiple fiber plies in the shrouds in the region of OSBs 1820. This observation indicated a total rub depth of over $2.5 \mathrm{~mm}(1.42 \mathrm{~mm}$ abradable $+0.43 \mathrm{~mm}$ EBC $+0.15 \mathrm{~mm}$ matrix surface layer $+0.51 \mathrm{~mm}$ of fiber plies $=2.51 \mathrm{~mm}$ total depth), which was much larger than anticipated or than was designed for.

- The six shrouds with the thinner diamond-patterned EBC continued to be free of any visible problems.

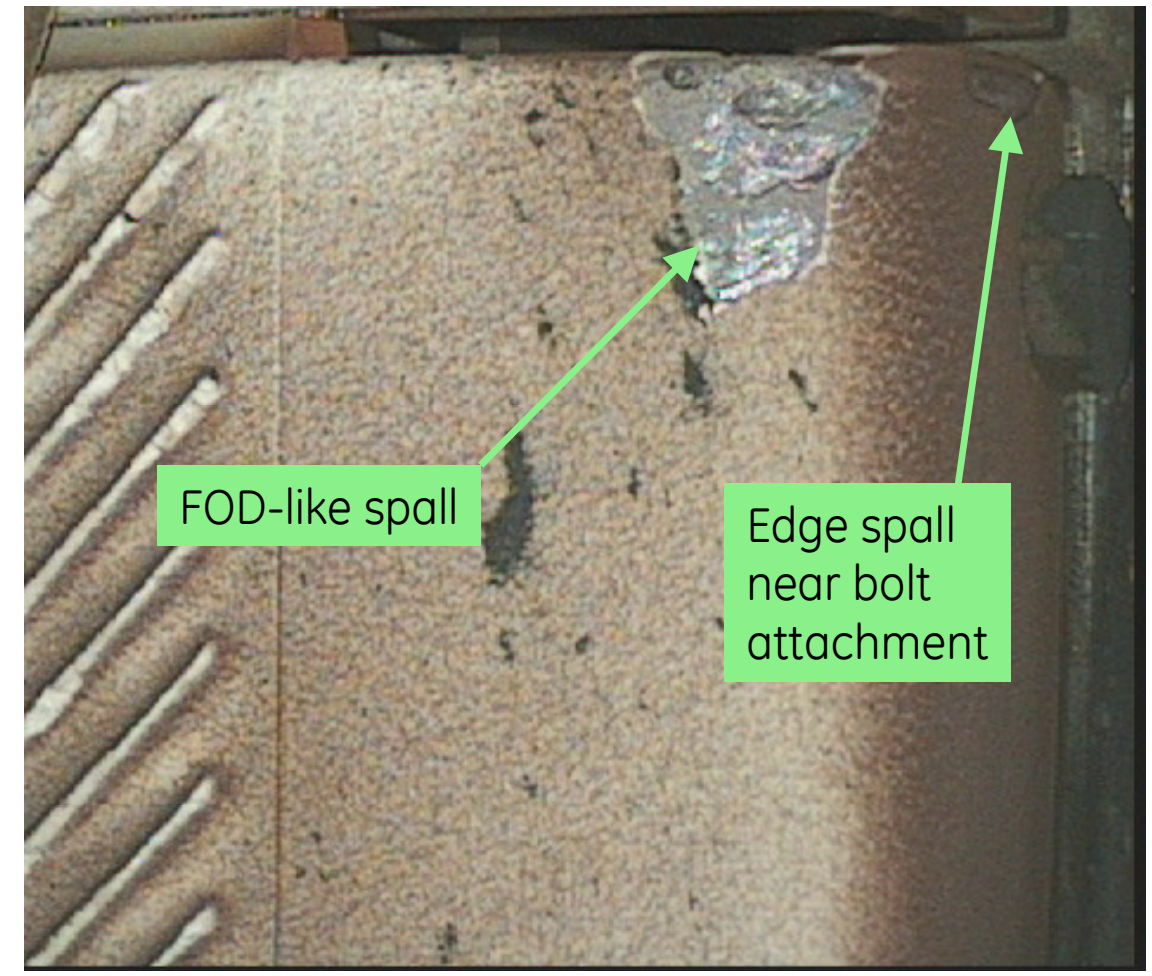

Figure 3-186. Photograph from borescope inspection \#4 showing the aft edge of a shroud having both a FOD-like spall just before the bend to the aft flange bend, and a nearedge spall on the aft flange close to the attachment bolt location.

Although borescope inspection access to all of the shrouds in the arc from 9 o'clock to 12 o'clock was somewhat limited, the final count of EBC damage was as follows:

- 3 shrouds, coated with an early version of the Gen2 EBC, with loss of EBC over the full hot gas path surface 
- 21 shrouds with large center spalls, including center spalls on leading and trailing edges

- 9 shrouds with center spalls within the region of bucket material transfer

- 23 shrouds with smaller edge spalls

- 40 shrouds with no observed EBC loss

The above list accounts for all 96 inner shrouds in the engine with each classified by the most severe damage noted. In reality 22 of the shrouds showed multiple types of damage, such that the occurrence of the smaller edge spalls was actually greater than indicated by the above list. Sixteen of the shrouds with large center spall or spalls in the bucket material transfer region also had additional smaller edge spalls, and six of the shrouds with smaller edge spalls only had multiple types of those spalls.

Numerous shrouds showed edge spalls, mostly on the forward flange bend at the upstream corner relative to the gas flow but also occasionally on the shroud hot gas path edges (again typically on the upstream side and even rarely on the aft flange edge). These spalls were not necessarily attributable to EBC defects, but may have been due to continuing small FOD events. There was quite ample evidence of repeated FOD events within this engine as there were numerous chips and spalls in the TBC coatings of the $1^{\text {st }}$ stage nozzles and buckets. One bucket was even observed to have a dent from a FOD event. There was also a significant amount of "dirt" spattered over the forward flange bends of the shrouds, as shown in the borescope photographs in Figure 3-187. The white spots on the leading edges suggest that the accumulated deposits were either flaking off or, more likely, were being chipped off by small FOD events. The spall at the upstream corner of the shroud in the left photograph in Figure 3-187 was the largest of the all the edge spalls observed and bore markings very suggestive of multiple FOD events.

Even if they were not caused by FOD, these edge spalls were not considered particularly threatening to the shrouds unless they started propagating across the hot gas path face. The leading edge was partially shielded from the combustion gases by cooling leakage from the $1^{\text {st }}$ stage nozzles so CMC recession in this region would be somewhat reduced. Furthermore, pre-existing edge spalls that occurred during engine assembly on shrouds 25-3 and 17-3 had not propagated appreciably.

Of the EBC damage observed, the large, center hot gas path spalls were the most disconcerting. These spalls were typically characterized as a loss of EBC over an area roughly greater than the size of a quarter near the center of the shroud. The spalls when initially observed were only in the center region of the shrouds and did not reach to the edges; however, as exposure had progressed several of the large spalls grew laterally outward and had reached to the edge of the shrouds. Spreading of the spalled regions forward and aft in the turbine axial direction was also occasionally noted. 

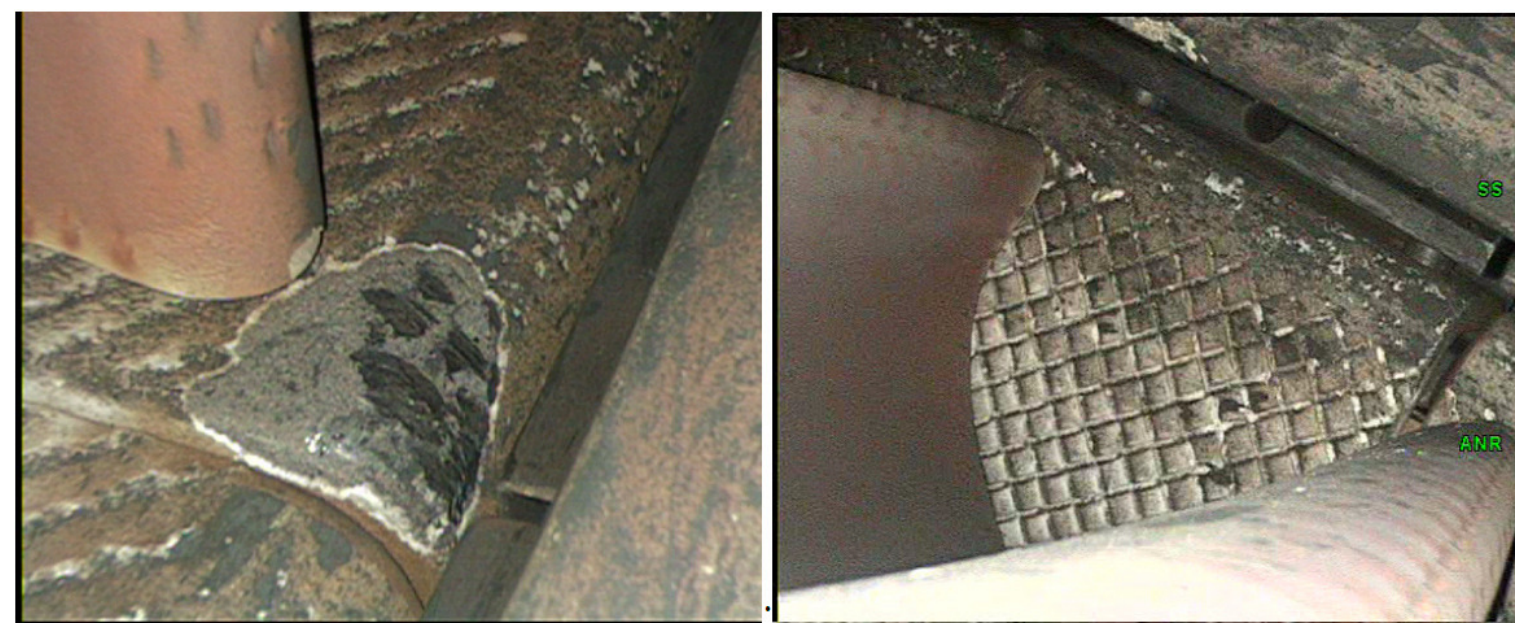

Figure 3-187. Photographs taken from borescope inspection \#4 of shrouds showing evidence of leading edge FOD events. Left - an EBC spall with evidence of FOD penetrating into the EBC bond coat and possibly the CMC; Right - leading edge bend of a shroud showing dark spatter and flecks of white indicating fresh chips in the EBC surface.

There were two sub-types of the large center spalls; those that occurred on shrouds with no or only light bucket tip rubs and those that occurred on shrouds with deep tip rubs. Deep rubs were universally accompanied by material having been smeared across the rubbed surface. Similar material smearing had been noted in laboratory bucket rub tests, and it consisted primarily of oxidized metal that had been rubbed off the bucket tips mixed with debris from the neighboring EBC coating. Borescope images of examples of each type of large center spall are shown in Figure 3-188. Lateral growth of the spalls with time, as described above, had not been noticed to the same degree in shrouds with deep rubs as it had been in shrouds with shallow or no rubs.

While spallation of EBC from the shrouds with shallow or no tip rubs suggested to probable defects in the EBC, the situation for center spalls in the shrouds with deep rubs was not as clear. The material being smeared onto the shrouds from the bucket tips and its oxidation products had the potential to react with the EBC coating. At the very least, the thermal expansion of this material was almost certainly much higher than that of the EBC, and, depending on how strongly bonded it was to the EBC, it could have lead to significant thermal stresses during the numerous thermal cycles that this engine had experienced. 

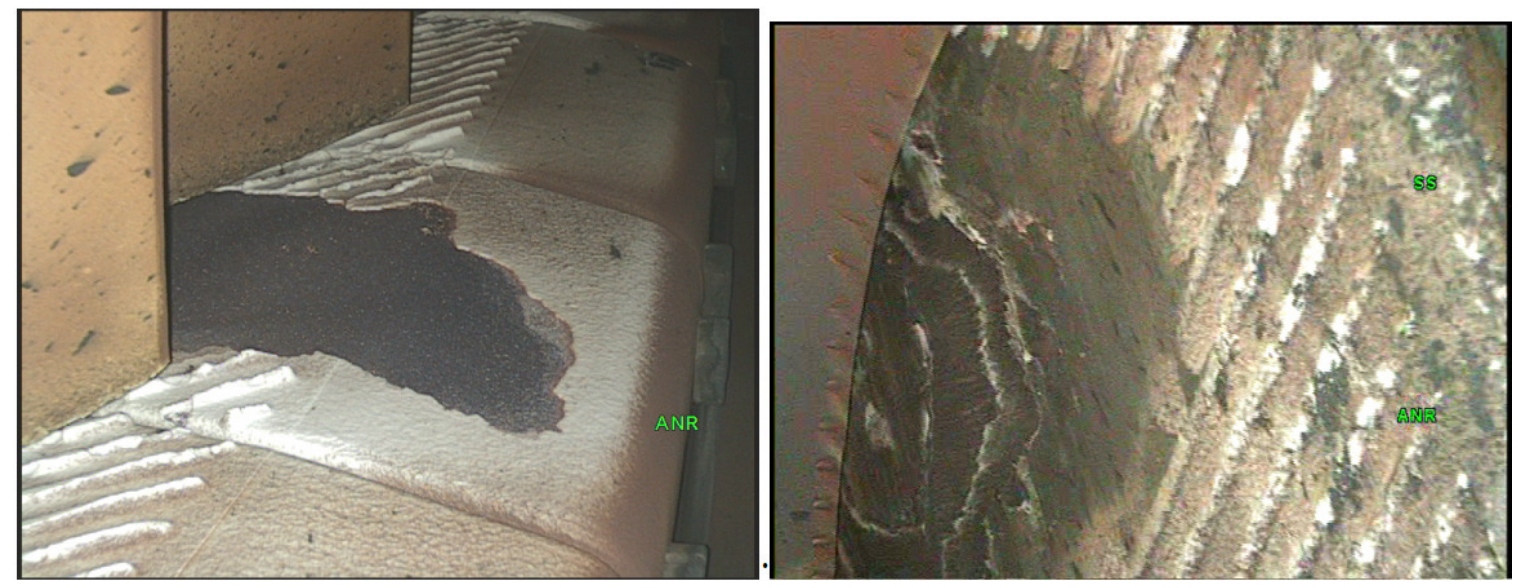

Figure 3-188. Photographs from borescope inspection \#4. Left - close up of large center spall on a shroud with limited, if any, bucket tip rubbing. Right - spall in the center of a deep rub surrounded by a region of bucket material transfer.

\subsection{GE Borescope Inspection \#5}

A fifth borescope inspection was performed on June 6, 2009. At that time the CMC shrouds had accumulated 1351 hours of engine operation, or 145 additional hours since the previous borescope inspection. The main purpose of the inspection was to examine the CMC shrouds for evidence of additional EBC coating spallation or damage.

The general observations from GE borescope \#5 were as follows:

- Only one additional large center spall was found since the previous inspection

- The extent of bucket tip rubbing looked similar to that seen in the previous inspection

- There was only moderate amounts of spotting on the surrounding hardware, suggesting that there were minimal small body FOD impacts since the last inspection

- There were only very moderate increases in spalls in the "bucket material transfer" (BMT) region, and in the number of leading and trailing edge flange spalls

- There was a substantial increase in the number of shroud edge spalls

- A crack-like feature was observed on two of the shrouds that had previously shown large EBC spalls

A new, potentially critical, observation made during this inspection was the possible cracking of at least two shrouds. Crack-like features were found in the spall region of two shrouds while reviewing the borescope videos several weeks after the inspection. Two still images from the borescope video showing the most distinct of the crack-like features are shown in Figure 3-189. In these photos the crack appears to have originated at the left edge of the shroud and progressed across the hot gas path face. Part of the crack is hidden under the bucket, but it extends nearly the entire width of the shroud, bifurcating as it approaches the right edge. The other crack-like feature is shown in Figure 3-190.

There are similarities between the two crack-like features seen in borescope \#5. Both shrouds showed spallation of the oxide top layers of the EBC coating (white in the photos) 
leaving behind the silicon bond coat (the lighter gray areas on the shroud surface). To the lower left side in Figure 3-189, and above the crack-like feature in Figure 3-190, the surface of the shrouds was a darker gray, which was interpreted as being regions where the silicon bond coat had recessed away exposing the $\mathrm{SiC}$ surface of the shrouds. In both instances the crack-like features were in regions where the bond coat was still intact.

Upon finding these features the records from the $4^{\text {th }}$ borescope inspection were re-examined to see if there was any evidence of these features having been present earlier. Surface features that mimicked the crack-like features were found in the photographs from borescope inspection \#4, which then called into question whether these features were really cracks.

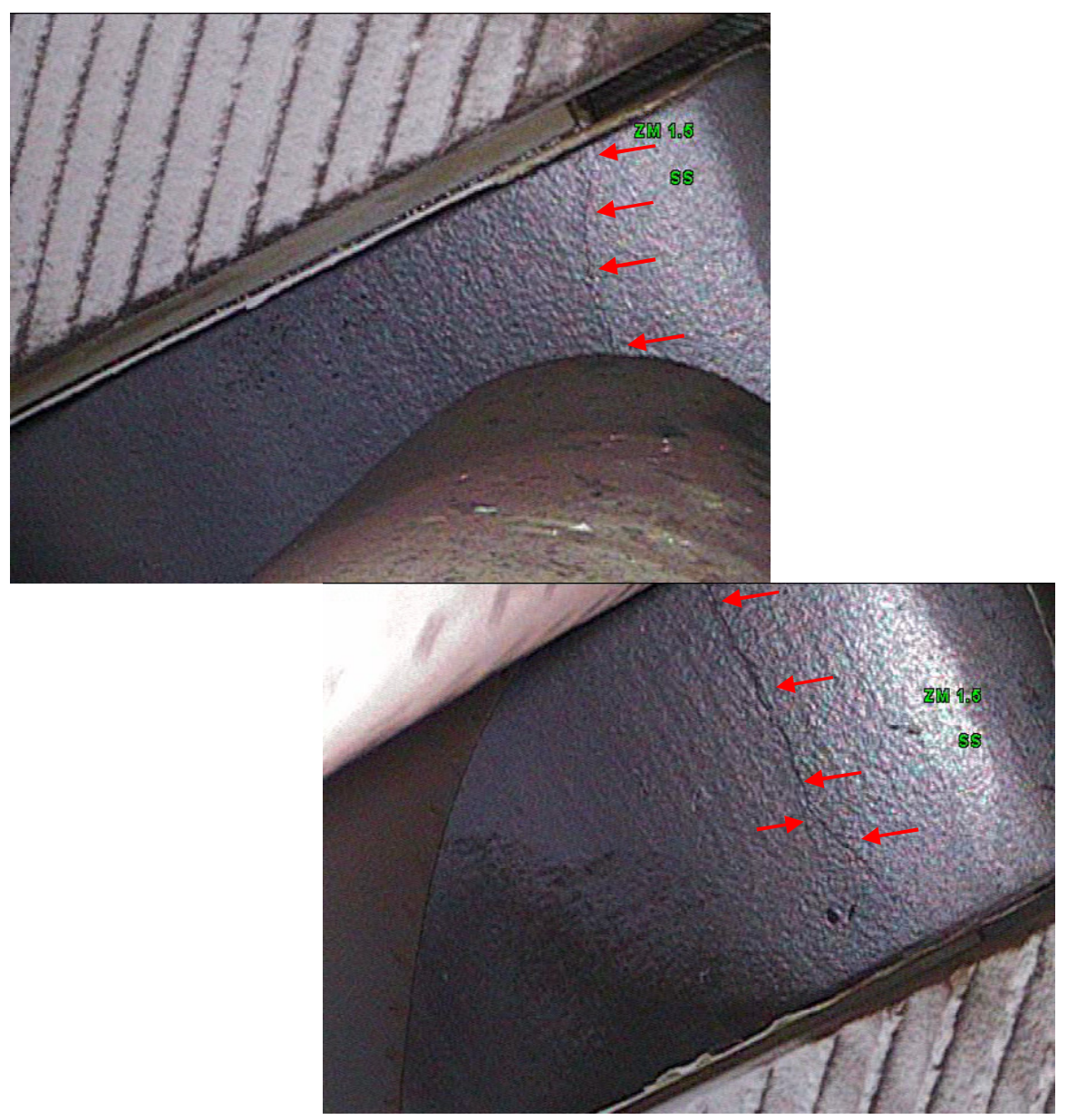

Figure 3-189. Borescope images of a crack-like feature found on shroud 4-1 during borescope inspection \#5. The arrows show the location of the feature. 


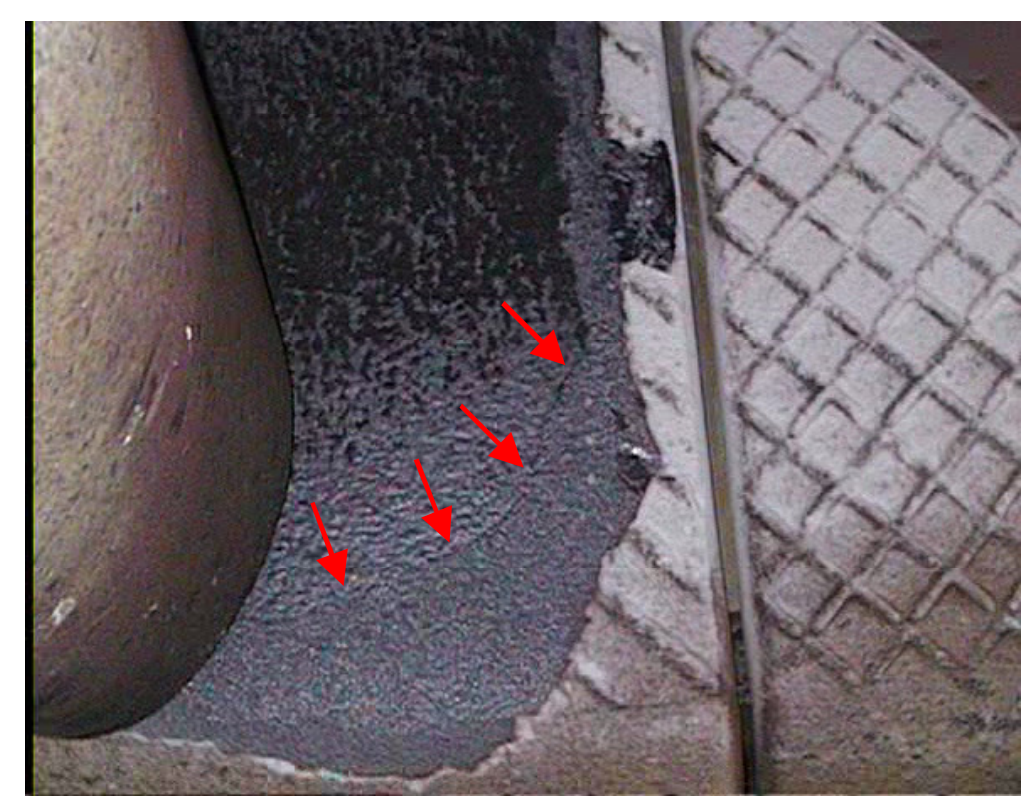

Figure 3-190. Borescope image of shroud 3-2 taken during borescope inspection \#5 showing a crack-like feature on the shroud similar to that shown in Figure 3-189.

Images from these same two shrouds taken during borescope inspection \#4 are shown in Figure 3-191, though in somewhat different orientations. The interpretation of the images in Figure 3-191 was that there was full EBC coating still present along the leading ends of the shrouds (upper edges in the photos). Just below are light gray regions where some EBC oxide was still adhering to the shroud, and then just below that were regions that were slightly darker, which correspond to the silicon bond coat being exposed. Going still lower the bond coat was thinning out, gradually transitioning to the spotted appearance where islands of the shroud surface were starting to show through (this was most visible on the top). The important feature of these images was that the demarcation line between the region that still had oxide and that with the silicon bond coat exposed corresponded quite closely to the position and shape of the crack-like features in Figure 3-189 and Figure 3190.

These observations from borescope \#4 suggested two possible explanations for the cracklike features. The first hypothesis was that there really were cracks in the CMC and that the edges of the EBC spalls simply terminated at these cracks. This hypothesis, however, did not explain why the spall should continue to propagate across the CMC crack.

The second hypothesis was that the EBC spalls tended to grow in a discontinuous, stepwise fashion, arresting at positions for a finite time between propagating events. This scenario also assumed that the main spall occurred between the bond coat and oxide transition layer of the EBC. In this case the silicon bond coat exposed after one expansion of the spall would recess while the adjacent bond coat still covered with oxide would not. At the next event that caused the spall to propagate new bond coat would be exposed, but because this layer had not yet recessed there would be a step in the height between the old 
and newly-spalled regions. When viewed with oblique lighting these steps in surface height appeared to be cracks. Unfortunately, the resolution of the borescope videos was not sufficient to distinguish between these two hypotheses.
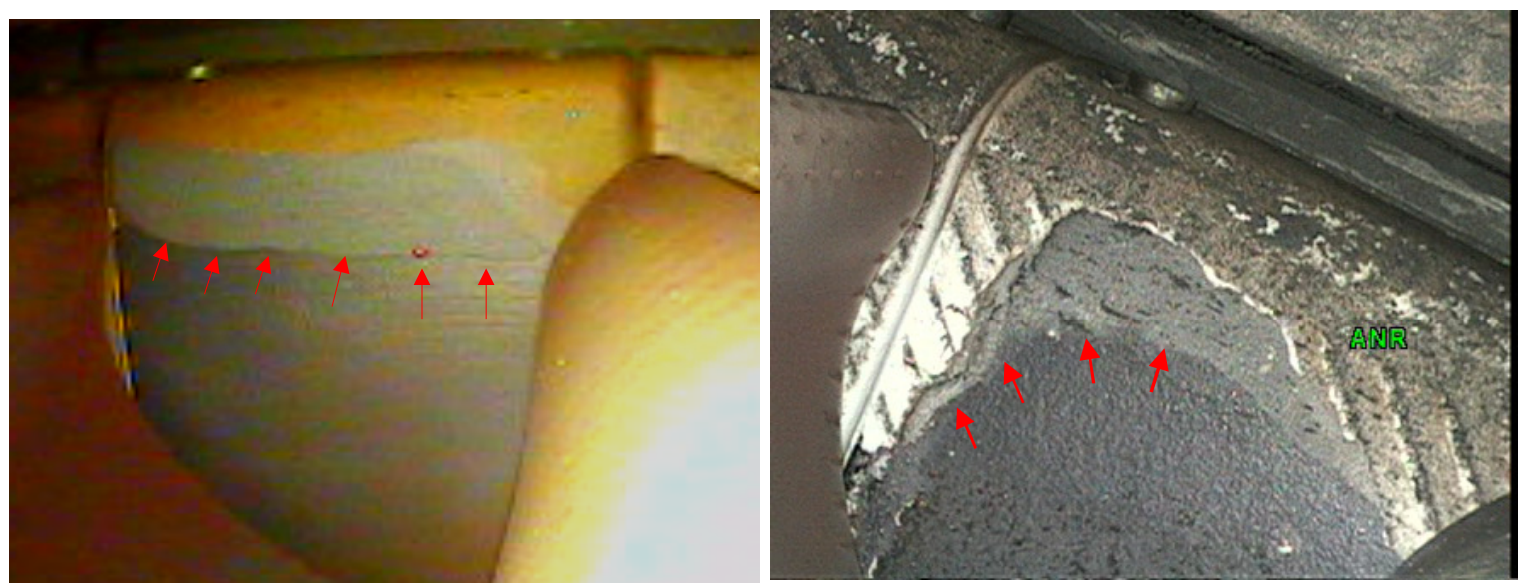

Figure 3-191. Borescope images from borescope inspection \#4 showing the same shrouds in Figure 3-189 (left) and Figure 3-190 (right). The edge of the EBC oxide transition layer is marked in each photo.

\subsection{GE Borescope Inspection \#6}

The sixth GE borescope inspection of the CMC shrouds at JEA was done on July 17, 2010, at which time the shrouds had been run for 1537 hours and 476 cycles. This represented over a one year interval since the last inspection. Since that previous inspection the shrouds had accumulated an additional 186 running hours and 70 start-stop cycles. The two main areas of interest for this inspection were to further document the occurrence and/or growth of EBC spalls on the shrouds, and to examine in detail the crack-like features seen on two of the shrouds during the $5^{\text {th }}$ borescope inspection.

As the engine test had progressed, and as the borescope technique had been refined and equipment upgraded, the quality of the borescope inspections improved. During the earliest borescope inspections not all of the shrouds were fully visible, particularly for shrouds in the upper left quadrant of the engine when viewed from a forward-looking-aft perspective, so that it was possible that the EBC defects were undercounted in the $1^{\text {st }} 3$ borescope sessions. In the $6^{\text {th }}$ inspection every CMC inner shroud was viewed so that a full accounting of the EBC spalls had been made.

Several important observations were made during this borescope inspection, which are summarized below:

- Four new HGP center spalls were observed, 2 of which were on shrouds with 30 mil diamond patterned abradable EBC layers. This was the first observation of center spalls on shrouds with the diamond abradable pattern, of which only 6 shrouds in the full set of 96 in this test had this pattern. 
- Fourteen new spalls were observed at the leading edge flange bend radius. These spalls were believed to be caused by FOD impact events.

- Ten new edge spalls were observed, mostly on the upstream edge of the shrouds. These spalls may have been due to microstructural errors created by masking seems from the plasma spray deposition process. Such seems (i.e. gaps or overlays of the EBC coating layers) had been seen in metallographic examination of quality control shrouds that were coated at the same time and by the same process as the shrouds in the JEA test.

- The large number of new edge and flange spalls observed was due in part to improved borescope equipment and technique, that resulted in improved resolution, and to access to virtually the full shroud set.

- Many pre-existing spalls had been observed to grow since the last borescope. Growth appeared to be stepwise, meaning that the edge of a defect would be stable over one or more borescope intervals but would then propagate over the next interval, occasionally leaving behind some observable feature at the previous spall edge location.

- The possible CMC crack observed during borescope inspection \#5 was viewed with a high magnification borescope tip. This closer examination revealed that the feature was merely a step in the height of the exposed SiC. The step was likely created early in the engine testing when large center spalls occurred. During additional engine operation, some of the exposed $\mathrm{Si}$ bondcoat and underlying $\mathrm{SiC}$ were removed by the water vapor recession processes. At a later time the spall propagated exposing a new surface of $\mathrm{Si} / \mathrm{SiC}$. The step in height between these two regions caused by different amounts of volatilization remained, and under oblique borescope lighting conditions this step resembled a crack.

Table 3-16 below lists the various types of EBC spall defects that have been observed throughout the JEA test borescope inspections. In general the EBC spalls were classified as to their size and location on the shrouds. The diagram below Table 3-16 shows where on the shroud convex surface the various categories of spalls were typically observed. The concave surface of the shrouds face outward to the outer shroud blocks and were not visible by borescope or any other means while the shrouds were in the engine. 
Table 3-16. Summary of Shroud EBC Coating Defects Observed During the JEA Engine Test. The diagram at the bottom indicates where on the CMC shroud the various types of EBC spalls typically occur.

\begin{tabular}{|c|c|c|c|c|c|c|c|c|c|}
\hline \multirow[b]{2}{*}{ Event } & \multirow[b]{2}{*}{ Date } & \multirow[b]{2}{*}{$\begin{array}{c}\text { Engine } \\
\text { operating } \\
\text { hours }\end{array}$} & \multicolumn{7}{|c|}{ \# of shrouds found with the listed type of EBC coating damage } \\
\hline & & & $\begin{array}{c}\text { Full } \\
\text { GEN2 } \\
\text { coating } \\
\text { spalls }\end{array}$ & $\begin{array}{c}\text { Large } \\
\text { center } \\
\text { spall }\end{array}$ & $\begin{array}{c}\text { Spall } \\
\text { in } \\
\text { BMT** }^{*}\end{array}$ & $\begin{array}{l}\text { Leading } \\
\text { edge } \\
\text { flange } \\
\text { spall }\end{array}$ & $\begin{array}{l}\text { Leading } \\
\text { edge } \\
\text { flange } \\
\text { edge } \\
\text { spall }\end{array}$ & $\begin{array}{l}\text { Trailing } \\
\text { edge } \\
\text { flange } \\
\text { spall }\end{array}$ & $\begin{array}{l}\text { Hot } \\
\text { gas } \\
\text { path } \\
\text { edge } \\
\text { spall }\end{array}$ \\
\hline Shroud installation & $4 / 8 / 06$ & 0 & 0 & 0 & 0 & 0 & 0 & 0 & 1 \\
\hline 1st GE borescope & $5 / 21 / 06$ & 35 & 0 & 0 & 0 & 0 & 4 & 0 & 2 \\
\hline 2nd GE borescope & $9 / 10 / 06$ & 165 & 0 & 0 & 0 & 0 & 4 & 0 & 2 \\
\hline JEA borescope & $10 / 25 / 07$ & 833 & $3 ?$ & $1 ?$ & $?$ & $?$ & $?$ & $?$ & $?$ \\
\hline 3rd GE borescope & $3 / 22 / 08$ & 1054 & 3 & 17 & 7 & 1 & 7 & 0 & 4 \\
\hline 4th GE borescope & $12 / 11 / 08$ & 1206 & 3 & 19 & 9 & 2 & 51 & 7 & 18 \\
\hline 5th GE borescope & 6/6/09 & 1351 & 3 & 20 & 9 & 2 & 56 & 7 & 34 \\
\hline 6th GE borescope & $7 / 17 / 10$ & 1537 & 3 & 24 & 10 & 2 & 70 & 7 & 44 \\
\hline
\end{tabular}

${ }^{\star}$ BMT = blade material that had been transferred to the shroud surface due to blade tip rubs

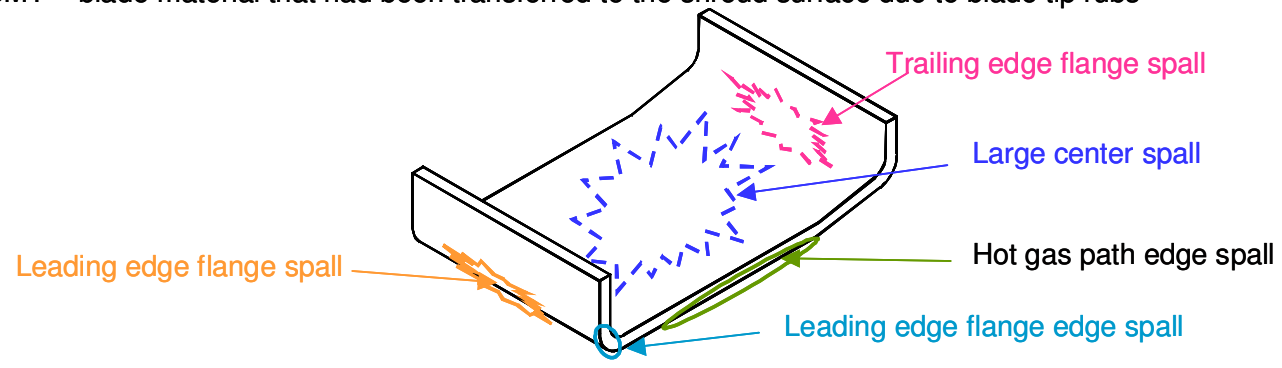

Figure 3-192 shows borescope images of one of the shrouds with the diamond pattern abradable EBC from the last three borescope inspections, showing that there were no obvious precursor event (FOD event, small chip or spall) to the large center spall. This particular shroud did show a small leading edge flange bend spall (right hand corner of the shroud in the upper left photograph and lower left corner of the shroud in the middle photograph) that was connected to the large central spall at borescope \#5. However, this connection between these two types of spalls does not occur in numerous other shrouds with large center spalls so it was not believed that the small flange bend spall grew to form the large center spall.

Figure 3-192 also provides some circumstantial evidence that the leading and trailing edge flange spalls may have been caused by FOD events. Clearly evident in this series of borescope images is the difference in the amount of "dirt" on the shrouds with time. The photograph in the upper left from borescope \#4 showed a large amount of this "dirt" on the shrouds, and there were also numerous small bright white patches on the EBC on the shroud leading edge. With additional engine exposure both the dark markings and the white specks on the coating tended to fade to a more uniform light gray. These markings were not limited to the shrouds but also show up on the $1^{\text {st }}$ and $2^{\text {nd }}$ stage nozzles and $1^{\text {st }}$ stage buckets. It is believed that the dark markings were evidence of dirt (external matter or rust and oxides from upstream engine hardware) getting through the engine and impacting the shrouds, and that the white spots were direct evidence of fresh EBC being exposed by small FOD events that occurred in conjunction with the dirt event. 


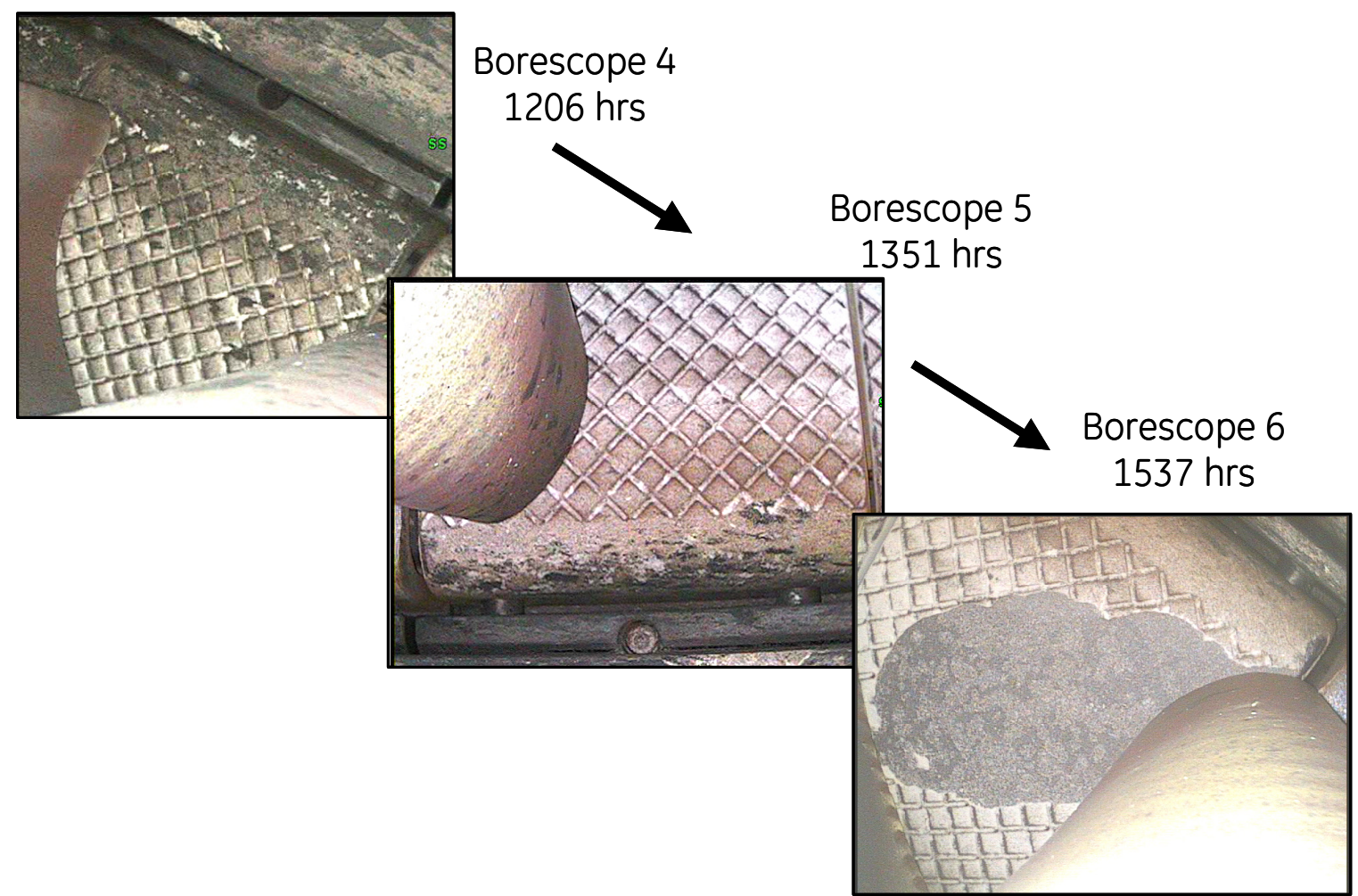

Figure 3-192. Borescope photographs of a single shroud with the diamond abradable EBC pattern taken during the last three borescope inspections.

Observation details of the CMC shroud "crack" are summarized in Figure 3-193. During borescope \#5 a feature was seen on two of the shrouds that appeared to be cracks in the CMC, the most prominent of which is shown in the top borescope photograph in Figure 3 193 , and is designated by the small red arrows. This same feature was seen during the $6^{\text {th }}$ borescope inspection using the normal observation mode, as shown in the middle photograph. However, when viewed with the high magnification tip on the borescope probe it was evident that this crack was really a step in the surface height of the shroud (the slight surface ridge highlighted by the green arrows in the bottom two photographs in Figure 3-193) that only appeared as a crack due to the oblique lighting under normal borescope inspection conditions. As described previously, the location of the ridge coincides with the edge of the EBC spall from earlier borescope inspections, and thus the surface step was caused by different amounts of CMC volatilization between the previously spalled and unspalled regions. 

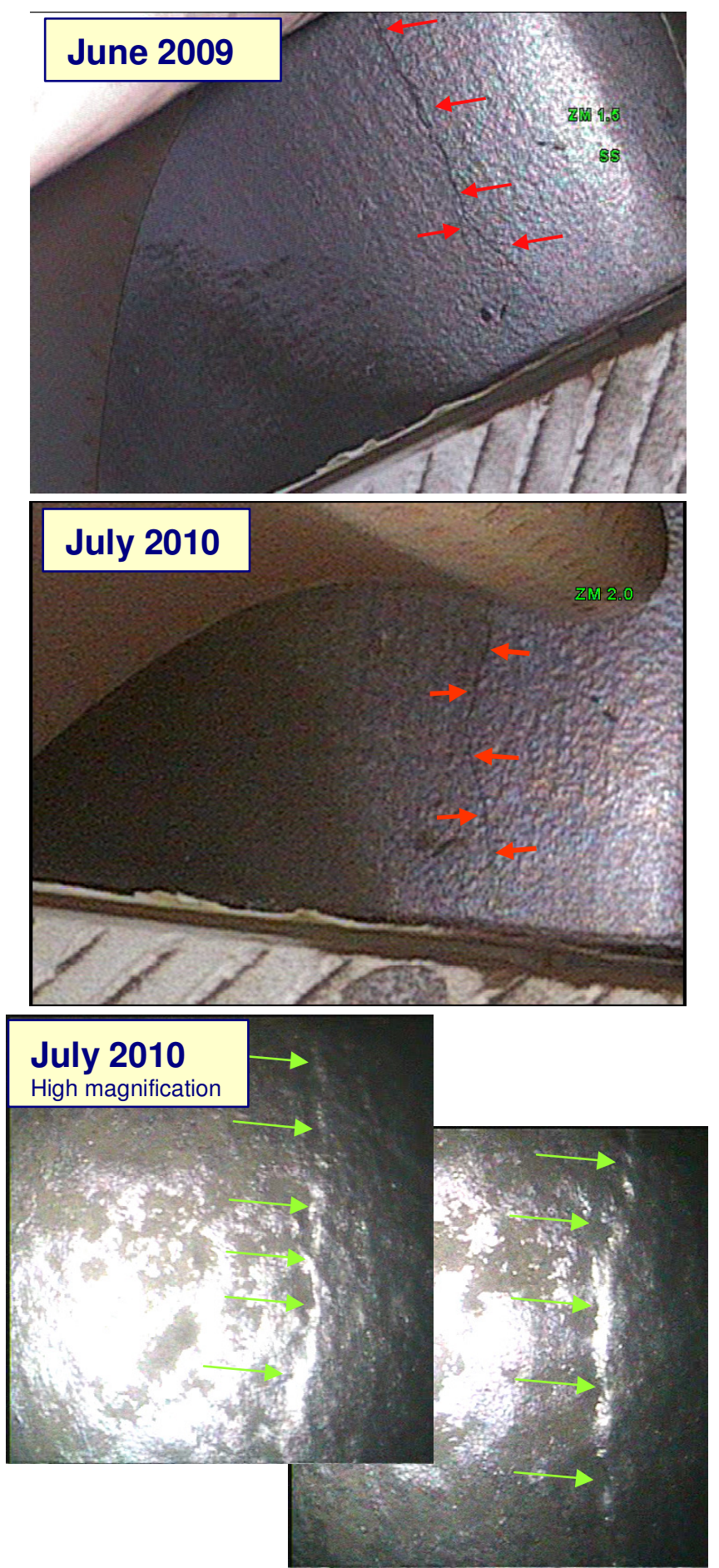

Figure 3-193. Borescope photographs of the CMC "crack" features seen in borescope \#5 (Top) and again in borescope \#6 (Middle). The bottom borescope photographs of this feature, which were taken with a high magnification tip on the borescope probe, show that the contrast is caused by a step in the surface height of the CMC and not by a crack. 


\subsubsection{EBC Spallation RCA}

Following GE borescope \#4, where large EBC spalls were seen on over 20 shrouds, a "root cause analysis" (RCA) was initiated to investigate the possible causes of the EBC spallation. The steps involved in this RCA are listed below:

1. Review and analyze observations from borescope inspections and engine operating history

2. Investigate any correlations between shroud type, EBC type and spall occurrences

3. Investigate correlations between EBC processing history and spall occurrence

4. Investigate correlations between EBC spall events and engine operation events

5. Describe any correlations between spall locations on the shrouds or shroud locations within turbine

6. Develop hypotheses to explain the observations

7. Consider supporting and refuting evidence for each hypothesis

8. Rank hypotheses by likelihood based on observations

9. Identify actions needed to further verify or refute leading hypotheses

10. Execute actions where possible

11. Re-rank hypotheses

12. Develop remediation actions

It should be noted that a major limitation to the RCA was the fact that none of the shrouds became available for actual destructive evaluation. Borescope images are limited in resolution and provide no information as to the chemistry or microstructure of the features being examined. Although the RCA team requested a partial engine teardown and replacement of key shrouds in order to make some of the spalled shrouds available for characterization, the cost of doing such was considered prohibitive. Consequently actual engine shroud characterization was limited to borescope images only, and any proposed spallation mechanisms had to be investigated using laboratory tests of new shrouds or on spare shrouds that had been coated at the same time as those in the JEA test.

There were two major changes in the engine operating conditions and EBC configuration between the JEA shroud test and the previous rainbow engine test, namely the high number of thermal cycles in the JEA engine and the presence of the abradable EBC ridges. These features therefore warranted increased scrutiny as part of the RCA.

A full accounting of the EBC damage seen in the various borescope inspections and the timeline of these inspections were given in Table 3-16 above. Two of the EBC spall types were not scrutinized as part of the RCA; these two being the full hot gas path face spalls of the Gen2 EBC coatings and spalls associated with the deep bucket tip rubs (listed as "Spall in BMT" in Table 3-16). The cause of the Gen2 EBC spalls was well understood as being related to phase instability in the rare-earth silicate used for these particular coatings, as described in Section 3.1.23.5.4. The spalls associated with the deep tip rubs and the BMT region were not scrutinized to the same level as the large spalls without BMT simply because the confounding effects of the bucket rubs could not be accounted for in any analysis. In most cases it was not clear whether spalls in shrouds with BMT were caused by the deep rub, by the accumulation of the BMT and consequent possible chemical reactions 
and thermal stresses, or by pre-existing EBC defects that just happened to located in the region of the turbine where the deep rubs were occurring.

Other than the Gen2 EBC issue, there were no correlations noted between the CMC type or EBC variant type and the occurrence of the large center spalls. There was also substantial evidence, to be discussed later, that a majority of the forward flange edge spalls were caused by FOD events. Consequently most of the RCA effort was focused on explaining the large center spalls and flange spalls.

Detailed review of the shroud fabrication and EBC deposition processes identified one important correlation that may have pointed to a source of EBC defects. Shrouds for the JEA test were fabricated in 2003 and 2004 with most of the EBC depositions having been done by the MP\&E group at GE Energy in late 2004 to early 2005. Figure 8 shows a histogram of the number of shrouds processed through the post-EBC heat treatment with the heat treatment date. The color coding indicates which shrouds have shown large central spalls, either with or without accompanying bucket material transfer. As noted above, spalls in conjunction with bucket material transfer may or may not be spalls in the normal sense, but actually caused by very deep rubs completely through the EBC coating. Of the spalls without bucket material transfer a large proportion of them were observed to have occurred in shrouds that were coated late in the EBC deposition campaign. Based on the spall counts from borescope \#3, in the shrouds heat-treated before 2/12/04 there were only 4 total observed large center spalls out of the 66 shrouds coated, or a $\sim 6 \%$ "failure rate." For the population heat treated after this date there were 11 spalled shrouds out of 20 coated, or a 55\% "failure rate." Statistical analysis clearly showed these two shroud populations to be different, suggesting that some process change had occurred around the middle of February. 


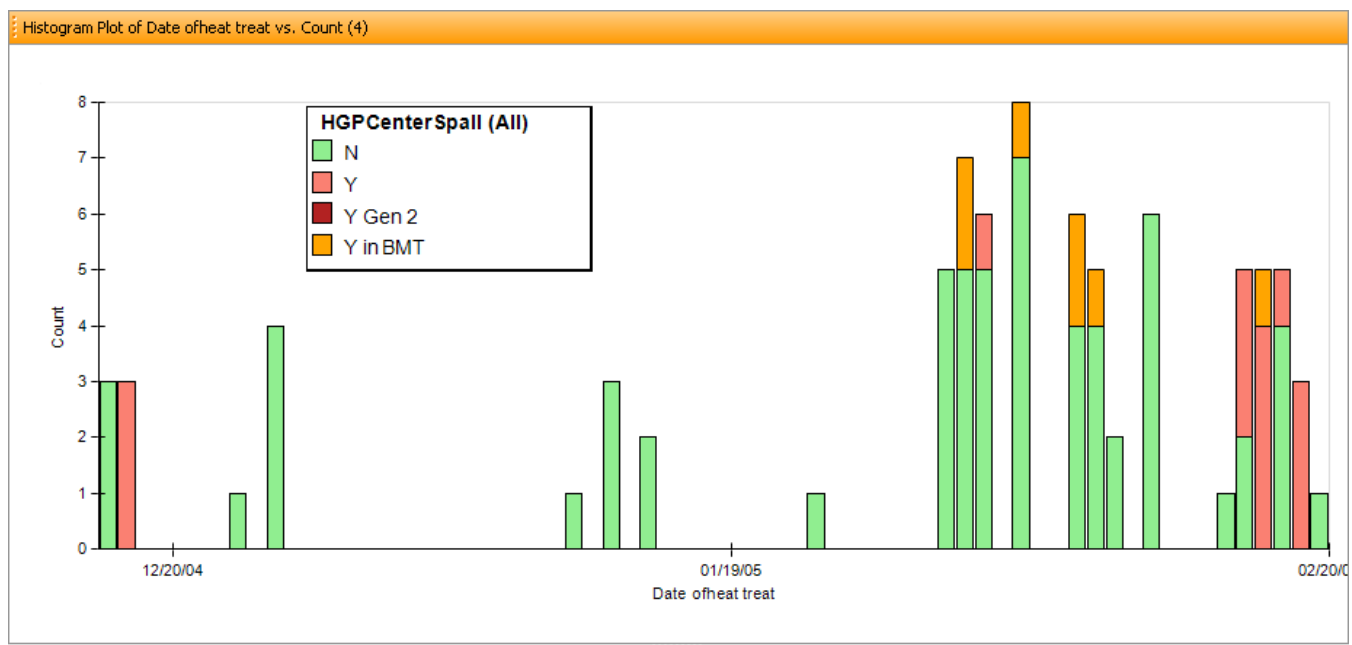

Figure 3-194. Histogram showing the count of shrouds with and without hot gas path spalls, as identified in borescope inspection \#3, according to the EBC heat treatment date. Green indicates no large central spall had as yet been observed in the JEA engine test; pink indicates that a large center spall was observed and the shroud did not show bucket material transfer from a deep bucket rub; yellow indicates that a large center spall was observed in combination with bucket material transfer.

Further review of the shroud coating history at MP\&E revealed additional information indicating a change in the shroud coating process around mid-February of 2005 . Weight gains of the shrouds during the coating deposition process are measured between layers to serve as an indication of the coating layer thicknesses. Due to the specific layer sequence and spray patterns used for the JEA shrouds a separate measure of the silicon bond coat weight gain was only available for the back side surface of the shrouds, but this can be assumed to be indicative of the silicon thickness for the hot gas path surface as well. During coating of the JEA shrouds at MP\&E two spray cells were utilized, both of which gave similar coating weight gains at the start of the coating campaign. However, as shown in the backside silicon bond coat weight data in Figure 3-195, the silicon weight gains diverged between the two cells starting in early February, with shroud coated in cell 1 having significantly lower bond coat weight gains than shrouds coated in cell 2. Moreover, for shrouds coated from February 14 through 20, the frequency of large center EBC spalls was much higher for the shrouds coated in cell $1(\sim 50 \%)$ compared to those with the higher weight gains in cell $2(27 \%)$. These results strongly suggested that the process change indicated by Figure 3-194, and the process drift indicated by Figure 3-195, contributed to the cause of the observed large center EBC spalls. 


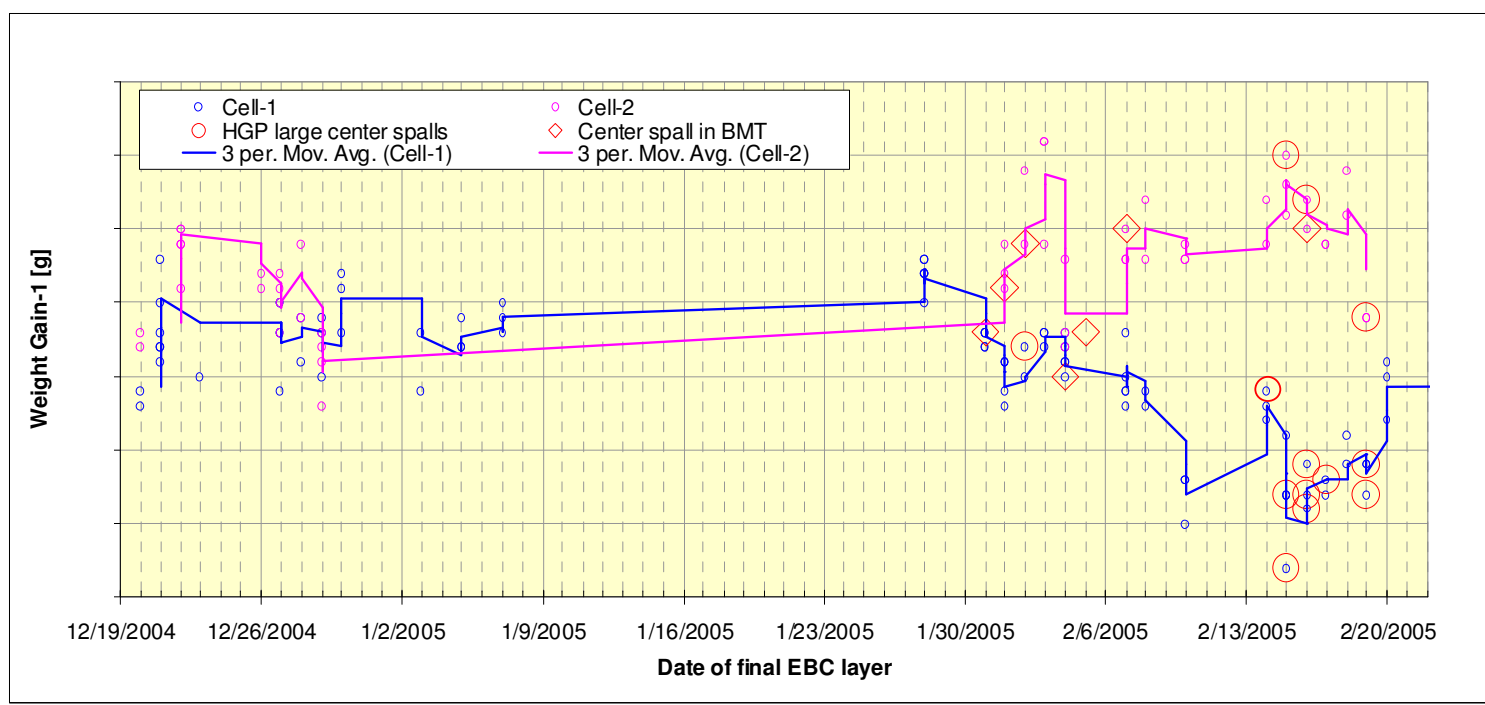

Figure 3-195. Weight gain of the backside silicon bond coat layer for shrouds coated at MP\&E during the JEA engine test shroud coating campaign as a function of coating date.

Review of all the process documentation revealed that on 2/14/05 oil contamination of the compressed air line feeding the EBC spray cells was noted and corrective action was taken. A stream of compressed air is normally directed at the shrouds ahead of and behind the plasma guns to help blow away any non-adhering spray particles. Due to the oil contamination of the feed line the cells were switched over to bottled nitrogen during this period to avoid oil spray onto the shrouds during EBC deposition. Although at the time this change was considered to be of low risk, and no appreciable change was noted in the overall EBC microstructure of the quality control shrouds that were coated and destructively evaluated at that time period. Nevertheless, the correlation of the occurrence of EBC spalls with this process change indicated otherwise.

After several months of painstaking searching of all the CMC archives at GE GRC, GE Energy and GE CCP three shrouds were recovered which had been coated during the critical period in February 2005 but not used in the engine test. The microstructural analysis results from these retrieved shrouds did indicate that the EBC coatings from this critical week time period had unusual features compared to the process qualification shrouds. These differences are shown in the micrographs in Figure 3-196. The qualification shroud showed a uniform EBC microstructure from edge to center with a relatively constant porosity of $\sim 6 \%$. The shroud from the critical period had a higher level of porosity along the edges, yet the pore density was lower. This indicates that the pores were significantly larger along the edge of the shroud from the critical coating period. However, on the flat face the shroud from the critical period showed a much lower level of porosity, and also the presence of vertical cracks through the oxide EBC layers. It is believed that the lower porosity in this region and vertical cracking were related, and it had been well established from furnace cyclic steam exposure testing that such vertical cracks can lead to enhanced bondcoat oxidation and EBC spalls. 

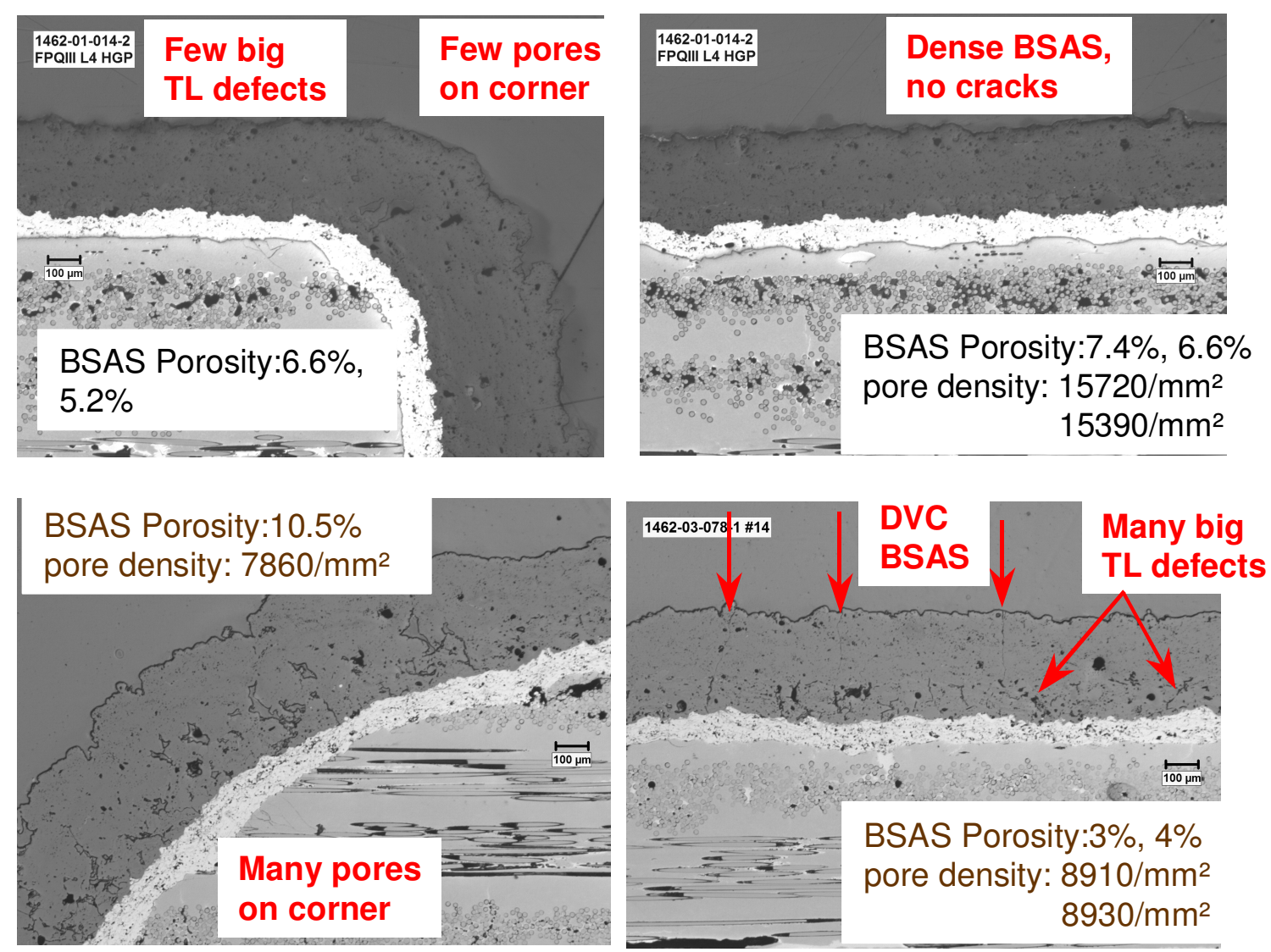

Figure 3-196. Micrographs of the EBC coating on a process qualification shroud from January 2005 (Top) and one of the engine-reject shrouds coated in mid-February 2005 (Bottom). The left-hand micrographs show the EBC structure along an edge of the shroud and the right-hand micrographs show the structure on the flat hot gas path face.

It therefore appears that at least some of the shrouds coated in the one week critical time period had pre-existing features that would make them susceptible to bond coat oxidation and coating spallation. The concurrent occurrence of the low bond coat thickness from cell 1 during this time period would only make the oxidation problems worse. However, it is still not known what exactly caused the coating process to produce lower-quality coatings during this time period. New EBC spray trials using bottled nitrogen as the cleaning gas were not able to reproduce the structures seen in the spare JEA shrouds, so this process change alone could not explain the EBC microstructural differences.

Another observation that was suspected as possibly being important for the understanding of the spallation mechanism had to do with the appearance of "white" and "gray" regions in the EBC coatings. Please recall that EBC-coated parts are subjected to a high temperature heat treatment after coating deposition in order to crystallize the coating and stabilize the microstructure. Following this heat treatment there was commonly a difference in visual 
appearance between the center of the shrouds, which typically appeared gray, and the region near the edges, which appeared white. This effect was occasionally seen in coated panels, but was more prominent in the coated shroud components. Figure 3-197 shows a photograph of three of the EBC-coated inner shrouds used in the JEA engine test that showed this gray-vs-white effect. The gray regions do continue into the region below the abradable ridges, but are just more difficult to see due to the abradable EBC coating. Investigations were therefore undertaken to try to understand the origins of the gray-vswhite regions.

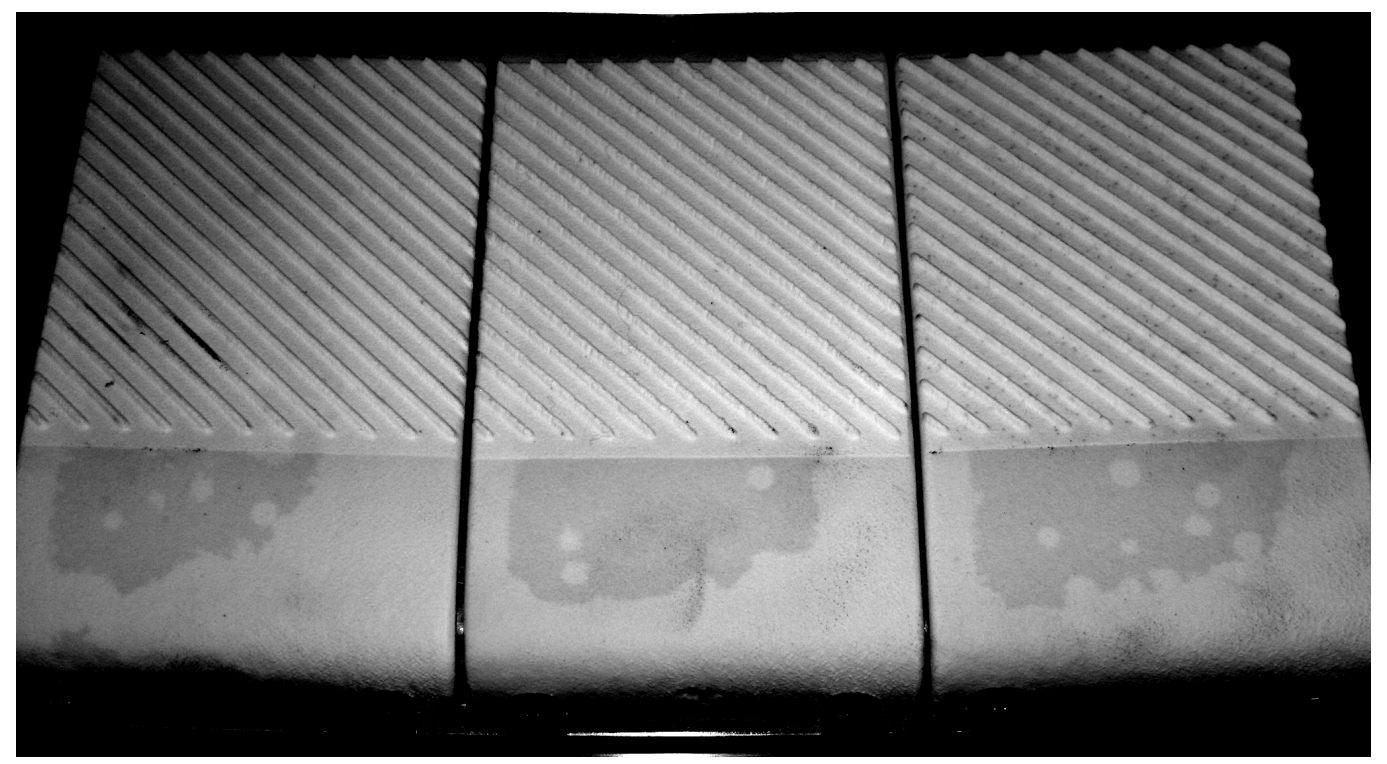

Figure 3-197. Photograph of three shrouds currently in the JEA engine test showing the gray-vs-white appearance of the EBC coating following EBC heat treatment.

Quite detailed quantitative metallography studies were required in order to accumulate sufficient data to identify the microstructural changes between the regions. As-sprayed EBC coatings often show numerous planar defects between the silicon bond coat and the oxide transition layer. These defects are typically small cracks formed by the solidification shrinkage of the oxides or from normal splat boundaries in the coating. Following the EBC post-deposition heat treatment most of these defects are observed to "heal", either by sintering or from being filled with oxidation product from the bond coat.

Quantitative metallography was performed on sections of shroud coatings that showed both white and gray regions. Once a proper method of image discrimination was found, the planar defects at the bond coat to transition layer interface could be counted as one translated across a shroud from a white to a gray region. Figure 3-198 shows the results of one such measurement made on one of the shrouds taken from the critical coating period. In the as-heat-treated coating, shown by the blue data, there was a distinct difference in the concentration of the planar defects between white and gray regions. This analysis verified 
that the gray regions did indeed have increased EBC coating defects that would be expected to cause decreased EBC adhesion, and thereby possibly lead to EBC spalls.

The observations were repeated on a second section from the same shroud, but after the shroud piece had been through an additional 24 hours of cyclic steam oxidation. The number of interfacial defects in what had originally been the gray region was greatly reduced by this heat treatment, largely due to healing of the defects from bond coat oxidation product. This observation suggests that a possible solution to the weaker, gray EBC regions is to simply extend the post-deposition heat treatment until all of the defects have been healed and the shrouds are uniformly white. However, this also begs the question as to why the shrouds in the JEA engine test did not heal themselves during normal engine exposure, for which an adequate explanation has not yet been determined.

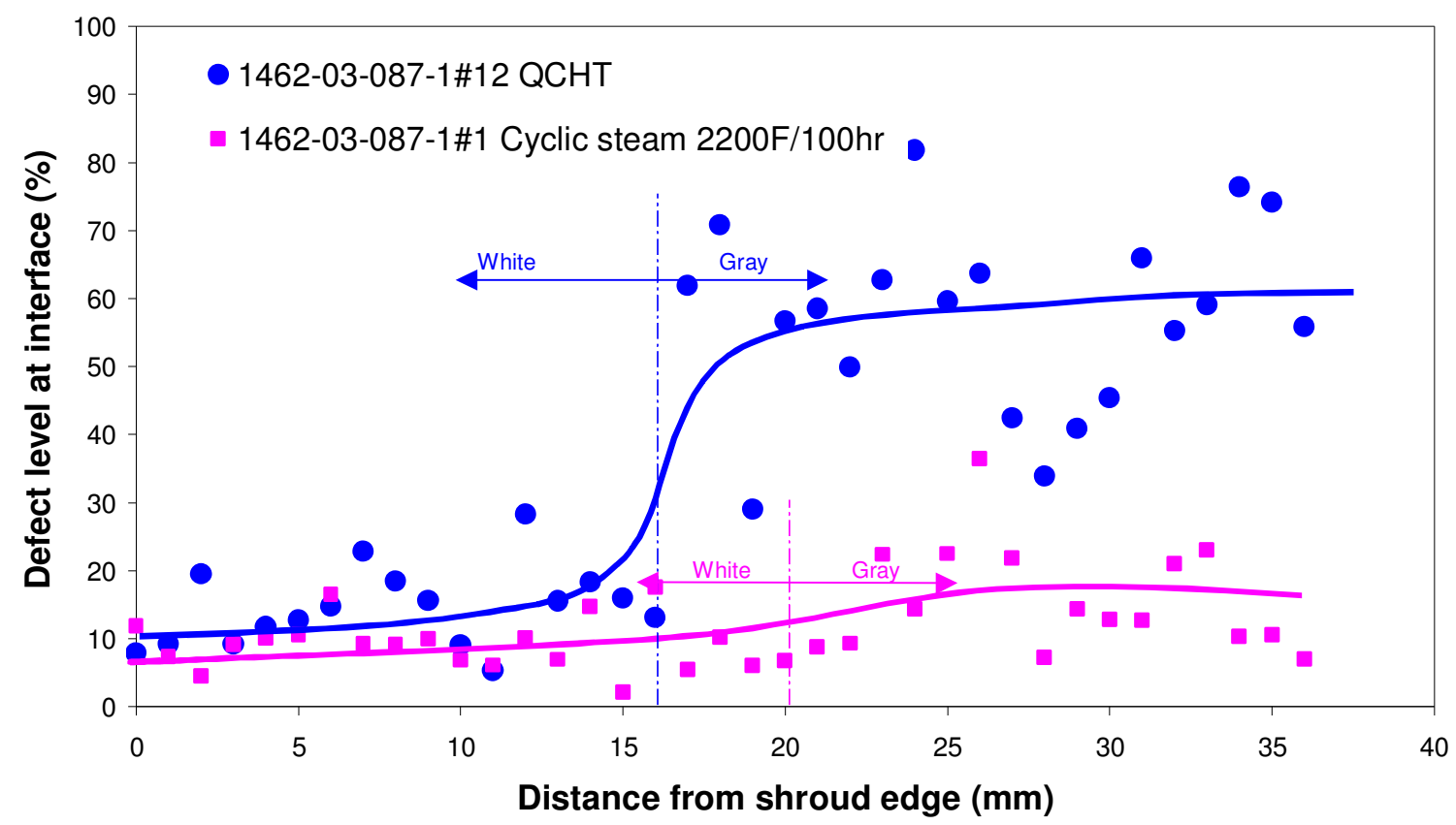

Figure 3-198. Plot of relative defect concentration at the bond coat to transition layer interface in EBC coatings that showed white and gray regions after heat treatment. The defects in the gray region were largely healed after an additional 24 hours of steam oxidation exposure at $1200^{\circ} \mathrm{C}$.

Specific aspects of the engine operation also appeared to have contributed to the occurrence of the large center spalls. In particular, the occurrence of the spalls was correlated with the number of turbine hot trips. Figure 3-199 shows a timeline accounting of the number of hot trips compared to the frequency of detected large center spalls. No large center spalls were observed in the engine until after several hot trips had occurred (although the large time between inspections cannot rule out that some spalls had occurred before the JEA borescope). Between the JEA borescope and the $3^{\text {rd }}$ GE borescope there was a large spike in the number of hot turbine trips, and this was also the interval between 
which the largest increase in the number of large center spalls was observed. Following borescope \#3 there had been a lower frequency of additional trips and also a limited number of additional center spalls.

Based on location and general appearance, the leading edge flange edge spalls were suspected of being caused primarily by foreign object damage, or "FOD". There have been two periods where significant FOD activity is believed to have occurred, the first of which was during initial engine start-up before borescope inspection \#1. At the first borescope inspection practically every shroud showed evidence of small impacts having knocked off the tops of the EBC abradable ridges. There was also substantial visual evidence of spotty brownish deposits on the $1^{\text {st }}$ stage nozzles and buckets as well as the shrouds. These brownish deposits were seen to fade with additional exposure, and there was no evidence of additional abradable ridge damage between borescopes \#1 and \#2. However, somewhere between GE inspections \#3 and \#4 the brownish spots returned, and there was a qualitative increase in the number of EBC chips along the shroud leading edges, as shown previously in Figure 3-192. During this same period there was also a sudden increase in the number of spalls at the leading edge flange edge location. The trend in number of spalls with time is shown in Figure 3-200, which also shows the times of the dirt accumulation events. The leading edge flange edge spalls, leading edge flange spalls and trailing edge flange spalls each showed the largest increases in their numbers during these dirt accumulation events. Moreover, the number of leading or trailing edge flange spalls were not seen to increase over any interval not associated with the dirt events. These observations tend to substantiate that the flange spalls were at least partially caused by FOD type events. The leading edge flange edge spalls were seen to continue to increase during intervals with dirt events, but as these types of spalls are much smaller and harder to detect the increased numbers may just be due to improvements in borescope technique and the thoroughness of the inspections.

The other type of coating damage that may be related to FOD events is the edge spalls on the hot gas path surface. These spalls tended to occur at the corner between the main shroud face and an edge face. While some of them were observed to grow inward across the main shroud face with time, most did not appear to be growing appreciably. As noted previously, many of these spalls show rather irregular, angled edges, which suggest that they may be caused at least partially by FOD events. However, the EBC spray deposition technique used on the majority of shrouds in the JEA engine test involved the use of masks to prevent overspray from one shroud surface to the adjacent surfaces. Depending on the precision with which the masks were positioned, this process had the potential to create "seams" in the EBC coating along the shroud edges. Such seem defects were indeed observed on at least one of the rejected engine test shrouds that were destructively characterized. A smaller number of shrouds in the JEA test were coated using a "single grip" process where no masking is needed, and those shrouds exhibited a much lower rate of occurrence of edge spalls. These observations suggest that these edge spalls are at least partly related to such EBC layer seem defects. 


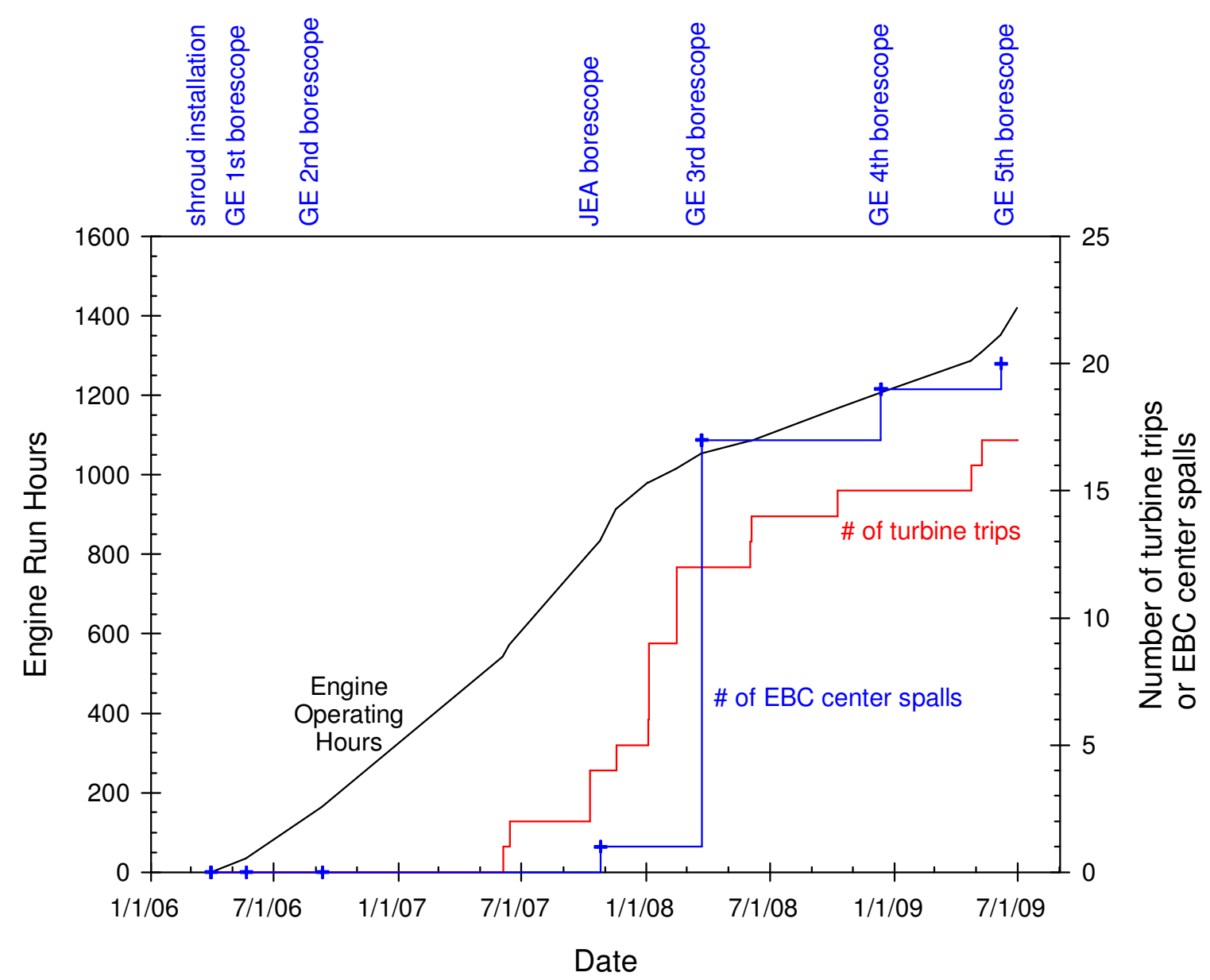

Figure 3-199. Timeline for engine operating hours, hot trips, and observed large center spalls of the EBC coatings. 


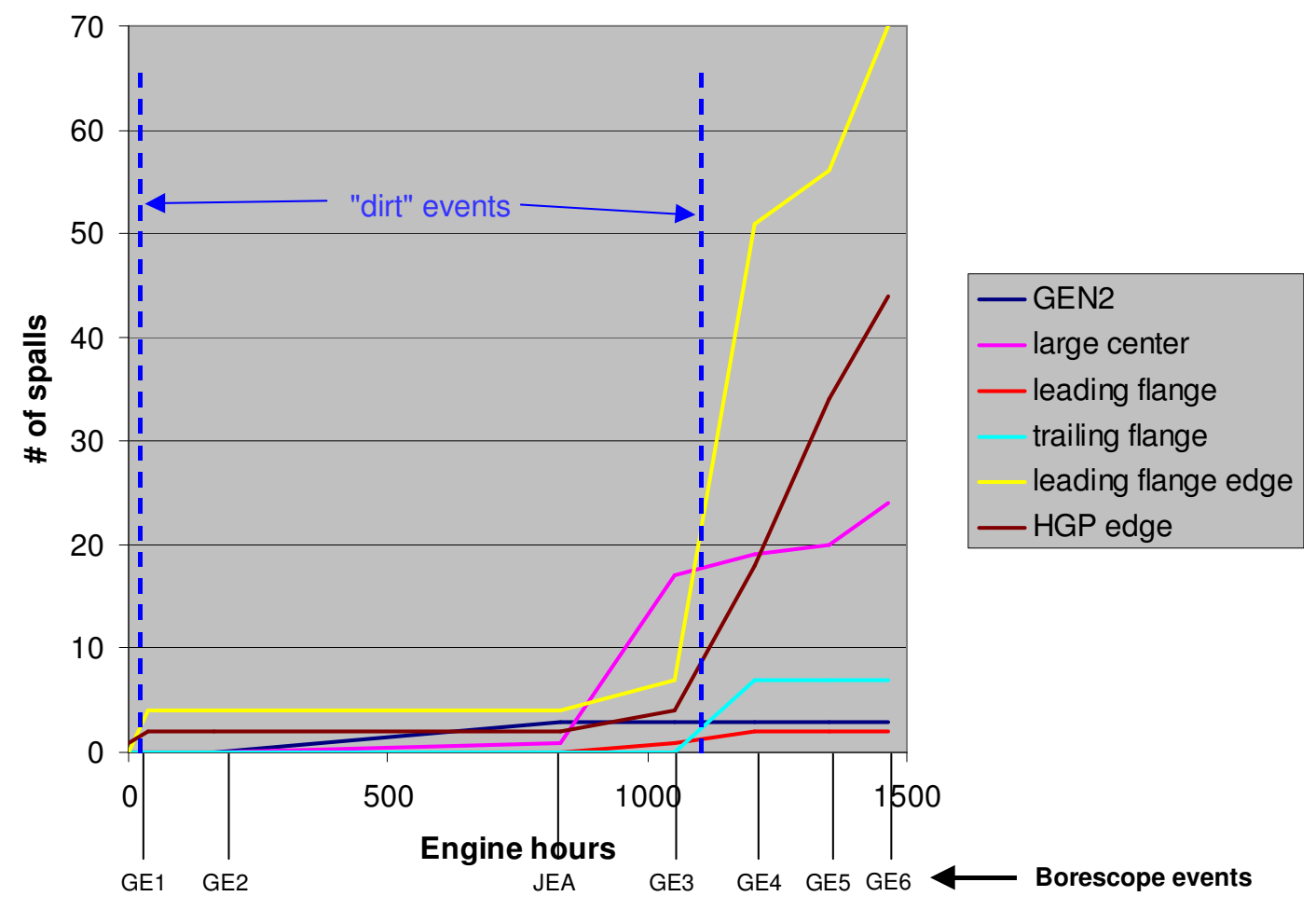

Figure 3-200. Historical occurrence of the various types of EBC spalls and their relation to the "dirt" events seen between borescope inspections. The numbers of detected leading flange, trailing flange and leading flange edge spalls all show their largest increases in the intervals where the "dirt" events also occurred.

The above observations and correlations represent information unveiled during steps 1 through 5 of the RCA process. Steps 6 through 8 were carried out through a series of brainstorming sessions held with the CMC and EBC teams at GRC and GE Energy. Initially twenty-seven potential spallation mechanisms were postulated, of which ten were subsequently ranked as "high probability." Throughout the RCA process as additional information was gathered the list of spallation mechanisms was periodically updated and reranked, and this ranking was used to prioritize subsequent laboratory investigations. Again, this part of the RCA focused primarily on the large center spalls, mostly because there were already known causes for the other types of spalls (such as the rare earth silicate instability causing the Gen2 EBC failures) or there were other factors strongly suspected of contributing to the other types of spalls (such as FOD or shroud coating seems). The large center spalls, simply because of the amount of CMC exposed and their location in the hottest part of the shroud, were also considered to be the most risky in terms of eventually leading to shroud failures.

A common feature of most of the highly ranked mechanisms was the presumed interaction between a pre-existing EBC defect (such as the gray patches) with a driving force for propagating this defect. While the EBC characterization described above had identified several EBC flaw candidates the driving force for spallation was still unknown. 
Consequently the following actions were initiated in order to try to understand which driving forces were most important:

- Performance of interlaced bucket rub and steam exposure testing on samples with abradable EBC coatings

- Estimation of the magnitude of the pressure pulse associated with bucket passing and its effect on the stress state in EBC abradable ridges

- Estimation of the stresses in the coating caused by bucket rubs into the abradable ridges

- Estimation of the severity of normal start-up and shut-down and turbine trip thermal transients and there effects on EBC coating stresses

- Simulation of severe thermal transients and examination of the effects of such transients on thru-thickness and lateral cracks in EBC coatings

One of the leading proposed spallation mechanisms involved the combined effects of bucket tip rubs on the abradable ridges and EBC bond coat oxidation. It was postulated that during a rub into the abradable EBC ridges that vertical cracks would be introduced in the EBC coating down to the bond coat. During engine exposure enhanced water and oxygen penetration through the vertical cracks would lead to rapid oxidation and depletion of the bond coat. It was well known from laboratory steam furnace exposure testing that once the silicon bond coat was consumed and oxidation of the underlying $\mathrm{SiC}$ had begun that the thermally grown oxide (TGO) changed from a protective, dense, amorphous $\mathrm{SiO}_{2}$ layer to a highly porous, non-protective $\mathrm{SiO}_{2}$. Rapid growth of the porous silica then caused upheaval and cracking of the EBC top layers, thus further enhancing the substrate oxidation. Eventually the EBC top layers would spall off due to the thick, porous (and therefore relatively weak) TGO.

Earlier bucket rub testing on abradable EBC had shown the initiation of vertical cracks within the EBC top layers, but these cracks had not been observed to penetrate to the silicon bond coat. Moreover, subsequent steam oxidation testing of rubbed coatings generally showed that any vertical cracks tended to heal due to sintering and/or viscous flow of residual glass within the BSAS layer, and thus no enhanced bond coat oxidation was observed. The difference between the engine test and these previous lab tests was postulated to be that the vertical cracks were being repeatedly re-opened from transient rubs during every thermal cycle.

In order to investigate this proposed mechanism a set of samples was cyclically subjected to simulated tip rubs into the EBC and then to steam furnace oxidation in order to determine if periodic bucket rubs would indeed enhance the bond coat oxidation rates. No evidence for enhanced oxidation of the bond coat in these tests was found. Also, there was no apparent enhancement of the rub damage caused by prior steam furnace exposures and normal bond coat oxidation. This mechanism of EBC spallation was subsequently considered to be unlikely.

The next two activities considered primarily mechanical methods of creating the driving force for EBC spallation. Here the presence of a pre-existing EBC defect was assumed and 
that mechanical stresses generated from bucket rubs on the abradable ridges, or mechanical stresses generated by the pressure pulses associated with bucket passing acting on the abradable ridges, was causing these defects to propagate, leading to EBC spalls. Of these, the pressure pulses from bucket passing were analytically determined to be unimportant. Computational fluid dynamics modeling of the bucket passing pressures were shown to generate a maximum of $\sim 0.7 \mathrm{MPa}$ of stress within the EBC coating, which was well below any strength values measured on EBC materials or the adhesive strengths between EBC layers.

Analysis of the bucket tip rubbing on the abradable ridges concluded that significant stresses could be generated within the coatings. However, these analyses necessarily included several assumptions as to the machining forces of the bucket tips on the EBC ridges since these had never been directly measured. This mechanism also did not correlate well with the observed damage, in that there were numerous shrouds that showed evidence of light bucket rubs but did not have large center EBC spalls. There were also at least two cases where spalls had been observed even when there was direct visual evidence from the remaining abradable EBC ridges around the spall that no bucket rub had occurred on those shrouds. Consequently this mechanism for driving damage in the coatings was also demoted in importance.

These analyses left thermal transient stresses at the most likely cause of EBC defect propagation. Transient thermal analyses of the shroud and EBC coating were run for the cases of normal start, normal shut-down and trip shut-down conditions. During such transients the thermal stresses within the coating reach a maximum in only $\sim 0.3$ seconds due to the high flow rates and consequently high heat transfer coefficients from the turbine gases. Stresses during the trip event were highest, as expected, and exceeded 200MPa, which is above the bend strength of sintered bulk BSAS. Given the microstructural defects introduced during a thermal spray process, the strength of the EBC coatings is expected to be even lower than sintered bulk material. Stresses during the normal transients were only $\sim 1 / 3$ lower than for the trip shut-down, and could thus also exceed the strength of a plasma sprayed EBC coating.

It thus appeared possible that the EBC coatings were developing cracks during the thermal transients of the engine, or that the stresses were propagating pre-existing lateral cracks. Such cracking would not have been observed in previous laboratory testing since the thermal shock transient of the cyclic steam furnace test is several order of magnitude slower than those of an engine transient.

An initial attempt was made to simulate in the laboratory the severe thermal shock that would be experienced by the shroud and EBC coating during a turbine trip event. Essentially a water-quench thermal shock treatment was performed where EBC-coated CMC samples were heated to high temperature in a laboratory furnace and then quickly removed and dropped into a bucket of room temperature water. Several attempts were made with such quenching experiments to initiate cracks in the EBC coatings, using starting furnace temperatures as high as $1250^{\circ} \mathrm{C}$; however, no coating cracks were observed 
following the quenching treatments. However, due to sample cooling during the transit time from the furnace to the quench bath, and due to the insulating vapor layer that is formed during such a quench into water, the estimated thermal transient was still not as severe as had been calculated for a turbine trip event.

In order to better simulate the rapid quench of a turbine trip a modified jet engine thermal shock (JETS) test was devised. Samples taken from JEA-vintage shrouds, and shrouds or coupons processed at a later date but that had key features representative of the JEA shrouds, were identified for testing. The objective was to determine if EBC cracking and delaminations could be generated at the interface between the transition layer and the silicon bond coat from such thermal shock events. This interface had been observed to contain crack-like defects, which can be related to the so- called gray patches (regions of discoloration observed on the shrouds prior to the engine test that bear strong similarity in shape to the spalled areas), and was judged to be the most likely location where the EBC spalls occurred.

Early JETS testing generated ambiguous results. Under testing conditions with a heat transfer coefficient comparable to that expected on the hot gas path side of the engine shrouds only one of seven shroud samples showed any signs of EBC delamination. The JETS test rig was then modified to increase the severity of the thermal shock in an attempt to increase the tendency for delamination. Nevertheless, the difficulty in creating delamination at the transition layer/Si bond coat interface remained.

Up to this point all of the EBC JETS testing had been carried out with a hot side sample temperature of $1316^{\circ} \mathrm{C}$. This temperature is higher than what an actual shroud sees in an engine, and was selected with the intention of having a higher driving force for thermally generated cracking. However, the higher compliance of the EBC materials associated with this higher testing temperature may have significantly decreased the sensitivity to cracking and delamination. With this in mind, JETS shock tests were conducted at lower temperatures to investigate the cracking/delamination behavior of Gen1 EBC (the same as used on the large majority of shrouds in the JEA engine test).

The samples used in this set of experiments were $2.5 \mathrm{~cm}$ diameter buttons machined from Shroud 2269-1 via water-jet cutting. This was a spare GRC-fabricated shroud coated with Gen1 EBC using a similar process to that used for the JEA shrouds. After heat-treatment this shroud showed typical gray patch features on both sides of the shroud, with only a narrow area along the edges appearing white (see the top photograph in Figure 3-201). The as heat-treated BSAS layer was free of vertical cracks, as shown in the middle micrograph in Figure 3-201. This EBC microstructure differed from that observed on other JEA quality control (QC) shrouds in that the JEA QC shrouds typically had vertical cracks in the BSAS with a density of around $1 / \mathrm{mm}$. The JETS buttons were cut from the gray areas. In these areas the interface between the EBC transition layer and the silicon bond coat layer showed crack-like defects and a lack of a glass reaction zone (shown in the bottom micrograph of Figure 3-201). This type of microstructural feature in the gray area was consistent with the observation made in the JEA QC shrouds. 
JETS tests were typically conducted by heating the front side (HGP side) of the sample with a torch to the designated temperature without any backside cooling (dubbed "isothermal" JETS test). When thermal equilibrium was achieved, the flame was shut off and a highpressure air jet that carried water mist was immediately applied to the center of the HGP surface. The peak heat transfer coefficient at the center of the specimen was calculated (based on thermal transients of instrumented test samples) to be on the order of $7 \times 10^{4}$ $\mathrm{W} / \mathrm{m}^{2}-{ }^{\circ} \mathrm{C}$, with an average heat transfer coefficient over the entire button of $2 \times 10^{4} \mathrm{~W} / \mathrm{m}^{2}-$ ${ }^{\circ} \mathrm{C}$. As a reference, the peak heat transfer coefficient for the air-jet only JETS test (without water mist added to the cooling jet) with a maximum flow capacity of 4.4 SCFM was $\sim 1.9 \times 10^{4} \mathrm{~W} / \mathrm{m}^{2}-{ }^{\circ} \mathrm{C}$, while the heat transfer coefficient for the HGP side of a shroud in the engine is estimated at $\sim 1.2 \times 10^{4} \mathrm{~W} / \mathrm{m}^{2}-{ }^{\circ} \mathrm{C}$.

To compare with earlier results obtained by shocking from higher temperature $\left(1316^{\circ} \mathrm{C}\right)$, one button each (2269-1\#6 and \#9) was shocked from HGP temperatures of $1093^{\circ} \mathrm{C}$ and $871^{\circ} \mathrm{C}$, respectively. Although the tests were called "isothermal shock", there was a significant thermal gradient across the thickness of the samples. The backside temperature measured for the above-mentioned two samples prior to the thermal shock were $\sim 816^{\circ} \mathrm{C}$ and $\sim 704^{\circ} \mathrm{C}$, respectively.

A third sample (2269-1\#8) was shocked from a $1316^{\circ} \mathrm{C}$ front temperature, but under a higher thermal gradient established by air-jet cooling from the backside. At maximum backcooling airflow (4.4 SCFM), temperature measured at backside was $\sim 650^{\circ} \mathrm{C}$, compared to $\sim 980^{\circ} \mathrm{C}$ under isothermal condition with a $1316^{\circ} \mathrm{C}$ front side temperature.

Four thermal shocks were applied to each sample under the conditions described above. The samples were then first analyzed by transient IR thermal imaging, and then sectioned and polished for metallographic and SEM examination. 

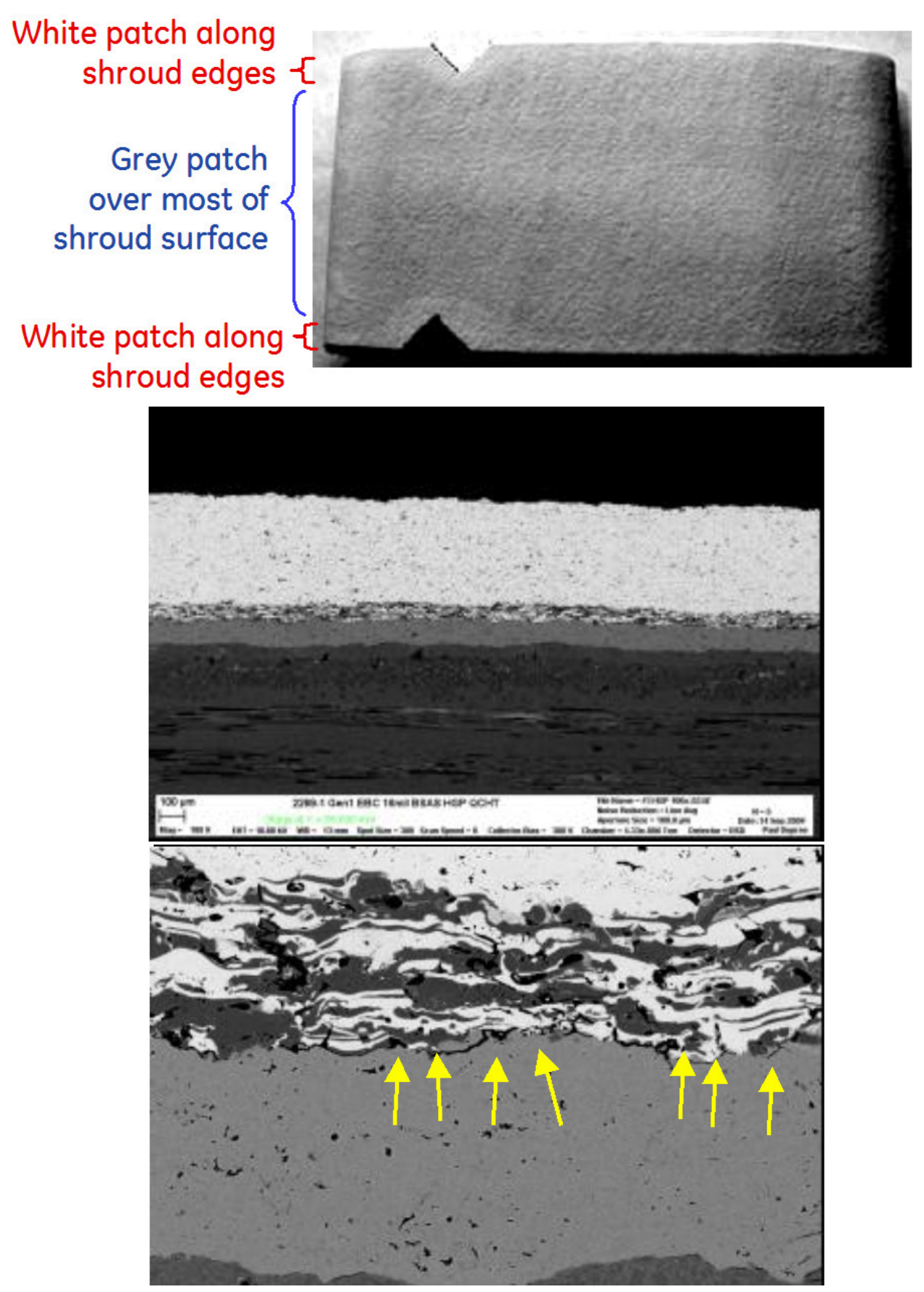

Figure 3-201. GRC replicate shroud 2269-1: Top - macroscopic appearance showing gray patch in center of shroud with white stripes along the edges; Middle - cross section of the EBC from the hot gas path face; Bottom - Si bond coat to transition layer interface in a gray region with arrows pointing to the crack-like features at the interface.

The IR imaging methodology used for these specimens did not reveal evidence of EBC delaminations in these samples, as shown in Figure 3-202. The images before and after the shocks appear mostly identical, except for some hot spots on both sides of 2269-1\#8. 
These hot spots were identified to be due to lateral cracking in the BSAS layer relatively close to the surface.

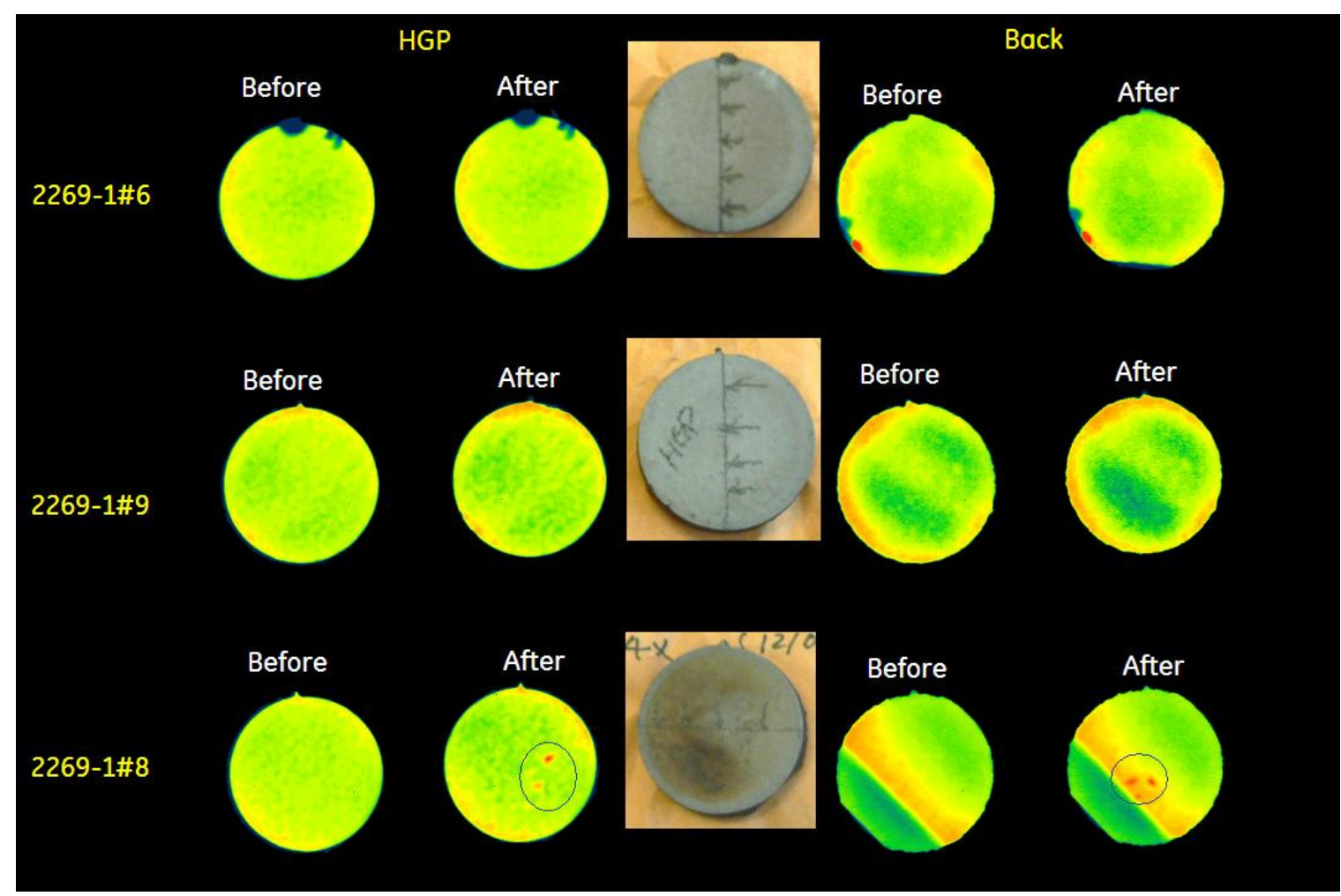

Figure 3-202. IR images of thermal shock test coupons taken before and after JETS testing. The temperatures from which the samples were down-shocked were $1093^{\circ} \mathrm{C}$ for sample $\# 6,871^{\circ} \mathrm{C}$ for sample \#9, and $1316^{\circ} \mathrm{C}$ for sample \#8. The lines marked on the central photographs mark cross-section location from which the SEM samples taken.

Despite the lack of thermal image evidence, SEM examination reveled rather extensive delamination behavior on the HGP side of all samples tested. Figure 3-203 and Figure 3204 show the cross-section of the delaminated zones in samples shocked from $1093^{\circ} \mathrm{C}$ $871^{\circ} \mathrm{C}$, respectively. Figure $3-205$ shows images taken of the $1316^{\circ} \mathrm{C}$-shocked sample from the previous set of testing.

The cracking/delamination behavior of these three samples showed some similarities as well as differences. For all three samples shown here, the event seemed to start with cracking at the surface of BSAS and propagation of the crack vertically through the BSAS layer to reach the transition layer/Si layer interface. The density of these vertical cracks was low, no more than a couple of them could be observed over the $1.3 \mathrm{~cm}$ footprint of the JETS flame. As is characteristic of cracks created by transient stress, these vertical cracks were very tight and difficult to observe. 


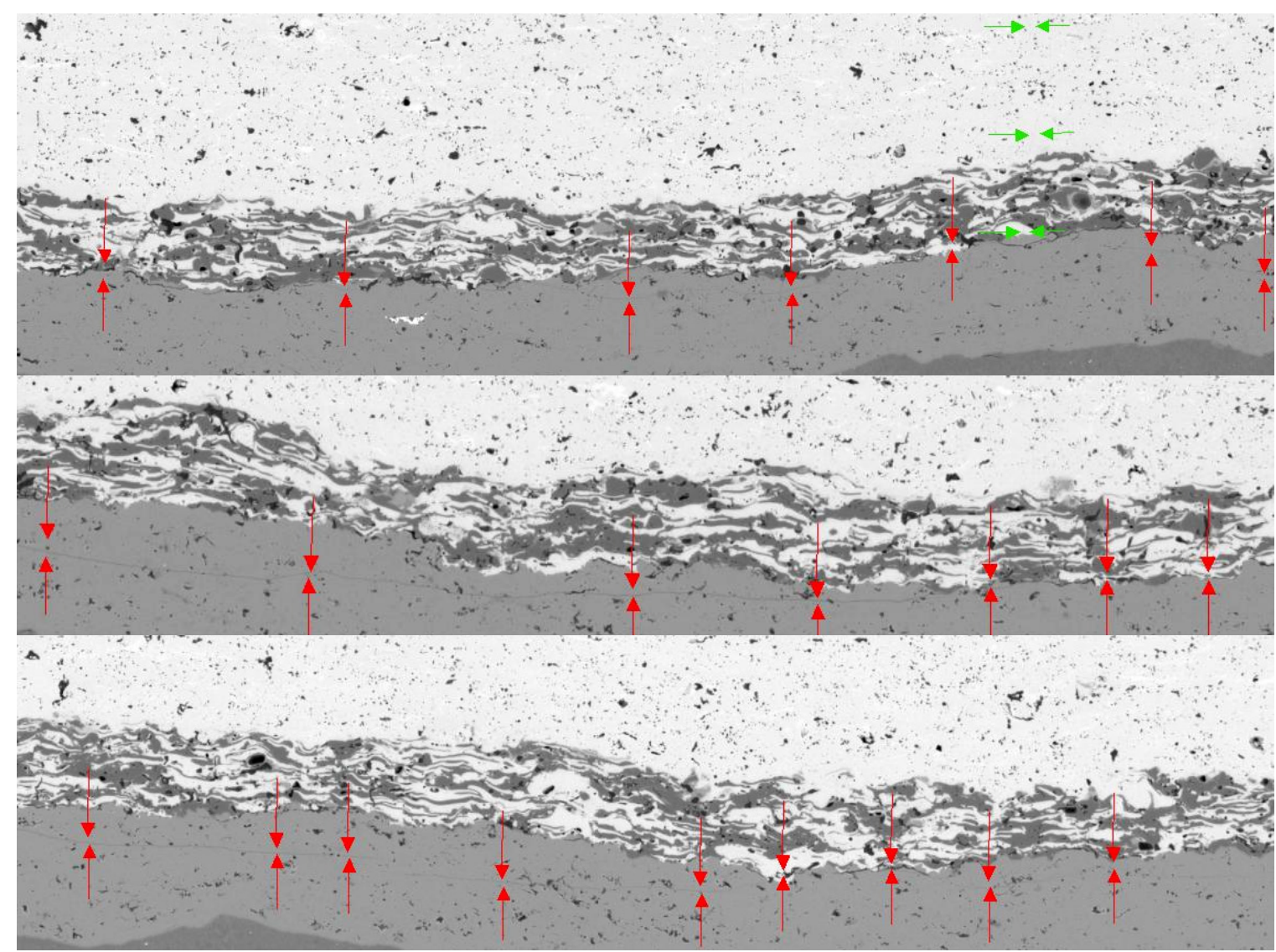

Figure 3-203. Photomicrographs of EBC cracking generated by watermist JETS thermal shock tests from $1093^{\circ} \mathrm{C}$ on the hot gas path side of sample 2269-1\#6. The green arrows in the top image track the vertical through-thickness crack and the red arrows track the lateral delamination crack

Due to the low toughness of the defective transition layer/Si bond coat interface, the vertical cracks did not propagate straight downward into the silicon layer, but initiated debonding along the interface instead. When the shock temperature was high $\left(1316^{\circ} \mathrm{C}\right.$, Figure 3-205), the debonding crack propagated along the interface for a short distance before kinking into the Si layer, and then continued to extend within the silicon layer, following a trajectory parallel to the interface. Therefore the delamination, although initiated at the interface, occured mostly within the silicon layer. 

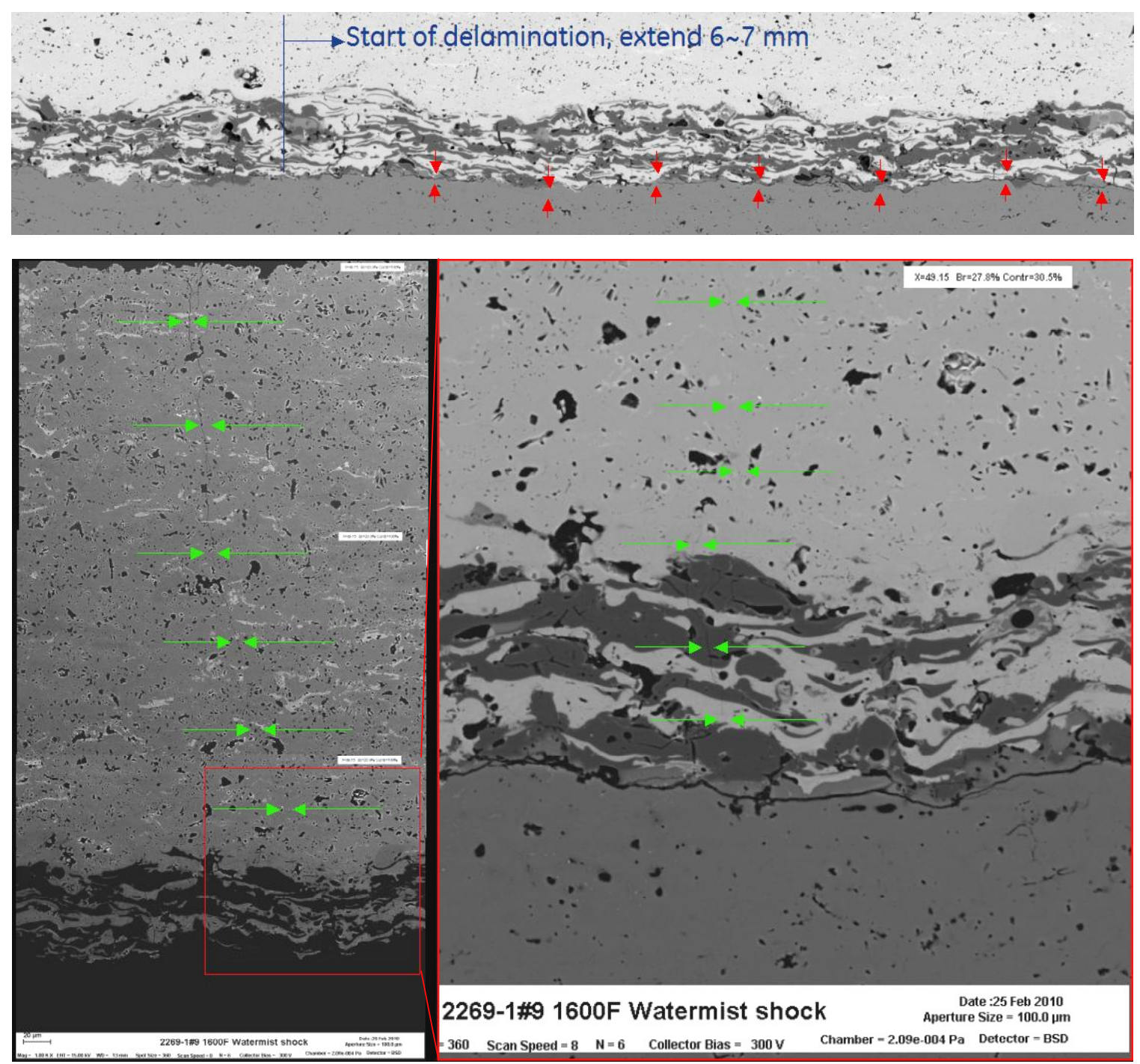

Figure 3-204. Photomicrographs of cracking generated by watermist JETS testing from $871^{\circ} \mathrm{C}$ at the hot gas path side of sample 2269-1\#9. Top - optical micrograph of the end of the extended delamination crack along the transition layer/bond coat interface; Bottom - SEM micrographs of a tight through thickness crack, indicated by the green arrows, penetrating the EBC and connecting to the lateral crack at the transition layer/bond coat interface. 


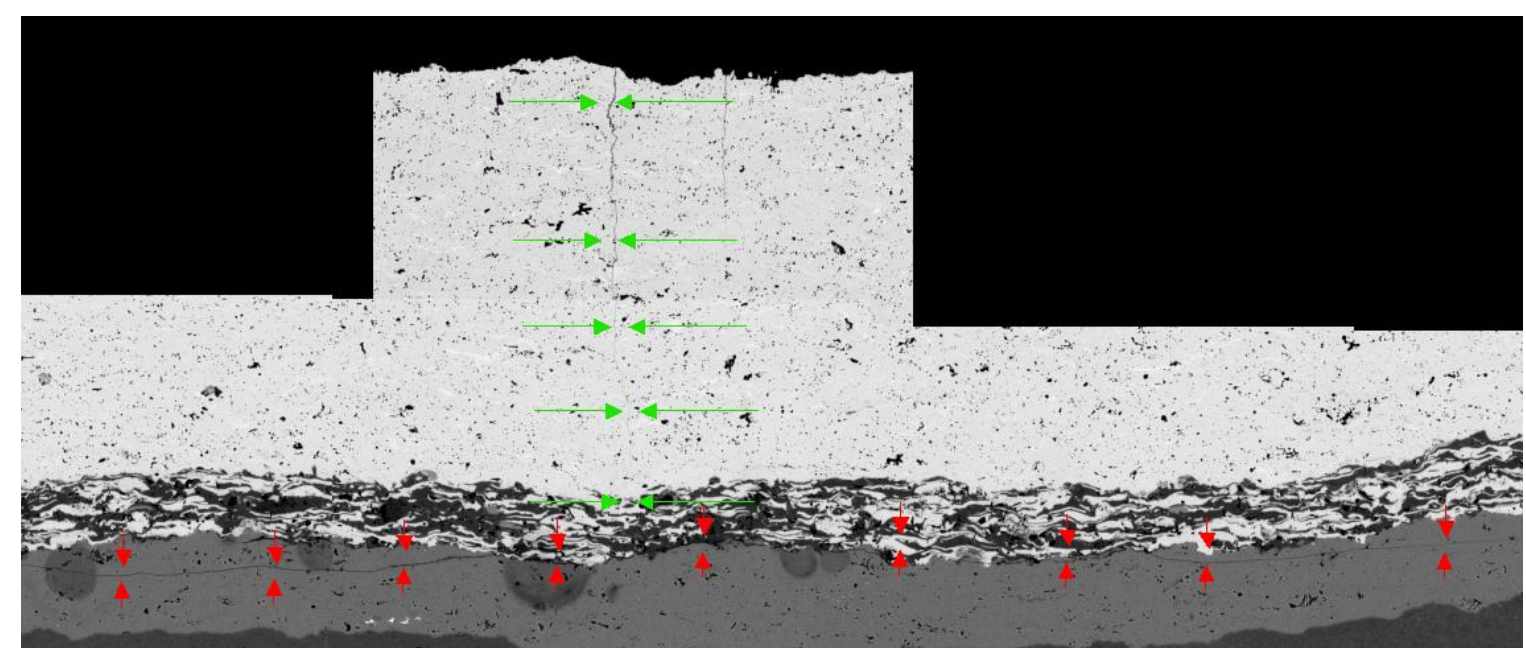

Figure 3-205. Photomicrograph of cracking generated by watermist JETS tests from $1316^{\circ} \mathrm{C}$ on the hot gas path side of sample $2269-1 \# 5$. The delamination initiated from a vertical crack (green arrows) that penetrated to the transition layer/Si bond coat interface, but the lateral crack extension (red arrows) occurs mostly within the Si layer and away from the interface.

With a low shock temperature $\left(871^{\circ} \mathrm{C}\right.$, Figure 3-204), the delamination crack propagated almost exclusively along the transition layer/Si interface, except occasionally cutting through asperities. Among the three samples in question, the delamination in this sample extended the longest, approximately $6 \sim 7 \mathrm{~mm}$. The maximum width of the crack, however, was only $\sim 2 \mu \mathrm{m}$, which could have been below the detection limit of the existing IR imaging technique.

Shocking from an intermediate temperature $\left(1093^{\circ} \mathrm{C}\right.$, Figure 3-203) seemed to result in delamination behavior that was somewhat between the above-mentioned cases. In this sample, the lateral delamination crack initiated at the interface and then meandered in and out of the interface into the interior of the silicon layer. The crack did deviate away from the interface but stayed closer to it than in the $1316^{\circ} \mathrm{C}$ shocked sample.

Although considered an unlikely scenario for the engine shrouds, thermal gradient across the thickness of the material was included in the JETS tests in order to examine the interplay of other thermal conditions with the down shock, which could have an impact on the EBC cracking behavior. Such a test on sample 2269-1\#8 suggested significant changes in crack morphology, especially in the BSAS top layer, as shown in Figure 3-206. In addition to significant debonding along the transition layer/Si interface (crack 2 in Figure 3206(a) and (c)), there was a multitude of lateral and vertical cracks in the BSAS layer as well. Some of the cracks were of significant width (cracks 3 and 4 in Figure 3-206(a)); others were tight hairline cracks (e.g., the crack tracked by the red arrows in Figure 3206(b)). One wide-open crack (crack 1) was seen to slant across the BSAS and intercept the debonding crack. The existence of these types of cracks in an engine environment could be significant, as they would provide a channel through which water vapor could penetrate 
to the Si bond coat and initiate water-enhanced oxidation, leading to failure of the EBC. In contrast, the vertical cracks seen in the isothermal shocked samples were expected to close at high temperatures if the matching of crack surfaces was not disturbed by, for example, internal stresses caused by a thermal gradient.

In summary, aggravated JETS tests conducted on a Gen1 EBC replicate shroud suggested that the pathway of delamination could be affected by the thermal shock starting temperature. Lower temperature tended to result in extensive debonding along the transition layer/Si bond layer interface, while at higher temperature the delamination was less severe and tends to propagate within the Si layer.

Although the above experiments demonstrated that thermal shock via the modified JETS test could generate cracks within the EBC coating, they did not result in any actual spalls of EBC coatings. This result suggested that the thermal stress alone was not likely to be the sole cause for the large central spall seen on the JEA engine shrouds. It was therefore suggested that a second root cause might be required for spallation. A likely second mechanism was water vapor oxidation of the bond coat through the cracks produced from the thermal shocks, leading to cristobalite formation at the interface between the Si bond coat and the transition layer. As cristobalite undergoes a phase transformation with a significant volume change at $\sim 250^{\circ} \mathrm{C}$, the silica TGO formed by water vapor oxidation is likely to be cracked, thereby leading to loss of strength at this interface. It was proposed that this weakened interface, in conjunction with the severe thermal stress during a trip event, might result in spallation. Evidence for this mechanism was provided by the fact that the JEA engine shrouds likely contained through thickness vertical cracks, as these were observed in microstructures of companion shrouds, and were therefore vulnerable to attack from water vapor in the environment.

In order to test this new proposed spallation mechanism two of the JEA EBC QC shrouds, with identification numbers 1462-03-078-1 and 1462-03-087-1, were subjected to cyclic steam furnace exposure before JETS thermal shock testing. These shrouds were coated at the MP\&E site on 2/14/05 and 2/18/05, respectively, and hence were expected to be representative of JEA engine shrouds showing the highest frequency of large center spalls. Both shrouds showed gray patches after heat-treatment similar to those seen on the JEA engine test shrouds. Photos of the shrouds after heat treatment are shown in Figure 3-208, and the locations from which the test samples were cut are marked by the green squares. The sample extracted from shroud 1462-03-078-1 had its HGP side composed mostly of gray area while the backside was essentially white. The shroud 1462-03-087-1 sample, however, was not clearly identifiable as white or gray due to the surface being smeared with dirt from handling. 

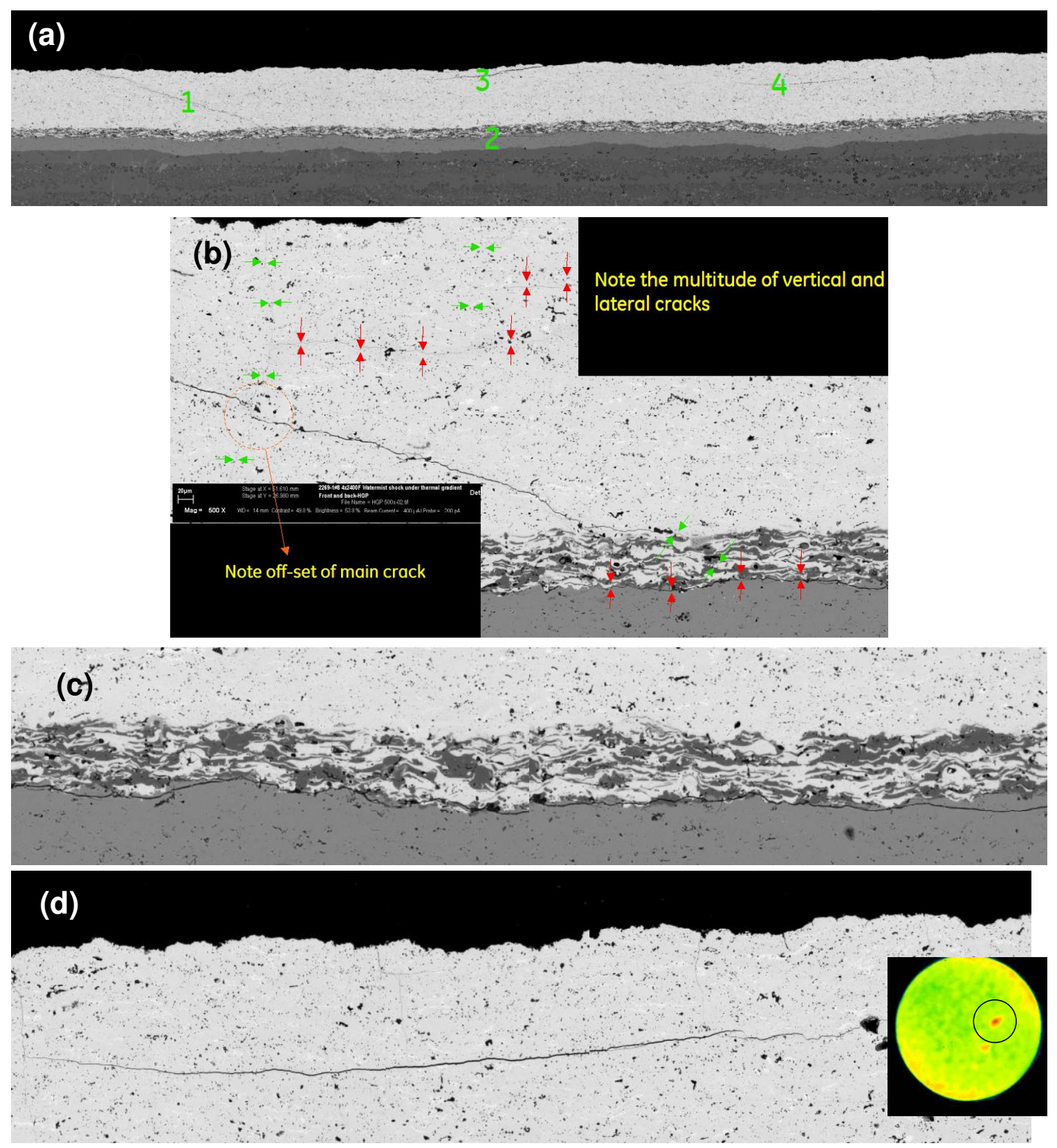

Figure 3-206. Various examples of EBC cracking on the HGP side of sample 2269-1\#8 generated by water mist JETS under a thermal gradient: (a) low magnification SEM image showing wide cracks in the EBC top layer; (b) higher magnification images showing "crack 1" with a network of finer vertical and lateral cracks; (c) close up of the crack running between the bond coat and transitions layer; (d) a lateral crack close to the BSAS surface, which was likely to be responsible for the hot spot seen in the IR image. 


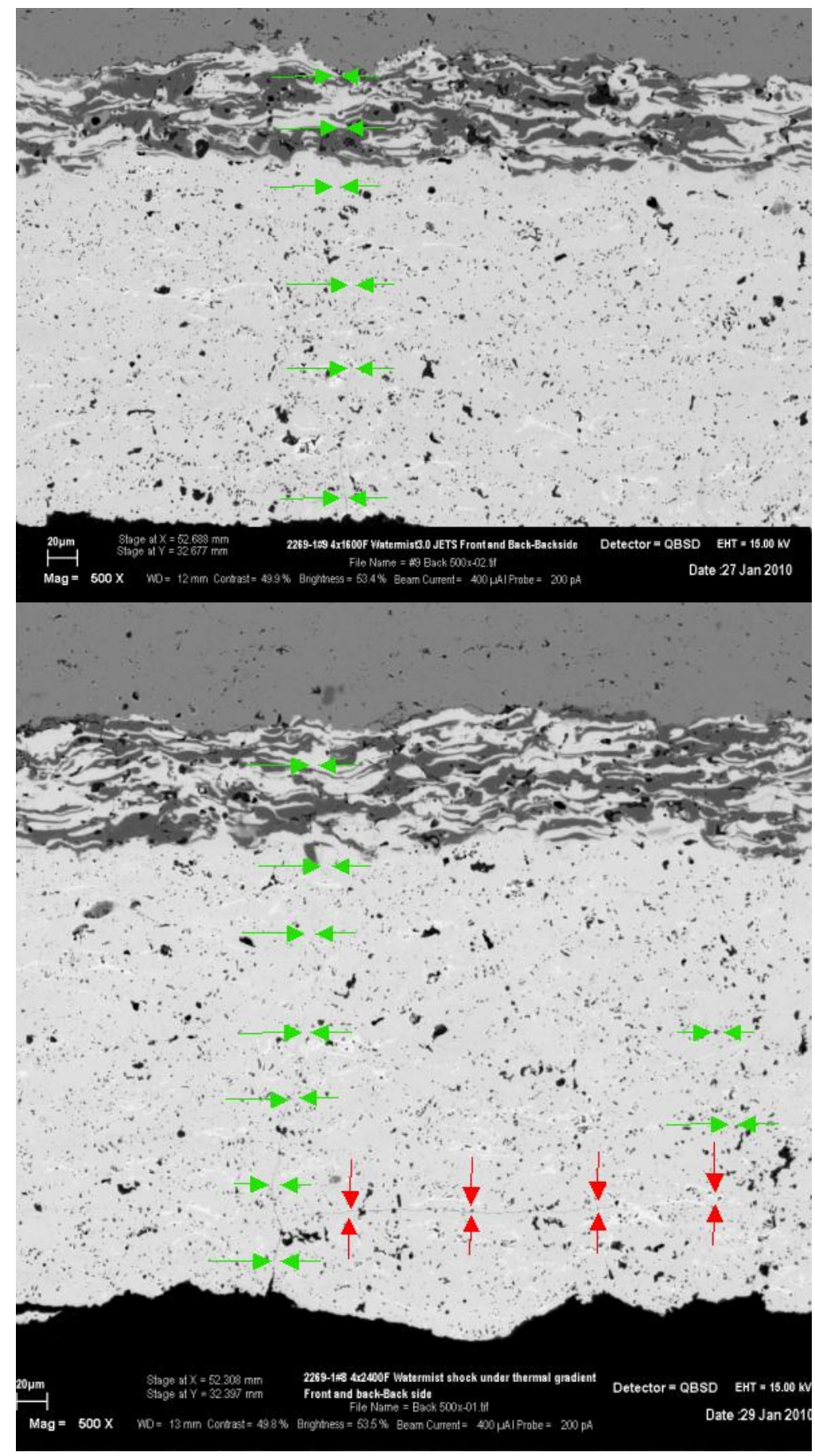

Figure 3-207. Examples of the cracks observed on the backside EBC from watermist JETS testing: Top - sample \#9 with isothermal shock from $871^{\circ} \mathrm{C}$; Bottom - sample \#8 with shock from $1316^{\circ} \mathrm{C}$ with a thermal gradient. 

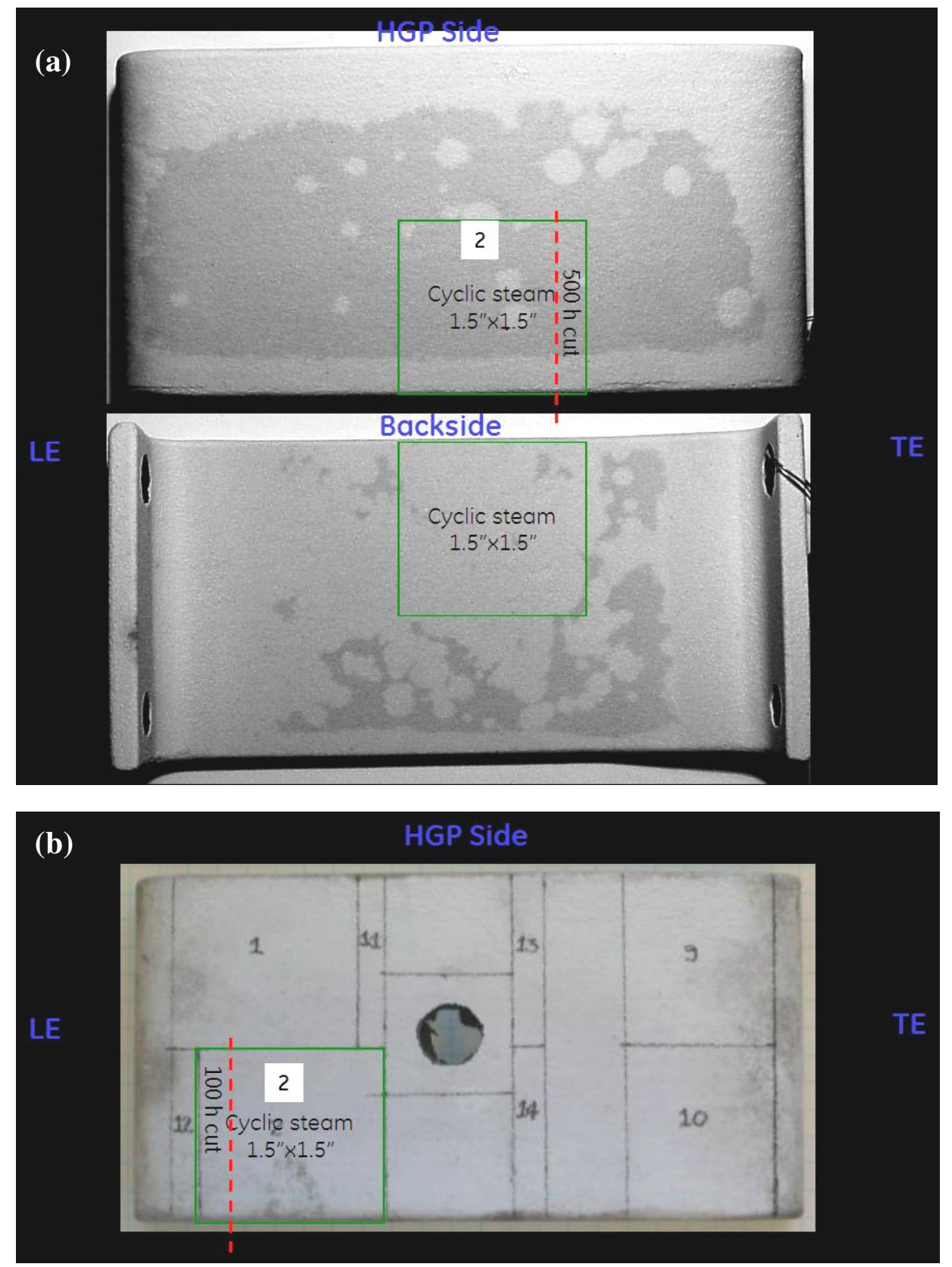

Figure 3-208. Photographs of shrouds 1462-03-078-1 (top) and 1462-03-087-1 (bottom), showing the locations from which the samples were cut for JETS testing following cyclic steam exposure.

The test samples were first subjected to $1315^{\circ} \mathrm{C}$ cyclic steam testing with $2 \mathrm{hr}$ cycles. The sample from shroud 1462-03-087-1 was exposed for 500hrs of cyclic steam testing, and that from shroud 1462-03-078-1 for 1000hrs. Both samples were then thermal shock tested on both faces from a maximum temperature of $1315^{\circ} \mathrm{C}$ in the JETS rig. The hot gas path side of each sample was tested using a forced air stream for cooling, but the backside tests used a water mist quench, which had a higher heat transfer coefficient, as described 
previously. Transient IR thermography was conducted at each stage of the tests to look for potential delaminations. After the jets tests the buttons were sectioned for metallography.

The original microstructures of the EBC coatings are shown in Figure 3-209. Like all other shrouds of this pedigree, the EBC on these shrouds was characterized by a relatively dense ( $<6 \%$ porosity) BSAS layer and an abundance of vertical cracks. These cracks typically ran through the BSAS and transition layers and then terminated at the transition/bond coat interface. The Si bond coat was of relatively poor quality with unmelted particles scattered throughout the layer.

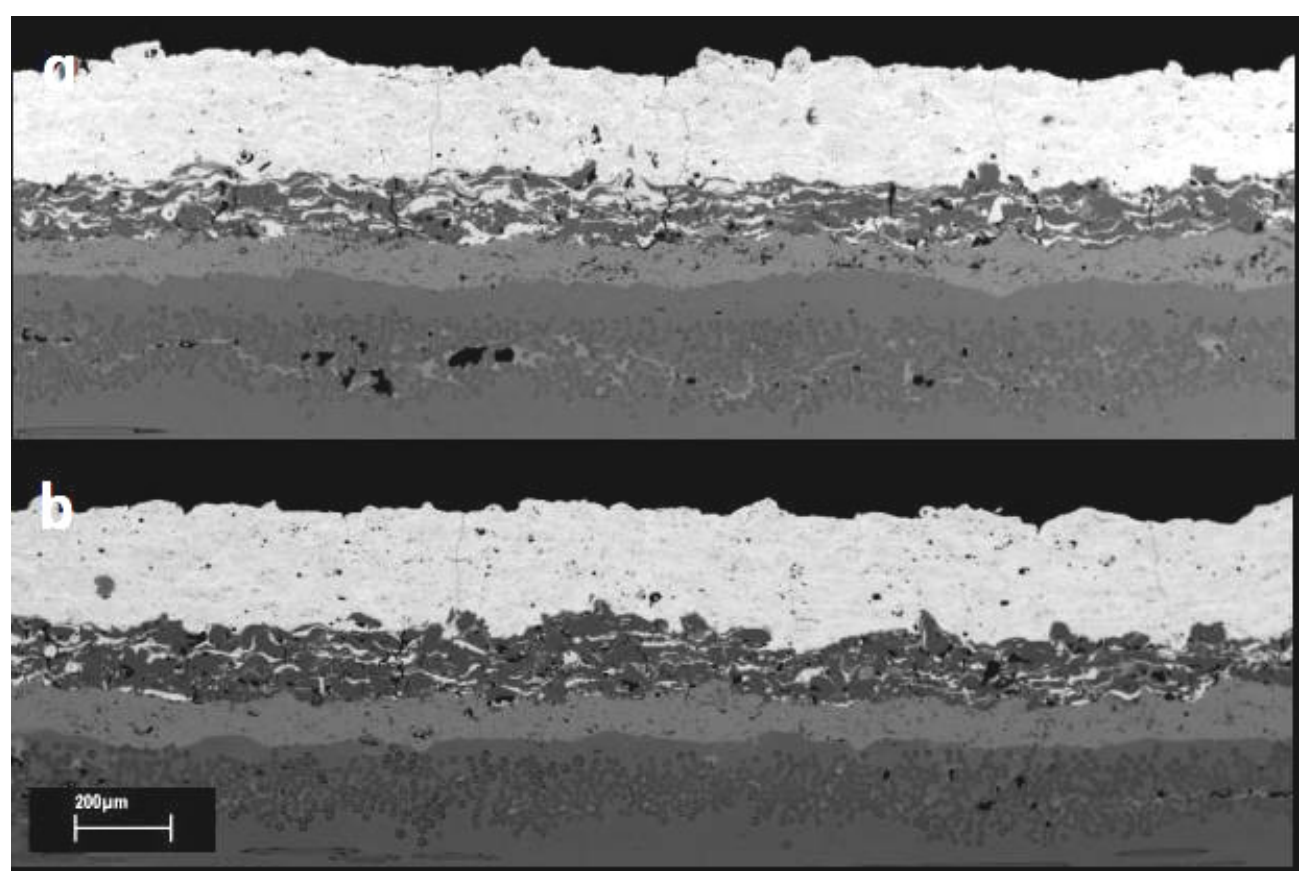

Figure 3-209. Optical micrographs of the starting EBC microstructure of the EBC coatings on the samples used for cyclic steam oxidation followed by JETS testing, showing the through-thickness vertical cracks typical in JEA QC shrouds in the as heattreated state: Top - sample 1462-03-078-1, Bottom - sample 1462-03-087-1

The evolution of the EBC microstructure during the cyclic steam test is shown in Figure 3210. Similar to previous Gen1 EBC's examined in the as-heat-treated state, there was a subtle structural difference between the white and gray regions, primarily at the interface between the mullite + BSAS transition layer and the Si bond coat. In the white regions this interface was decorated with a reaction zone that was essentially a silica rich BSAS glass. After $100 \mathrm{hrs}$ in steam a pure silica TGO layer grows between the reaction zone and silicon. At $500 \mathrm{hrs}$ vertical cracks can be seen in this silica TGO, indicating the formation of cristabolite; meanwhile, the glassy reaction zone first devitrifies and then largely disappears. At $1000 \mathrm{hr}$ lateral debonding can be observed within the cristobalite layer, most likely from reaction with water vapor. This lateral debonding, if given the time to develop further, could lead to EBC spallation. 


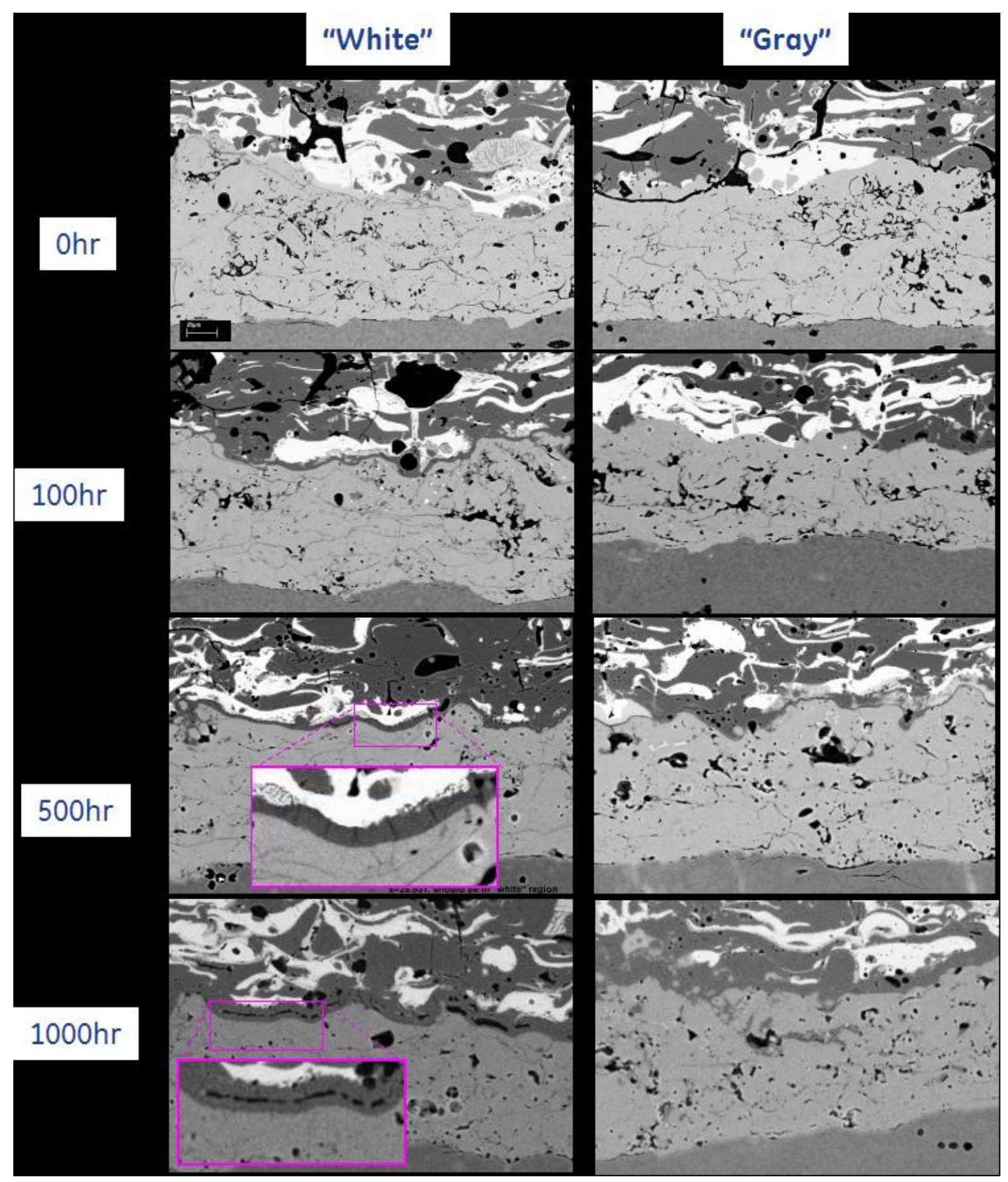

Figure 3-210. SEM micrographs of the EBC coating on sample 1462-03-078-1 during cyclic steam furnace testing, showing the evolution of the transition layer to $\mathrm{Si}$ interface during cyclic steam tests for white (left column) and gray (right column) regions 
In the gray regions in the as heat-treated state, there was no visible reaction zone between the mullite + BSAS and silicon layers. Instead the transition layer/bondcoat interface was characterized by crack-like defects or debonding. After $100 \mathrm{hrs}$ of steam testing, however, these defects were substantially healed. This healing effect, whose mechanism was not clear, decreased the number and size of the interface crack-like defects to a level comparable to what is seen in the white regions. After $500 \mathrm{hr}$ in steam test a glassy reaction layer was observed with a developing silica layer separating it from the silicon layer. Upon further steam exposure to $1000 \mathrm{hrs}$ the glassy reaction zone was largely gone while the silica TGO grew thicker.

The above observations tend to contradict the correlation between EBC spallation and gray region as seen in the engine test. Although the gray region started out with a higher concentration of lateral cracks between the bond coat and transition layer, these cracks were quickly healed and bond coat oxidation proceeded in a normal fashion. Conversely it was the white regions that showed enhanced steam penetration and formation of cristobalite in the TGO, and thus these regions would be expected to grow weaker with time and additional thermal cycles.

IR thermography imaging of the samples did indicate the possiblity of EBC debonding, as shown in Figure 3-211; however the indications were present following cyclic steam oxidation and did not appear to grow with JETS thermal shock testing. It is interesting to note that the indications in the IR images for sample 1462-03-078-1 correspond to the white spots in the original coating on the shroud. Cross-sectioning one of the spots revealed a large pocket of cristobalite, again suggesting that the white areas were more vulnerable to water vapor attack.

The cross-sections of the shocked samples were examined by SEM, and representative images are shown in Figure 3-212 and Figure 3-213. The micrographs preferentially show the roots of the through thickness vertical cracks within the footprint of the JETS flame because that is the location where the spallation cracking was most likely to occur.

It was obvious that the thermal stress conditions provided by JETS shock tests, be it forced air shock or water mist shock, did not lead to macroscopic spallation behavior. Regardless of the white or gray nature of the EBC, and regardless of the fact that there was significant cristobalite formation at the roots of the vertical cracks, the damage zone seemed to be defined almost exclusively by the cyclic steam exposure. Thermal shock did not appear able to extend the delaminations into areas that were not previously affected by the steam exposure. 


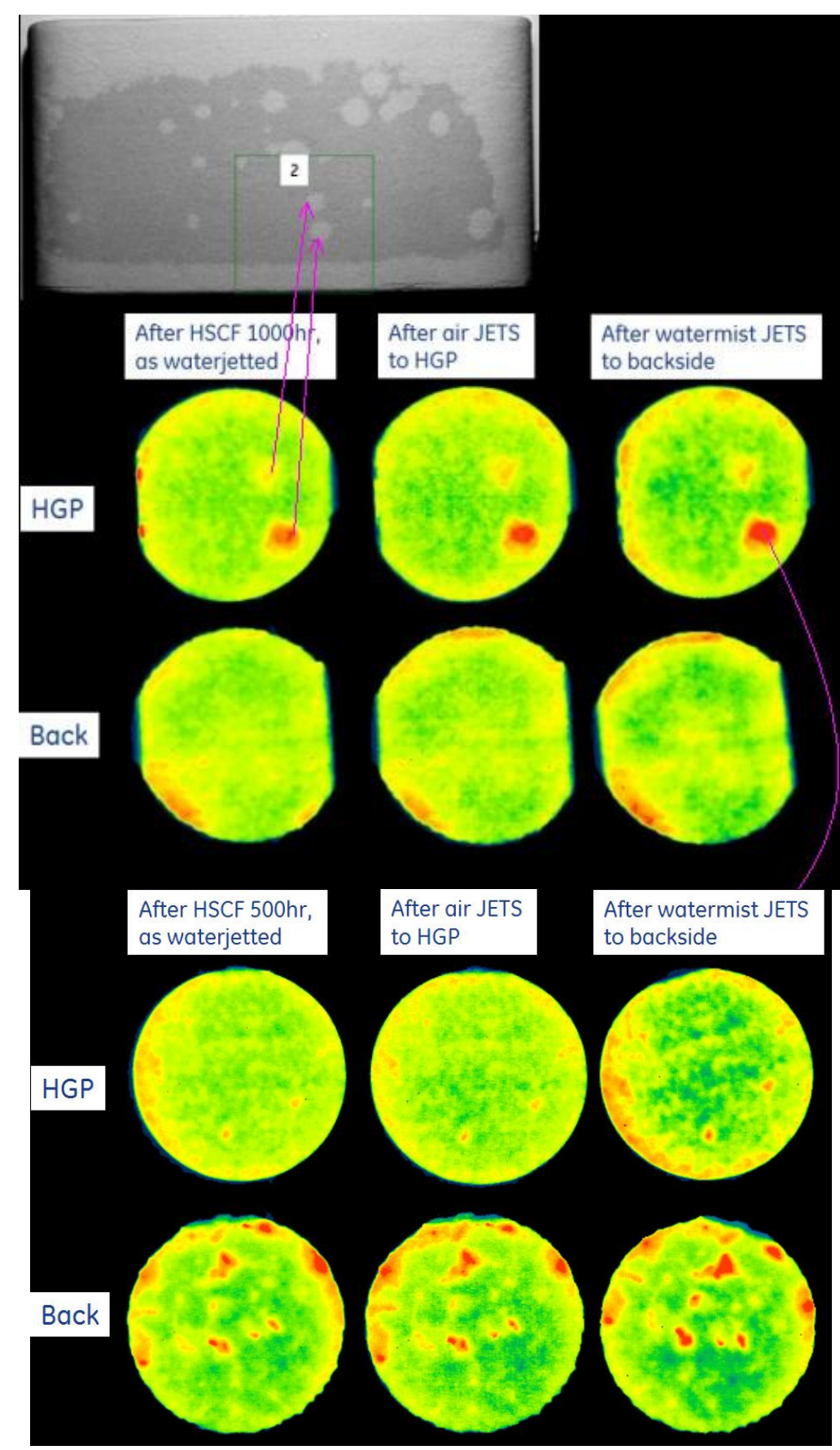

Figure 3-211. IR thermography images of the JETS samples cut from shrouds 1462-03078-1 (Top) and 1462-03-087-1 (Bottom) during the course of JETS shock tests. Features seen in the IR images of the the sample from shroud 1462-03-078-1 correlated with white spots seen on EBC coating following initial heat treatment. 

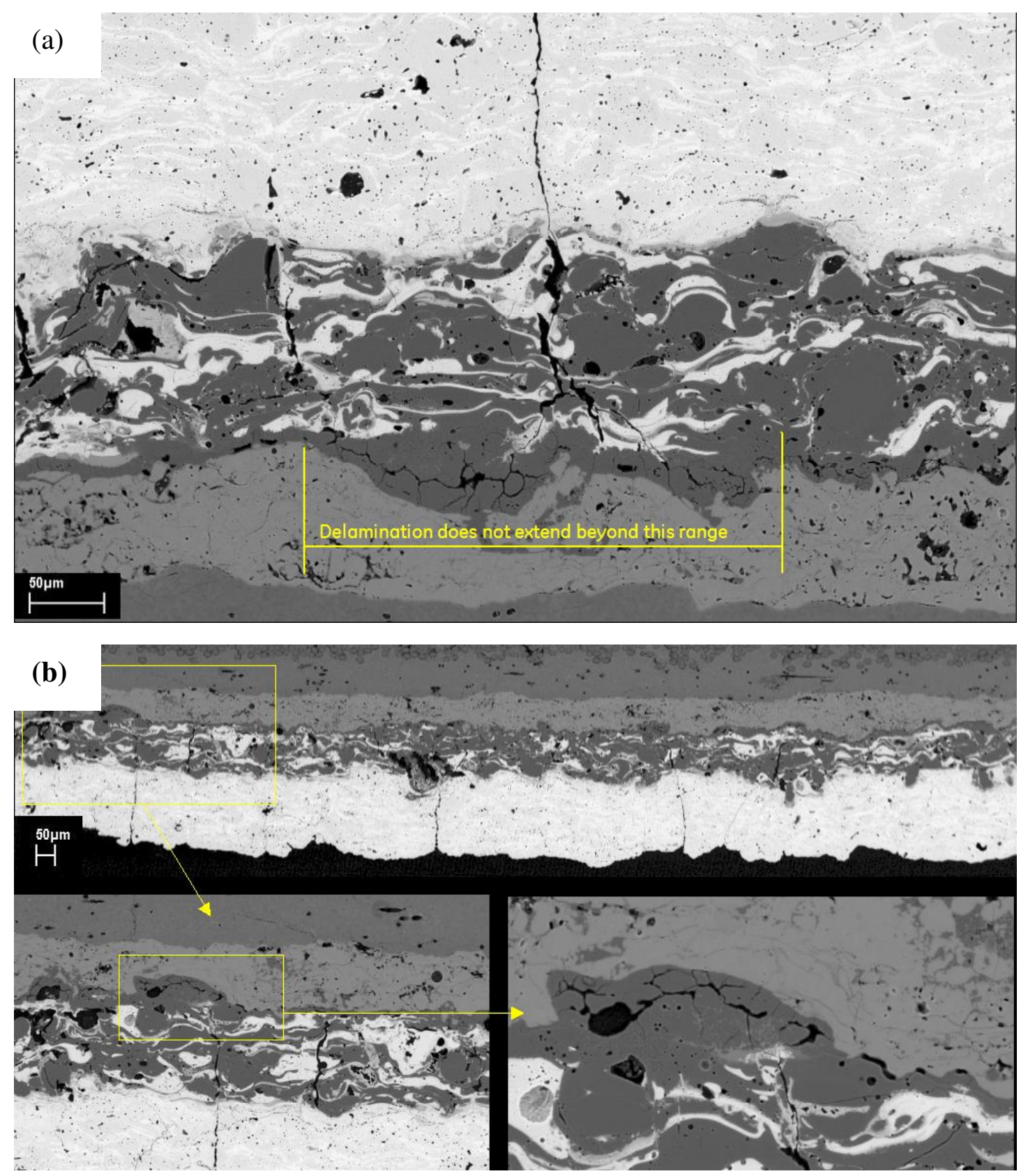

Figure 3-212. SEM micrographs of the EBC cross section from sample 1462-03-078-1 following JETS testing: (a) face quenched using forced air cooling, (b) face quenched water mist impingement. 

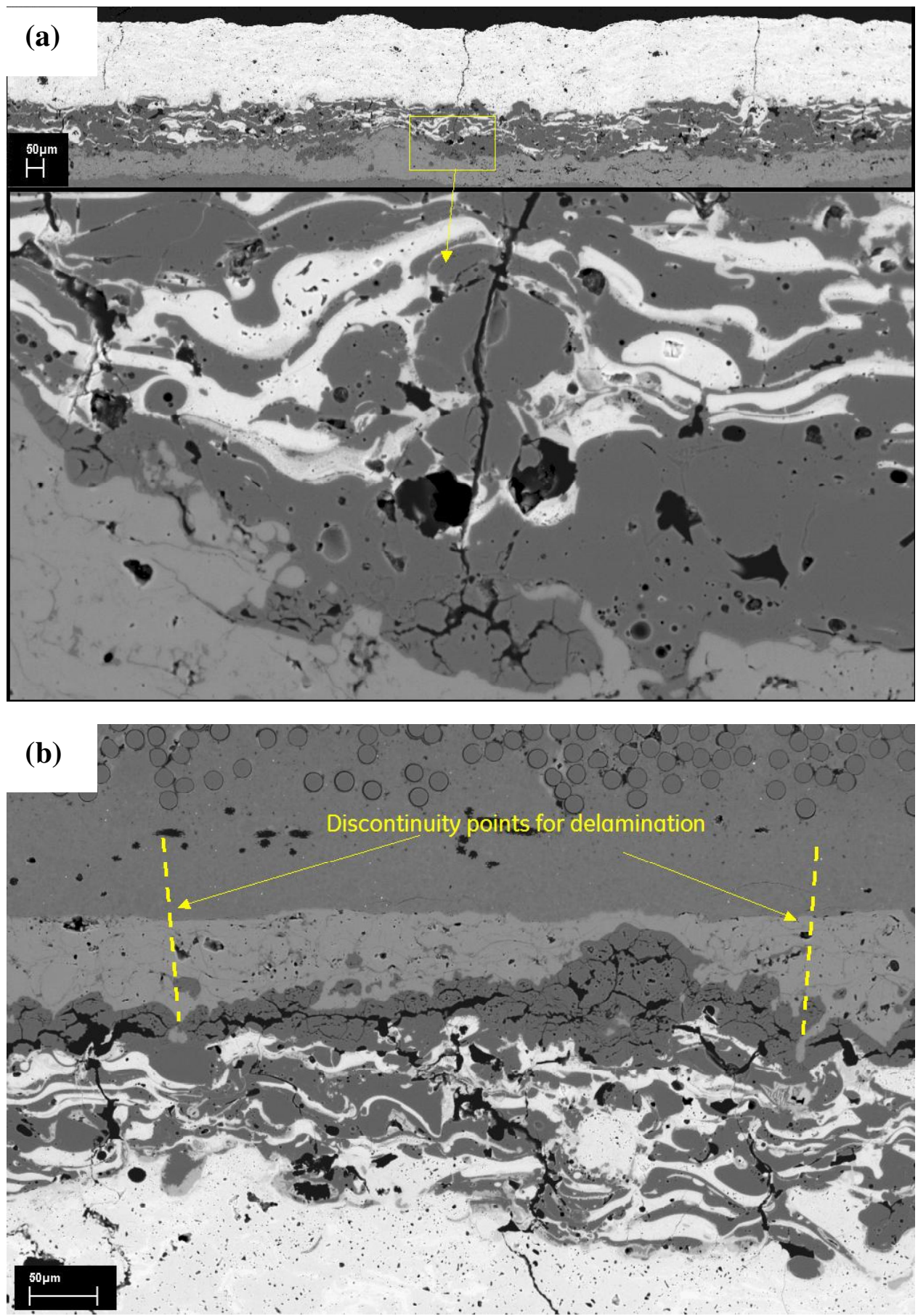

Figure 3-213. SEM micrographs of the EBC cross section from sample 1462-03-087-1 following JETS testing: (a) face quenched using forced air cooling, (b) face quenched water mist impingement.

Despite the extensive analysis and experimentation described above, a definitive root cause for the large center EBC spalls seen in shroud engine test \#2 was not identified. Although thermal shock quenching could introduce cracks in the EBC coatings, no actual spalls were 
observed. Several other potential mechanisms were postulated and will be investigated past the end of this program.

Although borescope inspection evidence suggests that most of the flange edge spalls are at least partly related to FOD events, there is no way to unambiguously confirm this without access to the shrouds. The current trend is to substitute Gen2 EBC for the Gen1 EBC used in engine test \#2 on the grounds that it will have enhanced life margin from volatilization of the oxide layers, and because of the desire to carry only one EBC composition into production. Evidence from this engine test is that the Gen2 EBC abradable ridges were more durable than ridges made from BSAS since they showed much less particle erosion early in the test, as shown in Figure 3-178. It is hoped that this improved erosion durability will translate to increased FOD resistance as well.

The performance of the shrouds in the engine test will continue to be monitored, and additional periodic borescope inspections will be conducted as the engine operating schedule and utility owner permit. Data regarding EBC spall growth rates and occurrences of new spalls will continue to be collected. At the next hot gas path rebuild, currently scheduled for the Fall of 2012, the shrouds currently in the engine will be removed and extensive post-test characterization is planned in order to better understand the chemical and microstructural features of the $\mathrm{EBC}$ and $\mathrm{CMC}$ that contributed to the formation of the EBC spalls.

\subsubsection{Task S3.3 - Shroud Material and Process Improvements}

In addition to the tasks needed to perform the shroud engine test, the 2006 program modification also included a new task to examine methods for improving the CMC inner shrouds. New Task S3.3 covered the development of new material modifications and/or processing techniques to improve the quality of the $\mathrm{CMC}$ inner shrouds or to reduce the cost of these components. Such improvements were necessary since the production costs of the CMC shrouds was still very high and was serving as an impediment to the commercial introduction of this technology. The goal of this task was to investigate methods of reducing the fabrication cost of CMC shroud components, either through direct process cost reductions or by improvement in shroud quality, and thereby overall process yields. Improvements in shroud quality were also expected to help ensure that the CMC shrouds could meet the desired 48,000 hours component life.

Two general approaches for lowering costs and improving quality were investigated. The first approach was to utilize a hybrid $\mathrm{CMC}$ /monolithic ceramic structure by combining layers of normal CMC with layers of monolithic $\mathrm{SiC}-\mathrm{Si}$. The intent of this structure change was to reduce the amount of coated fiber needed per inner shroud, thereby lowering the cost of the shrouds. It was also anticipated that the change in architecture would reduce microstructural defects in the shrouds by helping to minimize the intra-ply delaminations that were commonly seen in the flange corners of the CMC inner shrouds produced up to that time. Since these intra-ply delaminations were a major cause of shrouds being rejected 
from the previous engine test populations, minimizing these defects would improve the shroud process yield, which would again lower the overall shroud costs.

The second major approach for reducing CMC shroud cost and improving quality was to further optimize the chemical vapor deposition (CVD) fiber coating operation, with the intent to reduce the coating layer number or thickness. The fiber CVD coating operation was, and still is, the most expensive process step in the fabrication of the MI CMC components. Simplifications to this process, by reducing or eliminating one or more coating layers, would have a direct impact on the cost of the coated fiber, and therefore on the overall CMC component cost. Coating process simplification could also help to improve $\mathrm{CMC}$ quality by minimizing potential mechanical damage to the fiber tows during the coating operation.

These two general approaches to $\mathrm{CMC}$ shroud cost reduction and quality improvement are described in the sections below.

\subsubsection{Investigation of Hybrid CMCs}

The goal of this subtask was to develop a technique for fabricating hybrid $\mathrm{CMC} /$ monolithic structures using the prepreg MI composite approach, evaluate the mechanical properties and damage resistance of such hybrid composites, and demonstrate that CMC inner shroud components could be fabricated using such composites. The term "hybrid CMC" in this report refers to component architectures where part of the fiber-reinforced CMC material has been replaced with a cheaper, monolithic $\mathrm{SiC}$ material.

In prepreg MI composites the obvious choice for the monolithic $\mathrm{SiC}$ is simply unreinforced matrix material. Also, since the composites are made up of individual ply layers, introducing the monolithic $\mathrm{SiC}$ via substitution of matrix-only plies for the normal fiberreinforced plies was expected to have the minimum disruptive impact on the overall CMC fabrication process. In this way the global fiber volume fraction, as well as the throughthickness distribution of monolithic and composite material, could be easily controlled by simply changing the ply stacking sequence.

A second method of producing "monolithic" plies would be to fabricate normal composite plies using uncoated fiber. Although utilization of uncoated fiber in the monolithic layer would not give the same raw material cost reduction as a completely unreinforced matrix layer, it would still eliminate the costly fiber coating process step for these layers. Fibers that would be viable for such application include carbon and SiC. Again, carbon fiber would offer greater raw material cost reductions that $\mathrm{SiC}$ fiber, but it was well known from prior work on monolithic Silcomp and on monofilament-reinforced MI CMCs that getting complete reaction of the carbon fiber during the melt infiltration times used for CMCs would be a problem [1, 2]. Any residual carbon, especially in the form of continuous fibers, would pose a great threat to the oxidative stability of the system, and thus uncoated SiC fibers were chosen for evaluation here. The description of the activity with the uncoated fiber plies is discussed later in this section. 


\subsection{Hybrid Structures Using Monolithic Matrix Plies}

The first development that was required for fabrication of the hybrid CMCs with monolithic matrix plies was a technique for preparing the matrix-only plies of comparable thickness to the normal composite plies. The technique chosen for preparation of the matrix plies was a simple doctor blade tape casting. This technique had been used for fabrication of CMC plies with Textron SCS monofilament SiC fibers in the late 80's to early 90's before the introduction of continuous fiber coating and wet drum winding technology [2]. Tape casting had also been used previously for the fabrication of thin matrix plies that are typically laminated onto the surfaces of prepreg MI CMC components to improve surface finish and protect the underlying fiber-containing plies from machining, handling and oxidation damage. Thus there was already substantial experience with tape casting and there were reasonable expectations that it would be successful.

The objective of the initial tape casting study was thus to determine whether consistent thickness, high quality matrix plies could be fabricated at a nominal thickness of roughly $0.27 \mathrm{~mm}$ in order to match the nominal composite ply thickness. However, a secondary goal was to see if this technique could be used to produce the surface matrix plies on a more consistent basis than the current hand-impregnation process, and thus a tape thickness of roughly $0.13 \mathrm{~mm}(0.005$ ") was also of interest. Experience with the surface matrix plies had demonstrated that the use of the carbon veil provided substantial handling robustness to the tapes [17], and thus it was desired to keep the veil in both the thicker monolithic matrix plies and the thinner surface matrix plies in order to ease sample lay-up.

The tape caster available for use at GRC was a fixed bed, moving head doctor blade arrangement, which is shown schematically in Figure 3-214. The tape casting process involved taping a carbon veil to a carrier film (typically silicone-coated mylar) that was placed on the bed of the tape caster. The moving doctor blade then "pushed" a pool of matrix slurry over the bed at a constant speed. The thickness of the final tape is controlled by the height of the doctor blade above the casting table, the translation speed of the doctor blade, and the rheology and drying shrinkage of the slurry. Standard composite matrix slurry was used for the initial experiments in order to ensure that the matrix composition of the composite and monolithic plies matched. This essentially fixed the rheology and drying shrinkage of the slurry, eliminating them as process variables.

A formal DoE was performed to examine the effects of blade height and casting speed on the final tape thickness. Five blade heights and four casting speeds were investigated. Sample tapes, nominally $30 \mathrm{~cm} \times 15 \mathrm{~cm}$ in size, were cast and allowed to dry. The tapes were then cut into thirty two $3.2 \mathrm{~cm} \times 3.2 \mathrm{~cm}$ squares for measurement of tape thickness and areal density. Ten of the squares from each tape were stacked and autoclave laminated to measure any lamination compaction. 


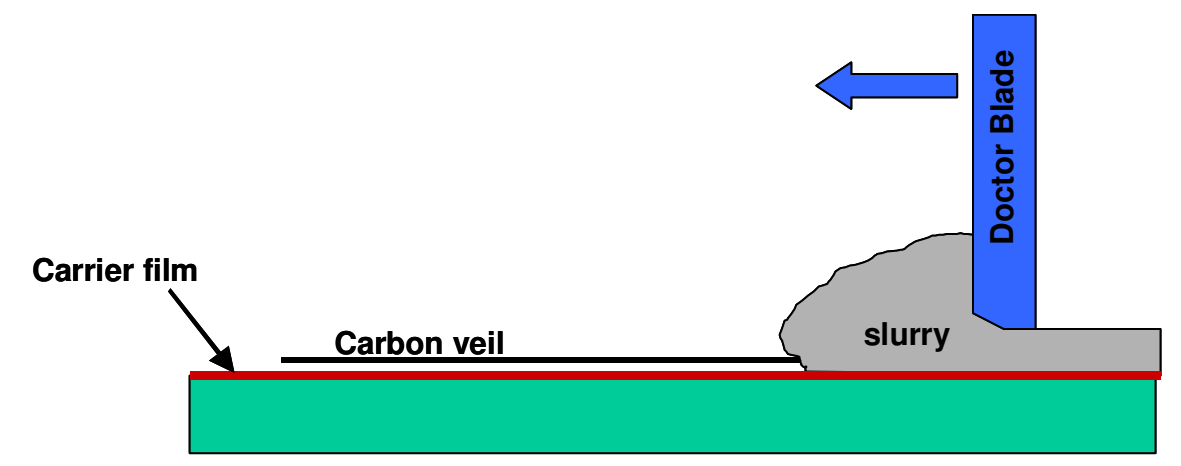

Figure 3-214. Conceptual diagram of the tape casting procedure used for monolithic matrix ply fabrication.

Figure 3-215 shows the results for tape thickness and areal density measurements. Overall the two measurements gave consistent trends as a function of casting speed and blade height, as would be expected. The box plot data points on these graphs represent the distribution of thicknesses from 10 to 12 measurements made a various locations across the entire $30 \mathrm{~cm} \times 15 \mathrm{~cm}$ tape. Regression was successfully used to fit the tape thickness measurements to an empirical relationship that described the data trends quite well. The lines in the plots of Figure 3-215 represent the predicted results from the regression, which had an $\mathrm{R}^{2}$ value of 0.999 .

The consistency and uniformity of thickness for the tape cast matrix plies was much better than for hand made plies. Figure 3-216 shows a comparison of the thickness measurements from four hand-made matrix plies and from three comparable tape cast plies. The target thickness for all of the tapes was $0.13 \mathrm{~mm}(0.005 ")$. The scatter in thickness for each hand made ply was as much as +/-3 mils, whereas the scatter in thickness for the tape cast plies was $+/-1$ mil or less. The variability in average thickness between plies was also much less for the tape cast plies. These results demonstrate the improved consistency that is achievable with tape casting compared to a hand impregnation operation. 

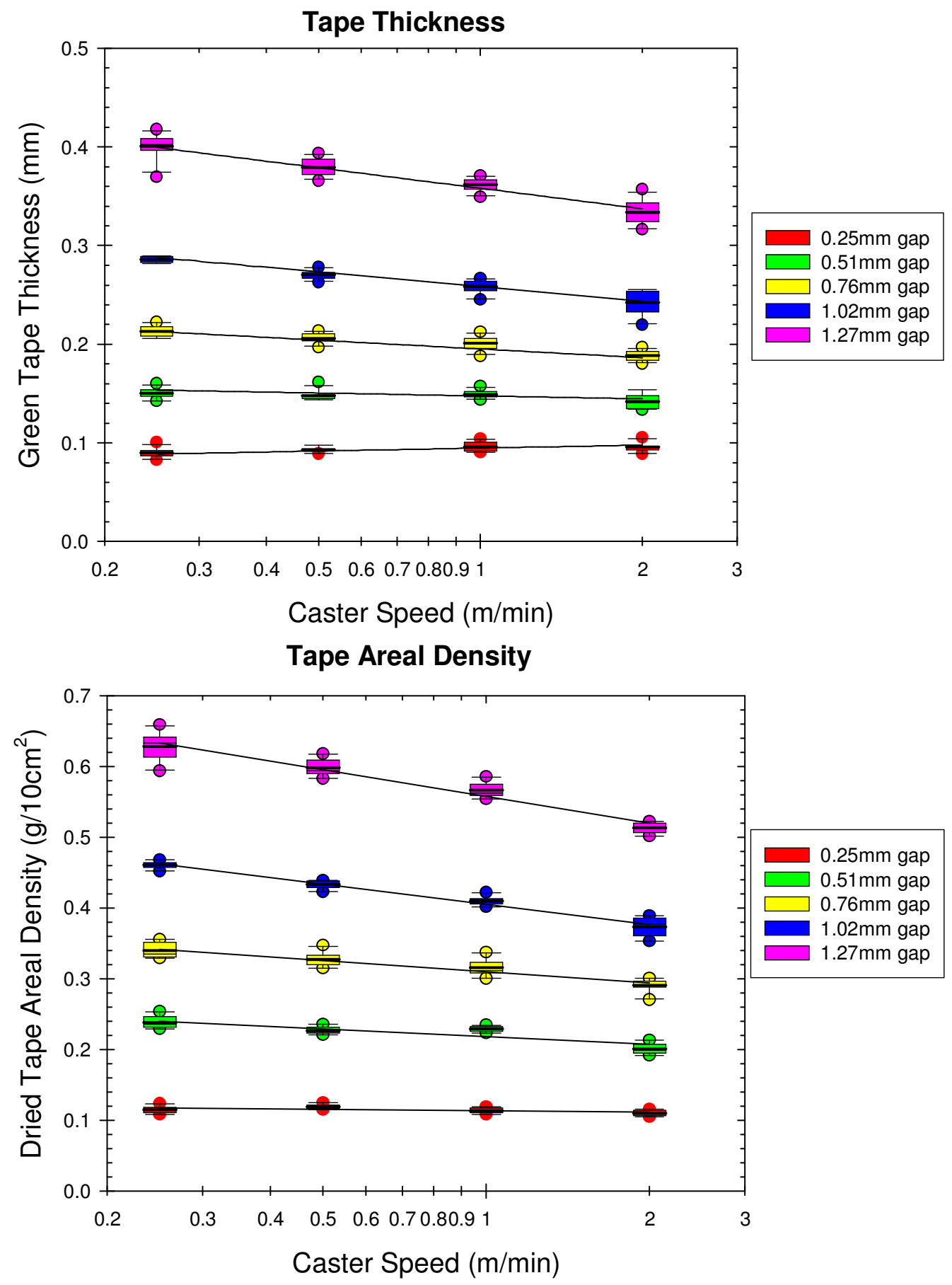

Figure 3-215. Tape thickness (top) and areal density (bottom) as functions of the casting speed and blade gap height for the tape casting design of experiments. Both measurements showed consistent trends. 


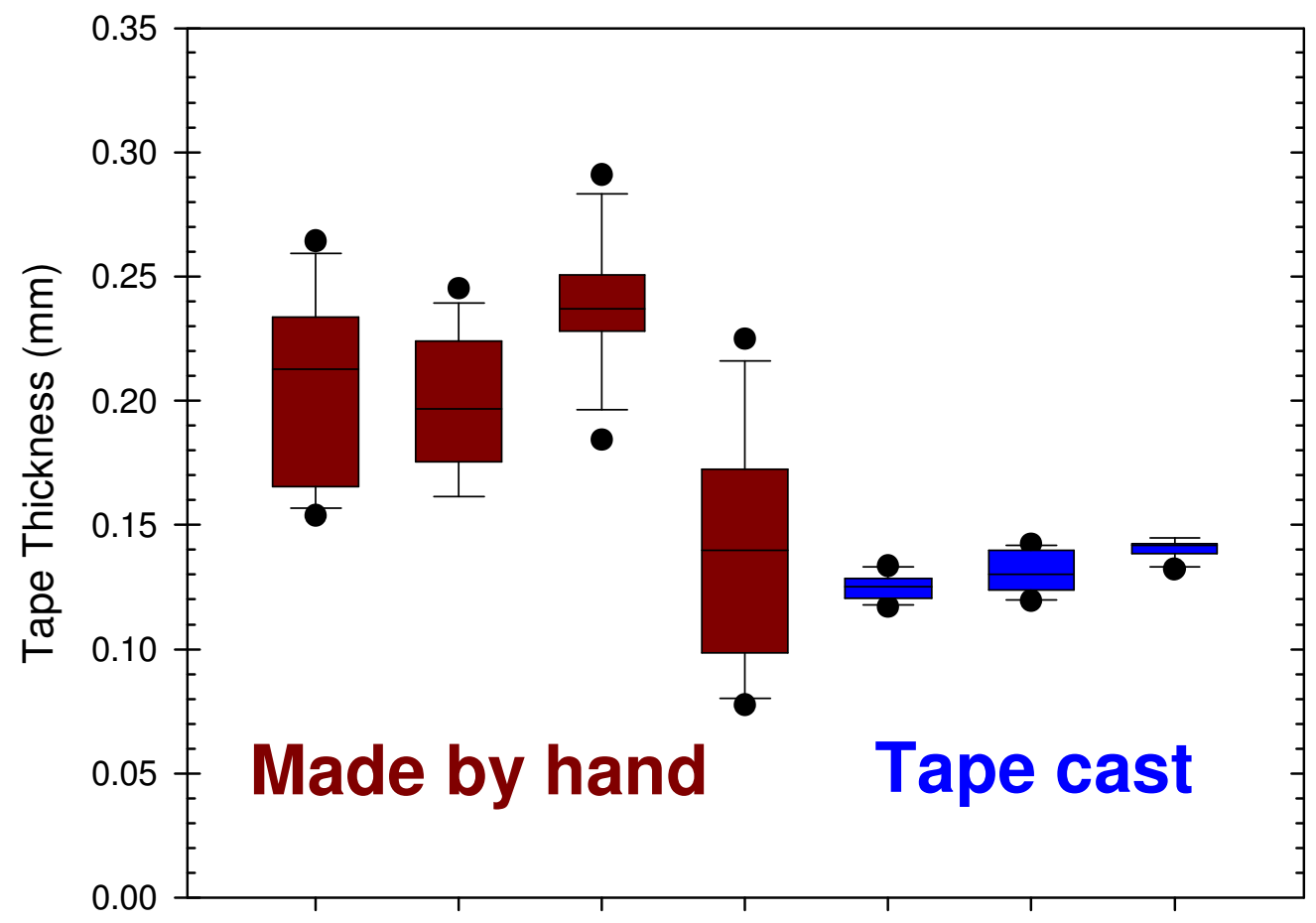

Figure 3-216. Comparison of the range in thickness of matrix plies made by hand impregnation of carbon veil with those made by tape casting.

The above results demonstrated how the thickness of tape cast matrix plies could be very consistent and controllable. However, the thickness that was of interest was that of the matrix plies after the autoclave lamination procedure where all residual solvents were driven off. Stacks of 10 layers of matrix plies were prepared and run through the standard autoclave lamination procedure in order to determine the per ply thickness after lamination. Figure 3-217 shows a plot of laminated ply thickness versus green ply thickness determined from these samples. The dashed line in the plot represents a perfect 1:1 correspondence between green tape thickness and laminated tape thickness. The trend line for the samples falls slightly below the 1:1 line, which was due to a modest $3 \%$ average compaction during lamination. However, two sets of samples fell significantly below the overall trend line. These were the samples made by hand impregnation (red) and those made at the lowest blade gap height of $0.25 \mathrm{~mm}$ (dark red). The extra compaction of these sets of samples were due to extra porosity in the as-cast tapes. When casting at the $0.25 \mathrm{~mm}$ gap height the carbon veil was initially fully saturated with matrix slurry. During drying there is sufficient volume reduction from loss of the solvents that the veil was no longer fully saturated with solids. Porosity and pin-holes through the tape cast plies were visually evident in tapes cast at the $0.25 \mathrm{~mm}$ gap height. Tapes cast at the higher gap heights still appeared fully saturated with solids after tape drying, and thus only very minor compaction occurred during autoclave lamination. The fact that the hand-made matrix plies also showed more compaction than the tape cast matrix plies suggests that they also contained porosity that was eliminated during autoclave lamination. 


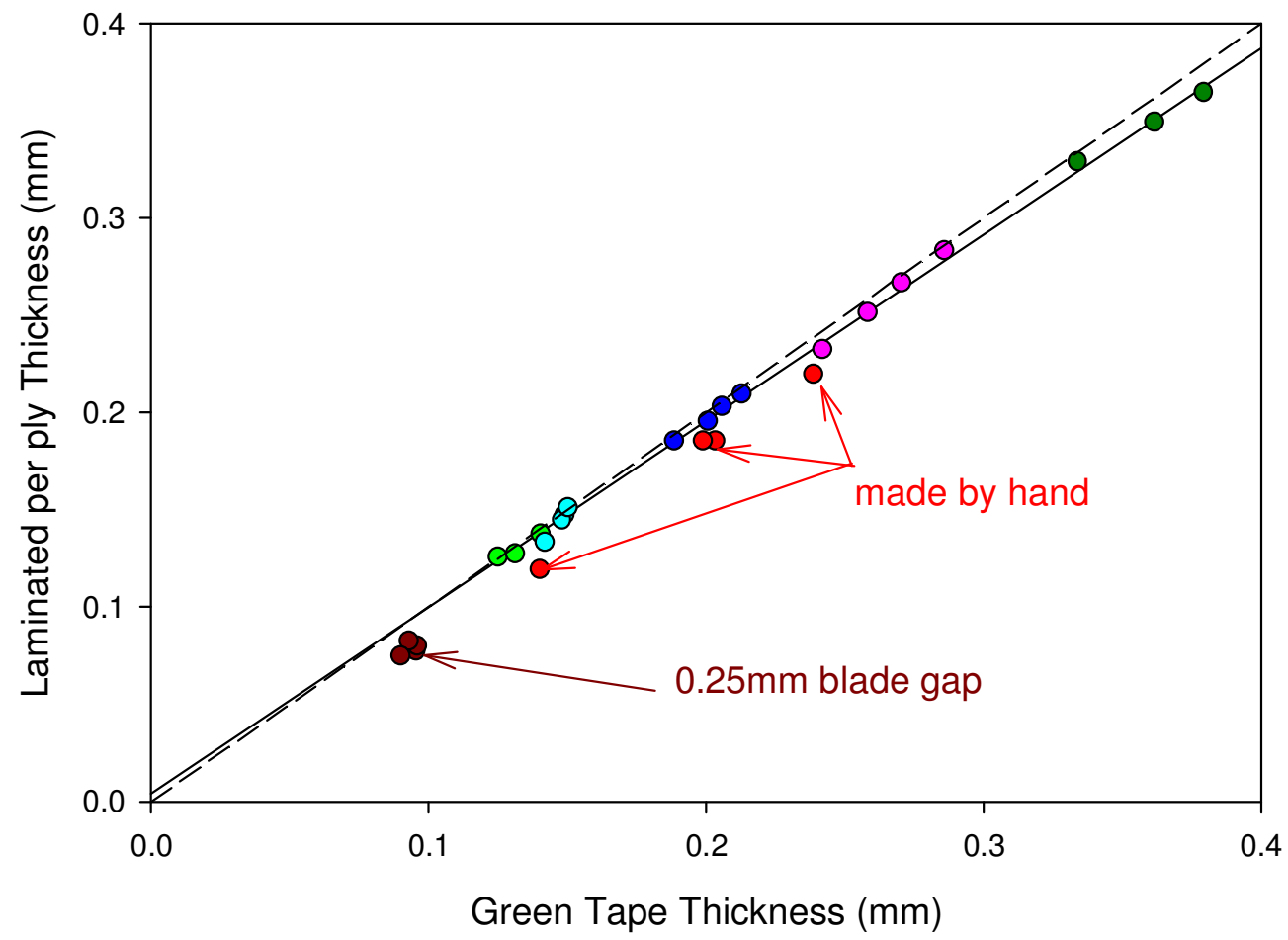

Figure 3-217. Relationship between measured green tape thickness and the afterlamination ply thickness for various matrix plies. The data that fall below the trend line were for the hand made plies and for those cast at $0.25 \mathrm{~mm}$ gap height, which had visible porosity in the tapes after drying.

Controllable tape thickness was therefore demonstrated over a wide range of tape casting conditions. Unfortunately, tape quality/uniformity issues were noted for many of the samples. During the casting process the matrix slurry tended to get pushed ahead of the doctor blade over the top of the carbon veil. At the higher casting rates the matrix slurry did not wet through the veil to completely fill in the space under the veil fast enough, leaving behind air bubbles trapped below the veil. This condition was actually noted, to a greater or lesser extent, on the majority of matrix plies produced. While the actual volume of material displaced by these bubbles was not sufficient to significantly affect the overall tape thickness and areal density measurements, it did lead to very localized thickness variations and cosmetically bad matrix plies.

Figure 3-218 plots out the regions in the casting rate vs. blade gap height process map where this bubble entrapment was observed. The region affected by the unsaturated carbon veil, as discussed above, is also shown. There was a relatively small region of the process conditions studied where neither of these tape defects occurred. Fortunately this window was large enough to give high quality matrix plies over a thickness range of 0.11 to $\sim 0.34 \mathrm{~mm}$, which covered the desired values of $\sim 0.27 \mathrm{~mm}$ for the hybrid material study and 
$\sim 0.13 \mathrm{~mm}$ thickness needed for the matrix surface plies. Obviously eliminating the carbon veil in the tapes would eliminate the bubble entrapment issue, and the window for producing high quality tapes would be greatly expanded.

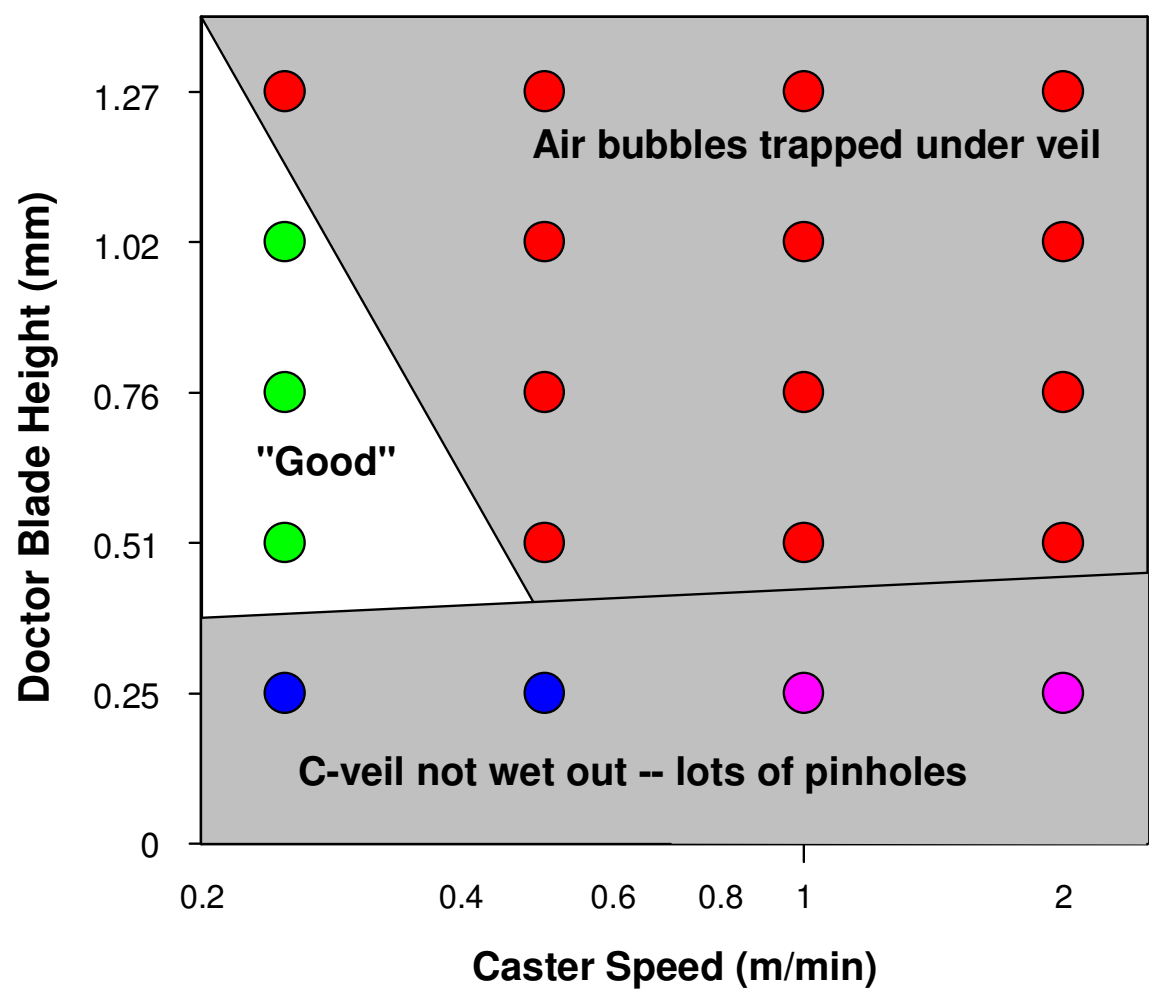

Figure 3-218. A process map for the tape casting of matrix plies showing the regions for combinations of casting speed and caster gap height combined to give various defects or good quality matrix plies.

Given the success of the tape casting approach, the decision was made to move forward with fabrication of the hybrid $\mathrm{CMC} /$ monolithic structures using tape cast matrix plies. Also, since the vast majority of shrouds fabricated for use in the engine tests contained Hi-Nicalon fiber this fiber was also used for this set of hybrid CMC samples. Nine different ply stacking configurations were chosen for evaluation, as listed in Table 3-17.

Some clarification of the "Architecture" column in Table 3-17 is in order. All of the configurations had 18 total plies with the additional surface matrix plies. Since the surface matrix plies were roughly $1 / 2$ the thickness of the body monolithic matrix plies, when added in with the normal ply count the surface plies brings the total ply count to 19 . In the allCMC sample there were 18 composite plies plus the two surface matrix plies, which are the equivalent of one normal ply, so that the "fraction composite" was $18 / 19$, or 0.947 , and the "fraction monolithic" was $1 / 19$, or 0.053 . This configuration represented what a normal shroud build typically looked like. 
For the $2 / 3 \mathrm{CMC}, 1 / 2 \mathrm{CMC}$ and $1 / 3 \mathrm{CMC}$ "distributed" configurations the $\mathrm{CMC}$ and monolithic matrix plies were interspersed through the thickness as uniformly as possible while trying to maintain symmetry between the halves of the layup. The " $1 / 2 \mathrm{CMC}$ on one side" samples had all of the CMC plies located in one half of the layup with the other half being entirely made of monolithic plies. The $1 / 2 \mathrm{CMC}$ skins sample had all the CMC plies near the outer faces and only monolithic plies in the center, and the $1 / 2 \mathrm{CMC}$ center sample was the opposite, with the monolithic matrix plies near the outer faces and the CMC plies all at the center of the layup. The full monolithic sample was, as the name suggests, made from all monolithic matrix plies and no CMC plies.

Table 3-17 Fiber Architecture Configurations of the First Set of Hybrid CMC/Monolithic Test Panels Made with Hi-Nicalon Fiber

\begin{tabular}{|c|c|c|c|c|c|c|}
\hline \multirow[b]{2}{*}{ Architecture } & \multicolumn{4}{|c|}{ Number of Each Ply Type } & \multirow[b]{2}{*}{$\begin{array}{c}\text { Fraction } \\
\text { CMC }\end{array}$} & \multirow[b]{2}{*}{$\begin{array}{c}\text { Fraction } \\
\text { monolithic }\end{array}$} \\
\hline & $\begin{array}{c}0^{\circ} \text { composite } \\
\text { plies }\end{array}$ & $\begin{array}{c}90^{\circ} \text { composite } \\
\text { plies }\end{array}$ & $\begin{array}{c}\text { monolithic } \\
\text { matrix plies }\end{array}$ & \begin{tabular}{|c|} 
surface \\
matrix plies
\end{tabular} & & \\
\hline Normal full CMC & 9 & 9 & 0 & 2 & 0.947 & 0.053 \\
\hline 2/3 CMC distributed & 6 & 6 & 6 & 2 & 0.600 & 0.368 \\
\hline $1 / 2$ CMC distributed & 4 & 4 & 10 & 2 & 0.421 & 0.579 \\
\hline 1/2 CMC skins & 4 & 4 & 10 & 2 & 0.421 & 0.579 \\
\hline 1/2 CMC center & 4 & 4 & 10 & 2 & 0.421 & 0.579 \\
\hline $1 / 2$ CMC on one side & 4 & 4 & 10 & 2 & 0.421 & 0.579 \\
\hline $1 / 2$ CMC on one side & 4 & 4 & 10 & 2 & 0.421 & 0.579 \\
\hline 1/3 CMC distributed & 3 & 3 & 12 & 2 & 0.316 & 0.684 \\
\hline Full monolithic & 0 & 0 & 18 & 2 & 0.000 & 1.000 \\
\hline
\end{tabular}

Fabrication of all nine test configurations was completed, but with very poor results. Fabrication through autoclave lamination proceeded normally, with no indication of panel distortions or delaminations. However, following the binder burn-out step most of the panels showed severe delaminations along the edges and distinct out-of-plane warping. Only the panels with the full normal CMC configuration or the full monolithic ply configuration showed no distortions or delaminations. Despite these dire results after burnout, most of the panels were completed through melt infiltration. Again, only the fully $\mathrm{CMC}$ and fully monolithic panels showed no distortion following infiltration, though the monolithic panel did show signs of edge-initiated cracking.

Transmission and reflection IR NDE images were taken of the infiltrated panels in order to gage the extent of the delaminations. The results of the IR transmission inspections are shown in Figure 3-219. All of the samples with mixed CMC and monolithic plies showed some level of delamination. In general the NDE indications, both in reflection and in transmission, were more severe as the thickness of the monolithic regions increased, with the worst samples being those with all CMC on one side and all monolithic plies on the other side. 

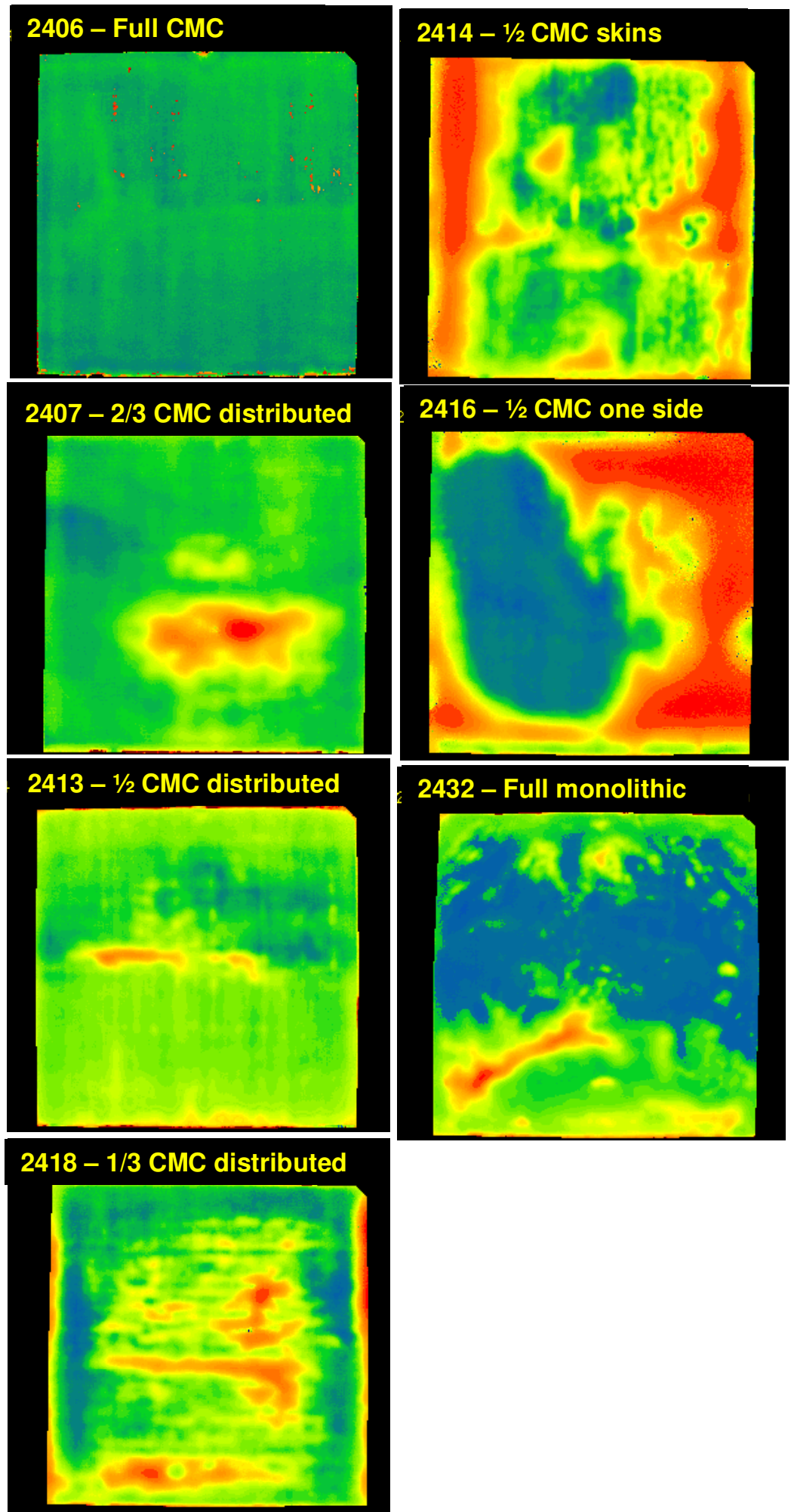

Figure 3-219. Transmission IR NDE images from several panels prepared for the hybrid CMC study. A uniform blue-green color, as seen in the full CMC panel image, indicates a lack of defect in that region, whereas red and orange indicate delamination. 
The results from these initial panels clearly indicated that the monolithic and CMC plies were exhibiting different shrinkage behavior during processing. Initially it was believed that the majority of this difference was coming during the binder burn-out step where the monolithic matrix material would tend to shrink whereas the composite plies, which were constrained from shrinking due to the presence of the continuous reinforcing fibers, would not. It was therefore speculated that all of the differential shrinkage could be eliminated by pre-firing the monolithic plies through the binder burn-out cycle before laminating them to the CMC plies.

In order to test this conjecture an additional panel was fabricated using the configuration with all monolithic plies on one side and all CMC plies on the other side. However, the monolithic side was laminated and processed through the binder burn-out step prior to laminating it together with the green CMC plies. After the second burn-out cycle, where the CMC plies went through binder burn-out, the panel remained flat and the edges showed no visual signs of delamination. Unfortunately following infiltration this panel again showed severe cupping distortion and delaminations were visible from the edges. A photograph of this panel along with the transmission IR NDE image are shown in Figure 3-220. The photograph clearly shows the cupping distortion, which was concave toward the CMC side of the panel, and the NDE image shows delaminations along the edges and corners.

The distortion and delamination of this last panel clearly indicated that there were still differential shrinkages occurring between the $\mathrm{CMC}$ and monolithic plies even beyond the binder burn-out cycle. Clearly a better understanding of the expansion/shrinkage behavior of both composite and monolithic matrix plies throughout the full range of processing temperatures was needed in order to develop a solution to this deformation problem. Dilatometer measurements of green composite and monolithic matrix materials were therefore performed using a heating cycle similar to what the materials see during composite processing.

The first samples examined included a monolithic matrix sample identical in composition to the monolithic plies used in the hybrid samples (aka GEN2 matrix) and a CMC sample using the same matrix reinforced with Hi-Nicalon fiber (aka GEN1.1 CMC), which was identical to the composite plies used in the hybrid samples. The elongations vs. temperature curves for these two samples are shown in Figure 3-221. 


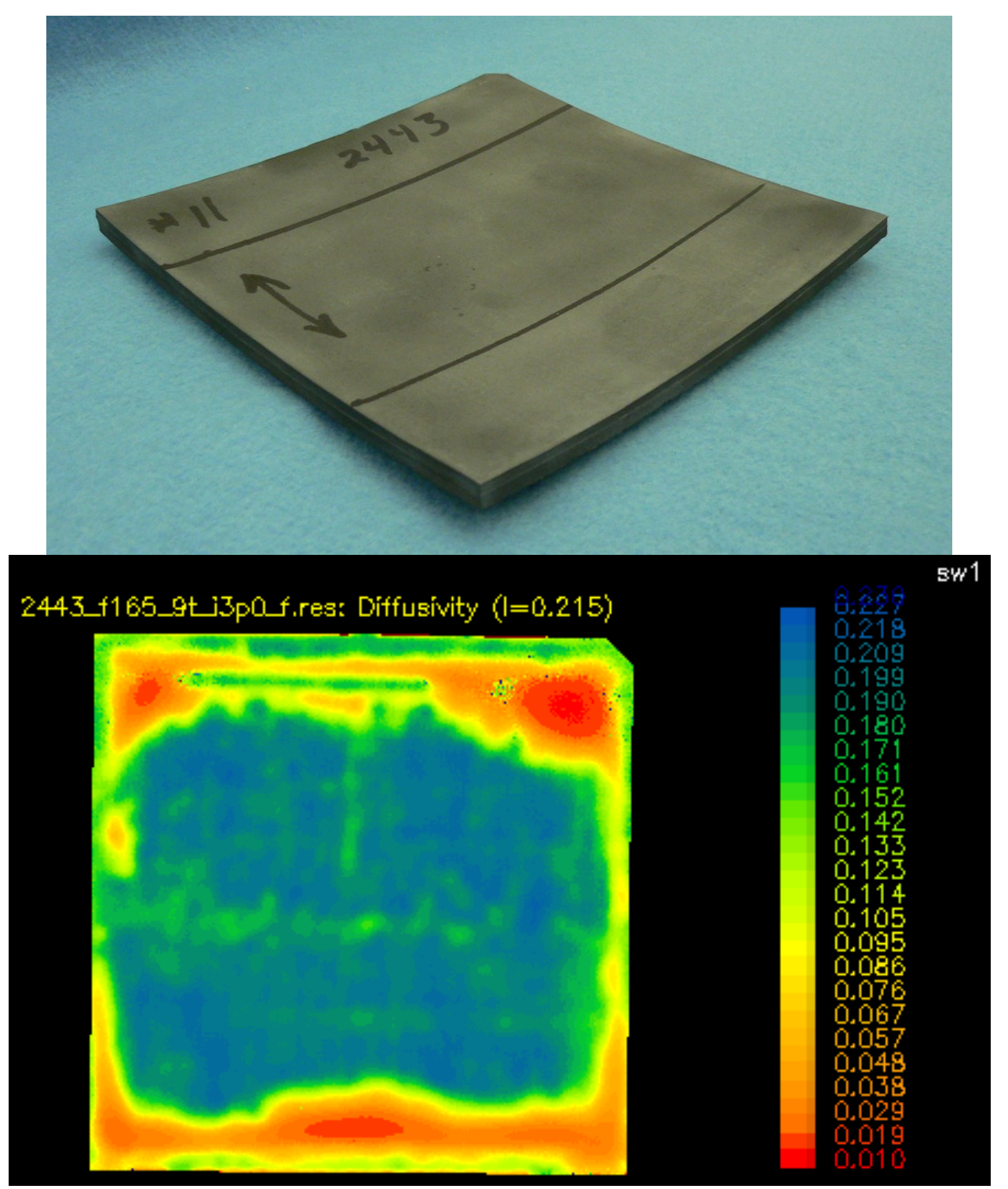

Figure 3-220. Photograph (top) and transmission IR NDE image (bottom) of the additional hybrid panel made with all CMC on one side and all monolithic plies on the other side, but with the monolithic plies having been through the binder burn-out cycle prior to lamination with the CMC plies.

The pink line in Figure 3-221 shows the behavior of the monolithic matrix only sample. The initial rapid expansion is undoubtedly due to the large amount of organic still in the sample. The curve then levels off from $100^{\circ} \mathrm{C}$ to $\sim 400^{\circ} \mathrm{C}$ where loss of the organic phase is compensating for the normal thermal expansion. Above $400^{\circ} \mathrm{C}$ practically all of the organics are gone, as shown by thermogravimetric analysis (TGA) of similar samples done several years prior, and thus one would expect normal thermal expansion to resume. However, the matrix only sample showed quite extensive shrinkage when heating above $400^{\circ} \mathrm{C}$, with the overall deformation being about $1.7 \%$ shrinkage for the entire thermal cycle. The cause of this shrinkage was not clear as the $\mathrm{SiC}$ and carbon particulate in the 
matrix should not sinter at such low temperatures. This would suggest that the carbon char holding the particulate together continued to densify as the temperature increased.

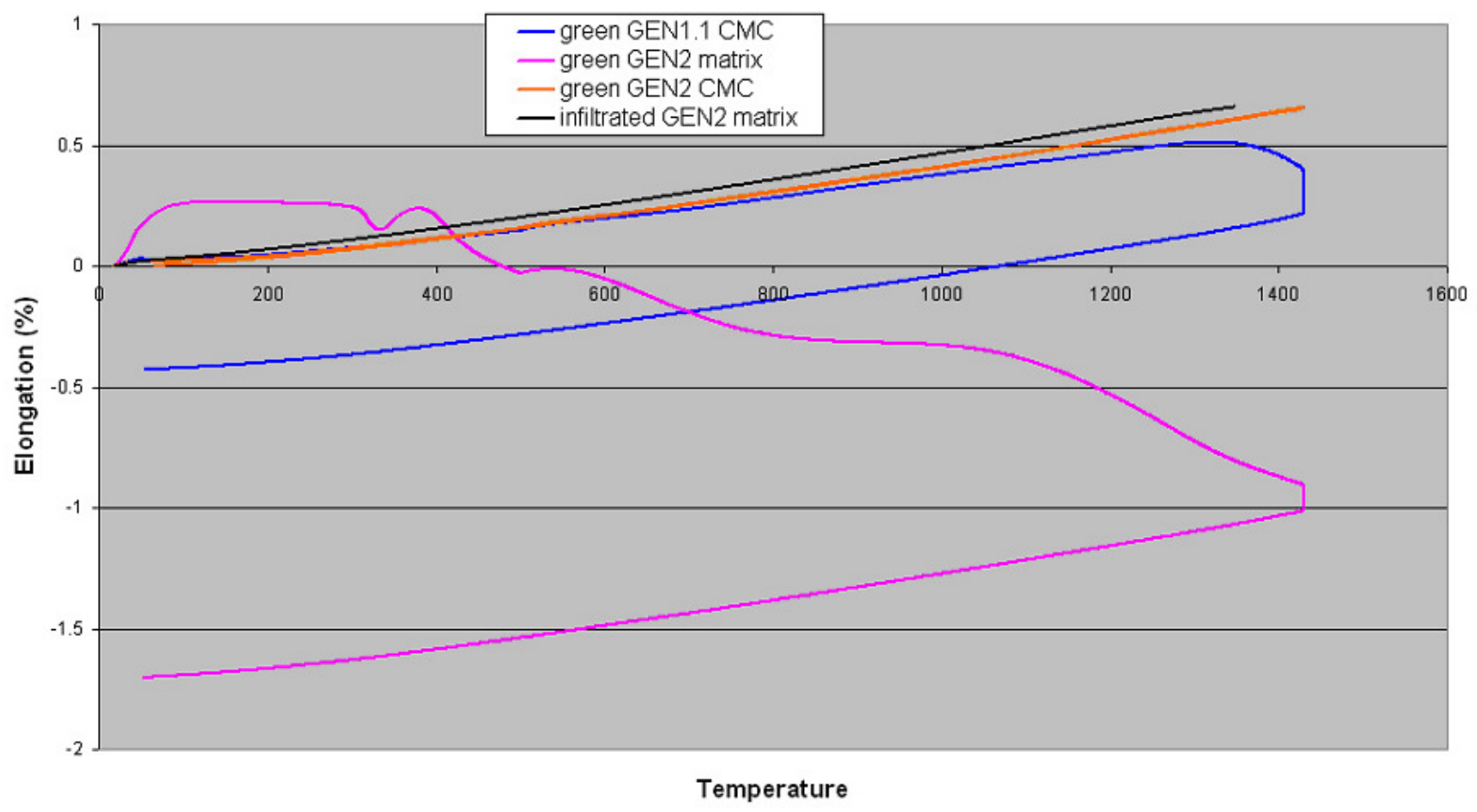

Figure 3-221. Results of dilatometer measurement of the firing expansion/shrinkage behavior of unfired $\mathrm{CMC}$ and monolithic matrix samples compared to the expansion behavior of an infiltrated CMC from previous measurements.

The unfired CMC sample with Hi-Nicalon fiber (blue line in Figure 3-221) showed much more uniorm expansion behavior during heating. This behavior was caused by the constraining effects of the continuous $\mathrm{SiC}$ fiber in the composite sample. However, at about $1300^{\circ} \mathrm{C}$ the expansion slows and eventually turns into a shrinkage with temperature, and this shrinkage continued during the 30 minute hold at $1430^{\circ} \mathrm{C}$. This result was a strong indication that the Hi-Nicalon fiber itself was densifying and shrinking at temperatures above $1300^{\circ} \mathrm{C}$. This observation was consistent with fiber creep measurements done at NASA that showed a tendency for Hi-Nicalon fiber to shrink, or sinter, in this temperature range [18].

The overall differential shrinkage between the two samples amounted to $\sim 1.3 \%$. Clearly such a level of differential strain cannot be accommodated by the hybrid samples during heating, especially when they are relatively weak following binder burn-out. The large shear stresses between the shrinking matrix plies and non-shrinking composite plies would explain the formation of delaminations seen in the samples following binder burn-out and infiltration. 
The initial response to this dilatometer data was that the matrix plies would need to be reformulated to eliminate the large shrinkage seen in the GEN2 matrix sample tested. One obvious way to do this would be to incorporate $\mathrm{SiC}$ or carbon fiber, either continuous or chopped, into the monolithic matrix plies to constrain the shrinkage of the matrix the way the normal Hi-Nicalon fiber does for the composite sample. However, even in a system where the shrinkage could be controlled during heat-up to the infiltration temperature, at infiltration the coated Hi-Nicalon fiber themselves were shrinking. It was unlikely that the carbon or $\mathrm{SiC}$ fiber, having formed continuous $\mathrm{SiC}$ reaction layers from the infiltrating alloy, would shrink in a consistent fashion with the un-reacted Hi-Nicalon reinforcement fiber in the composite plies. Consequently it was necessary to find ways to deal with both the matrix shrinkage during heat up and the fiber shrinkage at infiltration temperatures.

Since Hi-Nicalon type-S fiber is processed at a much higher temperature, and is close to stoichiometric $\mathrm{SiC}$ in composition, it was not expected to show the same shrinkage above $1300^{\circ} \mathrm{C}$ that the Hi-Nicalon did. Dilatometry was therefore performed on a green composite sample having the same matrix as before but with Hi-Nicalon type-S fiber (GEN2 CMC). The results from this sample are shown by the orange line in Figure 3-221, which showed a normal thermal expansion curve with no hysteresis, and therefore no shrinkage of the fiber at melt infiltration temperatures. This result suggested that a dimensionally stable and compatible hybrid system should be achievable with type-S fiber in the composite plies, provided the unusual shrinkage behavior of the matrix plies could be controlled and minimized.

An inelegant way of eliminating the irregular matrix ply shrinkage would be to pre-fire the matrix plies, removing the polymer and allowing for the matrix shrinkage, prior to combining them with the composite plies. The cooling part of the expansion curve for the GEN2 matrix sample (pink line in Figure 3-221) closely matches the heating curve for the unfired CMC with Hi-Nicalon type-S fiber (orange line in Figure 3-221) fairly closely. Thus pre-firing the monolithic section prior to adding the $\mathrm{CMC}$ plies would minimize differential strains during heating of the full hybrid structure. This approach was considered to be inelegant due to the fact that using pre-fired plies for lay-up of composite parts was impractical due to the low strength of the monolithic material after burn-out, and because the extra infiltration step would increase the overall cost of the process. Nevertheless the approach was useful for at least providing proof of concept.

Consequently two new hybrid panel samples were fabricated having $1 / 2$ of the thickness being monolithic and the other $1 / 2$ of the thickness being composite (this was the configuration for which differential shrinkages would give the greatest likelihood of generating delaminations and/or distortions). First the monolithic matrix half of each panel was processed through the binder burn-out stage, thus allowing for all the matrix shrinkage to occur unimpeded by any composite plies. The composite halves of the panels were then laminated onto the burned-out monolithic halves, and the full panels were again put through burn-out and then melt infiltration. Two such panels were fabricated, one with Hi-Nicalon fiber in the composite half, and one with Hi-Nicalon type S fiber. Based on the dilatometer data the panel with the Hi-Nicalon fiber was expected to bow toward the composite side 
due to the shrinkage of the fiber at the infiltration temperature, whereas the panel with the type $S$ fiber should remain flat due to the stability of the type $S$ fiber.

Both panels were still flat and intact following binder burn-out. Following melt infiltration the panel with Hi-Nicalon bowed by $8 \mathrm{~mm}$ over the $152 \mathrm{~mm}$ length, being concave toward the composite side of the panel. The panel with type $S$ fiber showed only $1.2 \mathrm{~mm}$ bow over the same length. A photograph of these panels taken on edge is shown in Figure 3-222. Sectioning of the two panels showed delamination cracks between the monolithic and composite halves of the panel made with Hi-Nicalon fiber, but no cracking the in the panel made with type $\mathrm{S}$ fiber. All of these observations are consistent with the dilatometer data that showed shrinkage of preforms containing Hi-Nicalon fiber at the infiltration temperature.

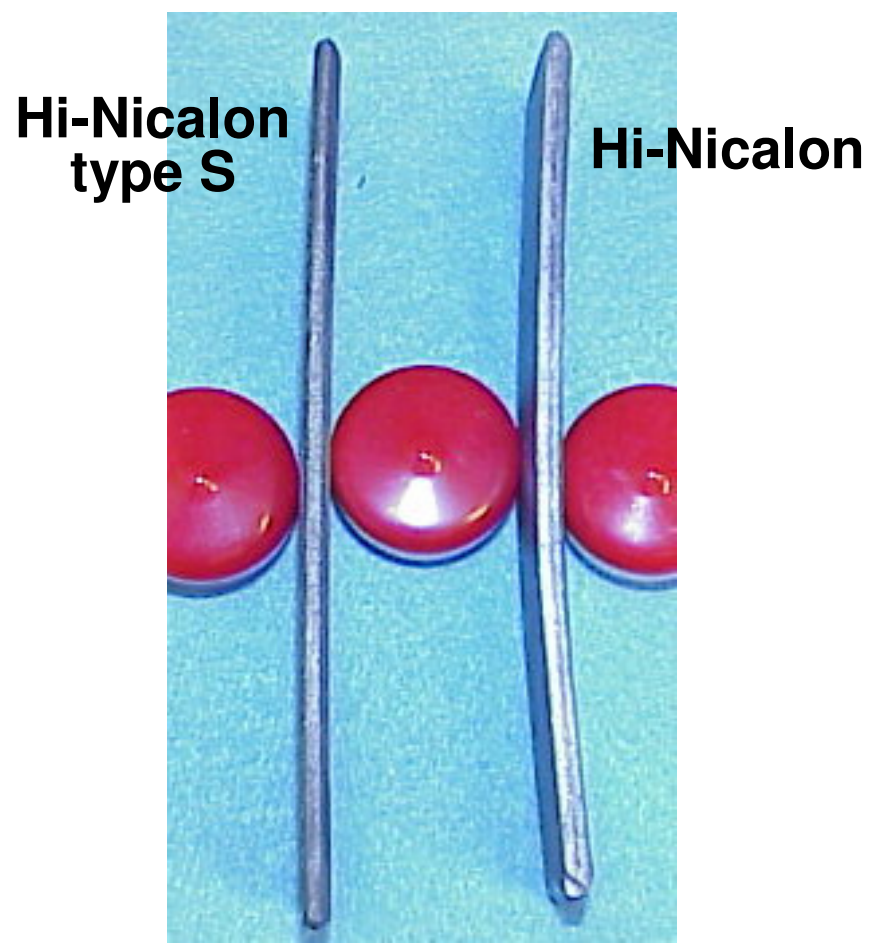

Figure 3-222. Edge-on photograph of hybrid composite panels made with one half of the panel being pre-fired monolithic matrix and the other half being normal CMC. The panel on the right, which shows a high degree of bow deformation, was made with Hi-Nicalon fiber whereas the panel on the left, which shows very minor bowing, was made with Hi-Nicalon type $\mathrm{S}$ fiber.

Although pre-firing the monolithic plies and utilizing type $S$ fiber was effective in minimizing panel delamination and bowing, such an approach is not viable for fabricating several of the hybrid configurations needed for the DoE experiment, or real shroud hardware. Also, it was noted that infiltration of the monolithic side of the panels was not complete due to the general difficulty of infiltrating the GEN2 matrix composition without 
the presence of fibers. It was therefore decided to try to reformulate the monolithic matrix material to minimize the firing shrinkage of the monolithic matrix plies and make them more compatible with the composite plies, and to also enhance the infiltration of the monolithic plies. One method of accomplishing this was to add chopped carbon fiber to the monolithic plies. Chopped fiber is used since continuous carbon fiber would present different thermal expansion compatibility problems relative to the composite plies due to the very low expansion of carbon fiber. If added as discontinuous fiber with the proper aspect ratio the chopped carbon fiber simply contributes to the overall thermal expansion of the matrix ply by a simple rule of mixtures, but can still act to locally suppress shrinkage of the matrix during the binder burn-out and melt infiltration steps. The chopped fiber also helps to maintain a semi-continuous path for silicon infiltration into the "monolithic" matrix.

Several formulations of matrix slurry were made by substituting chopped carbon fiber for part of the particulate carbon that is a normal matrix slurry ingredient. These slurries were fabricated into monolithic preform panels using a tape casting and lamination process. Dilatometry was used then to evaluate the expansion/shrinkage behavior of the different matrix preform compositions. Figure 3-223 shows several of the important dilatometer curves from these experiments.

Both the GEN1 and GEN2 composite matrix compositions showed similar firing shrinkage (the blue and magenta lines in Figure 3-223), so most development was directed toward the GEN2 composition as it was generally somewhat easier to process through lamination. Half of the particulate carbon in the normal GEN2 composition was replaced by milled carbon fiber, and the other half of the particulate carbon was replaced by an equal volume of the normal $\mathrm{SiC}$ powder. The new slurry was then tape cast and autoclave laminated to give a monolithic preform, which was subjected to the same dilatometer measurements as the previous composite and matrix samples.

The red line in Figure 3-223 shows the expansion/shrinkage behavior of the new matrix with milled carbon fiber. The overall firing shrinkage of the new composition was $\sim 0.4 \%$, as compared to $1.7 \%$ for the normal GEN1 and GEN2 matrix compositions. While this is much closer to the nearly $0 \%$ net shrinkage observed in the composite preform samples with Hi-Nicalon Type S fiber (green line in Figure 3-223), there is still a $0.7 \%$ difference in expansion between the composite preform and the milled carbon fiber monolithic matrix preforms at $1400^{\circ} \mathrm{C}$.

Although the new milled carbon fiber matrix composition had a much better match to the composite ply expansion/shrinkage behavior than the normal GEN1 and GEN2 matrix compositions, it was still not clear whether the milled carbon fiber monolithic plies would be compliant enough that they could accommodate the mechanical constraint applied by the composite plies during heating to MI temperatures. An attempt to fabricate several of the hybrid structure panels using the new milled carbon fiber composition for the monolithic matrix plies was therefore attempted to see if the remaining shrinkage differences would be accommodated. 


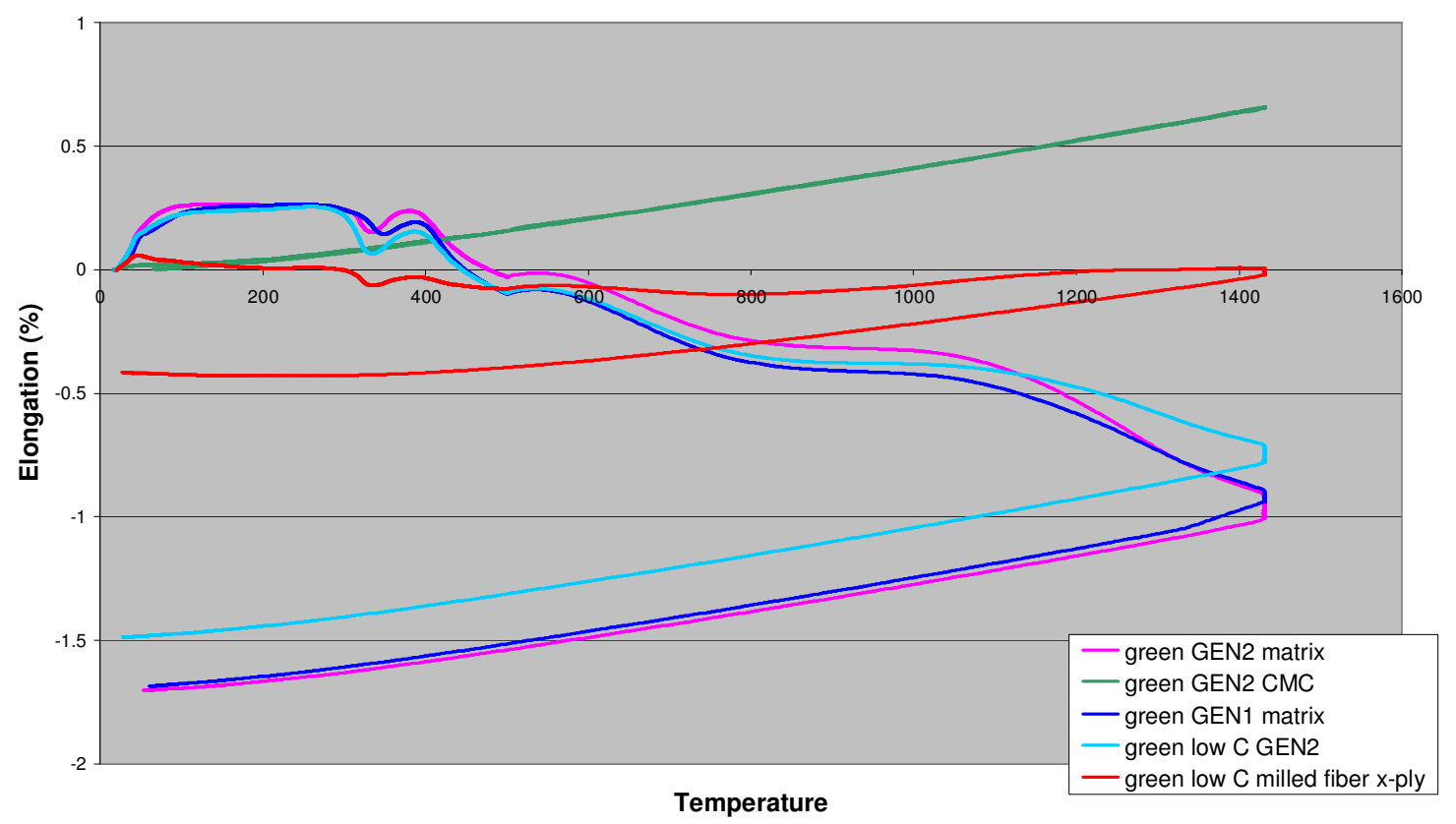

Figure 3-223. Dilatometer expansion/shrinkage curves for several monolithic matrix compositions as compared to the expansion/shrinkage of a CMC composite preform (green line).

Three panel configurations were chosen to evaluate the new milled carbon fiber matrix plies. All three had roughly $44 \%$ of the normal number of composite plies, but the ply stacking sequence varied. The first had the monolithic plies interspersed with the composite plies uniformly through the thickness, similar to the " $1 / 2 \mathrm{CMC}$ dispersed" configuration in Table 3-17. The second new panel had the monolithic plies all in the center with composites plies on either surface, similar to the "1/2 CMC skins" configuration, and the third had all monolithic plies on one side of the panel and all of the composite plies on the other, similar to the " $1 / 2 \mathrm{CMC}$ on one side" configuration in Table 3-17. This third configuration represents the worst configuration for accommodating any differential strains between the two ply types. Hi-Nicalon type $\mathrm{S}$ fiber was used for all three panels in order to eliminate the effects of fiber shrinkage during MI.

All of the three new hybrid panels processed through lay-up and autoclave lamination without incident. Following binder burn-out small delamination cracks were noted on two edges of the second panel, and on all edges of the third. No cracking was noted on the first panel.

Following melt infiltration the first panel remained intact and relatively flat $(0.5 \mathrm{~mm}$ bow across the $152 \mathrm{~mm}$ panel). Post-infiltration IR NDE inspection of the panel showed it to be very uniform and dense, with only two minor indications about $1.5 \mathrm{~mm}$ in from the back surface detected in the reflection IR images, as shown in Figure 3-224. The transmission IR image (bottom picture in Figure 3-224) also showed these flaws and apparently a 
lowered diffusivity around the panel edges, which was likely a spurious indication due to edge effects of the relatively thick panel. Please note that the diffusivity scale used for this image is much higher and more compressed than normally used for typical CMC panels, and even the "flawed" regions have much higher diffusivity than a normal CMC panel. As such, the indications likely represented very minor non-uniformities and the panel was judged to be acceptable for impact and mechanical testing.

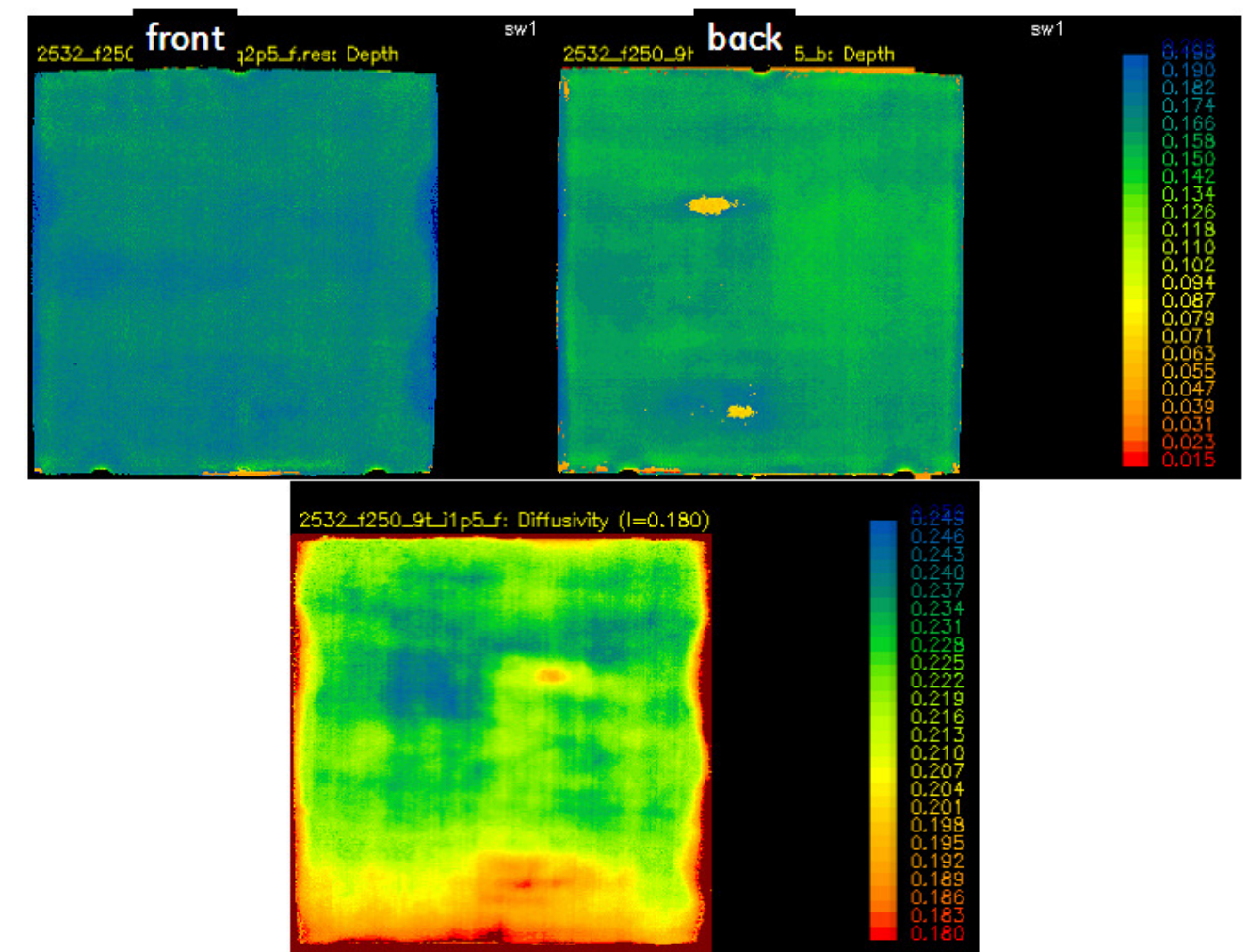

Figure 3-224. IR NDE images of panel 2532, the first of the new hybrid panels made with distributed monolithic matrix plies: Top - reflection images from the front and back surfaces showing flaw depth; Bottom - transmission image showing thermal diffusivity values.

The second new hybrid panel, which was made with composite surface plies and a monolithic center, came out of infiltration with a distinct bow in the side-to-side direction, concave toward the "front" of the panel, amounting to more than $5 \mathrm{~mm}$ over the $152 \mathrm{~mm}$ panel. The side edges also showed a step in the surface corresponding to the boundary between the front CMC skin and the monolithic core. These observations indicated that the panel had delaminated between the front $\mathrm{CMC}$ and monolithic layers inward from the side edges during heat-up to infiltration. The differential shrinkage between the monolithic center and the back CMC skin, which were still bonded, caused the panel to bow forward. The differential strain between the bent panel and the front CMC skin were relieved at the edges by the delaminations, thereby forming the steps in the side surfaces. 
IR NDE images of the second panel are shown in Figure 3-225. The reflection images, which show the depth of any discontinuities in the panel, also verified the apparent delamination between the front CMC skin and the monolithic core. The near-solid orange and green colors of the front and rear images, respectively, indicated a discontinuity at a depth of $1.2 \mathrm{~mm}$ from the front surface, corresponding to $3.8 \mathrm{~mm}$ from the rear surface, which again correlated with the interface of the front CMC skin and the monolithic center. The transmission image surprisingly indicated that a majority of the panel still has throughthickness diffusivity greater than a normal CMC panel (blue to green colors), which would suggest that the delamination was subsequently filled with silicon alloy during infiltration. (Please note that the transmission image in Figure 3-224, when scaled to the same diffusivity scale used in Figure 3-225, would be totally blue to green in color.)

The third of the new hybrid panels came through melt infiltration intact, with roughly the same amount of deformation as the first panel. Some delamination-like cracks appeared on the panel edges, but there were no steps in the edge surfaces. IR NDE of this panel, as shown in Figure 3-226, is inconsistent between the front and back reflection images. The front image indicates delaminations progressing inward from the edges around the full periphery, but a relatively intact center region (blue region). However, the rear image indicates a uniform indication at $\sim 1.8 \mathrm{~mm}$ depth over the entirety of the panel. Please note that these depths are calculated assuming a uniform diffusivity through the panel thickness, whereas the monolithic half of the panel had a higher diffusivity than the composite half. Thus the depth of the back-side indication was actually deeper than indicated by the colored shading. Whether this indication corresponded to a real flaw or simply to the change in diffusivity between the high-diffusivity monolithic side of the panel (on the back) and the lower diffusivity composite side (toward the front) was not clear. The transmission image still showed a relatively high diffusivity value over the majority of the panel, which would suggest that the indications in the reflection images were not very severe.

The overall visual observations and NDE results from these panels indicated that the new monolithic matrix composition did not have a sufficiently reduced shrinkage to make it compatible with the composite plies in all configurations. In cases where the monolithic regions were kept thin and interspersed with the composite plies, such as with the first new hybrid panel, the shrinkage strains in the monolithic plies were sufficiently constrained by the neighboring composite plies that the panel remained intact. However, when the monolithic sections became several plies thick, as with the second and third new hybrid panels, the differential strains were not accommodated without some degree of panel delamination. The thickness limit of the monolithic plies for panel stability could not be determined from the panel configurations investigated, but was somewhere between the single ply $(\sim 0.25 \mathrm{~mm})$ and ten ply $(\sim 2.5 \mathrm{~mm})$ thicknesses used in these panels. 


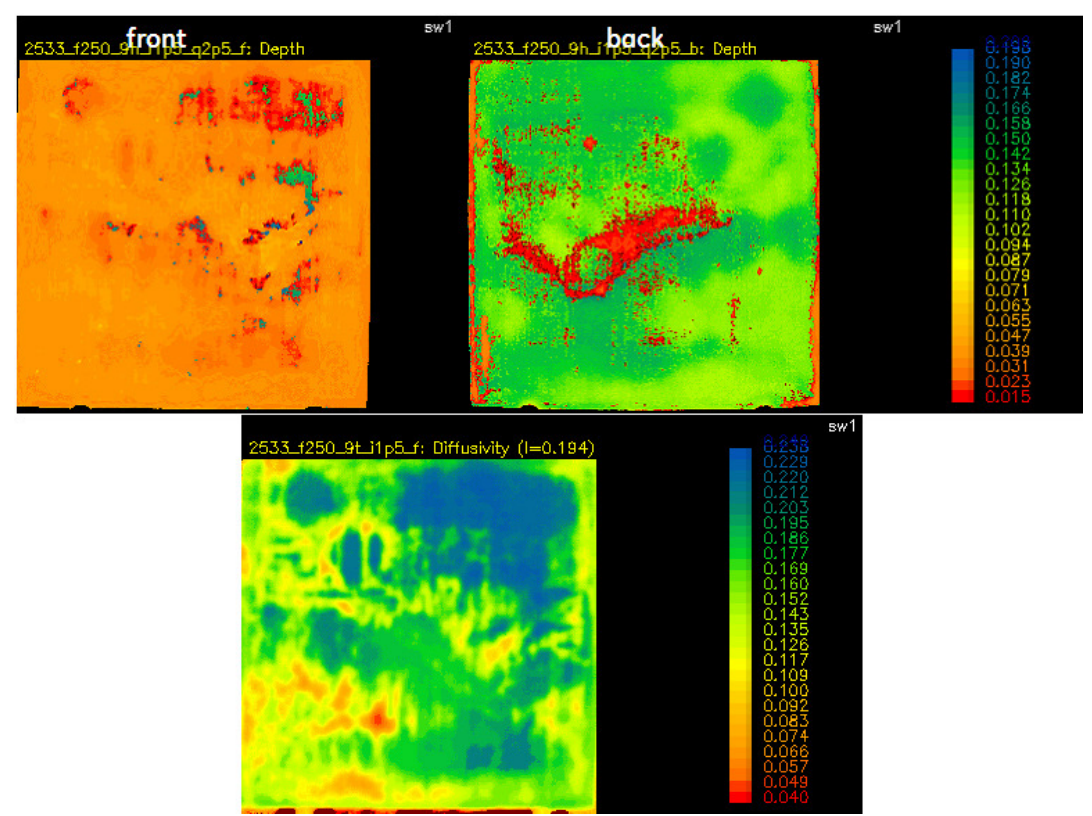

Figure 3-225. IR NDE images from panel 2533, the second of the new hybrid panels made with CMC skins over a monolithic matrix core: Top - reflection images from the front and back surfaces showing flaw depth; Bottom - transmission image mapping thermal diffusivity values.

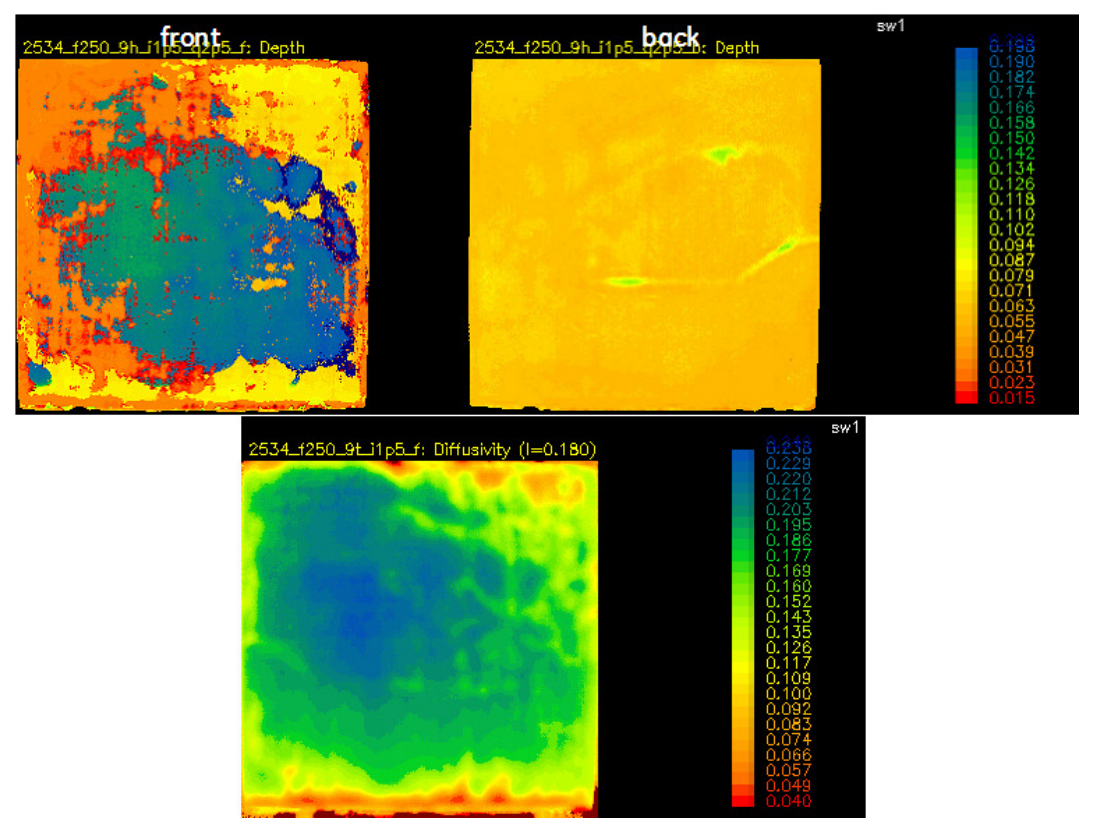

Figure 3-226. IR NDE images from panel 2534, the third of the new hybrid panels made with one half of the thickness being $\mathrm{CMC}$ and the other half being monolithic matrix: Left - reflection images from the front and back surfaces showing flaw depth; Right - transmission image mapping thermal diffusivity values. 
These observations indicated that hybrid panel configurations that tend to separate the composite and monolithic plies through the thickness, such as having one side of the panel being composite and the other side monolithic, cannot be fabricated using the monolithic ply substitution technique. However, panels with the composite and monolithic plies intermixed at a ply-by-ply level could still be viable. The hybrid panel configurations that required monolithic layer thicknesses greater than an equivalent of 2-plies were therefore removed from the design of experiments. Where necessary, the ply stacking sequence was adjusted to ensure that any monolithic layer was no more than 2 plies in thickness.

It was also noted with the early hybrid samples that the monolithic regions of the specimens tended to be harder to fully infiltrate than the composite ply regions. This difference was likely due to the continuous fibers, with their surface carbon coating, providing a continuously wettable surface for the infiltration alloy. The addition of the milled carbon fiber would help to maintain a semi-continuous path for silicon infiltration into the monolithic matrix plies, but would not likely compensate fully for the lack of a continuous fiber surface. It was therefore decided to decrease the overall carbon content of the monolithic plies in order to decrease the formation of $\mathrm{SiC}$ during infiltration, and thereby keep more channels of silicon alloy present to help feed the infiltration front. A coarser grade of silicon carbide powder was also used in the slurries used for tape casting the monolithic plies in order to increase the inter-particle pore size, thereby also helping to keep infiltration channels open and improve infiltration of the monolithic plies.

Using the matrix slurry modifications mentioned above several of the hybrid panel configurations selected to the DoE were re-fabricated using Hi-Nicalon Type-S fiber. A total list of the hybrid samples that were fabricated in both the original set, in the three trial samples described above, or as new samples with the modified matrix compositions are listed in Table 3-18. NDE images of the new samples with modified matrix and type-S fiber are also shown in Figure 3-227 for completeness.

Note that during panel fabrication the intent was to keep the ply thicknesses the same between the different types of fiber and monolithic tape compositions so that the same ply configurations would give the same overall fiber content. However, the prepregging process for Hi-Nicalon type-S fiber does produce thinner plies than that used for Hi-Nicalon fiber. Also, the laminated thickness of the monolithic plies was found to change when the matrix composition was adjusted to control shrinkage. The consequence of these two effects was that the panel thicknesses varied considerably, from $4.2 \mathrm{~mm}$ to $6 \mathrm{~mm}$. This panel thickness variation caused additional panel-to-panel fiber volume fraction variations in addition to the intended variations from the changes in ply lay-up configurations. The result was that the total fiber volume fraction was not directly determined by only the ply configuration. For instance, panel 2416, which was intended to have $42 \%$ CMC plies from the lay-up configuration, actually had less fiber content than panel 2585 , which was intended to have $\sim 32 \% \mathrm{CMC}$.

An additional panel was cut from an old body of monolithic Silcomp, which was GE's version of a reaction-bonded $\mathrm{SiC}$ made from reacting carbon fiber with silicon. No carbon 
fiber remains intact in the Silcomp material, and thus it was used to represent an alternate form of totally monolithic SiC.
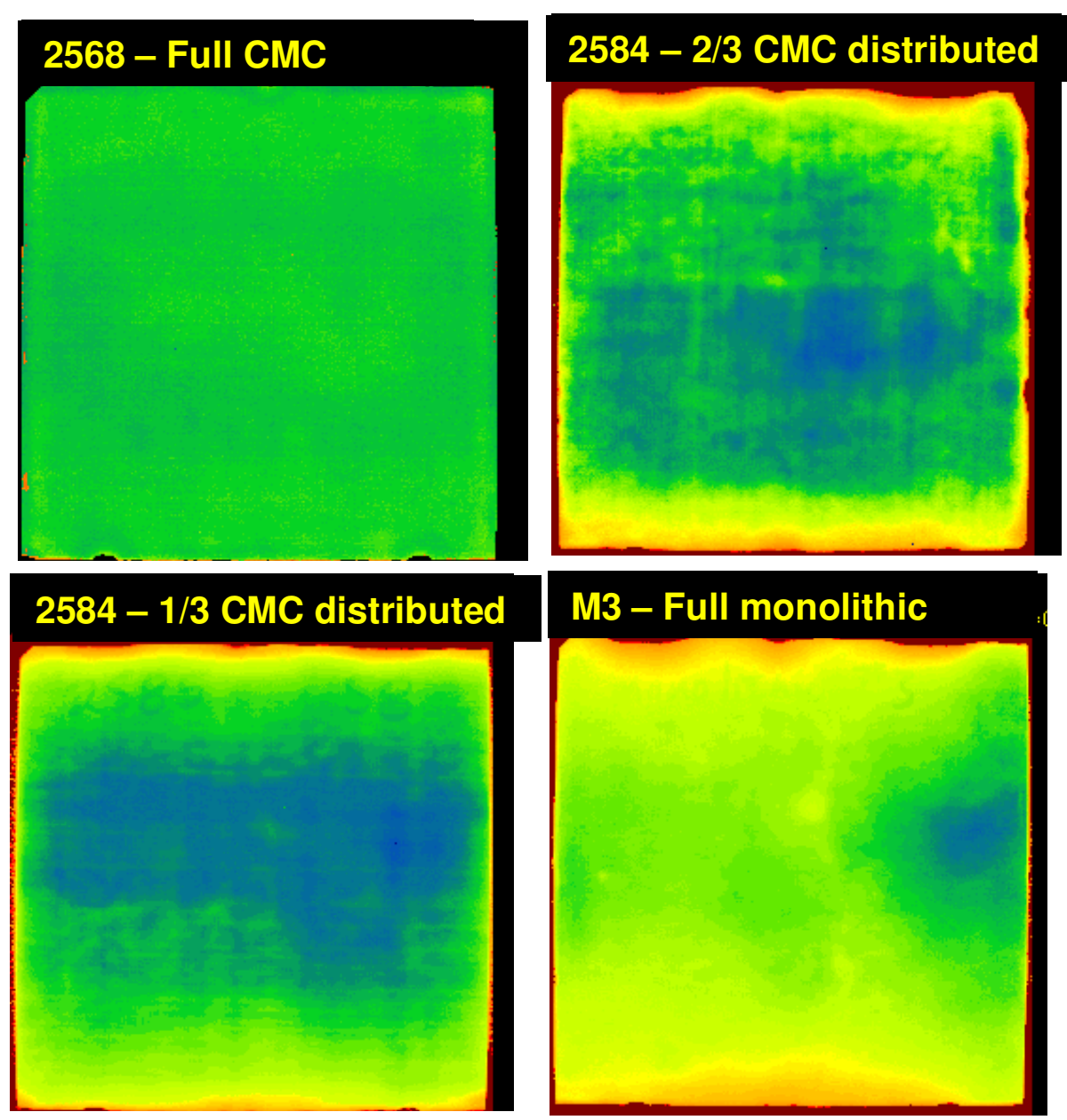

Figure 3-227. Transmission IR NDE images of the remaining hybrid panels made with HiNicalon Type-S fiber and modified matrix compositions.

Based primarily on the IR NDE images of the panels, a subset of the monolithic-ply hybrid panels listed in Table 3-18 were selected for mechanical and ballistic impact tests, as indicated in the last column of the table. Several of the panel configurations had significant NDE indications, as described in the table, but were included in the mechanical and ballistic tests in order to quantify the effects of the defects. The panels were cut in half, with one half going to ballistic testing and the other half being used for tensile and pin pull-out testing. 
Table 3-18. Fiber Type, Monolithic Ply Types, and Architecture Configurations of the Hybrid CMC/Monolithic Test Panels

\begin{tabular}{|c|c|c|c|c|c|c|}
\hline $\begin{array}{l}\text { Panel } \\
\text { ID \# }\end{array}$ & $\begin{array}{c}\text { Reinforcing } \\
\text { fiber type in } \\
\text { composite } \\
\text { plies }\end{array}$ & $\begin{array}{c}\text { Monolithic } \\
\text { ply type }\end{array}$ & Configuration & $\begin{array}{c}\text { Maximum } \\
\text { number of } \\
\text { adjacent } \\
\text { monolithic } \\
\text { plies } \\
\end{array}$ & Status & $\begin{array}{c}\text { To be } \\
\text { used for } \\
\text { ballistic } \\
\text { testing? }\end{array}$ \\
\hline 2406 & Hi-Nicalon & none & All CMC & 0 & Good & Yes \\
\hline 2407 & Hi Nicalon & $\begin{array}{l}\text { standard } \\
\text { slurry }\end{array}$ & $\begin{array}{c}\text { 2/3 CMC } \\
\text { distributed } \\
\text { plies }\end{array}$ & 1 & $\begin{array}{c}\text { Center } \\
\text { delamination }\end{array}$ & Yes \\
\hline 2413 & Hi-Nicalon & $\begin{array}{l}\text { standard } \\
\text { slurry }\end{array}$ & $\begin{array}{c}\text { 1/2 CMC } \\
\text { distributed } \\
\text { plies }\end{array}$ & 2 & $\begin{array}{c}\text { Center } \\
\text { delamination }\end{array}$ & Yes \\
\hline 2414 & Hi-Nicalon & $\begin{array}{l}\text { standard } \\
\text { slurry }\end{array}$ & $\begin{array}{c}1 / 2 \mathrm{CMC} \\
\text { composite } \\
\text { skins }\end{array}$ & 10 & $\begin{array}{c}\text { Large edge } \\
\text { delaminations }\end{array}$ & No \\
\hline 2415 & Hi-Nicalon & $\begin{array}{l}\text { standard } \\
\text { slurry }\end{array}$ & $\begin{array}{l}1 / 2 \mathrm{CMC} \text { in } \\
\text { center }\end{array}$ & 5 & $\begin{array}{c}\text { Total } \\
\text { delamination } \\
\text { on burn-out }\end{array}$ & No \\
\hline 2416 & Hi-Nicalon & $\begin{array}{c}\text { standard } \\
\text { slurry }\end{array}$ & $\begin{array}{c}1 / 2 \mathrm{CMC} \text { on one } \\
\text { side }\end{array}$ & 9 & $\begin{array}{c}\text { Large edge } \\
\text { delaminations }\end{array}$ & Yes \\
\hline 2417 & Hi-Nicalon & $\begin{array}{l}\text { standard } \\
\text { slurry }\end{array}$ & $\begin{array}{l}\text { 1/2 CMC on } \\
\text { second side }\end{array}$ & 9 & $\begin{array}{c}\text { Complete } \\
\text { delamination }\end{array}$ & No \\
\hline 2418 & Hi-Nicalon & $\begin{array}{l}\text { standard } \\
\text { slurry }\end{array}$ & $\begin{array}{c}\text { 1/3 CMC } \\
\text { distributed } \\
\text { plies }\end{array}$ & 3 & $\begin{array}{c}\text { Center } \\
\text { delamination }\end{array}$ & No \\
\hline 2568 & Type $\mathrm{S}$ & None & All CMC & 0 & Good & Yes \\
\hline 2584 & Type $\mathrm{S}$ & $\begin{array}{l}\text { modified } \\
\text { slurry }\end{array}$ & $\begin{array}{c}\text { 2/3 CMC } \\
\text { distributed } \\
\text { plies }\end{array}$ & 1 & Good & Yes \\
\hline 2532 & Type $S$ & $\begin{array}{l}\text { modified } \\
\text { slurry }\end{array}$ & $\begin{array}{c}\text { 1/2 CMC } \\
\text { distributed } \\
\text { plies }\end{array}$ & 2 & Good & Yes \\
\hline 2533 & Type $S$ & $\begin{array}{l}\text { modified } \\
\text { slurry }\end{array}$ & $\begin{array}{c}1 / 2 \mathrm{CMC} \\
\text { composite } \\
\text { skins }\end{array}$ & 8 & $\begin{array}{c}\text { Moderate } \\
\text { delamination }\end{array}$ & Yes \\
\hline 2534 & Type $S$ & $\begin{array}{c}\text { modified } \\
\text { slurry }\end{array}$ & $\begin{array}{c}1 / 2 \mathrm{CMC} \text { on one } \\
\text { side }\end{array}$ & 9 & $\begin{array}{c}\text { Edge } \\
\text { delaminations }\end{array}$ & Yes \\
\hline 2585 & Type S & $\begin{array}{l}\text { modified } \\
\text { slurry }\end{array}$ & $\begin{array}{c}\text { 1/3 CMC } \\
\text { distributed } \\
\text { plies }\end{array}$ & 2 & Good & Yes \\
\hline M3 & None & $\begin{array}{l}\text { modified } \\
\text { slurry }\end{array}$ & all monolithic & 18 & Good & Yes \\
\hline Silcomp & None & - & $\begin{array}{c}\text { Converted } \\
\text { carbon cloth }\end{array}$ & - & Good & Yes \\
\hline
\end{tabular}

Ballistic impact testing of the hybrid CMC-monolithic SiC panels was performed at the University of Dayton Research Institute (UDRI). Each panel was shot twice using a $12.7 \mathrm{~mm}$ Monel steel ball as the projectile, and a high-speed video was taken during every 
impact event. An attempt was made to pre-heat the samples to $1200 \mathrm{C}$ prior to the impact test, but the sample size made this impossible with UDRI's existing furnace equipment and sample temperatures of only $\sim 900 \mathrm{C}$ were obtained. Furtermore, while heating the $2^{\text {nd }}$ sample to be tested to temperature for its $2^{\text {nd }}$ impact test the sample fractured from the thermal gradients. Heating of the samples was therefore stopped, and all further testing was done with the samples at RT. Only samples 2406 and 2407 were impacted at elevated temperature; however, there was no obvious differences in impact response between the room temperature tests and the heated tests.

Overall 22 tests were conducted on 13 different panels, as listed in Table 3-19. Two different impact velocities were used. Based on previous impact testing of CMC shroud components, at the higher velocity the projectiles were expected to fully penetrate the panels. The lower impact velocity was chosen to be slightly below the threshold velocity at which the projectile would be expected to fully penetrate a full-CMC panel. It was hoped that by testing near the penetration threshold that changes in the impact response would be more apparent.

The general observations from the ballistic testing was that all of the panels containing coated-fiber CMC plies survived intact whereas the monolithic panels, whether made from CMC matrix material or from carbon fiber-derived Silcomp, shattered upon impact. All of the CMC panels tested at the higher impact velocity showed complete penetration of the panel by the projectile, and most of the CMC-containing panels tested at the lower impact velocity caused the projectile to rebound. Even though they were not penetrated, all panels tested at the lower velocity did exhibit through-thickness holes at the impact sites with significant material having been ejected from the backsides. Close-up photographs of the front and rear surfaces for each of the impacted composite panels at the impact sites are shown in Figure 3-228. Since the monolithic panels shattered the photographs of those entire panels, or rather the fragments remaining from those panels, are shown in Figure 3229. 
Table 3-19. Summary of the Ballistic Impact Tests Conducted on the Monolithic Ply Hybrid CMC Panels

\begin{tabular}{|c|c|c|c|c|c|c|c|}
\hline $\begin{array}{l}\text { Panel } \\
\text { ID \# }\end{array}$ & $\begin{array}{l}\text { Fiber } \\
\text { type }\end{array}$ & $\begin{array}{l}\text { Monolithic } \\
\text { ply type }\end{array}$ & Type & $\begin{array}{l}\text { Thickness } \\
\text { (mm) }\end{array}$ & $\begin{array}{c}\text { Fiber } \\
\text { volume } \\
(\%)\end{array}$ & $\begin{array}{l}\text { Impact } \\
\text { velocity }\end{array}$ & Result \\
\hline \multirow{2}{*}{2406} & \multirow{2}{*}{$\begin{array}{l}\text { Hi- } \\
\text { Nicalon }\end{array}$} & \multirow{2}{*}{ none } & \multirow{2}{*}{ All CMC } & \multirow{2}{*}{5.41} & \multirow{2}{*}{20.8} & low & $\begin{array}{c}\text { Partial penetration; } \\
7.5 \mathrm{~mm} \text { hole }\end{array}$ \\
\hline & & & & & & high & $\begin{array}{c}\text { Full penetration; } \\
12.7 \mathrm{~mm} \text { hole }\end{array}$ \\
\hline \multirow{2}{*}{2407} & \multirow{2}{*}{$\begin{array}{c}\mathrm{Hi} \\
\text { Nicalon }\end{array}$} & \multirow{2}{*}{ standard } & \multirow{2}{*}{$\begin{array}{c}\text { 2/3 CMC } \\
\text { distributed } \\
\text { plies }\end{array}$} & \multirow{2}{*}{6.12} & \multirow{2}{*}{12.3} & low & $\begin{array}{c}\text { Partial penetration; } \\
7.5 \mathrm{~mm} \text { hole } \\
\end{array}$ \\
\hline & & & & & & - & $\begin{array}{c}\text { Cracked during } \\
\text { heating for } 2^{\text {nd }} \text { shot }\end{array}$ \\
\hline \multirow{2}{*}{2413} & \multirow{2}{*}{$\begin{array}{c}\mathrm{Hi}- \\
\text { Nicalon }\end{array}$} & \multirow{2}{*}{ standard } & \multirow{2}{*}{$\begin{array}{c}1 / 2 \mathrm{CMC} \\
\text { distributed } \\
\text { plies }\end{array}$} & \multirow{2}{*}{5.44} & \multirow{2}{*}{9.2} & low & $\begin{array}{c}\text { Partial penetration; } \\
10 \mathrm{~mm} \text { hole }\end{array}$ \\
\hline & & & & & & high & $\begin{array}{l}\text { Full penetration; } \\
12.7 \mathrm{~mm} \text { hole }\end{array}$ \\
\hline \multirow{2}{*}{2416} & \multirow{2}{*}{$\begin{array}{c}\text { Hi- } \\
\text { Nicalon }\end{array}$} & \multirow{2}{*}{ standard } & $\begin{array}{c}1 / 2 \mathrm{CMC} ; \\
\text { matrix side }\end{array}$ & \multirow{2}{*}{5.77} & \multirow{2}{*}{8.7} & low & $\begin{array}{c}\text { Full penetration; } \\
12.7 \mathrm{~mm} \text { hole }\end{array}$ \\
\hline & & & $\begin{array}{l}1 / 2 \text { CMC; } \\
\text { CMC side }\end{array}$ & & & low & $\begin{array}{c}\text { Partial penetration; } \\
10 \mathrm{~mm} \text { hole }\end{array}$ \\
\hline \multirow{2}{*}{2568} & \multirow{2}{*}{$\begin{array}{c}\text { Hi- } \\
\text { Nicalon } \\
\text { Type S }\end{array}$} & \multirow{2}{*}{ none } & \multirow{2}{*}{ All CMC } & \multirow{2}{*}{4.52} & \multirow{2}{*}{24.9} & low & $\begin{array}{c}\text { Partial penetration; } \\
10 \mathrm{~mm} \text { hole; }\end{array}$ \\
\hline & & & & & & high & $\begin{array}{c}\text { Full penetration; } \\
12.7 \mathrm{~mm} \text { hole }\end{array}$ \\
\hline \multirow{2}{*}{2584} & \multirow{2}{*}{$\begin{array}{c}\text { Hi- } \\
\text { Nicalon } \\
\text { Type S }\end{array}$} & \multirow{2}{*}{ modified } & \multirow{2}{*}{$\begin{array}{c}\text { 2/3 CMC } \\
\text { distributed } \\
\text { plies }\end{array}$} & 416 & 180 & low & $\begin{array}{l}\text { Partial penetration; } \\
21 \mathrm{~mm} \text { hole }\end{array}$ \\
\hline & & & & 4.10 & 18.0 & high & $\begin{array}{l}\text { Full penetration; } \\
12.7 \mathrm{~mm} \text { hole }\end{array}$ \\
\hline & $\mathrm{Hi}^{-}$ & & $1 / 2 \mathrm{CMC}$ & & & low & $\begin{array}{c}\text { Partial penetration; } \\
10 \mathrm{~mm} \text { hole } \\
\end{array}$ \\
\hline 2532 & $\begin{array}{l}\text { Nicalon } \\
\text { Type S }\end{array}$ & modified & $\begin{array}{l}\text { distributed } \\
\text { plies }\end{array}$ & 4.65 & 10.8 & high & $\begin{array}{c}\text { Full penetration; } \\
12.7 \mathrm{~mm} \text { hole }\end{array}$ \\
\hline 2533 & Hi- & modified & $1 / 2$ CMC & 505 & 00 & low & $\begin{array}{l}\text { Full penetration; } \\
12.7 \mathrm{~mm} \text { hole }\end{array}$ \\
\hline 2533 & $\begin{array}{l}\text { Nicalon } \\
\text { Type S }\end{array}$ & modif1ed & $\begin{array}{l}\text { composite } \\
\text { skins }\end{array}$ & 3.05 & 9.9 & high & $\begin{array}{l}\text { Full penetration; } \\
12.7 \mathrm{~mm} \text { hole }\end{array}$ \\
\hline 2534 & $\mathrm{Hi}^{-}$ & modified & $\begin{array}{l}1 / 2 \mathrm{CMC} ; \\
\text { matrix side }\end{array}$ & 460 & 100 & high & $\begin{array}{l}\text { Full penetration; } \\
12.7 \mathrm{~mm} \text { hole }\end{array}$ \\
\hline 2034 & Type S & ก110 & $\begin{array}{l}\text { 1/2 CMC; } \\
\text { CMC side }\end{array}$ & 4.00 & 10.3 & high & $\begin{array}{c}\text { Full penetration; } \\
12.7 \mathrm{~mm} \text { hole }\end{array}$ \\
\hline 2585 & $\begin{array}{c}\mathrm{Hi}- \\
\text { - }\end{array}$ & modified & 1/3 CMC & 4.19 & 90 & low & $\begin{array}{c}\text { Partial penetration, } \\
12 \mathrm{~mm} \text { hole } \\
\end{array}$ \\
\hline 2585 & $\begin{array}{l}\text { Nicalon } \\
\text { Type S }\end{array}$ & modiried & $\begin{array}{l}\text { distributed } \\
\text { plies }\end{array}$ & 4.19 & 9.0 & high & $\begin{array}{c}\text { Full penetration; } \\
12.7 \mathrm{~mm} \text { hole }\end{array}$ \\
\hline M3A & None & modified & $\begin{array}{c}\text { all } \\
\text { monolithic }\end{array}$ & 4.34 & 0 & low & Shattered \\
\hline M3B & None & modified & $\begin{array}{c}\text { all } \\
\text { monolithic }\end{array}$ & 4.34 & 0 & low & Shattered \\
\hline $\begin{array}{l}\text { Silco } \\
\text { mp }\end{array}$ & None & $\begin{array}{l}\text { converted } \\
\text { C-fiber } \\
\text { cloth }\end{array}$ & $\begin{array}{c}\text { all } \\
\text { monolithic }\end{array}$ & 5.49 & 0 & low & Shattered \\
\hline
\end{tabular}



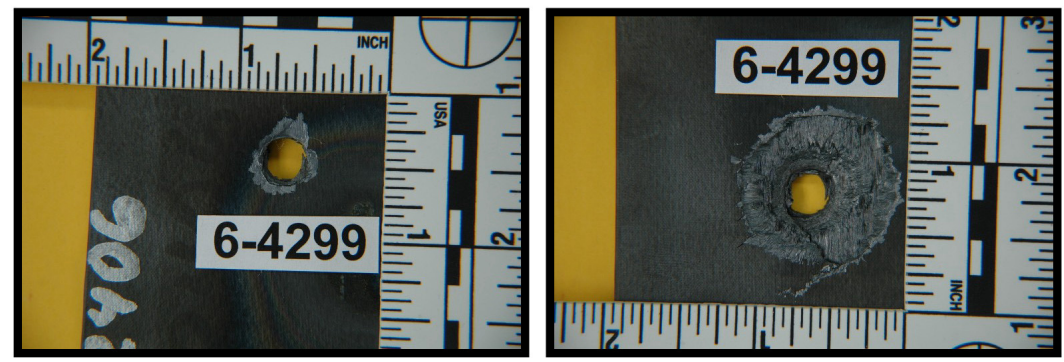

Panel 2406

Low Velocity
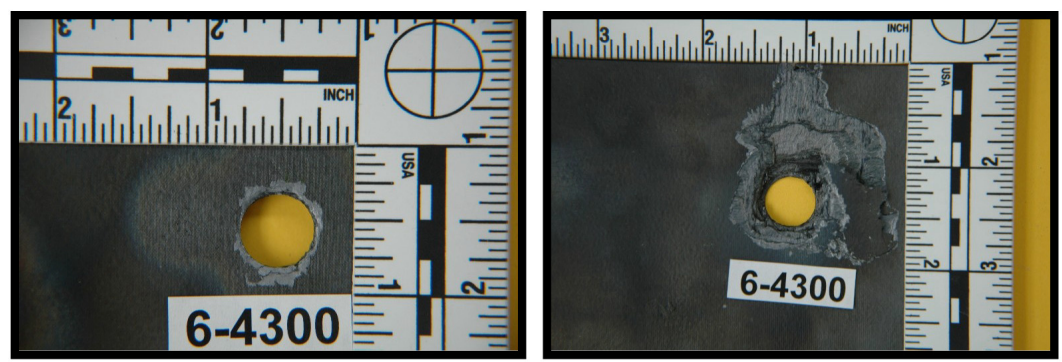

Panel 2406

High Velocity
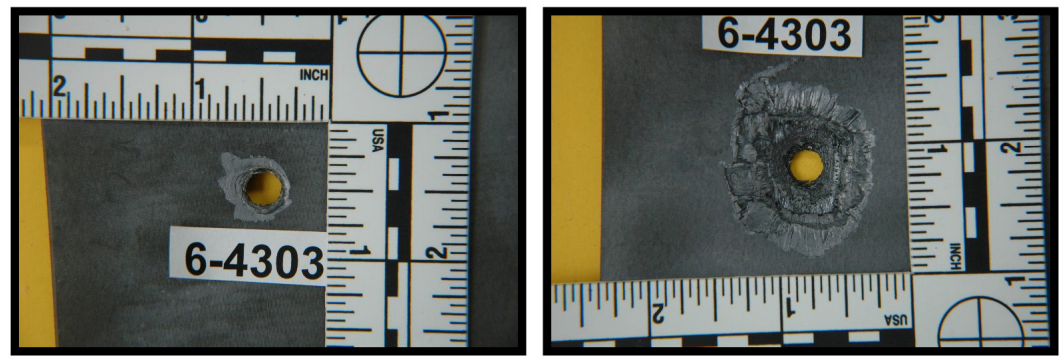

\section{Panel 2407}

Low Velocity
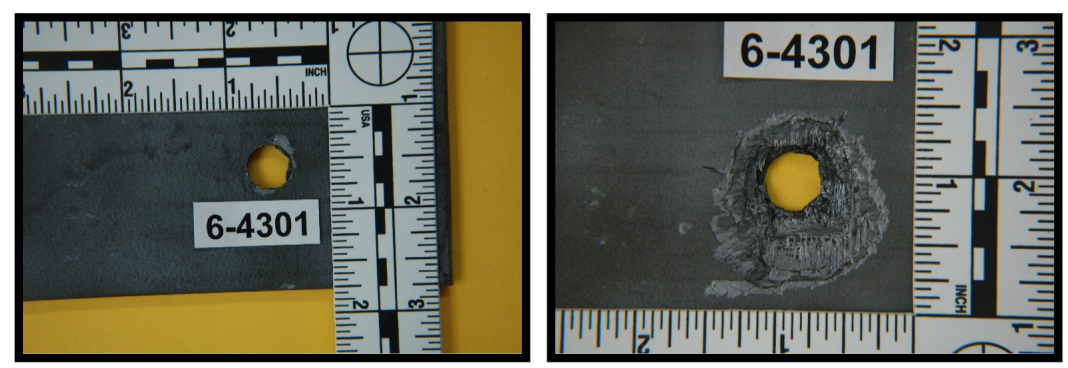

\section{Panel 2413}

Low Velocity
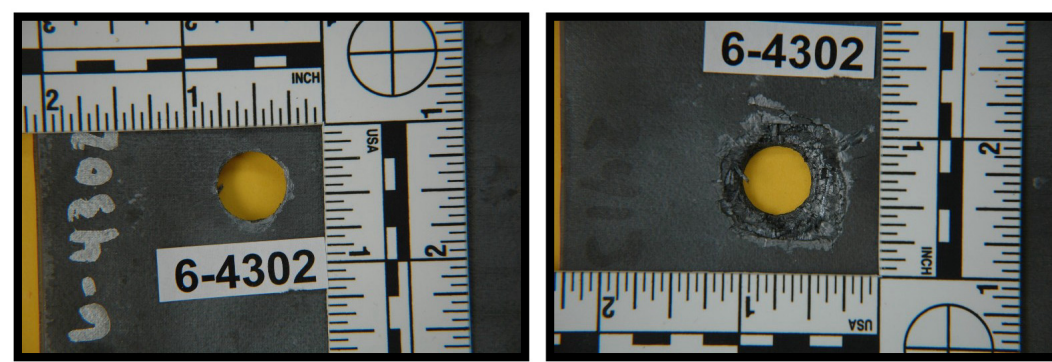

Panel 2413

High Velocity

Figure 3-228. Photographs of ballistic impact panels following impact testing. Photos on the left are the entry (front) side and photos on the right are exit (back) side. See Table 3-19 for an explanation of panel configurations. 

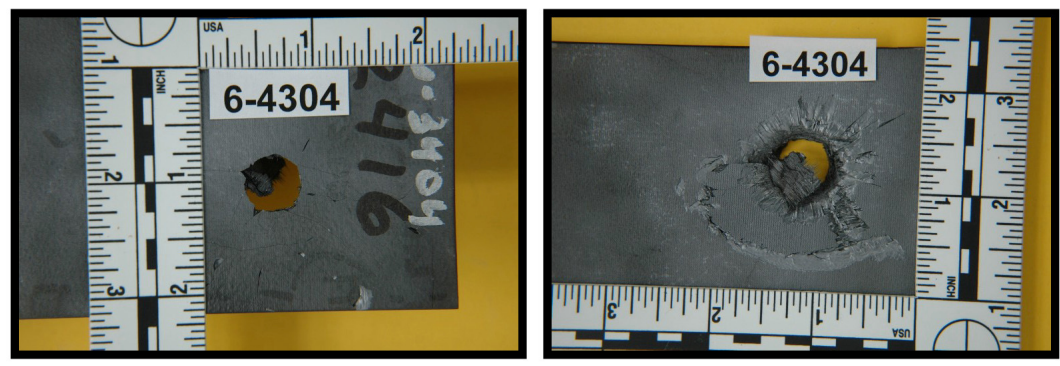

Panel 2416

Low Velocity

Matrix side
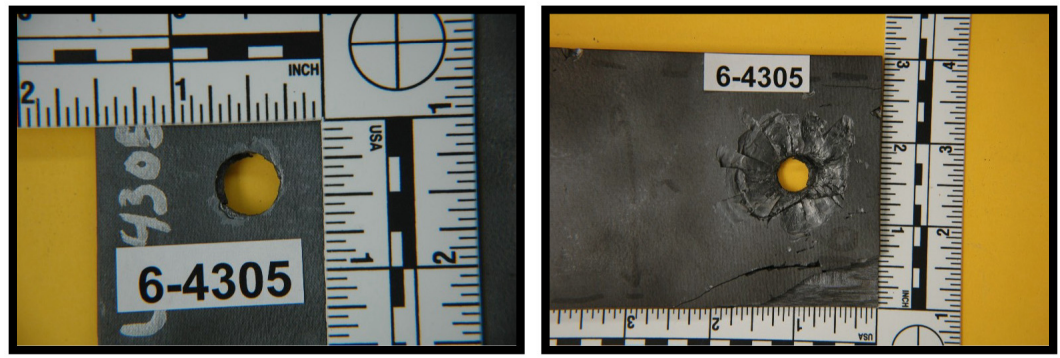

Panel 2416

Low Velocity

CMC side
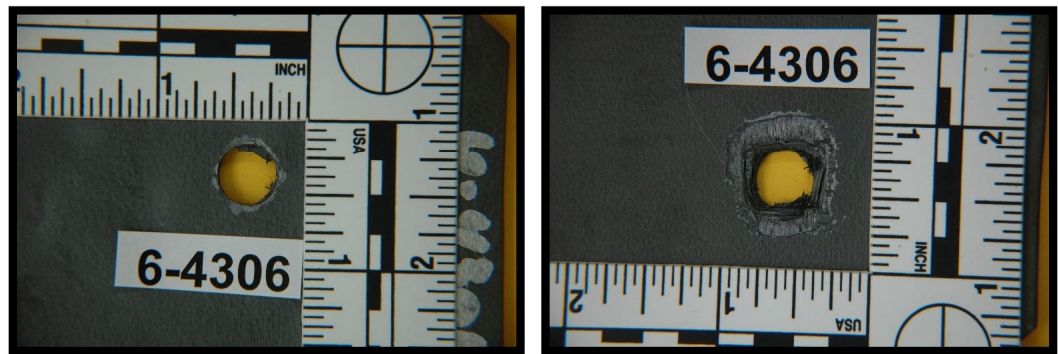

Panel 2568

Low Velocity
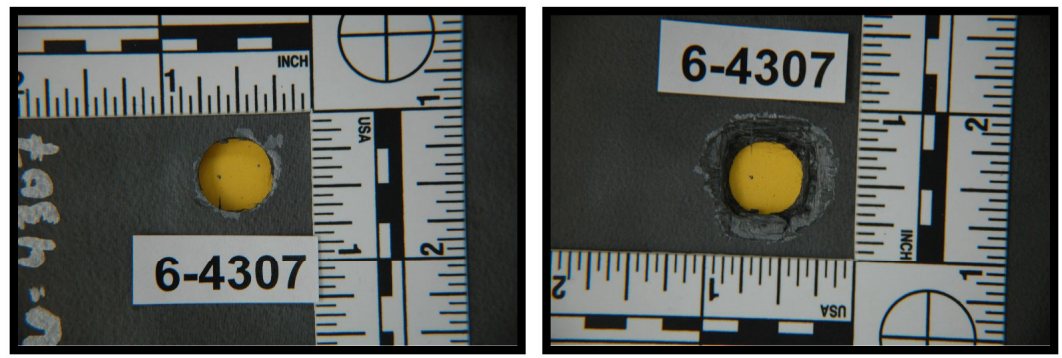

Panel 2568

High Velocity
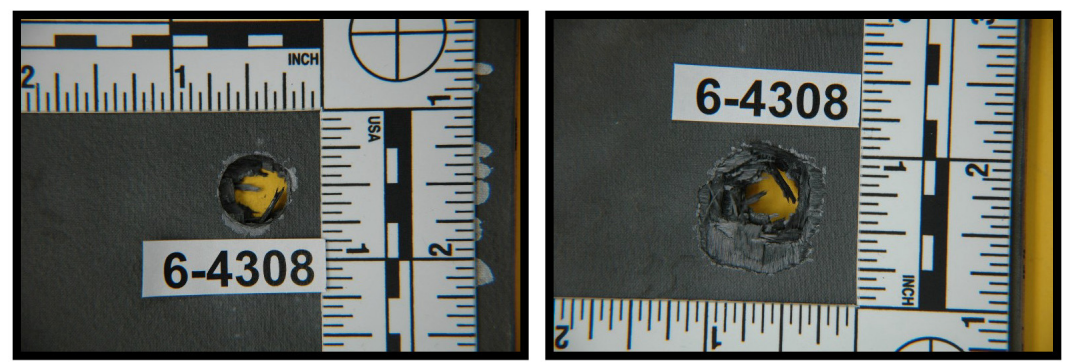

Panel 2584

Low Velocity

Figure 3-228, continued. Photographs of ballistic impact panels following impact testing. Photos on the left are the entry (front) side and photos on the right are exit (back) side. See Table 3-19 for an explanation of panel configuration. 

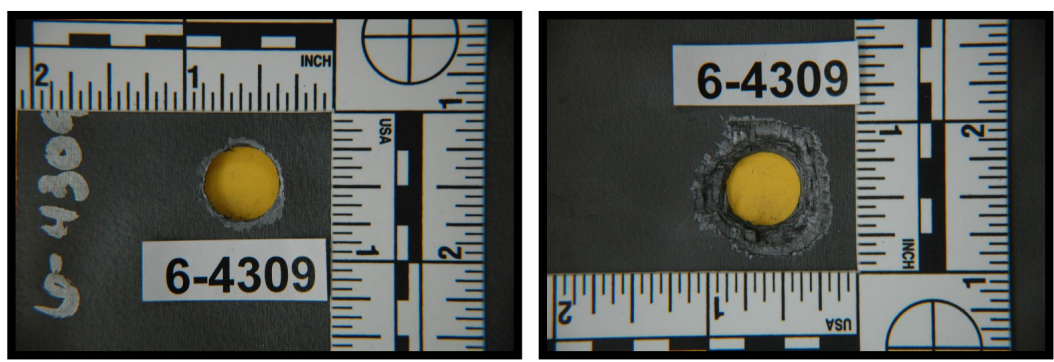

Panel 2584

High Velocity
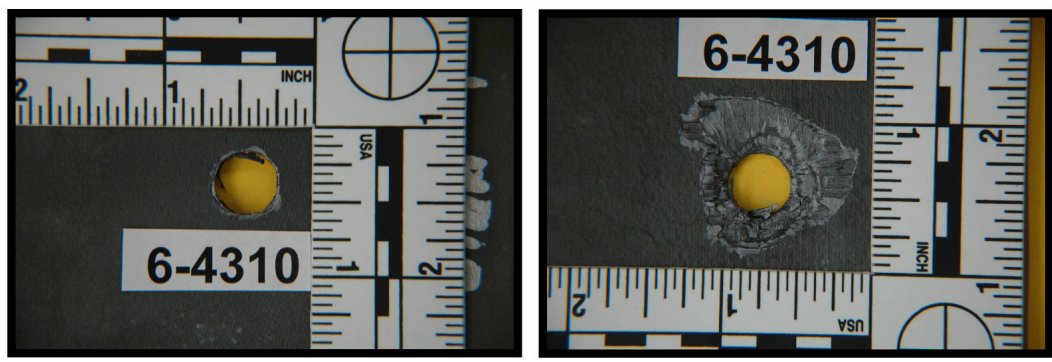

Panel 2532

Low Velocity
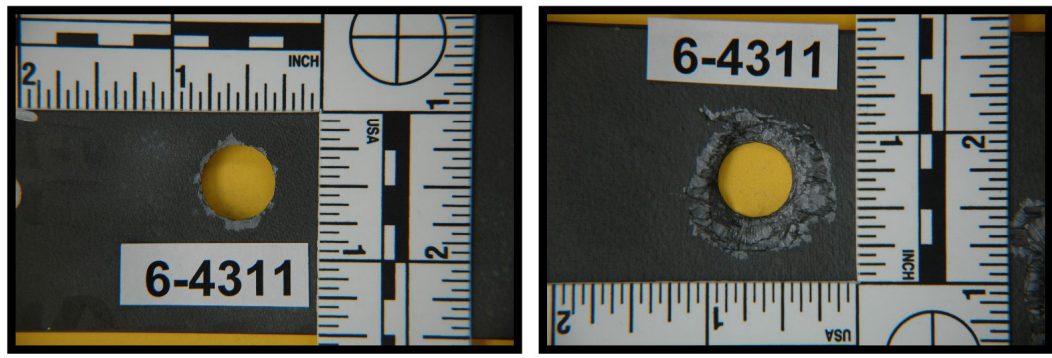

Panel 2532

High Velocity
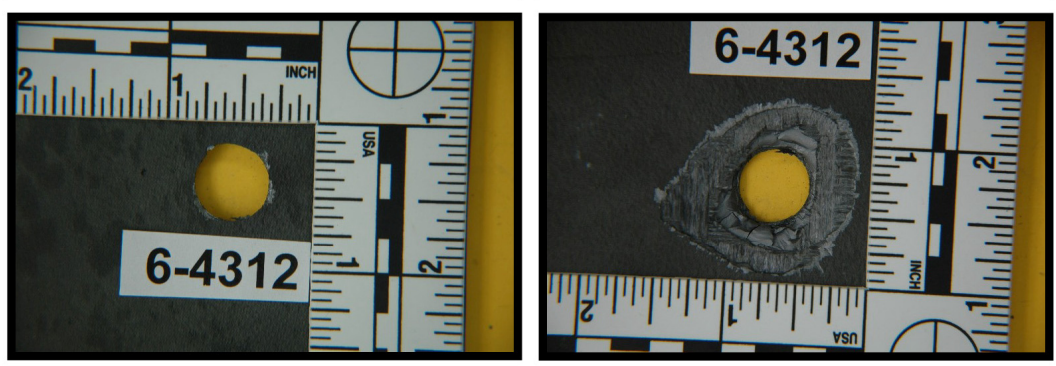

Panel 2533

Low Velocity
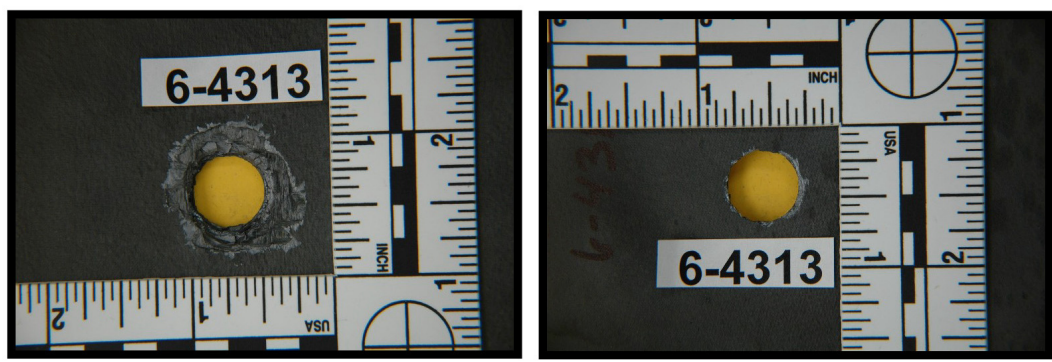

Panel 2533

High Velocity

Figure 3-228, continued. Photographs of ballistic impact panels following impact testing. Photos on the left are the entry (front) side and photos on the right are exit (back) side. See Table 3-19 for an explanation of panel configuration. 

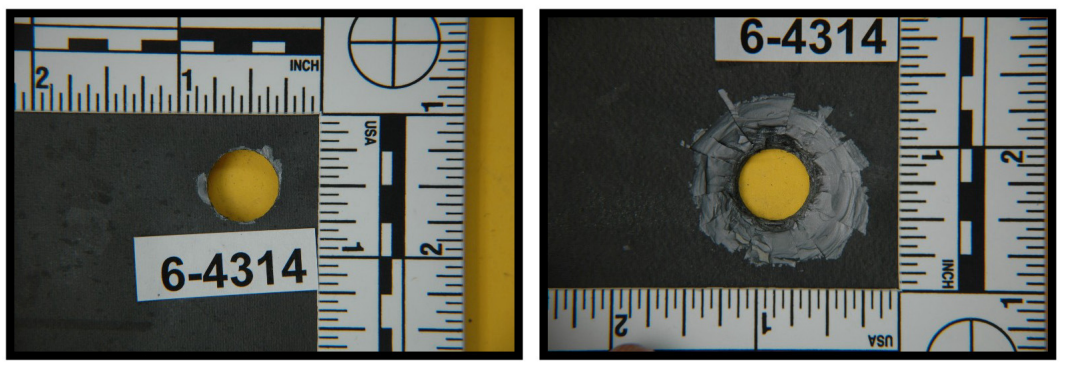

Panel 2534

High Velcity

CMC side
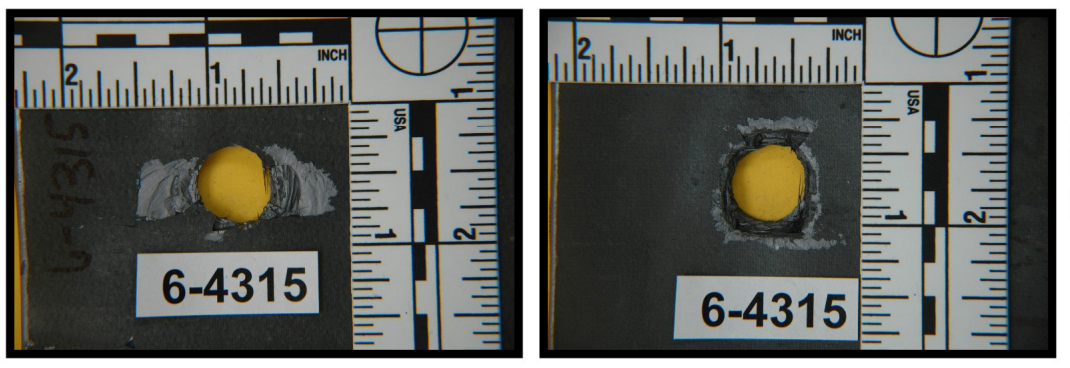

Panel 2534

High Velocity

Matrix side
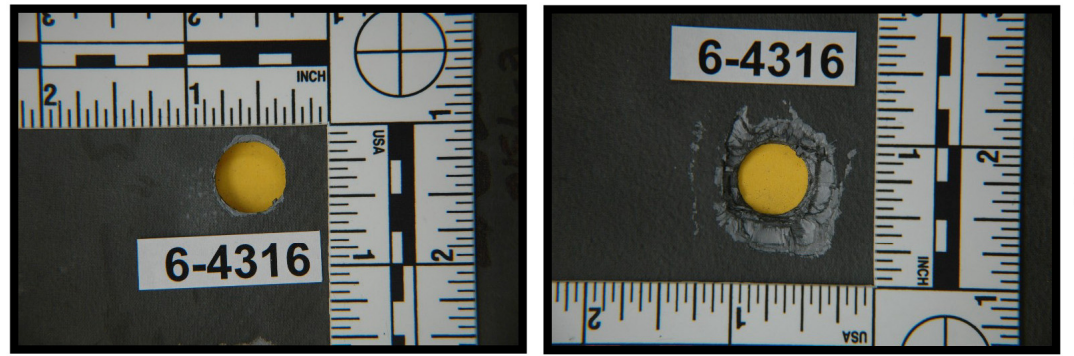

Panel 2585

Low Velocity
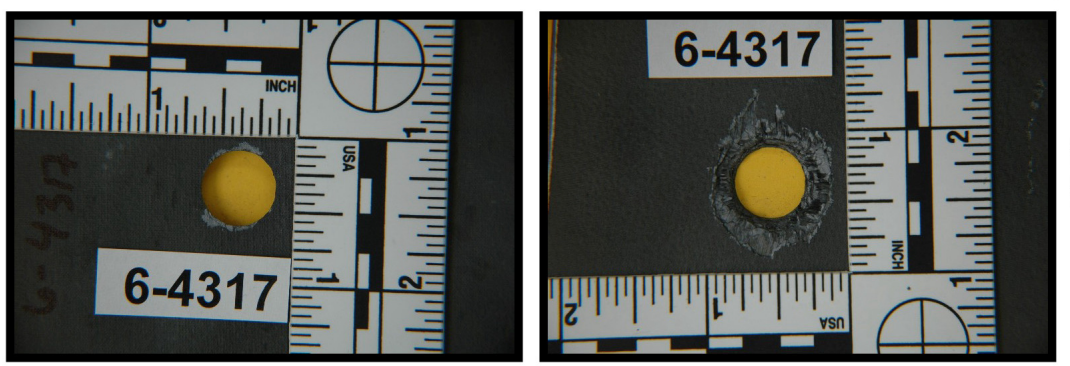

Panel 2585

High Velocity

Figure 3-228, continued. Photographs of ballistic impact panels following impact testing. Photos on the left are the entry (front) side and photos on the right are exit (back) side. See Table 3-19 for an explanation of panel configuration.

The first of the two panel configurations that had complete penetration of the projectile at the lower test velocity was the $1 / 2$ CMC panel made with Hi-Nicalon where all of the CMC plies were on one side of the panel and all of the monolithic plies were on the other side (panel 2416). This panel was completely penetrated when the projectile impacted the monolithic side of the panel first, but was not penetrated when impacted on the CMC side of the panel. As noted previously, the panels with relatively thick regions of CMC distinct from thick regions of unreinforced matrix tended to show delamination during processing from the shrinkage of the matrix only regions. These delams were worse for the samples where one side was $\mathrm{CMC}$ and the other side monolithic matrix, and were also worse for the initial samples made with Hi-Nicalon fiber and the standard matrix composition compared 
to those made later with Hi-Nicalon Type-S fiber and the chopped fiber modified matrix composition. Thus panel 2416 was the worst of the entire set in terms of having preexisting delamination defects in the panel before ballistic testing.

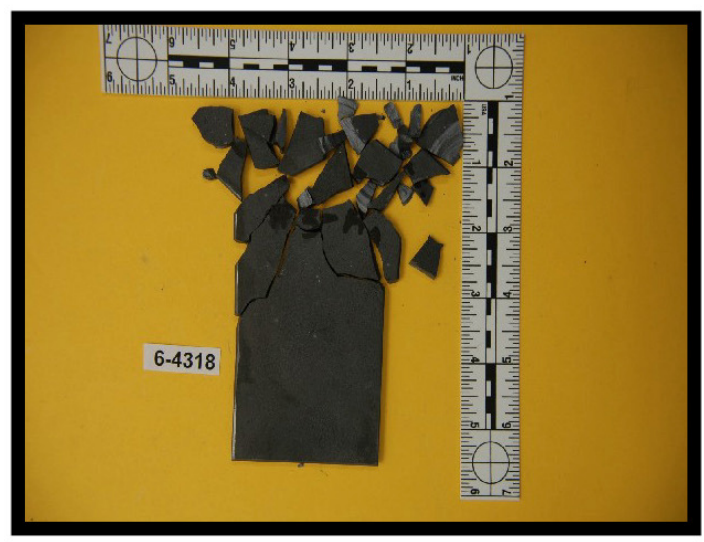

Monolithic matrix

Low Velocity

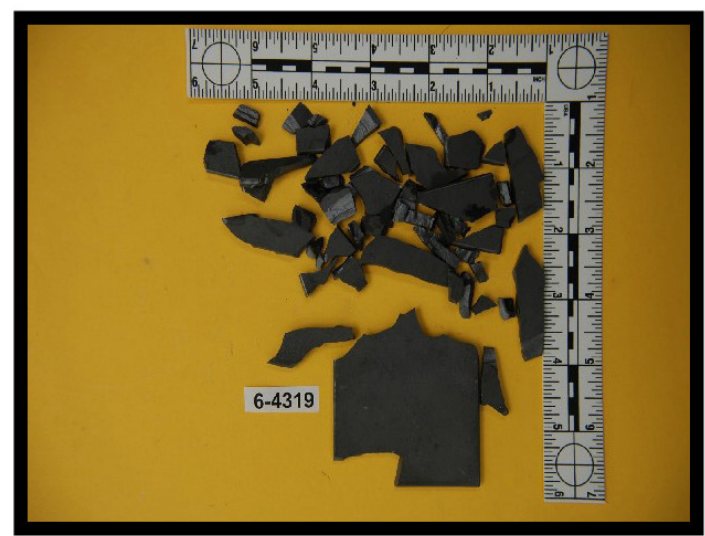

Monolithic matrix High Velocity
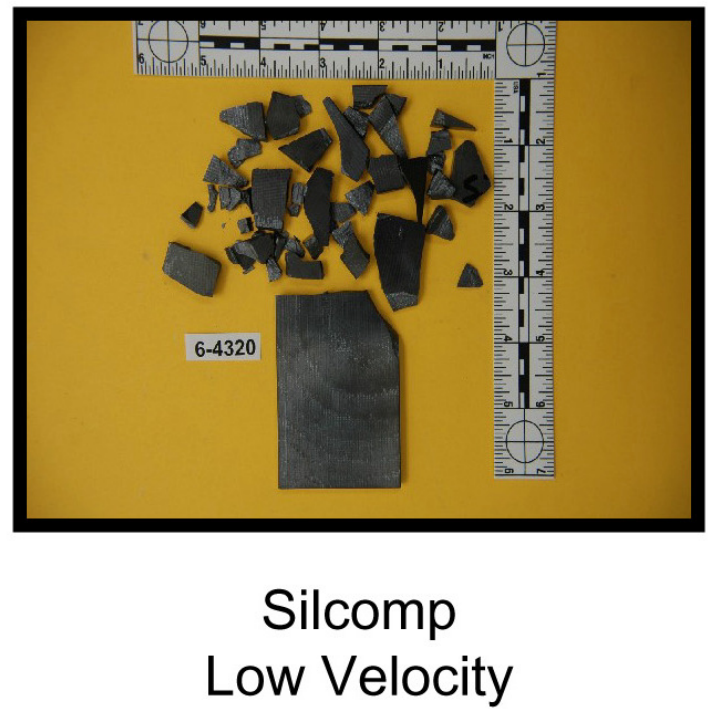

Figure 3-229. Post-test impact photographs of the monolithic matrix and C-cloth based Silcomp panels showing how the panels shattered into fragments.

Figure 3-230 shows a still frame taken from the high-speed video of the low speed impact event that penetrated panel 2416. In this test the monolithic half of the panel was in front, i.e. toward the incoming projectile, while the composite half of the panel was opposite to the projectile. During the impact event the projectile was stopped before full penetration, and at that moment the pre-existing edge delamination could be clearly seen opening up as the back half of the panel bent outward from the momentum of the projectile. The pre-test 
NDE image on the upper left shows the positions of the two impact tests done on this panel and the close proximity of the test location to the pre-existing delamination (red to yellow in the image). The NDE image in the lower left clearly shows that the pre-existing defect propagated significantly across the sample during the impact event. While the other end of the panel also contained a large pre-test delamination defect, the impact test done on the CMC side of this panel was farther removed from the pre-existing delaminations and centered more within the "good" section of the panel. Consequently there was no indication of delamination propagation in the test video of the impact on the CMC side, and the projectile did not penetrate the panel from this direction. It was thus concluded that the difference in ballistic impact resistance of this panel from the two sides was influenced more by the presence of the pre-existing defects than the difference in direction of impact.

The other panel that showed complete penetration from a low velocity impact was panel 2533, which had CMC skin plies over a monolithic core. This panel also had substantial pre-existing interlaminar defects, though not as extensive as those in panel 2416. There was also no indication in the test videos of delamination separation or propagation during impact testing. Overall it was unclear why this panel allowed complete penetration at the low velocity whereas panel 2585, which had even fewer CMC plies, did not. This result may be indicating that having the CMC plies more evenly distributed throughout the panel (as in samples 2532 and 2585) is more effective at resisting ballistic impact events than configurations where the CMC and monolithic plies are more segregated.

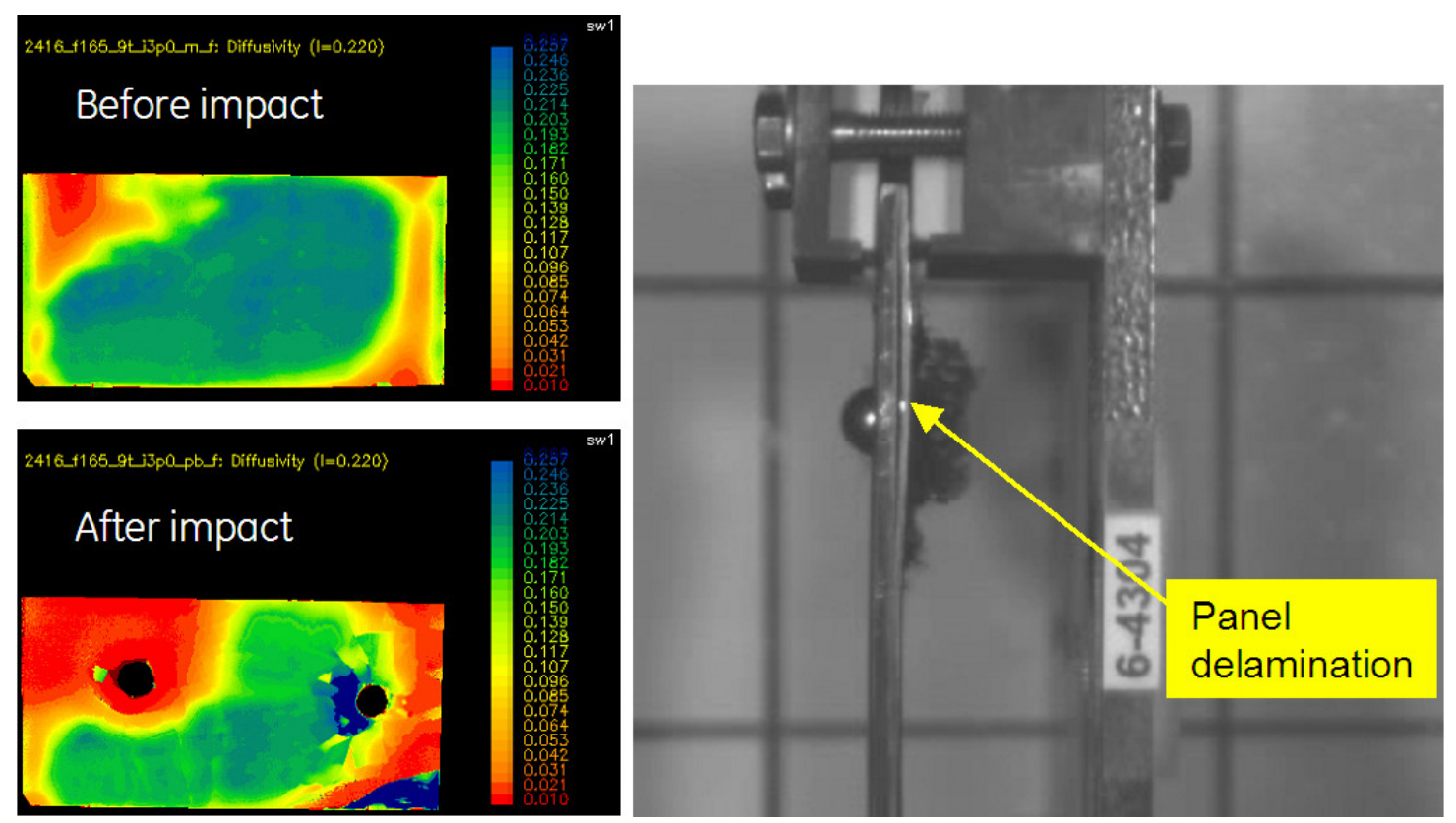

Figure 3-230. Transmission IR thermography images of hybrid panel 2416 before (upper left) and after (lower left) ballistic impact testing. The image on the right is a still photograph from the high-speed video of the impact event that shows the opening of a pre-existing delamination along the edge of the panel. 
In an attempt to quantify the ballistic resistance of the hybrid CMC panels the high-speed videos of each impact event were examined. The velocity of the projectile prior to impact was measured by UDRI and the post-impact velocities were estimated from the videos. The difference in kinetic energy of the projectile before and after impact was used as an estimate of the amount of energy dissipated during the impact event. There was a small variation in panel-to-panel thickness, so the energy values were normalized according to thickness. While the energy absorbed by a continuous fiber composite from a ballistic impact event is not strictly a linear function of thickness [19], over small ranges of thickness the variation is approximately linear, so that a simple normalization by panel thickness is acceptable.

Figure 3-231 shows a plot of the energy dissipated during the impact events versus the volume fraction of fibers, which scales with the fraction of CMC plies, in each panel. For the low velocity impacts without penetration $>99 \%$ of the projectile energy was absorbed during the collision with very little kinetic energy remaining in the rebounding projectile. Since the impact velocity, and thus the impact energy, was maintained relatively constant in these tests the amount of energy absorbed was also relatively constant, with most of the variation coming from the normalization by thickness.

Conversely there was a difference seen in the amount of energy absorbed from the high velocity impact events, where the projectile had excess kinetic energy to cause complete penetration. There appeared to be an approximately linear relationship between the energy dissipated and the volume fraction of fibers, which correlates with the fraction of the panel thickness that was made of CMC plies. The energy dissipated by the monolithic matrix sample at the high velocity was artificially high because of the very large number of small fragments, and consequent high amount of new surface area, produced from the impact event. The fact that the other two monolithic samples failed catastrophically at the lower impact velocity was an indication of the low fracture toughness of the monolithic materials compared to CMCs with even a very low effective fiber volume fraction (as low as 8.7\%). 


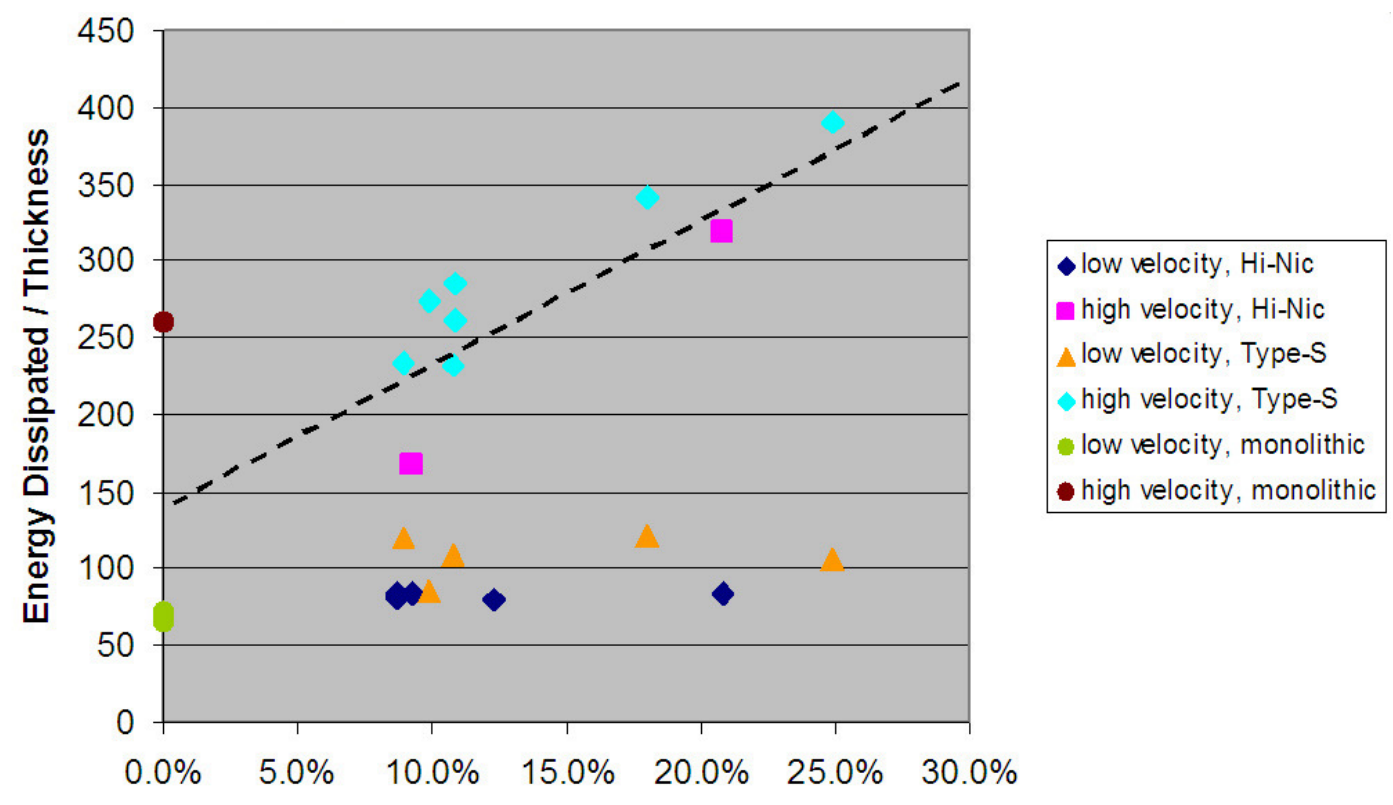

Fiber Volume Fraction

Figure 3-231. Plot of energy dissipated per unit thickness (in arbitrary units) during the ballistic impact tests versus the volume fraction of fiber in the target panel.

Overall the ballistic impact tests of the $\mathrm{CMC} /$ monolithic hybrid panels were quite successful. Even at very low levels of fiber content the hybrid panels remained tough enough to prevent catastrophic failure. Visual damage on the majority of panels was limited to the region near the impact site, with the maximum damage zone on the exit side of the panels being limited to $\sim 3 \mathrm{X}$ the size of the projectile.

Although the ballistic data indicated that the hybrid structures, over the range of configurations tested, maintained adequate FOD resistance, the impact of fiber reduction on the normal mechanical properties of the panels was also of interest. Room temperature tensile testing was therefore done on test bars cut from each of the hybrid panels, the results of which are summarized in Figure 3-232 through Figure 3-234.

Figure 3-232 shows the tensile stress-strain behavior for the hybrid panel set made with HiNicalon fiber and the standard monolithic matrix composition. Panels made from these constituents displayed various issues with delaminations and deformation during fabrication due to differential expansion/shrinkage of the CMC and monolithic plies, and consequently most of the panels had significant pre-existing defects. Panels from the $1^{\text {st }}$ set not shown in Figure 3-232 were either too warped or had severe enough defects that tensile testing was impractical.

As expected, the ultimate strengths of the panels decreased considerably as the net fiber volume fraction was lowered by the addition of the monolithic plies. The strain to failure also tended to decrease, but the data were more scattered. As the number of monolithic plies increased, especially for configurations that had thicker monolithic regions, there was a 
greater tendency for opening of large matrix cracks and for shear modes of failure. Both of these phenomena tended to interfere with the tracking of the face-mounted extensometer, resulting in jogs in the stress-strain curves, and sometimes clearly erroneous readings, as show for the panel 2416 samples.

The tensile data from the samples made with Hi-Nicalon type-S fiber and using the modified matrix composition for the monolithic plies, are shown in Figure 3-233 and Figure 3-234. Figure 3-233 shows only the data from the panels with distributed plies, meaning that the $\mathrm{CMC}$ and monolithic plies were interspersed through the thickness with no region of monolithic material being more than 2 plies thick. Again, the ultimate strengths and strain to failure values tended to decrease as monolithic plies were substituted for the CMC plies, but both values appear to be somewhat larger than in the older Hi-Nicalon panels. This apparent difference was really a secondary effect of the changes in composition made for this newer set of panels. The process used to fabricate type-S fiber composites inherently results in thinner plies, and the monolithic plies of the modified composition also tended to be thinner than the standard matrix composition. Consequently the overall panel thicknesses from this set were smaller than for the panels made with Hi-Nicalon fiber and the standard matrix, giving them a higher overall fiber volume fraction. Other CMC testing [20] had shown a surprisingly large effect of fiber volume fraction on the strain to failure response of prepreg MI CMC materials, so that the apparently higher strain to failure, and higher ultimate strengths, of the newer composition hybrid panels compared to the older composition was really due to the higher fiber volume fraction. This difference in panel thickness, and its effect on fiber volume fraction, can be seen in the data in Table 3-19. For instance, the new composition panel with 1/3 CMC plies (panel 2585) had a comparable overall fiber volume fraction as panels of the older composition made with $1 / 2 \mathrm{CMC}$ plies (panels 2413 and 2416). 


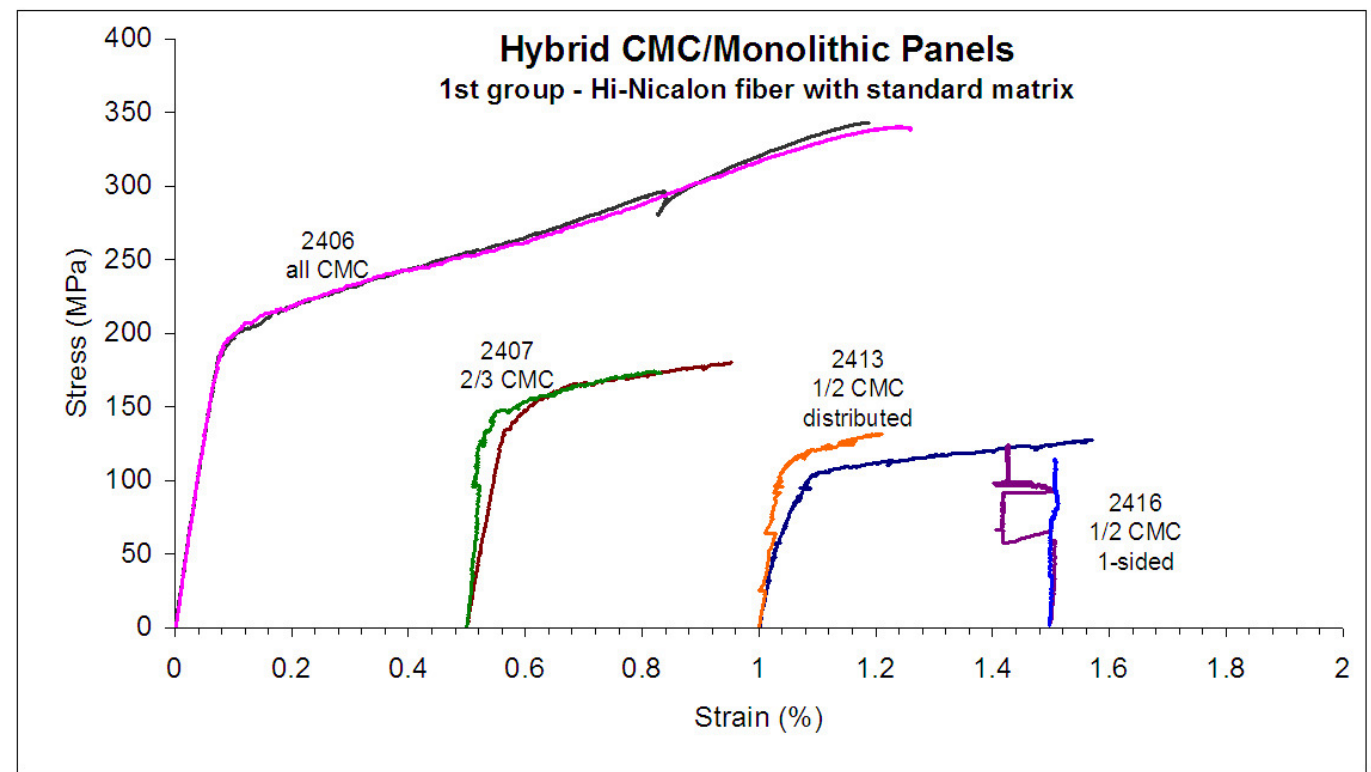

Figure 3-232. Tensile stress-strain data from hybrid CMC/monolithic panels made with HiNicalon fiber and the standard matrix composition. The panel numbers and ply configurations are as indicated, and the curves are offset on the strain axis for clarity.

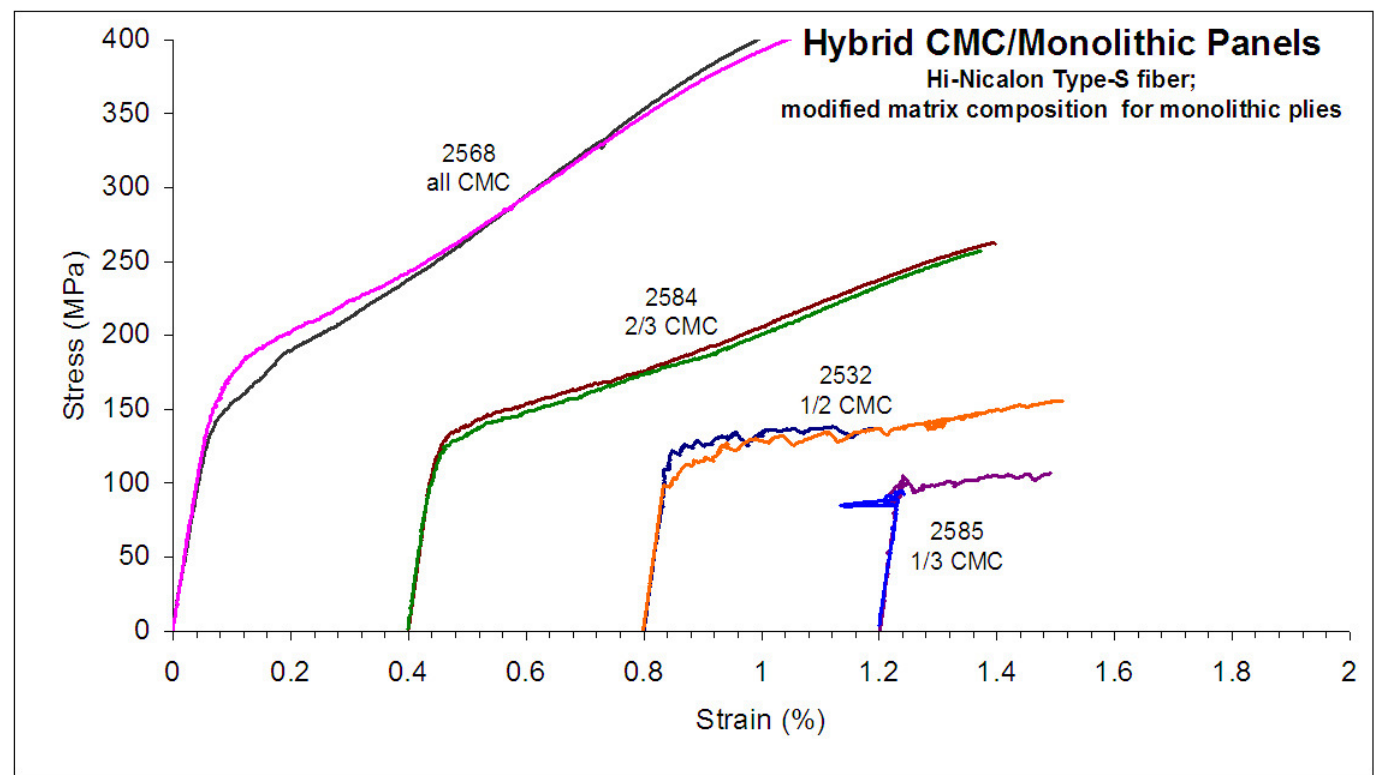

Figure 3-233. Tensile stress-strain data from hybrid CMC/monolithic panels made with HiNicalon type-S fiber and the modified matrix composition for the monolithic plies. The panel numbers and ply configurations are as indicated, and the curves are offset on the strain axis for clarity. 
Figure 3-234 shows the stress-strain plots from the newer composition hybrid panels each having $8 \mathrm{CMC}$ plies out of 18 total. In going from distributed plies to CMC skins to onesided CMC the thicknesses of the separate CMC and monolithic regions was increasing, with additional non-symmetry being added for the one-sided configuration. Although the changes in stress-strain response were smaller than in Figure 3-232 or Figure 3-233, the data still indicated a reduction in tensile fracture properties as the $\mathrm{CMC}$ monolithic plies became more segregated through the thickness. This observation suggested that the most effective use of fiber in a low fiber volume fraction configuration would be to have the fiber uniformly distributed rather than segregated on a ply-by-ply basis.

The effect of fiber volume fraction on ultimate properties was also clear from the plots in Figure 3-235, which show the measured ultimate strength and strain to failure values as a function of fiber volume fraction for all of the hybrid samples. The strength data clearly followed a simple linear relationship, as would be expected. The plot of strain to failure showed the same trend, although the data was more scattered due to the extensometer errors described previously.

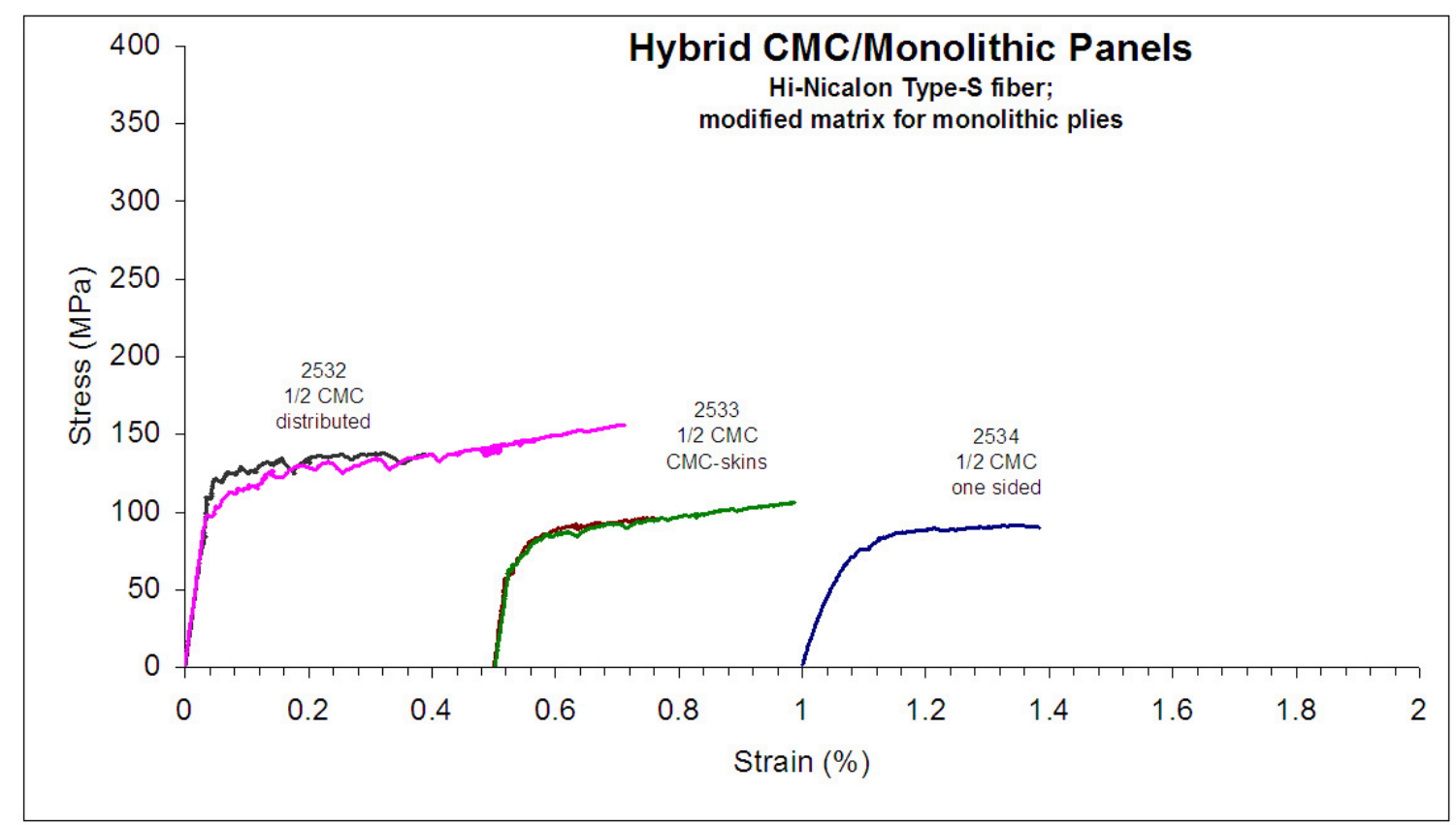

Figure 3-234. Tensile stress-strain data from hybrid CMC/monolithic panels made with HiNicalon type-S fiber and the modified matrix composition for the monolithic plies. The panel numbers and ply configurations are as indicated, and the curves are offset on the strain axis for clarity.

The trends in proportional limit strength of the hybrid samples were more difficult to analyze. Accurate determination of proportional limit requires very clean extensometer readings. The issues mentioned previously regarding extensometer tracking errors, particularly on samples with high amounts of monolithic material, made much of the data 
rather questionable in quality. Nevertheless, it is clear from the data in Figure 3-232 and Figure 3-233 that the overall trend was for lowered proportional limits with fewer CMC plies. This general trend can also be seen in the plot in Figure 3-235 despite the considerable amount of scatter in the values.

At first glance it may seem surprising that the proportional limit stress would decrease with increased amount of monolithic plies (i.e. lowered fiber volume fraction). From testing done during the CFCC program [2] the strength of the unreinforced matrix material was shown to be $\sim 400 \mathrm{MPa}$, which would be considered the cracking stress of the matrix plies. One might therefore expect that substitution of monolithic plies with a 400MPa cracking stress for composite material that typically shows a cracking stress of $\sim 170 \mathrm{MPa}$ would lead to an increase in the overall proportional limit of the hybrid structures. However, recent investigations $[20,21]$ into the effects of ply-level properties on CMC proportional limit indicate that the overall composite matrix cracking strength is generally controlled by the cracking stress of the $90^{\circ}$ plies in 0-90 layups. Since the structure of the $90^{\circ}$ plies were not altered intentionally during hybrid sample fabrication, one would expect the cracking stress of these plies to remain constant. It has also been shown that the cracking stress of $0^{\circ}$ plies is inversely proportional to the fiber volume fraction, but still remains higher than the cracking stress of $90^{\circ}$ plies. Thus, assuming the hybrid panel proportional limit stress was controlled primarily by the cracking stress of the $90^{\circ}$ plies, the best one should hope for would be a constant proportional limit with fiber volume fraction in the hybrid structures.

Unfortunately there were also significant microstructural defects added to the hybrid panels as noted on NDE images. Small un-infiltrated islands still persisted irregularly within the monolithic plies, and the size and number of these un-infiltrated islands increased with increasing thickness of the overall monolithic layers. Consequently as the amount of monolithic material increased and overall fiber volume fraction decreased, the strength of the monolithic layers would also be expected to have decreased significantly due to the increase in these microstructural defects. Thus the overall trend of reducing the fiber volume fraction would be to decrease the cracking stress of the $0^{\circ}$ plies, reduce the strength of the monolithic plies (from the defects), and maintain the cracking stress of the $90^{\circ}$ plies, leading to an overall lowering of proportional limit in the hybrid structures, as was observed. With additional process optimization the monolithic ply and interlaminar defects could be reduced or eliminated, gaining back the inherent material strength of the monolithic plies. However, since the proportional limit strength will still be dominated by the presence of the $90^{\circ}$ plies it is likely that the proportional limit of the hybrid structures will not be any higher than that for normal full CMC structures. 

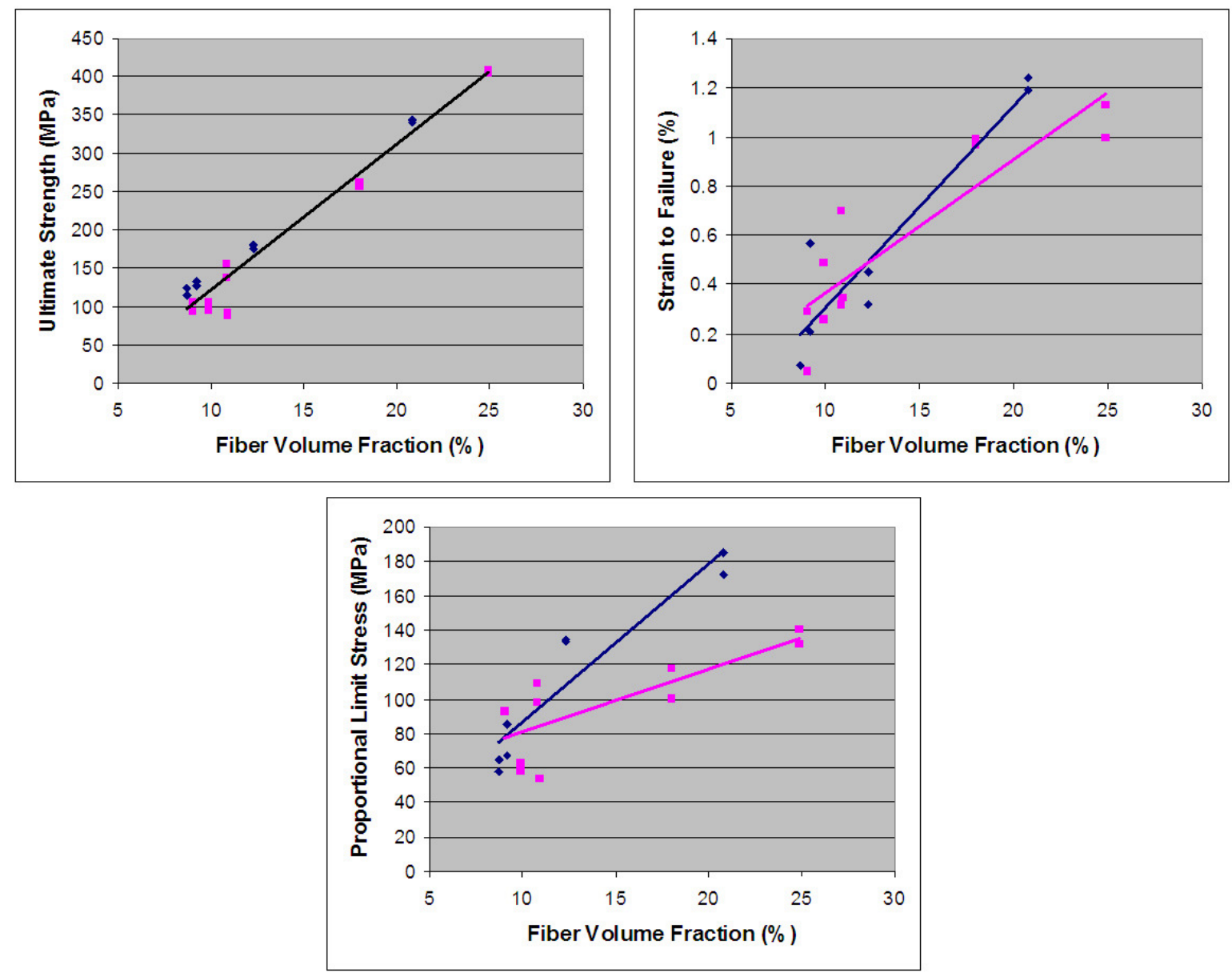

Figure 3-235. Plots of ultimate strength (top left), strain to failure (top right) and proportional limit (bottom) measured on the hybrid test panels as a function of actual fiber volume fraction. Panels made with Hi-Nicalon fiber are indicated by the blue symbols, and those with Hi-Nicalon Type-S fiber by the magenta symbols.

Despite the rather significant reductions in ultimate strength, strain to failure and proportional limit stress values for the hybrid panels indicated above, there was no apparent increase in the extent of damage from the impact events. Figure 3-236 shows post-impact NDE images of the set of panels made using Hi-Nicalon type-S fiber and with distributed monolithic plies throughout the thickness. These panels were selected as they had the most comparable fiber architectures and were generally free of pre-existing processing defects. In each of the images the higher velocity impact, which resulted in full penetration of the panels, is on the left side and the lower velocity impact, in which the projectile did not fully penetrate the panels, is on the right. In each case the size of the damaged zones, as indicated by the orange colored disks around each hole, were rather consistent. In fact, it could be argued that the damage zone was actually moderately larger in the normal CMC panel with the highest fiber content. This result strongly indicated that resistance to damage initiation from a ballistic event was insensitive to the fiber content of the composites over the range tested. Of course, at some lower, as-yet unknown, fiber content the extent of 
damage from the impact event would be expected to grow, eventually transitioning to a purely brittle, catastrophic failure as seen in the monolithic samples with no fiber content.

Additional mechanical testing was done on the hybrid structure panels in the form of pin pull-out tests. For this test a thru-thickness hole was cut near the end of a tensile bar and the bar was loaded in tension using a metallic pin going through the hole (the opposite end of the bar was held in a conventional hydraulic face-load wedge grip fixture normally used for tensile testing). The samples were loaded to failure and the maximum load recorded. The aim of this test was to simulate the loading on the shroud attachment to the outer shroud block.
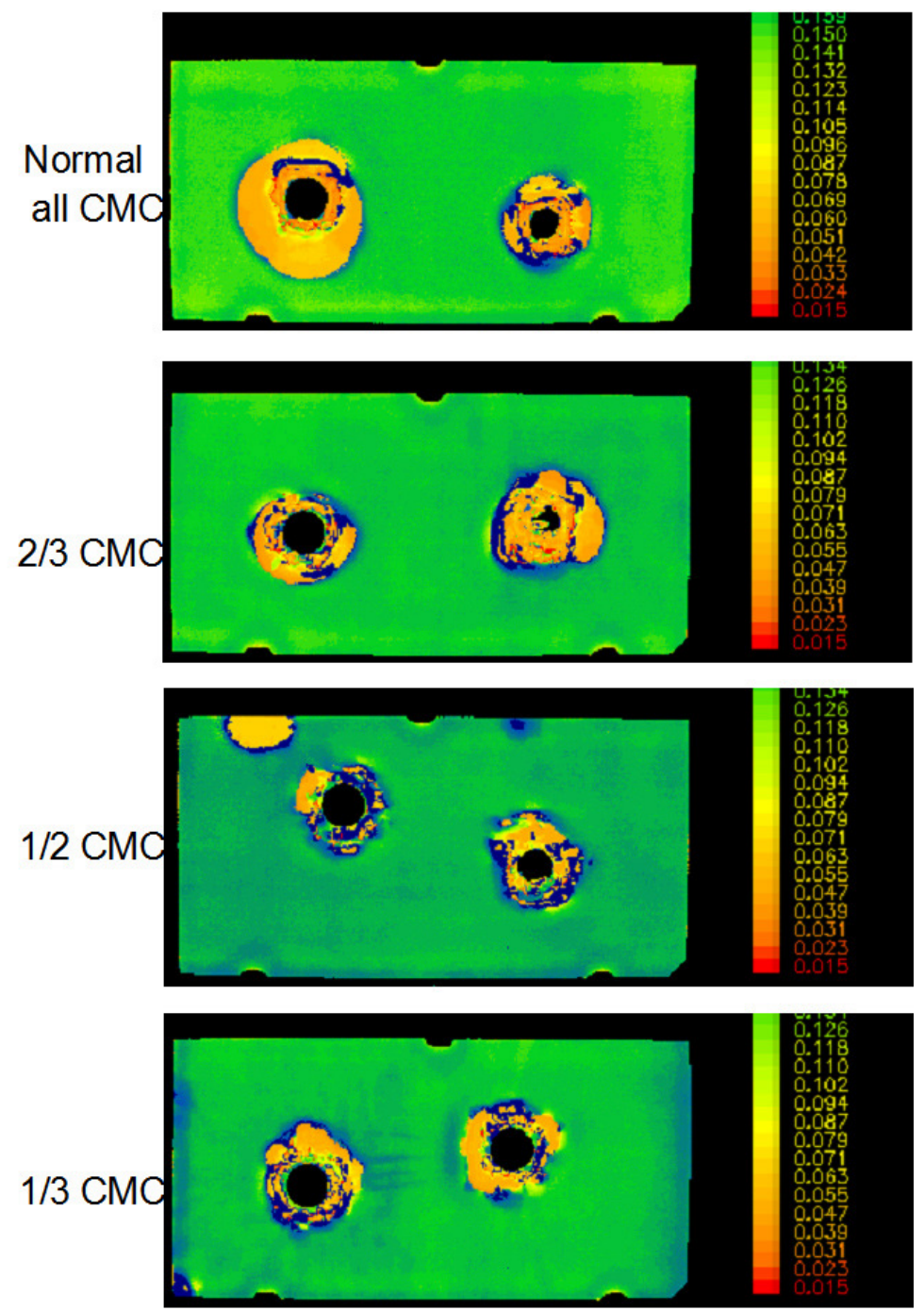

Figure 3-236. IR reflection thermography images of the hybrid CMC panels with distributed composite plies made with Hi-Nicalon Type-S fiber following ballistic impact testing. 
Figure 3-237 shows the results of the pin pull-out tests, and plots the net section stress at failure versus the overall fiber volume fraction of the composites. As can be seen, the pin pull-out strength decreased linearly with reductions in fiber volume fraction, mirroring the behavior of the ultimate tensile strength (as shown in Figure 3-235). The red dash-dot line near the bottom of the plot indicates the level of stress expected in a CMC shroud if all of the attachment load were carried on just one pin. The strengths of even the lowest fiber volume fraction samples were more than sufficient to support such a load, indicating that the same attachment scheme could be utilized for hybrid shroud components.

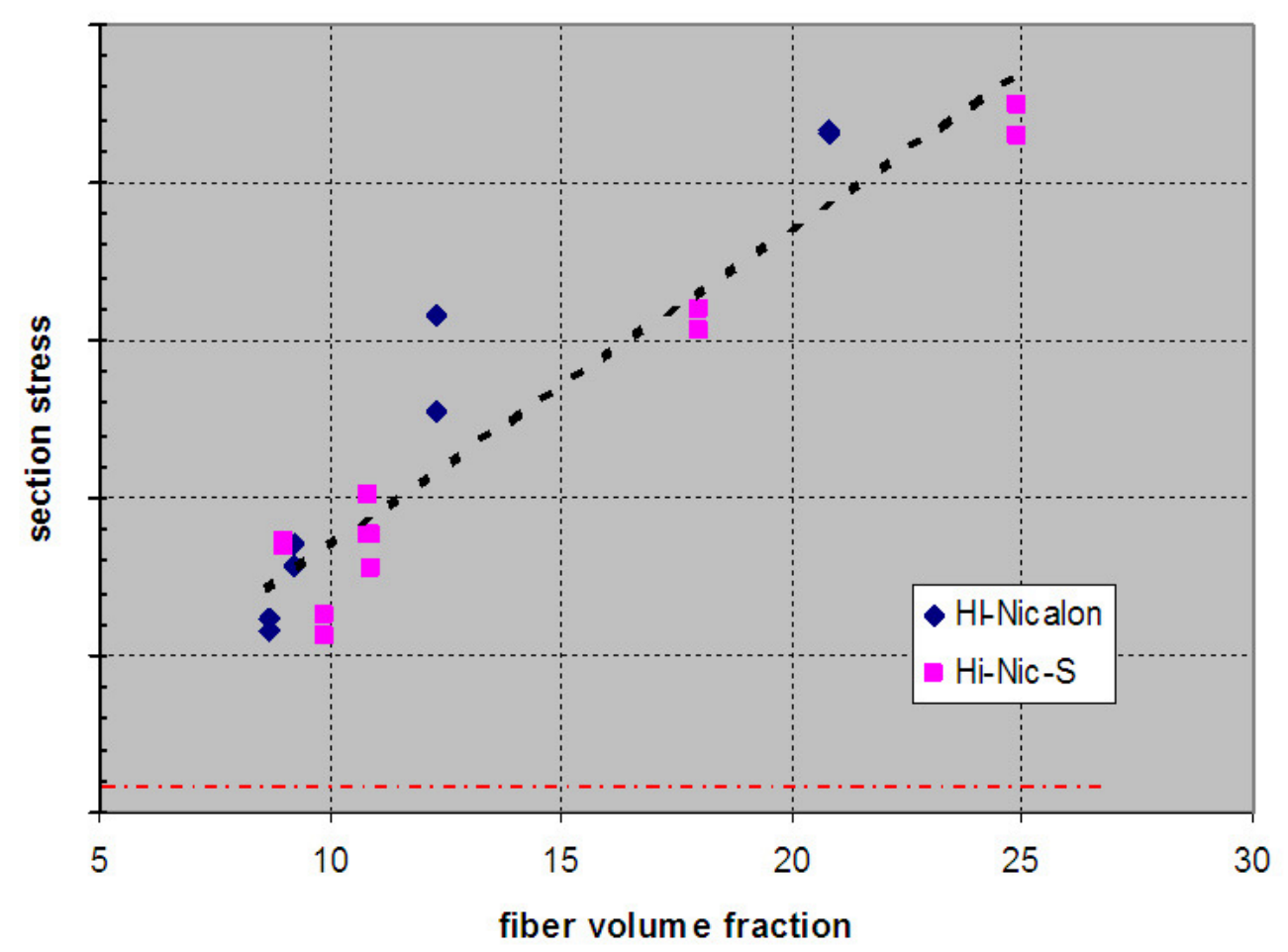

Figure 3-237. Pin pull-out strength as vs fiber volume fraction for hybrid CMC panels.

The red dot-dashed line shows the maximum pin attachment load on the shrouds.

\subsection{Hybrid Structures Using Uncoated Fiber Plies}

The second method of obtaining hybrid structures of CMC and monolithic layers that was investigated was to utilize uncoated fiber for the monolithic plies. In this technique the preforms were fabricated from tapes made with coated (for the composite plies) and uncoated (for the monolithic plies) fiber. Uncoated fiber reacts with the CMC matrix during melt infiltration, becoming strongly bonded to the matrix, and thus behaves as a brittle monolithic SiC ceramic in normal mechanical tests. This approach was not considered the preferred technique for making hybrid structures since it still utilized SiC fiber in the "monolithic" plies, and thus the cost saving associated with this approach was not as great as would be realized with matrix-only monolithic plies. However, the presence of the continuous fiber was expected to constrain the shrinkage of the monolithic plies just 
as it did for the composite plies, and thus better panel dimensional stability and freedom from delamination was an expected outcome.

Since the uncoated fiber does not contribute to the composite ultimate strength, strain or toughness properties, but simply acts as a filler, there are no strict mechanical requirements for this fiber. It would thus be advantageous to utilize the lowest cost fiber that is chemically and thermo-mechanically compatible with the MI CMC system. Carbon fiber would be chemically compatible, but in continuous form the low thermal expansion behavior of the carbon fiber compared to the $\mathrm{SiC}$ fiber used in the composite plies would cause expansion compatibility problems, similar to those experienced with the monolithic matrix ply preforms described earlier. It was therefore necessary to utilize $\mathrm{SiC}$ fiber for the uncoated fiber plies. The lowest cost SiC-based fiber is ceramic grade Nicalon, but this fiber is incompatible with the melt infiltration step due to its high oxygen content. During reaction with the silicon alloy the oxygen is liberated as $\mathrm{CO}$ and $\mathrm{SiO}$, which form gas bubbles within the preform and prevents full infiltration. Hi-Nicalon has a sufficiently low oxygen content that it can be reacted during melt infiltration without such gas evolution, but it still has excess carbon within the fiber $(\mathrm{C}: \mathrm{Si}$ ratio $~ 1.4)$. Because this excess carbon contributes to the overall $\mathrm{C}$ content of the matrix when the fibers react with the Si infiltrant, the excess carbon content had to be compensated for by reducing the particulate or resinderived carbon content of the matrix slurry so as to prevent pore choke-off during melt infiltration.

Two hybrid configurations were fabricated using the uncoated fiber ply approach. Both configurations had roughly $45 \%$ of the normal amount of coated fiber. In the first configuration the coated fiber plies and uncoated fiber plies were alternated so that the reinforced plies were evenly distributed through the thickness. In the second configuration the coated fiber plies were preferentially placed at the surfaces of the panel with the center region being only uncoated fiber plies. The exact ply sequence for these samples is listed in Table 3-20. Both of these configurations had been attempted earlier with the matrix-only monolithic ply approach, allowing for a one-to-one comparison of the monolithic ply hybrid structures with the uncoated fiber ply hybrid structures. Also listed in the table is the ply sequence for the witness panel made from the same batch of coated Hi-Nicalon Type-S fiber and used as a reference for the mechanical properties that would be expected from a full-CMC configuration.

Both of the uncoated fiber hybrid panels appeared to process normally up until melt infiltration. Densification of the panel with the uncoated plies concentrated in the center (panel U2 in Table 3-20) was somewhat below normal. Upon sectioning the panels in order to machine out test coupons it was noticed that there was excessive porosity in the panel, particularly in the center region with uncoated fiber. The panel made with interspersed coated and uncoated fiber plies (panel U1 in Table 3-20) appeared denser. However, both samples displayed various levels of pealing of the surface plies after infiltration, requiring them to be surface ground to obtain flat specimens for mechanical testing. 
Metallography was performed on pieces trimmed from each panel. Photomicrographs of each panel are shown in Figure 3-238, where the tensile testing direction is left-to-right in the micrographs. Porosity within the uncoated fiber plies is evident on both samples. Fiber dispersion of the uncoated fiber tow was rather poor, leading to highly concentrated regions of uncoated fiber. Tow wet-out during prepregging was hindered by the dense packing of the uncoated fiber, and it is evident that reaction of the fiber during melt infiltration also contributed to "choke-off" of the infiltration process. This porosity tended to be higher in the sample with the uncoated plies concentrated in the center than in the sample with distributed uncoated fiber plies. It should be noted that the level of porosity found on the edges of the tensile bars cut from the panel with uncoated plies in the center qualitatively had higher porosity levels than shown in Figure 3-238, as the samples in the figure were cut from an edge of the panels and don't show the full development of the delamination/porosity.

Table 3-20. Ply Configuration of the Hybrid CMC Panels Made With Uncoated Fiber

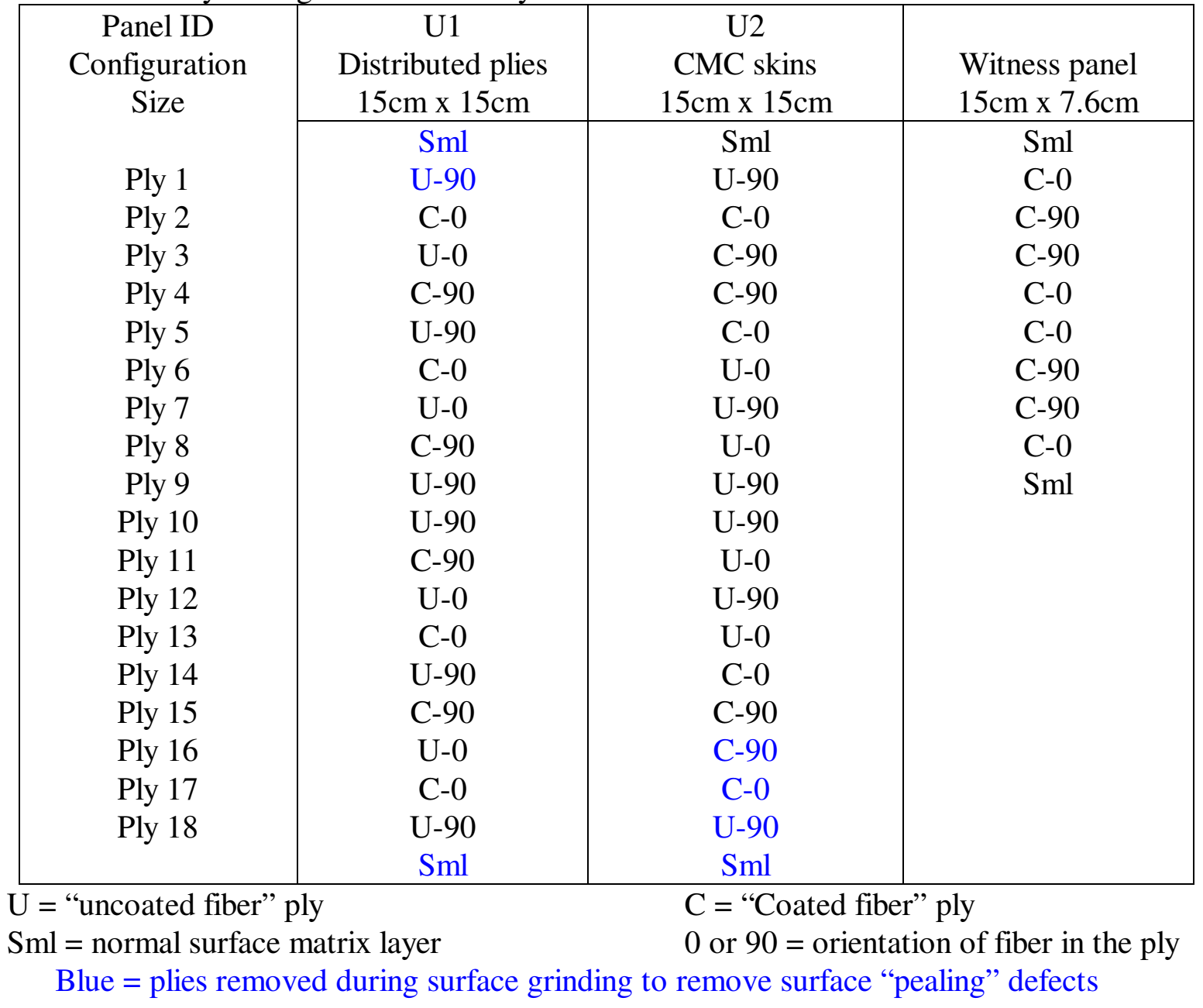


Also seen in the micrographs are layers of silicon alloy. These layers tended to be concentrated along the middle of the uncoated fiber plies, and represented delaminations caused by the high fiber packing, and therefore poor tow wet-out, that occurred in the uncoated fiber plies. As seen in Table 3-20, each sample had been laid-up with uncoated $90^{\circ}$ plies adjacent to the panel surfaces, and it was similar delaminations in these plies that caused the pealing of the surface plies observed after infiltration. Machining of the panels to remove these partially pealed plies and obtain flat surfaces for mechanical testing meant that the final panels did not have the full number of plies originally intended. In Table 3-20 the plies that were completely or partially removed during the surface grinding operation are listed in blue type. The surface ply pealing was mostly on only one side of panel U2, but it required more surface removal than did the surface pealing on panel U1. Consequently panel U1 had all of the coated fiber plies intact whereas panel U2 had $\sim 1.5$ of 8 of the coated fiber plies removed.

Half of each panel was cut off for use in the ballistic impact evaluations at UDRI. IR transmission NDE images of the half-panels prior to impact testing are shown in Figure 3239. The NDE results were consistent with visual observations as the panel with the uncoated fiber plies concentrated in the center showed a low diffusivity (high porosity) region over roughly $1 / 3$ of the panel, whereas the panel with interspersed uncoated fiber plies was very uniform. The remaining half of each panel was cut into tensile bars and sent to Cincinnati Testing Labs (CTL) for tensile testing at room and elevated temperatures. 

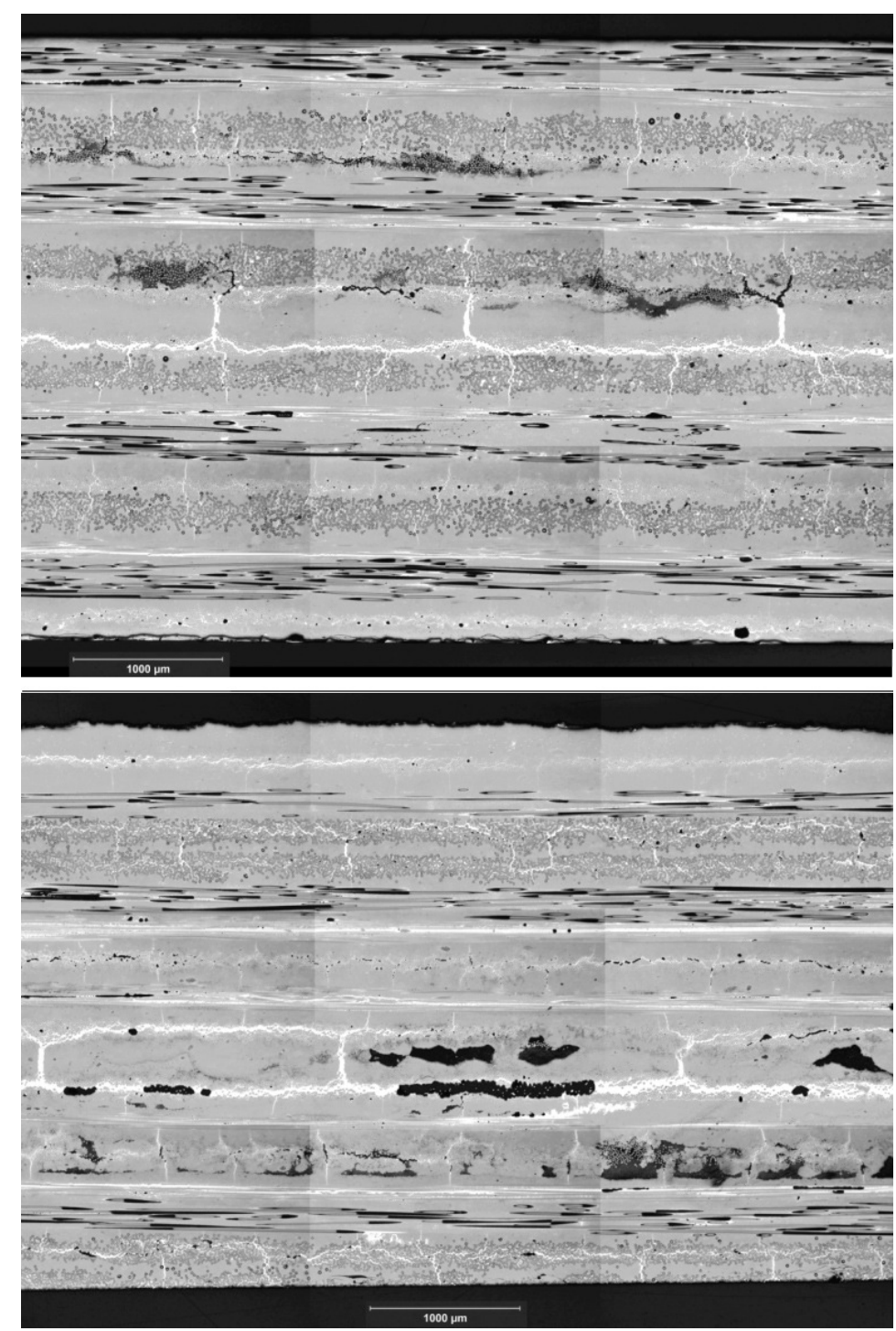

Figure 3-238. Micrographs of uncoated fiber hybrid panels with distributed uncoated fiber plies (top) and with the uncoated fiber plies concentrated in the center (bottom). The tensile testing direction is left-to-right in the micrographs. Several of the surface plies had been ground off during sample preparation, as described in the text. 

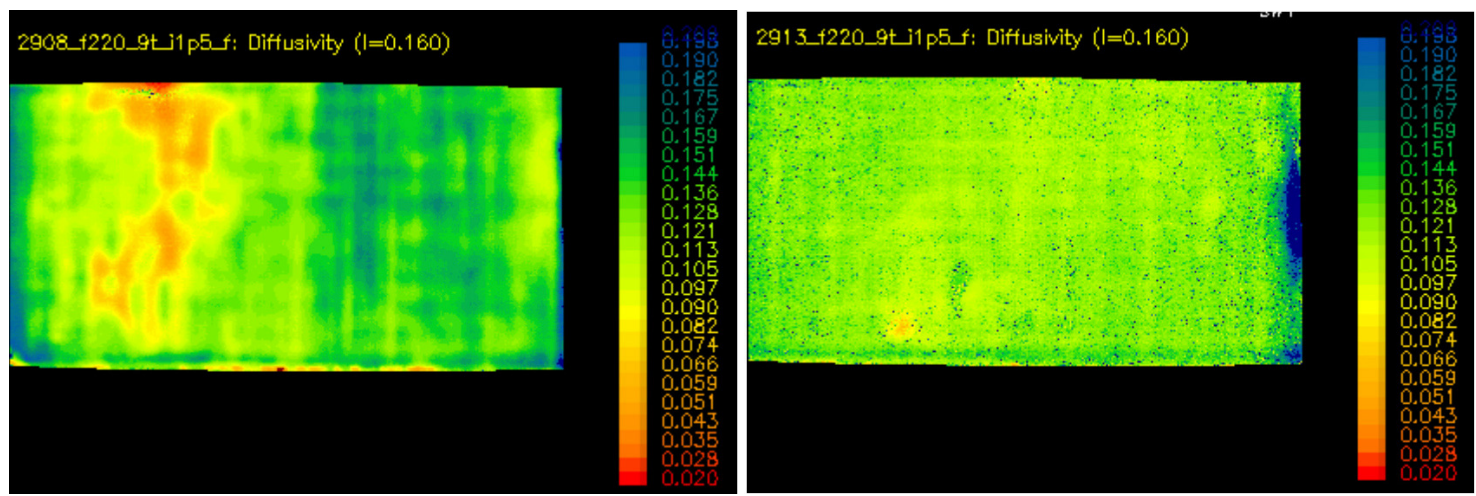

Figure 3-239. Transmission IR thermal diffusivity images of the hybrid CMC panels made with uncoated fiber plies. Top - panel with the uncoated fiber plies concentrated toward the middle of the thickness (U2); Bottom - panel with the uncoated fiber plies interspersed uniformly through the thickness (U1).

Two impact tests were conducted on each panel, with the first at a nominal projectile velocity of $75.6 \mathrm{~m} / \mathrm{s}$ and the second impact at a nominal velocity of $169 \mathrm{~m} / \mathrm{s}$, all using a $12.7 \mathrm{~mm}$ diameter monel steel ball impactor. Results of the ballistic tests are summarized in Table 3-21.

Both panel configurations experienced complete penetration at the higher impactor velocity. At the lower velocity the panel with CMC skins (panel U2) displayed complete penetration whereas the panel with the dispersed plies (panel U1) managed to stop the projectile, although a large hole was punched in the plate nearly as large as the diameter of the impactor. The slightly poorer stopping power of panel U2 compared to panel U1 may have been due to the greater degree of surface grinding required on panel U2, as described above.

Reflection IR NDE images taken of the panels prior to and after ballistic impact are shown in Figure 3-240 and Figure 3-241. The NDE results were generally consistent with the visual observations. For panel U1, with distributed coated fiber plies, there was little difference in the images away from the immediate impact region. The size of the affected region around the impact locations was $\sim 3 \mathrm{X}$ the diameter of the impactor, or $\sim 38 \mathrm{~mm}$. There was not a substantial difference in the damage region size between the low velocity and high velocity impacts. On the other hand, panel U2 had a large area of pre-existing porosity and/or delamination (the yellow area in the left side of the upper left image, or in the right side of the lower left image of Figure 3-241) that was observed to grow laterally after impact. Most of the growth was toward the middle of the panel, and may have been influenced by both impact events. However, even after two penetrating impact events both panels remained intact. 
Table 3-21. Ballistic Testing Results for the Uncoated Fiber Hybrid CMC Samples

\begin{tabular}{|c|c|c|c|}
\hline Sample ID & $\begin{array}{c}\text { Impact } \\
\text { Velocity } \\
(\mathrm{m} / \mathrm{s})\end{array}$ & $\begin{array}{c}\text { Impact } \\
\text { Energy } \\
(\mathrm{J})\end{array}$ & Result \\
\hline U1-A & 78.6 & 29.4 & $\begin{array}{c}\text { Partial penetration; 11 mm hole with 20mm x 20mm } \\
\text { spalled area on back side }\end{array}$ \\
\hline U1-B & 173 & 143 & $\begin{array}{c}\text { Complete penetration; } 12.7 \mathrm{~mm} \text { hole with } 30 \mathrm{~mm} \times \\
\text { 30mm spalled area on back side }\end{array}$ \\
\hline U2-A & 77.4 & 28.5 & $\begin{array}{c}\text { Complete penetration; } 12.7 \mathrm{~mm} \text { hole with 30mm x } \\
\text { 33mm spalled area on back side }\end{array}$ \\
\hline U2-B & 174 & 144 & $\begin{array}{c}\text { Complete penetration; 12.7mm hole with 20mm x } \\
\text { 20mm spalled area on back side }\end{array}$ \\
\hline
\end{tabular}
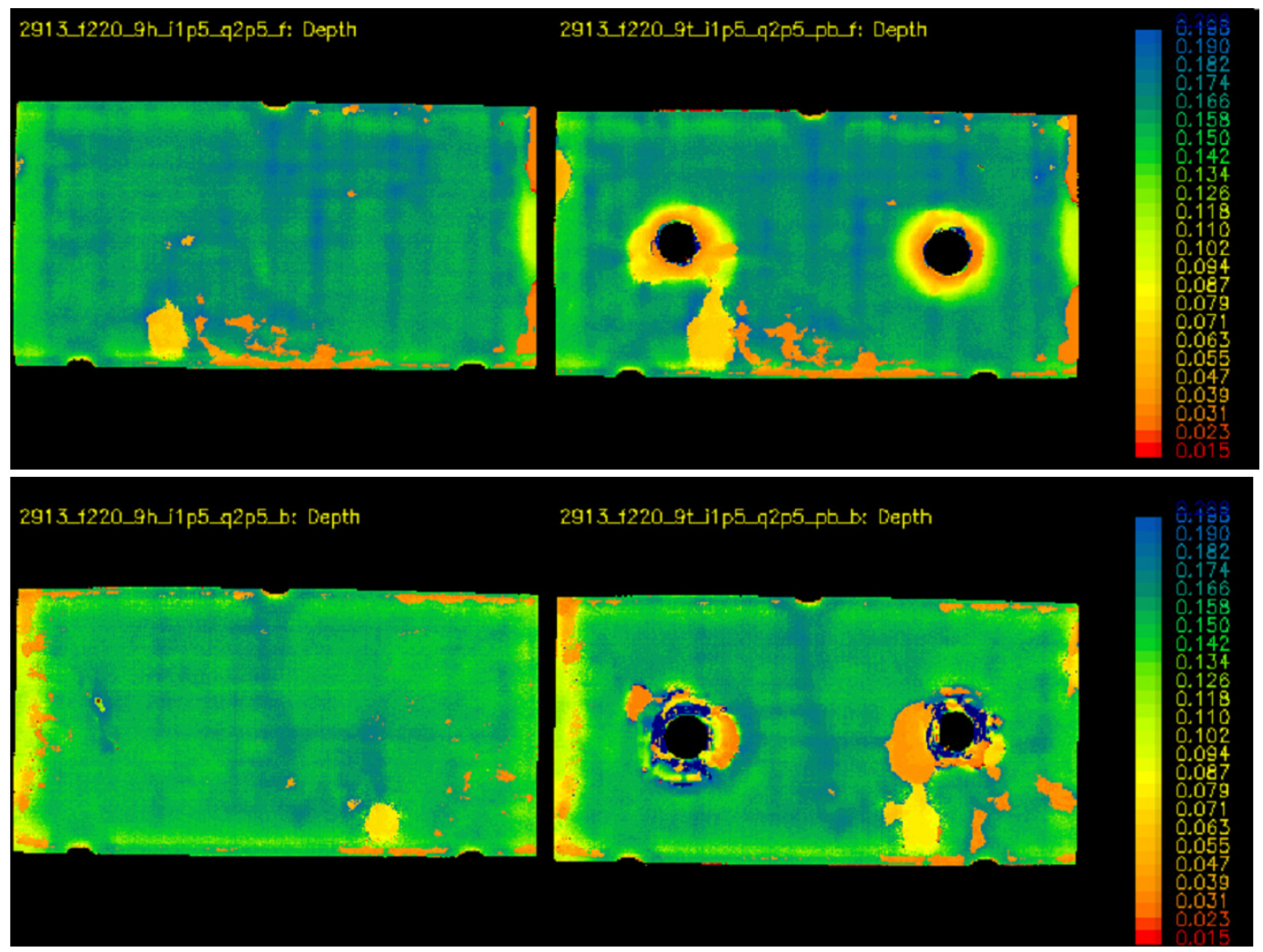

Figure 3-240. Reflection IR thermal diffusivity images of the hybrid CMC panel U1. The left-hand images are from before impact testing, and the right-hand images are after impact. The top images are for the entrance side of the panel and the bottom images from the exit side. 

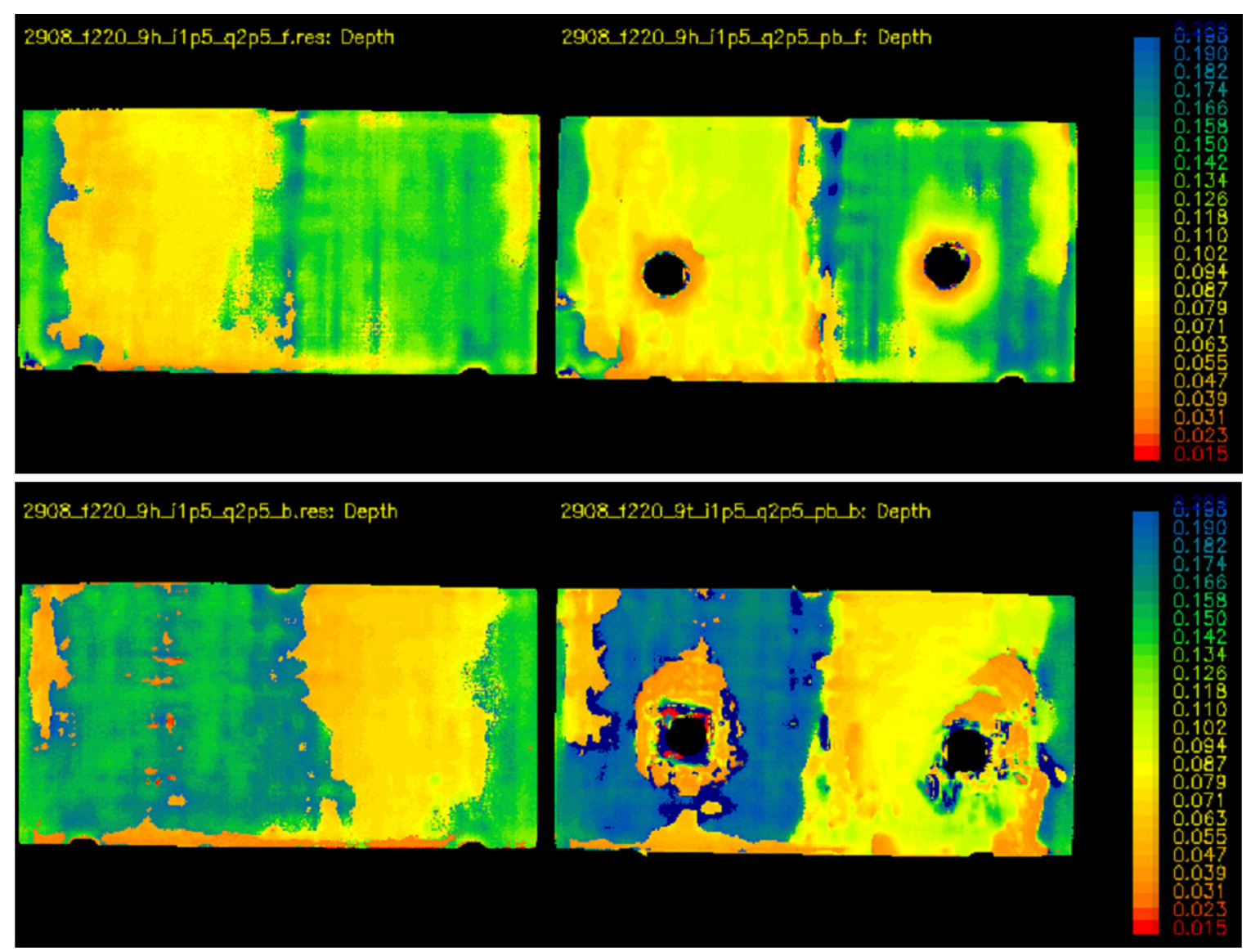

Figure 3-241. Reflection IR thermal diffusivity images of the hybrid CMC panel U2. The left-hand images are from before impact testing, and the right-hand images are after impact. The top images are for the entrance side of the panel and the bottom images from the exit side.

As mentioned above, tensile testing of the uncoated fiber hybrid panels at room temperature and at $1200^{\circ} \mathrm{C}\left(2200^{\circ} \mathrm{F}\right)$ was performed at CTL. Tensile bars from the witness panel, made from the same lot of coated fiber and using the normal all CMC ply configuration, were also tested for comparison. The tensile stress strain curves for the room temperature tests are shown in Figure 4, and those for the $1200^{\circ} \mathrm{C}$ tests are in Figure 3-243. The tensile data is also summarized in Table 3-22.

As was seen previously, reducing the amount of effective (coated) fiber in the composite led to substantial reductions in the ultimate strength, strain to failure and proportional limit stress of the composites. These strength reductions were worse for the U2 sample, but this is likely to be at least partially due to the extra fiber ply removed during grinding. Taking into account the fiber plies removed during grinding, the remaining fiber volume fraction in the tensile direction for the three types of samples were $11.9 \%$ for the witness panel, $6.4 \%$ for the U1 panel, and $4.6 \%$ for the U2 panel. The extra porosity in the U2 panel would also certainly have contributed to the lower proportional limit. 
Overall the results on the uncoated fiber ply hybrid panels were consistent with those obtained with the monolithic matrix ply hybrid structures. Having uncoated fiber did help to control shrinkages of the monolithic plies, but difficulty dispersing the uncoated fiber during prepregging caused different types of microstructural defects. The ballistic response and tensile properties were all consistent with the monolithic ply samples that had comparable levels of coated fiber. The overall general conclusion was that the reductions in tensile properties outweighed the potential cost benefits of using uncoated fiber within the CMC structure.

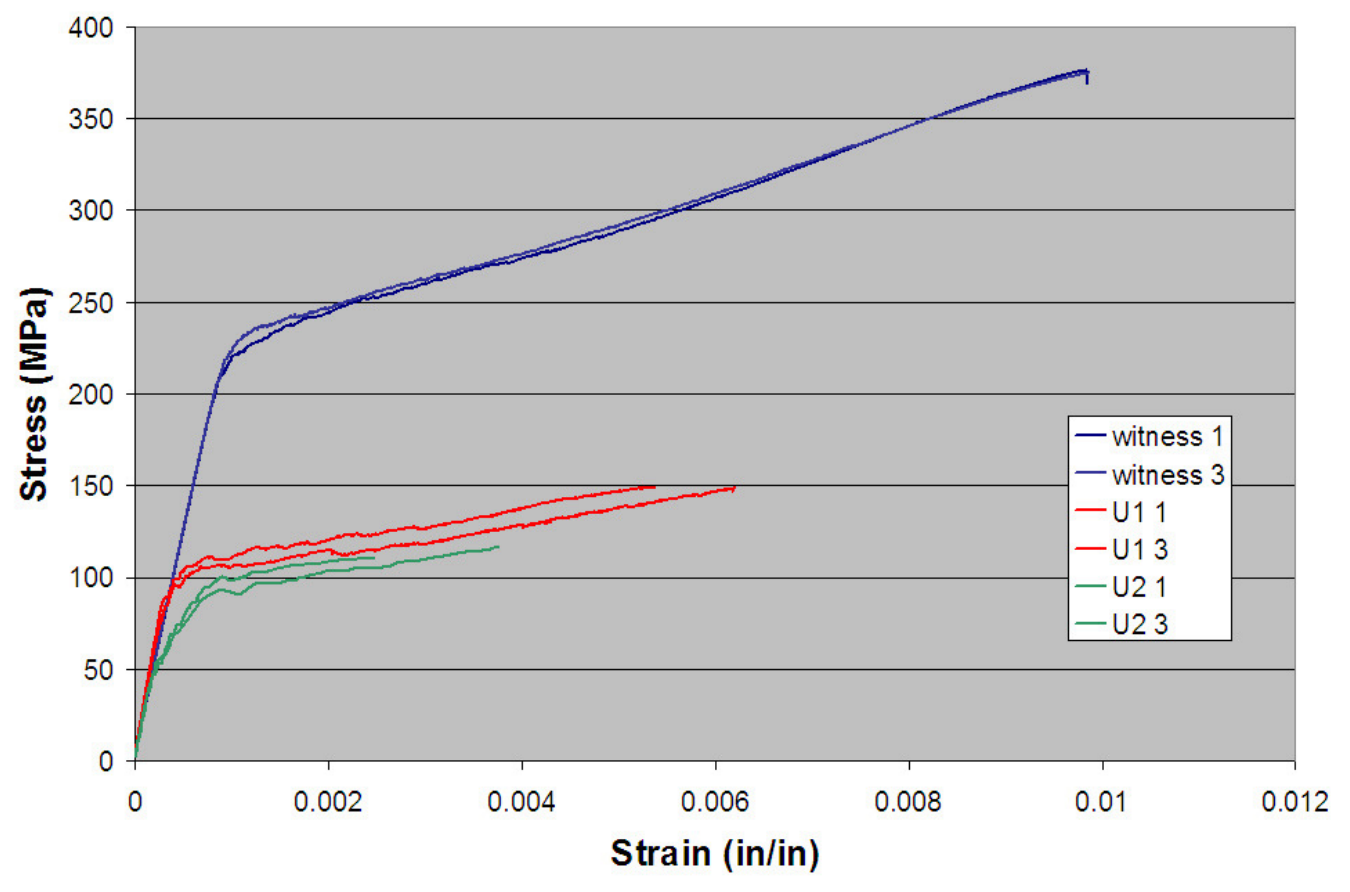

Figure 3-242. Room temperature tensile stress-strain data for the uncoated fiber hybrid panels and comparable witness coupon. 


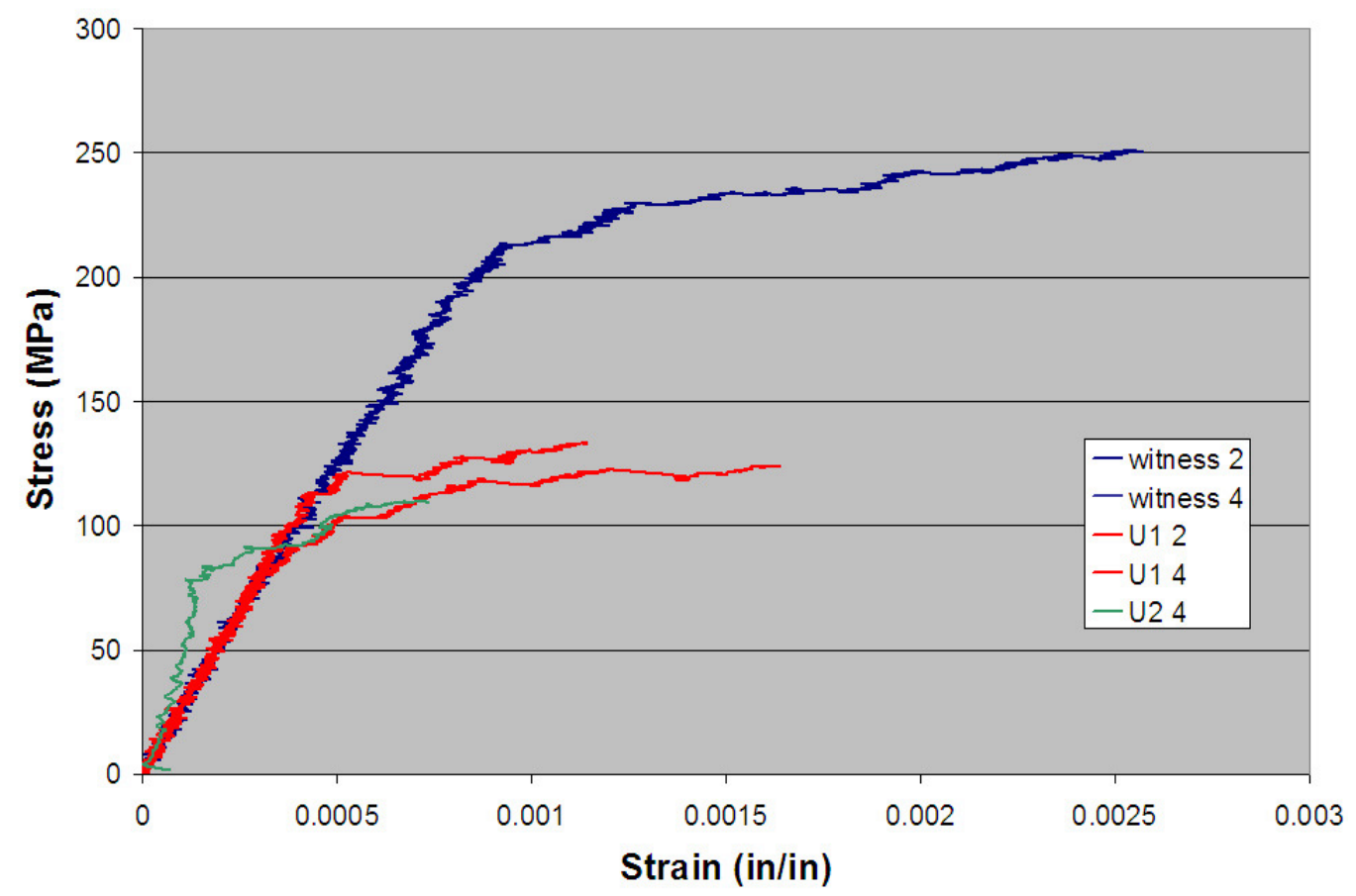

Figure 3-243. Tensile stress-strain data for the $1200^{\circ} \mathrm{C}$ tensile tests of the uncoated fiber hybrid panels and comparable witness coupon.

Table 3-22. Tensile Testing Results of the Uncoated Fiber Hybrid CMC Samples

\begin{tabular}{|c|c|c|c|c|}
\hline Sample \# & $\begin{array}{c}\text { Proportional } \\
\text { Limit } \\
(\mathrm{MPa})\end{array}$ & $\begin{array}{c}\text { Initial } \\
\text { Modulus } \\
(\mathrm{Gpa})\end{array}$ & $\begin{array}{c}\text { Ultimate } \\
\text { Strength } \\
(\mathrm{MPa})\end{array}$ & $\begin{array}{c}\text { Strain to } \\
\text { Failure } \\
(\%)\end{array}$ \\
\hline Room Temperature Tests & \multicolumn{5}{|c|}{} \\
\hline Witness 1 & 209 & 248 & 376 & 0.98 \\
\hline Witness 3 & 208 & 247 & 375 & 0.99 \\
\hline U1-1 & 84.8 & 294 & 149 & 0.62 \\
\hline U1-3 & 90.3 & 305 & 149 & 0.53 \\
\hline U2-1 & 55.8 & 273 & 116 & 0.38 \\
\hline U2-3 & 49.6 & 271 & 110 & 0.24 \\
\hline $1200^{\circ}$ C Tests & & \multicolumn{5}{|c|}{} \\
\hline Witness 2 & 154 & 256 & 251 & 0.26 \\
\hline Witness 4 & 119 & 270 & 256 & 0.27 \\
\hline U1-2 & 112 & 267 & 133 & 0.11 \\
\hline U1-4 & 91.7 & 228 & 124 & 0.16 \\
\hline U2-2 & 60.0 & 235 & 105 & 0.13 \\
\hline U2-4 & 91.0 & 296 & 107 & 0.06 \\
\hline
\end{tabular}




\subsection{Shroud Fabrication from Hybrid CMC}

The remaining goal of this subtask was to fabricate a shroud component using the "best" of the hybrid configurations. In general increasing processing difficulties were observed with the panels as the thickness of the monolithic plies increased. This was due to the finite shrinkage that occured in the monolithic plies during the binder burn-out and melt infiltration processes, which is hindered by the presence of the reinforcing fibers in the composite plies. As discussed in Section 3.1.24.1.1 this differential shrinkage between the ply types caused delamination and warping of the hybrid panels. When the monolithic plies were kept thin and are inter-dispersed with composite plies the composite plies were able to constrain the shrinkage of the monolithic matrix plies, such that the tendency for delamination or warping was minimized. Thus the hybrid structures that had the composite and monolithic plies alternating through the lay-up tended to have fewer defects than those that had all of the composite or all of the monolithic plies together.

The relative impacts on the in-plane tensile properties for the hybrid configurations with matrix plies distributed throughout the thickness (i.e. those that were relatively free of shrinkage-strain induced defects) are summarized in Table 3-23. The mechanical properties of the hybrid panels were seen to decrease quite substantially with the reduction in the number of composite plies, and thus the reduction of the overall fiber volume fraction. Reductions in the ultimate strength and strain to failure values were expected as these are fiber-dominated properties. Initially we were surprised by the substantial reduction in proportional limit stress with reduced fiber volume fraction, but subsequent analysis showed the trend to be in rough agreement with the BHE model [22] for brittle matrix composites.

Table 3-23. Relative Effects of Replacing Composite Plies With Matrix Plies on In-Plane Tensile Properties of Hybrid CMC Structure Samples Made With Hi-Nicalon TypeS Fiber.

\begin{tabular}{|c|c|c|c|c|c|}
\hline & & & \multicolumn{3}{|c|}{ Relative to 100\% CMC Configuration } \\
\hline $\begin{array}{c}\text { Fraction } \\
\text { CMC plies }\end{array}$ & $\begin{array}{c}\text { \# CMC } \\
\text { plies }\end{array}$ & $\begin{array}{c}\text { \# Matrix } \\
\text { Plies }\end{array}$ & $\begin{array}{c}\text { Proportional } \\
\text { Limit Stress }\end{array}$ & $\begin{array}{c}\text { Ultimate } \\
\text { Strength }\end{array}$ & $\begin{array}{c}\text { Strain to } \\
\text { Failure }\end{array}$ \\
\hline $100 \%$ & 18 & 0 & $100 \%$ & $100 \%$ & $100 \%$ \\
\hline $67 \%$ & 12 & 6 & $80 \%$ & $63 \%$ & $92 \%$ \\
\hline $45 \%$ & 8 & 10 & $75 \%$ & $36 \%$ & $47 \%$ \\
\hline $33 \%$ & 6 & 10 & $68 \%$ & $25 \%$ & $18 \%$ \\
\hline
\end{tabular}

Based on the observations discussed above, the fiber architecture chosen for the hybrid shroud prototype included $12 \mathrm{CMC}$ plies and 6 matrix plies, thereby reducing the overall fiber content by $33 \%$. The composite plies were concentrated at the surfaces, with intermixed composite and matrix-only plies interspersed through the center. This configuration limited the thickness of the monolithic matrix regions to only one ply thick, except for a single 2-ply thick region at the centerline. 
A single shroud component was fabricated using the hybrid architecture configuration described above. Processing of this shroud proceeded quite normally through the lay-up and autoclave lamination procedures. Following binder burn-out there appeared to be ply delaminations opening along the side edges of the shroud; however, there was little change in the thickness of the shroud, suggesting that the delaminations did not penetrated far into the shroud. The part was subsequently melt infiltrated successfully, and a photograph of the fabricated shroud blank (in a state prior to final machining) is shown in Figure 3-244.

Reflection IR thermography was used for NDE inspection of the shroud, and the results are shown in Figure 3-245. The shroud NDE image was relatively clean with no indications of large, or severe defects. The apparent delaminations seen after binder burn-out do not appear to have penetrated any significant distance inward from the edges of the shroud, and were not seen at all by the IR NDE inspection. The only abnormal observation on the hybrid shroud was an unusually high value for the thermal diffusivity, which was expected since the diffusivity of the monolithic matrix plies is actually higher than that of the composite material.

This exercise demonstrated that shroud components could be manufactured from a hybrid $\mathrm{CMC}$ /monolithic matrix configuration. However, as noted before, the trade-off in mechanical properties is so large that making use of such hybrid structures in any of the remaining engine tests was not yet warranted.

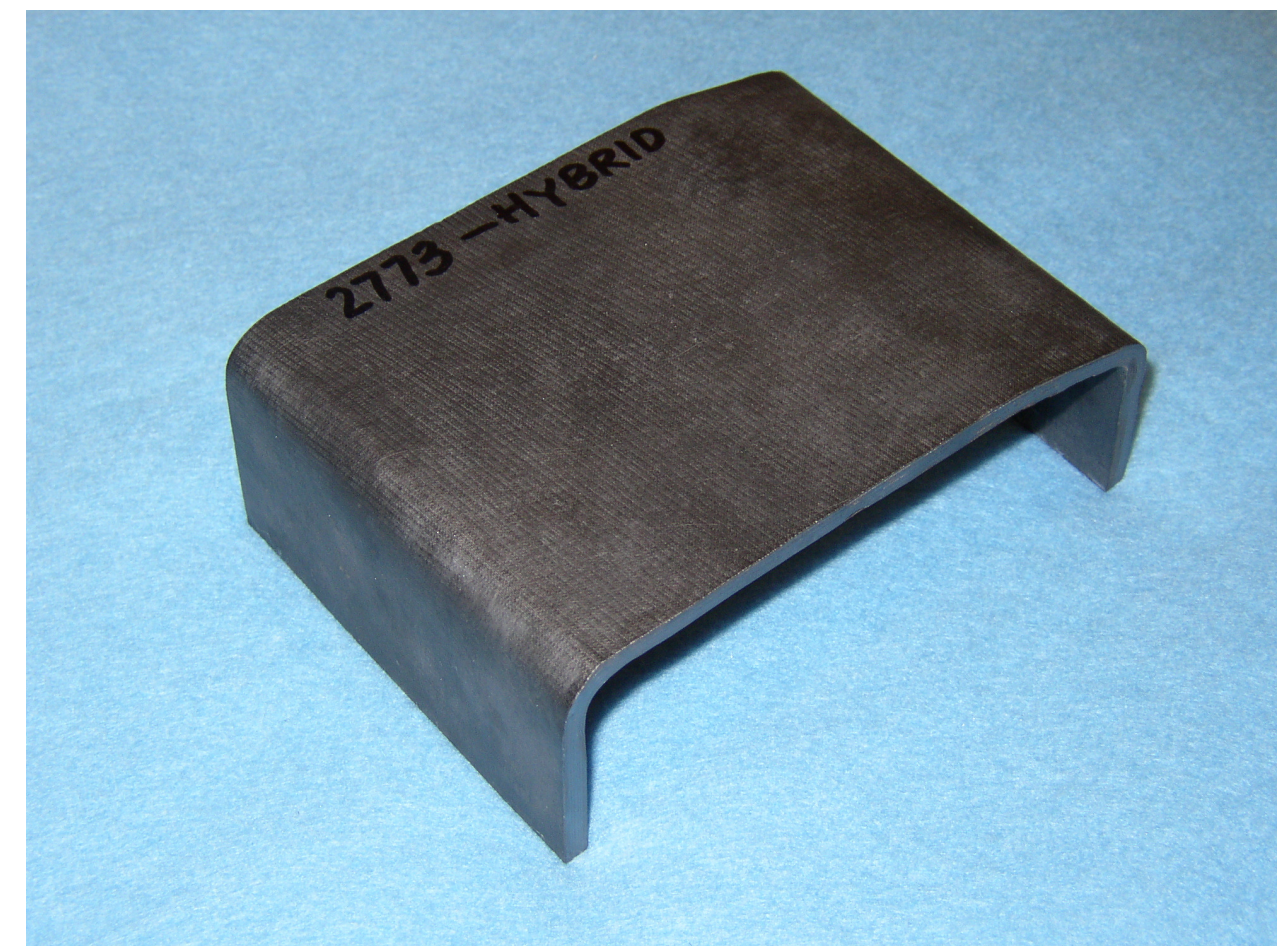

Figure 3-244. Photograph of the hybrid structure shroud blank following melt infiltration. 


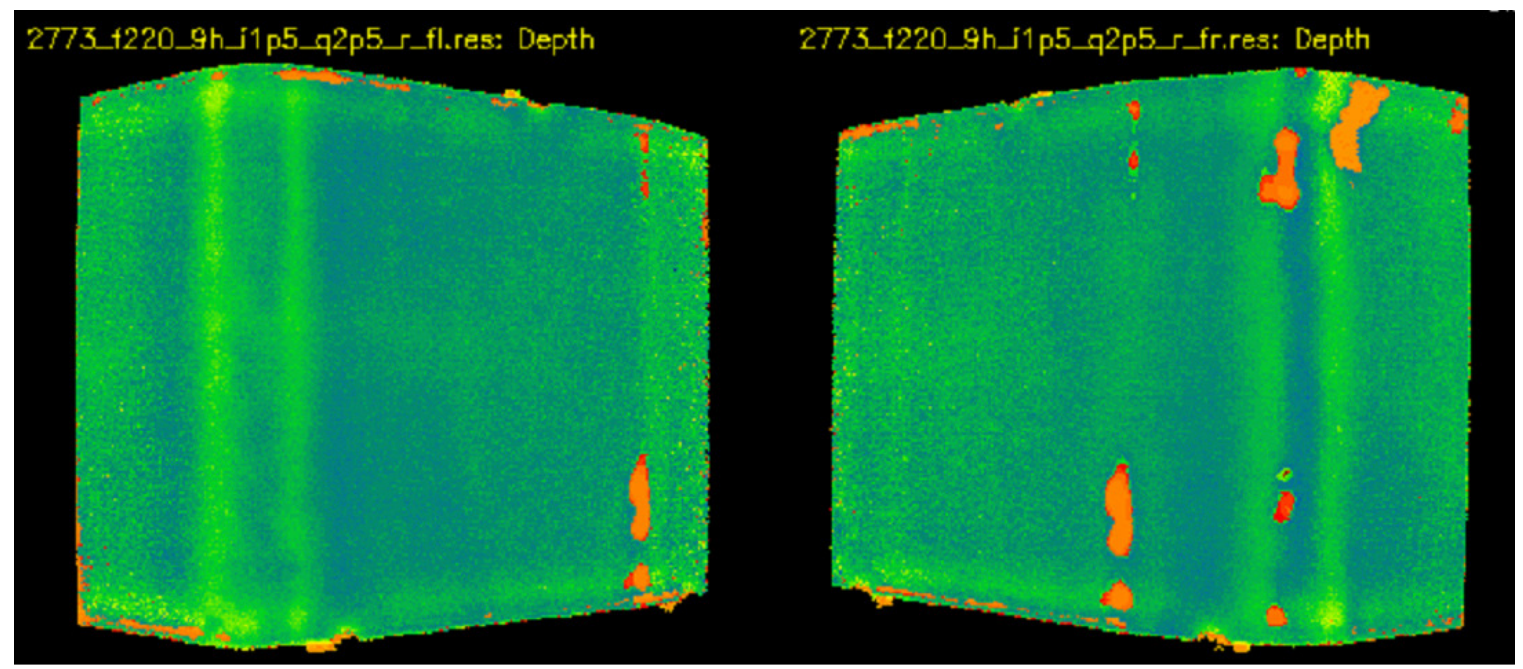

Figure 3-245. IR thermography NDE images of the hybrid shroud following melt infiltration densification. Some small isolated delaminations were detected (orange), but the majority of the shroud was defect-free.

\subsubsection{Evaluation of Tow Coating Process Modifications}

The fiber CVD coating operation is the most expensive process step in the fabrication of the MI CMC components. Simplifications to this process would have a direct impact on the cost of the coated fiber, and therefore on the overall CMC component cost. Coating simplification could also help to improve CMC quality by minimizing potential mechanical damage to the fiber tows during the coating operation. The goal of this task was therefore to examine approaches to simplify the overall tow coating process.

The optimized fiber coating configuration developed during the CFCC program [2] has four layers, the first two layers of which are based on boron nitride. During the initial development and optimization of the tow coating process at GRC there was considerable anecdotal evidence that relatively thin $1^{\text {st }}$ or $2^{\text {nd }}$ layers in the fiber coatings produced composites with increased proportional limit strength, but with considerably lower strain to failure, to the point where many samples were brittle. This very early data was, however, confounded by continuous modifications to the CMC fabrication process being made at the same time. The actual fiber coating thicknesses were also subject to considerable unintentional variability. Consequently there was insufficient statistical data to confirm the anecdotal trends of higher proportional limit with decreased $1^{\text {st }}$ layer or $2^{\text {nd }}$ layer coating thickness.

During the optimization of the large fiber coater at GRC numerous fiber coating runs were performed with intentional adjustments to the thicknesses of the various coating layers. Analysis of this data again indicated that there may be a trend toward higher proportional limit and ultimate strengths, again at the cost of lowered strain to failure. These data trends from the large GRC coater optimization fiber coating runs are shown in Figure 3-246. The 
obvious feature of this data is the high amount of scatter, and thus relatively low certainty that the indicated trends were real.

If these data trends were indeed real then reductions in the thickness of the $1^{\text {st }}$ and/or $2^{\text {nd }}$ layers represented an opportunity to both improve the quality, i.e. strength, of the CMC system while simultaneously reducing cost. As the fiber coating procedure is the most expensive step in the entire CMC fabrication process, reducing the coating thickness, and thereby the coater residence time of the fiber, directly reduced the cost of this step. Again, the likely penalty for the thinner coatings was a reduction in the strain to failure values; however, ballistic impact testing of panels and shrouds, as discussed in the previous sections, had shown that a high strain to failure was less important to damage tolerance than had been originally expected. Consequently a reduction in strain to failure could be an acceptable trade-off for increased proportional limit and lowered cost.

The first step in examining the feasibility of having thinner $1^{\text {st }}$ or $2^{\text {nd }}$ layers was to first determine that the trends suggested by the old large GRC coater data were indeed true. Since these data were collected there had been considerable improvements in the reproducibility and uniformity of the fiber coatings in the small GRC reactor and in the consistency of CMC processing in gengerl. It was therefore considered possible that the real effects of $1^{\text {st }}$ and $2^{\text {nd }}$ layer reductions on the mechanical properties of prepreg MICMCs could be determined using a controlled DoE approach.

A detailed DoE was planned to look at the effects of thinner $1^{\text {st }}$ and $2^{\text {nd }}$ layers on the CMC tensile mechanical properties. Four levels of $1^{\text {st }}$ layer thickness and two levels of $2^{\text {nd }}$ layer thickness were used, with all test conditions having three replicate test panels made for evaluation. The levels of the $1^{\text {st }}$ layer used were $1 \mathrm{X}$ normal, $1 / 2 \mathrm{X}$ normal, "flash" and none, whereas the levels of $2^{\text {nd }}$ layer used were $1 \mathrm{X}$ normal and $1 / 2 \mathrm{X}$ normal.

During the early development and implementation of the $2^{\text {nd }}$ layer coatings there was considerable evidence that deposition of the $2^{\text {nd }}$ layer directly onto Hi-Nicalon caused significant degradation to the fiber. It was speculated at the time that there was reaction between one of the $2^{\text {nd }}$ layer precursor gases and the excess carbon in Hi-Nicalon fibers, causing mechanical defects in the fibers. Pre-coating the fiber with the $1^{\text {st }}$ layer coating to protect the fiber surface eliminated the reaction and degradation, and made the overall CMC system more consistent. This was the reason why a "flash" coating of the $1^{\text {st }}$ layer was included in the design of experiments. Having no $1^{\text {st }}$ layer coating could again make the fiber susceptible to degradation by reaction with the $2^{\text {nd }}$ layer precursors, so a "flash" coating of the $1^{\text {st }}$ layer was used to protect the fiber while using the minimum amount possible.

Fiber coating runs corresponding to the intended coating modifications were performed at GRC in the small tow coater using Hi-Nicalon fiber. Standard 8-ply 0-90 test panels were subsequently fabricated from the fiber from these coating runs. The panels were then cut into tensile test specimens and tensile tested at room temperature and $1200^{\circ} \mathrm{C}$ at CTL. 

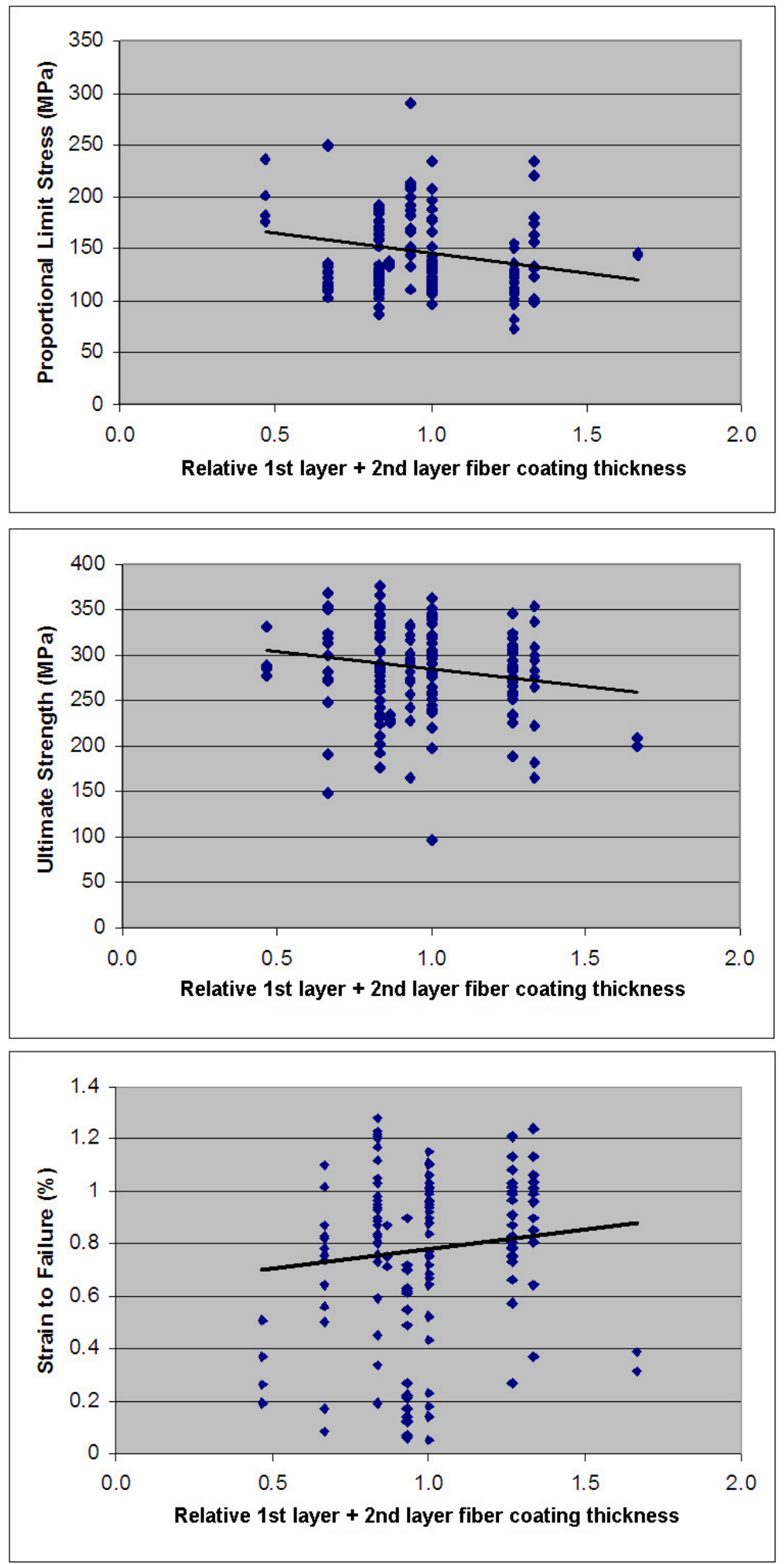

Figure 3-246. Historical data from fibers coated in the large GE fiber coater on the effects of $1^{\text {st }}$ layer and $2^{\text {nd }}$ layer coating thickness on the mechanical properties of prepreg MI CMC composites. 
Unfortunately the fabrication of these test samples was not without issues. These test specimens were originally processed through melt infiltration in mid February through early March of 2008. During this time it was discovered that the batch of silicon alloy being used for infiltrations was contaminated with small amounts of excess carbon and iron. Specimens produced with this particular batch of silicon were observed to yield slightly lower density and lower proportional limit values than normal, but the effects were not large enough and not consistent enough to be identified immediately. Consequently roughly $2 / 3$ of the DoE samples had been processed through infiltration with this unusual batch of silicon before the problem was recognized. The decision was made not to change the silicon batch in the middle of the DoE in order to not further confound the data with additional variables, so all of the DoE samples were infiltrated with the poorly performing silicon. As a result the proportional limits of all of the test panels was lower than normal, ranging from 55 to 155MPa. After the DoE sample fabrication was completed a switch to a new batch of silicon alloy was made, whereupon the proportional limit values of subsequent samples returned to the 165-180 $\mathrm{MPa}$ range, which was more typical for the combination of fiber and matrix composition that was used in the DoE samples.

Secondly, it had been well established that there was a side-to-side variation in fiber coating thicknesses produced in the small CVD fiber coater. In order to minimize the effect of this variability on the test panels made from each coating run, the coated tows selected for each test panel were chosen to represent the full width of the coated ribbon. It was also known that variations in fiber coating thickness contribute to prepreg tape thickness variations. By selecting tow from both the "thick" and "thin" side of the ribbon for each panel, the tape thickness non-uniformity within the panels was somewhat exaggerated, leading to bowing of some of the panels during melt infiltration. While small to moderate bowing of the test specimens does not typically have an appreciable effect on ultimate strength or strain to failure, it can have a significant effect on proportional limit. Consequently the bow of each tensile specimen was measured before testing so that any effects of the bowing could be accounted for in the mechanical data.

The relative effects of sample density and curvature, or "bow", on the measured proportional limit stresses are shown in Figure 3-247. Surprisingly there was no appreciable correlation of proportional limit with density. It should be noted that the density values measure were those of the panels, and not of the individual test bars, so that if there were a correlation it may be hidden by this averaging of density over a panel. Proportional limit did show a weak correlation with specimen curvature, as expected. All subsequent data analysis of proportional limit was therefore done for two cases: first using the raw proportional limit data and secondly using proportional limits that were corrected for the bowing effect. However, in no case was there a significant difference in the observed trends or conclusions between the raw or corrected proportional limit data. Likewise, there were no observed correlations between either density or curvature with any of the other tensile properties, so that no additional data corrections were made. 

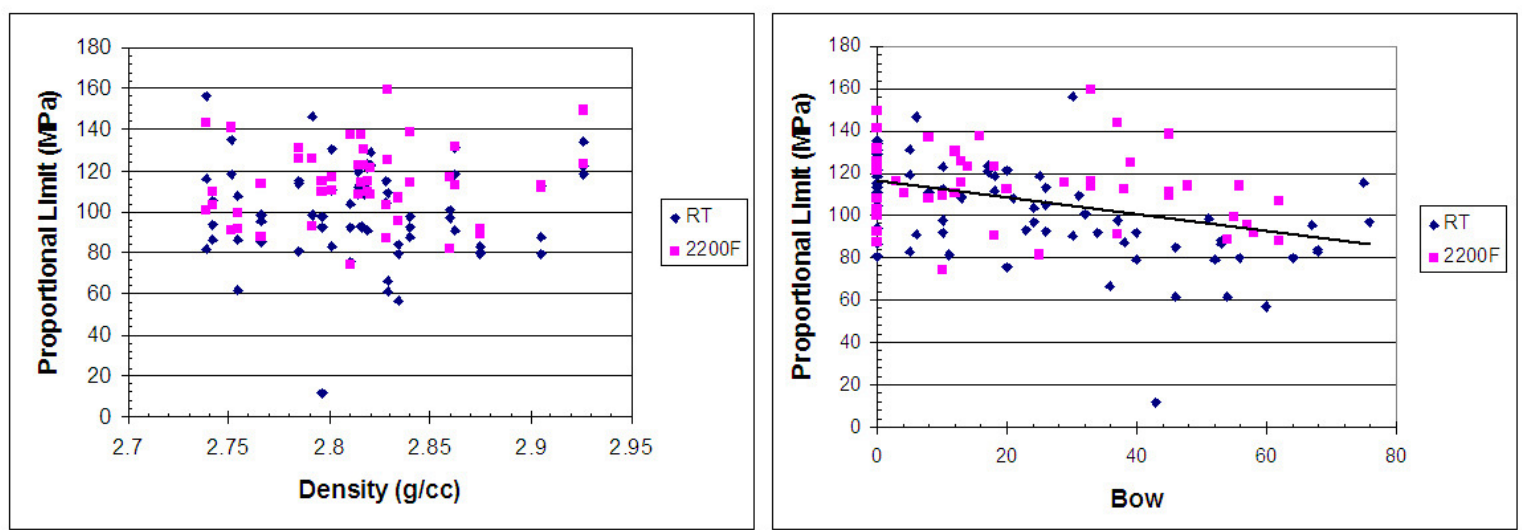

Figure 3-247. Dependence of proportional limit stress measured on the fiber coating DoE samples on the test panel density (left) and on the amount of curvature, or bow, in the test samples (right).

Figure 3-248 shows the trends in tensile properties as a function of coating layer thicknesses. The $\mathrm{x}$-axis of each plot indicates the thickness of the $1^{\text {st }}$ coating layer, and the different symbols indicate the difference between normal and $1 / 2$ normal level of the $2^{\text {nd }}$ coating layer thickness. In each plot pair the left plot shows the room temperature data, and the right plot shows the data measured at $1200^{\circ} \mathrm{C}$.

Overall the proportional limit showed no discernible trends with either the $1^{\text {st }}$ or $2^{\text {nd }}$ layer thickness. The data for ultimate strength and, particularly, strain to failure show general reductions in the properties with reductions in coating thicknesses, particularly for reductions in the $2^{\text {nd }}$ layer. Practically all of the conditions with $1 / 22^{\text {nd }}$ layer showed reduced strength and strain relative to the normal thickness of the $2^{\text {nd }}$ layer. Moreover, the amount of scatter in the tensile data increased dramatically at the $1 / 22^{\text {nd }}$ layer coating level. This increased scatter was consistent with the anecdotal observations made during the optimization of the small and large fiber coaters at GRC, where reductions in coating thickness typically led to poorly-reproducible tensile properties.

At the normal $2^{\text {nd }}$ layer thickness the room temperature ultimate strength and strain are nearly constant down to the "trace" level of the $1^{\text {st }}$ layer coating, but there does appear to be a minimum in strength and strain at $1200^{\circ} \mathrm{C}$ for this same coating condition. However, this drop of ultimate strength and strain to failure at $1200^{\circ} \mathrm{C}$ for a trace of the $1^{\text {st }}$ layer and normal $2^{\text {nd }}$ layer appears to be caused by a single test specimen that showed unusually low properties. If this single test point is ignored the average strength and strain to failure values for this condition are more comparable to the other conditions. This coating condition of a trace of the $1^{\text {st }}$ layer followed by the normal thickness $2^{\text {nd }}$ layer would represent a significant reduction in fiber coating time, and therefore cost. One could envision doing the trace $1^{\text {st }}$ layer and full $2^{\text {nd }}$ layer coatings in the same reactor pass by modifying the positions of the reactant gas injectors, thus eliminating one of the three passes normally needed in the low-pressure reactor. 
RT
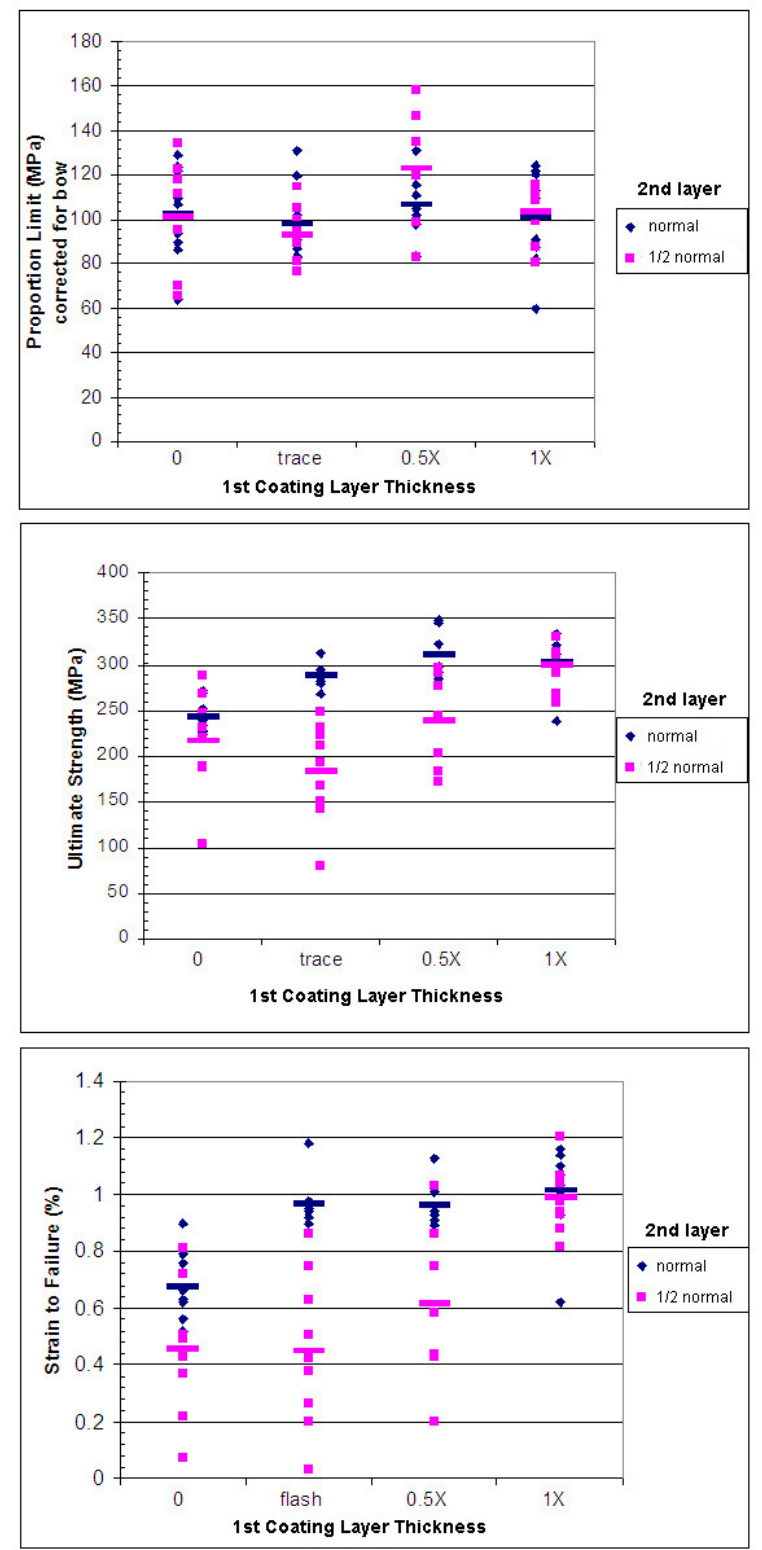

$1200^{\circ} \mathrm{C}$
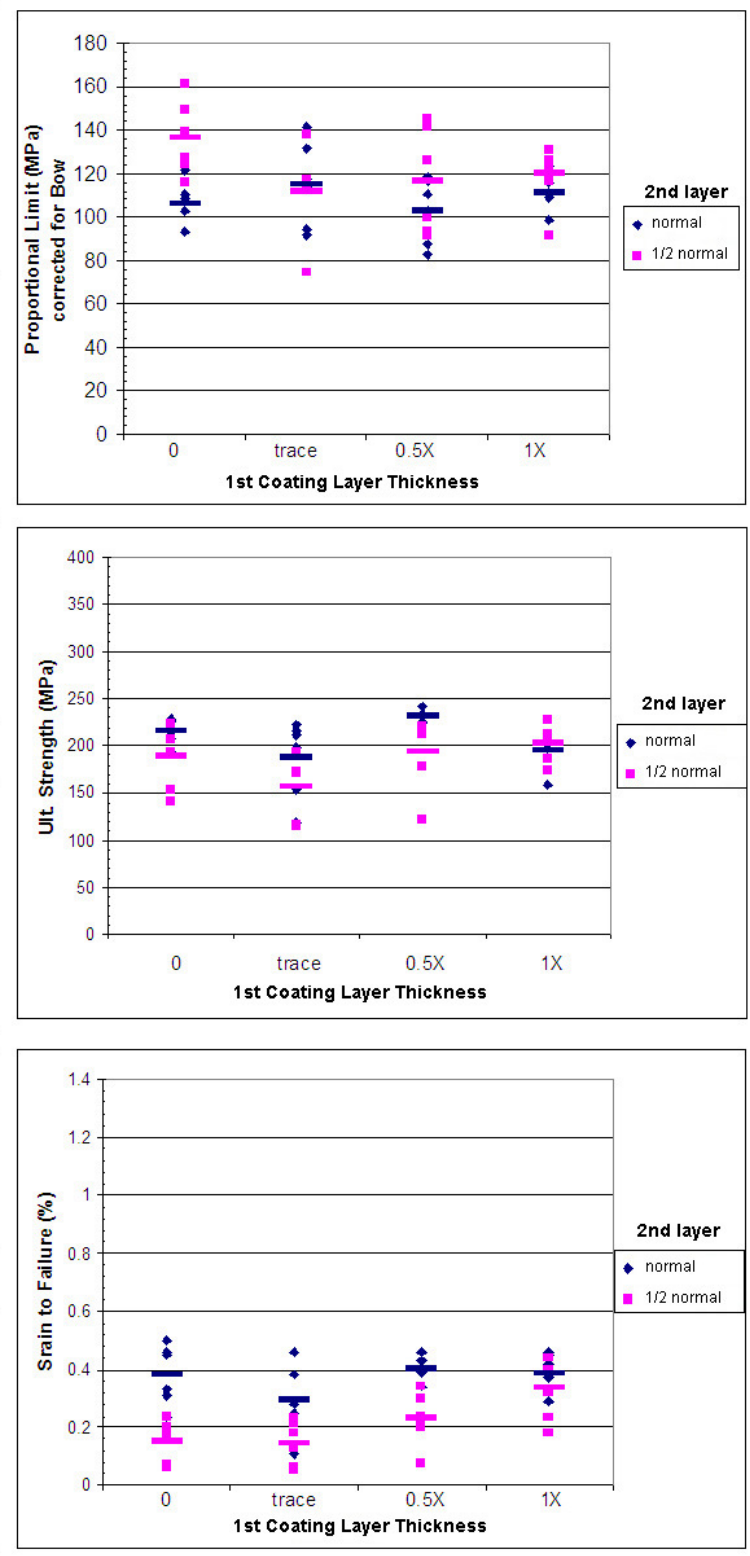

Figure 3-248. Trends of proportional limit (top), ultimate strength (middle) and strain to failure (bottom) with fiber coating layer thickness. Plots on the left are for RT tensile tests and those on the right are for testing at $1200^{\circ} \mathrm{C}$. The smaller symbols represent the individual data points and the wider dash symbols represent the average value for that condition.

The other coating composition that gave interesting results was that of no $1^{\text {st }}$ layer with the normal thickness $2^{\text {nd }}$ layer. Previous attempts at coating Hi-Nicalon fibers directly with the $2^{\text {nd }}$ layer composition generally yielded brittle, or nearly brittle, composites. The DoE coating with no $1^{\text {st }}$ layer and the normal $2^{\text {nd }}$ layer did show significant drops in the room temperature ultimate strength and strain to failure values, but they were still far from brittle. 
Moreover, the $1200^{\circ} \mathrm{C}$ strength and strain values were surprisingly good, being as good as any other coating condition.

Based on the results of this initial DoE it was decided to perform an additional round of coating trials. The first configuration was a re-make of the flash $1^{\text {st }}$ layer with normal $2^{\text {nd }}$ layer to test whether the observed results were reproducible, particularly when using a new batch of silicon alloy for infiltration that would give high density and proportional limit. The second configuration was no $1^{\text {st }}$ layer with $1 / 2$ the normal $2^{\text {nd }}$ layer, again with the intent to reproduce the results seen in the DoE. Unfortunately, due to a minor error during the coating of the fiber for these trials the $2^{\text {nd }}$ layer came out closer to $2 / 3$ the normal value instead of the intended $1 / 2$. A third configuration having no $1^{\text {st }}$ layer but with a thicker than normal $2^{\text {nd }}$ layer was also made. With this configuration the hope was to gain back some of the room temperature strength and strain lost with the no $1^{\text {st }}$ layer and normal $2^{\text {nd }}$ layer configuration while maintaining the adequate high temperature behavior. A fourth coating, having standard amounts of $1^{\text {st }}$ and $2^{\text {nd }}$ layers was also made to serve as a baseline. None of the processing issues experienced with the DoE samples were noted during fabrication of this new set of samples, such that the data on this new set was considered to be more reliable.

Results of the tensile tests on the new fiber coating configurations at room temperature are shown in Figure 3-249. At room temperature the largest differences between the coating configurations were in the strain to failure values. While the configuration with a flash of the $1^{\text {st }}$ layer coating gave an increased strain to failure, and perhaps a slight increase in ultimate strength, compared to the normal coating configuration, both no- $1^{\text {st }}$ layer configurations showed very significant drops in strain to failure. The no- $1^{\text {st }}$ layer and thin $2^{\text {nd }}$ layer configuration also showed significantly lower ultimate strengths than the other configurations.

Results from the tensile tests done at $1200^{\circ} \mathrm{C}$ are shown in Figure 3-250. Here the strain to failure values were rather low, but consistent, between the different configurations, with the exception of the no- $1^{\text {st }}$ layer and thin $2^{\text {nd }}$ configuration, which was only very marginally better than brittle. The modulus of this configuration was also higher than the other coating configurations, which was likely due to the low volume fraction of fiber coating, but also showed increased scatter. There was some gain in ultimate strength for the no- $1^{\text {st }}$ layer plus thick $2^{\text {nd }}$ layer configuration, but otherwise the samples gave very similar tensile results. 


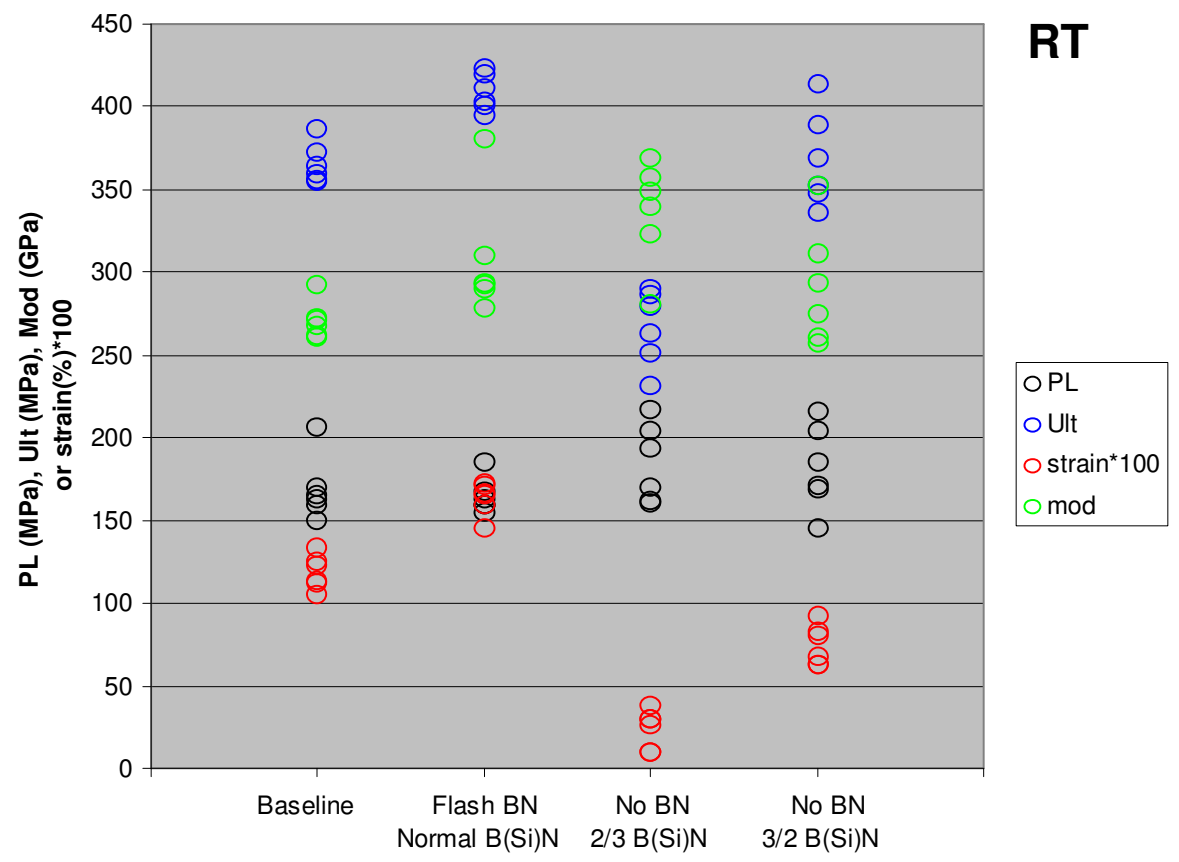

Figure 3-249. Results of the room temperature tensile tests on sample made from the new set of fiber coating configurations.

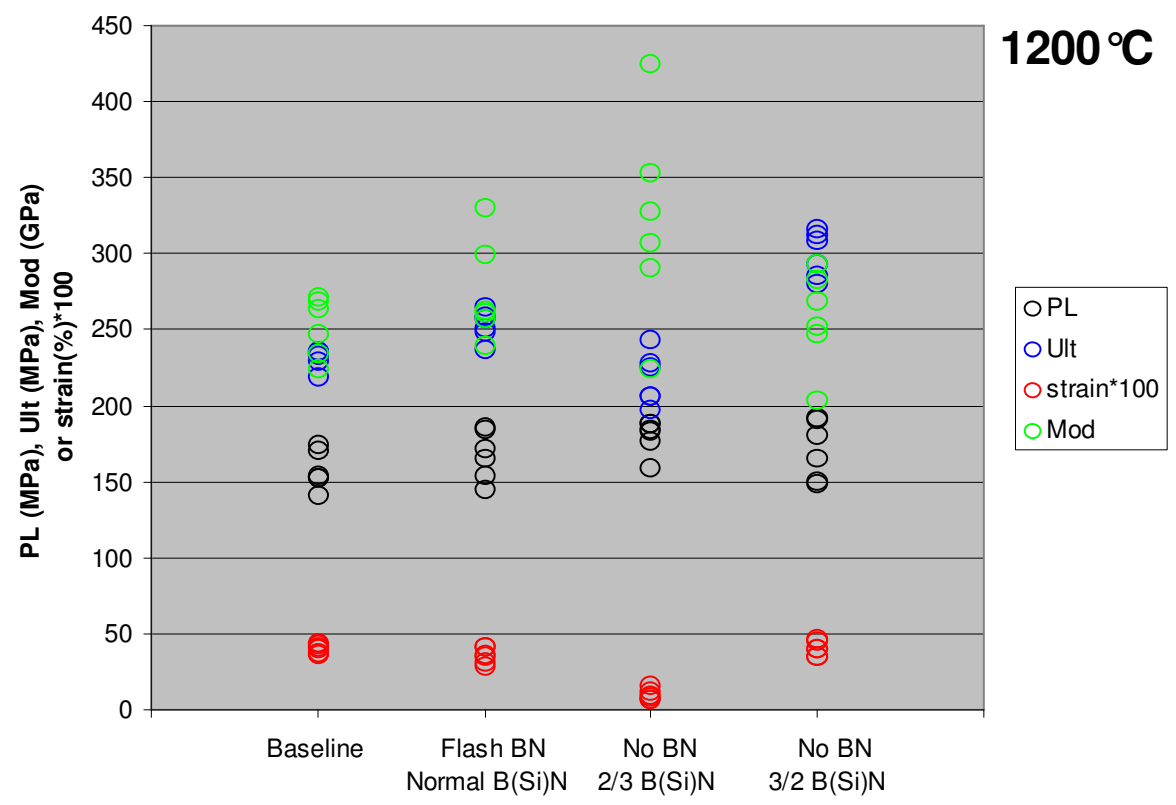

Figure 3-250. Results of the high temperature tensile tests on sample made from the new set of fiber coating configurations.

Overall the results of this study were somewhat underwhelming. While the flash-level of the $1^{\text {st }}$ layer and normal $2^{\text {nd }}$ layer configuration did appear to have some advantages at room temperature, the high temperature properties were similar to the standard coating. 
Moreover, utilizing a "flash" coating in a production environment may be difficult. There is little difference between a flash of a coating and no coating, and normal production process variability and drift would make it difficult to guarantee the presence of the very thin flash coating. Clearly the case with no $1^{\text {st }}$ layer and thin $2^{\text {nd }}$ layer gave very poor results in terms of strain capability. Operating a process so close to a condition that would have a strong impact on the quality of the product is not a desirable situation. Also, having a flash of the $1^{\text {st }}$ layer compared to the normal thickness would only shorten the processing time for one of the four coating layers, giving a marginal impact on the overall coating process cost.

The configuration with no $1^{\text {st }}$ layer and a thicker $2^{\text {nd }}$ layer was actually more attractive than the flash $1^{\text {st }}$ layer configurations in that an entire coating step could be skipped. However, the cost reduction associated with eliminating the $1^{\text {st }}$ layer is partly compensated for by the need for a thicker $2^{\text {nd }}$ layer. At $3 / 2$ the normal value the $2^{\text {nd }}$ layer is becoming quite thick and the tendency to "weld" fibers together by such a thick coating is a significant problem. Consequently such a thick layer would likely require the deposition to be done in two passes through the coater to minimize fiber welding, which would again eliminate the cost advantage of the coating.

The final conclusion from the fiber coating simplification study was that none of the alternate coating configurations evaluated yielded a sufficient improvement in composite properties, or a substantial enough reduction in fiber coating process costs, to warrant changing the coating production process at CCP. If anything, the results of the earlier DoE and from this newer set of coating trials indicated that the fiber coating optimization work done over a decade ago had arrived at a reasonably optimized coating configuration, and that the processing window around that configuration was reasonably large, which should make for a robust process capability.

\subsubsection{Task S3.4 and S3.5 - Design Support for Engine Test \#3}

With the change in emphasis of engine test \#2 from a shroud system durability demonstration to a validation of the CMC shroud system benefits to the engine performance, there was still a need for a long-term engine test to demonstrate CMC shroud and EBC coating durability. After the initiation of engine test \#2 a third program modification was applied for and granted in 2006. This modification allowed for the performance of up to two additional field engine tests in order to generate long-term engine exposure data.

The allowance for two additional engine tests in the third program modification was based on the assumption that these tests would be rainbow tests where only a small number of CMC shrouds would be used in each test, similar to the first shroud engine test. The program modification was set up in this manner to allow for the $3^{\text {rd }}$ engine test to start quickly using then-existing shroud and EBC coating technology, which would then be followed at a later time with the $4^{\text {th }}$ engine test that would incorporate and CMC or EBC modifications that could be developed as part of this program or under separate GE-funded efforts. 
Soon after starting work under this $3^{\text {rd }}$ contract modification GE Energy management decided that additional partial shroud tests would not be feasible. Their position was that getting permission to perform new technology tests in a customer's engine generally requires significant financial incentives from GE. With only a partial shroud set in each test there would be practically no engine performance benefit to the customer, so that the incentives would have to be funded independently of the test. However, with a full shroud engine set test the engine performance benefit, as demonstrated from engine test \#2, would serve as the incentive to the customer. GE would provide the new CMC shroud set at no cost to the utility and the utility would get full benefit of the improved engine performance during the test. GE Energy management therefore decided that they could only support additional engine tests if a full shroud set was being tested. As a result of the GE Energy management decision, it was necessary to combine the resources that had been planned for the two partial shroud set tests into a single engine test of a full shroud set.

As a result of the GE Energy management decision, it was necessary to combine the resources that had been planned for the two partial shroud set tests into a single engine test of a full shroud set. Consequently the efforts originally planned as Tasks S3.4 and S3.5, which allowed for the development and incorporation of shroud system design changes prior to engine tests \#3 and \#4, respectively, were combined. Similarly, Tasks S4.4 and S4.5, which included fabrication of hardware for, and execution of, engine tests \#3 and \#4, were also combined.

Only two shroud system design changes were made between the full shroud set engine test \#2 at JEA and the "durability demonstration" engine test \#3. First, the shape of the damper block was modified primarily to make it easier to manufacture. This design change did not impact the interface of the damper with the inner shrouds or change the modal response of the shrouds in any significant manner.

The other design change had to do with the cooling flow to the spring cavity. Recall that higher than desired spring cavity temperatures had been observed in three of the four instrumented outer shroud blocks in the ongoing shroud engine test \#2 at JEA (see Section 3.1.23.4). The intentional coolant flow to the outer shroud blocks had been reduced to near zero for the JEA test, leaving only cooling air leakages to control outer shroud block temperatures. Such flows are difficult to calculate and control, and thus the minimum amount of intentional cooling air needed is nearly impossible to predict analytically.

The shroud design engineers therefore decided to introduce an outer shroud block cooling flow circuit that had the ability to be adjusted from outside the engine. The cooling air passage to the spring cavity was routed through the locator hole for the radial locator pin, and the pins were modified so that part of the pin could be rotated from outside the turbine casing. The end of the pin that engaged the outer shroud blocks was shaped so that it would partially block the cooling air flow depending upon its rotational position. In this way the hole/pin created an adjustable orifice through which the cooling air flow could be adjusted. In this way the amount of intentional cooling could be adjusted during engine 
operation until the desired outer shroud block temperature distribution was achieved. Future outer shroud blocks would then be fabricated with fixed internal features to control at this optimized amount of cooling air, such that in-the-field adjustments would not be necessary.

Both of these design changes were incorporated into the overall shroud system design. Full 3D FEA flow, temperature and stress analyses were conducted to ensure that the changes had a minimal impact on the stress and temperature conditions of the CMC inner shrouds. The design changes were then approved by GE Energy Chief Engineers' Office, and were subsequently included in the hardware fabricated for engine test \#3.

\subsubsection{Tasks S4.5 and S4.6 - Field Engine Test \#3}

The purpose of this task was to plan, fabricate hardware for, and conduct a third field engine test of the CMC shroud system. As noted above, due to the change from two partial shroud set engine tests to a single full shroud set test, the activities and resources originally planned for tasks S4.5 and S4.6 were eventually combined.

\subsubsection{Fabrication of CMC Inner Shrouds for Engine Test \#3}

Shroud fabrication for engine test \#3 was started in September of 2006, at which time the test was still planned to include only a partial set of shrouds. Prepreg HiPerComp® CMC inner shrouds were being fabricated at both GRC and at CCP. The initial plan for this task was to fabricate 18 inner shrouds of acceptable quality to use in engine test \#3, consisting of a mix of shrouds from GRC and CCP. The plan was that the CCP shrouds would be coated with standard Gen1 EBC coatings at GE Energy MP\&E, and the GRC shrouds would be coated with developmental Gen2 varieties of EBC at GRC.

Following the shroud fabrication campaign for the JEA shroud engine test, CCP had been working internally on further developing and optimizing their shroud fabrication process to eliminate the defects in the shroud flange bend regions. Six of the shrouds from these fabrication trials had very good IR NDE results, and thus were considered as potential candidates for use in engine test \#3.

Fabrication of new CMC shrouds for the anticipated partial shroud set test had been completed by January of 2007. Overall CCP had fabricated 20 new shrouds in addition to the six pre-existing shrouds mentioned above. GRC had fabricated 32 new shrouds. All of the shrouds were put through a pre-screening process where they could be rejected based on fabrication process anomalies, poor witness bar mechanical properties, or on the preliminary NDE images. Of the 58 starting shrouds, 17 CCP and 14 GRC shrouds passed through the initial screen.

These 31 shrouds were then machined to final dimensions, inspected using a CMM for dimensional accuracy, and re-evaluated by IR thermography NDE. The shrouds were then ranked using this characterization information, and a cut-off line was established beyond 
which the number or severity of shroud non-conformities was severe enough that they could not be used in the long-term engine test. This left 21 shrouds of sufficient quality to be recommended for inclusion in the next engine test. It should be noted that the overall quality in this population of shrouds exceeded that of the shrouds used in the $1^{\text {st }}$ engine test, and greatly exceeded the quality of the population used in the $2^{\text {nd }}$ engine test at JEA.

These 21 shrouds were then released for EBC coating application, ten of which were to be coated at the MP\&E lab at GE Energy using the standard Gen1 BSAS-based coating, and the remainder to be coated at GRC using both standard Gen1 and various configurations of the Gen2 type EBC coatings. One of the MP\&E shrouds displayed extensive grit blasting damage during surface preparation for coating, and was subsequently rejected from the engine test, leaving 20. A substitute shroud was given to MP\&E for coating, leaving 10 shrouds for coating at GRC.

MP\&E completed coating of all of their 10 engine shrouds with Gen1 EBC, plus an additional QC ("quality control") shroud selected from the previously rejected shrouds, by the end of June 2007. Three of the allocated to GRC for EBC deposition were also coated with normal Gen1 EBC coating. Application of the Gen2 EBC coatings at GRC was then delayed. At that time (mid 2007) a suitable field engine test site had not yet been identified, and EBC durability data was being generated as part of the JEA shroud test EBC RCA, and from parallel steam oxidation studies being done under the IGCC programs. It was hoped that the additional information from the ongoing testing would aid in the selection of the most robust Gen 2 coating configuration for the engine test shrouds. Without the scheduling pressures of an impending engine installation, it was decided to delay the Gen2 coating application to allow for as much of this data to be collected as possible before deciding on the final EBC configuration.

By late 2007 a suitable test site had still not been identified, although screening of potential engines with scheduled maintenance outages in the Spring of 2008 was in full progress. However, it was at this time that the decision was made to forgo a partial shroud set test and to instead test of a full shroud set. This decision obviously meant that a large number of additional shrouds would be needed for the engine test. Fabrication of these shrouds was to be done primarily at CCP to serve as a demonstration of their readiness to produce larger quantities of shrouds. As part of this fabrication readiness demonstration CCP was required to complete formal GE Energy "First Piece Qualification" (FPQ) and "Pilot Lot Qualification" (PLQ) processes.

The purpose of the FPQ was to have CCP demonstrate that they had a well-defined and controlled fabrication process that was capable of producing a small number of shrouds that met all specifications. The PLQ process is intended to ensure that a vendor can then utilize the process defined in the FPQ for consistent production of larger quantities of components. The number of parts required for the PLQ varies from depending on the type of component and type of processes being considered. For the CMC shroud fabrication process the decision was made that the goal for the FPQ would be a minimum of 10 pieces that met all component specifications, and then the production of the shrouds needed to complete the 
full engine set for the field test would constitute the "lot" of material for the PLQ process. Shrouds produced for the FPQ would be subject to both non-destructive and destructive evaluations to ensure that the material structure and properties were uniform throughout the parts. Characterization of the PLQ parts would be limited to non-destructive evaluations along with mechanical tests of witness coupons fabricated with the shroud components.

Shroud fabrication trials in preparation for the FPQ were started in early 2008. CCP fabricated fifteen shroud doublets using various lay-up and autoclave process modifications in order to identify the combination of conditions that would give the best quality shrouds. (A shroud doublet is a CMC part from which two finished shrouds can be machined.) Of these ten, the first five had acceptable NDE images but did not meet dimensional specifications, the next three met dimensional specifications but had unacceptable NDE indications, and the last two had acceptable NDE and met dimensional specifications. It should be noted that of the three shrouds that failed NDE inspection, two of the failures were caused by surface-related defects that were eventually traced to changes made in the normal surface ply preparation procedures and the use of a different peel film during autoclave lamination. The last two shrouds, that met dimensional and NDE requirements, were made with the traditional process and peel film.

The process trial shrouds met all of the room temperature mechanical property requirements with the exception of strain to failure. Of the nine doublets for which witness bar data was available, only two would have met the existing strain to failure specification.

The specification for room temperature strain to failure was based on setting a minimum value of strain to failure at the shroud use temperature of $1200^{\circ} \mathrm{C}$. Using data from the existing CMC database a transfer function between the strain to failure at $1200^{\circ} \mathrm{C}$ and that at room temperature was established, thus setting the lower spec limit for strain to failure from the RT witness bar tests used to evaluate the shrouds. However, the prepreg MI CMC material used for the database was made at GRC in 1999-2000, from fiber coated at GRC, and using the original GEN1 matrix composition. Although the fabrication process established at $\mathrm{CCP}$ mimicked the GRC process as much as possible, there were differences in the details of the process steps due to differences in equipment. In addition, numerous process modifications had been instituted at CCP in order to improve quality, lower cost and increase productivity, including a change over to the GEN2 matrix composition. Consequently it was unlikely that data from the old CMC database that was used to establish the room temperature mechanical property requirements was representative of the behavior of the prepreg MI CMC material then being made at CCP.

It was therefore decided to cut up several of the processing trial shrouds for tensile testing in order to evaluate the trend between room temperature and high temperature strain to failure for actual $\mathrm{CCP}$ shroud material to see if any relaxation of the strain to failure specification was warranted. Figure 3-251 shows the results of these tests on the CCP processing trial shrouds. The plot shows the relationship between the strain to failure measured at $1200^{\circ} \mathrm{C}$ compared to the strain to failure measured at RT for several different shrouds. Also shown is the trend in the data from the old GRC material database. It was 
obvious that the knockdown from RT to high temperature strain was much greater for the old GRC material than for the CCP processing trial shrouds.

The result in Figure 3-251 suggested that the RT strain to failure specification for CCP shrouds could be reduced substantially from the existing specification based on the older GRC material data. However, the tensile data only reflected short-term strength trends and did not evaluate any effect the lowered strain to failure could have on material life properties, such as fatigue or creep rupture. It was therefore decided to also do fatigue and crack growth testing of some "low strain" coupons.

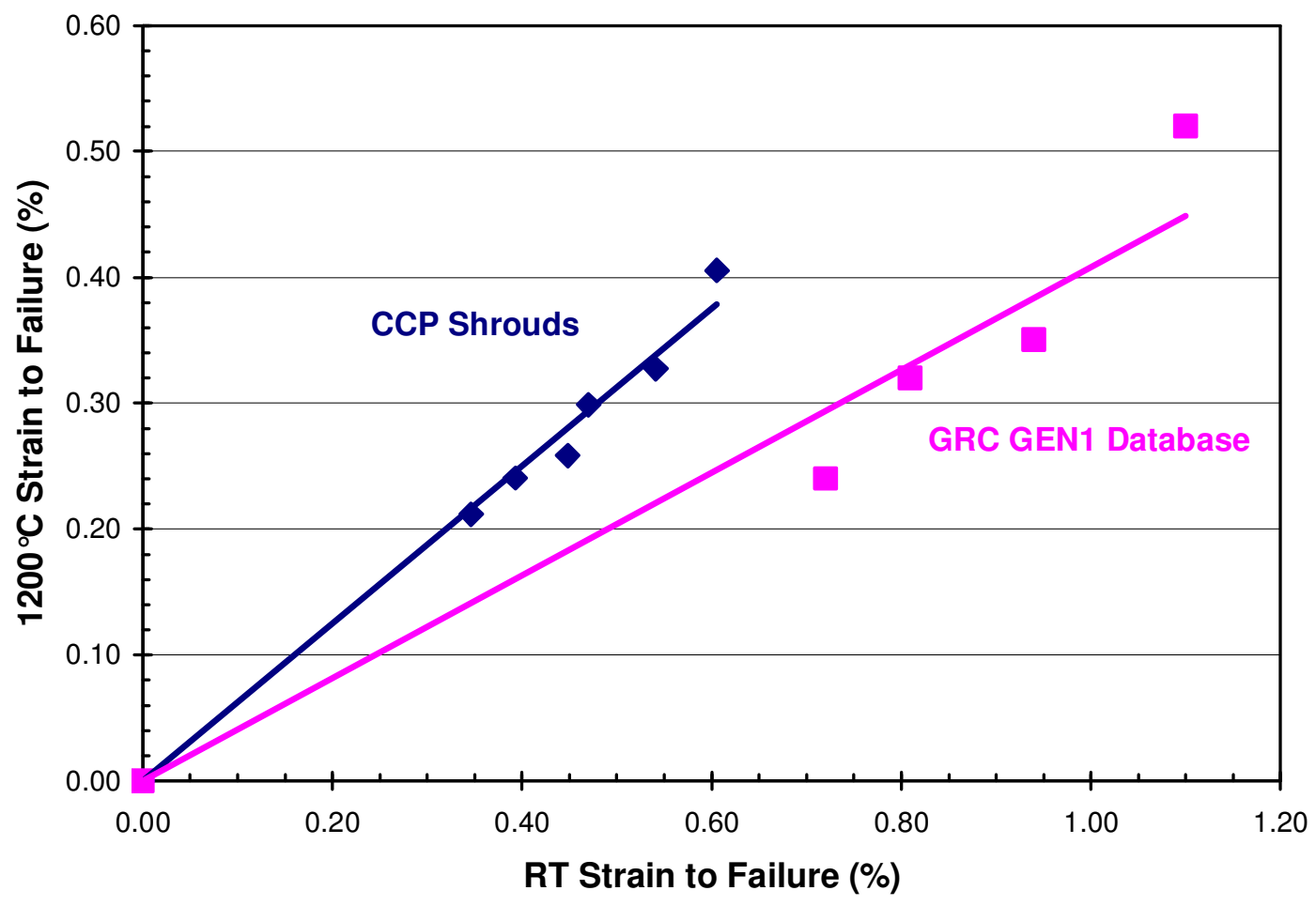

Figure 3-251. Trend between RT and $1200^{\circ} \mathrm{C}$ strain to failure measurements on older GRC-generated material (from the 2000 database) and from CCP-fabricated shrouds from early 2008 .

There was insufficient material and resources to do a full characterization of the effect of low strain to failure on the fatigue of prepreg MI CMC material. Consequently a cursory measurement of the low cycle fatigue response was conducted and compared to data in the existing GRC database measured on older, GEN1 material. MI-CMC shrouds with materials properties consistent with this database had successfully gone through $>5800$ hours of field engine testing in engine test \#1 with no indications of degradation. The expectation was that if the newer, lower strain material from CCP was at least as good as the older material in fatigue that it would be acceptable for a shroud engine test as well. 
Several test samples were obtained from CCP from panels showing nominally $0.4 \%$ strain to failure during room temperature tensile testing. Fatigue testing was done in air at $1200^{\circ} \mathrm{C}$ at $0.33 \mathrm{~Hz}$ and a load ratio, or "R" value, of 0.01 . All of these conditions were chosen to be identical with the prior low cycle fatigue testing conditions used in the older GRC material database. Again due to time constraints, testing was carried for a maximum of 10,000 cycles ( 8.3 hours) for any given specimen. The older GRC material had shown a fatigue life of about 10,000 cycles at a maximum stress level of approximately $138 \mathrm{MPa}$, so that level of stress was chosen for the initial tests. Test run-outs were observed at $138 \mathrm{MPa}$ for three separate samples, so the maximum applied stress was then increased until several fatigue failures were observed. Figure 3-252 shows the low cycle fatigue response of the newer CCP material with relatively low strain to failure as compared to the data from the older GRC GEN1 material.

At the relatively low cycle numbers tested the newer CCP material with low strain to failure clearly out-performed the older GRC material. The stress needed to generate fatigue failure in $6,000-8,000$ cycles was $\sim 190 \mathrm{MPa}$ for the CCP GEN material whereas it was only $\sim 140 \mathrm{MPa}$ for the older GRC GEN1.0 material.

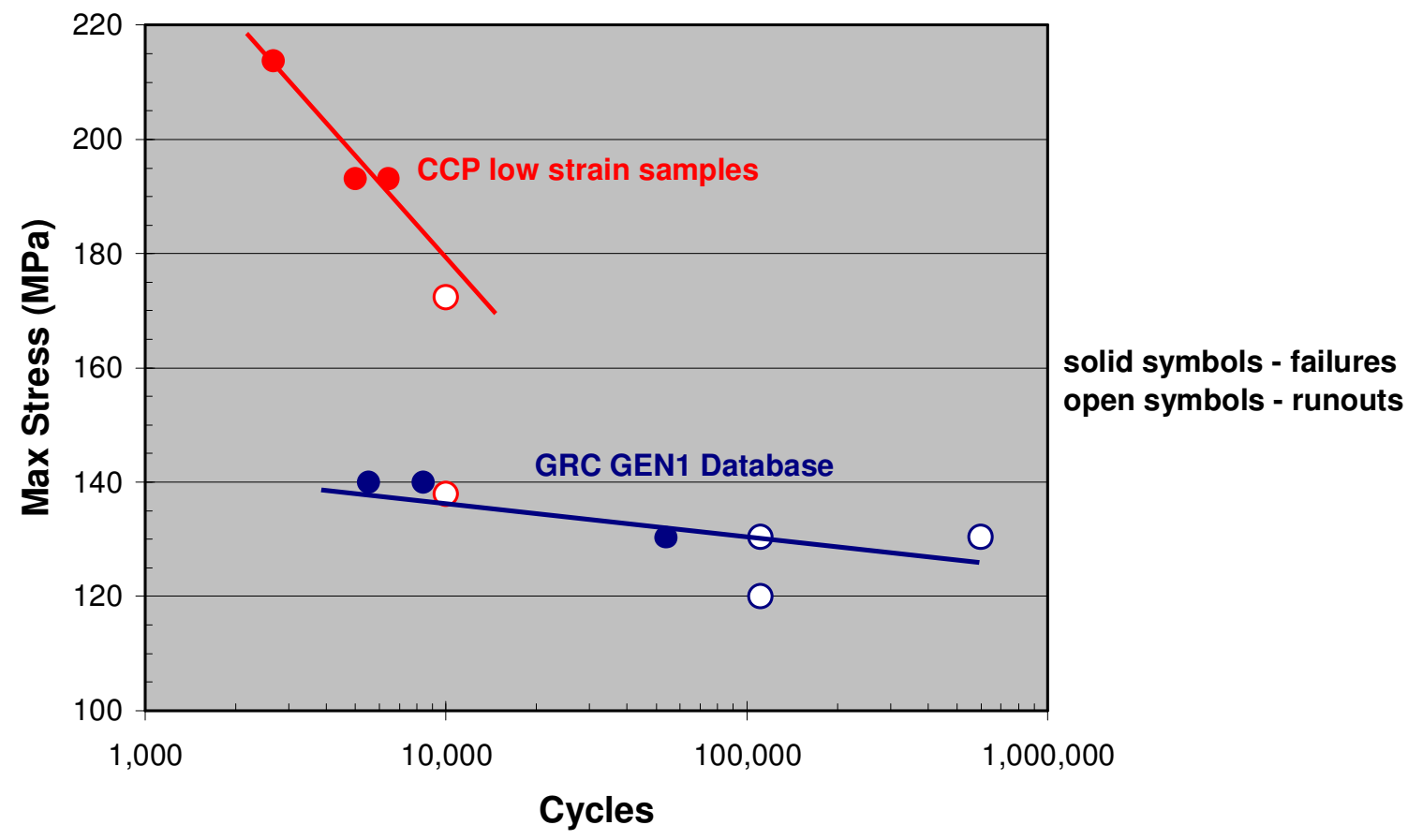

Figure 3-252. Low cycle fatigue response of "low-strain" CMC material from CCP (red) compared to older GRC-fabricated GEN1 material (blue). All testing was done at $1200^{\circ} \mathrm{C}$ in air at $0.33 \mathrm{~Hz}$ and an R-ratio of 0.01 .

Based on the results in Figure 3-252 the short-term fatigue response of the newer material from CCP was deemed to be adequate. However, these tests were performed on "pristine" test samples, i.e. these samples had no pre-existing defects, and thus represented the 
resistance of the material to damage initiation. The question remained as to whether the low strain material would have adequate toughness to resist the propagation of damage that may be caused by other transient events, such as foreign object damage (FOD).

In an attempt to measure the damage propagation response of the low strain material small notches were machined into the edges of several fatigue specimens at the center of the gage section. The size and shape of these notches is shown in Figure 3-253. The intent was to pre-load the notched specimens in tension at RT to generate matrix cracks at the notch roots. (The stress concentration factor referenced to the gross gage section dimensions for such notches should be 3.06 based on standard mechanics of materials texts.) These specimens would then be fatigue tested to see if the matrix cracks would propagate to failure.

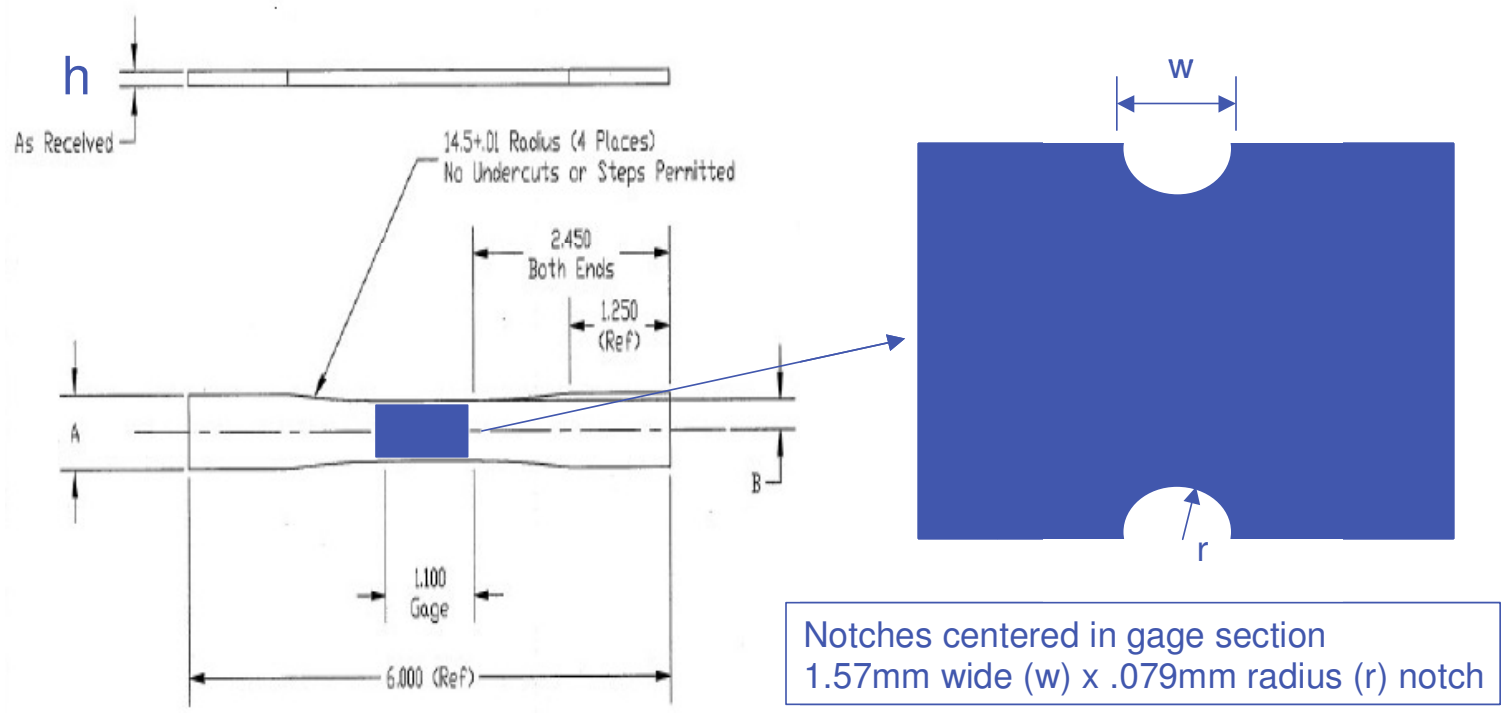

Figure 3-253. Size and location of notches machined into the edges of tensile low cycle fatigue specimens.

The first set of notched bars were preloaded to a gross section stress of 79MPa, which was close to the expected maximum stress in the shroud component at steady state. At that load the local stress concentration at the root of the notches should have been $243 \mathrm{MPa}$, or well above the matrix cracking stress. These specimens were then fatigue tested at a maximum gross section stress of $25 \mathrm{MPa}$, which corresponds to a concentrated stress of $76 \mathrm{MPa}$, again close to the maximum normal operating stress expected in the shrouds. All three samples tested in this fashion showed run-out at 10,000 cycles in the low cycle fatigue test at $1200^{\circ} \mathrm{C}$.

The next notched sample was preloaded to a gross section stress of $148 \mathrm{MPa}$, which corresponds to a localized stress of $454 \mathrm{MPa}$, or well above the ultimate strength of the CMC. This sample was then fatigue tested at a gross section stress of 52Mpa, 
corresponding to a localized concentrated stress of $158 \mathrm{Mpa}$. This sample also showed runout at 10,000 cycles.

Finally, two notched samples were fatigue tested, but without pre-stressing them. The maximum gross section stresses used for the fatigue tests were $37 \mathrm{MPa}$ and $79 \mathrm{MPa}$, which correspond to concentrated stress levels of $114 \mathrm{MPa}$ and $243 \mathrm{MPa}$, respectively. These concentrated stress levels represent one test below the matrix cracking stress and one test above. However, both samples showed run-out at 10,000 cycles.

All of the run-outs in the notched sample fatigue testing called into question whether the simple elastic stress concentration factors were appropriate for the $\mathrm{CMC}$, and that perhaps none of the test samples had ever been loaded to a sufficient level to form a matrix crack. Fluorescent dye penetrant inspection was performed on the bar loaded to the highest preload stress (148MPa gross section stress), but no cracks were identified. However, it had been previously observed via microscope that pre-cracked samples can have such small crack opening displacement when not under load as to be undetectable. The test bar was then placed into a tensile test rig and loaded to the preload used before fatigue testing, and the fluorescent dye was reapplied. This should have opened any cracks in the composite to allow for the dye to penetrate. This time when the specimen was unloaded and examined with UV light a very short crack emanating from the root of one of the notches was visible, as shown in Figure 3-254. The fact that the crack was so small on the sample that had been preloaded to the highest stress suggests that the other fatigue samples were likely not cracked, either by the preloads or by the fatigue stress loads.

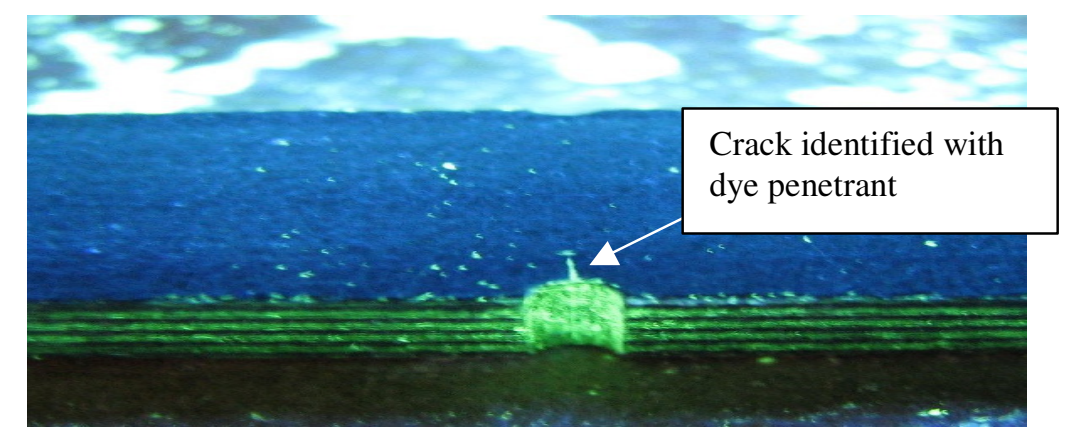

Figure 3-254. Photograph under UV lighting of the notched region of the notched fatigue sample that was preloaded to a gross section stress of $148 \mathrm{MPa}$. A very short crack was detected propagating out from one of the notches, but only after applying the fluorescent dye while the specimen was under tensile load.

The absence of cracks in most of the notched fatigue specimens, and the very small size of the crack in the specimen loaded to the highest preload, indicated that the CMC material was very insensitive to the notches. Even though no fatigue failures were generated in the notched samples, the notch insensitivity was a positive result and indicated that the low strain to failure material should still be fairly durable, even in the presence of a defect. 
While the fatigue tests did not proceed entirely as planned, they did help to retire some of the risk of the low strain to failure material. The un-notched fatigue tests showed that the low strain material from CCP was actually superior to the older GRC GEN1 material at low numbers of cycles. The notched fatigue tests indicated that the low strain material was still very notch-insensitive, which is a major reason why CMCs are used in place of monolithic ceramics. Even in the most highly loaded sample there was no evidence of crack propagation or embrittlement during fatigue testing. All of these observations indicated that there were no "red flags" associated with the low strain to failure CMC material from CCP and that the strain to failure specification for shrouds could be lowered to a level consistent with the value displayed by these test specimens.

With the lowering of the strain to failure spec limit, nearly $80 \%$ of the shrouds made as part of the processing trials would now pass the mechanical property requirements as opposed to the less than $40 \%$ that would have passed with the older spec limit. This result, along with the good quality of the NDE and dimensional inspections of the latter process trial shrouds, was judged to be sufficient justification to proceed with the formal FPQ process.

For the FPQ GE Energy established a goal of $80 \%$ or better yield on a trial batch of twelve shrouds. CCP then produced six shroud doublets, corresponding to twelve finished shrouds, starting in July of 2008. Reflection IR NDE images of each of these doublets are shown in Figure 3-255. Delamination defects in the bends to the forward and aft flanges were largely eliminated compared to shrouds from the earlier fabrication trials. However, two of the shroud doublets did show excessively large NDE indications on the hot gas path faces. The location and sizes of these defects would have caused the likely rejection of three of the twelve shrouds that would be machined from these doublets based on the NDE acceptance criteria.
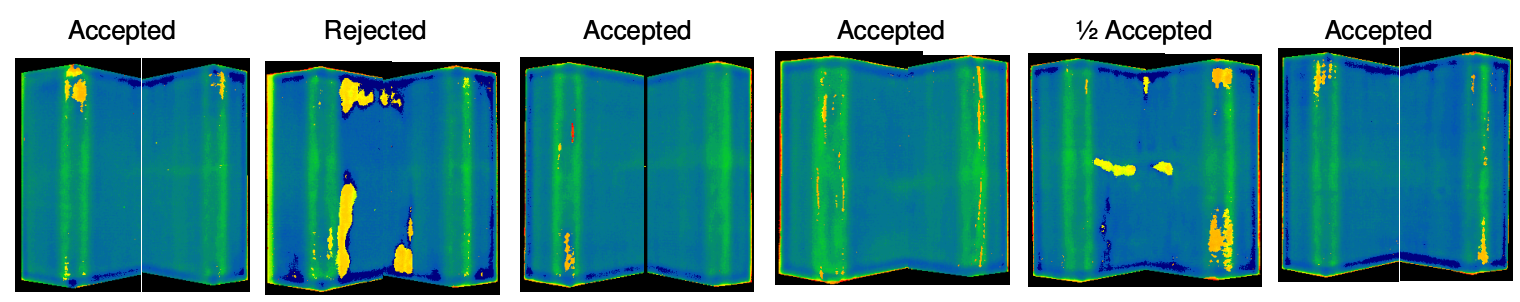

Figure 3-255. Transmission IR NDE images on the six shroud doublets fabricated by CCP for the shroud FPQ process.

Mechanical testing of witness bars cut from the shrouds indicated that they passed all mechanical requirements except, once again, for strain to failure. The coating qualification samples made from the same fiber coating lots that went into the FPQ shrouds had strain to failure values ranging from 0.42 to $0.49 \%$. However, the witness bars cut from the shroud doublets were significantly lower than that, ranging from 0.24 to $0.48 \%$, as shown in Figure $3-256$. 
Mechanical data from the earlier processing trial shrouds showed good correlation between the 8-ply coating run qualification panels and the 18-ply shrouds, so this discrepancy with the FPQ shrouds was surprising. Between the NDE and mechanical property criteria discussed above, nine of the twelve shrouds that would have been produced from the six shroud doublets would have been rejected due to their not meeting specifications. Since the goal of the FPQ process was to demonstrate $80 \%$ yield with $50 \%$ yield as an absolute minimum, this batch of shrouds was considered to have failed the overall FPQ.

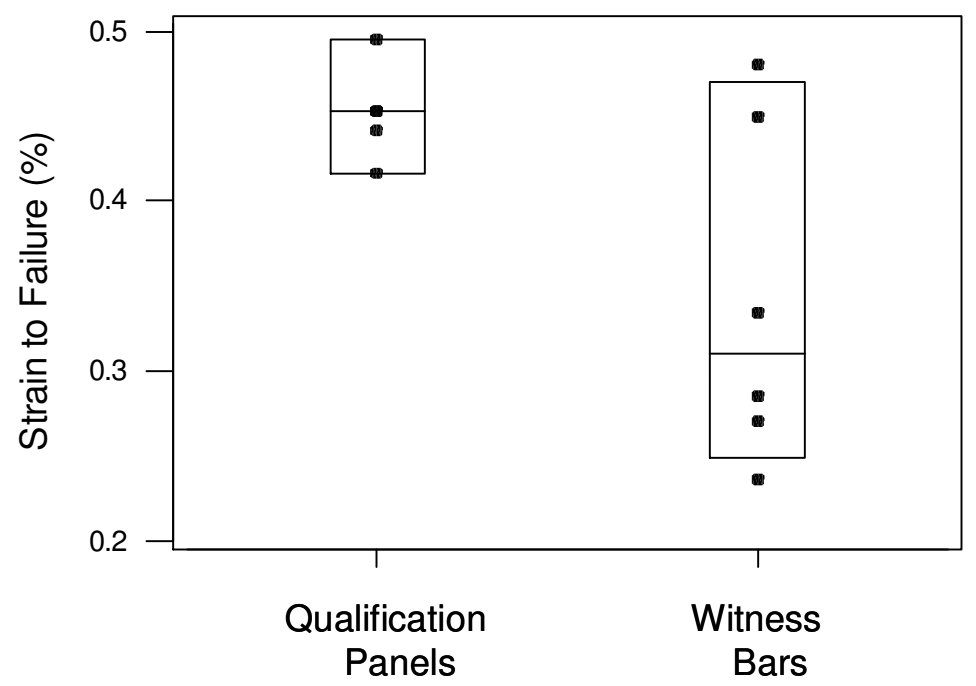

Figure 3-256. Boxplots of the strain to failure values measured from the qualification panels of the fiber coating lots used for the FPQ shrouds (8-ply lay-up), and from the witness bars cut from the flange ends of the FPQ shrouds (18 ply lay-up). The box limits represent $95 \%$ confidence intervals.

Characterization of the shrouds from the first FPQ process was completed. All of the shrouds tested passed the modal frequency and dimensional tolerance evaluations. Thus the final outcome of the process is that only three of the twelve shrouds would have passed all of the specifications. In particular, three would have been rejected based on defects, as detected by NDE, and eight would have been rejected based on missing the strain to failure specification. Since some shrouds missed on both specifications, only 3 of the twelve were considered acceptable.

Since the fabrication of the $1^{\text {st }}$ FPQ shrouds CCP has focused considerable effort on understanding the low strain to failure issue. Unfortunately no solution has as yet been demonstrated. CCP has selected lay-up configurations and consolidation conditions that they feel will help to further minimize defects in the shroud bends, but a more fundamental change in the fiber coating or melt infiltration processes may be needed to address the strain to failure issue. Fabrication of shrouds for the $2^{\text {nd }}$ FPQ process has been on hold due to a need for CCP to focus resources on other programs in the short term, and to allow time for solution to the low strain problem to be found. 
A second FPQ process for qualifying shroud production at CCP was therefore started. From late 2008 through early 2009 CCP continued to investigate various process modifications to address the low strain to failure problem with little success. However, in the Spring of 2009 there was a breakthrough in the understanding of the low strain to failure problem. During a silicon melt infiltration run of several parts and coating qualification panels the CCP site experienced a power failure that shut down the infiltration cycle prematurely. As a consequence the samples being processed at the time only saw roughly $1 / 3$ of the normal infiltration time. Although the larger CMC components were incompletely infiltrated, several of the smaller coating qualification panels did appear to infiltrate completely, and so were subsequently tested. Surprisingly, the strain to failure values of these panels were more than $2 \mathrm{X}$ of the average values that $\mathrm{CCP}$ had been getting for panels infiltrated in the full, normal cycle.

This observation prompted numerous experiments to investigate the effect of the time during the silicon infiltration process (i.e. the time spent above the melting point of silicon) on the mechanical properties of the CMC. The goal of these experiments was to balance the improvement in strain to failure at shorter infiltration times against the need for longer times to fully infiltrate large parts, such as shrouds.

The trend in strain to failure with infiltration time is shown in Figure 3-257. Early shroud batches infiltrated under the old standard conditions (represented by the blue bars in Figure 3-257) rarely met the minimum strain to failure specification. Initial modifications to the MI cycle (shown by the orange bars in the figure) gave uniformly high strain to failure, but shrouds infiltrated under these conditions often did not fully infiltrate. Subsequently an intermediate MI condition (shown by the green bars in Figure 3-257) produced shrouds that consistently exceeded the strain to failure specification and still were fully infiltrated.

Unsurprisingly it was also found that the density tended to decrease (i.e. the residual porosity increased) with shorter infiltration times, negatively impacting the proportional limit values, but these values still remained above the shroud specification limits. All other shroud material specs were also met utilizing the $33 \%$ time reduction MI conditions. The six shroud doublets represented by the green bars in Figure 3-257, corresponding to 12 finished shrouds, were subsequently accepted by GE Energy as fulfillment of the FPQ requirements, and $\mathrm{CCP}$ started fabrication of the engine set of shrouds using these processing conditions.

Fabrication of the new engine test shrouds proceeded fairly well at CCP. By the end of 2009 seventy-one shrouds of sufficient quality as to be accepted by GE Energy engineering had been produced, which was sufficient to declare the fabrication campaign a success.

It should be noted that all of the shroud fabrication work described above in this section utilized CMC made from Hi-Nicalon fiber and the low silicon matrix composition (sometimes referred to as GEN1.1 material). Since many of the future CMC applications that GE Energy was considering would require the use of a higher temperature fiber, 
namely Hi-Nicalon type-S, it was highly desired to have such shrouds available for the durability engine test. (CMC made from Hi-Nicalon type-S fiber and the low silicon matrix composition were generally referred to as GEN2 type CMC.) However, fabrication of the GEN2 shrouds was considered to be a higher risk undertaking since CCP had less experience fabricating the GEN2 material in general, and no experience with GEN2 shrouds. A shortened FPQ process for GEN2 shrouds was passed in the Fall of 2009, with GEN2 shroud fabrication for the engine test continuing into January of 2010. Overall 41 GEN2 shrouds were produced by CCP for engine test consideration.

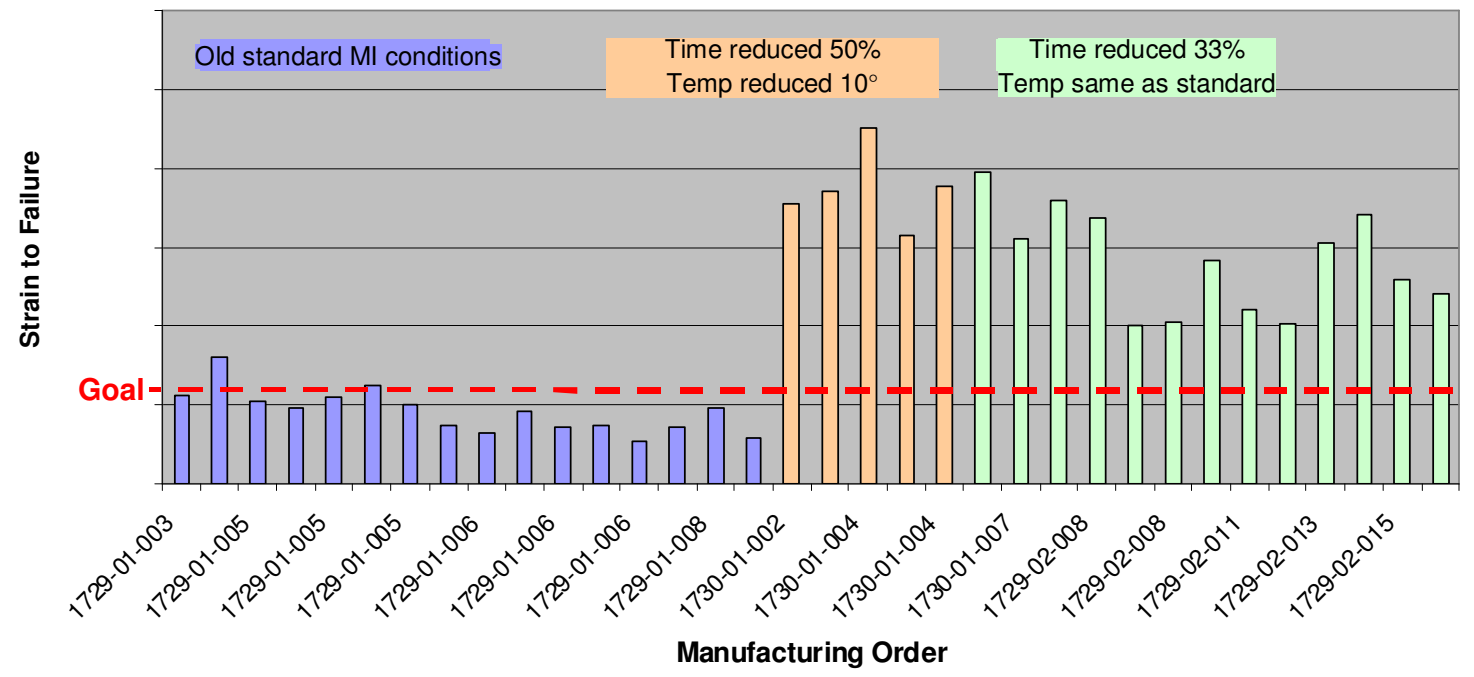

Figure 3-257. Trend of shroud strain to failure for three different melt infiltration conditions at CCP. The green bars represent conditions where the minimum strain to failure specification was routinely met and the shrouds were completely infiltrated.

Similarly to the FPQ process for the CMC inner shroud fabrication, there were also FPQ processes for EBC application at MP\&E and at GRC. For this procedure rejected engine test shrouds were coated with EBC using the identical process to be used for the engine shrouds, and then the shrouds were cut up for metallographic examination of the coatings in critical regions. The main criteria for assessing the coatings were the thickness of the coating layers and absence of excessive porosity or cracking in the coatings. This process started in September of 2009, but continued through late January 2010 due to various issues seen in the coatings produced at MP\&E. Table 1 lists the various FPQ EBC spray trials, the observations and mitigations put in place to address the issues seen in the FPQ coatings.

In the first of these trials there was excessive vertical cracking of the BSAS layer, which was attributed to a new source of the BSAS powder. For the $2^{\text {nd }}$ and later trials the BSAS powder used was from an older, more reliable source, but the observed coating thickness variations were still excessive in trials 2 and 3. It was thought that the quality of the CMC 
shroud substrate could be influencing the deposition uniformity so in the $4^{\text {th }}$ trial a better quality shroud was used as a substrate; however, it still showed excessive thickness variation in the silicon bond coat and mullite-BSAS transition layers. There were even isolated regions around the shroud edges where very little Si deposition had occurred, as shown in Figure 3-258. This situation was found to have been caused by a robot programming error, and was addressed by adjusting the robot programming to re-center the plasma plume on the side of the shroud showing the thin coating. On the fifth trial all of the coating layer thicknesses were within spec, but the BSAS layer now showed higher than normal density and increased vertical cracks.

The final two FPQ trials were completed in late January. Based on the microstructural uniformity and coating layers being within specification, the conditions used for the FPQ\#6 coating were chosen for application of Gen1 EBC coatings to the engine shrouds.

The FPQ process for the Gen2 EBC coatings, which were deposited at GRC, proceeded with fewer problems than for the Gen1 EBC. The first Gen2 FPQ trial shroud showed acceptable coating layer thicknesses in all regions, but in certain regions the silicon and BSAS layers were near the lower end of the specification range. The spray process was then adjusted to slightly increase the thickness of these layers over the entire shroud. The $2^{\text {nd }}$ FPQ shroud, which was coated with these process modifications, was deemed acceptable and the spray process for the Gen2 EBC was locked down.

By the end of February 2010 the full engine set of shrouds needed for engine test \#3 had been completed. CMC inner shroud fabrication was completed in January, and EBC coating of the shrouds was completed in February. Included in the shroud engine set were 60 GEN1.1 CMC inner shrouds (made with Hi-Nicalon fiber and the low silicon matrix, similar to the shrouds in engine test \#2 at JEA), and 36 GEN2 CMC shrouds (made with Hi-Nicalon Type-S fiber). All of the shrouds with Hi-Nicalon fiber were coated with the Gen1 EBC configuration, which again is similar to the coatings used in the JEA test and consists of a silicon bond coat, BSAS plus mullite transition layer, BSAS top coat, and a patterned abradable layer. The only modifications made to these coatings was the use of an improved deposition process (all shrouds were sprayed with the SG100 gun and process) and a shorter crosshatched abradable pattern. Fourteen of the GEN2 CMC shrouds were also coated with this Gen1 EBC coating. The remaining twenty-two GEN2 CMC shrouds were coated with one of three variations of the Gen2 EBC coating, which utilizes rare earth silicates for enhanced coating recession resistance in combination with a BSAS or an yttrium-alumino-silicate hermetic layer. An additional twelve shrouds were also fabricated and coated to be used as spares in case there were any shrouds damaged during the shroud assembly or engine installation processes. 
Table 3-24. Results of the Gen1 EBC FPQ Shroud Coating Evaluations in Preparation for Coating of the Shrouds for Engine Test \#3.

\begin{tabular}{|c|c|c|c|c|}
\hline $\begin{array}{l}\text { FPQ } \\
\text { No. }\end{array}$ & $\begin{array}{l}\text { Analysis } \\
\text { date }\end{array}$ & Objectives & $\begin{array}{c}\text { Process Change From } \\
\text { Previous FPQ }\end{array}$ & Observations \\
\hline 1 & $9 / 15 / 09$ & $\begin{array}{c}\text { Demonstrate first } \\
\text { part quality }\end{array}$ & NA & $\begin{array}{c}\text { Extensive fine vertical } \\
\text { cracking in BSAS } \\
\text { layer }\end{array}$ \\
\hline 2 & $10 / 16 / 09$ & $\begin{array}{l}\text { Mitigate BSAS } \\
\text { cracking }\end{array}$ & $\begin{array}{c}\text { Changed BSAS feed } \\
\text { powder }\end{array}$ & $\begin{array}{c}\text { Uncracked BSAS; low } \\
\text { Si and BSAS } \\
\text { thickness along edges }\end{array}$ \\
\hline 3 & $11 / 14 / 09$ & $\begin{array}{c}\text { Improve coating } \\
\text { thickness on } \\
\text { edges }\end{array}$ & $\begin{array}{c}\text { Increased APS pass } \\
\text { count on edges; } \\
\text { corrected spray plume } \\
\text { offset }\end{array}$ & $\begin{array}{l}\text { Low Si and BSAS } \\
\text { thickness in several } \\
\text { edge sections; high } \\
\text { BSAS thickness in } \\
\text { fillets }\end{array}$ \\
\hline 4 & $11 / 25 / 09$ & $\begin{array}{l}\text { Improve coating } \\
\text { thickness on } \\
\text { edges, front and } \\
\text { back flanges and } \\
\text { fillets }\end{array}$ & $\begin{array}{l}\text { Correct APS pass } \\
\text { count on edges and } \\
\text { fillets; correct spray } \\
\text { gun edge alignment }\end{array}$ & $\begin{array}{l}\text { BSAS thickness } \\
\text { largely in spec; low to } \\
\text { no Si thickness } \\
\text { flanged edges; some } \\
\text { vertical cracks in } \\
\text { BSAS on edges }\end{array}$ \\
\hline 5 & $12 / 18 / 09$ & $\begin{array}{c}\text { Improve Si layer } \\
\text { thickness on } \\
\text { edges } \\
\end{array}$ & Increase $\mathrm{Si}$ pass count & $\begin{array}{c}\text { Numerous wide BSAS } \\
\text { vertical cracks on } \\
\text { edges }\end{array}$ \\
\hline 6 & $1 / 26 / 09$ & $\begin{array}{l}\text { Mitigate BSAS } \\
\text { edge cracking }\end{array}$ & $\begin{array}{c}\text { Freeze Si and } \\
\text { BSAS/mullite spray } \\
\text { conditions; increase } \\
\text { gun standoff distance } \\
\text { and speed for BSAS } \\
\text { on edges }\end{array}$ & $\begin{array}{l}\text { BSAS cracking largely } \\
\text { remediated; Selected } \\
\text { this process for engine } \\
\text { shrouds }\end{array}$ \\
\hline 7 & $1 / 26 / 09$ & $\begin{array}{l}\text { Mitigate BSAS } \\
\text { edge cracking }\end{array}$ & $\begin{array}{c}\text { Freeze Si and } \\
\text { BSAS/mullite spray } \\
\text { conditions; increased } \\
\text { gun standoff distance } \\
\text { even more }\end{array}$ & $\begin{array}{l}\text { BSAS cracking largely } \\
\text { remediated }\end{array}$ \\
\hline
\end{tabular}




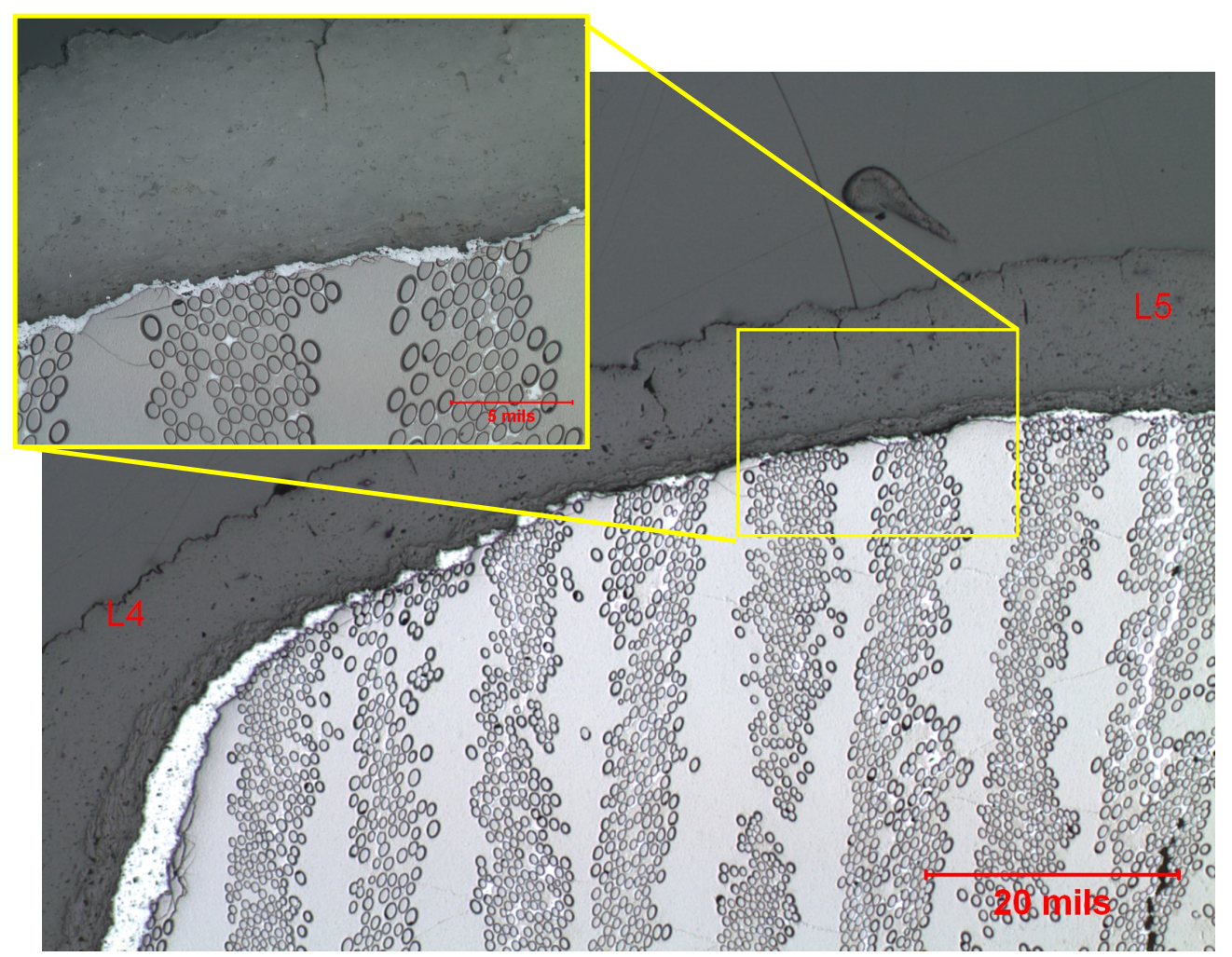

Figure 3-258. Micrographs of an edge section from the 4th Gen1 EBC FPQ shroud showing very thin silicon bond coat, to the point of becoming discontinuous, on the edge of the shroud.

Practically the last step in qualifying the CMC inner shrouds for use in the engine test was to measure the resonant modal frequencies of the shrouds to ensure compliance with the required margin to the blade passing frequency. Past experience had indicated that the GEN2 CMC material with Type-S fiber posed a higher risk in terms of frequency margin. Past measurements had revealed that when manufactured with the same number of plies, the shrouds made of GEN2 material often were less thick than their GEN1.1 counterparts and also had a tendency to have lower elastic moduli. The combination of these factors had led to frequencies low enough that blade-passing margins were not met on occasion and shrouds were rejected.

As a result of this prior experience, two GEN2 shrouds were tested early in the qualification process. Both shrouds passed the standard for frequency margin, although they did exhibit slightly lower thicknesses and frequencies. As a result, all GEN2 shrouds were manufactured with two additional plies. After this manufacturing decision, 15 additional GEN2 shrouds with the additional plies were measured for frequency. All of these shrouds passed the frequency margin requirements and in general, showed improved consistency of frequencies in comparison to past experience.

In general, past experience with frequency requirements for shrouds made of GEN1.1 material had shown fewer problems; however, there had been limited instances of rejection on the basis of frequency margin. Rather than perform modal testing on all of the GEN1.1 
shrouds, only those shrouds that already had some other marginal quality control indicator were evaluated. Thickness deviation, low modulus, and infra-red NDE indications were used to identify shrouds that were selected for resonant frequency measurement. Twentytwo (22) of the GEN1.1 shrouds were identified for frequency test, and all of these targeted shrouds passed the frequency margin requirement. In general, frequency margins for this set of shrouds were significantly improved when compared to the set of shrouds installed in engine test \#2 at JEA.

\subsubsection{Fabrication of Metallic Hardware for Engine Test \#3}

Fabrication or acquisition of all the other hardware for the shroud system, including the outer shroud blocks, damper blocks, springs, seals, attachment pins and all instrumentation was the responsibility of GE Energy. The only issue experienced in the fabrication of this hardware was the need to find an alternate alloy for the damper blocks.

In all the previous rig and engine tests the preferred damper material was an oxidedispersion strengthened (ODS) FeCrAlY alloy with a trade name of PM2000. Unfortunately the supplier of this alloy decided to remove it from the market due to low demand, requiring the identification of a suitable substitution. The prior damper material was chosen mostly based on oxidation resistance, and the specific ODS alloy was chosen using creep resistance as a secondary factor. The design of the damper blocks had changed since this original material selection process such that creep of the damper was much less of a concern. Thus chemically similar FeCrAlY alloys with good oxidation resistance but lower creep resistance than PM2000 were likely damper material candidates. After consideration of several candidate alloys with regard to oxidation resistance, mechanical properties, and material availability, Kanthal-A was selected as the replacement damper material. A sufficient quantity of this material was procured and the needed damper blocks fabricated along with the other metallic hardware.

All metallic hardware, including the outer shroud blocks, damper blocks, damper spring loading mechanisms and inner shroud attachment features, were all completed and/or delivered to GE Energy by January 2010. Instrumentation was applied to four of the outer shroud blocks, and then all shroud system parts were transported to CCP for final assembly. Final assembly of the shroud blocks was done at CCP during the first two weeks of March. There were no anomalies noted during assembly with all of the shrouds fitting into the outer

shroud blocks within desired tolerances. All of the shroud blocks, along with the spare CMC shrouds and metallic hardware, were then packaged and shipped to the anticipated engine test site on March 12, 2010.

\subsubsection{Performance of Engine Test \#3}

The purpose of this task was the actual performance of field engine test \#3. In this task GE was to identify an appropriate engine test site, with preference given to base-load installations, to acquire all necessary approvals from the engine operator to allow for CMC shroud testing to be conducted for up to 24,000 hours, to supply the operator with the preassembled outer shroud blocks, along with all necessary instrumentation, and to work with the operator to oversee the installation of these shrouds into the engine. GE would then 
monitor the start-up and operation of the engine, and perform periodic borescope inspections of the shroud system as allowed by the engine operating schedule.

The search for a suitable engine test site was started in early 2006, when engine test \#3 was still intended to be a partial shroud set test. Although a population of shrouds with sufficient quality for use in an engine test had been fabricated by early 2007 , no acceptable engine test sites had been identified. Consequently the planned start of engine test \#3 was pushed from the Spring of 2007 to the Fall of 2007, and then to the Spring of 2008.

As discussed previously, one of the issues hampering the selection of a test site was that the utility engine operators were reluctant to participate in this test without GE providing significant economic incentives. Since the plan at that time was that the shroud test would be a rainbow test, meaning that only a portion of the $1^{\text {st }}$ stage shrouds would be replaced, there would be no real engine performance benefit to be realized by the engine operator. Also, there was a perception that running such a test with a new material system would pose a risk to the test engine and its uninterrupted operation. Consequently the utilities were requiring quite substantial financial incentives from GE for allowing the CMC shroud hardware into their engines. This difficulty in obtaining permission from the utilities to perform the shroud test was one of the reasons GE Energy decided to go to a full shroud set test instead of the planned partial set test.

The change in the scope of the test necessarily further delayed its start while additional shroud hardware was being prepared, as described in the previous section. It was not until mid-2009 that sufficient progress had been made on the fabrication of the shroud test hardware that active negotiations with utility engine operators were pursued. A promising test site in South Carolina was identified, and by late 2009 the shroud engine test was being planned for this site.

Informal negotiations between the GE site representative and the generating station management started in November of 2009. The site management team from the utility seemed very positive about the prospect of hosting the CMC shroud test. The major point of negotiation had to do with who would bear the liability should a shroud failure occur and cause damage to the other turbine hardware. GE Energy accepted the responsibility for repairing any damage that might occur to the gas turbine as a result of the test, opening the door for a formal agreement.

On February 9 a formal presentation was made to the utility generating site management and to the utility management team. Verbal feedback at the time was very positive and the utility requested that GE submit a formal proposal to cover the shroud test activities. GE agreed that a formal proposal would be submitted within five days. Unfortunately the final GE internal legal review of the proposal was substantially delayed such that the agreement was not submitted to the utility until March 19. The schedule for the outage dictated that an agreement had to be reached by March 23 in order for work to proceed with installation of the CMC shrouds. The utilities management, having been given only 2 business days to review and accept GE's proposal, was not comfortable with having to make the decision 
that quickly. Consequently they rejected GE's proposal, and the CMC shroud test could not occur at the planned site.

During the run-up to this decision the shroud technical team at GE proceeded as though an agreement would be reached. As described above, the shroud blocks were assembled and shipped to the utility site, and 3 members of the shroud team traveled to the site between March 16 and March 22 in order to make preparations for the shroud test. The assembled shroud blocks were subsequently shipped back to GE Energy in Greenville, SC, to await the next suitable engine test opportunity.

There were no other prospects for a Spring 2010 engine test start at another utility site. All remaining units with a planned Spring outage were peaker units, which would not give the desired hours of exposure. Also, there was not enough time to negotiate a firm agreement with any of the remaining hot-gas-path overhaul customers prior to the need for summer peak-service operation. Consequently the start of engine test \#3 was delayed at least until the Fall 2010 outage season, which was beyond the end date of the cooperative agreement with DOE.

In spite of this test being delayed past the end of this DOE program, GE remains committed to performance of this field engine test. GE Energy has continued to search for an available test site with an appropriate base-loaded ( $>6,000$ hours per year of operation) 7FA-type engine. Currently the leading candidate test site is in Texas, but the outage for this engine is not scheduled until January of 2011. Technical negotiations have been initiated and a representative of the CMC shroud technical team made a site visit in June of 2010.

GE is preparing agreement documents for this test site, while at the same time still looking for suitable engine sites with a Fall 2010 outage. In either case the shroud installation will fall beyond the completion of this cooperative agreement, so all preparations and negotiations for the new test site, shroud installation, test monitoring and post-test characterization will be done using GE internal funding. 


\subsection{Combustor Activities}

An effort to design, fabricate and field test an MI-CMC combustor liner system was part of the original AMAIGT program proposal; however, that part of the program was not initially approved because of resource constraints. In 2002 a contract modification was approved which included the development of MI-CMC combustor liner components, with the target engine being a 7FA-class machine. A further contract modification was made in 2004 that included an effort on the fabrication a combustor liner for engine testing by Solar Turbines under their Ceramic Stationary Gas Turbine (CSGT) program. The work performed on these two components are described separately below.

\subsubsection{FA Combustor Development}

Using the lessons learned from work on the shroud component performed up to that time, the combustor liner program plan was slightly modified compared to the original AMAIGT proposal. However, the overall technical objectives of the program remained the same:

- Design a reliable, cost-effective combustor system containing Melt Infiltrated-Ceramic Matrix Composite (MI-CMC) with the necessary metallic support structures.

- Validate the combustor system durability and design robustness by rig and gas turbine engine testing.

The development effort involved a team of turbine hardware designers from GE Energy and GE Aviation with materials scientists from GE GRC and GE Energy. Materials scientists from Oak Ridge National Lab (ORNL) were also to be involved in the post-test characterization of the liners from both the rig and engine test. A block diagram of the Work Breakdown Structure for this effort is shown Figure 3-259.

As shown in Figure 2-5, the combustor development tasks of the program started with the conceptual design process in early 2002. Work on the development of a 7FA-sized CMC combustor liner system continued for $\sim 2$ years until early 2004. It was at this point in the program that GE Energy management decided to postpone further development of The CMC 7FA combustor. The successful preliminary field engine testing of the shroud component in 2002-2003 had resulted in an accelerated schedule for shroud commercialization. On the other hand, the potential benefits from utilization of a CMC combustor liner, though substantial, were not enough to offset the high cost of the CMC liner components. The difficulty experienced in the fabrication of a complete CMC liner, to be discussed in the following sections, had also indicated that further process improvements would be needed to successfully fabricate such a large part with high yields. The added resource needs of the accelerated shroud program, along with the problems mentioned with the 7FA combustor liner component, necessitated that the work on the 7FA combustor liner be discontinued. However, fabrication and testing of the smaller, inner combustor liner for one of the Solar Turbines CSGT engines did continue, as will be described in section 3.2.2. 


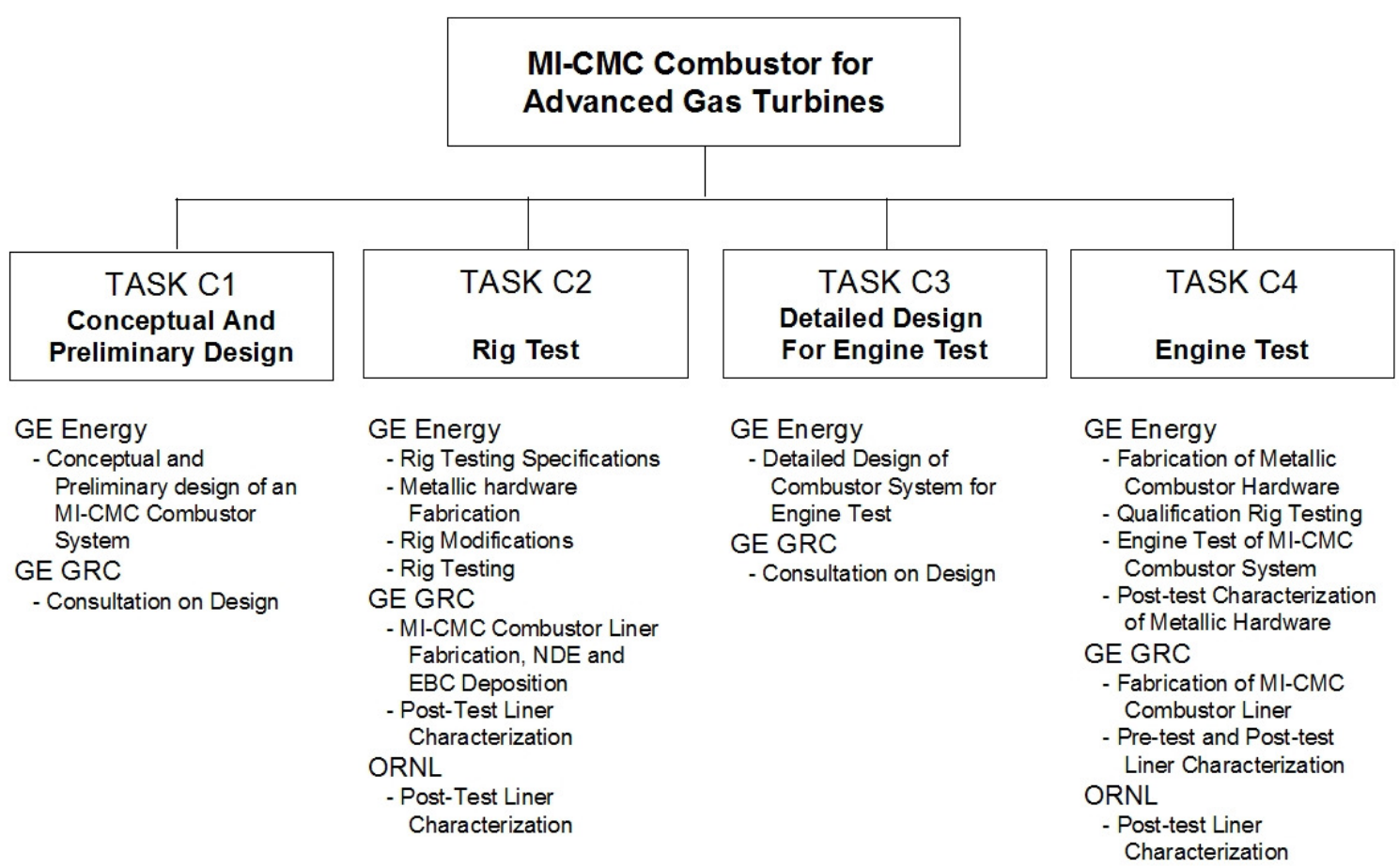

Figure 3-259. Work Breakdown Structure for the 7FA MI-CMC Combustor Liner Efforts

\subsubsection{Task C1.1 - Conceptual and Preliminary Design and Task C3 - Detailed Design}

Task 1 efforts of the combustor part of the program were directed at the development of the conceptual and preliminary designs of the MI-CMC-containing combustor system. This work was built on previous design experience gained in the CFCC and AMAIGT Shroud programs, and made use of GE's proven Design For Six Sigma (DFSS) methodology. GE GRC, acting as the MI-CMC fabricator, consulted with GE Energy throughout the design process. Material properties data for prepreg MI-CMCs were available from the CFCC and AMAIGT shroud programs and were utilized during the design process.

Various concepts for the liners were debated early on, including using a full, one-piece liner, a liner divided into segments, a metal liner with CMC "tiles" on the inner surface, and others. All of the segmented and tiled designs were rejected because of the difficulty in developing hot seals between the individual segments, and because of the added complexity of the CMC and metallic hardware needed to allow for attaching and locating multiple $\mathrm{CMC}$ pieces. Consequently the majority of the design effort was directed to a single, fullsized liner concept. Although four variations of "hybrid" CMC-metallic liner structures were considered, where the cooler part of the liner would be metal and the hotter part $\mathrm{CMC}$, the thermal expansion mismatch between the two materials made such an approach highly unlikely to be successful.

The overall geometry of a full 7FA combustor liner is relatively simple, as shown in Figure 3-260. It is essentially a tapered cylinder roughly 39.4 " (1m) long with a diameter of 
roughly $18 "(0.46 \mathrm{~m})$ at the head (fuel nozzle) end and a diameter of roughly $14 "(0.36 \mathrm{~m})$ at the aft end (feeding into the transition piece). The major design difficulties are the attachments and seals between the CMC liner and the metallic support hardware, and the presence of several penetrations into the liner (for flame sensors, cross-fire tubes, etc.). The three main areas requiring some design innovation, namely the attachment/seal at the head end of the liner, the attachment/seal to the transition piece at the aft end of the liner, and the liner penetrations/attachments, were considered as individual elements. Overall eight design concepts for the head end attachment, eight for the aft end attachment, and six for the penetrations were developed and evaluated. Preferred concepts for each feature were selected based on how well they could accommodate the thermal strain differences and how well they limited potential wear issues between the CMC and metal. The selected concepts for both the head and aft end seals were based on modified hula seals, with the aft seal incorporating some cooling leakage. The preferred penetration design involved clamping the metal attachments onto a raised lip in the CMC surrounding the penetration hole.

The use of CMC as a combustor liner is a radically new approach for GE Energy, entailing many new material capabilities and limitations, especially with regard to attachments and seals. Consequently the Chief Engineers' Office felt that more regular interactions with the design team would be necessary than for a normal metallic alloy liner design. Consequently the "Conceptual Design Review" (CDR), which is a normal step on the overall design approval process at GE Energy, was expanded into three separate reviews, followed by a single "Preliminary Design Review" (PDR).

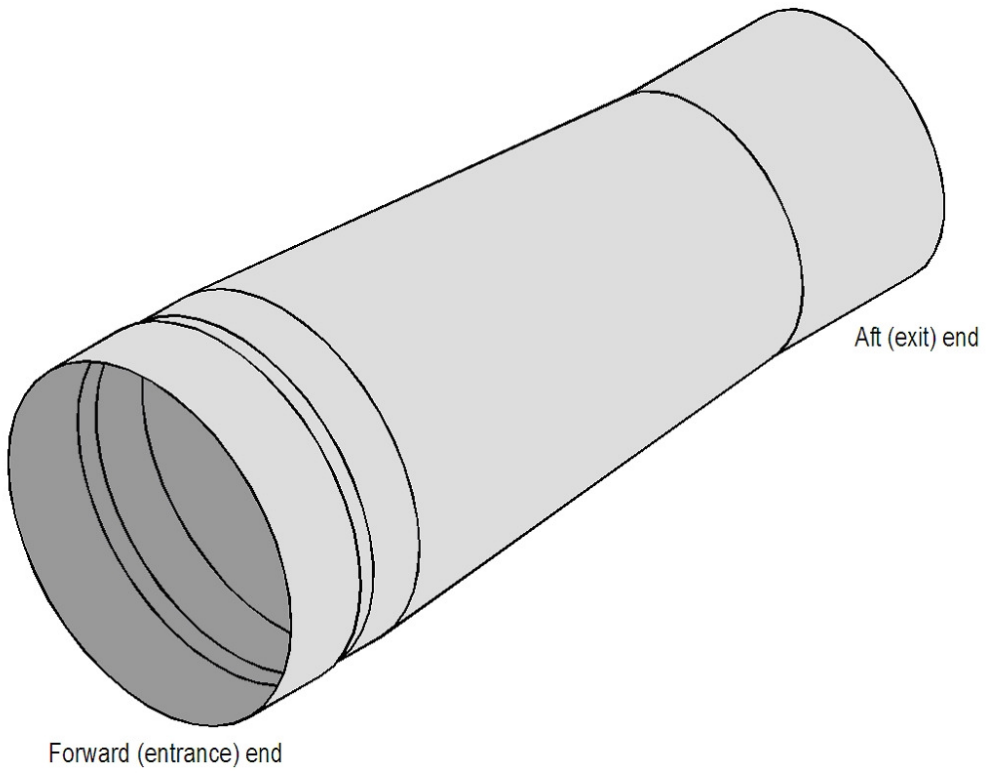

Figure 3-260. Simplified model of the 7FA CMC combustor liner concept used in Conceptual Design Review \#1. 


\subsection{Conceptual Design Review \#1}

The $1^{\text {st }}$ CDR was held with the GE Energy Chief Engineers' Office on May 22, 2002. Very preliminary stress and temperature calculations were done on the simplified geometry shown in Figure 3-260. Gas temperature and heat transfer coefficient maps were taken from a typical metal liner analysis, which are consistent with the current metallic liner geometry, attachments and impingement cooling hardware. The predicted temperatures on a $72^{\circ}$ sector (consistent with the fuel nozzle cup spacing) of the CMC liner are shown in Figure 3-261. Overall the predicted EBC and CMC temperatures were well below the $2200^{\circ} \mathrm{F}\left(1200^{\circ} \mathrm{C}\right)$ material limit, indicating a substantial potential for reduced cooling of the liner, and consequent reduction in the combustor pressure drop. CMC stresses calculated in this analysis were also all below the material design limits, again indicating significant margin for optimizing the pressure drop of the combustor design.

Although not shown on the initial combustor solid models, each combustor liner has four penetrations to accommodate two crossfire tubes, a flame detector and a spark plug. Each of these penetrations would require a metallic adapter attached to the liner in order to interface with the appropriate hardware. Several concepts were developed for forming these penetrations and attaching the desired metallic hardware. The primary concept is shown in Figure 3-262, where a hemispherical "dimple" would be fabricated on the CMC liner, which would then be machined off leaving a hole with conical edges extending outward from the liner surface. The metallic adapter, or "ferrule", would consist of two pieces, one held against the ID of the liner and the other against the outer diameter (OD), and then the pieces would be welded together effectively clamping onto the liner wall. The intent of the dimple in the CMC liner was to protect the inside piece of the metallic adapter from direct impingement of the combustion gases.

A buckling analysis was performed to set the wall thickness of the liner. Although a wall thickness of 0.1 " $(2.5 \mathrm{~mm})$ was determined to be able to meet the design requirements, a wall thickness of 0.125 " $(3.2 \mathrm{~mm})$ was selected since it provided $2 \mathrm{X}$ margin of the design requirement, and even had increased margin compared to the existing metallic liners.

The $3.2 \mathrm{~mm}$ wall thickness was then used to do a preliminary modal analysis of the liner. The modal frequencies for a CMC liner were calculated both without and with the influence of the aft hula seal, and were compared to similar modal frequencies calculated for metallic liners. The results of the modal analyses are shown in Figure 3-263. Due to the higher modulus and lower density the CMC liners had higher modal frequencies than the metallic liner. The presence of the hula seal is seen to increase the effective stiffness of the liners, as the resonant modes are shifted to higher frequencies with the hula seals included in the analyses.

The red crosshatched areas in Figure 3-263 represent the frequency ranges where modes should be avoided due to the presence of known vibration drivers (mechanical vibration at $60 \mathrm{~Hz}$ and acoustic combustion dynamics at 90,125 and $230 \mathrm{~Hz}$ ). Clearly there are 
frequencies of the $\mathrm{CMC}$ liner within the undesirable ranges, but the metallic liners also show undesirable resonances and the $\mathrm{CMC}$ liner is no worse in this regard.
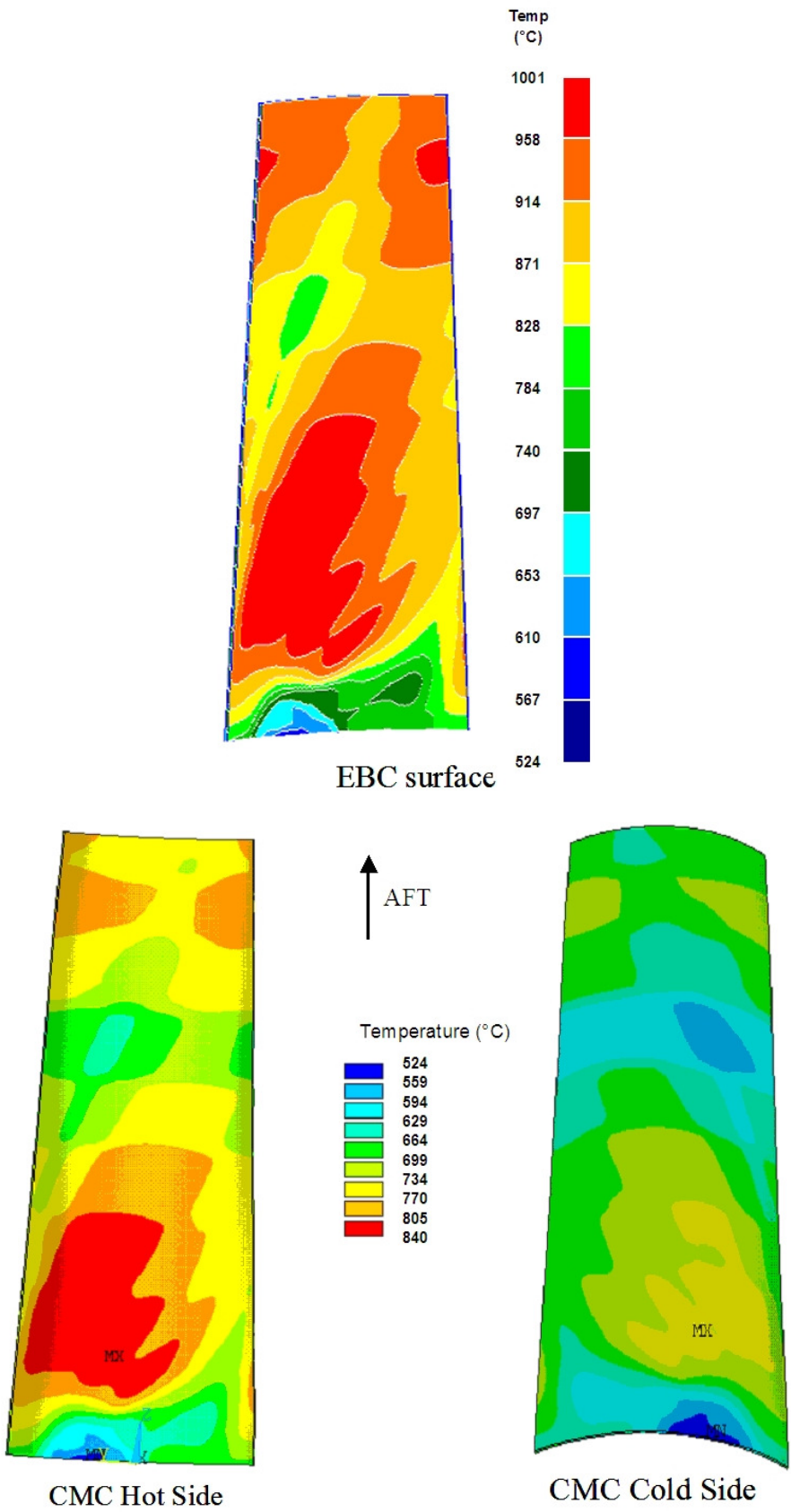

CMC Cold Side

Figure 3-261. Temperatures of the EBC coating and CMC liner surfaces predicted from the $1^{\text {st }}$ round of FEA using the heat surface transfer coefficient and gas temperature boundary conditions from the existing metallic liner design. 


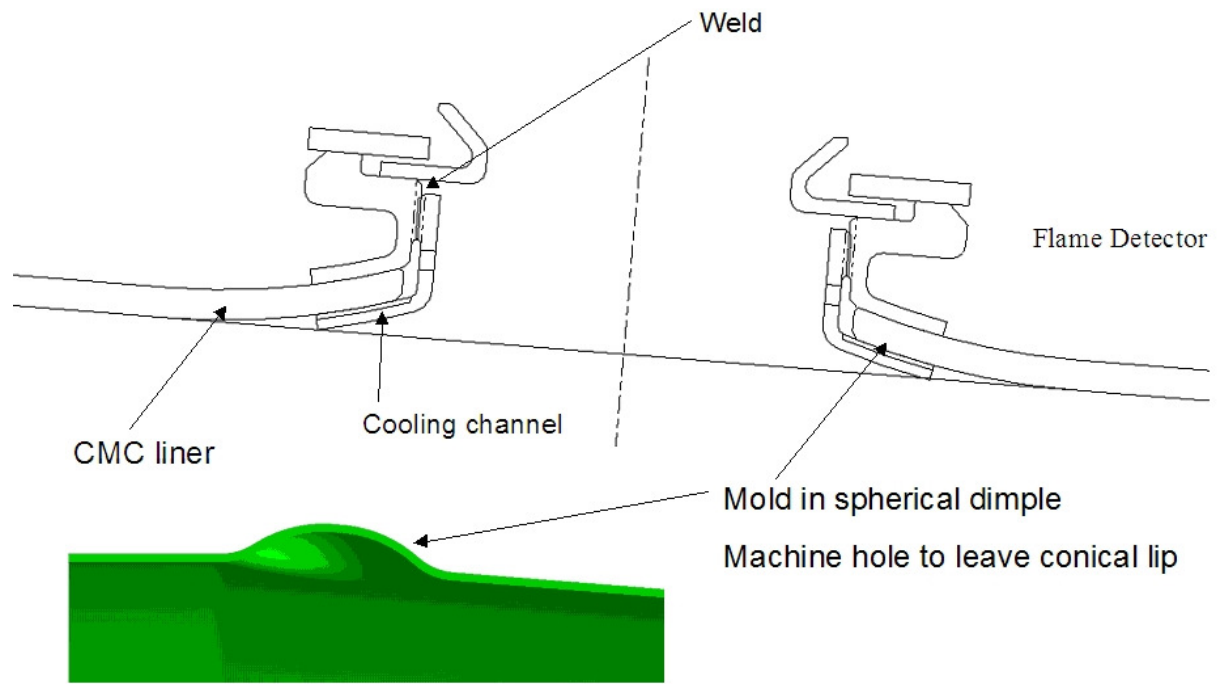

Figure 3-262. Schematic of a fabricated "dimple" on the CMC combustor liner surface and how the metallic "ferrules" for the cross-fire tubes, flame detector and spark plug would be attached to the liner wall.

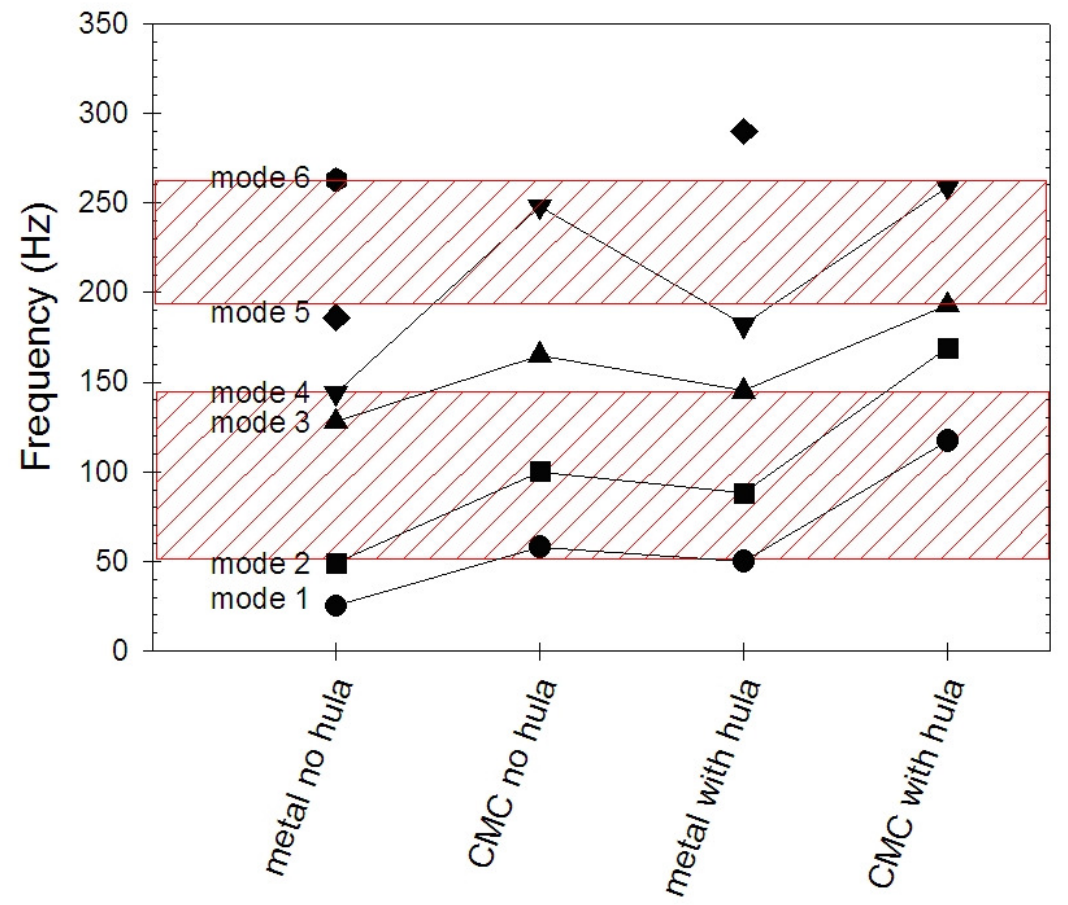

Figure 3-263. Initial calculations of resonant frequencies for the first six modes of metal and CMC combustor liners both without and with the effects of the aft hula seal. The red hatched areas are ranges of modal frequency that are normally avoided since vibration driving forces are present in these frequency ranges. 
The result of the $1^{\text {st }}$ CDR was that the Chief Engineers' concurred that the initial temperature/stress analysis results were promising enough to warrant further detailed analysis and optimization. They also approved of the attachment concepts selected by the design team. The preliminary design of the CMC liner was also approved so that the design and acquisition of the lay-up tooling for liner fabrication could be started.

\subsection{Conceptual Design Review \#2}

Additional design refinement was done in preparation for the $2^{\text {nd }}$ CDR, held on July 11 , 2002. The metallic impingement and flow sleeve outside of the combustor liner was modified to reduce the pressure drop of the combustor. Computational fluid dynamic (CFD) and flow net analyses were then performed to determine the gas velocity and pressure outside of the liner, and these results were used to develop a map of surface heat transfer coefficient on the outside surface of the liner. Previous metallic combustor CFD analysis results were used to determine the local gas temperature and heat transfer coefficient on the inside of the CMC liner as shown in Figure 3-264. The solid model of the liner itself was further modified to include the penetration holes and attachments, and the new external boundary conditions were mapped onto the liner model for FEA.
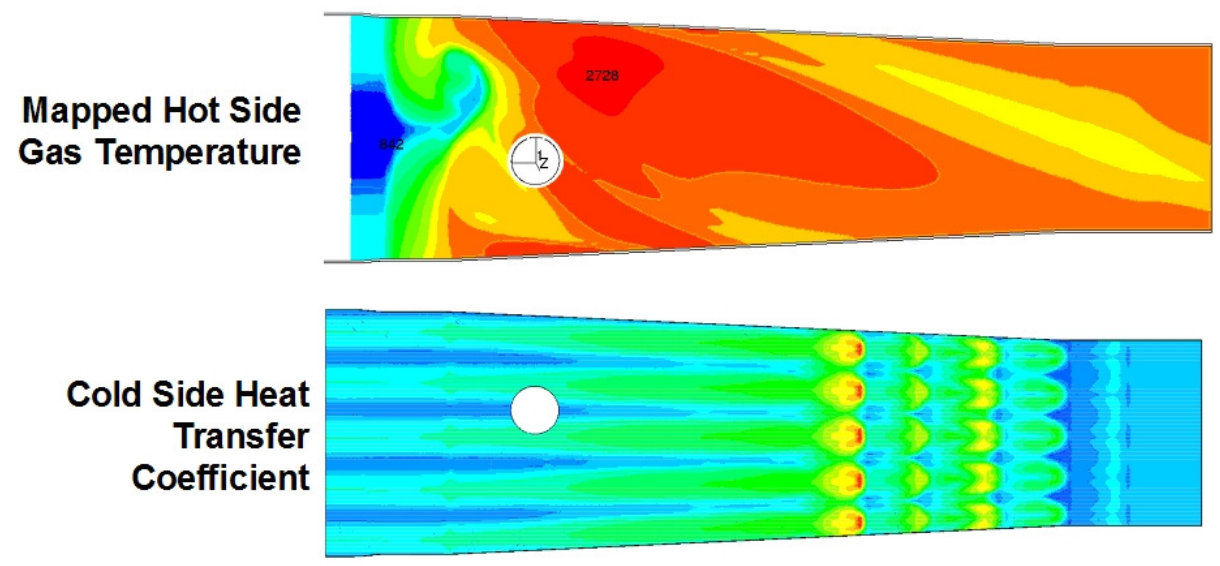

Hot Side Heat

Transfer Coefficient

Figure 3-264. Patterns of the combustion gas temperature and surface heat transfer coefficients used for the FEA of the CMC combustor liner for CDR \#2.

The liner temperature predictions from the FEA using the boundary conditions shown in Figure 3-264 are shown in Figure 3-265. The overall temperature distribution is a combination of the gas temperature map and the heat transfer coefficient map. The maximum EBC surface temperature was $2161^{\circ} \mathrm{F}\left(1183^{\circ} \mathrm{C}\right)$, with the maximum $\mathrm{CMC}$ 
temperature being $2010^{\circ} \mathrm{F}\left(1099^{\circ} \mathrm{C}\right)$. Both temperatures were within the expected functional range of the GEN1 EBC and GEN1 CMC materials, and indicated that a CMC combustor system with reduced liner cooling and reduced pressure drop was feasible.
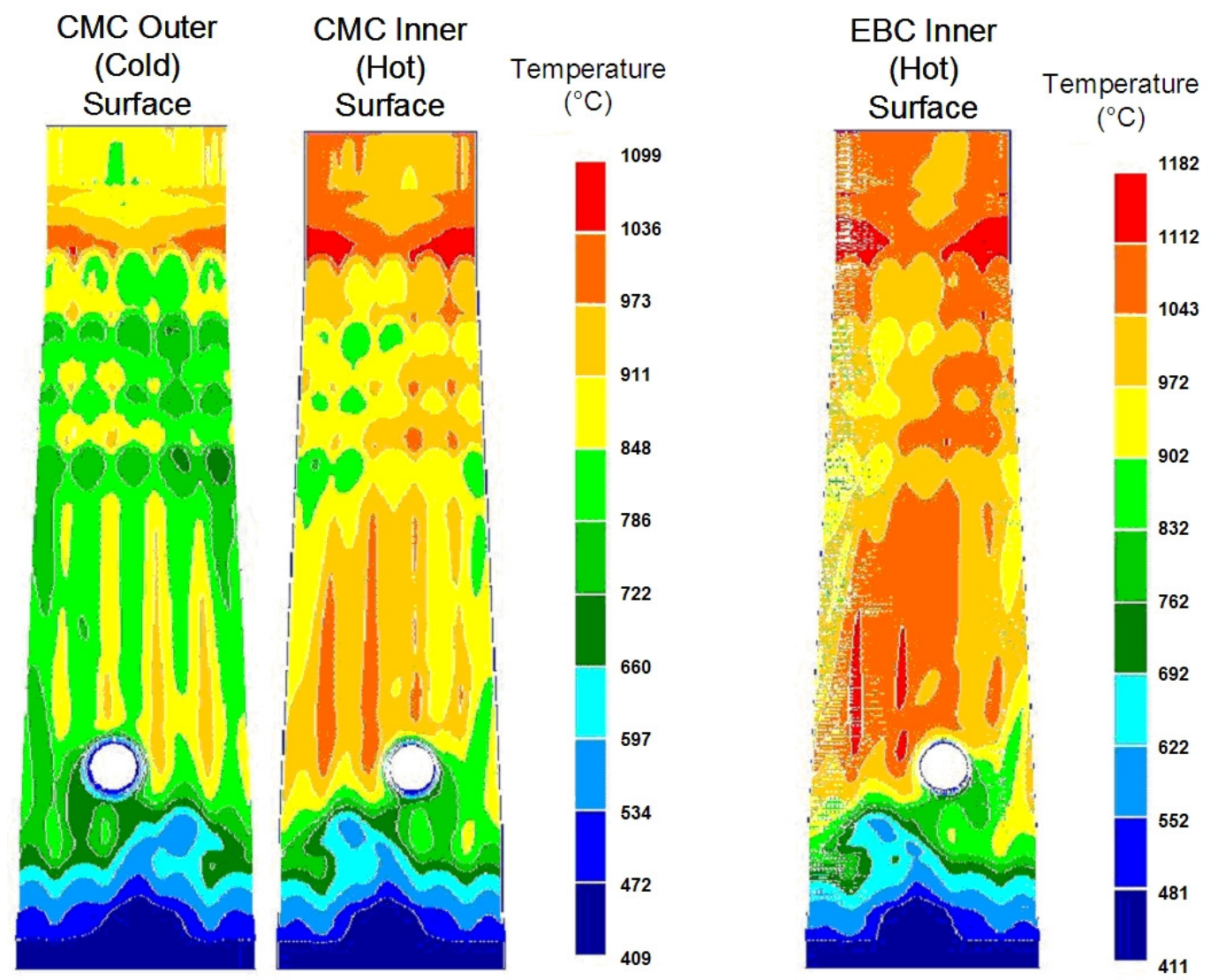

Figure 3-265. Temperature predictions of the CMC liner surface and EBC coating surface temperatures from FEA using the boundary conditions in Figure 3-264.

As might be expected, the thermal gradients shown in Figure 3-265 caused significant thermal stresses within the liner, as shown in Figure 3-266. The maximum stresses typically occur near the liner penetration hole, but field stress levels away from the holes were also above the design limits.

Stresses at the penetration holes were unusually high due to the attached metallic ferrule assembly acting as a heat sink and significantly cooling the inside edge of the holes. Figure 3-267 shows the predicted temperature distributions through the cross-over tube ferrule assembly that would be attached to the liner at the penetration hole. As can be seen, the majority of the ferrule is relatively cool since it extends outward into the backside compressor discharge flow, thereby drawing heat away from the liner. In the first case a small amount of leakage air was allowed between the ferrule and the CMC liner in order to cool the portion of the inside the liner. The temperature distribution in the liner around the penetration hole for this case is shown in the center diagram of Figure 3-267, and shows 
the very steep thermal gradient formed at the hole edges due to this cooling effect. However, even if the leakage air is totally blocked so that there is no active cooling of the hole edges, just the thermal conduction through the cross-fire tube ferrule is sufficient to cause a significant gradient at the hole edge, as shown in the right-most diagram of Figure $3-267$.
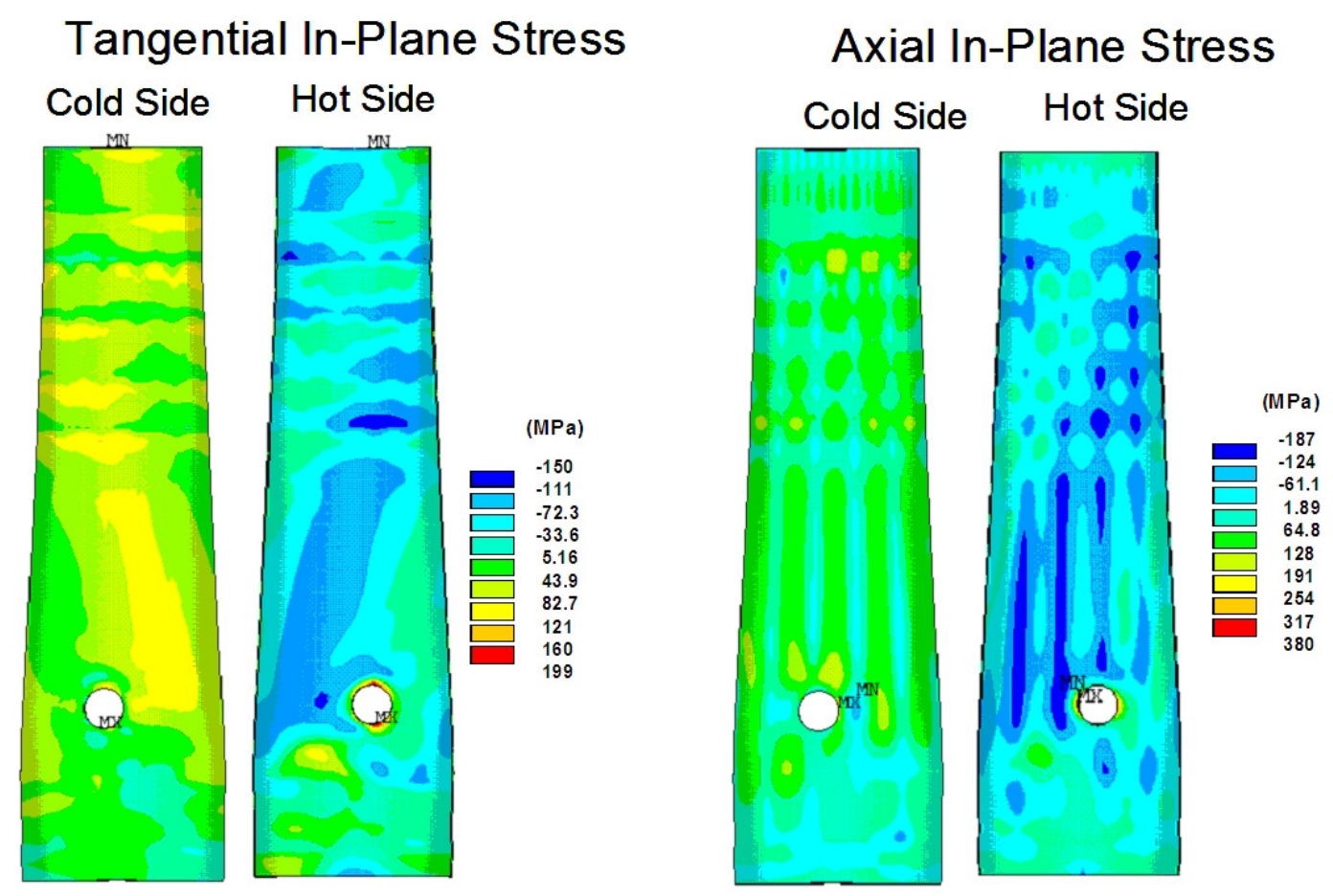

Figure 3-266. FEA predicted in-plane stresses of the CMC liner based on the temperature distribution shown in Figure 3-265 and gas pressure loads.

The effect of these radial thermal gradients at the penetration hole locations is to generate tensile thermal stresses at the hole edges. FEA predictions of the in-plane stresses around the cross-fire tube hole are shown in Figure 3-268. While the stress levels are substantially higher for the case where cooling was allowed, even in the case of no cooling from air leakage the stress concentrations exceeded the in-plane allowed stress values.

The above results were presented to the Chief Engineers' Office at the $2^{\text {nd }}$ CDR on July 11, 2002. Overall the reviewers were pleased with the progress and suggested several areas to focus further design work. Particular areas of concern were the additional stresses caused by attachments and seals, especially for the attachments at the liner penetrations. Considerable thermal and stress analysis work was subsequently aimed at defining the critical parameters controlling the thermal gradients and stresses around such penetrations. 

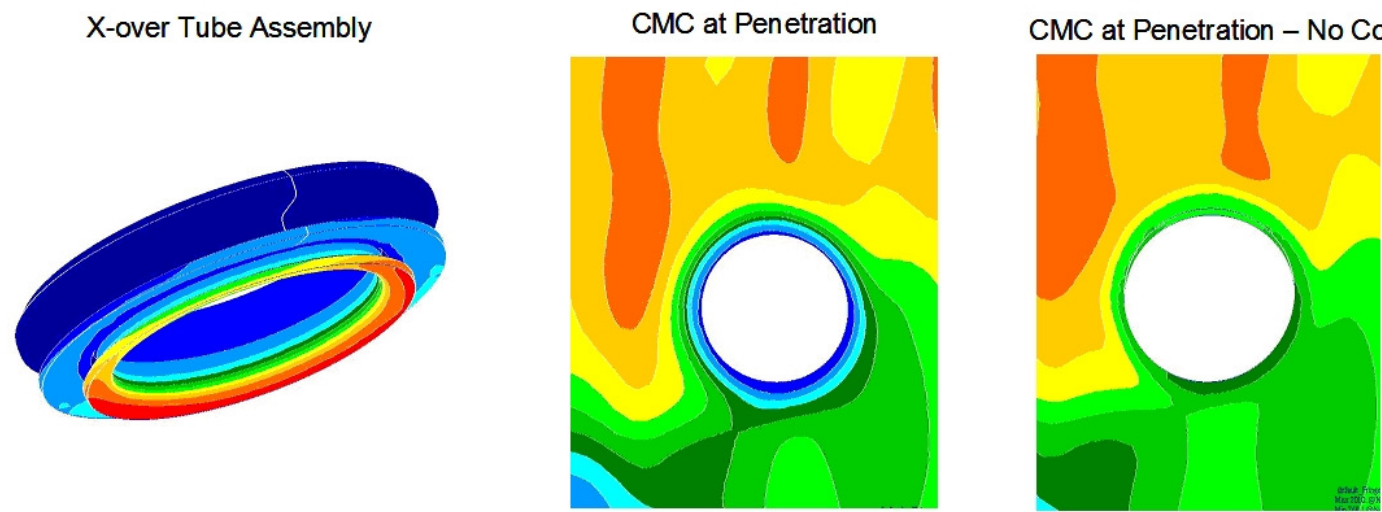

Figure 3-267. FEA predictions of the temperature distribution in the metallic cross-over tube ferrule assembly attached at the liner penetration (left), and of the temperature of the CMC liner at the penetration for the cases where heat loss through the crossover tube assembly is allowed (middle) or prevented (right).
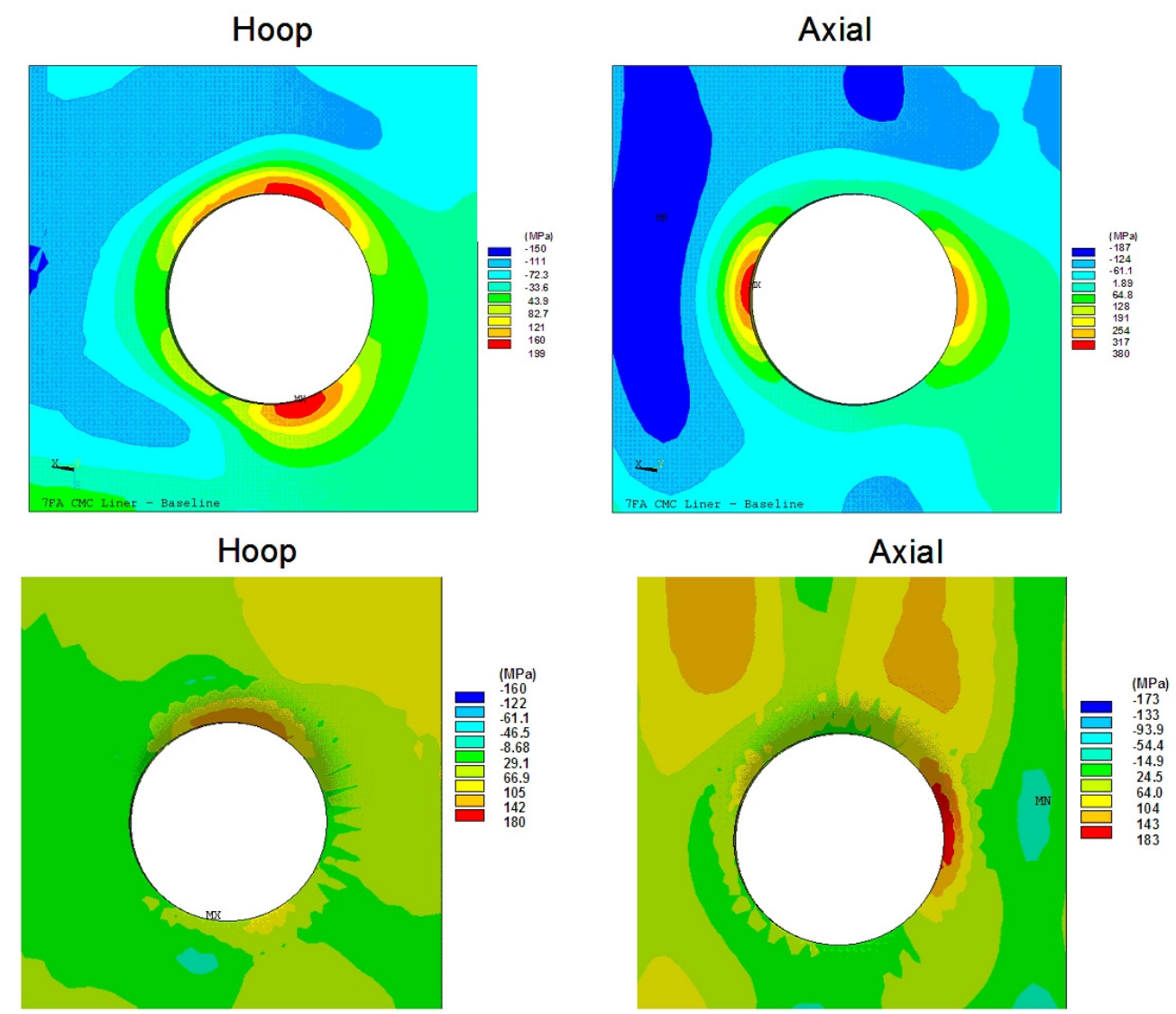

Figure 3-268. In-plane stress predictions for the region around the cross-fire tube penetration hole in the CMC liner for the cases where the cross-fire tube assembly is cooled with leakage air (top) and where no cooling from leakage air is allowed (bottom). 


\subsection{Conceptual Design Review \#3}

The $3^{\text {rd }}$ CDR was held with the GE Energy Chief Engineers' Office on October 28, 2002. The results of extensive FEA of the liners were presented, which were a refinement of, but still consistent with, the results described above for CDR \#2.

Further modifications were made to the flow sleeve, which is a metallic structure outside of the combustor liner that direct the compressor discharge air from the compressor plenum to the head end of the combustor. The flow sleeve controls the direction and velocity of the compressed air on the backside of the liner, and thus controls the liner convective cooling. The size and spacing of the inlet holes to the flow sleeve were changed to make the backside heat transfer coefficient more uniform than in the previous design, which helped to reduce the thermal gradients in the liner and the thermal stresses.

The positioning of the liner penetrations relative to the fuel nozzle orientation was also evaluated as a method of reducing liner stresses. As shown in Figure 3-264 the combustion gas temperatures and heat transfer coefficients at the inside surface of the liner vary considerably with location. This variation partly depends on the proximity to one of the five fuel nozzles at the head end of the combustor. By rotating the positions of the fuel nozzles relative to the positions of the penetration holes the temperature gradient also rotates, such that the holes can be at a higher or lower temperature location. The FEA was run for various orientations of the liner relative to the fuel nozzles and the orientation that gave the minimum liner thermal stresses was selected.

Even with the changes in backside cooling uniformity and optimization of the fuel nozzle positions, the FEA of the updated combustor system design predicted in-plane stresses in the liner away from penetration holes to reach a maximum of about $20 \mathrm{ksi}(138 \mathrm{MPa})$. This was higher than the initial design limit for the prepreg MI CMC material, but since the stresses were very localized their effect on the overall reliability of the liner need was not clear. The FEA stress predictions for the refined liner model are shown in Figure 3-269, where the color scales for the stress plots have been adjusted so that red areas represent stresses above the anticipated material allowables. The in-plane stresses all show regions where the stress exceeded the material allowable, but typically by only a small amount. Surprisingly, the interlaminar stresses were within the material allowables even though the allowable stresses are significantly lower for interlaminar stresses than for in-plane stresses.

As before, stresses near liner penetration holes, such as are necessary to accommodate cross-fire tubes and igniters, were typically even higher than the body stresses shown in Figure 3-269, but also more highly localized. The magnitude of the stresses around the holes were strongly dependent on the cooling effects of leakage air between the metallic ferrules and the CMC liner, and somewhat less sensitive to thermal conductance of heat from the CMC liner to the metallic structure. 

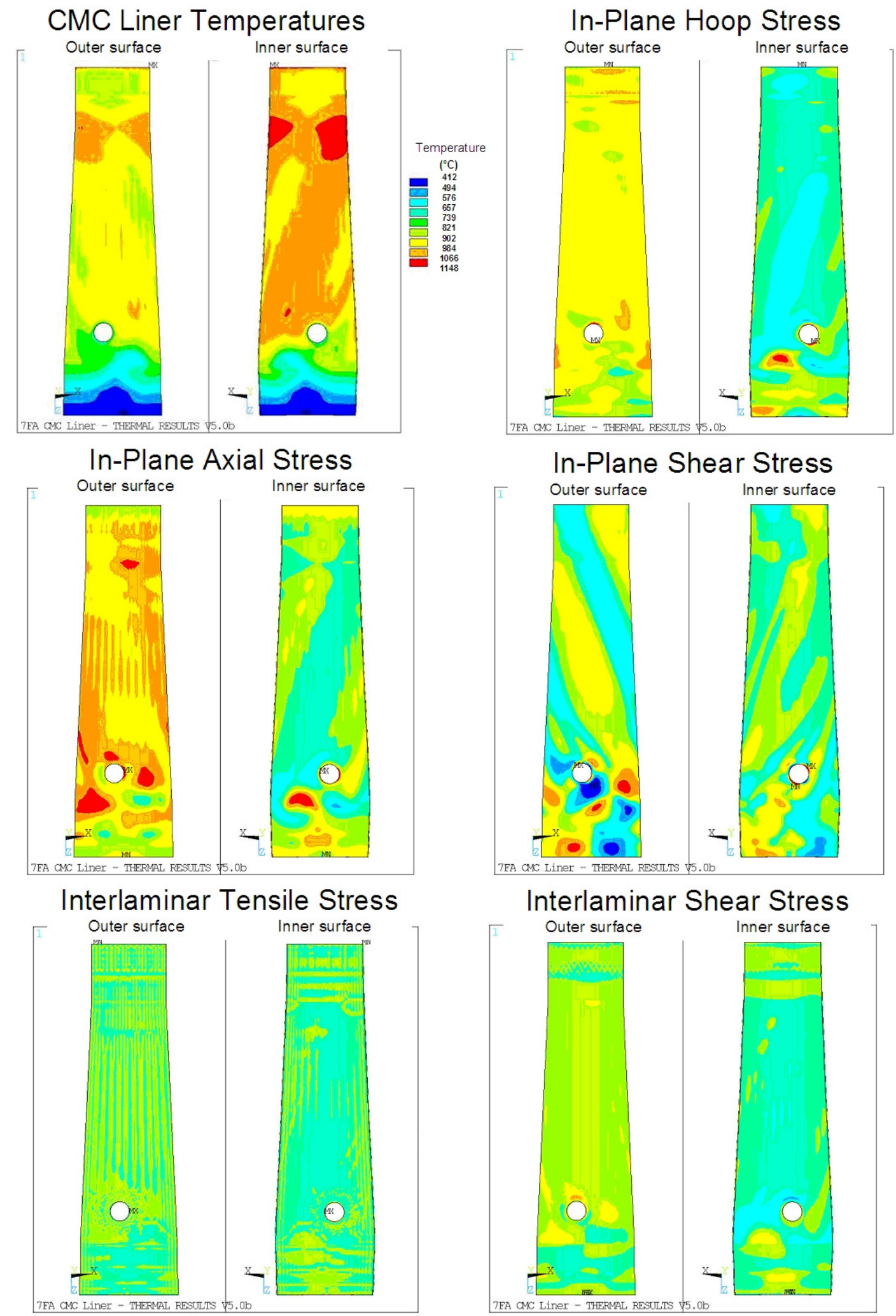

Figure 3-269. Temperature and stress results from the refined FEA presented at CDR \#3. 
Considerable effort was also directed to the analysis of several sealing concepts. (Seals are needed at the front and aft ends of the liner where it interfaces with the combustor cap and transition piece, respectively, to prevent uncontrolled air leakage into the combustor.) The primary sealing concept was to use versions of hula seals, which are normally used with metallic liners. However, since the seals could not be directly attached to the CMC liner they would need to be "reversed", meaning they would be attached (welded) to the outer surrounding metallic structures and then the seal fingers would be compressed outward during insertion of the $\mathrm{CMC}$ liner.

At the front end of the combustor the liner extends back further than the fuel nozzles, such that the location of the hula seal would be relatively cool (the interface temperature estimated from the FEA was $\left.\sim 430^{\circ} \mathrm{C}\left(800^{\circ} \mathrm{F}\right)\right)$. However, at the seal at the aft end of the combustor, between the combustor liner and transition piece, the liner is so hot that thermal conduction to the seal would overheat the metal. Consequently a corrugated metal sleeve was added to the inside of the seal to provide for a controlled leakage of the compressor air through the seal, thus cooling the metal to keep it from creep relaxing and/or oxidizing excessively. Even with this corrugated sleeve the maximum metal temperature at the metalto-CMC contact for the rear hula seal was estimated to be $\sim 1300^{\circ} \mathrm{F}\left(705^{\circ} \mathrm{C}\right)$ from the FEA.

Wear between the metal hula seal and the CMC combustor liner during thermal cuycling was a concern for both the forward and aft seals. Consequently wear testing was done between the proposed hula seal materials (X-750 alloy both with and without Stellite 6 wear coating) and bare and EBC-coated CMC. The test used was a reciprocating pin-on-plate test, and a schematic of the test equipment and specimen configuration is shown in Figure 3-270. Testing was performed at the anticipated maximum metal temperatures at the forward and aft hula seals, which was $430^{\circ} \mathrm{C}\left(800^{\circ} \mathrm{F}\right)$ for the forward seal and $\sim 1300^{\circ} \mathrm{F}$ $\left(705^{\circ} \mathrm{C}\right)$ for the rear seal. However, this latter temperature was at the limit of the wear tester capability and thus the real temperature of the couple during testing may have been up to $55^{\circ} \mathrm{C}\left(100^{\circ} \mathrm{F}\right)$ below this.

Results of the wear tests are shown in Figure 3-271, where the top two graphs show the wear data from testing at $427^{\circ} \mathrm{C}\left(800^{\circ} \mathrm{F}\right)$. In the top graph the indicated wear rates for the EBC-coated CMC samples were very high, and comparable to the worst case metal wear couples shown for comparisons. Even the wear rate of the X-750 pins was relatively high, which was due to the wear debris from the EBC acting as an abrasive grit on the X-750. In contract the wear rates for the bare CMC against X-750 were very low, and comparable to the very best metal couples. The middle graph of Figure 3-271 shows the wear data using the Stellite 6-coated pins. Here the wear rate of the EBC coating is still very high, although the pin wear rate was reduced by the Stellite 6 coating. The data for Stellite 6 vs. the bare CMC shows some of the lowest wear rates measured. 


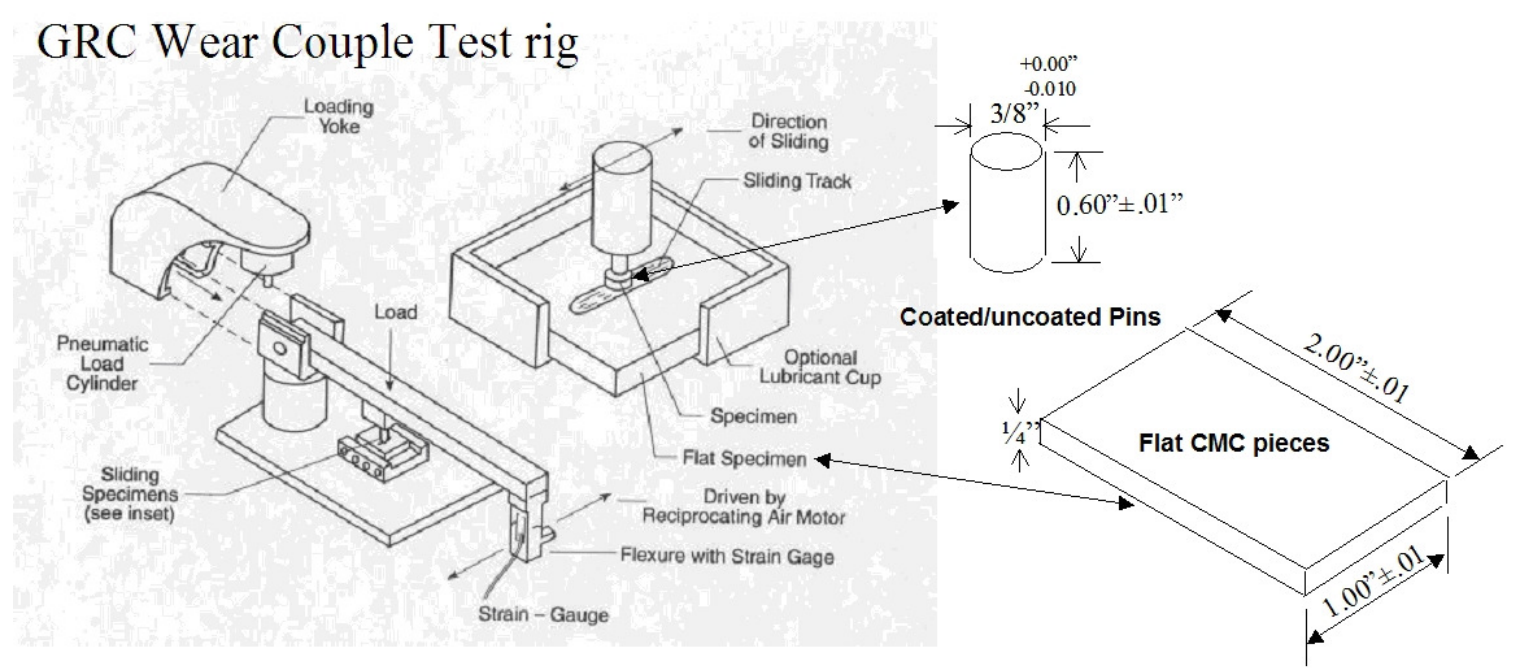

Figure 3-270. Schematic diagram of the wear test configuration used for testing wear of hula seal material pins against $\mathrm{CMC}$ and $\mathrm{EBC}$-coated CMC panels.

The bottom graph in Figure 3-271 shows the wear data measured at $650-705^{\circ} \mathrm{C}$, which was intended to simulate the conditions of the aft seal. Testing of EBC-coated CMC was not done at this higher temperature due to the very poor behavior of the EBC during the lower temperature tests. In this case the wear rates of the X-750, both with and without Stellite 6 coating, and of the bare $\mathrm{CMC}$ were very low, and even lower than typical wear-resistant metal couples used in similar applications. Since the bare CMC-to-X-750 wear rates were lower than for the metal-to-metal couples, and because these metal couples are known to last the desired 24,000 hours in turbine seal applications, it was expected that the hula seal concept using bare CMC against X-750 would also have acceptable wear life.

Preliminary modal analyses were also performed on the modified liner design. The effects of liner wall thickness and the addition of stiffening rings to each end of the liner on the modal frequencies and mode shapes were investigated. However, it was recommended that the modal response of the $1^{\text {st }}$ fabricated liner be measured in order to validate the accuracy of the models before any major design changes were made as a result of the modal analyses.

Overall GE Energy Engineering management was very pleased with the progress and completeness of the combustor design. Action items from the review were primarily directed at updating the FEA models with the most recent information regarding engine boundary conditions, testing the sensitivity of the predicted liner temperatures and stresses to engine operating conditions (full load vs. part load, uneven fuel splits, etc.), and better defining the ultimate material property requirements for the design. 

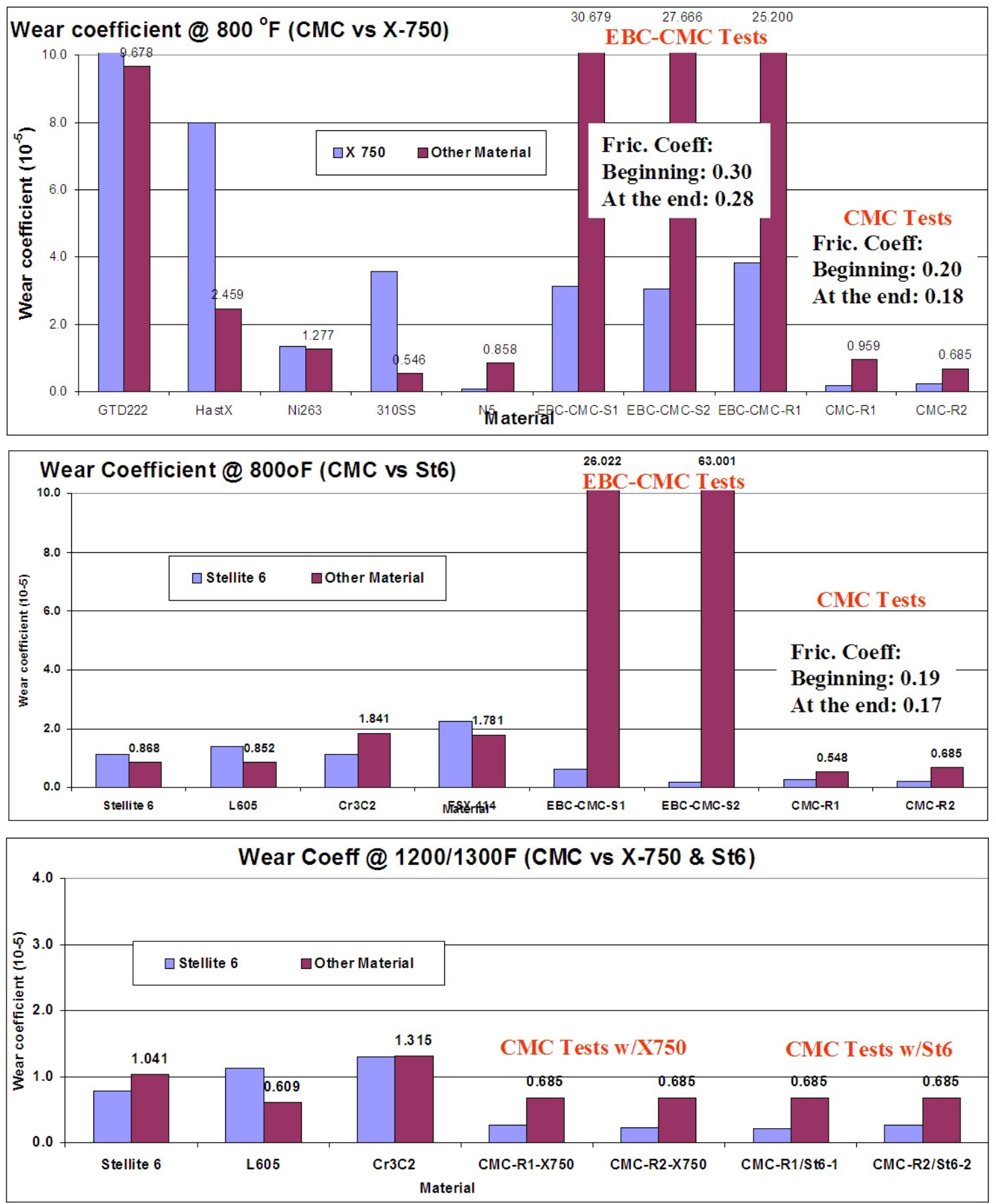

Figure 3-271. Results of the wear tests of hula seal metals (X-750 and X-750 with Stellite 6 coating) against various other materials, including bare and EBC-coated CMC: Top - wear of bare X750 against the other materials at $427^{\circ} \mathrm{C}\left(800^{\circ} \mathrm{F}\right)$; Middle wear of Stellite 6 coated X-750 again the other materials at $427^{\circ} \mathrm{C}\left(800^{\circ} \mathrm{F}\right)$; Bottom - wear of bare X-750 and Stellite 6 coated X-750 against bare CMC at $650-705^{\circ} \mathrm{F}$ $\left(1200-1300^{\circ} \mathrm{F}\right)$. 


\subsection{Preliminary Design Review}

Most of the design effort in preparation for the Preliminary Design Review (PDR) was concentrated on four issues: 1) attachments between the CMC liner and the metallic support hardware, 2) attachments needed for liner penetration features, such as cross-fire tubes, sparkplug holes, etc., 3) attachment and proper cooling conditions for seals between the $\mathrm{CMC}$ liner and the combustor head end, and the CMC liner and the transition piece, and 4) interfacing the metallic supports to the "standard" 7FA combustor casing. This later effort included further optimization of the "flow sleeve" in order to minimize liner thermal stresses and limit any over-temperature regions, and also to minimize the pressure drop through the combustor imposed by the flow sleeve. The calculated reduction in pressure drop due to the flow sleeve served as a verification of the pressure drop benefits to be derived from the $\mathrm{CMC}$ liner component. Initial calculations indicated a reduction in combustor pressure drop of $1.2 \%$ of compressor discharge.

The Preliminary Design Review for the CMC combustor was held on April 11, 2003. The final conceptual designs for the CMC liner, attachments, liner penetration fixtures, seals, and flow sleeve were presented to the GE Energy Chief Engineers. Minor modifications were suggested to a few of the metallic hardware features; however, final approvals were given for fabrication of the $\mathrm{CMC}$ liner for rig testing.

The final design for the CMC liner to be used for rig testing differed slightly from the earlier configuration described previously and used in the fabrication trials (to be discussed later). In the earlier design there were "bumps" molded into the liner at the locations of the penetrations for the cross-fire tubes, igniter, etc. that were added to keep the metallic ferrules at these penetrations away from direct combustion gas flow. More extensive thermal modeling of these features, however, had indicated that the metallic ferrules were adequately cooled on the backside of the liners by the compressor discharge air flow and did not need to be recessed outward from the liner ID. With the "bumps" removed the liner structure was less complicated and completely axisymmetric, which was expected to make tooling design and lay-up of the liner much easier.

Updated thermal and structural FEA showed only minor reductions in the liner body stresses compared to those shown in Figure 3-266. Although there were still small regions where the in-plane stresses exceeded the material allowable stress, the majority of stresses on the liner were significantly below the allowables. It was therefore decided to proceed to rig testing with this design and to examine the liner after testing to look for evidence of damage in the highly stressed regions.

Much of the discussion at the design review focused on the management of temperatures and stresses in several of the metallic structures that will be attached to the CMC liner. These attachments include the above-mentioned penetration ferrules and the aft seal between the liner and transition piece. One important aspect of the ferrule design is the gas leakage rate around the edges of the ferrules as this highly influences the temperature distributions around the penetration holes, and therefore the liner thermal stresses, as discussed previously. A parametric study looking at the liner stress levels as a function of 
leakage rate (expressed as an equivalent $\mathrm{CMC}$-to-ferrule gap height) was performed. Figure 3-272 summarizes the results of this analysis. As can be seen, the local stress around the penetration holes increases very dramatically with increased leakage around the ferrule. It should be noted that these maximum stresses occur right at the edges of the penetration holes and drop off to below $100 \mathrm{MPa}(14.5 \mathrm{ksi})$ within $5 \mathrm{~mm}$ of the hole edges.

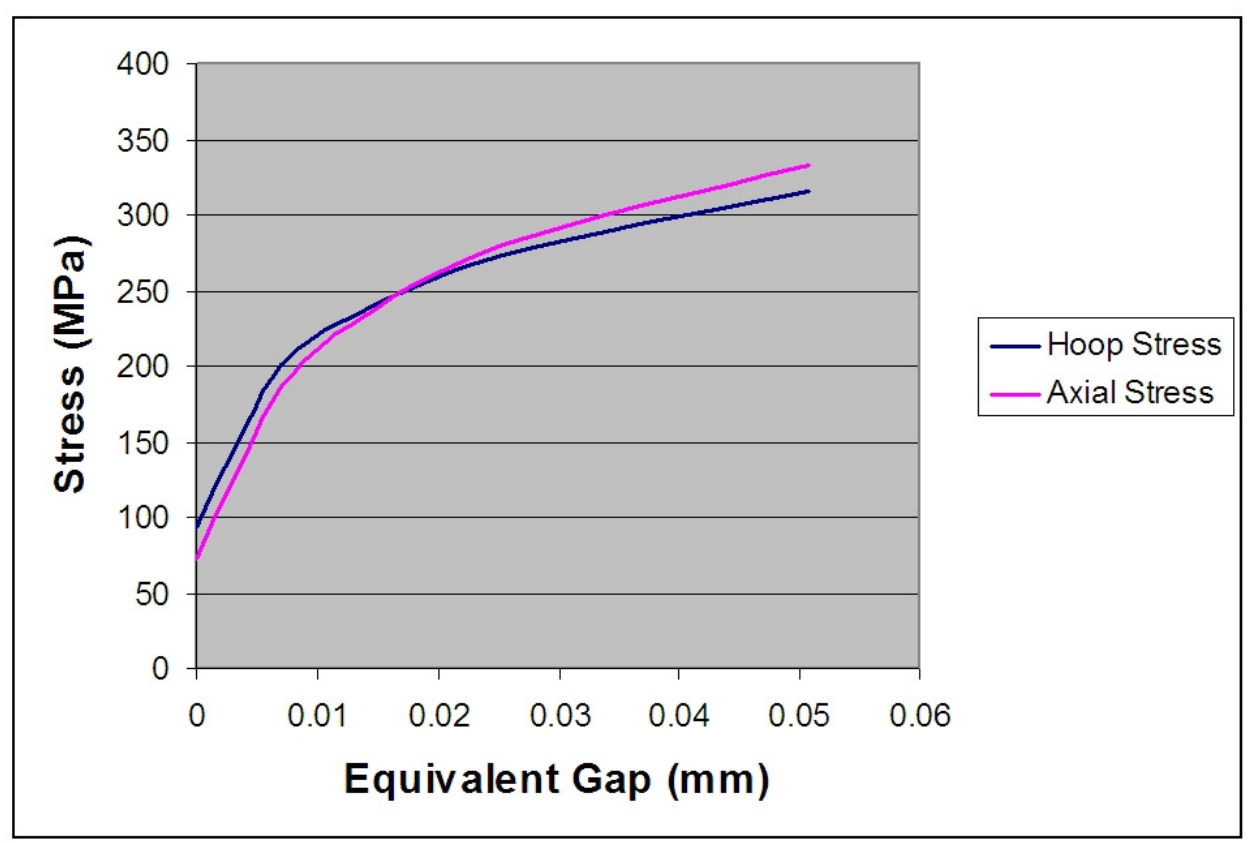

Figure 3-272. Calculated maximum tensile stress in the CMC combustor liner near a penetration hole as a function of the leakage rate (equivalent seal gap) of the ferrule seal.

The large increase in liner stress with ferrule leakage has made it necessary to add a seal between the CMC and metallic ferrule in order to get the equivalent leakage gap below $0.003 \mathrm{~mm}$. However, a hot seal system compatible with CMC and able to achieve such a small effective gap was not known at the time. After considerable discussion and consultation with GE's sealing experts, it was determined that a ceramic rope seal was the most promising technology for achieving such performance, but since quantitative measurements of rope seals against CMC surfaces had never been performed it was unclear whether such a seal could meet the performance goal. It was therefore necessary to perform seal leakage tests.

Seal leakage tests were performed, using a seal test rig at GE Aircraft Engines, in order to quantify the leakage to be expected around the penetration ferrules. Tests were performed using two different sized ceramic fiber rope seals and three different geometries of the seal groove. Tests were run against both bare and EBC-coated CMC, and leakage rates were measured as a function of clamping pressure and pressure drop across the seal. Figure 3273 is a graph of the results for one of the tests using a particular geometry of seal groove. 
The outside-to-inside pressure drop for a 7FA liner in the region of the penetrations is shown by the dashed vertical line on the graph of Figure 3-273. Extrapolating the leakage curves to this pressure drop indicates that as long as the seal is even moderately compressed an equivalent gap height on the order of $0.002 \mathrm{~mm}$ can be achieved. Compression load cycle tests on the seals, which simulate combustor thermal cycling, also indicated that sufficient seal compression can be maintained through thermal cycling. Based on the results of the seal leakage tests, a final design for the penetration ferrules was developed.

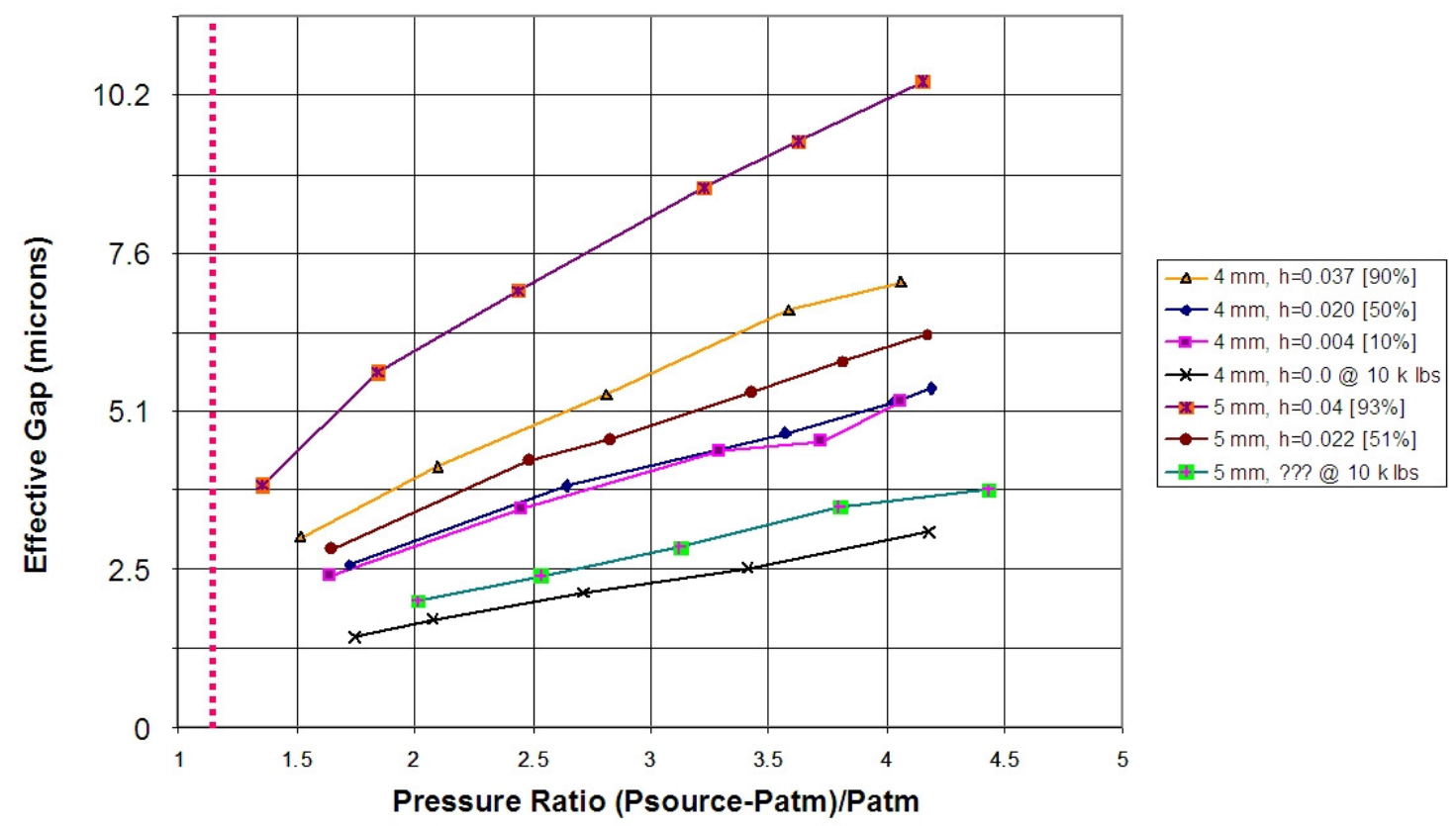

Figure 3-273. Leakage rate (equivalent gap height) of $4 \mathrm{~mm}$ and $5 \mathrm{~mm}$ ceramic rope seals as a function of compression and pressure difference. The dotted vertical line represents the relative pressure drop across the ferrules in the 7FA engine combustor system.

Full CAD solid models for all of the combustor system hardware were generated, and modal analyses performed on the full CMC liner assembly. In general there are ranges of frequencies over which combustion dynamics are known to occur, and combustor designers attempt to keep any of the combustor system resonant frequencies outside of these ranges; however, it is often impossible to completely do so. In such cases it is necessary to perform a forced response analysis in order to estimate the actual stresses imposed on the hardware.

The first step of the modal analysis was to validate that the FEA model predictions were indeed representative of actual liner behavior. To do this, the free resonance response of the liner was calculated and compared to measurements on an actual CMC liner after it had been machined. The results of these calculations and measurements are shown in Figure 3274, which shows that the predicted modal frequencies from the FEA were all within $3 \%$ of the actual measured frequencies, and that both sets of frequencies were relatively well matched by an analytical shell equation solution based on a simple cylinder. (There were 
actually 2 slightly different frequencies measured at each mode because of non-symmetry introduced by the presence of the penetration holes.)

The second part of the modal analysis was the frequency response analysis of the entire combustor liner assembly, including the CMC liner and attaching metal hardware. The resonant modes calculated from this analysis are shown in Figure 3-275. The two shaded bands represent the $+/-15 \%$ ranges for the $1^{\text {st }}$ and $2^{\text {nd }}$ harmonics of the typical combustion dynamic frequency. These two bands together form a region from $\sim 85 \mathrm{~Hz}$ to $161 \mathrm{~Hz}$ where combustor resonances should be avoided. It is clear that there are several resonances within this range of frequencies that could not be eliminated without a drastic change of the combustor design. Consequently a forced response analysis was performed to assess the stress levels that these resonances would likely impose on the liner.

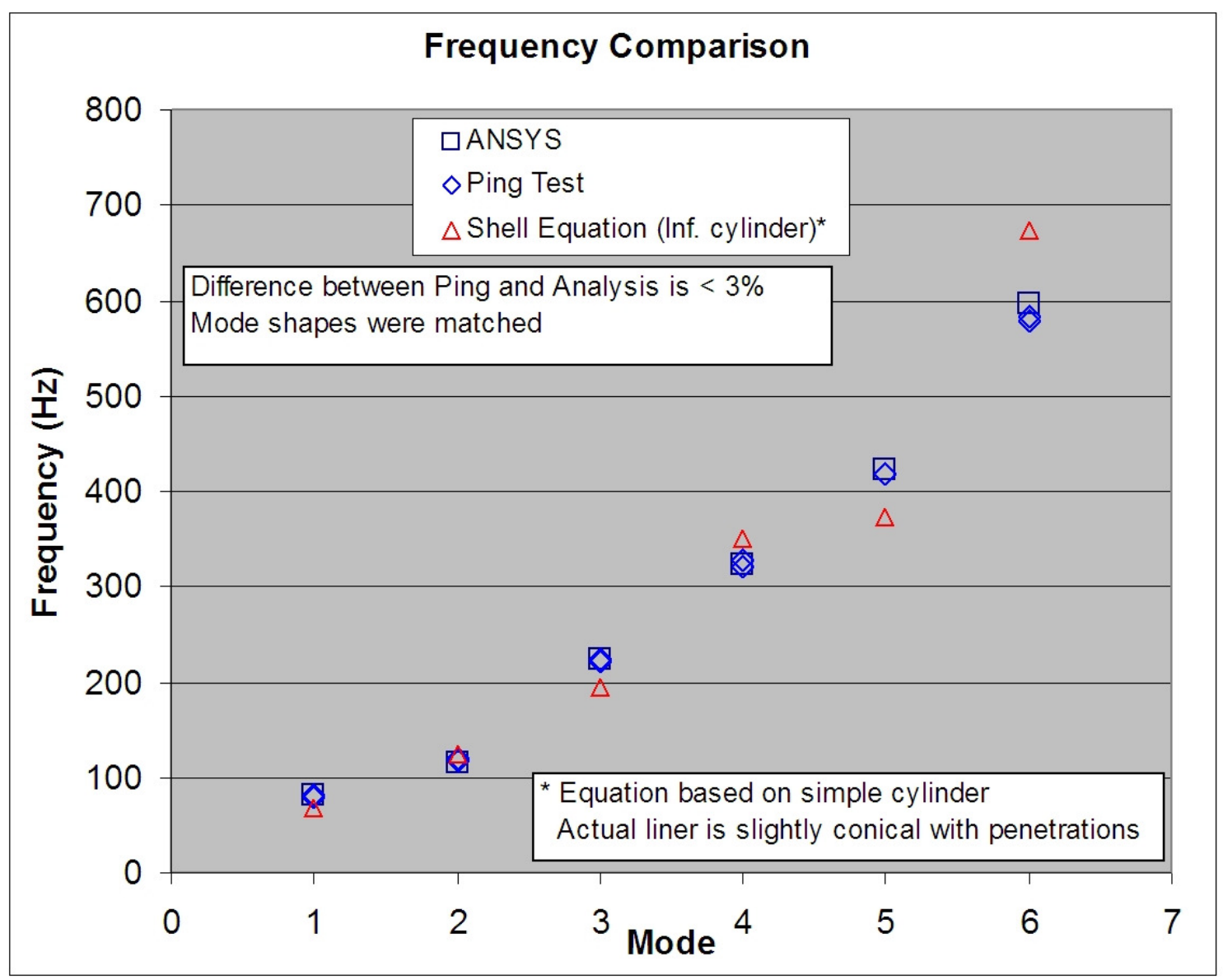

Figure 3-274. Predicted modal frequency results from ANSYS FEA analysis and analytical calculations compared to actual measured modal frequencies.

The results of the forced response analysis are shown in Figure 3-276 for a pressure fluctuation of $0.07 \mathrm{bar}(1 \mathrm{psi})$. The curves in the plot represent the predicted maximum cyclic stresses in the $\mathrm{CMC}$ liner at three locations, as well as in the forward metallic 
attachment. Over the critical frequency range of 85 to $161 \mathrm{~Hz}$ the stresses induced by the resonant modes remain relatively low. The stresses in the metal attachment and CMC liner both tend to peak at the $254 \mathrm{~Hz}$ resonance. This particular mode involves a "rolling" deformation in the metallic attachment and simple forward-to-aft motion of the CMC liner. The high stresses in the liner are simply a result of the inertia of the liner resisting the relatively large displacements that are predicted. However, this mode would require substantial sliding of both the forward and aft liner seals, whereas it is much more likely that the presence of the seals would very effectively damp this particular motion (damping from the seals was not included in the model calculations). Coupled with the fact that there are no pressure fluctuations at this frequency to drive the motion, this particular resonance is not anticipated to cause any problems. Nevertheless the forward attachment was slightly modified to minimize stresses in the metallic parts should some motions of this type occur.

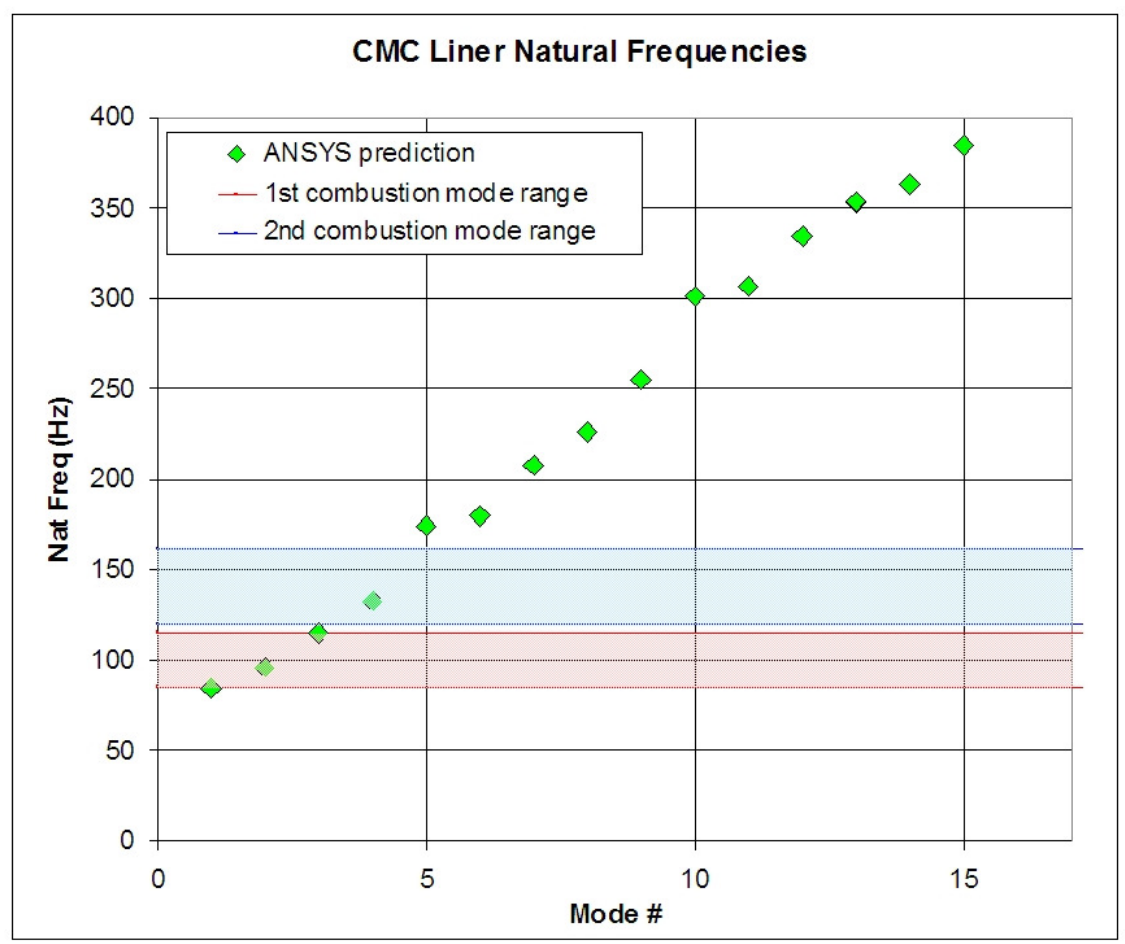

Figure 3-275. Modal frequency analysis of the CMC combustor system.

With all the technical progress with the combustor design described above, it was decided to proceed with acquisition of hardware for the combustor rig test. Engineering drawings were prepared for each of the combustor parts and acquisition of the metallic hardware for the rig test was started in October, 2003, with most of the hardware having been delivered by February, 2004.

It was at this point in the program that further development work on the CMC 7FA combustor was suspended. Hardware for the combustor test rig, entirely procured using 
GE Energy funds, was mothballed at GE Gas Turbines, Greenville, SC, in anticipation that combustor testing of a similar liner system may occur in the future.

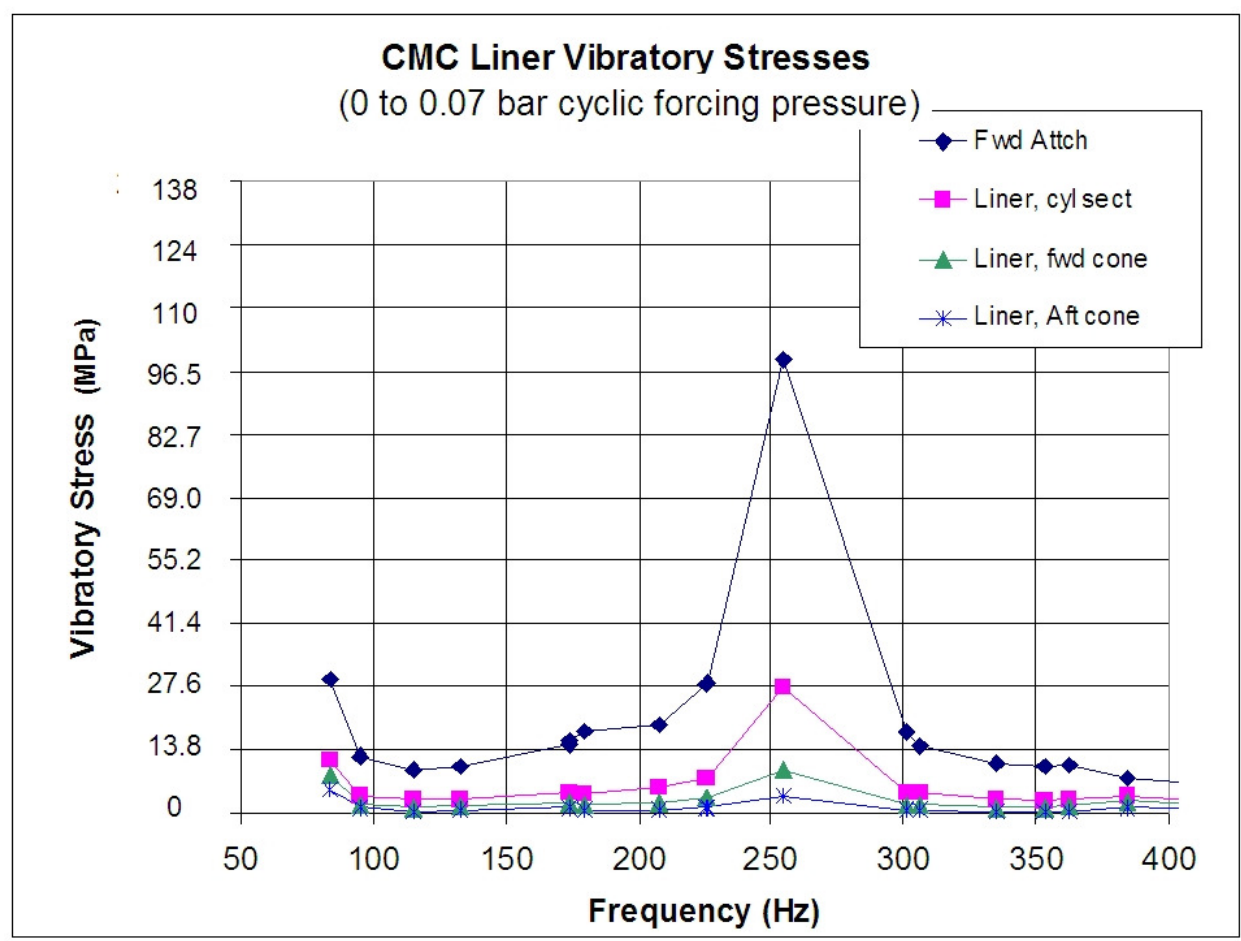

Figure 3-276. Forced response stress predictions as a function of driving frequency for a 0.07 bar pressure fluctuation.

\subsubsection{Task C2 - 7FA Combustor Rig Testing}

The main goal of this task was to test the CMC combustor design developed under task $\mathrm{C} 1$, as described above. In order to adequately evaluate the combustor performance it would be necessary to perform full-scale, high-pressure, high-flow combustion rig testing.

This task was further broken down into three subtasks. First, fabrication of the combustor liner was to be done at GE GRC. This program was GE's first attempt to fabricate any part of this size out of prepreg MI CMC. Consequently, in order to ensure that the CMC liner would be of sufficient quality for rig testing, it was anticipated that three liners would be fabricated: one "trial" liner with uncoated fiber and two "real" liners using coated fiber. The second subtask was the design and the fabrication and/or procurement of the necessary metallic hardware and instrumentation needed for the test. This work was to be performed by GE Energy with support from GRC. The third subtask was the actual performance of the rig tests at GE Energy, where all the necessary facilities were in place for conducting single can combustor testing at conditions that exactly simulate turbine engine conditions. 


\subsection{Task C2.1 - CMC Liner Fabrication for Rig Test}

Working from the approved CMC liner design from the $1^{\text {st }} \mathrm{CDR}$, a graphite lay-up tool was designed and procured. The tool was essentially a longitudinally segmented cylinder with two end rings to position the segments. The segments were designed to be internally collapsible following part lay-up, thus minimizing any damage to the preform from tool removal.

Fabrication of the trial liner, using mostly un-coated fiber, was begun in the Fall of 2002. The overall layup process used was to directly wind continuous hoop plies and lay in the axial plies by hand. There were several penetrations needed in the liner to allow for attachment of various connectors and probes (cross-fire tubes, igniters, etc). Getting the prepreg tape to fully conform around these new penetration/attachment features was a significant problem, and it took several trials to develop workable solutions.

One of the problems with using continuously wound hoop plies is that they have a tendency to form ply wrinkles during lamination, eventually leading to delaminations. Such defects were seen in previous cylindrical components, such as the GE-2 shrouds and Frame 5 combustor liners made under the CFCC program [2]. Work on the 7FA shroud component, and on other internal programs for GE Aircraft Engines, had shown that allowing proper drying time and utilizing intermediate de-bulking steps were crucial to minimizing wrinkling and delaminations. Consequently increased drying time and physical debulking steps were incorporated into the overall layup procedure for the liner, which slowed the layup process. A custom-made heat blanket was also procured so that the debulks could be done under "warm" conditions to promote evolution of solvents.

Fiber supply issues also played a role in slowing progress on layup of the trial liner. During this time period the quantity and quality of incoming Hi-Nicalon fiber from NCK had been rather poor, and this dramatically affected the throughput of GRC's fiber coating operation. Consequently good quality coated fiber was in very short supply. However, some coated fiber content was needed to provide the liner with some minimal toughness, which would hopefully be sufficient for it to survive the thermal stresses following infiltration, as well as resist any subsequent damage during handling, machining, or EBC spray trials. The layup of the liner was therefore started using uncoated fiber for the $1^{\text {st }}$ five plies, with the outer five plies utilizing the available coated fiber. The final five plies utilized fiber that had been coated in the new large CVD coater at GRC, and it was known that at this point in its development the coater was producing highly damaged tows that were difficult to process to complete density even in flat coupon samples.

Lay-up of the trial liner was completed in early December, 2002. Figure 3-277 shows some photographs of the liner during the lay-up process.

The liner was physically larger than any of the available autoclave equipment at GRC, so it was necessary to make arrangements with another source for the lamination/cure treatment. A suitable and available autoclave was found at Lexgard (a GE Plastics subsidiary) in Pittsfield, MA. GRC personnel visited Lexgard in order to evaluate the autoclave 
capabilities and to make sure the necessary support structures and instrumentation were in place. Once satisfied that the autoclave would meet our needs, the liner was vacuum bagged and kept under vacuum overnight to remove any last traces of residual solvent. The liner was then transported to Lexgard, autoclave laminated using a 1-day cycle, and then returned to GRC. Operation of the autoclave through this cycle was very good, with the desired time-temperature-pressure cycle being adhered to quite closely.
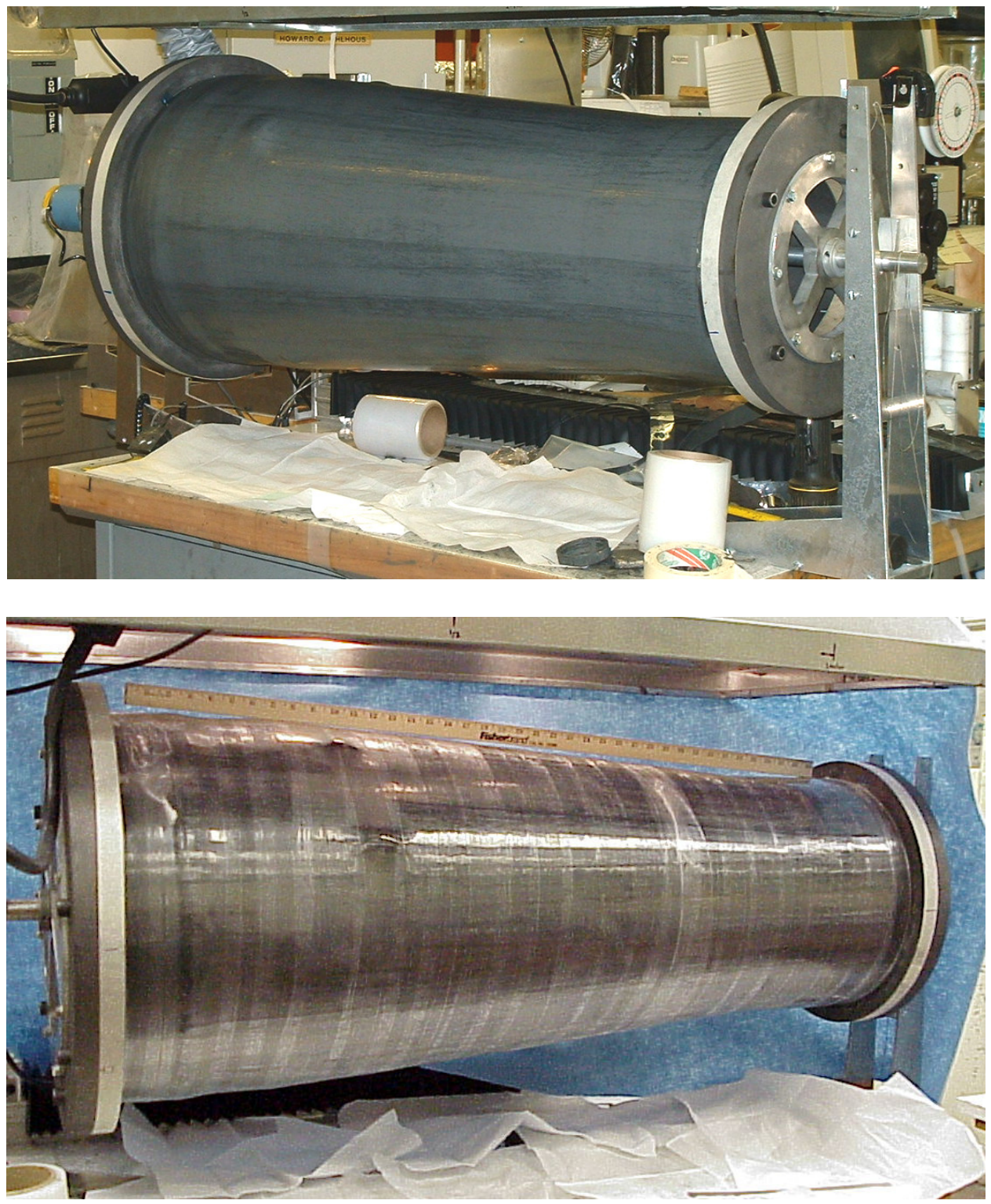

Figure 3-277. Photographs of the 7FA CMC combustor liner during composite lay-up.

Top: Liner after application of an axial ply. Bottom: Liner with overwrap of stretch film used to prevent excessive preform drying during the lay-up process. 
Upon removal from the vacuum bag it was evident that the liner had been compacted and cured. A photograph of the liner following autoclave lamination and removal of the vacuum bagging materials is shown in Figure 3-278. Unfortunately, it was also evident that several wrinkles had formed during the autoclave lamination. The worst of these wrinkles ran about $2 / 3$ of the length of the liner from the outlet end, and involved the entire wall thickness. A photograph of the outer surface of the liner at the exit end showing this wrinkle is shown in Figure 3-279. This wrinkle coincided with a seam in the lay-up mold near the end of the liner, but deviated slightly from following the mold seam exactly. A few much smaller wrinkles were also noted, primarily in the vicinity of the penetration hole features, but did not affect the entire liner thickness.

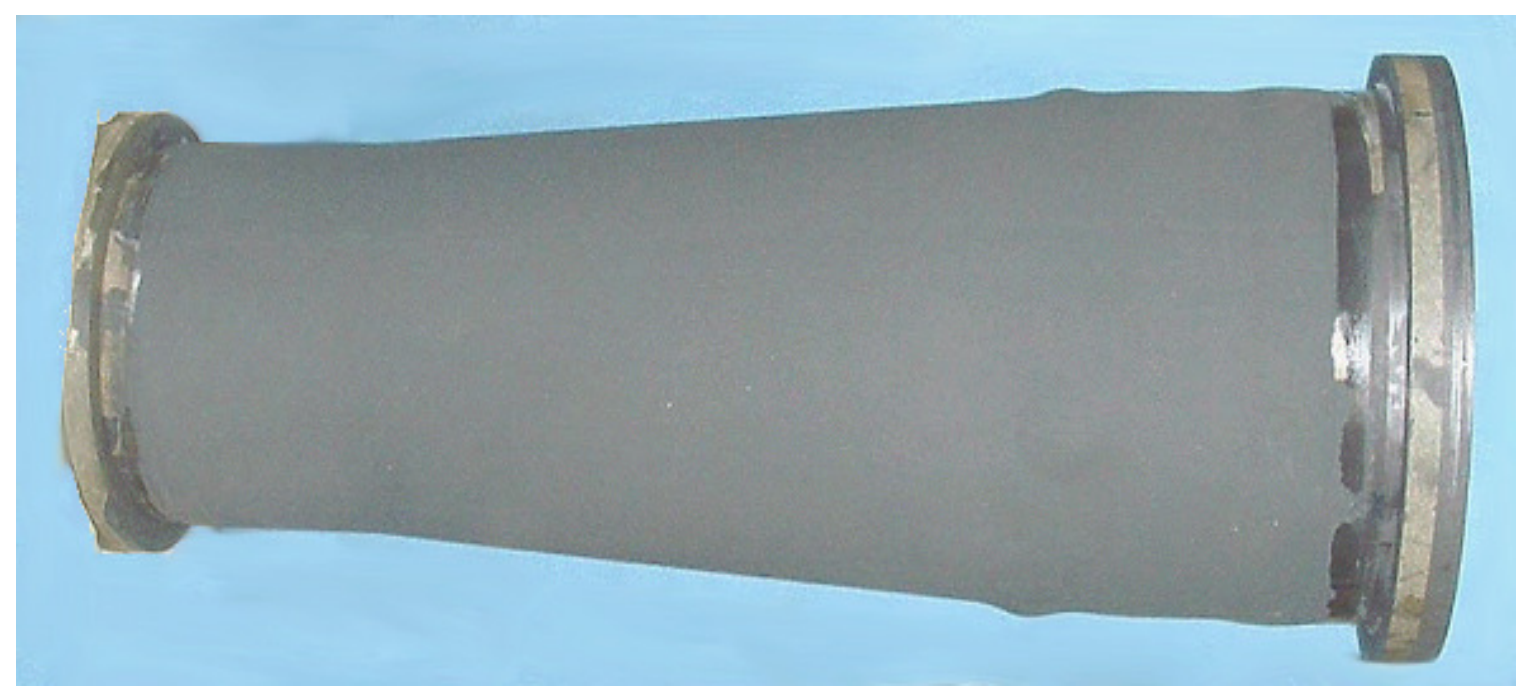

Figure 3-278. Photograph of trial 7FA combustor liner (still on the lay-up and lamination tool) following autoclave lamination.

Despite the wrinkles seen in the trial liner the processing of the liner was completed (i.e. binder burn-out and silicon infiltration) as practice for the liners to be used for rig testing. Again, the liner was too large to use the existing furnaces at GRC for these heat treatments, and thus it was necessary to find alternate facilities for binder burn-out and melt infiltration.

Arrangements were made to do the binder burn-out heat treatment at GE CCP in Newark, $\mathrm{DE}$, using one of their SiC CVD deposition furnaces (at this point in time dedicated facilities for burn-out and melt infiltration for this size part were not yet installed and operational at CCP). Similarly, arrangements were made to perform the infiltration step at Solar Atmospheres in Sauderton, PA. Solar Atmospheres is a commercial vacuum heat treating house primarily serving the metallurgical industries. Their concerns regarding silicon contamination of the vacuum furnace made it necessary to utilize a graphite "box" during infiltration to act as a retort. Negotiating the requirements for this box, its design, fabrication and "bake-out" unfortunately added several weeks to the overall fabrication process. The binder burn-out heat treatment was delayed until all of the details for the infiltration had been worked out in order to minimize the amount of time between burn-out and infiltration. That is the stage where the composite is in its weakest state and most 
susceptible to damage. Once these issues were resolved the binder burn-out was carried out at CCP, and subsequent melt infiltration at Solar Atmospheres, in late March of 2003.

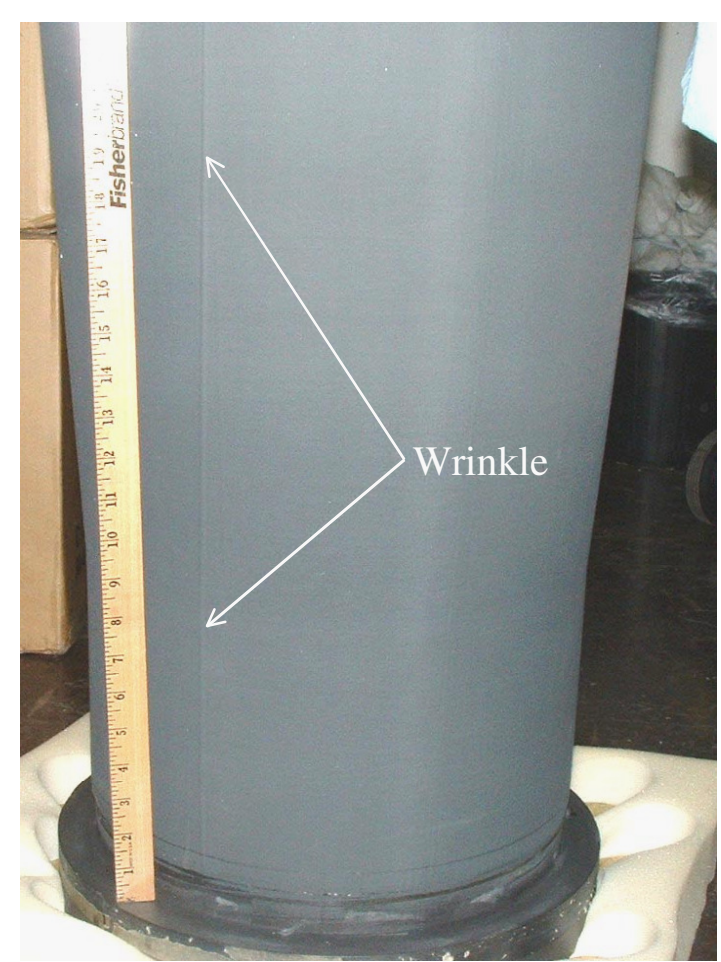

Figure 3-279. Photograph of the trial combustor liner preform (still on the lamination tool) following autoclave lamination. The exit end of the liner is down, and the location of an axial ply wrinkle in the liner is indicated.

During the binder burn-out and melt infiltration steps the liner was supported on the lay-up tool as an internal mold. However, only 3 of the 6 staves of the tool were used in order to evaluate the effects of contact with the tool on the degassing behavior during burn-out, and on the extent of infiltration of the inner surface during melt infiltration. Photographs of the liner on the burn-out/MI tooling before and after the binder burn-out process are shown in Figure 3-280. Visual inspection of the liner showed no anomalies after burn-out, with minimal lateral spreading of the wrinkle defects and excellent overall shape retention.

The melt infiltration step was done using the "pack method," which is where a mixture of silicon alloy powder and BN powder are mixed with water and a binder and spread over the surface of the part, similar to the way one would put icing on a cake. During infiltration the silicon melts to form a continuous liquid phase that is in contact with the preform surface through the $\mathrm{BN}$ skeleton. The silicon wicks into the composite preform via capillarity, leaving behind the BN skeleton largely depleted of alloy, which is in turn friable and relatively easy to remove from the composite surface after MI. 

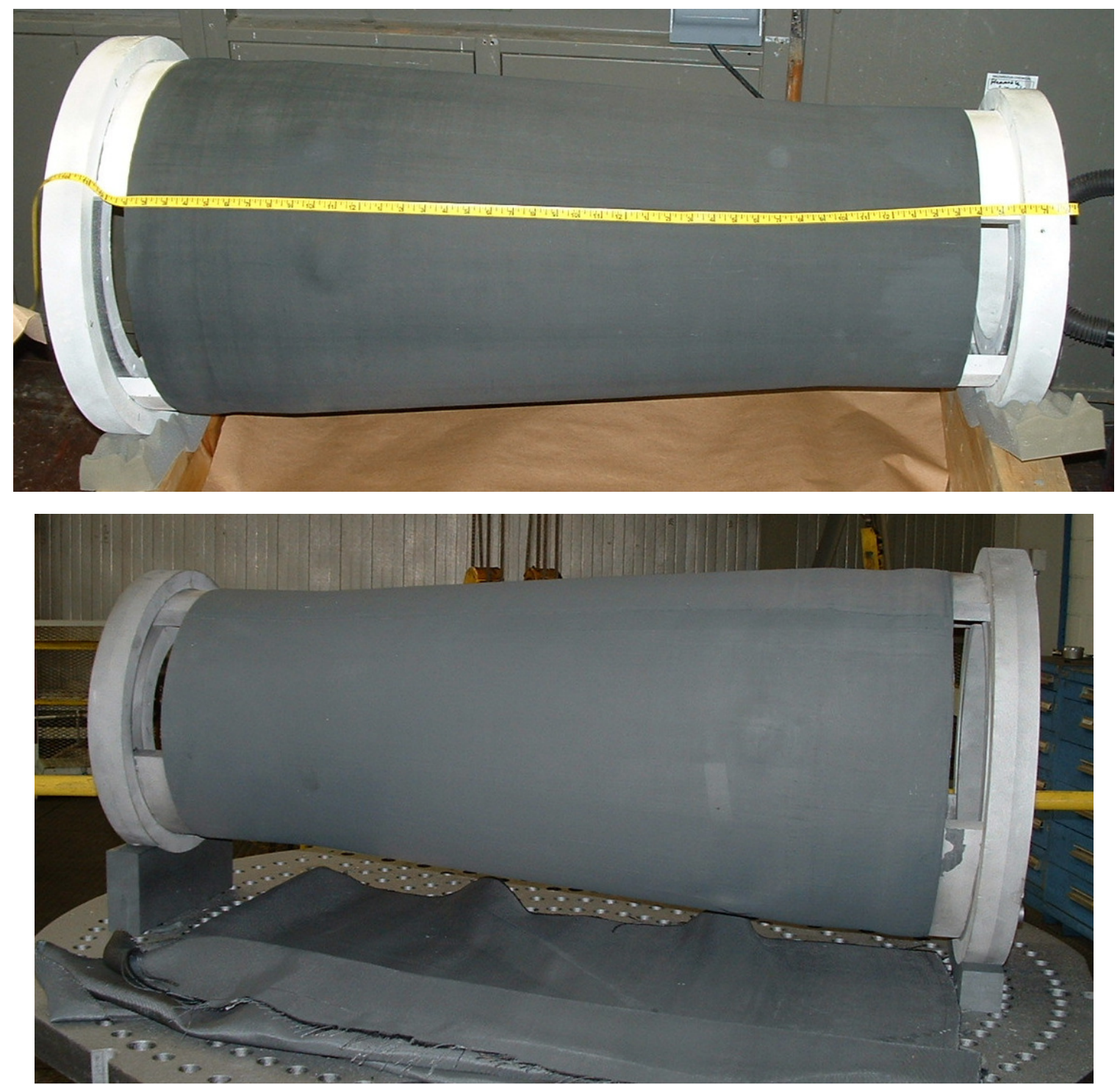

Figure 3-280. Photographs of the trial combustor liner during preparation for binder burnout (top) and following burn-out at CCP (bottom)

There were several concerns with using this method with the liner due to gravitational effects. The liner would need to be infiltrated in the horizontal position due to the size limitations of the vacuum furnace, and thus there would be a tendency for the alloy to flow within the pack from the top to the bottom of the liner. There was also the possibility that the pack on the bottom of the liner would loose adherence during the heat-up to MI temperatures and fall off the liner before infiltration could occur. To counter these possibilities the pack was made thicker on the top of the liner than on the bottom so that sufficient silicon would still be present at the top even if some of the silicon was pulled to the bottom by gravity. The pack was also overwrapped with carbon cloth in order to ensure contact between the pack and the liner. 
Silicon pack application was done immediately following the burn-out step at CCP. The liner with pack was dried overnight and then transported to Solar Atmospheres for melt infiltration. Figure 3-281 shows photographs of the trial liner following pack application at CCP, during MI furnace loading at Solar Atmospheres (with the partially assembled carbon retort box), and following the melt infiltration heat treatment. The liner was then transported back to GRC for removal of the pack and inspection.

Preliminary inspection of the trial liner following infiltration showed several potential problems. First, there was more than normal excess silicon left on the liner surface, suggesting the possibility of incomplete infiltration. The exterior surface of the liner, as shown in Figure 3-282, showed an unusual surface waviness, appearing like wrinkles in elephant skin. This was the first time such a surface appearance on the prepreg MI CMC had ever been observed. It was also evident that the liner had deformed out-of-round during infiltration. It was strongly suspected that the out-of-roundness at least partly resulted from the same mechanism that caused the wrinkling of the outer surface; however, the fact that the liner was not fully supported over its entire inner surface allowed for this deformation to occur even if it was not a direct cause of the deformation. The positive outcome from this experiment was that there were no observable differences in the extent of densification between the supported and unsupported segments of the liner, so that a full infiltration mold could be used with future liners to prevent such deformations. During clean-up of the excess silicon from the liner surface several "chips" came off the liner surface, indicating regions of partial infiltration and/or delaminations. 

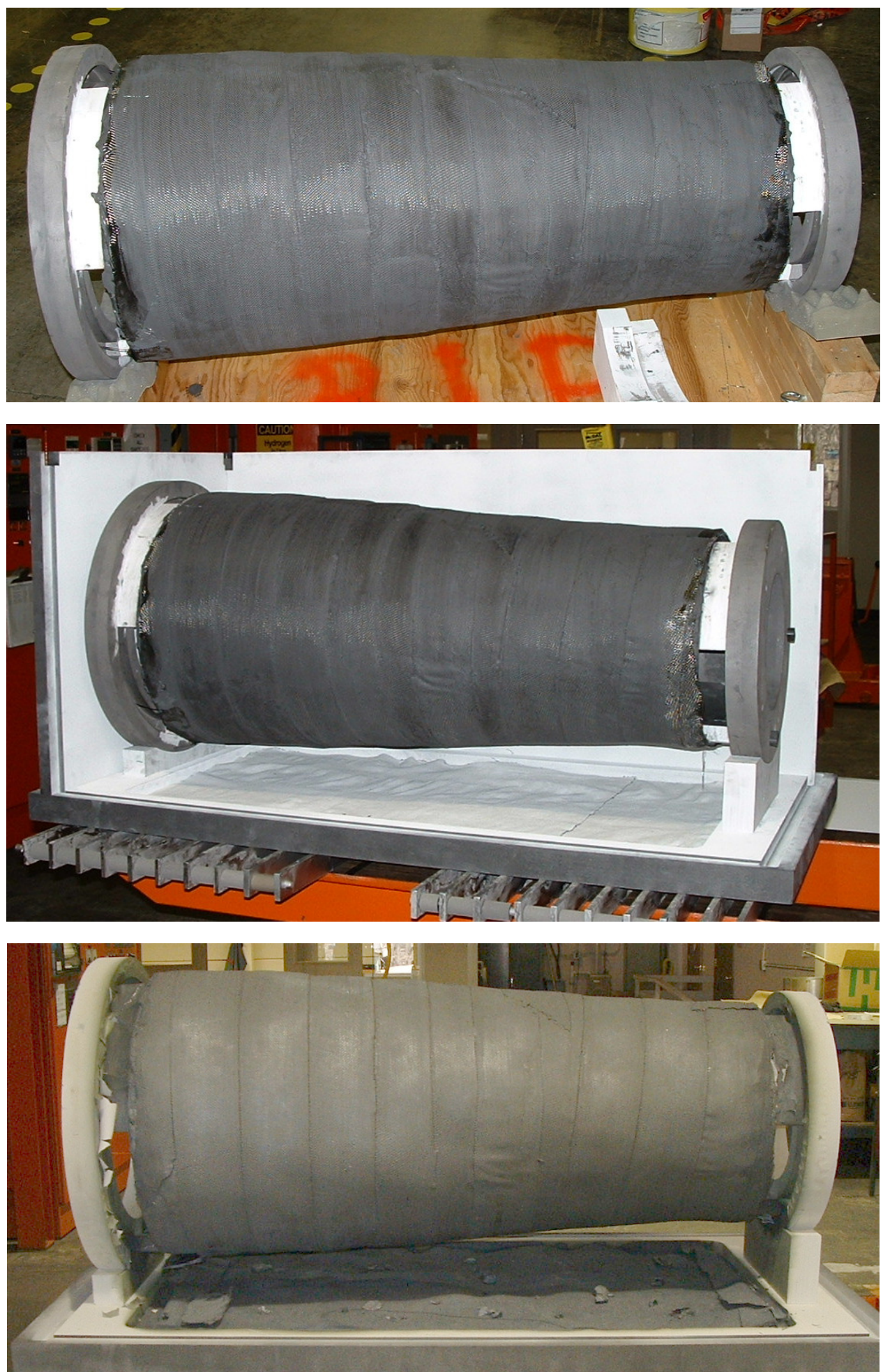

Figure 3-281. Photographs of the trial CMC combustor liner following pack application at CCP (top); during loading into the MI furnace at Solar Atmospheres (middle); and immediately following the melt infiltration heat treatment (bottom). 


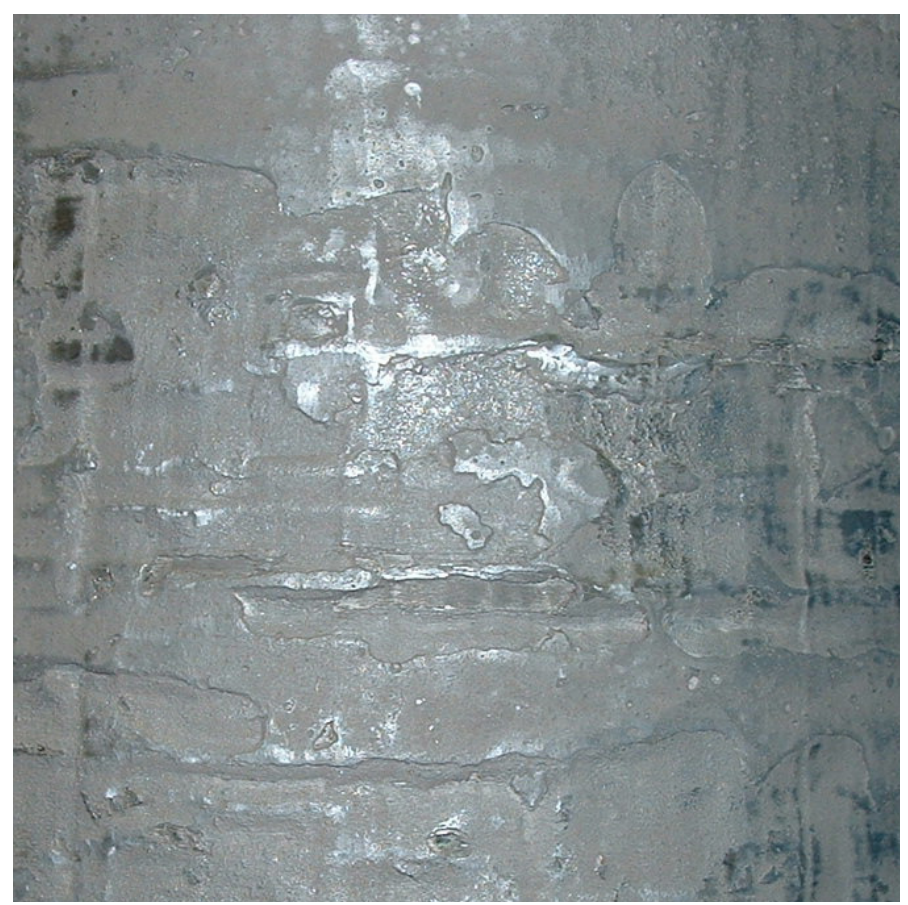

Figure 3-282. Photograph of the outer surface of the trial liner following infiltration and pack removal, showing the surface "wrinkling" and waviness. A layer of excess silicon is still present on much of the surface.

Sections were cut from the liner and polished for metallographic examination. Figure 3283, below, shows montage photomicrograph of a typical cross section. In all cases the inner plies of the composite, fabricated from un-coated fiber, were relatively well infiltrated and intact. The outer plies, which were fabricated using coated fiber, tended to be delaminated, and in some instances poorly wet-out with matrix and/or poorly infiltrated. The delaminations were generally worse around the "bumps" located at the penetration locations. In nearly all cases the poorly infiltrate regions corresponded to areas that were more severely delaminated, suggesting that the delaminations were limiting silicon infiltration, as would be expected. Given that the silicon proceeds from the outer surface inward during infiltration, and that some form of delamination was seen in nearly every section of the liner, it was surprising that the inner plies were infiltrated as well as they were.

The delaminations, surface wrinkling and out-of-roundness of the liner all suggested a dimensional instability in the liner. The leading suspect was an incompatibility between the plies made with uncoated and with coated fiber. All uncoated fiber or alternating plies of coated and uncoated fiber had been used previously in test components where the goals was to check the overall fabrication process without having to utilize a large amount of coated fiber; however, this liner was the first instance where all of the coated or uncoated fiber was completely segregated to one side of the lay-up. Based on previous experience, a large dimensional stability difference between the coated and uncoated plies was not expected, but the results on the trial liner were indicating otherwise. 


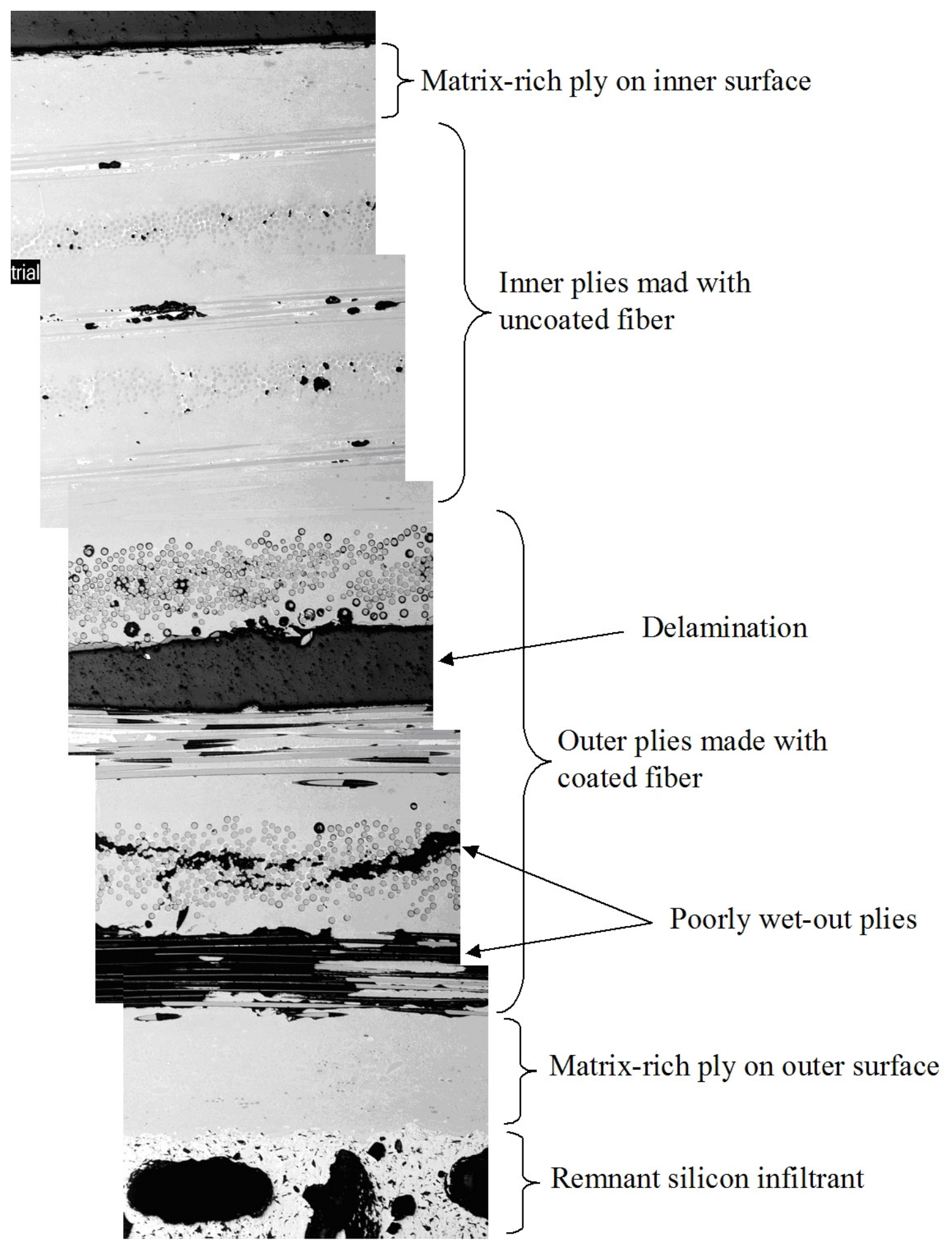

Figure 3-283. Montage of photomicrographs of a cross section through the trial liner (liner inner surface toward the top and outer surface at the bottom). The relatively dense and coherent inner plies, made with uncoated fiber, contrast with the delaminated and poorly densified outer plies, made with coated fiber. 
In order to determine if such a dimensional instability exists between the coated and uncoated plies a 6"x6" panel was fabricated using the same ply arrangement as in the trial liner. This panel processed normally all the way up to infiltration, but following infiltration it was substantially warped. A photograph of this panel is shown in Figure 3-284. The pattern of the deformation indicated that the side with uncoated fiber actually contracted slightly during infiltration. (The alternate interpretation would be that the side with coated fiber expanded; however, there had never been evidence of such dimensional changes in any of the panels or components made entirely from coated fiber.)

Such shrinkage in the uncoated fiber plies is consistent with the various features seen in the trial liner. In the panel, the differential strain was manifested by the warping of the panel. However, the cylindrical geometry of the liner would be self-constrained from such warping and would instead tend to cause the observed delaminations and buckling (wrinkling) of the outer, coated fiber plies. The out-of-roundness of the liner is attributable to the shrinkage of the inner plies coupled with the fact that only one half of the liner was directly supported by the tooling at three circumferential locations. Thus, rather than shrinking uniformly the liner was forced to distort toward a triangular shape.

Despite the delamination/infiltration problems caused by the mixed fiber, the overall processing trial was quite successful. The 7FA liner was roughly $3 \mathrm{X}$ larger than any other MI composite component ever made. This trial liner had demonstrated that the lay-up, lamination, burn-out and infiltration processes, many of which were performed at vendor sites using unfamiliar equipment, could be done successfully on a CMC part of this size. Moreover, the part was still solid enough to be used for EBC coating trials so that the EBC team could work out robotic spray patterns and thermal spray conditions to give the optimum microstructure and coating uniformity on a full-sized combustor.

Lessons learned from the fabrication of the trial liner were utilized to improve the process for the $1^{\text {st }}$ rig test liner. The issues caused by having mixed coated and uncoated fiber would not be present in the rig test liner, which was made entirely from coated fiber. Changes made to the design of the liner penetration features eliminated the "bumps" on the liner, which in turn eliminated much of the layup difficulty associated with these bumps and also made it possible to use a single piece lay-up tool. The single piece tool was more structurally sound, thereby helping to limit any composite wrinkles associated with seams in the tooling. Finally, tooling that fully supported the entire liner was used during infiltration to prevent any tendency for the liner to deform and go out-of-round, even though the tendency to do so was greatly reduced by not using mixed coated and uncoated fiber. 


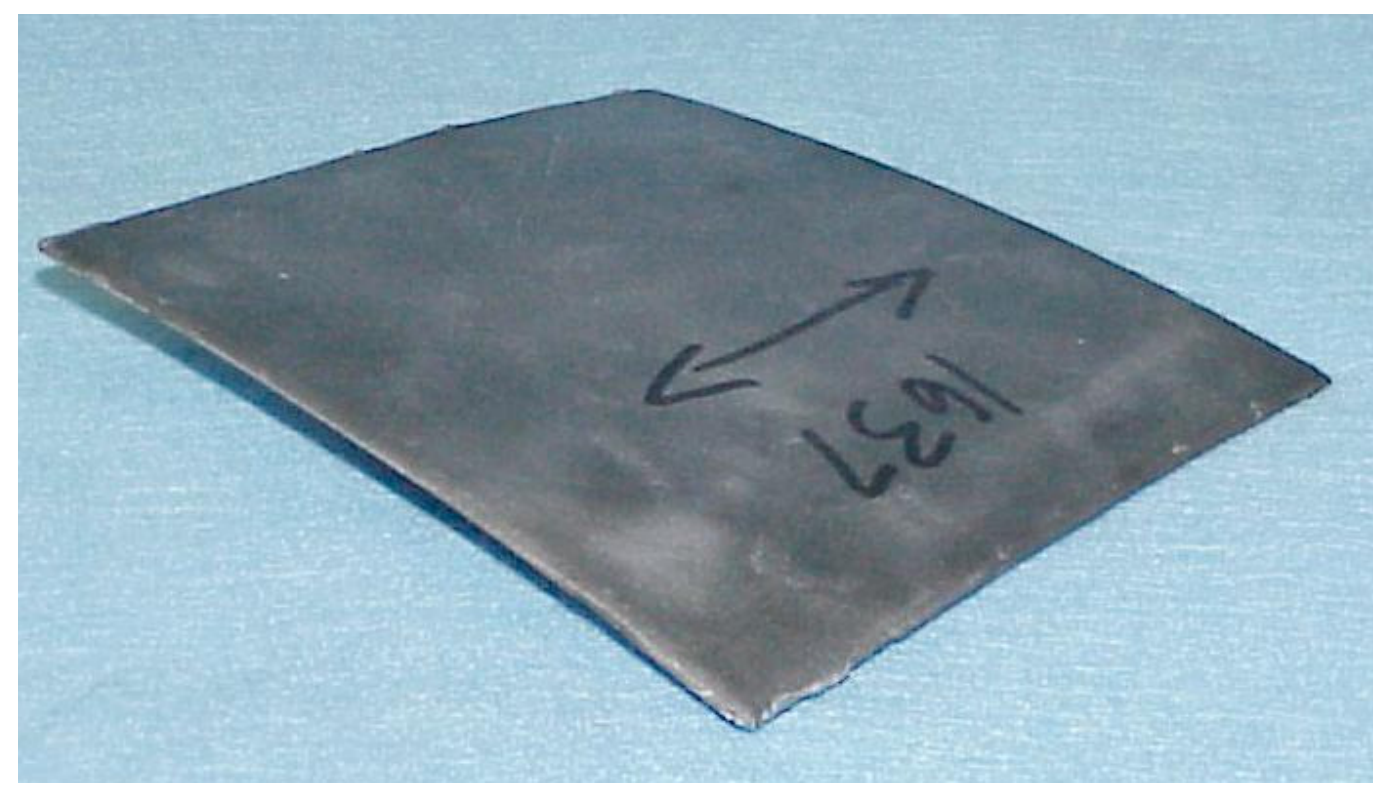

Figure 3-284. Photograph of a panel made with $1 / 2$ uncoated and $1 / 2$ coated fiber. Severe warpage of the panel (concave toward the uncoated fiber side) occurred during infiltration.

Fabrication of the $1^{\text {st }}$ liner for rig testing was started following the release of the design at the Preliminary Design Review. New lay-up and infiltration tooling was designed and procured. At the same time fixtures for mounting the tooling into the tow winder were designed and fabricated. The tooling was mounted in the winder and layup of the liner started in late May, 2003, and completed in late June. Debulking treatments were used after every other ply during layup, using a combination of heat-shrink tape wrapping and vacuum bagging, to minimize the likelihood of ply wrinkles.

Again, the size of the liner prevented the subsequent processing steps from being done inhouse at GE GRC. However, unlike the trial liner where the autoclave lamination, burn-out and infiltration steps were all performed at different vendor sites, equipment installation at GE CCP had progressed to the point where all remaining process steps could be done at CCP.

Although lay-up of the $1^{\text {st }}$ rig-test liner was completed in late June autoclave lamination did not occur until early August. The new, large production autoclave had been installed at $\mathrm{CCP}$, and calibration test runs had been performed; however, there was very little experience with this new autoclave for lamination of actual CMC parts. Consequently it was necessary to laminate a test panel using the new autoclave while having the CMC liner tooling inside the autoclave to simulate the thermal load of the liner. Subsequent infiltration and testing of this panel at GRC indicated that the achieved density and mechanical properties were consistent with a panel made from the same fiber coating lot and laminated at GRC. At that time the liner was transported to GE CCP for lamination in their production autoclave. 
Figure 3-285 shows a photograph of the liner, with vacuum bag, being loaded into the autoclave. The autoclave lamination treatment went well overall, with the autoclave following the desired time-temperature-pressure profile very precisely. On removal from the autoclave the liner was inspected and found to have several small wrinkles, but none nearly as sever as the large wrinkle seen in the trial liner. In this respect, the use of the intermediate vacuum bag debulking treatments, and the use of a shrink film wrap during debulk and lamination, appeared to be successful in eliminating most of the liner wrinkling. Unfortunately, the shrink film became bonded to the liner surface during the autoclave treatment. This same shrink film had been used during the vacuum bag debulk cycles at GRC without incident, but the extended time at temperature needed for the final lamination and cure of the liner caused the film to bond to the liner. Photographs of the liner following removal from the autoclave, and showing the bonded shrink wrap film, are shown in Figure 3-286.

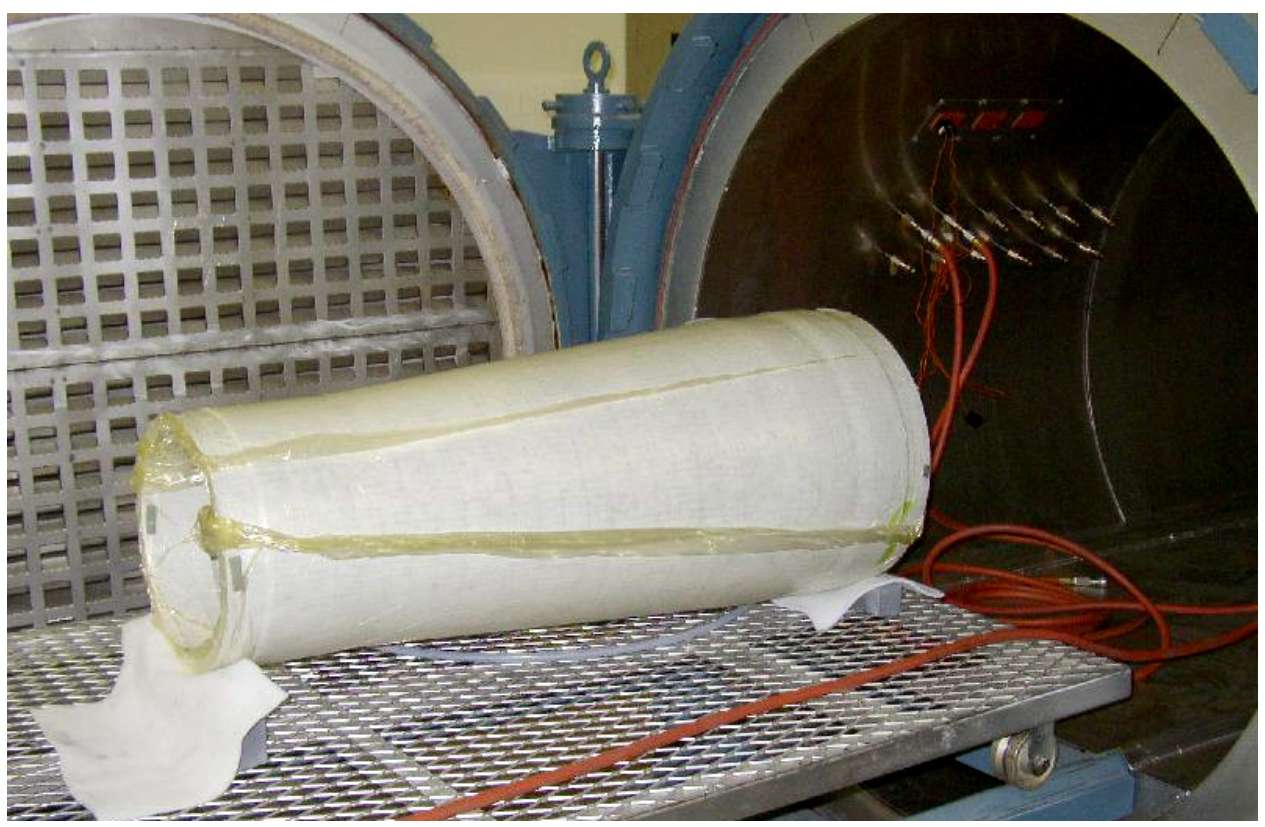

Figure 3-285. Photograph of 7FA liner being loaded into the large production autoclave at CCP. Length of the liner tool is $1.2 \mathrm{~m}$.

It was at this time (mid-August of 2003) that a water leak in the CVD reactor used for depositing the fiber coatings used in the liner was detected. Throughout the mid to late summer there had been significant problems with the infiltration problems of test panel specimens. During a maintenance check of the CVD reactor a water leak was found in the reactor jacket at one of the power feed-through locations. Although it could not be determined when the leak first occurred, based on infiltration issues observed with the fiber coatings it was determined that the leak possibly started as far back as April of 2003, and therefore affected much of the coated fiber used for the liner. The combustor liner would have been difficult to infiltrate even with good fiber coatings, and the presence of the contaminated coatings would only add to this difficulty. Consequently several infiltration 
experiments were performed in the large $\mathrm{CCP}$ infiltration furnace in order to try to evaluate whether line infiltration could be expected.
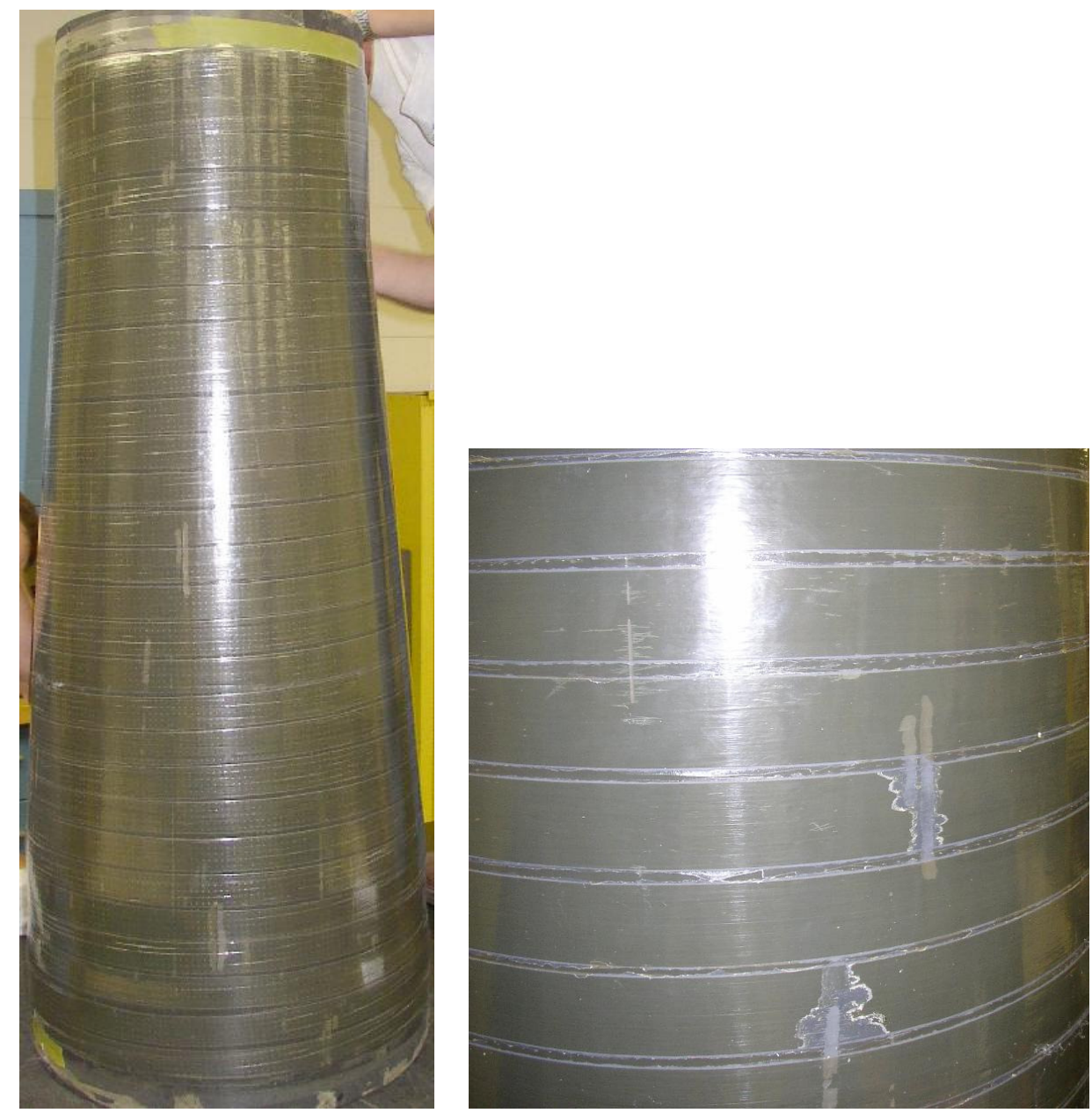

Figure 3-286. Photographs of the 7FA rig test combustor liner following autoclave lamination:

Left - Full liner after removal of the vacuum bag, breather and bleeder layers. Right - Close up photograph showing shrink film wrap bonded to the surface.

Three panels were prepared using fiber from the same coating vintage as that used in the combustor liner. The panels were then cut in half and one half of each infiltrated at CCP and the other half at GRC in order to verify that the large infiltration furnace was giving comparable, or better, results as the GRC infiltration furnace. One of the panel halves had the same shrink film as on the liner laminated onto the surface in order to simulate any effects this film might have on the infiltration process. Three of the half-panels were infiltrated for various times in the large furnace at $\mathrm{CCP}$, again having the combustor liner tooling and protective carbon box in the furnace at the same time to simulate the actual conditions that the liner would experience. The other halves, including the half with the shrink film, were infiltrated at GRC, though under slightly different conditions. 
Densities of the infiltrated test panels are shown in Figure Figure 3-287. Overall the panels infiltrated at CCP showed consistently higher density than those infiltrated at GRC. It was speculated that the higher vacuum level (lower pressure) in the CCP infiltration furnace compared to the GRC furnace was partially compensating for any possible outgassing from the contaminated fiber coatings during the infiltration treatment. Unfortunately, the half panel with the surface shrink film showed the lowest density of all the panels; however, this was only partially caused by the presence of the shrink film as the companion half panel infiltrated at CCP without shrink film also showed the lowest density of all the panels infiltrated at CCP. Nevertheless this result indicated that removal of the shrink film, or its char product, prior to infiltration would be beneficial. The mechanical properties from the panels in Figure 3-287 were all consistent with the density values, i.e. the half panels infiltrated at CCP showed better strength values than the half panels infiltrated at GRC. Based on these panels, infiltration conditions were selected for the liner that gave the best combined density and mechanical property results.

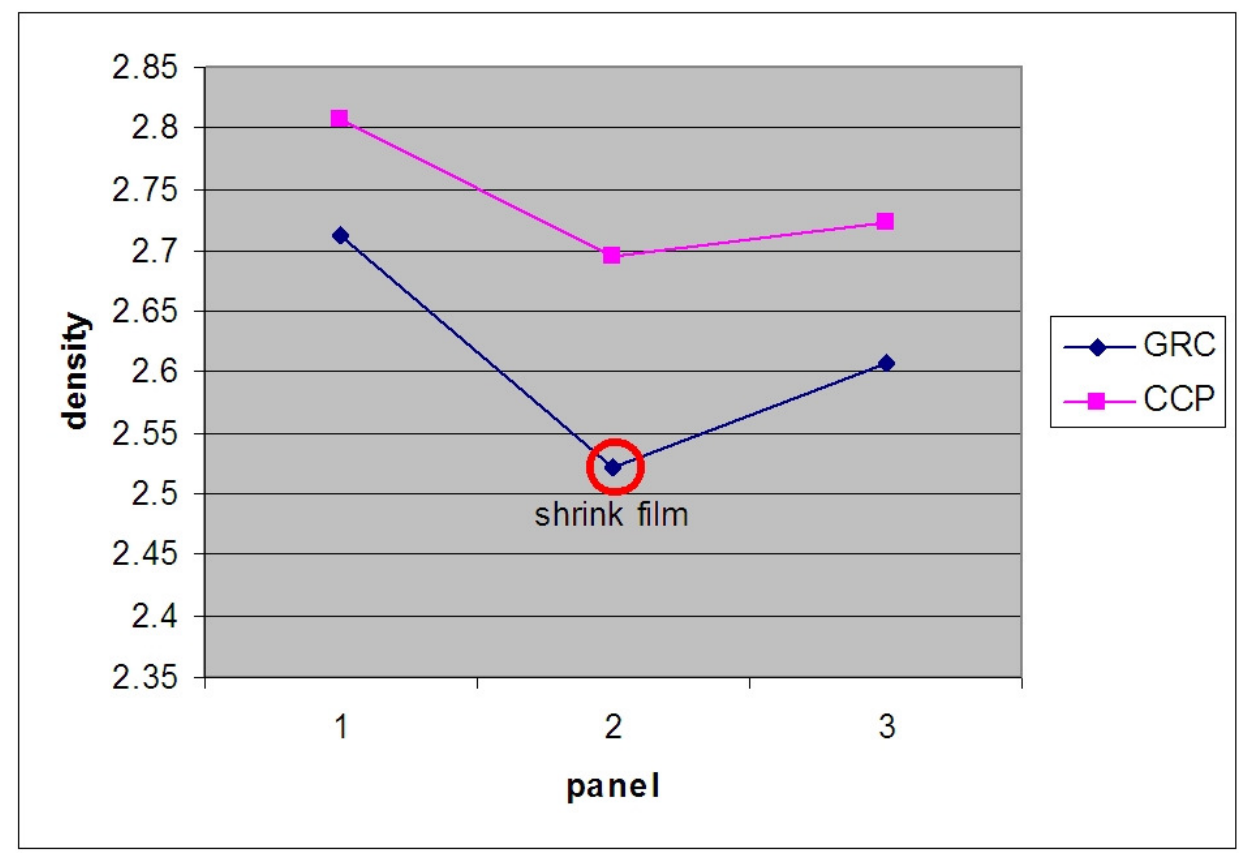

Figure 3-287. Density of the half-panels infiltrated at CCP and GRC as part of the liner infiltration condition selection study.

The liner was subsequently returned to CCP in late September, 2003, to undergo the binder burn-out and infiltration cycles. As before, the binder burn-out heat treatment was done in a vacuum furnace normally used for deposition of CVI carbon. The liner was left on the lay-up tool during burnout, and still had the layer of polyester shrink film on the outer surface as well as teflon and polyester separation films between the liner and the carbon tool. The liner was wrapped with a carbon cloth to protect it from any potential surface contamination. 
Figure 3-288 shows photographs of the liner as it was removed from the burn-out furnace. During the binder burn-out step the liner shifted forward (toward the smaller diameter end) on the lay-up tool, eventually pushing the tool off of the forward support block. The most likely reason for this is that the gas pressure produced from the decomposition of the separation films between the liner and the tooling, in conjunction with the conical shape of the liner, produced a sufficient forward force to push the liner forward on the tool.

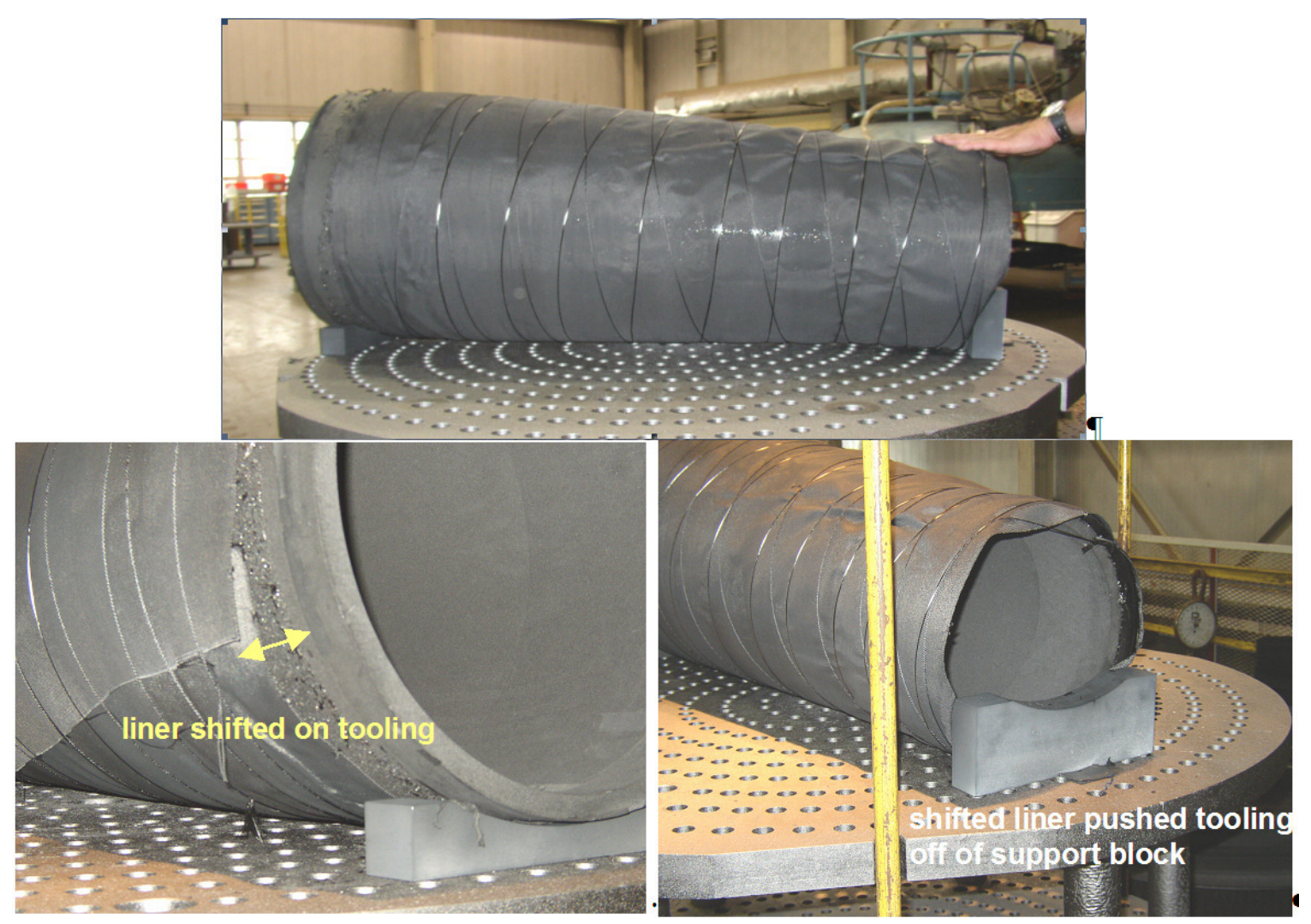

Figure 3-288. Photographs of rig test 7FA liner during removal from binder burn-out furnace: Top - Overall view of liner with carbon cloth wrap; Bottom left - Close-up of large end of liner showing how liner shifted on the tooling; Bottom right - The shifted liner pushed the tooling off of the forward support block.

After removing the carbon cloth wrap the liner was removed from the lay-up tool without much difficulty. Both the inner and outer surfaces of the liner had a layer of glassy carbon adhering to them, which was a result of the pyrolysis of the polyester films, as shown in Figure 3-289. The outer surface matrix layer on the liner was also damaged in a few locations, apparently caused by shrinkage of the adhering polyester film during pyrolysis. Attempts were made to repair the surface damage using fresh matrix slurry, and the outer surface of the liner was lightly sanded to remove $>50 \%$ of the glassy carbon coating. The liner was then placed on the BN-coated infiltration tooling, as shown in Figure 3-289. 


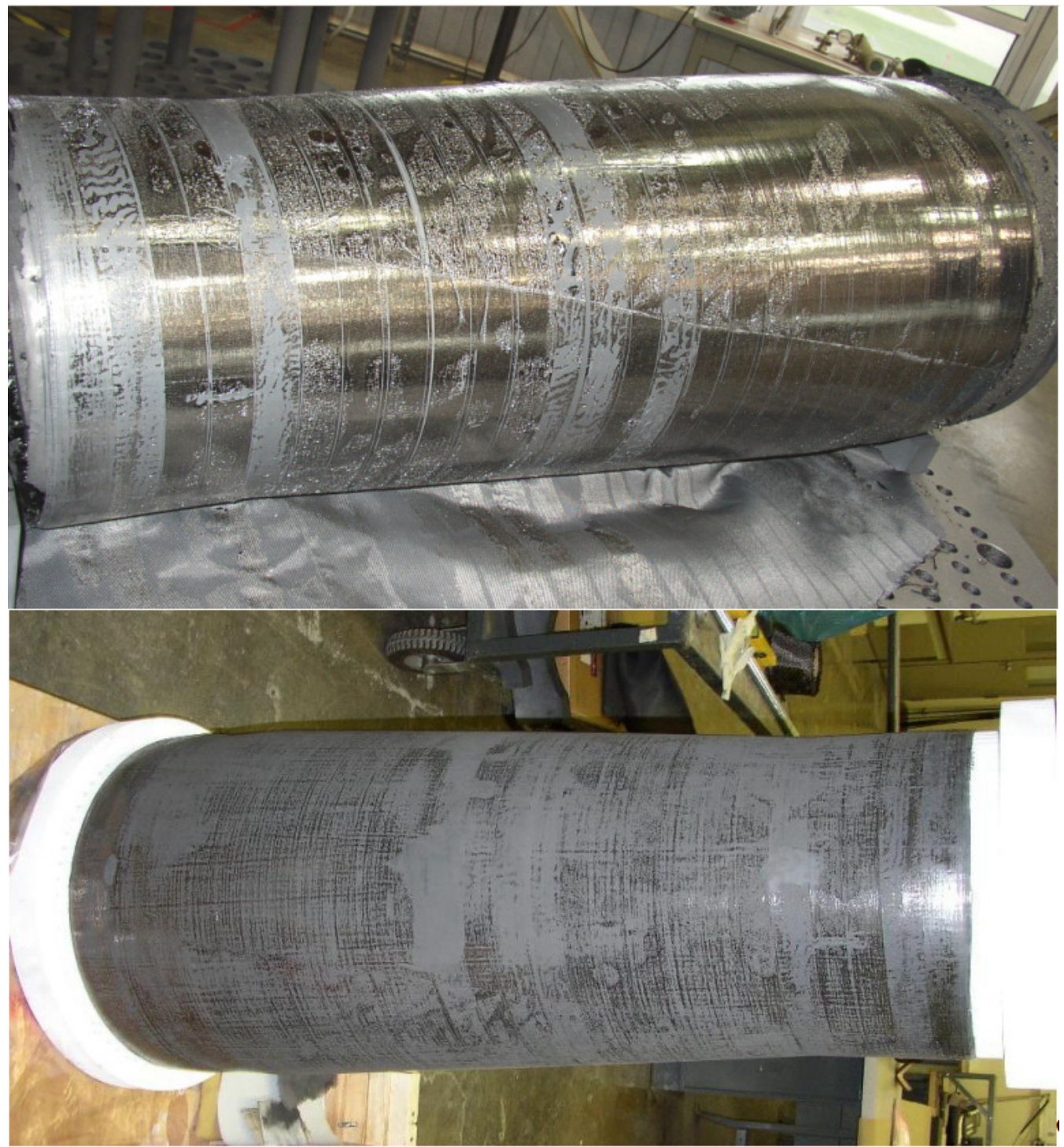

Figure 3-289. Photographs of the 7FA rig test liner following burn-out:

Top - Surface immediately after burn-out showing glassy carbon on surface Bottom - After surface sanding and placement onto the infiltration tooling

As had been done with the trial liner, a silicon-containing "pack" was applied to the liner surface and over-wrapped with a carbon tape to keep the pack stable during drying and infiltration. The pack was dried overnight and the liner loaded into the infiltration furnace. The same carbon box used for infiltration of the trial liner at Solar Atmospheres was used with this liner at CCP in order to limit the amount of $\mathrm{Si}$ vapor that would be available to react with the furnace heating elements and insulation. Figure 3-290 shows the liner during the furnace loading process with the carbon box partially assembled. The liner was then infiltrated under vacuum using the best time-temperature cycle identified from the panel tests discussed above. Figure 3-290 also shows a photograph of the liner following infiltration, but with the carbon tape and remaining pack still in place. 
Removal of the pack following infiltration was somewhat difficult, with substantial silicon remaining in the pack. Residual silicon tended to be concentrated at the bottom of the liner (according to its orientation in the infiltration furnace). The liner was then returned to GRC where the outer surfaces were further cleaned using grinding and grit blasting. The rough liner following clean-up of the residual infiltration pack is shown in Figure 3-291.

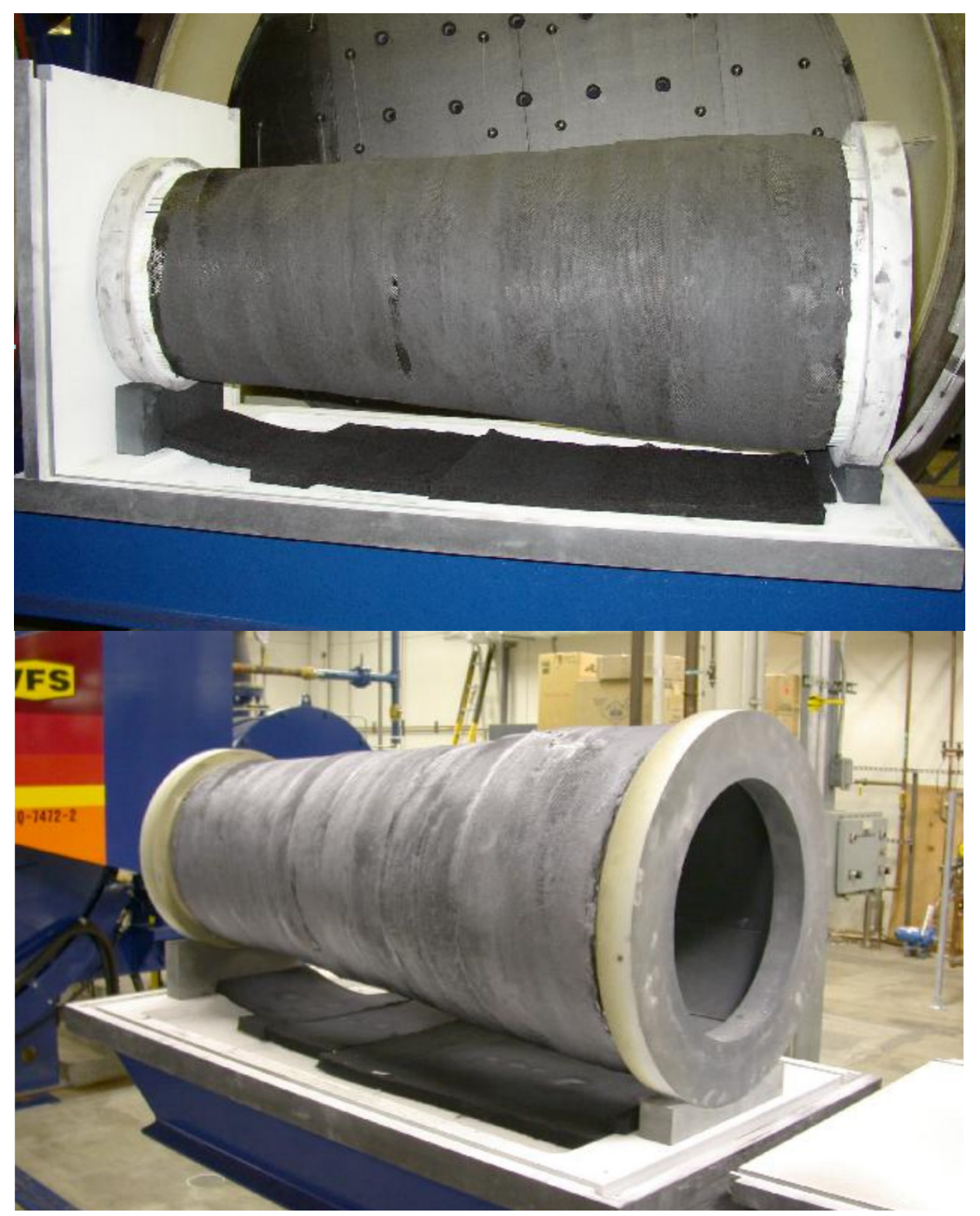

Figure 3-290. Photographs of the 7FA rig test liner during loading (top) and removal (bottom) from the infiltration furnace at PSC. 


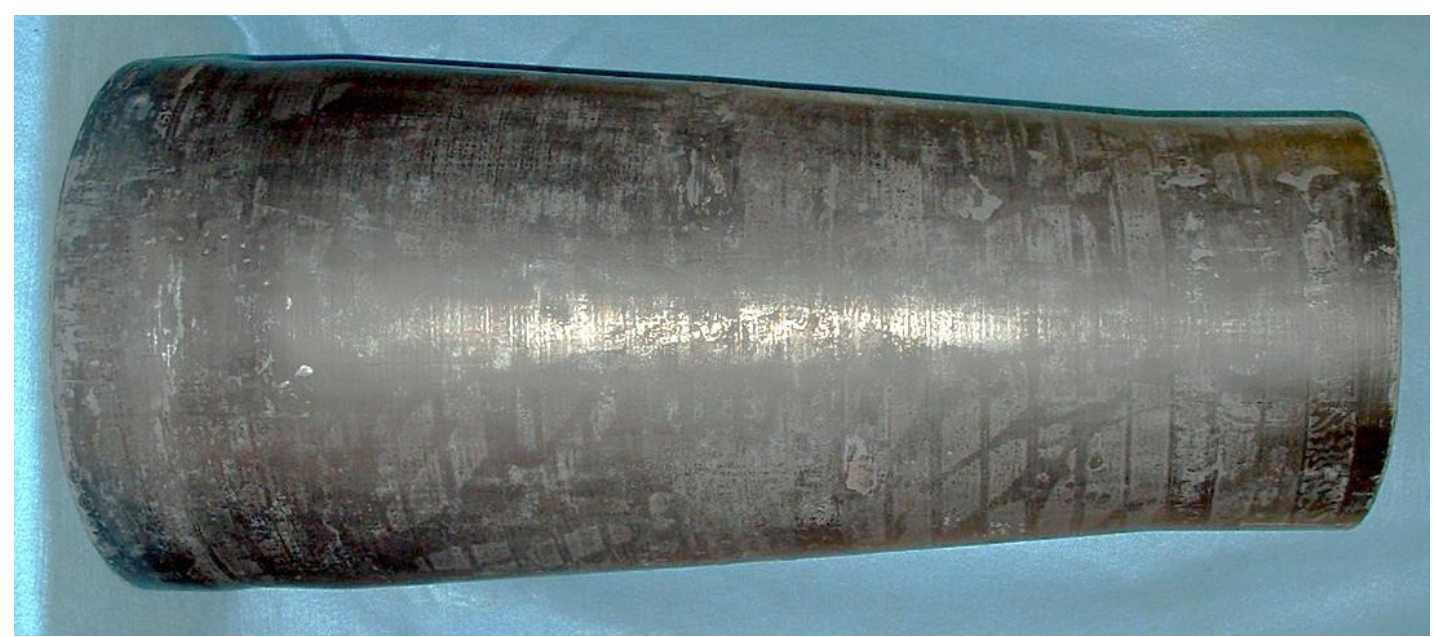

Figure 3-291. Photograph of the 7FA rig test liner after removal of the excess infiltrant pack.

The liner was then NDE inspected using both transient and thru-thickness IR thermography. Two important findings came out of the NDE inspections. First, the rig liner was demonstrably better than the earlier trial liner in terms of freedom from major defects. Figure 3-292 compares the amount of defected area found in this $1^{\text {st }}$ rig test liner as compared to the trial liner based on the NDE results. Although there are obviously defects in the rig liner, most notably delaminations or concentrated porosity (from un-infiltrated regions), the quality of this liner is much improved over the previous trial liner.

The second important NDE finding was that the overall thermal diffusivity of the liner was only about 50\% of that of more "normal" shroud components and panels. The range of thermal diffusivity observed during inspection of the liner is shown qualitatively in Figure 3293 as compared to the range found for typical shroud components. This result suggested the presence of a low level of distributed porosity throughout the liner.

Despite the known defects and low thermal diffusivity from the NDE inspection, the liner was sent to a vendor for machining. Machining was necessary in order to allow the liner to be held in the tooling fixtures for EBC coating, and would also provide samples for metallographic examination from the various pieces cut from the liner. Machining ran from early October through late November, 2003. Pieces cut from the liner included rings trimmed from both ends and "plugs" core drilled out from various locations during machining of the attachment and liner penetration holes. Metallographic examination of these pieces verified the low diffusivity measurements from the NDE examination in that distributed intra-ply porosity was found in all of the pieces. A typical microstructure from the liner is shown in Figure 3-294 compared to a more typical microstructure as found in panels and shrouds. Such distributed porosity has been seen in test panels on occasion, and was typical of many of the samples that were made from the water-contaminated fiber coatings. Unfortunately none of the parts cut from the liner were suitable for performing mechanical testing. 


\section{Trial Liner}

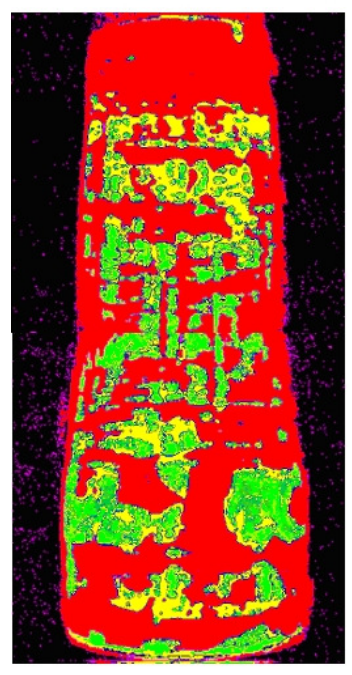

\section{1st Rig Liner}

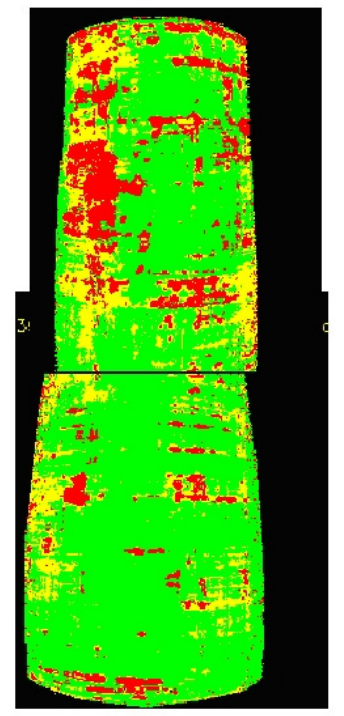

\section{Bad (delaminated or concentrated porosity) \\ Poor (distributed porosity) \\ Good}

Figure 3-292. Representative liner NDE images from transient IR thermography showing the relative proportions of good and defective areas between the current (i.e. $1^{\text {st }}$ rig) liner and the trial liner fabricated previously.

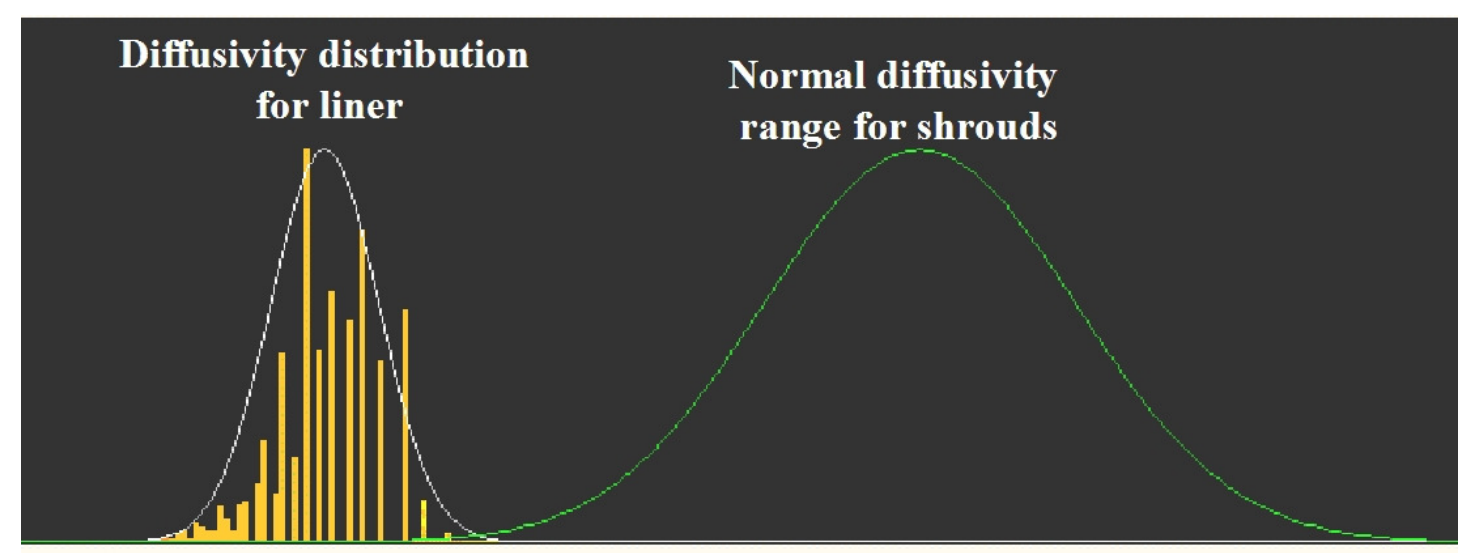

Figure 3-293. Qualitative ranges for thermal diffusivity measured in the $1^{\text {st }}$ rig test combustor liner compared to the typical range measured for shroud components. 
1st Rig Liner

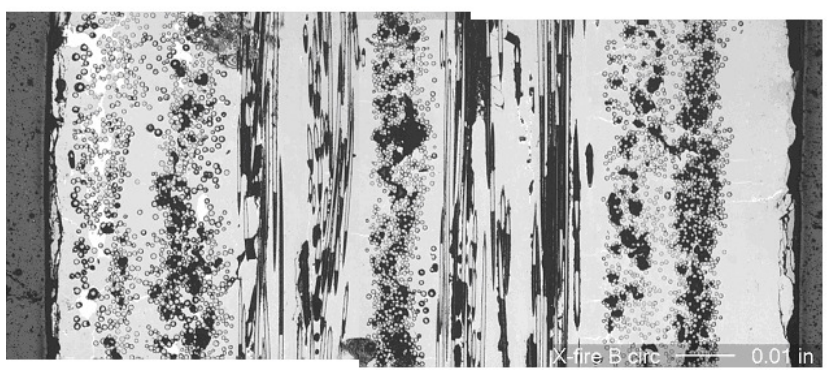

"Normal"

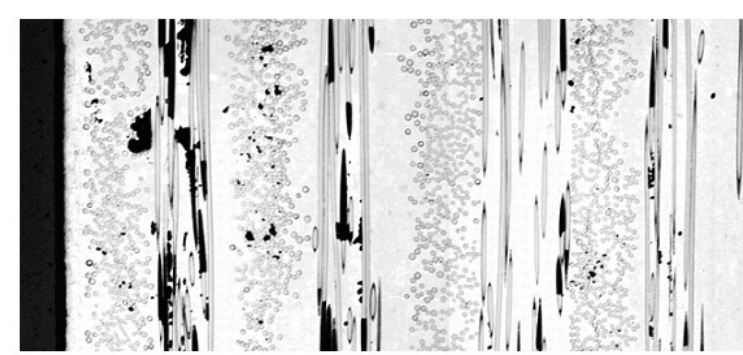

Figure 3-294. Comparison of the microstructure of the 7FA rig test liner (left) with a more normal microstructure typical of a panel or shroud component (right). The intra-ply porosity evident in the rig liner microstructure is responsible for the lower than normal thermal diffusivity of the part.

Regardless of the known defects and poor microstructure of the liner, for program schedule and cost reasons it was still hoped that this $1^{\text {st }}$ rig liner could be utilized for rig testing at GE Energy. The liner therefore needed to be prepped for EBC coating application. The typical surface prep process is to grit blast the CMC to roughen the surface, and thereby improve the adhesion of the air plasma spray coating. Grit blasting of the liner was started in early January, 2004, followed by initial EBC spray coating at GE Energy M\&PE Lab in Schenectady, NY. During spraying of the initial Si bond coat layer spalling of the coating was noted in various locations, as shown in Figure 3-295. It was determined that the liner had not been adequately grit blast to completely clean the surface and provide the necessary roughness for the EBC bond coat. Consequently the liner was grit blast a second time under more aggressive conditions (higher nozzle air pressure and harder grit) to remove the sprayed silicon layer and increase the roughness of the surface. Following this second grit blasting treatment several problems with the liner were noted.

There were several regions from the IR NDE images that appeared to be of very low thermal diffusivity, which would suggest high concentrations of porosity and/or delaminations. From the outer surface of the liner before grit blasting these regions appeared normal. However, during the more aggressive grit blasting it was discovered that only a thin surface layer of the liner had actually infiltrated with silicon in these regions, and that the underlying composite was very poorly, if at all, infiltrated. The un-infiltrated regions are very soft and were easily damaged during the grit blasting treatment. In one particularly bad location the grit blasting actually blew a hole $\sim 9 \mathrm{~mm}$ in diameter completely through the liner. Pictures of the liner regions damaged during grit blasting, which were mostly on the inner surface, are shown in Figure 3-296. The area of the NDE image corresponding to the damaged region of the liner is also indicated. 


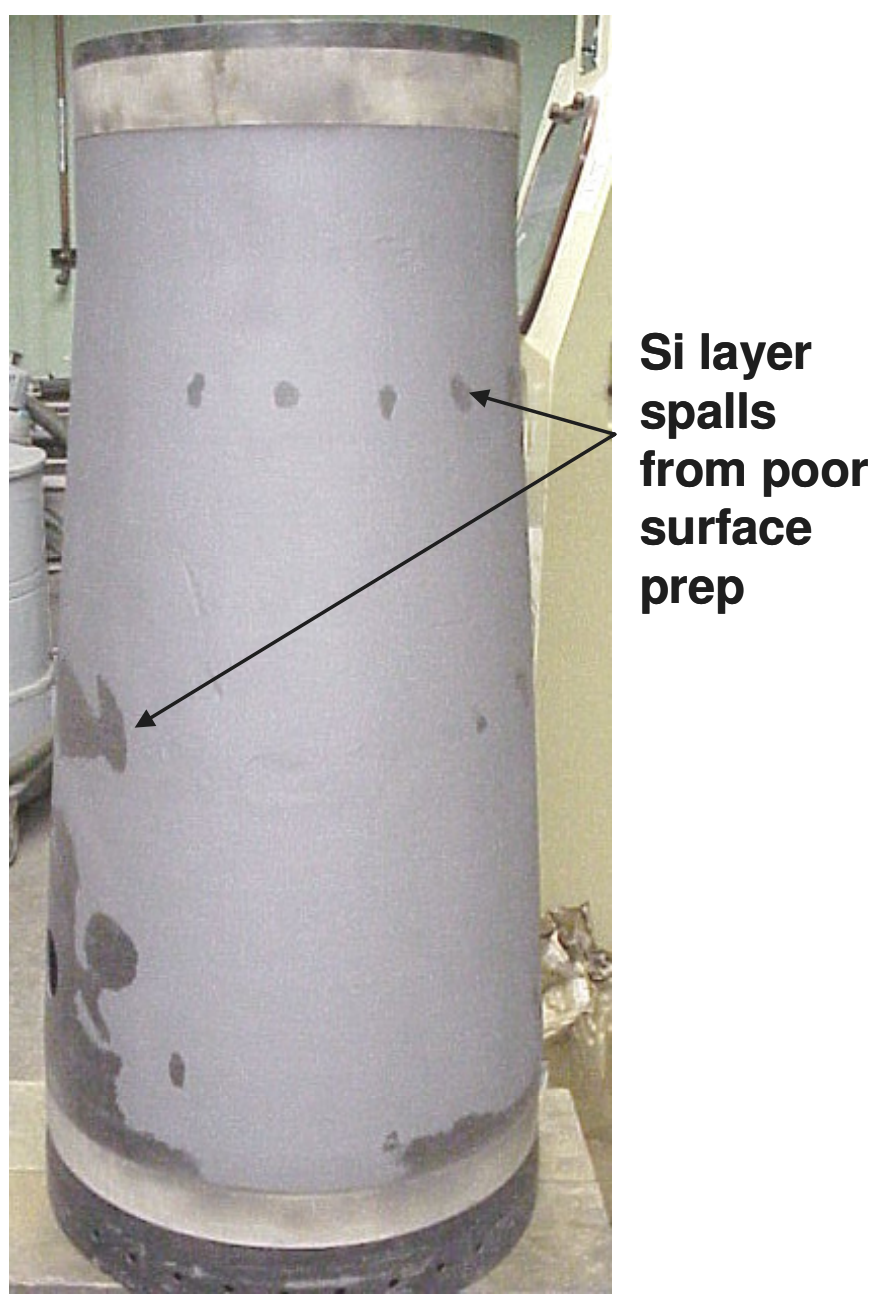

Figure 3-295. Photograph of the 7FA rig test liner following attempted thermal spray of the silicon EBC bond coat. Dark gray areas represent regions where the silicon layer has spalled from the substrate.

A Root Cause Analysis (RCA) was performed on the $1^{\text {st }}$ rig liner to come to a consensus as to the causes of the overall low matrix density, and particularly the poorly infiltrated regions that were damaged during grit blasting. The problem of low matrix density was attributed to a combination of issues already discussed, namely the oxygen-contaminated fiber coatings caused by the water leak in the coating reactor, and the glassy carbon char residue on the surface of the liner, which likely impeded silicon infiltration. The first cause (fiber coating contamination) is obviously remedied by ensuring proper operation of the fiber coater, complimented by additional fiber screening tests prior to using any fiber in a future liner. The glassy carbon layer was a result of the inadvertent bonding of a shrink-tape wrap to the liner during the autoclave lamination/cure treatment. Future liners would not utilize this shrink wrap during final consolidation, thus eliminating the glassy surface carbon issue. 

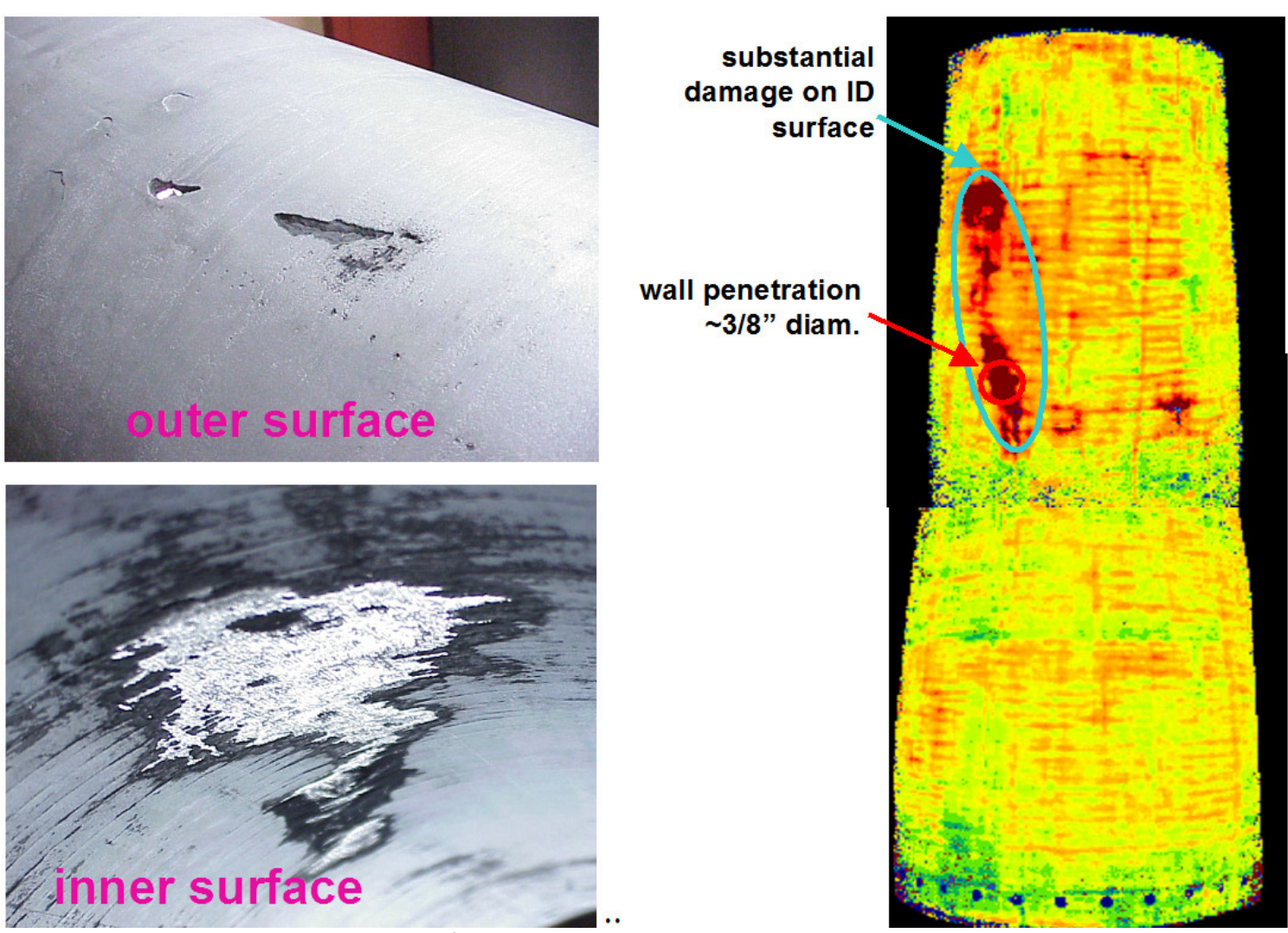

Figure 3-296. Damage to the $1^{\text {st }}$ rig test liner caused by the second grit blasting treatment.

Left: Photographs of the most severely damaged area shown on the outer and inner surfaces, including the through-wall hole.

Right: IR NDE image of the liner showing the pre-existing defect at the damage location.

Causes of the un-infiltrated region were less certain, but the leading candidates were separation of the infiltrant pack from the liner either during pack application or during the infiltration heat treatment itself. A second possible cause is a simple gravity effect. The liner was held in a horizontal orientation during infiltration, in which gravity would tend to pull the silicon pack away from the liner along the bottom. While this intuitively would seem to be a likely cause, the trial liner processed earlier was also infiltrated in a horizontal position and it did not display a difference in the extent of infiltration between the top and bottom sections. Fixes for these issues include applying the pack in multiple steps with intermediate drying cycles in order to ensure that the pack maintains contact with the liner during application and drying. Alternate methods for applying the pack, such as spraying, could also be considered. Finally, during infiltration the liner should be held in a vertical position. Due to its conical shape, any "slumping" or sliding of the pack during infiltration will tend to force the pack tighter onto the liner surface, and thus enhance the contact between the two.

Several possible scenarios were developed for repairing the damaged section of the $1^{\text {st }}$ rig liner. However, the final decision was to proceed with fabrication of the $2^{\text {nd }}$ rig liner as had 
originally been in the program plan. There had been substantial improvement in the quality of the liners from the initial trial liner to the $1^{\text {st }}$ rig liner, and it was anticipated that the $2^{\text {nd }}$ trial liner would show another step in quality improvement. The $1^{\text {st }}$ rig test liner, though of insufficient quality for rig testing, still met practically all of the dimensional requirements, and could therefore still be used for assembly trials in the test rig at GE Energy - Greenville.

Completion of the RCA of the $1^{\text {st }}$ rig liner carried into late March 2004. At that point the fiber coater at $\mathrm{CCP}$ was fully operational, and initial evaluations of the fiber indicated that it was capable of producing relatively good quality coated fiber. Due to ongoing operational difficulties with the large coater at GRC, it was decided to utilize fiber coated by CCP for the $2^{\text {nd }}$ rig test liner. It was in April, while the detailed evaluations of fiber coating quality and reproducibility of the CCP fiber coater were in progress, that the emphasis of the overall CMC efforts at GE Energy was shifted. As noted earlier, the difficulties with fabricating such a large CMC part, coupled with the high cost projections for the liners, made the combustor liner application less attractive for commercialization compared to the shroud component, which had undergone a very successful field engine test. GE effort and resources were therefore shifted to accelerating the development and commercialization of the shroud component, effectively putting development of the 7FA combustor on hold.

\subsection{Task C2.2 - Metallic Hardware and Rig Test}

Due to the change in program emphasis to the shroud component, much of the work originally planned for this task was not performed. However, a significant amount of effort was done on establishing a rig test plan, including instrumentation needs, and the subsequent evaluation of instrumentation alternatives.

An important operating parameter for the combustor system is the detailed temperature distribution of the liner. Fully instrumenting the liner with thermocouples over the entire surface would be impractical, so use of a thermal paint was selected for the initial rig tests. During the initial tests the liner would have a minimum number of thermocouples on a few critical features, but would have thermal paint over most of the outer surface. The actual locations for most of the thermocouple and strain gage instrumentation, which would be added following the initial test, would then be determined from the relative temperature distribution as indicated by the thermal paint. This testing scenario requires 1) a thermal paint that is active over the desired temperature range, that doesn't degrade the CMC and/or EBC coating, and that can be removed after the initial tests without damaging the liner, and 2) a robust technique for applying thermocouples (and possibly strain gages) to either CMC or EBC surfaces.

In order to address the $1^{\text {st }}$ requirement several thermal paints were evaluated at GRC. CMC test samples, both with and without EBC coating, were painted with one of four candidate thermal paints. These samples were then exposed in a laboratory furnace for 20 hours at $1200^{\circ} \mathrm{C}$. After exposure the samples were evaluated as to the adherence of the paints and whether there was any sign of degradation of the CMC or EBC by the paints. 
From these initial results two of the paints were selected for subsequent temperature calibration measurements. Again, CMC test samples both with and without EBC coating had one of the two indicating paints applied and were then exposed in a laboratory furnace at a variety of temperatures. The main evaluation criteria from this test was how discernible the color changes were for the paints at the different temperatures. Figure 3-297 shows an example of a set of samples after exposure. By and large, no detrimental interactions were found between the paints and the substrates, and, in general, the paints adhered better to the EBC coated specimens and had more easily distinguishable color changes on the EBC coated specimens. Subsequent grit blasting trials on some of the specimens demonstrated that the selected thermal paint could be easily removed from the substrate without damage to the EBC or to other attached instrumentation, as described below.
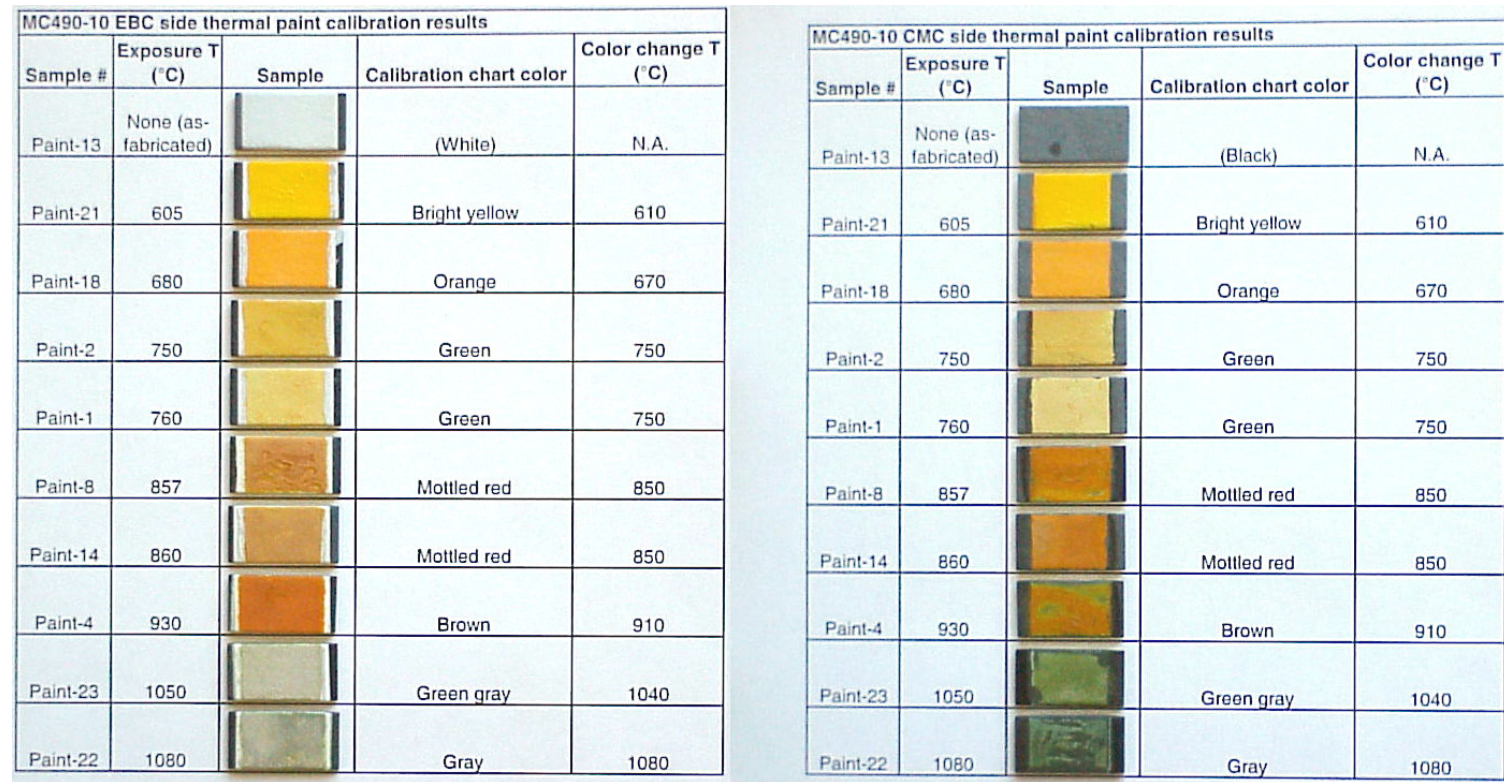

Figure 3-297. Examples of the thermal paint calibration test results on EBC-coated (left) and uncoated (right) CMC test specimens.

In past rig testing of shroud and combustor components the reliability of instrumentation applied to CMC parts has been less than desired. Typically the thermocouples required that a slot be cut into the $\mathrm{CMC}$, which is not desirable from a mechanics perspective, into which the thermocouple was embedded and then covered with a ceramic mortar. Such thermocouples often failed relatively early during the test either due to chemical interaction with the CMC and breakage of the thermocouple, or from simple pull-out of the thermocouple from the slot.

GE Aviation had demonstrated some success during CMC rig testing under the HSCT/EPM program using thermocouples applied by a vendor using a thermal spray process. Two vendors were identified who had experience instrumenting ceramics using this techinque, namely HiTec Corp. and HiTec Products. The thermocouple attachment process is to first 
arc spray a "pad" of oxide (typically alumina) onto the ceramic surface, affix the wires which are pre-bent into a zig-zag pattern for strain relief, and then overcoat strips of the wires with additional arc-sprayed alumina. CMC test samples, both with and without EBC coatings, were supplied to both companies for instrumentation trials.

Initial trials were done with Type K thermocouples (chromel vs. alumel) that demonstrated very poor durability during furnace exposure tests at $1200^{\circ} \mathrm{C}$. The cause of the failures was attributed to oxidative embrittlement of the thermocouple wires so a change was made to Type B (Pt-6\%Rh vs. Pt-30\%Rh) thermocouples. Both companies were able to produce bonded thermocouples that survived 20 hour $1100^{\circ} \mathrm{C}$ furnace exposure tests, including thermal cycling, but HiTec Corp. was selected as the preferred supplier based on its superior response time.

Finally, two tests were performed to evaluate the potential interaction of the thermocouples with the thermal paints, since both would be present during the initial rig test, and on the ability to remove the thermal paint via grit blasting without damaging the attached thermocouples. Figure 3-298 is a photograph of one of the HiTec Corp. attached thermocouples following overcoating with the thermal paint, exposure at $1100^{\circ} \mathrm{C}$ for 20 hours, and then grit blasting of the exposed paint from the surface. This treatment left the thermocouple intact and functional.

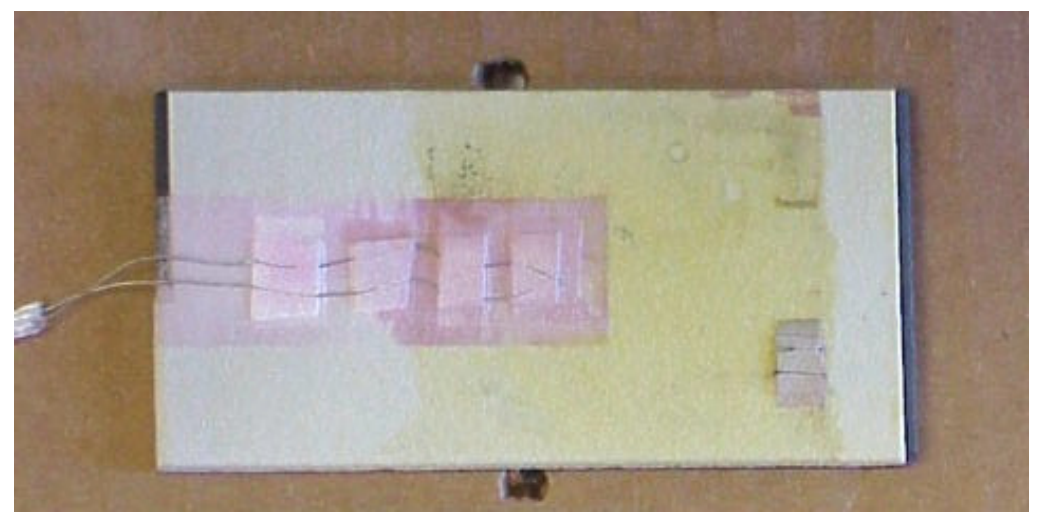

Figure 3-298. Photograph of a HiTec Corp. applied type B thermocouple on an EBCcoated CMC sample following thermal paint application, thermal exposure, and removal of the thermal paint via grit blasting. The thermocouple is still wellattached and functional.

\subsection{Task C3 - Detailed Design for Engine Testing}

The purpose of this task was to finalize the design of the combustor system in preparation for engine testing. Since rig and engine testing of the combustor system was cancelled little work was actually performed under this task. Nevertheless, much of the design work done toward the end of the combustor effort applied equally well to both the design for rig test as well as the eventual design for the engine test. For instance, as part of the overall combustor design effort the flow sleeve of the combustor system was re-designed to 
minimize both the thermal stresses introduced onto the CMC liner (by eliminating most of the backside impingement cooling holes) and to minimize the associated pressure drop. This re-design permitted the validation of earlier estimates of pressure drop benefits to be achieved with a CMC combustor system. However, a lowered pressure drop system would not be allowed in a field engine as it would upset the flows between the 14 separate combustor cans in a 7FA machine. Consequently hardware would have to be added back to the CMC combustor system to maintain the normal system pressure drop. The design of this extra hardware (the so-called "dP increaser") was largely a requirement of the engine test; however, the performance and durability of the $\mathrm{dP}$ increaser would need to be verified in the rig tests before being allowed in an engine test. This desire to evaluate engine-related hardware during the rig tests has caused the efforts this subtask to start earlier than in the initial program plan.

Fluid flow models were used to determine the location and rough size of the pressure drop increaser, but determining its exact size was beyond the precision of the models. Flow testing was therefore performed in a combustor flow simulation rig at GRC. During this testing, the size of the pressure drop increaser was varied and the pressure drop through the combustion system was monitored. The results of this testing are shown in Figure 3-299. The overall pressure drop of the simulated combustor system $(\mathrm{dP} / \mathrm{P})$ is plotted versus the relative fraction of flow area locally blocked by the pressure drop increaser. The goal was to match the pressure drop to that of the standard metal combustor system, which is shown by the red dashed line. The results of this testing allowed for the $\mathrm{dP}$ increaser to be sized properly to give the same pressure drop in the overall CMC combustor as the standard metallic combustion system.

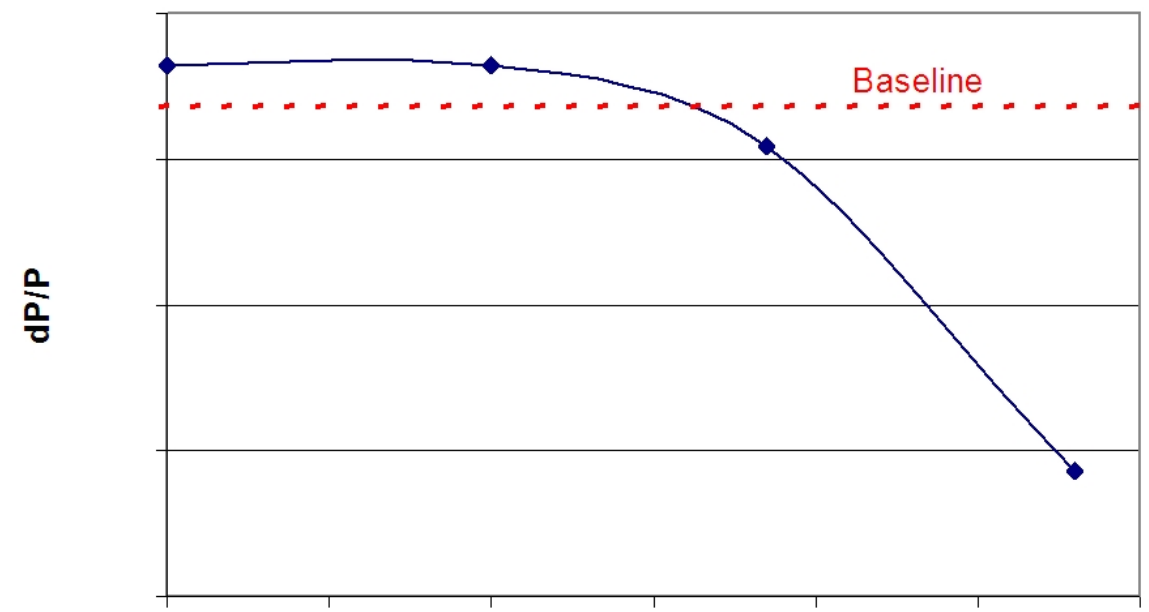

$\%$ blockage

Figure 3-299. Combustor system pressure drop as a function of the flow blockage caused by the pressure drop increaser ( $\mathrm{dP}$ increaser). 


\subsection{Task C4 - Engine Testing}

The goals of this task were to fabricate an MI-CMC combustor system according to the design from Task $\mathrm{C} 3$, to perform qualification rig testing of the sub-system, and to perform at least 4000 hours of engine exposure testing on at least one of 14 combustor systems. This task was dropped from the program when emphasis on component development shifted completely to the shroud component.

\subsubsection{Task C4.1a - CSGT Inner Liner Engine Test}

This section describes the fabrication, engine testing and post-test analysis of a prepreg melt infiltrated CMC inner combustor liner that was run in a Solar Turbines Ceramic Stationary Gas Turbine (CSGT) engine. The fabrication of the combustor liner was begun in 2003 under an internal program with GE Energy. Work on the combustor liner was then included in the contract modification proposal made in 2003, and as of the beginning of 2004 all work on this combustor liner demonstration was performed as task C4.1a within the AMAIGT program.

Solar Turbines had been under contract from DOE since 1992 to demonstrate a small $(\sim 5 \mathrm{MW})$ gas turbine engine that would utilize ceramic turbine hardware. The original plan of the program was to modify a Centaur $50 \mathrm{~S}$ engine to incorporate monolithic ceramic (sintered $\mathrm{Si}_{3} \mathrm{~N}_{4}$ ) $1^{\text {st }}$ stage nozzles and blades and a ceramic composite combustor liner. These components were expected to enable an increase in the turbine rotor inlet temperature from $1010^{\circ} \mathrm{C}$ to $1121^{\circ} \mathrm{C}$, thereby improving simple cycle efficiency from $29.6 \%$ to $31.3 \%$, and increasing engine output from $4144 \mathrm{~kW}$ to $5217 \mathrm{~kW}$. Unfortunately engine testing with monolithic ceramic nozzles and blades led to catastrophic failures so that these components were dropped from the program. The CMC combustor liner component, however, continued to be developed, with field engine testing of liners made from various SiC-based and oxide-based CMC materials occurring through 2006. The history of the CSGT engine program is described in references 23 and 24.

Fabrication of the combustor liner was begun in 2003, with the initial plan to fabricate three liners. The first of these was meant as a processing trial that would then be used for EBC spray process development. Liners \#2 and \#3 were to then be fabricated using lessons learned from liner \#1, and the best of these two chosen for engine testing by Solar Turbines, Inc. Due to processing issues experienced with liner \#2, to be discussed below, a $4^{\text {th }}$ inner liner was also produced. It was this $4^{\text {th }}$ liner that was finally selected and used for engine testing.

\subsubsection{Combustor Liner Fabrication}

The combustor system in the Solar CSGT engine is an annular combustor having cylindrical inner and outer liner sections that are made of CMC. A schematic of this combustor system is shown in Figure 3-300. Only the inner liner was made from prepreg HiPerComp® CMC. This liner is a simple right cylinder with nominal target dimensions of $20.5 \mathrm{~cm}$ long $\times 33.4 \mathrm{~cm}$ ID x $3.05 \mathrm{~mm}$ wall thickness. 


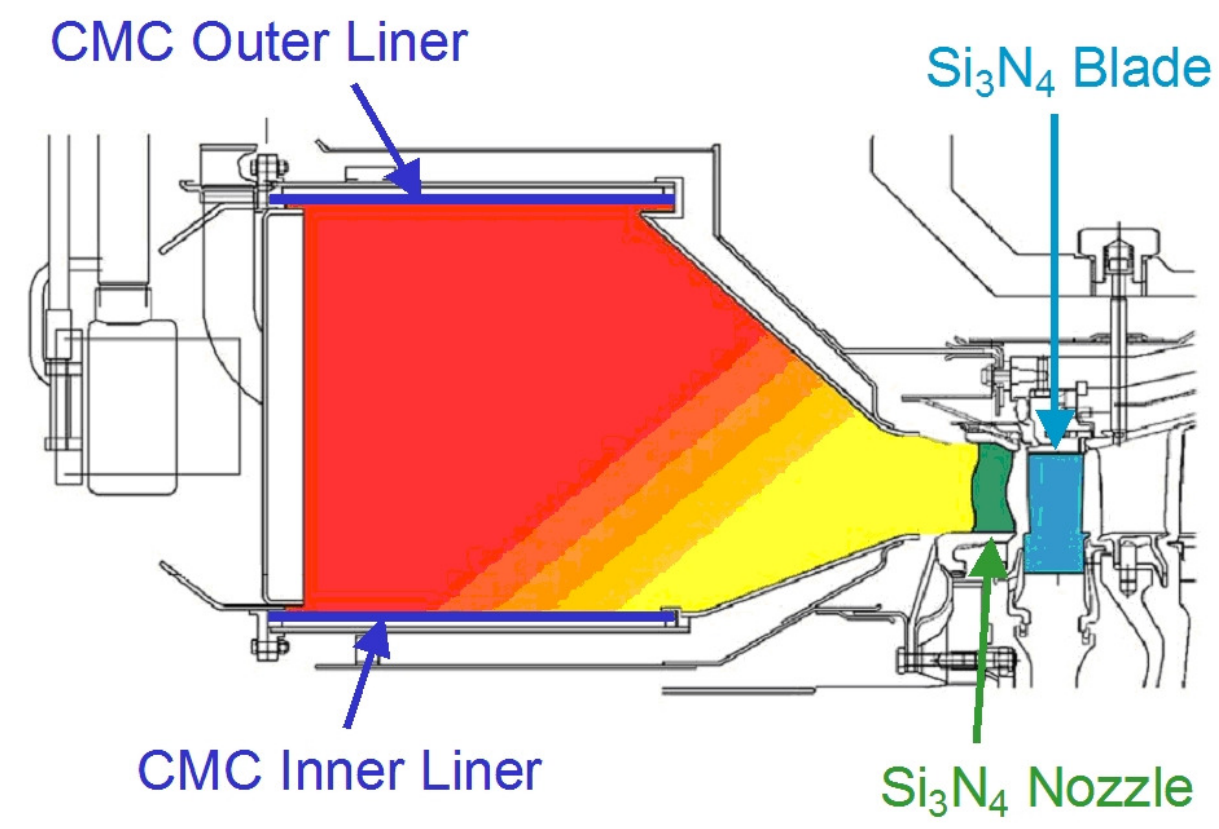

Figure 3-300. Schematic diagram of the Solar CSGT engine combustor system feeding into the turbine section. Ceramic components are highlighted.

The HiPerComp liners were fabricated using the standard prepreg MI CMC process. HiNicalon fiber tows were coated with "standard" 4-layer fiber coatings. The lot of fiber and reactor used for fiber coating varied from liner to liner due to the liner fabrication occurring over an extended time period. Liner \#1 was started in January of 2003 whereas lay-up of liner \#4 was not started until August of 2004. The fiber coatings used for each liner are listed in Table 3-25.

Table 3-25. Summary of the coated fibers used in the prepreg HiPerComp CSGT combustor liners.

\begin{tabular}{|cclc|}
\hline Liner & Fiber Lot \# & Fiber Coater Used & Fiber Coating Run \# \\
\hline 1 & 347 & Large GRC coater & SRM29 and SRM30 \\
2 & 348 & Large GRC coater & SRM31 \\
3 & $?$ & CCP coater & T0041 and T0042 \\
4 & $364,367,374$ & CCP coater & T0102 and T0111 \\
\hline
\end{tabular}

\subsection{Liner \#1}

The main purpose of the $1^{\text {st }}$ inner liner was to practice the overall fabrication process and identify any areas where additional process development might be needed. It was also intended to be used, provided it turned out to be of sufficient quality, as a practice substrate for EBC spray process development. The two main concerns regarding processing of the liner were consolidation of the liner preform without forming wrinkles, and obtaining complete infiltration of the liner without distortion. 
Fabrication of the $1^{\text {st }}$ inner liner was started in January, 2003, with the design and procurement of graphite tooling. Coating of the fiber for the liner was performed during February and March using the large GRC CVD coater. Lay-up of the $1^{\text {st }}$ liner was started in April 2003 using a 0-90 lay-up pattern. A graphite mold, nominally 33.4cm OD, was used as the lay-up tool. A $0.13 \mathrm{~mm}$ thick Teflon sheet was applied to the graphite to prevent bonding of the CMC preform with the mold. A monolithic matrix ply nominally $0.15 \mathrm{~mm}$ thick was then placed over the Teflon sheet. The first hoop (0) ply was then directly wound onto the matrix layer on the drum. A photograph of the direct wind process for the hoop plies of a cylindrical component is shown in Figure 3-301. (Note that the cylinder being wound in Figure 3-301 is a previous Frame 5 liner segment and not a CSGT liner, but the process and winder arrangement were identical.) Axial (90) plies were then cut from prepreg tapes and laid on by hand. In order to minimize the consumption of coated fiber tow the lay-up of this $1^{\text {st }}$ liner was only 8-plies thick, which is a typical lay-up for test panels but was known to be insufficient to give the desired $3 \mathrm{~mm}$ wall thickness.

Vacuum bagging in a laboratory oven was used to consolidate the liner after lay-up. During this process the liner tooling slipped from its support and came to rest with the liner against one of the shelf brackets. The pressure from the shelf bracket caused an indentation into the liner outer surface, which later cracked during the burn-out and infiltration steps.

Burn-out was done in the Centorr vacuum furnace at GRC while still on the lay-up tool. During burn-out the Teflon burned-off leaving a small amount of a gritty carbon char and porosity. There was sufficient clearance following burn-off of the Teflon sheet, and the remaining carbon char was sufficiently friable, to allow the liner to be slid off of the graphite mold. The liner was then placed on a BN-coated, slotted graphite mold for infiltration.

Melt infiltration was done at GRC in early June, 2003. Infiltration was done using a pack infiltration process with the pack applied over the outer surface of the liner. A photograph of the liner following infiltration, with the indented region marked, is shown in Figure 3302. 


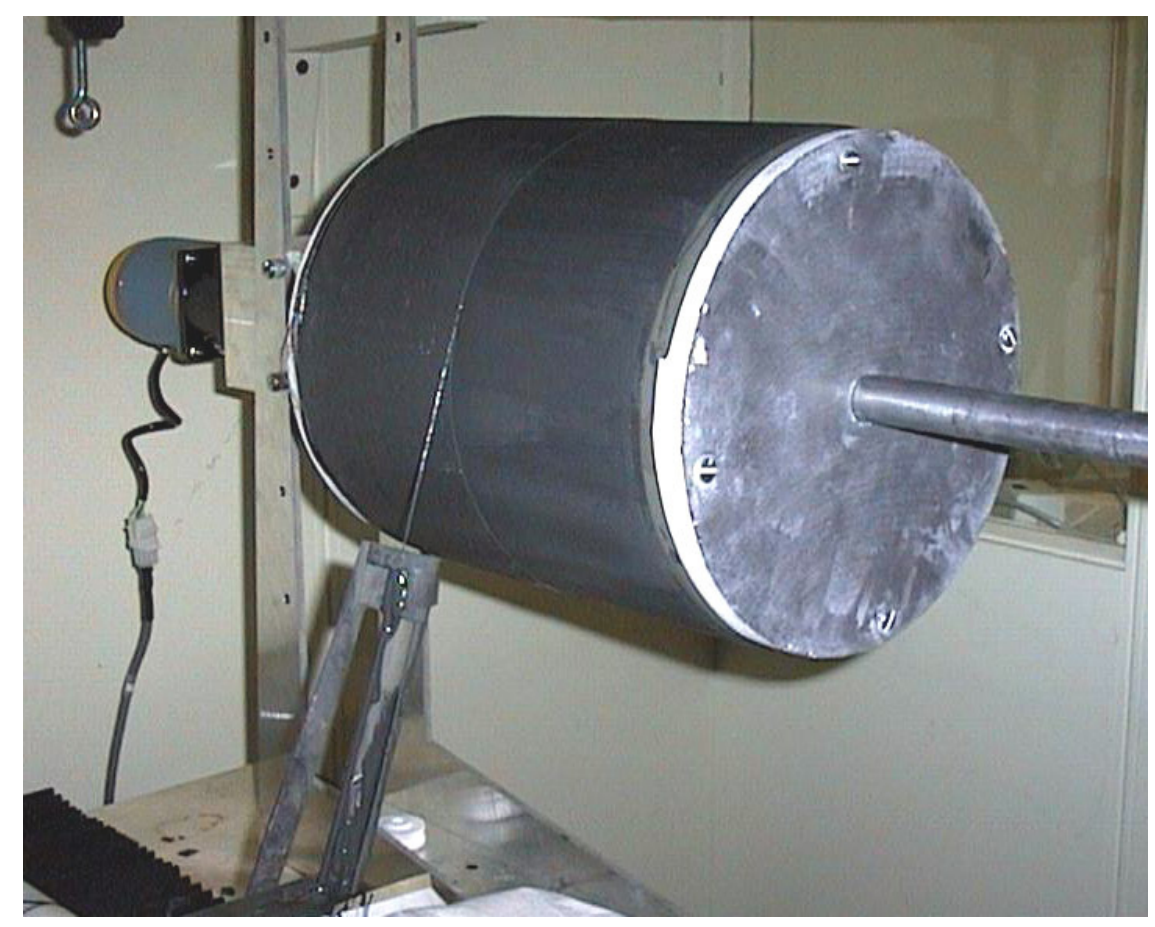

Figure 3-301. Photograph of the direct-wind process for lay-up of the hoop plies of a cylindrical component such as the CSGT combustor liners.

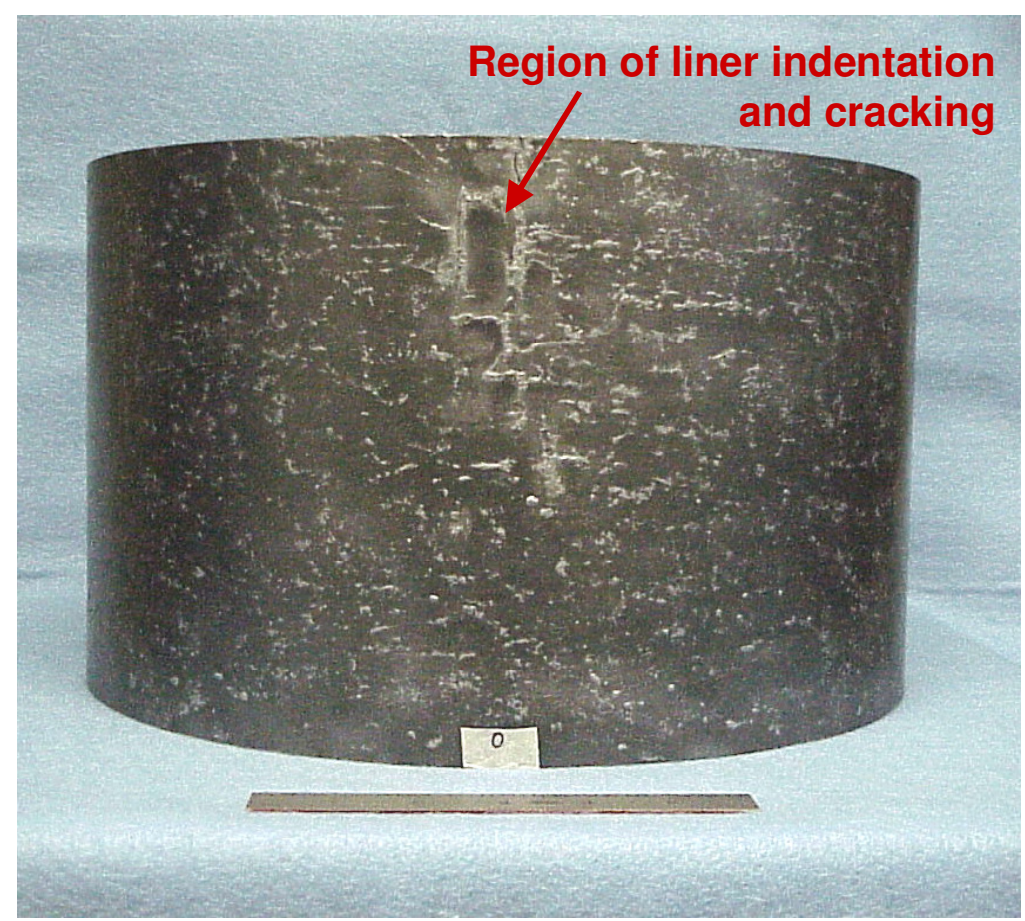

Figure 3-302. Photograph of the $1^{\text {st }}$ prepreg CSGT inner liner after partial grit-blast cleanup following melt infiltration. The region of the liner that was indented during vacuum bagging is indicated. 
In addition to the indentation defect, the liner also had an overall low density with distributed porosity throughout the microstructure. After fabrication of this liner a cooling water leak was found in the large GRC fiber coater. Although we could not be certain whether the water leak influenced the particular fiber coating runs used for the liner, the low density and porous microstructure were consistent with observations on other panels and parts made with fiber that was definitely affected by the leak.

The relatively mild vacuum bagging treatment (i.e. 1 atmosphere of consolidation pressure) used with liner \#1 did not cause any ply wrinkles in that liner, but there were still indications of delamination defects and porosity in the NDE images, as shown in Figure 3-303. (Initial NDE inspections of all liners was done at GRC using back-scattered and transmission IR thermography.) These defects indicated the need for a higher consolidation pressure during lamination. However, in previous fabrication trials of smaller cylindrical components and the 7FA combustor liner components, where a higher consolidation pressure was used in conjunction with a 0-90 fiber architecture, ply wrinkles were a common problem. The need for higher consolidation pressure, plus the desire to minimize ply wrinkles, led us to utilize a $+/-45$ degree fiber architecture in the second liner.
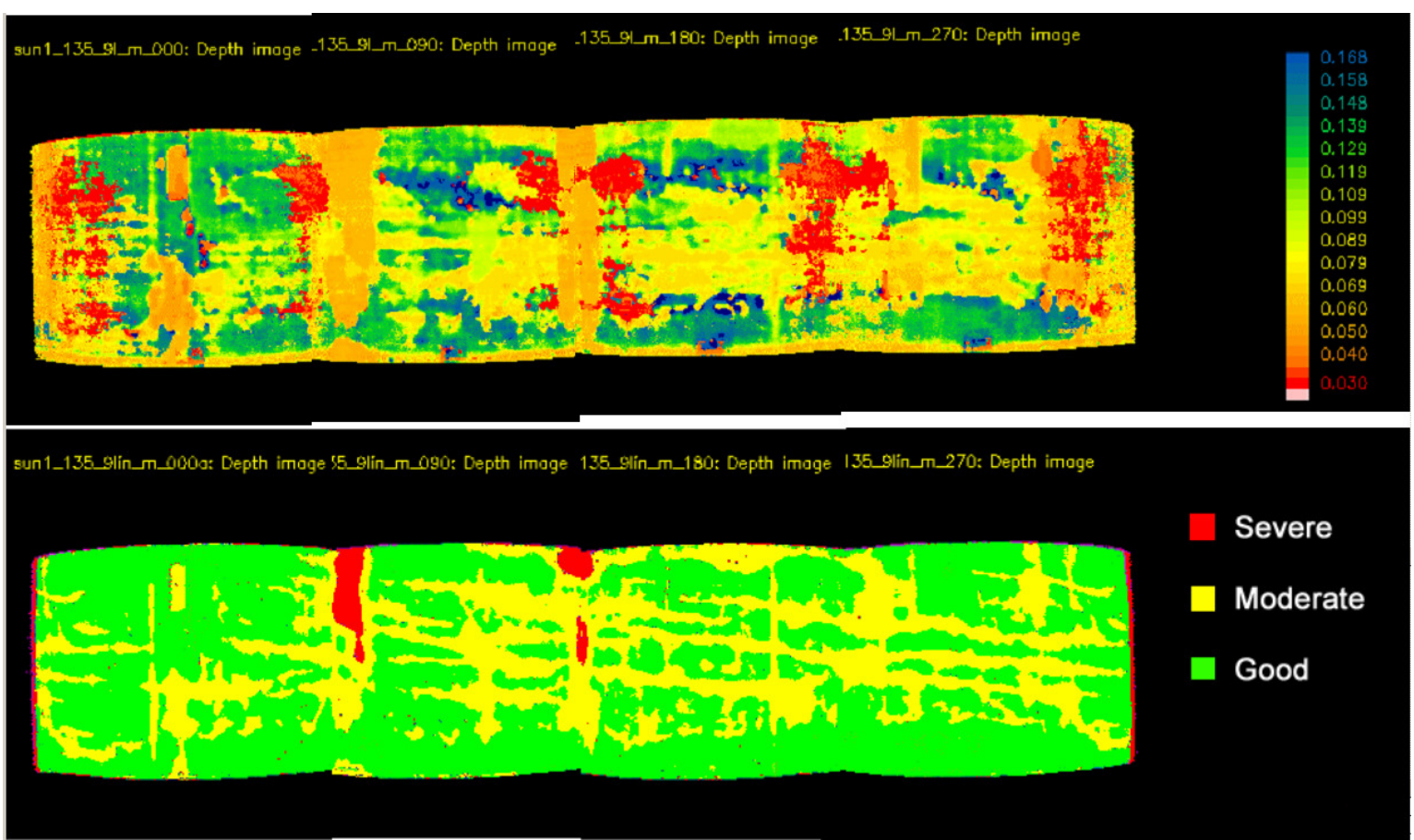

Figure 3-303. Montage IR NDE images from CSGT liner \#1 shot at 4 orientations. The upper image is a reflection image showing the depth of any detected defect and the bottom image is an amalgam of the reflection and transmission images scaled based on the relative severity of the detected defects. 


\subsection{Liner \#2}

The $2^{\text {nd }}$ liner was processed through winding and lay-up during June-July, 2003. As noted above, $a+/-45$ fiber architecture was used with this liner to try to minimize the occurrence of ply wrinkles during lamination. Due to this architecture all of the plies had to be laid by hand onto the cylindrical graphite mold. Thermal shrink tape was wrapped around the preform at several points of the lay-up process to debulk the preform and smooth the surface for application of subsequent plies. Photographs of the liner during the lay-up process are shown in Figure 3-304 where the +/-45 architecture is evident from the angled lines on the surface whereas the hoop lines are from the seems in the shrink wrapping.
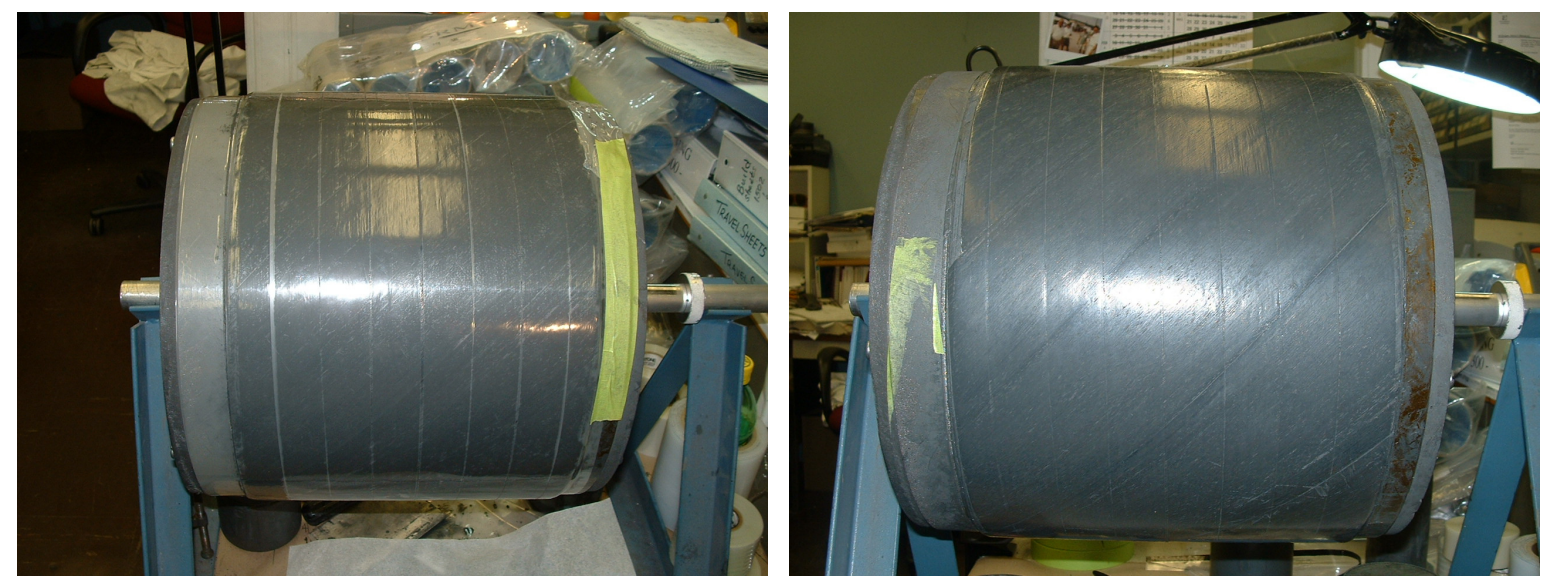

Figure 3-304. Photographs of CSGT combustor liner \#2 during the lay-up process. Left liner on lay-up tool with thermal shrink tape used for debulking in place; Right liner on lay-up tooling after removal of the shrink tape.

The CSGT liner was too large to fit in the autoclave available at GRC at that time, so lamination/consolidation was done in the large autoclave at CCP in early August, 2003. Unfortunately the full extent of the reactor water leak problem was not known at the time when the liner was fabricated, and consequently this liner was also fabricated using questionable coated fiber. Once it was realized that this fiber may have been affected by the coating reactor water leak it became necessary to perform a series of infiltration experiments in an attempt to maximize the likelihood that liner would be infiltrated successfully. These experiments were done through the Fall and early Winter of 2003. During this time modifications were made to the infiltration furnace vacuum system, which was also as a response to the poor infiltratability of the large GRC reactor coated fiber. Through these experiments it became clear that the best chance of complete infiltration would be with a silicon wicking method rather than the infiltration pack method.

Burn-out and infiltration of the liner was done in January, 2004. Burnout was done while still on the lay-up tool. A photograph of the liner following burnout and removal from the lay-up tool is shown in Figure 3-305. 
The liner was placed on $\mathrm{BN}$-coated graphite tooling, similar to that used for liner \#1, and oriented with its axis vertical in the furnace. Carbon cloth wicks were attached at the top and bottom edges for feeding the silicon alloy into the liner. A photograph of the liner inside the infiltration furnace following the infiltration run is shown on the left of Figure $3-$ 306. Despite there being a substantial excess of alloy on both the top and bottom wicks (5X the mass of the burned-out liner and wicks), and the use of an extended infiltration time of 2 hours, there was still a 1.5" wide strip around the center of the liner that was not infiltrated. This un-infiltrated band is more clearly seen in the right photograph in Figure $3-$ 306, which shows the liner following removal from the infiltration furnace and tooling. This band was not a result of insufficient Si alloy as there was still a large excess of alloy on both top and bottom wicks after the furnace run.

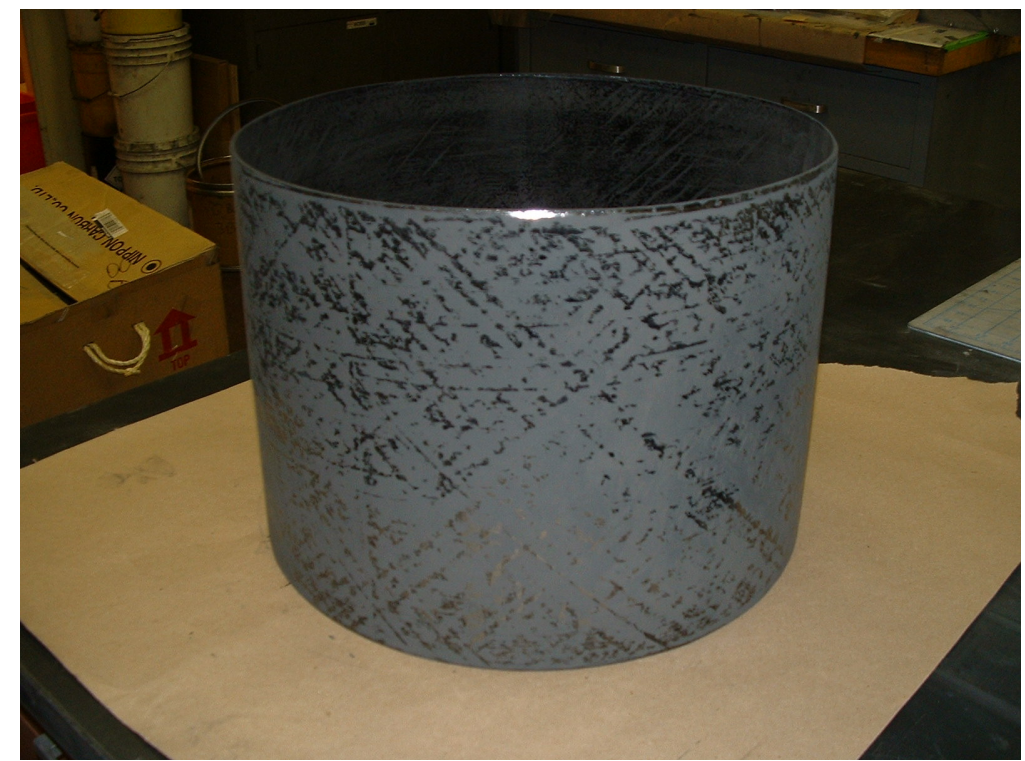

Figure 3-305. Photograph of liner \#2 following burn-out and removal from the graphite lay-up tool.

This $2^{\text {nd }}$ liner was clearly not usable for engine testing in this condition, and was not even suitable as a potential EBC practice piece. Historically the success rate for re-infiltrating parts that had only been partially infiltrated was very poor. Thermal mismatch strains are created between the infiltrated and un-infiltrated regions during the thermal cycling between infiltration runs that tend to create large defects in the parts. Also, there appears to be a change in the wetting characteristics of the preform following an incomplete infiltration cycle, as there have been cases where CMC panels would not infiltrate to completion during a second infiltration cycle under conditions where a fresh panel would infiltrate completely. Nevertheless this $2^{\text {nd }}$ liner was put through a second infiltration cycle in an attempt to at least get infiltration of the outer surface region, thereby making it acceptable for EBC deposition trials. Following the second infiltration both the NDE images, as shown in Figure 3-307, and damage noted during surface cleaning via grit blasting clearly showed that the liner had still not infiltrated to completion. It should be noted that many of the 
defects observed in the NDE inspection occurred in the regions of the liner that appeared well infiltrated from the outer appearance, which would suggest that there were still delamination defects in the liner independent of the infiltration problem. Again, these delaminations were believed to result from poor compaction during the simple vacuum bag lamination treatment.
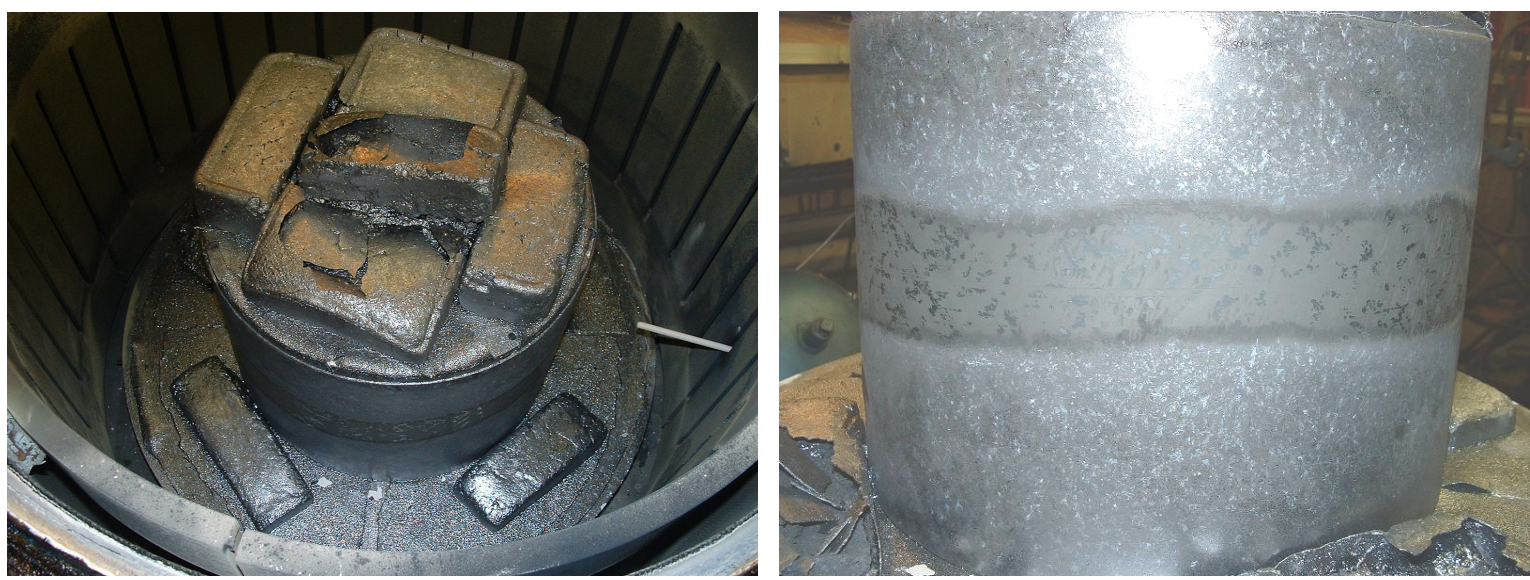

Figure 3-306. CSGT combustor liner \#2 following melt infiltration: Left - the liner inside the furnace showing the positioning of the liner, tooling and silicon alloy source blocks; Right - side view of the liner showing the un-infiltrated band along the center of the liner.

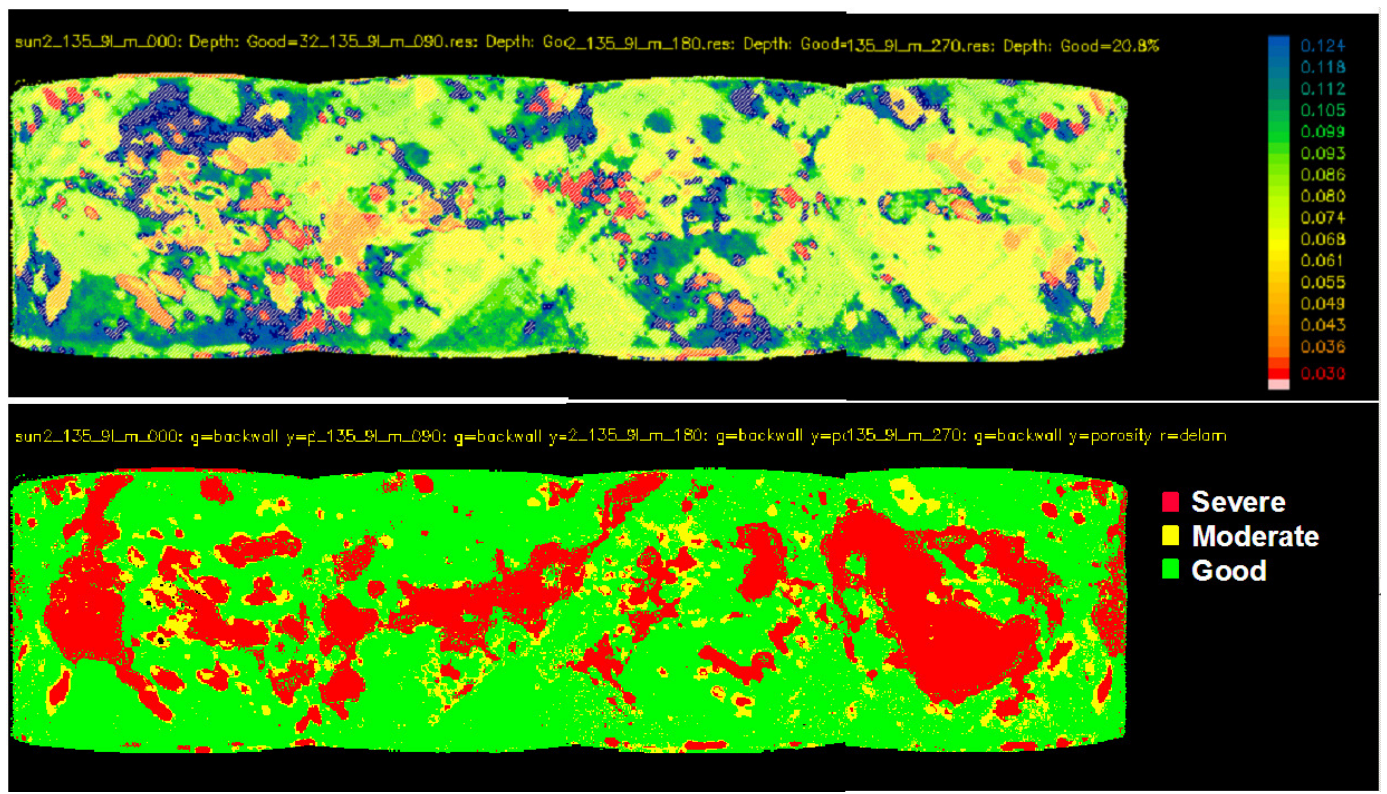

Figure 3-307. Montage IR NDE images of CSGT liner \#2 following the $2^{\text {nd }}$ infiltration treatment shot at 4 different orientations. The upper images are reflection IR showing defect depth whereas the lower images use the reflection and transmission IR data to derive a map of the severity of the detected defects. 


\subsection{Liner \#3}

The large concentration of defects in liner \#1 and the incomplete infiltration of liner \#2 were troublesome. Although only a $3^{\text {rd }}$ liner had been planned, it was decided to make an additional liner \#4 to try to maximize the likelihood that at least one of the remaining liners would be of acceptable quality for engine testing. This also allowed for investigation of two infiltration techniques for the liners, as discussed below.

Due to resource needs of other CMC programs the start of fabrication of the $3^{\text {rd }}$ liner was delayed until July 2004. Part of this delay was related to the source of coated tow. Coated tow from the large GRC reactor had consistently shown quality issues, both related to the water leak described previously and to the generally higher level of physical tow damage from this reactor. The size of the liner is such that producing the necessary coated fiber in the small GRC reactor was not an attractive option. During this time period (Winter 2003 Spring 2004) the fiber tow coating operation at CCP had come on line and early indications were that they were producing good quality coated tow, which was actually superior in physical handle-ability to the quality of the coated tow coming from the large GEN2.0 GRC reactor. It was therefore decided that the best solution would be to utilize coated tow from CCP to make the additional liners.

Work on other CMC turbine components, particularly the 7FA shrouds and combustor liners, had demonstrated the value of performing intermediate de-bulking steps during the lay-up of those components in order to minimize ply wrinkling. Such de-bulking treatments were subsequently used during fabrication of the $3^{\text {rd }}$ liner rather than utilize the $+/-45$ degree architecture that had been used in liner \#2.

Based on the observations from the $1^{\text {st }}$ and $2^{\text {nd }}$ liners, the size of the liner was still expected to present infiltration difficulties, especially when using the standard "pack" infiltration process. For this reason a new infiltration technique utilizing bonded wicks was adopted from some earlier in-house component work on 7FA nozzle airfoils. This technique had been effective in the earlier nozzle study, but had not been practiced to any great degree since, and thus the robustness of the new technique was not known. Since it was not certain that either infiltration technique would guarantee success, it was decided to utilize the pack infiltration process for one of the remaining liners (\#3), and to use the newer bonded-wick infiltration technique on the other (\#4), in the expectation that at least one of the techniques would be successful.

Fiber for liner \#3 was received from CCP in early July, but do to commitments on other programs the fabrication of the liner did not start until late July. Tape winding and lay-up of the liners proceeded normally. The lay-up procedure for liner \#3 was similar to that for liner \#1 in that hoop plies were directly wound and axial plies were laid by hand. The major difference with liner \#1 was the utilization of the warm vacuum bag debulking treatment periodically during the lay-up process, and the use of 11 plies to get the required wall thickness. Lay-up of the liner, which was done in parallel with liner \#4, was completed in late August. 
As noted earlier, simple vacuum bag lamination did not appear to be sufficient to fully compact the liners and eliminate interlaminar defects. However, the liners were too large to fit into the small laboratory autoclave that was typically used for CMC panels and shroud components. This situation necessitated the use of a larger pilot-plant scale autoclave operated by GRC's polymer composites group. Unfortunately, the autoclave lamination and cure process step was delayed by about 2 weeks due to control system maintenance issues with this autoclave. The added delay caused by the controller problem made it necessary to run both liner \#3 and \#4 simultaneously through the autoclave cycle in order to maintain the overall process schedule. During the run a vacuum bag leak occurred, which caused the liners to be consolidated at a somewhat reduced pressure, and this pressure lasted only for 8 of the intended 18 hours of the lamination cycle, at which point the pressurizing gas (bottled $\mathrm{N}_{2}$ ) was depleted. Similar vacuum bag failures have been noted previously when processing other CMC components (panels and shrouds) with no ill effects on the final CMC density. Following autoclave curing the liners were removed from the vacuum bags and examined. Liner \#3, which is the one that had the vacuum bag leak, appeared smooth and well compacted. A photograph of Liner \#3 after autoclave treatment but prior to removal from the lay-up/lamination tool is shown in Figure 3-308.

Figure 3-308. Photograph of Liner \#3 following autoclave lamination.

During fabrication of the previous liners, the cured liner preforms were put through the binder burn-out cycle while still on the lay-up tooling. This was done in order to thermally decompose the tooling separation film at the same time as the liner binder burn-out, thereby creating a gap between the liner and the tool, which would aid in removing the liner preform 
from the tool with minimal force. However, we had seen evidence in the earlier liners and with the 7FA combustor liner that the glassy carbon char left behind from the tooling separation film could interfere with complete infiltration of the part. We therefore decided to press the liners off of the lay-up tool so that the separation film could be removed prior to burn-out. This process was entirely successful for liner \#3.

Again due to the size of the liners, the binder burn-out step was done at CCP using their $\mathrm{N}_{2}$ retort furnace. This furnace is commonly used for burn-out of HiPerComp composite preforms at CCP. The liners were then returned to GRC for melt infiltration. Following burn-out there were no overall dimensional changes noted in the liner.

As noted previously, liner \#3 was infiltrated using standard pack infiltration procedures. The liner was placed on a BN-coated, multipart carbon tool during infiltration in order to maintain roundness, and the infiltration pack was applied entirely to the outer surface of the liner. The infiltration was then done in a standard vacuum furnace. After infiltration the pack remnants were removed by a combination of grit blasting and grinding with a handheld air grinder. Visual inspection of the liner after clean up suggested that it was generally well infiltrated. Figure 3-309 shows photographs of liner \#3 following post-infiltration grit blasting. The grayish blotches on the liner surface, particularly around the bottom half, are areas where hand grinding was required to remove some remnant adherent silicon alloy, but they did not compromise the integrity of the liner or of the surface finish.

Despite the good visual appearance of the liner, NDE examination showed quite extensive and severe internal defects. Montage images from the NDE inspections are shown in Figure $3-310$. It is likely that these defects were caused by a combination of poor compaction during the autoclave treatment, due to the vacuum bag leak, and incomplete infiltration from the pack source through the full thickness of the part. 


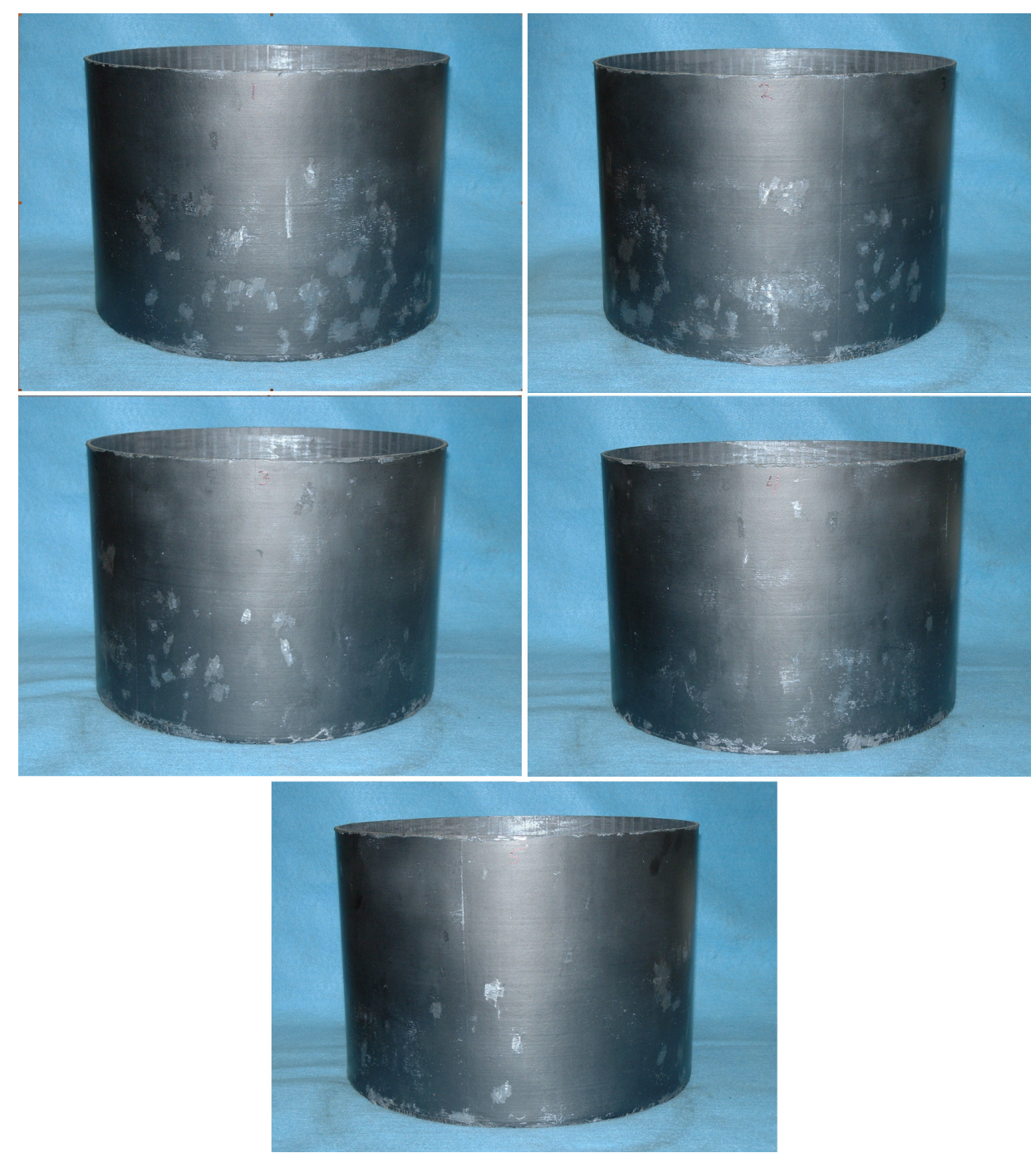

Figure 3-309. Photographs of HiPerComp CSGT liner \#3 at roughly $72^{\circ}$ intervals following surface cleaning after infiltration. 

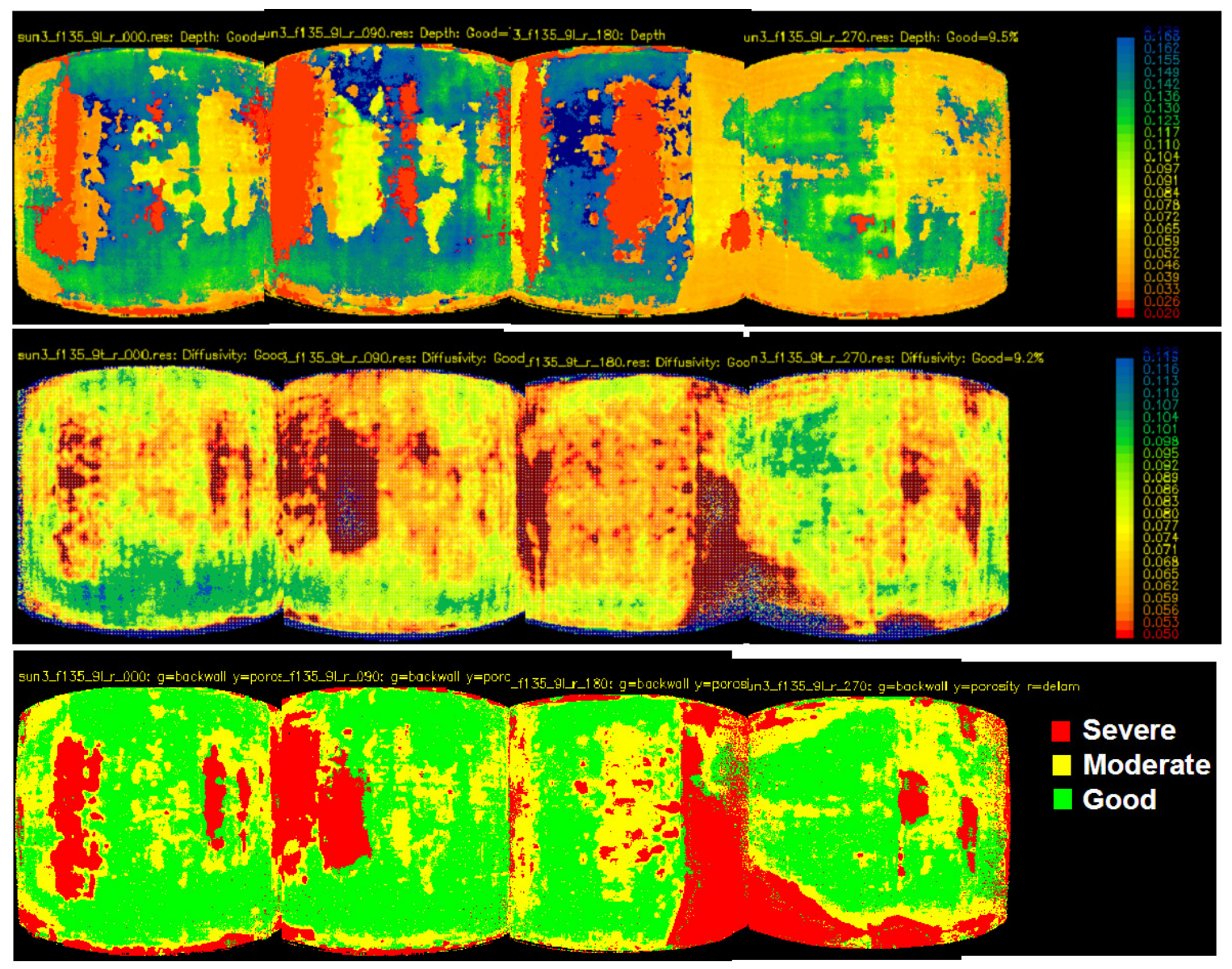

Figure 3-310. Montage NDE images of CSGT liner \#3 taken from four orientations: Top - reflective IR image showing defect size and depth; Middle - transmission IR image imaging showing thermal diffusivity values; Bottom - defect severity image based on the upper 2 images.

\subsection{Liner \#4}

Coated fiber for use in liner \#4 was received from CCP in mid-August, 2003. The lay-up procedure was the same as that used for liner \#3 except that an internal bonded carbon cloth wick was applied to the lay-up cylinder tool prior to winding of the $1^{\text {st }}$ ply. The carbon cloth was the same material used for wicking during infiltrations. It was pre-impregnated twice with a solution containing the organic ingredients and solvents of the normal matrix slurry at twice the normal concentration, but without any of the inorganic solid ingredients (carbon or $\mathrm{SiC}$ powders). After air drying the cloth was coated on one side with normal matrix slurry. The cloth was impregnated with the resin solution in order to provide resins within the carbon cloth to help stabilize its dimensions and provide for good bonding to the CMC matrix. The pre-impregnation also helped to prevent full wet-out of the cloth by matrix slurry during the surface coating step. The desire was to keep carbon cloth mostly free of matrix slurry so that the pore channels within the cloth would act as effective wicking paths for the silicon infiltrant, and it was anticipated that if the cloth was completely impregnated with matrix that the remaining pore concentration in combination with the 
increased carbon concentration from the presence of the cloth, would be insufficient to prevent choke-off during infiltration. The surface of the cloth was pre-coated with matrix slurry to prevent the cloth from wicking the slurry from the SiC fibers during winding of the $1^{\text {st }}$ composite ply. This impregnated and coated carbon cloth was then wrapped over the polymer separation sheet on the graphite lay-up tool to take the place of the initial monolithic matrix layer normally used in the lay-up process. Due to the added thickness of the carbon cloth wick layer the number of composite plies was dropped to 9 instead of the 11 used in liner \#3. The lay-up configuration, from inner surface to outer surface, was as follows: carbon wick layer; 2 hoop plies; 2 axial plies; single hoop ply; 2 axial plies; 2 hoop plies; outer surface matrix layer.

As noted above, liner \#4 and liner \#3 were laminated in the same autoclave run using the autoclave in the GRC polymer composite development group, and that during this run a vacuum bag leak occurred that reduced the compaction pressure seen by the liners. Liner \#4, which had the intact vacuum bag throughout the lamination/cure step, appeared well compacted, but had developed one large and two small wrinkles aligned axially along the liner. It is likely that the cause of wrinkling in liner \#4 was due to compaction of the inner carbon cloth wick material. Liner \#3, which did not have an internal wick and was otherwise processed identically, did not have any visible ply wrinkles following autoclave lamination.

Also as described previously, the liner was pressed off of the lay-up/lamination cylinder so that the separation film could be removed prior to burn-out. This process proceeded well for liner \#3, but liner \#4 experienced some buckling damage extending roughly 3/4" in from the end being pressed. Luckily the liner had been fabricated slightly longer than needed so that this damaged area would be removed during final machining. Photographs of liner \#4 following removal from the lamination tooling are shown in Figure 3-311. The liner end that buckled during removal from the tooling is at the bottom in the photos, and pieces of the bonded internal wick can be seen extending upward from the top edge of the liner.

Burn-out of the liner was done at $\mathrm{CCP}$ in their $\mathrm{N}_{2}$ retort furnace at the same time as liner \#3. Following burn-out there were no overall dimensional changes noted in the liner, but the surface wrinkles were observed to decrease in height but "spread out" slightly in the radial directions. Several photographs of the liner after burn-out are shown in Figure 3312. 


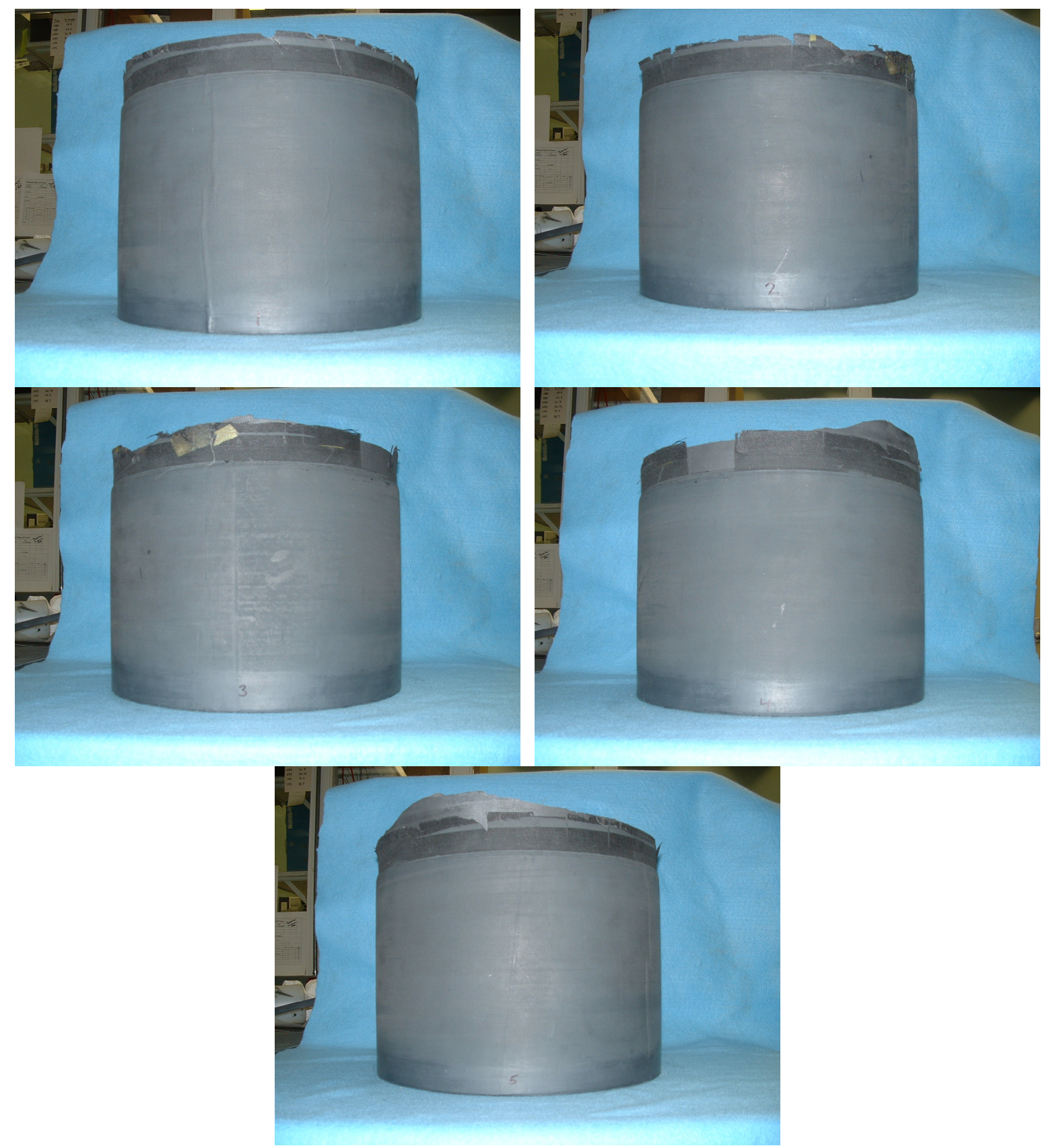

Figure 3-311. Photographs of liner \#4 following autoclave lamination and removal from the tooling. The main axial ply wrinkle, extending from top to bottom of the liner, can be seen in the top left photograph 


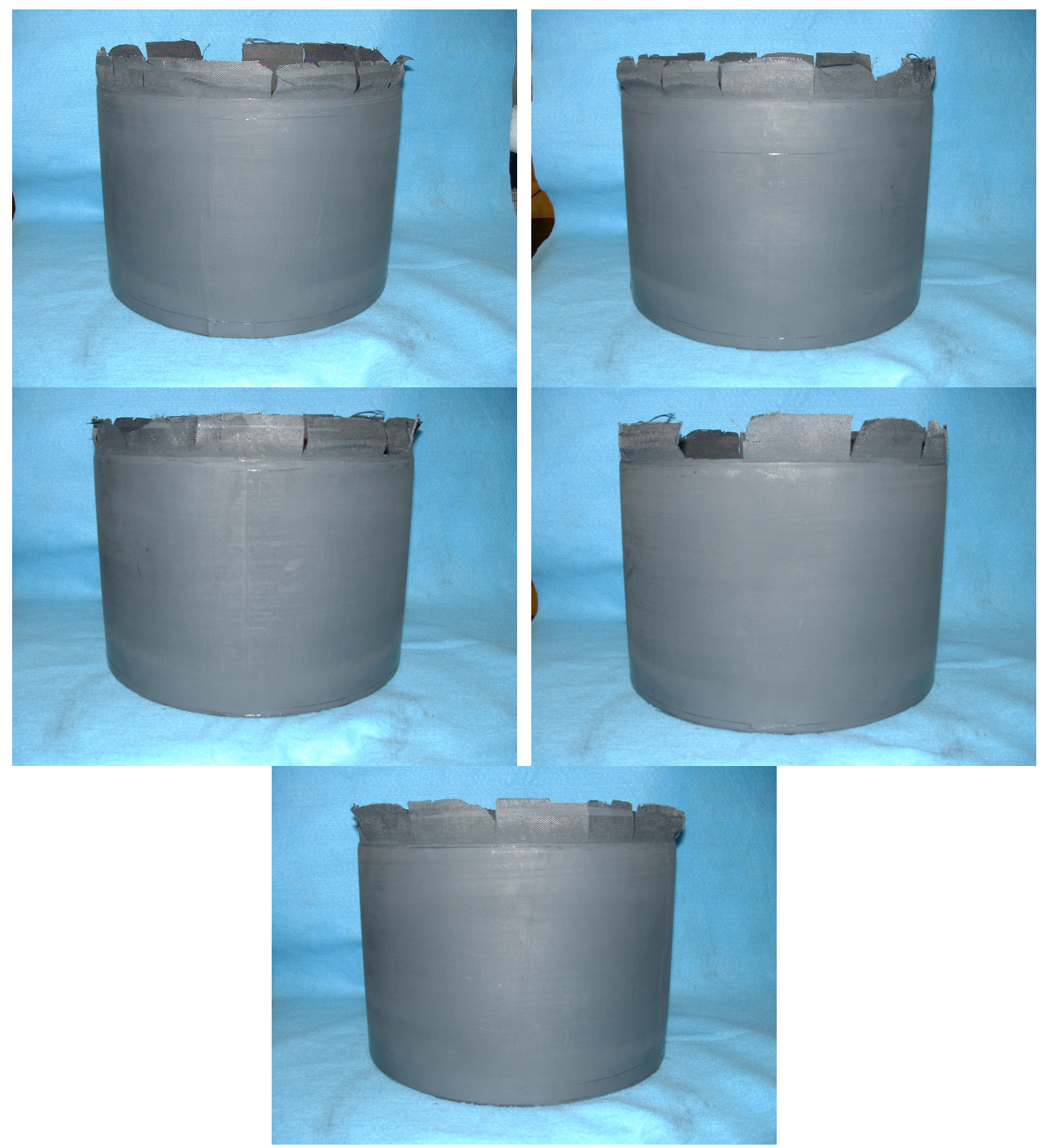

Figure 3-312. Photographs of liner \#4 following the burn-out heat treatment and removal from the tooling. The main axial ply wrinkle, extending from top to bottom of the liner, can be seen in the top left photograph

The liner was again placed on a multi-part, slotted, BN-coated graphite cylinder as tooling for infiltration. Blocks of Si+B alloy powders were used as the alloy source for infiltration. The overall arrangement of the liner, tool, wicks and silicon pucks in the infiltration furnace is shown in the diagram and photograph in Figure 3-313. Following infiltration the liner appeared as shown in Figure 3-314. There are some dark, irregular markings on the surface of the liner that were caused by a blackening of the excess silicon alloy on the liner 
surface. These markings did not correspond to any detectable liner defect, and grit blasting of these marks during clean-up of the liner was no different than grit blasting of the other shinier regions. Photographs of the liner following grit blasting to clean off the excess silicon alloy are shown in Figure 3-315.

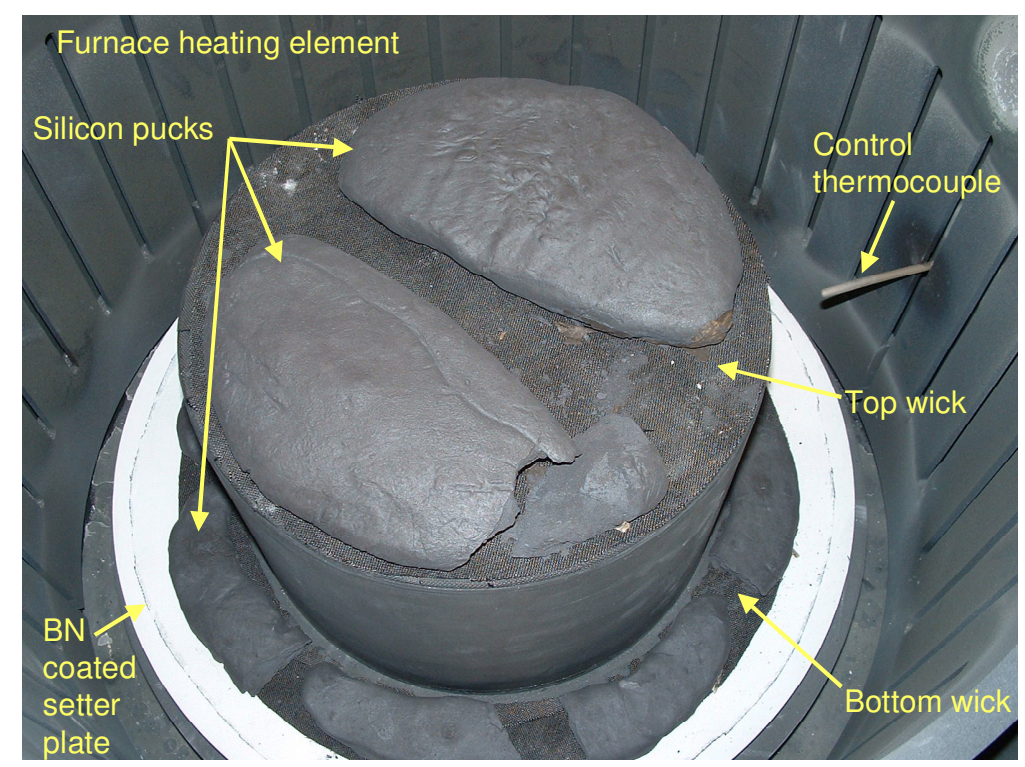

Figure 3-313. Photograph of the infiltration set-up for the $4^{\text {th }}$ liner prior to the infiltration run.

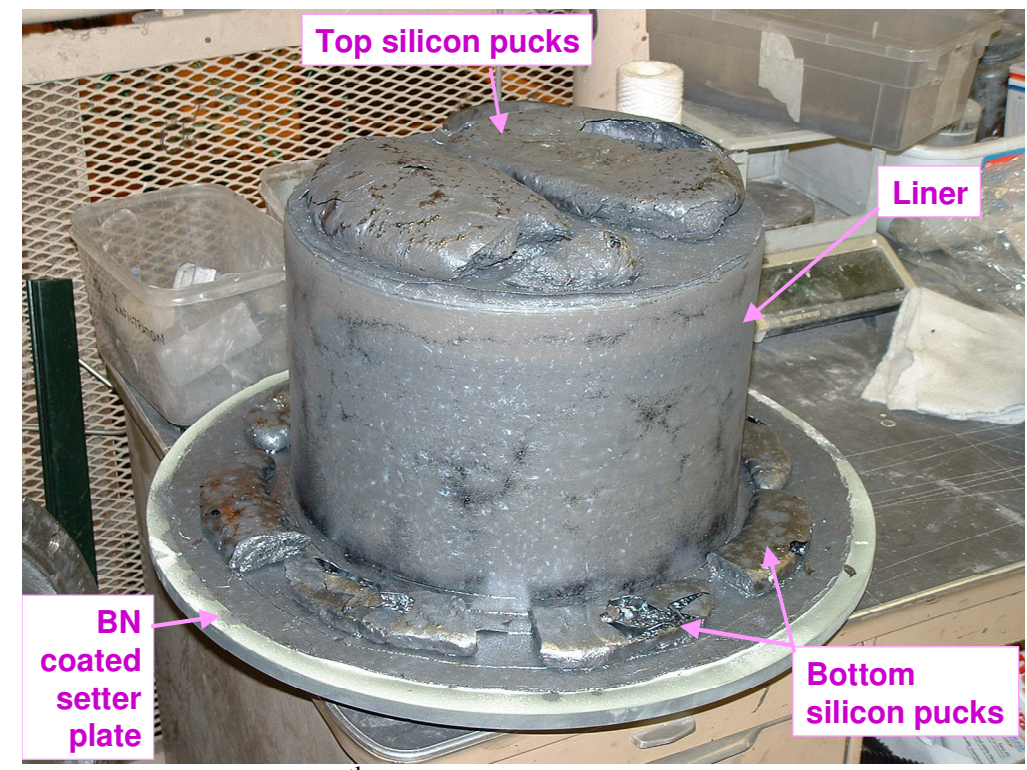

Figure 3-314. Photograph of the $4^{\text {th }}$ CSGT liner immediately following infiltration. 


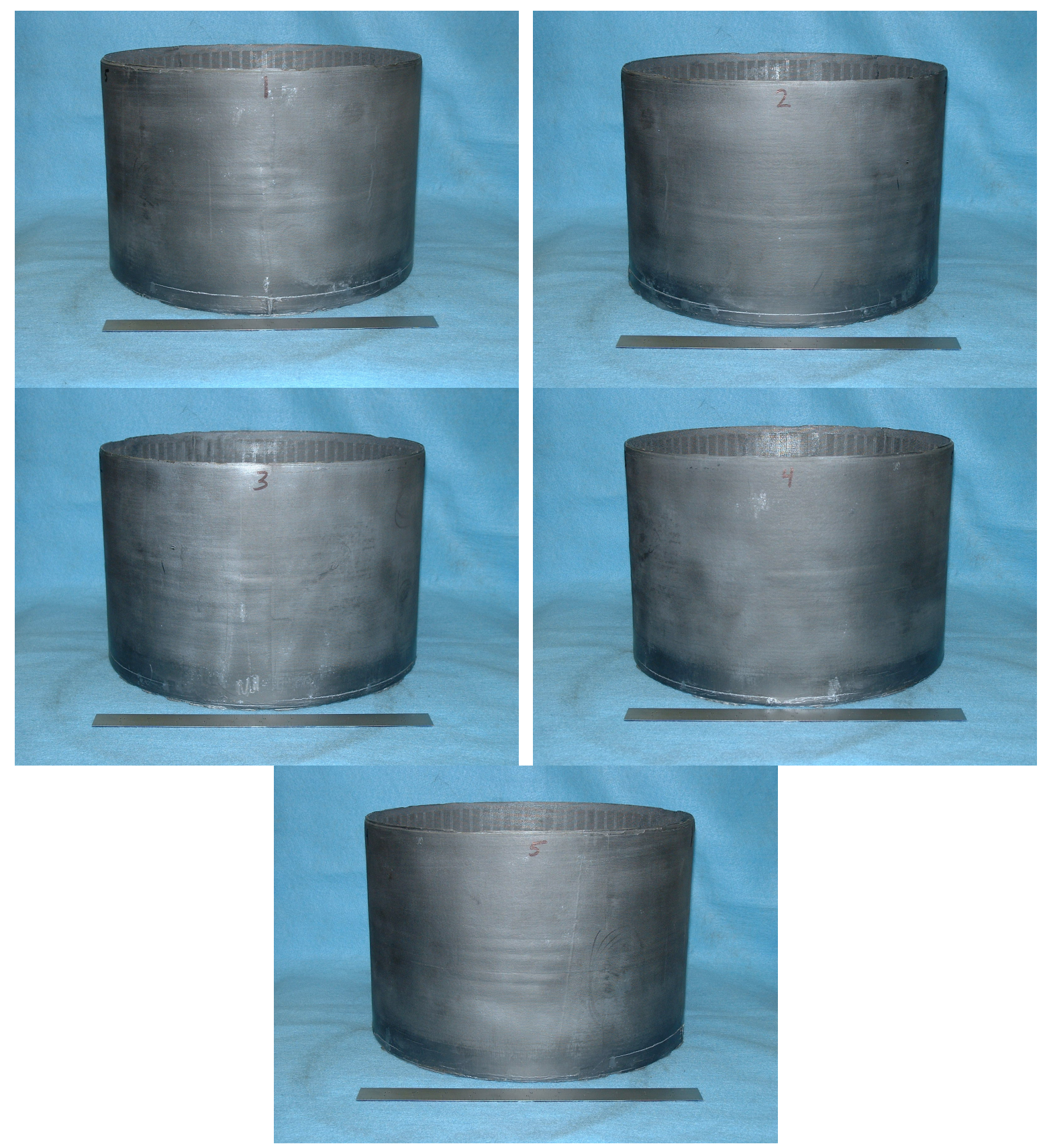

Figure 3-315. Photographs of HiPerComp CSGT liner \#4 following infiltration and gritblast clean-up. The photographs are from 5 angles around the circumference showing the entire liner surface.

NDE of liner \#4 was done using IR thermography. Images from the NDE inspection are shown in Figure 3-316. A large fraction of the liner showed no discernible defects (the green to bluish regions in the top thermal diffusivity images), but there were still substantial regions with significant defects. These defects tended to correlate with the positions of the axial wrinkles, and radiated out circumferentially from these wrinkles. The relationship of the defects to the wrinkles is indicated more clearly in Figure 3-317. 


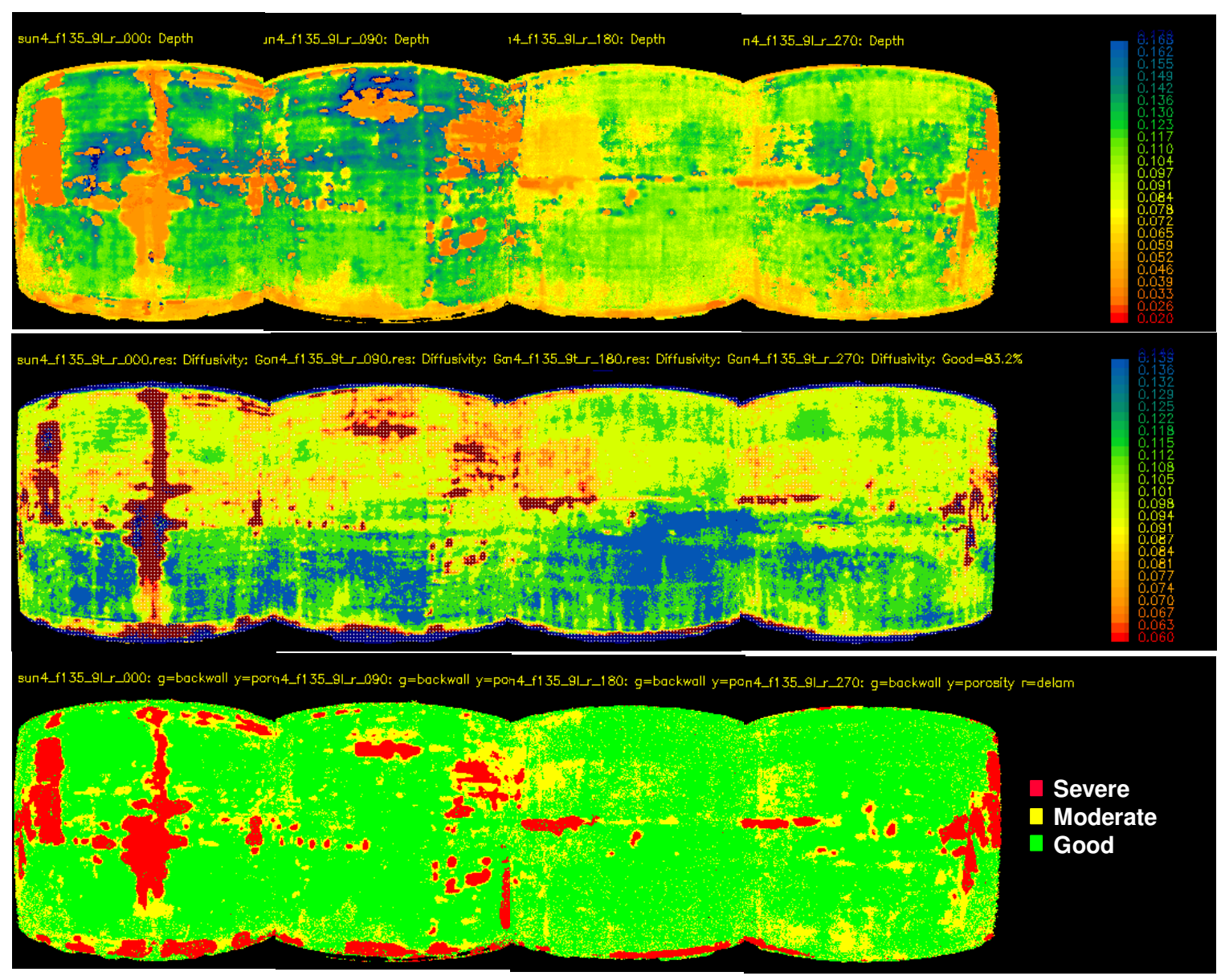

Figure 3-316. Montage IR thermography images of Liner \#4 taken from four orientations: Top - reflective IR image showing defect size and depth; Middle - transmission IR image imaging showing thermal diffusivity values; Bottom - defect severity image based on the upper 2 images. 

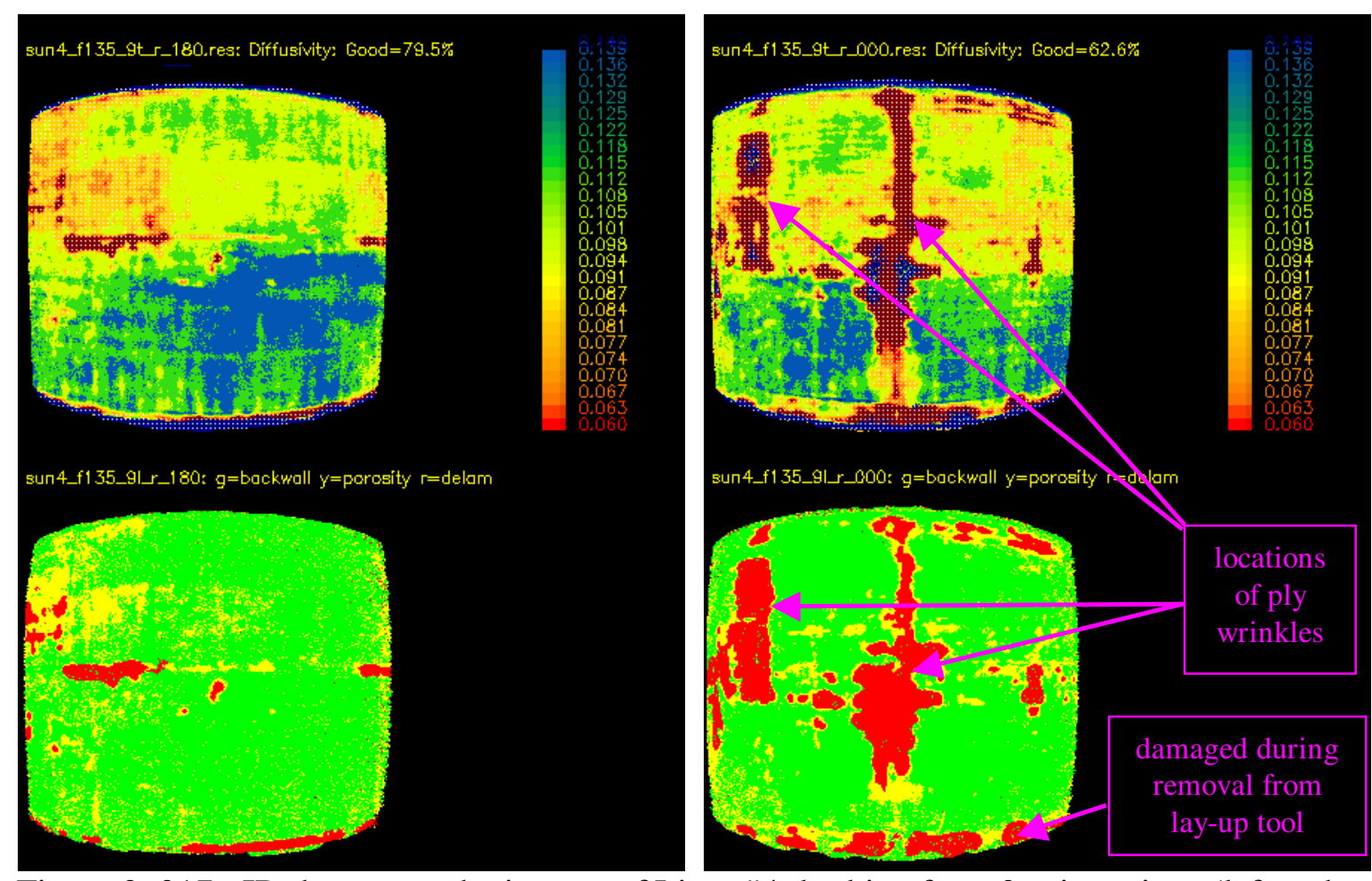

Figure 3-317. IR thermography images of Liner \#4, looking from 2 orientations (left and right). The top images are scaled by the thermal diffusivity values, and the bottom images are artificially colored according to flaw severity (green - good, yellow marginal, red - bad). Locations of the ply wrinkles noted after autoclave lamination are indicated, and represent the major cause of defects in liner \#4.

\subsection{Pretest Characterization of Liners 3 and 4}

During fabrication of the liners small "witness" coupons were also fabricated from the same prepreg tapes that were used in the liner axial plies. These coupons were processed in parallel with the respective combustor liners, although several process steps, most importantly the infiltration step, had to be done separately from the liners due to equipment limitations. These coupons were nevertheless expected to be representative of the material in the liners. These coupons were tensile tested to estimate the properties of the CMC liners. Results of these tensile tests are shown in Figure 3-318. The failure of these coupons was unusual in that rather than having a planar failure surface the panels failed in a tensile fashion through part of the cross section, the failure crack then propagated via interlaminar shear for some distance, and then the remaining cross section would then fail in a tensile manner. This mixture of tensile and shear failure caused the stress-strain curves to display two large load drops, one during the initial tensile/shear crack propagation, and a second drop (to near zero load) when the remaining cross section failed. This failure mode also caused extensometer slips during testing, making it necessary to manually correct the strain data following the test. Metallographic examination of the witness coupons after testing showed the clear presence of intra-tow porosity, often at a level approaching near continuity within a ply. This relatively poor densification of the mid-ply planes allowed for the observed interlaminar shear failures. 


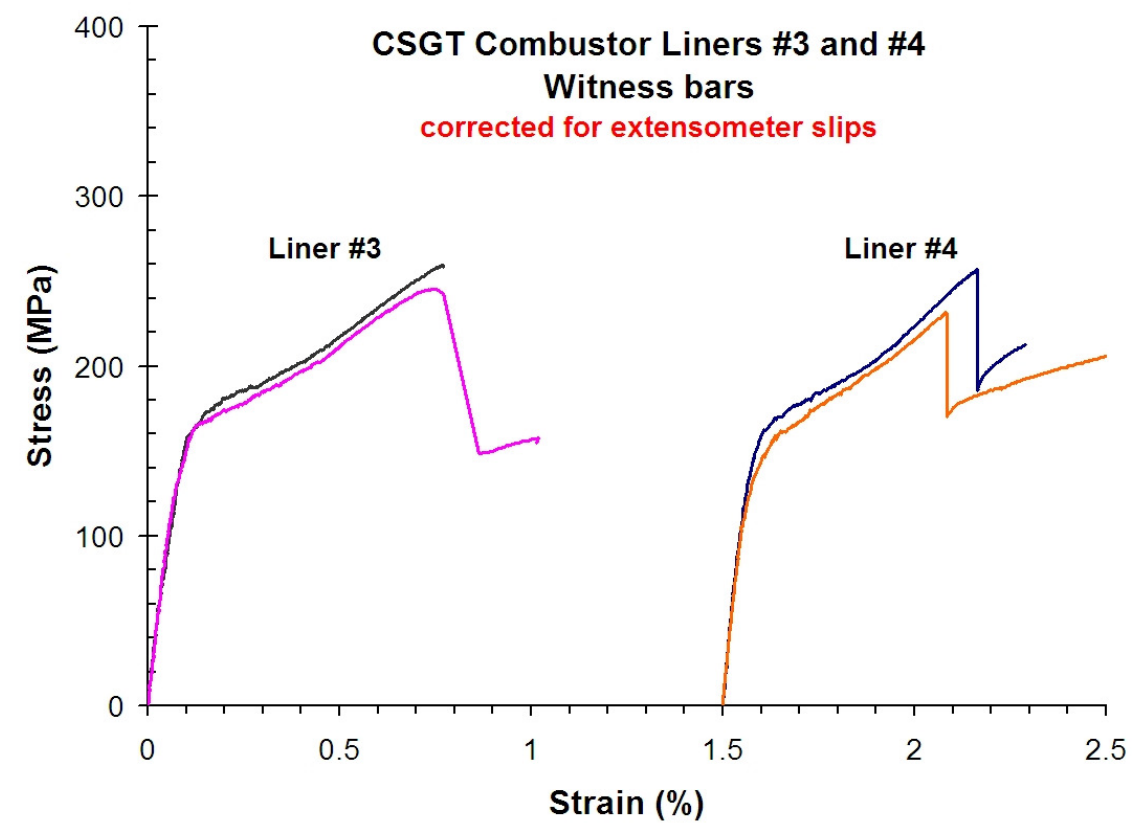

Figure 3-318. Tensile stress-strain response of the witness coupons processed in parallel with CSGT liners \#3 and \#4.

Both liners were forwarded to $\mathrm{CCP}$ for machining and dimensional inspection via CMM. The ends trimmed from the liners were returned to GRC for metallographic examination. Figure 3-319 shows photomicrographs of typical cross sections from each liner. Both liners showed significant amounts of intra-tow porosity that was evident in both the axial and hoop plies. This porosity is consistent with the similar patterns of porosity seen in the witness coupons.

The thickness of liner \#3 is somewhat above nominal, whereas that of liner \#4 was somewhat below nominal. Part of this difference was due to compaction of the inner carbon cloth wick (seen in the bottom of the right side micrograph in Figure 3-319). Normal compaction of the CMC plies during the autoclave cycle is on the order of 5\% to $7 \%$. Compaction of the cloth wick layer was $\sim 40 \%$ based on the starting thickness of the cloth and the thickness of this layer after infiltration.

Overall the mechanical properties and microstructures of the two liners appeared to be comparable. Liner \#4 was therefore selected to be used in the CSGT engine test based primarily on its higher overall thermal diffusivity and better NDE images. Quantitatively, Liner \#4 was judged to have $~ 81 \%$ of "good" material based on the bottom NDE image in Figure 3-317, whereas liner \#3 only had $\sim 57 \%$ good material based on the bottom NDE image in Figure 3-310. 


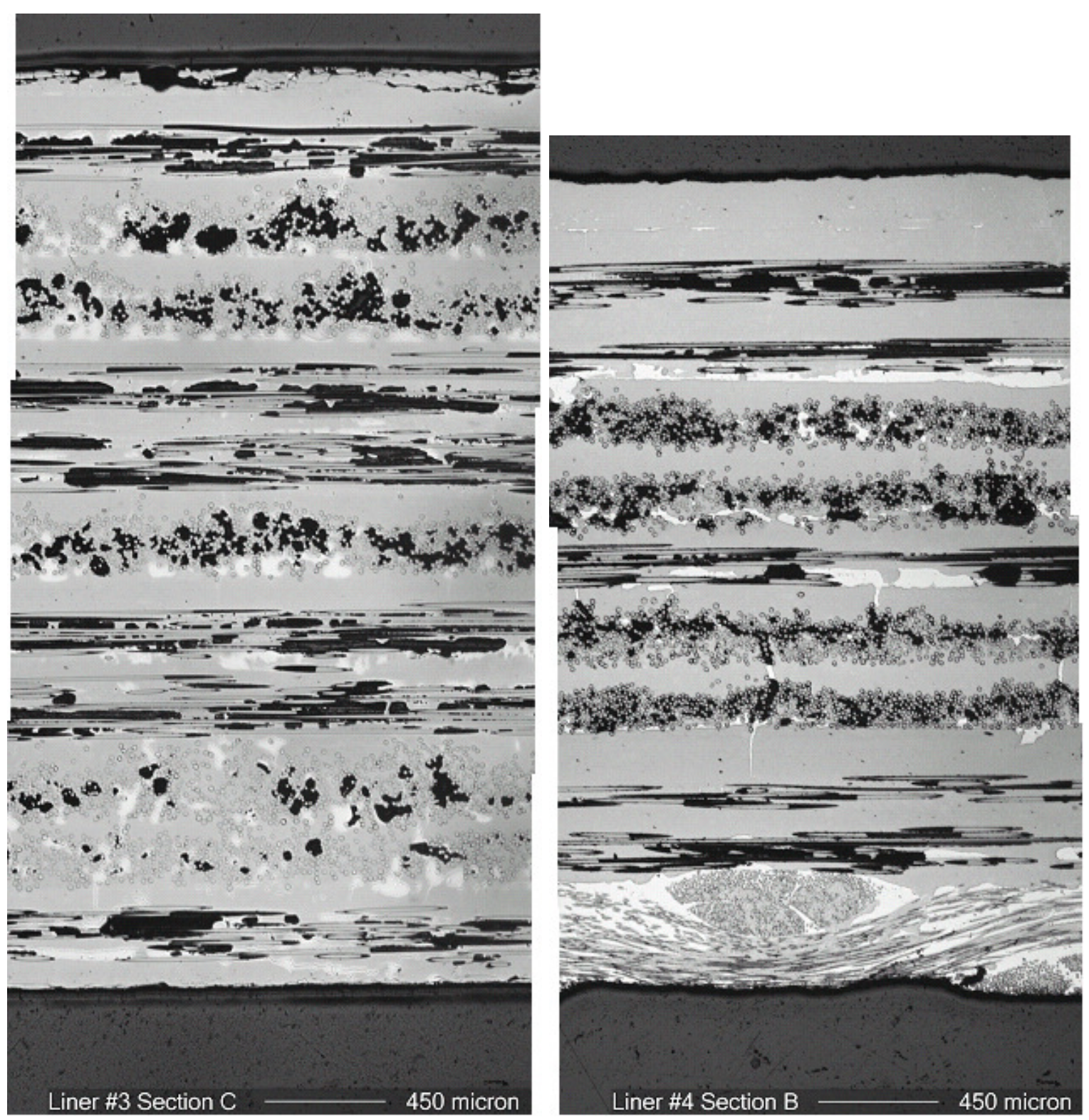

Figure 3-319. Photomicrographs of the through-wall cross sections of Liner \#3 (left) and Liner \#4 (right).

\subsection{EBC Coating}

Combustor liner \#4 was machined (i.e. cut to length) at CCP, and was then forwarded to Argonne National Laboratory (ANL) for additional NDE examinations. Both IR thermography and X-ray computed tomography (CT) scans were done on the liner at ANL. Results of the IR thermography examination at ANL are shown in Figure 3-320. The ANL thermography results were wholly consistent with those obtained at GRC. The CT inspections were done largely to characterize the type of defect in the regions where IR indications were present, and indicated regions of low density (porosity or delaminations) extending circumferentially from the ply wrinkles. 


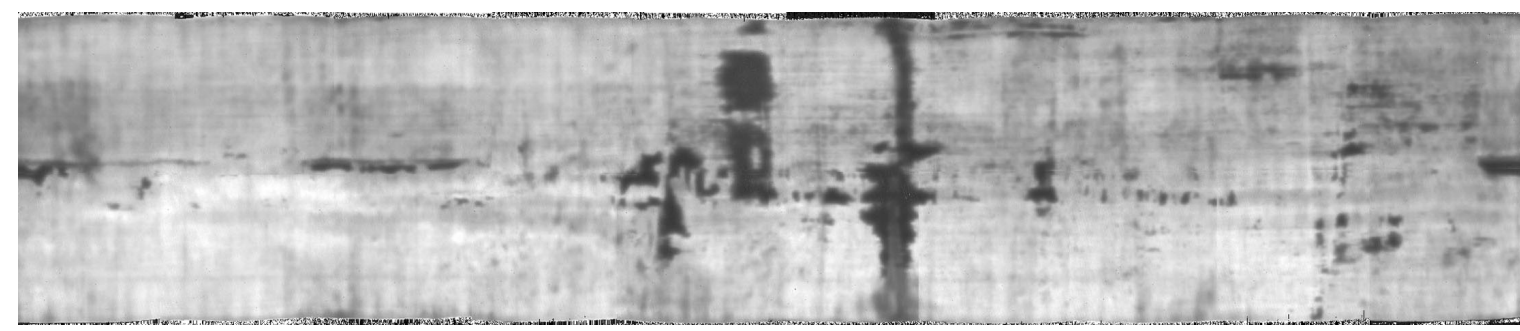

Figure 3-320. IR thermal diffusivity image measured at ANL on liner \#4. The main ply wrinkle is the dark vertical strip near the center of the image. The location, size and severity of defects correlate very well with those observed in the GRC IR thermography images.

The liner then went to Solar Turbines for trial fit-up to the metallic combustor hardware. The liner was then returned to GRC for additional machining, which primarily consisted of grinding off small bumps on the ID surface so that the liner would fit over the metallic inner liner support structure.

EBC coating of the liner was done at GRC using the standard 3-layer EBC coating of $\mathrm{Si}$ bond coat / mullite + BSAS transition layer / BSAS top layer. Coating was applied to the outer surface of the liner using the 7MB stpray gun and process. Weight gain of the liner was measured between coating layers as an indication of the EBC layer thicknesses. Small witness coupons were coated at the same time and sectioned to more directly measure the layer thicknesses. Following EBC coating the liner was put through the standard 24 hour heat treatment at $1250^{\circ} \mathrm{C}$ to crystallize the EBC into the proper phases. IR thermography $\mathrm{NDE}$ was attempted with the coated liner, but the only indications seen were those already observed in the CMC liner substrate and no new indications of defects in the EBC coating were noted.

During grit blasting, which is done as a surface preparation step before deposition of the EBC, the large axial ply wrinkle showed some breakthrough of the buckled plies, causing pits in the liner outer surface. Photographs of these pits are shown in Figure 3-321. After EBC coating most of the pits, including the side walls of the pits, were visually covered with EBC; however, there was still a small gap in the EBC coating near the base of the largest pit. Close-up photographs of this pit and the gap in EBC coating are also shown in Figure 3-321. 

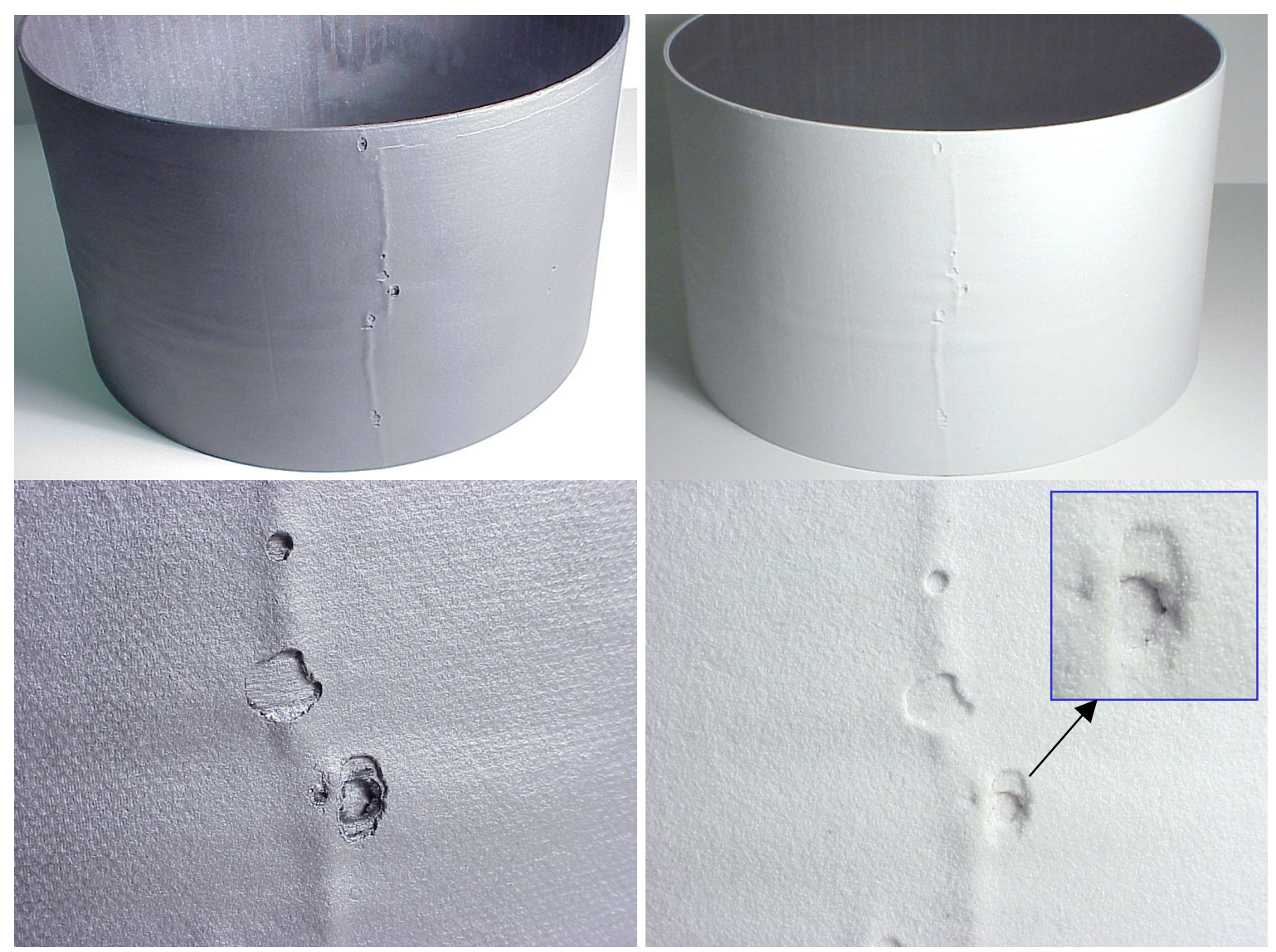

Figure 3-321. Photographs of liner \#4 following grit-blast surface preparation (left) and after EBC coating application (right). The top photographs show the breakthrough of the liner surface along the main ply wrinkle during grit blasting, and the coating of these pits during EBC deposition. The bottom photographs show close-up views of the larges of the pits, and the insert of the bottom right photo shows the bottom of the largest pit where the EBC coating was not continuous.

\subsubsection{CSGT Engine Test Performance}

The GE HiPerComp liner \#4 was put into service on January 20, 2005 in the CSGT engine at the Chevron/Texaco refinery in Bakersfield, CA. The CSGT engine is a modified Solar Centaur 50S engine with an output of $\sim 4 \mathrm{MW}$ and a firing temperature of $\sim 1250^{\circ} \mathrm{C}$. Prior measurements on a test rig meant to simulate CSGT operation had shown that combustor wall hot streak temperatures could reach the full $1250^{\circ} \mathrm{C}$ gas temperature as the liners are run in a nominally uncooled, isothermal state. The engine has a nominal pressure ratio of 10:1 and was fired with natural gas, giving a nominal water vapor pressure of $\sim 1 \mathrm{~atm}$ in the combustor.

The liner was removed from service in December of 2006, following 12,822 running hours in the CSGT engine, including 46 start/stop cycles. The engine operated normally during this entire period with no operational anomalies attributed to the HiPerComp inner liner or 
the oxide-oxide CMC outer liner (fabricated by Composite Optics, Inc. with a "friable gradient coating" supplied by Siemens-Westinghouse).

During the engine test borescope inspections were performed on July 11, 2005 (after 3,983 hours of engine operation), November 30, 2005 (6,706 hours), and July 10, 2006 ( 9,500 hours). Although the liner appeared to be in generally good shape during each of these inspections, there were some unusual features noted on the liner and, particularly, the EBC coating.

The first EBC issue noted during the test was some limited chipping of the EBC coating at the edges of the liner, particularly the aft edge. Borescope images of this chipping are shown in Figure 3-322.

There are two contributing factors that lead to this chipping. First, an attempt was made to coat the ends of the liner with $\mathrm{EBC}$ due to a last-minute request from Solar Turbines, despite the fact that the EBC deposition parameters and robotic programming had not been optimized for spraying on the ends of the liner. As a consequence the EBC thickness was non-uniform at the liner ends, with the thickest part of the coating being at the outer edge of ends.

The second contributing factor is that the inner liner on the CSGT engine is a "floating liner." The liner is simply trapped between metallic flanges fore and aft and sits on some compressed Nextel fiber cloth on the inner surface. This attachment scheme was used to eliminate any thermal expansion mismatch stresses between the liner and the metallic support structure. As a consequence of this loose mounting the liner is free to vibrate against the retaining flanges. Given that the EBC coating was thicker along the outer edge of the liner ends, such chattering would load the EBC near the ends in shear, leading to the observed EBC chipping.

A second unusual feature noted on the liner during borescope inspections was the lifting of a region circumferential from the worst of the EBC pits described previously. As noted before, the deepest of the surface pits in the liner following pre-coating grit blasting was not completely sealed by the EBC coating. It is therefore not unexpected that oxidation of the CMC substrate would occur in this region. What was unusual is the fact that "bump" seemed to appear in the liner surface running circumferetially out from this pit, and that the EBC appeared to be cracked along the peak of this bump. Photographs of the liner in this region both before engine service and from the various borescope inspections are shown in Figure 3-323. A whitish feature can be seen growing at the base of the pit, which appears to be a "fluffy" oxide presumably formed by oxidation of the liner below the break in the EBC coating. 


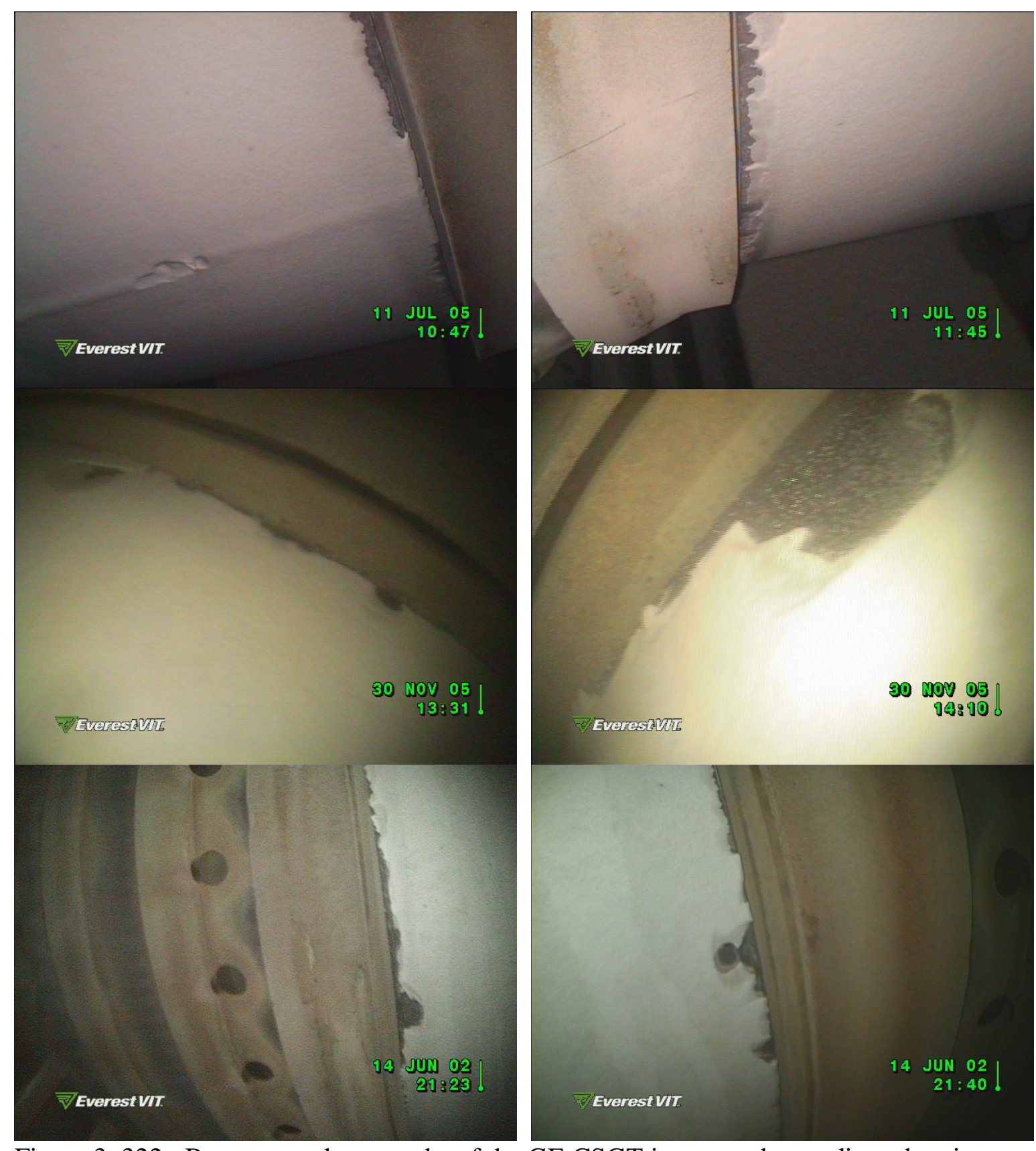

Figure 3-322. Borescope photographs of the GE CSGT inner combustor liner showing EBC chipping along the aft edge. The top set of photos are from the July 2005 borescope inspection, the middle set from the November 2005 inspection, and the bottom set from the July 2006 inspection. 

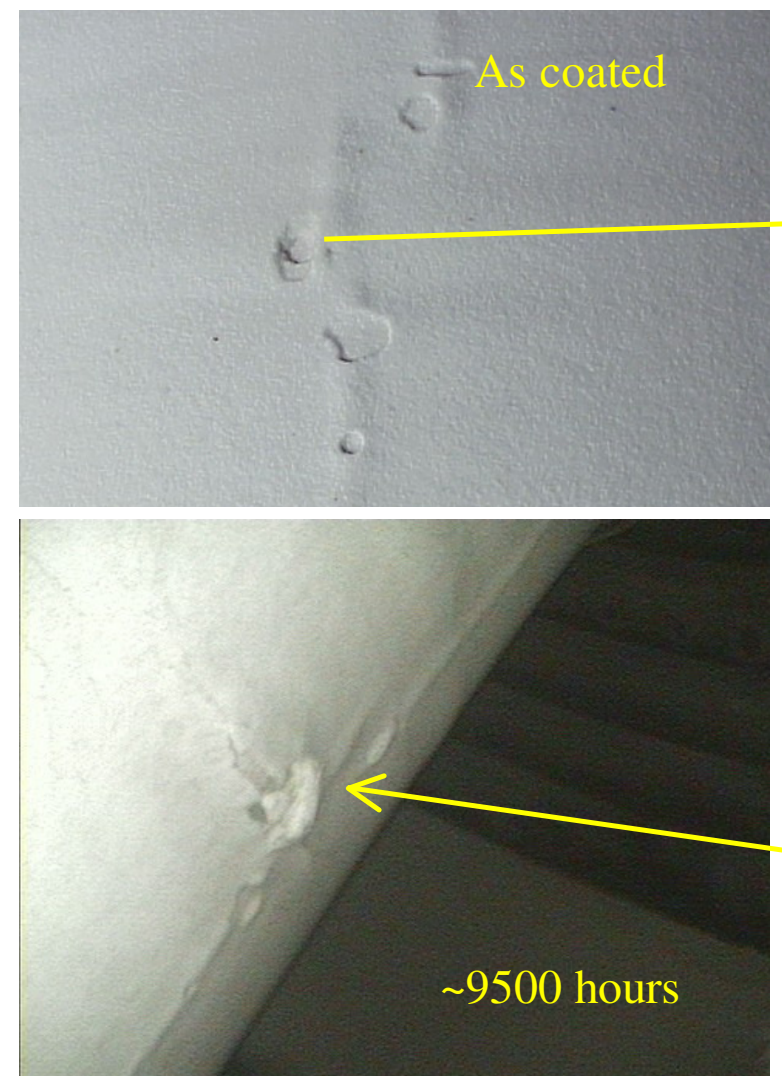

Figure 3-323. Photographs of the largest pit in the CSGT inner liner before engine service (top left), after 3983 hours (top right) and after 6706 hours (bottom right), and after $\sim 9500$ hours (bottom left).

The other unusual feature seen on the liner during borescope examination was the occurrence of white ridges on the liner surface. These ridges were in an irregular pattern, but were oriented mostly in the circumferential direction. These ridges were called "spider web ridges" due to their appearance. They tended to occur near the center of the liner in the axial direction, and covered an arc of about $60^{\circ}$ around the liner. Borescope photographs of the "spider web ridges" at the three borescope inspections are shown in Figure 3-324. Similar features had not been seen in any laboratory furnace exposure testing, combustion rig testing or prior engine tests of shroud components.

At first it was unclear what these features were, but it was speculated that they were localized delaminations of the oxide EBC layers from the bond coat or substrate. With continued engine exposure the ridges increased slightly in width, but did not propogate outward around the liner or toward the liner ends. At the first borescop inspection at 3983 hours it was unclear whether the ridges were accompanied by cracks in the EBC, but by the second borescope interval at 6706 hours it was clear that there were EBC cracks peaks of the ridges. Also at the second borescope the first example of EBC spallation associated with the spider web ridges was noted. This spall grew, and a second separate EBC spall formed, by the third borescope inspection. 


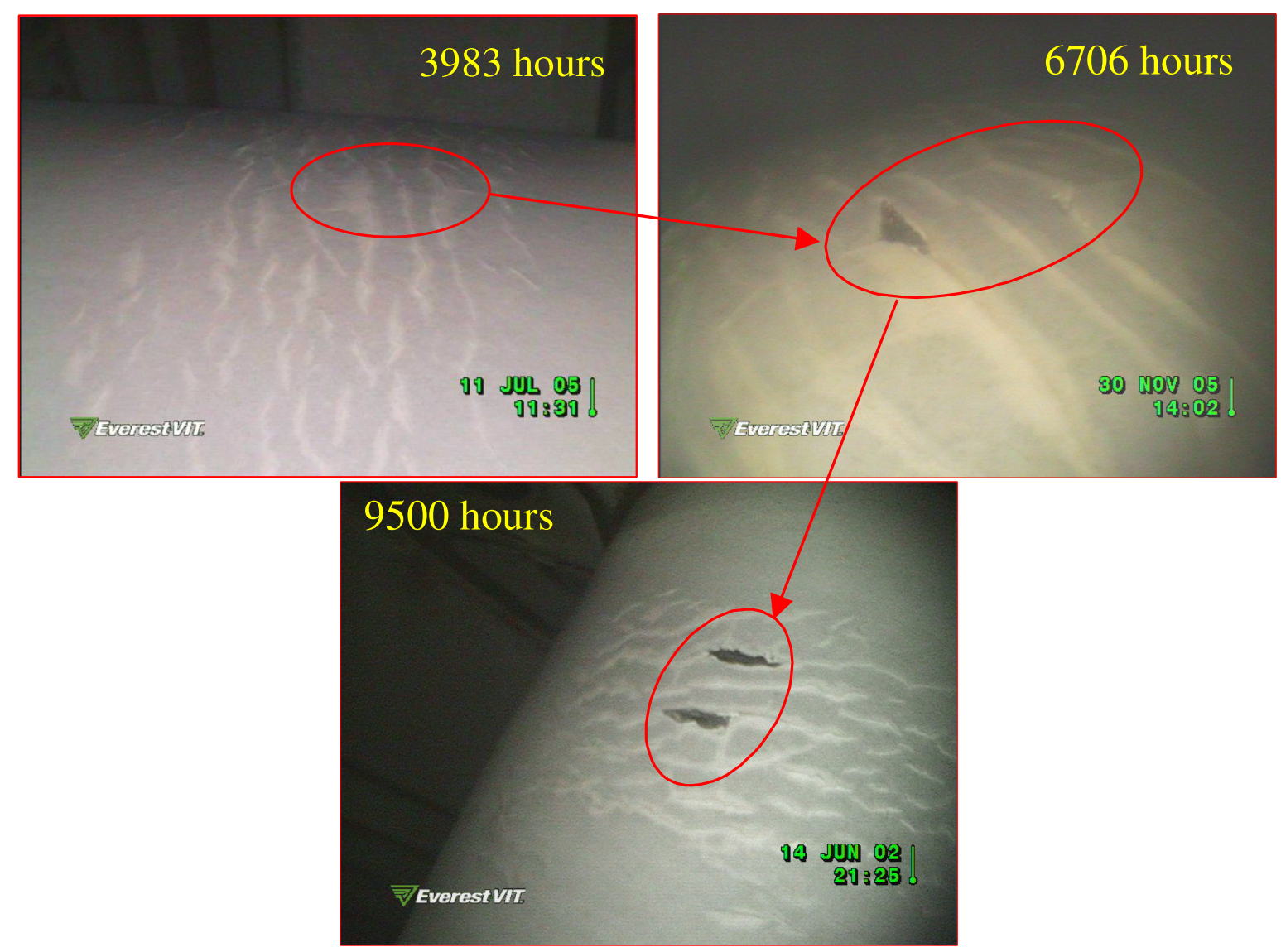

Figure 3-324. Borescope photographs of the "spider web" surface feature on the CSGT combustor liner, showing the growth of the width of the ridges and eventual EBC spallation with engine exposure time.

Despite the issues seen with the EBC, the performance of the liner for 12,822 hours was considered a huge success. Solar personnel [25] indicated that upon removal from the engine that the GE prepreg MI liner "looks better than any other EBC-coated SiC liner that we've tested."

\subsubsection{CSGT Combustor Post-Test Characterization}

Although operation of the CSGT engine in Barkersfield was stopped in December of 2006, the engine was not disassembled and the CMC combustor liners extracted until January of 2007.

The initial liner post-test inspection was done by Solar Turbines personnel, including visual inspection and photography. Solar had a custom arrangement for photographing the cylindrical combustor liners where the liner would be placed on a turntable and photographed with a slit camera, which captured only a thin, axial line image from the liner. 
As the liner rotated on the turntable the film in the camera was translated sideways in synchronization with the turntable rotation. The resultant exposure captured the entire inner or outer surface of the liner as a continuous linear image, much like slicing the liner axially at one location and flattening it out. The photographs taken by Solar with this technique are shown in Figure 3-325.

The upper photograph in Figure 3-325 shows the inside (colder) surface of the liner and the bottom photo shows the outer surface. The whitish appearance of the outer surface is due to the EBC coating applied prior to testing, which is still mostly continuous except for a few small spalls. The inner surface of the liner was not coated with EBC, and the white appearance of this surface is due to the formation of a silica film from oxidation. There are also several regions near the top of the inner surface, which corresponds to the aft edge of the liner as it was located in the engine, where the oxide layer is still thin enough to see the underlying $\mathrm{CMC}$, and the $\mathrm{CMC}$ has in fact recessed somewhat in these regions. This observation suggests that there was substantial recirculation flow of combustion gases behind the liner in these regions, sufficient to allow for the $\mathrm{SiO}_{2}$ volatilization reaction.

Most of the features noted on the liner from the borescope inspections can be seen in the outer surface photograph. First the chipping of the EBC along the aft edge can be seen by the dark EBC spalls along the top edge of the liner. It was difficult to see the leading edge of the liner during borescope inspection, so it was unclear as to whether similar chipping occurred along the leading edge. The post-test photograph shows that such chipping did occur, but to a much smaller extend than on the aft edge.

The second feature noted in the borescope inspections was the oxidation of the partiallycoated surface pit at the center of the main ply wrinkle. This oxidized region is at the left edge of the bottom photograph in Figure 3-325. Although this oxidation had not yet lead to EBC spallation in the borescope inspections, an EBC spall associated with the oxidize pit can be seen at the extreme left and right edges of the photo. The spall just below and to the left of the "A" in the word "GAS" did not appear to have substantial oxidation of the bond coat or substrate, and thus was probably caused during engine disassembly.

The "spider web" ridges seen in the borescope inspections can be clearly seen near the center of the lower image in Figure 3-325. The two spalls associated with these ridges are also visible, as are two additional small spalls (to the right of the spider web region) not observed in the borescope inspections.

Following visual inspection at Solar the liner was sent to ANL for transmission IR thermography NDE inspection. ANL had a very similar set-up to the photographic arrangement at Solar, except that an IR camera was used in place of the film camera and the continuous image was collected in software. The resulting images show the thru-thickness diffusivity continuously around the circumference of the liner, again as if the liner had been sliced axially and then laid out flat. The ANL thermal diffusivity images of the liner, taken both before the engine test and after the engine test, are shown in Figure 3-326. The orientation of the liner in these NDE images is very close to that of the visual photographs 
of the liner in Figure 3-325. In each the edges of the images correspond roughly to the location of the main axial wrinkle in the liner, as described previously and shown in Figure 3-321. The dark features top to bottom along the NDE image edges are representative of the delamination associated with the ply wrinkle. The pre-test NDE image in Figure 3-320 is oriented so that this delamination occurs slightly to the right of the center of the image.

In general the before and after images in Figure 3-326 are quite similar. Major indications are consistent between the two images, indicating little or no growth of the pre-existing defects. The lightening in the image of the post-test liner, particularly along the top (aft) edge, is due to thinning of the liner from back-side recession. There are two indications that appear to have changed during the engine test, and they are indicated by the yellow circles in Figure 3-326. In the pre-test image there appears to be a significant delamination in lower region of the liner near the $35^{\circ}$ position that stands out distinctly from the surrounding material; however, in the post-test image the defect is much less well delineated. This may be an indication of internal oxidation filling up the delamination and providing a conduction path for the thermal wave. The second change is the appearance of a subtle indication in the middle of the liner at the $260^{\circ}$ position in the post-test image that does not appear in the pre-test image. This indication seems to correspond, in location but not in size, to a mark on the inner surface of the liner that appears to the eye like an "oil stain", but its source is not known.

Similar IR thermography NDE inspections were done once the liner was received at GE GRC. Figure 3-327 shows the results from the GRC NDE inspection, with the images arranged to match the location and orientation of the ANL images. These particular images are through-wall transmission thermal diffusivity images where the diffusivity values are scaled by the false color (red = low diffusivity and blue = high diffusivity) as compared to the gray-scale images from ANL in Figure 3-326. The locations of the indications that have shown some changes that are not from visible surface effects are also marked on the GRC images, and show the same differences as noted in the ANL images.

The GRC images also accentuate a plateau in EBC thickness observed near the leading edge of the liner and most prominently at the bottom dead center position within the turbine (the orange band along the bottom center region in the post-test image). Visual observations of the liner suggest that the plateau in the EBC was caused by recession and/or densification of the EBC above the plateau line; however, if such were the case one would expect the through-thickness thermal diffusivity to have increased above this line and remained constant below the line. The GRC diffusivity images indicate that the thermal diffusivities immediately above the plateau line are relatively unchanged whereas they have instead decreased below the plateau line. 
Inner Liner Cold Side

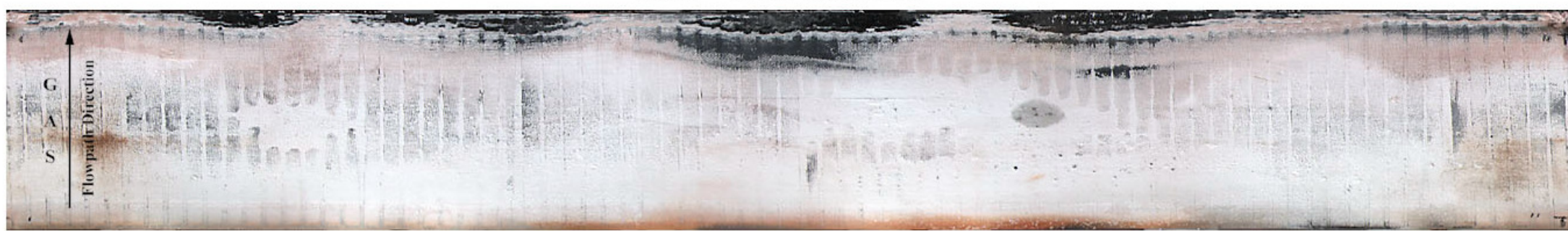

T

Inner Liner Hot Side

T
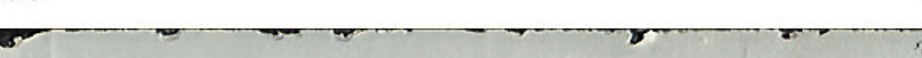

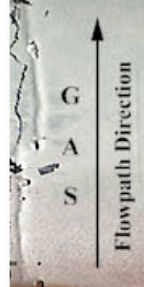

Figure 3-325. Continuous surface photograph of the inside surface (top) and outside surface (bottom) of the GE HiPerComp® inner combustor liner after 12,822 hours of service in the Solar CSGT engine. 
After 12822 hr engine run with 46 starts, Feb. 2007

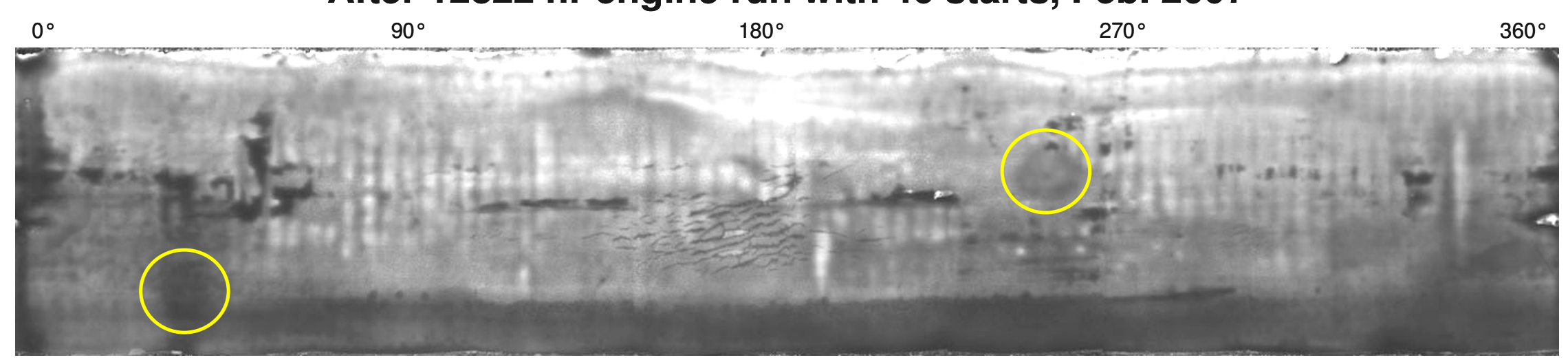

As-processed, after EBC coating, Jan. 2005

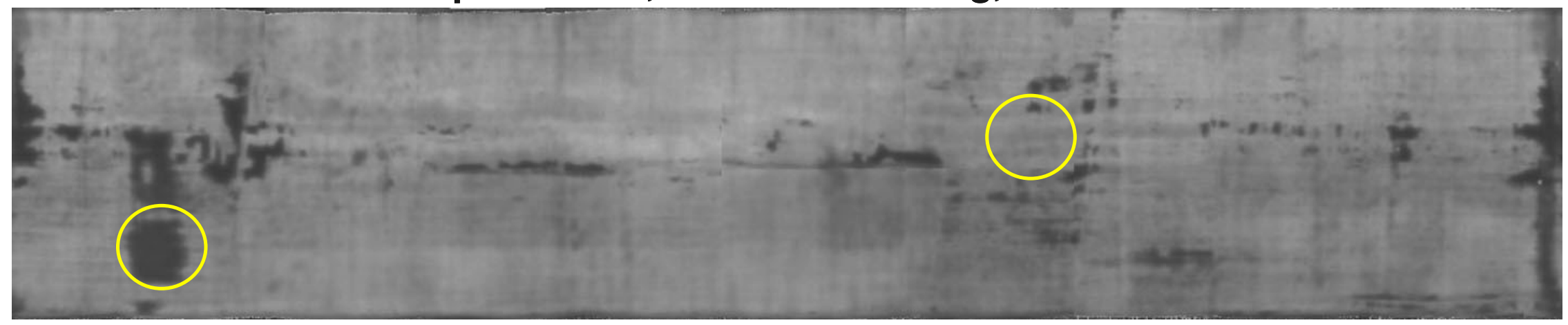

Low diffusivity

High diffusivity

Figure 3-326. Transmission IR diffusivity images of the GE Prepreg combustor liner both before (lower) and after (top) the Solar CSGT engine test. 

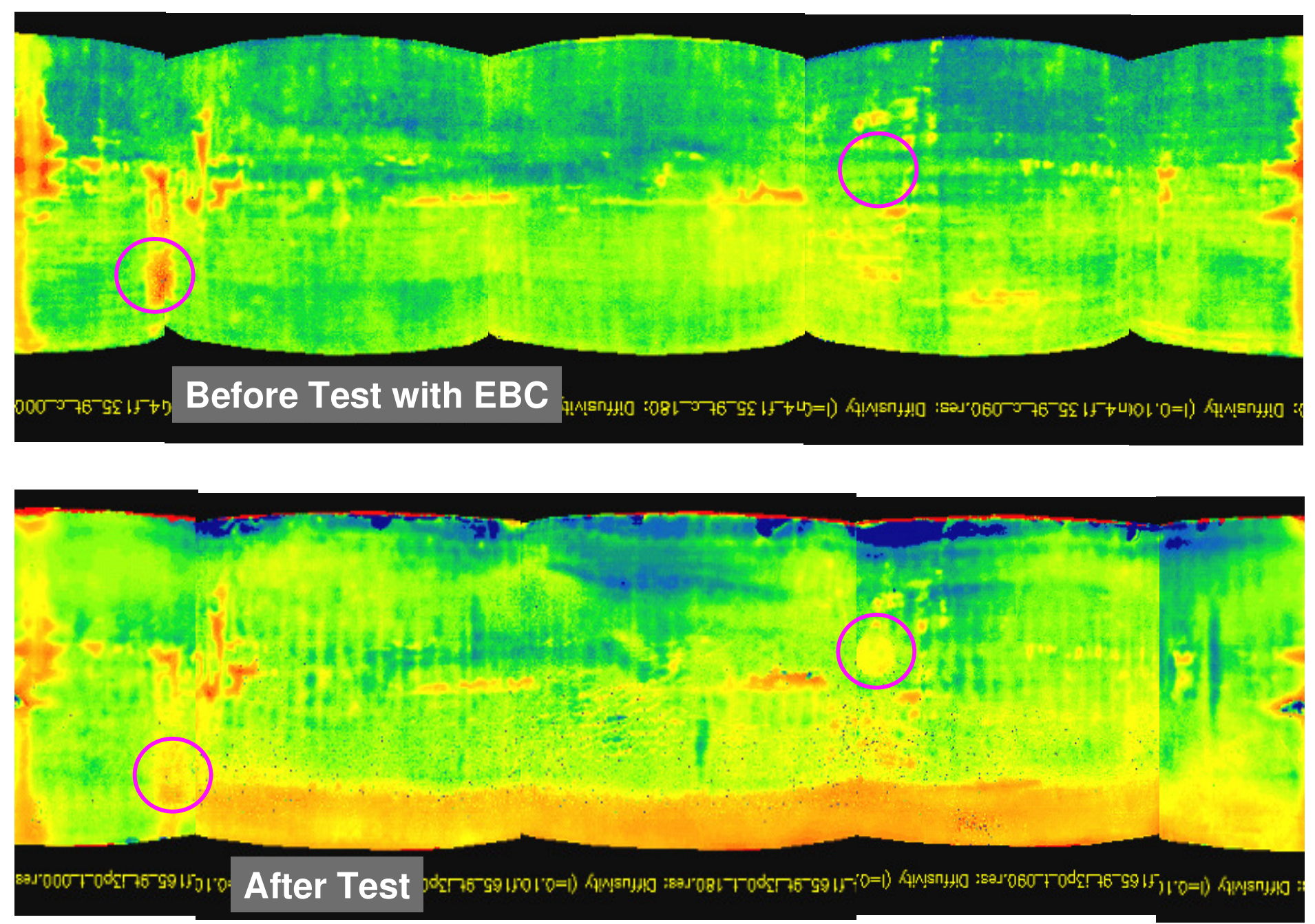

Figure 3-327. Transmission IR thermal diffusivity NDE images of liner \#4 taken at GRC before engine testing (top) and after engine testing (bottom) . 
One of the prime areas of interest for the performance of the combustor was the extent of retention of the EBC coating. There were numerous defects found in the EBC coating after the engine test, as will be discussed in the following pages; however, the overall retention of the EBC coating was quite good. Figure 3-328 shows the same photographic image of the outside surface of the liner as shown in Figure 3-325, along with a bicolor image generated from the photo. In the bicolor image the gray area represents intact EBC and the black represents those areas where the EBC is spalled. Analysis of the bicolor image indicated that only $0.6 \%$ of the liner outer surface showed visual evidence of EBC spalls, and the majority of that was due to the edge spalls along the aft edge of the liner (the upper edge of the images in Figure 3-328).

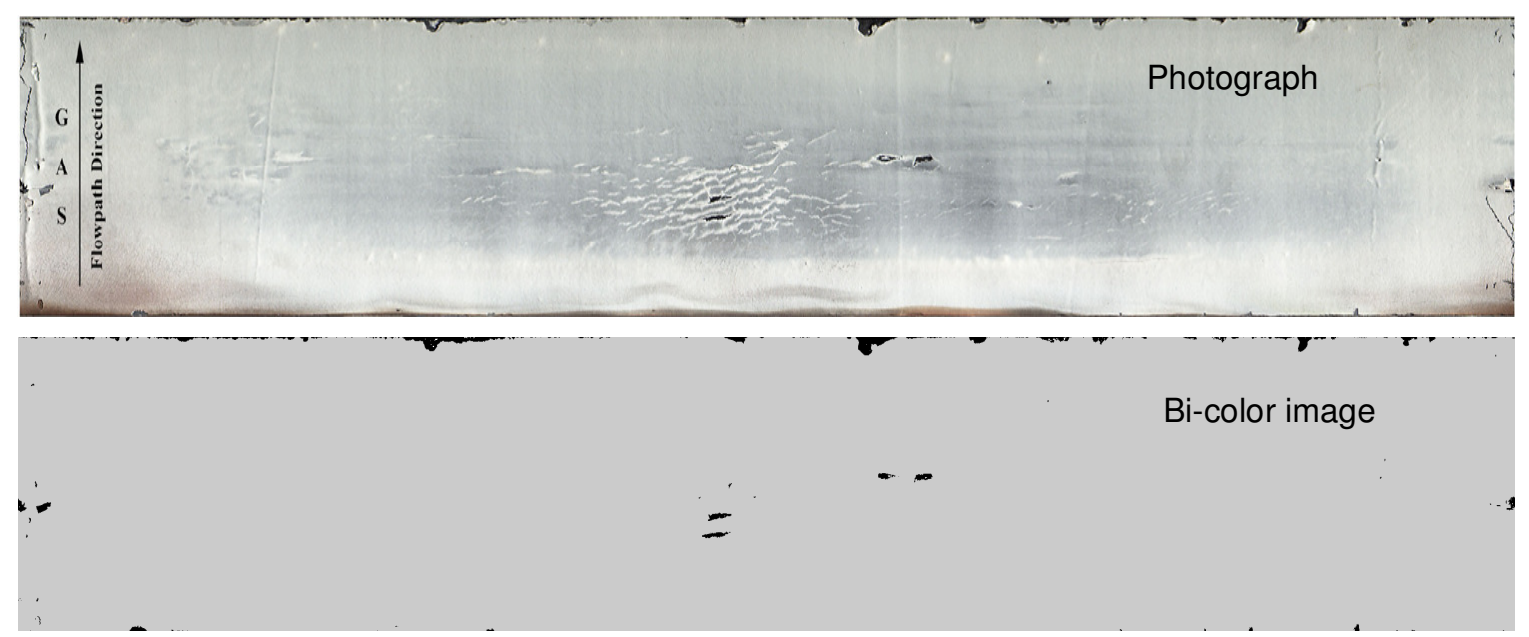

Figure 3-328. Photograph (top) and bicolor image (bottom) of the GE CSGT combustor liner after the engine test. Visible EBC spalls are represented by the black areas in the bicolor image.

Extensive photo-documentation was done at GRC to serve as a record of the condition of the liner after engine testing. Photographs of certain features were compared to the pre-test photographs of the same features, and to the borescope images of these features if they were available. This procedure documented the progression of damage or change of surface features with exposure time.

An example of such a progression of damage is shown in Figure 3-329. As noted earlier, the as-fabricated liner had a prominent ply wrinkle that proceeded axially along the liner. During surface preparation for EBC coating there was actual break-through from of the surface of the liner to this wrinkle in a few locations, leaving pits on the liner surface. The size and shape of these pits made it unlikely that the EBC coating would be hermetic along the pit walls, and thus these were prime candidate sites for enhanced substrate oxidation and additional EBC cracking. The photos in Figure 3-329 indicate that such oxidation did occur during engine exposure, leading to an EBC spall at the location of the deepest pit, with subsequent oxidative swelling of the $\mathrm{CMC}$ and additional EBC cracking. CMC 
oxidation/volatilization is also clearly evident at the spall location; however, the recession has not penetrated the full CMC liner thickness and there is no direct evidence of larger scale mechanical damage to the liner (i.e. cracking).

Other surface features seen on the as-fabricated liner were also documented before and after the engine test. Figure 3-330 shows several comparison photographs of some of these typical features. Only one of these features, the pit shown in the lower right set of photographs that was located along the same ply wrinkle as the pit in Figure 3-329, showed any tendency for EBC spallation. On nearly all of the other pre-existing defects the EBC remained intact and protective.

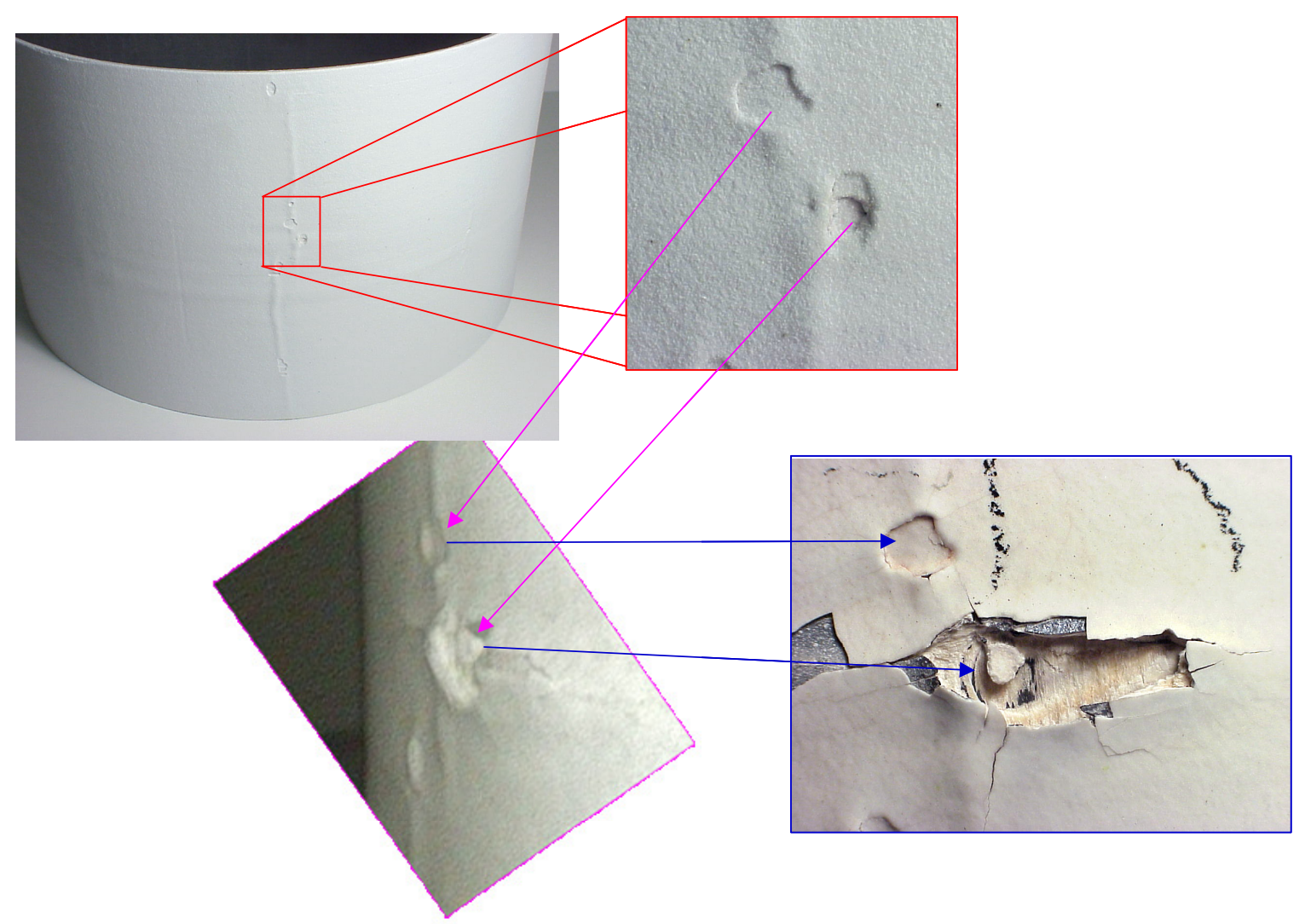

Figure 3-329. Photographs of the CSGT liner surface in the location of the ply wrinkle pits. Top Left - macro photograph before the engine test showing the location of the pits and ply wrinkle on the liner surface; Top Right - close up photograph of the most severe pits prior to engine test; Bottom Left - a borescope photograph showing progression of oxidation within the deepest pit and raising and cracking of the EBC adjacent to the pit; Bottom Right - close up photograph after the engine test showing growth of the pit due to oxidation/volatilization of the CMC substrate, oxidative swelling of the $\mathrm{CMC}$ and resulting cracking/spallation of the EBC. The width of the EBC spall in the lower right photograph is $\sim 1 / 2$ inch $(\sim 13 \mathrm{~mm})$. 


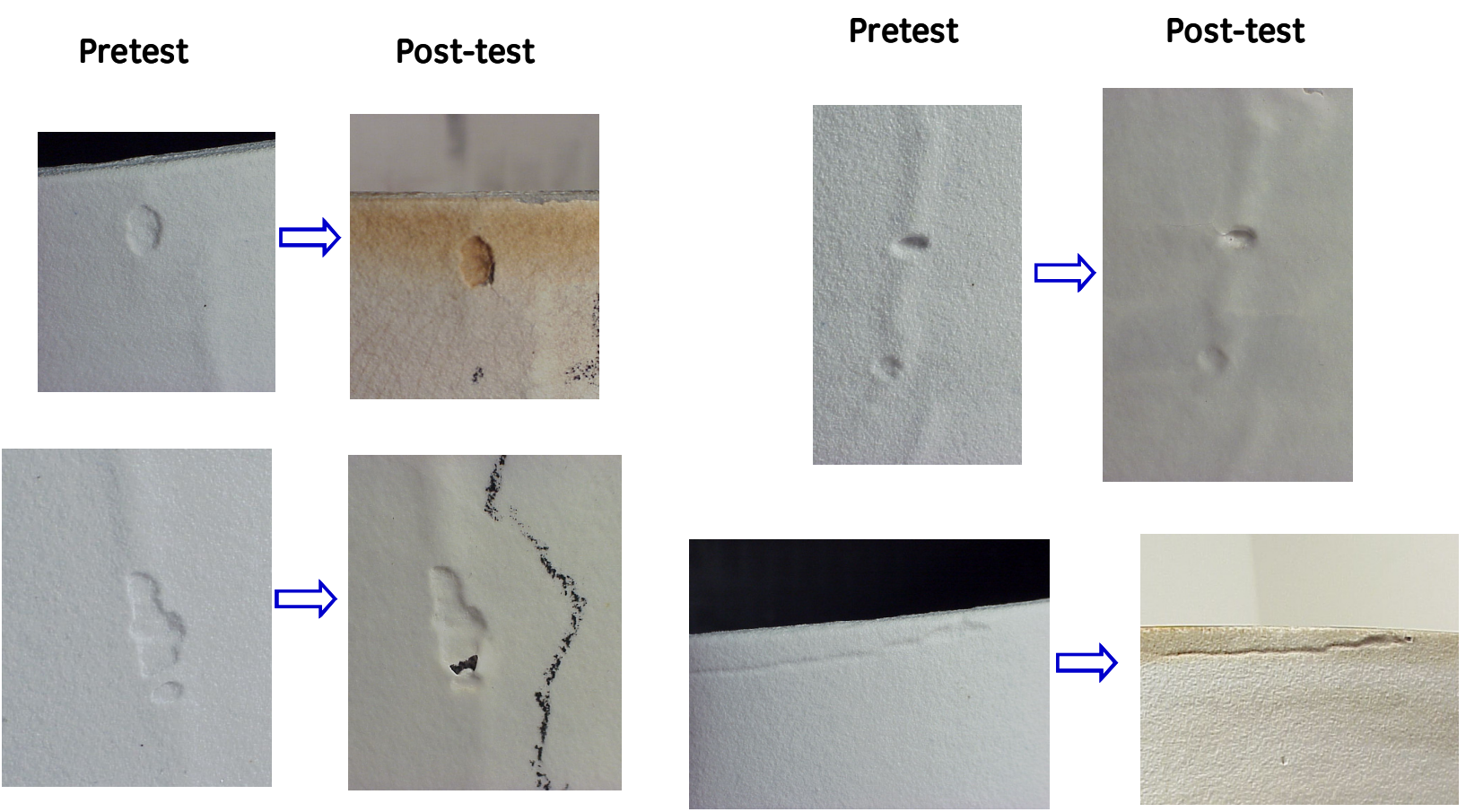

Figure 3-330. Photographs of several examples of pre-existing surface defects on the GE CSGT inner liner and corresponding photographs of the same features after the engine test, showing minimal change in the defects and only very minor loss of EBC.

The ply wrinkle defect and resultant surface pits compromised the performance of the EBC on the surface of the liner, and also contributed to internal oxidation of the liner from edgeon oxidation. Figure 3-331 shows photographs of the location where the ply wrinkle met the end of the liner. The relatively large void where the ply wrinkle came to the edge surface could not be spanned with the EBC coating, so that the open pore at the edge of the liner, as shown in the left-most photograph, existed from the beginning of the test. During high temperature exposure the CMC was oxidized inside this ply wrinkle, with the silica oxidation product building up to such a degree that it caused swelling of the CMC. This swelling pushed the inner surface of the CMC liner inward, and thus was not evident during engine borescope examinations. The center and right photos in Figure 3-331 show the localized "exfoliation" and loss of liner plies due to oxidation on the inner edge. Despite this oxidative swelling there was still no visible evidence of CMC cracking in this region. 


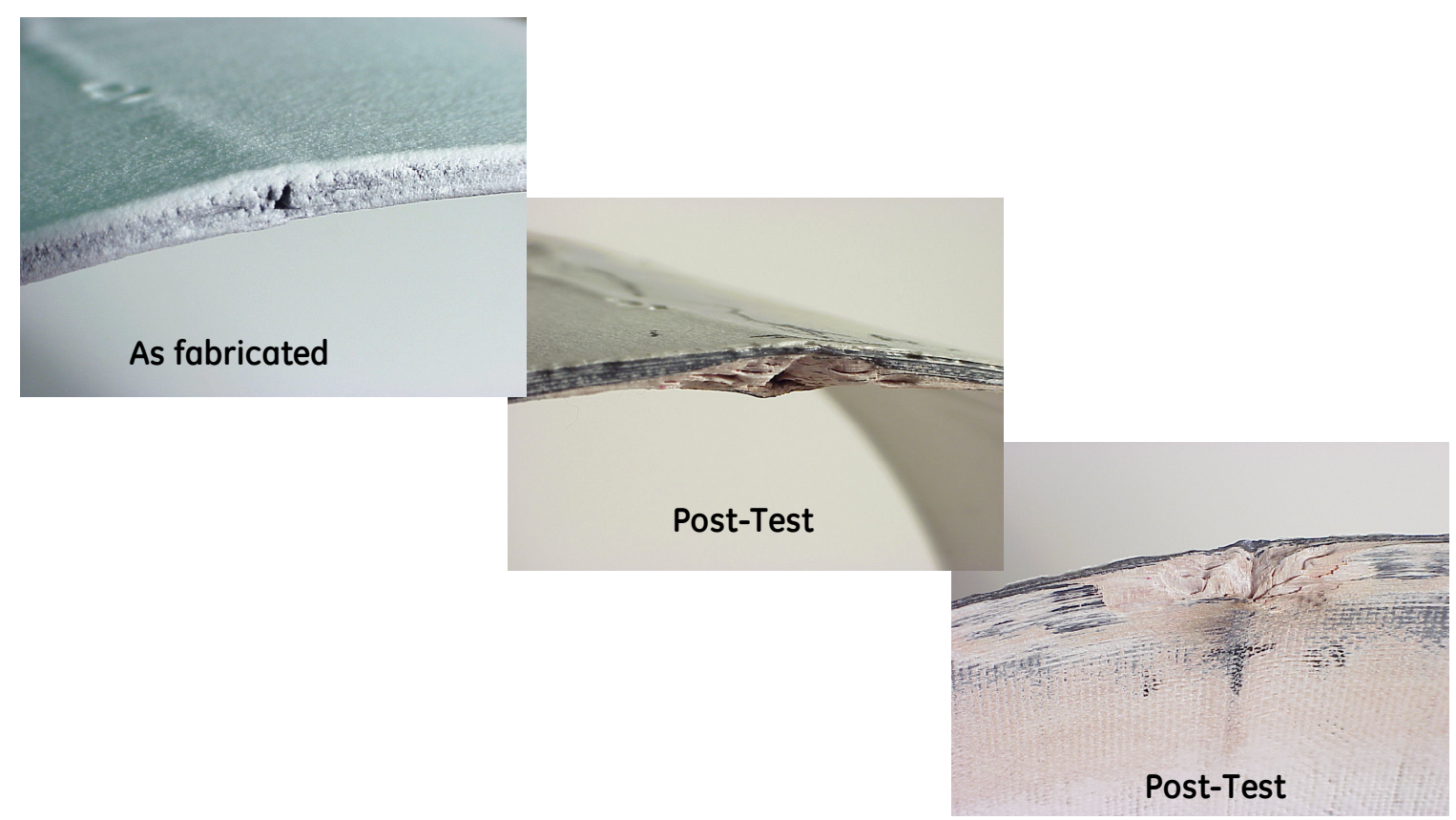

Figure 3-331. Photographs of the end of the ply wrinkle defect where it intersected the trailing edge of the liner. The left photo shows the as fabricated edge with EBC not fully covering the edge void caused by the ply wrinkle. The center photo shows how oxidation down the wrinkle led to oxidative swelling toward the inside of the liner. The right photo shows the local loss of several CMC plies due to oxidation immediately adjacent to the wrinkle at the end of the liner.

Another type of liner damage observed in the borescope examinations was the chipping of the EBC coating along the aft edge of the liner. Figure 3-332 shows several photographs of such chipped regions. It is evident that the $\mathrm{CMC}$ has recessed in these regions of chipped EBC, in some cases consuming several plies of the CMC. However, the liner was not completely breached in any of these regions.

There were two other locations where significant spallation of the EBC coating occurred. The first was at a mid-liner position near bottom dead center (relative to the liner position in the engine) where an $\mathrm{EBC}$ spall and $\mathrm{CMC}$ oxidation is evident. However, this feature corresponds exactly to a pre-existing indication in the liner as found by NDE before the test. It is therefore likely that this spall was in some way related to or caused by the CMC defect, and thus may not indicate an EBC failure. Additional metallographic analysis is needed to identify the likely scenario that lead to this EBC spall. 


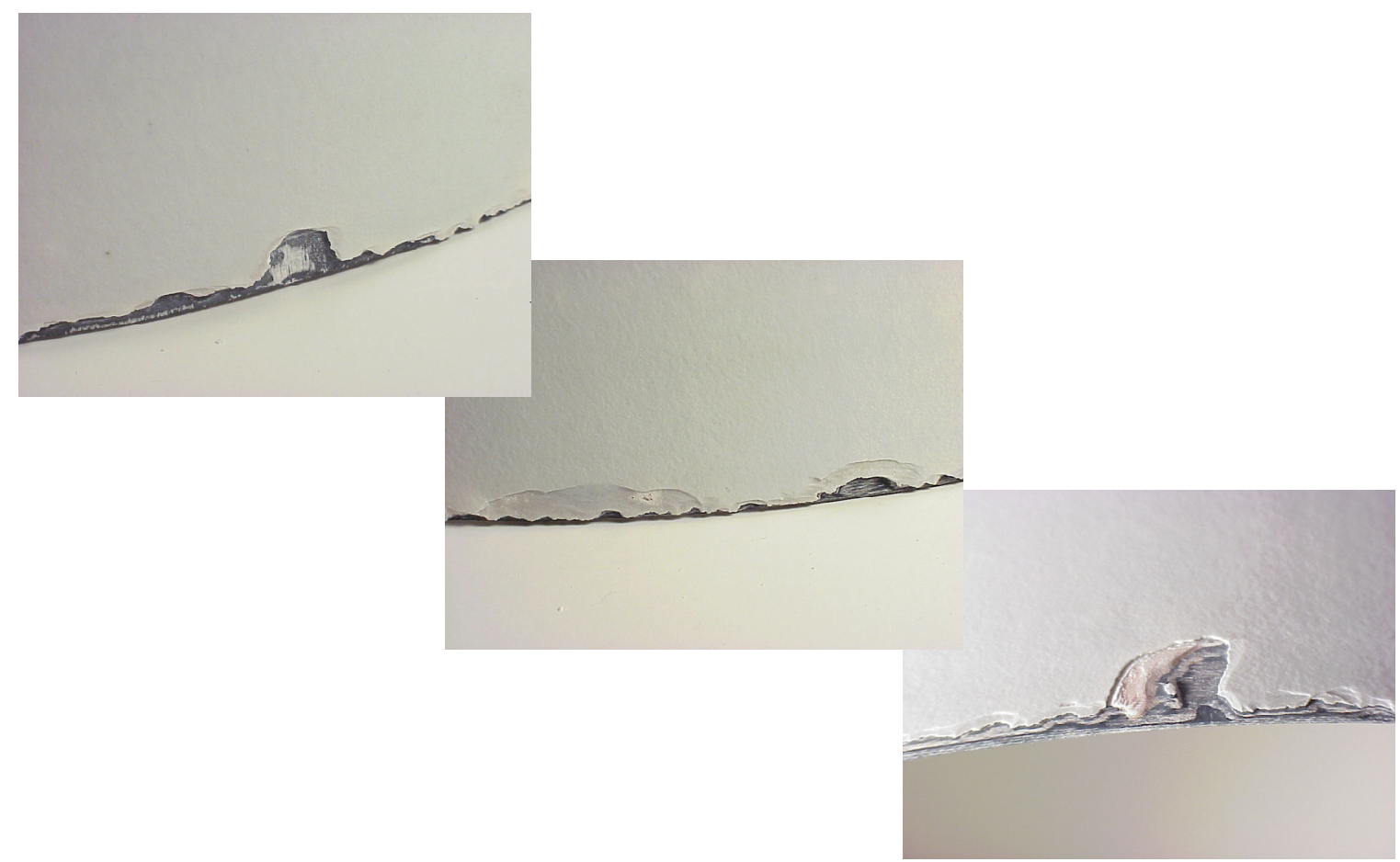

Figure 3-332. Photographs of EBC chipping and CMC oxidation damage along the aft edge of the GE combustor liner. The nature of the EBC fracture suggests that chipping was initiated by mechanical impacts along the liner edge.

The second location of interest was a relatively large region on the liner, slightly forward of the middle and also near the bottom dead center location. This is the region that showed the formation of the spider web ridges that were seen in the borescope examinations. These features started in a small region, and first appeared as some lighter-colored wavy lines in the EBC. At later borescope inspections the extent of the affected region increased, the lines appeared to be bulging slightly out of the liner surface to form ridges, and EBC cracks started to form along the peaks of the ridges. These EBC cracks seem to have propagated with exposure time, eventually connecting and forming EBC spalls.

The photographs in Figure 3-333 show the nature of these spider web ridges after completion of the engine test. The upper left photo is a macro view of the affected region, showing the extent of the spider web wavy features and formation of $2 \mathrm{EBC}$ spall regions along the ridges in the center of the region, which presumably were the first to form. The middle photo is a close-up of the ridges showing the pattern of EBC cracking along the tops of the ridges. The lower right photo shows a region near the periphery of the ridges where cracks in the EBC are evident in a pattern that matches that of the wavy ridges, but the ridges have not yet formed for all of the cracks.

This later observation may provide some insights into the mechanism by which these features were formed. It appears likely that vertical cracks formed in the EBC coating, possibly due to densification of the coating with time. As these cracks propagated inward 
and widened they allowed for direct water-enhanced oxidation of the EBC silicon bond coat. The oxidation of the bond coat would explain the whitish appearance of the waves, and as oxidation proceeded the buildup of oxidation product would lead to swelling of the EBC to form the observed ridges. Ridge formation would consequently lead to additional crack propagation and opening. Eventually lateral oxidation of the bond coat from adjacent cracks would completely undercut the EBC and result in spalls of the top layers. The borescope examinations did not pick up any crack formation until the ridges were fully developed, but this was probably due to the limited viewing angle and resolution provided by the borescope.

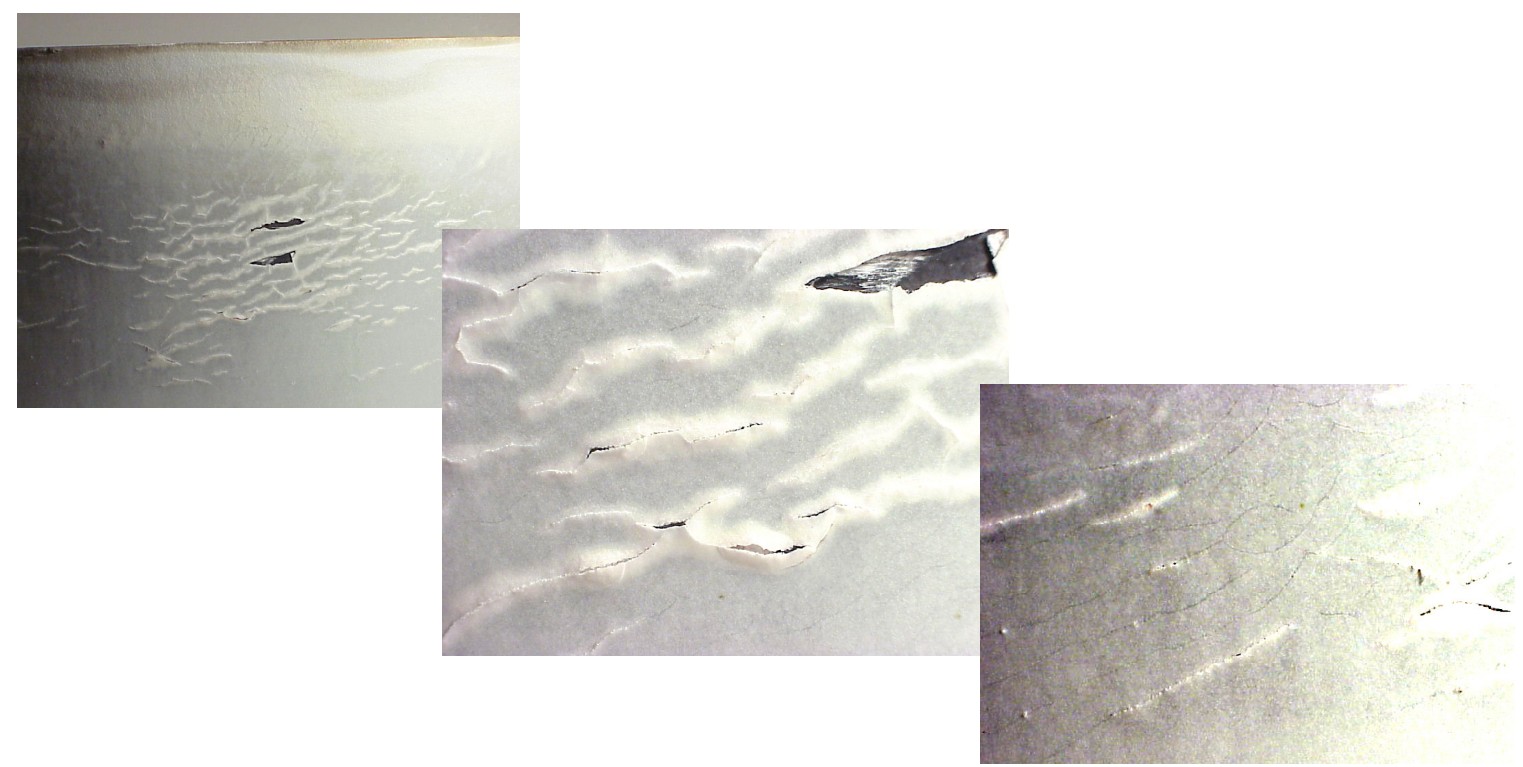

Figure 3-333. Photographs of the "wavy" EBC ridge features observed on the liner hot gas path surface. See the text for a description.

Following post-test NDE inspection and detailed visual inspection, as described above, the liner was sectioned for destructive characterization. The size of the combustor liner was such that it needed to be initially sectioned into six equal segments, labeled sections $\mathrm{A}$ through F, before individual test samples could be machined from it. All machining of the liner was done using diamond abrasive machining, with final cuts for metallographic examination being done using a low-speed diamond saw where possible. The top part of the photograph in Figure 3-334 shows the initial sampling plan superimposed over a photograph of the liner outer surface. Samples for metallographic analysis were cut from areas that had either interesting features visible on the outer or inner surfaces, or from areas of strong NDE indications. The bottom part of Figure 3-334 shows a montage of the liner sections following machining of the individual test samples.

Tensile test bars were cut from 4 regions of the liner. Bars D-F and J-L were cut from regions that had limited NDE indications and relatively "clean" surface conditions. These bars were expected to reflect the properties of normal $\mathrm{CMC}$ following the engine test 
exposure. Bars A-C were cut from the region of section $B$ that showed large, strong NDE indications, and thus would represent material that had significant processing defects prior to exposure. Bars G-I were cut from the region of section D where the "spider web" ridges and cracking were observed in the EBC coating following the engine test. These samples were intended to represent material where localized failure of the EBC had occurred during service. None of the bars were cut from sections where major EBC spalls and liner recession had taken place, as these samples were deemed to be more important for microstructural characterization than for mechanical characterization.

The tensile test bars were ground into a dogbone configuration, and the EBC coating was grit blast off of the bar surfaces prior to testing. Testing was done with face-loaded frictional grips, and it was feared that shear failure in the EBC coating would compromise the integrity of the tensile tests. Most of the bars showed no unusual surface features following EBC removal, except for bars G-I, which were cut from the "spider web ridge/crack" region. On these bars the spider web ridges/cracks in the EBC did lead to enhanced localized oxidation of the CMC surface along the ridges, which will be described in more detail later with the microstructural analysis data. This oxide was subsequently removed during grit blasting operation, leaving shallow troughs running across the bar surfaces, as shown in Figure 3-335. Based on direct observations of the test bars, and from the metallographic data from this same region, the maximum depth of these troughs was only just to the $1^{\text {st }}$ composite ply. 

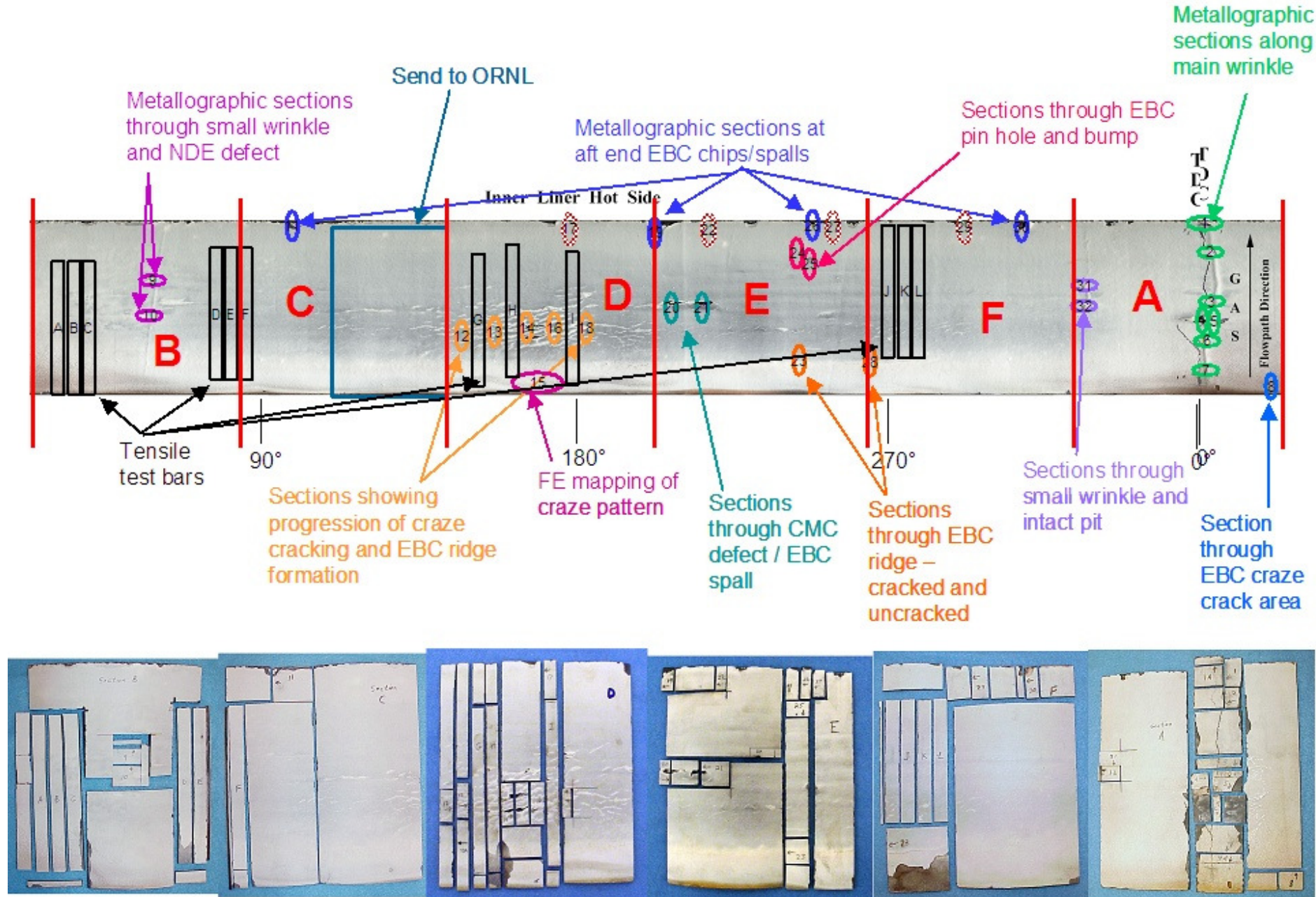

Figure 3-334. Top - Photograph of the outer surface of liner \#4 with the location of the various samples desired for post-test characterization indicated; Bottom - Montage photograph of the liner following sectioning and machining for extraction of the individual characterization specimens 


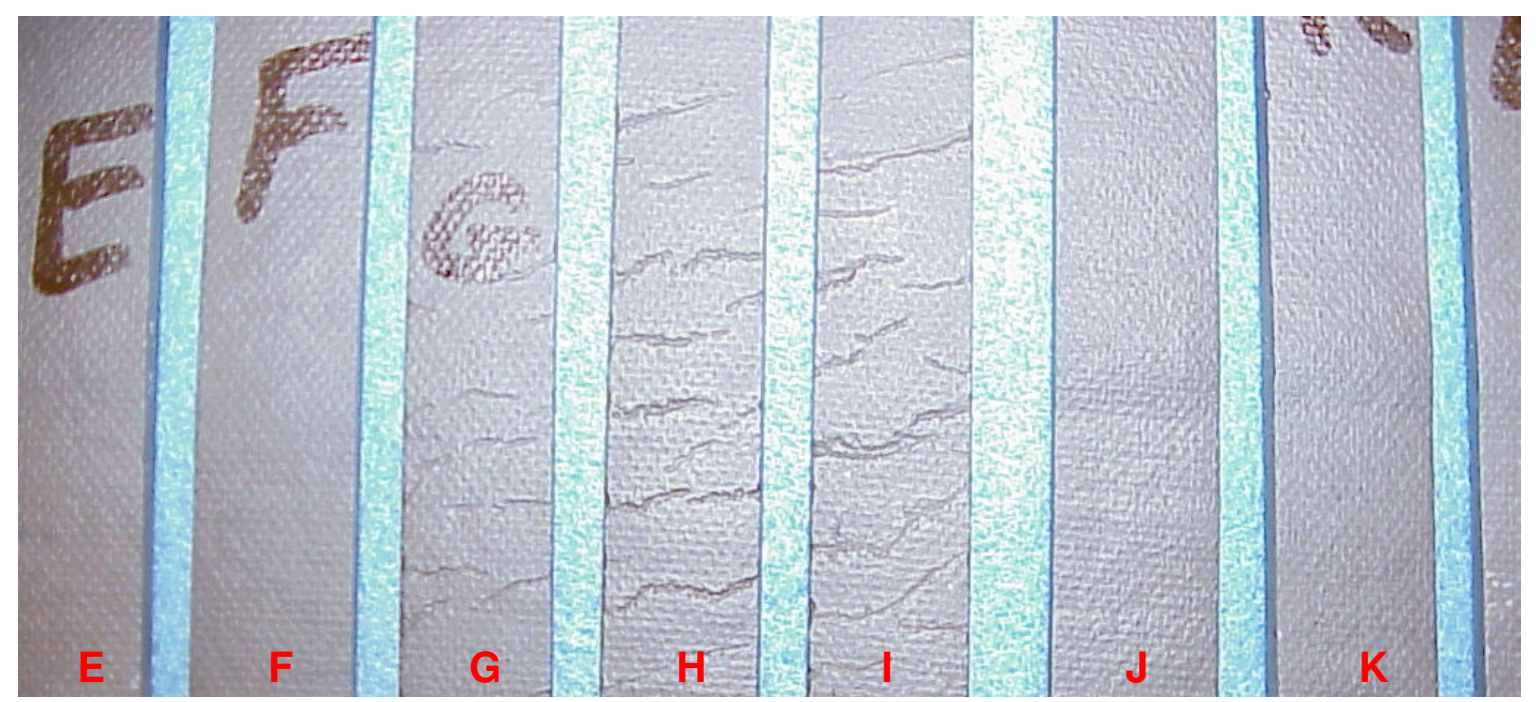

Figure 3-335. Photograph of tensile bar surfaces following removal of the EBC coating via grit blasting. The irregular troughs seen in bars $\mathrm{G}, \mathrm{H}$ and I correspond to the locations of the spider web ridges/cracks in the EBC coating. The surfaces of tensile bars cut from other regions of the liner were relatively unaffected by engine exposure.

The tensile stress-strain curves measured on these test bars are shown in Figure 3-336. In both of the plots the first set of curves is from witness bars fabricated with the combustor liner using the same batches of coated fiber. However, it should be noted that the fiber architecture and specimen thickness of the witness bar samples differed from those of the bars cut from the liner. The witness bars were built with a balanced 8-ply 0-90 layup having 4 plies in the $0^{\circ}$ direction and 4 plies in the $90^{\circ}$ direction. The combustor liner was laid up with 9 plies in order to reach the desired wall thickness, four plies being in the axial direction of the liner and five being in the hoop direction. Since the liner test bars were cut from the liner with the axial orientation being the tensile test direction, these samples had only $4 / 9$ of their reinforcing fiber in the tensile direction whereas the witness bars had $1 / 2$ of their fiber in the tensile direction. Also, the combustor liner had a layer of impregnated carbon cloth bonded to the inner surface to serve as a silicon wick during melt infiltration. This wick effectively adds thickness to the liner that is unreinforced, and thus does not contribute to the ultimate strength. Taking into account the different fiber architectures and thickness added by the bonded wick, the net fiber volume fraction in the tensile direction for the witness bars was $10.9 \%$ whereas that of the combustor liner samples was $7.9 \%$, or $\sim 28 \%$ lower than the witness bars. Consequently we would expect the ultimate strength of the combustor liner samples to be $\sim 28 \%$ lower than those of the witness bars even if no degradation had occurred during testing. The observed average ultimate strength of the liner samples was $189 \mathrm{MPa}(27.4 \mathrm{ksi})$, or $23 \%$ lower than that of the witness bar samples at $244 \mathrm{MPa}(35.4 \mathrm{ksi})$. There was a similar $\sim 20 \%$ difference in strain to failure between witness and liner samples. The conclusion drawn from this data is there there was no overall degradation in CMC strength as a consequence of the 12,822 hours of engine exposure. 

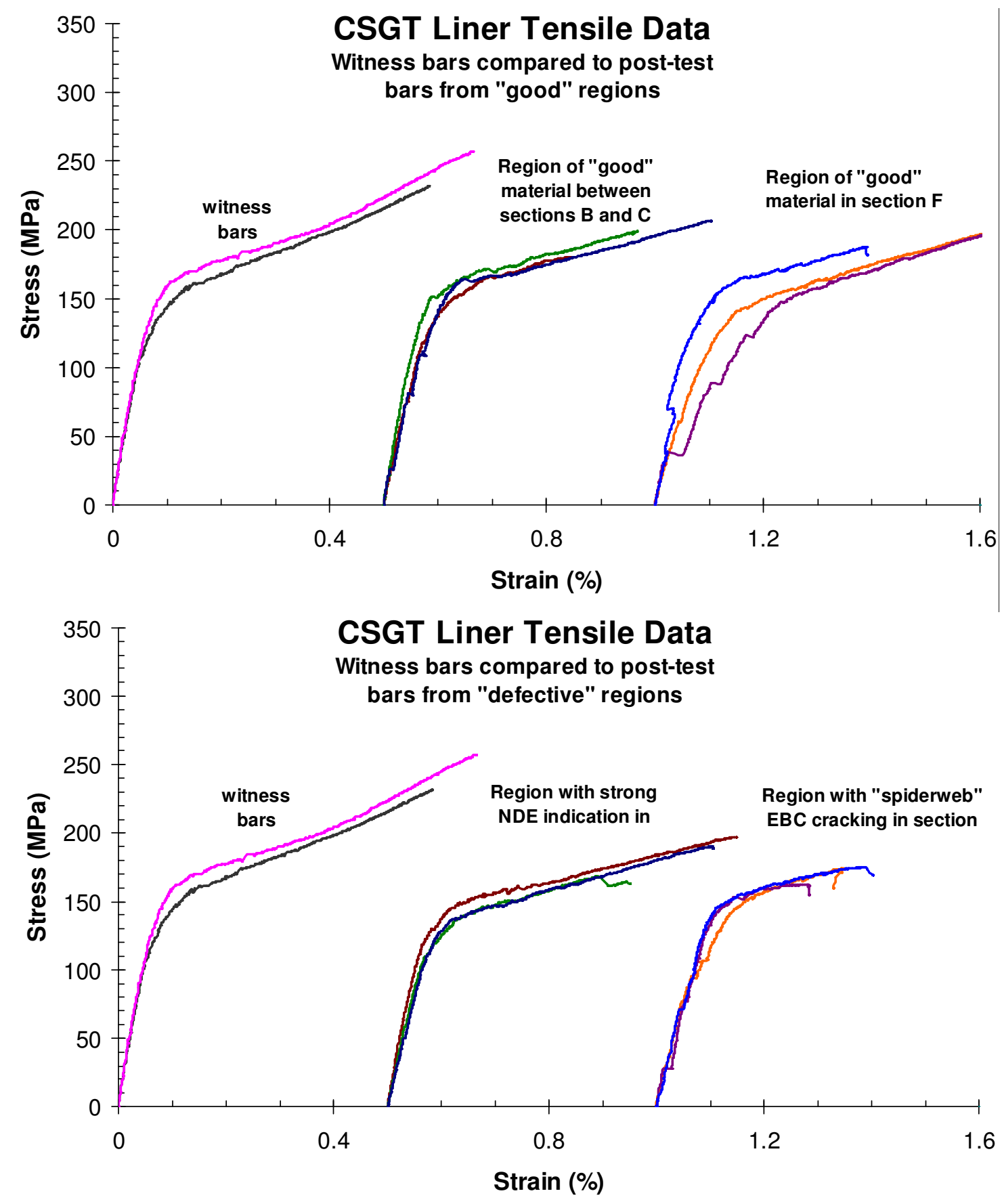

Figure 3-336. Tensile stress-strain behavior of samples cut from the HiPerComp® CSGT liner compared to that of witness bars fabricated with the liner: Top - Samples taken from areas of the liner with no visible defects and only minor indications on the NDE images; Bottom - Samples taken from regions of strong NDE indications or from the region of "spider web" cracking 
Comparisons of proportional limit strength and modulus between the witness bars and liner bars were compromised by the presence of delaminations in many of the liner test bars. These delaminations caused irregularities in the loading curves by interfering with the extensometer. Of the liner samples with "clean" loading curves, the average proportional limit of the liner samples was $104 \mathrm{MPa}(15.1 \mathrm{ksi})$, which was practically identical with the witness bars at $106 \mathrm{MPa}(15.4 \mathrm{ksi})$. Both of the values are lower than typical for prepreg MI CMC material, but are consistent with the microstructures of the samples and level of residual porosity, to be discussed later. This residual porosity was a characteristic of the fiber coatings in use at the time the liner was fabricated, and subsequent fiber coating and $\mathrm{CMC}$ fabrication process changes have been instituted to eliminate these defects in later materials. The initial modulus values averaged $\sim 17 \%$ lower for the liner bars compared to the witness bars; however, this difference is also easily attributable to the extra porosity in the liner samples.

The other interesting observation regarding the post-test tensile data is that there was not a systematic difference between the samples taken from "good" and "defective" regions of the liner. This result suggests that the "defects" did not appreciably degrade the mechanical performance of the CMC even after 12,822 hours of engine exposure.

Microstructural analysis of the liner will be broken down and discussed according to the type of defect being examined. These defect types include: 1) the main ply wrinkle defect in section A, 2) three smaller ply wrinkle defects in sections A,B and E, 3) EBC delams associated with a strong NDE indication in section E, 4) EBC chips/spalls along the aft edge of the liner, 5) backside recession of the liner mostly in sections D-F, 6) isolated bumps and pits in the EBC, 7) the "spider web" EBC cracking in section D, and 8) an apparent step in EBC height parallel to the forward edge, most prominent in sections C-E. Several samples of each defect type were prepared for metallographic examination, and detailed discussion of every sample would be impractical for this report. Therefore, selected metallographic sections will be presented and described that capture the salient features of the different defects.

The most prominent defect on the liner was the main ply wrinkle in section A. This wrinkle was present in the as-fabricated liner, and also caused pitting of the CMC surface during grit-blast surface preparation for EBC application. At the location where the ply wrinkle reached the end of the liner a void associated with the wrinkle was exposed even before engine testing. This void is shown in the left photo in Figure 3-331. During engine operation internal oxidation into this void caused the liner to swell and further delaminate. The swelling deformation was toward the inner surface of the liner, and thus was not visible during the borescope inspections, but was clearly visible after the test, as shown in the right photos in Figure 3-331.

Metallographic sections through this region of the liner in both the axial and hoop orientations, are shown in Figure 3-337. The top micrograph, which is the axial section (i.e. the liner axial direction is left to right in the plane of the micrograph), shows that the oxidation has penetrated into the liner for more than $2 \mathrm{~cm}$. It also clearly shows how the 
inner plies of the CMC curled inward from the force of the oxidation product that had filled up the void at the wrinkle. The bottom micrograph, which shows a hoop section cut at a depth of $\sim 6 \mathrm{~mm}(\sim 1 / 4 ")$ from the end of the liner with the position of the original wrinkle at the far left of the micrograph, indicates that the internal oxidation extended almost $2 \mathrm{~cm}$ outward laterally from the wrinkle. In both sets of micrographs the oxidation penetration was greatest in the $5^{\text {th }}$ and $7^{\text {th }}$ plies (counting from the outer surface inwards), and there is a delamination of the surface matrix layer at the wrinkle location that is largely filled with silicon. Both micrographs also indicate that the EBC coating remained intact right up to the aft edge of the liner, with very little lateral oxidation of the EBC bond coat inward from the edge. In this region the inner carbon cloth wick ply has been completely consumed by oxidation and has spalled away.

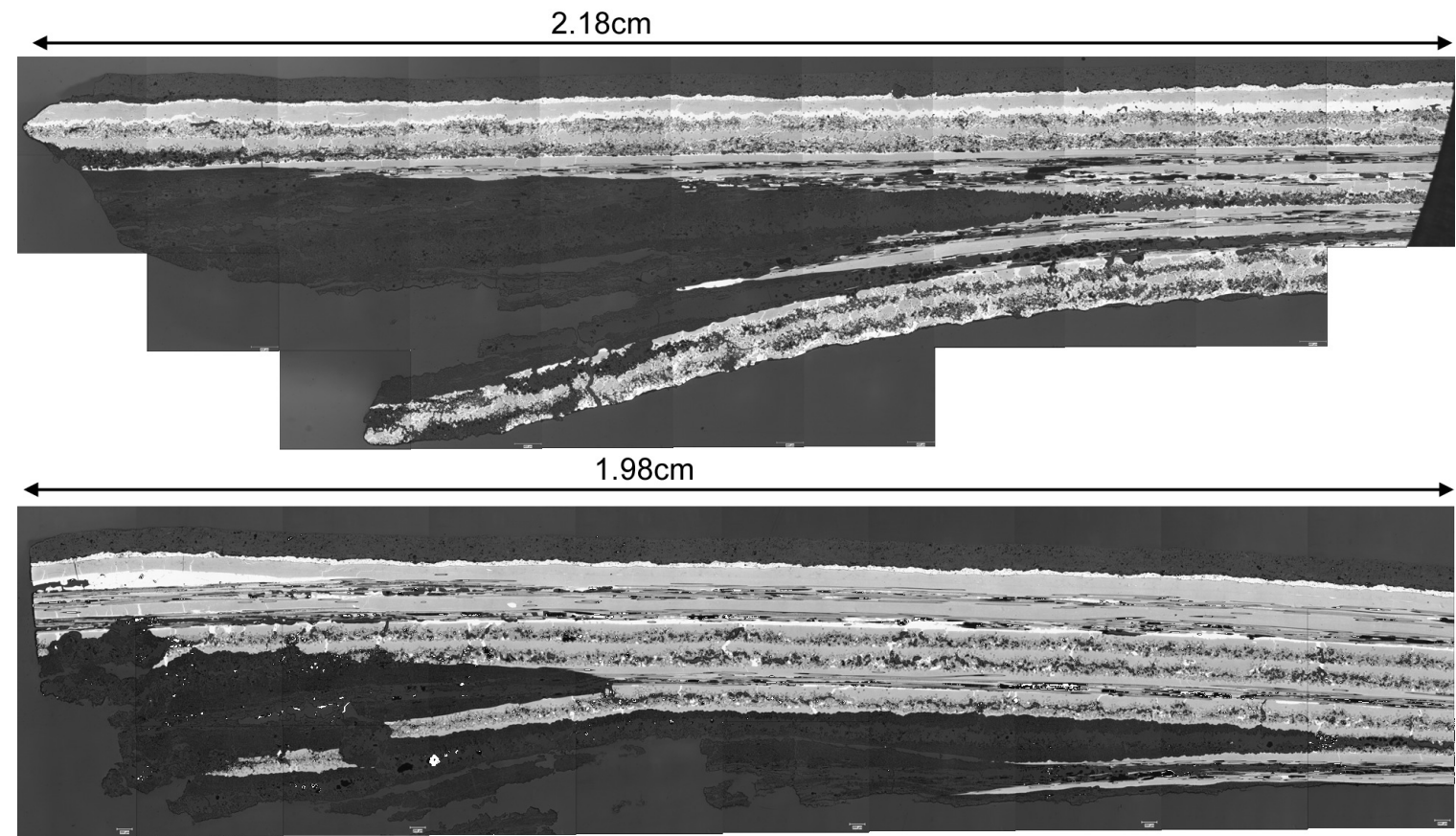

Figure 3-337. Montage micrographs of the main wrinkle defect where it reached the aft edge of the liner: Top - axial section; Bottom - hoop section $\sim 6 \mathrm{~mm}(\sim 1 / 4 ")$ in from the aft edge.

Additional samples were cut from the liner at various axial locations along the main wrinkle, generally in regions with CMC surface pits. An example of such a sample is shown in Figure 3-338. This axial cut section shows the cross section of the main wrinkle looking in the hoop direction. A relatively large, but shallow, pit from the EBC grit blasting treatment is seen along the top surface. The surface matrix ply is delaminated and filled with silicon on either side of the pit, and the pit depth is just into the $1^{\text {st }}$ ply. It is likely that the delam under the surface layer was not filled with silicon in this region, leading to removal of this thin surface layer during grit blasting. The EBC coating is seen to coherent across the liner surface and along the pit bottom, with only moderate indications of discontinuity of the EBC and enhanced bond coat oxidation at the left side of the pit in the micrograph, which 
corresponds to the small EBC crack/spall at the bottom of the pit in the surface photograph in the lower right part of the figure. The inner carbon wick ply has been completely oxidized in this region, but the porous oxide is still adherent to the inner surface of the liner.

$1.78 \mathrm{~cm}$

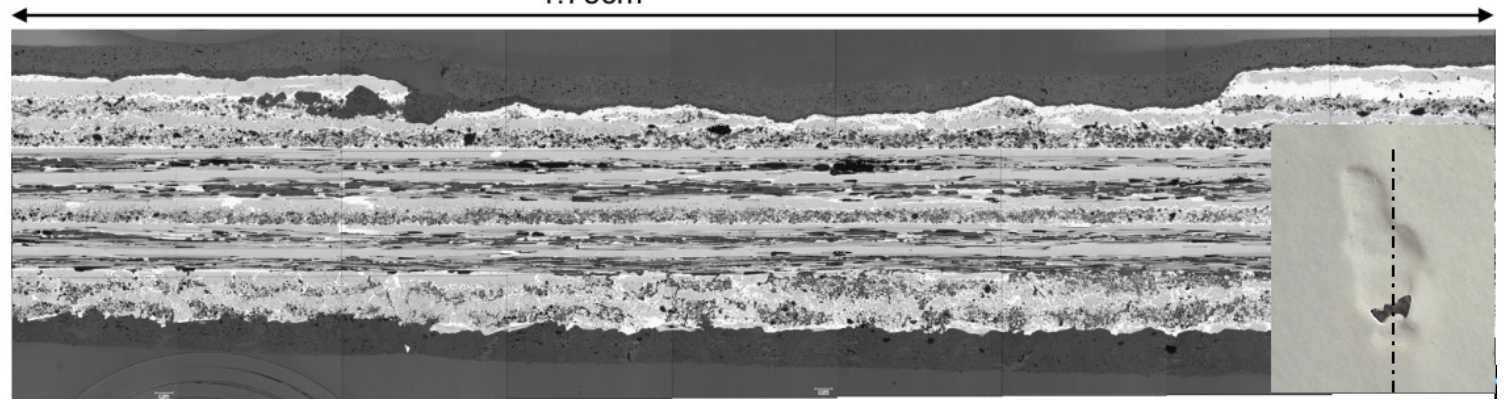

Figure 3-338. Montage micrograph of a section through a surface pit on the main wrinkle of the CSGT liner. A photograph of the pit on the surface is shown in the small inset in the lower right, and the dashed line indicates the location of the cross section surface used for metallography. The small spall at the bottom of the inset photograph corresponds to the left edge of the pit in the micrographs.

Figure 3-339 shows a montage micrograph taken of a sample toward the forward edge of the liner in a region with no CMC surface pits. It more clearly shows the cross section of the main wrinkle and the disturbance of the CMC plies. This view also shows the delamination of the surface matrix layer at the peak of the wrinkle, and the delam under the $2^{\text {nd }}$ ply (counting downward from the outer surface) that was present in many sections of the liner. Again, it is believed that the CMC surface pits that formed along the wrinkle during grit blasting was caused by the region under the surface matrix layer being devoid of silicon in various regions, leaving the thin, fragile surface matrix layer unsupported and susceptible to damage. In regions where the grit blast pits were deeper it was likely caused by an open delamination underneath the $2^{\text {nd }}$ ply, resulting in the same effect.

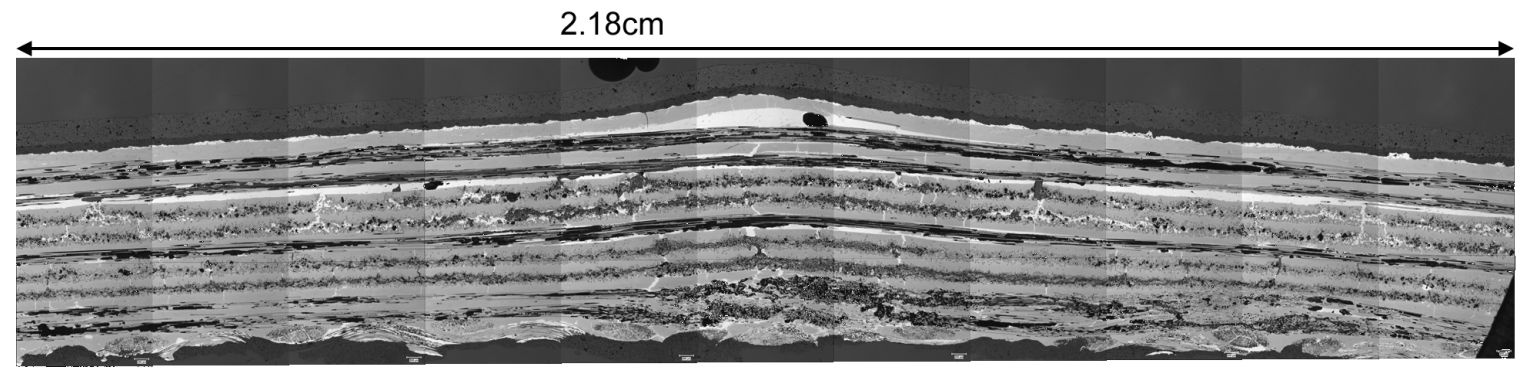

Figure 3-339. Micrograph montage of the main wrinkle defect near the forward edge of the liner away from any surface pits. 
Figure 3-340 shows a photograph of the deepest surface pit region along the main wrinkle following the ending test. This defect was observed to show oxidative attack early in service via borescope inspection. At the conclusion of the test the oxidation had caused localized uplifting of the CMC surface and an EBC spall $\sim 1 \mathrm{~cm}$ in size around the pit. The uplifting was greater in the hoop direction, causing the $\mathrm{EBC}$ spalls to extend further in this direction. Metallographic samples were cut from the pit region as shown in Figure 3-340.

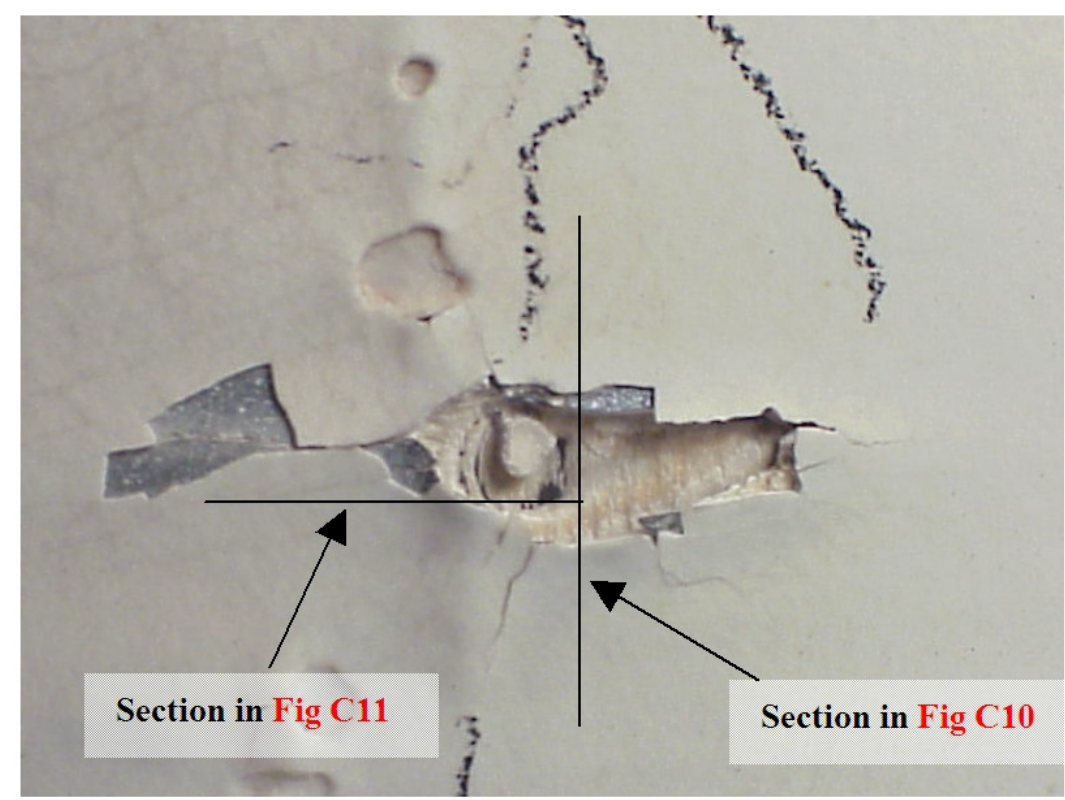

Figure 3-340. Close up photograph of the deepest surface pit region along the main ply wrinkle following the engine test. The axial direction of the liner is vertical in the photograph.

Micrographs from the metallography sample cut parallel to the axis of the liner and through the deepest pit is shown in Figure 3-341. There was substantial penetration of oxidation axially from the pit location, extending about $2 \mathrm{~cm}$ in total. The main penetration was below the $2^{\text {nd }}$ ply of the CMC, suggesting that the $2^{\text {nd }}$ ply delam was open in this region and probably contributed to the original formation of the pit. Buildup of porous silicon dioxide within the delam has lifted the upper plies of the CMC around the pit. Despite this substantial strain, the EBC coating remained intact and protective on the outer surface of the liner. (The EBC coating on the left side of the micrograph in Figure 3-341 was intact after engine test, but spalled from the CMC during sectioning of the metallographic specimen.) Overall depth of oxidation/recession was down to the $4^{\text {th }}$ composite ply, or $\sim 1.3 \mathrm{~mm}$. 


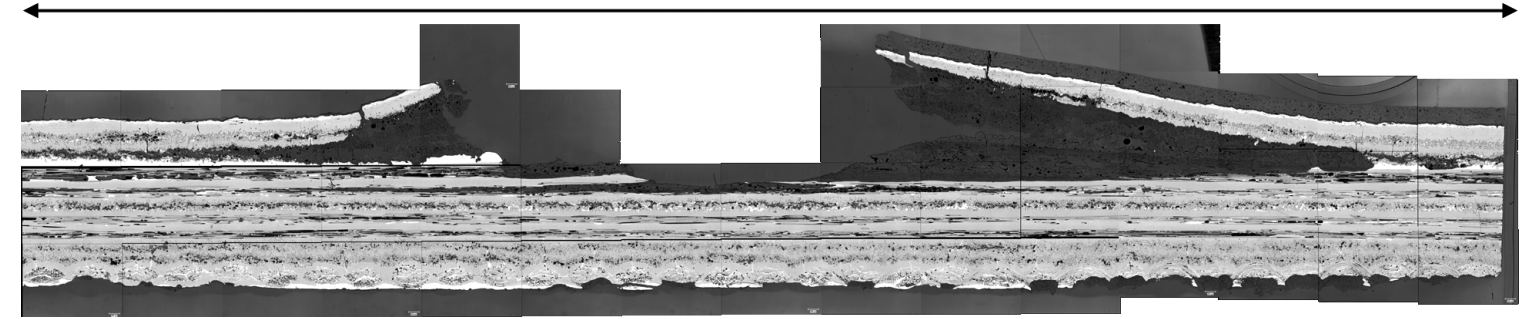

Figure 3-341. Montage micrograph of the cross section of the main CMC surface pit. Left to right in the micrograph is the axial direction of the liner, with the aft of the liner being to the right.

While the section shown in Figure 3-341 was at the center of the CMC pit, it did not intersect the actual middle of the wrinkle in this region. The micrographs in Figure 3-342 show a cross section of the main wrinkle in a region adjacent to the large pit. The disruption of the ply orientations is seen in the "bump" at the left side of the figure. Oxidation has spread laterally in the hoop direction a substantial distance from the pit and wrinkle, resulting in uplifting of the CMC outer plies that undoubtedly contributed to EBC spallation seen to the left of the wrinkle in Figure 3-340. The greatest penetration is again below the $2^{\text {nd }}$ composite ply, strongly suggesting that the delamination was unfilled with Si in this area, leading to the rapid lateral oxidation.

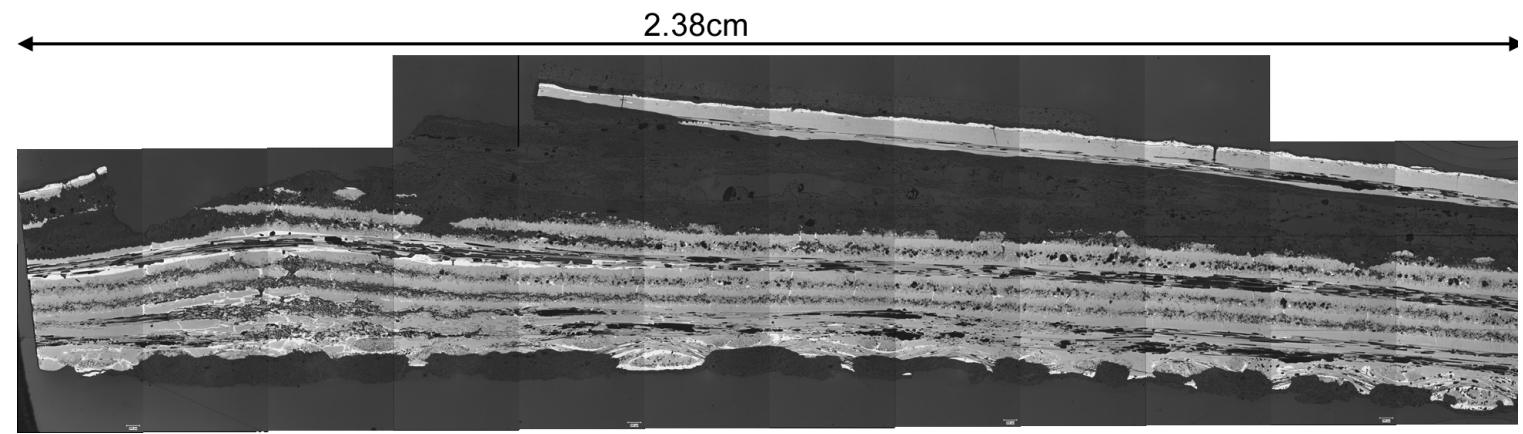

Figure 3-342. Montage micrograph of a cross section of the main wrinkle at a region adjacent to the deepest CMC pit, as shown in Figure 3-340. Lateral oxidation in the liner hoop direction has extended more than $2 \mathrm{~cm}$ from the wrinkle position at this location.

The second type of liner defect to be described are the smaller ply wrinkles seen in sections A, B and E. These wrinkles were all less severe than the main wrinkle in Section A. Samples were deliberately cut from liner regions that showed strong NDE indications so that the structure of the wrinkle and the cause of the NDE indication could be determined simultaneously. 
Figure 3-343 shows a montage micrograph of the cross section of the wrinkle in Section B. The overall height of the surface wrinkle was very small, only a small fraction of a millimeter, as indicated by the parallel red lines at the top of the micrograph; however, the internal defect at the wrinkle was more substantial than what showed at the surface. This wrinkle appears to have developed from an overlap seam in the $2^{\text {nd }}$ ply as the underlying CMC appears undisturbed. During lamination the material on either side of the overlap would have been compressed together, but during binder burn-out and infiltration the plies appear to have sprung back, opening up the delamination under the $2^{\text {nd }}$ composite ply on both sides of the overlap seam. In this particular region the delamination to the left of the wrinkle filled with silicon, but on the right side it did not. It is this unfilled delamination that accounts for the strong NDE indication in this region. Despite the open nature of the delamination, it is unclear whether any internal oxidation occurred. There is some material inside the delamination that may be related to limited internal oxidation, but this may also be cutting debris or remnants of the glue used during sample sectioning.

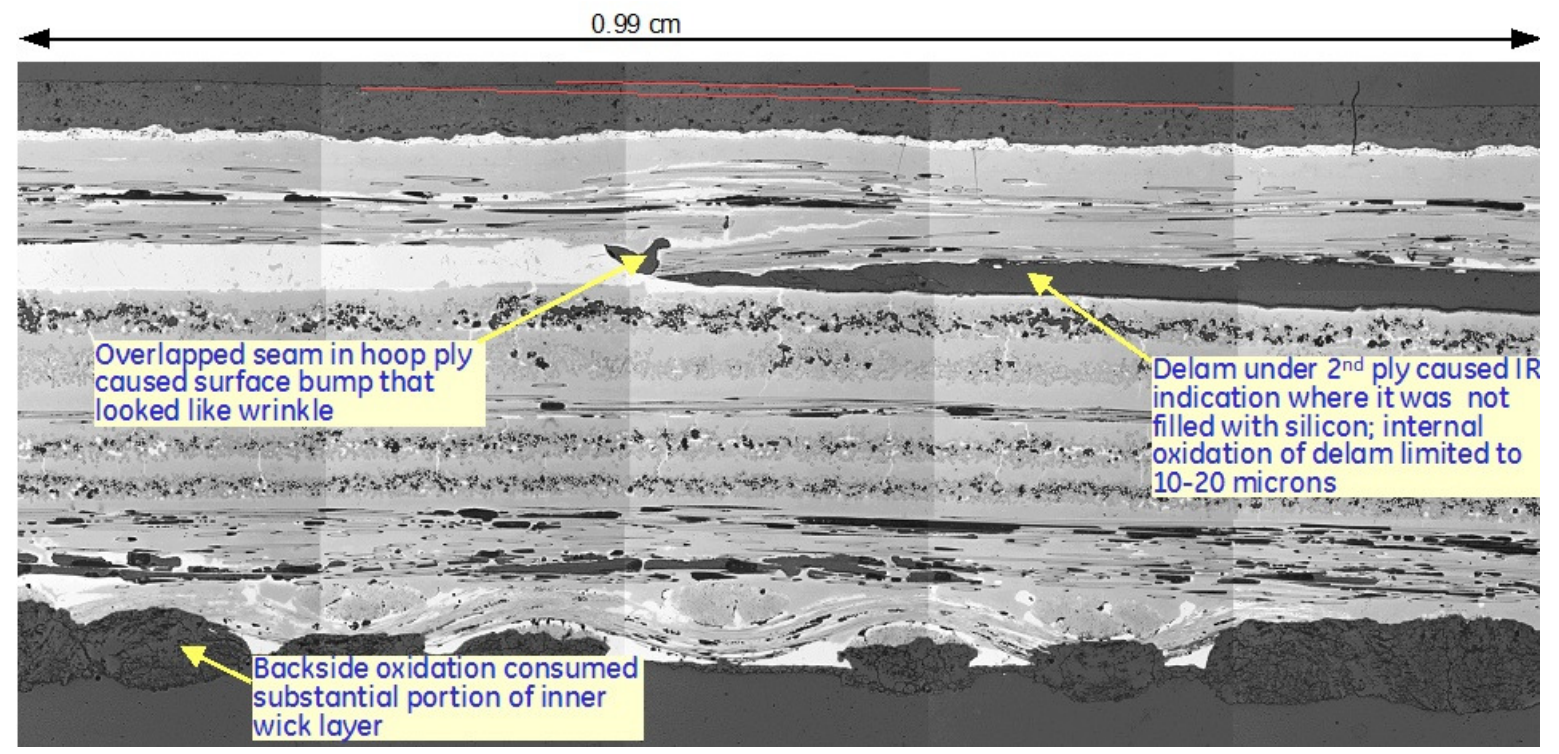

Figure 3-343. Montage micrograph of a cross section of the small wrinkle in Section B.

The wrinkle corresponds to an overlap seam in the $2^{\text {nd }}$ composite ply that resulted in lateral delaminations. The part of the delamination that did not fill with silicon during infiltration account for the strong NDE indication in this area.

The small surface wrinkle in Section A differed from that in Section B. Figure 3-344 shows a montage micrograph of the cross section of the small wrinkle from Section A. Here the defect is a true liner wrinkle as plies at least as deep as the $7^{\text {th }} \mathrm{CMC}$ ply show distortion at the wrinkle location. The height of the surface bump was larger for this wrinkle, being $\sim 1 / 4 \mathrm{~mm}$. Again the delamination under the $2^{\text {nd }}$ ply has opened up substantially, causing the strong NDE indication in this region. There are indications of limited internal oxidation of the delaminations in this region, which may have come from a nearby surface pit that exhibited EBC cracking during service. 


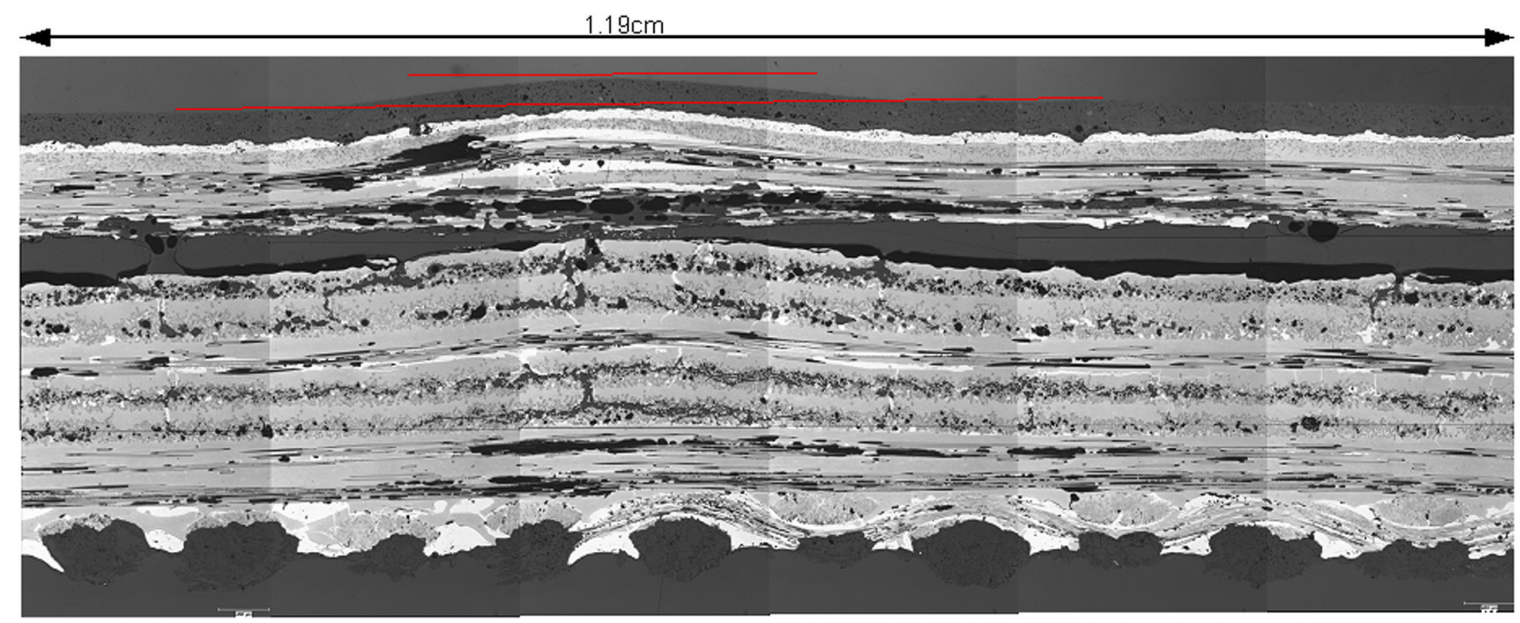

Figure 3-344. Montage micrograph of the cross section of the small liner ply wrinkle in Section A.

The third liner feature to be characterized was the two EBC spalls and pits in the CMC in Section E. These spalls/pits flanked the small wrinkle in Section E and corresponded to a strong indication in the NDE image. Sections were taken through the center of each spall in the axial direction. Figure 3-345 shows the cross section of one of these spalls looking in the hoop direction with the liner axial direction being left to right in the micrograph.

This spall again appears to involve lateral oxidation along a delamination underneath the $2^{\text {nd }}$ ply of the composite. There were several shallow, broad ridges along the hoop direction of the liner, which likely correspond to the regions where this delamination below the $2^{\text {nd }}$ ply had opened during fabrication. The delamination had obviously opened in the region of these spalls/pits, as shown by the thickening lenses of Si alloy filling the delamination on either side of the spall. Although the inner surface of the delamination is now consumed by recession and oxidation, it is likely that the delamination was not filled with silicon at this location, which resulted in the strong NDE indication. The round feature seen at the left side of the spall looks very much like a recession hole as was seen below EBC pin holes on the shrouds from the first engine test. A likely scenario for the formation and growth of this defect is that a pinhole in the EBC allowed the start of the recession pit. Eventually this pit reached the depth of the delamination below the $2^{\text {nd }}$ ply, at which time enhanced lateral oxidation along the open delamination caused additional lifting of the upper plies and opening of the hole in the $\mathrm{CMC}$, with eventual spallation of the unsupported upper layers of $\mathrm{CMC}$ and EBC. The fact that these spalls/pits occur at the location of the strong NDE indication suggests that the CMC defect had something to do with the initiation of the EBC failure and/or pin hole; however, at this state of damage it is not possible to say this with any certainty. 


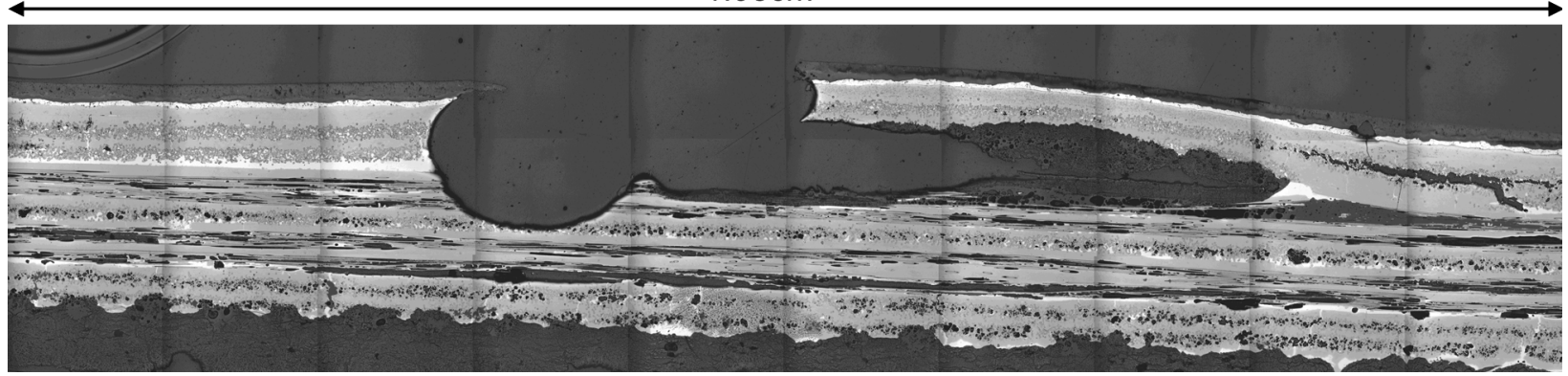

Figure 3-345. Montage micrograph of the cross section of one of the EBC/CMC spall regions near the center of Section E.

The fourth type of liner feature/defect was the chips/spalls of the EBC coating along the aft edge of the liner. These chips appeared in the $1^{\text {st }}$ borescope inspection, and showed relatively sharp edges, reminiscent of a conchoidal fracture. A borescope photograph of one of these chips from the $1^{\text {st }}$ borescope inspection at 3983 hours is shown in Figure 3346. Due to the lack of reference points in the borescope photos, and due to changes in the chips/spalls with exposure time, it is very difficult to positively correlate the chips in the EBC after test with specific borescope photographs.

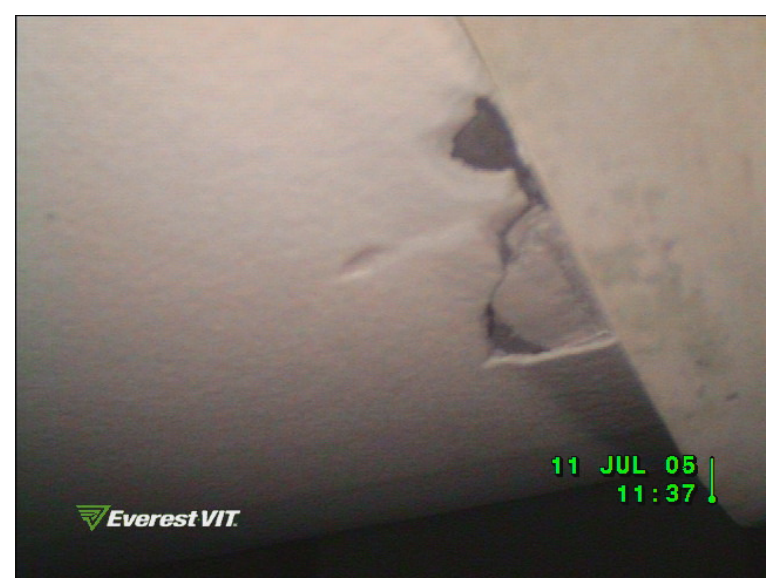

Figure 3-346. Borescope photograph of one of the chips in the EBC at the aft edge of the combustor liner. The sharp edges and shape of the chips suggest that they were caused by mechanical pressure and/or impacts along the aft edge of the liner.

Metallographic sections were cut axially through several of the larger EBC chips/spalls along the aft edge of the liner. Photographs of two of these chips/spalls and the corresponding micrographs of the spall cross sections are shown in Figure 3-347 and Figure 3-348.

The EBC chip in Figure 3-347 shows well intact EBC right up to the chip edge with a slight undercutting of the EBC by CMC recession. There is no enhanced lateral oxidation 
of the EBC bond coat from the edge of the chip, and thus the EBC has remained protective right up to the edge of the chip. The maximum recession near the aft edge is on the order of $1.34 \mathrm{~mm}$. Since many of these EBC chips were seen in the initial borescope inspection it is likely that the larger of these chips occurred very early during the test. Thus the recession rate in this region could be estimated as approximately $1.3 \mathrm{~mm}$ in 12,000 hours.

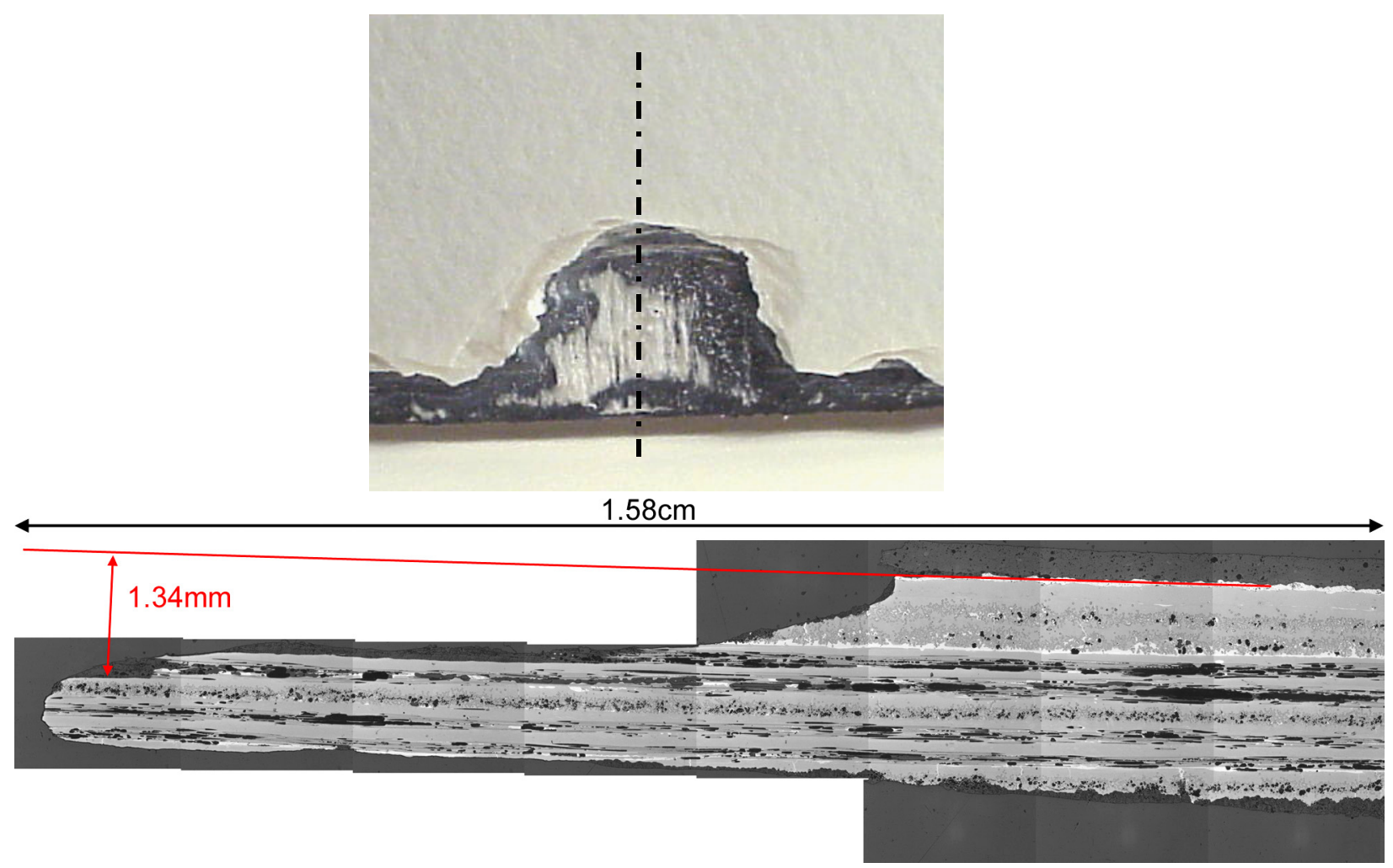

Figure 3-347. Photograph (top) and montage micrograph (bottom) of one of the larger EBC chips along the aft edge of the CSGT liner following the 12,822 hour engine test. The dashed line in the top photo shows the position of the cross section that is shown in the lower micrograph.

Figure 3-348 shows a second cross section through an aft edge EBC chip. The montage micrograph shows the recession thinning of the liner getting deeper toward the liner aft edge, with a maximum recession depth below the EBC bond coat of $1.16 \mathrm{~mm}$. The yellow dashed line in the lower photograph show the location of the cross section relative to the EBC chip. Both the photograph and micrograph show the presence of a small pit in the CMC immediately aft of the intact EBC. 


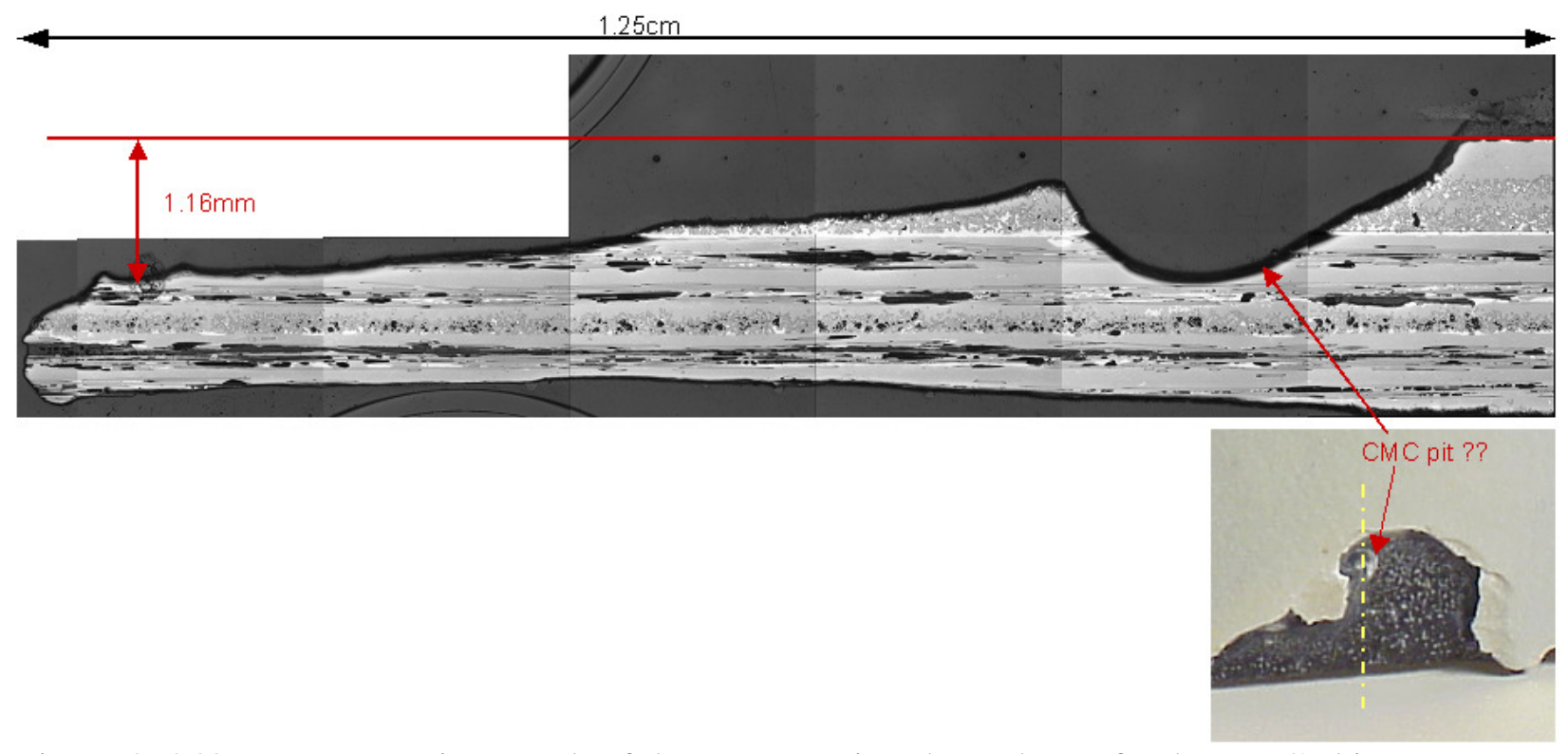

Figure 3-348. Montage micrograph of the cross section through an aft edge EBC chip. The yellow dashed line in the lower photograph shows the location of the cross section.

Additional samples from the aft edge were sectioned and polished in order to examine the extent of recession on the backside (i.e. inside) surface of the liner. These sections generally showed gradual thinning of the aft edge from the inside surface as one approached the edge. The maximum amount of recession seen on any of the aft edge samples was no more than is indicated in Figure 3-348. In this sample the backside recession has consumed the inner bonded wick layer and three full plies of CMC. The ply that comes out right to the edge in the micrograph in Figure 3-348 (far left edge) was actually the $4^{\text {th }}$ ply inward from the inside (lower) surface on the as-fabricated liner. Remnants of the $3^{\text {rd }}$ ply can be seen to the left and right edges of the micrograph. Unfortunately, due to the very irregular surface condition of the inner carbon cloth wick ply on the liner after test, it was not possible to get fully quantitative measures of the recession of the liner from the inner surface. Moreover, because there was significant continuous residual carbon within the inner wick layer this layer would have oxidized much faster than typical CMC. Both of these conditions make it impossible to determine a quantitative recession rate for the inner surface; however, the mere fact that recession did occur strongly indicates that there had to be some level of combustion gas circulation behind the liner during service.

The next types of features to be examined were isolated pits and bumps in the EBC layer. There were several examples of each type of feature on the liner, but only one set from section A has been examined to date. Figure 3-349 shows a photograph of the liner surface showing the pit and bump features that were characterized. The bump was actually very subtle and doesn't show up well on the photograph, but visually it appeared as a slightly whiter spot compared to the surrounding EBC 


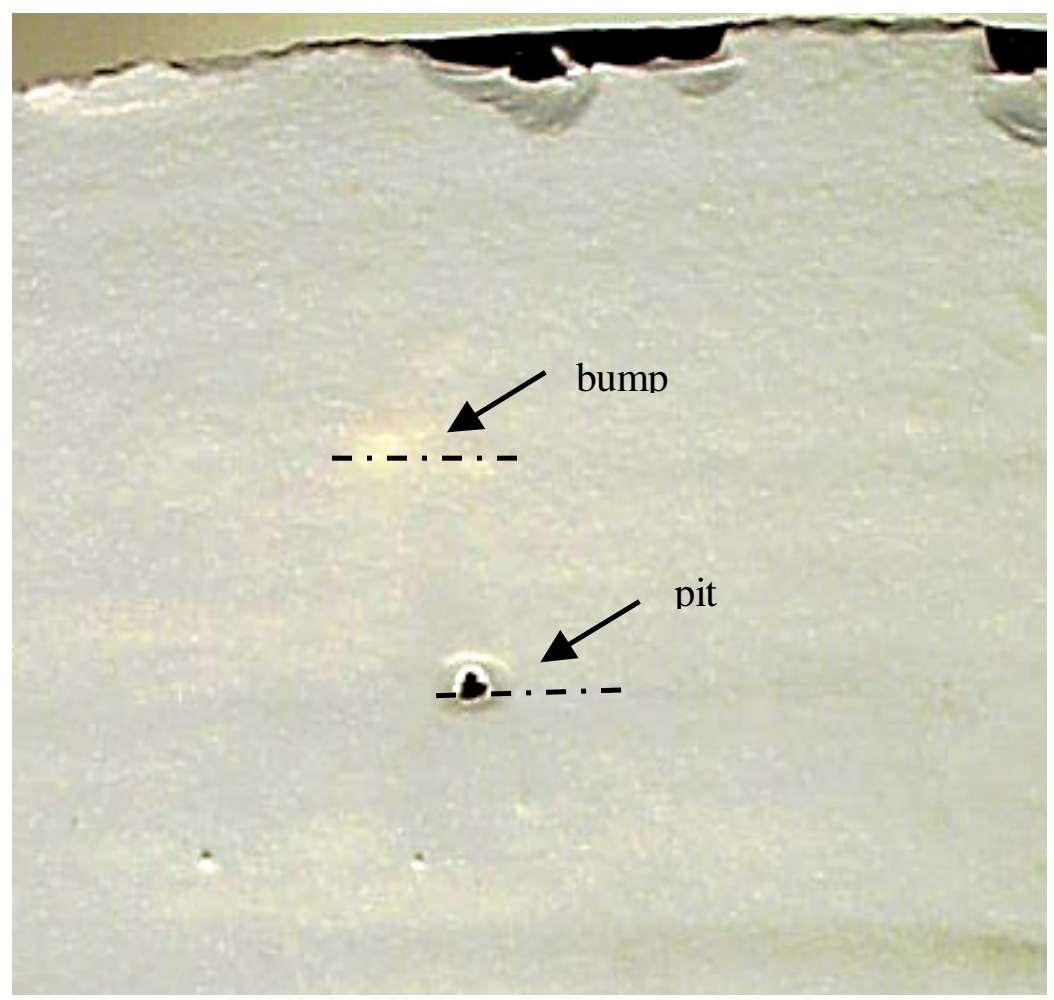

Figure 3-349. Photograph of the surface of the liner after the 12,822 hour engine test, showing the positions of characterization samples cut from the liner for examination of isolated EBC pit and bump features.

A mosaic micrograph of the cross section of the EBC pit is shown in Figure 3-350. It should be noted that this particular pit was chosen for characterization based in its association with an NDE indication. The cause of the NDE indication is the delamination beneath the $2^{\text {nd }}$ composite ply, as shown in the figure. At the left and right edges of the micrograph the delam is seen to be filled with Si alloy, but directly underneath the pit the delam is open. It is not clear whether the presence of the delamination contributed to the initial formation of EBC pit.

There is substantial oxidation product on this inside of the delamination, indicating that the pit had penetrated the CMC to this level out of the plane of view. The section shown in Figure 3-350 does not intersect the center of the pit, but rather shows a view along one edge of the pit, as evidenced by the thin cap of the EBC outer layer still remaining above the pit. The EBC adjacent to the pit is undercut by $\mathrm{CMC}$ oxidation and volatilization. A subsequent attempt to re-polish the specimen down to the center of the pit was unsuccessful as the entire pit defect was ground away. 


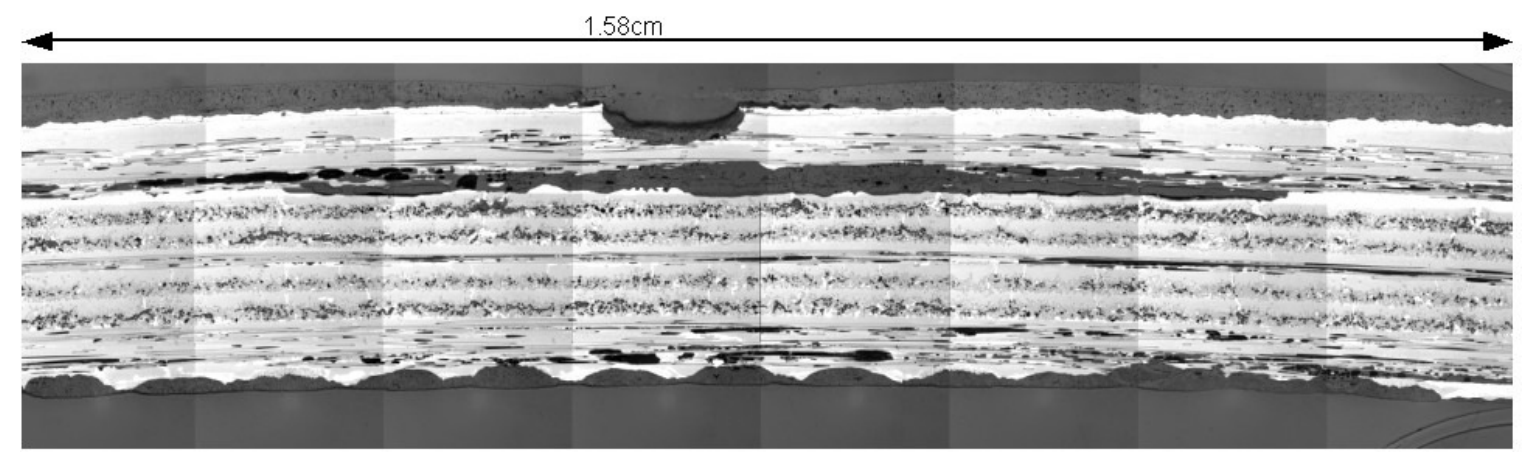

Figure 3-350. Montage micrograph of the section cut along the edge of the pit feature in Figure 3-349.

A cross section of the EBC bump feature is shown in Figure 3-351. The EBC bond coat was completely consumed at the location of the bump, with the oxidation of the substrate $\mathrm{CMC}$ yielding a highly porous oxide. It is the formation of this porous oxide that has pushed up the upper layers of the EBC, causing the bump on the surface. The EBC layers tend to be somewhat translucent; however, the porous oxide formed on the CMC substrate scatters light more effectively than the normal glassy oxidation product, and thereby turns the EBC more opaque, giving it the whitish color when contrasted with the surrounding translucent EBC. The remaining upper layers of EBC do have a very thin through-thickness crack at the peak of the bump, but it is not clear whether this crack was originally present and contributed to the accelerated consumption of the bond coat and subsequent oxidation of the CMC substrate, or if it formed as a consequence of the lifting of the EBC top layers from the formation of the porous oxide. Overall less than $0.05 \mathrm{~mm}$ of CMC has been consumed by the oxidation, and the lateral extent of the accelerated oxidation is only $\sim 4 \mathrm{~mm}$.

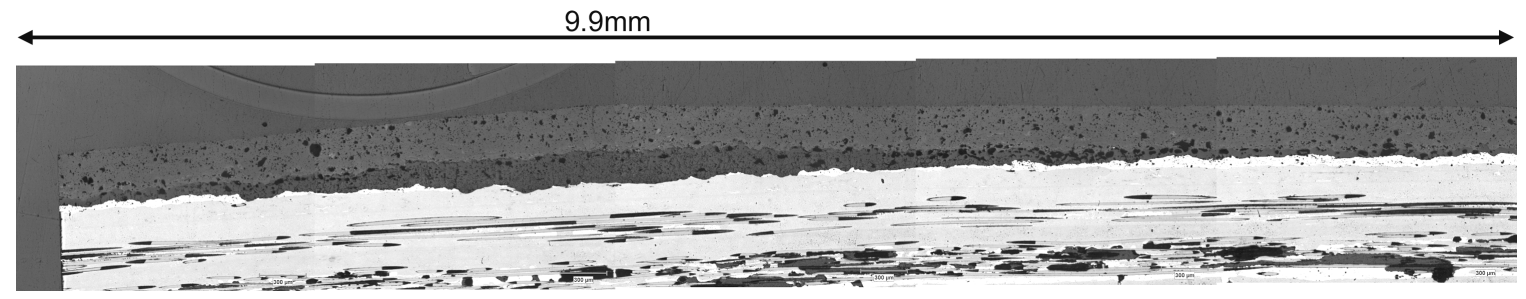

Figure 3-351. Photomicrograph of the cross section of the "bump" feature shown in Figure 3-349.

Whereas all of the previously described features could be relatively easily understood as to their source, method of progression, and consequences to the performance of the combustor liner, there are two types of features found for which we do not as yet have potential explanations. Moreover these features have not been seen in previous steam rig, combustion rig or engine tested hardware, and thus represent new phenomena in our experience. 
The first of these new types of features are the "spider web" ridges and cracks in the EBC. These ridges are prevalent over a small area of the liner just forward of the center at a location that was near bottom dead center when installed in the engine. The network of ridges in this region covered an area roughly 6" $62.5 "$ in size. Many of the ridges had visible cracks running along the peaks, and two of the ridges near the center of this region had resulted in EBC spalls. These ridges were seen to develop rather early in the engine test, as they were present at the $1^{\text {st }}$ liner borescope inspection at 3983 hours and progressed with additional exposure. Figure 3-333 shows photographs of the spider web features on the liner after the engine test. This region of the liner is relatively clean in the NDE images, and there were no anomalies found in the photographic record of this region following EBC coating.

Several metallography samples were cut from the spider web region for microstructural characterization, but all of these samples showed very similar features for the ridges. Figure 3-352 shows a series of photomicrographs for a sample with a high concentration of the spider web ridge features. In general, the ridges were formed by the outer layers of the EBC coating being pushed upward by accelerated oxidation of the CMC at the ridge location. In these regions the $\mathrm{EBC}$ bond coat has been completely consumed, and oxidation of the CMC substrate is forming a highly porous oxidation product. There is a gap between the thermally grown oxide on the $\mathrm{CMC}$ and the top layers of $\mathrm{EBC}$, and in all cases there is a through-thickness crack in the EBC top layers at the peak of the ridge. Although the size and severity of the ridges increases going top to bottom and left to right through this series, eventually reaching a full ridge spall in the lower micrographs, all of the ridges had these same features.

The overall internal structure of one of the spider web ridges is shown more clearly in Figure 3-353. The top micrograph shows the cross section of a well-developed ridge prior to it causing an EBC spall. The diagram on the bottom of the figure gives an interpretation of the features seen in the micrograph. 


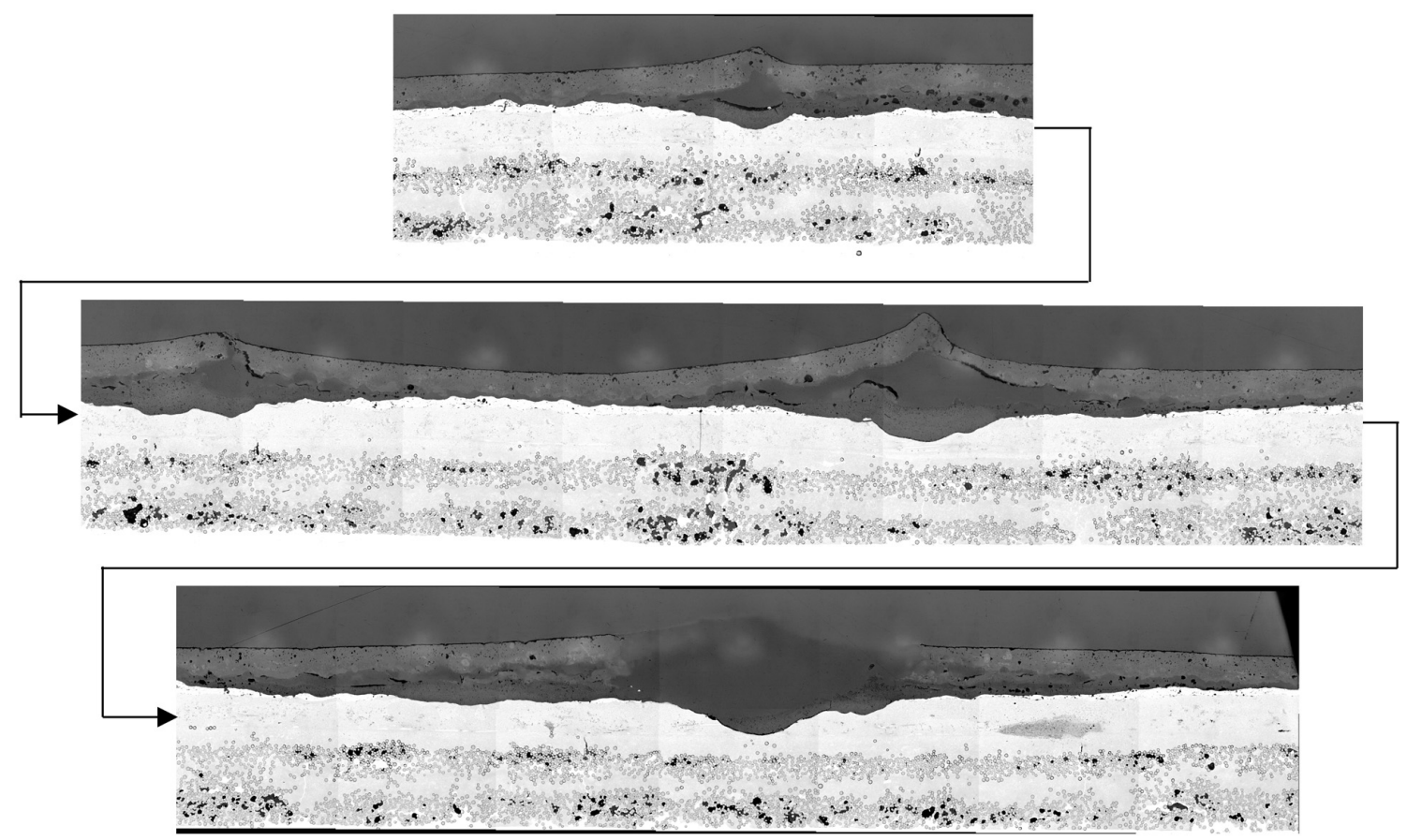

Figure 3-352. Photomicrographs of a series of spider web ridge features. The total width of the area shown is $1.9 \mathrm{~cm}$ and includes four ridges of varying severity.

The micrograph and schematic shown in Figure 3-353 was representative of the majority of EBC ridges examined within the "spider web ridge" region. The differences between the well-developed and just-starting ridges were primarily in the size of the bond coat breach, the amount of porous oxide formed, and thus the height of the ridge of the upper EBC layers. In addition to the ridges in the concentrated spider web region, there were several examples of smaller whitish bumps or ridges in the EBC at other locations on the liner surface. Several of these smaller whitish regions, whose locations on the liner are shown in Figure 3-354, were also examined metallographically. Micrographs of the whitish EBC feature from these regions are shown in Figure 3-355.

There are several features common to each of the small whitish EBC defects that are also common with the larger EBC spider web ridges. First, in all cases the silicon EBC bond coat layer has been breached by oxidation. The breach of this layer has in all cases lead to the formation of relatively porous oxidation product from oxidation of the $\mathrm{CMC}$, and this porous oxide has pushed up the upper layers of EBC, forming the surface relief noted in each case. 


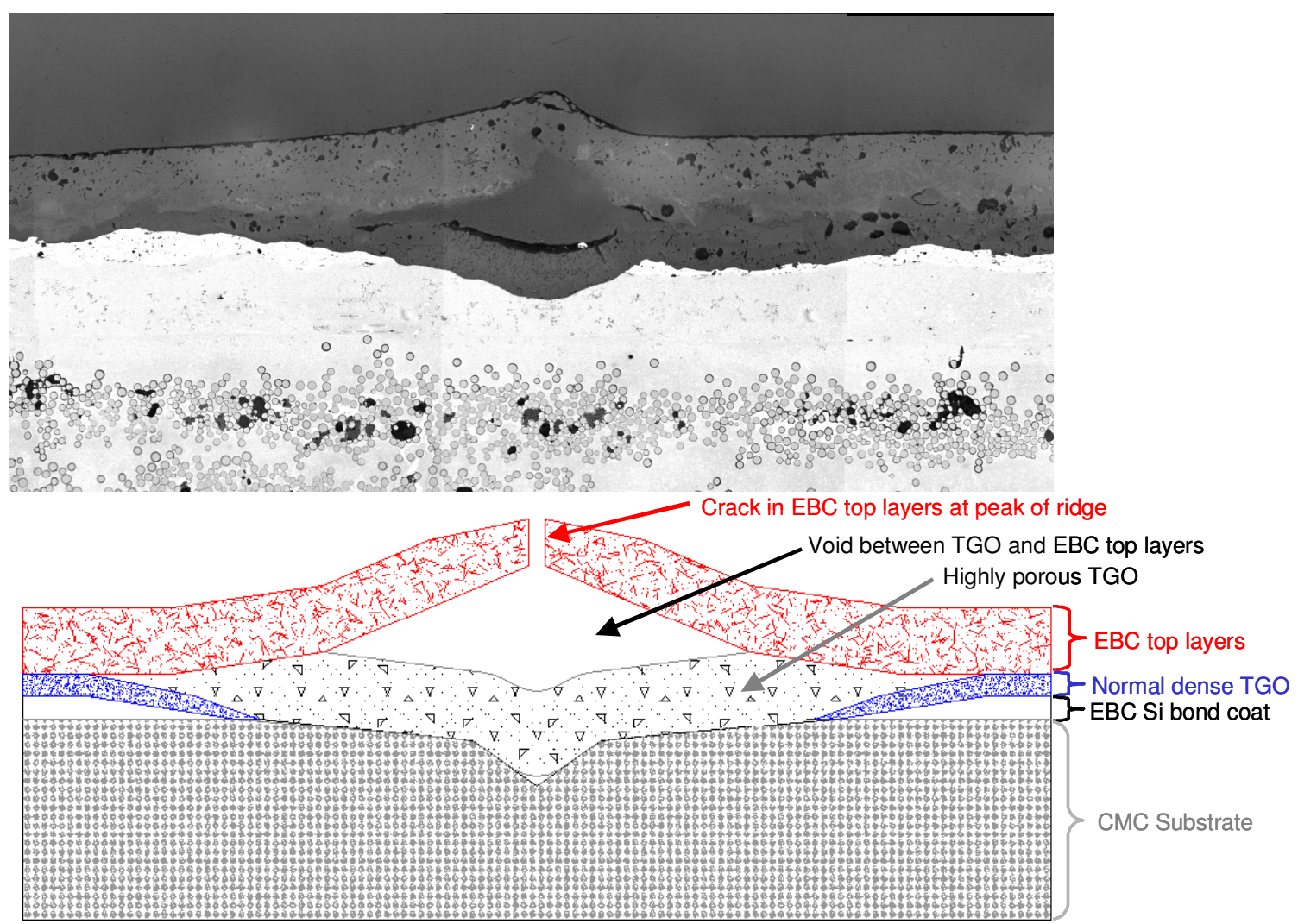

Figure 3-353. The top image is a photomicrograph of the cross section of a typical EBC spider web ridge. The bottom schematic shows the various important microstructural features found in the majority of the ridges examined.

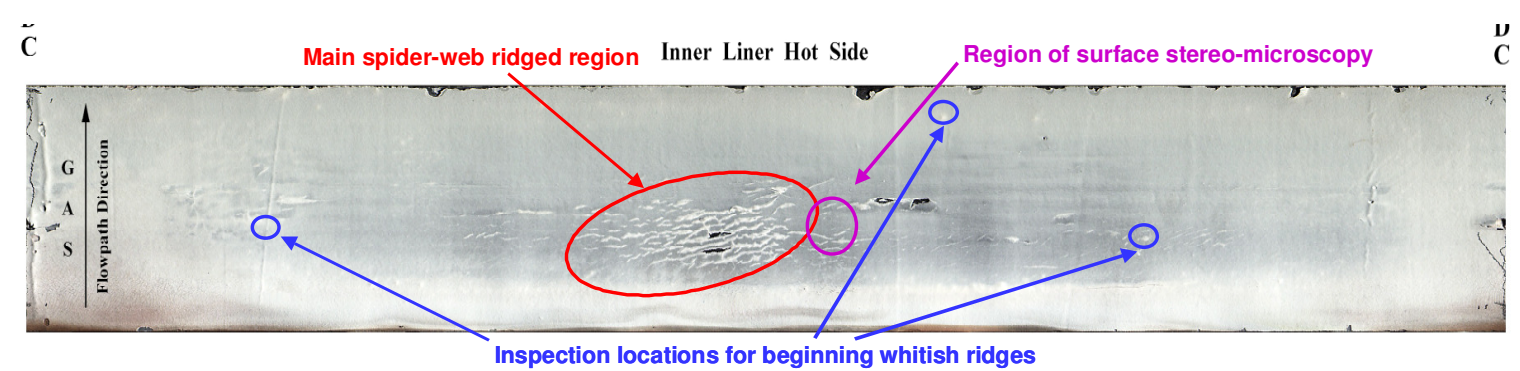

Figure 3-354. Photograph of the outer surface of the liner showing the locations of the region with spider web ridges, the additional smaller whitish EBC defects that were examined metallographically, and the surface area examined via stereomicroscope to look at the morphology of EBC surface cracks. 


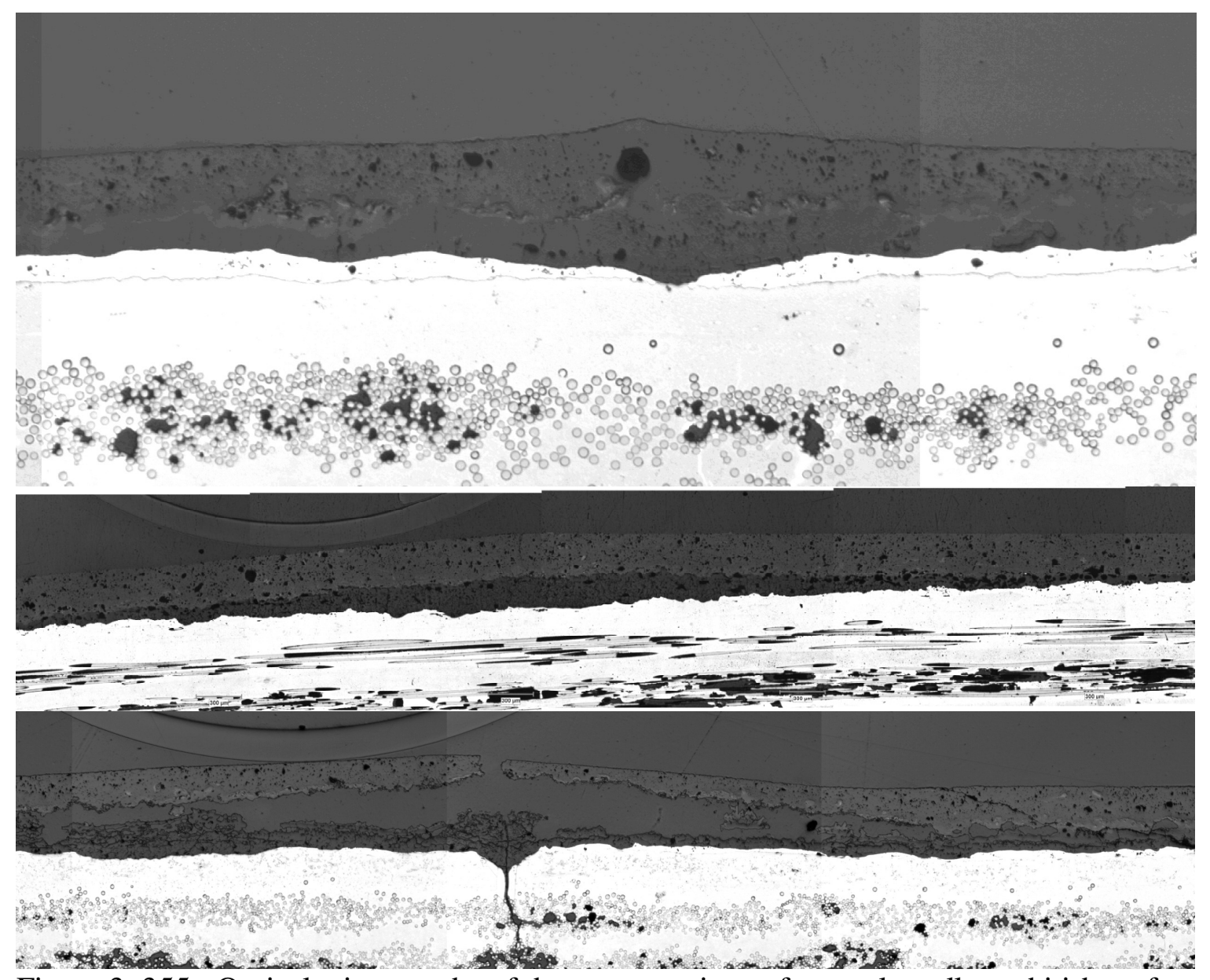

Figure 3-355. Optical micrographs of the cross sections of several smaller, whitish surface bumps possibly corresponding to the start of an EBC ridge: Top - small whitish ridge corresponding to the right-most spot in Figure 3-354; Middle - small isolated whitish bump in EBC corresponding to the middle spot in Figure 3-354; Bottom small whitish ridge along small surface wrinkle at left-most spot in Figure 3-354.

The origin of the bond coat breach is still not clear. In the large majority of ridges examined in the spider web ridge region had a crack in the EBC outer layers, but it is still not clear whether the cracks caused the accelerated local oxidation of the bond coat or formed as a result of the lifting of the EBC outer layers. The ridge-like defects examined away from the main spider web region were also inconclusive, in that one of the defects showed a clearly defined crack, one showed only a large pore in the outer EBC layer (which could still lead to enhanced oxygen transport locally), and one showed no defect in the EBC outer layers at all. The formation of the gap between the porous oxide and EBC top layers does appear to be highly correlated with the presence of an EBC crack. This would suggest that an open crack is necessary to allow water-vapor transport to the thermally-grown oxide and its volatilization, thereby forming the gap under the EBC top layers.

The optical examinations discussed so far show that these smaller EBC bump features are similar to, and are perhaps very early versions of, the more severe spider web ridges 
localized near the bottom dead center position of the liner. The question remains, however, as to why the ridges formed so early and grew to such an extent in one region of the liner and not in the other regions. A clue as to why this would be so was found by doing stereomicroscope examination of the EBC surface in regions adjacent to the spider web ridge region. A mosaic photomicrograph of the surface of the EBC next to the highlyridged region is shown in Figure 3-356.

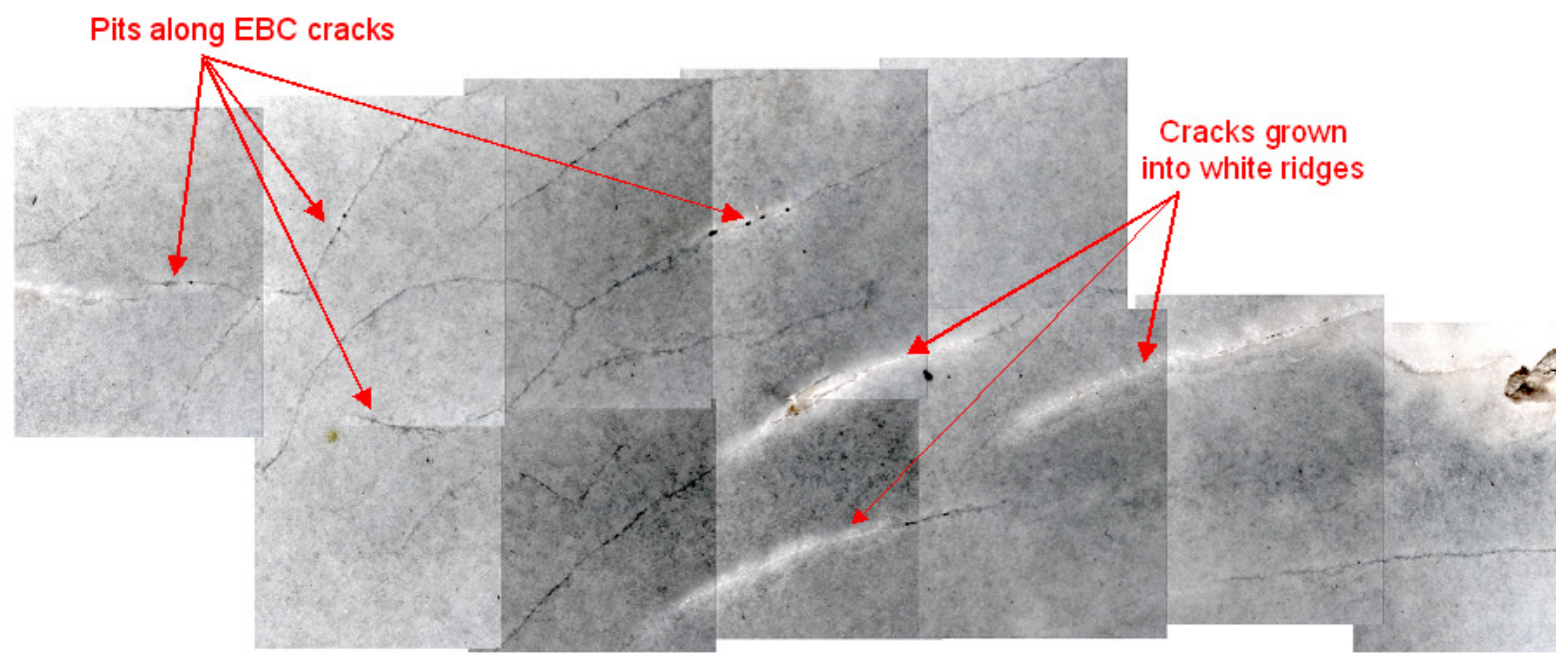

Figure 3-356. Stereomicroscope image of the EBC surface in a region adjacent to the main spider web ridge region, corresponding to the magenta oval in Figure 3-354.

The EBC coating adjacent to the spider web ridge region shows a pattern of vertical cracking that mirrors the pattern seen in the spider web ridges themselves. The cracks seem to have a preferential orientation (upper right to lower left in the micrographs of Figure 3356) similar to the spider web ridges, and show the same irregular low-angle branching pattern. Some of the cracks have actually progressed to the whitish ridge stage of an early spider web ridge. There are also numerous pores decorating the cracks, which on closer examination appear to be vents where glassy oxide is coming out onto the surface of the EBC. This cracking pattern was not seen in other regions of the liner where the small whitish ridge features remained small and relatively isolated.

SEM, EDAX and XRD examinations of several polished sections from the spider web ridge region were performed to gather additional microstructural and chemical information about the EBC. Figure 3-357 shows a back-scattered electron (BSE) image from the SEM looking at a representative spider web ridge in cross section. The features in this ridge match those of the schematic in Figure 3-353. The inset photo shows a close-up of the peak of the EBC where the through-thickness crack through the EBC outer layers is evident on the top and bottom of the large pore. A whitish phase within the EBC top layer around the peak is also evident in the inset micrograph. EDAX of this phase showed it to be rich in alkaline earth ( $\mathrm{Ba}$ and $\mathrm{Sr}$ ) and depleted in $\mathrm{Si}$ and $\mathrm{Al}$ relative to normal BSAS. This phase 
was also present on a smaller scale throughout most of the EBC top layer, and was especially concentrated at the surface.

XRD was used to identify the whitish phase seen in the EBC top layers in SEM. XRD of the as-exposed EBC surface gave the best pattern, which was indexed to march the hexagonal compound $\mathrm{Ba}_{13} \mathrm{Al}_{22} \mathrm{Si}_{10} \mathrm{O}_{66}$. There was a slight shift in lattice parameters for the measure pattern compared to the standard, but that is attributable to the presence of $\mathrm{Sr}$ as well as $\mathrm{Ba}$ in the structure. The composition of this phase suggests that it is an intermediate reaction product of the volatilization of $\mathrm{Si}$, as $\mathrm{Si}(\mathrm{OH})_{4}$, from the BSAS coating.

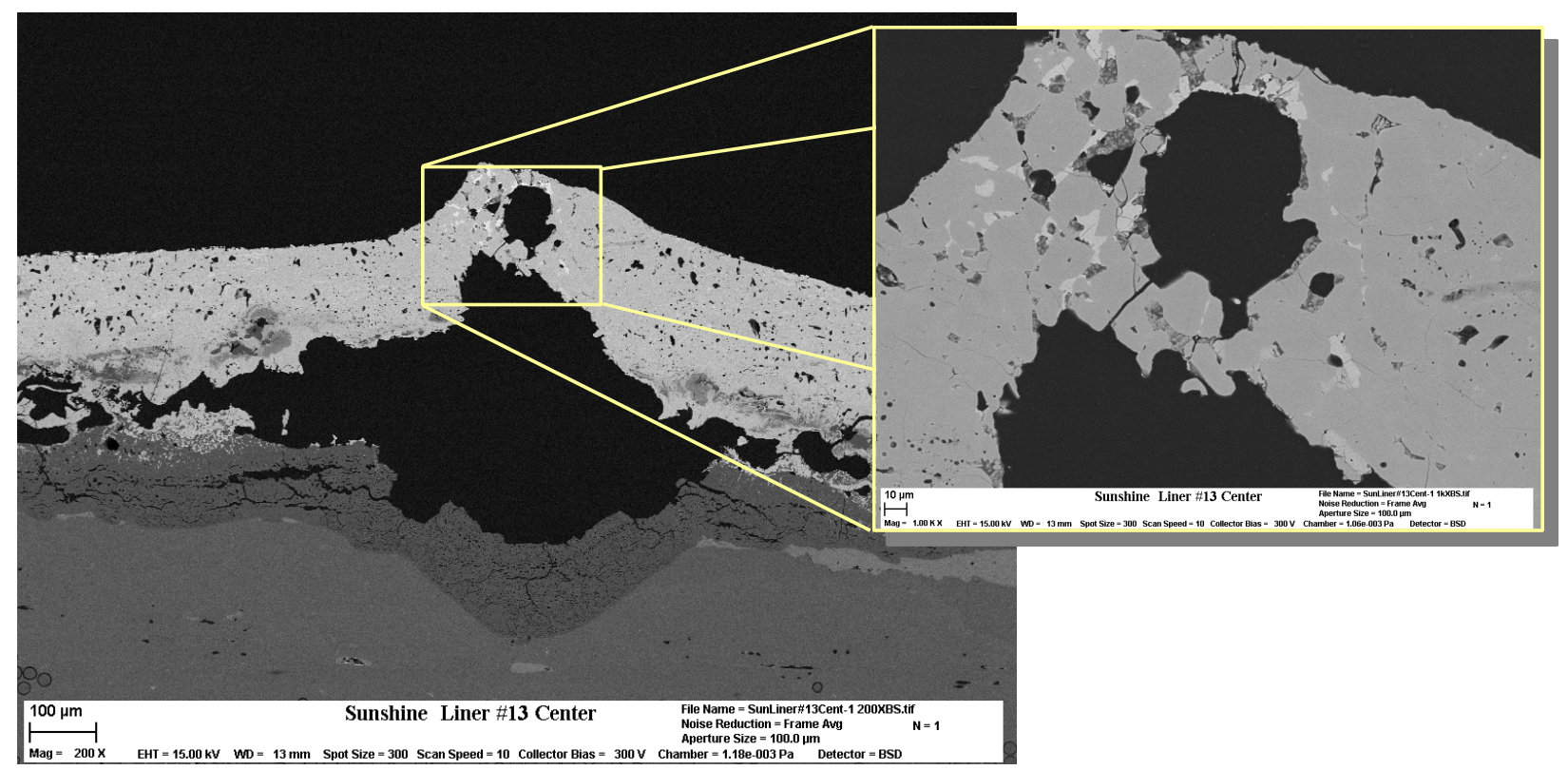

Figure 3-357. SEM micrographs of the cross section of a typical "spider web ridge"

feature. The inset shows a higher magnification view of the EBC top coat which has been pushed upward and shows through-thickness cracks connecting to the large pore.

The concentration of this $2^{\text {nd }}$ phase in the BSAS EBC top coat was measured using semiquantitative XRD. Three additional samples were taken at three different axial locations along the liner near the bottom dead center position. The center sample thus corresponded to the location where the concentrated spider web ridging was noted. The surfaces of the samples were lightly sanded to remove the high concentration of $2^{\text {nd }}$ phase on the surface, so the XRD results are indicative of the amount of $2^{\text {nd }}$ phase within the bulk of the BSAS coating. The amount of $2^{\text {nd }}$ phase detected were as follows: sample near the leading edge 9.7\%; sample near the center - 20.6\%; sample near the trailing edge - $14.3 \%$. This pattern of concentration of $2^{\text {nd }}$ phase suggests that the center of the combustor liner was running hotter than either end, as that is where the greatest volatilization of Si took place. 
This same pattern of thermal exposure also showed up in the characterization of the EBC transition layer microstructures. The 3-layer EBC system used has a silicon bond coat, a transition layer of mixed BSAS and mullite, and a final top coat of BSAS. During operation oxygen diffusion through the BSAS and transition layers oxidizes the silicon bond coat, forming a $\mathrm{SiO}_{2}$ reaction layer. Extensive furnace and rig testing has shown that this thermally grown oxide (TGO) layer remains as essentially amorphous silica, with some dissolved alumina from the mullite in the transition layer, for many thousands of hours at $1200^{\circ} \mathrm{C}$. However, exposure at higher temperatures leads to a reaction between the TGO and transition layers. This reaction product has dendritic crystals growing within the silica, which is often crystallized to cristobalite. This change in morphology of the TGO does not show up well in optical microscopy due to the limited contrast between the phases, but is easily noticed using BSE imaging in the SEM.

Examination of the EBC transition layers from the combustor liner showed that over the majority of the liner the normal, amorphous TGO layer was formed with little or no reaction with the EBC transition layer. However, in the region of the spider web ridges there was substantial TGO-transition layer reaction. SEM micrographs of typical TGO layers from inside and outside the spider web ridge region are shown in Figure 3-358. Outside of the spider web ridge region the TGO and transition layer appear very normal and match the microstructure seen in samples exposed in the steam furnace tests at $1200^{\circ} \mathrm{C}$ and below. There is some evidence that the TGO layer is partially crystalline, but it remains dense. The samples within the spider web ridge region show substantial reaction between the TGO and transition layer, forming the needle-like interpenetrating phases. This extent of reaction is greater than we have seen in any previous rig-tested or engine-tested hardware, and is even greater than what is seen in steam furnace testing at $1315^{\circ} \mathrm{C}$ for 500 hours. The presence of this reaction strongly suggests that the spider web ridged region of the liner was exposed to temperatures above $1200^{\circ} \mathrm{C}$, and possibly as high as $1315^{\circ} \mathrm{C}$, for at least part of the engine test.

Another piece of information that points to an over-temperature condition in the spider web ridge region is the measured recession of the EBC BSAS layer. The metallography samples were surveyed and the remaining thickness of BSAS top coat was estimated at each location. Optical contrast between the BSAS top coat and the BSAS plus mullite transition layer is rather pore, plus the interface between the layers is rather irregular as a result of the plasma spraying process, so the measured BSAS thickness values are only approximate. Nevertheless, the BSAS thickness shows a definite pattern over the liner surface, as shown in Figure 3-359. The thickness values on the figure are color coded such that remaining BSAS layer thicknesses above $300 \mu \mathrm{m}$ are labeled in black, between 250 and $300 \mu \mathrm{m}$ are violet, between 200 and $200 \mu \mathrm{m}$ are blue, between 150 and $200 \mu \mathrm{m}$ are green, between 100 and $150 \mu \mathrm{m}$ are yellow, and below $100 \mu \mathrm{m}$ are red. As can be seen in Figure 3-359, the thinnest regions of the remaining BSAS layer tend to occur toward the bottom dead center position and near the center of the liner in the axial direction. The area with the thinnest remaining BSAS corresponded to the spider web ridge region. Assuming the BSAS top coat was relatively constant in thickness prior to the engine test, this result indicates that the greatest amount of BSAS volatilization occurred in the spider web ridge region of the liner, 
which again strongly indicates that this region was exposed to higher temperatures than the other regions.

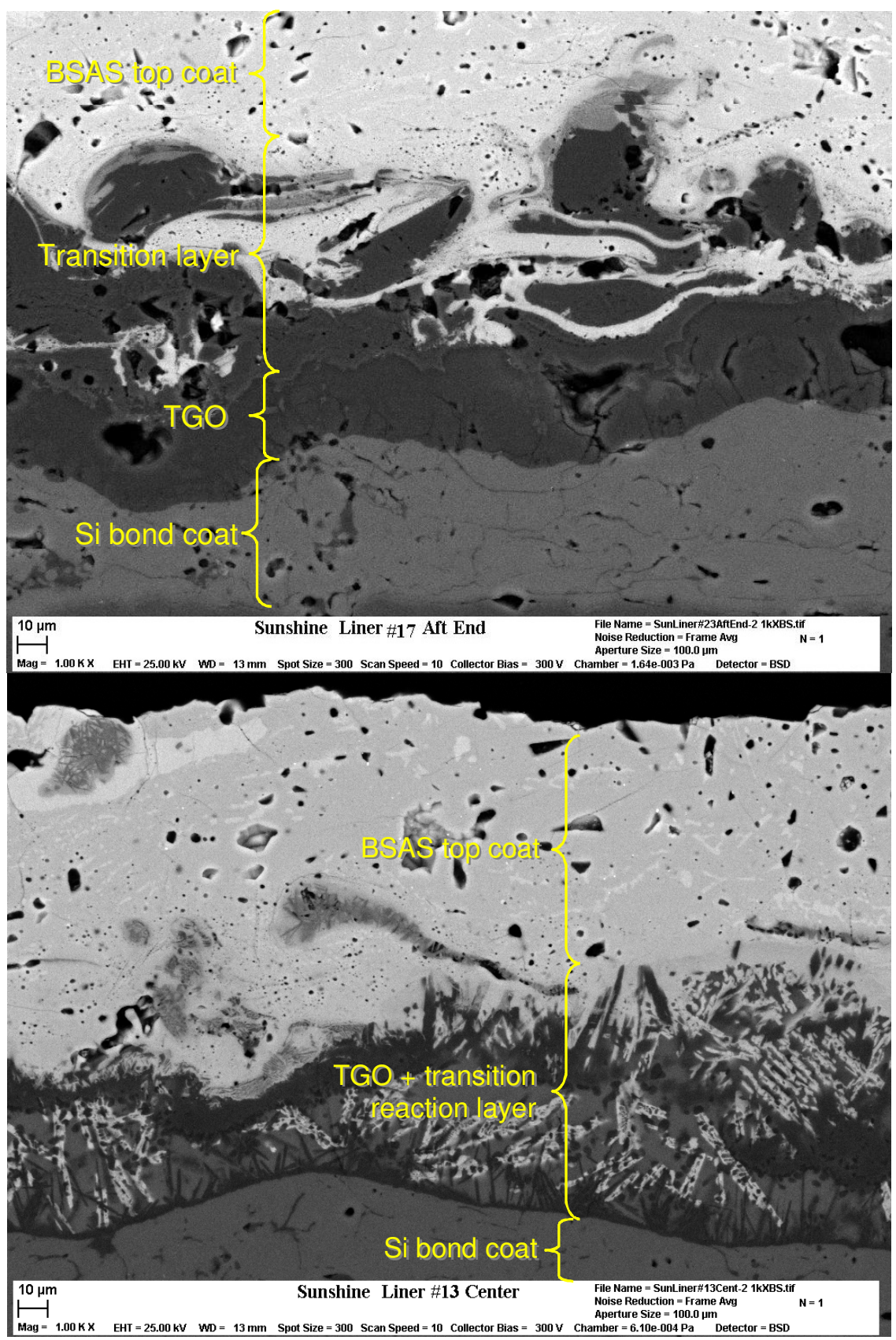

Figure 3-358. SEM images of the EBC layers focusing on the transition layer.

Top - area aft of the spider web ridge region showing normal dense TGO with little to no reaction with the EBC transition layer.

Bottom - area within the spider web ridged region showing extensive reaction between the TGO and EBC transition layer to form the needle-like phases between the silicon bond coat and BSAS outer coating. 


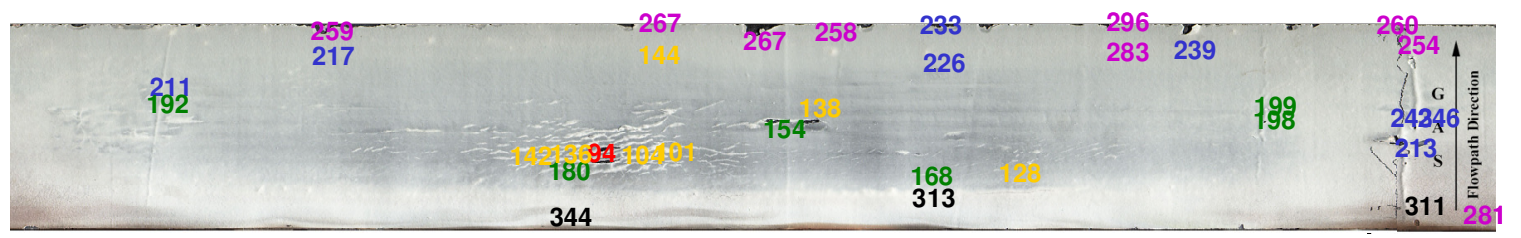

Figure 3-359. Measured remaining thickness of the EBC BSAS top coat, in microns, for various locations on combustor liner \#4 after engine testing.

In summary, there are several pieces of microstructural evidence that the spider web ridged region of the liner was exposed to higher temperatures than the remainder of the liner. It appears that this higher temperature exposure caused the unique web-like pattern of vertical $\mathrm{EBC}$ cracks found in this region. Although the mechanism of formation of the cracks is not well understood, the eventual progression of oxidation through these cracks can be seen to lead to the macroscopic spider web ridge features. The current proposed model for the formation of the spider web ridges and EBC spallation is as follows: 1) an overtemp condition on the liner surface causes vertical cracking of the EBC oxide coatings, 2) the vertical cracks would allow locally accelerated oxidation of the silicon EBC bond coat, 3) once the bond coat is consumed the nature of the thermally grown oxide changes to a porous, voluminous structure due to the evolution of $\mathrm{CO}$ from the oxidation of the $\mathrm{SiC}, 4$ ) growth of the porous oxide pushes upward on the outer EBC layers, forming the ridges and further opening the vertical cracks, 5) further opening of the EBC crack allows for volatilization of the TGO and formation of an open region below the EBC top layers, 6) lateral growth of the oxidized region eventually links with oxidation from adjacent cracks, leading to EBC spallation between the cracks. In other regions of the liner where the whitish regions did not grow appreciably the local consumption of the bond coat did not appear to be associated with EBC cracks, but was probably just a result of a locally thin bond coat caused by simple statistical variations from the thermal spray process. Growth of the bond-coat consumed region is limited for these smaller defects due to the lack of a fast oxidation path through the EBC, and probably also due to the lower liner temperatures in these regions.

The second unexplained feature on the combustor liner is the apparent whitish band $25 \mathrm{~mm}$ $(\sim 1$ ") back along the forward edge of the liner, most prevalently seen near the bottom dead center position of the liner as it was positioned in the engine. It is not surprising that this band is white, given that the original EBC coating is white in color, but that there is an abrupt transition in appearance from an opaque white forward of this band to a grayish, almost translucent appearance aft of this band. One can also see and feel a definite step in the height of the surface going over this transition, with the surface being higher and rougher in the whitish region and lower and smoother in the grayish region. There were also locations where a crack could be seen in the EBC running along the edge of this transition. A photograph of the liner surface that highlights transition is shown in Figure 3360. 


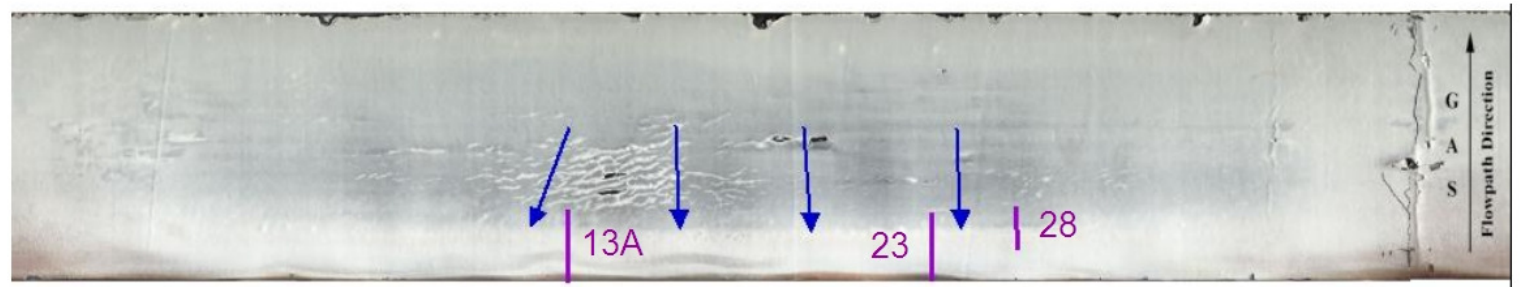

Figure 3-360. Photograph of the combustor liner surface. The blue arrows point out the transition from whitish to grayish appearance of the EBC coating parallel to the forward (lower) edge of the liner. The violet lines indicate the locations of metallographic samples examined to date to characterize this feature.

Micrographs of the middle sample (sample 23) from Figure 3-360 are shown in mosaic fashion in Figure 3-361. This region showed a very abrupt transition from the raised, whitish EBC near the front of the liner (to the right side of Figure 3-361) and the lower, grayish EBC region (to the left in Figure 3-361). The micrographs show that the surface height change is due entirely to a thick layer of TGO in the raised, whitish band and relatively thin TGO in the grayish region. At its maximum the thickness of the TGO is actually greater than the thickness of the EBC. All of the region to the right of the transition region in Figure 3-361 shows the EBC bond coat to have been consumed by oxidation with consequent oxidation of the CMC substrate yielding the highly porous silica, as seen in the spider web cracks and EBC bump specimens described above.

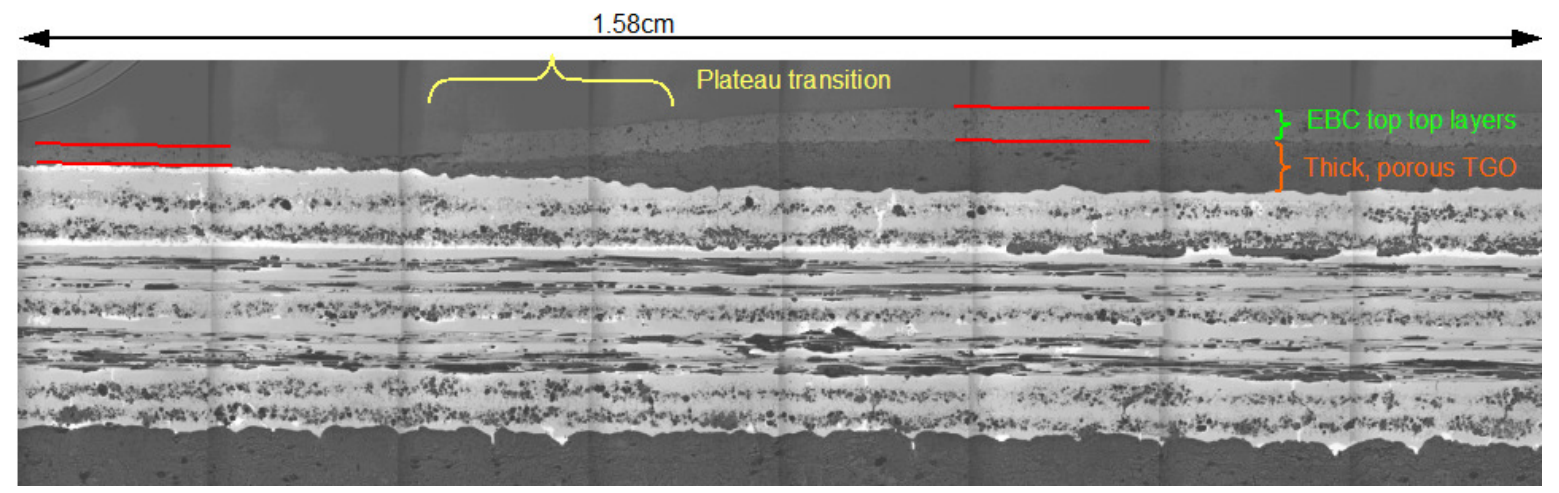

Figure 3-361. Photomicrograph mosaic from the transition region between the whitish leading edge of the liner (to the right) and the grayish liner region (to the left).

A photomicrograph mosaic image of the right-most sample (sample 28) from Figure 3-360 is shown in Figure 3-362. The transition height was not as severe in this sample even though there was a through-thickness crack in the EBC running along the ridge edge. It is also apparent that the thickness of the TGO layer is tapering off as you go toward the leading edge of the liner (to the left in Figure 3-362). 


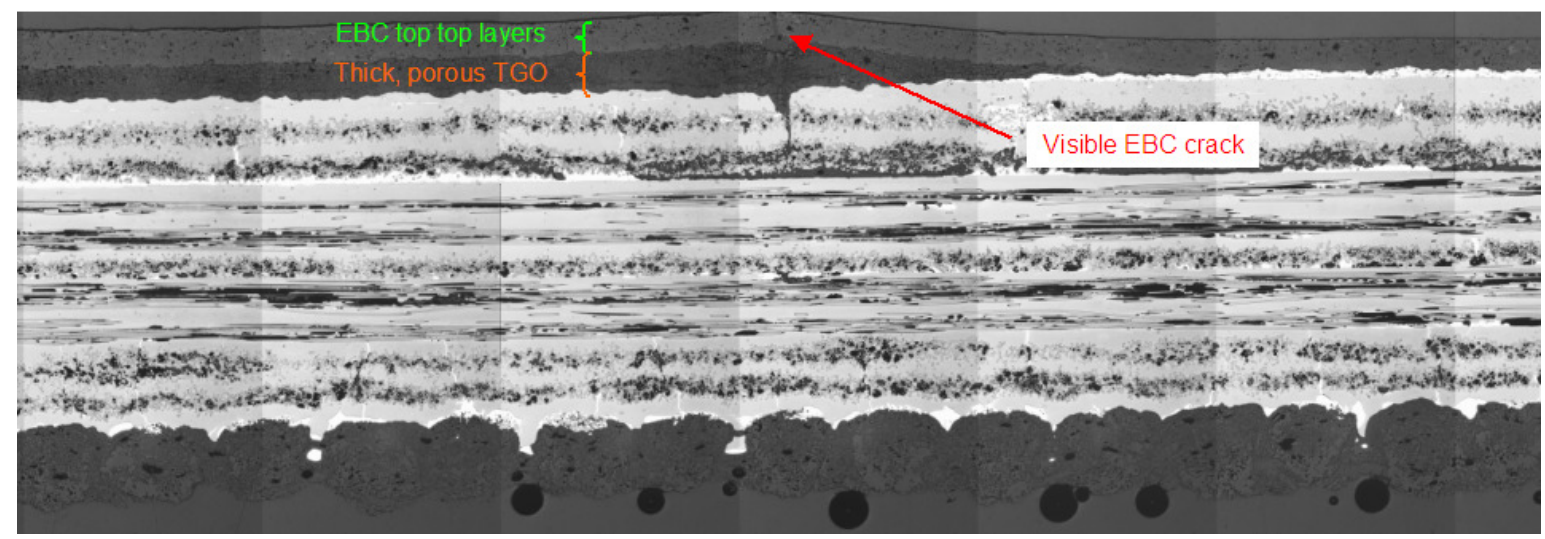

Figure 3-362. Mosaic photomicrograph from the right-most sample in Figure 3-360 showing the cross section of the transition region between the raised whitish band parallel to the liner leading edge (to the left) and lower grayish region (to the right).

The transition in EBC height for the left-most sample from Figure 3-360 (sample 13A) was much more gradual, making it impractical to display in a simple micrograph. Nevertheless, there was a definite trend that the thickness of the TGO layer was a maximum at the transition between the white and gray regions and tapered toward more normal thickness going toward the leading edge of the liner. In order to quantify this trend the thickness of the TGO layer was measured as a function of distance from the liner leading edge. A plot of the results is shown in Figure 3-363. This plot demonstrates how the transition in EBC height and color change corresponds to the rapid decrease in TGO thickness at 35 to $40 \mathrm{~mm}$ from the leading edge. Also, the thickness of the TGO decreases more gradually moving from the transition region toward the liner leading edge. While the TGO thickness is somewhat higher near the leading edge than at locations past the transition region, the very porous oxide does not extend the entire way to the liner leading edge. These observations tend to rule out oxygen penetration from the liner leading edge as the cause of the highly oxidized band.

SEM examination of several samples from this whitish band region and the transition region corroborated the general observations made in the optical examinations. Close to the transition region the EBC was lifted by a voluminous, porous TGO formed following complete consumption of the silicon bond coat. Directly aft of the transition the TGO remained dense, making the $\mathrm{EBC}$ more translucent and thereby showing more of the grayish color of the underlying CMC. 


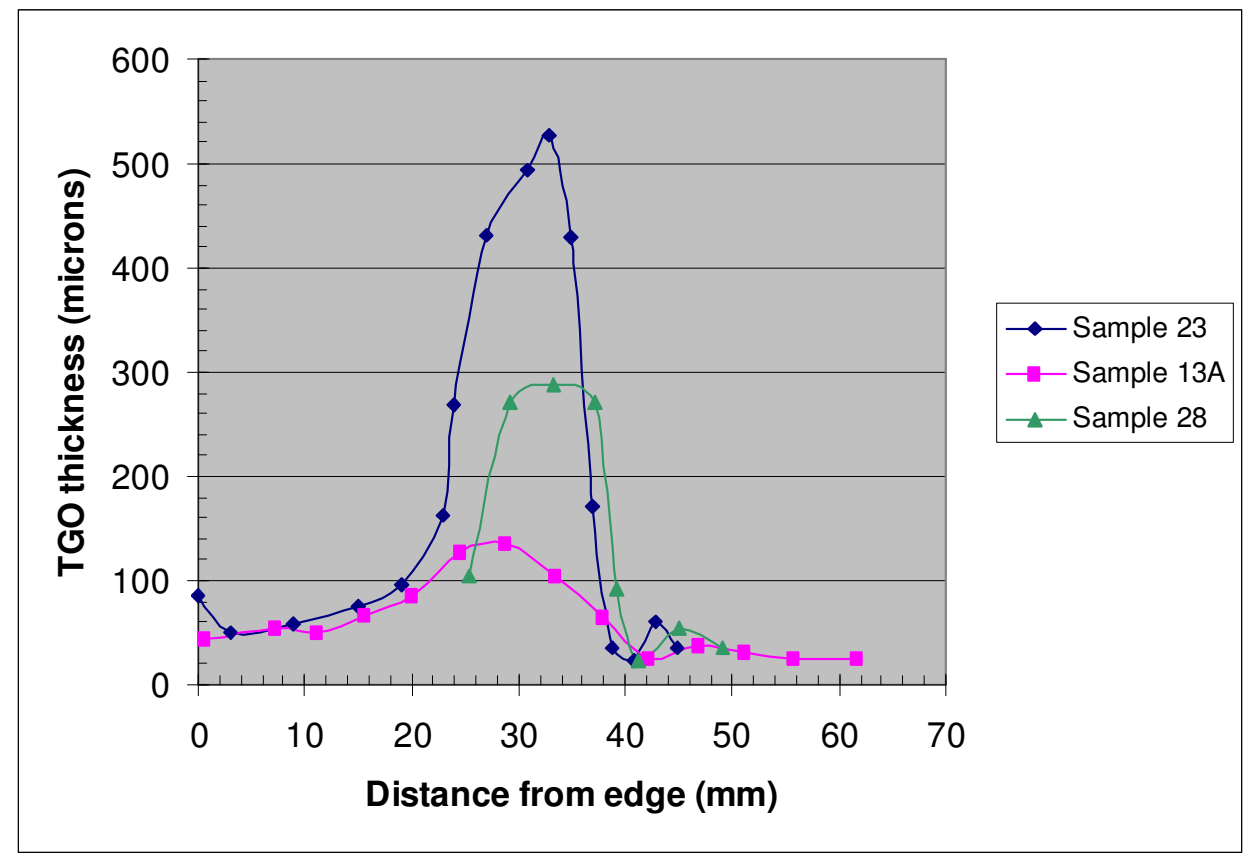

Figure 3-363. Plot of the thickness of the thermally grown oxide layer formed on the EBC bond coat and/or CMC substrate as a function of distance from the leading edge of the combustor liner. The sharp drop in thickness at 35 to $40 \mathrm{~mm}$ marks the transition between the raised whitish band and normal EBC.

The high amount of porous TGO at the step transition on the liner would explain the white appearance, since the porous oxide would scatter light more effectively than the denser EBC coating, which would appear more translucent as it does aft of the transition. However the data in Figure 3-363 would suggest that the whitish color should diminish moving toward the forward edge of the liner due to the decreasing thickness of the TGO. The reason the band maintains the whitish appearance all the way to the leading edge likely has to do with the exposure temperature. The data in Figure 3-359 indicate that the remaining thickness of the BSAS top coat was actually greatest along the leading edge in this region, suggesting that the very leading edge of the liner was running rather cool and thus showed lower BSAS volatilization. The thermal sprayed EBC always contains some level of residual porosity, which tends to diminish from EBC sintering with higher temperature exposure. The cooler temperatures along the leading edge would have caused less densification, and thus a higher level of residual porosity in this BSAS layer. This lack of densification plus the fact that the layer is thicker in this region combine to make it more opaque and less translucent than the EBC immediately aft of the transition. Thus the entire band forward of the transition appears whiter due to a combination of the porous TGO and/or the greater thickness and opacity of the BSAS layer.

Even after this substantial characterization effort there was no clear explanation as to why the oxidation of the bond coat should be accelerated in this area of the liner. There was no photographic evidence from the EBC application process to suggest that the bond coat was any thinner in this region, and indeed the remaining thickness of bond coat near the leading 
edge of the liner is consistent with the remaining bond coat thickness in other regions of the liner.

The only additional information that would indicate something unusual about the exposure conditions in this region is the BSAS thickness data in Figure 3-359. The steepest gradient in remaining BSAS thickness, and thereby presumably also in the exposure temperature, is found in this banded region. It may be that some unusual oxidation mechanism is occurring due to the high thermal gradient and specific temperature range that this part of the liner experienced. Since all previous furnace and combustion rig testing was done under isothermal (or nearly isothermal) conditions any effects of such steep thermal gradients would not have been seen. However, shroud engine testing up to 5366 hours did not show any signs of a similar mode of degradation, and they certainly would have been exposed to high thermal gradients in the transition from gas path to mounting flange regions. Consequently the root cause of this anomalous oxidation is still not known. 


\section{SUMMARY AND CONCLUSIONS}

Overall GE considers this program to have been a resounding success. Many important milestones in the development of CMC turbine components were accomplished, as listed below:

- A shroud system for a 7FA-class engine, incorporating CMC inner shrouds, was designed and analyzed using 3D finite element analytical tools.

- A procedure for fabrication of CMC inner shrouds to the new design was developed, including the application of the environmental barrier coatings.

- The robustness of the environmental barrier coating to a turbine blade rub event was evaluated using simulated blade rub tests.

- A high-temperature, high-pressure combustion rig was designed and built for testing of the CMC shroud design.

- The design of the CMC shroud system was validated and refined using a series of rig tests to simulate the gas turbine engine environment.

- Shroud systems, consisting of CMC inner shrouds, metallic outer shroud blocks and all intermediate attachment hardware, were successfully fabricated for a partial shroud field engine test.

- Nine CMC inner shrouds were installed in a utility 7FA-class gas turbine engine in Florida, and run successfully for 5366 hours.

- Post-test characterization of the shroud system validated that the prepreg melt infiltrated shrouds survived the engine exposure test with minimal material degradation, even in regions where the environmental barrier coating had spalled.

- An improved shroud system, incorporating improved shroud-to-shroud seals and more robust inner shroud damping system, was designed.

- A methodology for applying abradable environmental barrier coatings was developed for the CMC inner shroud components, and the coating robustness was tested using simulated blade rub testing.

- The fabrication process for the prepreg melt infiltrated CMC material in general, and for the CMC inner shrouds specifically, was transitioned to GE Ceramic Composite Products.

- The improved shroud system was validated using a second set of combustion rig tests.

- An accidental over-temperature condition in one of the rig tests caused melting of the silicon phase in the CMC matrix and $\mathrm{EBC}$ bond coat, leading to $\mathrm{EBC}$ coating loss, but surprisingly limited degradation to the MI CMC shrouds, which clearly demonstrated the robustness of the CMC material to extreme engine conditions.

- A full engine set, consisting of $96 \mathrm{CMC}$ inner shrouds on 32 outer shroud blocks, of the improved CMC shroud system was fabricated

- The full set of CMC engine shrouds was installed in unit \#1 at the Brandy Branch generating station of the Jacksonville Electric Authority in April 2006. 
- As of end of this program (September 2010) the shrouds in test at Jacksonville have accumulated 1673 hours of engine running time with 497 start-stop cycles, and continue to operate without incident.

- Several borescope inspections were performed on the shrouds in the Jacksonville test that indicated issues with spallation of the environmental barrier coatings. The loss of the coatings is not a threat to the ongoing operation of the engine, and the shrouds are anticipated to continue in the engine until the Fall of 2012.

- A detailed root cause analysis was performed on the environmental barrier coating spallation issue seen in the Jacksonville test.

- A second full engine set of CMC shroud components has been fabricated and assembled, and is awaiting an appropriate opportunity for insertion into a third field engine test. The goal of this third shroud test will be to demonstrate the long-term (up to 24,000 hours of engine operation) durability of the CMC shroud system.

- The design of a 7FA-class engine CMC combustor liner was developed, including the conception and analyses of novel liner attachment and sealing schemes.

- Fabrication trials of the 7FA combustor liner, measuring up to $0.46 \mathrm{~m}$ in diameter and $1 \mathrm{~m}$ in length, were performed that demonstrated a path to successful liner fabrication.

- Four CMC combustor liners, $34 \mathrm{~cm}$ in diameter and $20.5 \mathrm{~cm}$ long, were fabricated in the development process for production of a liner for testing in Solar Turbines Ceramic Stationary Gas Turbine (CSGT) engine.

- One of the CMC combustor liners was successfully engine tested in the Solar CSGT engine at Chevron/Texaco in Bakersfield, CA, for a total of 12,822 hours. This test represents the longest gas turbine exposure for the GE HiPerComp ${ }^{\circledR} \mathrm{CMC}$ material to date.

- The environmental barrier coating (EBC) on the CSGT combustor liner survived the full 12,822 hours of engine testing with $>99 \%$ of the EBC remaining intact.

- Post-test characterization of the CSGT combustor liner indicated minimal degradation of the $\mathrm{CMC}$ material, and elucidated important degradation mechanisms for the EBC.

Most importantly, the feasibility of utilizing the HiPerComp ${ }^{\circledR}$ CMC material for large-frame industrial turbine hardware has been clearly demonstrated. First stage shrouds have undergone nearly 7,000 of field engine test hours, and a combustor liner over 12,800 hours, without a single failure. Moreover, the engine performance benefits predicted for the $\mathrm{CMC}$ shroud component have been quantitatively validated during these engine tests.

The fabrication of the three shrouds sets during the performance of this program has led to a number of design changes to address fabrication issues associated with fiber stiffness and the shaping of the plies over curved features, such as the leading and trailing edge flange bends on the shrouds. The part quality feedback from the two early shroud production runs led to improvements in the component ply designs, which subsequently led to a $20 \%$ improvement in production yields during the third shroud set fabrication. The process improvements implemented for the shrouds will provide benefits to other CMC components as well as GE moves into commercialization of CMC turbine hardware. 
The images collected during the non-destructive evaluation (NDE) of the CMC components fabricated under this program has helped to build a of reference database of images to support CMC component evaluations. The location and severity of defects in NDE images are difficult to assess without reference points of complimentary images that are paired with section cut-ups of the CMC ply laminates. The complete NDE record of the shroud and combustor components used in the field tests will enable the establishment of quantitative part quality criteria. The NDE feedback has also enabled continued production process yield improvements.

Clearly technical and business challenges still remain to the full commercial introduction of CMC turbine hardware. The long-term durability of the EBC coatings still needs to be demonstrated, and that is precisely the objective of the third shroud field engine test that GE hopes to initiate in early 2011. The high cost of HiPerComp® components is still a major challenge, but at least now that the projected benefits have been quantified a realistic costto-performance tradeoff can be done to arrive at justifiable cost targets for the CMC.

The benefits of this program will extend beyond its completion, both in terms of actual technical data that will be derived from the ongoing $2^{\text {nd }}$ shroud engine test and the $3^{\text {rd }}$ test planned to start in 2011, and also in terms of other applications for CMC technology that will be inspired by this work. For instance, GE Aviation has already announced that HiPerComp ${ }^{\circledR}$ CMCs will be used in future military and commercial aircraft engines [3-5], the commitment to which would not have been possible without the industrial gas turbine successes demonstrated in this program. 


\section{ACKNOWLEDGEMENTS}

This work was performed under the U.S. Department of Energy Advanced Materials for Advanced Industrial Gas Turbines (AMAIGT) program, contract numbers DE-FC2600CH11047 and DE-FC02-00CH11047. The support of DOE and the contributions of the Project Managers, Jill Jonkowski, Joseph Mavec, Paul Bakke, and Donald Geiling, and of Project Monitors Debbie Haught and Merrill Smith are greatly appreciated.

The contractor team consisted of GE Global Research Center (formerly known as GE Corporate Research and Development), GE Energy (formerly known as GE Industrial and Power Systems-Power Generation Systems Division), GE Ceramic Composite Products (formerly known as GE Power System Composites and Honeywell Advanced Composites, Inc.). Other organizations that contributed significantly to the effort include Oak Ridge National Laboratory, Argonne National Laboratory, Solar Turbines, University of Dayton Research Institute, and Cincinnati Testing Laboratories. The authors would like to acknowledge the contributions of the following individuals: R. Nimmer, D. Dunn, P. Meschter, M. Brun, M. Gifford, W. Minnear, C. Johnson, R. Seffari-Nour, L. Rosenswieg, J. Wan, D. Lipkin, H. McGuigan, G. Buczkowski, L. Szala, D. VanUithuizen, B. Pickard, R. DiDomizio, B. Fusaro, S. Bullis, E. Moran, A. Barbuto, R. Schnoor, K. McManus, S. Brabetz, J. Hibshman, M. Roos, H. Ringermacher, D. Howard, B. Knight, D. Bodner, A. Vallee Jr., J. Vartuli, and K. Battista of GE Global Research; P. Dimascio, H. Roberts, M. Schroder, S. Shirzad, C. Grace, K. Bruce, R. Reed, J. Lipinski, J. Margolies, D. Baldwin, S. Breitenbach, R. Shalvoy, Y.C. Lau, R. Cairo, K. Parker and R. Coign of GE Energy; P. Craig, D. Landini, R. Matsumoto, P. Gray, B. Patterson, J. Halada, A. Ingram and H. Wang of GE Ceramic Composite Products; D. Bulman, J. Bibler and I. Prentice of GE Aviation; K. More of Oak Ridge National Laboratory; W. Ellingson and J.G. Sun of Argonne National Laboratory; M. van Roode, J. Price and J. Kimmel of Solar Turbines: K. Poorman of the Universtiy of Dayton Research Institute; and D. Abeln of Cincinnati Testing Laboratories. 


\section{LIST OF FIGURES}

Figure 2-1. Trend in material temperature capability (based on 1000 hour creep rupture at $103 \mathrm{MPa}$ tensile stress) over time for gas turbine engine structural materials.

Figure 2-2. Cross sectional view of a GE 7FA class gas turbine engine. The blow-up view shows the positions of several components for which use of ceramic composite materials would be highly desireable. The specific components that were the focus of this program, namely the combustor liner and $1^{\text {st }}$ stage shroud, are labeled in blue.

Figure 2-3. Schematic diagram showing the historic progression from CMC material and process development to feasibility rig and small engine testing under the DOE CFCC program, transitioning to more extensive rig and field engine testing under the AMAIGT program.

Figure 2-4. Overall program task performance for the shroud-related tasks. Black lines are from the original program started in 2000; blue lines are from the 2003 contract modification; green lines are from the 2006 contract modification. Tasks S4.3 and S4.5 are continuing past the end of the program.

Figure 2-5. Overall program schedule for the combustor-related tasks. Red lines are from the 2002 contract modification and blue lines from the 2003 contract modification.

Figure 3-1. Cross section diagram of the turbine section of a 7FA engine showing the position of the $1^{\text {st }}$ stage inner shroud and outer shroud block.

Figure 3-2. Simplified diagram of the CMC shroud system that was combustion rig tested under the CFCC program.

Figure 3-3. Diagram of the final CMC shroud system design generated under the CFCC program. This concept served as the starting point for shroud design for the AMAIGT program.

Figure 3-4. Schematic of the new CMC shroud system design incorporating a springloaded damper block. This configuration was used in shroud rig test \#1.

Figure 3-5. Temperature prediction results from the initial FEA of the new shroud design.

Figure 3-6. Schematic of the revised new CMC shroud system design used for rig tests \#3 and \#4 and for the first field engine test....

Figure 3-7. Photograph of the initial trial CMC shroud parts made with external (right) and internal (left) lay-up molds. Dimensional fidelity of the shrouds was comparable for either lay-up mold, but the surface finish and flatness was slightly better for the surfaces directly against the molds (outer surface for the external mold and inner surface for the internal mold.)

Figure 3-8. Clevis/pin test fixtures used for evaluating the pin-in-hole shroud attachment failure loads.

Figure 3-9. Photographs of the pin pull-out test samples after testing to failure: Left - prepreg MI samples; Right - slurry cast MI samples. 
Figure 3-10. Stress-displacement curves for pin pull-out tests on as-fabricated MI

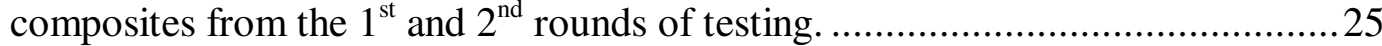

Figure 3-11. Stress-displacement plots for the third round of pin pull-out testing on samples with round holes or elongated slots..............................................26

Figure 3-12. Cross sectional schematic of the shroud test rig design including the

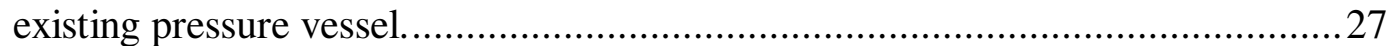

Figure 3-13. Cut-away view of the shroud test section and exhaust diffuser of the shroud test rig.

Figure 3-14. Computational fluid dynamics (CFD) prediction of the combustion gas temperature profile in the shroud section of the test rig compared to the nominal temperature drop in the $1^{\text {st }}$ stage shroud section of a 7FA engine.

Figure 3-15. Diagram of the shroud test rig showing the location of various sections within the pressure vessel, and also indicating various inlet flows....................29

Figure 3-16. Photograph of the shroud test rig internals during initial assembly............ 30

Figure 3-17. Instrumentation plan for the shroud test section of the shroud test rig, showing planned positions of thermocouples and pressure taps........................30

Figure 3-18. Photograph of the second failed cast alumina refractory lower wall from the exit end of the shroud test section of the shroud test rig.

Figure 3-19. Photograph of the shroud rig lower wall made from castable refractory and $\mathrm{CMC}$ forward and aft brackets showing the failure of the castable refractory section.

Figure 3-20. Photographs of the inside leading edge of as-machined prepreg (left) and slurry cast (right) CMC inner shroud components. Chipping around the mounting holes can be seen.

Figure 3-21. Photographs of a Goodrich slurry cast MI CMC shroud after EBC coating: Left - hot gas path face, Right - inside surface.

Figure 3-22. Temperature-time history of a typical transient cycle during shroud rig testing.

Figure 3-23. Photograph of the shroud rig transition piece (on the right) and shroud test section (on the left) following the initial set of shroud rig tests. The seal between the aft flange of the transition piece and the forward flange of the test section leaked, causing the flanges to overheat and warp.

Figure 3-24. Photograph of shroud rig test section exit nozzle showing constriction of the flow path near the center and right edge.

Figure 3-25. Photograph of Hastelloy $X$ lower wall from the shroud rig test section showing heat damage to the center section of the wall. The combustion gas flow direction was from top to bottom.

Figure 3-26. Photograph of prepreg MI shroud front attachment holes showing chipping of the EBC coating and composite at the contact point with the mounting pins.

Figure 3-27. Photograph of front mounting hole on the CCP slurry cast MI shroud showing damage to the EBC and underlying CMC. Some of the T800 wear coating from the support pin is adhered to the inside of the mounting hole..........41

Figure 3-28. Photograph of front mounting holes on the Goodrich slurry cast MI shroud showing chipping damage to the EBC. 
Figure 3-29. Micrograph of attachment hole region of the CCP shroud following 30 hours of combustion rig testing. Crushing of the composite and buckling of the fiber plies is seen at the forward edge of the attachment hole.

Figure 3-30. Micrograph of attachment hole region of the GE prepreg MI shroud following 30 hours of combustion rig testing. Edge chipping damage to the composite at the forward edge of the attachment hole was limited to one to two plies.

Figure 3-31. Photograph of a finished shroud rig CMC lower wall sitting on the part lay-up tooling.

Figure 3-32. Comparison of predicted and measured axial pressure profile shape in shroud rig test section with the CMC lower wall and surrogate metal shrouds installed.

Figure 3-33. Delamination on the side of Goodrich slurry cast CMC shroud following completion of rig test \#2.

Figure 3-34. Photographs of the front flanges of the CMC shrouds from rig test \#2 showing chipping near leading edge hole on the GE prepreg shroud (top) and Goodrich slurry cast shroud (bottom left), but no chipping on the CCP slurry cast shroud (bottom right).

Figure 3-35. Schematic diagrams of proposed shroud hole chipping mechanisms: (a) attachment hole loading due to dynamic excitation causing cyclic vertical motion (chatter) between pin and flange; (b) hole edge loading due to pin binding caused by relative rotation of pin and CMC inner shroud; (c) pin binding from relative rotation combined with lateral sliding on the pins during thermal cycling.

Figure 3-36. Photograph of the chatter test set-up and furnace (left), and a close-up schematic of the sample fixture.

Figure 3-37. Schematic diagram of the pin binding test configuration.

Figure 3-38: Photographs of EBC chipping damage on a coated pre-preg CMC (left) and a coated slurry cast CMC (right) following room temperature pin binding testing.

Figure 3-39. Photographs of an uncoated slurry cast composite specimen following testing in the pin binding test showing (Left) macroscopic interlaminar failure, and (Right) local crushing damage in the pin-bearing area of the hole.

Figure 3-40. Photographs of uncoated prepreg MI composite samples following pin binding testing. Left - macroscopic bending failure of the CMC. Right limited local chipping of the monolithic outer layer of the composite in the vicinity of the pin-bearing location.

Figure 3-41. Photographs of the center shroud damper block indicating cracks from swelling/oxidation of the piston retaining bolts...........................................54

Figure 3-42. Comparison of spring length for new (left) and rig tested (right) springs showing permanent creep relaxation from overheating.

Figure 3-43. Photograph of the shroud damper spring creep relaxation test

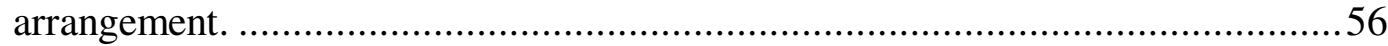

Figure $3-44$. Creep relaxation performance of R-41 springs. ................................56 
Figure 3-45. Photograph of the transition section of the shroud test rig following test \#3. Several loose pieces of rubble are visible at the exit to the transition section. Pieces of refractory smaller than those seen here would have passed through the shroud test section during the rig test.

Figure 3-46. Upstream end of the hot gas path surface of one of the prepreg MI shrouds from rig test \#3 showing surface chipping of the EBC coating likely to have been caused by foreign object damage from pieces of the cast refractory transition section of the test rig.

Figure 3-47. Photographs of CMC inner shrouds from the $3^{\text {rd }}$ rig test showing minor edge chipping damage to the EBC coatings caused by foreign object damage. ....59

Figure 3-48. Photograph of a CMC inner shroud from the May rig tests showing EBC loss from of the front inside edge where the EBC was thicker than desired.

Figure 3-49. Photographs of the CCP slurry cast shroud from rig test \#3, which had the older attachment hole design, showing EBC and CMC chipping around the forward attachment hole.

Figure 3-50. Photomicrographs of a T-800 coated shroud attachment pin: Top - Assprayed coating microstructure; Bottom - area of the pin showing coating wear down to the bond coat in localized areas.

Figure 3-51. Photographs of the rig shroud section lower wall after rig test \#3. Cracks in the forward corner of the CMC wall are indicated.

Figure 3-52. Photographs of the outer shroud block for rig test \#4 with instrumentation being installed: Left - view of the top of the outer shroud block inside the casing hook channel; Right - view of the bottom of the outer shroud block.

Figure 3-53. Micrographs of shroud used in rig test \#4 from cross sections taken the center of the hot gas path face: Left - Prepreg MI shroud with Hi-Nicalon fiber showing delamination in the $4^{\text {th }}$ ply from the hot gas path surface; Center - Prepreg MI shroud with Hi-Nicalon Type S fiber showing high porosity in the $17^{\text {th }}$ ply (near the inner surface); Right - Slurry cast shroud showing distributed large pores.

Figure 3-54. Photomicrographs of the forward attachment hole cross-sections for the three shrouds in rig test \#4. No wear was evident in the attachment contact regions.

Figure 3-55. Tensile stress-strain behavior of shrouds used in rig test \#4. The prepreg shrouds had been exposed in both rig test \#3 and \#4 for a total accumulated rig exposure of 290 hours. The slurry cast shroud had been exposed only in rig test \#4 for 148 hours. The tensile strength behavior of the shrouds after rig testing (dashed lines) is compared to the behavior before rig testing (solid lines).

Figure 3-56. Load-displacement behavior for forward slot samples cut from the shrouds exposed in rig test \#4.

Figure 3-57. Photographs of shroud attachment pins following rig test \#4, showing wear marks at the shroud contact region: Left - pin with metallic oxidation coating; Right - pin with TBC coating. 
Figure 3-58. Example of optical profilometry results from the shroud attachment pins from rig test \#4. These results are from an Ultimet alloy pin coated with a metallic CoNiCrAlY oxidation coating.

Figure 3-59. Photographs of the blade tip rub test rig showing the test specimen assembly and rub tip (metallic simulated blade) in place.

Figure 3-60. Photographs of rub specimen S-31 (prepreg MI CMC substrate with no EBC) following rub testing at $\sim 65^{\circ} \mathrm{C}$ substrate surface temperature with a $0.38 \mathrm{~mm}$ incursion distance

Figure 3-61. Photographs of rub specimen S-32 (slurry cast substrate with no EBC) following rub testing at $1200^{\circ} \mathrm{C}$ substrate surface temperature with a $0.38 \mathrm{~mm}$ incursion distance.

Figure 3-62. Specimen S-36; Prepreg MI composite substrate with EBC following rub testing at $1200^{\circ} \mathrm{C}$ substrate surface temperature with a $0.38 \mathrm{~mm}$ incursion distance.

Figure 3-63. Specimen S-38; Slurry cast MI composite substrate with EBC following rub testing at $1200^{\circ} \mathrm{C}$ substrate surface temperature.

Figure 3-64. Transient IR image of the trial prepreg "delamination standard". The yellow and blue squares indicate the presence of the simulated delaminations......77

Figure 3-65. IR thermography images of the CCP delamination standard panel both as fabricated (left) and after cutting and oxidation of the internal carbon shims (right)

Figure 3-66. Scanning Electron Microscope (SEM) micrograph of the 3-layer EBC coating on a slurry cast CMC substrate.

Figure 3-67. Relationship between BSAS layer porosity and vertical crack density. The insert micrographs show typical examples of a high density BSAS layer with vertical cracks, and a low density BSAS layer with no observable vertical cracking.

Figure 3-68. Examples of SEM micrographs of samples from the isothermal steam test after 2500 hours oxidation. Top - back-scattered electron micrograph of the full coating and slurry cast CMC substrate; Middle - higher magnification micrograph of the bond coat-to-transition layer interface; Bottom - EDAX elemental map of the interface region region showing the TGO layer (depleted in silicon relative to the bond coat, but without the $\mathrm{Al}$ that was present in the BSAS plus muullite transition layer).

Figure 3-69. Bond coat oxide thickness as a function of exposure time in the isothermal steam test. Data points at 1300 and 4500 hours are from an older version of the EBC coating (data determined under the CFCC program) whereas the data points at 2500 and 8000 hours are for newer coatings deposited under this program. 
Figure 3-70. Microstructural and EDAX chemical analysis of the TGO layer formed on the EBC bond coat after 8000 hours isothermal steam exposure. The micrograph shows the interface between the EBC bond coat, at the bottom, and the transition layer coating at the top. EDAX spectra show that in addition to the normal EBC phases (Si bond coat at spot 1, BSAS at spot 5 and mullite at spot 4) that there are two oxidation reaction products $\left(\mathrm{SiO}_{2}\right.$ at spot 2 and a reaction product of $\mathrm{SiO}_{2}$ and BSAS at spot 3)....

Figure 3-71. Photograph of one of the shrouds used for EBC coating trials showing how it was sectioned for metallographic characterization of the coating thickness and microstructure.

Figure 3-72. EBC coating microstructure typical of that seen on the trial coating shrouds, showing relatively low and uniform porosity and no evidence of vertical cracking.

Figure 3-73. Micrographs of EBC coatings taken from trial shroud section \#6 showing variation of EBC thickness that resulted from varying the thermal spray deposition conditions across this region.

Figure 3-74. Quantitative variation of EBC layer thickness across trial shroud section \#6 as a result of intentional EBC deposition condition changes across this section.

Figure 3-75. Diagram of how shrouds selected for destructive analysis were sectioned (left), and photograph of the GE prepreg shroud following sectioning (right).

Figure 3-76. Photomicrograph montage of the cross section of the GE prepreg MI CMC shroud 1112-2 near the center of bar $\mathrm{C}$, showing the presence of a delamination resulting from poor infiltration of the $5^{\text {th }}$ ply.

Figure 3-77. Photomicrograph montage of the center section of bar $\mathrm{C}$ from the $\mathrm{CCP}$ slurry cast shroud 1216-01-004 showing extensive residual porosity and generally poor infiltration of this shroud.

Figure 3-78. Photomicrograph montage of the center section of bar $\mathrm{C}$ from Goodrich slurry cast shroud 4104-1-1 showing extensive residual porosity and generally poor infiltration, particularly near the inner surface of the shroud.

Figure 3-79. Photograph of test bars, shown edge-on, cut from engine shrouds and following $400 \mathrm{~h}$ steam oxidation at $1200^{\circ} \mathrm{C}$. The top bar is from Goodrich shroud 4101-1-1, the middle bar from CCP shroud 1216-01-004, and the bottom bar from GRC shroud 1112-2. Swelling caused by extensive internal oxidation is apparent at the right end of the CCP bar.

Figure 3-80. Tensile test results for witness bars cut from engine shrouds both asfabricated and after $400 \mathrm{~h}$ steam oxidation exposure at $1200^{\circ} \mathrm{C}$. Curves are offset on the strain axis for clarity.

Figure 3-81. Load vs. displacement curves for pin pull-out tests on the cut-up engine shrouds both as fabricated and after $400 \mathrm{~h}$ steam oxidation at $1200^{\circ} \mathrm{C}$. The curves are offset on the strain axis for clarity.

Figure 3-82. Photograph (edge-on) of the steam oxidized pin pull-out test specimens cut from the three engine shrouds. The delamination failure of the CCP shroud test sample is evident. 
Figure 3-83. Photograph of a CMC shroud suspended from strings as used for measurement of shroud modal frequencies................................................. 104

Figure 3-84. Typical modal frequency response of a prepreg shroud in the unconstrained condition. The three curves correspond to excitations in the three locations indicated in Figure 3-83.

Figure 3-85. Photograph of the shroud dimensional check tool, with an EBC coated CMC shroud installed, used for verifying the attachment hole alignments and overall shroud dimensional accuracy.

Figure 3-86. Photograph of three CMC inner shrouds assembled into a single outer shroud block assembly in preparation for field engine testing. The tubes coming out the back of the outer shroud block (bottom of the picture) are the thermocouple and pressure tap instrumentation.

Figure 3-87. Photograph of an outer shroud block with CMC inner shrouds (left) and a transition shroud block with metallic shrouds (right), showing the step in radial shroud position between the CMC and metallic shrouds.

Figure 3-88. Schematic diagram showing the positions of the special shroud blocks within the engine. The lower part shows the circumferential location of the shroud blocks within the engine (forward looking aft perspective). The upper part is a blowup of the CMC shroud section showing the locations of the individual inner shrouds.

Figure 3-89. Photograph of the top half of the turbine shell after removal from the engine. The view is forward looking aft and the $1^{\text {st }}$ stage shrouds and $2^{\text {nd }}$ and $3^{\text {rd }}$ stage nozzles are still installed on the casing. The positions of the five outer shroud blocks that were replaced for this test are marked by the light blue outlines. The CMC shrouds were in OSB positions 7 through 9.

Figure 3-90. Photographs of the turbine casing penetration that was added to accommodate the CMC shroud instrumentation wiring: Top left - at the beginning of drilling; Top right - the finished drilled and tapped instrumentation hole; Bottom left - after installation of the "chico bowl" seal and threading of the instrumentation wiring; Bottom right - the finished and sealed instrumentation bundle after the turbine shell had been re-assembled on the engine.

Figure 3-91. Photograph of the test set of shrouds after installation into the upper turbine casing. The nine white EBC-coated CMC shrouds are in the center three shroud blocks, with the transition shroud blocks that interfaced between the CMC and normal metal shroud systems, on either side. The wires hanging from the outer shroud blocks are the thermocouple and pressure tap instrumentation.

Figure 3-92. Photograph of the shroud instrumentation wiring after being tack welded to the casing and routed through the casing hole.

Figure 3-93. Photograph of the turbine top shell after completed installation of the $1^{\text {st }}$ stage shrouds and $2^{\text {nd }}$ and $3^{\text {rd }}$ stage nozzles. Outer shroud block \#1 is to the right and the white EBC-coated CMC shrouds in OSB positions 7 through 9 are obvious 
Figure 3-94. Variation of shroud test engine operation based on time of day for the period of December 23, 2002 to August 14, 2003...................................... 115

Figure 3-95. Borescope photographs from borescope inspection \#2 showing small indents or pits in the EBC surface of GE prepreg MI shroud 1359-1 (left) and on slurry cast MI shroud 1243-10-012 (right).

Figure 3-96. Borescope photograph showing the EBC chip at the rear hole bolt attachment of shroud 1109-2.

Figure 3-97. Schematic of the progression of EBC damage noted during the shroud engine test. Each row represents a separate inspection, from borescope \#3 at the top to the post-test condition of the shrouds across the bottom.

Figure 3-98. Borescope photograph of the surface EBC chips on shroud 1243-10-12 taken during the $3^{\text {rd }}$ borescope inspection on $02 / 15 / 2003$. The dark areas at the bottom of the pits indicate that $\mathrm{EBC}$ bond coat and/or CMC has been exposed....

Figure 3-99. Borescope photographs of two of the initial EBC crack/spall defects seen during borescope inspection \#3: Left - shroud 1118-1; Right - shroud 1359-1.

Figure 3-100. Left - borescope photograph of the "bulge" detected in shroud 1106-1 during borescope inspection \#4. Right - corresponding IR NDE image of this shroud indicating that a near-surface delamination was in this same location on the shroud.

Figure 3-101. Borescope photographs of slurry cast shrouds 1243-10-24 and 124310-23 taken during borescope inspection \#5, showing the regular, periodic spacing of the EBC pits on these shrouds.

Figure 3-102. Borescope photographs from borescope inspection \#5 showing the large area EBC spalls first noted at this interval.

Figure 3-103. Photograph of the shroud test engine upper turbine shell after it had been lifted off the turbine showing the location and condition of the CMC shrouds (white rectangles in the center of the shroud half ring)

Figure 3-104. Photographs of shroud outer blocks \#6 (top), \#7 (middle) and \#8 (bottom) while still mounted in the turbine upper casing following the shroud engine test \#1.

Figure 3-105. Photographs of the CMC inner shrouds after the engine test and after removal from the outer shroud blocks.

Figure 3-106. Examples of EBC damage noted on the shrouds following the 5366 hour engine test.

Figure 3-107. Photograph (top) and IR NDE image (bottom) of prepreg shroud 1299-1. The green-yellow areas on the NDE image indicate regions where the EBC has lost intimate contact with the substrate.

Figure 3-108. NDE images showing the rear bend region of shroud 1299-1 prior to EBC coating (left) and after EBC removal following the field engine test (right).

Figure 3-109. Diagram of how the shrouds were sectioned for destructive evaluations (left), and a view of the pieces of shroud 1299-1 after sectioning (right) 
Figure 3-110. Top - Micrograph montage of the CMC recession at the EBC spall location on prepreg shroud 1299-1. Bottom - Micrograph montage of CMC recession under an EBC tooling bump pit on slurry cast shroud 1243-10-12 .... 131

Figure 3-111. Micrographs of a pin-hole defect in the EBC coating of shroud 11181. Top left - stereomicroscope image of the surface of the shroud showing the EBC pin hole which was $<0.5 \mathrm{~mm}$ in size; Upper right - SEM micrograph of the same pin hole showing the local appearance of the EBC coating; Bottom - Optical micrograph of the cross section of the recession pit in the $\mathrm{CMC}$ below the EBC pin hole.

Figure 3-112. Photomicrographs of spare engine test shroud 1365-1 at various locations showing the corner of the hot gas path surface (top surfaces) and the shroud edges (vertical surfaces).

Figure 3-113. Photomicrographs of the hot gas path corner region of a slurry cast shroud from rig test \#4 (left) and a prepreg shroud used in rig tests \#2 and \#3 (right). Enhanced oxidation of the porous silicon bond coat in these regions has caused swelling of the bond coat and cracking of the outer oxide EBC layers.

Figure 3-114. Photographs from the edge of prepreg shroud 1299-1 showing the proposed time progression of EBC damage along the shroud hot gas path edges

Figure 3-115. FEA results for model of EBC bond coat oxidation and its effects on EBC stresses along the shroud edges.

Figure 3-116. Photomicrographs around the edge of shroud 1365-1 (a spare from the field engine test) near the forward flange bend showing exaggerated porous bond coat on the inside of the shroud (bottom surface in micrographs), much thicker and more porous than any porous bond coat layer on the hot gas path to side corner.

Figure 3-117. Photographs (top) and IR NDE images (bottom) of shroud 1359-1 (left) and 1243-10-12 (right) following the engine test with the EBC coating still intact. The NDE images are scaled so that regions with a thermal break between the EBC and CMC (i.e. heavily oxidized porous silicon bond coat) shows as greenish yellow and intact EBC shows as dark blue.

Figure 3-118. Photographs of the back side surface of shroud 1106-1 and its damper block after engine testing. The wear marks in the EBC on the back side of the shroud corresponding to the feet on the damper block are indicated.

Figure 3-119. Top left - photograph of wear footprint on shroud from damper block foot showing the direction of the profilometer trace Bottom left - profilometer trace across the wear footprint in the above photo showing wear preferentially at the edges of the damper foot through the complete depth of the EBC coating Right - micrograph of the cross section of the damper foot in contact with this shroud at this location showing greater material loss at the center of the foot than at the edges 
Figure 3-120. Photographs of the regions of the attachment holes from shroud 11181 that would have been in contact with the attachment pins or bolts during the engine test, showing very minimal, if any, indications of wear or chemical interaction between the $\mathrm{CMC}$ and metallic pins.

Figure 3-121. Micrographs of the cross sections of the forward attachment holes from three of the engine-tested shrouds. No evidence for CMC wear or chemical interaction of the CMC with the attachment pins was found. The slightly irregular surface on the hole of the slurry cast shroud (1243-10-12) was a result of the machining operation and fiber architecture.

Figure 3-122. In-plane tensile stress-strain response of test bars cut from prepreg shrouds after 5366 hours of engine testing compared to as-fabricated material cut from the same shrouds.

Figure 3-123. In-plane tensile stress-strain response of test bars cut from the slurry cast MI shrouds after 5366 hours of engine testing compared to as-fabricated material cut from the same shrouds.

Figure 3-124. Left - Schematic of pin pull-out test performed on the front flange attachment slots of the shrouds from the field engine test. Right - Loaddisplacement curves from the pin pull-out tests.

Figure 3-125. Photograph of the damper block from shroud 1106-1 showing how one of the damper retention pins broke the tack welds and came out of the damper block, and the corresponding hole that was worn into the outer shroud block by the pin.

Figure 3-126. Photographs of the forward attachment pins (left) and rear attachment bolts (left) used with shroud 1118-1 in the shroud engine test showing the regions that contacted the shroud.

Figure 3-127. 3-D optical profilometry images of the attachment pins (forward) and bolts (rear) used with shroud 1116-1 in the shroud engine test. The areas shown are from the wear tracks caused by contact with the CMC inner shroud.

Figure 3-128. Schematic cross section of the overall new shroud system design with the various major components indicated.

Figure 3-129. Schematic diagram illustrating the additional blade tip leakage area (in pink) caused by the use of the flat CMC shrouds (the curvature of the bucket tip path is exaggerated relative to the size of the shroud).

Figure 3-130. Schematic diagram illustrating how bucket rubbing into the abradable EBC layer (light blue) would compensate for the flat shroud surface and minimize the effective bucket to shroud gap. The palest blue represents abradable EBC that would be removed by the bucket tip rub.

Figure 3-131. Solid model diagram of the shroud system flow test cell with the end cover plate removed. The leakage flow path through the T-hanger slot, shown by the red line, is the one originally identified through flow-net analyses as requiring the addition of the metallic V-seal. 
Figure 3-132. Diagram showing re-positioning of the cloth seal slot on the end of the outer shroud block closer to the $\mathrm{V}$-seal between the outer shroud block and the T-hanger. (This diagram shows the opposite end of the outer shroud block as what was shown in Figure 3-131.).

Figure 3-133. Temperatures in the shroud test rig vs. time during the two air compressor trips during rig test \#5.

Figure 3-134. Photograph of the shroud test section CMC lower wall following rig test \#5.

Figure 3-135. Photograph of the CMC shrouds, still mounted in the rig outer shroud block, following rig test \#5. Areas of EBC spallation are circled.

Figure 3-136. Close-up photographs of several of the EBC spalls seen on the shrouds from Rig Test \#5.

Figure 3-137. Photographs of melted silicon on the surface of shrouds from Rig Test \#5.

Figure 3-138. Photograph (top) and SEM micrograph (bottom) of an edge spall region of a shroud from rig test \#5 showing what appears to be surface cracking of the CMC shroud.

Figure 3-139. Photograph of Shroud 2003-1-B following rough sectioning for metallographic sample preparation. The position of section R6 is marked by the dashed line.

Figure 3-140. Photomontage of the edge of shroud 2003-1-B in region R6. The silicon EBC bond coat was missing over nearly all of the edge and a large portion of the hot gas path face.

Figure 3-141. Photomicrographs of shroud 1574 showing the appearance of normal and "depleted" silicon veins. The depleted vein appears wider than the filled vein due to damage and rounding of the edges during polishing.

Figure 3-142. Tensile stress-strain results of shrouds from before (-W samples) and after (-C and $-\mathrm{E}$ samples) exposure in Rig Test \#5. The color coding of the fracture data above the graph serves as the legend for identifying the different curves. The curves for each shroud are offset on the strain axis for clarity........ 172

Figure 3-143. Borescope photograph of the shroud test rig showing fragments of the rig transition piece blocking the entrance to the shroud test section................. 175

Figure 3-144. Photographs of shroud rig components indicating the location of a crack in one of the cooling air lines found during rig disassembly (top) and cracked potting compound at the thermocouple penetrations into the shroud test section (bottom).

Figure 3-145. Trend of spring cavity temperature versus cooling flow used to determine a minimum cooling flow to prevent hot gas ingestion into the spring cavity.

Figure 3-146. Attachment temperature as a function of cooling air flow rate for several rig firing temperature conditions and two levels of spring cavity cooling air flow, indicating the worst case minimum cooling flow needed to keep the attachments below their temperature limits. 
Figure 3-147. Photograph of the back side of one of the shrouds from rig test \#6 (left) compared to the corresponding damper block surface (right) showing that the contact marks on the two components match and are of relatively minor severity.

Figure 3-148. EBC crack on the rear face edge of shroud 1374-1 following rig test \#6.

Figure 3-149. Optical micrographs of the EBC-crack region from shroud 1374-1 showing accelerated oxidation of the porous silicon and subsequent swelling of the bond coat and coating cracking.

Figure 3-150. Distributions of density and ultimate strength values from prepreg HiPerComp ${ }^{\mathrm{TM}}$ shrouds produced at GRC and at CCP both before and after technician retraining at $\mathrm{CCP}$. The pink lines indicate the property acceptance criteria for the shrouds.

Figure 3-151. Examples of silicon nodules found on the surfaces of shrouds after post-EBC heat treatment at M\&PE: Left and Center - nodules seen in shroud mounting holes; Right - nodules seen on the EBC surface with concurrent dark patches in the EBC.

Figure 3-152. Microstructure of a "normal" EBC coating region on shroud 3312-01041.

Figure 3-153. Micrographs of the EBC coating from different areas of shroud 331201-041 showing a densified bond coat with gaps (top), and a largely missing bond coat (bottom).

Figure 3-154. Micrographs from shroud 3312-01-041 showing an area of the CMC with excessive fiber coating degradation and reaction of the Hi-Nicalon ${ }^{\mathrm{TM}}$ fiber with the silicon alloy. The lighter colored fibers have been reacted with molten silicon.

Figure 3-155. Distributions of strain to failure values from shroud witness bars taken from three populations of GEN1 CMC inner shroud components: GRC shrouds fabricated at GRC from June 2004-Jan. 2005, CCP'04 - shrouds fabricated at CCP during the Fall and Winter of 2004, and CCP'05 - shrouds fabricated at CCP during Jan.-Feb. 2005.

Figure 3-156. Photographs of CMC shroud samples following ballistic impact testing. Top - complete projectile penetration at $42.4 \mathrm{~J}$. Bottom - partial projectile penetration at $31.3 \mathrm{~J}$.

Figure 3-157. IR NDE thermal diffusivity images from the front bend region of GEN1 prepreg CMC shrouds: Top - CCP shroud from Nov.-Dec. '04; Middle - CCP shroud from Jan.-Feb. '05; Bottom - GRC shroud from Jan.Feb. '05.

Figure 3-158. Photomicrographs of the CCP shroud 1411-06-043-2 forward bend in a region appearing yellow to orange in the thermal diffusivity image, showing multiple examples of intra-ply delaminations and mid-ply cracks.

Figure 3-159. Photograph of the shroud flange bend test apparatus.

Figure 3-160. Plot of interlaminar strength from the flange bend tests versus the thermal diffusivity of the bend as determined by flash IR NDE. 
Figure 3-161. IR thermal diffusivity images of the leading edge (left) and trailing edge (right) bend regions from CCP shroud 1411-06-043-2 used for oxidation and bend testing. The short red lines show the positions of the slices and the sample labels are color coded according to the relative defect severity in that slice.

Figure 3-162. Interlaminar strength data from shroud corner bend tests on slices of shrouds. The yellow triangles represent the prior tests done on as-fabricated shrouds made in early 2005. The other data points are for shroud 1411-06043-2 which was tested both as-fabricated and after steam oxidation exposure for 250 to 1000 hours. Additional data from a shroud used in the 2003 field engine test are also shown.

Figure 3-163. Photographs of CMC samples with abradable EBC layers applied over the normal 3-layer, BSAS-based EBC.

Figure 3-164: JEA Brandy Branch generating station with the dashed blue ellipse highlighting the location of the 7FA+e gas turbine in which the CMC stage 1

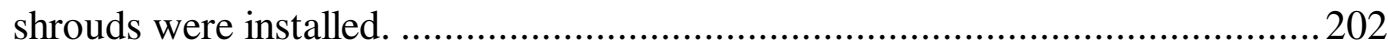

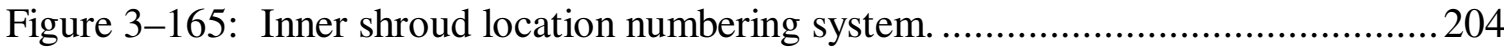

Figure 3-166: Location of interference between retention peg and T-slot hanger........205

Figure 3-167. Photograph of an outer shroud block being positioned onto the Thanger rail on the inside of the upper turbine casing....................................206

Figure 3-168. Photograph of the outside surface of the upper turbine casing showing the locations of the shroud block circumferential positioning holes....................207

Figure 3-169: Photograph showing the location of circumferential positioning hole on an outer shroud block. .................................................................... 207

Figure 3-170: Diagram showing the alteration of the circumferential positioning hole in the outer shroud blocks to allow fitting with the positioning pins in the axial

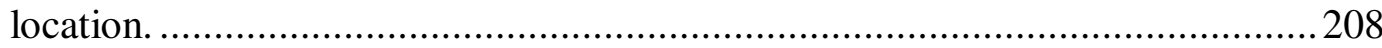

Figure 3-171. Photographs of the largest (top) and smaller (bottom) chips in the EBC of shroud 25-03 following re-machining of the circumferential location pin hole in the outer shroud block.

Figure 3-172. Photograph of edge of shroud block 17 showing the damaged EBC coating on the side of the rear flange of the CMC shroud at the split line, and its location relative to the $2^{\text {nd }}$ stage nozzle.

Figure 3-173: Photographs showing the bucket tip to shroud radial clearance at the location of outer shroud block 17 (top) and block 32 (bottom).

Figure 3-174. Comparison of turbine power output (top) and heat rate (bottom) before and after installation of the CMC shroud system. The progression of points shows the corrections made to the measured performance based on the other hardware changes as listed in Table 3-15, resulting in the actual engine performance change attributable to the CMC shroud system. The expected benefits from the cooling flow reductions are also shown for comparison..........215

Figure 3-175. Borescope photograph showing the speckled appearance of the $1^{\text {st }}$ stage turbine hardware after 35 hours of engine operation. ...........................2 217

Figure 3-176. Borescope photograph showing a shallow bucket tip rub region where only the peaks of the abradable ridges have been contacted by the bucket tips...218 
Figure 3-177. Borescope photographs showing relatively deep bucket tip rub events on shrouds from outer shroud blocks 16 and 17. The rub appears to have proceeded down through the abradable ridges to the main EBC coating. There does not appear to be any damage to the main EBC coating, but smearing of the bucket tip debris across the shrouds makes observation of the EBC very difficult.

Figure 3-178. Borescope photographs showing erosion of the abradable EBC ridges in regions without bucket tip rubs. Erosion was typically limited to the ridges of the abradable EBC layer as there was no evidence of erosion of the primary EBC. The right photo shows a comparison of adjacent Gen2 and Gen1 EBC coatings, suggesting that the Gen2 EBC was more resistant to erosion.

Figure 3-179. Evidence for a chip/spall in the EBC on shroud 20-02 near the forward flange bend on the left (upstream) edge.

Figure 3-180. Borescope photographs of deep rubs into the abradable EBC taken during the $2^{\text {nd }}$ borescope inspection on September 10, 2006. The rub into the shrouds on outer shroud block 16 (top) was somewhat deeper than observed in the first borescope examination, and additional deep rubs on other shrouds, such as 23-01, were also noted.

Figure 3-181. Borescope photographs of inner shrouds 24-1 and 25-3 taken during the $1^{\text {st }}$ (left) and $2^{\text {nd }}$ (right) borescope inspections. Note the similar features on the abradable EBC ridges at 165 hours exposure vs. that at 38 hours. Very little additional erosion of ridges was noted.

Figure 3-182. Photographs of the EBC chips on the edge of shroud 25-03 that was created during shroud installation (top left photograph). No obvious growth of the chips was noted at either 38 hours (lower left borescope photograph) or 165 hours (right borescope photograph). The similarity of the chips on EBC ridges from erosion suggests little additional erosion between the $1^{\text {st }}$ and $2^{\text {nd }}$ borescope inspections.

Figure 3-183. Select borescope pictures from the JEA hot gas path inspection performed in November, 2007. The shrouds indicated show evidence of large area EBC spalls and/or deep bucket tip rubs through the EBC abradable layers and into the base EBC.

Figure 3-184. Borescope photographs of several examples of EBC spalls: ................226

Figure 3-185. Several examples of the variations in bucket tip rubs on the shrouds that were observed during the March 2008 borescope inspection.....................2228

Figure 3-186. Photograph from borescope inspection \#4 showing the aft edge of a shroud having both a FOD-like spall just before the bend to the aft flange bend, and a near-edge spall on the aft flange close to the attachment bolt location.

Figure 3-187. Photographs taken from borescope inspection \#4 of shrouds showing evidence of leading edge FOD events. Left - an EBC spall with evidence of FOD penetrating into the EBC bond coat and possibly the CMC; Right leading edge bend of a shroud showing dark spatter and flecks of white indicating fresh chips in the EBC surface. 
Figure 3-188. Photographs from borescope inspection \#4. Left - close up of large center spall on a shroud with limited, if any, bucket tip rubbing. Right - spall in the center of a deep rub surrounded by a region of bucket material transfer...233

Figure 3-189. Borescope images of a crack-like feature found on shroud 4-1 during borescope inspection \#5. The arrows show the location of the feature. ...........2234

Figure 3-190. Borescope image of shroud 3-2 taken during borescope inspection \#5 showing a crack-like feature on the shroud similar to that shown in Figure 3189.

Figure 3-191. Borescope images from borescope inspection \#4 showing the same shrouds in Figure 3-189 (left) and Figure 3-190 (right). The edge of the EBC oxide transition layer is marked in each photo.

Figure 3-192. Borescope photographs of a single shroud with the diamond abradable EBC pattern taken during the last three borescope inspections.......................2239

Figure 3-193. Borescope photographs of the CMC "crack" features seen in borescope \#5 (Top) and again in borescope \#6 (Middle). The bottom borescope photographs of this feature, which were taken with a high magnification tip on the borescope probe, show that the contrast is caused by a step in the surface height of the CMC and not by a crack.

Figure 3-194. Histogram showing the count of shrouds with and without hot gas path spalls, as identified in borescope inspection \#3, according to the EBC heat treatment date. Green indicates no large central spall had as yet been observed in the JEA engine test; pink indicates that a large center spall was observed and the shroud did not show bucket material transfer from a deep bucket rub; yellow indicates that a large center spall was observed in combination with bucket material transfer.

Figure 3-195. Weight gain of the backside silicon bond coat layer for shrouds coated at MP\&E during the JEA engine test shroud coating campaign as a function of coating date.

Figure 3-196. Micrographs of the EBC coating on a process qualification shroud from January 2005 (Top) and one of the engine-reject shrouds coated in midFebruary 2005 (Bottom). The left-hand micrographs show the EBC structure along an edge of the shroud and the right-hand micrographs show the structure on the flat hot gas path face.

Figure 3-197. Photograph of three shrouds currently in the JEA engine test showing the gray-vs-white appearance of the EBC coating following EBC heat treatment.

Figure 3-198. Plot of relative defect concentration at the bond coat to transition layer interface in EBC coatings that showed white and gray regions after heat treatment. The defects in the gray region were largely healed after an additional 24 hours of steam oxidation exposure at $1200^{\circ} \mathrm{C}$.

Figure 3-199. Timeline for engine operating hours, hot trips, and observed large center spalls of the EBC coatings 
Figure 3-200. Historical occurrence of the various types of EBC spalls and their relation to the "dirt" events seen between borescope inspections. The numbers of detected leading flange, trailing flange and leading flange edge spalls all show their largest increases in the intervals where the "dirt" events also occurred.

Figure 3-201. GRC replicate shroud 2269-1: Top - macroscopic appearance showing gray patch in center of shroud with white stripes along the edges; Middle cross section of the EBC from the hot gas path face; Bottom - Si bond coat to transition layer interface in a gray region with arrows pointing to the cracklike features at the interface.

Figure 3-202. IR images of thermal shock test coupons taken before and after JETS testing. The temperatures from which the samples were down-shocked were $1093^{\circ} \mathrm{C}$ for sample $\# 6,871^{\circ} \mathrm{C}$ for sample $\# 9$, and $1316^{\circ} \mathrm{C}$ for sample \#8. The lines marked on the central photographs mark cross-section location from which the SEM samples taken.

Figure 3-203. Photomicrographs of EBC cracking generated by watermist JETS thermal shock tests from $1093^{\circ} \mathrm{C}$ on the hot gas path side of sample 2269-1\#6. The green arrows in the top image track the vertical through-thickness crack and the red arrows track the lateral delamination crack

Figure 3-204. Photomicrographs of cracking generated by watermist JETS testing from $871^{\circ} \mathrm{C}$ at the hot gas path side of sample 2269-1\#9. Top - optical micrograph of the end of the extended delamination crack along the transition layer/bond coat interface; Bottom - SEM micrographs of a tight through thickness crack, indicated by the green arrows, penetrating the EBC and connecting to the lateral crack at the transition layer/bond coat interface.

Figure 3-205. Photomicrograph of cracking generated by watermist JETS tests from $1316^{\circ} \mathrm{C}$ on the hot gas path side of sample 2269-1\#5. The delamination initiated from a vertical crack (green arrows) that penetrated to the transition layer/Si bond coat interface, but the lateral crack extension (red arrows) occurs mostly within the Si layer and away from the interface.

Figure 3-206. Various examples of EBC cracking on the HGP side of sample 22691\#8 generated by water mist JETS under a thermal gradient: (a) low magnification SEM image showing wide cracks in the EBC top layer; (b) higher magnification images showing "crack 1" with a network of finer vertical and lateral cracks; (c) close up of the crack running between the bond coat and transitions layer; (d) a lateral crack close to the BSAS surface, which was likely to be responsible for the hot spot seen in the IR image.

Figure 3-207. Examples of the cracks observed on the backside EBC from watermist JETS testing: Top - sample \#9 with isothermal shock from $871^{\circ} \mathrm{C}$; Bottom sample \#8 with shock from $1316^{\circ} \mathrm{C}$ with a thermal gradient......................... 262

Figure 3-208. Photographs of shrouds 1462-03-078-1 (top) and 1462-03-087-1 (bottom), showing the locations from which the samples were cut for JETS testing following cyclic steam exposure. 
Figure 3-209. Optical micrographs of the starting EBC microstructure of the EBC coatings on the samples used for cyclic steam oxidation followed by JETS testing, showing the through-thickness vertical cracks typical in JEA QC shrouds in the as heat-treated state: Top - sample 1462-03-078-1, Bottom sample 1462-03-087-1.

Figure 3-210. SEM micrographs of the EBC coating on sample 1462-03-078-1 during cyclic steam furnace testing, showing the evolution of the transition layer to Si interface during cyclic steam tests for white (left column) and gray (right column) regions

Figure 3-211. IR thermography images of the JETS samples cut from shrouds 146203-078-1 (Top) and 1462-03-087-1 (Bottom) during the course of JETS shock tests. Features seen in the IR images of the the sample from shroud 1462-03-078-1 correlated with white spots seen on EBC coating following initial heat treatment

Figure 3-212. SEM micrographs of the EBC cross section from sample 1462-03078-1 following JETS testing: (a) face quenched using forced air cooling, (b) face quenched water mist impingement.

Figure 3-213. SEM micrographs of the EBC cross section from sample 1462-03087-1 following JETS testing: (a) face quenched using forced air cooling, (b) face quenched water mist impingement.

Figure 3-214. Conceptual diagram of the tape casting procedure used for monolithic matrix ply fabrication.

Figure 3-215. Tape thickness (top) and areal density (bottom) as functions of the casting speed and blade gap height for the tape casting design of experiments. Both measurements showed consistent trends.

Figure 3-216. Comparison of the range in thickness of matrix plies made by hand impregnation of carbon veil with those made by tape casting.

Figure 3-217. Relationship between measured green tape thickness and the afterlamination ply thickness for various matrix plies. The data that fall below the trend line were for the hand made plies and for those cast at $0.25 \mathrm{~mm}$ gap height, which had visible porosity in the tapes after drying.

Figure 3-218. A process map for the tape casting of matrix plies showing the regions for combinations of casting speed and caster gap height combined to give various defects or good quality matrix plies.

Figure 3-219. Transmission IR NDE images from several panels prepared for the hybrid CMC study. A uniform blue-green color, as seen in the full CMC panel image, indicates a lack of defect in that region, whereas red and orange indicate delamination.

Figure 3-220. Photograph (top) and transmission IR NDE image (bottom) of the additional hybrid panel made with all CMC on one side and all monolithic plies on the other side, but with the monolithic plies having been through the binder burn-out cycle prior to lamination with the CMC plies.

Figure 3-221. Results of dilatometer measurement of the firing expansion/shrinkage behavior of unfired CMC and monolithic matrix samples compared to the expansion behavior of an infiltrated CMC from previous measurements. 
Figure 3-222. Edge-on photograph of hybrid composite panels made with one half of the panel being pre-fired monolithic matrix and the other half being normal CMC. The panel on the right, which shows a high degree of bow deformation, was made with Hi-Nicalon fiber whereas the panel on the left, which shows very minor bowing, was made with Hi-Nicalon type S fiber.

Figure 3-223. Dilatometer expansion/shrinkage curves for several monolithic matrix compositions as compared to the expansion/shrinkage of a CMC composite preform (green line).

Figure 3-224. IR NDE images of panel 2532, the first of the new hybrid panels made with distributed monolithic matrix plies: Top - reflection images from the front and back surfaces showing flaw depth; Bottom - transmission image showing thermal diffusivity values.

Figure 3-225. IR NDE images from panel 2533, the second of the new hybrid panels made with CMC skins over a monolithic matrix core: Top - reflection images from the front and back surfaces showing flaw depth; Bottom - transmission image mapping thermal diffusivity values.

Figure 3-226. IR NDE images from panel 2534, the third of the new hybrid panels made with one half of the thickness being $\mathrm{CMC}$ and the other half being monolithic matrix: Left - reflection images from the front and back surfaces showing flaw depth; Right - transmission image mapping thermal diffusivity values.

Figure 3-227. Transmission IR NDE images of the remaining hybrid panels made with Hi-Nicalon Type-S fiber and modified matrix compositions.

Figure 3-228. Photographs of ballistic impact panels following impact testing. Photos on the left are the entry (front) side and photos on the right are exit (back) side. See Table 3-19 for an explanation of panel configurations.

Figure 3-229. Post-test impact photographs of the monolithic matrix and C-cloth based Silcomp panels showing how the panels shattered into fragments.

Figure 3-230. Transmission IR thermography images of hybrid panel 2416 before (upper left) and after (lower left) ballistic impact testing. The image on the right is a still photograph from the high-speed video of the impact event that shows the opening of a pre-existing delamination along the edge of the panel. ..300

Figure 3-231. Plot of energy dissipated per unit thickness (in arbitrary units) during the ballistic impact tests versus the volume fraction of fiber in the target panel..302

Figure 3-232. Tensile stress-strain data from hybrid CMC/monolithic panels made with Hi-Nicalon fiber and the standard matrix composition. The panel numbers and ply configurations are as indicated, and the curves are offset on the strain axis for clarity.

Figure 3-233. Tensile stress-strain data from hybrid $\mathrm{CMC} /$ monolithic panels made with Hi-Nicalon type-S fiber and the modified matrix composition for the monolithic plies. The panel numbers and ply configurations are as indicated, and the curves are offset on the strain axis for clarity. 
Figure 3-234. Tensile stress-strain data from hybrid $\mathrm{CMC} /$ monolithic panels made with Hi-Nicalon type-S fiber and the modified matrix composition for the monolithic plies. The panel numbers and ply configurations are as indicated, and the curves are offset on the strain axis for clarity.

Figure 3-235. Plots of ultimate strength (top left), strain to failure (top right) and proportional limit (bottom) measured on the hybrid test panels as a function of actual fiber volume fraction. Panels made with Hi-Nicalon fiber are indicated by the blue symbols, and those with Hi-Nicalon Type-S fiber by the magenta

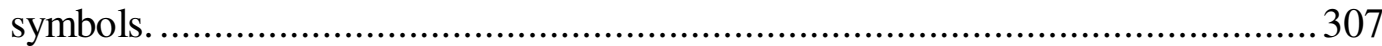

Figure 3-236. IR reflection thermography images of the hybrid CMC panels with distributed composite plies made with Hi-Nicalon Type-S fiber following ballistic impact testing. ..................................................................... 308

Figure 3-237. Pin pull-out strength as vs fiber volume fraction for hybrid CMC panels. The red dot-dashed line shows the maximum pin attachment load on the shrouds

Figure 3-238. Micrographs of uncoated fiber hybrid panels with distributed uncoated fiber plies (top) and with the uncoated fiber plies concentrated in the center (bottom). The tensile testing direction is left-to-right in the micrographs. Several of the surface plies had been ground off during sample preparation, as described in the text

Figure 3-239. Transmission IR thermal diffusivity images of the hybrid CMC panels made with uncoated fiber plies. Top - panel with the uncoated fiber plies concentrated toward the middle of the thickness (U2); Bottom - panel with the uncoated fiber plies interspersed uniformly through the thickness (U1)....... 314

Figure 3-240. Reflection IR thermal diffusivity images of the hybrid CMC panel U1. The left-hand images are from before impact testing, and the right-hand images are after impact. The top images are for the entrance side of the panel and the bottom images from the exit side.

Figure 3-241. Reflection IR thermal diffusivity images of the hybrid CMC panel U2. The left-hand images are from before impact testing, and the right-hand images are after impact. The top images are for the entrance side of the panel and the bottom images from the exit side.

Figure 3-242. Room temperature tensile stress-strain data for the uncoated fiber hybrid panels and comparable witness coupon.

Figure 3-243. Tensile stress-strain data for the $1200^{\circ} \mathrm{C}$ tensile tests of the uncoated fiber hybrid panels and comparable witness coupon.

Figure 3-244. Photograph of the hybrid structure shroud blank following melt infiltration.

Figure 3-245. IR thermography NDE images of the hybrid shroud following melt infiltration densification. Some small isolated delaminations were detected (orange), but the majority of the shroud was defect-free.

Figure 3-246. Historical data from fibers coated in the large GE fiber coater on the effects of $1^{\text {st }}$ layer and $2^{\text {nd }}$ layer coating thickness on the mechanical properties of prepreg MI CMC composites. 
Figure 3-247. Dependence of proportional limit stress measured on the fiber coating DoE samples on the test panel density (left) and on the amount of curvature, or bow, in the test samples (right).

Figure 3-248. Trends of proportional limit (top), ultimate strength (middle) and strain to failure (bottom) with fiber coating layer thickness. Plots on the left are for RT tensile tests and those on the right are for testing at $1200^{\circ} \mathrm{C}$. The smaller symbols represent the individual data points and the wider dash symbols represent the average value for that condition.

Figure 3-249. Results of the room temperature tensile tests on sample made from the new set of fiber coating configurations.

Figure 3-250. Results of the high temperature tensile tests on sample made from the new set of fiber coating configurations.

Figure 3-251. Trend between RT and $1200^{\circ} \mathrm{C}$ strain to failure measurements on older GRC-generated material (from the 2000 database) and from CCPfabricated shrouds from early 2008.

Figure 3-252. Low cycle fatigue response of "low-strain" CMC material from CCP (red) compared to older GRC-fabricated GEN1 material (blue). All testing was done at $1200^{\circ} \mathrm{C}$ in air at $0.33 \mathrm{~Hz}$ and an R-ratio of 0.01 .

Figure 3-253. Size and location of notches machined into the edges of tensile low cycle fatigue specimens.

Figure 3-254. Photograph under UV lighting of the notched region of the notched fatigue sample that was preloaded to a gross section stress of $148 \mathrm{MPa}$. A very short crack was detected propagating out from one of the notches, but only after applying the fluorescent dye while the specimen was under tensile load.

Figure 3-255. Transmission IR NDE images on the six shroud doublets fabricated by CCP for the shroud FPQ process.

Figure 3-256. Boxplots of the strain to failure values measured from the qualification panels of the fiber coating lots used for the FPQ shrouds (8-ply lay-up), and from the witness bars cut from the flange ends of the FPQ shrouds (18 ply layup). The box limits represent $95 \%$ confidence intervals.

Figure 3-257. Trend of shroud strain to failure for three different melt infiltration conditions at CCP. The green bars represent conditions where the minimum strain to failure specification was routinely met and the shrouds were completely infiltrated.

Figure 3-258. Micrographs of an edge section from the 4th Gen1 EBC FPQ shroud showing very thin silicon bond coat, to the point of becoming discontinuous, on the edge of the shroud.

Figure 3-259. Work Breakdown Structure for the 7FA MI-CMC Combustor Liner Efforts

Figure 3-260. Simplified model of the 7FA CMC combustor liner concept used in Conceptual Design Review \#1.

Figure 3-261. Temperatures of the EBC coating and CMC liner surfaces predicted from the $1^{\text {st }}$ round of FEA using the heat surface transfer coefficient and gas temperature boundary conditions from the existing metallic liner design. 
Figure 3-262. Schematic of a fabricated "dimple" on the CMC combustor liner surface and how the metallic "ferrules" for the cross-fire tubes, flame detector and spark plug would be attached to the liner wall.

Figure 3-263. Initial calculations of resonant frequencies for the first six modes of metal and CMC combustor liners both without and with the effects of the aft hula seal. The red hatched areas are ranges of modal frequency that are normally avoided since vibration driving forces are present in these frequency ranges.

Figure 3-264. Patterns of the combustion gas temperature and surface heat transfer coefficients used for the FEA of the CMC combustor liner for CDR \#2 ............354

Figure 3-265. Temperature predictions of the CMC liner surface and EBC coating surface temperatures from FEA using the boundary conditions in Figure 3264.

Figure 3-266. FEA predicted in-plane stresses of the CMC liner based on the temperature distribution shown in Figure 3-265 and gas pressure loads.

Figure 3-267. FEA predictions of the temperature distribution in the metallic crossover tube ferrule assembly attached at the liner penetration (left), and of the temperature of the CMC liner at the penetration for the cases where heat loss through the cross-over tube assembly is allowed (middle) or prevented (right).. 357

Figure 3-268. In-plane stress predictions for the region around the cross-fire tube penetration hole in the $\mathrm{CMC}$ liner for the cases where the cross-fire tube assembly is cooled with leakage air (top) and where no cooling from leakage air is allowed (bottom).

Figure 3-269. Temperature and stress results from the refined FEA presented at CDR \#3.

Figure 3-270. Schematic diagram of the wear test configuration used for testing wear of hula seal material pins against CMC and EBC-coated CMC panels.......361

Figure 3-271. Results of the wear tests of hula seal metals (X-750 and X-750 with Stellite 6 coating) against various other materials, including bare and $\mathrm{EBC}$ coated CMC: Top - wear of bare X750 against the other materials at $427^{\circ} \mathrm{C}$ $\left(800^{\circ} \mathrm{F}\right)$; Middle - wear of Stellite 6 coated X-750 again the other materials at $427^{\circ} \mathrm{C}\left(800^{\circ} \mathrm{F}\right)$; Bottom - wear of bare X-750 and Stellite 6 coated X-750 against bare $\mathrm{CMC}$ at $650-705^{\circ} \mathrm{F}\left(1200-1300^{\circ} \mathrm{F}\right)$.

Figure 3-272. Calculated maximum tensile stress in the CMC combustor liner near a penetration hole as a function of the leakage rate (equivalent seal gap) of the ferrule seal

Figure 3-273. Leakage rate (equivalent gap height) of $4 \mathrm{~mm}$ and $5 \mathrm{~mm}$ ceramic rope seals as a function of compression and pressure difference. The dotted vertical line represents the relative pressure drop across the ferrules in the 7FA engine combustor system.

Figure 3-274. Predicted modal frequency results from ANSYS FEA analysis and analytical calculations compared to actual measured modal frequencies.............366

Figure 3-275. Modal frequency analysis of the CMC combustor system....................367

Figure 3-276. Forced response stress predictions as a function of driving frequency for a $0.07 \mathrm{bar}$ pressure fluctuation. 
Figure 3-277. Photographs of the 7FA CMC combustor liner during composite layup. Top: Liner after application of an axial ply. Bottom: Liner with overwrap of stretch film used to prevent excessive preform drying during the lay-up process..................................................................................... 370

Figure 3-278. Photograph of trial 7FA combustor liner (still on the lay-up and lamination tool) following autoclave lamination.

Figure 3-279. Photograph of the trial combustor liner preform (still on the lamination tool) following autoclave lamination. The exit end of the liner is down, and the location of an axial ply wrinkle in the liner is indicated.

Figure 3-280. Photographs of the trial combustor liner during preparation for binder burn-out (top) and following burn-out at CCP (bottom)

Figure 3-281. Photographs of the trial CMC combustor liner following pack application at CCP (top); during loading into the MI furnace at Solar Atmospheres (middle); and immediately following the melt infiltration heat treatment (bottom).

Figure 3-282. Photograph of the outer surface of the trial liner following infiltration and pack removal, showing the surface "wrinkling" and waviness. A layer of excess silicon is still present on much of the surface.

Figure 3-283. Montage of photomicrographs of a cross section through the trial liner (liner inner surface toward the top and outer surface at the bottom). The relatively dense and coherent inner plies, made with uncoated fiber, contrast with the delaminated and poorly densified outer plies, made with coated fiber... 377

Figure 3-284. Photograph of a panel made with $1 / 2$ uncoated and $1 / 2$ coated fiber. Severe warpage of the panel (concave toward the uncoated fiber side) occurred during infiltration.

Figure 3-285. Photograph of 7FA liner being loaded into the large production autoclave at CCP. Length of the liner tool is $1.2 \mathrm{~m}$.

Figure 3-286. Photographs of the 7FA rig test combustor liner following autoclave lamination: Left - Full liner after removal of the vacuum bag, breather and bleeder layers. Right - Close up photograph showing shrink film wrap bonded to the surface.

Figure 3-287. Density of the half-panels infiltrated at CCP and GRC as part of the liner infiltration condition selection study.

Figure 3-288. Photographs of rig test 7FA liner during removal from binder burn-out furnace: Top - Overall view of liner with carbon cloth wrap; Bottom left Close-up of large end of liner showing how liner shifted on the tooling; Bottom right - The shifted liner pushed the tooling off of the forward support block

Figure 3-289. Photographs of the 7FA rig test liner following burn-out: Top Surface immediately after burn-out showing glassy carbon on surface Bottom - After surface sanding and placement onto the infiltration tooling.

Figure 3-290. Photographs of the 7FA rig test liner during loading (top) and removal (bottom) from the infiltration furnace at PSC.

Figure 3-291. Photograph of the 7FA rig test liner after removal of the excess

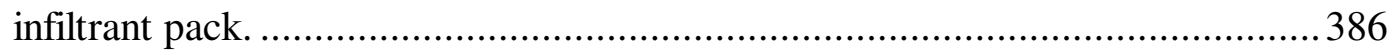


Figure 3-292. Representative liner NDE images from transient IR thermography showing the relative proportions of good and defective areas between the current (i.e. $1^{\text {st }}$ rig) liner and the trial liner fabricated previously.

Figure 3-293. Qualitative ranges for thermal diffusivity measured in the $1^{\text {st }}$ rig test combustor liner compared to the typical range measured for shroud components.

Figure 3-294. Comparison of the microstructure of the 7FA rig test liner (left) with a more normal microstructure typical of a panel or shroud component (right). The intra-ply porosity evident in the rig liner microstructure is responsible for the lower than normal thermal diffusivity of the part.

Figure 3-295. Photograph of the 7FA rig test liner following attempted thermal spray of the silicon EBC bond coat. Dark gray areas represent regions where the silicon layer has spalled from the substrate.

Figure 3-296. Damage to the $1^{\text {st }}$ rig test liner caused by the second grit blasting treatment. Left: Photographs of the most severely damaged area shown on the outer and inner surfaces, including the through-wall hole. Right: IR NDE image of the liner showing the pre-existing defect at the damage location. ........390

Figure 3-297. Examples of the thermal paint calibration test results on EBC-coated (left) and uncoated (right) CMC test specimens.

Figure 3-298. Photograph of a HiTec Corp. applied type B thermocouple on an EBC-coated CMC sample following thermal paint application, thermal exposure, and removal of the thermal paint via grit blasting. The thermocouple is still well-attached and functional.

Figure 3-299. Combustor system pressure drop as a function of the flow blockage caused by the pressure drop increaser ( $\mathrm{dP}$ increaser).

Figure 3-300. Schematic diagram of the Solar CSGT engine combustor system

feeding into the turbine section. Ceramic components are highlighted.

Figure 3-301. Photograph of the direct-wind process for lay-up of the hoop plies of a cylindrical component such as the CSGT combustor liners.

Figure 3-302. Photograph of the $1^{\text {st }}$ prepreg CSGT inner liner after partial grit-blast clean-up following melt infiltration. The region of the liner that was indented during vacuum bagging is indicated.

Figure 3-303. Montage IR NDE images from CSGT liner \#1 shot at 4 orientations. The upper image is a reflection image showing the depth of any detected defect and the bottom image is an amalgam of the reflection and transmission images scaled based on the relative severity of the detected defects.

Figure 3-304. Photographs of CSGT combustor liner \#2 during the lay-up process. Left - liner on lay-up tool with thermal shrink tape used for debulking in place; Right - liner on lay-up tooling after removal of the shrink tape........................400

Figure 3-305. Photograph of liner \#2 following burn-out and removal from the graphite lay-up tool.

Figure 3-306. CSGT combustor liner \#2 following melt infiltration: Left - the liner inside the furnace showing the positioning of the liner, tooling and silicon alloy source blocks; Right - side view of the liner showing the un-infiltrated band along the center of the liner. 
Figure 3-307. Montage IR NDE images of CSGT liner \#2 following the $2^{\text {nd }}$ infiltration treatment shot at 4 different orientations. The upper images are reflection IR showing defect depth whereas the lower images use the reflection and transmission IR data to derive a map of the severity of the detected defects.

Figure 3-308. Photograph of Liner \#3 following autoclave lamination. 404

Figure 3-309. Photographs of HiPerComp CSGT liner \#3 at roughly $72^{\circ}$ intervals following surface cleaning after infiltration.

Figure 3-310. Montage NDE images of CSGT liner \#3 taken from four orientations: Top - reflective IR image showing defect size and depth; Middle transmission IR image imaging showing thermal diffusivity values; Bottom defect severity image based on the upper 2 images.

Figure 3-311. Photographs of liner \#4 following autoclave lamination and removal from the tooling. The main axial ply wrinkle, extending from top to bottom of the liner, can be seen in the top left photograph

Figure 3-312. Photographs of liner \#4 following the burn-out heat treatment and removal from the tooling. The main axial ply wrinkle, extending from top to bottom of the liner, can be seen in the top left photograph

Figure 3-313. Photograph of the infiltration set-up for the $4^{\text {th }}$ liner prior to the infiltration run.

Figure 3-314. Photograph of the $4^{\text {th }}$ CSGT liner immediately following infiltration...... 411

Figure 3-315. Photographs of HiPerComp CSGT liner \#4 following infiltration and grit-blast clean-up. The photographs are from 5 angles around the circumference showing the entire liner surface.

Figure 3-316. Montage IR thermography images of Liner \#4 taken from four orientations: Top - reflective IR image showing defect size and depth; Middle - transmission IR image imaging showing thermal diffusivity values; Bottom defect severity image based on the upper 2 images.

Figure 3-317. IR thermography images of Liner \#4, looking from 2 orientations (left and right). The top images are scaled by the thermal diffusivity values, and the bottom images are artificially colored according to flaw severity (green good, yellow - marginal, red - bad). Locations of the ply wrinkles noted after autoclave lamination are indicated, and represent the major cause of defects in liner \#4.

Figure 3-318. Tensile stress-strain response of the witness coupons processed in parallel with CSGT liners \#3 and \#4.

Figure 3-319. Photomicrographs of the through-wall cross sections of Liner \#3 (left) and Liner \#4 (right)

Figure 3-320. IR thermal diffusivity image measured at ANL on liner \#4. The main ply wrinkle is the dark vertical strip near the center of the image. The location, size and severity of defects correlate very well with those observed in the GRC IR thermography images. 
Figure 3-321. Photographs of liner \#4 following grit-blast surface preparation (left) and after EBC coating application (right). The top photographs show the breakthrough of the liner surface along the main ply wrinkle during grit blasting, and the coating of these pits during EBC deposition. The bottom photographs show close-up views of the larges of the pits, and the insert of the bottom right photo shows the bottom of the largest pit where the EBC coating was not continuous.

Figure 3-322. Borescope photographs of the GE CSGT inner combustor liner showing EBC chipping along the aft edge. The top set of photos are from the July 2005 borescope inspection, the middle set from the November 2005 inspection, and the bottom set from the July 2006 inspection.

Figure 3-323. Photographs of the largest pit in the CSGT inner liner before engine service (top left), after 3983 hours (top right) and after 6706 hours (bottom right), and after $\sim 9500$ hours (bottom left)....

Figure 3-324. Borescope photographs of the "spider web" surface feature on the CSGT combustor liner, showing the growth of the width of the ridges and eventual EBC spallation with engine exposure time.

Figure 3-325. Continuous surface photograph of the inside surface (top) and outside surface (bottom) of the GE HiPerComp® inner combustor liner after 12,822 hours of service in the Solar CSGT engine.

Figure 3-326. Transmission IR diffusivity images of the GE Prepreg combustor liner both before (lower) and after (top) the Solar CSGT engine test.

Figure 3-327. Transmission IR thermal diffusivity NDE images of liner \#4 taken at GRC before engine testing (top) and after engine testing (bottom)

Figure 3-328. Photograph (top) and bicolor image (bottom) of the GE CSGT combustor liner after the engine test. Visible EBC spalls are represented by the black areas in the bicolor image. .......................................................428

Figure 3-329. Photographs of the CSGT liner surface in the location of the ply wrinkle pits. Top Left - macro photograph before the engine test showing the location of the pits and ply wrinkle on the liner surface; Top Right - close up photograph of the most severe pits prior to engine test; Bottom Left - a borescope photograph showing progression of oxidation within the deepest pit and raising and cracking of the EBC adjacent to the pit; Bottom Right - close up photograph after the engine test showing growth of the pit due to oxidation/volatilization of the CMC substrate, oxidative swelling of the CMC and resulting cracking/spallation of the EBC. The width of the EBC spall in the lower right photograph is $\sim 1 / 2$ inch $(\sim 13 \mathrm{~mm})$.

Figure 3-330. Photographs of several examples of pre-existing surface defects on the GE CSGT inner liner and corresponding photographs of the same features after the engine test, showing minimal change in the defects and only very minor loss of EBC. 
Figure 3-331. Photographs of the end of the ply wrinkle defect where it intersected the trailing edge of the liner. The left photo shows the as fabricated edge with EBC not fully covering the edge void caused by the ply wrinkle. The center photo shows how oxidation down the wrinkle led to oxidative swelling toward the inside of the liner. The right photo shows the local loss of several CMC plies due to oxidation immediately adjacent to the wrinkle at the end of the liner

Figure 3-332. Photographs of EBC chipping and CMC oxidation damage along the aft edge of the GE combustor liner. The nature of the EBC fracture suggests that chipping was initiated by mechanical impacts along the liner edge.

Figure 3-333. Photographs of the "wavy" EBC ridge features observed on the liner hot gas path surface. See the text for a description.

Figure 3-334. Top - Photograph of the outer surface of liner \#4 with the location of the various samples desired for post-test characterization indicated; Bottom Montage photograph of the liner following sectioning and machining for extraction of the individual characterization specimens

Figure 3-335. Photograph of tensile bar surfaces following removal of the EBC coating via grit blasting. The irregular troughs seen in bars $\mathrm{G}, \mathrm{H}$ and $\mathrm{I}$ correspond to the locations of the spider web ridges/cracks in the EBC coating. The surfaces of tensile bars cut from other regions of the liner were relatively unaffected by engine exposure.

Figure 3-336. Tensile stress-strain behavior of samples cut from the HiPerComp® CSGT liner compared to that of witness bars fabricated with the liner: Top Samples taken from areas of the liner with no visible defects and only minor indications on the NDE images; Bottom - Samples taken from regions of strong NDE indications or from the region of "spider web" cracking

Figure 3-337. Montage micrographs of the main wrinkle defect where it reached the aft edge of the liner: Top - axial section; Bottom - hoop section $\sim 6 \mathrm{~mm}$ $(\sim 1 / 4 ")$ in from the aft edge.

Figure 3-338. Montage micrograph of a section through a surface pit on the main wrinkle of the CSGT liner. A photograph of the pit on the surface is shown in the small inset in the lower right, and the dashed line indicates the location of the cross section surface used for metallography. The small spall at the bottom of the inset photograph corresponds to the left edge of the pit in the micrographs.

Figure 3-339. Micrograph montage of the main wrinkle defect near the forward edge of the liner away from any surface pits.

Figure 3-340. Close up photograph of the deepest surface pit region along the main ply wrinkle following the engine test. The axial direction of the liner is vertical in the photograph.

Figure 3-341. Montage micrograph of the cross section of the main CMC surface pit. Left to right in the micrograph is the axial direction of the liner, with the aft of the liner being to the right.... 
Figure 3-342. Montage micrograph of a cross section of the main wrinkle at a region adjacent to the deepest CMC pit, as shown in Figure 3-340. Lateral oxidation in the liner hoop direction has extended more than $2 \mathrm{~cm}$ from the wrinkle position at this location.

Figure 3-343. Montage micrograph of a cross section of the small wrinkle in Section B. The wrinkle corresponds to an overlap seam in the $2^{\text {nd }}$ composite ply that resulted in lateral delaminations. The part of the delamination that did not fill with silicon during infiltration account for the strong NDE indication in this

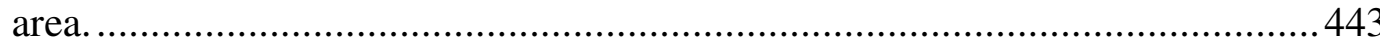

Figure 3-344. Montage micrograph of the cross section of the small liner ply wrinkle in Section A.

Figure 3-345. Montage micrograph of the cross section of one of the EBC/CMC spall regions near the center of Section E................................................ 445

Figure 3-346. Borescope photograph of one of the chips in the EBC at the aft edge of the combustor liner. The sharp edges and shape of the chips suggest that they were caused by mechanical pressure and/or impacts along the aft edge of the liner.

Figure 3-347. Photograph (top) and montage micrograph (bottom) of one of the larger EBC chips along the aft edge of the CSGT liner following the 12,822 hour engine test. The dashed line in the top photo shows the position of the cross section that is shown in the lower micrograph.

Figure 3-348. Montage micrograph of the cross section through an aft edge EBC chip. The yellow dashed line in the lower photograph shows the location of the cross section.

Figure 3-349. Photograph of the surface of the liner after the 12,822 hour engine test, showing the positions of characterization samples cut from the liner for examination of isolated EBC pit and bump features.

Figure 3-350. Montage micrograph of the section cut along the edge of the pit feature in Figure 3-349.

Figure 3-351. Photomicrograph of the cross section of the "bump" feature shown in Figure 3-349.

Figure 3-352. Photomicrographs of a series of spider web ridge features. The total width of the area shown is $1.9 \mathrm{~cm}$ and includes four ridges of varying severity...451

Figure 3-353. The top image is a photomicrograph of the cross section of a typical EBC spider web ridge. The bottom schematic shows the various important microstructural features found in the majority of the ridges examined.

Figure 3-354. Photograph of the outer surface of the liner showing the locations of the region with spider web ridges, the additional smaller whitish EBC defects that were examined metallographically, and the surface area examined via stereomicroscope to look at the morphology of EBC surface cracks. 
Figure 3-355. Optical micrographs of the cross sections of several smaller, whitish surface bumps possibly corresponding to the start of an EBC ridge: Top small whitish ridge corresponding to the right-most spot in Figure 3-354; Middle - small isolated whitish bump in EBC corresponding to the middle spot in Figure 3-354; Bottom - small whitish ridge along small surface wrinkle at left-most spot in Figure 3-354.

Figure 3-356. Stereomicroscope image of the EBC surface in a region adjacent to the main spider web ridge region, corresponding to the magenta oval in Figure 3-354.

Figure 3-357. SEM micrographs of the cross section of a typical "spider web ridge" feature. The inset shows a higher magnification view of the EBC top coat which has been pushed upward and shows through-thickness cracks connecting to the large pore.

Figure 3-358. SEM images of the EBC layers focusing on the transition layer. Top - area aft of the spider web ridge region showing normal dense TGO with little to no reaction with the EBC transition layer. Bottom - area within the spider web ridged region showing extensive reaction between the TGO and EBC transition layer to form the needle-like phases between the silicon bond coat and BSAS outer coating.

Figure 3-359. Measured remaining thickness of the EBC BSAS top coat, in microns, for various locations on combustor liner \#4 after engine testing. ......................458

Figure 3-360. Photograph of the combustor liner surface. The blue arrows point out the transition from whitish to grayish appearance of the EBC coating parallel to the forward (lower) edge of the liner. The violet lines indicate the locations of metallographic samples examined to date to characterize this feature.

Figure 3-361. Photomicrograph mosaic from the transition region between the whitish leading edge of the liner (to the right) and the grayish liner region (to the left).

Figure 3-362. Mosaic photomicrograph from the right-most sample in Figure 3-360 showing the cross section of the transition region between the raised whitish band parallel to the liner leading edge (to the left) and lower grayish region (to the right).

Figure 3-363. Plot of the thickness of the thermally grown oxide layer formed on the EBC bond coat and/or CMC substrate as a function of distance from the leading edge of the combustor liner. The sharp drop in thickness at 35 to $40 \mathrm{~mm}$ marks the transition between the raised whitish band and normal EBC. ..461 


\section{LIST OF TABLES}

Table 3-1. Summary of Drop-Dart Impact Damage Tests on Prepreg MI Composites... 20

Table 3-2. Summary of Shroud Rig Shakedown Tests .............................................. 31

Table 3-3. Tensile Strength Data from CCP and Goodrich Slurry Cast and GE

Prepreg MI Shroud Witness Coupons.............................................................35

Table 3-4. Summary of Shroud Rig Tests Run During the $1^{\text {st }}$ Testing Campaign ........... 38

Table 3-5. Test Matrix Used for the Blade Tip Rub Tests .......................................... 71

Table 3-6. Summary of Blade Tip Rub Test Results.............................................. 72

Table 3-7. Summary of Pin-On-Disk Wear Test Data from ORNL .............................76

Table 3-8. Summary of Tensile Strength Data From the CMC Engine Shroud

Witness Coupons from the $1^{\text {st }}$ Shroud Fabrication Campaign ...........................93

Table 3-9. Summary of CMC Shroud Inspections Done During Engine Test \#1 ......... 115

Table 3-10. Results of Pre-Test and Post-test Measurements on the Damper Springs

Used in the 5366 Hour Shroud Engine Test ................................................. 148

Table 3-11. Type of CMC Inner Shroud, EBC Coating and Metallic Hardware

Configurations Used in Rig Test \#5 ........................................................ 161

Table 3-12. CMC Inner Shroud EBC Configurations Used in Rig Test \#6. .................. 173

Table 3-13. Effect of Sample Orientation on the Ultimate Strength and Strain to Failure Properties of Test Bars Cut from GEN1 Shroud Components Prepared for the Abandoned Spring 2005 Engine Test.................................................. 188

Table 3-14. List of CMC Shroud Material Variations Included in Field Engine Test

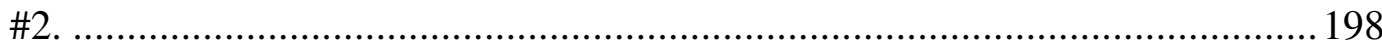

Table 3-15: List of Potential Sources for Engine Performance Change Following the Hot Gas Path Maintenance and the Actions Taken to Estimate Their Potential Effects......

Table 3-16. Summary of Shroud EBC Coating Defects Observed During the JEA Engine Test. The diagram at the bottom indicates where on the CMC shroud the various types of EBC spalls typically occur. ........................................2238

Table 3-17 Fiber Architecture Configurations of the First Set of Hybrid CMC/Monolithic Test Panels Made with Hi-Nicalon Fiber..............................2278

Table 3-18. Fiber Type, Monolithic Ply Types, and Architecture Configurations of the Hybrid CMC/Monolithic Test Panels

Table 3-19. Summary of the Ballistic Impact Tests Conducted on the Monolithic Ply Hybrid CMC Panels.

Table 3-20. Ply Configuration of the Hybrid CMC Panels Made With Uncoated

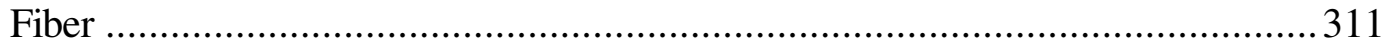

Table 3-21. Ballistic Testing Results for the Uncoated Fiber Hybrid CMC Samples .... 315

Table 3-22. Tensile Testing Results of the Uncoated Fiber Hybrid CMC Samples ....... 318

Table 3-23. Relative Effects of Replacing Composite Plies With Matrix Plies on In-

Plane Tensile Properties of Hybrid CMC Structure Samples Made With Hi-

Nicalon Type-S Fiber. .................................................................... 319

Table 3-24. Results of the Gen1 EBC FPQ Shroud Coating Evaluations in Preparation for Coating of the Shrouds for Engine Test \#3............................ 343 
Table 3-25. Summary of the coated fibers used in the prepreg HiPerComp CSGT

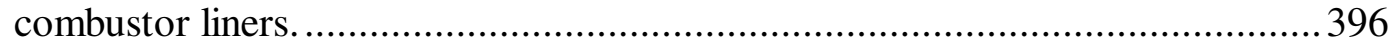




\section{LIST OF ACRONYMS}

AMAIGT

ANL

ANSYS

APS

ASME

BSAS

$\mathrm{B}(\mathrm{Si}) \mathrm{N}$

$\mathrm{CCP}$

CFCC

CFD

$\mathrm{CMC}$

CMM

CT

CTL

CVD

CVI

DOE

DoE

EBC

EPM

FEA

FOD

FPQ

GE

GRC

GE-2

HSCT

ID

IR
Advanced Materials for Advanced Industrial Gas Turbines

Argonne National Laboratory

Name for a particular finite element modeling code and for the company that produces that code

Air plasma spray

American Society of Mechanical Engineers

Barium-strontium-aluminosilicate

Silicon-doped boron nitride

Ceramic Composite Products, LLC; a subsidiary of GE Aviation

Continuous Fiber Ceramic Composite (refers to the DOE-sponsored program)

Computational fluid dynamics

Ceramic matrix composite

Coordinate measuring machine

Computed tomography; a methodology of x-ray imaging

Cincinnati Testing Labs

Chemical vapor deposition

Chemical vapor infiltration

U.S. Department of Energy

Design of experiments

Environmental barrier coating

Enabling Propulsion Materials; a part of the HSCT program

Finite element analysis

Foreign object damage

First piece qualification

General Electric Company

GE Global Research; previously known as GE Corporate Research and Development

2MW gas turbine engine fabricated by GE Oil\&Gas, previously known as a PGT-2

High Speed Civil Transport

Inner diameter

Infrared 
JETS

LVDT

MI

NASA

NDE

NOx

OD

ORNL

RT

SCS

SEM

TBC

UDRI

UHC
Jet engine thermal shock; a type of thermal fatigue testing Linear variable differential transformer

Melt infiltration or melt infiltrated (refers to the process or to the class of materials)

National Aeronautics and Space Administration

Nondestructive evaluation

Oxides of Nitrogen

Outer diameter

Oak Ridge National Laboratory

Room temperature; $\sim 23^{\circ} \mathrm{C}$

Trade name for $\mathrm{SiC}$ monofilament fibers from Textron Specialty Materials

Scanning electron microscope

Thermal Barrier Coating

University of Dayton Research Institute

Unburned Hydrocarbons 


\section{REFERENCES}

1. G.S. Corman, K.L. Luthra, M.K. Brun and P.J. Meschter, "Toughened Silcomp Composites for Gas Turbine Engine Applications," DOE report DOE/CE/41000-2, July 1994.

2. G.S. Corman and K.L. Luthra, "Melt Infiltrated Ceramic Composites (HiPerComp®) for Gas Turbine Engine Application," DOE contract final report DOE/CE/41000-3, Jan. 2006.

3. http://www.compositesworld.com/news/ge-aviation-to-use-ceramic-matrix-compositesin-jet-engines

4. http://www.aviationweek.com/aw/generic/story.jsp?id=news/avd/2010/09/17/10.xml\&h eadline $=$ New $\% 20 \mathrm{GE} \% 20$ Engine $\% 20 \mathrm{Has} \% 20 \mathrm{Potential} \% 20 \mathrm{For} \% 20 \mathrm{Commercial} \% 20 \mathrm{Use}$ \&channel $=$ mro

5. http://www.genewscenter.com/content/detail.aspx?ReleaseID=6246\&NewsAreaID=2\& PrintPreview $=$ True

6. "Continuous Fiber Ceramic Composite Benefit Analysis," DOE OIT report, 1993.

7. D. Brewer, "HSR/EPM Combustor materials Development Program," Mat. Sci. Eng., A261, (1999) 284-291.

8. G.S. Corman, K.L. Luthra and M.K. Brun, "Silicon Melt Infiltrated Ceramic Composites - Processes and Properties," in Progress in Ceramic Gas Turbines Volume 2I: Ceramic Gas Turbine Component Development and Chatacterization, M. van Roode, M. Ferber and D. Richerson, Editors, ASME PRESS, New York, USA (2003) 291-312.

9. G.S. Corman and K.L. Luthra, "Silicon Melt Infiltrated Ceramic Composites (HiPerComp®)" in Handbook of Ceramic Composites, edited by N.P. Bansal, Kluwer Academic Publishers, Boston, MA (2005) 99-116.

10. D.E. Brandt, "Heavy-Duty Turbopower: The MS7001F," Mechanical Engineering, (July, 1987) 28-36.

11. C.M. Grondahl and T. Tsuchiya, "Performance Benefit Assessment of Ceramic Components in and MS9001FA Gas Turbine," Journal of Engineering for Gas Turbines and Power, 123, July 2001, 513-519.

12. B. E. Deal and A. S. Grove, "General Relationship for the Thermal Oxidation of Silicon," J. Appl. Phys., vol. 36, pp. 3770-3778, 1965.

13. E.J. Opila, and R.E. Hann, "Paralinear Oxidation of CVD SIC in Water Vapor," J. Am. Ceram. Soc., Vol 80 (1), pp. 197-205, 1997.

14. E.J. Opila, D.S. Fox, N.S. Jacobson, "Mass Spectrometric Identification of Si-O-H(g) Species from the Reaction of Silica with Water Vapor at Atmospheric Pressure," J. Am. Ceram. Soc., Vol 80 (4), pp. 1009-1012, 1997.

15. M. Van Roode, J. Price, J. Kimmel, N. Miriyala, D. Leroux, A. Fahme and K. Smith, "Ceramic Matrix Composite Combustor Liners: A Summary of Field Evaluations," J. Eng. Gas Turbines and Power, 109, Jan. 2007, pp 21-30.

16. K. Bruce, R. Cairo, R. Nimmer, C. Johnson, G. Corman and H. Roberts, "Gas Turbine Shroud Support Apparatus," U.S. patent application US2009/0053050 A1, Feb. 26, 2009. 
17. G.S. Corman, H.C. McGuigan, M.K. Brun, "Process of Producing a Ceramic Matrix Composite Article and Article Formed Thereby, US Patent 7,708,851, May 4, 2010.

18. H.M. Yun and J.A. DiCarlo, "High Temperature Contraction Behavior of PolymerDerived SiC Fibers,'Cer. Eng. and Sci. Proceedings, 18A, 1997, pp. 135-146.

19. G. Caprino, V. Lopresto and D. Santoro, "Ballistic Impact Behavior of Stitched Graphite/Epoxy Laminates," Composites Science and Technology, 67 (2007) 325335.

20. D. Dunn and S. Subramanian, "Effect of Fiber Volume Fraction on HiPerComp® CMC," presented at the $32^{\text {nd }}$ Annual Conference on Composites, Materials and Structures, Daytona Beach, FL, Jan. 28-31, 2008.

21. D. Dunn and S. Subramanian, "The Effect of Fiber Architecture on Flexure Properties of HiPerComp® CMCs," to be presented at the $33^{\text {rd }}$ Annual Conference on Composites, Materials and Structures, Cocoa Beach, FL, Jan. 26-29, 2009.

22. Budiansky, Hutchinson, Evans, J. Mech. Phys. Solids 34 (1986) 167.

23. W. D. Brentnall, M. van Roode, P.F. Norton, S. Gates, J.R. Price, O. Jimenez and N. Miriyala, "Ceramic Gas Turbine Development at Solar Turbines Incorporated," in Progress in Ceramic Gas Turbine Development, Volume 1, Ceramic Gas Turbine Design And Test Experience, M. vanRoode, M.K. Ferber and D.W. Richerson, eds., ASME Press, 2002.

24. M. van Roode, J. Price, J. Kimmel, N. Miriyala, D. Leroux, A. Fahme and K. Smith, "Ceramic Matrix Composite Combustor Liners: A Summary of Field Evaluations," Journal of Engineering for Gas Turbines and Power, Vol 129, Jan. 2007, pp. 21-30.

25. M. van Roode, personal communication. 


\section{APPENDIX: PUBLIC DOCUMENTATION}

\subsection{Patents Granted or Applied For}

1. U.S. Patent 6,726,448, "Ceramic Turbine Shroud," E.L. McGrath, G.S. Corman, A.J. Dean, M.S. Schroder, C.B. Jiomacas, T.R. Farrell, K.L. Parks, April 27, 2004.

2. U.S. Patent 7,117,983, "Support Apparatus And Method For Ceramic Matrix Composite Turbine Bucket Shroud," R.R. Goode, K.L. Bruce, G. S. Corman, D.J. Mitchell, M.S. Schroeder, and C. Grace, Oct. 10, 2006.

3. U.S. Patent 7,381,445, "Method of Coating a Ceramic Matrix Composite Fiber", M.K. Brun, June 3, 2008.

4. U.S. Patent 7,434,670, "Support Apparatus and Method For Ceramic Matrix Composite Turbine Bucket Shroud," R.R. Goode, K.L. Bruce, G. S. Corman, D.J. Mitchell, M.S. Schroeder, and C. Grace, Oct. 14, 2008.

5. U.S. Patent 7,708,851, "Process of Producing a Ceramic Matrix Composite Article and Article Formed Thereby", G.S. Corman, M.K. Brun and H.C. McGuigan, May 4, 2010.

6. U.S. Patent Application, "Improved lay-Up Method for Prepreg Ceramic Matrix Composites," G.S. Corman and H.C. McGuigan, filed Nov. 27, 2005.

7. U.S. Patent Application US2009/0053050 A1, "Gas Turbine Shroud Support Apparatus,” K.L. Bruce, R.R. Cairo, R.P. Nimmer, C.A. Johnson, G.S. Corman, H.C. Roberts, filed August 23, 2007.

8. U.S. Patent Application US20070099527 A1, "Method and Reactor to Coat Fiber Tows and Article," M.K. Brun, K.L. Luthra, H.C McGuigan, G.S. Corman, filed Nov. 1, 2005.

9. U.S. Patent Application US20100279845 A1, "Process of Producing Ceramic Matrix Composites", A. Kebbede, K. Luthra and G. Corman, filed April 30, 2009.

10. U.S. Patent Application US2010/0284810 A1, "Process for Inhibiting Delamination in a Bend of a Continuous Fiber-Reinforced Composite Article," G.S. Corman and H.C. McGuigan, filed May 7, 2009.

\subsection{Publications}

1. "Silicon Melt-Infiltrated Ceramic Composite for Gas Turbine Engine Applications," R.M. Orenstein, M.S. Schroder, G.S. Corman, and K.L. Luthra, in Proceedings of PowerGen International 2000, Orlando, Florida, November 14-16, 2000.

2. "Rig and Gas Turbine Engine Testing of MI-CMC Combustor and Shroud Components, " G.S. Corman, A.J. Dean, S. Brabetz, K. McManus, M.K. Brun, P.J. Meschter, K.L. Luthra, H. Wang, R. Orenstein, M. Schroder, D. Martin, R. De Stefano and L. Tognarelli, paper no. 2001-GT-593 presented at the $46^{\text {th }}$ ASME Gas Turbine and Aeroengine Technical Congress (ASME Turbo Expo, Land, Sea \& Air) New Orleans, LA, June 4-7, 2001. 
3. "Melt Infiltrated (MI) SiC/SiC Composites for Gas Turbine Applications," K.L. Luthra and G.S. Corman, in High Temperature Ceramic Matrix Composites, W. Krenkel, R. Naslain and H. Schneider, eds., Wiley/VCH, Weinheim, FRG, 2001, pp. 744-53.

4. "Rig and Engine Testing of Melt Infiltrated Cermic Composites for Combustor and Shroud Applications," G.S. Corman, A.J. Dean, S. Brabetz, M.K. Brun, K.L. Luthra, L. Tognarelli and M. Pecchioli, Transactions of the ASME - Journ. Eng. for Gas Turbines and Power, vol. 124, Issue 3, July 2002.

5. "Ceramic Gas Turbine Programs at GE Power Systems," P.S. DiMascio, R.M. Orenstein, M.S. Schroder, L. Tognarelli, G.S. Corman and A.J. Dean, in Ceramic Gas Turbine Design and Test Experience: Progress in Ceramic Gas Turbine Development, Vol. 1, edited by Mark van Roode, Mattison K. Ferber, and David W. Richerson, ASME Press, New York, USA, 2002.

6. "Silicon Melt Infiltrated Ceramic Composites - Processes and Properties," G.S. Corman, K.L. Luthra, and M.K. Brun, in Progress in Ceramic Gas Turbines Volume II: Ceramic Gas Turbine Component Development and Evolution: Fabrication, NDE, Testing, and Life Prediction, M. van Roode, M. Ferber and D. Richerson, Editors, ASME PRESS, New York, USA, 2003.

7. "Silicon Melt Infiltrated Ceramic Composites (HiPerComp®)" G.S. Corman and K.L. Luthra, in Handbook of Ceramic Composites, edited by N.P. Bansal, Kluwer Academic Publishers, Boston, MA, 2005, pp. 99-116.

\subsection{Technical Presentations}

1. "Silicon Melt-Infiltrated Ceramic Composite for Gas Trubine Engine Applications," R.M. Orenstein, M.S. Schroder, G.S. Corman and K.L. Luthra, Paper 00157 presented at Power Gen International, Orlando, FL, Nov. 14-16, 2000.

2. "Engine and High Pressure Combustion Rig Testing of of MI SiC/SiC-Si Composites," G.S. Corman, K.L. Luthra, A.J. Dean, S. Brabetz, P. Meschter, R. De Stefano and L. Tognarelli, presented at the $25^{\text {th }}$ Annual Conferenc on Composites, Materials and Structures, Cocoa Beach FL, Jan. 22-25, 2001.

3. "Life Prediction for SiC/SiC Composites, Issues and Approaches", K. L. Luthra, 24th Annual Conference on Composites, Materials, and Structures, Cocoa Beach, Florida, January 22-25, 2001

4. "Rig and Gas Turbine ENGINE Testing of MI-CMC Combustor and Shroud Components, " G.S. Corman, A.J. Dean, S. Brabetz, K. McManus, M.K. Brun, P.J. Meschter, K.L. Luthra, H. Wang, R. Orenstein, M. Schroder, D. Martin, R. De Stefano and L. Tognarelli, paper no. 2001-GT-593 presented at the $46^{\text {th }}$ ASME Gas Turbine and Aeroengine Technical Congress (ASME Turbo Expo, Land, Sea \& Air) New Orleans, LA, June 4-7, 2001.

5. "Melt Infiltrated CMCs for Gas Turbine Engine Applications," G.S. Corman, K.L. Luthra, K.R. McManus, P.J. Meschter, M.K. Brun, D. Mitchell, M.S. Schroder, and $\mathrm{H}$. Wang, presented at the $26^{\text {th }}$ Annual Conference on Composites, Materials and Structures, Cocoa Beach, FL, Jan. 28 - Feb. 1, 2002. 
6. "Melt Infiltrated CMC Gas Turbine Shroud Development and Testing," G.S. Corman, K.L. Luthra, M.K. Brun, D. Mitchell, K. McManus, K. Bruce, M. Schroder, H. Wang, and D. Landini, presented at the $27^{\text {th }}$ Annucal Conference on Composites, Materials and Structures, Cape Canaveral, FL, January 27-30, 2003.

7. "Melt Infiltrated Ceramic Matrix Composites (Mi-CMCs) for Gas Turbine Applications," K.L. Luthra and G.S. Corman, Invited talk for the Conference on Interfaces Within and Between Composites," Lake Louise, Canada, October 19-24, 2003.

8. "Melt Infiltrated CMC Gas Turbine Shroud Development and Testing," G. Corman, K. Luthra, D. Mitchell, P. Meschter, R. Nimmer, K. Bruce, and D. Landini, presented at the $28^{\text {th }}$ International Cocoa Beach Conference and Exposition on Advanced Ceramics \& Composites, Cape Canaveral, FL, January 26-30, 2004.

9. "Melt Infiltrated CMC Gas Turbine Shroud Development and Testing," G. Corman, K. Luthra, D. Mitchell, P. Meschter, R. Nimmer, K. Bruce, and D. Landini, presented at the $28^{\text {th }}$ Annual Conference on Composites, Materials, and Structures, Cape Canaveral/Cocoa Beach, FL, January 26-30, 2004.

10. "Status and Challenges for the Use of Melt Infiltrated CMCs (HiPerComp®) in Industrial Gas Turbine Applicaions," K.L. Luthra and G.S. Corman, presented at HTCMC-5, Seattle, WA, September 12-16, 2004.

11. "Orthotropic Mechanical Data Characterizing Uni-Directional and Cross-Plied HiPerComp® Compoiste Material," R. Nimmer, G. Corman and R. Gilmore, presented at the $29^{\text {th }}$ Annual Conference on Composites, Materials and Structures, Cocoa Beach, FL, January 24-27, 2005.

12. "Prepreg CMC Technology Transition and Process Capability at PSC," H. Wang, D. Landini, K. Luthra and G. Corman, presented at the $29^{\text {th }}$ Annual Conference on Composites, Materials, and Structures, Cocoa Beach, FL, January 24-27, 2005.

13. "Melt Infiltrated CMCs (HiPerComp $\AA)$ for Gas Turbine Applications, K.L. Luthra and G.S. Corman, presented at the ASME Turbo Expo 2006, Barcelona, Spain, May $10,2006$.

14. "Melt Infiltrated CMCs (HiPerComp®) for Gas Turbine Applications," G.S. Corman and K.L. Luthra, presented at the 2006 ASM/TMS Northeast Section Spring Symposium, Niskayuna, NY, may 22-23, 2006.

15. "melt Infiltrated CMC Gas Turbine Shroud Testing," G. Corman, K. Luthra, C. Johnson, R. Nimmer, H. Roberts, D. Landini, R. Matsumoto and B. Patterson, presented at the $31^{\text {st }}$ Annual Conference on Composites, Materials and Structures, Daytona Beach, FL, January 22-25, 2007.

16. "Melt Infiltrated SiC/SiC Composites for Gas Turbine Applications," K.L. Luthra and G.S. Corman, presented at the 2007 Gordon Research Conference on Solid State Studies in Ceramics, August 9, 2007.

17. "SiC-SiC Composites for Gas Turbine Applications," K.L. Luthra and G.S. Corman, presented at the $9^{\text {th }}$ International Symposium on Ceramic Materials and Components for Energy and Environmental Applications, Shanghai, China, November 11, 2008. 